

\section{Leptoderris congolensis}

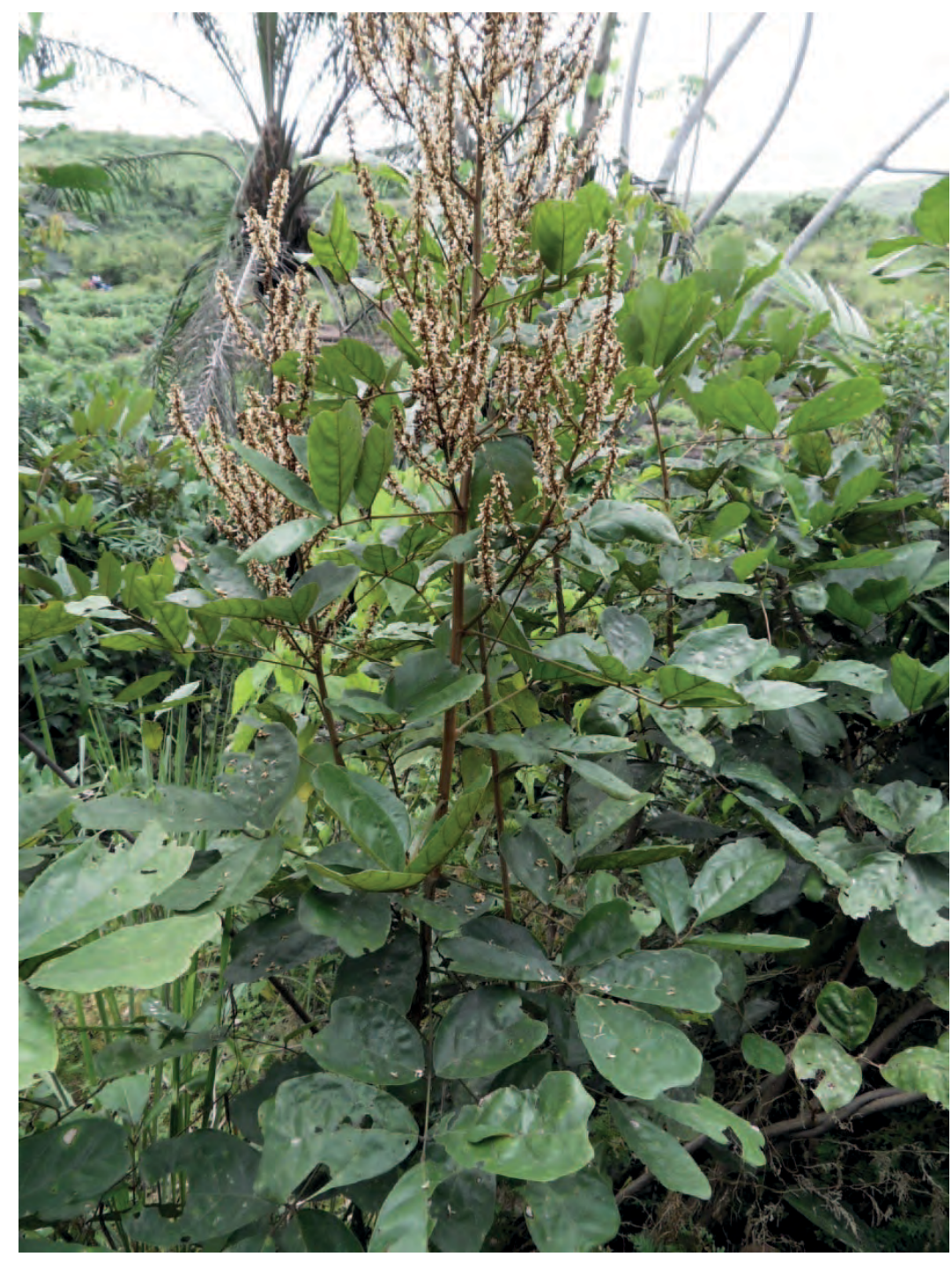

(Fabaceae)

Noms courants : Kifundi, futi (Kikongo). Ce nom kifundi désigne aussi Millettia barteri, $M$. theuszii et d'autres lianes du genre Millettia.

Description : Liane ou buisson grimpant pouvant atteindre $15 \mathrm{~cm}$ de diamètre. Les tiges sont couvertes d'un épais tissu de fins poils bruns. Les feuilles, coriaces, ont 9 à 15 sur 5 à $8 \mathrm{~cm}$. Les fleurs jaune crème, en panicules terminaux pouvant avoir $40 \mathrm{~cm}$ de long, sont visibles toute l'année. Le fruit est une gousse jaune ou brune de 6 à $9 \mathrm{~cm}$ de long.

Ecologie: Plante présente au Kongo Central en forêt secondaire et savane boisée, sur terre sèche ou inondable, dans les marécages et les forêts galerie inondées. Présente du sud du Nigéria à l'Angola.

Reproduction : par graines.

Gestion : Se conduit en taillis, recèpe bien après abattage.

Usages : Les chenilles comestibles Nsanga ou Mimbota bota (Epidonta brunneomixta), Mfundi et Nziozu (Kikongo) se nourrissent des feuilles. Les fleurs sont un fourrage important pour les abeilles. Les abeilles récoltent le nectar en janvier. Au Gabon, on sait que les

abeilles récoltent le nectar de novembre à janvier. La plante contient de la roténone ; on s'en sert au Gabon pour empoisonner les poissons.

Références : Gillet et Paque 1910, Renier 1948, Hauman et al. 1954, Daeleman et Pauwels 1983, Ambougou 1991, Burkill 1995, Latham 2008

Les chenilles comestibles Mfundi

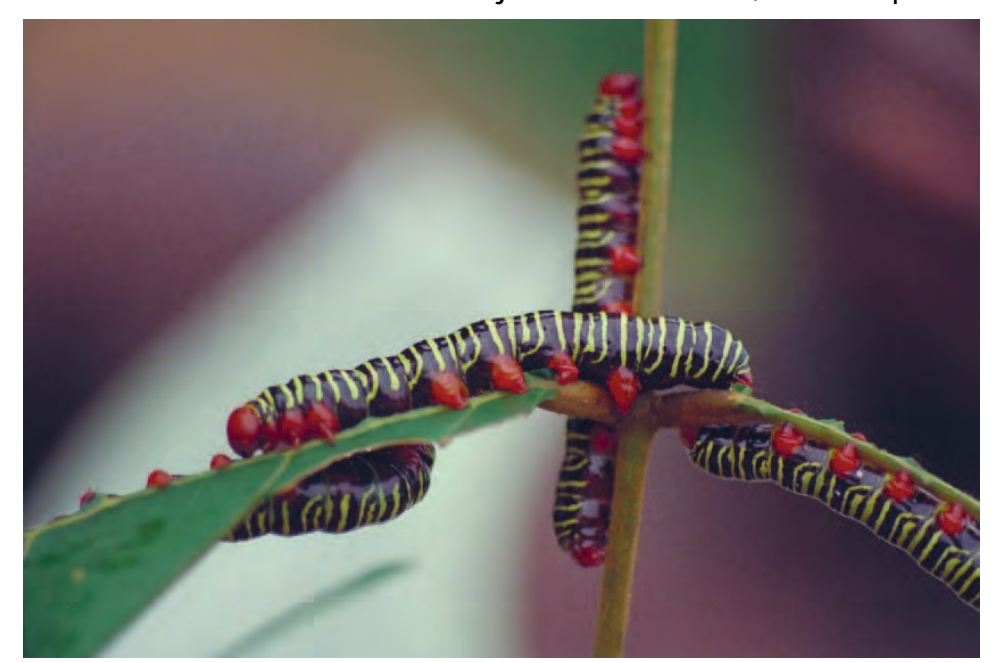




\section{Leptoderris ferruginea}

(Fabaceae)

Description : Liane avec des tiges pouvant avoir $10 \mathrm{~cm}$ de diamètre. Les tiges sont couvertes de fins poils rouge brun. Feuilles plutôt coriaces, glabres, de 8 à 16 sur 4 à $9 \mathrm{~cm}$, sur un pétiole de 6 à $18 \mathrm{~cm}$. Inflorescence en panicules terminaux ou axillaires, ayant jusqu'à $40 \mathrm{sur} 20 \mathrm{~cm}$. Fleurs blanches. Gousses oblongues, non ailées, asymétriques, de 8 à 10 sur 2,5 à $3 \mathrm{~cm}$, d'abord velues ou soyeuses, puis glabres et brillantes.

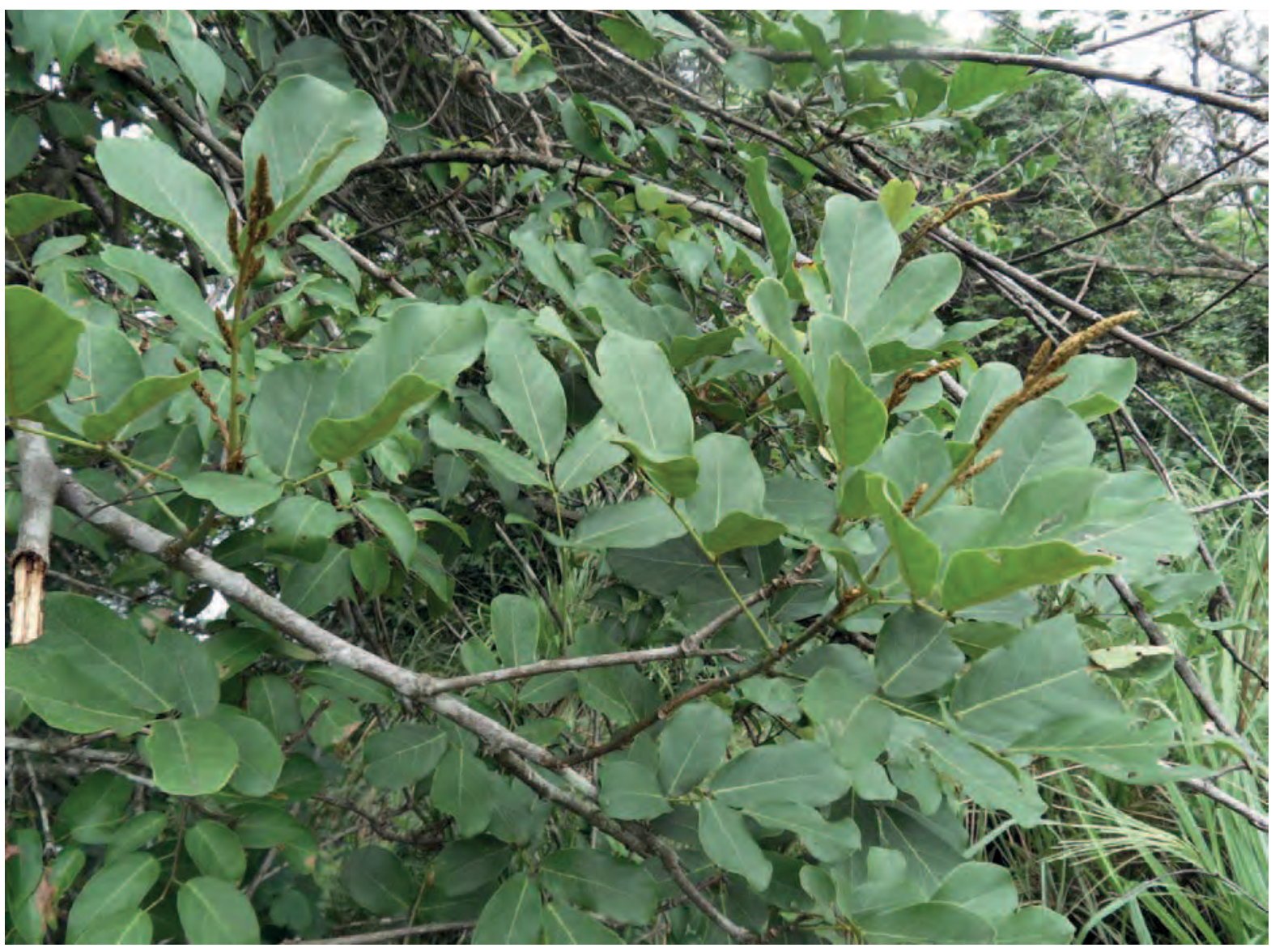

Ecologie : Plante présente au Kongo Central et en RD Congo, et probablement aussi au Tchad, en Centrafrique, au Cameroun, au Congo Brazzaville et au Gabon, dans les forêts pluviales, les îles des rivières et les forêts galeries.

Usages : Probablement un bon fourrage pour les abeilles, comme L. congolensis.

Références : Hauman et al. 1954, Ambougou 1991 


\section{Leucaena leucocephala}

Nom courant : Leucaena (Fr. et Angl.)

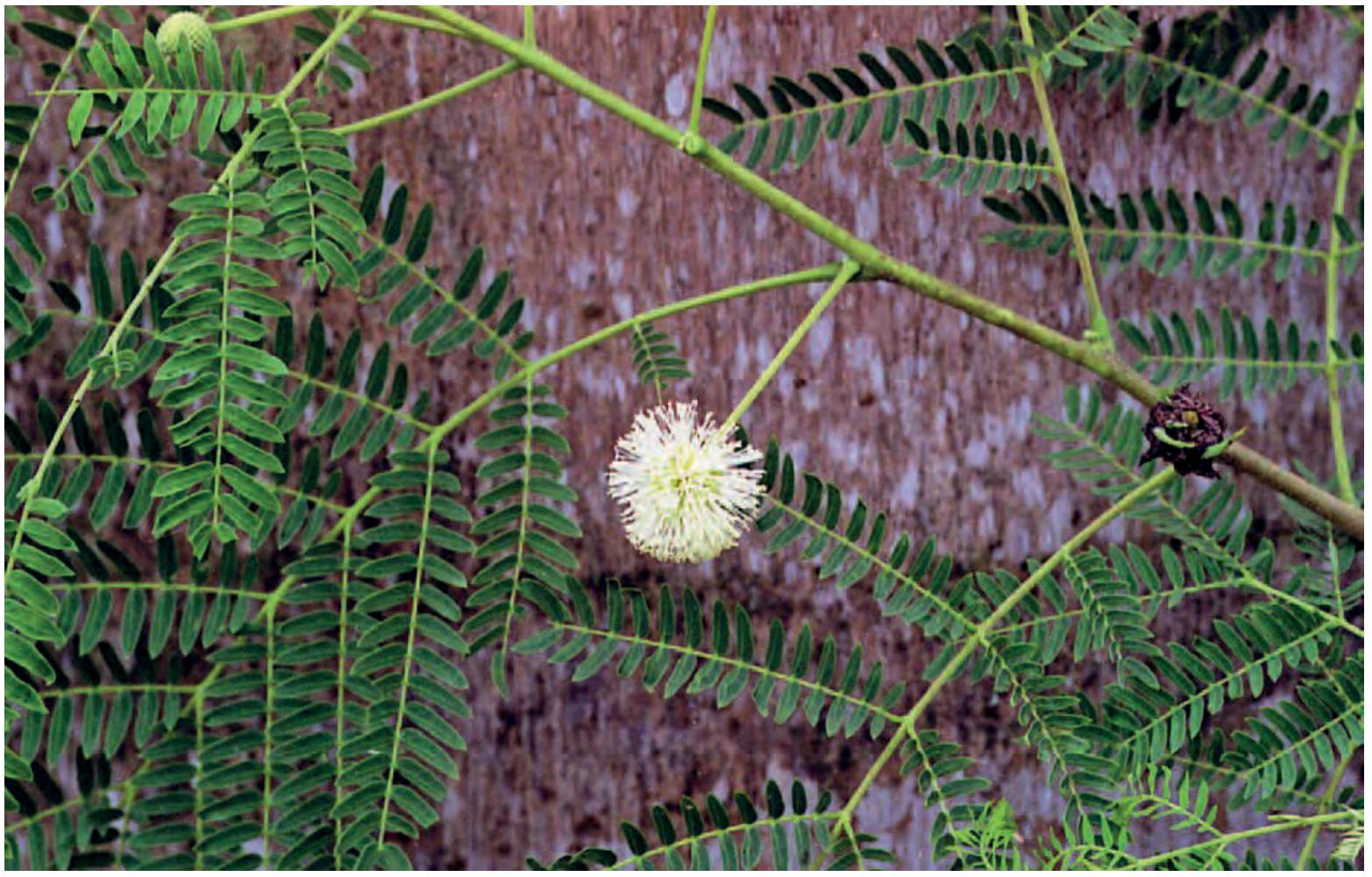

Description : Arbuste ou petit arbre pouvant avoir jusqu'à $9 \mathrm{~m}$ de haut, développant une racine pivotante profonde. Feuilles composées bipennées, avec 2 à 6 paires de pennes portant chacune 9 à 17 folioles de 7 à 18 $\mathrm{mm}$ sur 1,5 à $5 \mathrm{~mm}$. L'arbre fleurit toute l'année, aussi longtemps qu'il y a suffisamment d'humidité.

Ecologie : Plante originaire d'Amérique Centrale, et largement plantée sous les tropiques. Elle pousse très bien sur les sols calcaires et alcalins, et n'est donc pas très commune au Kongo Central, où les sols sont acides et pauvres en phosphore. Elle ne pousse pas sur les sols inondables. On la trouve occasionnellement autour des villages, là où l'on a jeté de la cendre, et près des maisons, où les racines entrent en contact avec le ciment.

Gestion : La plante reprend vigoureusement après abattage.

Usages: On a observé la collecte du pollen par les abeilles à Kavwaya en janvier et à Mbanza Ngungu et Kingemba. En janvier, juin et novembre. On signale que les fleurs donnent du nectar aux périodes où les autres sources sont rares.

Références : Pauwels 1993, Fichtl et Adi 1994, Burkill 1995, Orwa et al. 2009

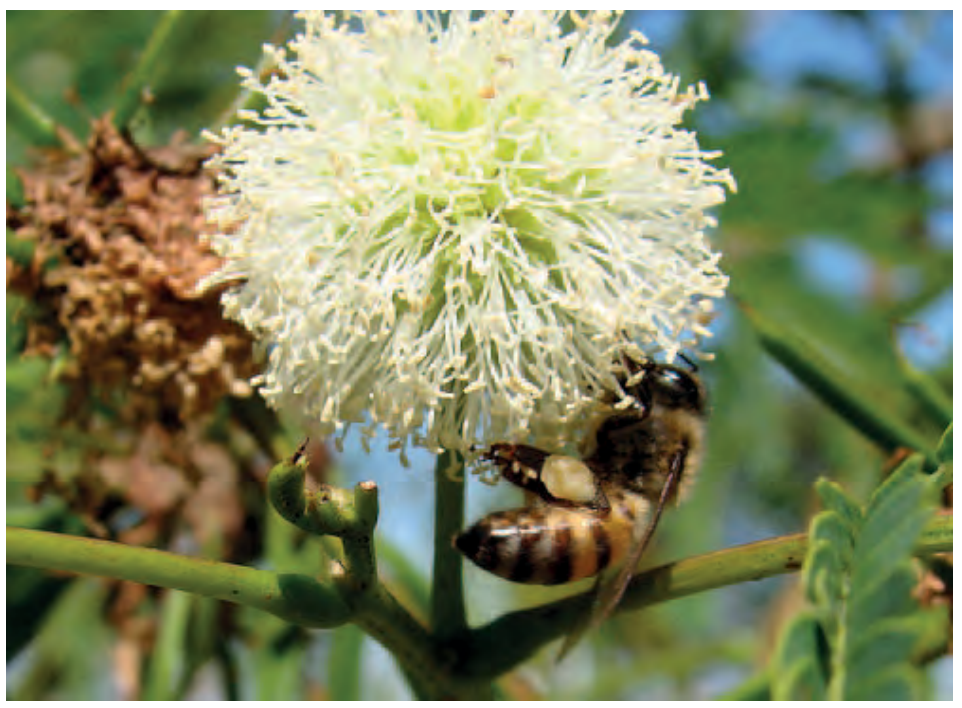

Photo : Mauro Halpern 


\section{Lippia multiflora}

Noms courants : Bulukutu, mbulunkutu (Kikongo) Ces noms désignent également Dactyladenia buchneri et Maranthes glabra. Verveine du Congo (Fr.), bush tea (Angl.).

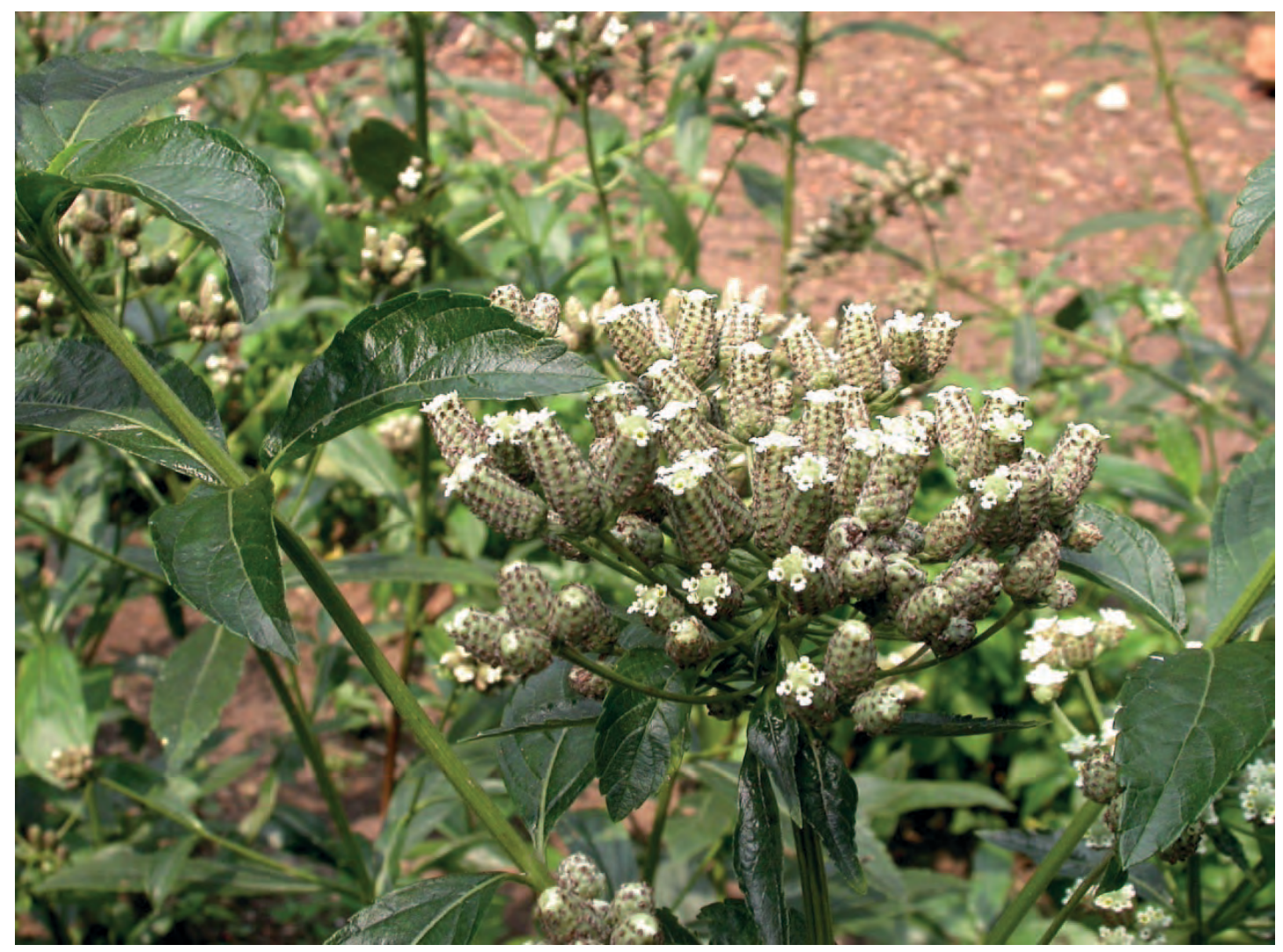

Description : Buisson bas de 1 à $3 \mathrm{~m}$ de haut, à tiges rigides. Les feuilles, de 9,5 à 11,5 sur 2 à $3 \mathrm{~cm}$, sont aromatiques, dentées, et poilues en-dessous. Les fleurs blanches à cœur jaunes sont disposées en bouquets.

Ecologie: Se rencontre en savane, en R.D. Congo, et dans toute l'Afrique de l'ouest tropicale. Parfois cultivée, pour l'usage domestique et pour la vente.

Reproduction : Par graines.

A droite : Paquet de feuilles séchées en vente au marché.

Usages: Les feuilles séchées, que l'on peut conserver, sont une infusion très populaire au Kongo Central, à Kinshasa, et dans la Province du Bandundu. L'infusion est calmante, et soignerait la toux, l'irritabilité, la nervosité voire la folie; on l'emploie aussi pour traiter les rhumatismes et le diabète. Les espèces de Lippia contiennent du carvacrol, dont les propriétés antiseptiques, antifongiques et larvicides ont été démontrées. L'huile obtenue par distillation peut s'employer, avec de la paraffine, pour traiter les abcès. On utilise également la plante pour faire baisser la tension

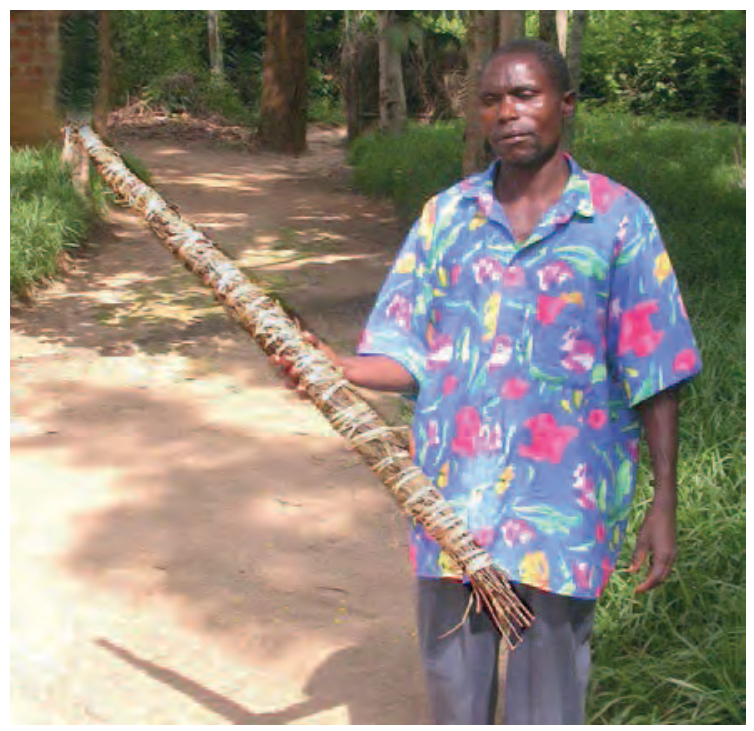
artérielle ; il est possible de l'employer comme insecticide. D'autres espèces, par exemple $L$. nodiflora, sont commues aux Amériques comme bon fourrage pour les abeilles. En Gambie, on utilise la fumée de cette herbe odorante pour attirer les abeilles dans les ruches. La cendre obtenue en brûlant les racines peut servir de sel végétal.

Références : Gillet et Pâque 1910, I rvine 1961, Nsimundele 1966 - 68, Crane et al. 1984, Mukoko Matondo 1991, Pauwels 1993, Burkill 2000, Kunle et al 2003, Nsimundele 2004, Pousset 2004 


\section{Loeseneriella clematoides}

Nom courant : Kinsundi (Kikongo)

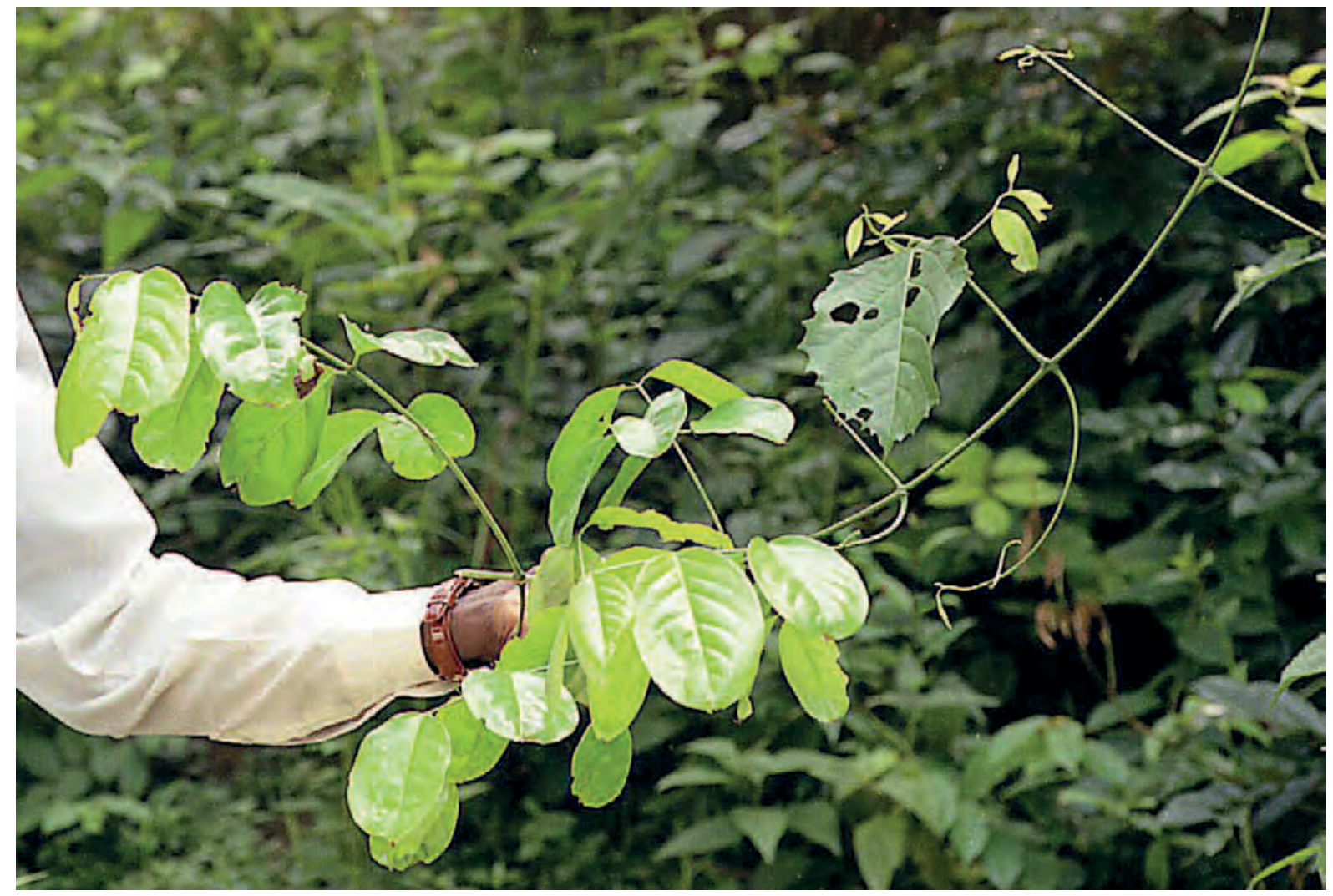

Description : Liane à tige lisse et glabre, pouvant atteindre $20 \mathrm{~cm}$ de diamètre, et 40 à $100 \mathrm{~m}$ de long. Les pétioles des feuilles ont 7 à $15 \mathrm{~mm}$ de long ; les feuilles sont ovales, arrondies ou pointues à la base, de 4,5 à 13 sur 2,5 à 7,5 cm. Les fleurs sont vert pâle, puis brun jaune, avec une colonne centrale jaune.

Ecologie: Pousse en forêts galeries et terrains marécageux dans toute la RD Congo ; présente aussi en Guinée, Gabon, Angola, Ouganda et Malawi.

Usages : Les feuilles se mangent comme légumes; elles seraient plus tendres que celles de Salacia pynaertii (mbondi). On instille la sève dans les narines des enfants souffrant de la fièvre. Les chenilles comestibles Minsundi se nourrissent des feuilles. La plante se raréfie suite aux récoltes excessives.

Références : Gillet et Pâque 1910, Wilczek 1960, Neuwinger 2000

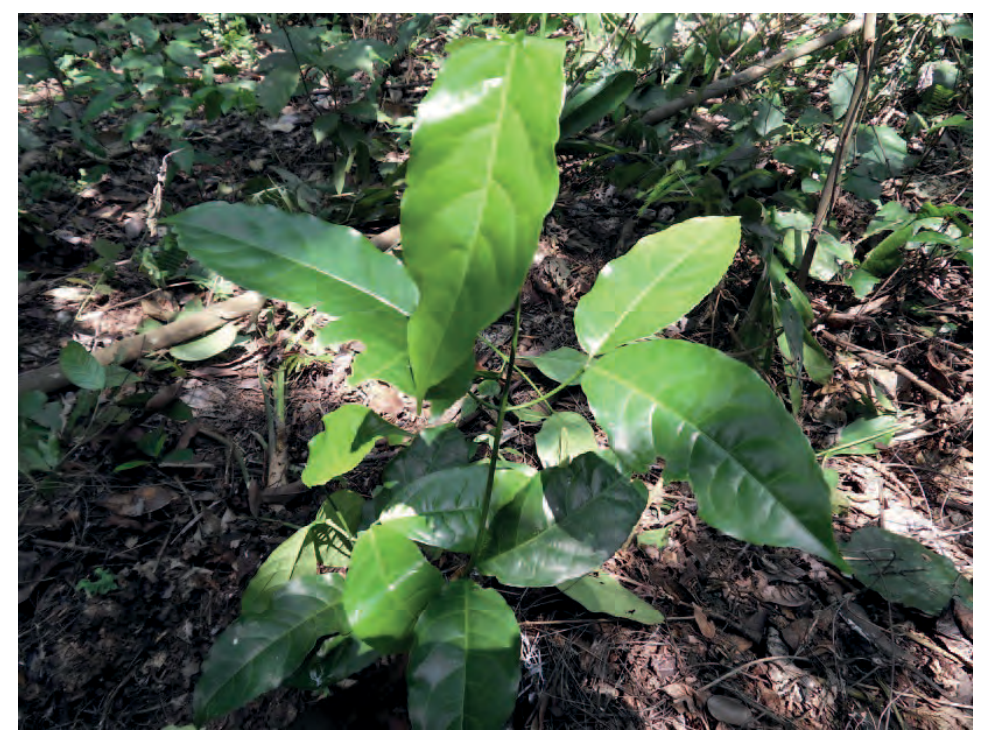




\section{Loudetia demeusei}

(Poaceae)

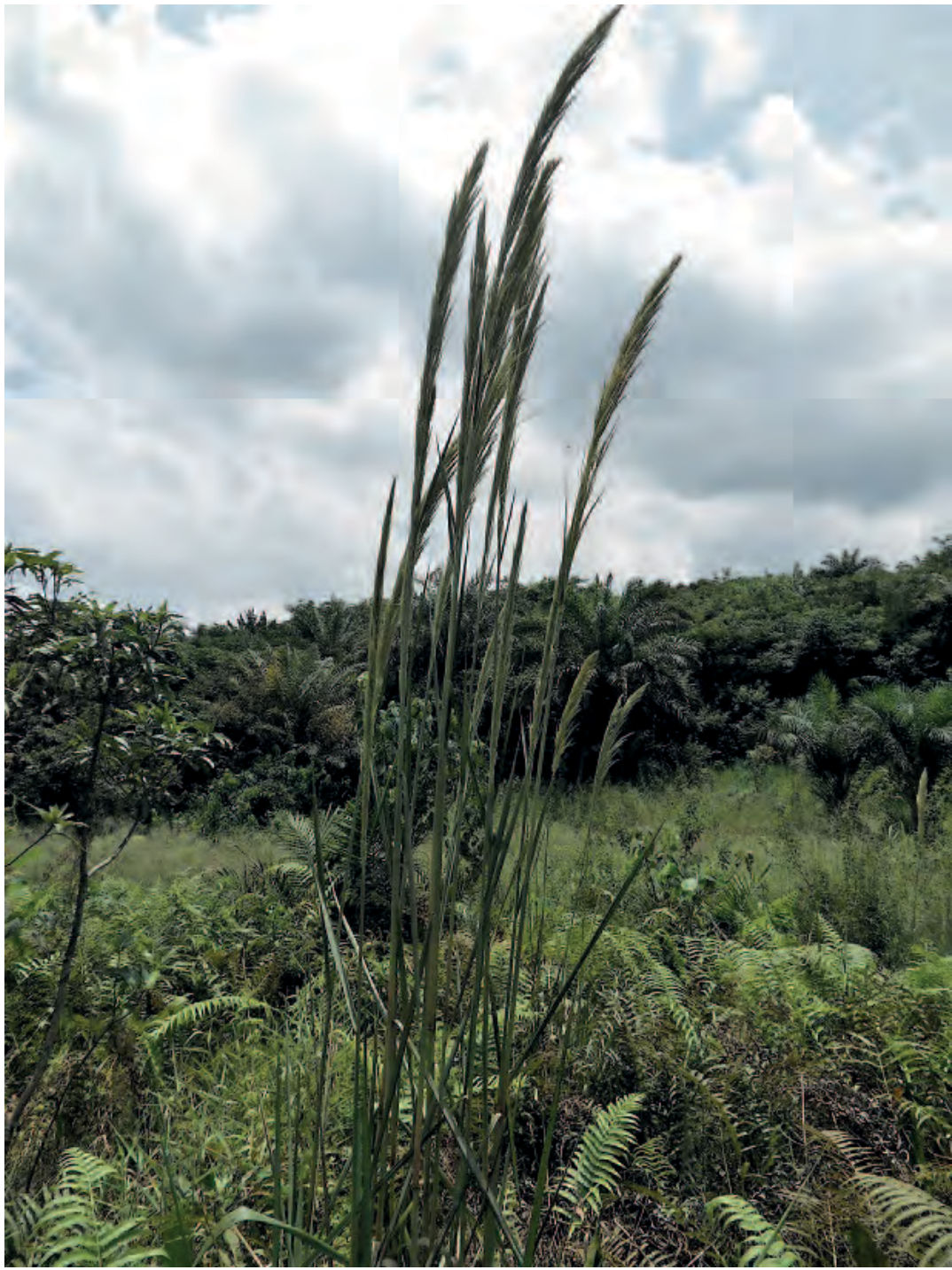

Nom courant : Mabama yange (Teke)

Description : Touffe pérenne d'herbes à feuilles rigides de 16 à $40 \mathrm{~cm}$ sur 4 à $8 \mathrm{~mm}$. L'inflorescence est une panicule de 16 à 40 sur 2 à $3 \mathrm{~cm}$.

Ecologie: espèce de savane présente en Afrique tropicale de l'ouest, du centre et du sud.

Usages: employée pour la couverture des toits, et pour confectionner des chapeaux.

Remarques: Quatre autres espèces, $L$. arundinacea (Kimbulu ou nyanga kimbulu - Kikongo), $L$. phragmitoides (Nzanza Kikongo), $L$. simplex et $L$. vanderstyii sont aussi présentes dans les savanes du Kongo Central. $L$. arundinacea sert aussi à la couverture des toits. Les enfants font des fléchettes avec $L$. phragmitoides.

References Daeleman et Pauwels 1983, Biloso et Lejoly 2006, Biloso 2010, Plants of the World Online (Consulté le 20.12.2018) 


\section{Lovoa trichilioides}

Noms courants : Noyer d'Afrique (Fr.), African walnut (Angl.)

Description : Arbre pouvant atteindre $45 \mathrm{~m}$ de haut, avec un tronc droit et de petits contreforts. L'écorce est lisse, gris foncé, et odorante. Les feuilles sont composées avec 5 à 15 folioles de 5 à 25 sur 2 à $10 \mathrm{~cm}$. La nervure centrale de la feuille est ailée. L'inflorescence peut atteindre $25 \mathrm{~cm}$ de long. Les fruits sont des capsules quadrangulaires de 4 à $7 \mathrm{~cm}$ de long. On trouve parfois des groupes de plusieurs arbres.

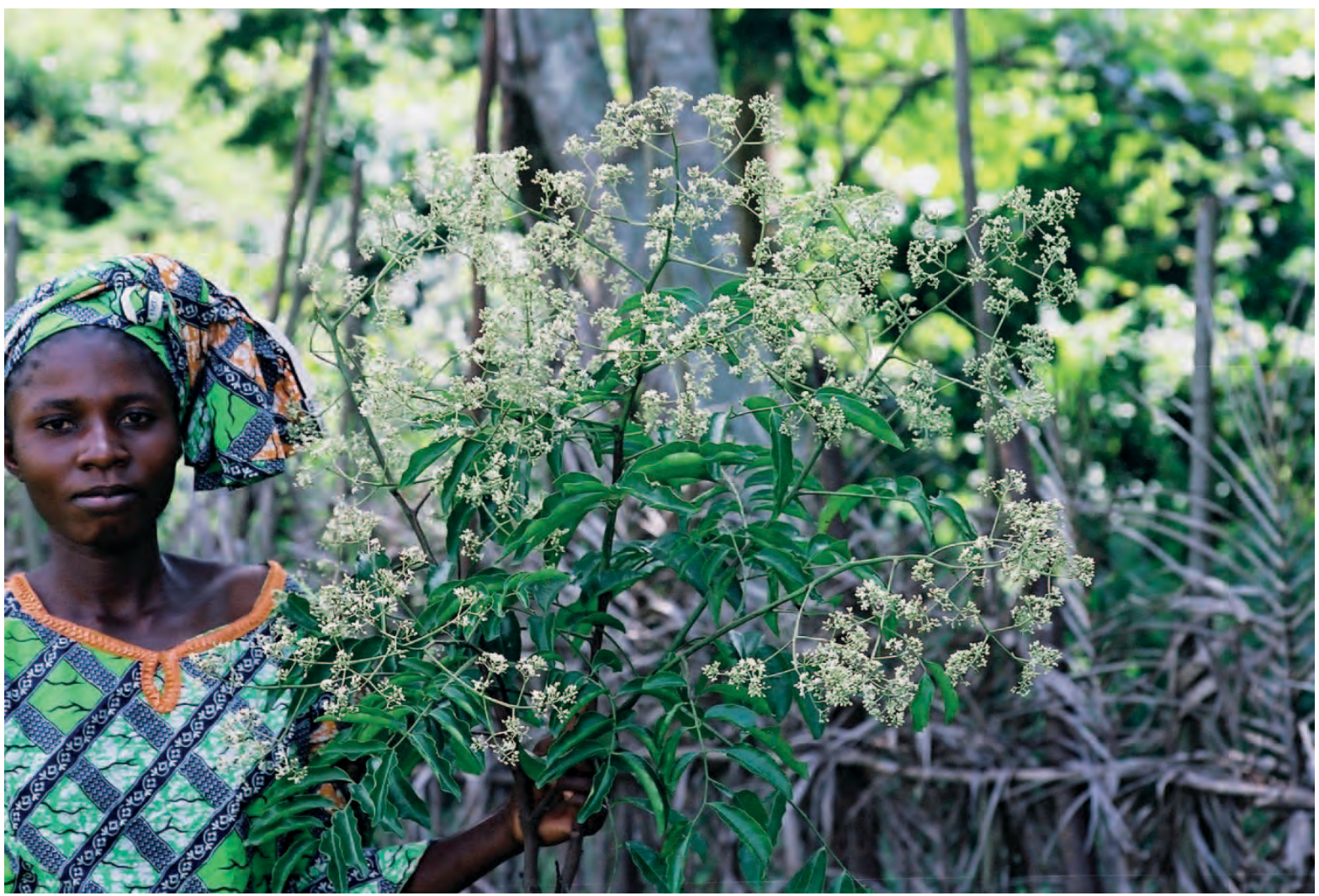

Branche en fleurs en janvier à la mission de Ndembo

Ecologie : Arbre présent dans les forêts pluviales de basse altitude, de la Sierra Leone au Nigeria, à l'Afrique équatoriale, à l'Ouganda et l'Angola. L'arbre pousse très bien sur des sols fertiles.

Reproduction : Cet arbre donne des graines tous les 3 ou 4 ans. Les graines perdent rapidement leur viabilité ; on les conserve quelque temps dans des boîtes avec de la cendre pour réduire les attaques d'insectes. On sème les graines les ailes en haut, et on ne les recouvre de terre que partiellement. La régénération naturelle est normalement bonne. Les semis tolèrent l'ombre et poussent rapidement une fois que la canopée a disparu ; mais ils sont souvent attaqués par les insectes. On peut planter des touffes de jeunes semis.

Gestion : Les semis atteignent $60 \mathrm{~cm}$ de haut après une quinzaine de mois.

Usages: Arbre intéressant pour la production de bois d'œuvre, donnant un aubier blanc et un bois de cœur brun clair. Le bois est dur et résistant aux termites et aux champignons; mais il peut être attaqué par les insectes perforants. II sèche bien s'il est convenablement empilé, et se travaille bien, supportant les clous, la colle et le vernis. On frotte la poitrine avec les feuilles pilées pour les douleurs du poumon. On a observé des abeilles très actives pour récolter le nectar, sur un arbre à midi en janvier à la mission de Ndembo. Les fleurs sont signalées comme fourrage pour les abeilles au Gabon en novembre.

Remarque : Cet arbre a été surexploité et n'est pas commun au Kongo Central. II est sur la liste rouge des espèces vulnérables de I'UICN.

Références; Renier 1948, Leloup 1956, Staner et Gilbert 1958, Bouquet 1969, Keay 1989, Ambougou 1991, Pauwels 1993, Katende et al. 1995, Burkill 1997, Hawthorne et Gyakari 2006 


\section{Ludwigia abyssinica}

Nom courant : Water primrose (Angl.)

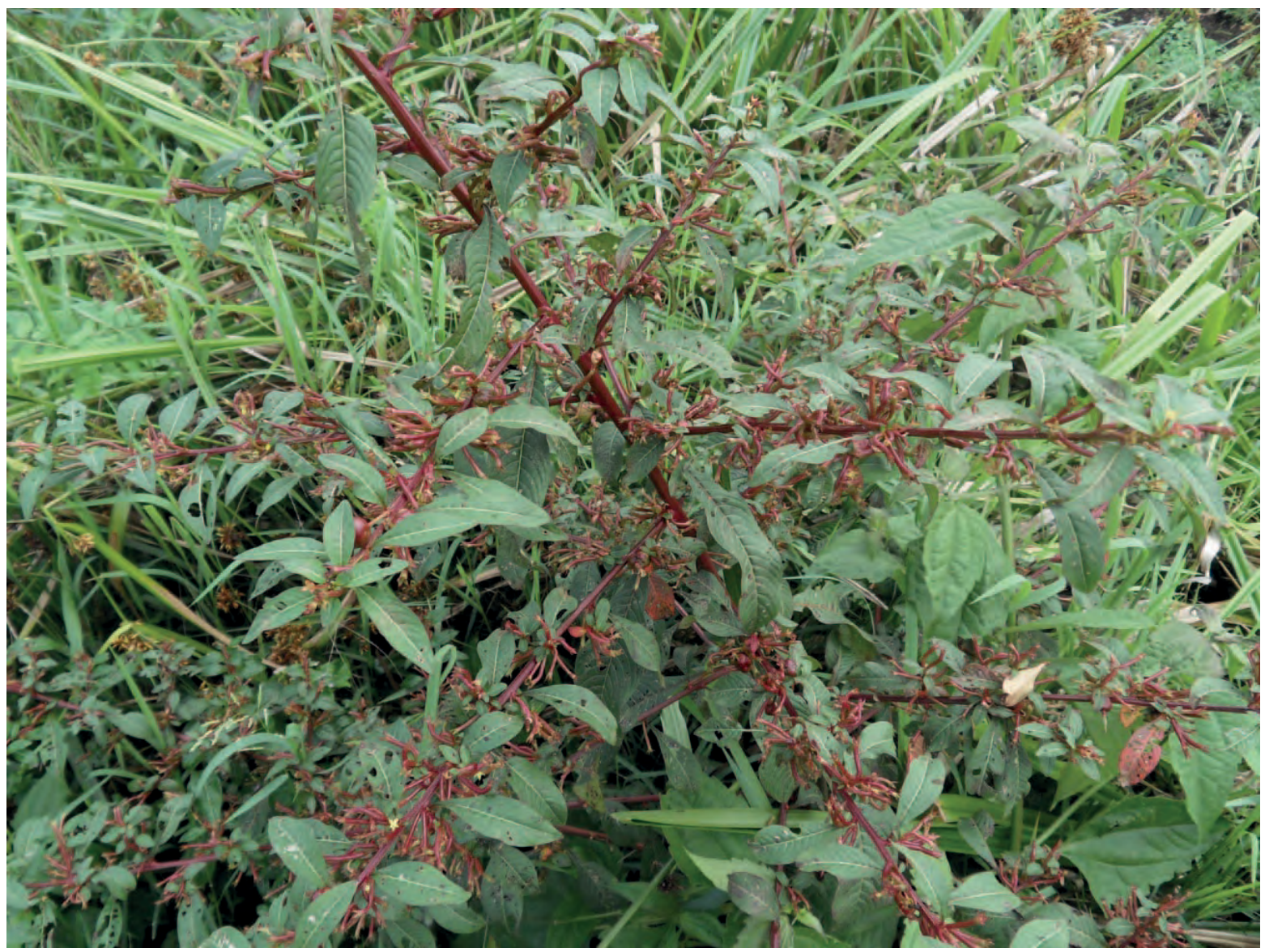

Description : Herbe vigoureuse, légèrement succulente, dressée ou rampante et ramifiée, pouvant atteindre $3 \mathrm{~m}$ de haut. Les feuilles mesurent de 1,6 à 19 sur 0,4 à $4,5 \mathrm{~cm}$. Le fruit est une capsule allongée couronnée de sépales persistants. La plante varie en couleur, du vert au rouge.

Ecologie: adventice commune des rizières. Se trouve dans toute l'Afrique, dans les marais et au bord des lacs et rivières.

Photo à droite : Robert von Blittersdorff www. africanplants. senckenberg. de

Usages : Les feuilles cuites se mangent comme légumes; on les emploie pour panser les blessures et pour traiter les maux d'estomac. Si l'on fait bouillir les feuilles avec les tiges, les feuilles donnent un liquide noir utilisé pour colorer les fibres. Une autre espèce, $L$. leptocarpa, est connue comme un bon fourrage pour les abeilles.

Références : Staner et Boutique 1937, Taton 1967, Williamson

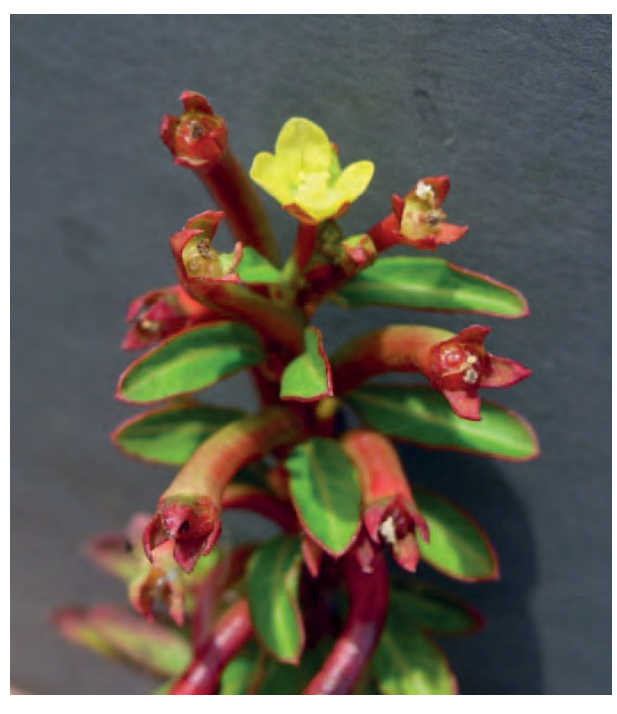
1975, Akobundu et Agyakwa 1987, Burkill 1997, Neuwinger 2000, van den Burg 2004. 


\section{Ludwigia leptocarpa}

Noms courants : J ussie (Fr.), anglestem primrose willow (Angl.),

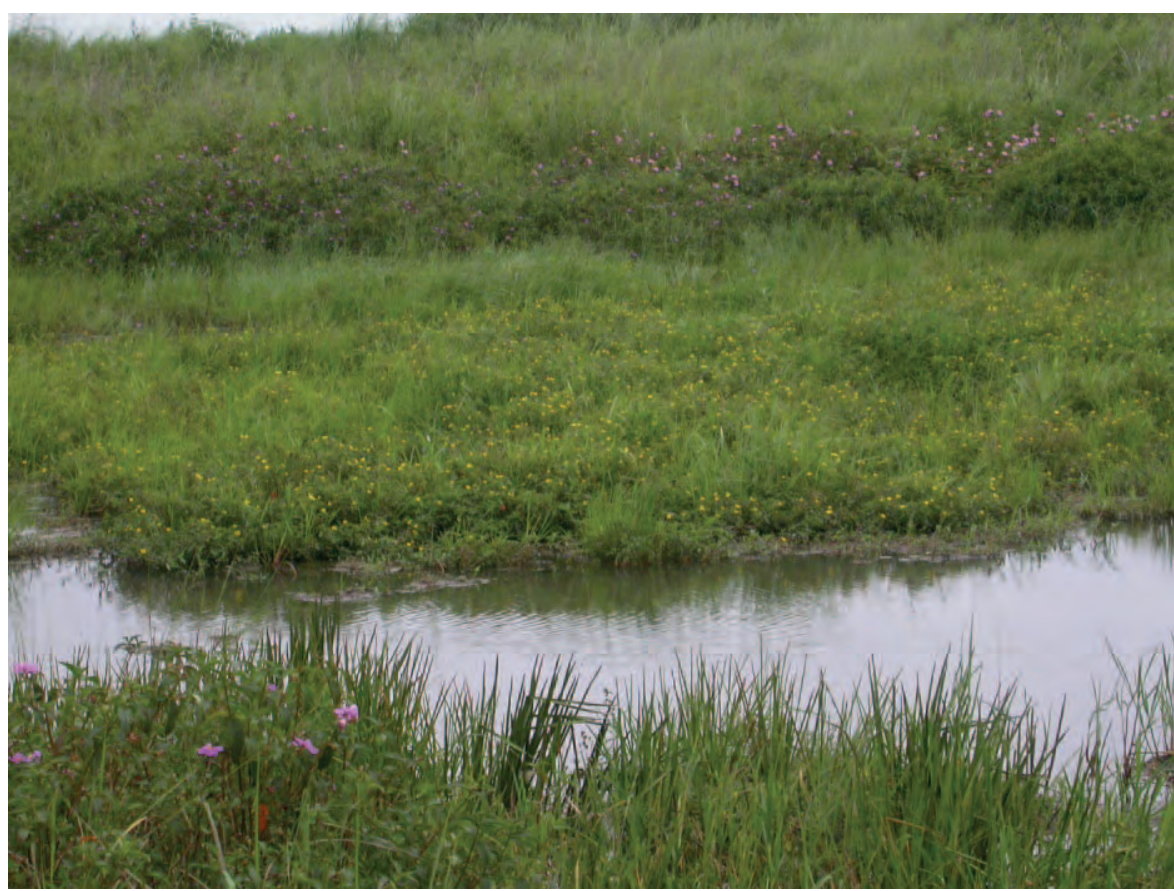

Afrique tropicale. Probablement originaire d'Amérique.
(Onagraceae)

Description : Plante herbacée annuelle, robuste et couverte de poils, jusqu'à $3 \mathrm{~m}$ de haut. Souvent submergée, avec des branches fleuries hors de l'eau. Feuilles alternes, simples et entières, de 3 à 15 sur 1 à $4 \mathrm{~cm}$. Fleurs solitaires toute l'année. Le fruit est une capsule brun pourpre, de section habituellement pentagonale, et contenant beaucoup de graines. Les graines flottent, mais adhèrent aux plumes des oiseaux, aux insectes, etc.

Ecologie: Adventice aquatique que l'on trouve dans les marais, les bancs de sable des cours d'eau, et les lieux humides en

A gauche: Matelas épais formé par la plante à la surface d'une mare saisonnière près de Mato, plateau Bateke

Usages : On signale que les abeilles récoltent le nectar et le pollen des fleurs. Au Venezuela, $L$. nervosa est une bonne source de nectar. Au Nigéria, on emploie la plante pour contrôler les érosions. En Tanzanie, la teinture noire produite à partir des feuilles permet de teindre les nattes, les paniers et les sacs en fibres de palme. En Centrafrique, on fait brûler la plante pour produire un sel végétal. L'infusion des feuilles est laxative ; on l'emploie pour expulser les vers intestinaux, pour traiter la dysenterie, et pour traiter les anomalies dans les battements du

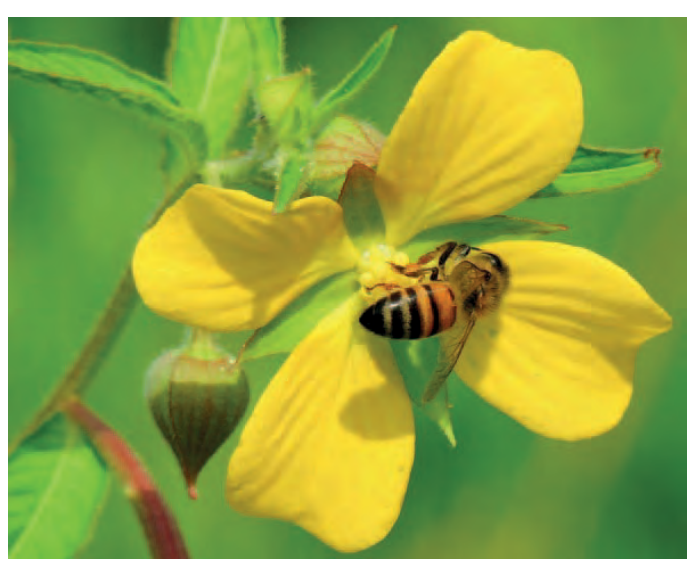

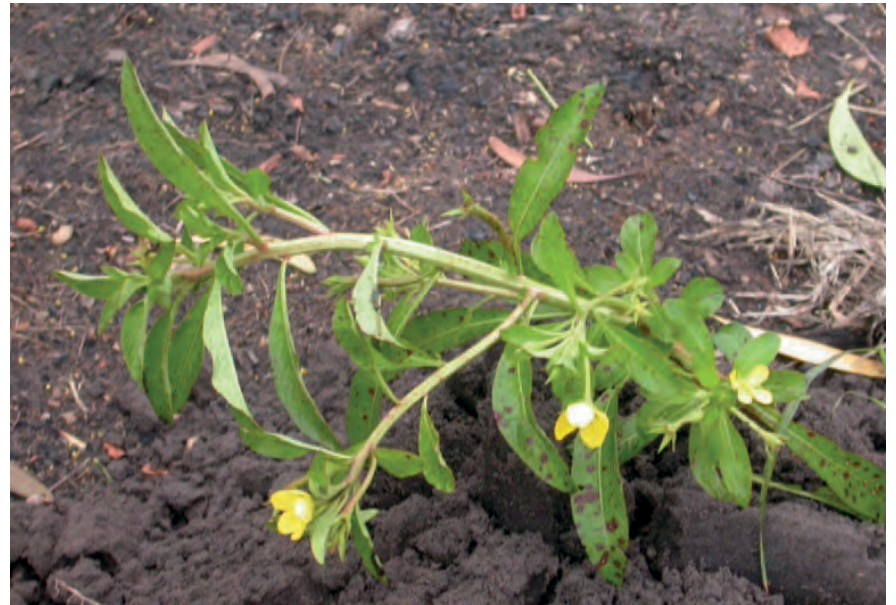

cœur. Au Nigéria, on emploie la plante pour calmer les rhumatismes.

Références : Williams 1949, Taton 1967, Bouquet 1969, Crane et al. 1984, Abbiw 1990, Burkill 1997, Mabberley 1997, Neuwinger 2000, Jansen 2005

Photo de gauche : Abeilles sur Ludwigia arcuata par Mary Wolfe 


\section{Luffa cylindrica}

Noms courants: Nsanu, musaka saka, sukula malonga (Kikongo), linuka (Lingala, pluriel manuka), éponge végétale, courge éponge (Fr.), loofah, vegetable sponge (Angl.)

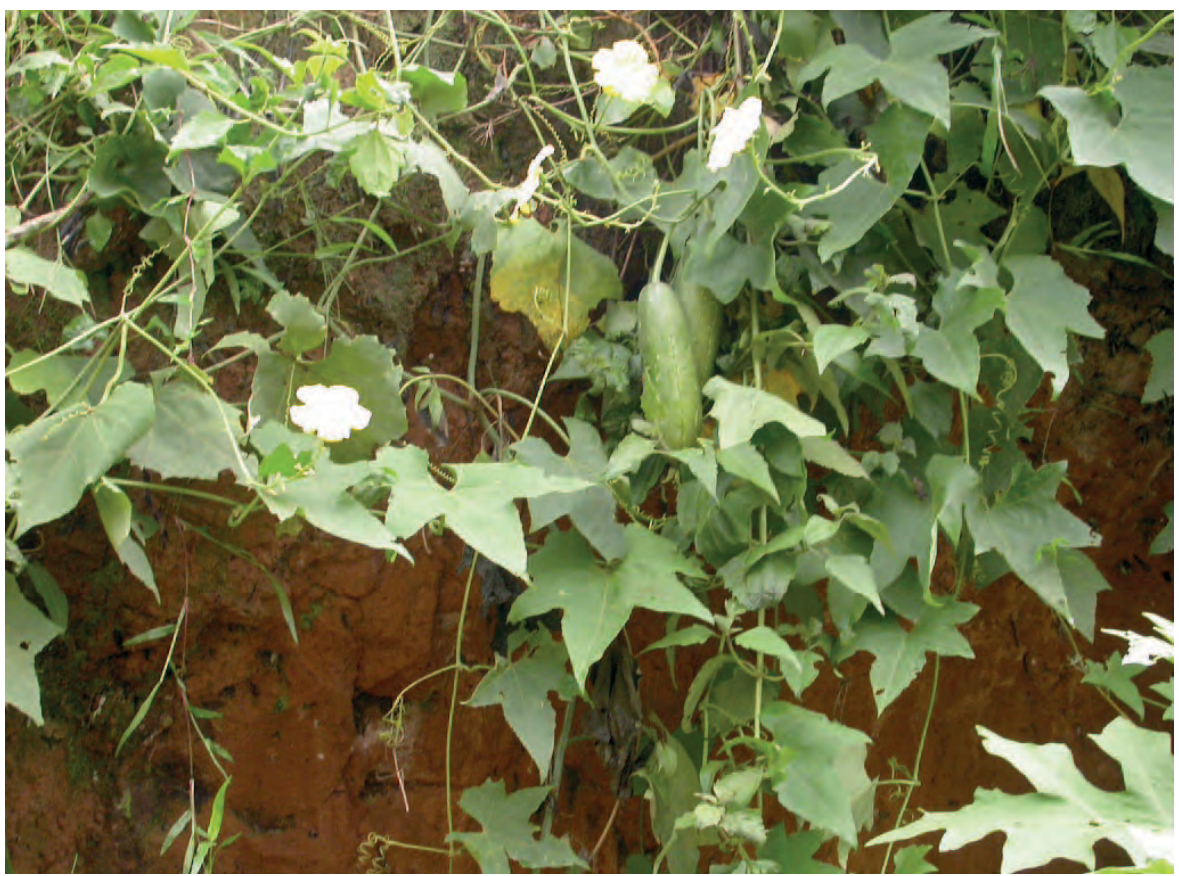

Description : Plante herbacée annuelle grimpante, de 3 à $6 \mathrm{~m}$ de long. Les tiges, légèrement poilues, ont une section pentagonale. La plante donne des fleurs jaunes tubulaires de 4 à $10 \mathrm{~cm}$ de diamètre. Elle sécrète de grandes quantités de nectar.

\section{Ecologie: Plante} originaire d'Inde, couramment cultivée et acclimatée sous les tropiques humides. Préfère les sols fertiles, légèrement acides ou neutres, bien drainés. Se développe bien dans des conditions ensoleillées, chaudes et cultiver la plante en saison sèche, parce que les fortes pluies endommagent les fleurs et les fruits, et réduisent la production de fruits.

Reproduction: Par graines, extraites des fruits pourris.

Gestion : Il faut cultiver la plante sur une treille. On taille les branches latérales pour stimuler la croissance de la tige principale ; on ne laisse que 20 à 25 fruits par pied. Récolter à pleine maturité, signalée par le jaunissement de la base et du bout 4 à 5 mois après la plantation. Immerger les fruits dans l'eau courante, jusqu'à désintégration de l'écorce. Laver alors pour extraire les graines.

\section{Luffa cylindrica en fleurs à Menkao en septembre}

Usages: Le squelette fibreux du fruit

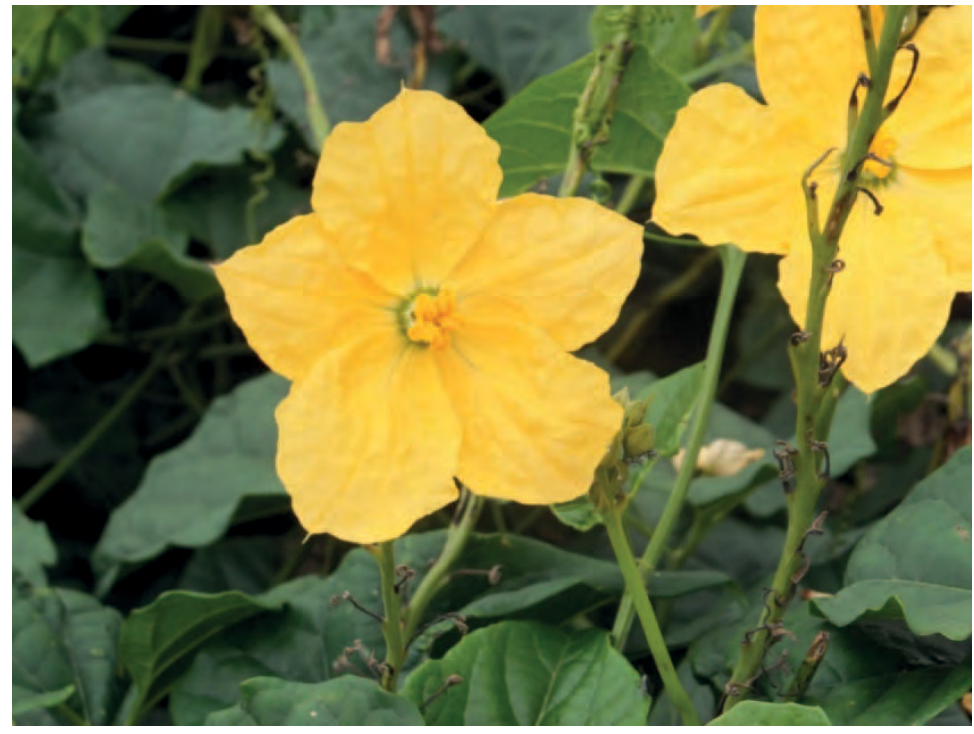

donne une excellente éponge, pour le bain et la douche, et pour la vaisselle. On l'obtient en laissant pourrir le fruit, puis en le lavant complètement. Cette éponge sert aussi de filtre pour le vin de palme. Au Kongo Central, on cuit les feuilles pour les manger ; et aussi pour panser les blessures. Les graines grillées sont comestibles ; les fruits verts sont donnés en nourriture aux cochons. On peut faire bouillir les fruits, récoltés à $10 \mathrm{~cm}$ de long, pour les

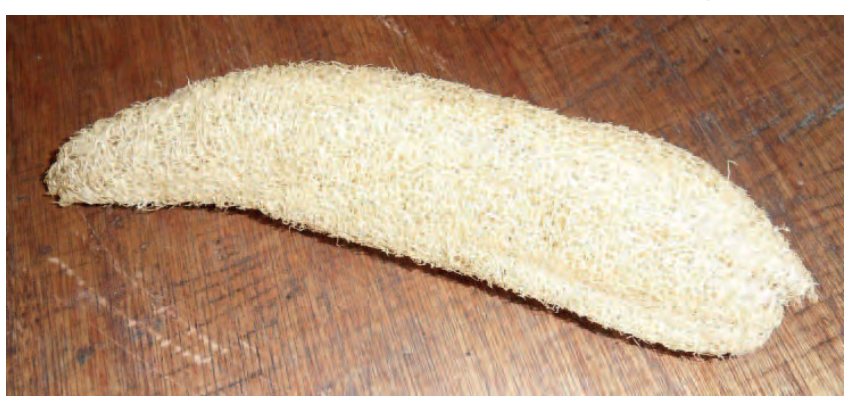
mettre dans le curry. L'éponge a un potentiel pour fabriquer des chapeaux, des semelles, des filtres, des nattes, des sets de table, des gants, et pour tout usage pour absorber les sons et les chocs. Comme pour les autres cucurbitacées, les fleurs * sont très attractives pour les abeilles.

Références : Gillet et Pâque 1910, Renier 1948, Purseglove 1968, Keraudren-Aymonin 1975, Burkill 1985, Robinson et Decker-Walters 1997 


\section{Lygodium microphyllum}

Noms courants : Kisola nkata (Kikongo), climbing maidenhair fern (Angl.)

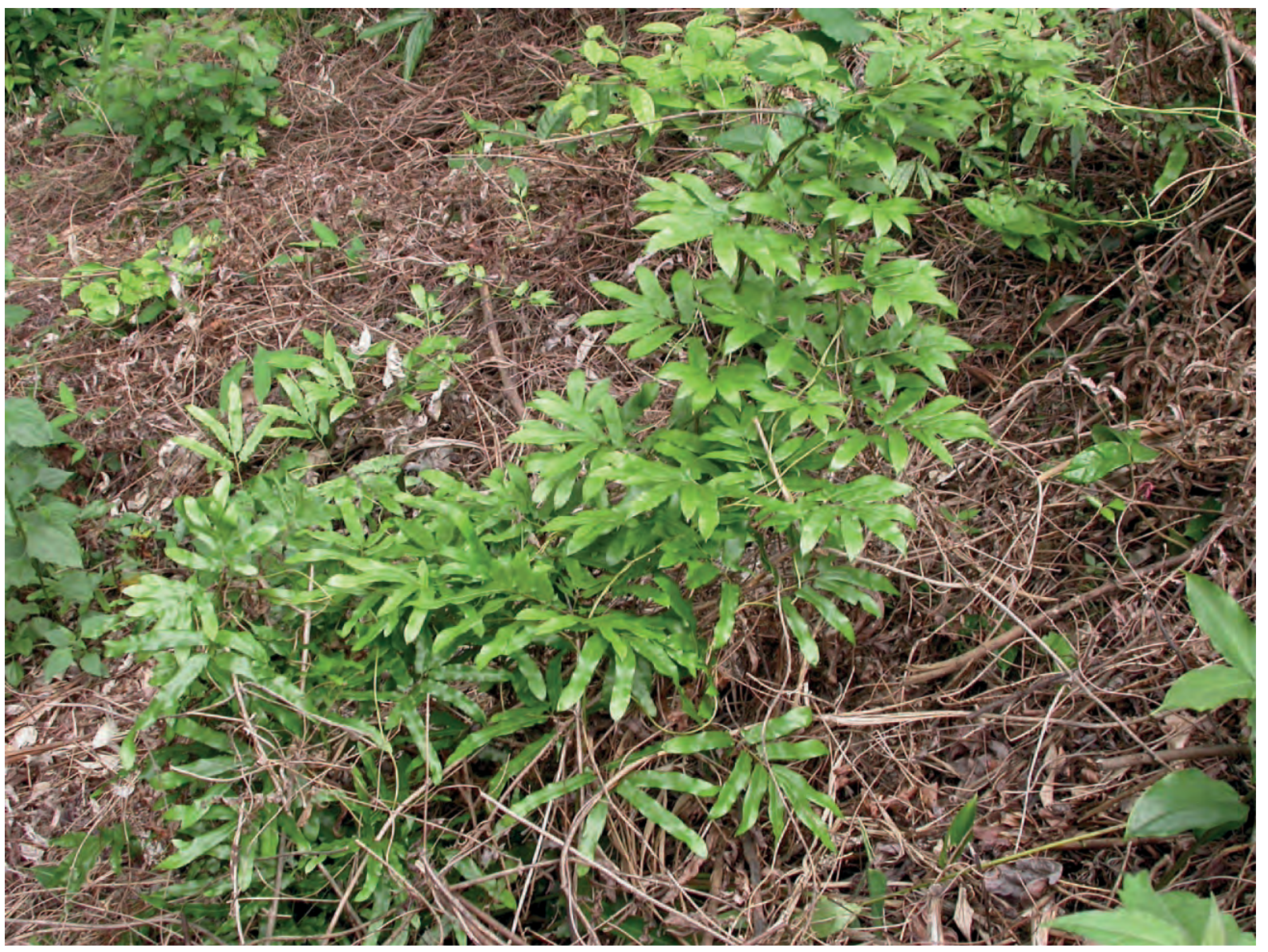

Photo prise près de Nkundi, Manianga, en mai

Description : Fougère grimpante pouvant avoir $10 \mathrm{~m}$ de long, poussant sur un rhizome couvert de poils noirs. La tige principale n'a pas de feuilles. Les branches issues de celle-ci portent des folioles longues de 5 à $12 \mathrm{~cm}$. Certaines folioles portent des spores, d'autres non.

Ecologie: Se rencontre sur des sites humides. Originaire d'Afrique tropicale, Asie du sud-est et Australie. Plante par endroits invasive. Quand elle est sèche, elle présente un risque d'incendie.

Photo : Peggy Greb ARC

Usages : Au Kongo Central, on enroule les feuilles pour former un coussinet (nkata) pour porter des charges sur la tête. Ailleurs, on emploie la plante pour soigner les

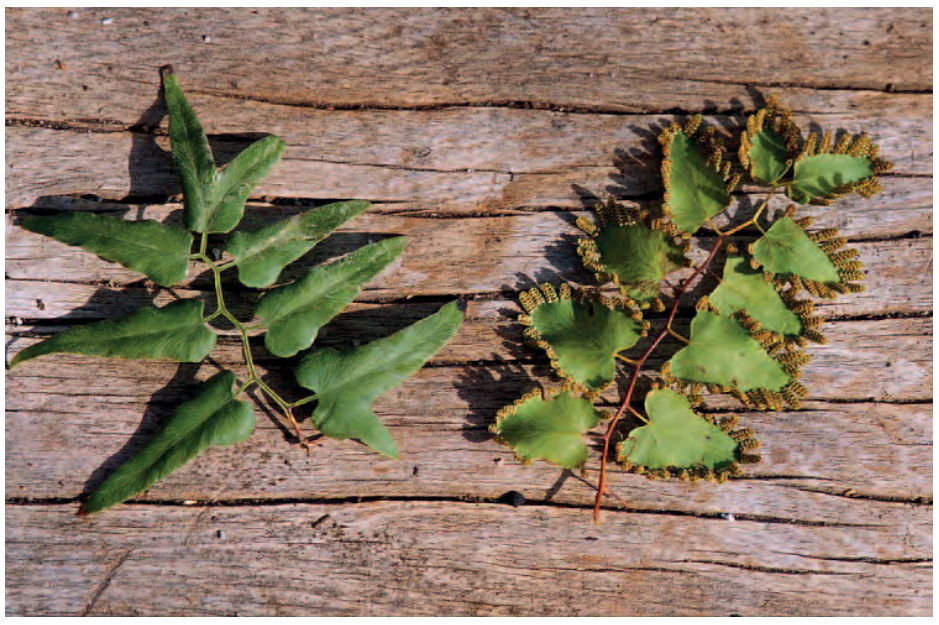
affections de la peau, les œdèmes, et la dysenterie.

Références : Lawalrée 1970, Daeleman et Pauwels 1983, Wikipedia (Consulté le 19.2.2016) 
Noms courants : Nkengi, yense (Kikongo)

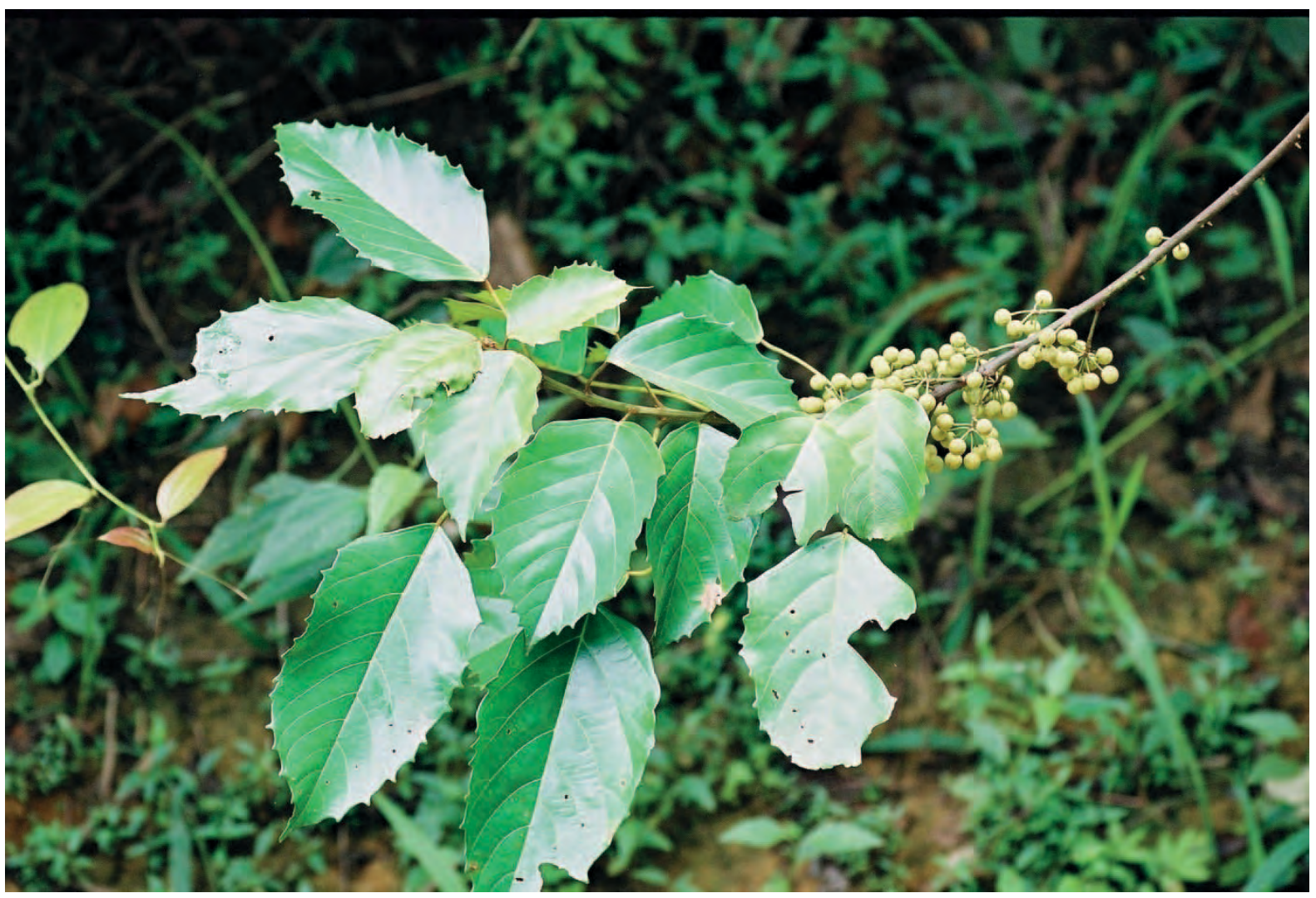

Description : Arbuste ou arbre de 6 à $25 \mathrm{~m}$ de haut. Le tronc porte des épines pouvant avoir 7,5 cm de long. Les feuilles mesurent 11 à 16 sur 6 à $10 \mathrm{~cm}$, sur un pétiole de 4 à $10 \mathrm{~cm}$. Les marges des feuilles sont d'ordinaire grossièrement dentées. La coupure de l'écorce des branches libère une gelée gluante.

Ecologie: Arbre présent dans les forêts marécageuses et les forêts riveraines, depuis le Sud du Nigéria et l'Ouest du Cameroun jusqu'à I'Angola et à la Tanzanie.

Imbrasia obscura

Reproduction : A partir de boutures.

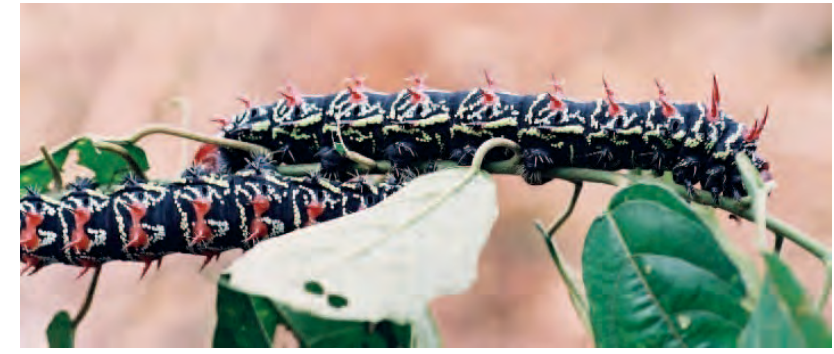

Usages : Le bois est léger et résiste aux insectes. Au Kongo Central, on l'emploie pour les charpentes. Les chenilles comestibles Minsendi (Imbrasia obscura), Miengeti (Phalera sp.), Kaba (Lobobunaea phaedusa), Nziemo et Nkulu se nourrissent des feuilles. Au Congo Brazzaville, on donne aux femmes une décoction de l'écorce, avec de l'écorce

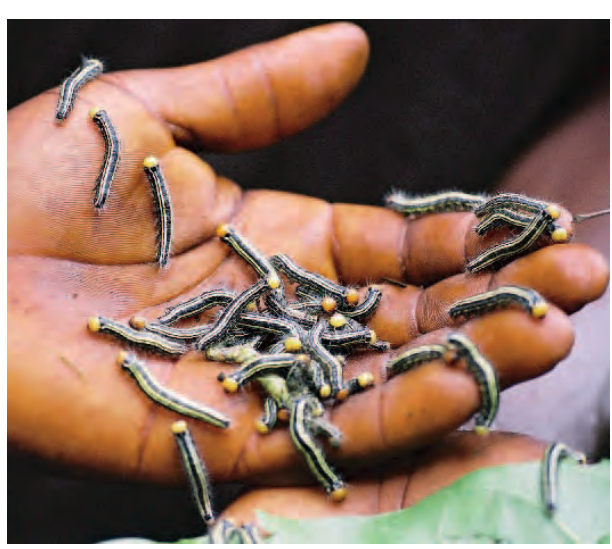
de Pentaclethra eetveldeana pour traiter la stérilité. Les feuilles, l'écorce et les racines contiennent des tannins, des stéroïdes et des terpènes. Au Gabon, on connait les espèces de Macaranga comme fourrage des abeilles.

A gauche : Chenilles Miengeti (Phalera sp.)

Références : Gillet et Pâque 1910, Renier 1948, Daeleman et Pauwels 1983, Lobreau-Callen et al. 1989, Ambougou 1991, Pauwels 1993, Burkill 1994, Latham 2008 
Noms courants : Nfumfu, nkengi, nkenkete (Kikongo)

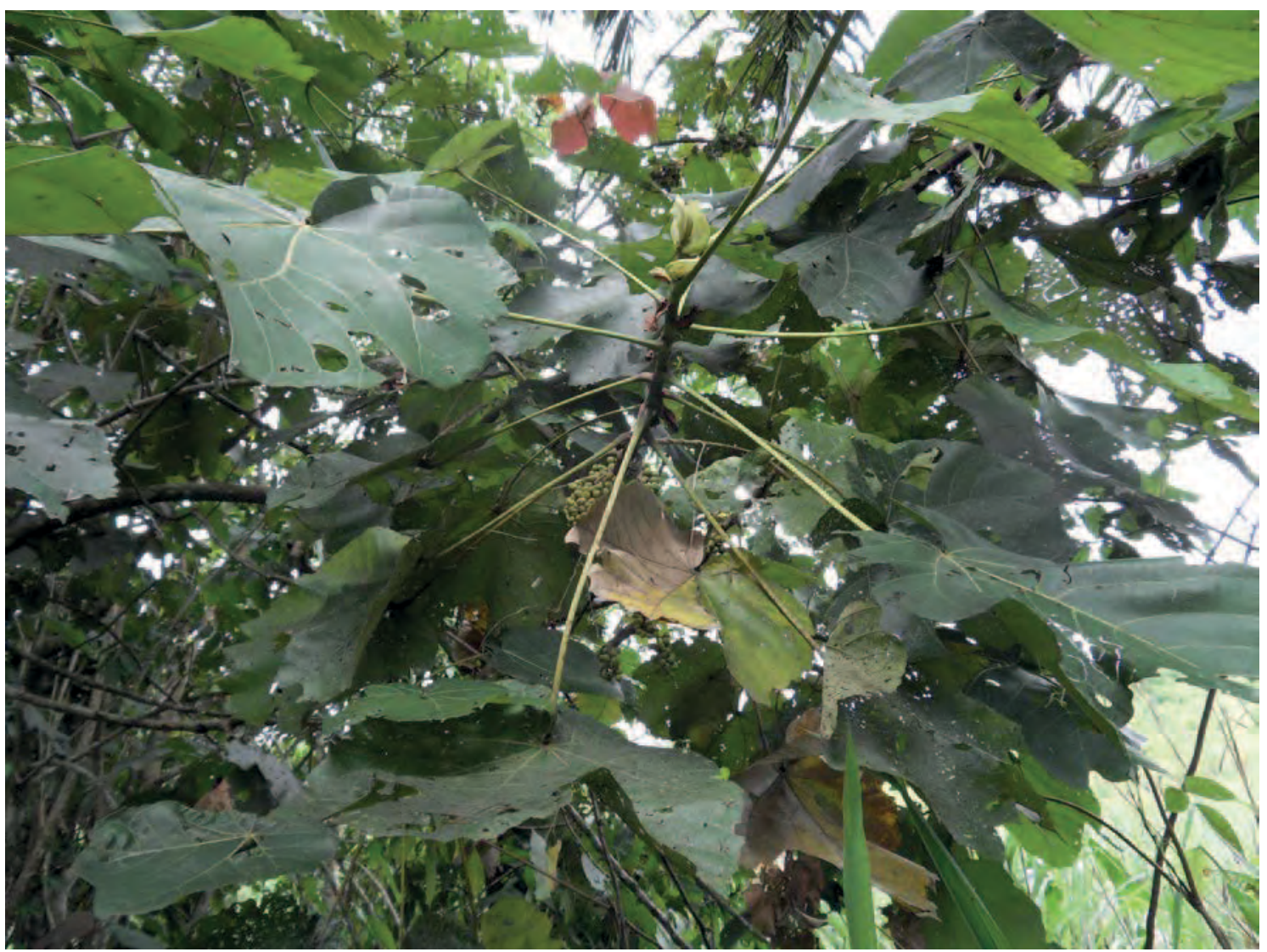

Description : Buisson rampant ou arbuste. Le tronc et les branches sont armés d'épines. Feuilles lobées aux marges irrégulières de 20 à $26 \mathrm{~cm}$ de diamètre, sur de longs pétioles. Des fourmis vivent en association avec cette plante.

Ecologie: Plante des forêts inondées et des rives de cours d'eau, du Cameroun et du Gabon à la R.D. Congo.

Usages : Les Macaranga spp. sont un fourrage important pour les abeilles dans les zones de savane ; on les connait pour être visitées par les abeilles au Gabon. Dans la Province de l'Equateur, on emploie l'écorce pour traiter les maux de tête. Au Katanga, on arrête les saignements de nez en insérant dans les narines la cendre des feuilles brûlées ; on panse aussi les blessures avec cette cendre. La chair des fruits serait comestible. Au Kongo Central, plante enregistrée comme nourriture d'une chenille comestible (à déterminer).

Photo: J os Stevens www.africanplants. senckenberg.de

Références: Gillet 1927, Renier 1948, Daeleman et Pauwels 1983, Lobreau-Callen et al. 1989, Pauwels 1993 , Kibungu Kembelo 1995, Hepburn et Radloff 1998 Stevens 2011, Konda Ku Mbuta et al. 2015a

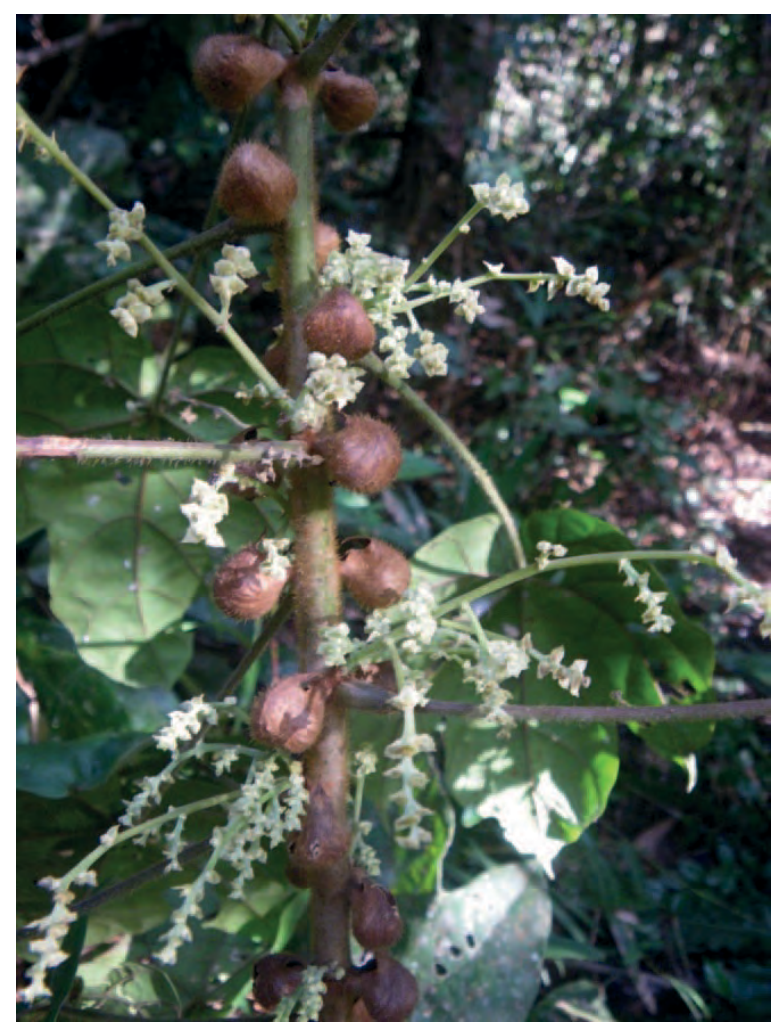




\section{Macaranga schweinfurthii}

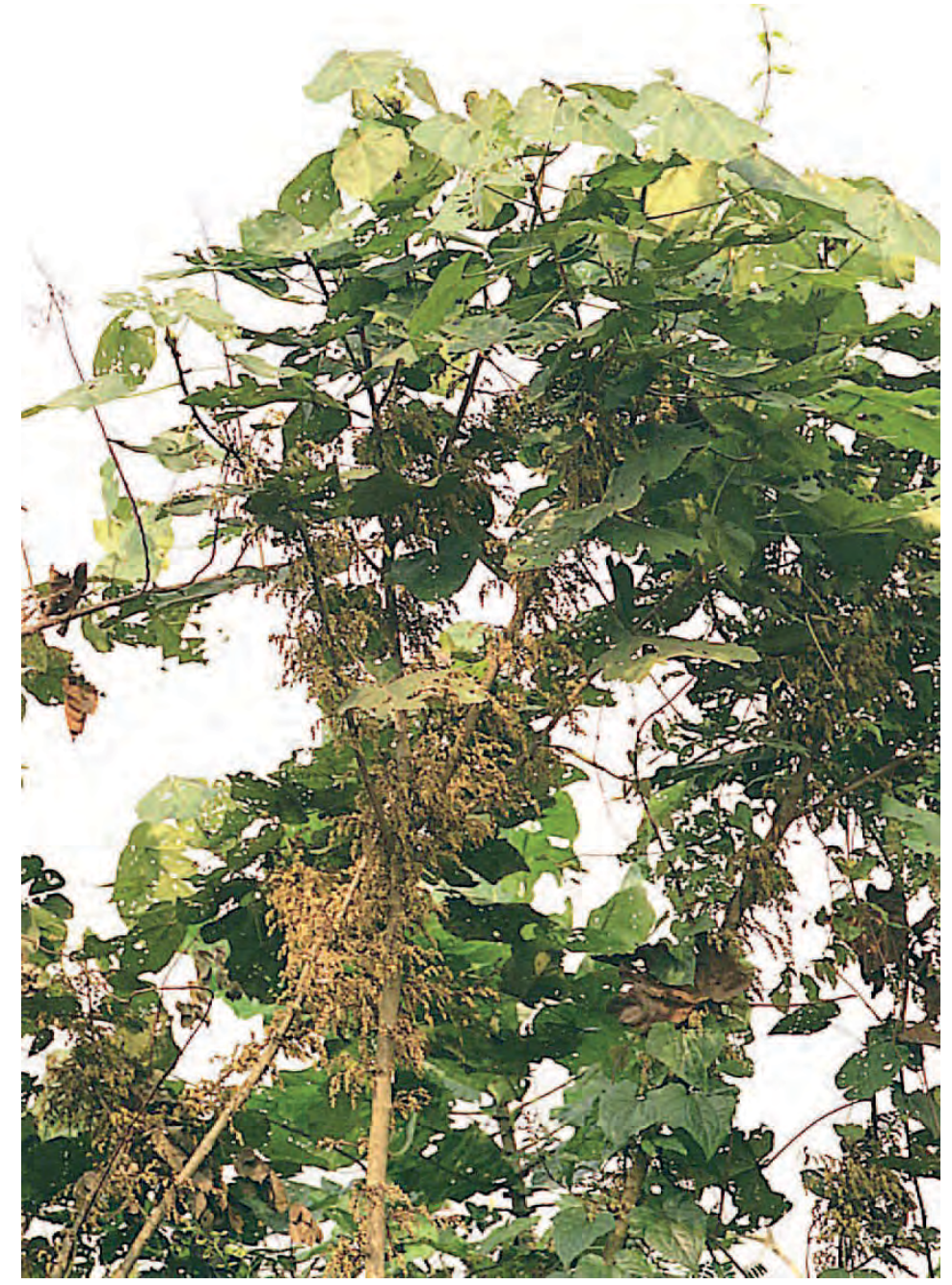

(Euphorbiaceae)

Noms courants : Nfumfu, nkengi, nkenkete (Kikongo)

Description : Buisson rampant ou arbuste jusqu'à $8 \mathrm{~m}$ de haut. Tronc et branches couverts d'épines. Grandes feuilles pouvant avoir de 25 à $50 \mathrm{~cm}$ de part en part.

Ecologie: Plante des forêts humides, souvent au bord de l'eau, du Sud-est du Nigéria à l'Ouganda et à la Zambie.

Macaranga schweinfurthii en fleurs au bord d'un ruisseau près de Kasangulu

Usages : Les abeilles récoltent le pollen des fleurs. Au Gabon, on signale que $M$. barteriand $M$. monandra sont aussi visitées par les abeilles. Dans certaines régions, la cendre du bois sert de sel végétal. Les feuilles servent de suremballage pour protéger les produits alimentaires de l'attaque des insectes.

Références: Gillet et Pâque 1910, De Wildeman 1934, Ambougou 1991, Pauwels 1993

\section{Ci-dessous : Branche fleurie}

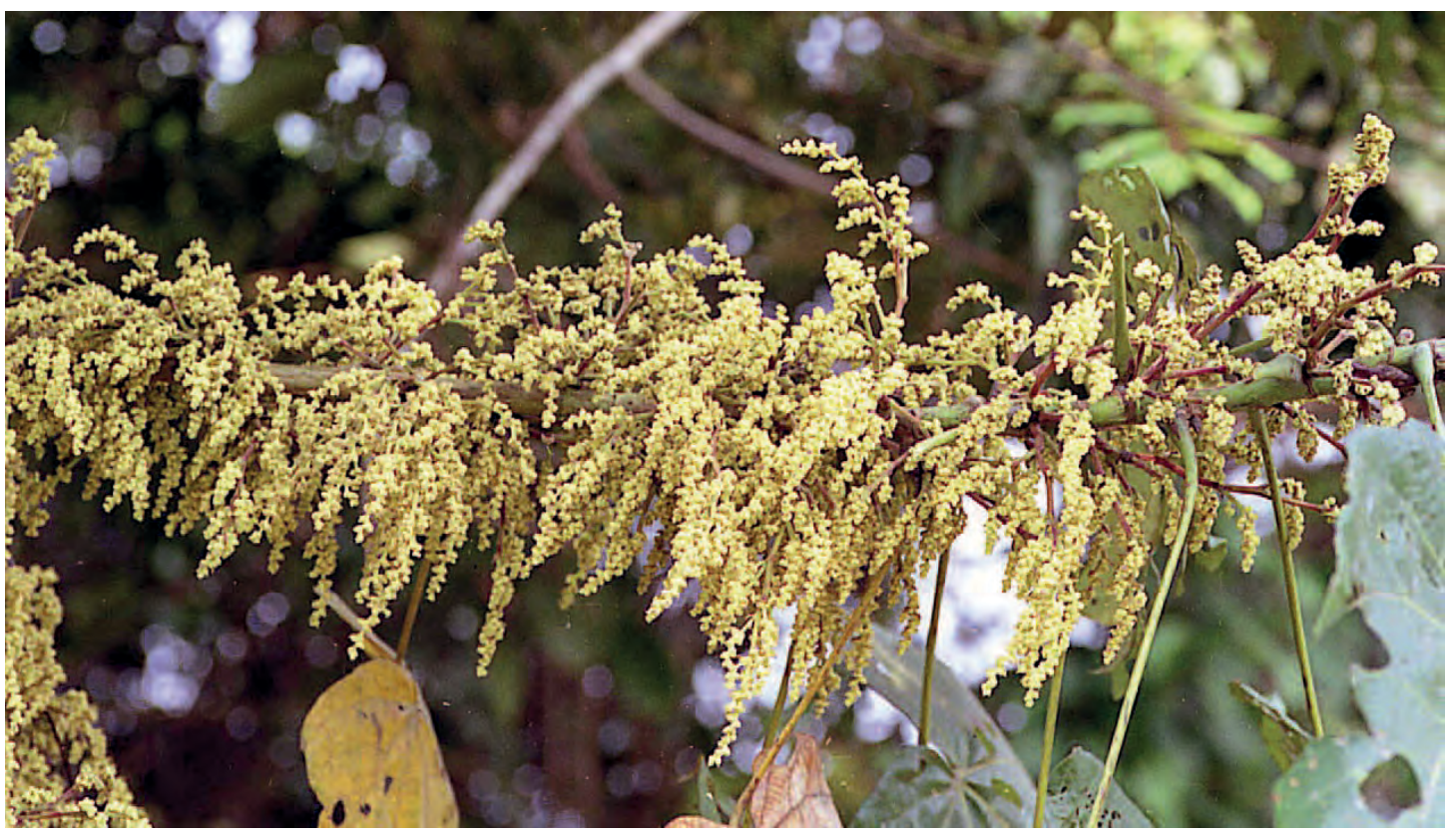


Nom courant : Sasa (Kikongo). Ce nom désigne aussi M. vermoesenii

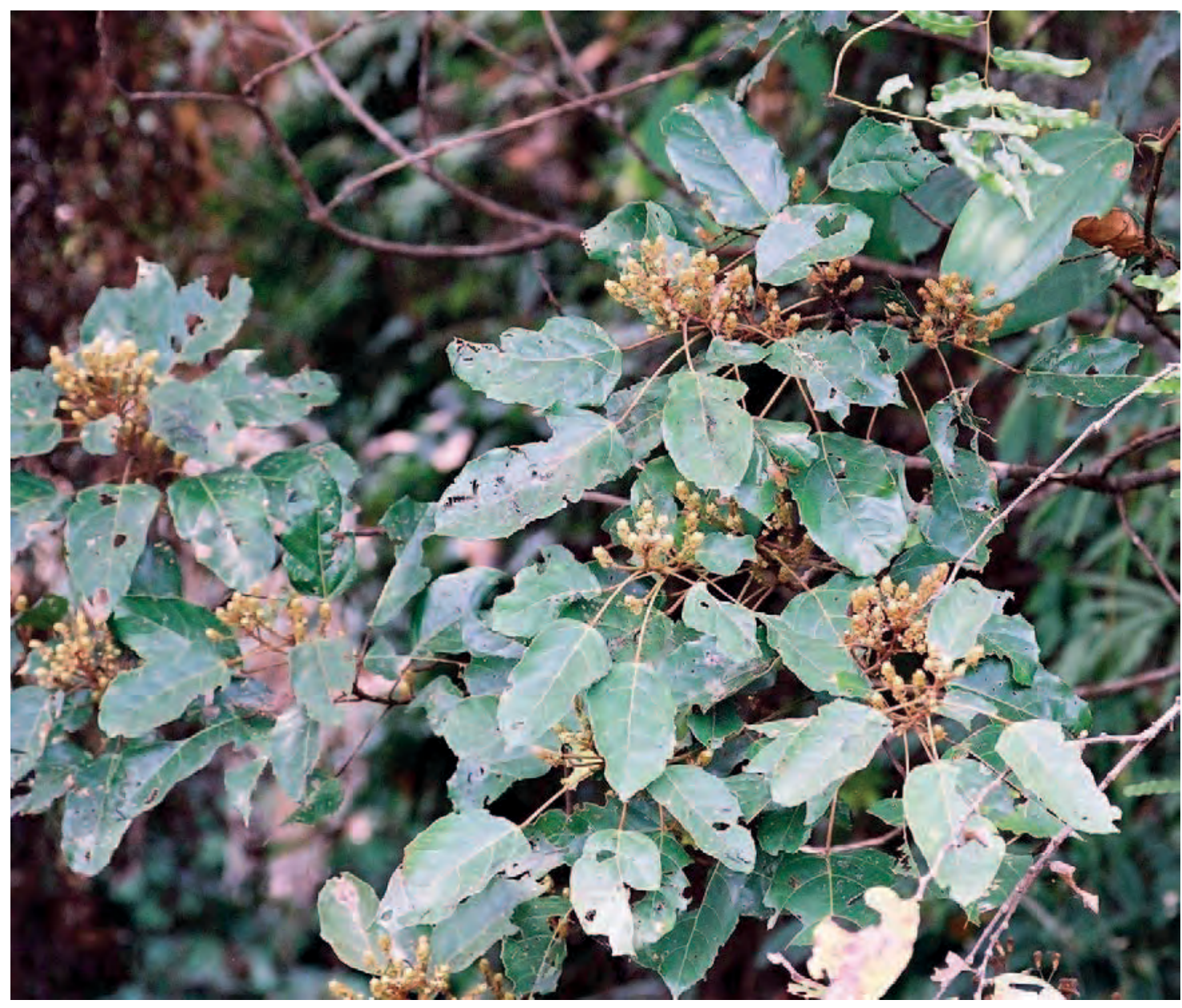

Macaranga spinosa en fleurs à Kintete, Manianga

Description : Arbuste ou arbre pouvant avoir $15 \mathrm{~m}$ de haut. Les longes branches, étalées ou tombantes, sont armées d'épines. Les feuilles ont 5 à 13 sur 3 à $6,5 \mathrm{~cm}$. Les fleurs mâles et femelles sont séparées, et disposées sur un épi axillaire de 3 à $6,5 \mathrm{~cm}$ de long.

Ecologie : Plante des forêts denses, du Libéria à l'Ouganda et à la Tanzanie.

Reproduction: Une espèce voisine, Macaranga barteri, donne beaucoup de graines et se bouture aisément.

Usages : Les troncs s'emploient en construction. En Côte d'l voire, la plante sert à traiter la dysenterie et la toux. Les chenilles comestibles Anaphe panda (N'kankiti) et Nkulu se nourrissent des feuilles. La chenille Nkulu se prépare avec soin : ôter la tête et les intestins, cuire dans un peu d'eau jusqu'à évaporation complète, griller au sel et au poivre. La plante, qui fleurit en octobre, est signalée dans le district de Manianga comme un bon fourrage pour les abeilles.

Remarque : II y a au Kongo Central cinq autres espèces de

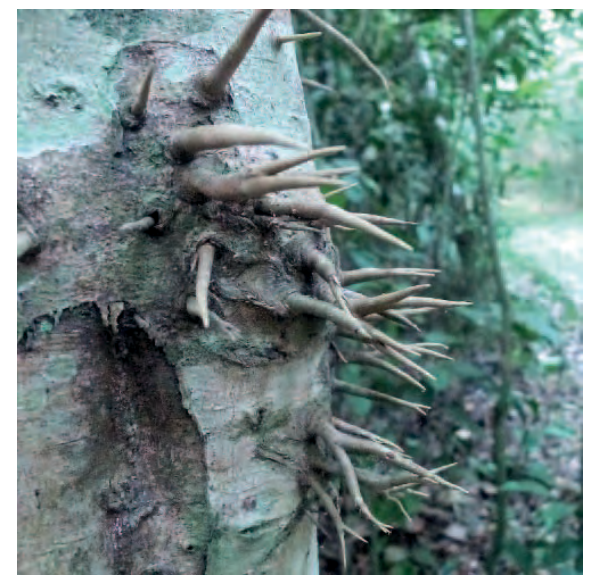
Macaranga.

Références : Irvine 1961, Cobbina et Reynolds 1988, Keay 1989, Lobreau-Callen et al. 1989, Ambougou 1991, Pauwels 1993, Burkill 1994, Kibungu Kembelo 1995, Schmelzer 2007 
Noms courants : Ntidi (Kikongo), false assegai (Angl.)

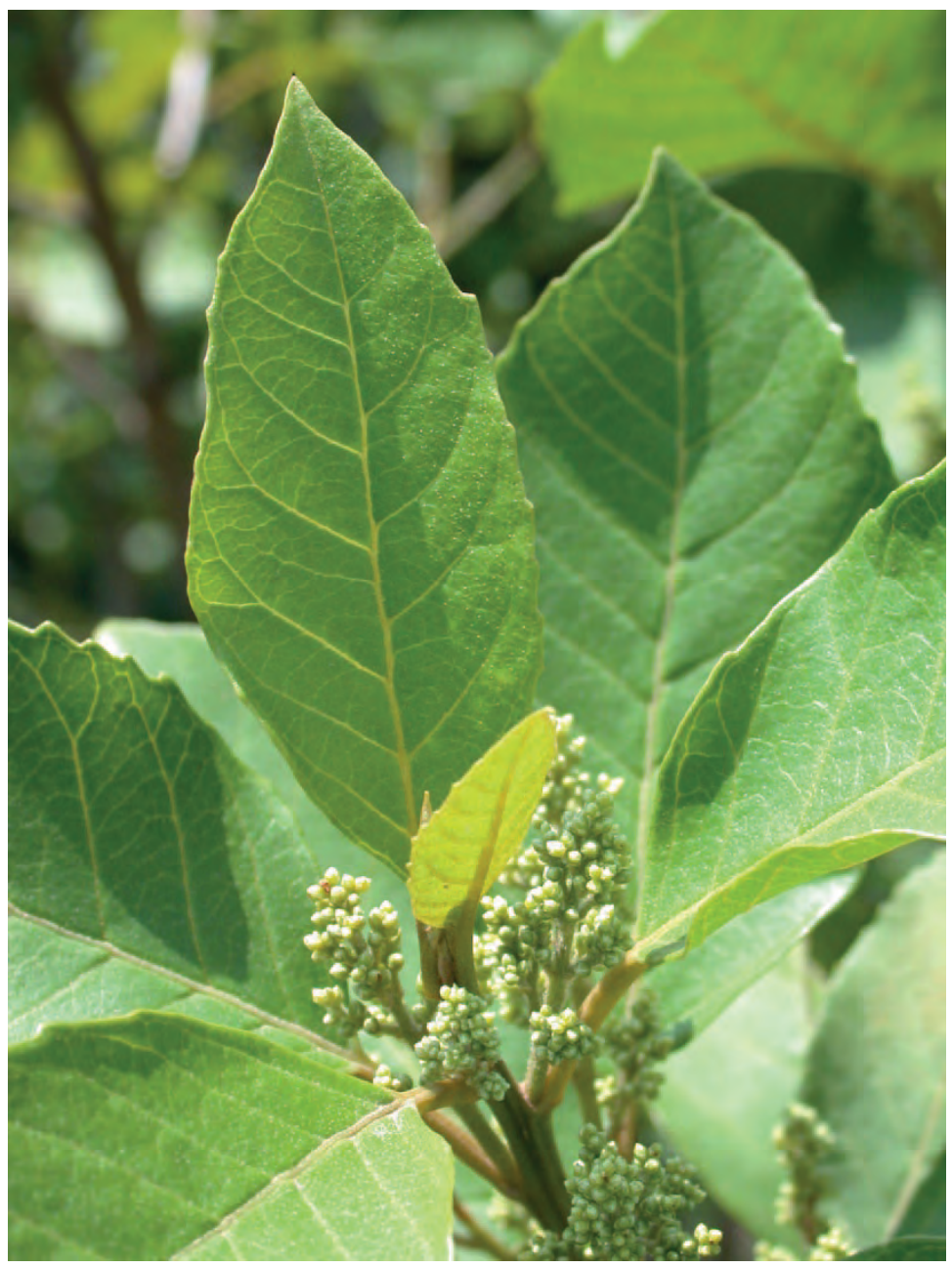

Description : Arbuste ou arbre à croissance rapide, de 2 à $10 \mathrm{~m}$ de haut, variable et parfois semi grimpant. Feuilles ovales de 5 à 22 sur 2 à $12 \mathrm{~cm}$. Le dessous des feuilles est pubescent. Petites fleurs blanc crème, disposées en têtes ramifiées et parfumées pouvant avoir $10 \mathrm{~cm}$ de long. Très petit fruit rond, blanc et charnu.

Les deux photos : Hugh Glen

Ecologie : Plante des recrus forestiers et forêts riveraines dans toute l'Afrique tropicale, en Afrique du Sud et à Madagascar. Pousse sur des sols pauvres ou dégradés.

Gestion : Plante à croissance rapide, qui recèpe bien et se conduit en taillis.

Usages : Le bois, blanc et mou, s'abime rapidement. En R.D. Congo, on emploie la racine pour traiter les abcès. Après décoction, on applique les feuilles pressées sur le corps pour traiter la variole. L'eau de la décoction se boit contre la diarrhée. Les jeunes feuilles se mangent comme légumes. Les abeilles visitent les fleurs, qui fleurissent souvent et sont donc un bon fourrage pour les abeilles. Le fruit aurait un goût sucré.

Références : Staner et Boutique 1937, Renier 1948, Taton 1980, Pauwels 1993,

Beentje 1994, Fichtl et Adi 1994, Katende et al. 1995, Burkill 1997, Glen et Mkhipheni 2005, Meunier 2010

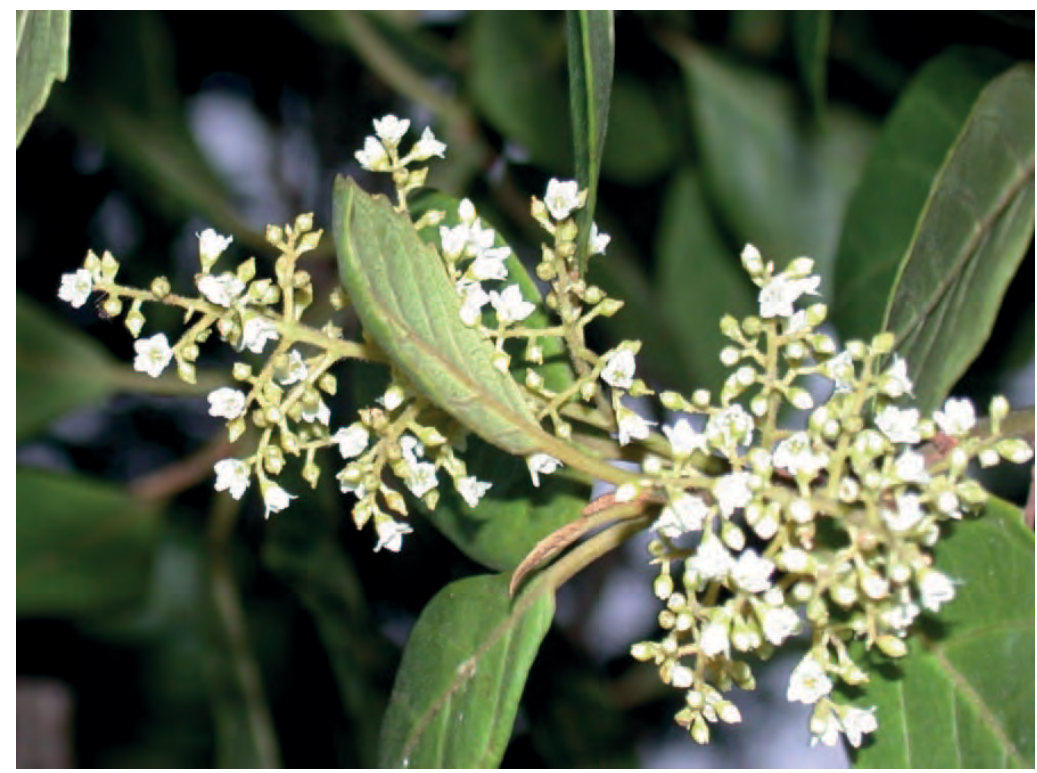




\section{Maesobotrya bertramiana}

Nom courant : Ngaingai ya mfinda (Kikongo)

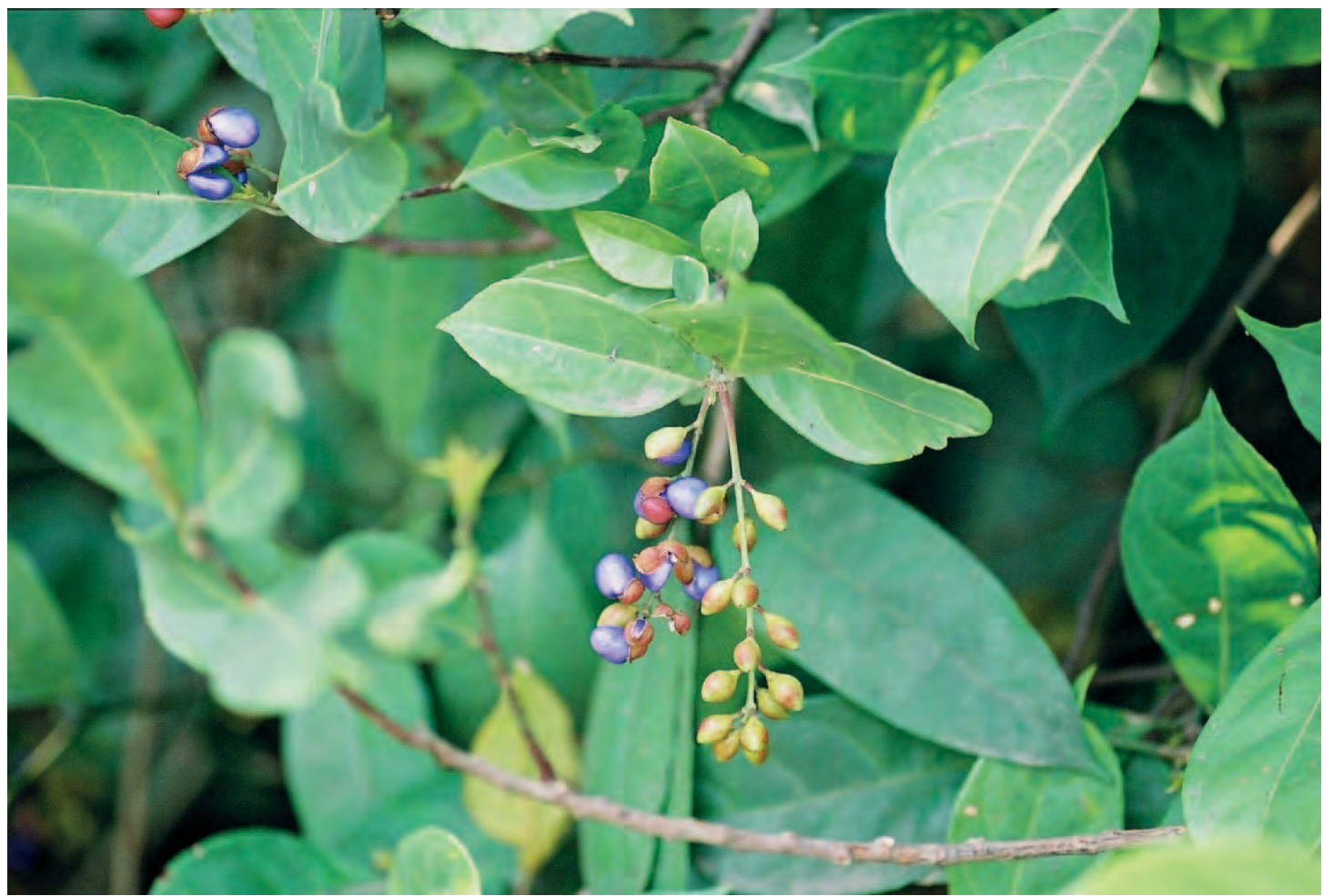

Description : Buisson ou arbuste de 2 à $10 \mathrm{~m}$ de haut. Les feuilles portent des stipules asymétriques, en faucilles, de 3 à $25 \mathrm{~mm}$ sur 1 à $12 \mathrm{~mm}$. Le pétiole mesure de 0,5 à $2 \mathrm{~cm}$. Le limbe des feuilles est oblong, de 3,5 à $25 \mathrm{~cm}$ sur 2 à 9,5 cm, avec de petites dents très visibles et bien espacées sur les jeunes feuilles. Inflorescences axillaires ou terminales, mesurant jusqu'à $21 \mathrm{~cm}$ de part en part quand elles portent des fruits. Le fruit est une capsule ellipsoïde, généralement pointue, de 7 à $10 \mathrm{~mm}$ de long sur 4 à $6 \mathrm{~mm}$ de diamètre.

Ecologie: Plante des sous-bois dans les savanes boisées, les forêts sèches, les forêts galeries et les forêts secondaires, du Gabon jusqu'à l'Est de la R.D. Congo.

Usages: On mange souvent les jeunes feuilles comme légumes. Au Katanga, elles servent à assaisonner les plats de poisson.

Références : Léonard 1962, Stevens 2011

Photo à droite, montrant les stipules

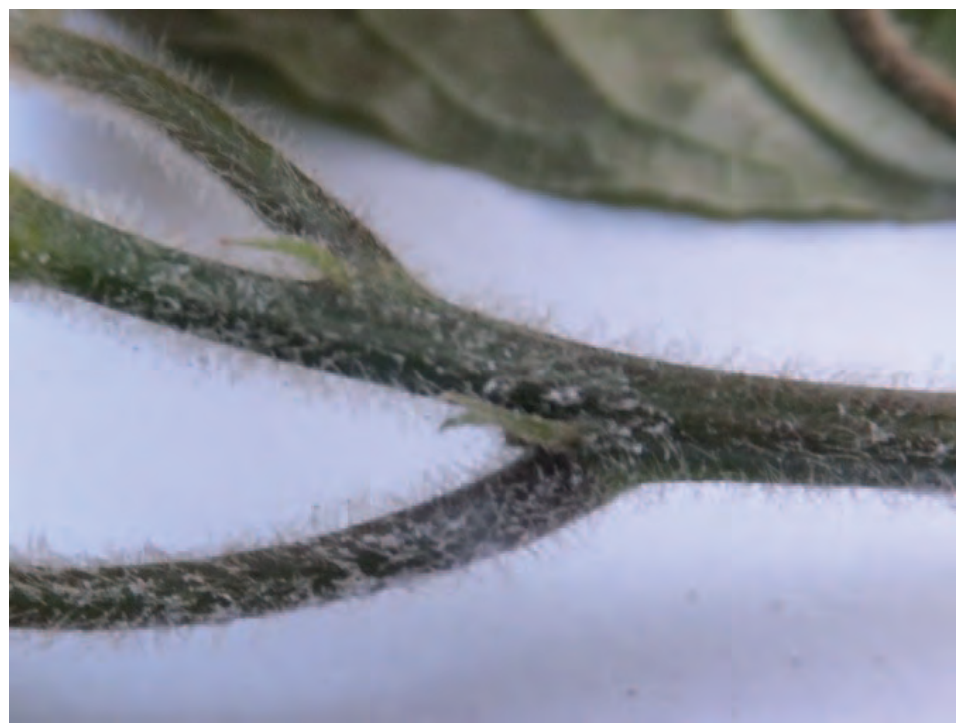


Maesobotrya staudtii

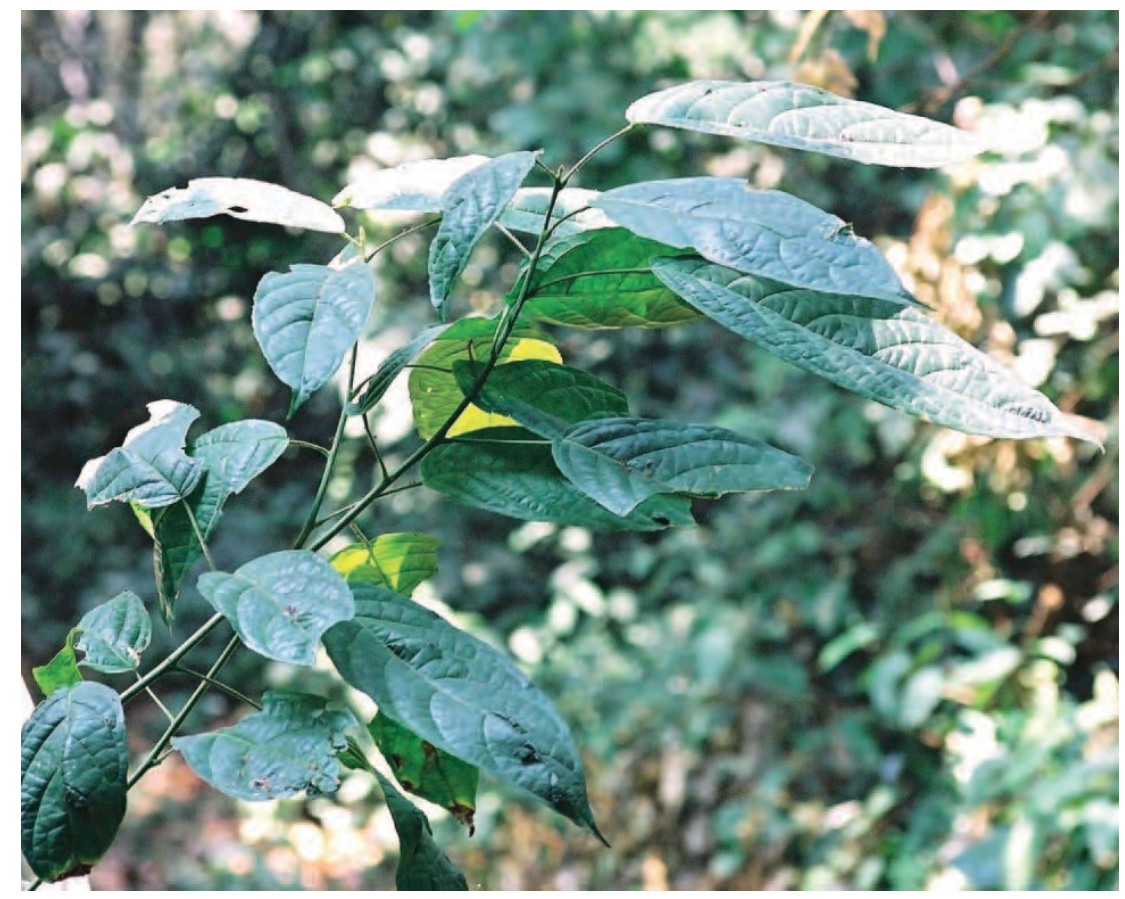

(Phyllanthaceae)

Noms courants : Mansiese,

mansiensi (Kikongo), raisinier des bois ( $\mathrm{Fr}$.)

Description : Buisson ou arbuste de 2 à $6 \mathrm{~m}$ de haut et de 4 à $10 \mathrm{~cm}$ de diamètre. Le bois est blanc à jaune, tendre. Les feuilles, de 7 à $28 \mathrm{~cm}$ sur 3 à 12 $\mathrm{cm}$, sont poilues sur les deux faces ; la nervure centrale et les nervures principales sont densément couvertes de poils raides. Le pétiole a 1 à $10 \mathrm{~cm}$. Les fleurs sont disposées sur le tronc, avec des inflorescences mâles longues de 3 à $11 \mathrm{~cm}$, et femelles de 1 à $5 \mathrm{~cm}$. Les fruits ronds ont $10 \mathrm{~mm}$ de diamètre.

Ecologie: Plante de sous-bois des forêts pluviales, que l'on trouve souvent dans les sites humides, notamment dans le

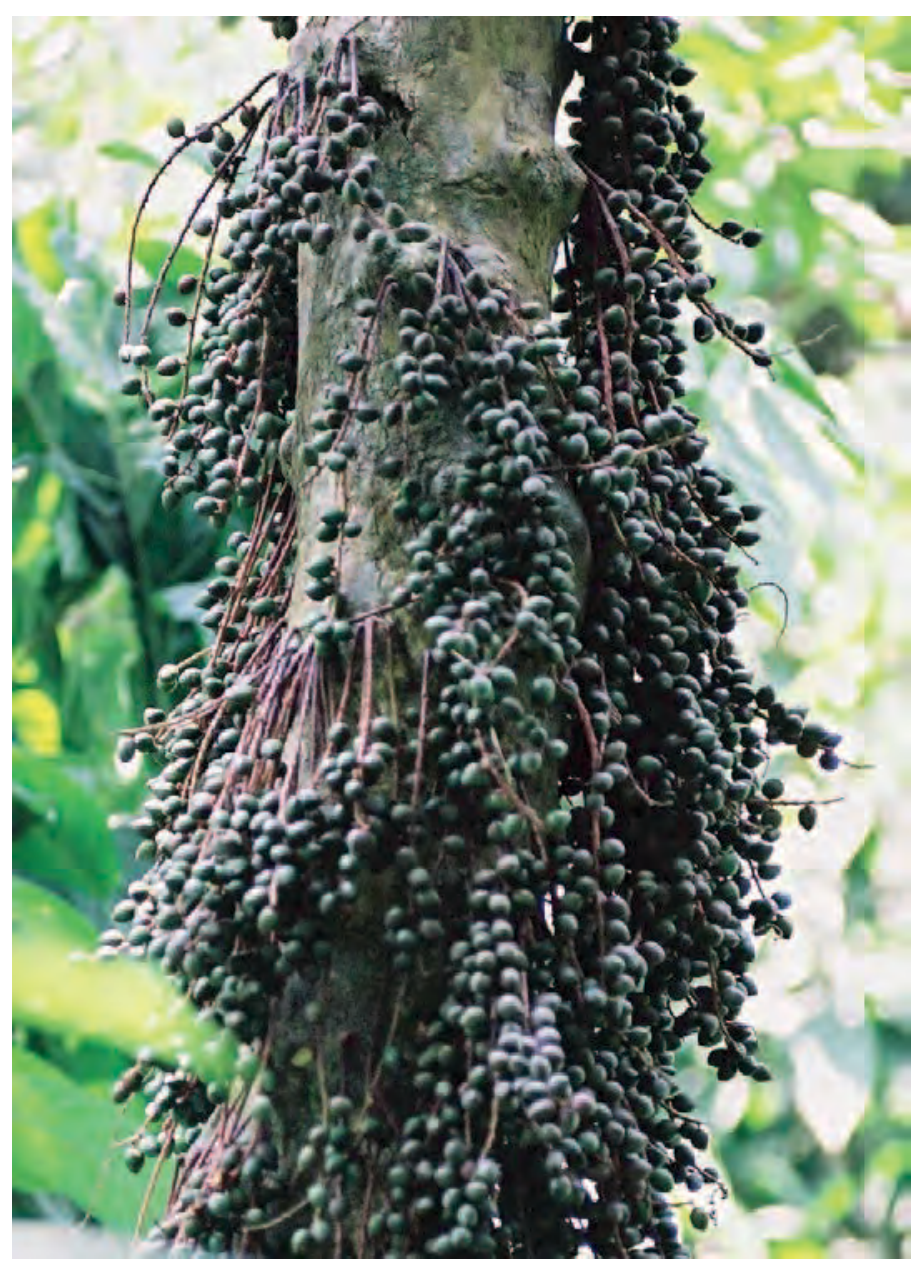

district du Mayombe au Kongo Central, associé avec Gilbertiodendron dewevrei, Scorodophloeus zenkeri et Cynometra alexandri.. Présente également au Sud du Nigéria et au Cameroun.

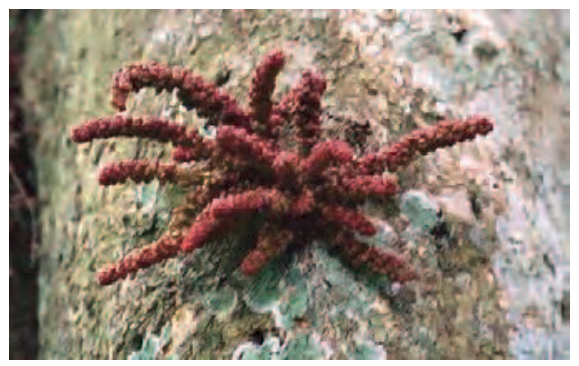

A gauche : Maesobotrya staudtii portant des fruits en septembre, au jardin botanique de Kisantu.

Usages : Le fruit, comestible, est acide et rafraichissant ; il donne une bonne confiture Les feuilles se mangent comme légumes.

Références : Gillet 1927, De Wildeman 1934, Renier 1948, Léonard 1962, Keay 1989, Burkill 1994 
Nom courant : Fitidi (Kikongo)

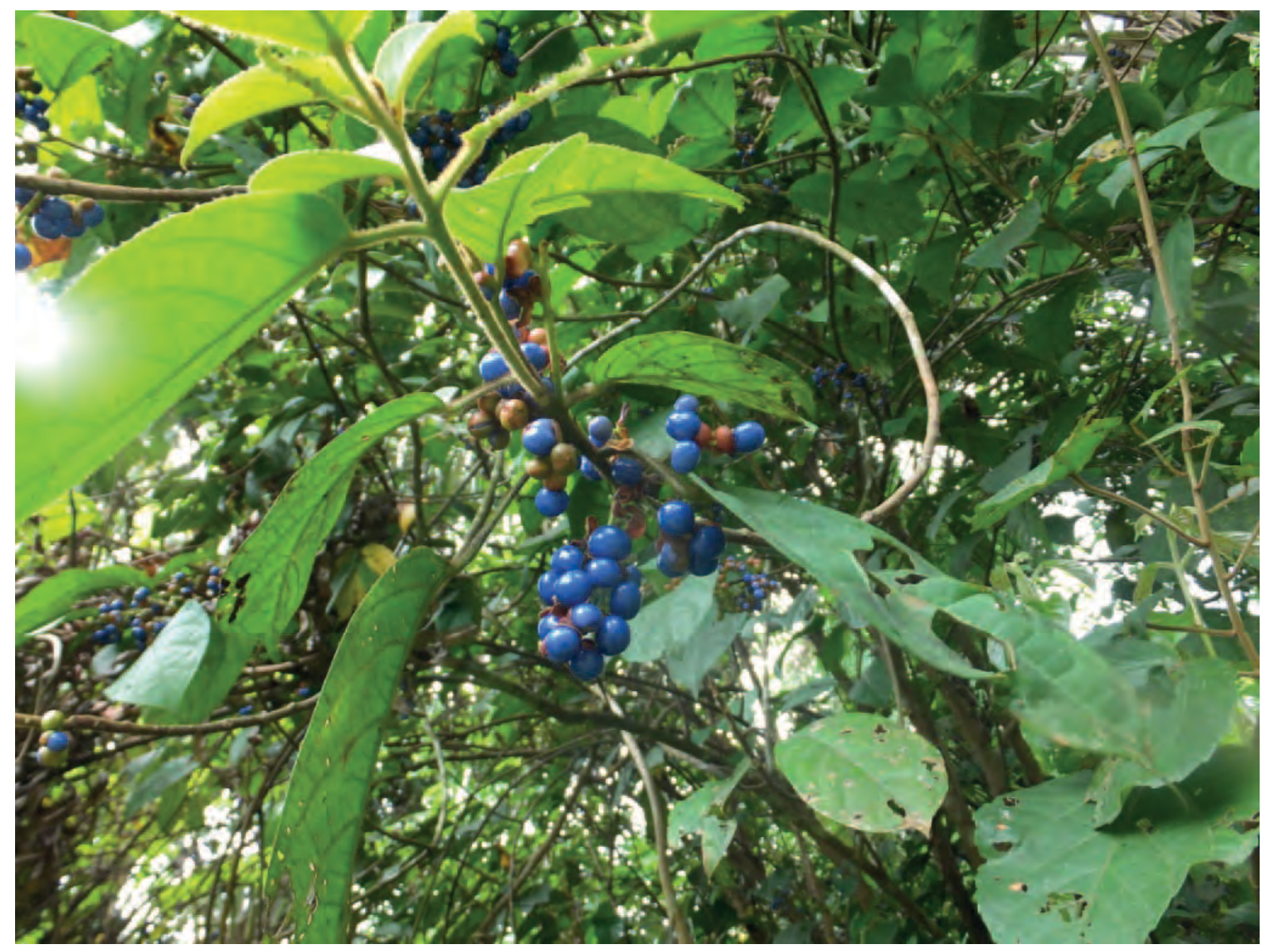

Description : Buisson ou arbuste de 4 à $5 \mathrm{~m}$ de haut. Jeunes feuilles pubescentes. Pétiole de 0,5 à $4,5 \mathrm{~cm}$ de long. Feuilles de 3 à 14 sur 1 à $6 \mathrm{~cm}$. Les fruits sont des baies rondes ayant environ $0,5 \mathrm{~cm}$ de diamètre, charnues et sucrées, très visibles en raison de leur couleur bleu clair.

Ecology : Arbuste des forêts galeries, du Sud du Nigéria au Gabon et à la R.D. Congo.

Usages: Dans les Provinces du Kwango et du Kwilu, les jeunes feuilles se mangent comme légumes. Une chenille comestible (Mimpemba) mange les feuilles. Au Congo Brazzaville, on prend une décoction des feuilles contre la lèpre. Les fleurs seraient visitées par les abeilles. A Congo Brazzaville et en Côte d'Ivoire, on emploie l'écorce pour traiter la lèpre.

Références : Renier 1948, Léonard 1962, Mbemba et Remacle 1992, Pauwels 1993, Burkill 1994, Neuwinger 2000

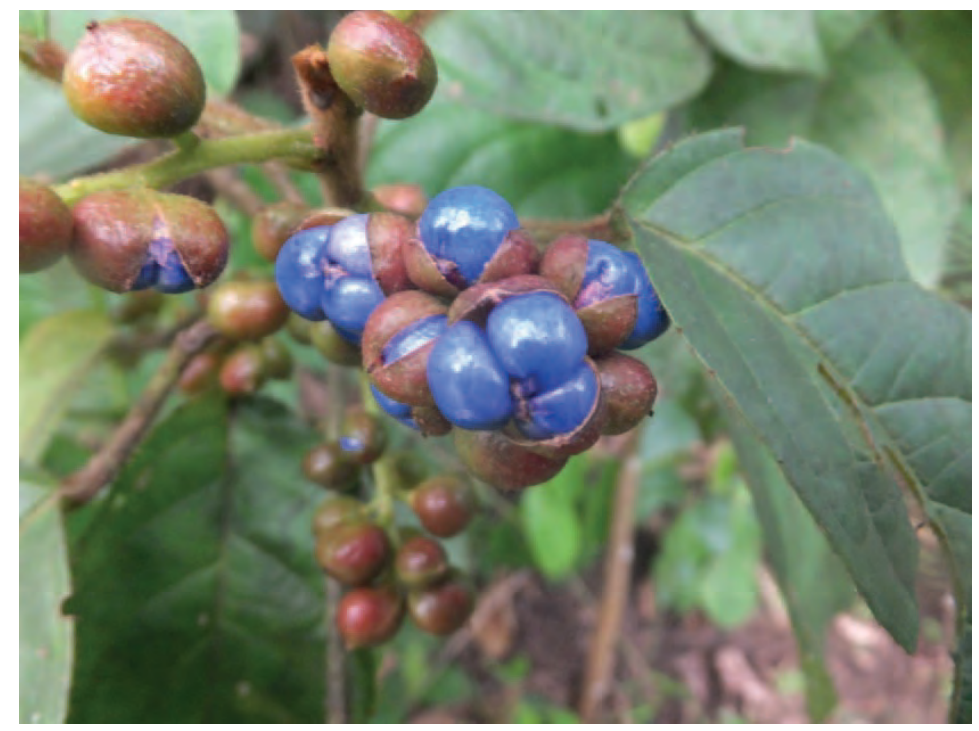


Noms courants : Kingembu, kingembwa, munsambi nsambi, ndunga (Kikongo), hornbill's calabash (Angl.)

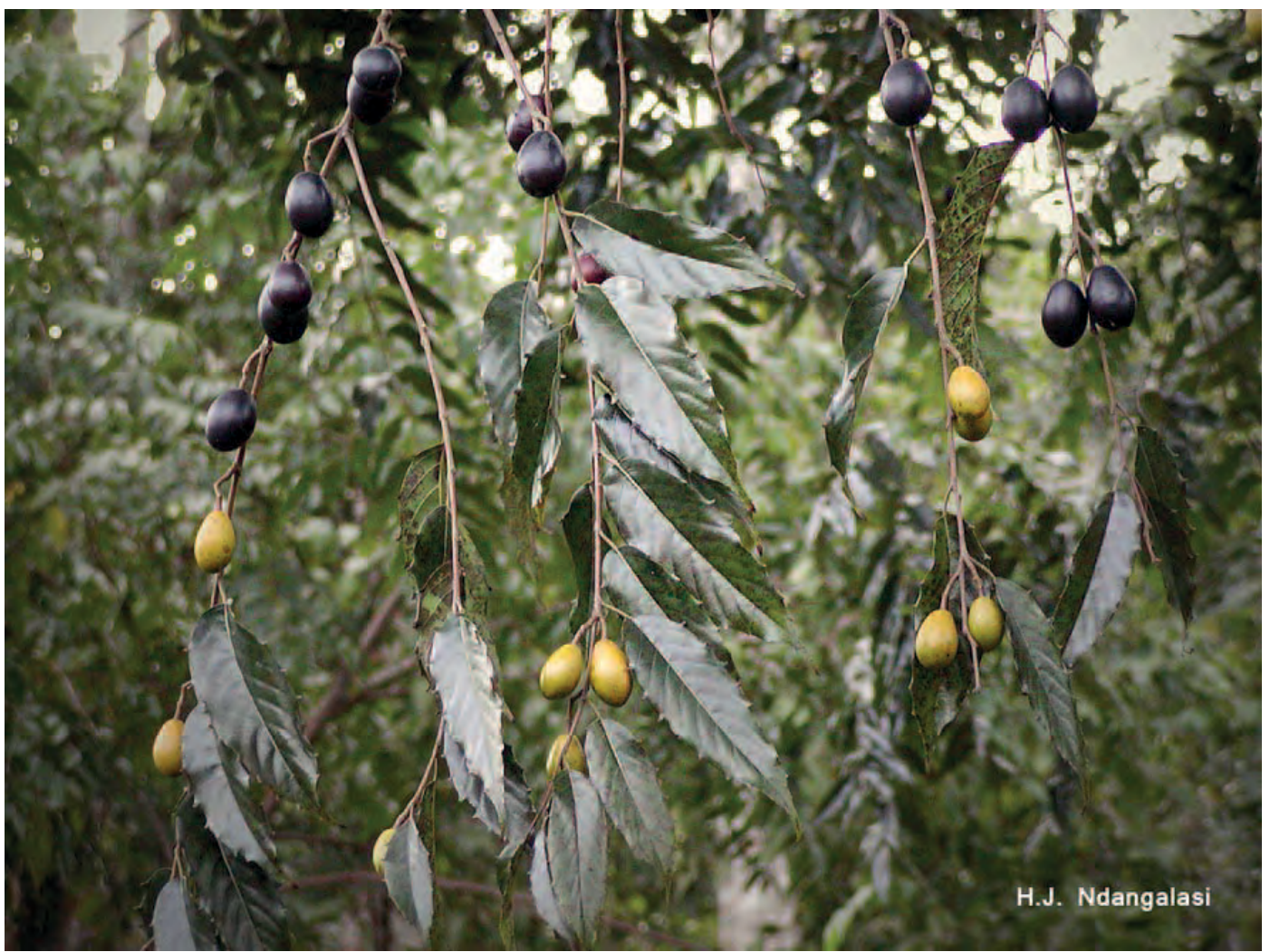

Photo : H.J . Ndangalasi Tanzania Plant Collaboration

Description : Arbre semi-décidu pouvant atteindre $35 \mathrm{~m}$ de haut. Ecorce gris brun clair. Feuilles alternes, de 8 à $15 \mathrm{~cm}$ de long, avec des dents caractéristiques sur les marges. Fleurs petites et vertes. Fruit ovale, jusqu'à $2,5 \mathrm{~cm}$ de long, jaune virant au pourpre, charnu, avec une ou deux graines dures. L'arbre se reconnait à ses feuilles, audessus desquelles se dressent les dents arrondies caractéristiques.

Ecologie: Grand arbre originaire d'Afrique orientale, centrale et occidentale. II pousse bien dans les sols sableux profonds et fertiles dans les zones tropicales humides. On le plante parfois dans des programmes de reforestation.

\section{Minsendi $=$ chenilles comestibles Imbrasia obscura se} nourrissant sur les feuilles

Reproduction: L'arbre se cultive à partir des graines. Ramasser les fruits par terre ; éplucher la chair, ou râper le fruit pour ôter la chair. Laver et sécher les graines. On ne peut les conserver que quelques mois. Avant de semer les graines, les tremper 3 jours en changeant l'eau toutes les 12 heures. Scarifier les graines avant de les semer. Le taux de germination est de 20 à $55 \%$, avec un délai de 4 à 78 jours. II vaut mieux semer en poquets, mais les semis doivent être

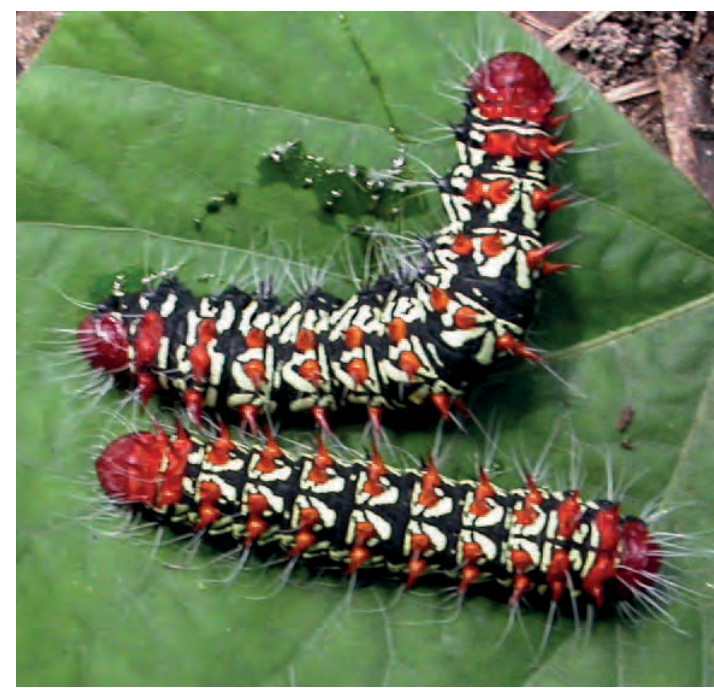
transplantés rapidement pour éviter d'endommager la racine pivotante. On peut aussi procéder par semis direct, mais les résultats peuvent décevoir s'il n'y a pas assez de pluie. On peut encore reproduire cet arbre par marcottage aérien, ou par transplantation des semis spontané.

Gestion : L'arbre pousse rapidement, de plus d'un mètre par an en moyenne sur les bons sites, et atteint sa maturité en 20 ans. Un insecte perforant, Monohammus scabiosus peut l'attaquer. Les jeunes plants doivent être soigneusement désherbés pour bien pousser. L'Imperata est particulièrement nuisible ; mais, une fois l'arbre établi, 
son ombre tend à la chasser. Les jeunes arbres sont sujets à des chancres causés par Fusarium solani et d'autres champignons.

Usages: L'aubier est presque blanc, et se distingue du bois de cœur, vert jaune, qui brunit en vieillissant. II tend

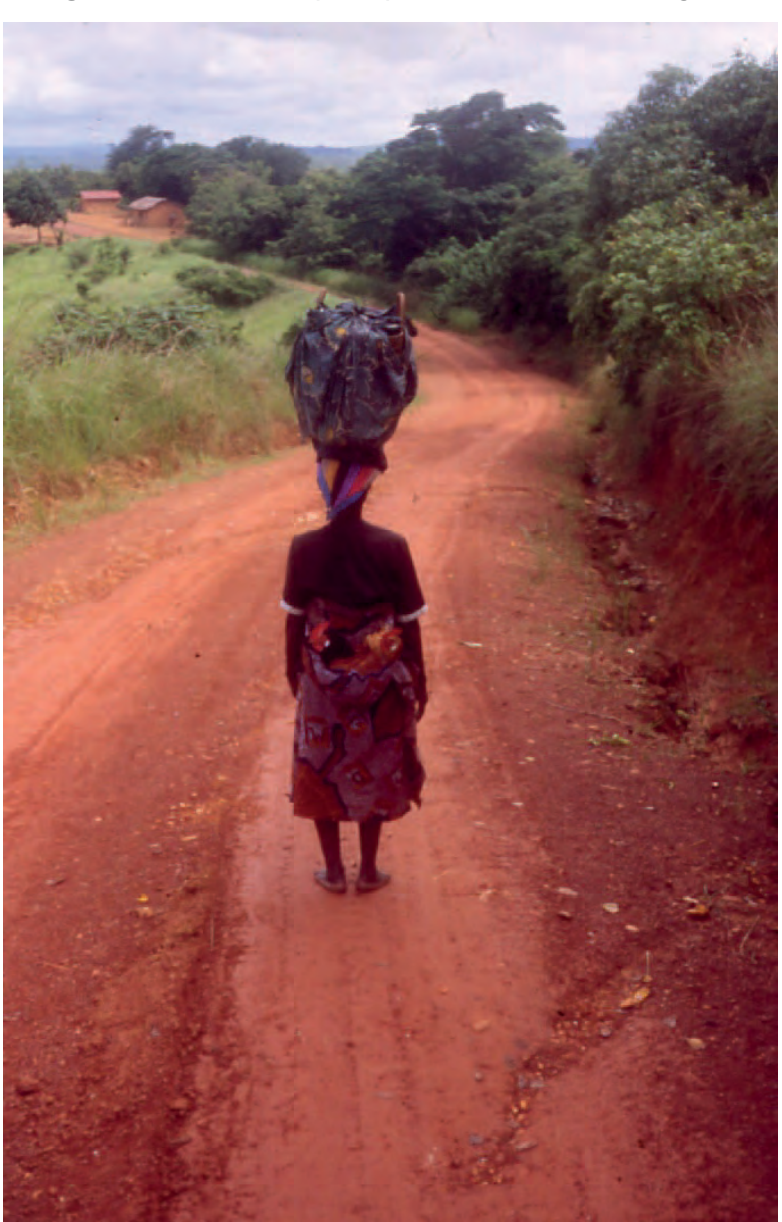

à se fendre en séchant, et ne résiste pas aux champignons, aux insectes perforants, et aux termites. Le bois de cœur est dur bien que léger, et de texture moyenne; il se travaille aisément et prend un lustre satiné. II se cloue et se colore bien, mais il tend à se soulever sous le rabot, et demande une préparation soignée avant d'être verni, poli, ou peint. Ce bois se fend facilement; il est utile pour faire des clôtures. II convient pour la menuiserie générale et la construction ; après traitement, on peut l'utiliser à l'extérieur. II sert aussi de bois de feu. On peut donner les feuilles comme fourrage au bétail ; l'arbre peut servir d'ombrage pour les plantations de thé et de café. Les fruits sont comestibles et contiennent une huile. L'écorce a des usages médicinaux au Kongo Central, comme purgatif et pour faciliter la miction. Les chenilles comestibles Kaba (Lobobunaea phaedusa) et deux types de Minsendi se nourrissent des feuilles; on les trouve parfois en grand nombre. Au Gabon, on indique que les abeilles visitent les fleurs.

Références : Gillet 1927, Renier 1948, Leloup 1956, Evrard 1960, Busson 1965, Nsimundele 1966 - 68, Daeleman et Pauwels 1983, NAS 1983, Egli et Kalinganire 1988, Ambougou 1991, Mbuya et al 1994, Katende et al. 1995, Msanga 1998, Meunier et al. 2010

En dessous: Les gens parcourront 20 à $30 \mathrm{~km}$ pour vendre des produits sur les marchés locaux. En plus de la charge que cette dame porte, elle a deux coqs dans une poche dans le dos.

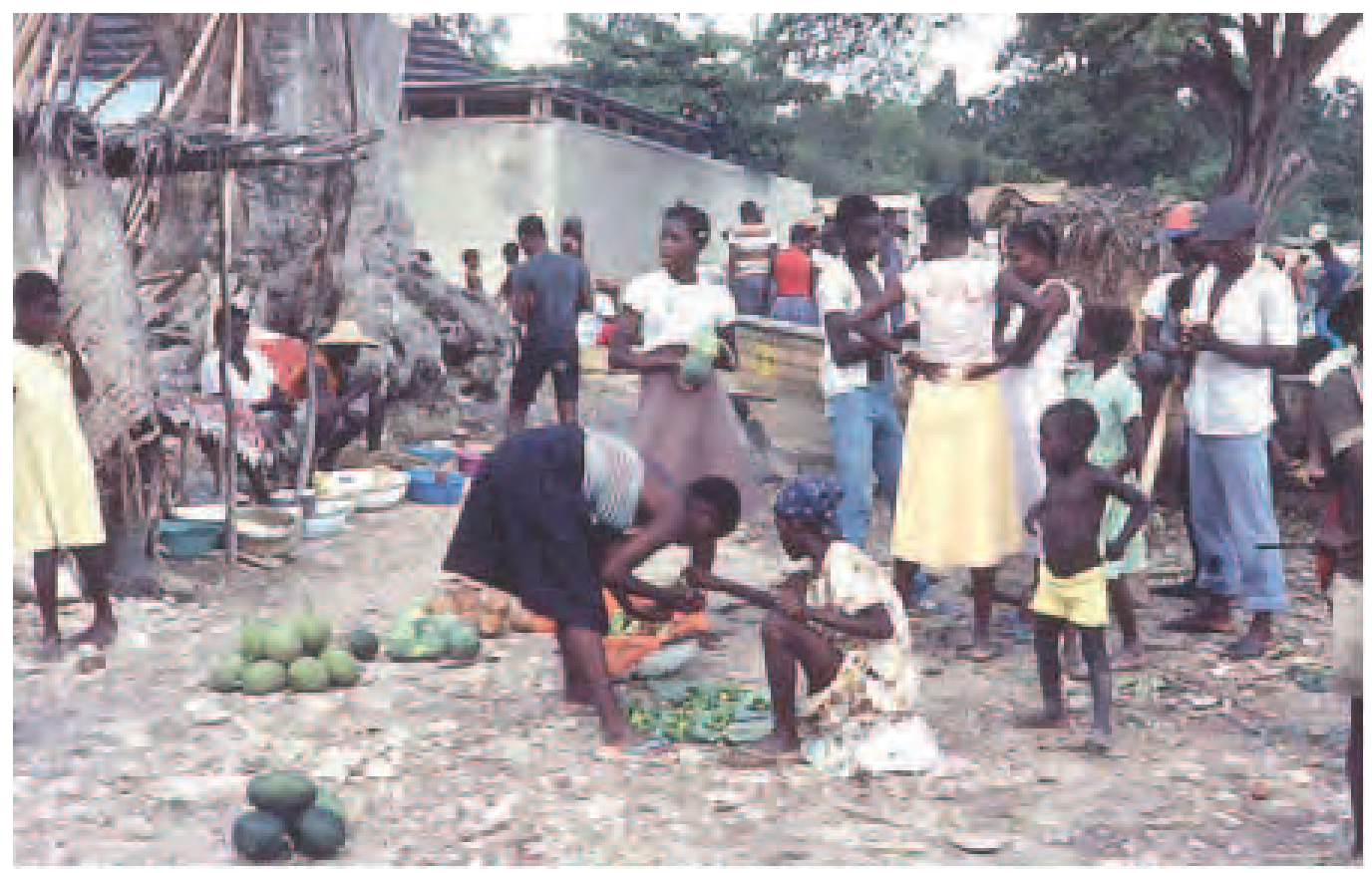


Synonyme : $M$. butayei

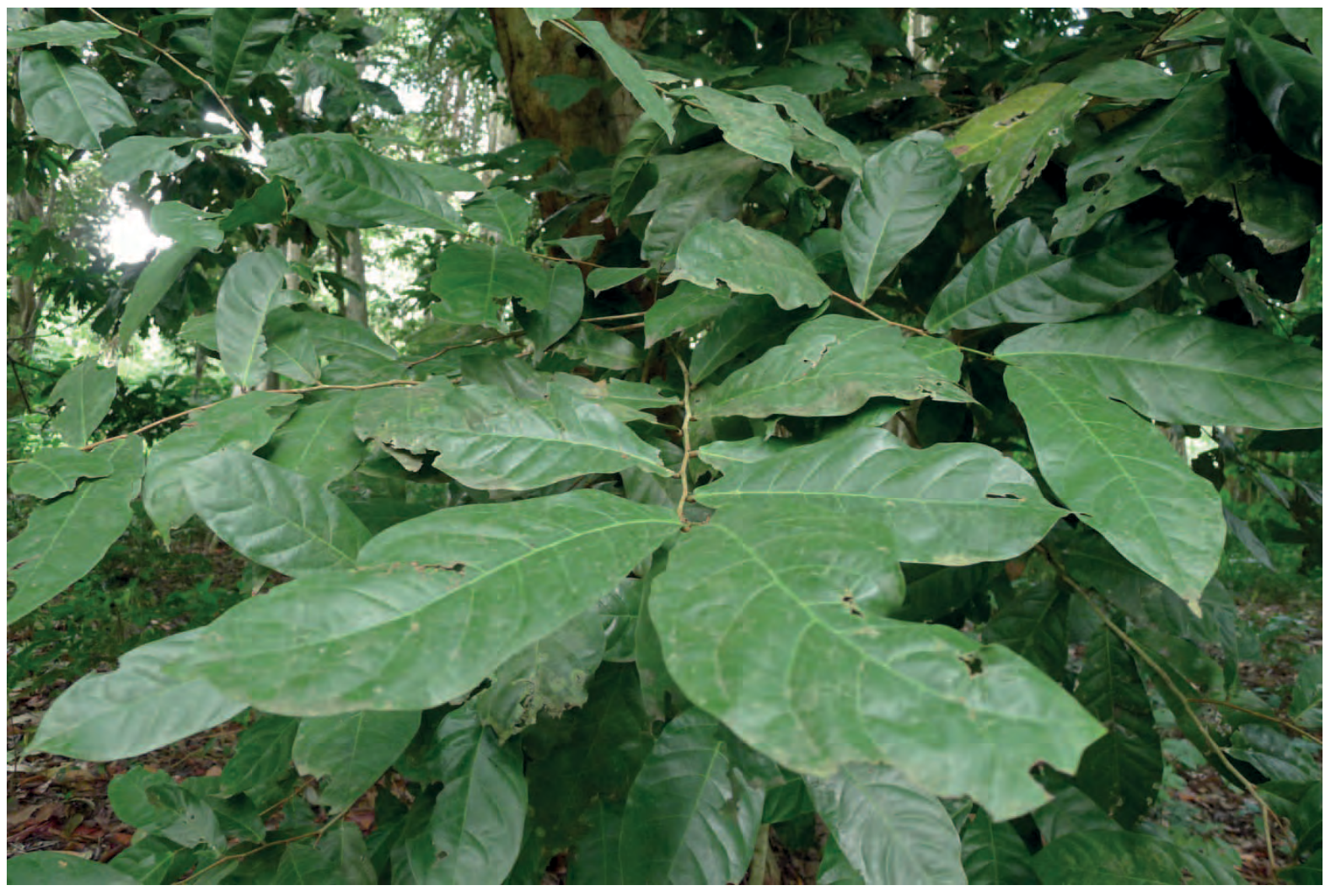

Description : Arbre de 15 à $20 \mathrm{~m}$ de haut, avec une écorce lisse grise. Les feuilles ont 8,5 à 15,5 $\mathrm{cm}$ sur 3,2 à $5 \mathrm{~cm}$. Les fruits ont $2,5 \mathrm{~cm}$ de diamètre ; ils sont durs et couverts d'une couche dense et veloutée de fins poils bruns.

Photo de droite : G. Baumann www. africanplants. senckenberg. de

Ecologie : Arbre des forêts humides inondables. Présent également au Ghana.

Reproduction: Probablement possible par graines.

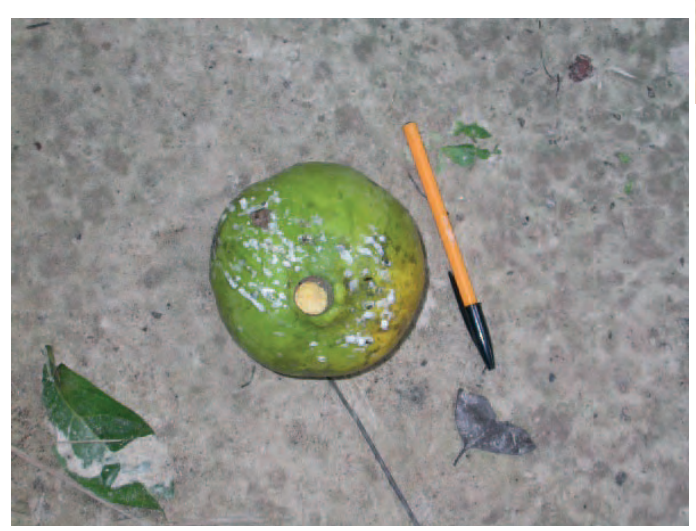

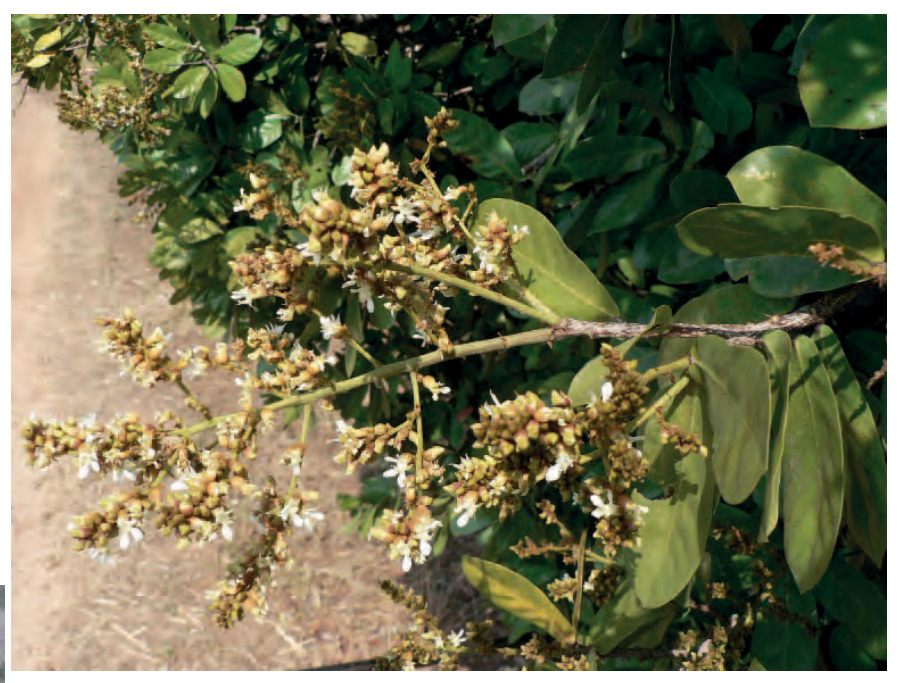

Usages : Le fruit serait comestible. On mange en Tanzanie $M$. butayei subsp. Bangweolensis, et en Centrafrique une espèce connue comme Dolea. Au Gabon, les céphalophes, les mandrills et les porcs mangent les fruits.

Références : Renier 1948, Irvine 1961, Williamson 1975, White 1978, Martin et al. 1987, Peters et al. 1992, Pauwels 1993, White et Abernethy 1997, Neuwinger 2000, Danforth et Noren 2012 
Noms courants : Barbados cherry, acerola (Angl.)

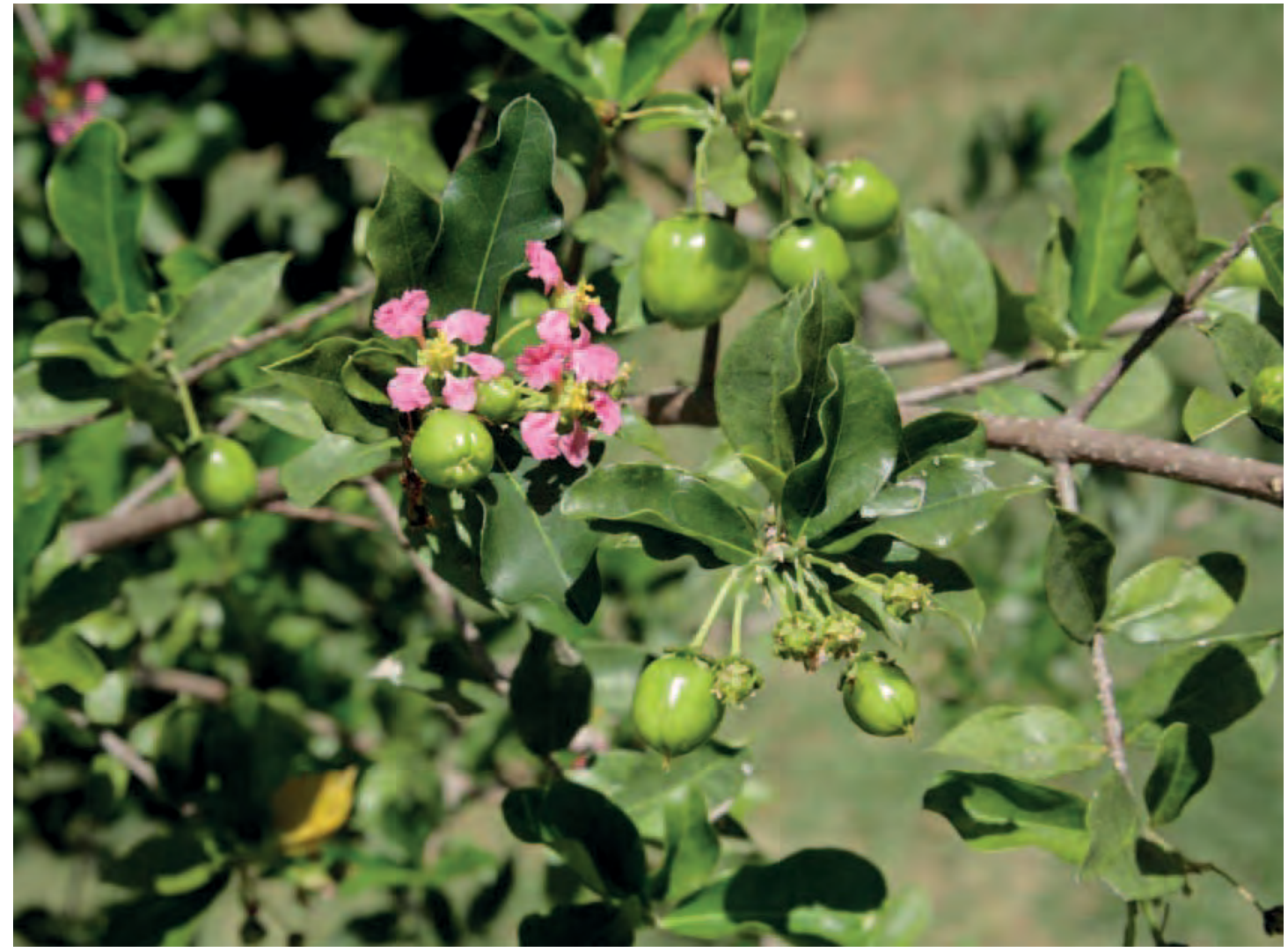

Photo : Eric Gaba Wikimedia Commons

Description : Arbuste pouvant avoir $3 \mathrm{~m}$ de haut. Feuilles de 2 à 8 sur 1 à $4 \mathrm{~cm}$, portant des poils blancs et soyeux, irritants, quand elles sont jeunes ; glabres et vert foncé brillant à maturité. Les fleurs ont 5 pétales roses ou pourpre clair. Fruits isolés à l'aisselle des feuilles, de 1 à $3 \mathrm{~cm}$, à fine peau brillante, et pulpe orange, juteuse et acide. Chaque fruit contient 3 petites graines triangulaires.

Ecologie: Plante originaire des Caraïbes et d'Amérique du Sud. Résiste à la sécheresse et ne supporte pas l'inondation. Elle pousse mal sur les sols acides, où elle risque l'attaque des nématodes des nœuds des racines. On la trouve au jardin botanique de Kisantu.

Reproduction : Par graines ou boutures. Transplanter les semis à $7,5 \mathrm{~cm}$ de haut. Les boutures doivent avoir 2 ou 3 feuilles.

Photo : Bùi Thụy Đào Nguyên Wikimedia Commons

Usages : Les fruits sont comestibles, ils sont aigres et riches en vitamine $C$. On en fait habituellement des confitures, ou bien on ajoute le jus à celui d'autre fruits. Un arbre peut donner de 13,5 à 28 $\mathrm{kg}$ de fruits. Les fruits sont très périssables. Leur consommation prévient les rhumes et refroidissements. On peut prendre le jus en gargarismes pour soulager le mal de gorge. Le bois, dur et lourd, ne

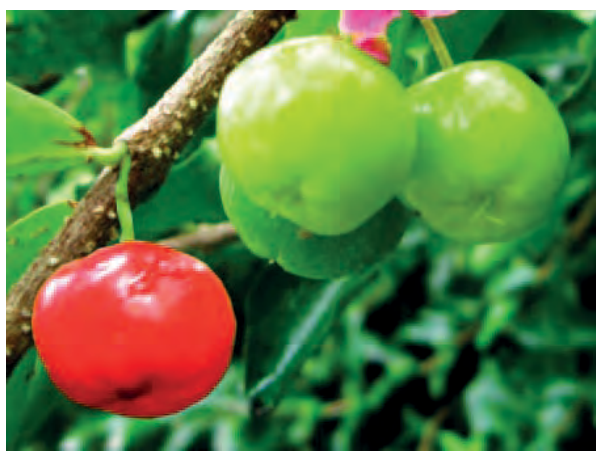
brûle que s'il est totalement sec. On peut cultiver cet arbuste pour faire des haies.

Références : Sri Setyati Harjadi 1991, Burkill 1997, van Wyk 2005, Orwa et al. 2009, Purdue University website (Consulté le 28.6.2016), 


\section{Mammea africana}

Noms courants: Mafambu, dimbu dingi (dingi = gum, resin, incense) (Kikongo), bokodji (Lingala), abricotier d'Afrique (Fr.), African mammee apple (Angl.), oboto ou djimbo (commerce)

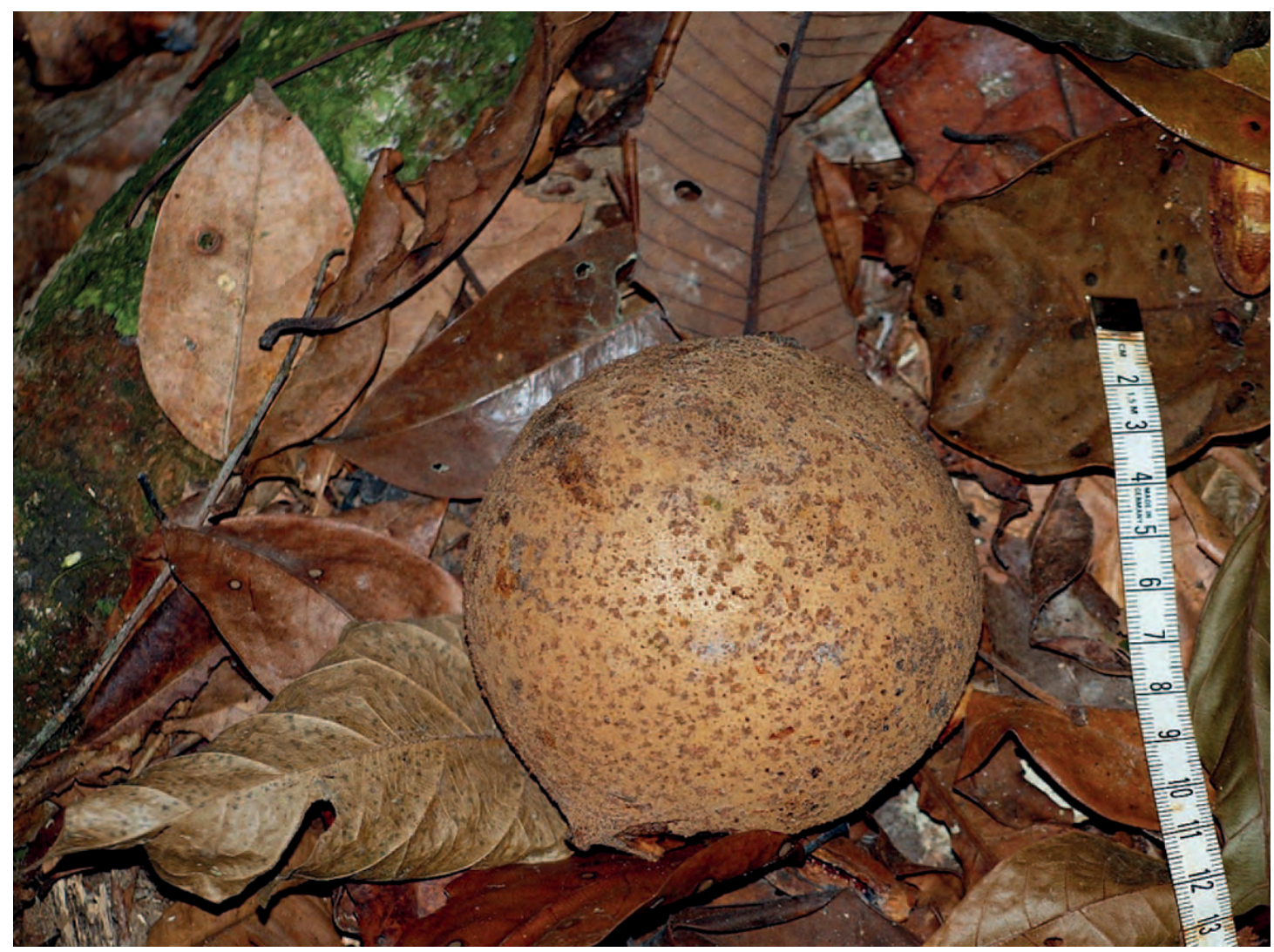

Photo : Julie Dewilde

Description : Grand arbre haut de $45 \mathrm{~m}$, à tronc droit cylindrique et écorce brune écailleuse. L'intérieur de l'écorce dégage une résine jaunâtre. Feuilles opposées, brillantes, de 9 à 35 sur 3 à $13 \mathrm{~cm}$; jeunes feuilles rouge cuivré. Fleurs à l'aisselle des feuilles, bisexuelles ou mâles, sur des arbres distincts. Les fleurs bisexuelles sont solitaires, blanches, ayant jusqu'à $2,5 \mathrm{~cm}$ de long. Les fleurs mâles sont plus petites et disposées en bouquets. Les fruits, jaune clair à orange, sont abondants, ronds ou en poires, à peau dure avec des verrues, de 10 à $18 \mathrm{~cm}$ de diamètre. La chair fibreuse contient de 1 à 4 gaines par fruit. Des fructifications en masse se produisent tous les 2 à 3 ans.

Ecologie : Arbre des forêts sempervirentes et semi-décidues, qui préfère les sols forestiers fertiles et humides. Présent du Sénégal à l'Ouganda, à l'Angola et à la R.D. Congo.

Reproduction: Tremper les graines 24 heures dans l'eau. Semer à l'ombre. La germination, irrégulière, peut durer 8 mois, mais avec un taux jusqu'à $90 \%$. Les semis grandissent lentement.

Usages: Le bois est dur, lourd et durable. II est facile à travailler, et s'emploie en construction, menuiserie générale, mobilier, construction navale. Les fruits complètement mûrs se mangent. On les laisse tomber au sol ; on les épluche et les coupe en tranches quand ils se sont ramollis. La chair jaune pâle est sucrée mais fibreuse ; certains arbres produisent des fruits acides. Les fruits qui pourrissent attirent des escargots comestibles. Les graines se mangent, et contiennent une huile utilisable en cuisine. La résine sert à réparer la vaisselle en terre cuite. Les coques de fruit servaient autrefois de grelots pour les chiens de chasse. Au Gabon, on sait que les abeilles visitent les fleurs.

References Gillet et Paque 1910, Gillet 1927, Renier 1948, Busson 1965, Bamps 1970, Ambougou 1991, Pauwels 1993, Vivien et Faure 1996, Danforth et Noren 1997, Lemmens 2008 


\section{Mangifera indica}

Noms courants : Manga (Kikongo), manguier (Fr.), mango (Angl.)

Description : Arbre de 10 à $40 \mathrm{~m}$ de haut, avec un houppier de $20 \mathrm{~m}$ de diamètre donnant une ombre épaisse. L'écorce est lisse, d'un gris-brun foncé à noir. Feuilles persistantes, oblongues et pointues, pouvant avoir 15 à 25 sur 6 à $10 \mathrm{~cm}$. Les feuilles froissées dégagent une odeur de térébenthine. Les jeunes feuilles sont rose orangé, puis rouges, et deviennent vert foncé brillant à maturité. Les petites fleurs, sont groupées en grappes terminales de 20 à $50 \mathrm{~cm}$ de long. Le fruit est une drupe oblongue, ronde ou réniforme, attachée à un long pédoncule, de tailles variables selon les variétés, de poids variant de 0,5 à 2,5 $\mathrm{kg}$. Le noyau, aplati, contient une graine unique de 4 à $7 \mathrm{~cm}$ de long, 3 à $4 \mathrm{~cm}$ de large, et $1 \mathrm{~cm}$ d'épaisseur, adhérant à la chair.

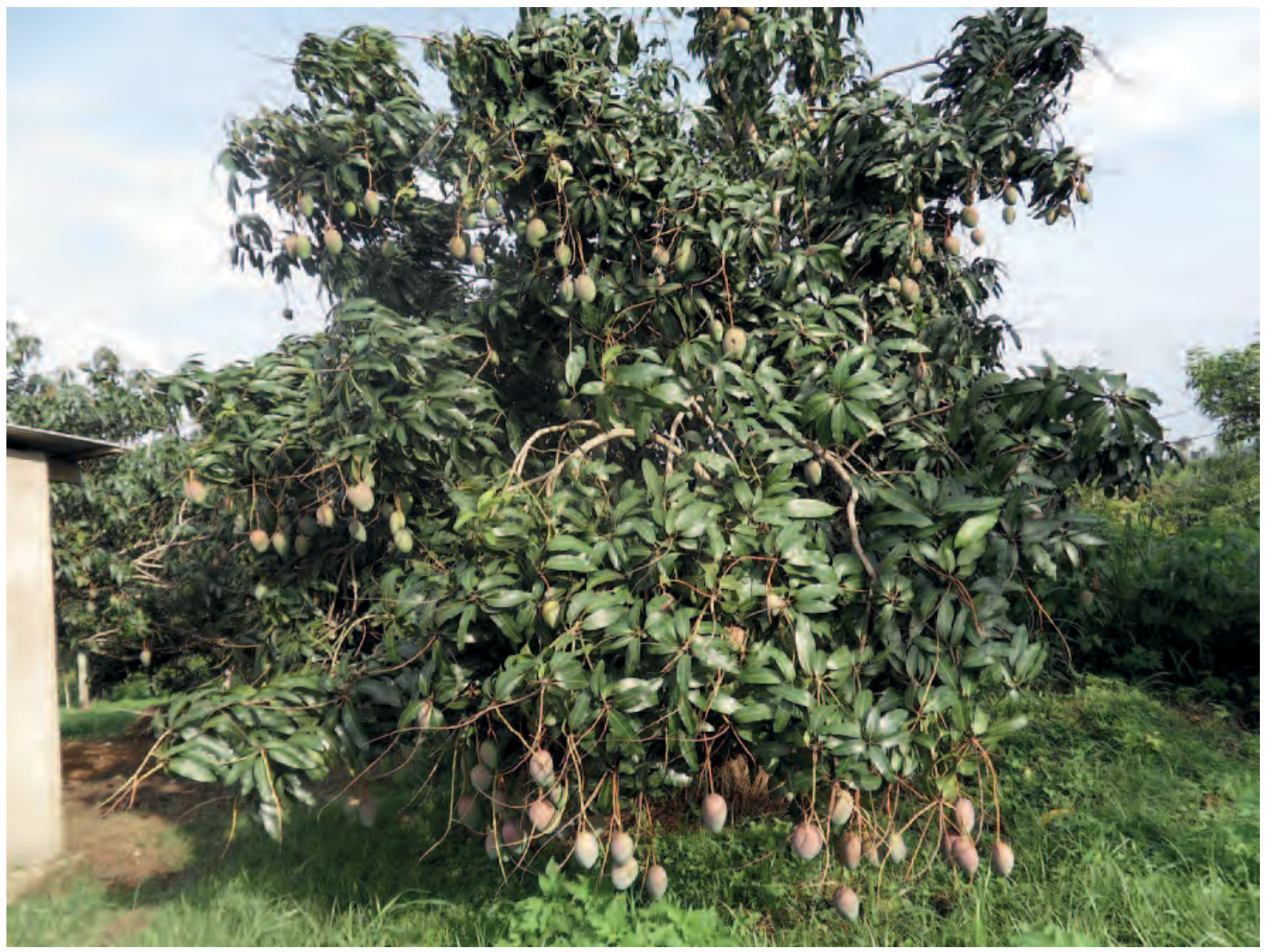

\section{Manguier greffé}

Ecologie : Arbre originaire d'Asie tropicale, couramment planté dans les villages. Sur les sites des anciens villages, on trouve souvent de véritables petites forêts, établies à partir des anciens semis.

Reproduction: Les grandes graines bien développées germent bien, surtout si la graine est détachée soigneusement de la chair, avec un taux de germination couramment supérieur à $80 \%$. Les graines doivent être semées en grands poquets ou paniers pour protéger la racine pivotante. Les variétés améliorées sont greffées latéralement, ou plus souvent en fente, sur des porte-greffes.

Les fleurs de manguier fournissent habituellement du pollen et du nectar aux abeilles pendant la saison sèche

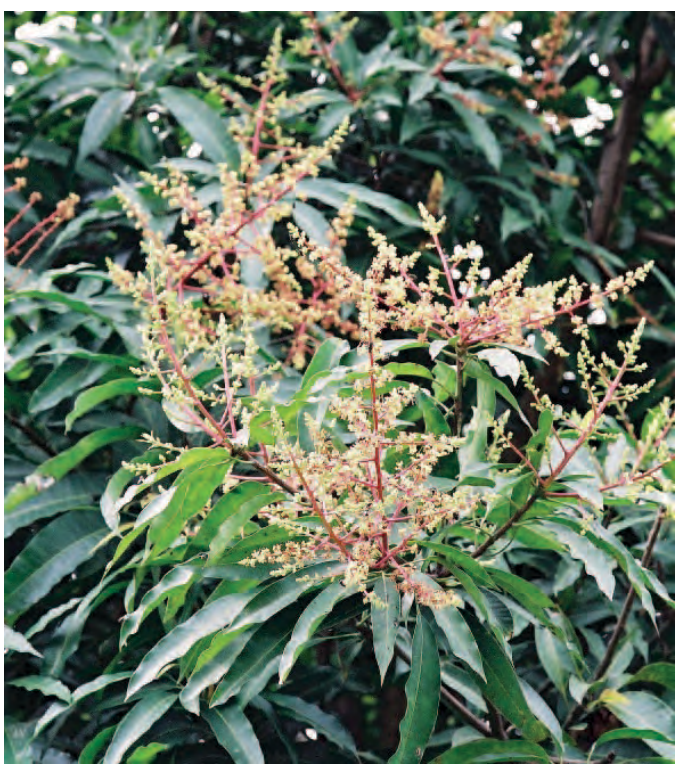


On ne doit utiliser comme greffon qu'un bourgeon terminal bien mûr, avec la section en dessous de lui (un rameau insuffisamment mûr peut conduire à l'échec). Le greffage peut se faire sur des porte-greffes beaucoup plus jeunes. On prépare les greffons à l'avance en ôtant le bourgeon apical d'un rameau terminal mûr : il en résulte des bourgeons axillaires se développant après 1 à 2 semaines. Le greffage conduit à une croissance plus rapide et à des fruits plus précoces. On peut aussi pratiquer le marcottage aérien.

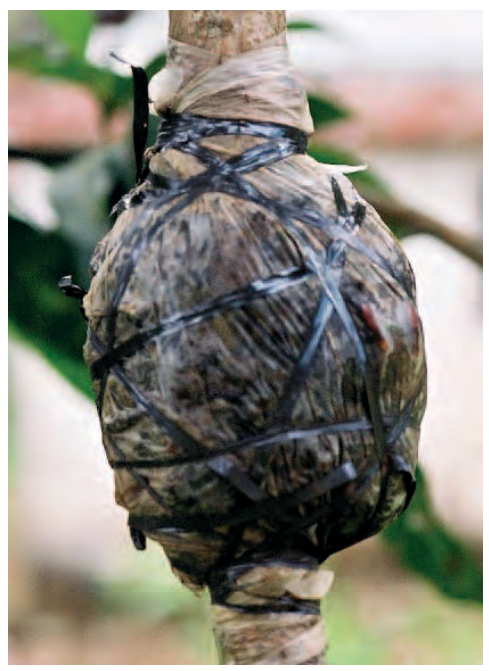

Gestion : Transplanter au début de la saison des pluies avec du compost dans un trou de $60 \times 60$ × $60 \mathrm{~cm}$. Laisser pousser la tige principale jusqu'à $1 \mathrm{~m}$ avant de la rabattre pour produire des branches bien équilibrées. Le sol doit être bien drainé et profond d'au moins $1 \mathrm{~m}$.

\section{A gauche : Marcottage aérien d'une bonne variété de mangue.}

Usages : Les mangues sont un fruit très populaire ; les variétés améliorées sont sucrées et juteuses, alors que les mangues ordinaires sont fibreuses, avec un goût de térébenthine. Elles sont habituellement une excellente source de provitamine $A$, mais une source variable de vitamine $C$ : quand elles mûrissent, leur taux de vitamine $\mathrm{C}$ diminue. Le bois sert en construction, parqueterie et mobilier. En Afrique Orientale, on en fait de grandes pirogues, lourdes et durables. Sa robustesse et sa taille en font un matériau de choix pour les pontons des bacs. Le bois sert aussi comme bois de feu et pour le charbon de bois. Les fleurs donnent en abondance pollen et nectar, et sont un important fourrage pour les abeilles. Les noyaux se mangent, grillés, séchés ou confits au vinaigre ; ils servent d'aliments pour le bétail et les volailles. L'écorce donne une teinture jaune, utilisable pour la soie. A Mbanza Ngungu, l'écorce, les feuilles et les racines s'emploient pour traiter les problèmes digestifs. On donne une décoction de l'écorce du tronc pour renforcer le système immunitaire et pour traiter la diarrhée. L'arbre donne une ombre épaisse très appréciée ; il peut servir de coupe - feu.

Références : Gillet 1927, Renier 1948, Van Der Veken 1960, Crane et al. 1984, Burkill 1985 et 2000, Martin et al. 1987, Fichtl et Adi 1994, Mbuya et al. 1994, Nakasone et Paull 1998, Pousset 2004, Latham 2008, Nzuki Bakwaye et al. 2013

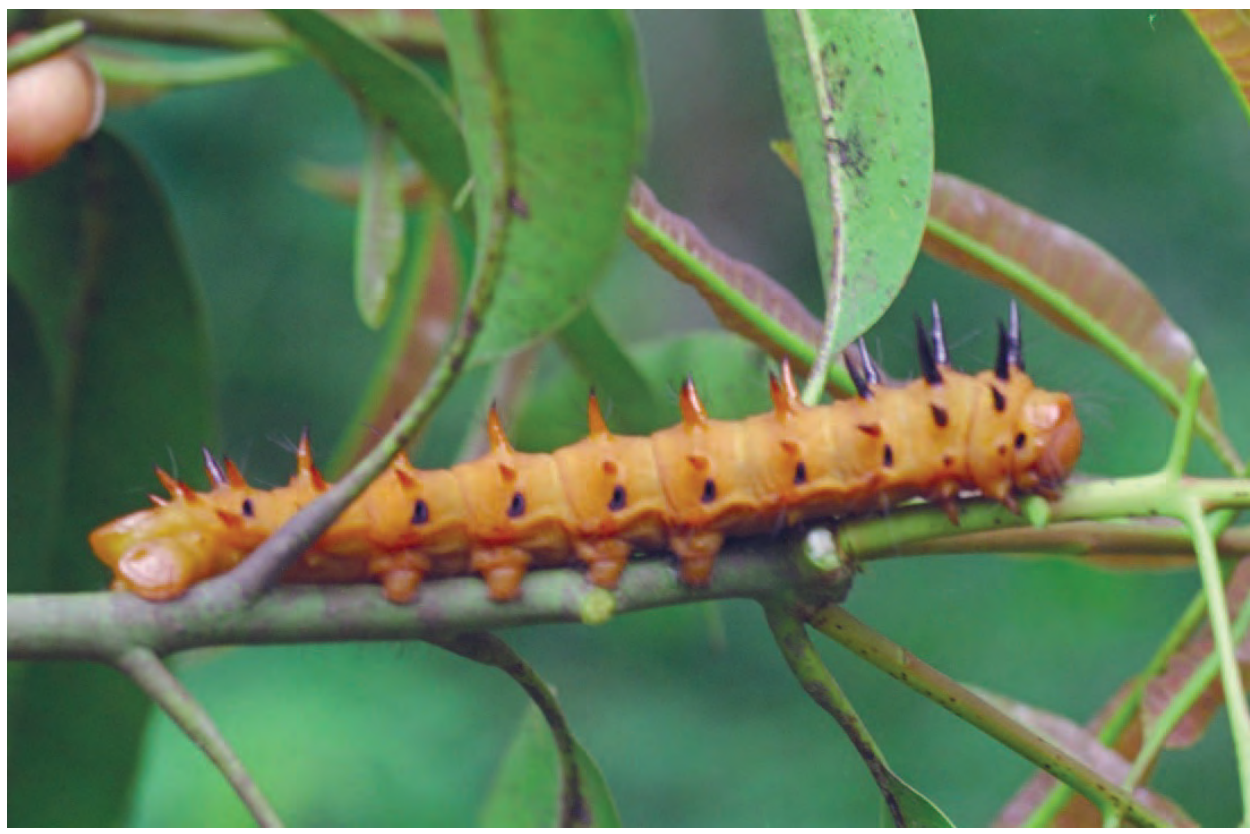

Minsongo sur un manguier près de Kasangulu en janvier 
Synonyme : M. utilissima

Noms courants: Dyoko, saka saka (Kikongo), manyoko, mbala, nsongo (Lingala), manioc (Fr.), cassava (Angl.)

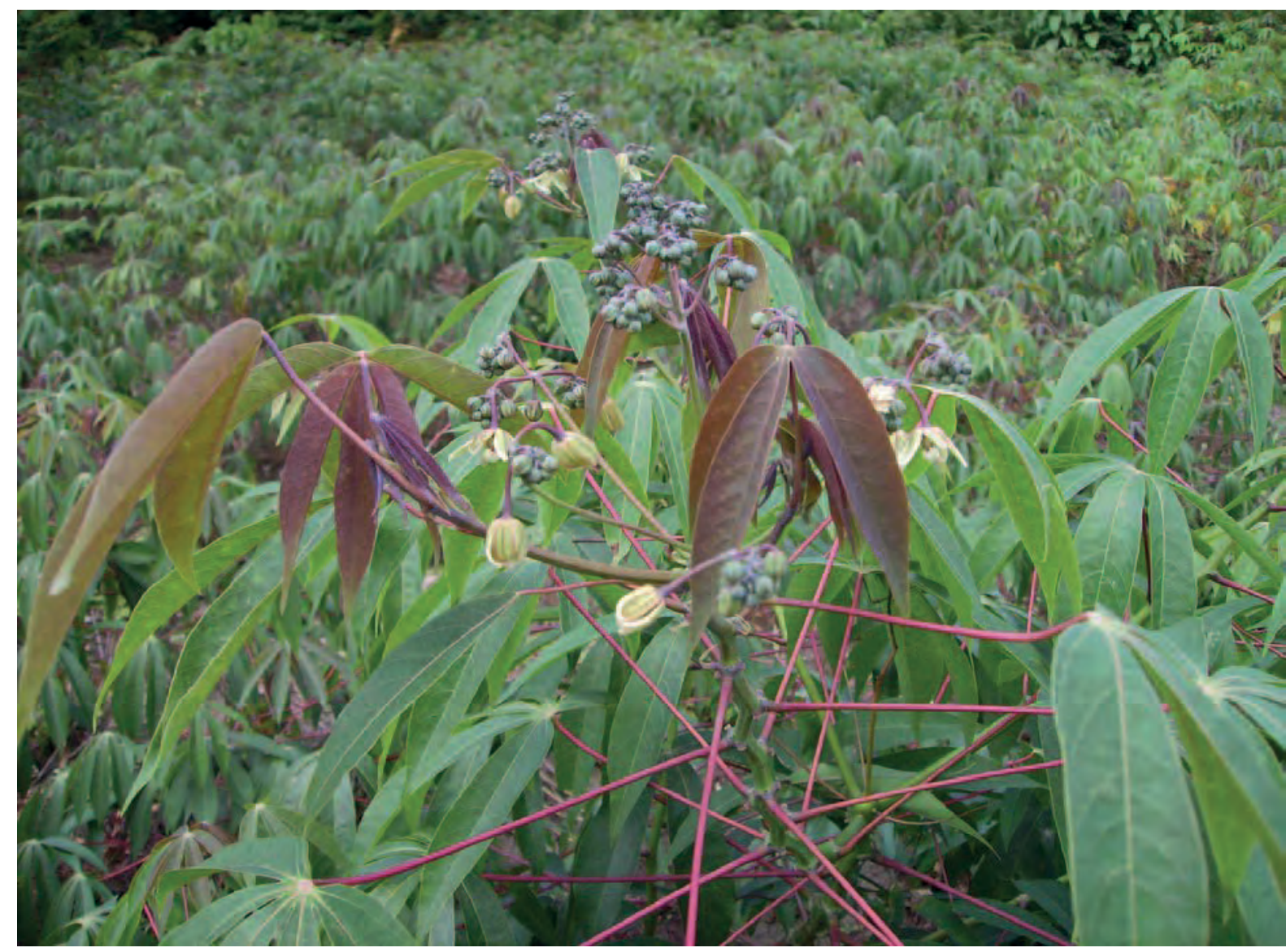

Description : Plante vivace, pouvant avoir $3 \mathrm{~m}$ de haut, avec un système racinaire bien développé, et des racines s'élargissant en tubercules. Les racines tubérisées sont farineuses et peuvent atteindre $50 \mathrm{~cm}$ de long; il y en a en général de 4 à 8 par plant. Toutes les parties de la plante contiennent un latex blanc. Les feuilles profondément lobées ont de 6 à $25 \mathrm{~cm}$ de large, avec un nombre de lobes impair, souvent de 3 à 7 . Il y a de nombreuses variétés, certaines amères et d'autres douces. Les variétés douces ont des cycles courts, et peuvent être récoltées à 6 à 9 mois ; certaines peuvent se manger crues. Les variétés amères ont des cycles de production allant jusqu'à deux ans; leurs tubercules sont toxiques et ne peuvent être consommés qu'après traitement par rouissage. La responsabilité de la sélection et de la diffusion de variétés améliorées, à haut rendements et résistantes aux maladies, revient au PRONAM (Programme National Manionc) et à I'IITA ; une variété améliorée recommandée au Kongo Central est Kinuani, ainsi que la variété locale Mpelolongi.

Ecologie : Plante cultivée depuis des millénaires en Amérique du Sud, probablement originaire du Sud du Bassin de l'Amazone, cultivée maintenant partout sous les tropiques, en cultures pures ou associée avec d'autres plantes. Les pluies doivent être bien réparties, mais la plante supporte des périodes de sécheresse. On obtient les meilleurs résultats sur sols argilo-sableux de fertilité moyenne, mais le manioc pousse bien sur sols infertiles, pourvu que ceux-ci soient labourés profondément pour permettre la pénétration des racines.

Reproduction : Planter des boutures de 10 à $30 \mathrm{~cm}$ avec au moins 3 bourgeons, prélevées entre la base et le milieu de plantes ayant au moins dix mois. Si les boutures sont sèches, on peut les conserver jusqu'à 8 semaines en conditions fraiches et aérées ; autrement, elles ne se gardent que 7 à 10 jours. Au Kongo Central, on plante au début des pluies sur des buttes ou des arêtes. En préparant le terrain, entourer les herbes dans les buttes pour accroitre le rendement. Planter les boutures inclinées, en enterrant les trois quarts de leur longueur, ce qui facilite la pénétration profonde des racines. Planter avec des écarts de $1 \mathrm{~m}$ dans toutes les directions en cultures pures ; ou de 2 à $3 \mathrm{~m}$ en cultures associées. Bien désherber jusqu'à ce que le manioc couvre le sol. Remonter les buttes après 8 à 12 semaines pour faciliter la formation des tubercules. 


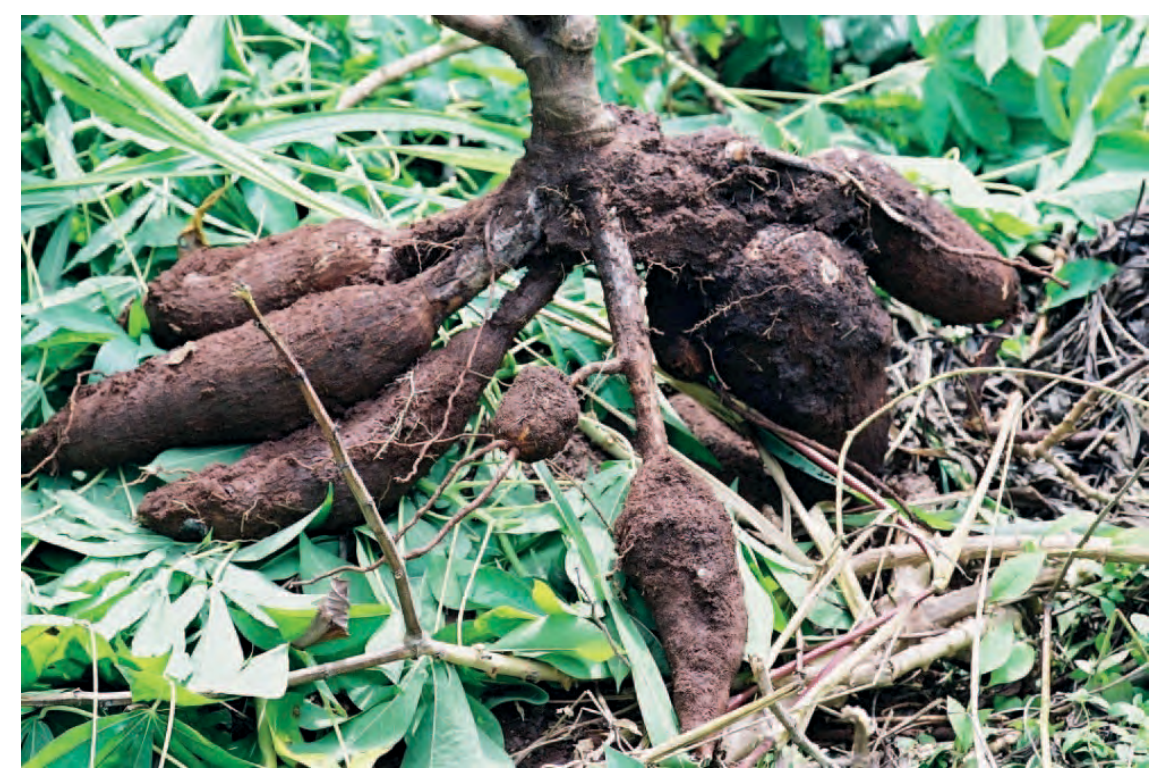

Gestion : II est avantageux d'installer une couverture permanente sur laquelle le manioc et les autres cultures vont pousser en intercalant du Stylosanthes guianensis. On ne doit pas récolter les feuilles plus souvent que tous les 2 mois, pour éviter de réduire les rendements en tubercules.

Belle récolte après une longue jachère

Usages: Les tubercules de manioc constituent l'aliment de base au Kongo Central, et dans tout l'Ouest de la R.D. Congo ; les carbohydrates se digèrent bien, mais sont pauvres en protéines et vitamines. Les tubercules des variétés douces se mangent après avoir été simplement bouillis ou frits. Les tubercules des variétés amères, qui constituent la plus grande part de la production et de la consommation, sont toxiques et doivent subir le rouissage, c'est-à-dire une fermentation de quelques jours dans l'eau. II y a deux types de procédés de rouissage : pour aboutir à la farine de manioc, on découpe les tubercules en gros morceaux, ou cossettes, que l'on met à tremper ; après trempage les cossettes sont totalement séchées au soleil, puis réduites en farine ; pour aboutir à la chikwangue, on trempe les tubercules ou les cossettes jusqu'à ce qu'ils soient ramollis, on les pétrit alors pour obtenir une pâte qui continue à fermenter, que l'on sèche et que l'on met en forme de pains pour donner la chikwangue ; les pains de chikwangue sont emballés dans des feuilles de Megaphrynium macrostachyum. Le procédé qui aboutit à la farine de manioc est quelquefois partiellement mécanisé.

La farine de manioc peut remplacer jusqu'à $20 \%$ de la farine de froment pour la préparation du pain ; le pain est meilleur en ajoutant $1 \%$ d'un conditionneur de pâte tel que le stearoyl lactylate de calcium. On peut aussi faire du pain avec $80 \%$ de farine de manioc et $20 \%$ de farine de soja, en ajoutant à la pâte $4 \%$ d'un émulsifiant comme le monostéarate de glycérol, ou bien de l'amidon de maïs extrudé (jusqu'à $15 \%$ de la farine de manioc).

Les feuilles de manioc sont cuites et constituent le principal légume dans l'alimentation; elles sont riches en protéines (plus de $6 \%$ de la matière fraiche), vitamines et sels minéraux.

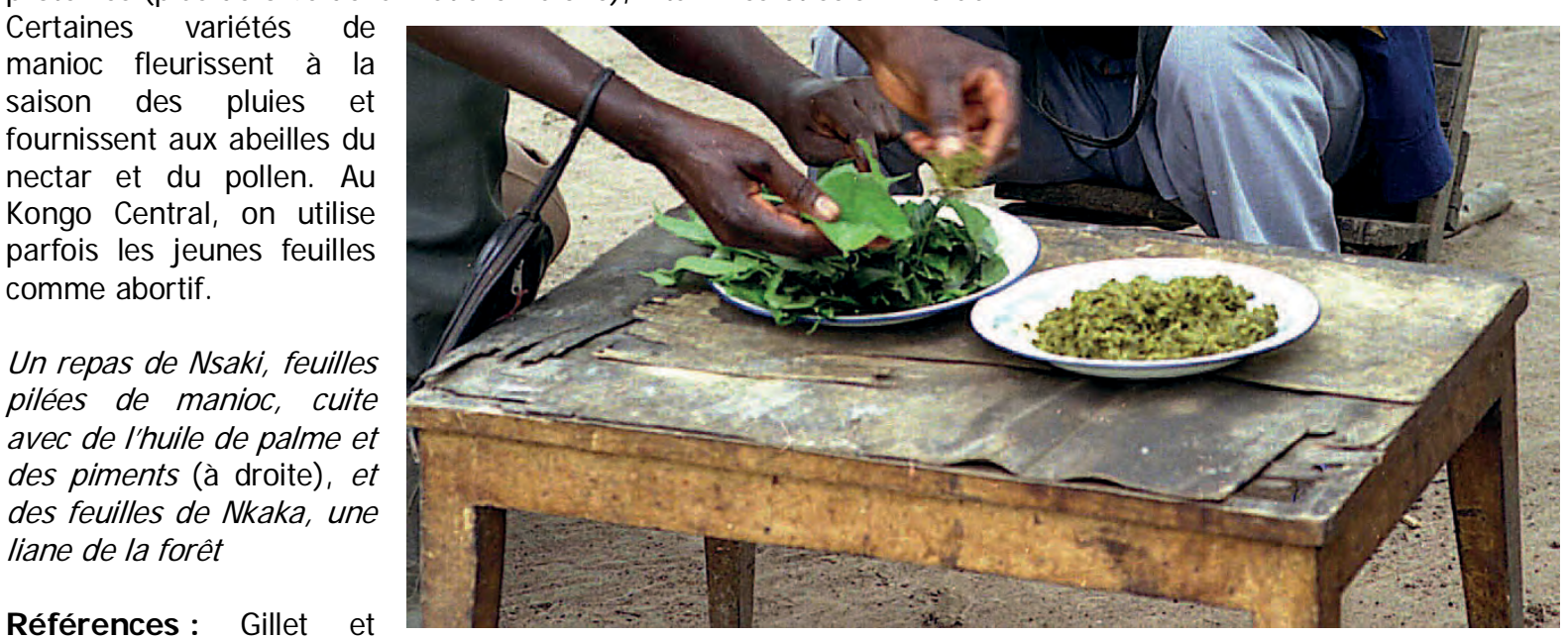

Références: Gillet et

Pâque 1910, Léonard 1962, Kay 1973, Daeleman et Pauwels 1983, Mbemba et Remacle 1992, Pauwels 1993, Burkill 1994, Raemaekers 2001, Bulakali et al. 2014 
Noms courants : Nkweso, nsaki kagusu (Kikongo), caoutchouc de Céara, manioc caoutchouc (Fr.), Ceara rubber, tree cassava (Angl.)

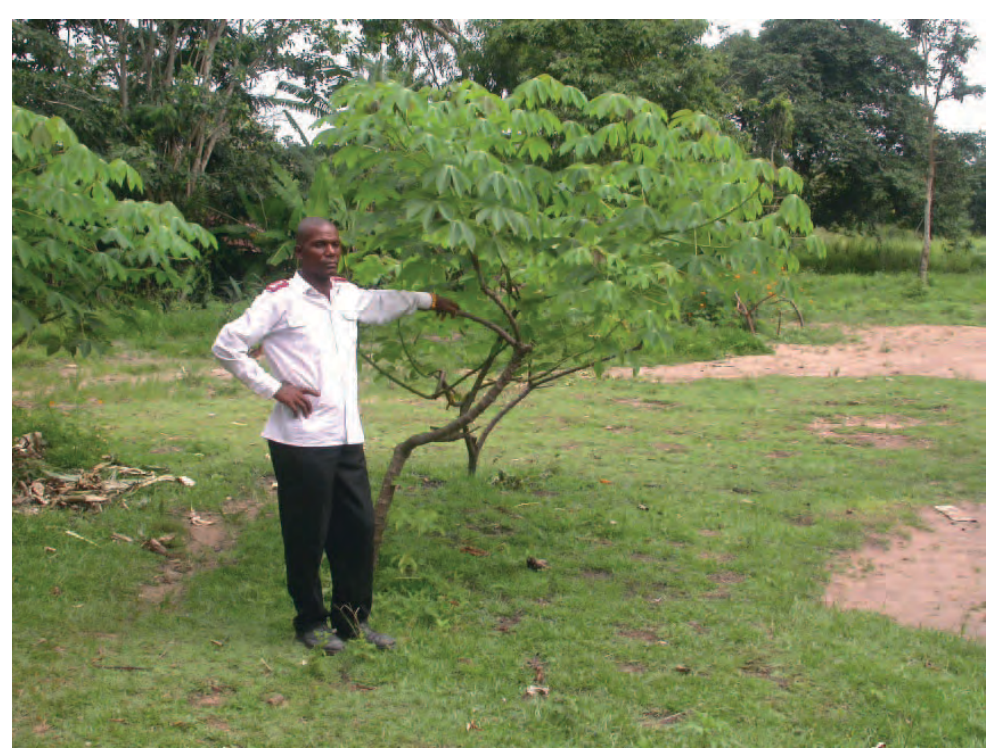

Description : Arbuste atteignant $6 \mathrm{~m}$ de haut, à tronc court et irrégulier, ramification buissonnante, et feuilles de 7 à 12 sur 4 à $8 \mathrm{~cm}$, à 3 ou 5 lobes. II produit un latex abondant à la coupure.

Ecologie: Originaire du Nord-Est du Brésil, maintenant largement planté partout sous les tropiques. Souvent cultivé pour marquer les limites de terrains.

Reproduction : par graines et boutures.

Usages: II y a deux variétés en R.D. Congo. L'une donne du latex pour réparer les chambres à air de bicyclettes et divers ustensiles. L'autre est cultivée, principalement autour de Kinshasa, pour ses feuilles mangées comme légumes; à

Kinshasa, les feuilles de «caoutchouc » entrent en concurrence avec les feuilles de manioc proprement dit et occupent une place importante sur le marché des légumes. Les fleurs sont une bonne source de nectar pour les abeilles durant la saison des pluies, mais donnent un miel amer. Le bois se casse facilement ; il est sujet à la pourriture blanche (Leptoporus lignosus). La racine est riche en amidon, mais dure et ligneuse; elle a des usages médicinaux. Le croisement avec le manioc donne des plants résistants aux ravageurs et aux maladies, mais avec des tubercules ligneux ; un deuxième croisement de ces plants avec le manioc donne des tubercules meilleurs au goût, et résistants aux

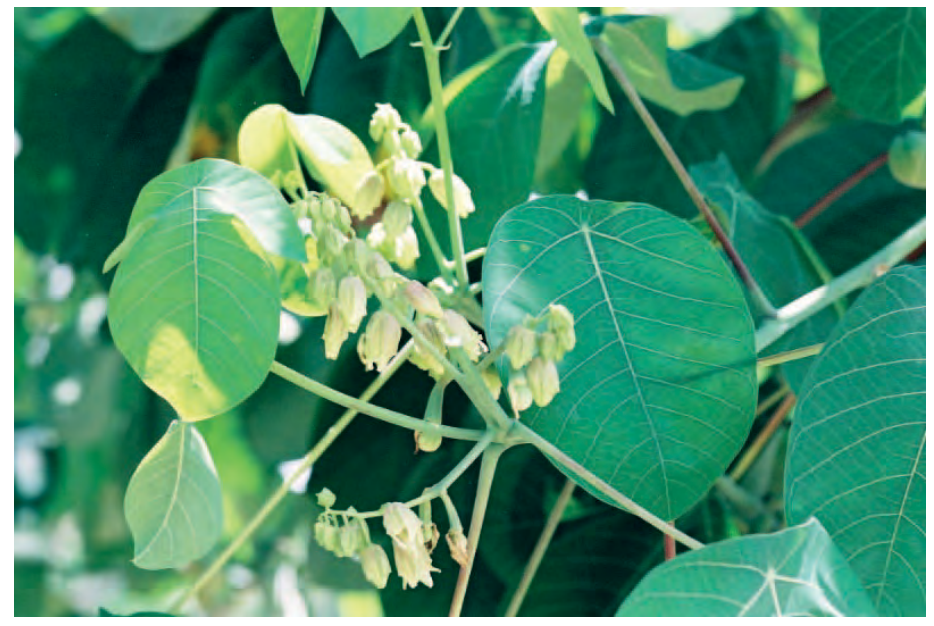
virus de la mosaïque et de la striure brune. Les tiges et les racines se mangent comme aliments de famine.

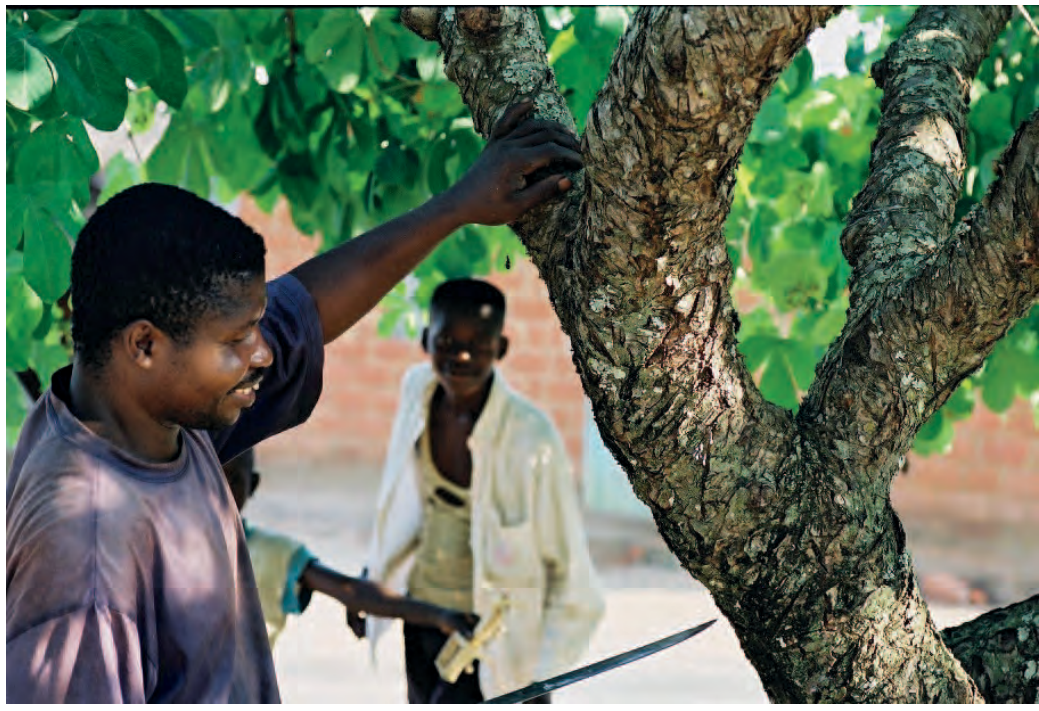

Références: Gillet 1927, Renier 1948, Uphof 1968, Pauwels 1993, Burkill 1994, Ambang et al. 2009

Au village de Mbanza Nzundu un arbre donne du latex pour réparer les chambres à air. 
Noms courants : Nkusa, nkuta, kilendila (Kikongo), kalunga (Lingala)

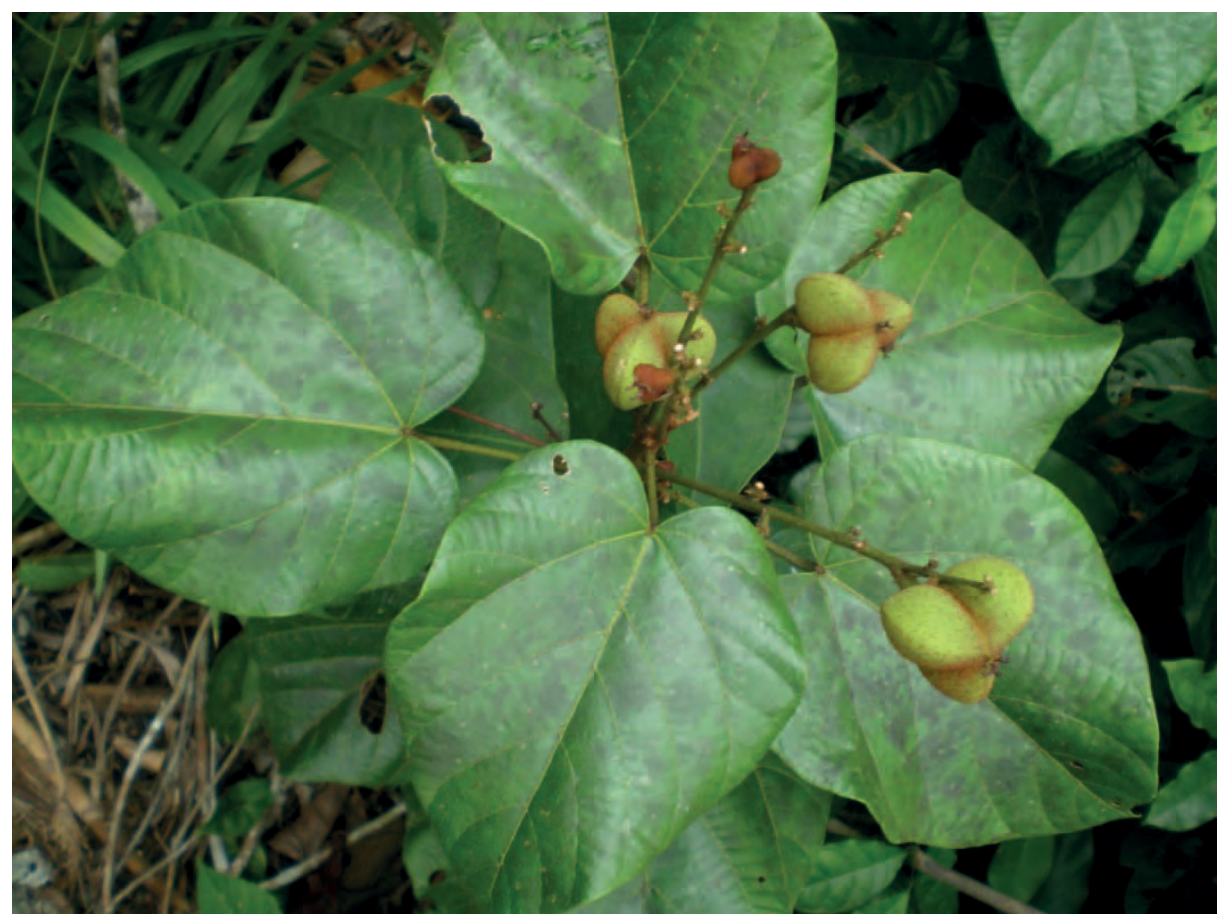

Description : Liane de 20 à $30 \mathrm{~m}$ de long, à tiges jusqu'à $10 \mathrm{~cm}$ de diamètre. Feuilles cordiformes ou divisées en 3 lobes, avec 5 nervures distinctes à la base, pouvant atteindre $35 \times 28 \mathrm{~cm}$. Les feuilles et les tiges sont abrasives comme du papier de verre. La coupure de la tige libère une sève rouge épaisse. Petites fleurs à pétales blancs. Les fleurs mâles sont disposées en panicules d'environ 25 $\mathrm{cm}$ de long. Les fleurs femelles se développent à l'intérieur d'une capsule sèche et poilue à 3 lobes profonds. A maturité, elles éclatent

en projetant les petites graines.

Ecologie : Au Kongo Central, plante des clairières de la forêt secondaire et des rives des cours d'eau. Présente dans les forêts semi-décidues et sempervirentes de la Sierra Leone au Cameroun et à l'Angola.

Usages: L'écorce est importante pour la fourniture de cordes et de liens dans toute I'Afrique Centrale. Au Congo, on l'emploie pour faire des lignes de pêche. L'écorce s'enlève facilement; une fois séchée et battue, elle devient moins abrasive et se travaille mieux. En Afrique centrale, on la tissait traditionnellement en longs filets de 1,5 m de large pour capturer les animaux de la forêt. Les chèvres broutent les feuilles. Les graines peuvent contenir $50 \%$ d'une huile jaune sans goût, qui est comestible après ébullition. On emploie parfois les graines pour expulser les vers intestinaux; la sève s'applique pour traiter les blessures. La plante a de nombreux autres usages médicinaux dans toute l'Afrique.

Références : De Wildeman 1903, Butaye 1909, Gillet et Pâque 1910, Gillet 1927, Renier 1948, Léonard 1962, Daeleman et Pauwels 1983, Burkill 1994, White et Abernethy 1997, Neuwinger 2000, Vande weghe 2004

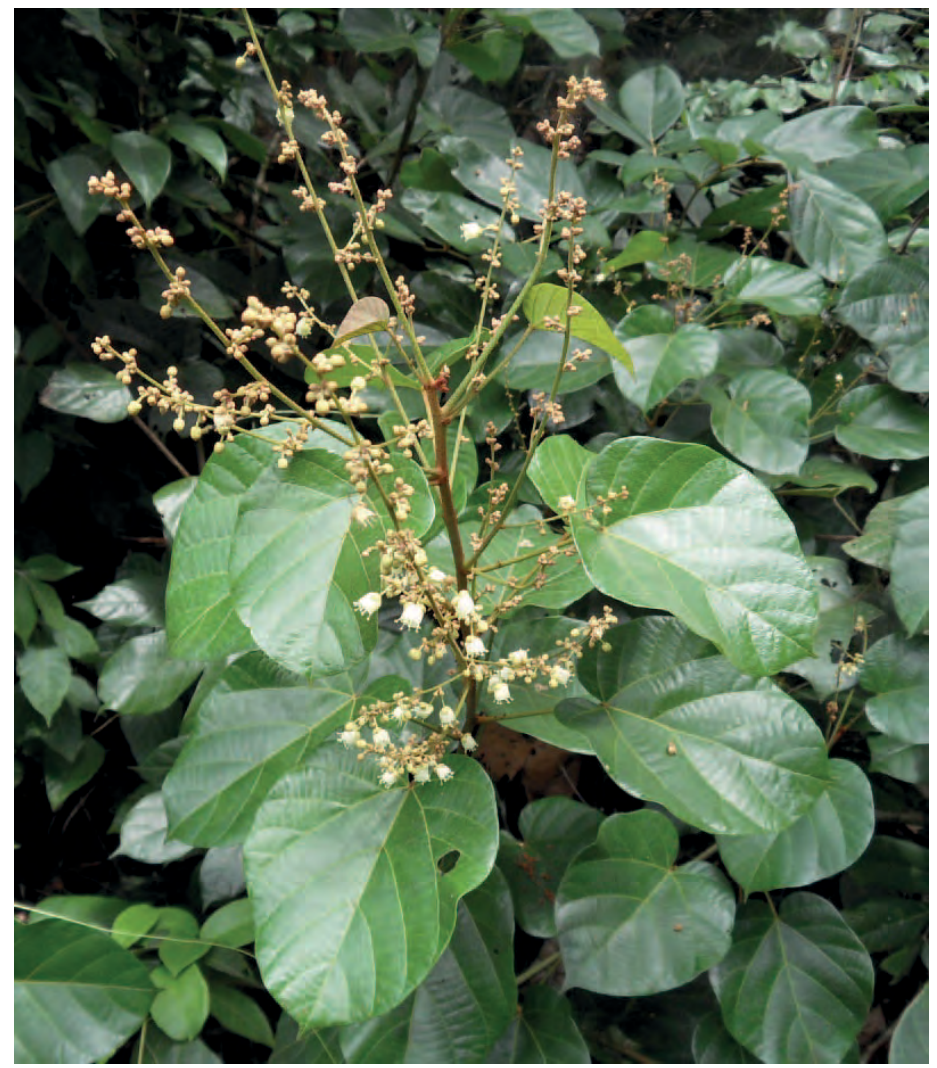


Noms courants : Diladila (Kikongo), dikedi (Lingala)

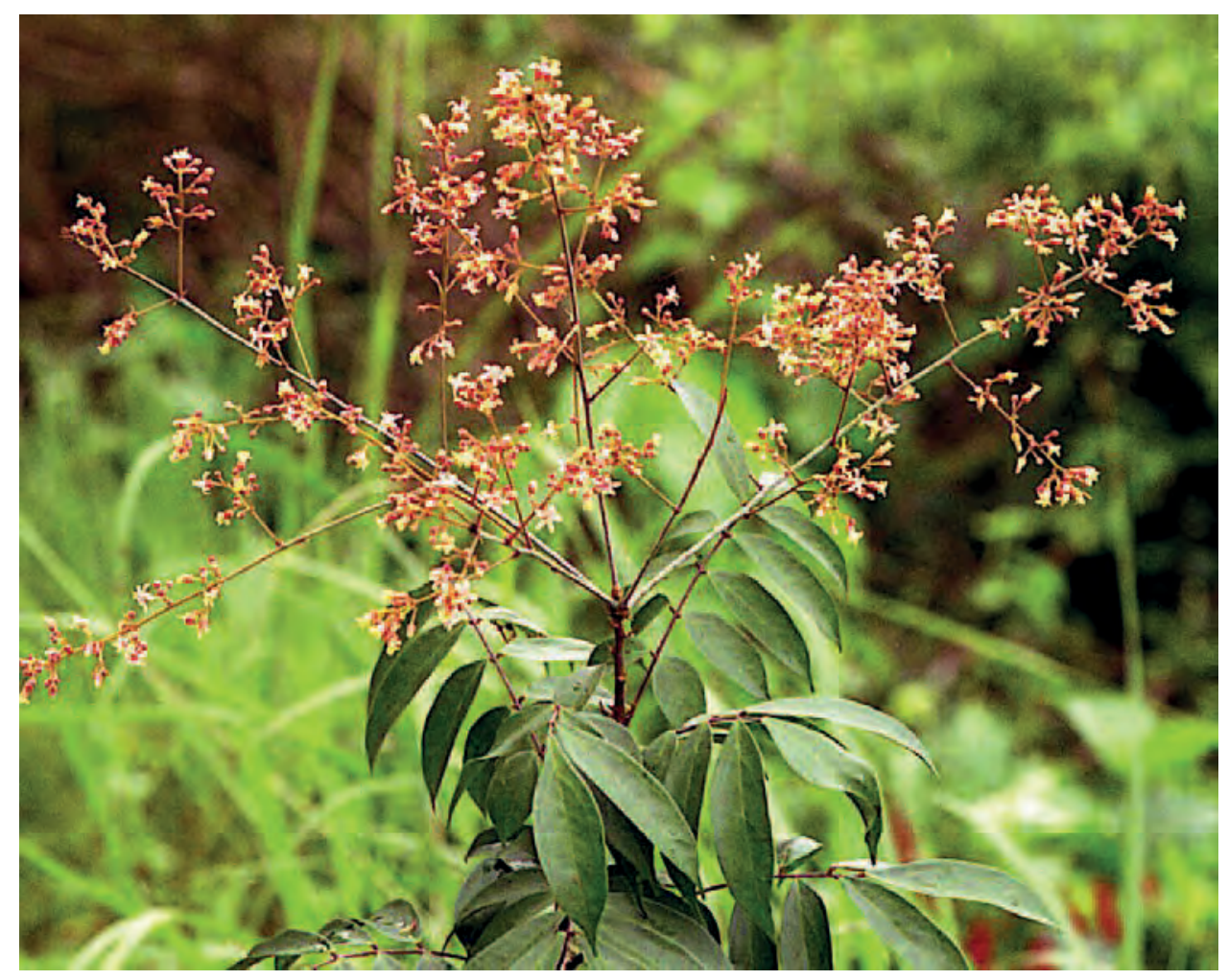

Description : Arbuste buissonnant jusqu'à $6,5 \mathrm{~m}$ de haut. Feuilles composées à 3 folioles elliptiques de 3 à 10 sur 1,5 à $5 \mathrm{~cm}$, sur des pétioles de 5 à $25 \mathrm{~cm}$. Le feuillage est épais ; les bouquets de jeunes feuilles ont une couleur rouge visible de loin. Les petites fleurs sont disposées en panicules sur des rameaux pouvant avoir $50 \mathrm{~cm}$ de long. Les fruits sont des graines noires entourées d'un arille rouge ; ils ont $1,5 \mathrm{~cm}$ de long.

Ecologie: Plante commune des forêts secondaires sur sols

sableux.

Gestion : La plante recèpe bien et se conduit en taillis ; elle pousse souvent dans les champs après les cultures.

Usages: Au Kongo Central, on mange les racines crues pour combattre la diarrhée et la dysenterie. On boit aussi la sève rouge des rameaux pour traiter la diarrhée, la dysenterie, l'anémie, etc. ; on l'injecte en gouttes dans les yeux contre la conjonctivite et les maux de tête; et dans les oreilles en cas d'inflammation. Dans le district de Manianga, on donne la sève aux mères allaitantes pour stimuler la lactation. On applique sur les brûlures une pâte de feuilles pilées. Les chenilles comestibles Kwesu (Gonimbrasia eblis) et Ndienga mangent les feuilles. La plante fleurit pendant les pluies: on a observé en février la récolte du pollen et du nectar par les abeilles.

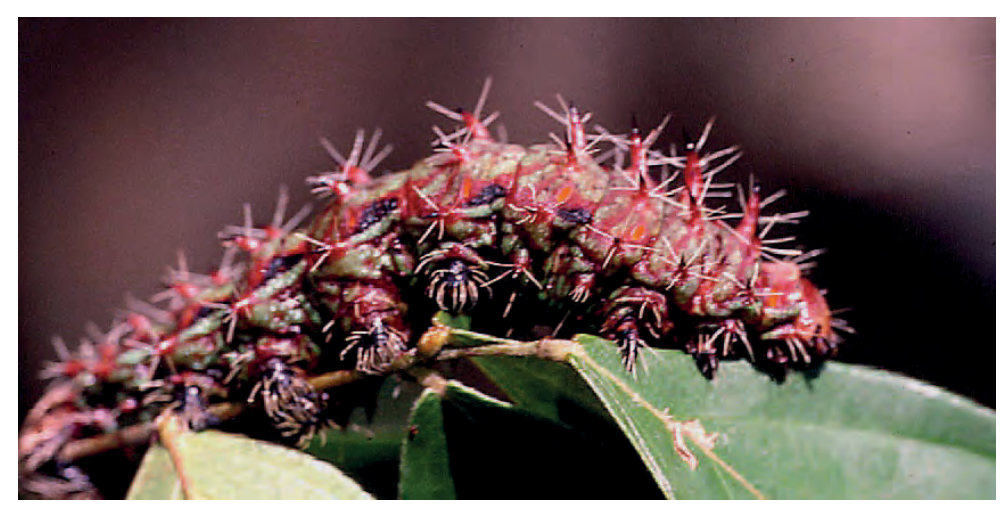

Gonimbrasia eblis se nourrissant sur les feuilles

Références : De Wildeman 1934, Renier 1948, Troupin 1952, Nsimundele 1966 - 68, Arkinstall 1979, Burkill 1985, Mukoko Matondo 1991, Kibungu Kembelo 1995, Neuwinger 2000, Latham 2008 


\section{Maprounea africana}

Noms courants : Kisele sele, kisiele siele (Kikongo)

Description : Arbuste de 3 à $7 \mathrm{~m}$, caducifolié, à écorce liégeuse profondément fissurée, grise ou brune, et rameaux brun rougeâtre. Feuilles alternes de 1,5 à 8 sur 2 à $4 \mathrm{~cm}$, sur des pétioles rouges de 0,5 à $3 \mathrm{~cm}$. Les fruits sont des capsules rouges, légèrement lobées, de 14 à 16 sur 8 à $12 \mathrm{~mm}$, contenant 3 à 5 graines. On trouve également au Kongo Central une seconde espèce.

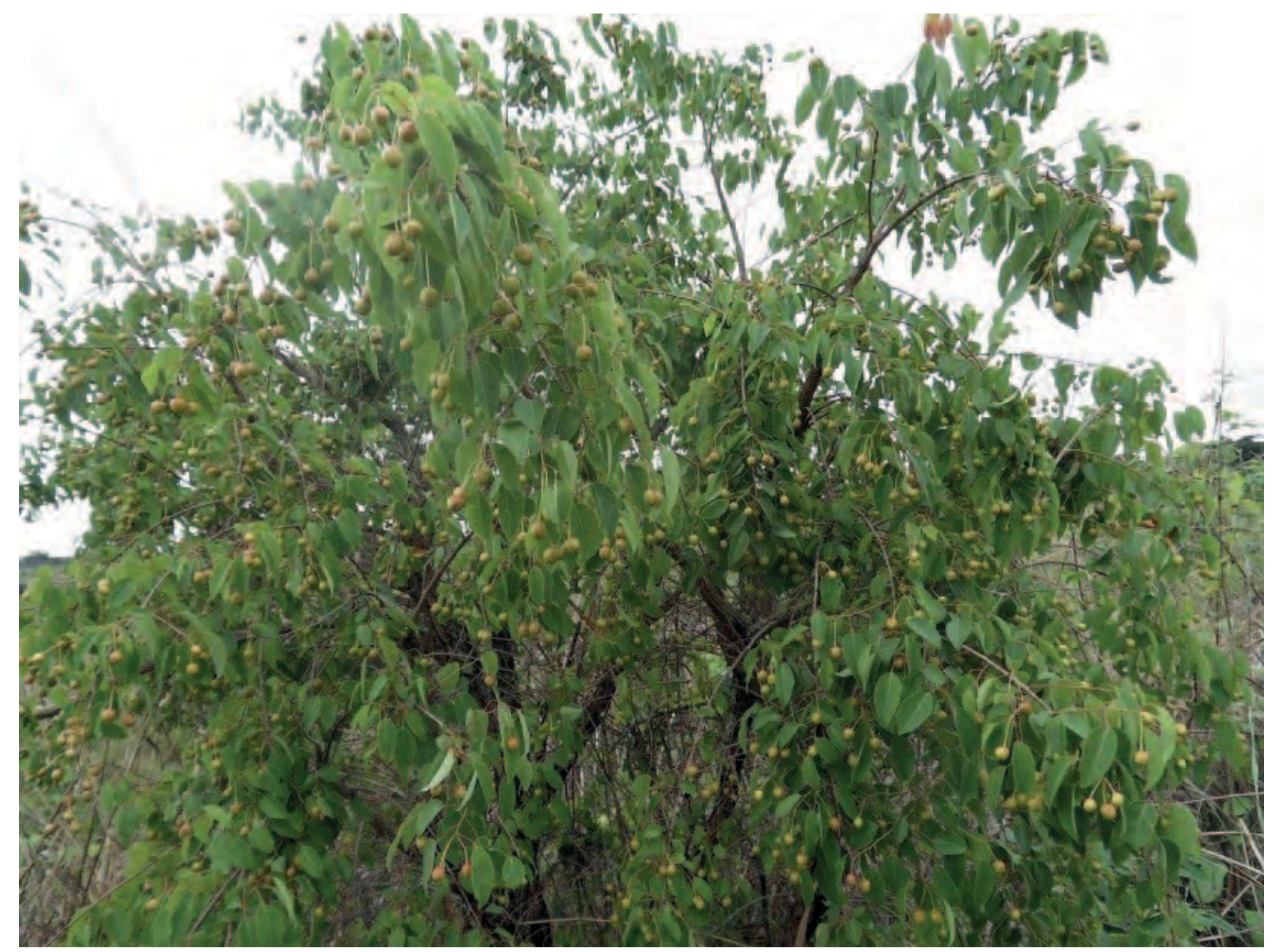

Maprounea africana portant des fruits en novembre

Ecologie : Plante des savanes et des forêts claires, du Nigéria et du Cameroun au Nord jusqu'au Mozambique et à I'Angola au Sud. Résiste au feu grâce à son écorce liégeuse.

Usages : Au Kongo Central, on mâche les feuilles pour soulager les maux de tête ; les petits rameaux servent de bâtons à mâcher; on applique l'écorce sur les caries dentaires. La décoction des racines serait diurétique. A Manianga, les racines servent à traiter les douleurs abdominales et les vers intestinaux. On traite les maux de dents en mâchant les feuilles on en faisant un bain de bouche avec une décoction des feuilles. Ailleurs en R.D. Congo, on mâche aussi les feuilles, et on avale la pâte amère des feuilles pilées pour soulager les maux d'estomac. La plante a beaucoup d'autres usages médicinaux; elle est très connue pour ses propriétés purgatives. L'écorce des racines contient des triterpènes pentacycliques, l'acide maprounique, l'acétate d'acide mapounique, et plusieurs dérivés, dont l'un a manifesté une activité significative contre des cellules cancéreuses P-33_in vitro, tandis que plusieurs autres dérivés ont fait ressortir une puissante activité inhibitrice conte la transcriptase inverse du VIH 1. On a observé en septembre des abeilles collectant le nectar des fleurs.

References Gillet et Pâque 1910, Staner et Boutique 1937, Renier 1947, Delaude et Breyne 1971, Arkinstall 1979, Pauwels 1993, Burkill 1994, Nsimundele 2004, Lautenschläger et al. 2018 


\section{Maranta arundinacea}

Noms courants: Midon (Kikongo d'après “amidon"), marante (Fr.), arrowroot (Angl.)

Description : Plante herbacée pérenne haute de 1 à $1,8 \mathrm{~m}$, à rhizomes charnus cylindriques et feuilles de $22 \times 8$ $\mathrm{cm}$. Les fleurs sont disposées en bouquets jumeaux de $1 \mathrm{~m}$ de haut ; elles donnent rarement des graines. Les racines sont superficielles.

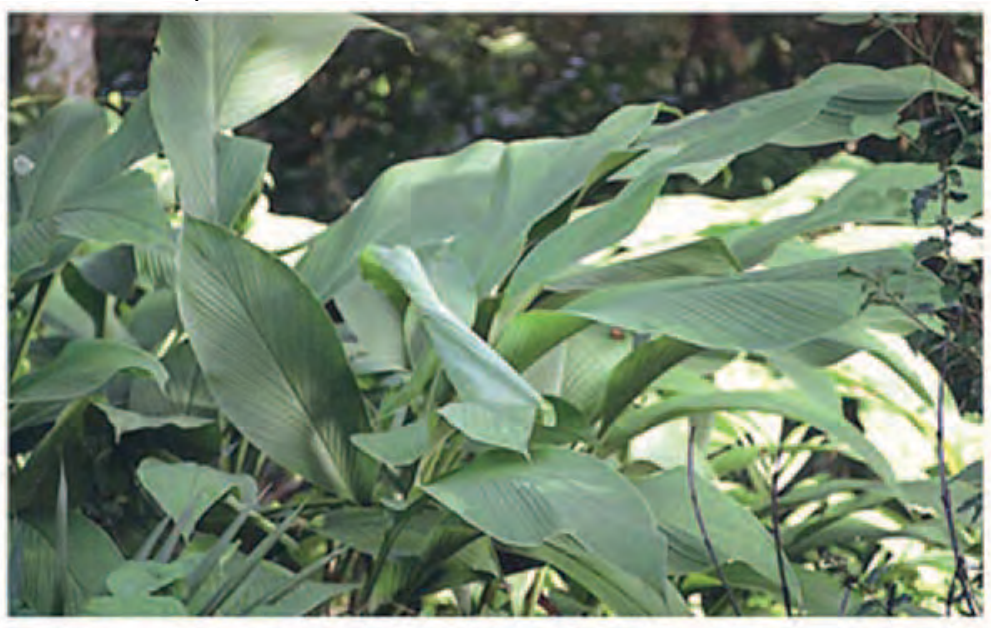

Ecologie: Plante originaire des Caraïbes, devenue pantropicale. On la cultive rarement au Kongo Central. Elle préfère un climat chaud et humide, avec une unique et brève saison sèche. Elle requiert des sols limoneux profonds, bien drainés, acides et fertiles. L'ombre est bénéfique pour les cultures sur sols sableux.

Reproduction: Habituellement à partir de morceaux de rhizomes portant des boutons, de 4 à $7 \mathrm{~cm}$ de long. Eviter d'utiliser les rhizomes trop minces. Planter les morceaux dans un terrain bien préparé, dans des trous de 5 à $7,5 \mathrm{~cm}$ de profondeur espacés de $30 \times 30 \mathrm{~cm}$.

Gestion : On doit bien désherber la plantation pendant les 3 ou 4 premiers mois, et enlever toutes les fleurs dès leur apparition. On récolte les rhizomes quand les feuilles commencent à dépérir et tomber, environ 11 mois après la plantation, quand ils ont de 20 à $45 \mathrm{~cm}$ de long.

Usages: Au Kongo Central, le rhizome sert à préparer une boisson, ou bien est séché pour être cuisiné; on le mange particulièrement avec le poulet. La farine des racines donne une pâte particulièrement souple, bien adaptée pour les préparations pour les jeunes enfants et pour les invalides. Elle est hautement digestible, et particulièrement utile pour traiter les problèmes digestifs. Sa préparation requiert la propreté de bout en bout : éplucher la racine pour ôter la substance amère et gluante de la peau; on en fait alors une pâte que l'on mélange avec de l'eau propre; on obtient l'amidon en filtrant à travers des tamis fins, et en le laissant se déposer. Le rhizome se mange aussi rôti ou bouilli. Il est intéressant par sa capacité à absorber les substances nuisibles du corps; on l'emploie aussi pour traiter les blessures. Le résidu après extraction de l'amidon peut remplacer le poivre. Les feuilles servent parfois à emballer les produits alimentaires.

Références : Gillet 1927, Renier 1948, Purseglove 1972, Kay 1973, Burkill 1997

Photo : http://www.aziatischeingredienten.nl/pijlwortel/

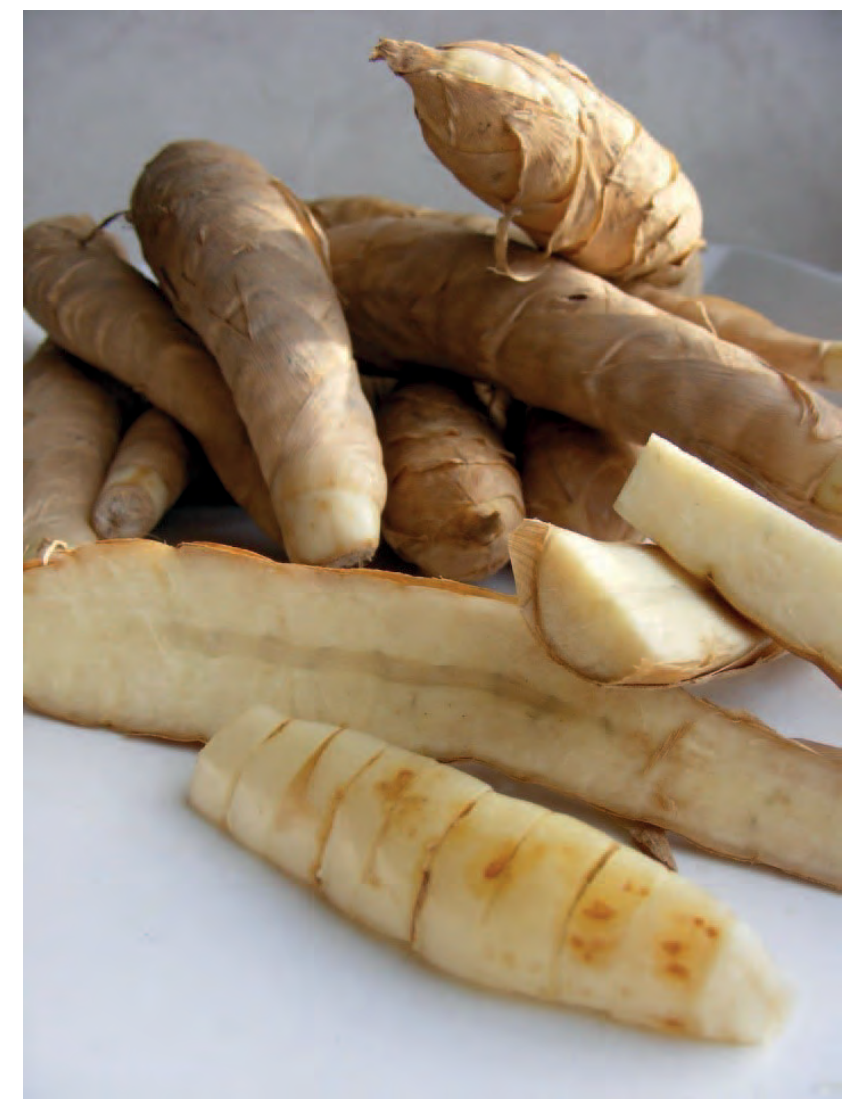




\section{Maranthes glabra}

Noms courants : Mbulunkutu (Kikongo)

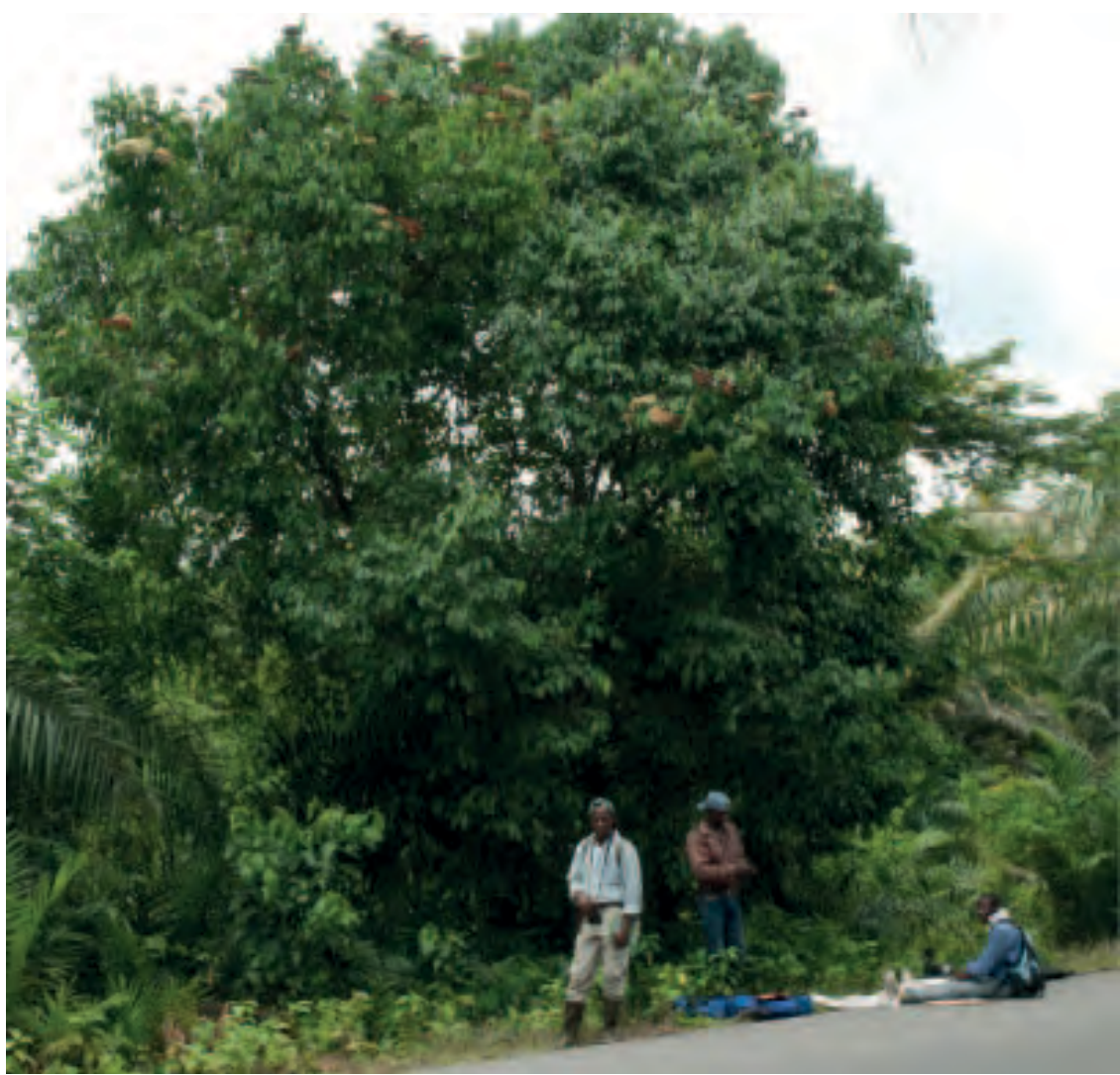

Description : Arbre à feuilles persistantes de 25 à $30 \mathrm{~m}$ de haut. Surface de l'écorce rugueuse avec des écailles de taille irrégulière. Feuilles de 10 à 14 sur 5,5 à $6,5 \mathrm{~cm}$, qui prennent une couleur brun rouge sombre quand elles sèchent. L'inflorescence est une panicule terminale ayant jusqu'à $20 \mathrm{~cm}$ de diamètre. Les fruits sont longs de 2,5 $\mathrm{cm}$. L'arbre commence à fleurir quand il a $5 \mathrm{~m}$ de haut, après quoi il fleurit et fructifie toute l'année.

Ecologie : Arbre des forêts, marécageuses ou autres, de la Sierra Leone à la Centrafrique et à l'Angola.

\section{Reproduction : La}

germination des graines est médiocre.

Les deux photos: David Harris africanplants. senckenberg.de

Usages : Le bois est difficile à travailler. II convient pour les constructions lourdes et pour les pirogues. II donne un bon bois de feu. Les chenilles comestibles Mbulunkutu broutent les feuilles. En Côte d'I voire et au Cameroun, on mange les graines, qui contiennent de l'huile. L'écorce s'emploie largement à des fins médicinales.

Références: Daeleman et Pauwels 1983, Pauwels 1993, Vivien et Faure 1996, Nsimundele 2004, Harris et al. 2011, Oyen 2012

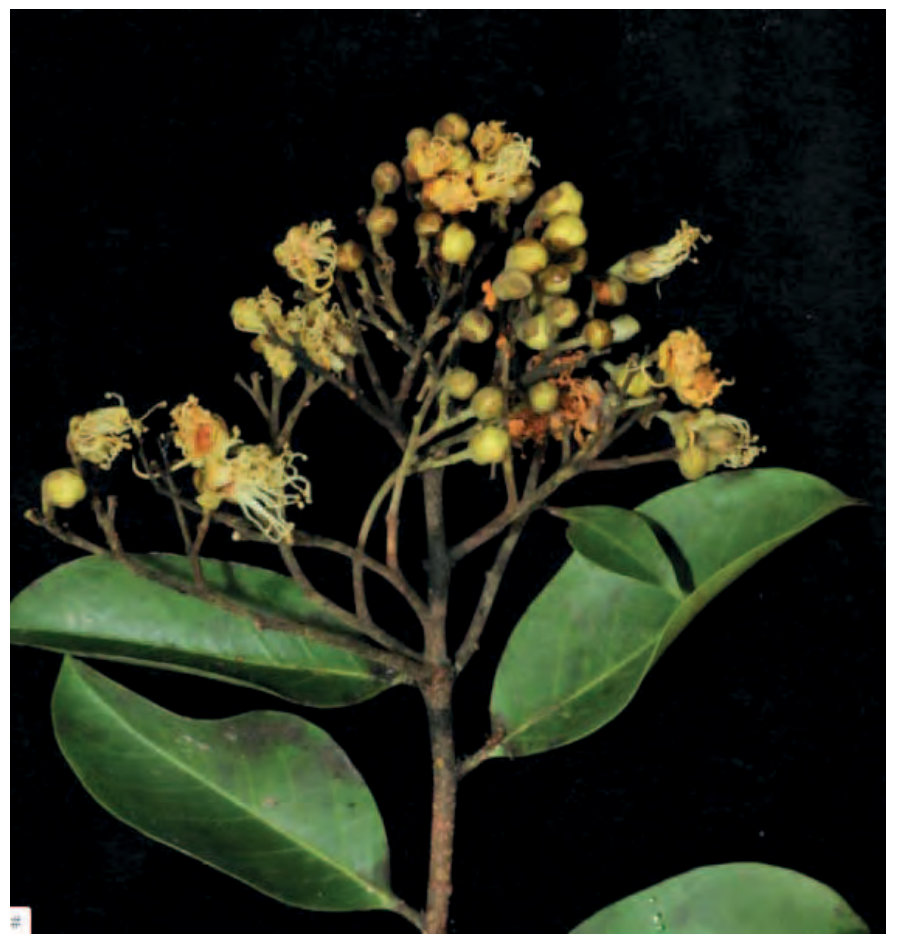


Nom courant : Matatele (à Kwango), Yoruba soft cane (Angl.)

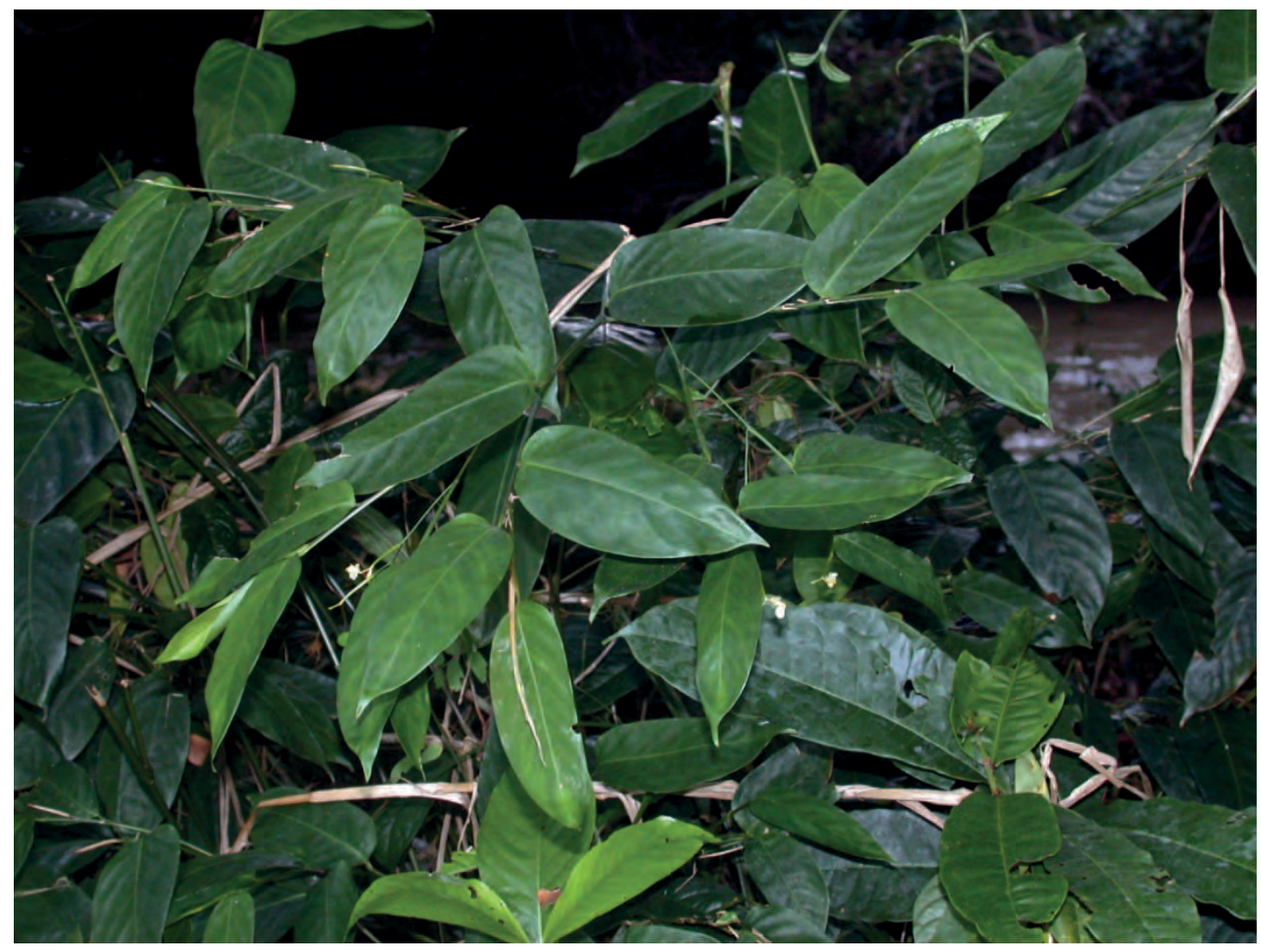

Description : Plante herbacée pérenne et dressée ou rampante, légère et ramifiée, formant des touffes de $4 \mathrm{~m}$ de haut. Feuilles alternes à limbe asymétrique, jusqu'à $20 \times 10 \mathrm{~cm}$, arrondies à la base et pointues au bout. Inflorescence jusqu'à $10 \mathrm{~cm}$ de long, portant 2 fleurs blanches ou jaune pâle, pollinisées par les abeilles. Le fruit est une capsule déhiscente à 3 lobes.

Les deux photos : Alexandra Ley www. africanplants. senckenberg. de

Ecologie: Plante des forêts et des recrus forestiers, de la Sierra Leone au Sud du Nigéria et à la R.D. Congo, du niveau de la mer à $1.200 \mathrm{~m}$ d'altitude.

Usages: A Kinshasa, on prend les feuilles pour emballer les produits alimentaires. La tige et l'écorce (et probablement aussi les pétioles) sont largement employés pour confectionner des cordages et pour des travaux de vannerie: nattes, paniers et objets d'ornement. Les cordages sont forts, mais les nattes et paniers ne sont pas durables, parce que les bandes d'écorce perdent rapidement leur souplesse, et deviennent cassantes en séchant. Les tiges séchées servent d'allume feu.

Références : Burkill 1997, Biloso et Lejoly 2006, Hawthorne et Jongkind 2006, Brink 2011, Dhetchuvi et Ley 2017 


\section{Margaritaria discoidea}

(Phyllanthaceae)

\section{Synonyme : Phyllanthus discoideus}

Noms courants : Kinsende, nkingidi (Kikongo), common pheasant-berry (Angl.)

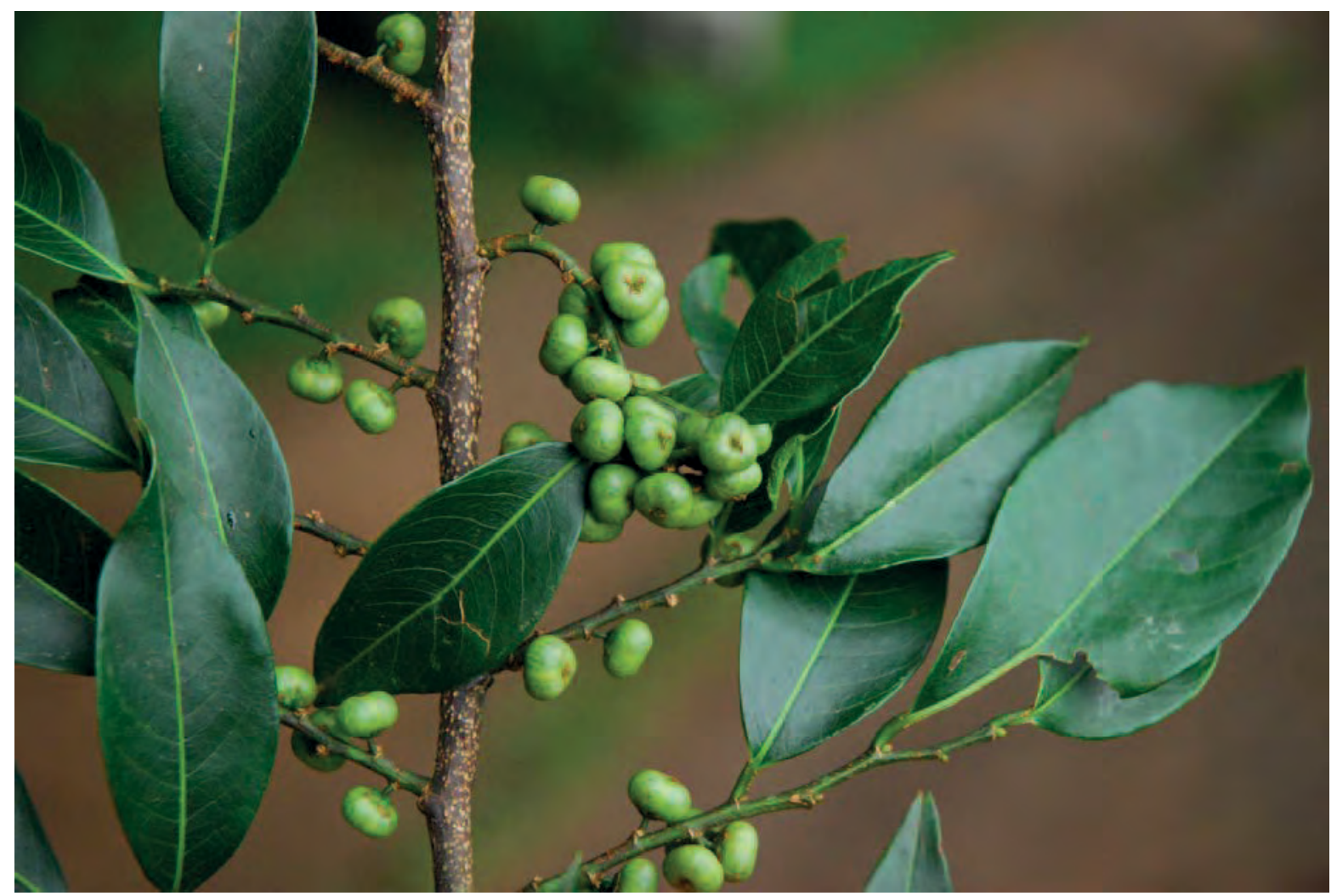

Photo : Quentin Meunier

Description : Arbre de taille moyenne, avec de longues branches légères tombantes. Les rameaux terminaux portent de nombreuses lenticelles. Les feuilles ont 1 à $12 \mathrm{~cm}$ de long. Petites fleurs vert jaune ; fleurs mâles et femelles sur des arbres distincts. Les fleurs mâles attirent l'attention, de même que les petites grappes de fruits à 3 à 4 lobes, de 6 à $9 \mathrm{~mm}$ de diamètre, et à couts pédoncules. II y a plusieurs sous espèces et variétés.

Ecologie : Espèce pionnière, qui peut devenir dominante, puis disparait, largement répandue en Afrique tropicale dans les forêts secondaires.

Reproduction : La plante donne beaucoup de graines. Récolter au sol les capsules fermées, et les piler pour avoir les graines. Les semer après trempage une nuit dans l'eau froide, en plein champ ; on peut aussi transplanter les semis spontanés.

Gestion : L'arbre grandit rapidement ; il recèpe bien et peut se conduire en taillis.

Usages: Le bois est dur et lourd, mais pas très durable à l'extérieur. On l'emploie pour les menuiseries et le mobilier d'intérieur ; il est facile à travailler et prend un beau poli. On l'emploie aussi comme bois de feu et pour le charbon de bois. Au Congo, on emploie le bois pour les coques de bateaux, car il s'arrondit bien une fois traité à la vapeur. La cendre du bois donne un sel végétal. On emploie les feuilles pour traiter les blessures. Au Gabon, on signale que les abeilles visitent les fleurs. Au Kongo Central, les chenilles comestibles Minsendi, une espèce très appréciée, se nourrissent des feuilles ; on doit enlever leurs épines avant de les cuire. On fait cuire les fruits noirs pour les manger avec des noix de coco. Les graines sont particulièrement appréciées des pintades.

Références : Gillet et Pâque 1910, Staner et Boutique 1937, Renier 1948, Daeleman et Pauwels 1983, Keay 1989, Ambougou 1991, Burkill 1994, Katende et al. 1995, Kibungu Kembelo 1995, Neuwinger 2000, Hawthorne et Gyakari 2006, Meunier et al. 2010, Harris et al. 2011, Meerts 2020 
Nom courant : Nsasa (Kikongo)

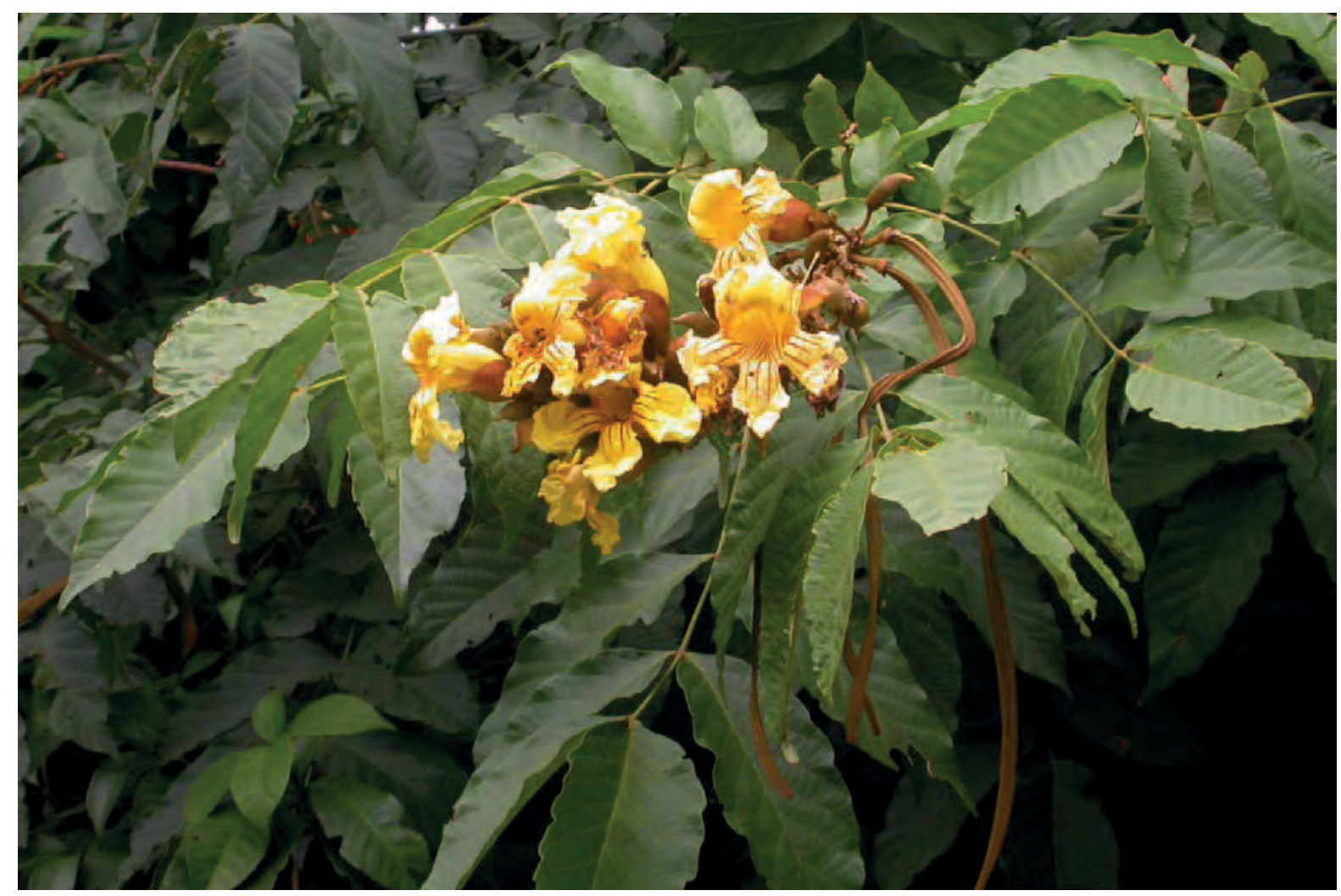

Description : Arbre jusqu'à $13 \mathrm{~m}$ de haut, dont les rameaux et les jeunes feuilles sont densément couvertes de très courts poils jaunes. Feuilles composées à 5 à 6 paires de folioles, de 10 à 21 sur 3,7 à 7 $\mathrm{cm}$. Belles fleurs jaunes striées de pourpre, zygomorphes, en panicules terminaux, à tubes de 3 à 4,5 cm, avec 2 lèvres et 5 lobes de 1,5 à 2,5 $\mathrm{cm}$ de long. Les fruits sont des siliques plates déhiscentes, ayant tendance à se courber, de 35 à 80 sur 1 à $2 \mathrm{~cm}$, s'ouvrant en 2 valves contenant beaucoup de graines. Les graines sont des carrés plats prolongés par 2 ailes transparentes. De $0,5 \times 2,5 \mathrm{~cm}$ en incluant les ailes.

Ecologie: Arbre des forêts, des lisières, et des savanes boisées en Afrique de l'Ouest et au Sud jusqu'à l'Angola.

Usages : Le bois, brun clair, est dur et convient pour les charpentes ; au Kongo Central, on en fait des mortiers et des instruments de musique. Les abeilles visitent les fleurs. Au Sud du Nigéria, le bois de petit diamètre sert à faire des manches de couteaux. L'arbre est parfois cultivé à titres ornemental et a de nombreux usages médicinaux. L'écorce peut s'employer pour le tannage.

Reproduction : Les graines fraiches germent bien.

Remarque : On signale la présence d'une deuxième espèce, $M$. Lutea, bien que rare. Elle n'a que trois paires de folioles. On la trouve du Ghana à l'Afrique Orientale, où on l'emploie beaucoup en agroforesterie ; ceci pourrait conduire à expérimenter le potentiel d'utilisation de $M$. tomentosa en agroforesterie en R.D. Congo.

Références : Gillet et Pâque 1910, Gillet 1927, Renier 1948, I rvine 1961, Liben 1977, Burkill 1985, Pauwels 1993, Katende et al. 1995

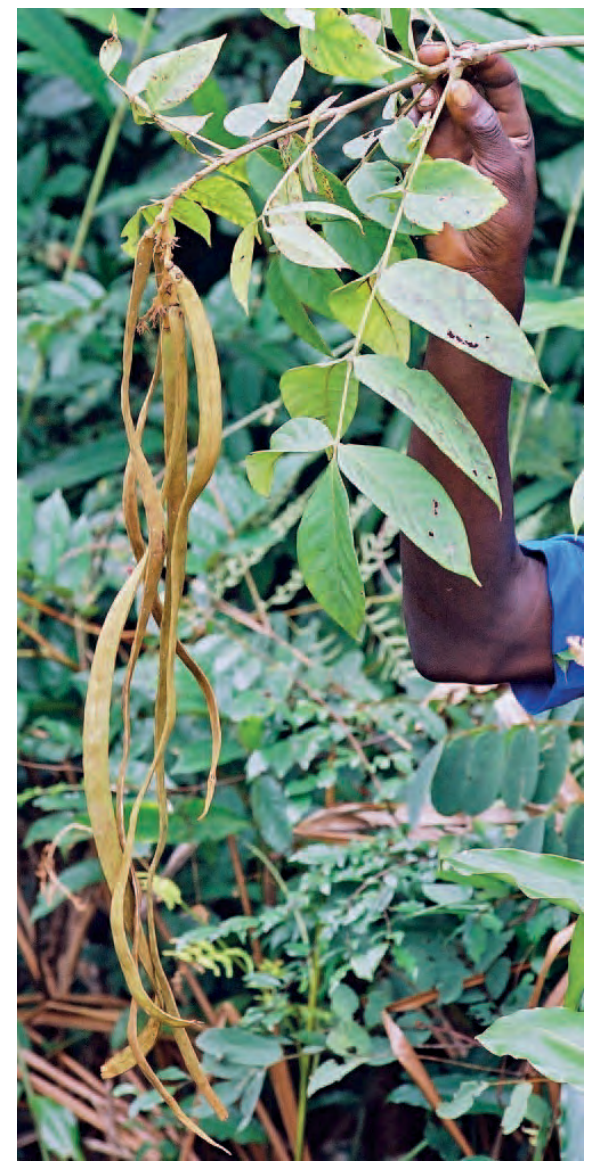




\section{Megaphrynium macrostachyum}

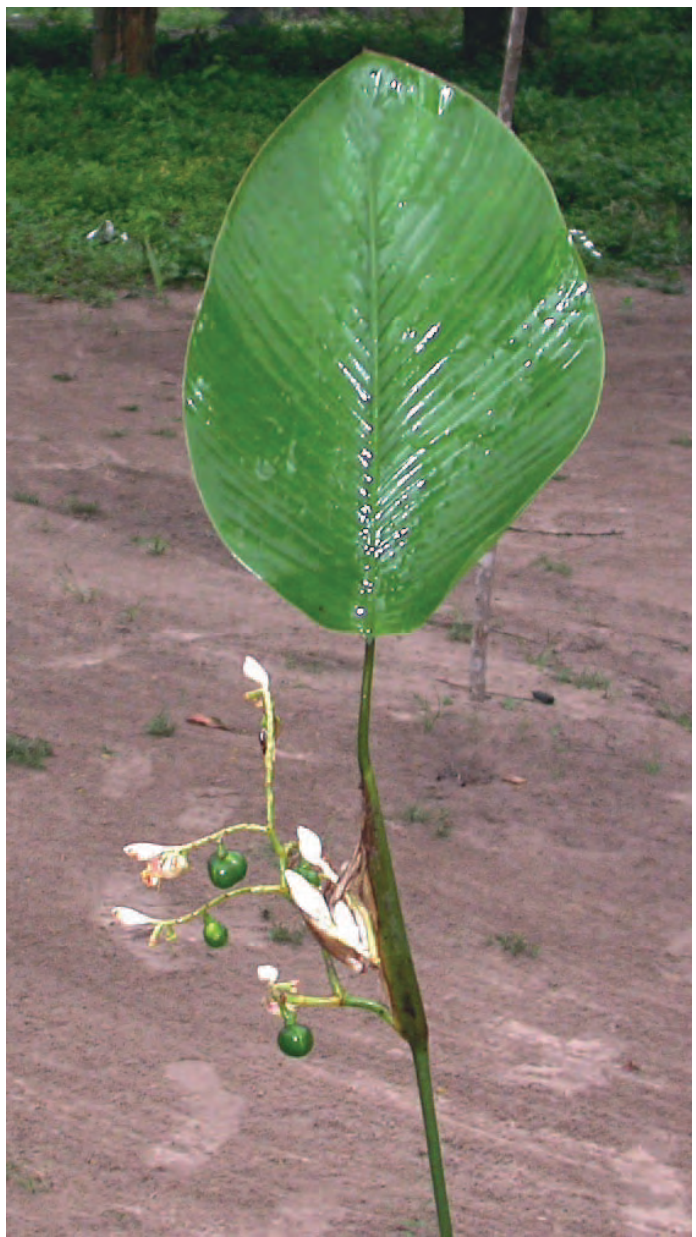

Synonyme : Sarcophrynium arnoldianum

Noms courants : Dingungu, bindiondi (Kikongo), yoruba soft cane (Angl.)

Description : Plante herbacée pérenne semi-ligneuse, formant des massifs étendus, avec des tiges hautes de 0.8 à $2,5 \mathrm{~m}$, portant chacune une seule grande feuille asymétrique, de 20 à 90 sur 15 à $50 \mathrm{~cm}$.

Ecologie : Plante des lieux humides dans la forêt primaire ou secondaire, de la Sierra Leone au Cameroun, et à tous les pays du bassin du Congo.

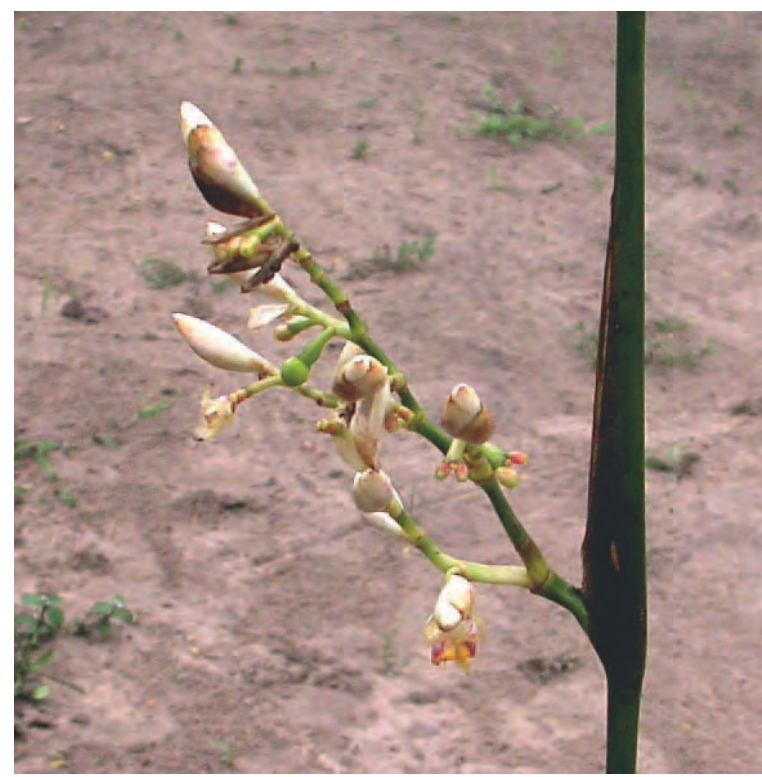

Tiges portant des fruits (à gauche) et des fleurs (ci-dessus).

Usages : En R.D. Congo, les tiges fendues s'emploient en vannerie pour faire des nattes et des paniers. Les feuilles s'utilisent largement pour emballer la chikwangue, à laquelle elles donnent un bon goût, ainsi que le poisson ou la

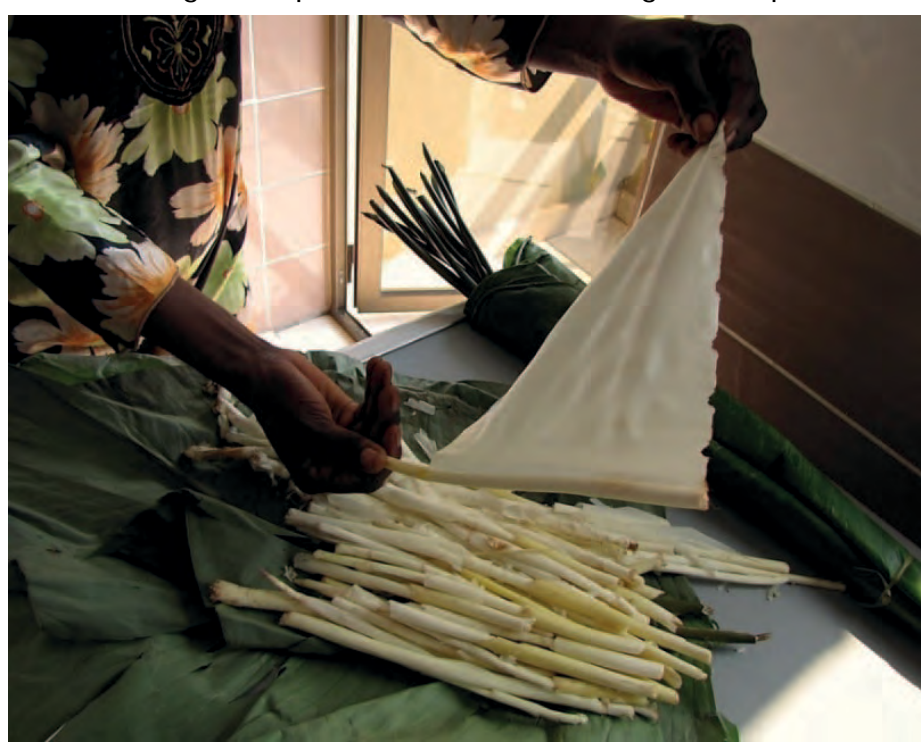
viande pour les cuissons à l'étouffée (maboke en lingala); on les emploie aussi pour emballer divers produits alimentaires; on en trouve beaucoup sur les marchés. Elles servent à la couverture des toits. Les jeunes feuilles encore blanches et non déroulées sont cuisinées comme légumes. Le fruit est comestible. En Côte d'Ivoire, on emploie la sève des feuilles pour traiter l'épilepsie, et un extrait des feuilles pour traiter les empoisonnements.

A gauche : Préparation des jeunes feuilles à cuisiner.

Photo : T.K. Naliaka

Références: Gillet et Pâque 1910, Gillet 1927, Renier 1948, Daeleman et Pauwels 1983, Konda Ku Mbuta et al. 1992, Burkill 1997, Neuwinger 2000, Nsimundele 2004, Vande weghe 2004, Dhetchuvi et Ley 2017 
Noms courants : White bottlebrush (Angl.)

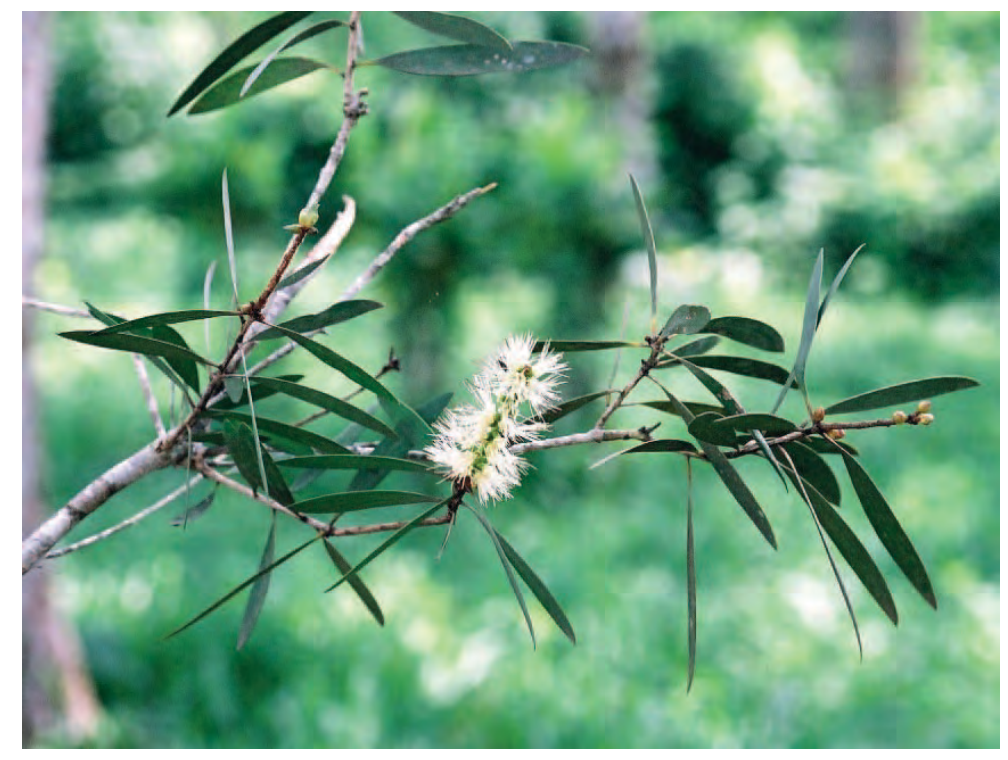

Description : Arbre à croissance rapide, e 6 à $16 \mathrm{~m}$ de haut, avec une couronne serrée ou ouverte. Le tronc est court et tortueux. L'écorce est blanchâtre, épaisse, liégeuse ou spongieuse, composé de multiples couches roses, légères et fibreuses, qui se desquament par plaques. Feuilles alternes de 4 à 9 sur 6 à $24 \mathrm{~cm}$, à odeur résineuse quand on les écrase. La floraison est abondante. Les inflorescences sont des épis cylindriques de 3 à $8 \mathrm{~cm}$ de long, groupant les fleurs par trois. Les fleurs blanches possèdent de nombreuses étamines de 7 à $16 \mathrm{~mm}$ de long, rassemblées en faisceaux opposés aux pétales. Chaque épi ressemble ainsi à une brosse à bouteilles.

Ecologie: Arbre introduit depuis I'Australasie, présent au jardin botanique de Kisantu. II prospère sur les sols marécageux ou inondés, mais pousse aussi sur les sols superficiels ou dégradés. On connait les espèces de Melaleuca pour leur adaptation à une grande variété de conditions.

Reproduction : L'arbre se reproduit par graines, à semer sur un sol humide. Le désherbage est requis les six premiers mois.

Usages : Les fleurs produisent un nectar abondant; on signale qu'à Kisantu elles sont visitées par les abeilles. L'arbre est connu en Australie et aux USA pour donner lieu à une abondante production de miel. Le miel est foncé, avec un goût fort ; il granule rapidement. On peut brûler l'écorce pour enfumer les abeilles. En Floride, le miel de cet arbre est abondant, mais certains trouvent son goût amer et désagréable. II parait que si ce miel est conservé quelque temps, il perd son goût désagréable. On ôte l'écorce pour faire du bois de feu; le bois a été employé en sculpture. L'écorce peut s'employer pour ses propriétés isolantes. Les feuilles donnent de l'huile de niaouli, qui est commercialisée pour ses propriétés antiseptiques, et peut traiter la toux, les névralgies et les rhumatismes.

Remarque : Ces arbres sont remarquables pour leur résistance aux nuisibles et aux maladies, mais peuvent souffrir de dépérissement.

Références: Morton 1964, NAS 1983,

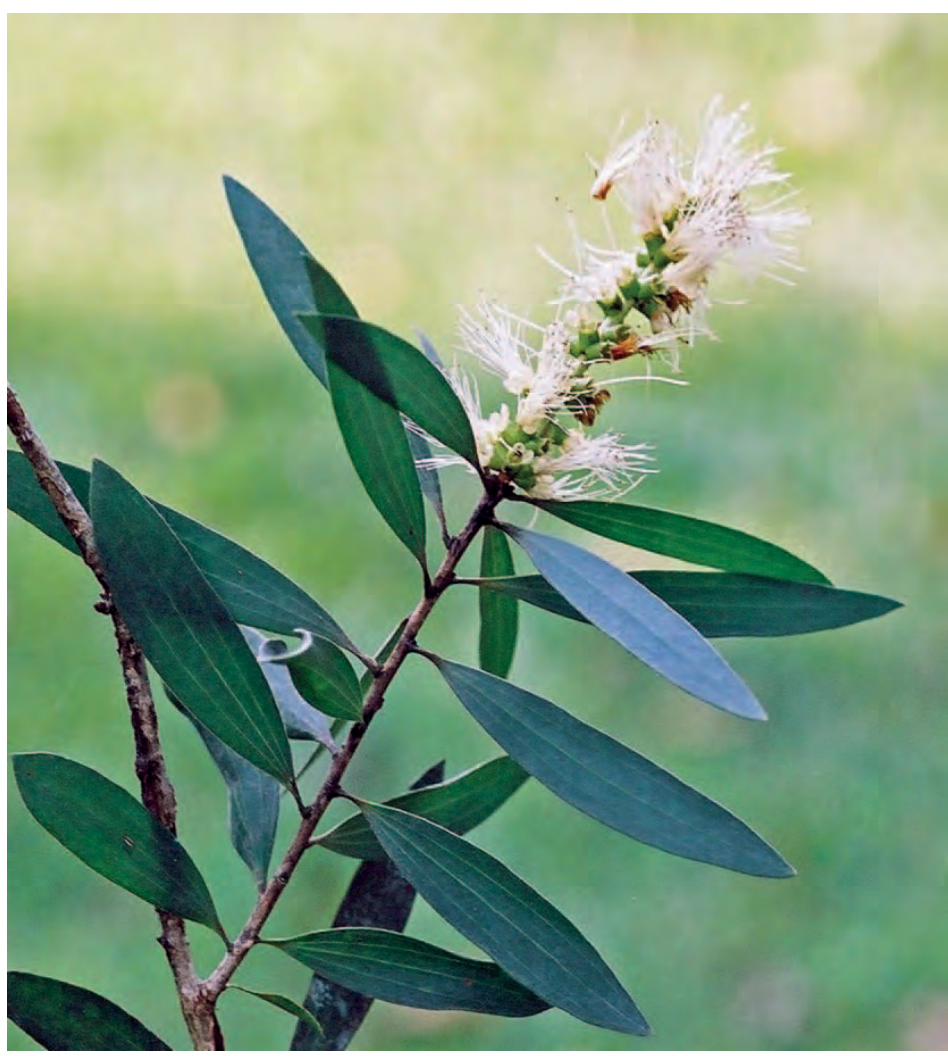
Little 1983, Crane et al. 1984, Burkill 1997 


\section{Melanthera scandens}

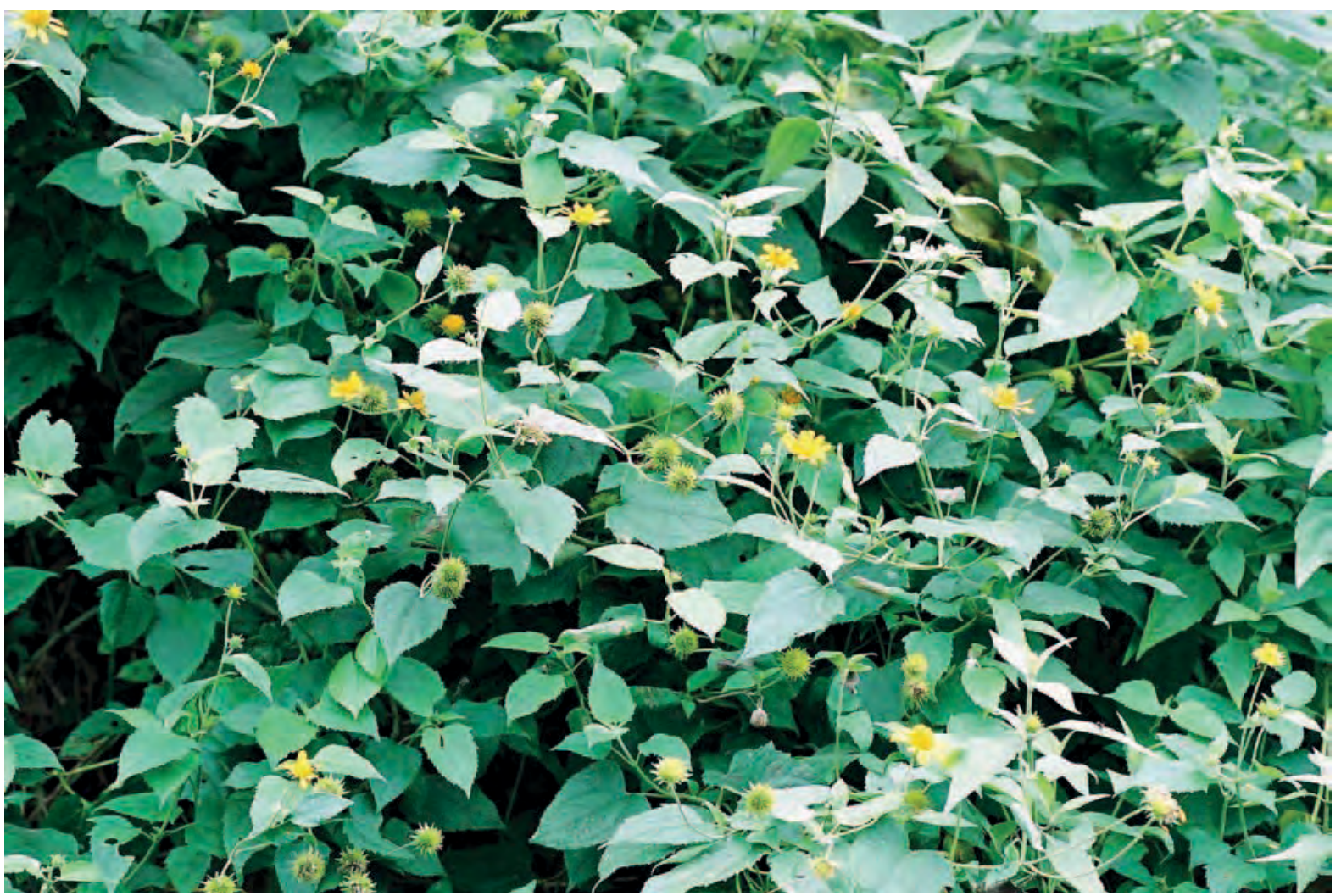

Melanthera scandens en fleurs en mai / juin

Description : Herbe rampante ou grimpante, qui peut atteindre $3 \mathrm{~m}$ de longueur. La tige est quadrangulaire, très ramifiée, et rêche au toucher. Feuilles opposées de 7 à 15 sur $3 \mathrm{~cm}$, sur de longs pédoncules, très pointues à l'extrémité. Inflorescence sur des tiges d'environ $15 \mathrm{~cm}$ de long, habituellement à l'aisselle des feuilles supérieures.

Ecologie: Plante de la savane, des bords de champs et des lisières de forêts, commune dans les régions forestières et dans toute l'Afrique tropicale.

Usages: On signale que les abeilles visitent cette plante au Sud du Nigéria. On peut l'employer pour nourrir le bétail ; au Nigéria, on fait une soupe avec les feuilles. Dans I'Uele et au Kongo Central, on applique sur les plaies ou les éruptions les racines brûlées, ou une macération des feuilles.

Références : Staner et Boutique 1937, Wild 1965, Burkill 1985, Akobundu et Agyakwa 1987, AchiganDako et al. 2009, Abdullahi et al. 2011

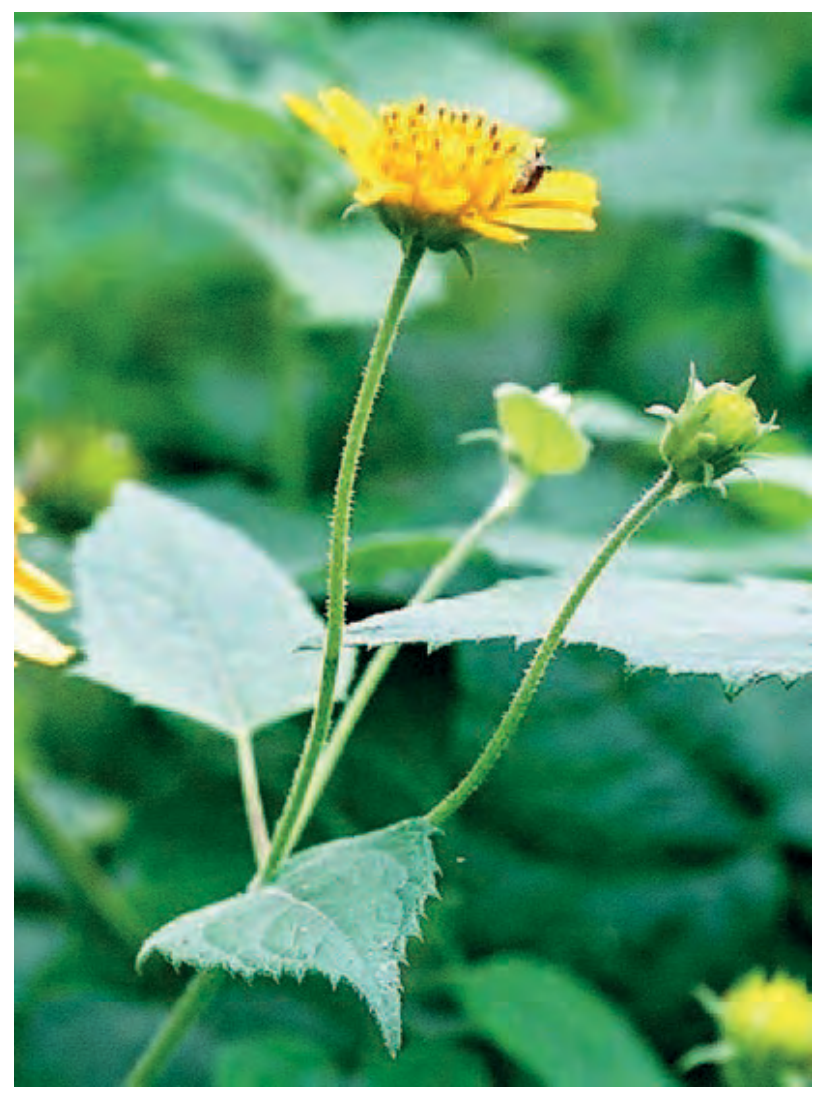




\section{Melia azedarach}

Noms courants : Lilas de Perse, margousier (Fr.), Persian lilac (Angl.)

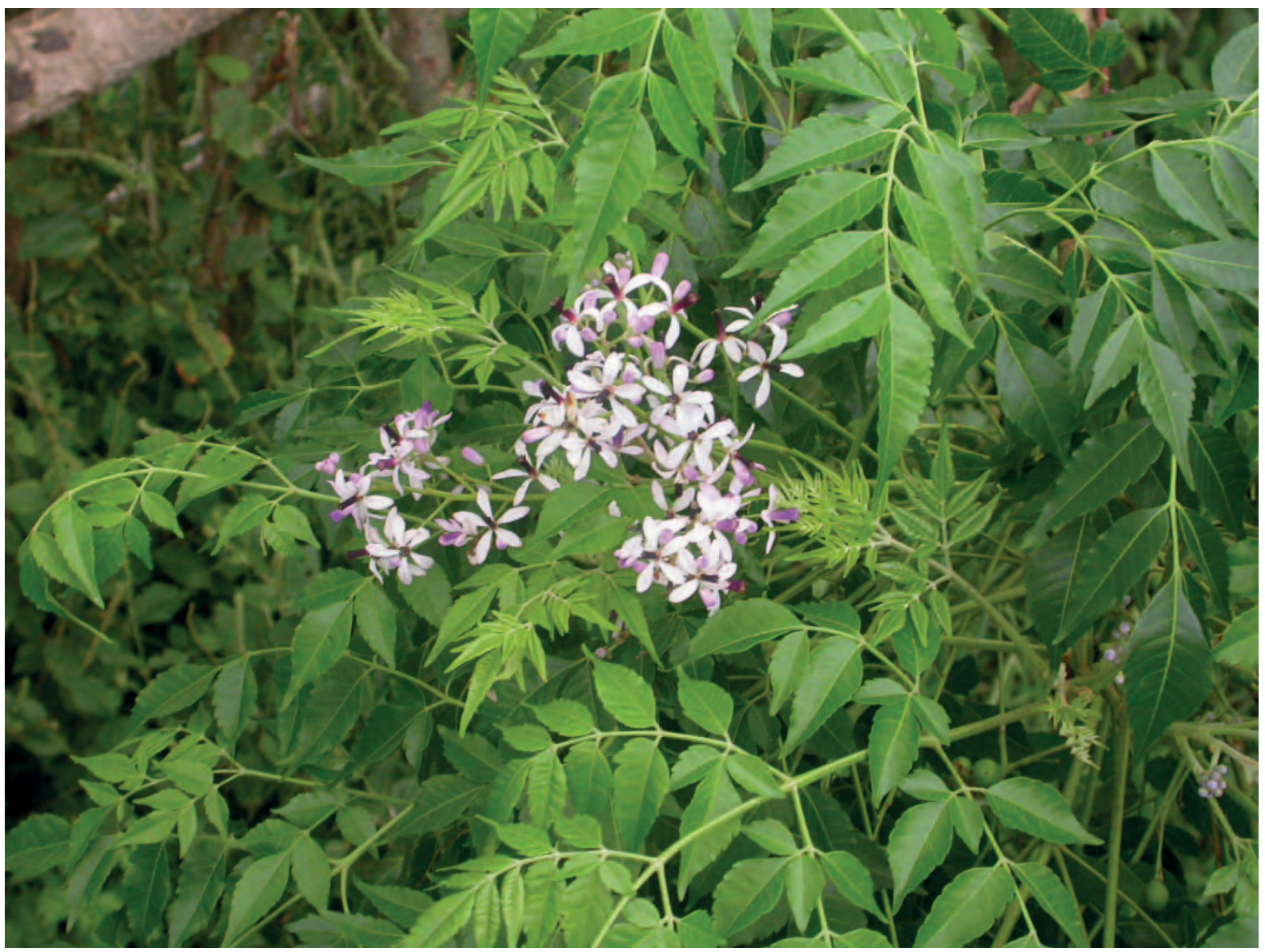

Description : Arbre à croissance rapide de $15 \mathrm{~m}$ de haut, habituellement décidu. Ecorce lisse brun rouge. Feuilles alternes bipennées imparipennées, avec un long pétiole et une longueur de 20 à $60 \mathrm{~cm}$. Chaque limbe comporte de 2 à 5 paires de pennes pseudo opposées, et le dernier limbe comportant une foliole terminale. Les folioles mesurent 2 à $8 \mathrm{~cm}$ de long; elles sont lancéolées, dentées, avec un apex acuminé et une base en coin. Inflorescences en panicules axillaires de 10 à $20 \mathrm{~cm}$ de long ; petites fleurs odorantes, tubulaires, violet clair. Les fruits sont ovales, charnus, jaune orange, en grappes, et restent sur l'arbre quand il a perdu ses feuilles. L'arbre fleurit et fructifie toute l'année.

Ecologie: Originaire d'Inde, du Sud de la Chine, et d'Australie, devenu pantropical. Planté le long des routes, dans les jardins et dans les villages au Kongo Central. Résiste à la sécheresse ; résiste modérément aux termites.

Reproduction : Les graines germent aisément ; on peut les tremper 24 heures avant de les semer, en pépinière ou en plein champ. Transplanter à 30 à $45 \mathrm{~cm}$. Stocker les graines au frais.

Gestion : L'arbre grandit rapidement, il se taille et recèpe bien : on peut le conduire en taillis. II produit des rejets qui peuvent devenir une nuisance. Si on le cultive pour le bois, enlever les branches latérales jusqu'à $6 \mathrm{~m}$ de haut.

Usages : L'écorce amère, ou une infusion des feuilles, est largement employée comme anti-helminthique. L'écorce et les feuilles s'emploient pour diminuer la fièvre. Les feuilles et les rameaux séchés peuvent servir à protéger le linge, les livres et le cuir. On peut les mettre entre les sommiers et les matelas pour contrôler les punaises des lits. L'arbre n'est mangé ni par les termites ni par les acridiens ; une infusion de feuilles permet de contrôler les attaques d'insectes sur les légumes. Les fruits sont connus pour être très toxiques pour les humains, le bétail et la volaille ; mais les moutons et les chèvres s'en régalent. Le fruit donne une graisse utilisée en savonnerie, pour fabriquer des peintures, et pour traiter les rhumatismes. Le bois ressemble à l'acajou ; c'est un bois de construction durable à l'extérieur. On l'emploie pour les poutres, les instruments de musique, et les manches d'outils. Les feuilles peuvent servir d'engrais vert. 
Remarque : Ne jamais laisser les fruits à portée des enfants. En manger 6 à 8 causes des nausées, des spasmes, et la mort.

Références: De Wildeman 1903, Gillet 1927, Staner et Boutique 1937, Renier 1948, Staner et Gilbert 1958, Pauwels 1993, Mbuya et al. 1994, Katende et al. 1995, Stoll 2000, Hirt et M'pia 2001

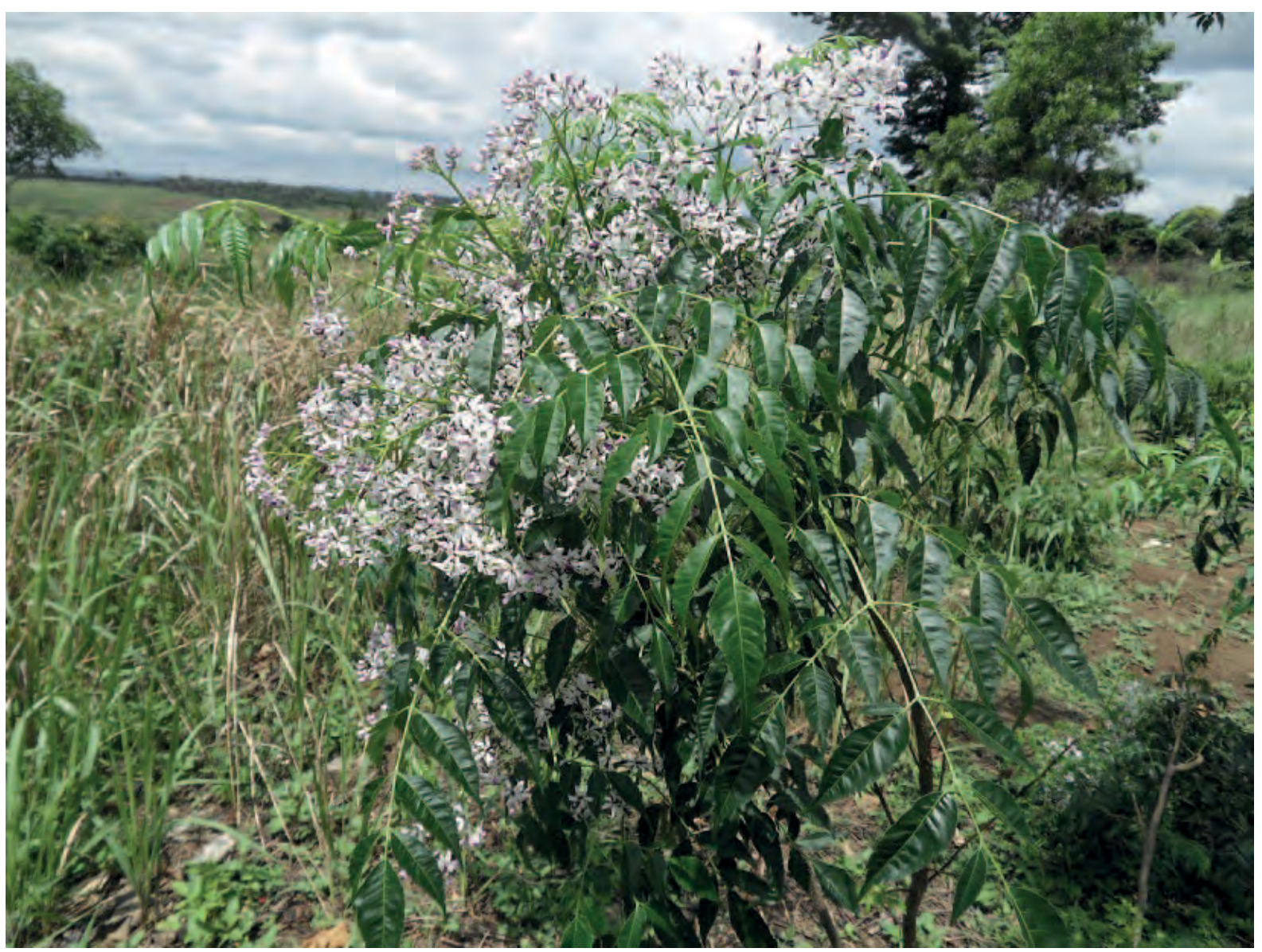

Melia azedarach en fleurs en novembre

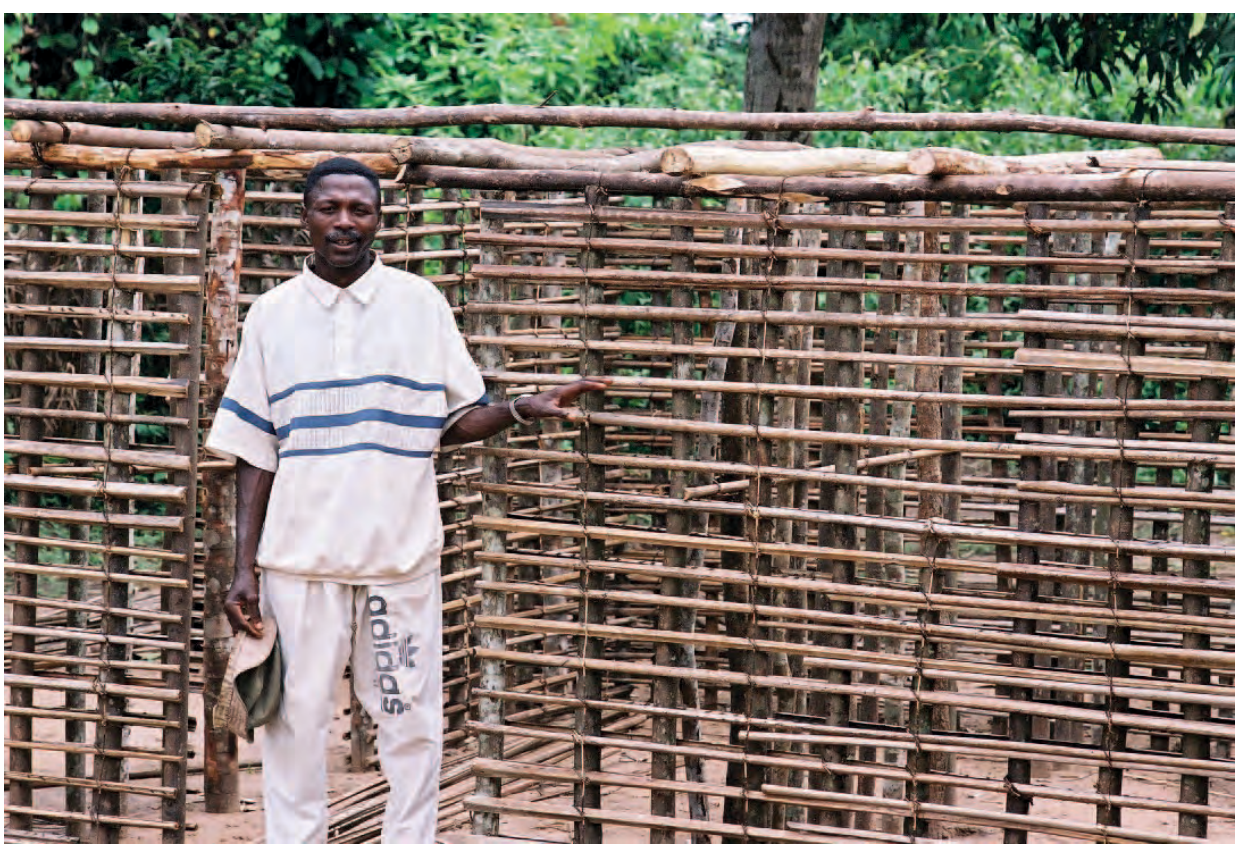

Papa Nsimba construit une maison à Kongo Central 


\section{Melinis amethystea}

Nom courant : Nkaka (Kikongo)

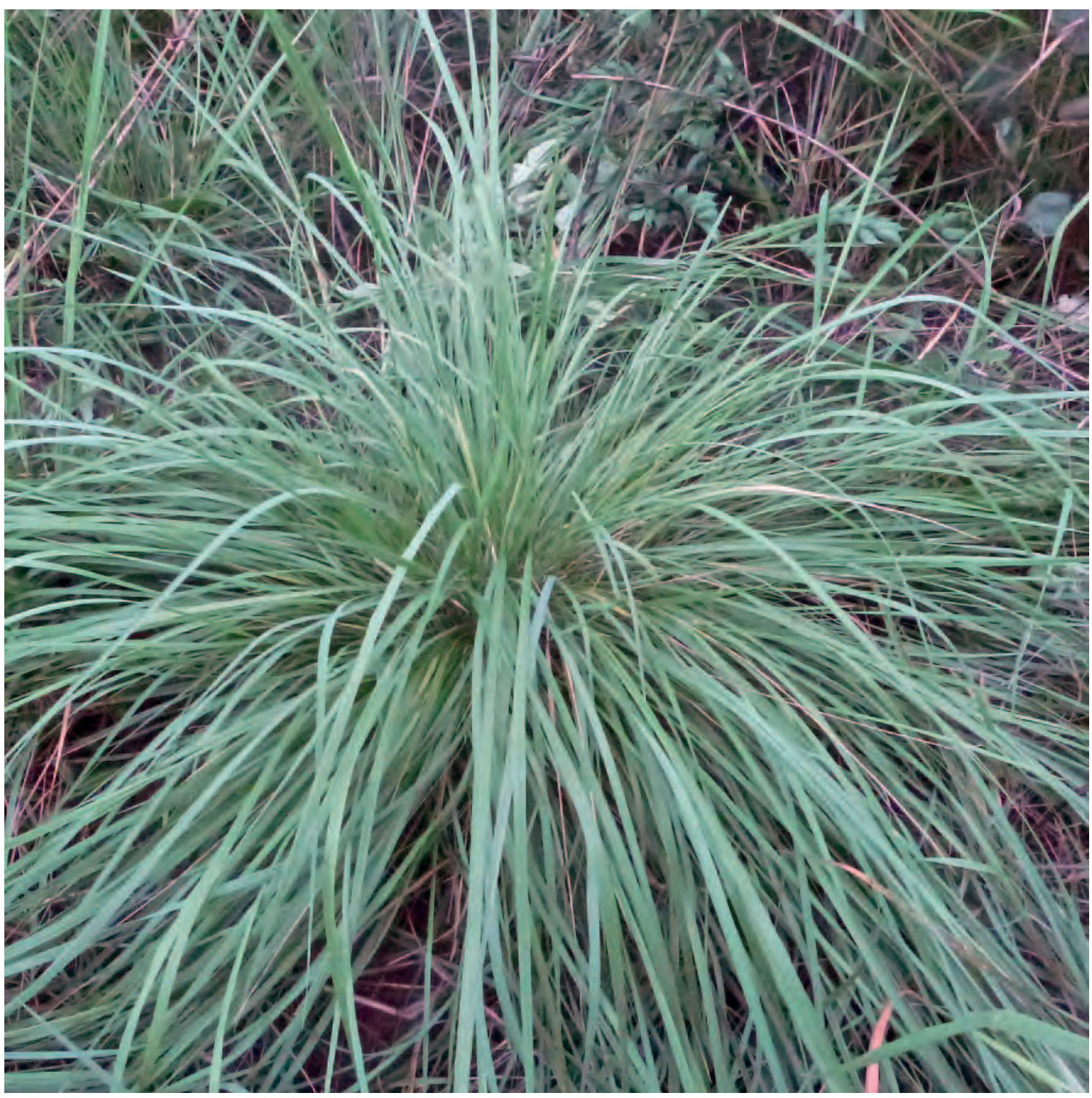

Description : Herbe pérenne en touffes de $1 \mathrm{~m}$ de haut. L'inflorescence est une panicule ouverte de 5 à $27 \mathrm{~cm}$ de long.

Ecologie : Herbe des savanes sèches, dans les deux Congos et en Angola.

Reproduction : par division.

Usages : couverture des toits, pour la variété connue comme nyanga-nkaka.

Références : Renier 1948, Daeleman et Pauwels 1983, Kew Science - Plants of the World online (Consulté le 30.7.2018) 
Noms courants : Leka mbwa (= lit de chien), fwetete (Kikongo)

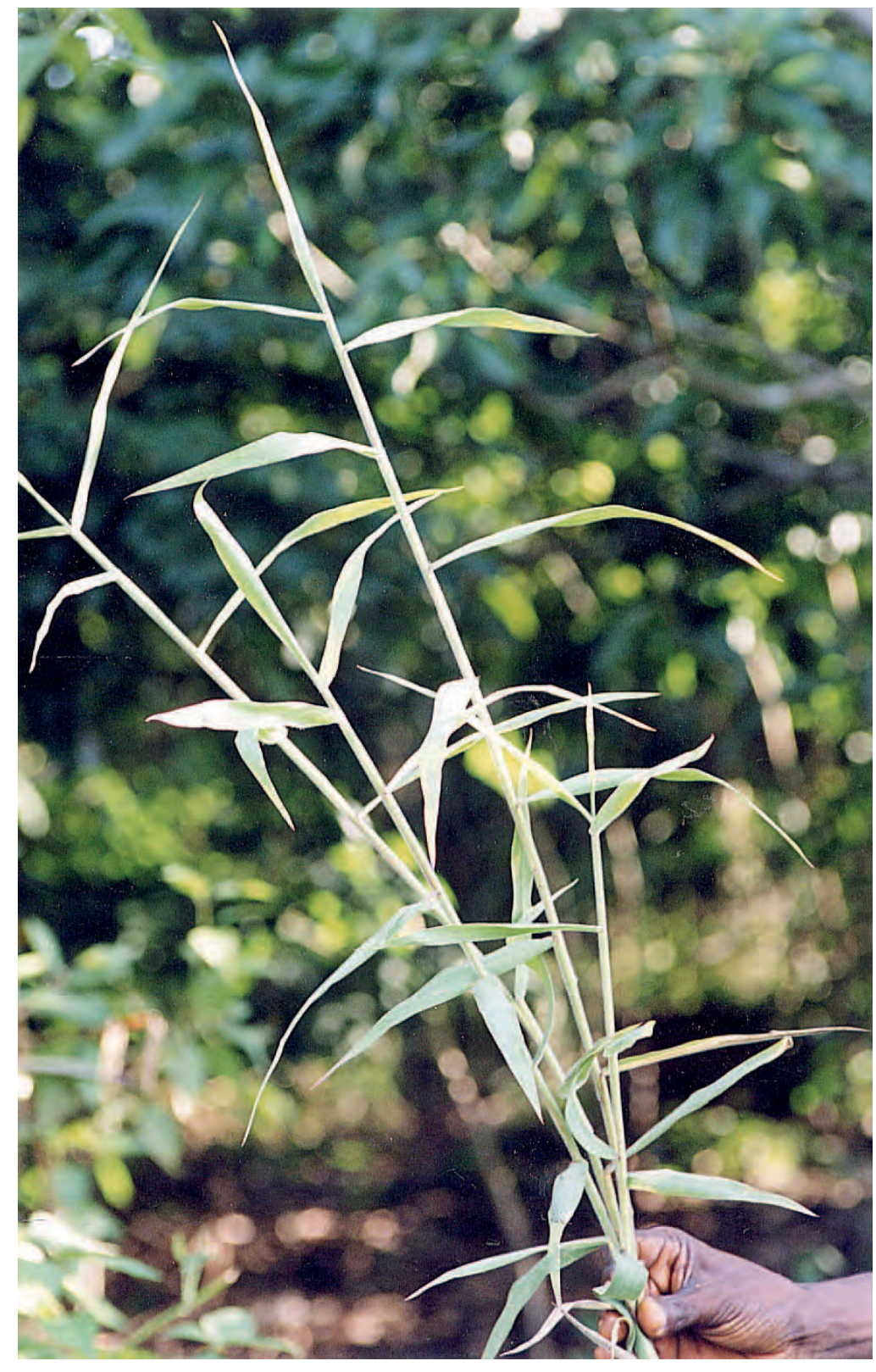

Description : Herbe pérenne en touffes avec des tiges de $2 \mathrm{~m}$ de long. Les feuilles sont couvertes de poils glandulaires qui sécrètent une substance visqueuse, dont l'odeur rappelle le cumin, la graine de lin ou la mélasse.

Ecologie: Plante des collines rocheuses et souvent escarpées, des savanes boisées, des lisières de forêts et des clairières dans toute l'Afrique tropicale, à des altitudes de 800 à $2500 \mathrm{~m}$. Cette herbe a été introduite dans d'autres pays hors d'Afrique.

Reproduction: Par graines ou boutures.

Gestion: On peut la rabattre à la hauteur de $12 \mathrm{~cm}$ pour faciliter la croissance latérale et une bonne couverture du sol, et pour retarder la floraison.

Usages: Toutes les parties de la plante sont signalées comme insecticides, et on la cultive parfois dans ce but. On couvre la couche des chiens avec la plante séchée pour repousser les insectes. En Tanzanie, on frotte le bétail avec les feuilles froissées, et on en fait des nids pour les volailles. Au Kongo Central, on utilise les feuilles et les tiges pour traiter les extinctions de voix, les gonflements d'estomac accompagnant la jaunisse, les problèmes cardiaques, les enflures de l'aine ou des aisselles. Le bétail peut la brouter, mais elle n'est pas très appétissante ; elle est moins productive que d'autres espèces. Elle couvre rapidement la terre cultivée en éliminant les mauvaises herbes. On emploie la plante comme purgatif, et pour traiter la folie et l'eczéma

Remarque: en Afrique orientale, on couvre parfois avec cette herbe les champs de maïs pour repousser les insectes perforants des tiges.

Références : Gillet 1927, Staner et Boutique 1937, Renier 1948, Watt et Breyer-Brandwijk 1962, Bogdan 1977, Daeleman et Pauwels 1983, Burkill 1994, Neuwinger 2000, Kibungu Kembelo 2003 


\section{Melochia corchorifolia}

Noms courants : Mulumbwa (Tshiluba), herbe à balai (Fr.), chocolate weed (Angl.)

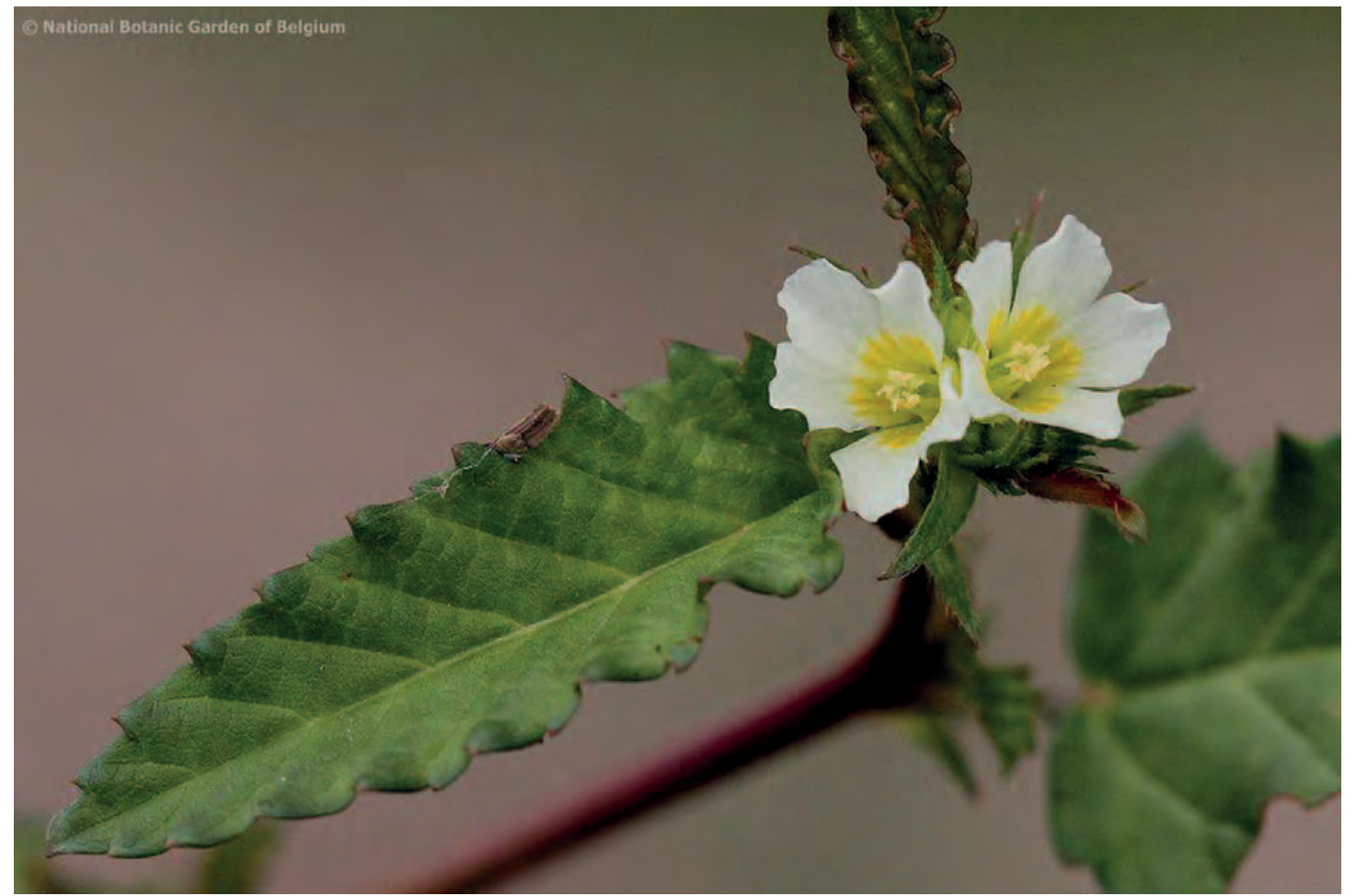

Photo : Bart Wursten. Jardin Botanique National de Berlgique

Description : Herbe très variable, annuelle ou pérenne, rampante ou dressée jusqu'à $1 \mathrm{~m}$ de haut. Les feuilles sont poilues et disposées en spirales, avec un limbe ovale pouvant avoir $6,5 \times 4 \mathrm{~cm}$. L'inflorescence est une cyme serrée, axillaire ou terminale. Les fleurs sont bisexuelles, avec une base jaune à l'intérieur. Les étamines sont soudées presque jusqu'au bout des filaments. Le fruit est une capsule ronde à cinq valves, de 5 à $6 \mathrm{~mm}$ de diamètre.

Ecologie: Herbe très répandue en Afrique tropicale, Asie et Australie, surtout dans les lieux humides.

Reproduction: Par graines. La scarification des graines améliore considérablement la germination.

\section{Photo : Phuong Tran}

Usages : On utilise cette plante comme antihelminthique. En Afrique de l'Ouest, on mange parfois les feuilles. Le bétail broute les feuilles. L'écorce donne une fibre fine et

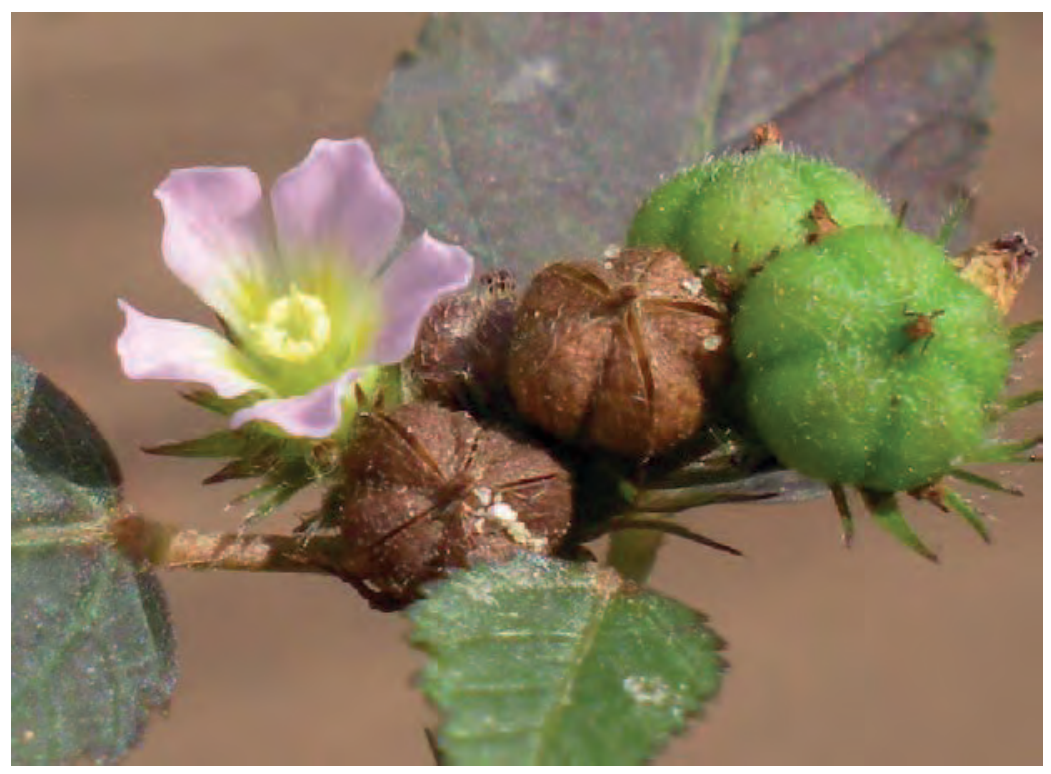
forte, employées pour les liens et pour les lignes de pêche. La solution aqueuse des feuilles a des propriétés insecticides. Les haricots et d'autres grains, gardés dans des sacs traités avec la solution, ont montré une réduction des œufs pondus par l'espèce de charançon Callosobruchus.

Références : Gillet 1927, Staner et Boutique 1937, Renier 1948, Germain 1963, Williamson 1975, Burkill 2000, Bosch 2004 


\section{Mentha arvensis et $\mathbf{M}$. suaveolens}

\section{(Lamiaceae)}

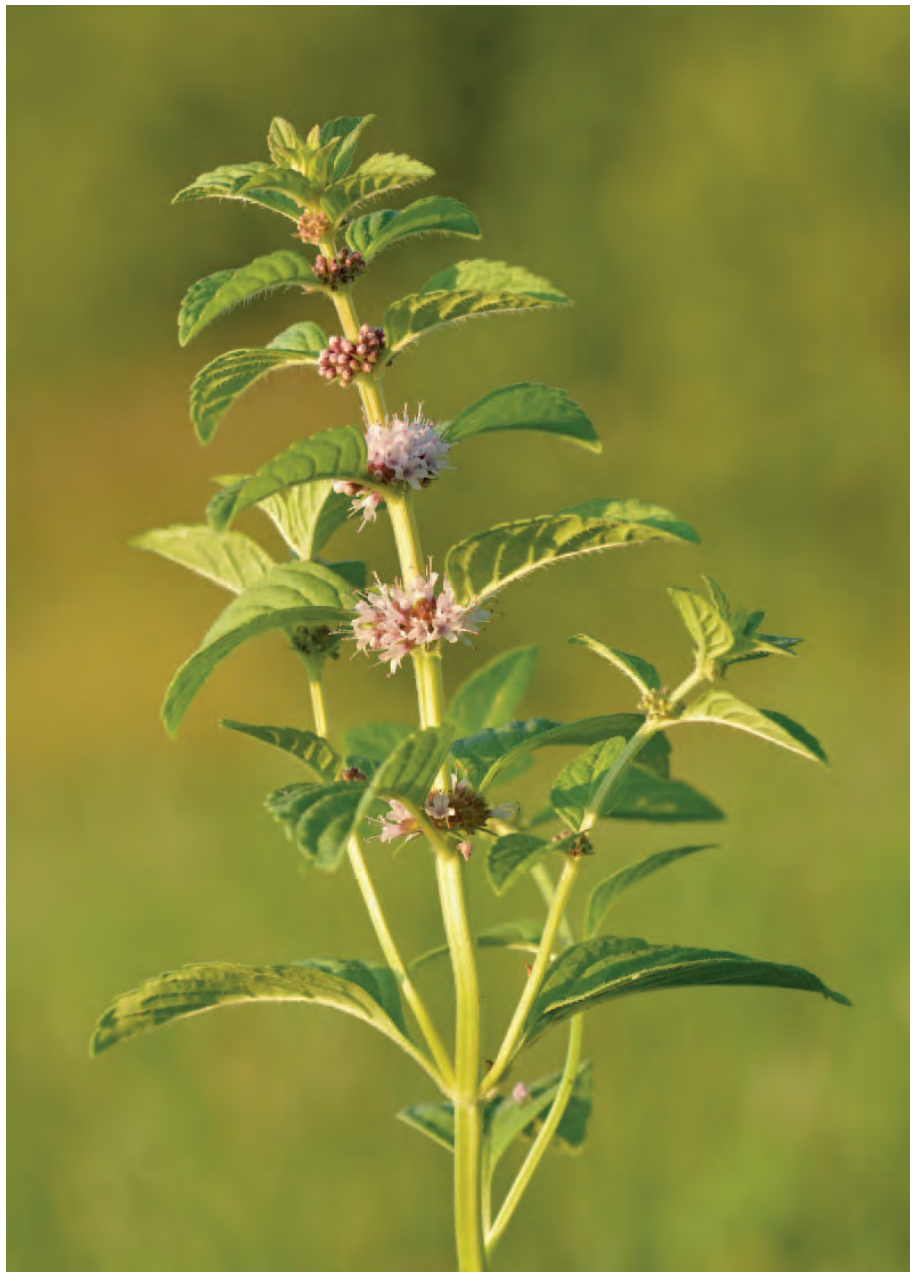

Noms courants : Nkwenta, ndamba, dinkondi (Kikongo), menthe (Fr.), apple mint (Angl.)

Description : Herbes pérennes à croissance lente poussant à partir de tiges souterraines ou stolons. Tiges quadrangulaires. Petites feuilles contenant des glandes aromatiques qui donnent l'odeur caractéristique de la menthe quand on les écrase.

Photo : Ivar Leidus / CC BY-SA

Ecologie : Plante originaire d'Europe, largement cultivée. Elle préfère les sols humides et fertiles. On la cultive souvent en pots à l'ombre.

Reproduction : Diviser les touffes de racines. Les plantes doivent être rempotées tous les deux ou trois ans. Les tiges prennent racine facilement à partir des nœuds du bas.

Gestion : On peut récolter les tiges selon les besoins, normalement 40 à 55 jours après la division.

Usages: On ajoute les feuilles aux aliments tels que le poisson le mbika (graines de diverses espèces de courges), le piment doux, pour leur donner du goût. On les mange aussi avec les safous ou avec le foufou. On emploie

aussi les feuilles pour faire une infusion à boire. Les feuilles contiennent du menthol, qui agit comme antiseptique et décongestionnant. Elle a été utilisée en médecine en Europe depuis l'antiquité.

References Gillet et Pâque 1910, Tindall 1983, Bown 1995

Pot de menthe cultivée sur une veranda.

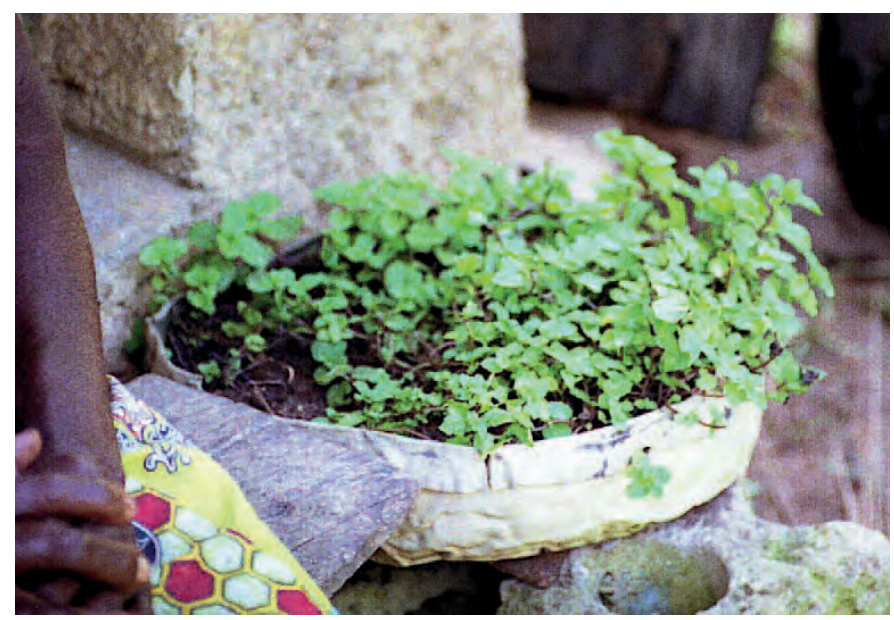


Noms courants : Ndamba (Kikongo) is used for Mentha spp., nsimasatu (Kikongo), menthe poivrée (Fr.), peppermint (Angl.)

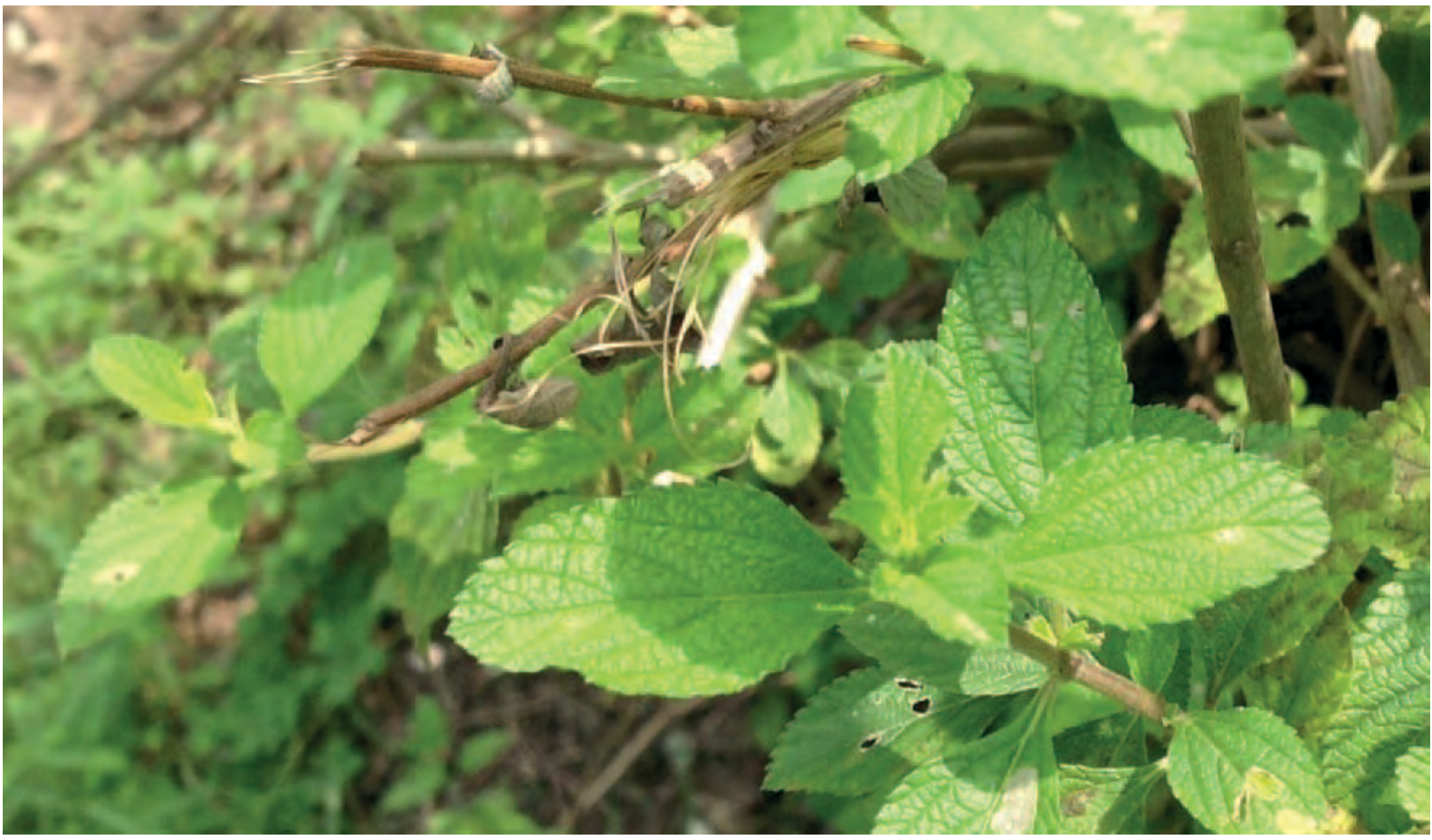

Photo : Trinto Mugangu

Description : Herbe ou Buisson aromatique pérenne de 30 à $90 \mathrm{~cm}$ de haut, à tiges quadrangulaires glabres rouge pourpré. Les feuilles écrasées ont une odeur forte caractéristique. Sous les tropiques, la plante ne donne pas de fleur.

Ecologie : Plante originaire d'Angleterre, et largement cultivée partout dans le monde, notamment dans les jardins au Kongo Central. Elle tolère une large gamme de sols et de climats. Elle est abondamment cultivée aux USA.

Reproduction : Facile à cultiver par boutures ou morceaux de rhizome.

Usages: Au Kongo Central, on emploie la plante pour traiter les rhumes et les nez bouchés, I'hypertension, ainsi que comme tonique et décongestionnant. Au Gabon, on en fait un stimulant et une aide à la digestion. Elle est la principale source du menthol (huile de menthe poivrée), bien connu pour les sensations rafraîchissantes qu'il donne dans la bouche et dans la gorge. On l'emploie pour parfumer les dentifrices, les aliments, les confiseries, les boissons ; en préparations pour la toux et en spray nasal. L'huile s'obtient par distillation des feuilles et des tiges fraiches ou séchées.

Remarque : $M$. x piperita dérive de 4 autres espèces: $M$. aquatica (menthe d'eau), $M$. spicata (menthe anglaise), dérivée elle-même $M$. suaveolens (menthe verte) and $M$. longifolia (menthe sylvestre).

Références : Gillet et Paque 1910, Laman 1936, Raponda - Walker et Sillans 1961, Tindall 1968, Uphof 1968, Macmillan 1991, Bown 1995, Burkill 1995, van Wyk 2005, Trinto Mugangu (communication personnelle 30.12.2016) 
Noms courants : Alamo vine (Angl.)

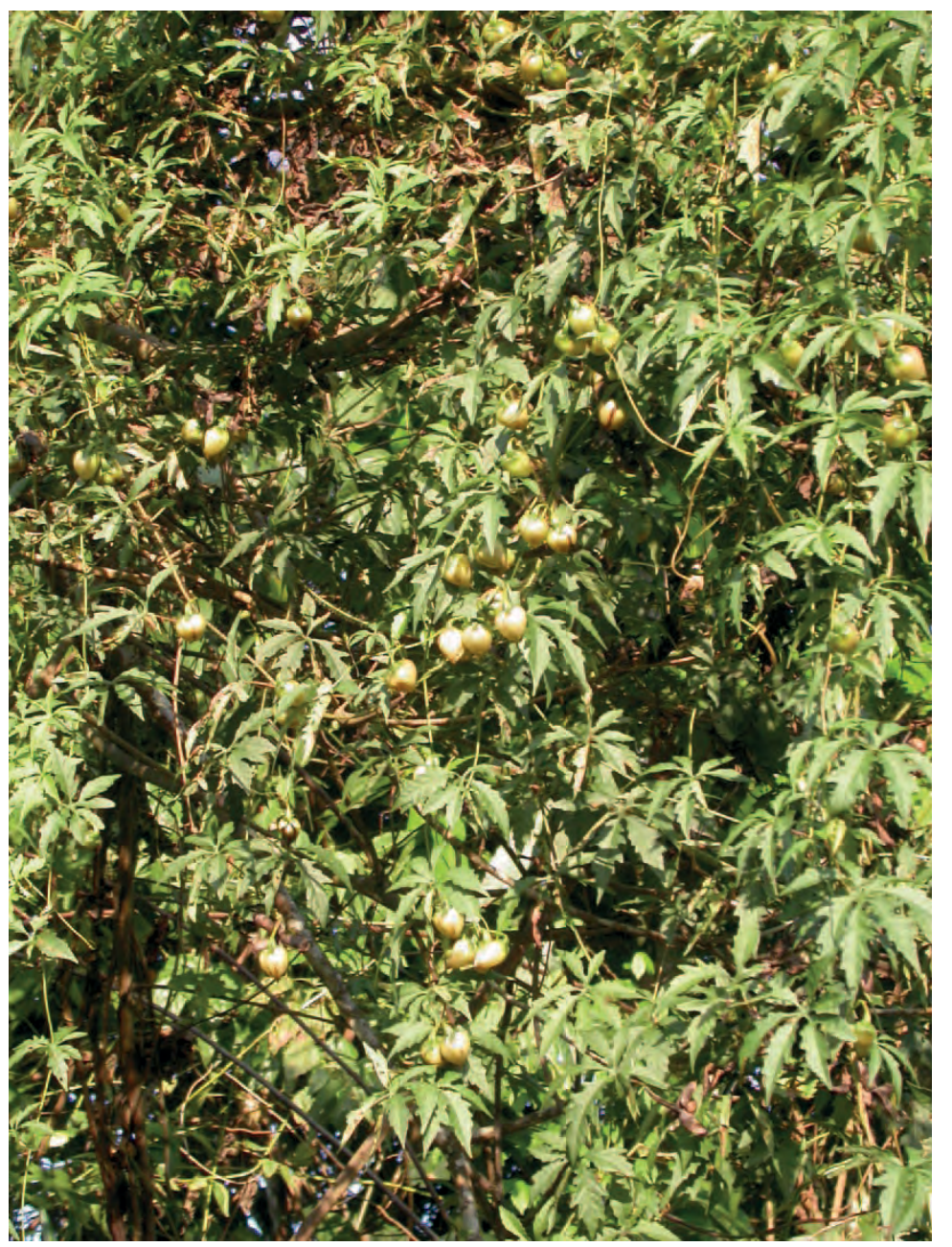

Description : Liane pérenne jusqu'à $6 \mathrm{~m}$ de long, à feuilles profondément lobées de 3,7 à 8,2 sur 5,6 à $12 \mathrm{~cm}$, sur un pétiole poilu de 2 à $7 \mathrm{~cm}$. Les fleurs, blanches mais parfois rouges ou pourpres, sont en cymes axillaires. Les fruits sont des capsules globulaires, dont la coque est comme du papier, de 1,5 à 1,8 cm de long.

Ecologie: Plante originaire d'Amérique Centrale, largement introduite ailleurs. Souvent cultivée autour des maisons, mais aussi dans les prairies et le long des routes.

Reproduction : Par graines ou boutures.

Usages : Parfois cultivée comme plante ornementale. La plate a le goût et l'odeur des amandes, et s'emploie pour les gâteaux et la confiserie. Au Nigéria, cette plante sert à repousser les serpents; on donne une infusion froide pour traiter les vertiges, les intoxications et les morsures de serpents. Les feuilles sont toxiques pour le bétail. Elles ont des propriétés antimicrobiennes. En Argentine, on mange les racines bouillies ou rôties sous la cendre, leur goût ressemble quelque peu à celui des patates douces.

Références : Burkill 1985, van Valkenburg et Bunyapraphatsara 2001, Fayaz 2011

Photo : Melody Lytle, Lady Bird Johnson Wildflower Center

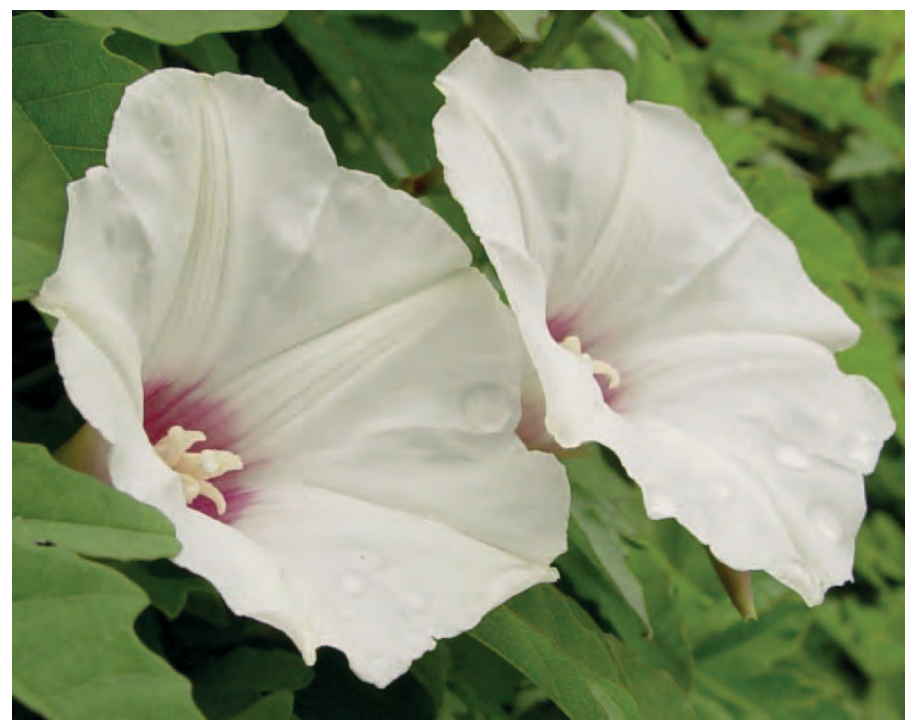




\section{Merremia tridentata subsp. angustifolia}

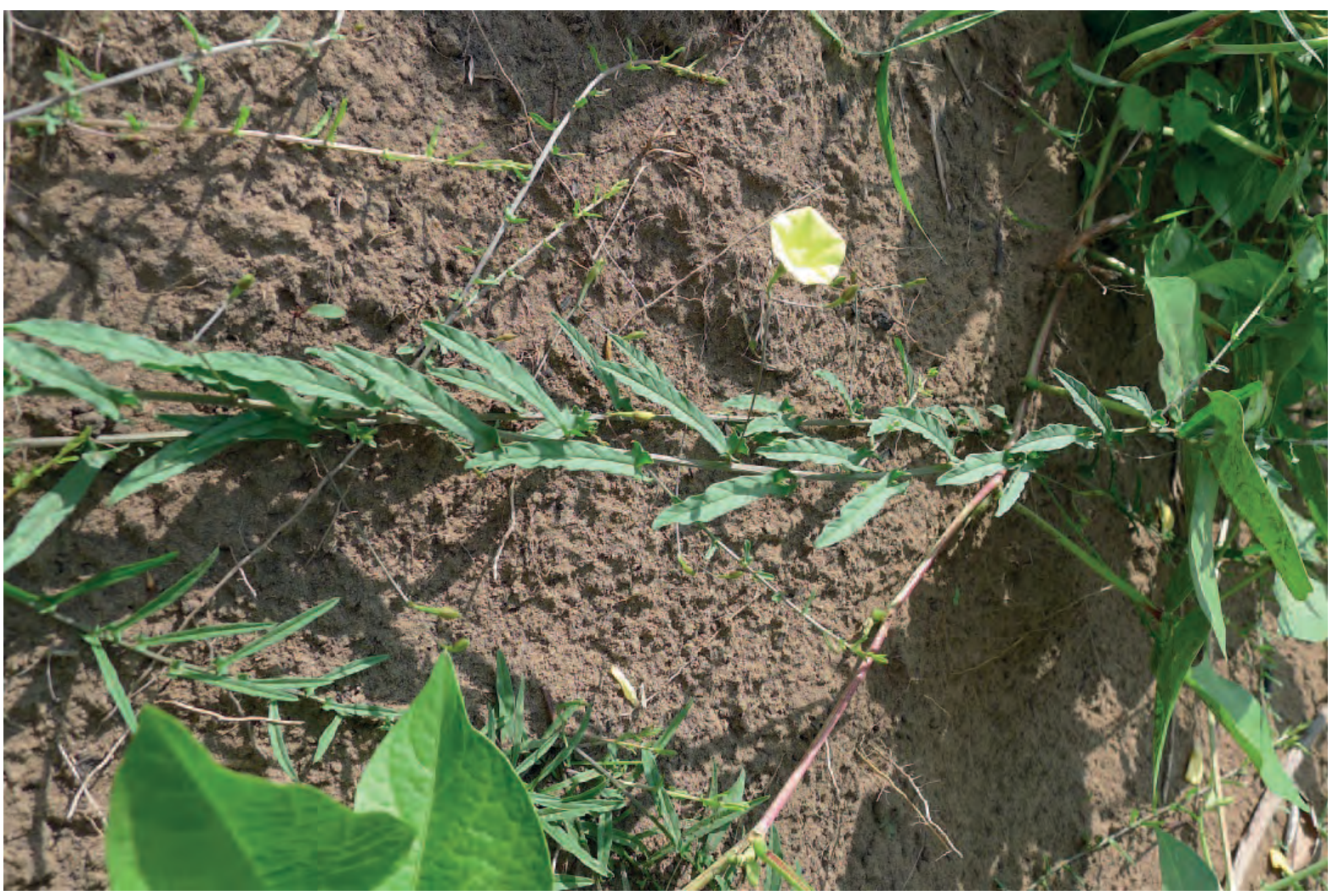

Merremia tridentata en fleurs en février

Description : Herbe annuelle volubile, de 0,6 à $2 \mathrm{~m}$ de long, poussant sur une racine droite, parfois prostrée. Feuilles étroites, de 2,5 à 10 sur 0,5 à $2 \mathrm{~cm}$, avec des lobes enserrant plus ou moins la tige. Boutons de fleurs coniques. Corolle en entonnoir, de 12 à $20 \mathrm{~mm}$ de long, blanche ou jaune pâle, pourpre ou brun foncé au centre.

Ecologie : Plante des savanes boisées ou herbeuses, des friches, et des lieux ouverts sableux. C'est la seule sous-espèce présente en Afrique occidentale; elle est très répandue dans toute l'Afrique tropicale et australe, aux Mascareignes et en Asie tropicale.

Usages: Cette plante est un bon fourrage pour les animaux domestiques. Au Congo et au Gabon, la sève des racines râpées s'emploie pour traiter les problèmes oculaires. Les Nyamwezi de Tanzanie prennent la feuille comme antidote pour les morsures de serpents. En Namibie, on boit une infusion des racines contre les douleurs cardiaques causées par la colère; on inhale la vapeur d'une décoction de la plante contre les maux de tête. Au Togo, on emploie les feuilles pour aider les accouchements difficiles. On emploie aussi la plante comme sédatif.

Références ; Staner et Boutique 1937, Bouquet 1969, Burkill 1985, Neuwinger 2000, van Valkenburg et Bunyapraphatsara 2001

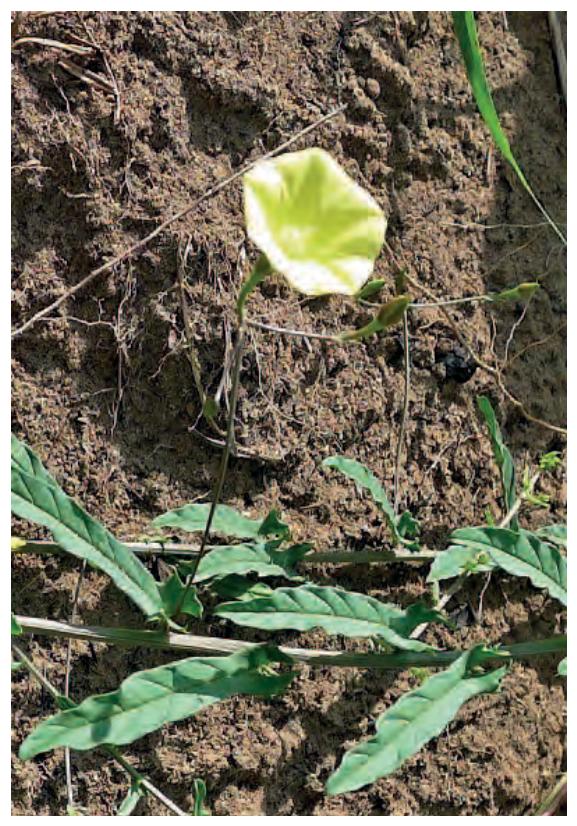




\section{Merremia tuberosa}

Noms courants : Rose de J éricho (Fr.), wood rose (Angl.)

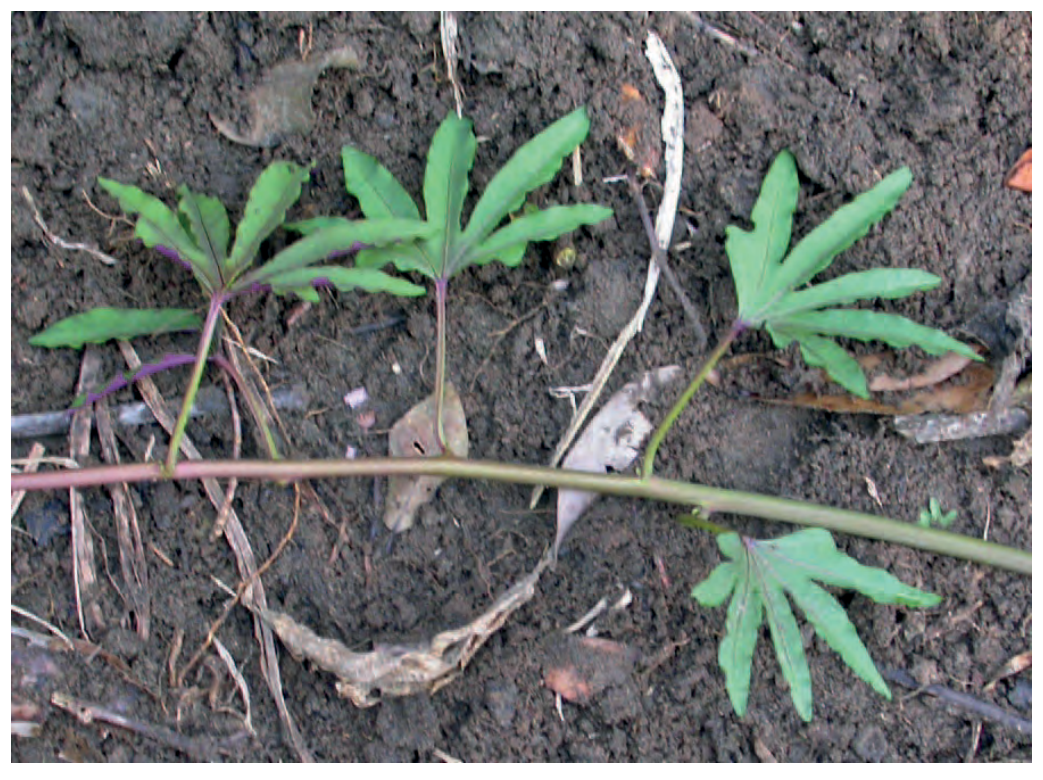

Description : Liane volubile sempervirente à croissance rapide jusqu'à $6 \mathrm{~m}$ de long. Elle pousse sur un gros tubercule souterrain. Les feuilles ont 7 lobes. Fleurs en entonnoirs, jaunes ou parfois blanches. Fruits brun ivoire.

Ecologie: Plante originaire d'Amérique Centrale, répandue dans toute l'Afrique tropicale et au Sri Lanka. Mauvaise herbe aux USA, où l'on emploie les capsules comme décoration florale.

Reproduction : Par boutures ou par graines.

Usages : Cultivée en Afrique comme plante ornementale. Ailleurs, on

emploie couramment les fleurs et les fruits dans des décorations florales. On donne le tubercule pelé et bouilli contre les kystes ovariens.

Références : Gillet 1927, Renier 1948, JexBlake 1957, Burkill 1985, van Valkenburg et Bunyapraphatsara 2001, Llamas 2003, Fayaz 2011

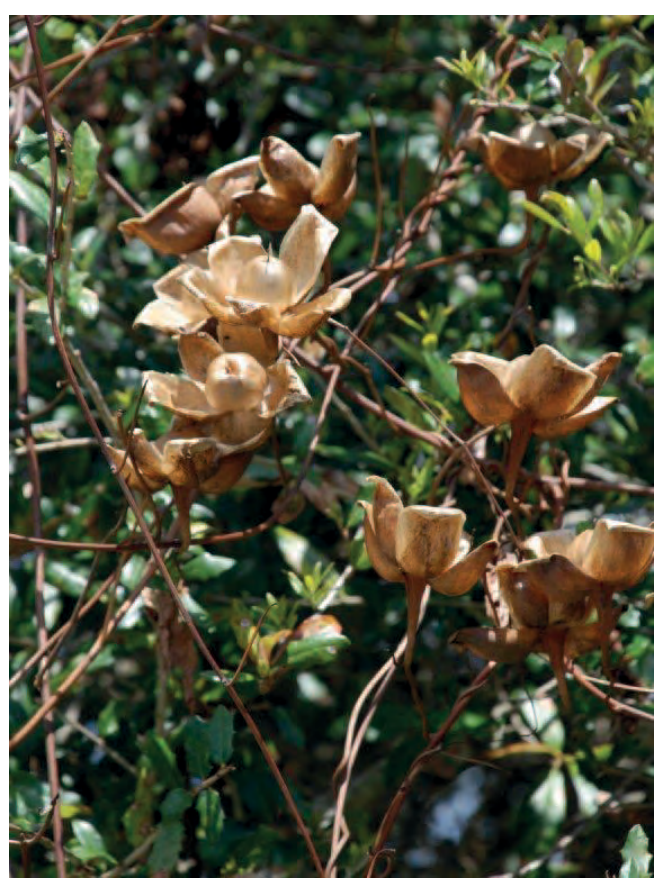

Photo de fruits : Kirsten Llamas 


\section{Noms courants : Velvet tree (Angl.)}

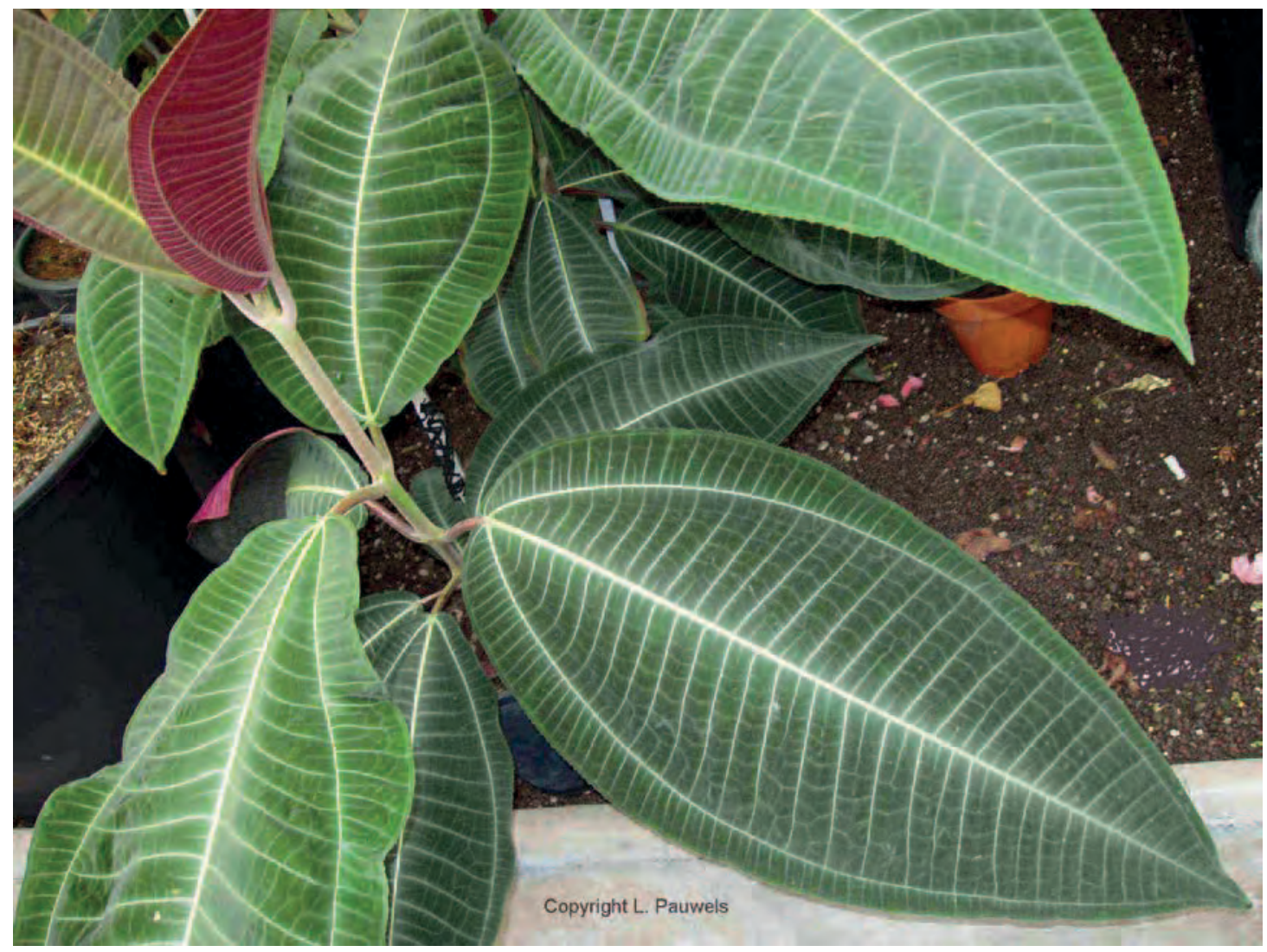

Photo : Luc Pauwels

Description : Arbre pouvant avoir $15 \mathrm{~m}$ de haut, avec de grandes feuilles rigides, épaisses, roulées, facilement reconnaissables à leur revers pourpre, ayant jusqu'à $1 \mathrm{~m}$ de long. L'arbre a des racines superficielles. Les fleurs blanches ou rose pâle sont disposées en grands panicules. Les fruits pourpre d'environ $0,5 \mathrm{~cm}$ de diamètre contiennent de 120 à 230 graines minuscules.

Ecologie: Originaire d'Amérique centrale et du sud. Plante très invasive.

Reproduction : Les fruits sucrés attirent les oiseaux et autres animaux qui dispersent les graines. Un jeune arbre avec seulement deux panicules floraux peut produire jusqu'à 200.000 graines dans sa première saison. Les graines restent viables jusqu'e 12 ans, attendant pour germer que la lumière perce la canopée.

Usages : Arbre ornemental.

Remarque : Le nombre et le potentiel de dispersion des graines font de Miconia une menace invasive importante. On a observé au Kongo Central que lorsque l'arbre a atteint toute sa taille, les énormes feuilles font de l'ombre à tout l'espace en dessous, empêchant toute plante de pousser.

Références: Pauwels 1993, Witt et Luke 2018, Wikipedia

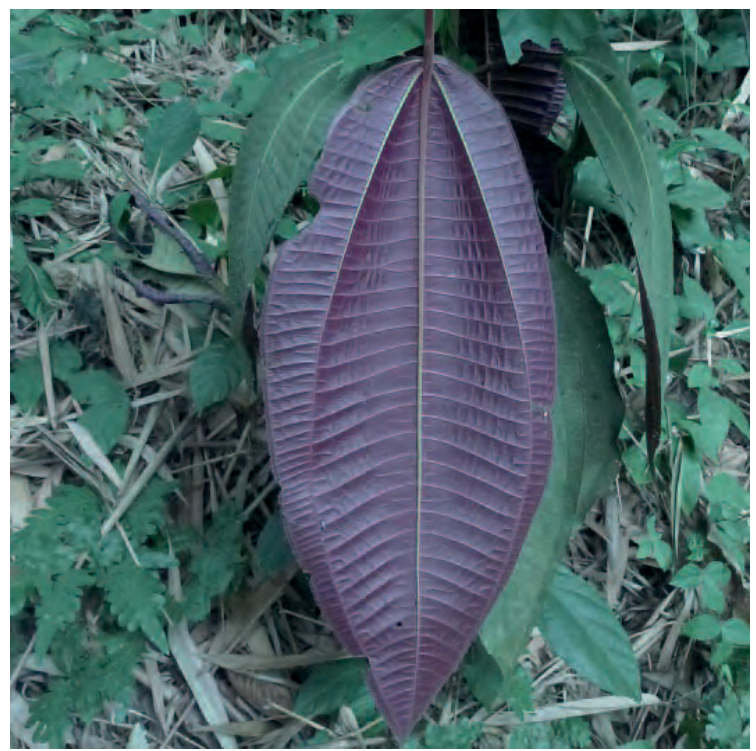
(Consulté le 7.11.2018) 


\section{Microdesmis puberula}

Noms courants : Ndomba ndomba fioti, nkubudi, mukubi (Kikongo), ichike, iseke (Lingala)

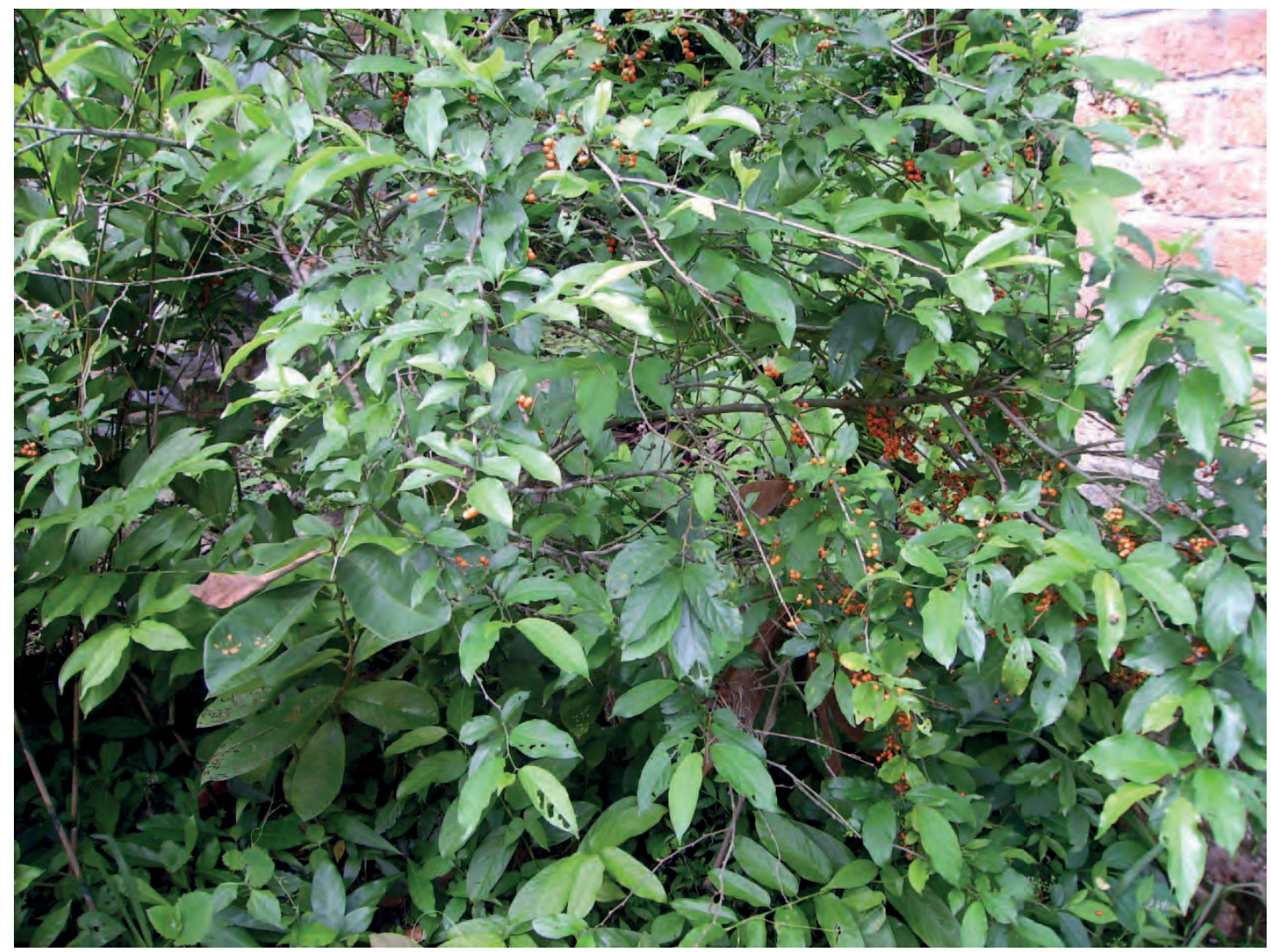

Description : Arbuste ou liane de 3 à $6 \mathrm{~m}$ de haut. Les rameaux et les pétioles sont couverts de poils désordonnés. Les feuilles, de 5 à 15 sur 2 à $6 \mathrm{~cm}$, ovales, sont pointues au bout et parfois asymétriques à la base. La plante porte beaucoup de fleurs mâles et quelques fleurs femelles. Les petites fleurs en bouquets, jaune orange, ont de 3 à $9 \mathrm{~mm}$. Les fruits sont de petites baies rouges ou noires.

Ecologie: Plante très commune des recrus forestiers et des lambeaux forestiers, du Sud du Nigéria à l'Angola et à l'Ouganda.

Usages: Le bois est brun, dur, flexible, bien structuré ; il se travaille bien et prend un poli lustré. On l'emploie pour les pièges à ressort, les manches de couteau, les cuillers, le mobilier et les cannes de marche. Au Kongo Central, on mange les jeunes feuilles comme légumes. Les fruits sont comestibles. La plante a de nombreux usages médicinaux. On emploie un extrait des racines bouillies pour traiter les rhumatismes. Dans la Province de l'Equateur, la plante s'emploie pour traiter la névralgie, l'épilepsie et la diarrhée. Les chenilles comestibles mbambi (/mbrasia truncata) se nourrissent des feuilles.

Références : De Wildeman 1934, Renier 1948, Léonard 1962, Keay 1989, Pauwels 1993, Burkill 1997, Mabberley 1997, Nsimundele 2004, Konda Ku Mbuta et al. 2015a

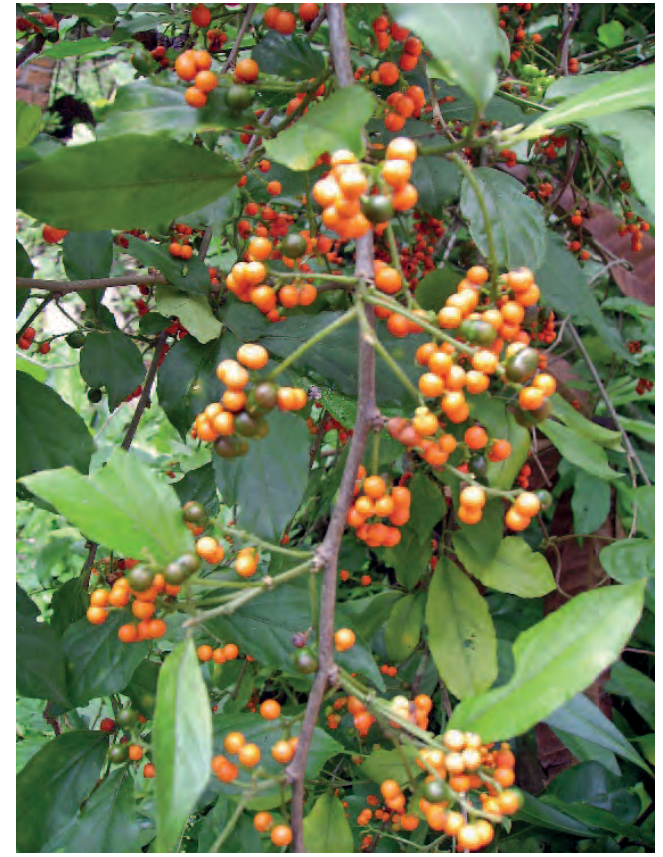




\section{Mikania chenopodiffolia}

Noms courants : Bodisa, kutia kateke, munkadikadi (Kikongo), climbing hemp-weed (Angl.)

Description : Liane pérenne, ligneuse à la base, longue de $8 \mathrm{~m}$ ou plus. Feuilles opposées, limbe de 3 à 8 sur 2 à $6 \mathrm{~cm}$. Fleurs blanches à crème.

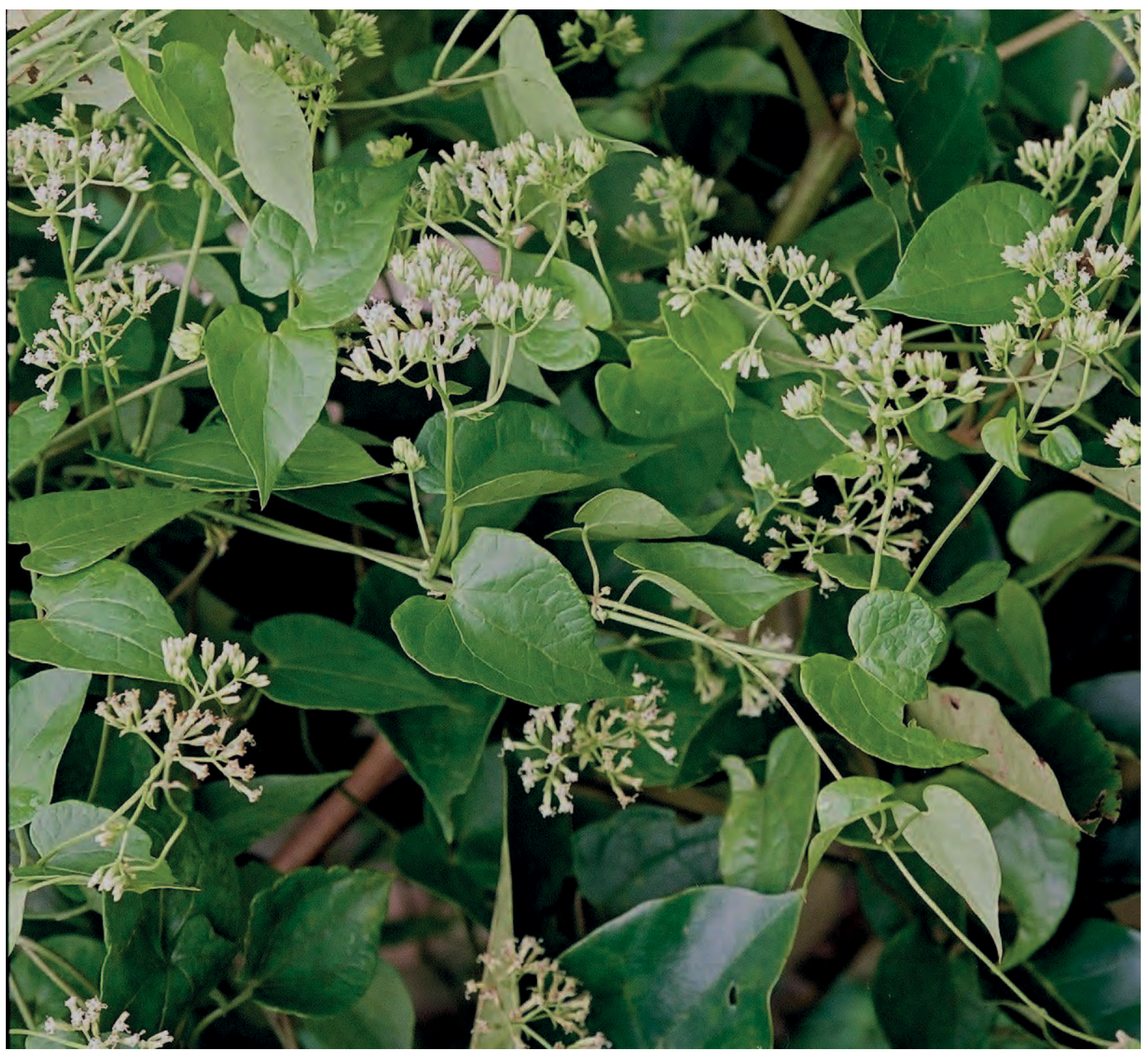

Mikania chenopodiifolia en fleurs en janvier, près de l'eau à Kisantu

Ecology : Plante des forêts secondaires, commune près de l'eau, des anciennes cultures et des friches, de la Sierra Leone à la R.D. Congo et à l'Angola.

Reproduction : à partir de bouture de bois tendre ou en cours de maturation.

Usages: On a observé la récolte de miel par les abeilles au Kongo Central, où on trouve aussi M. Microptera. Les espèces de Mikania spp. sont connues comme très bonnes pour le fourrage des abeilles aux USA et en Amérique centrale. On cultive occasionnellement cette plante comme plante de couverture, mais elle est vigoureuse, et consomme beaucoup de potasse, qui peut cependant revenir au sol comme engrais vert. On peut cuire les feuilles pour les ajouter à la soupe. Au Congo, on cultive une variété avec des fleurs charnues que l'on mange comme des épinards. Le bétail broute cette plante. Elle a aussi de nombreux usages médicinaux.

References Morton 1964, Busson 1965, Crane et al. 1984, Burkill 1985, Lisowski 1991, Bakenga et al. 2000, Neuwinger 2000 


\section{Milicia excelsa}

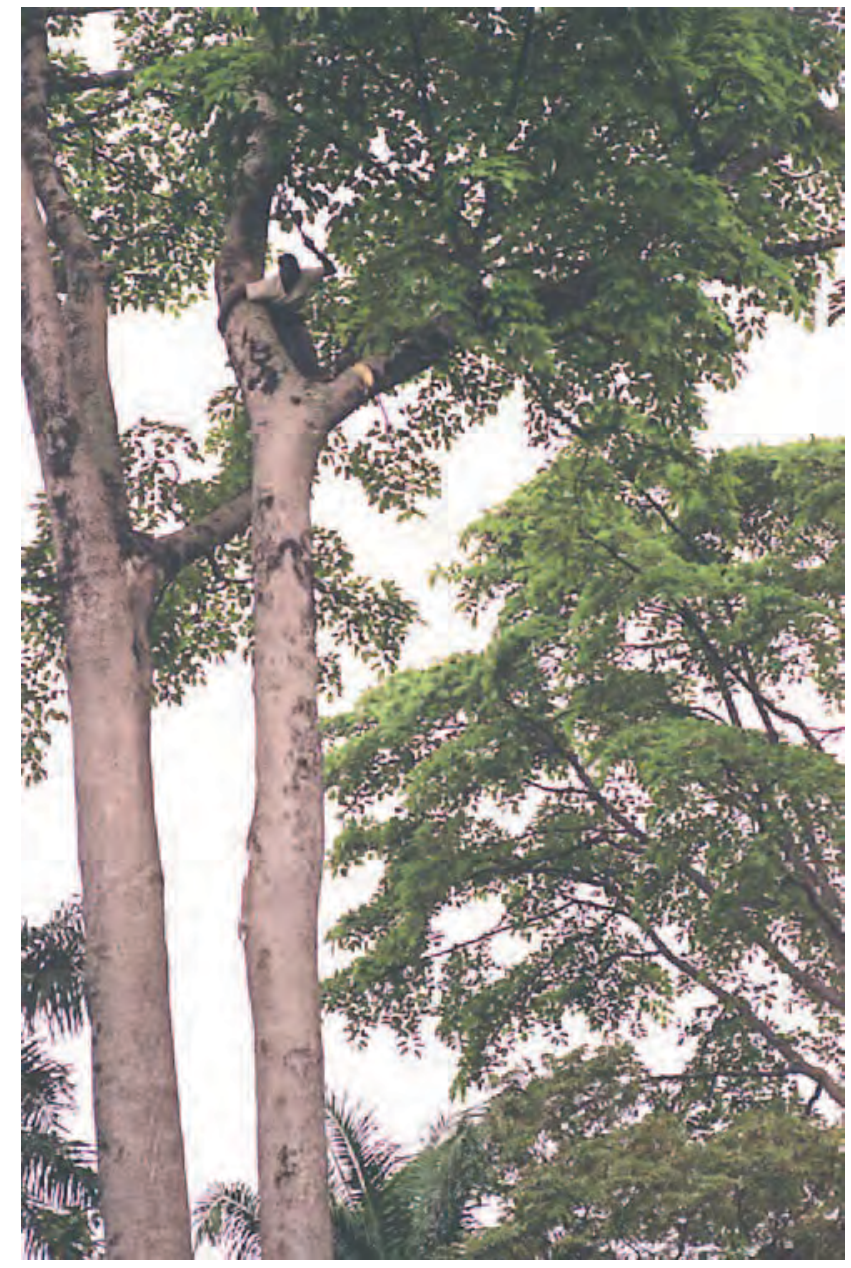

tombe à $50 \%$. Les jeunes arbres se transplantent bien, mais doivent avoir au moins $3 \mathrm{~cm}$ de diamètre et $25 \mathrm{~cm}$ de haut, ou même plus. Les jeunes arbres doivent être plantés comme une partie d'une forêt diversifiée, plutôt qu'en peuplements purs. Ils n'aiment pas la compétition des herbes, mais peuvent être plantés sous les bananiers. Dans la tradition du Kongo Central, on plantait souvent les arbres près des villages pour le bois, et pour attirer les chenilles comestibles Bisu (Nudaurelia petiveri).

A droite: Jeunes arbres dans une plantation d'Acacia auriculiformis

Gestion : Les jeunes arbres recèpent vigoureusement. Une masse de rejets peut émerger de la base de la souche, spécialement après un feu de brousse ; si on les éclaircit à un ou deux, ils peuvent remplacer l'arbre parent. Les racines sont très proches de la surface et vont à de grandes distances (par ex. $50 \mathrm{~m}$ ) ; elles donnent des rejets si elles sont endommagées ; ceci est probablement un important moyen de régénération dans les terres cultivées.

Usages: Le bois est excellent, dur, durable, facile à travailler, et prenant un beau poli. II est largement employé pour le mobilier, la parqueterie, la construction navale. Il est l'une des principales essences exportées d'Afrique pour la construction les parquets, le mobilier d'intérieur et d'extérieur, l'ébénisterie. Le bois de cœur résiste aux termites, à l'eau et aux maladies fongiques. Au Kongo Central,

\section{Synonyme : Chlorophora excelsa}

Noms courants : Nkamba (Kikongo), kambala or iroko (noms commerciaux), chêne d'Afrique (Fr.), African teak (Angl.)

Description : Grand arbre pouvant atteindre 30 à $50 \mathrm{~m}$ avec un tronc droit; contreforts petits ou absents. Ecorce de gris cendré clair à presque noir. Les feuilles, ovales, ont 5 à $10 \mathrm{~cm}$ de long et sont finement dentées. Celles des jeunes arbres ont une face supérieure rugueuse. L'arbre est dioïque; les arbres mâles portent des chatons longs de 15 à $20 \mathrm{~cm}$; les arbres femelles portent des épis de fleurs vertes à styles proéminents de 5 à 6 sur $2 \mathrm{~cm}$. Les fruits ridés de forme allongée ont environ $2 \mathrm{~cm}$ de long; ils sont charnus, avec beaucoup de petites graines dans la pulpe.

Ecologie: Arbre des forêts pluviales de plaine, des forêts secondaires et des savanes boisées; on le laisse souvent debout lors du défrichement des champs cultivés. Présent de la Guinée Bissau au Mozambique.

Reproduction : Récolter les fruits tombés au sol et les tremper 6 heures. Extraire les graines en écrasant les fruits, et les laisser tomber au fond. Jeter les débris et sécher les graines. Les graines fraiches germent facilement. Séchées, on peut les conserver un an, mais leur taux de germination

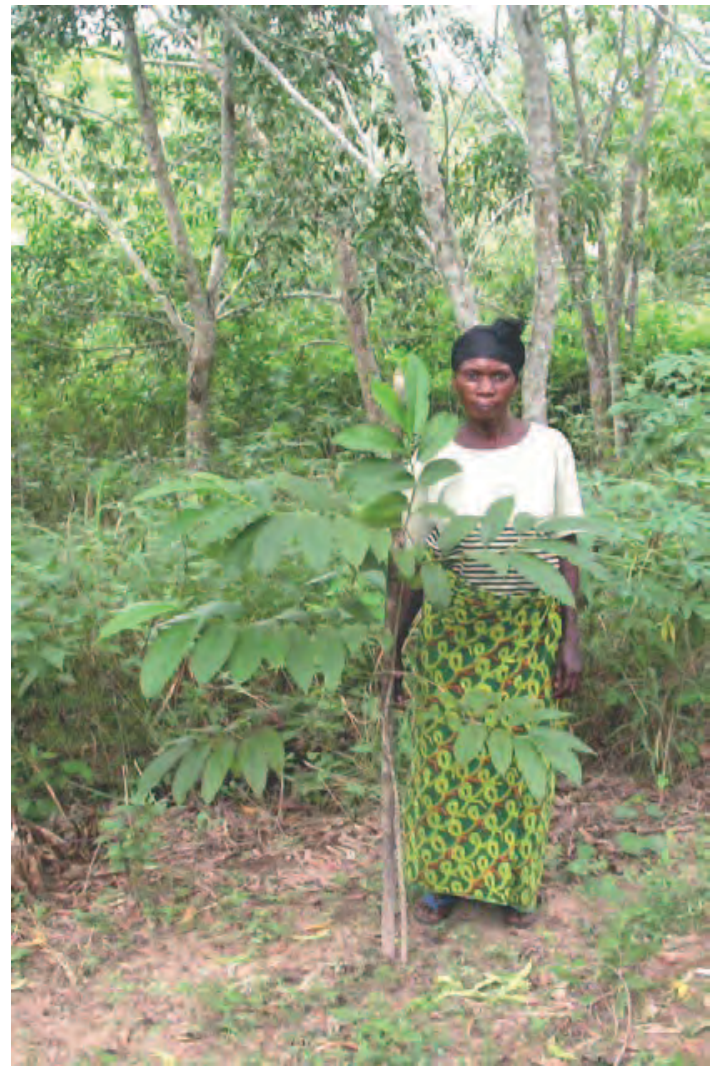


on l'emploie aussi pour le charbon de bois et pour marquer les limites. Les chenilles comestibles Bisu (Nudaurelia petiveri) se nourrissent des feuilles ; on peut connaître leur présence en observant leurs déjections au sol, mais pour les atteindre, il faut grimper à l'arbre, ce qui n'est pas facile avec son grand tronc sans branche!

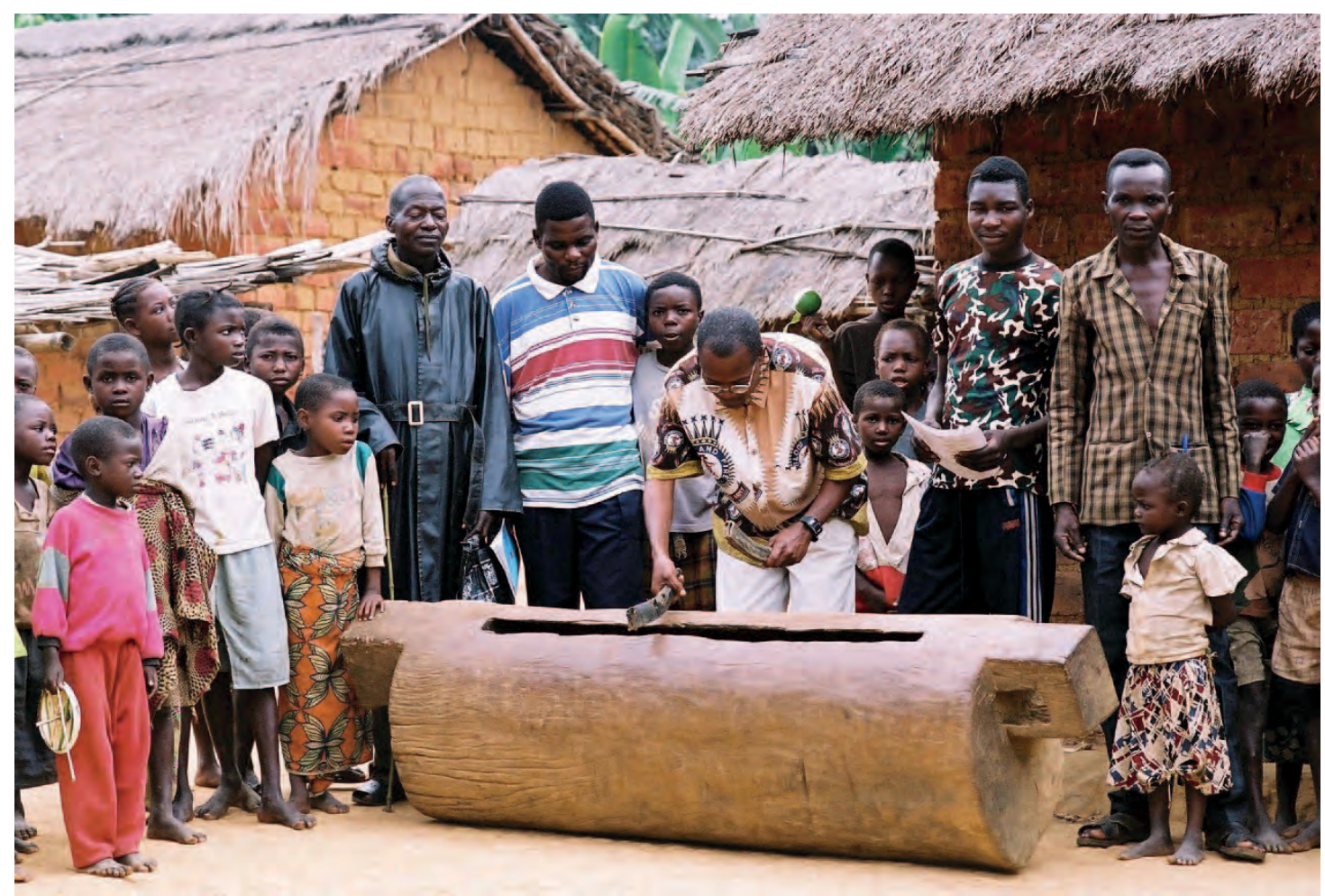

Tambour Mondo fait de Milicia excelsa pour appeler les villageois qui sont aux champs

L'écorce donne aussi un bon charbon de bois. A Kongo Central, on prend une décoction contre les calculs biliaires ; le latex s'emploie comme purgatif. II a des propriétés antiseptiques et cicatrisantes ; on l'applique sur les plaies, les tumeurs et les inflammations de la peau. Le latex pilé dans un mortier peut remplacer le ciment. La combustion du bois dégage une fumée avec laquelle on traite les ulcères. On a montré qu'un extrait de la plante était actif contre le termite du bois Reticuli tremis. Les jeunes feuilles cuites se mangent comme légumes. Les feuilles adultes servent de papier de verre. L'écorce fibreuse sert à la couverture des toits ; on en extrait une teinture pour le cuir et les vêtements. On a obtenu à partir du bois un produit chimique fongicide, la chlorophorine.

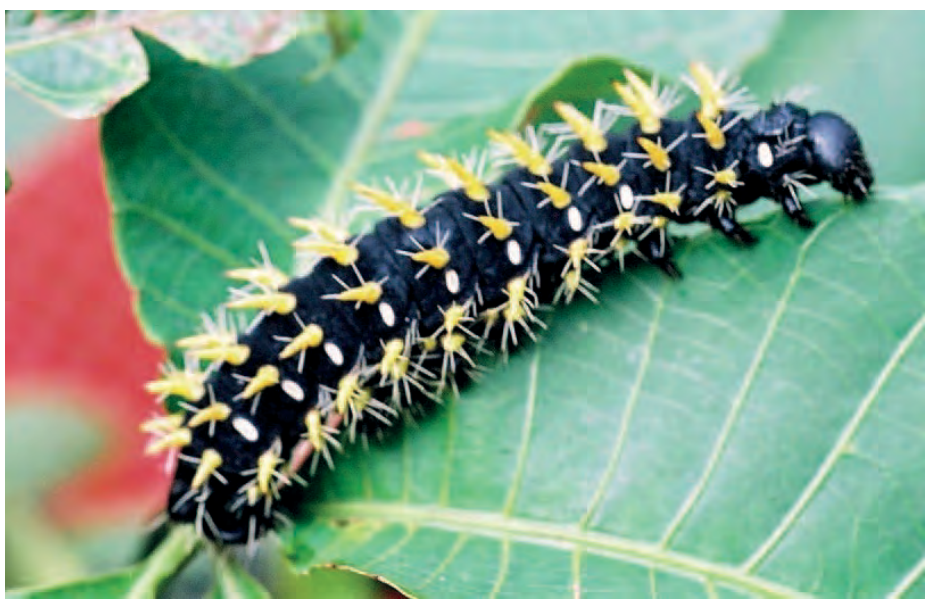

Remarques: Les semis sont souvent attaqués par la punaise Reticuli tremis. (voir à droite). Les jeunes arbres se débarrassent finalement du parasite, mais si on les transplante dans un bois fournissant de l'ombre, avec par exemple Acacia auriculiformis, l'attaque est moins sévère. On peut obtenir des plants résistants à partir de boutures de tiges ou de racines.

Photo : Bisu (Nudaurelia petiveri)

Références: Gillet et Pâque 1910, Gillet 1927, De Wildeman 1934, Hauman 1948, Renier 1948, Leloup 1956, Irvine 1961, Watt et Breyer Brandwijk 1962, Nsimundele 1996 68, Williamson 1975, Okigbo 1978, Daeleman et Pauwels 1983, Mukoko Matondo 1991, Iwu 1993, Pauwels 1993, Beentje 1994, Msanga 1998, Ofori 2007, Latham 2008, Meunier et al. 2010 
Noms courants : Mbwenge, mwengete (Kikongo)

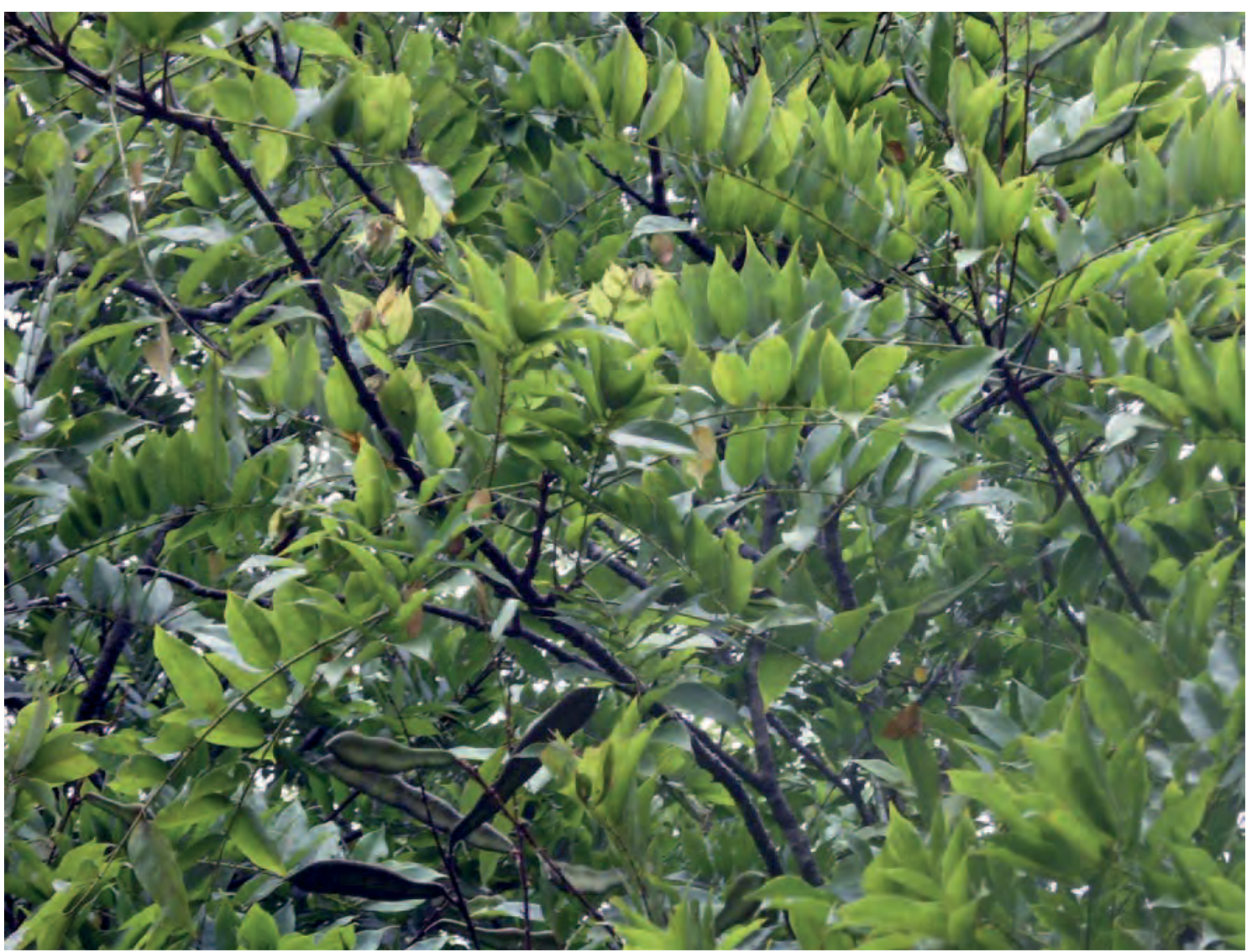

Description : Arbre de 10 à $20 \mathrm{~m}$ de haut. Feuilles coriaces de 4 à 9 sur 2 à $3 \mathrm{~cm}$, sur un pétiole de 3 à $7 \mathrm{~cm}$. Inflorescences terminales ou axillaires en racèmes, avec des fleurs bleues ou pourpre rouge. Gousses linéaires plates jusqu'à $18 \mathrm{~cm}$ de long et $2 \mathrm{~cm}$ de large, glabres et très finement plissées, portant 5 à 6 graines plates de 6 à $7 \mathrm{~mm}$ de diamètre.

Ecologie : Arbre des forêts secondaires, du Cameroun à l'Angola.

Usages: L'arbre donne un bois dur utilisé en construction. Les graines pilées servent à panser les blessures. On emploie en bains de pieds une décoction de l'écorce pour traiter la déhydrose, un type de dermatite caractérisé par des ampoules qui démangent aux mains et aux pieds. On l'emploie aussi pour traiter les craquelures sèches de la peau et pour se débarrasser des chiques (Tunga penetrans). On suce les racines pour soulager les maux de tête et la sinusite. Le liquide extrait de l'écorce s'emploie pour calmer les personnes atteintes de problèmes mentaux. Dans la Province de l'Equateur, on emploie diverses parties de la plante pour traiter la diarrhée, les vers intestinaux, les maux de dents, et la stérilité. Les chenilles comestibles Nsanga (Epidonta brunneomixta), Mbwenge et Miengeti (Phalera sp.) se nourrissent sur les feuilles. Les Millettia spp. sont d'importants fourrages pour les abeilles dans les savanes humides du Sud et les savanes sèches du Nord.

References Staner et Boutique 1937, Hauman et al. 1954, Bouquet 1969, Daeleman et Pauwels 1983, Mukoko Matondo 1991, Pauwels 1993, Burkill 1995, Hepburn et Radloff 1998, Biloso et Lejoly 2006, Konda Ku Mbuta et al. $2015 \mathrm{a}$ 
Noms courants : Mbwenge, mwengete (Kikongo)

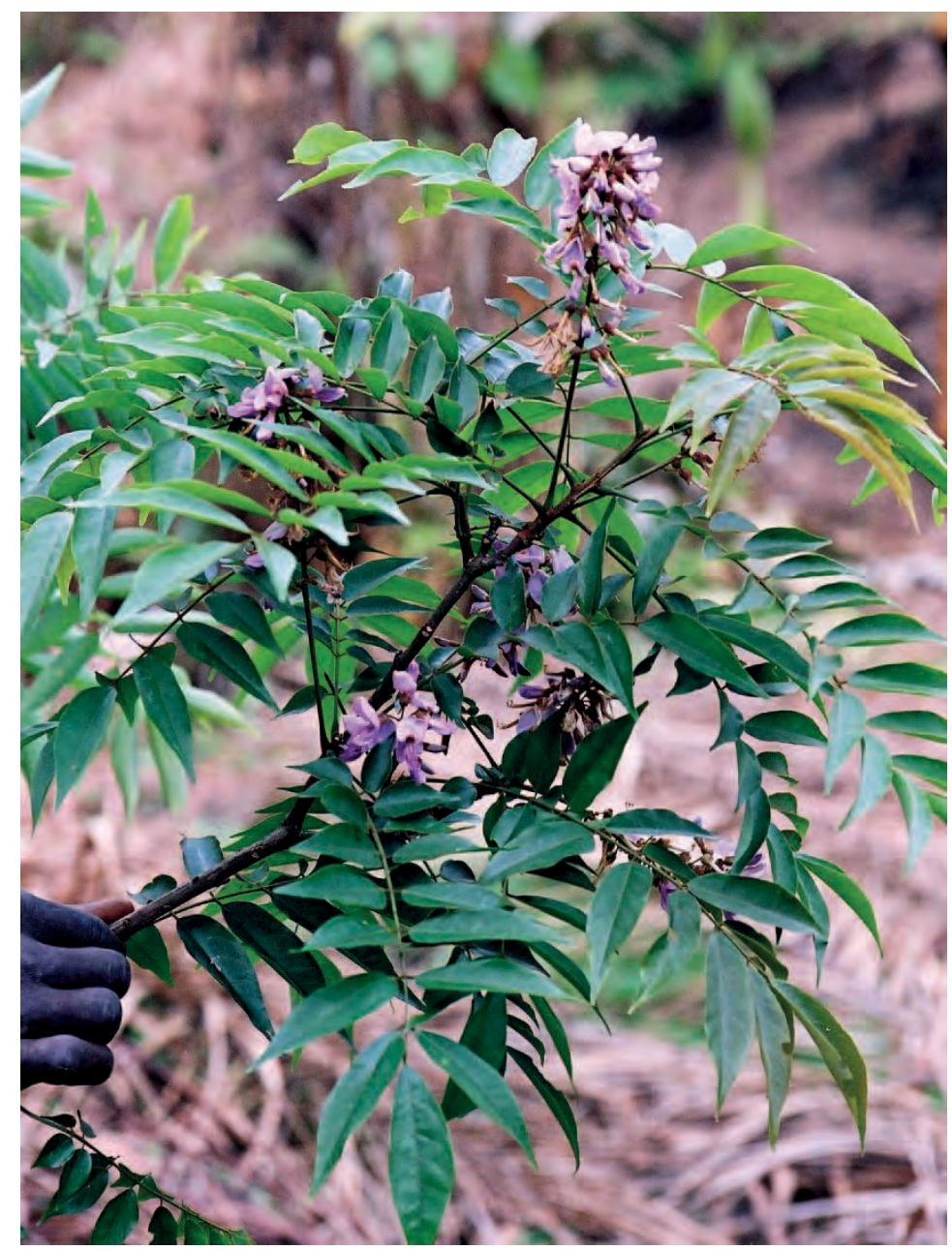

Usages : L'arbre est couramment utilise pour faire des clôtures vertes. Le bois, jaune et très dur, sert pour la construction et le mobilier. L'eau de trempage de l'écorce se prend comme laxatif. Malgré la présence de roténone et autres produits insecticides dans les Millettia spp, plusieurs espèces de chenilles comestibles, probablement toutes les Notodontides (Miengeti, Mfundi et Malombaloka = Epidonta spp.), se nourrissent des feuilles. Les abeilles récoltent le pollen et le nectar des fleurs. Cet arbre a de nombreux usages médicinaux au Kongo Central.

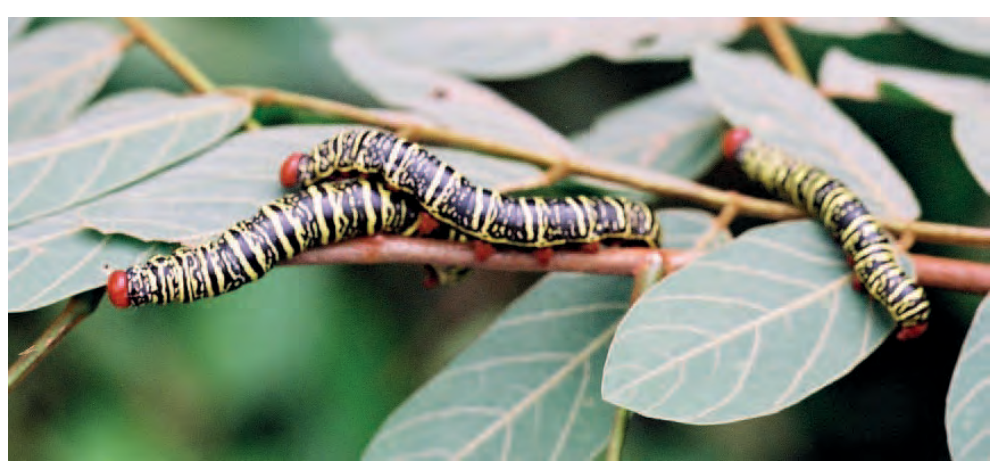

Description : Arbre pouvant atteindre 20 $\mathrm{m}$ de haut. Feuilles composes de 7 à12 paires de folioles, chacune de 4 à $7.5 \mathrm{~cm}$ sur 2 à $3 \mathrm{~cm}$. Inflorescences axillaires ou terminales en racèmes de fleurs mauve pâle, fleuries abondamment en novembre et décembre. Les fruits sont des gousses longues de 5 à $6 \mathrm{~cm}$ et contenant de 5 à 6 graines.

A gauche : Millettia Eetveldeana en fleurs.

Ecologie : Arbre des forêts primaires et secondaires, des lisières forestières, des forêts galeries et des savanes boisées, présent en R.D. Congo, Angola, Zambie et Mozambique.

Reproduction : Les boutures poussent bien, reprenant en une semaine. Les graines germent sans traitement préalable.

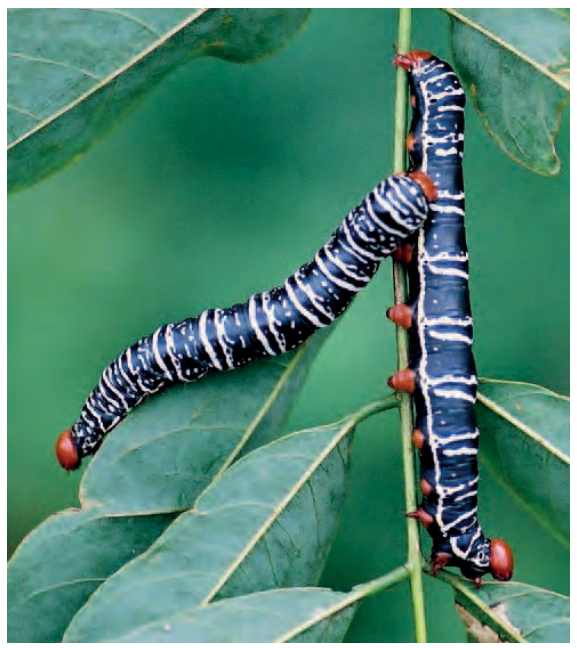

Chenilles Malombaloka (Epidonta sp.) se nourrissant sur Millettia eetveldeana

A gauche: Chenilles comestibles Mfundi (Epidonta sp.).

Références : Butaye 1909, Hauman et al. 1954, Cobbina et Reynolds 1988, Pauwels 1993, Neuwinger 2000, Latham 2008 


\section{Millettia griffoniana}

(Fabaceae)

Synonyme : Lonchocarpus griffonianus

Noms courants : Mbota masa (Kikongo), bobwote, igogo (Lingala)

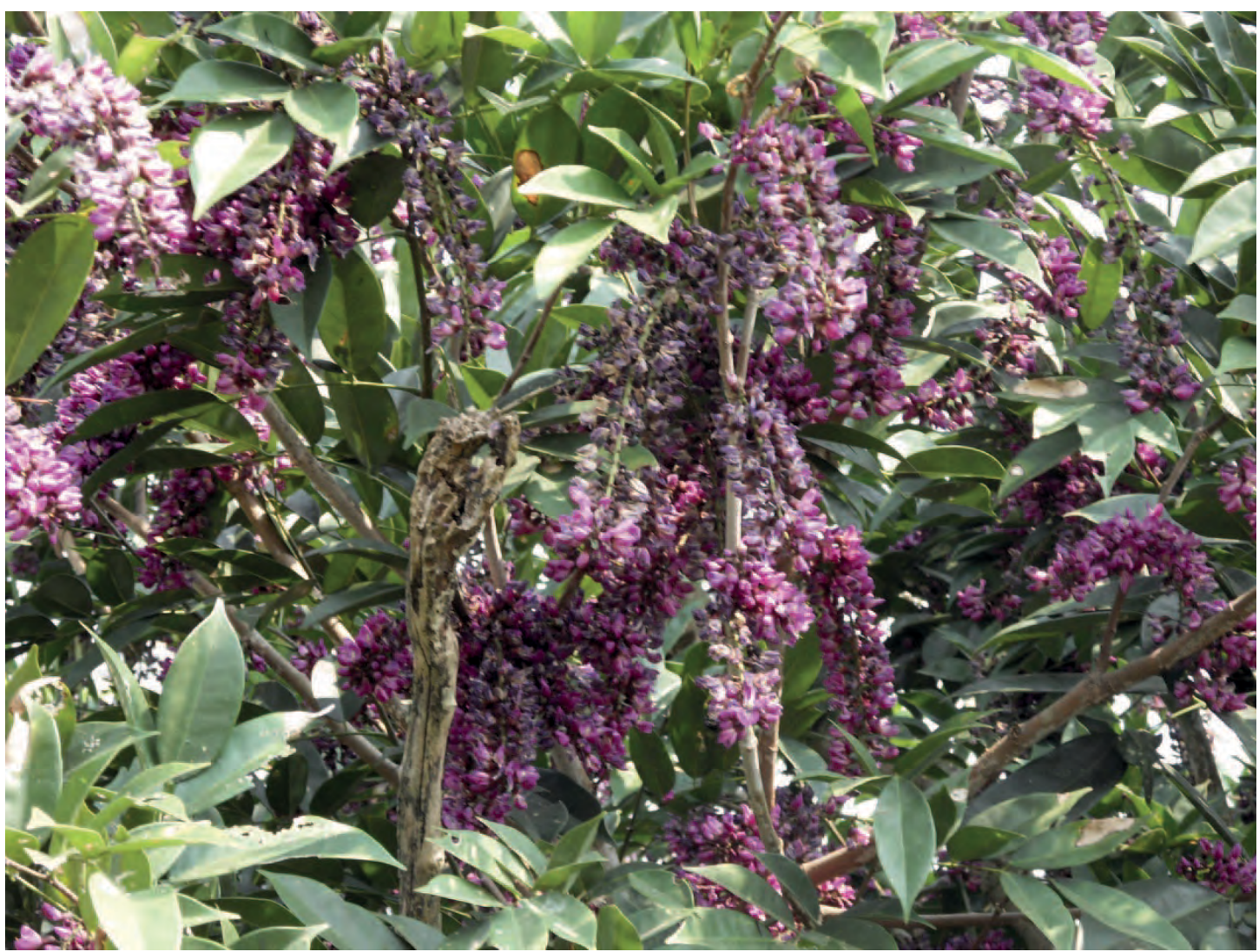

Millettia griffoniana en fleurs en juillet à Kilueka

Description : Arbre de 10 à $20 \mathrm{~m}$ de haut. Feuilles composées avec 3 à 5 paires de folioles de 5 à 10 sur 2 à 4 $\mathrm{cm}$. Les fleurs violettes ou lilas, à l'odeur forte, ayant jusqu'à $1,5 \mathrm{~cm}$ de long, apparaissent avec les feuilles pendant la saison sèche. Les fruits sont rares ; ce sont des gousses de 4 à $8 \mathrm{~cm}$ sur 2 à 3,5 cm, brun clair ; elles restent fermées assez longtemps avant de s'ouvrir. Cette espèce porte des stipules recourbés, longs de $2 \mathrm{~mm}$, qui la distinguent de $M$. thonningii.

Ecologie : Pousse près de l'eau, notamment au bord des cours d'eau, du Nigéria à l'Angola. Espèce commune au Kongo Central.

Reproduction : Facile à reproduire à partir de graines ou boutures.

Usages: Au Kongo Central, on emploie l'écorce pour traiter les maux d'estomac. Au Gabon, on prend les fleurs comme savon pour laver les vêtements; et les feuilles pour des fumigations. Millettia griffoniana est un bel arbre d'ornement. L'écorce des racines a des propriétés anti inflammatoires.

Références : Renier 1948, Hauman et al. 1954, Raponda-Walker et Sillans 1961, Keay 1989, Pauwels 1993, Burkill 1995, Hepburn et Radloff 1998, Nsimundele 2004, Hawthorne et Jongkind 2006, African Plant Database (3.4.0) (Consulté le 4.5.2016). 


\section{Millettia laurentii}

Noms courants : Kiboto, ntoka (Kikongo), mokonge (Lingala), bois noir (Fr.), wenge (commerce)

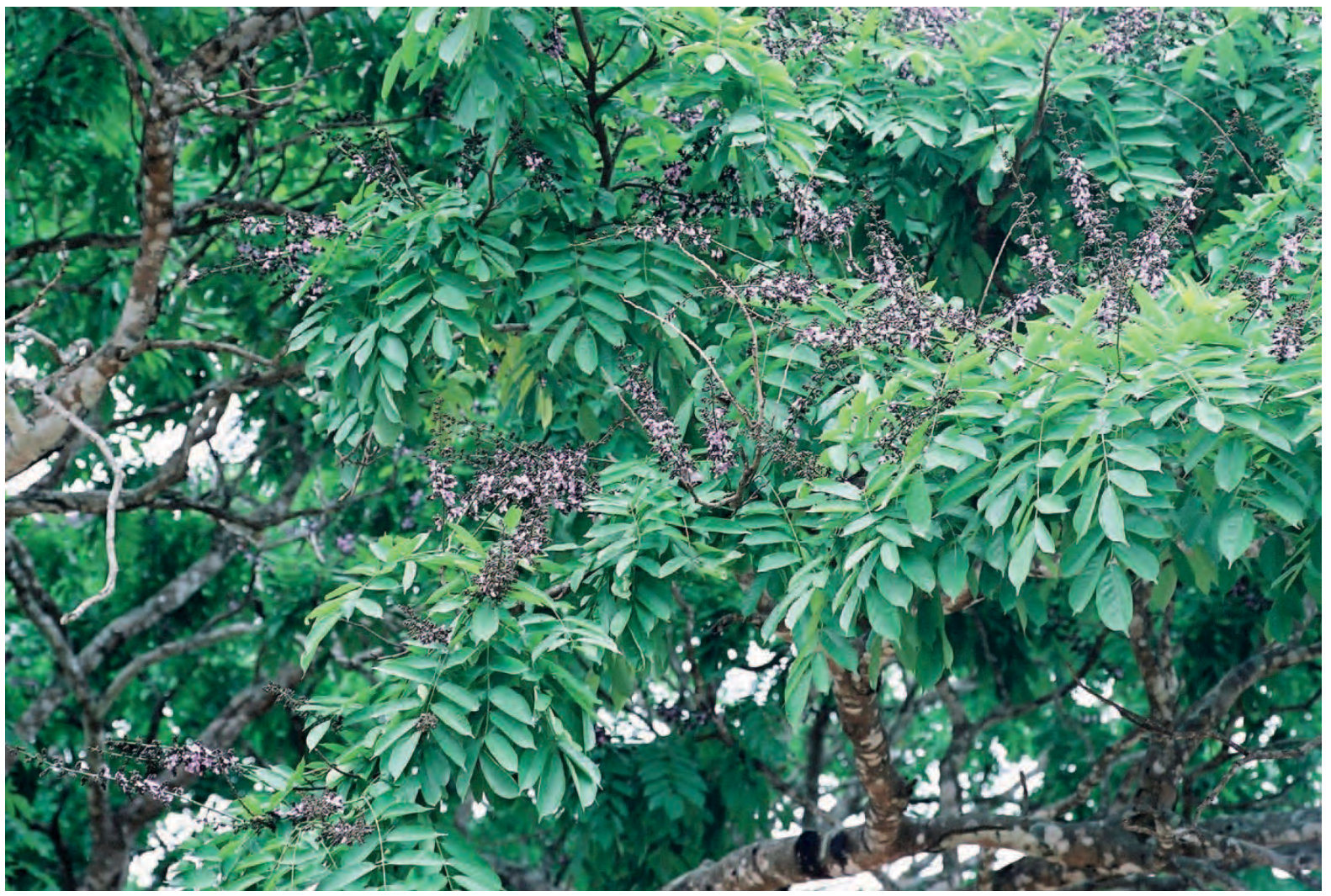

Millettia laurentii en fleurs à Kasangulu en décembre

Description : Grand arbre atteignant $30 \mathrm{~m}$ de haut. Le tronc est gris clair, avec à la base de légers contreforts arrondis. Les feuilles composées comprennent de 4 à 9 paires de folioles opposées plus une foliole terminale.

Le feuillage est touffu et tombant. Les inflorescences sont disposées en grandes grappes violettes au-dessus de la canopée entre mars et décembre. Le fruit est une gousse linéaire déhiscente de 15 à $30 \mathrm{~cm}$, contenant 2 à 3 graines aplaties de 2 à $2,5 \mathrm{~cm}$ de diamètre. L'espèce, surexploitée pour son bois, est en danger.

Ecologie: Arbre de l'Afrique Centrale, sur des sols argileux consistants, dans des forêts fermées, des forêts galerie, des savanes boisées. Souvent planté dans les villes pour l'ombrage.

Reproduction : Par grandes boutures ou par graines.

Gestion : Les jeunes arbres ont tendance à s'incliner si on les plante isolément, ce qui nuit à la qualité du bois. Pour les obliger à pousser droits, il faut les encadrer par d'autres arbres, par exemple Acacia Auriculiformis, que l'on peut couper quand le tronc de Millettia laurentii a atteint 5 mètres de haut

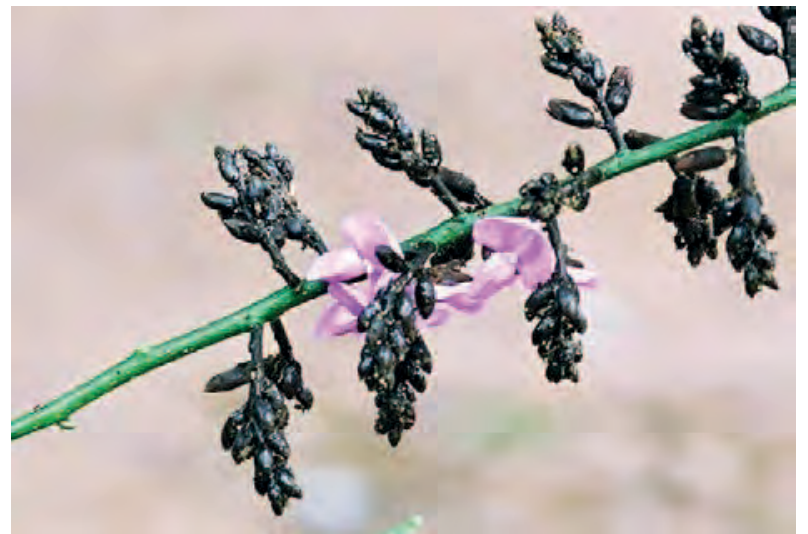

Usages : Le bois, brun sombre marbré, est d'excellente qualité, très dur et dense. On l'emploie en construction, pour le mobilier et la sculpture. On l'exporte pour la parqueterie, l'ameublement, les panneaux etc. II résiste aux champignons et aux insectes, et prend un beau poli. L'arbre est ornemental, et a été largement planté à Kinshasa pour les avenues. Au Kongo Central, on emploie une infusion des feuilles pour traiter les pimples, les infections hépatiques, le diabète et les rhumatismes; et une infusion des feuilles pour les problèmes hépatiques et le diabète. Une substance toxique est extraite des tissus pour les harpons à poisson, et pour composer des insecticides; et 
aussi, à faible dose, pour expulser les vers intestinaux et pour faire baisser la fièvre. On a observé en décembre la collecte du nectar par les abeilles. Les chenilles comestibles N'boto (Coeliades libeon), Munsona (Platysphinx stigmatica) et Ntesi se nourrissent sur les feuilles. Elles peuvent devenir toxiques si elles ne sont pas bien cuites, ou si on les mange en grandes quantités.

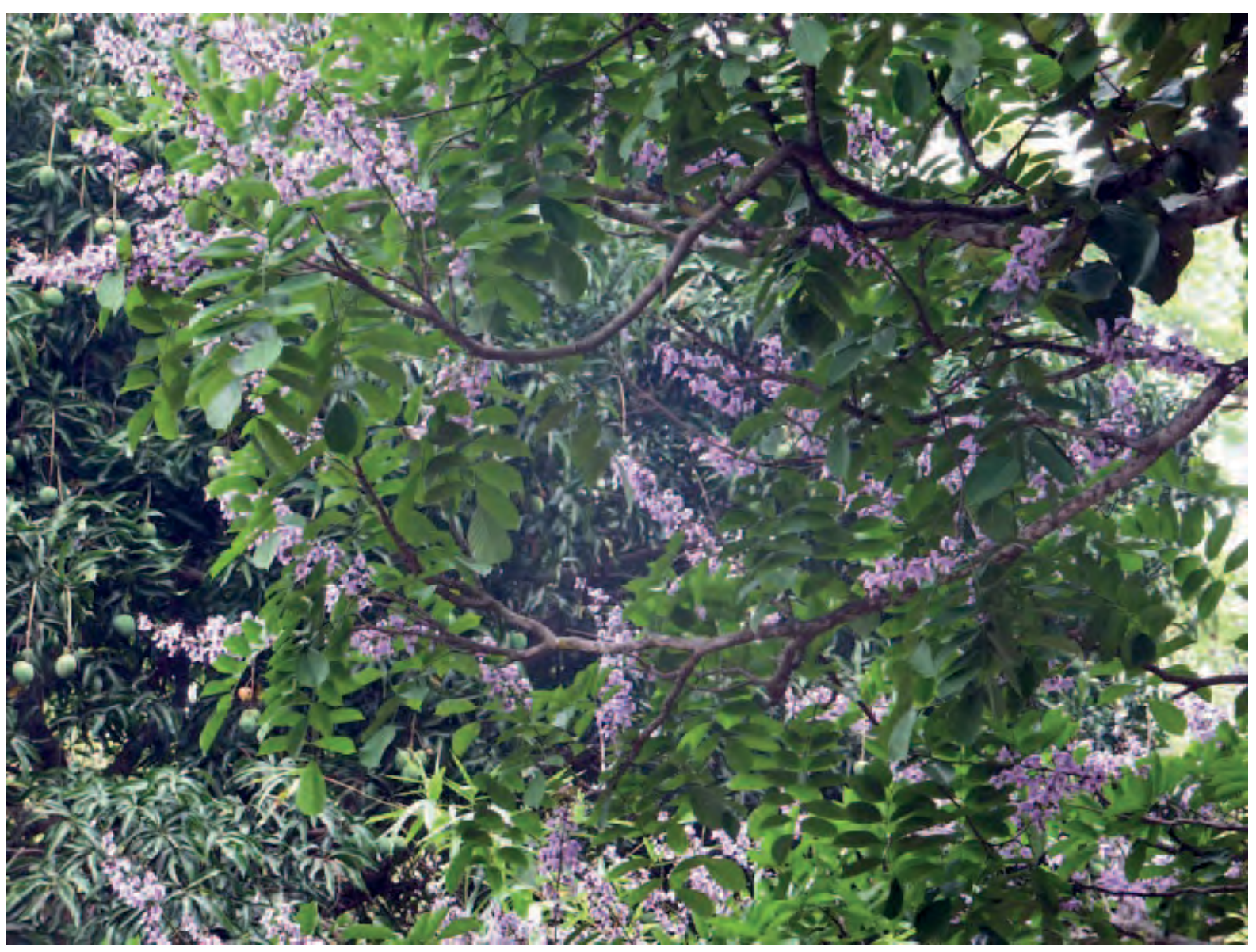

Arbre en fleurs près de Kimwenza en octobre

Références : Gillet et Pâque 1910, Renier 1948, Dartevelle 1951, Hauman et al. 1954, Nsimundele 1966 - 68 , Daeleman et Pauwels 1983, Mukoko Matondo 1991, Pauwels 1993, Kibungu Kembelo 1995, White et Abernethy 1997

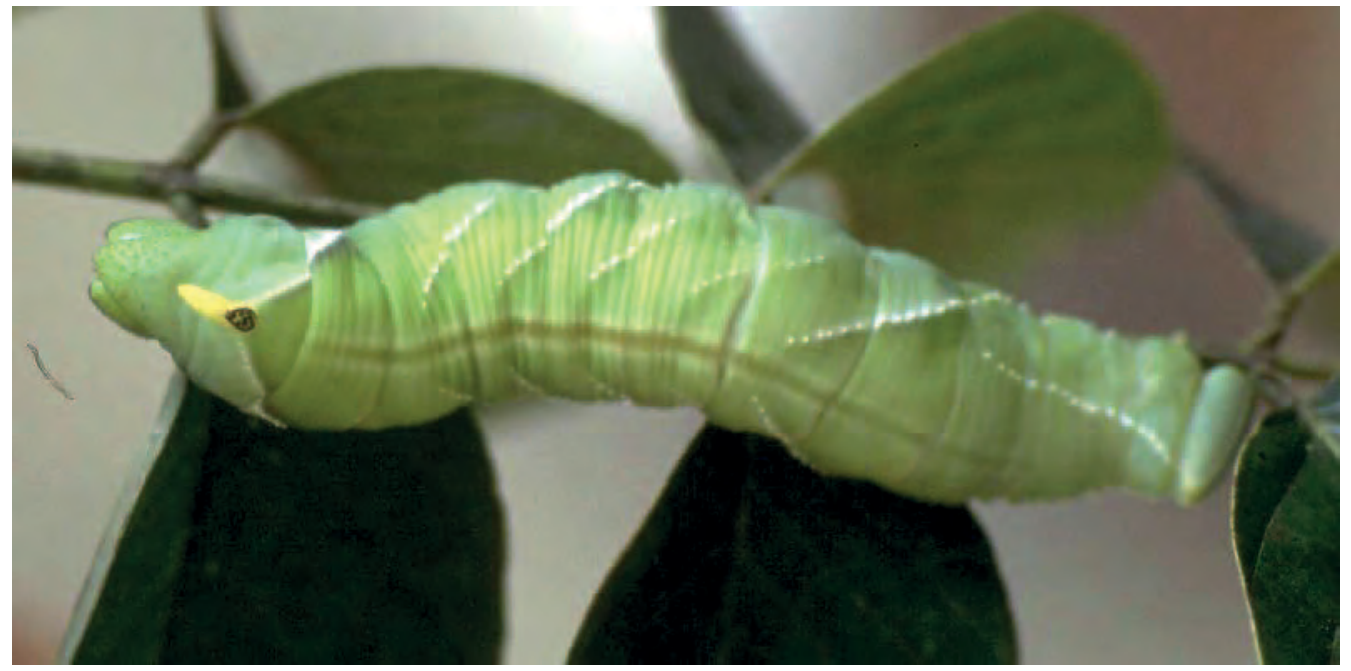

Munsona (Platysphinx stigmatica) Se nourrissant de Millettia versicolor 


\section{Millettia macroura}

Noms courants : Kifundi, fundi (Kikongo), bokonge (Lingala)

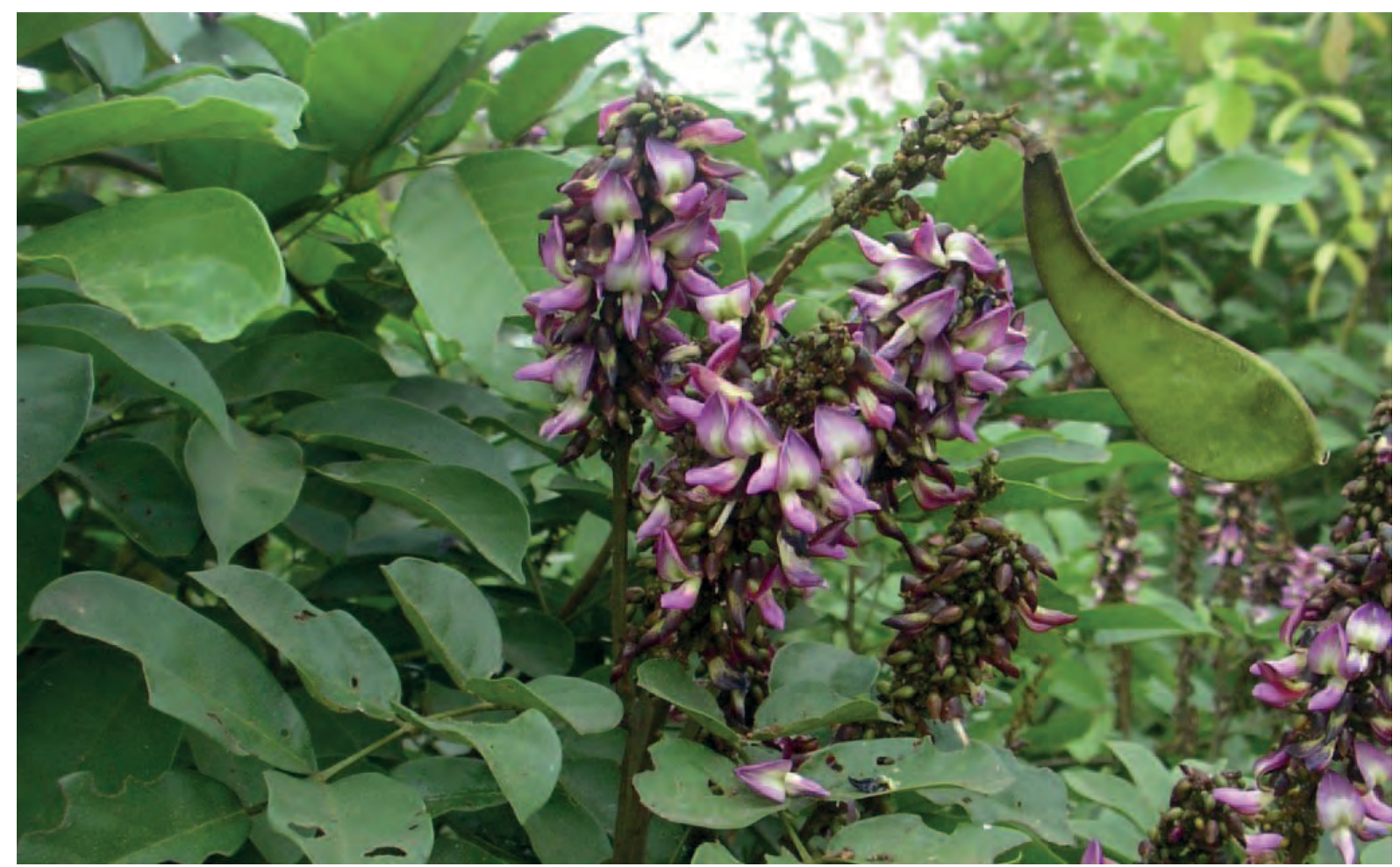

Description : Arbuste ou liane jusqu'à $9 \mathrm{~m}$ de long et $9 \mathrm{~cm}$ de diamètre. Les feuilles composées ont 2 à 4 paires de folioles, chacune de 6 à 17 sur 2,5 à $9 \mathrm{~cm}$. Les fleurs bleues ou violettes sont disposées sur une branche non ramifiée. Le fruit est une gousse plate de 6 à 10 sur 1,5 à $1,8 \mathrm{~cm}$, contenant de 3 à 5 graines.

Ecologie: Plante localement commune au Kongo Central, dans les savanes boisées, les lisières forestières, et au bord de l'eau. Présente dans toute l'Afrique Centrale.

Usages: Plante signalée comme fourrage pour les abeilles. Les tiges servent en construction et pour faire des liens.

Références : Hauman et al. 1954, Pauwels 1993, African Plant Database (3.4.0) (Consulté le 16.4.2020)

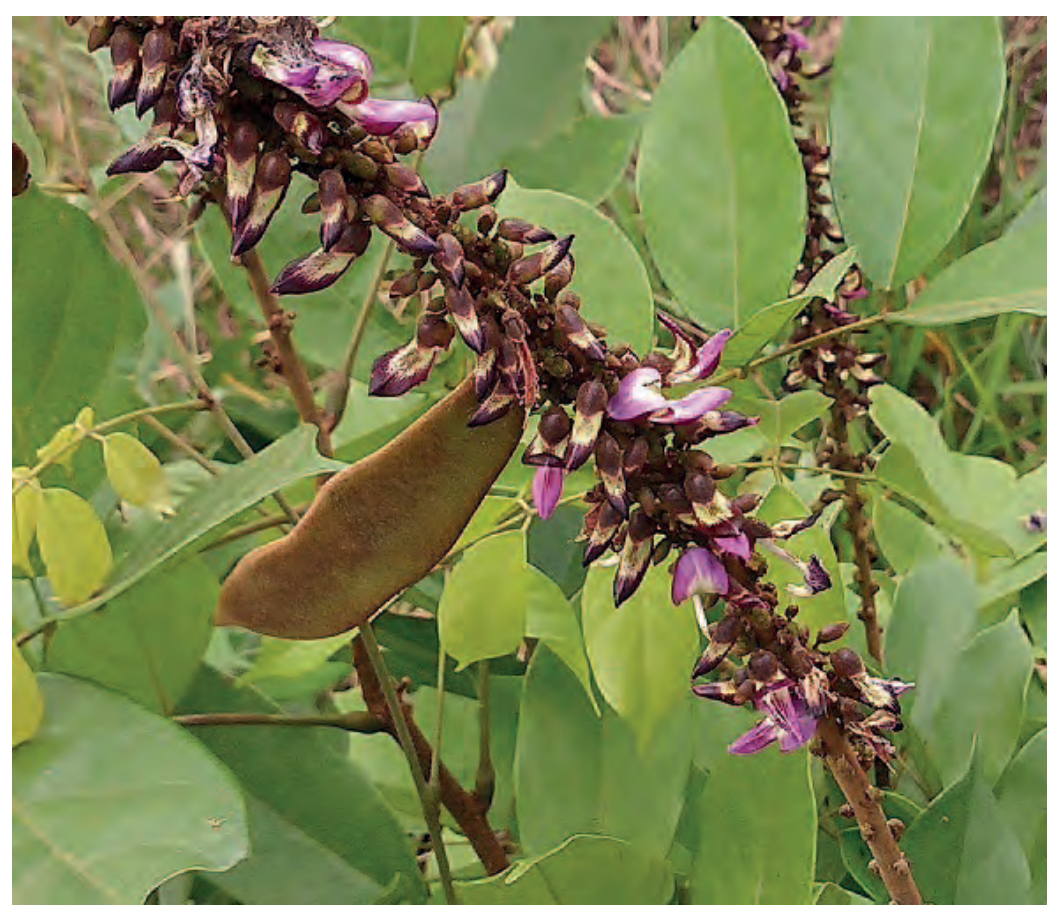

Photo : Anny Mandungu 


\section{Millettia theuszii}

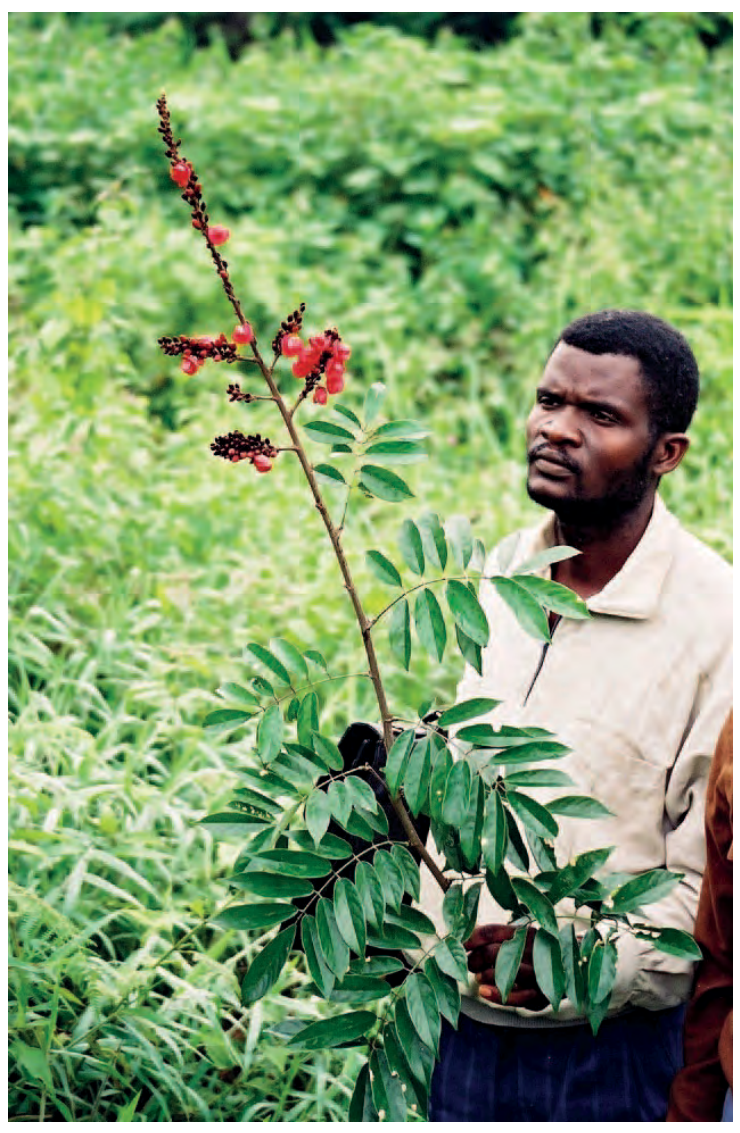

(Fabaceae)

Noms courants : Kifundi ki masa (Kikongo), kitoko (Lingala = "beauté")

Description : Arbuste ou liane pouvant atteindre $25 \mathrm{~m}$ de long, avec de très belles fleurs rouges. La plante produit probablement des nodules qui enrichissent le sol en azote.

Ecologie: Plante des forêts secondaires, des lisières de forêts, des bords de cours d'eau, des zones inondables, des savanes boisées et des clairières au Kongo Central. Présente également au Gabon et en Angola.

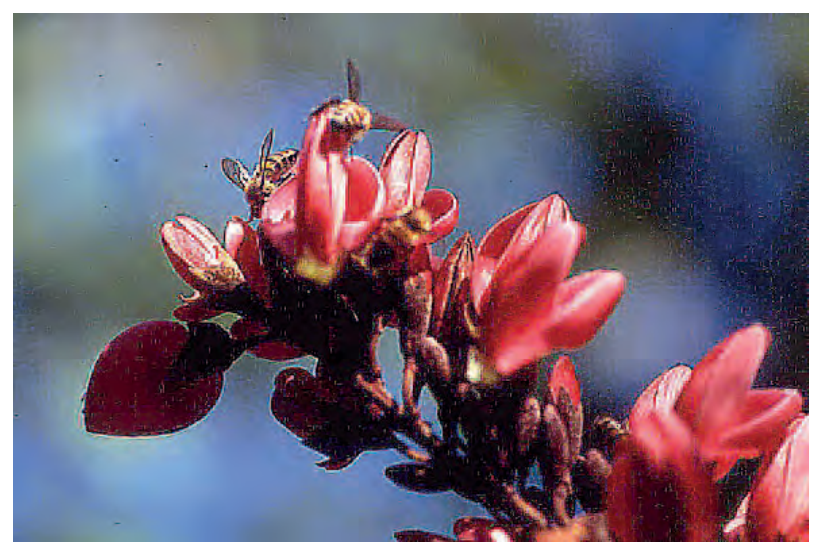

Usages : Les abeilles récoltent tôt le matin un nectar abondant. Traditionnellement, la plante servait, avec l'écorce de Pentaclethra eetveldeana, à empoisonner les poissons. Les tiges servent en construction et pour faire des liens. Plante nourricière de la forme tachetée de la chenille comestible Mfundi.

Références : Gillet et Pâque 1910, Hauman et al. 1954

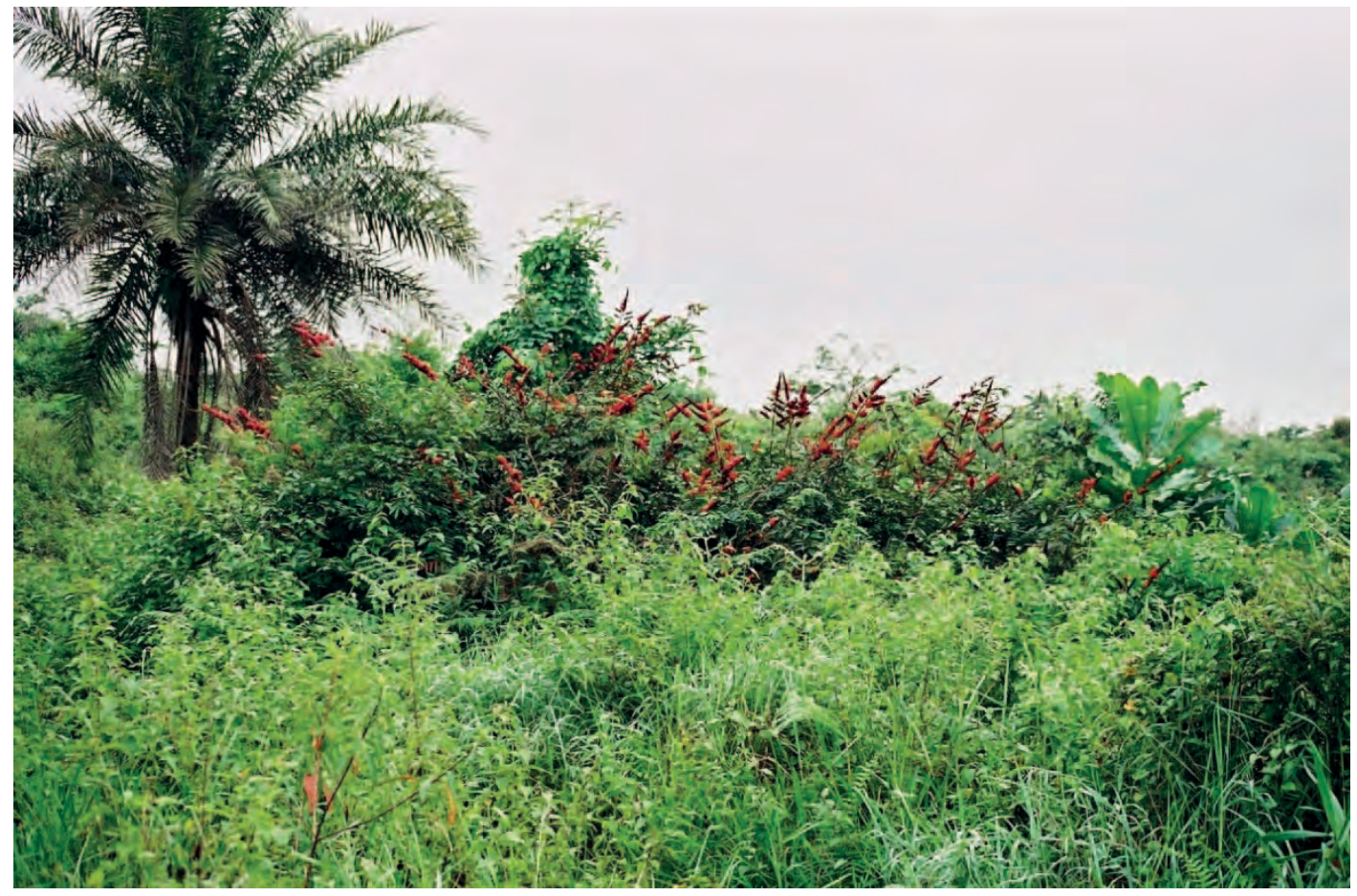

Millettia theuszii fleuri en décembre sur un terrain humide à Kingunda, 


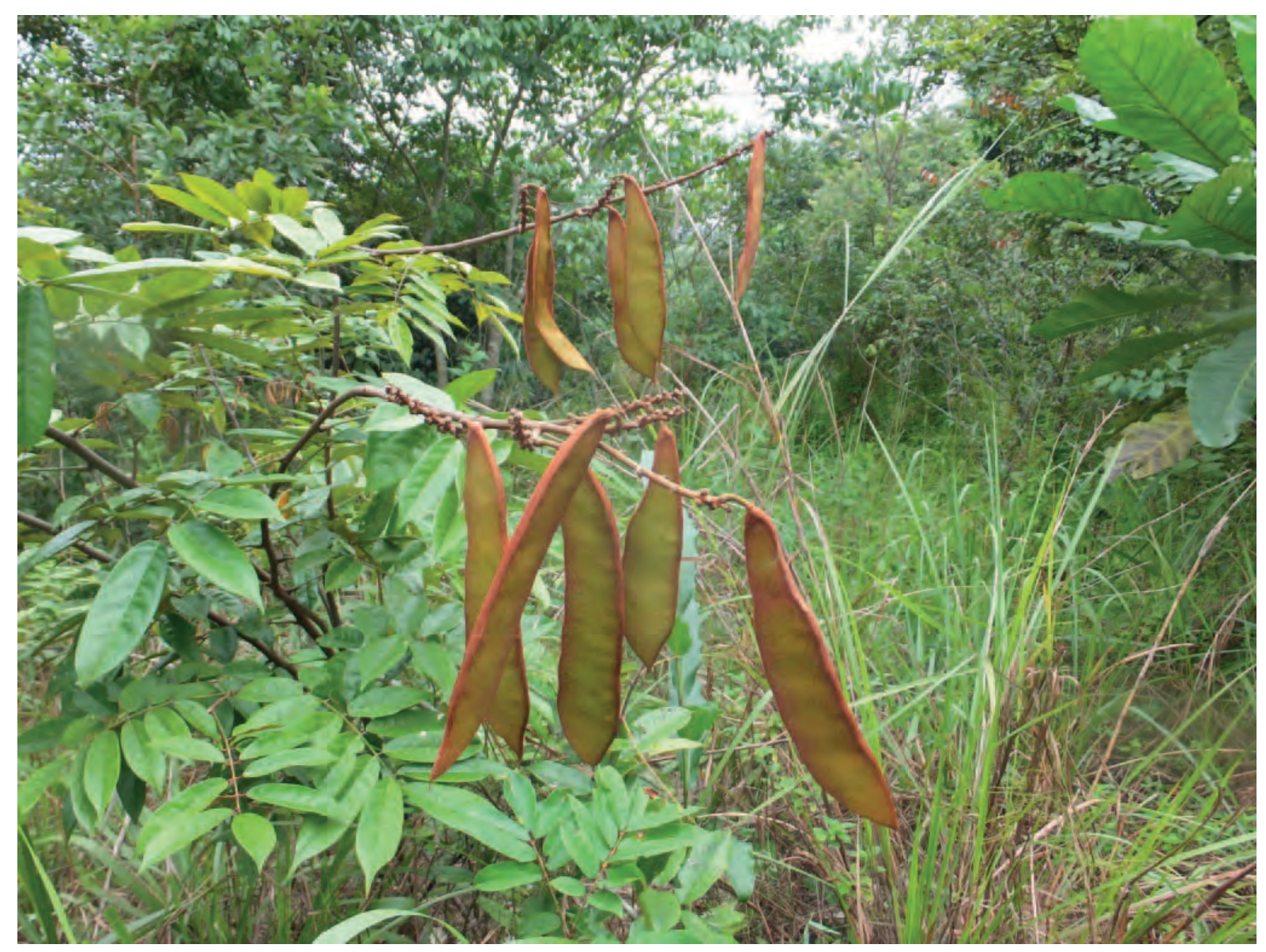

Gousses de Millettia theuszii en janvier près de Kimwenza

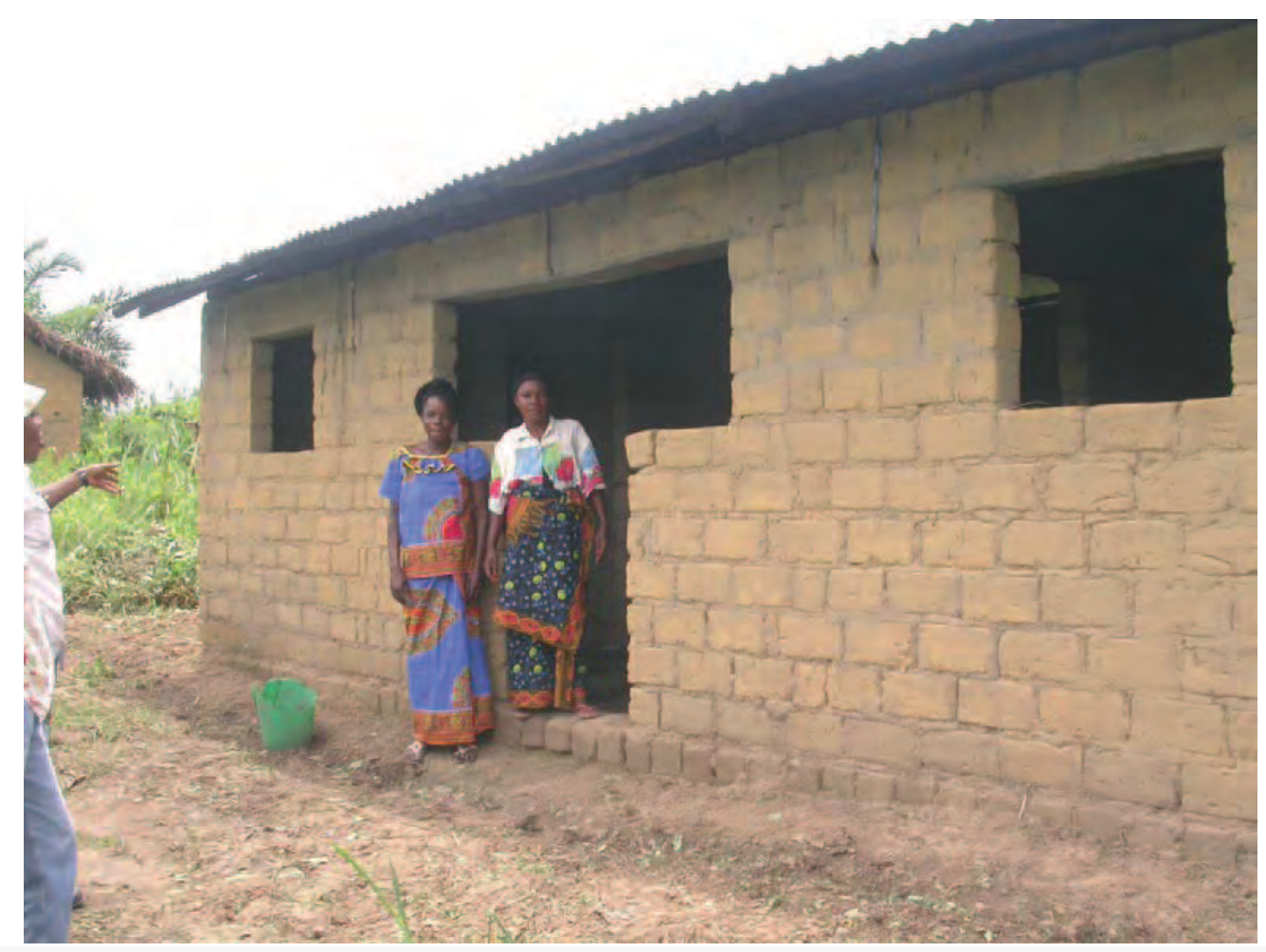

Une maison construite à partir de la vente de miel près de Kavwaya 
Noms courants : Mbota, lubota (Kikongo), bois d'or (Fr.)

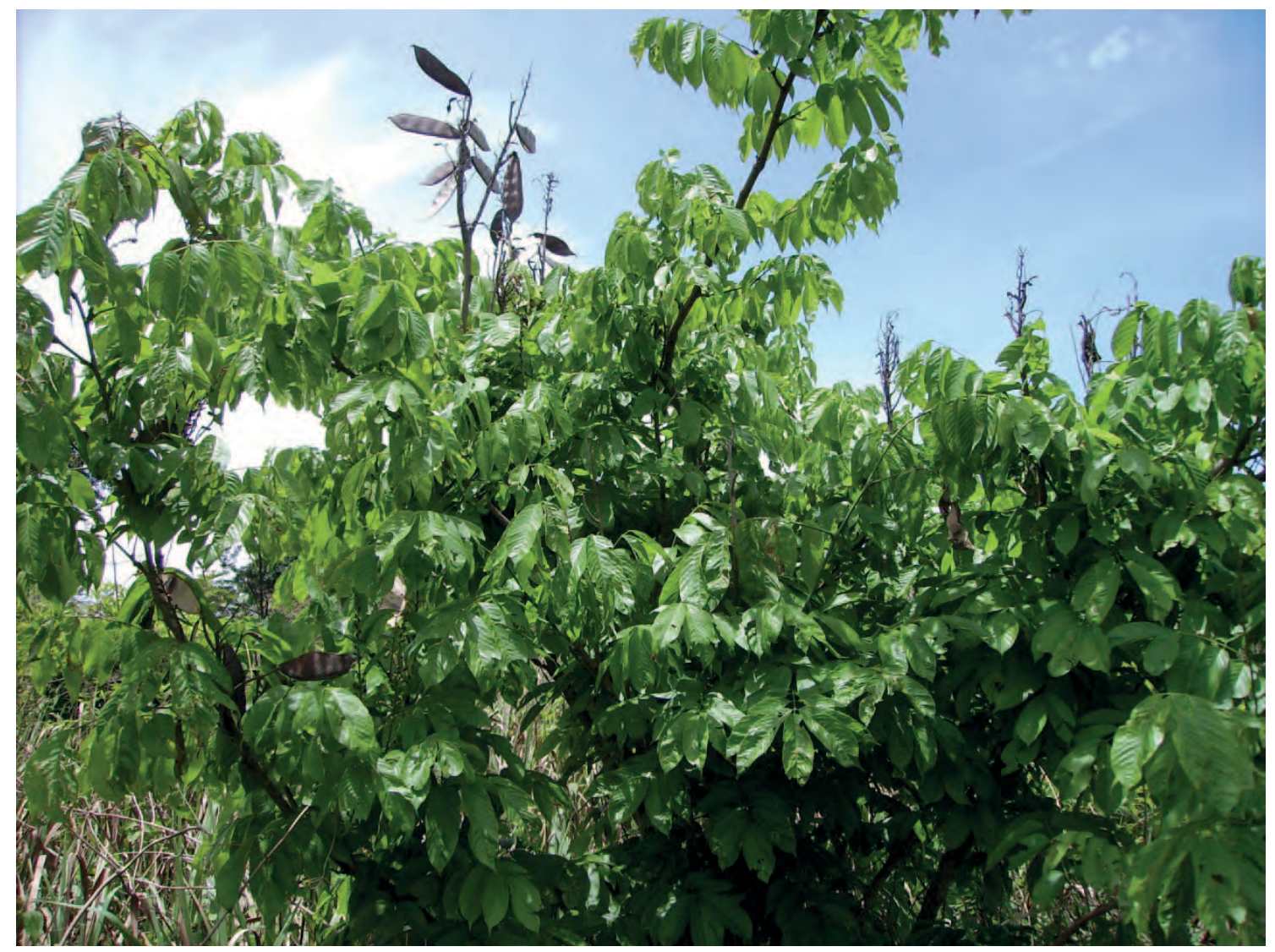

Description : Arbre de 20 à $30 \mathrm{~m}$ de haut, ou souvent arbuste de 3 à $4 \mathrm{~m}$ de haut. Feuilles composées de 5 paires de folioles et d'une foliole terminale. Le dessous des feuilles est glabre. Les gousses s'ouvrent soudainement, projetant les graines jusqu'à $15 \mathrm{~m}$ de distance.

Ecologie : On trouve fréquemment cet arbre dans les savanes en reforestation et les forêts secondaires, où il est commun aux lisières. II reprend bien après le feu. On le trouve également au Gabon, en Centrafrique et en Angola.

Usages : Le bois, dur et élastique, est très intéressant pour l'ébénisterie et la sculpture. On plante les grosses branches droites comme barrières autour des concessions. On plante aussi cet arbre pour l'ombrage. II y a des fleurs toute l'année; elles attireraient les abeilles, mais nous ne l'avons jamais observé.

Références : Drachoussoff 1947,

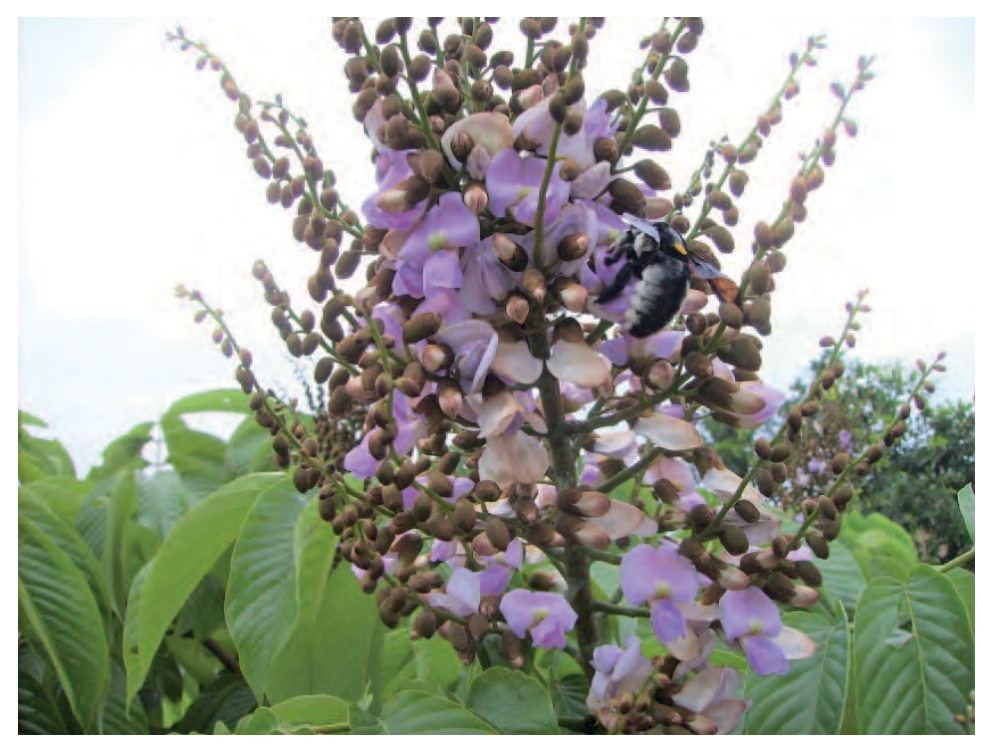

Hauman et al. 1954, Aumeeruddy et Pinglo 1988, Mukoko Matondo 1991, Pauwels 1993, Kibungu Kembelo 1995, White et Abernethy 1997, Nsimundele 2004 
Noms courants : Kikoke (= épine)(Kikongo), alanganya, alankagna (Lingala), cat's claw (Angl.)

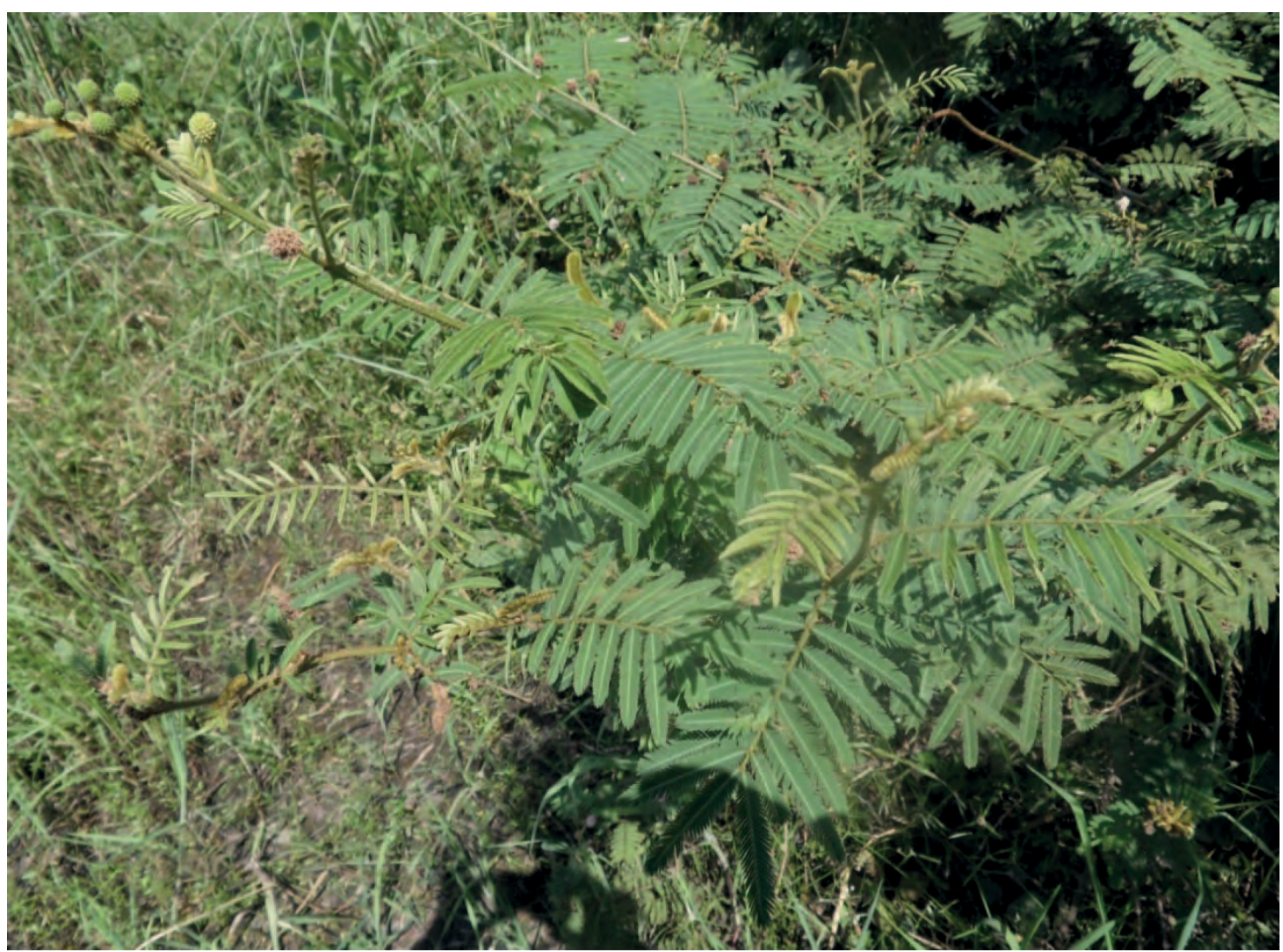

Description : Arbuste de $4 \mathrm{~m}$ de haut, parfois grimpant. Les tiges portent des épines pouvant avoir $7 \mathrm{~mm}$ de long. Les feuilles composées sont sensitives; elles ont de 25 à 40 paires de folioles de 4 à 6 sur 0,5 à $2 \mathrm{~mm}$. Les fleurs sont mauves à roses. Les gousses brunes, de 3,5 à 8 sur 0,8 à 1,2 $\mathrm{cm}$, sont disposées en bouquets et couvertes de poils ; elles sont divisées transversalement en segments longs de 3 à $6 \mathrm{~mm}$, déparés par des plages vides.

Ecologie: Plante originaire des Amériques, répandue partout sous les tropiques, et parfois envahissante. Plante des lisières de forêts, des bords de cours d'eau, et des lieux humides.

Usages: Au Kongo Central, on injecte le jus dans les narines des chiens de chasse pour les rendre capables de mieux flairer les pistes. Là où la plante est commune, on sèche les tiges

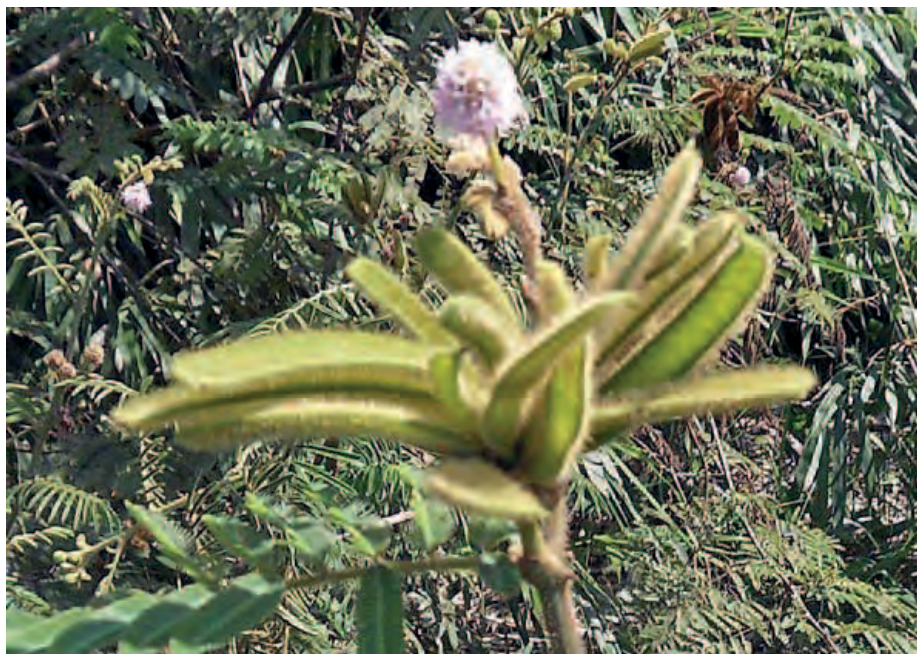
et les branches pour en faire du bois de feu. Les racines contiennent $10 \%$ de tannins. On emploie cette plante comme tonique, pour traiter la diarrhée, la gonorrhée, et l'empoisonnement du sang. En Afrique tropicale, les graines sont émétiques; on les emploie aussi comme expectorant et pour traiter les maux de dents. Les feuilles contiennent de la mimosine, utilisée comme purgatif et comme tonique. En Thailande, les apiculteurs indiquent que les fleurs sont une source de pollen pour les abeilles.

Références : Butaye 1909, Gillet et Pâque 1910, Renier 1948, Gilbert et Boutique 1952, Pauwels 1993, Orwa et al. 2009 
Common names Bikoki, kimfwa ngambu, kanga nzo (Kikongo), herbe sensible (Fr.)

Description : Plante herbacée épineuse pérenne à feuilles sensitive, à tiges habituellement courbées vers le bas, mais pouvant atteindre $1 \mathrm{~m}$ de haut. Les feuilles se ferment au moindre toucher et pendant la pluie.

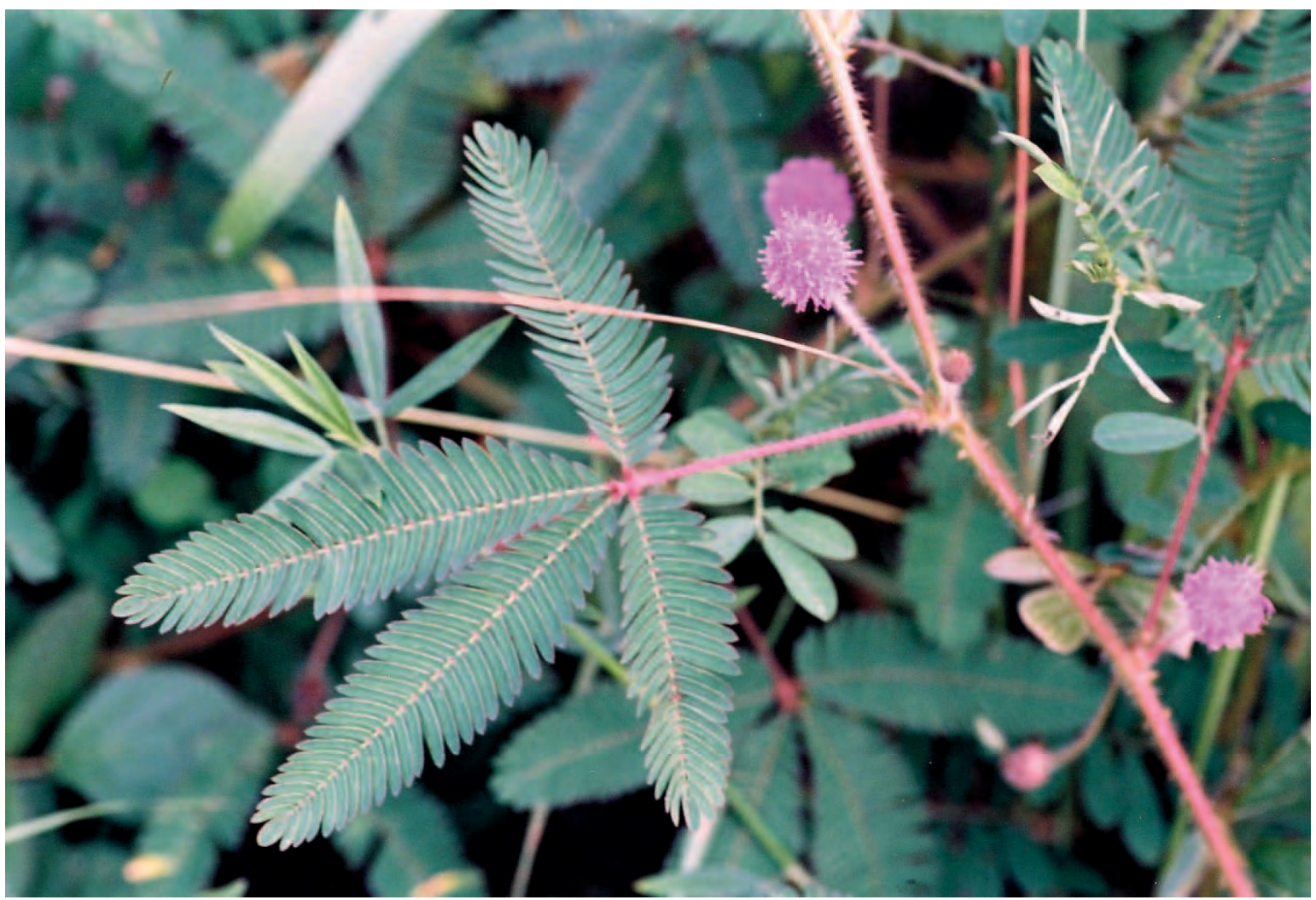

Mimosa pudica en fleurs en janvier près de Kavwaya

Ecologie: Plante originaire du Brésil, commune le long des routes et dans les friches; nuisible dans les pâturages. Au Kongo Central, on la trouve souvent près de l'eau.

Usages : Source de pollen, connue comme fourrage pour les abeilles au Gabon et en Amérique Centrale. Utile comme engrais vert. Le bétail broute les jeunes pousses, mais il faut un pâturage régulier pour prévenir la formation

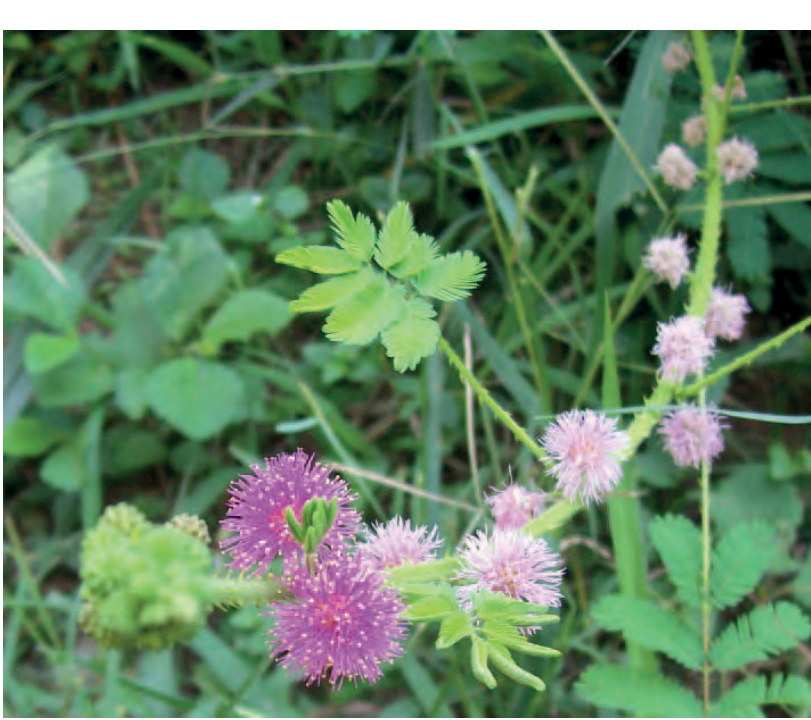
de tiges dures et épineuses. Ne convient pas pour l'alimentation des volailles. On signale de nombreux usages médicinaux.

Remarque: $M$. diplotricha (Koki ki nseke), plante très invasive poussant autour de Mvuazi, est également présente, et fournit probablement du pollen aux abeilles.

Références: Gillet et Pâque 1910, Daeleman et Pauwels 1983, Espina et Ordetx 1983, Akobundu et Agyakwa 1987, Ambougou 1991, Macmillan 1991, Pauwels 1993, Burkill 1995, Vande weghe 2004

Mimosa diplotricha en fleur en février. 


\section{Mitracarpus hirtus}

Synonyme : M. villosus

Noms courants : Mbanda nzazi, bana ba nzazi (Kikongo), button grass (Angl.)

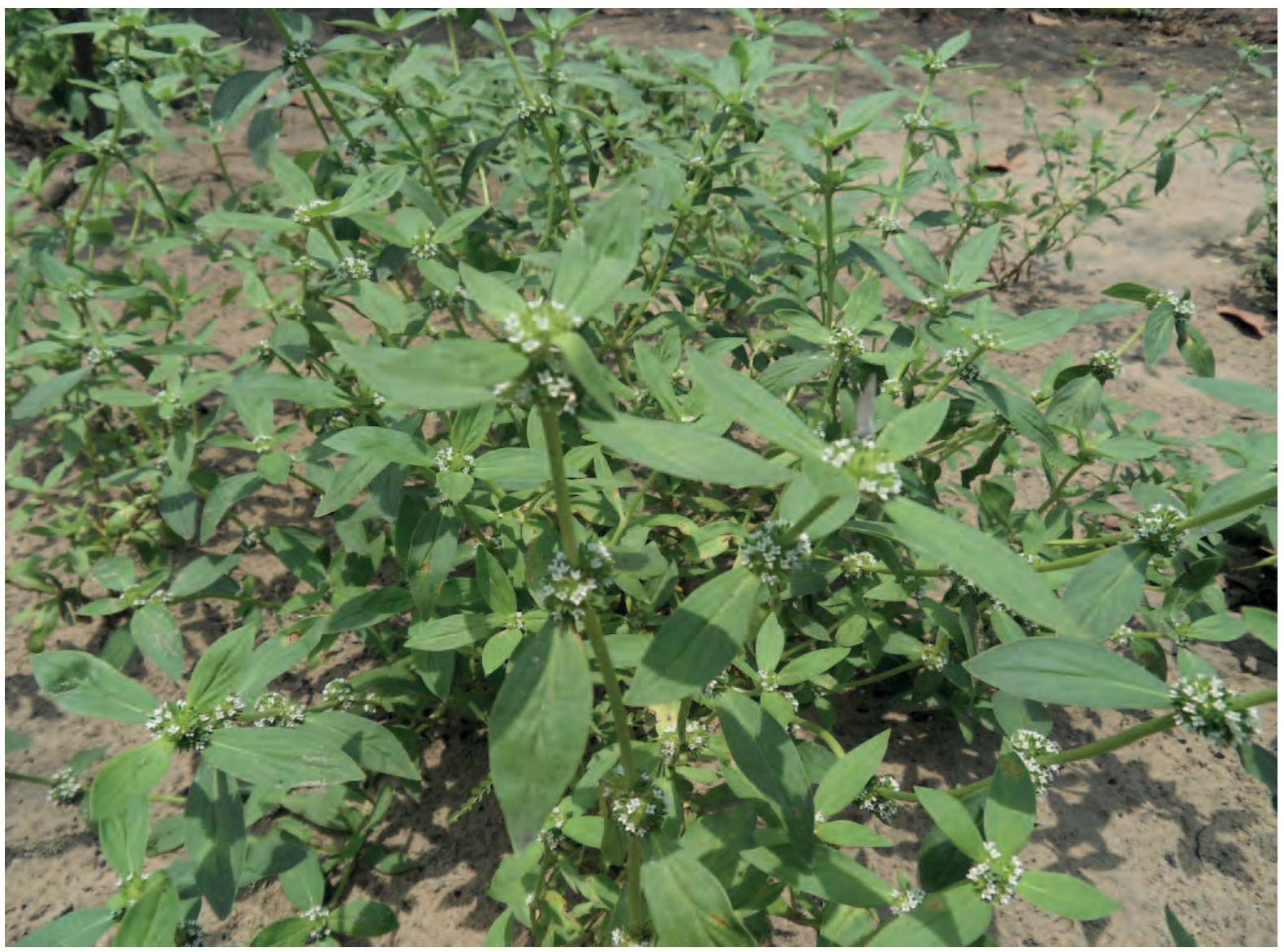

Mitracarpus hirtus à Mingadi

Description : Petite herbe annuelle très ramifiée, de 10 à $50 \mathrm{~cm}$ de haut. La tige est quadrangulaire, poilue, ligneuse à la base et segmentée par des nœuds portant chacun une paire de feuilles. L'inflorescence est une tête ronde de 1 à 1,8 cm de diamètre émergeant à l'aisselle d'une feuille, et portant de petites fleurs blanches.

Ecologie: Adventice commune des villages, des bords de route, des friches, des cultures, et des savanes herbeuses, dans toute l'Afrique tropicale.

Usages: Au Kongo Central, on emploie la plante entière, et plus spécialement les feuilles, pour traiter les infections cutanées fongiques, les éruptions et les refroidissements des enfants. Le jus des feuilles pilées est considéré comme fongicide ; on l'emploie largement pour traiter l'herpès, les mycoses cutanées et les teignes. On signale que l'eczéma et les ulcères réfractaires se soigneraient en nettoyant le visage avec la plante ou son extrait aqueux.

Références: Gillet et Pâque 1910, Staner et Boutique 1937, Daeleman et Pauwels 1983, Akobundu et Agyakwa 1987, Burkill 1997, Neuwinger 2000, Kibungu Kembelo 2003

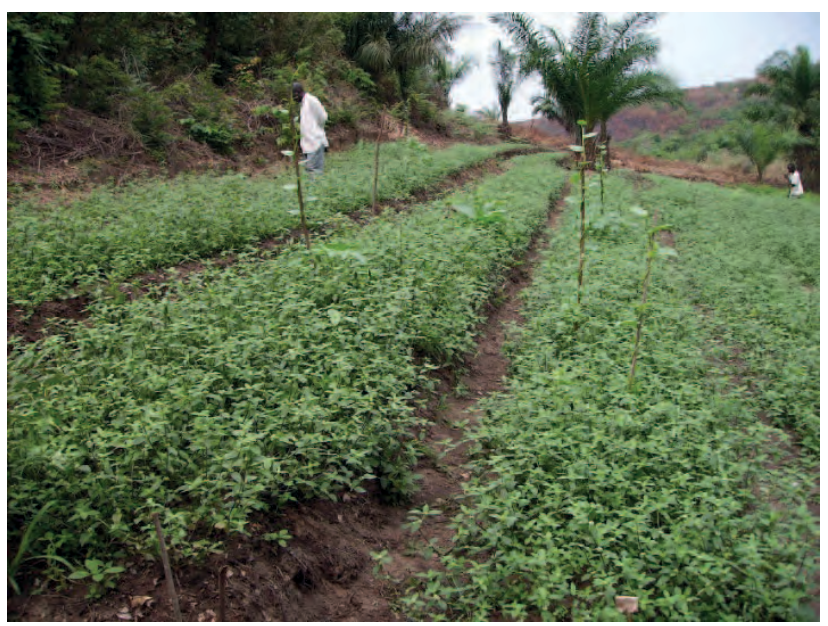

À droite: Plantation de Mitracarpus hirtus cultivée par ANAMED Kinshasa 


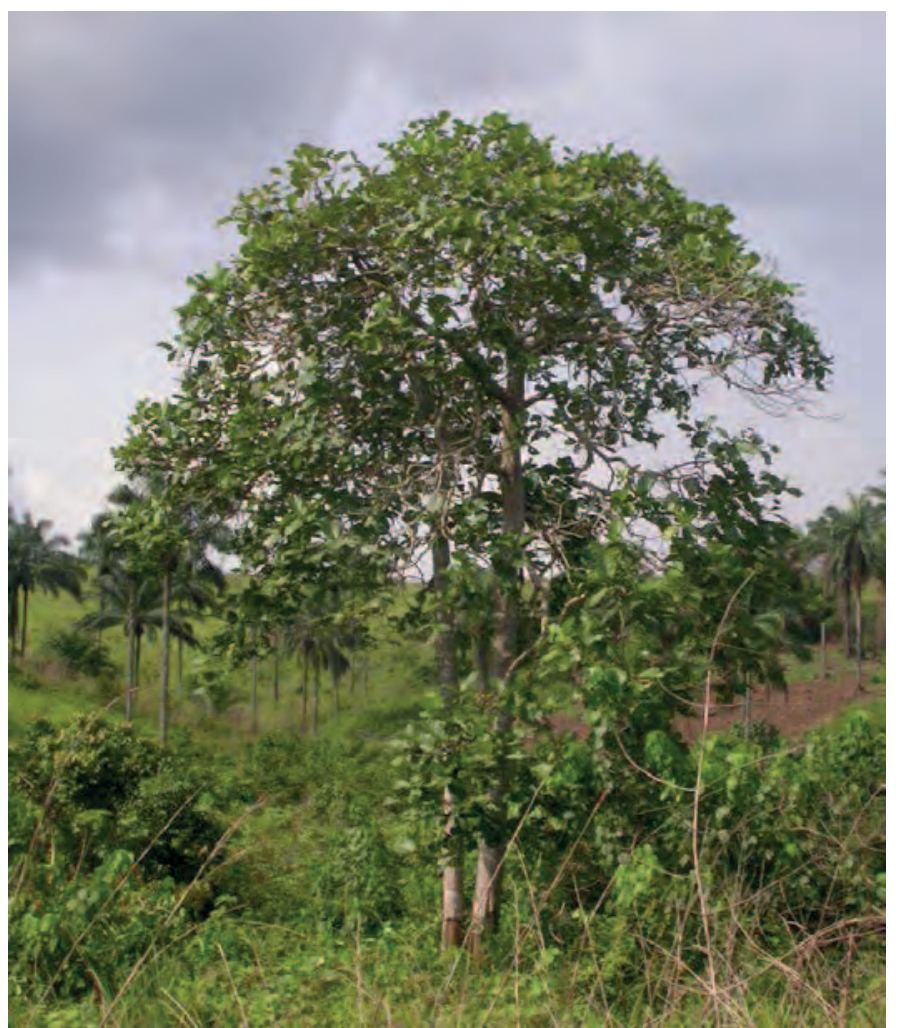

Reproduction: L'arbre se cultive à partir de grandes boutures, marcottage aérien, ou transplantation des semis spontanés. Concernant la germination des graines, des avis indiquent qu'on l'obtient facilement après 5 à 8 jours ; d'autres prétendent qu'elle est irrégulière et faible. En tout cas, on doit semer les graines dans un sol provenant d'un marécage.

Usages : Cette espèce est utile pour l'afforestation des marais. Le bois est tendre et à grain fin. Bien que fragile et attaqué par les insectes perforants, on l'emploie pour les tambours, les récipients, les pirogues, les mortiers et pilons, etc. II convient aussi pour faire du papier. Au Kongo Central, on emploie toutes les parties de l'arbre, et spécialement l'écorce, pour faire baisser la fièvre. La décoction de l'écorce sert à traiter le diabète, les rhumatismes, l'onchocercose et les abcès. On emploie contre les hémorroïdes un bain fait avec l'écorce pilée. On

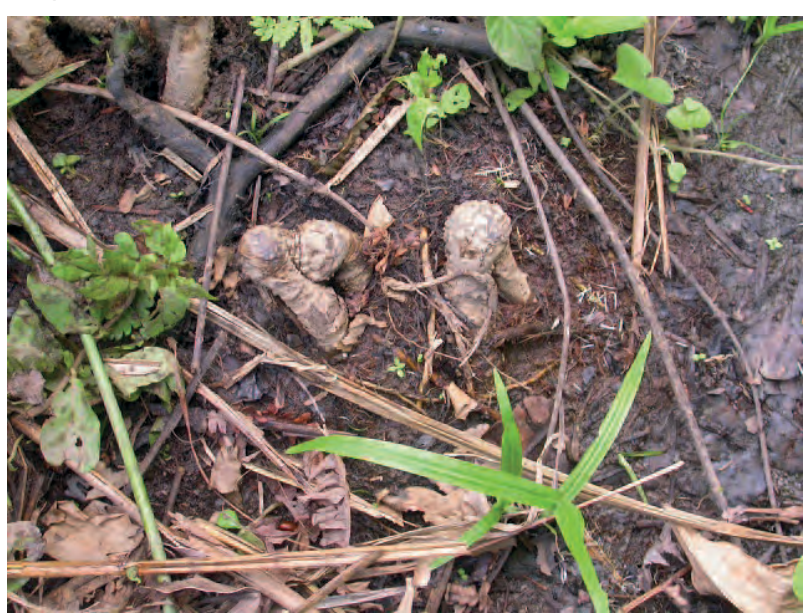
emploie l'écorce pour traiter le vin de palme. Les abeilles visitent les fleurs en mars et avril. Le champignon Lulongu pousse sur le bois.

Références: Butaye 1909, Gillet et Pâque 1910, Gillet 1927, Renier 1948, Leloup 1956, Irvine 1961, Nsimundele 1966 - 68, Daeleman et Pauwels 1983, Mukoko Matondo 1991, Pauwels 1993, Burkill 1997, Katende et al. 1995, Meunier et al. 2010

A gauche : Pneumatophores, sortant au-dessus du soll 
Noms courants : Lumbusu (Kikongo), bitter gourd (Angl.)

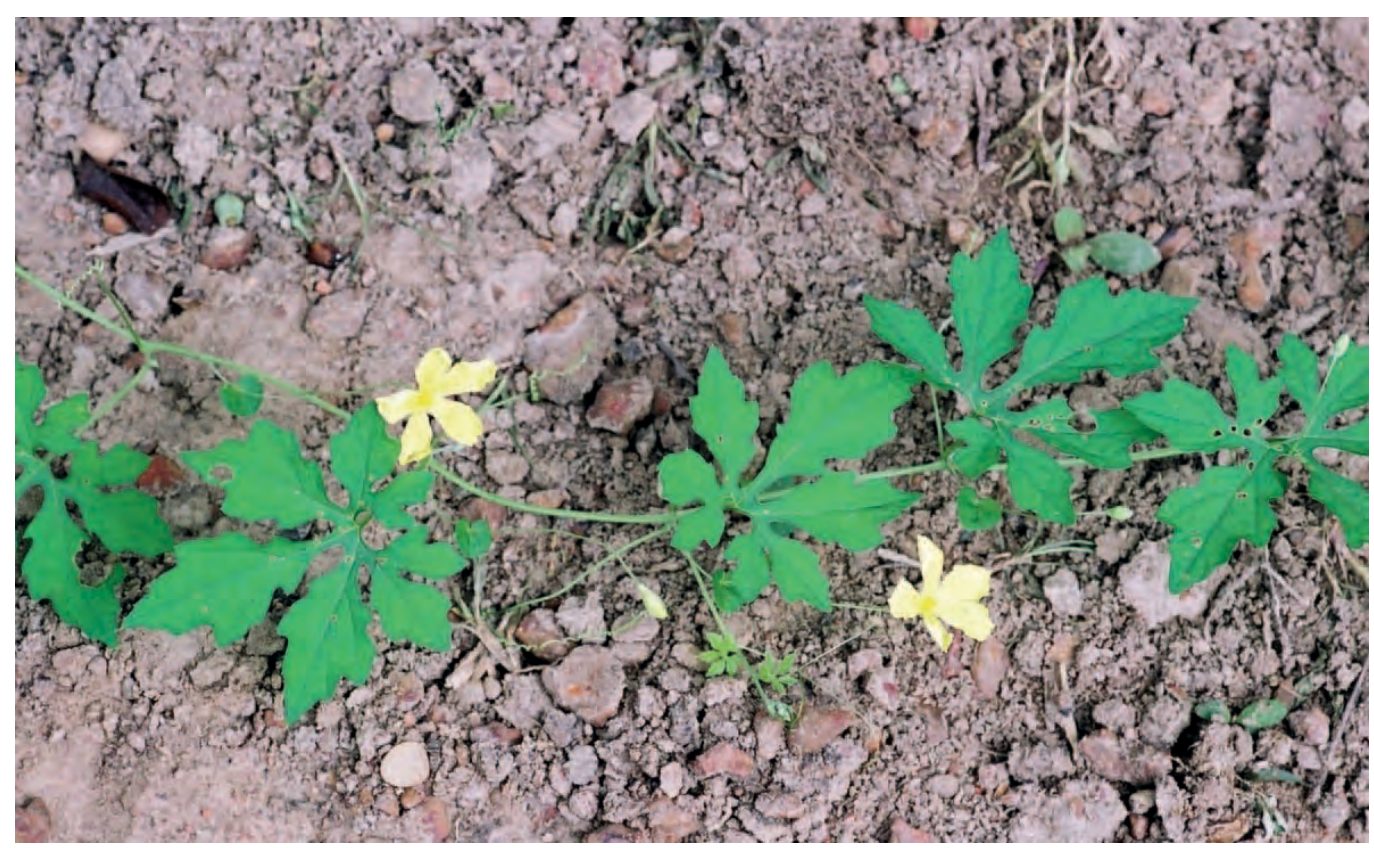

Description : Liane couverte de poils portant des vrilles qui lui permettent de grimper. Les tiges peuvent avoir 4 $\mathrm{m}$ de long. Quand elles meurent, de nouvelles tiges poussent à la base. La tige est creuse et anguleuse. Feuilles alternes, lobées, jusqu'à $5 \mathrm{~cm}$ de long, et grossièrement dentées. Le pétiole écrasé dégage une odeur déplaisante. Les fleurs jaunes ont jusqu'à $8 \mathrm{~cm}$ de long ; elles poussent à l'aisselle des feuilles. Le fruit mûr est jaune, oblong, portant des verrues, avec des rainures longitudinales; il éclate en libérant des graines rouges.

Ecologie; Liane commune des champs cultivés et des jachères à travers les tropiques, qui prospère dans des conditions chaudes et humides en-dessous de $500 \mathrm{~m}$ d'altitude, sur des sols riches capables de retenir l'humidité.

Reproduction : Extraire les graines de fruits, et les sécher au soleil avant de les semer.

Usages: Au Kongo Central, on pile les jeunes pousses et les feuilles pour les faire bouillir et les manger avec du beurre d'arachide et de la sauce tomate. Leur goût est parfois amer ; pour réduire l'amertume, on peut changer l'eau de cuisson, ou tremper une nuit. On mange aussi les feuilles de Momordica foetida. On emploie une décoction des feuilles de $M$. charantia pour traiter les maux d'estomac. On utilise aussi cette plante pour traiter les éruptions cutanées, les mastites, la tuberculose, les caries dentaires, les règles douloureuses, et les pleurs prolongés des enfants. Ailleurs en R.D. Congo, on emploie les feuilles pour traiter la colique, et les graines contre les ascaris. Au Nord de l'Angola, on emploie l'infusion des feuilles pour traiter la typhoïde, les maux d'estomac et la fièvre. La plante est connue pour ses propriétés insecticides. En Asie, on cultive cette plante pour ses fruits comestibles, et ses pousses tendres. On emploie parfois les fruits en guise de savon pour la lessive; on peut utiliser les feuilles pour décaper les métaux. Les abeilles visitent les fleurs pour le nectar et le pollen.

Références: Gillet et Pâque 1910, De Wildeman 1934, Staner et Boutique 1937, Watt et Breyer-Brandwijk 1962, Morton 1967, Burkill 1985, Akobundu et Agyakwa 1987, Robinson et Decker-Walters 1997, Martin et al. 1998, Amponsah et al. 2002, Schippers 2002, Kibungu Kembelo 2003, Heinze et al. 2019

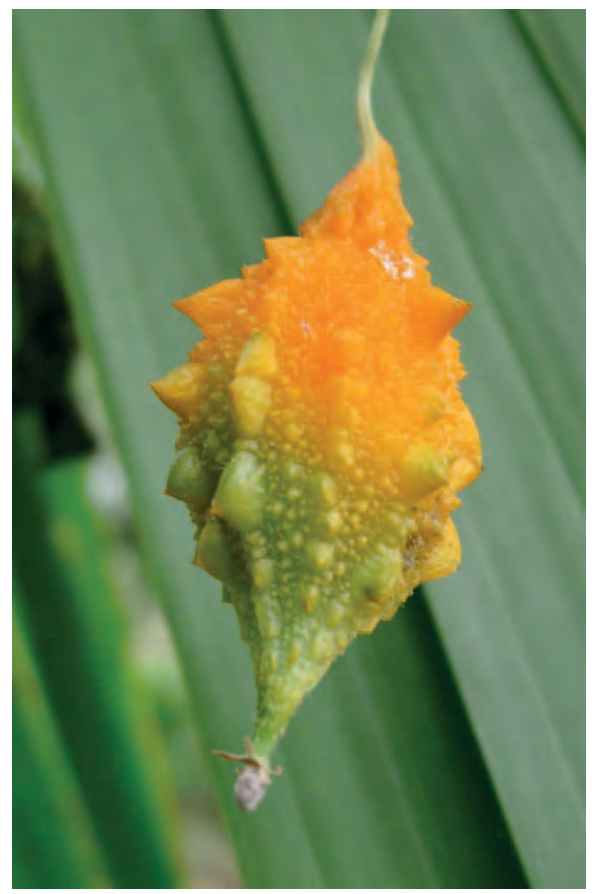


Mondia whitei

(Apocynaceae)

Synonyme : Chlorocodon whitei

Noms courants : Kimbiolongo, ntubungu (Kikongo)

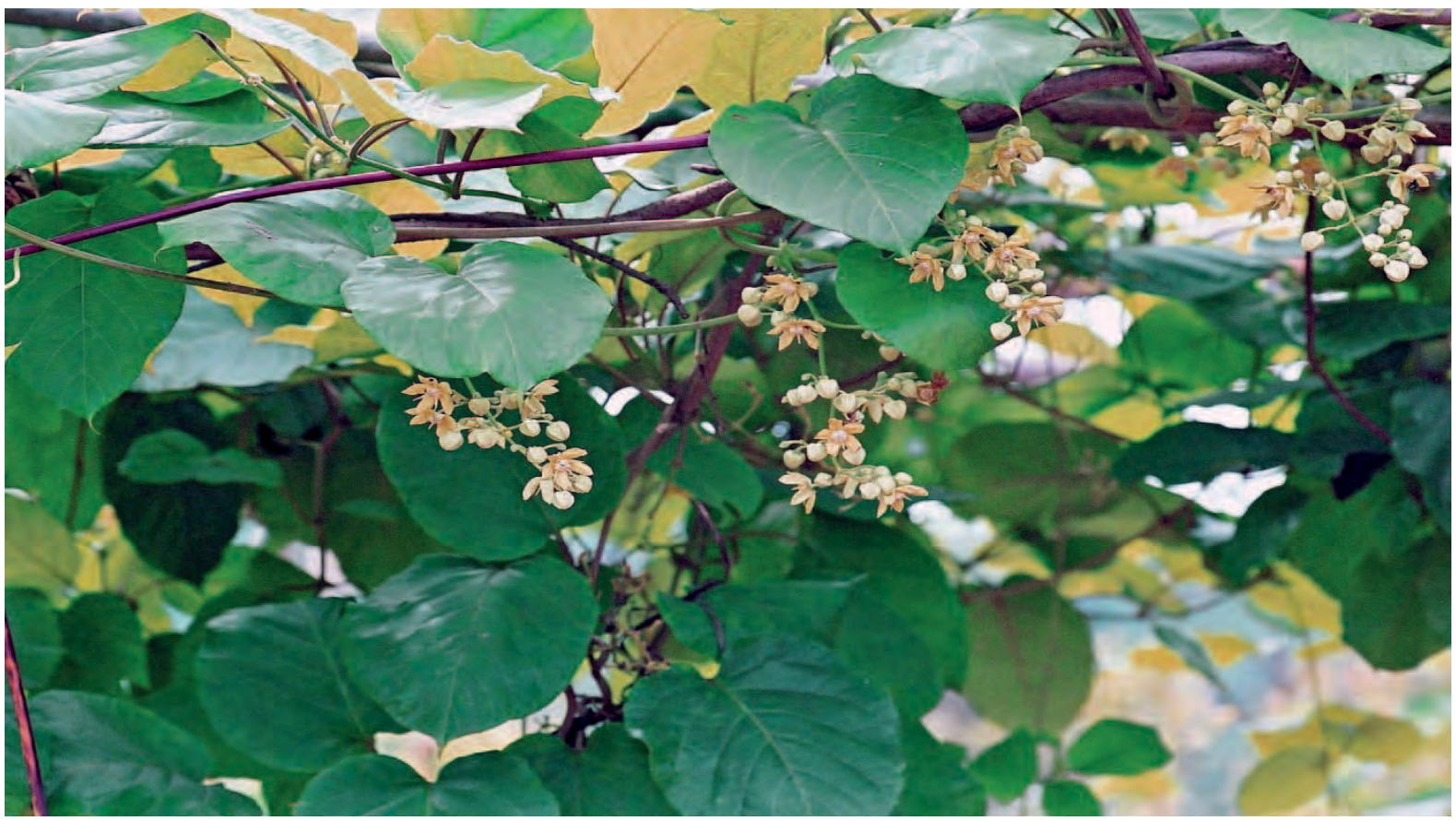

Description : Plante grimpante ou rampante, à tiges minces et poilues de 3 à $6 \mathrm{~m}$ de long. Les racines se développent juste en dessous du sol et peuvent couvrir de grandes surfaces; elles sont jaunes et très odorantes. Les tiges, les racines et les feuilles produisent un latex blanc. Grandes feuilles opposées, en forme de cœur, et couvertes de poils fins.

Ecologie : Liane forestière des zones très arrosés dans toute l'Afrique tropicale. Au Kongo Central, on la cultive occasionnellement en espalier ou pergolas.

Reproduction : Par graines, ou boutures prises sur les racines ou les rejets.

Usages: Les feuilles (nlondo en kikongo) se mangent comme légumes. On les découpe en petits morceaux, qui sont légèrement séchés, puis bouillis ou cuits avec du beurre d'arachide. L'écorce charnue des racines a une odeur de vanille et un arrière-goût sucré ; elle se mange crue, ou parfois séchée, pour rafraichir la bouche, comme aphrodisiaque et comme apéritif. On emploie aussi les racines pour calmer la toux, les maux d'estomac et les hémorroïdes. C'est la deuxième plante médicinale la plus utilisée dans les territoires de Kisantu et Mbanza Ngungu.

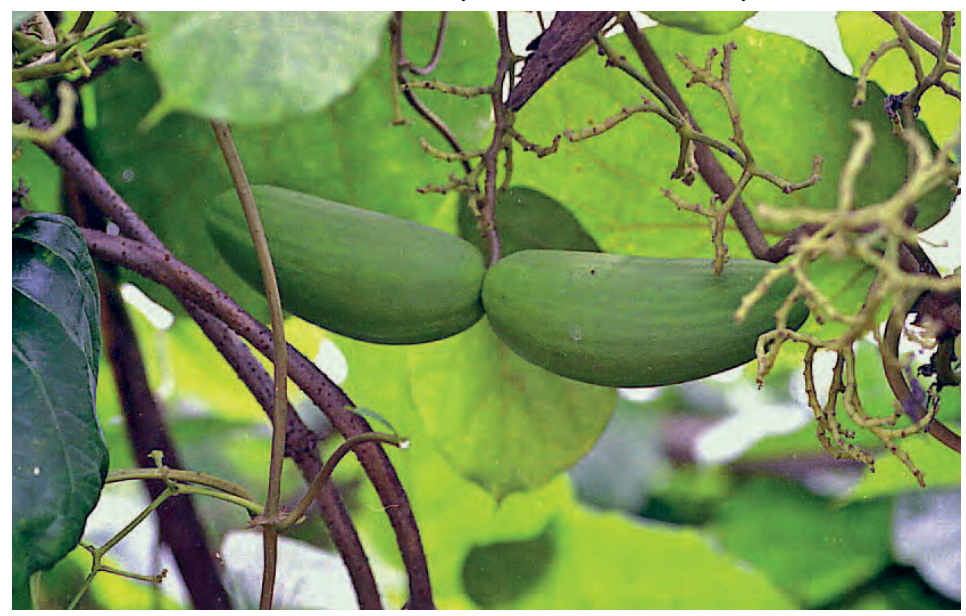
La plante donne des fibres ayant jusqu'à 1,5 $\mathrm{m}$ de long.

Fruits d'une plante grimpant sur une treille

Références: Gillet et Pâque 1910, De Wildeman 1934, Renier 1948, Watt et Breyer-Brandwijk 1962, Nsimundele 1966 68, Daeleman et Pauwels 1983, Mukoko Matondo 1991, Konda Ku Mbuta et al. 1992, Beentje 1994, Maundu 1999, van Wyk et Gericke 2000, Kibungu Kembelo 2003, Nsimundele 2004, Nzuki Bakwaye et al. 2013, Heinze et al. 2019, Kibungu et al. 2021 


\section{Monodora angolensis}

Noms courants : Mpeya (Kikongo), faux muscadier (Fr.)

Description : Arbuste ou arbre pouvant atteindre $20 \mathrm{~m}$ de haut et $40 \mathrm{~cm}$ de diamètre, ramifié dès la base. Les feuilles ont 4,5 à 20 sur 2,8 à $5 \mathrm{~cm}$, avec de courts pétioles de 2 à $8 \mathrm{~mm}$. Les fleurs, parfumées, ont des sépales (long : 5-10 mm), vert maculé de pourpre, des pétales externes vert jaunâtre à oranges, maculés de pourpre, ovales à oblongs (long : 3-6 cm), les internes blancs ou roses https://www.plantes-botanique.org. Les fruits sont ronds ou coniques, de 5,5 à $8 \mathrm{~cm}$ de long, et 5 à $7 \mathrm{~cm}$ de large à la base.

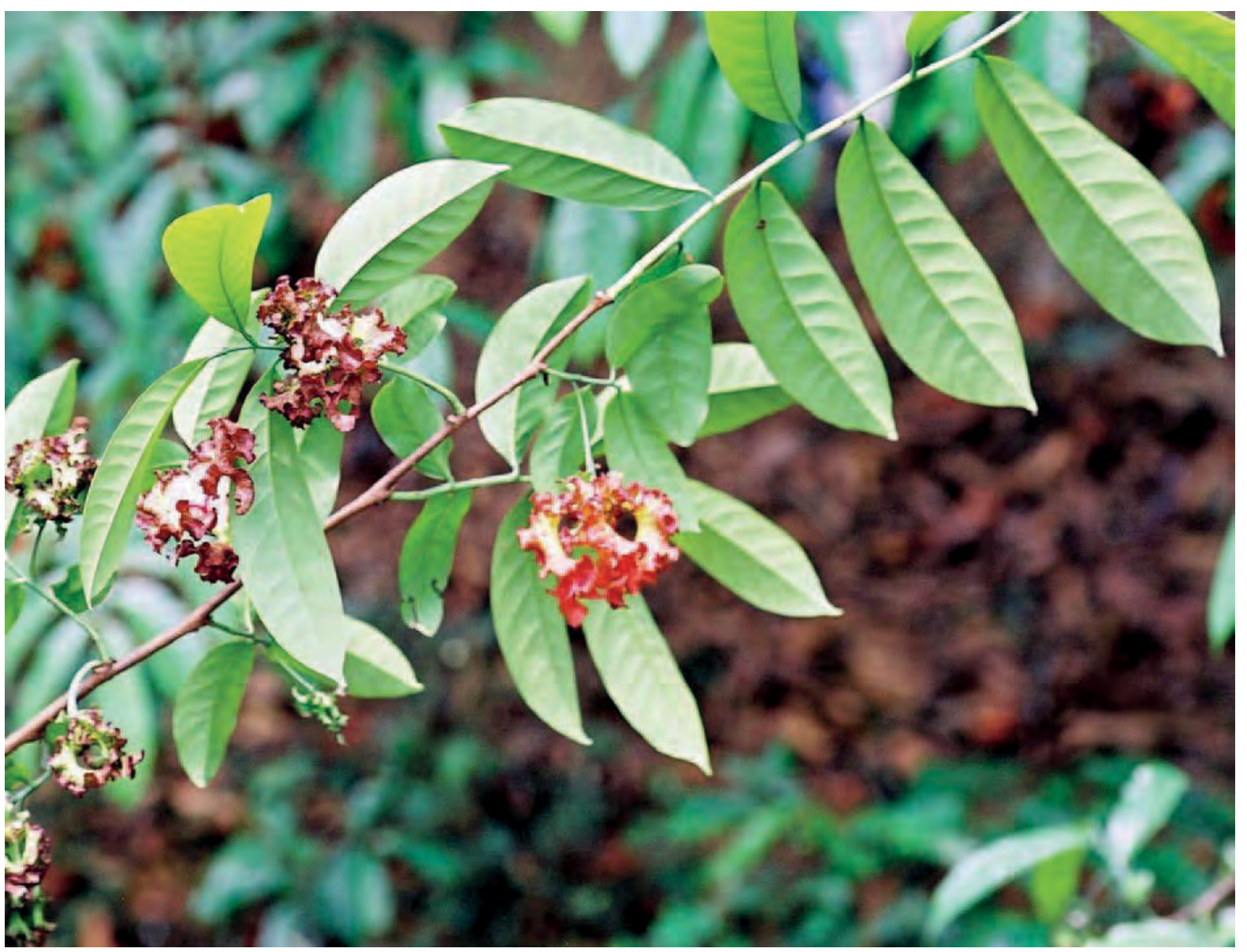

Monodora angolensis en fleurs au jardin botanique de Kisantu

Ecologie : Plante des forêts humides, au Cameroun, en Centrafrique, en Ouganda, Tanzanie, Gabon, R.D. Congo et Congo Brazzaville.

Reproduction : M. myristica se cultive à partir des graines, semées après trempage de 12 heures dans l'eau froide. Les graines ne se conservent pas. On peut aussi transplanter les semis spontanés.

Usages: On emploie les graines aromatiques de cet arbre et de $M$. myristica, dont l'odeur rappelle la noix muscade, pour assaisonner la viande, les soupes et les légumes. Elles s'utilisent aussi comme tonique, stimulant, et pour faciliter la digestion; et encore pour parfumer le linge et le protéger des insectes. Le bois sert en construction, et pour faire des manches d'outils. Au Kongo Central, on traite les hernies en prenant dans un peu d'eau une poudre finement pilée et tamisée, contenant ces graines avec un mélange de feuilles séchées des plantes suivantes : Pentadiplandra brazzeana, Piper nigrum, Securidaca longipedunculata, Xylopia aethiopica, Aframomum melegueta et Croton mubango. On prend les feuilles pour traiter la colique et la constipation. On frictionne les douleurs des jointures et du bas du dos avec un mélange de l'écorce réduite en poudre et de graines d'Aframomum melegueta et Garcinia kola. Les graines pilées peuvent servir de savon.

References Butaye 1909, Gillet et Pâque 1910, Gillet 1927, De Wildeman 1938, Renier 1948, Boutique 1951, Bouquet 1969, Daeleman et Pauwels 1983, Pauwels 1993, Moore 1994, Katende et al. 1995, Kibungu Kembelo 2003, Harris et al. 2011 
Noms courants : Mpeya, bendo bendo, mukasa (Kikongo), fausse noix muscade, muscadier du Gabon, muscadier calebasse (Fr.), African nutmeg (Angl.)

Description : Arbre pouvant atteindre $30 \mathrm{~m}$ de haut et $60 \mathrm{~cm}$ de diamètre, avec des branches horizontales, et une écorce lisse et fine. Feuilles alternes, épaisses, de 7 à 50 sur 2,5 à $14,5 \mathrm{~cm}$, s'élargissant souvent vers l'extrémité. Les fleurs, semblables à des orchidées, sont pendantes et parfumées. Les sépales sont tachetés de

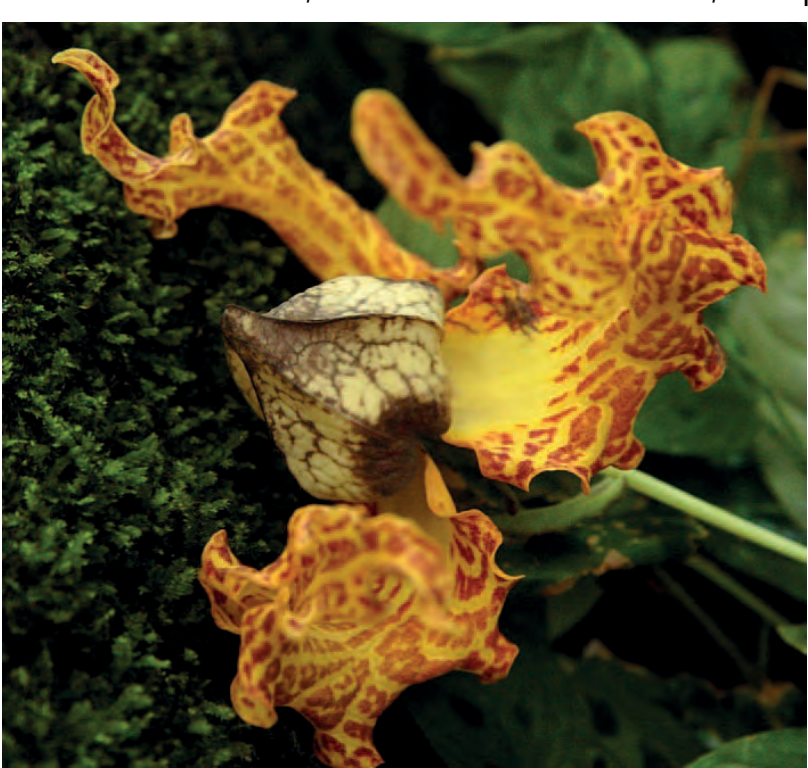

Gestion : Cet arbre reprend bien après avoir été écimé ou coupé. II faut le tailler de temps en temps.

Usages : Au Kongo Central, on pile les graines aromatiques pour les ajouter aux aliments, avec un goût comparable à celui de la noix muscade. Elles servent à traiter la colique et la constipation, les maux de tête et les douleurs; comme stimulant ; et pour éloigner les insectes. Avec l'écorce, on traite les hémorroïdes, les maux d'estomac, la fièvre, les douleurs, les maladies des yeux. En Afrique de l'Ouest, on trouve souvent les graines sur les marchés. L'arbre est parfois cultivé pour ses belles fleurs. Le bois, dur et facile à travailler, convient pour les charpentes et le tournage. On l'emploie pour les cannes traditionnelles, pour le bois de feu et le charbon de bois.

Références: Gillet 1927, Renier 1948, Boutique 1951, Irvine 1961, Nsimundele 1966 - 68, Katende et al. 1995, de Guzman et Siemonsma 1999, Harris et Wortley 2008, Göhre et al. 2016, Heinze et al. 2019
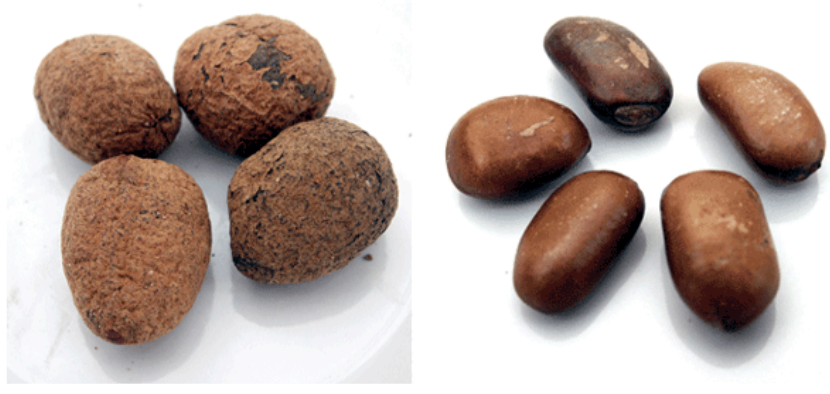

rouge. La corolle est formée de six pétales frisés. Les trois pétales intérieurs sont presque triangulaires et forment un cône jaunâtre marbré de rouge à l'extérieur et vert à l'intérieur. Ces caractéristiques font de Monodora myristica un arbre ornemental exceptionnel. Le fruit est une baie de $15 \mathrm{~cm}$ de diamètre, brune et dure à maturité. II contient de nombreuses graines brillantes, de $2 \mathrm{~cm}$ de long, enfoncées dans une pulpe blanche.

Photo à gauche : Van Swearingen

Ecologie : Arbre originaire d'Afrique occidentale et centrale, parfois cultivé.

Reproduction : Par graines, ou transplantation des semis spontanés. Attendre que le fruit soit mûr et sec pour extraire les graines, les tremper 12 heures avant de les semer en poquets. Les graines perdent rapidement leur viabilité.

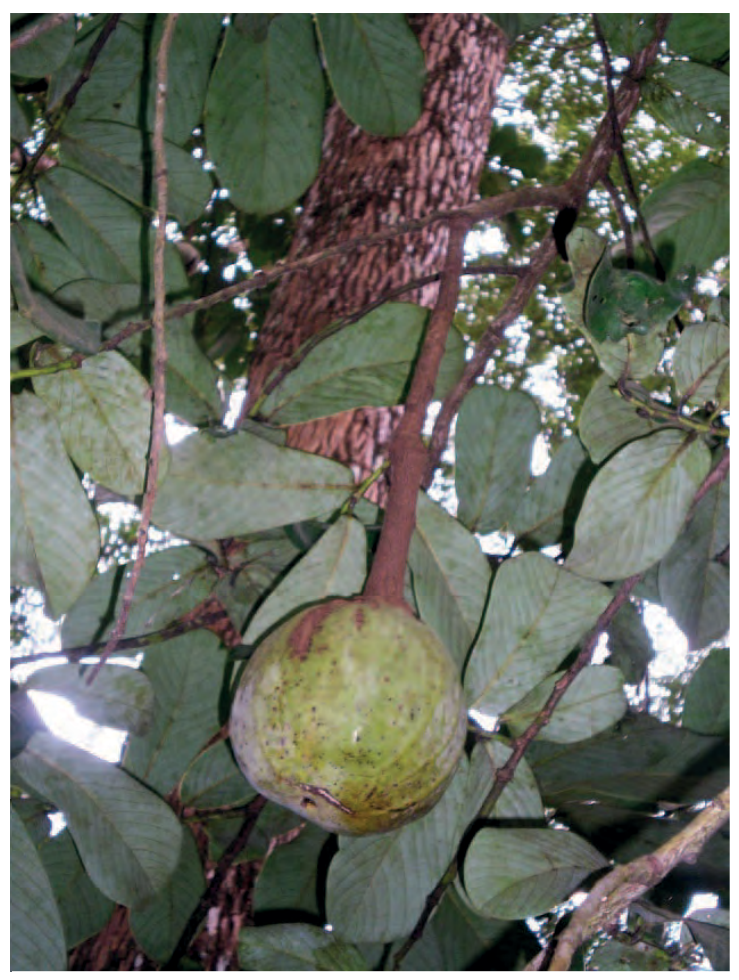


Noms courants : Nsiki (Kikongo), brimstone tree (Angl.)

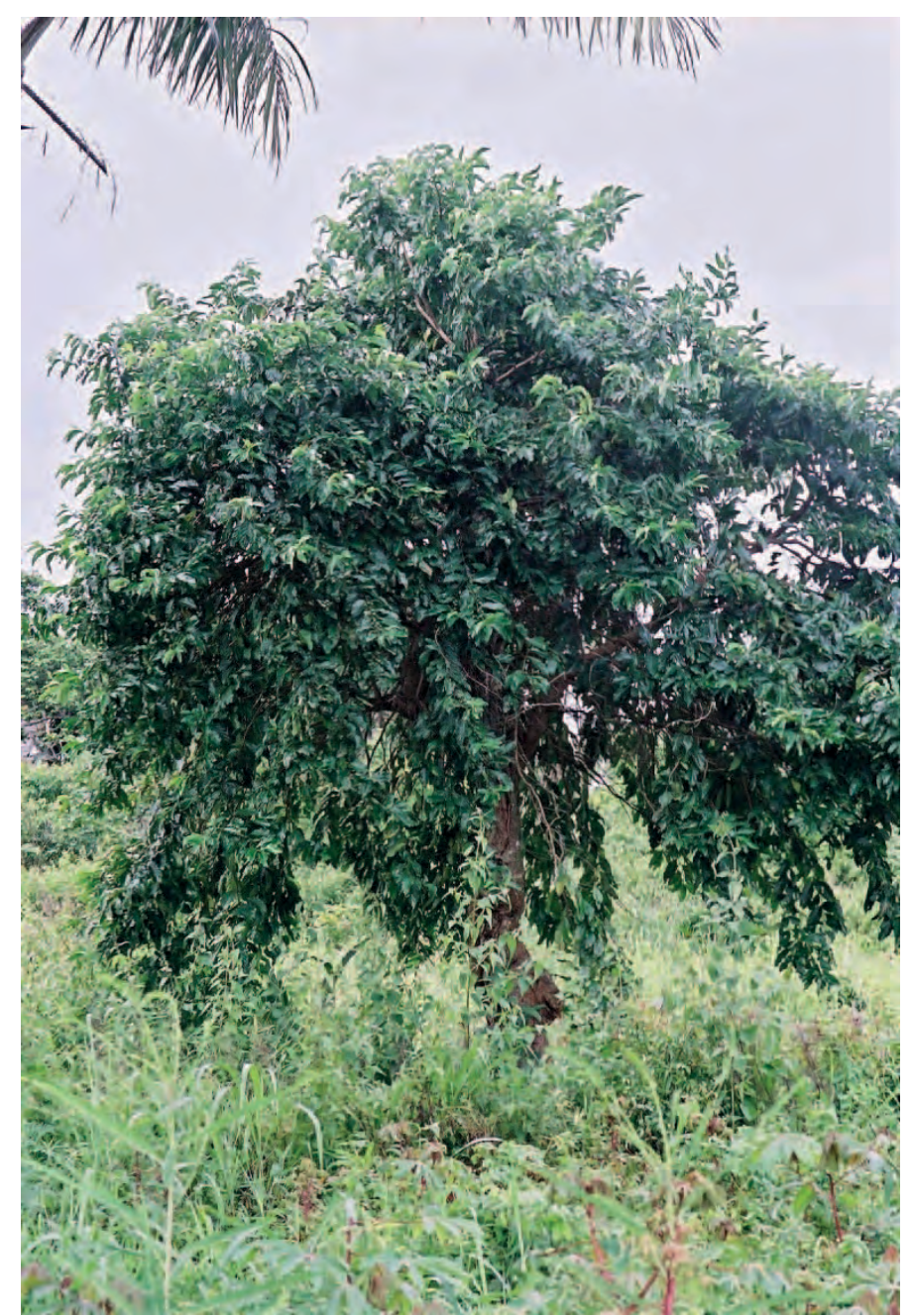

Description : Arbre de 15 à $20 \mathrm{~m}$ de haut, avec un tronc généralement tortueux, et portant une couronne dense de branches légères mais tortueuses. L'écorce grise s'écaille. Les feuilles, opposées, ont de 7 à $15 \mathrm{~cm}$ de long. Les fleurs sont parfumées, blanches ou jaune verdâtre. Les fruits sont des drupes, qui se soudent en syncarpes globulaires succulents de 1 à $2,5 \mathrm{~cm}$ de diamètre. Ils restent longtemps verts sur l'arbre puis parfois noircissent.

Jeune arbre près du village de Kintenda

Ecologie: On trouve souvent cet arbre dans les recrus forestiers, et parfois dans les zones inondables, où il peut être abondant, du Sénégal à l'Ouganda et à l'Angola.

Reproduction : Par graines ou boutures.

Usages : Au Kongo Central, on prend une décoction des feuilles pour traiter les coliques, le diabète, les rhumatismes, et les vers intestinaux. Pour le traitement de la variole, on prend un bain dans de l'eau qui a bouilli avec les feuilles pilées; on fait aussi ce bain avec une décoction de l'écorce des racines. Pour traiter les hémorroïdes, on les lave avec de l'eau où I'on a trempé de la poudre d'écorce pilée. Cet arbre a aussi de nombreux usages médicinaux en Afrique de I'Ouest. Ailleurs au Congo, ainsi qu'en Afrique de l'Ouest, on tire de l'arbre des teintures vertes, jaunes et rouges, et on le

plante parfois pour cet usage. Le bois est jaune et dur; on l'emploie en construction, pour les poutres et pour les planchers; mais il faut bien le traiter. On l'emploie aussi comme bois de feu. Les racines servent de bâtons à mâcher.

\section{Remarque :}

proverbe kikongo "Nkunku n'siki vwaangi": d'abord on protège la brousse, puis le n'siki apparait, et enfin se crée la forêt.

Références : Gillet et Pâque 1910, Gillet 1927, Delaude et al 1971, Keay 1989, Mukoko Matondo 1991, Pauwels 1993, Burkill 1997, Kibungu Kembelo 2003, Pousset 2004, Zimudzi et Cardon 2005, Lautenschläger et al. 2018

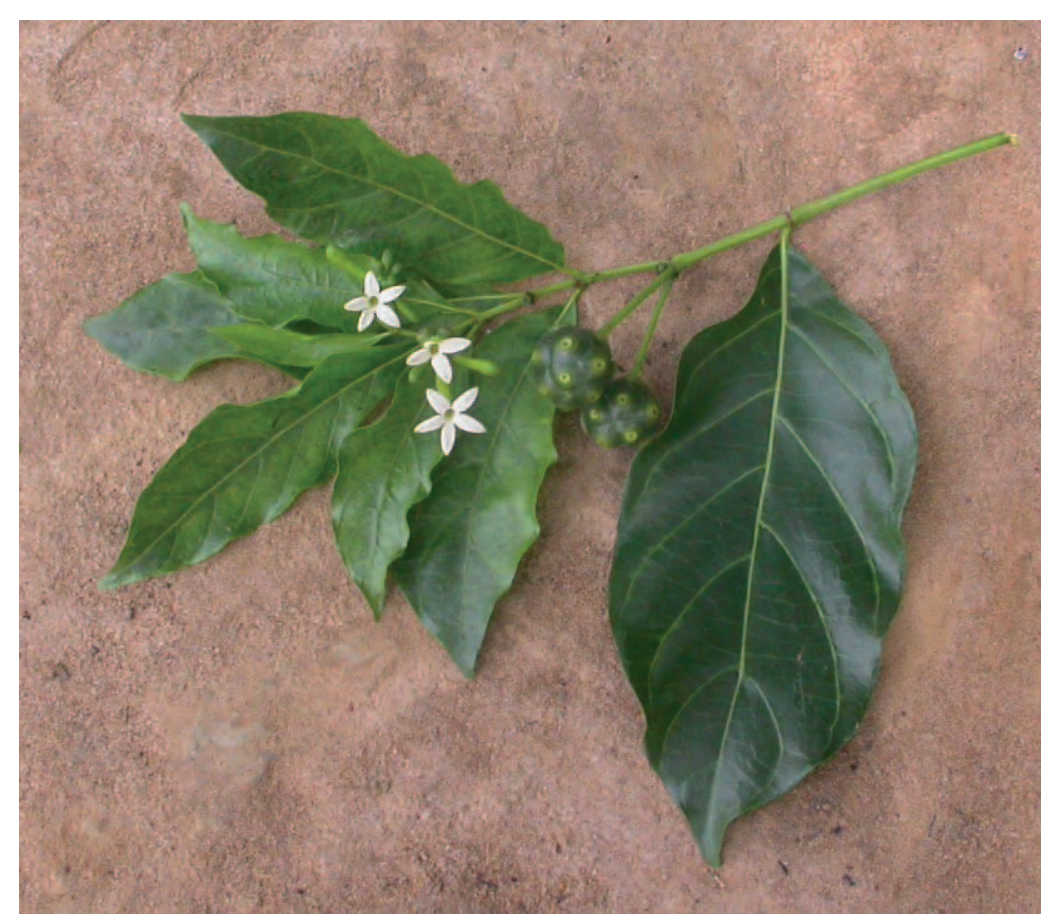


Morinda morindoides

(Rubiaceae)

Noms courants : Kimeso nkama (Kikongo : "la plante aux cent yeux"), kongo bololo (Lingala).

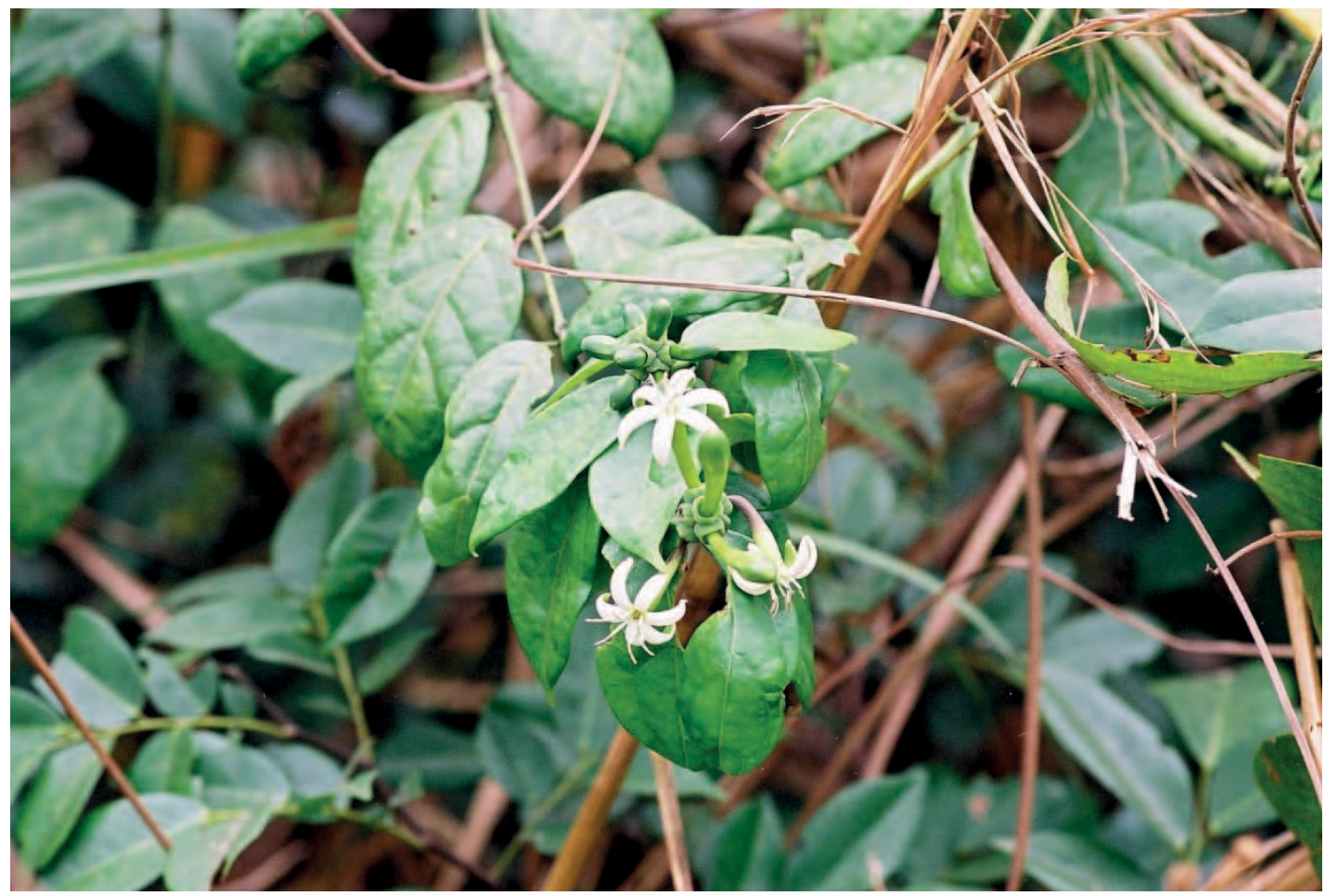

Description : Buisson touffu d'environ 1,5 m de haut en terrain découvert, ou liane grimpant à $10 \mathrm{~m}$ de haut en forêt, donnant de belles fleurs blanches parfumées. Les fruits sont très caractéristiques. Ce sont des drupes dont les bases se soudent par groupes de 9 à 12, pour former une boule d'environ $2 \mathrm{~cm}$ de diamètre dont émergent des tubes creux en direction radiale, l'ensemble ayant 2,6 à 3,6 cm dans sa plus grande dimension ; le nom kikongo de la plante (aux cent yeux) donne une belle image pétique de ces fruits.

Ecologie: Plante de la grande forêt, des forêts sèches décidues, et des savanes côtières, du Sénégal au Cameroun, au bassin du Congo et au Soudan.

Reproduction: par graines ou boutures.

Usages: Plante populaire en médecine traditionnelle, que l'on trouve facilement sur les marchés urbains. Au Kongo Central, on fait bouillir les feuilles dans l'eau, et on boit le liquide pour traiter la malaria, la diarrhée, le diabète, les maux d'estomac. Pour éliminer les vers intestinaux, on peut donner ce liquide à boire, ou l'appliquer par voie rectale. L'écorce et les racines servent à traiter les douleurs articulaires, le diabète, les éruptions cutanées, les blessures, et les hémorroïdes. Les études disponibles indiquent que les feuilles et les racines contiennent plusieurs substances semblables à la quinine.

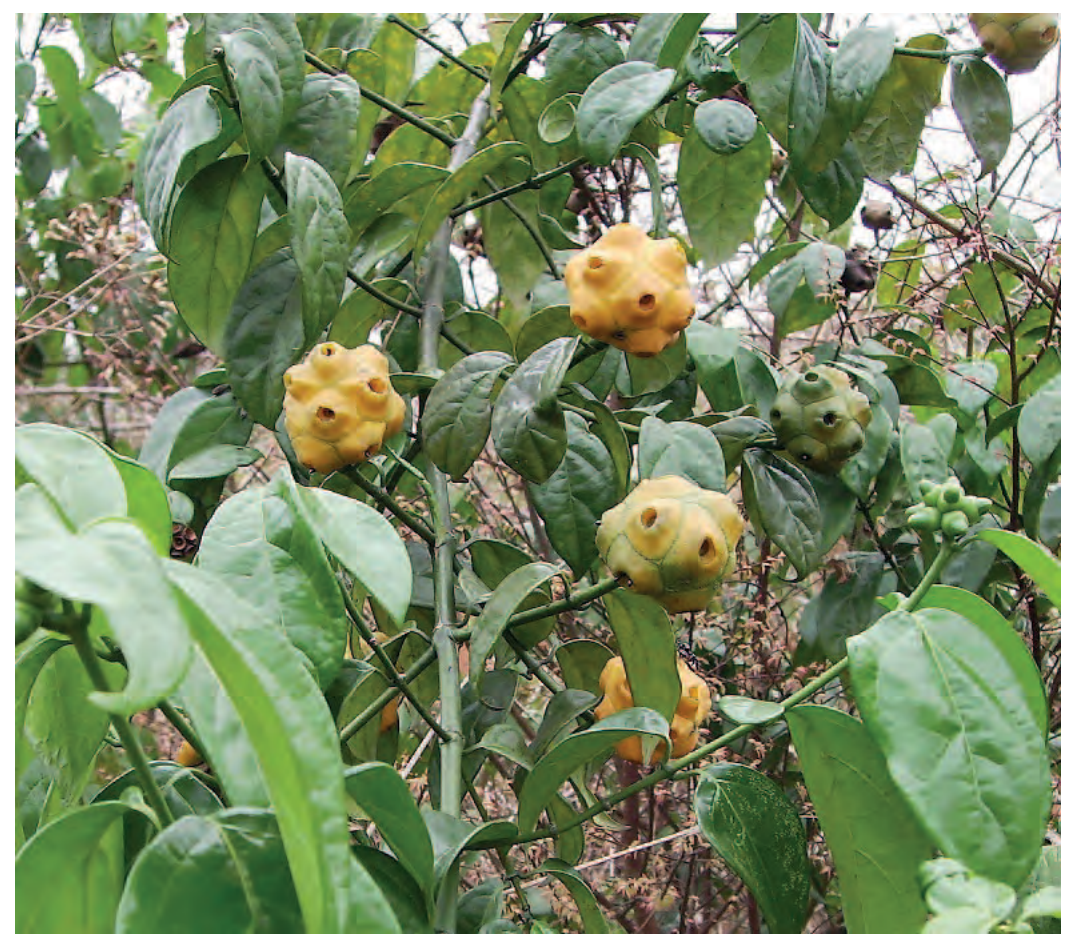


Références : Nsimundele 1966 - 68, Delaude et al. 1971, Daeleman et Pauwels 1983, Mukoko Matondo 1991, Burkill 1997, Kibungu Kembelo 2003, Makumbelo et al. 2008, Lautenschläger et al. 2018

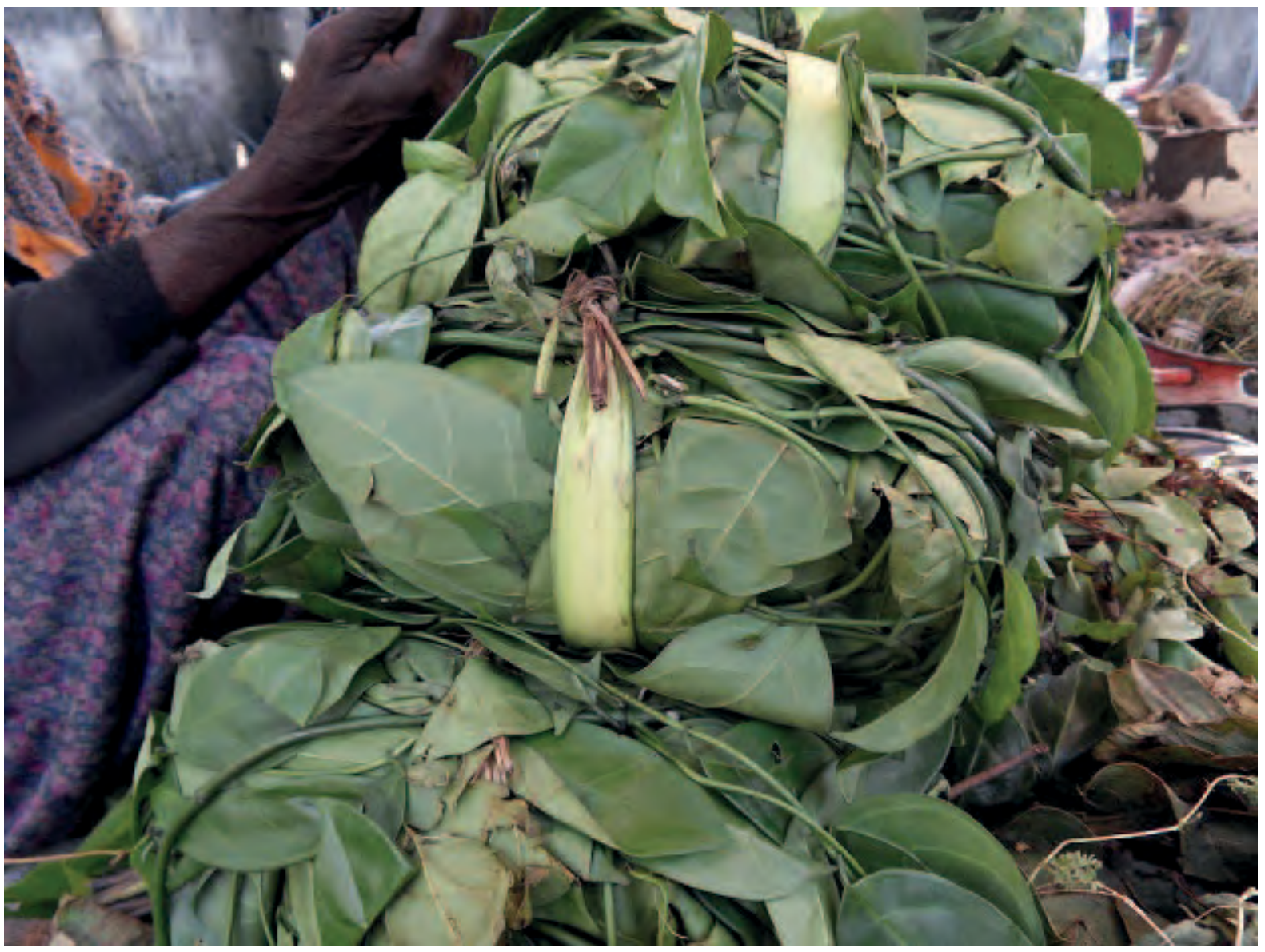

Paquets de feuilles de Morinda morindoides en vente au marché de Bumbu (Kinshasa)

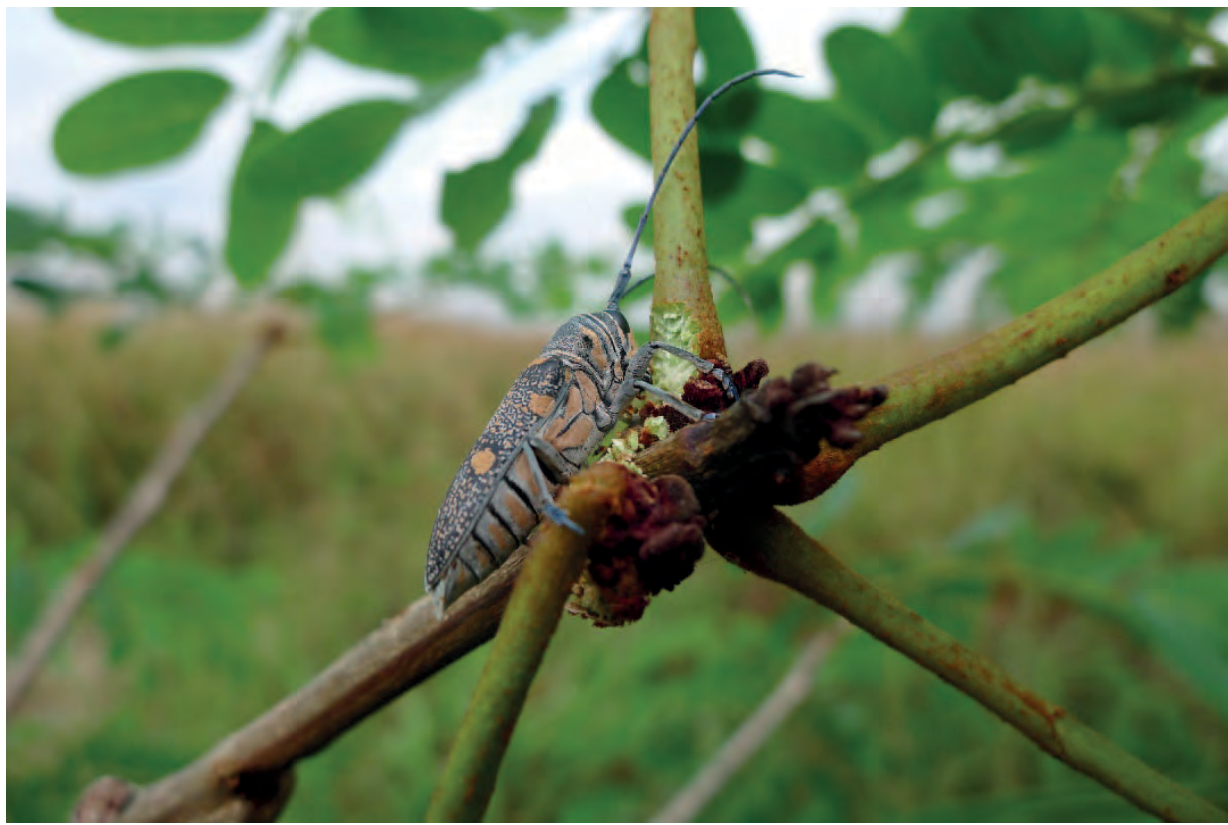

L'insecte Nsingi nsingi, un ravageur majeur de Burkea africana. 
Noms courants: Mouroungue, ben ailé, moringa ailé, pois quénique, néverdié (Fr.), horseradish tree (Angl.)

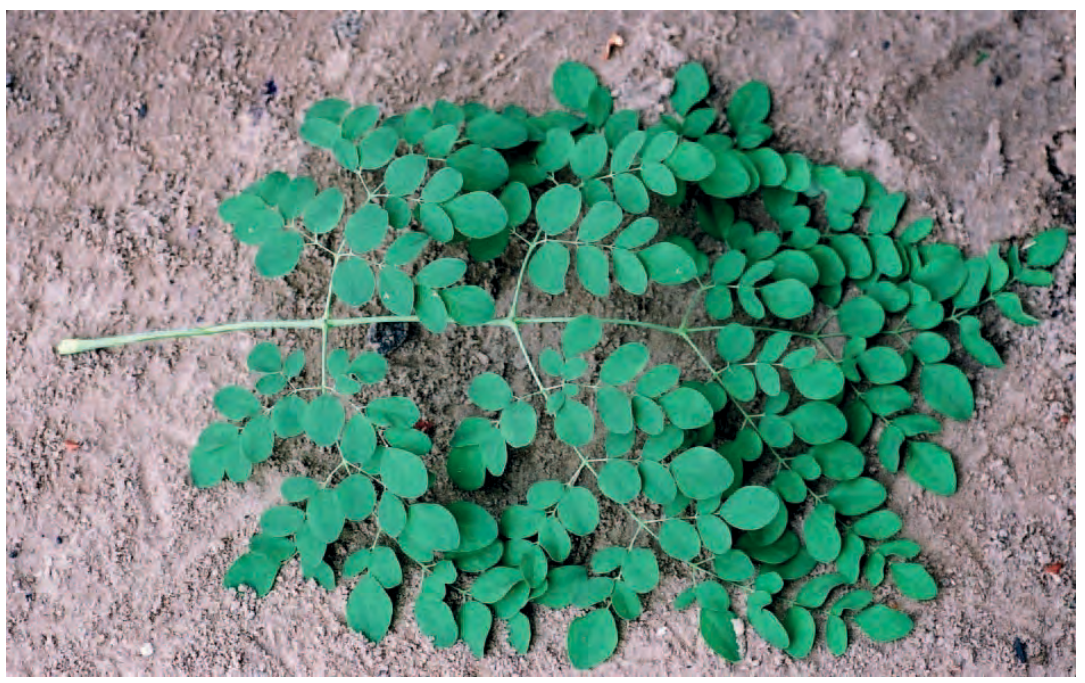

Description : Petit arbre à croissance rapide, souvent fourchu près de la base, pouvant avoir $8 \mathrm{~m}$ de haut, avec un feuillage clairsemé, qui porte toute l'année des fleurs à l'odeur sucrée. Feuilles alternes bi- ou tri-pennées, de 6,5 à $60 \mathrm{~cm}$ de long, munies de 4 à 6 paires de pennes; foliolules elliptiques à obovales, de 0,5 à 3 $\mathrm{cm}$ sur 0,3 à $2 \mathrm{~cm}$. L'inflorescence est une panicule étalée de 8 à $30 \mathrm{~cm}$ de long, portant un grand nombre de fleurs. Fleurs bisexuées, zygomorphes, à pétales libres, oblongs-spatulés, de 1 à $2 \mathrm{~cm}$ de long, inégaux, le plus grand dressé, blancs ou crème. Le fruit est une capsule allongée à 3 valves, à section transversale en étoile, de 10 à 50 $\mathrm{cm}$ de long, brune à maturité, et contenant de nombreuses graines. Les graines rondes, de 1 à $1,5 \mathrm{~cm}$ de diamètre, sont pourvues de 3 ailes minces de 0,5 à $2,5 \mathrm{~cm}$ de long.

Ecologie: Originaire de l'Inde du Nord, cet arbre est maintenant largement cultivé partout sous les tropiques; il est peu commun au Kongo Central. Il pousse bien sur des sols sablonneux bien drainés, pauvres, et supporte de longues périodes de sécheresse.

Reproduction: Les graines germent aisément et poussent rapidement. Les boutures poussent bien, surtout si elles sont de grande taille, même dans les sols pauvres. On emploie normalement des boutures lorsqu'on veut établir des haies.

Gestion : Cet arbre peut se cultiver en haies. II recèpe bien, et il vaut mieux le rabattre périodiquement pour accroitre la production de feuilles.

Usages : Les feuilles sont comestibles, crues ou cuites, et servent dans les soupes et les sauces. Cent grammes de jeunes feuilles contiennent 9,4 $\mathrm{g}$ de protéines, et sont riches en calcium, fer, phosphore, vitamines $A$ et $C$. Les feuilles sont donc très utiles pour combattre la malnutrition. On peut aussi sécher les feuilles, 3 jours à l'ombre, après quoi on les réduit en poudre pour les conserver. Les fruits verts coupés en morceaux peuvent se consommer comme légumes. On peut frire les graines ou les manger crues. Les fleurs et

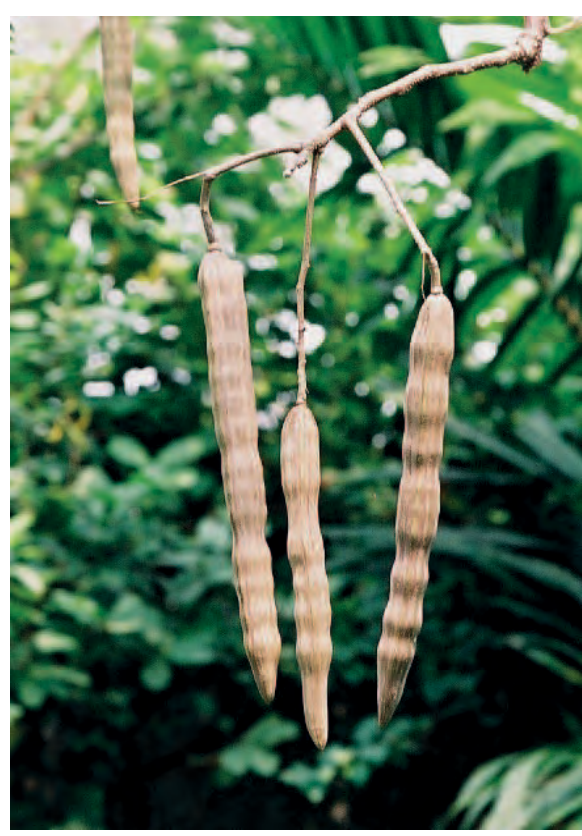

les graines rôties sont aussi hautement nutritives, et se mangent dans de nombreux pays. On tire des graines une huile utilisable en cuisine, pour lubrifier les machines à coudre, pour l'éclairage, ou en savonnerie. Le tourteau peut servir d'engrais ou de supplément alimentaire pour les volailles. On peut utiliser les graines, entières ou pilées, ou le tourteau, pour purifier l'eau. On a montré que cette plante contient plusieurs substances antibiotiques; la poudre des graines entre dans la composition d'une pommade utilisée pour traiter les infections bactériennes courantes de la peau. On indique que les feuilles soigneraient la diarrhée, l'anémie et les ulcères. On donne une infusion de feuilles contre le diabète. L'huile de graines sert à traiter la goutte, les maux d'estomac, et les rhumatismes. La racine râpée donne un condiment comparable au raifort. Les abeilles récoltent le nectar des fleurs.

Références : Greenway 1944, Robyns 1951, Busson 1965, Crane et al. 1984, Keay 1989, Beentje 1994, Folkard et Sutherland 1994, Burkill 1997, Hirt et M'pia 2001, Bosch 2004, Pousset 2004 
Noms courants : Moringa éthiopien (Fr.), African moringa tree (Angl.)

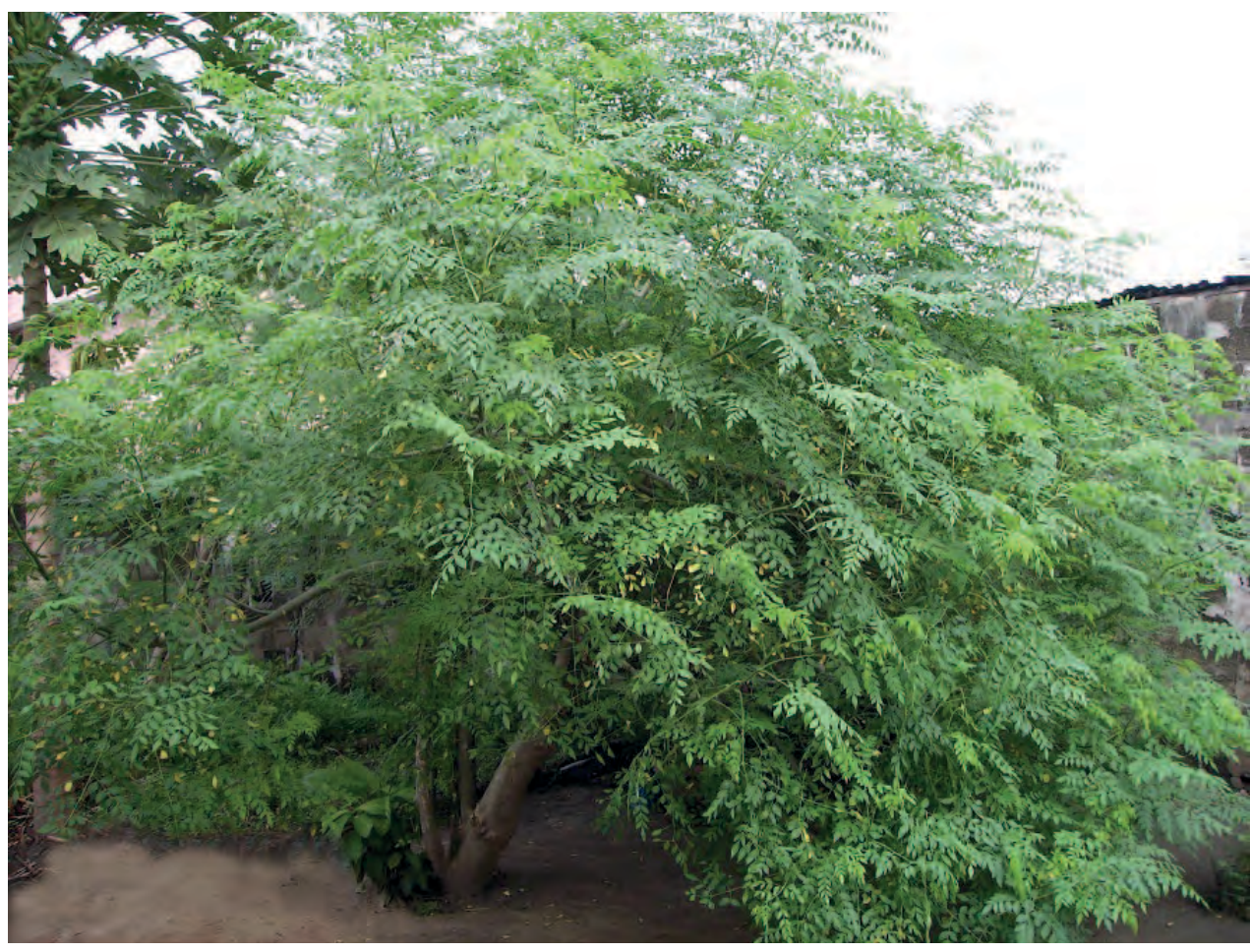

Description : Petit arbre pouvant avoir $10 \mathrm{~m}$ de haut. Le tronc, souvent fourchu, accumule l'eau et peut avoir 1 $\mathrm{m}$ de diamètre. Les feuilles, bi- ou tripennées, peuvent avoir $50 \mathrm{~cm}$ de long; les foliolules, elliptiques ou ovales, ont 3,5 à 6 sur 2 à $3,5 \mathrm{~cm}$.

Moringa stenopetala à Bumbu (Kinshasa)

L'inflorescence est une panicule portant de nombreuses fleurs parfumées, et pouvant avoir $60 \mathrm{~cm}$ de long. Les fleurs blanches ont de pétales de 8 à 10 $\mathrm{mm}$ de long. Le fruit est une capsule rougeâtre à trois valves, de 20 à $50 \mathrm{~cm}$ de long, contenant de nombreuses graines.

Ecologie : Arbre originaire d'Afrique orientale, très cultivé en Ethiopie. Récemment, on a introduit cet arbre dans de nombreux pays tropicaux, et notamment en RD Congo par ANAMED. II préfère les sols bien drainés avec une nappe phréatique peu profonde, mais supporte bien des conditions plus sèches.

Reproduction: Semer les graines à $1 \mathrm{~cm}$ de profondeur dans des poquets en polyéthylène. Le taux de germination est bon jusqu'à un an après la récolte des graines. Transplanter à $20 \mathrm{~cm}$ de hauteur. On peut faire des boutures, mais les plantes ont souvent un système racinaire trop faible.

Gestion : On peut tailler l'arbre tous les cinq ans pendant la saison des pluies.

Usages: Les feuilles, les graines, les fleurs et les jeunes pousses sont comestibles, et largement consommées au Sud de l'Ethiopie. Les feuilles sont très riches en protéines, et riches en vitamines $C$ et $A$, en calcium, fer et phosphore. En Afrique orientale, elles ont des usages médicinaux, et servent d'aliment du bétail. Les graines donnent une huile aromatique comestible, utilisable pour la cuisine et pour les salades. Les graines entières ou en poudre servent pour la purification de l'eau. Les fleurs sont couramment visitées par les abeilles.

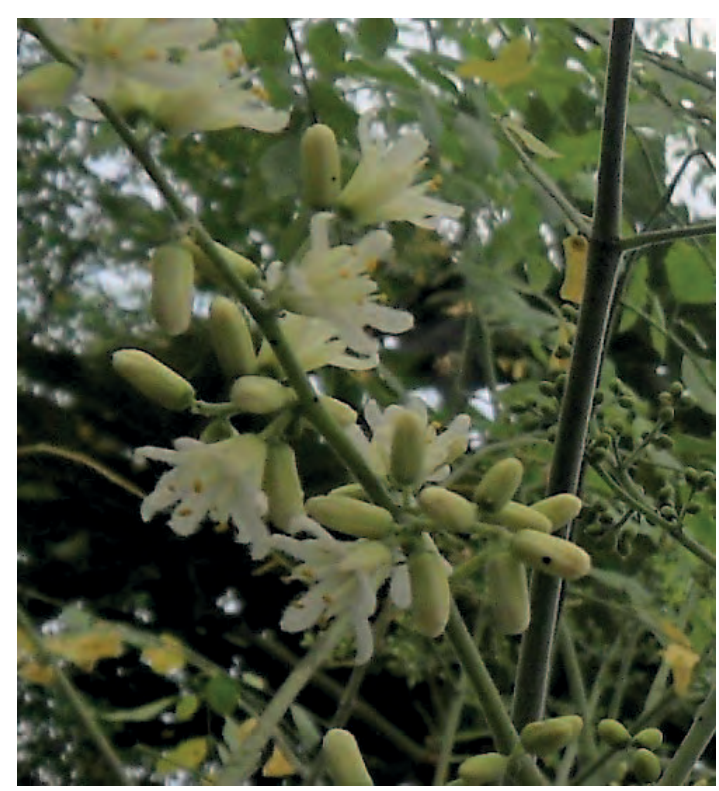

Références : Maundu 1999, Bosch 2004 
Noms courants: Dinkundi, mokende, makondia (Kikongo), pois pouilleux, pois mascate, poil à gratter ( $F r$.), velvet bean (Angl.)

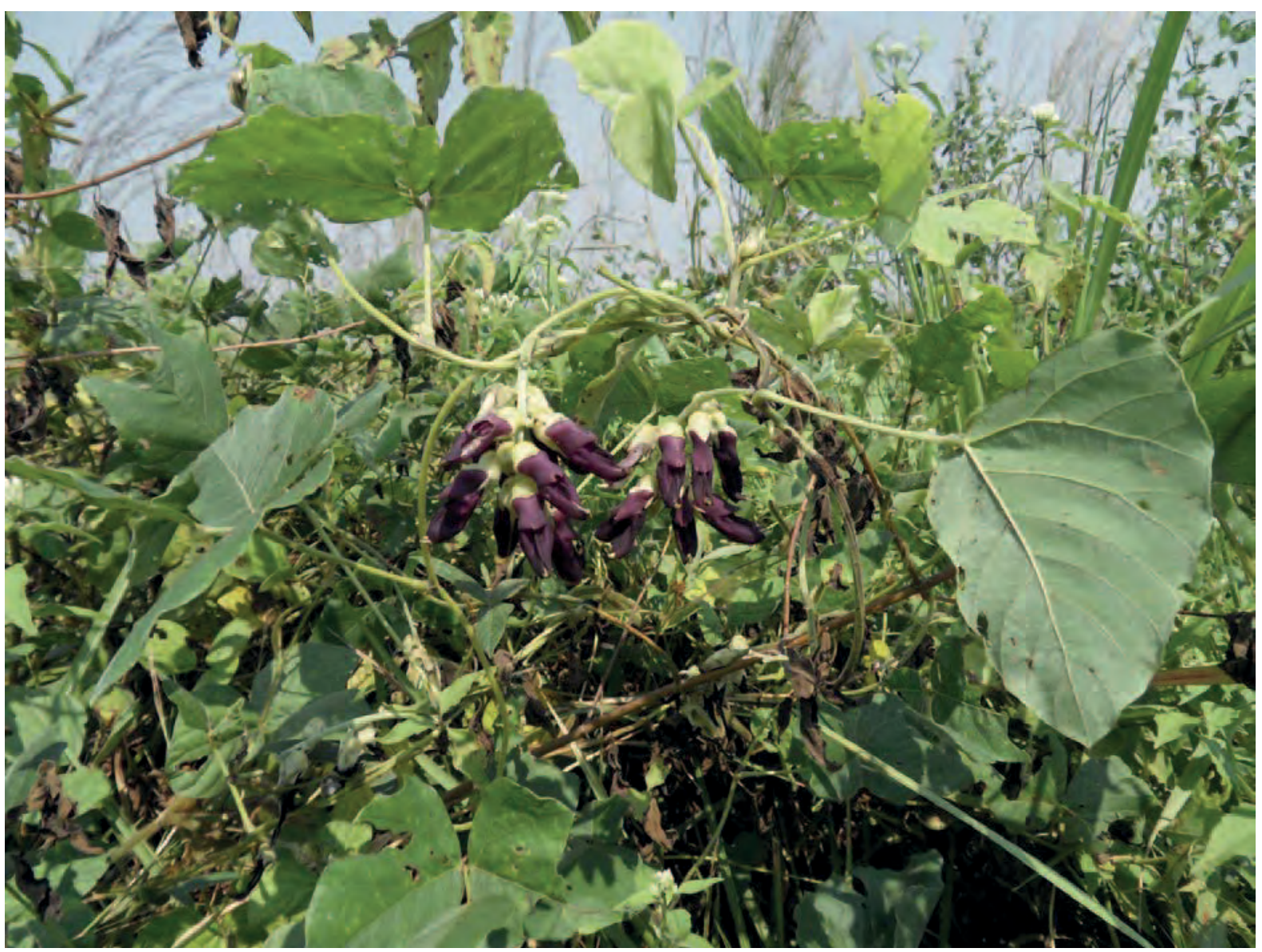

Description : Liane annuelle poilue, à feuilles composes. La tige peut avoir $10 \mathrm{~m}$ de long, et la plante forme une couverture épaisse du sol, dont la canopée peut atteindre $1 \mathrm{~m}$ au-dessus du sol. Les folioles sont asymétriques, et longues de 5 à $13 \mathrm{~cm}$. Les fleurs sont pourpres, en racèmes tombants contenant beaucoup de fleurs, longues chacune de de 3,5 à $4 \mathrm{~cm}$. Les gousses densément poilues ont de 4 à $7 \mathrm{~cm}$; leurs poils bruns se détachent facilement et sont très irritants pour la peau. Les graines sont brunes mouchetées de noir. La plante perd avant maturité beaucoup de feuilles, qui se décomposent progressivement pour former une couche de litière sous la plante en croissance. La production de gousses est variable, mais peut aisément dépasser $2 \mathrm{t} / \mathrm{ha}$, notamment si les lianes ont la possibilité de grimper aux arbres. Le mucuna fixe l'azote atmosphérique que les rhizobiums des racines convertissent en azote organique présent dans les feuilles, les tiges et les graines. Au Congo, la plante a montré une bonne nodulation, avec un fort pourcentage de nodules actifs.

Ecologie : On rencontre parfois cette plante dans les forêts secondaires. Elle est tolérante à la sécheresse et aux sols peu fertiles ou acides. Elle prospère dans des conditions chaudes, humides, et très arrosées.

Reproduction : Par graines ou boutures.

Gestion : La plante meurt après avoir donné des graines, environ 45 à 60 jours après la floraison.

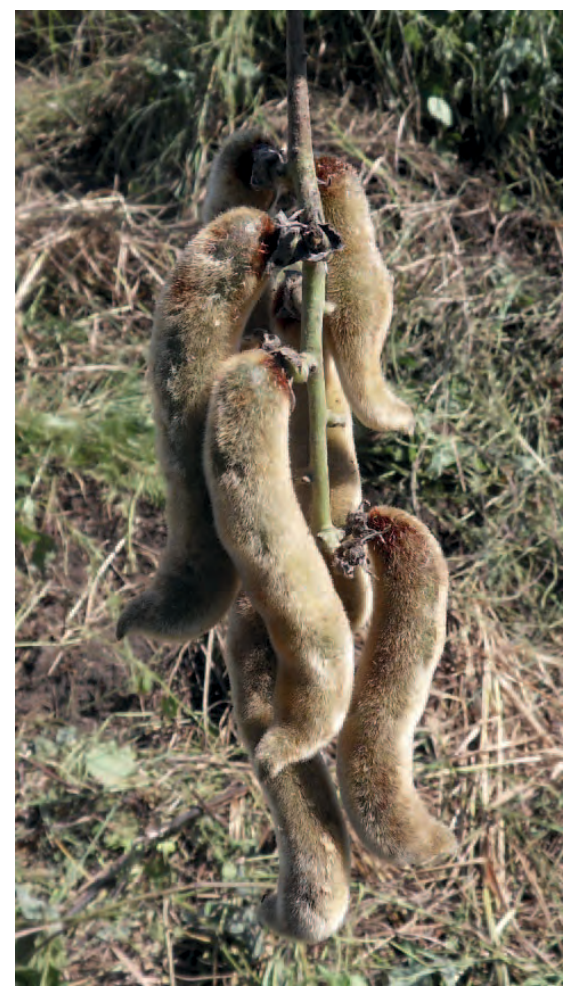


Usages : Les graines bouillies se mangent au Kongo Central, mais il faut jeter l'eau de cuisson. On peut également manger les gousses vertes bouillies. On peut aussi griller et piler les graines pour en faire une sorte de café. On prend une infusion des feuilles pour traiter la colique. Ailleurs, on cultive souvent la plante pendant les jachères pour étouffer les adventices. On la cultive aussi pour le fourrage. Elle est bien connue pour sa capacité à contrôler les nématodes quand on la cultive en rotation avec diverses cultures commerciales. On indique qu'on peut frotter sur la peau l'huile des graines pour réduire l'irritation causée par les poils. Les graines moulues permettent de traiter la maladie de Parkinson.

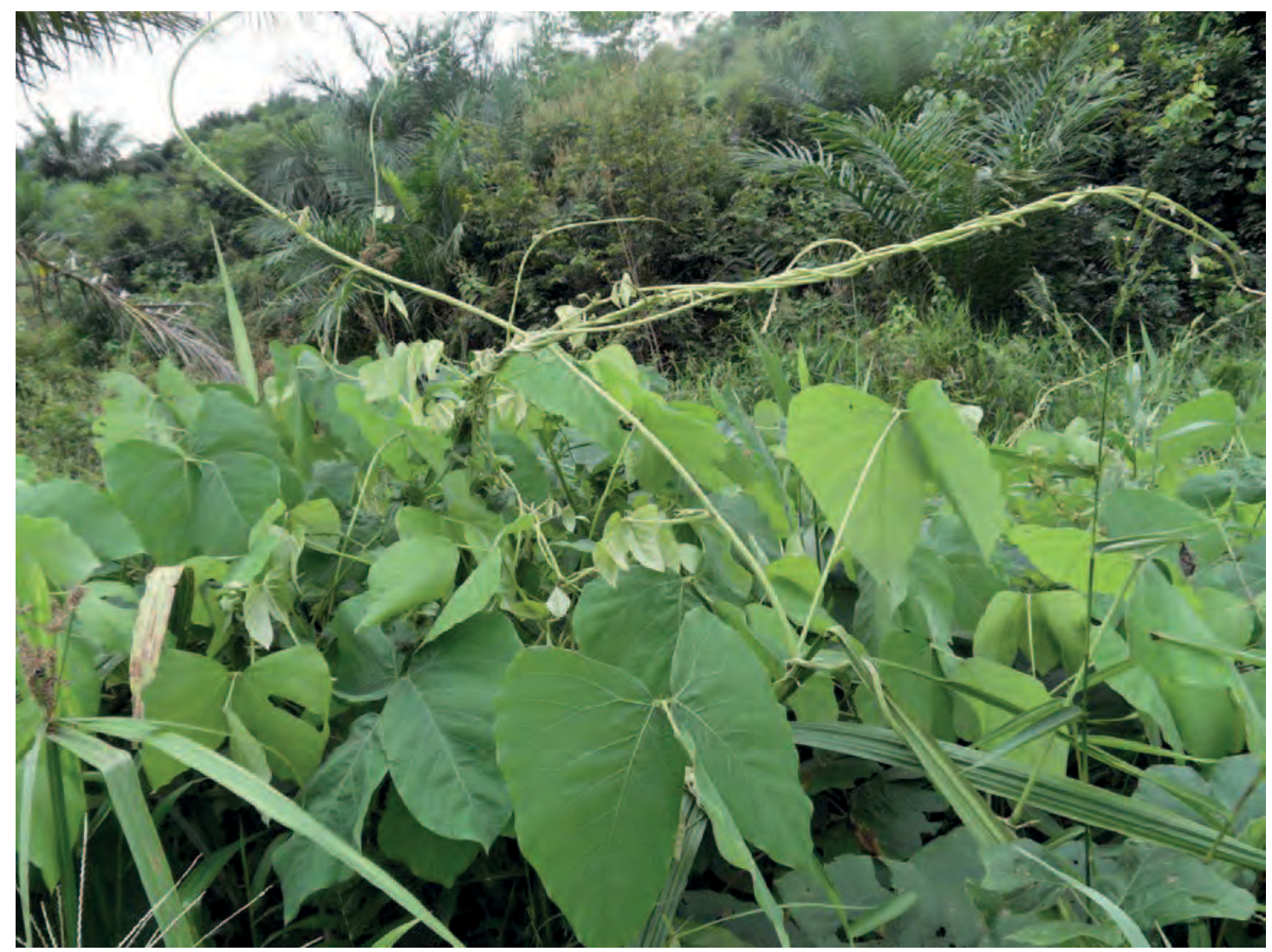

La mucuna est cultivé pour éviter la croissance d'Imperata cylindrica et comme engrais vert pour le maïs, le manioc et le sorgho. On emploie des outils à traction animale pour abattre et découper l'engrais vert qu'on laisse au sol. Avec un autre outil à traction animale, on dégage un sillon étroit dans le paillage pour y semer la prochaine culture. Ainsi, il n'est pas nécessaire de labourer. Au Bénin, la culture du mucuna s'est rapidement répandue ces dernières années : les sols des plateaux du Sud du Bénin et du Togo sont proches de l'épuisement, et des chercheurs ont introduit la culture du mucuna comme plante de couverture, pour pallier la carence d'éléments nutritifs pour la culture de base, le maïs; plus de 14.000 paysans cultivent maintenant le mucuna au Bénin. Les paysans qui l'ont adopté bénéficient de meilleurs rendements, avec moins de travaux de désherbage : le maïs après mucuna donne 3 à 4 tonnes/hectare sans application d'engrais azoté, rendement équivalent à celui que l'on obtient avec la dose recommandée d'engrais azoté, soit $130 \mathrm{~kg}$ d'azote à I'hectare ; tandis que les rendements antérieurs sur des champs de maïs associé au niébé étaient de 1,3 t/ha. Le mucuna fournit plus de $100 \mathrm{~kg}$ d'azote à l'hectare à la culture de maïs qui le suit.

Références : Gillet et Pâque 1910, Gillet 1927, Hauman et al. 1954, Nsimundele 1966 - 68, Skerman 1977, Duke 1981, Daeleman et Pauwels 1983, Drachoussoff 1993, Burkill 1995, Pousset 2004

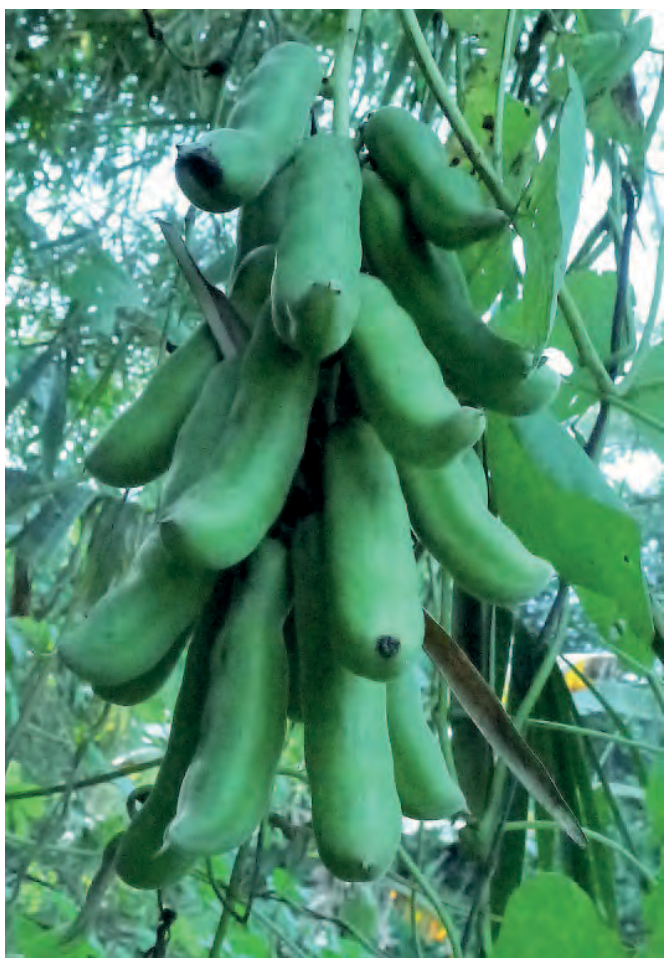


Description : Plante herbacée pérenne, dressée ou rampante, pouvant avoir 1,3 $\mathrm{m}$ de haut, ayant parfois une

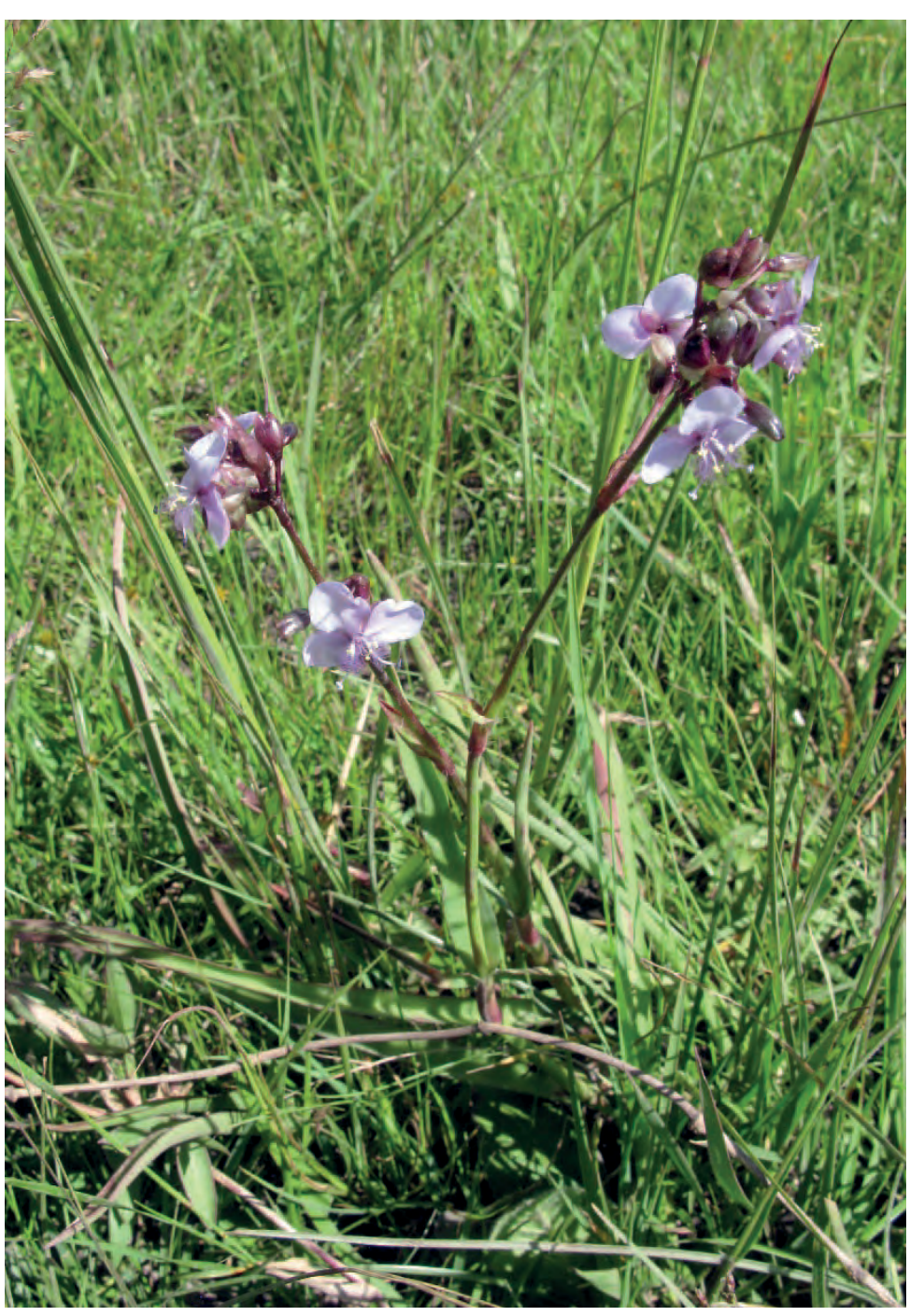
racine tubéreuse. Les feuilles linéaires, de $20 \mathrm{~cm}$ sur $1 \mathrm{~cm}$, sont cannelées, et engainent la tige à leur base. Les fleurs bleues sont disposées en racèmes terminaux. Chaque fleur a 3 pétales arrondis, de couleur mauve pâle à bleue. Toutes les fleurs regardent la même direction. Les boutons de fleur sécrètent un liquide gluant.

Ecologie : Plante largement répandue en Afrique tropicale, à Madagascar et en Asie, souvent dans des lieux humides, et parfois au bord des routes.

Usages : Les tubercules seraient comestibles selon certains ; pour d'autre, ils seraient toxiques et utilisés comme fétiches. Au Ghana, on cultive cette plante comme plante ornementale; au Kenya, elle est broutée par tous les animaux domestiques; en Tanzanie, elle a des usages médicinaux.

References De Wildeman 1934, Renier 1948, Williams 1949, Burkill 1985, Blundell 1987, Baumann 2005, African Plant Database (3.4.0) (Consulté le 22.5.2015), Wikipedia (Consulté le 22.5.2015)

Les deux photos : Robert von Blittersdorf www.africanplants. senckenberg.de

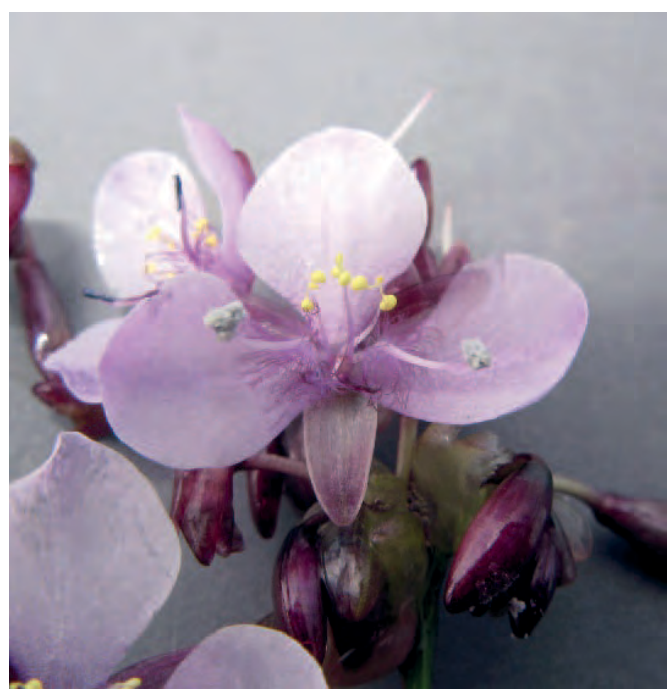


Noms courants : Bananier d'ornement, bananier à fleurs roses (Fr.), flowering banana (Angl.)

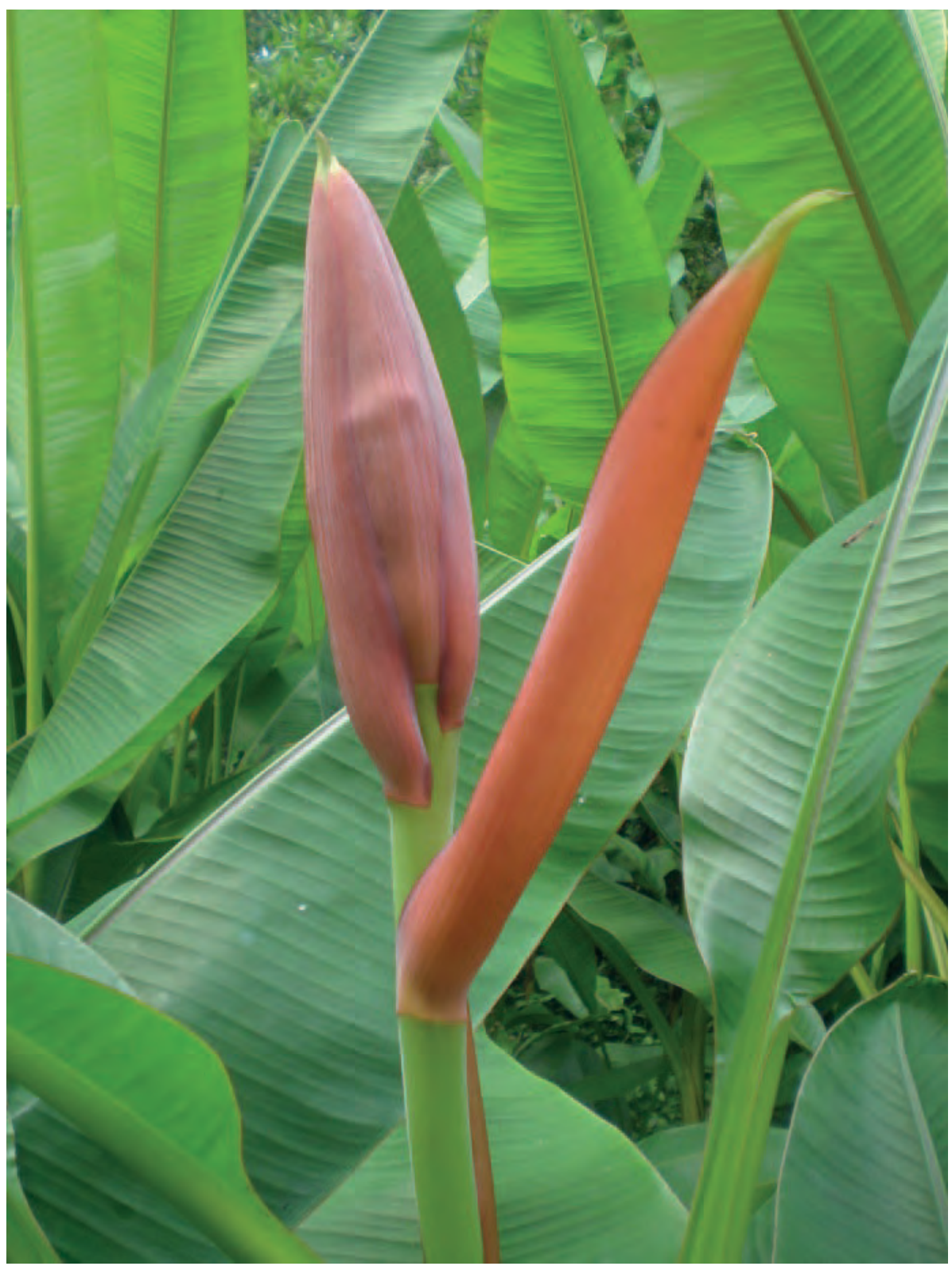

ornemental.
Description : Plante de 1,5 à $3 \mathrm{~m}$ de haut. Les feuilles peuvent atteindre $1,80 \mathrm{~m}$ de long et $36 \mathrm{~cm}$ de large. Les fleurs sont roses et les fruits rose foncé à cramoisi. Les fruits contiennent des graines, ils ne sont pas comestibles. La plante s'hybride librement avec d'autres espèces.

\section{Ecologie : Plante} originaire d'Inde, maintenant largement cultivée dans les régions tropicales.

\section{Reproduction : Par} séparation des bulbes.

Photo prise au jardin botanique de Kisantu.

Usages : Les boutons de fleurs mâles peuvent se cuire ou se manger en salades; les feuilles sont souvent incorporées dans la préparation des sauces. Dans le Nord-Est de I'Inde, la racine a des usages médicinaux. On emploie la cendre de la tige, le bulbe, les tiges portant des fruits et la peau des fruits pour prévenir le scorbut, pour faciliter la digestion et comme tonique. On cultive la plante à titre

Références Llamas 2003, Wikipedia (Consulté le 26.7.2018). 


\section{Camions jouet fabriques par les enfants.}

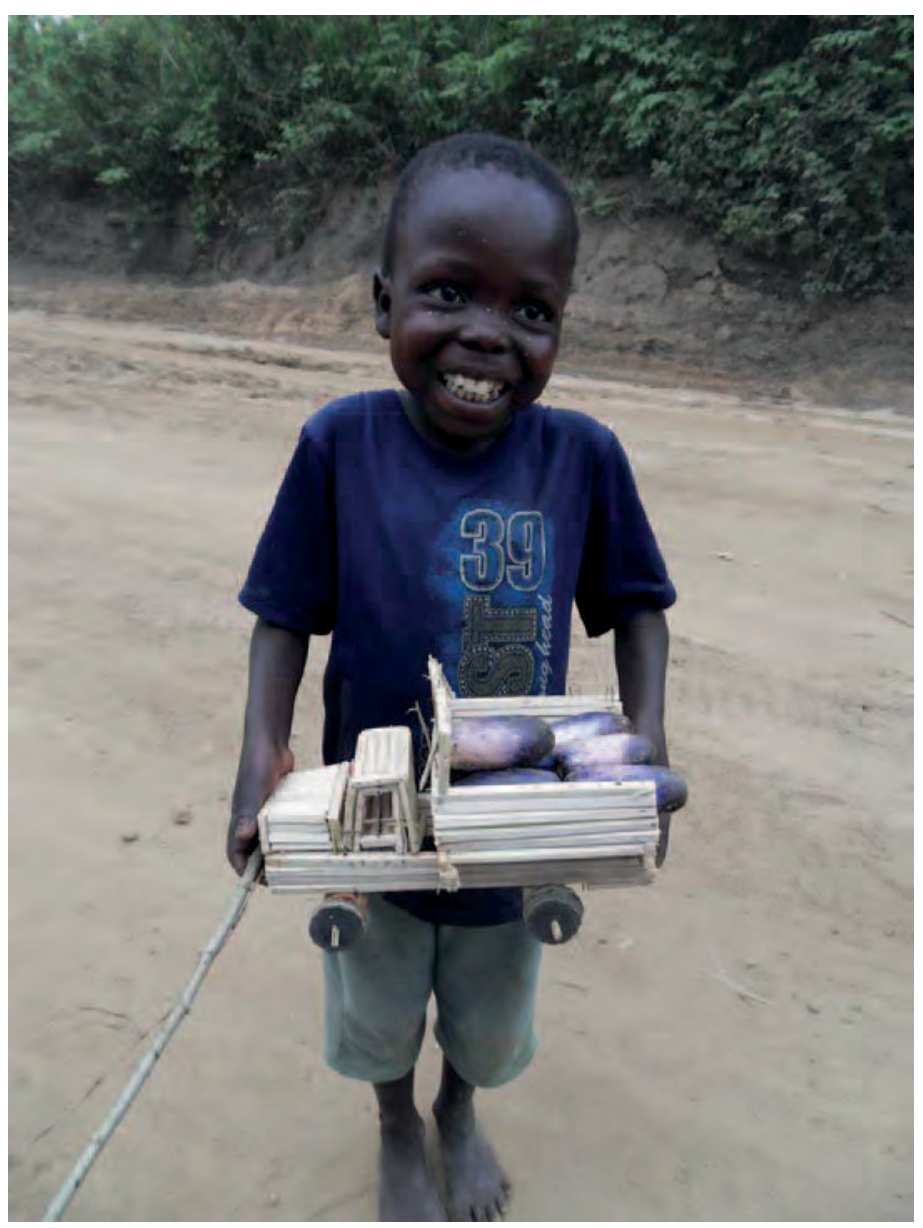

Transporteur nsafu.

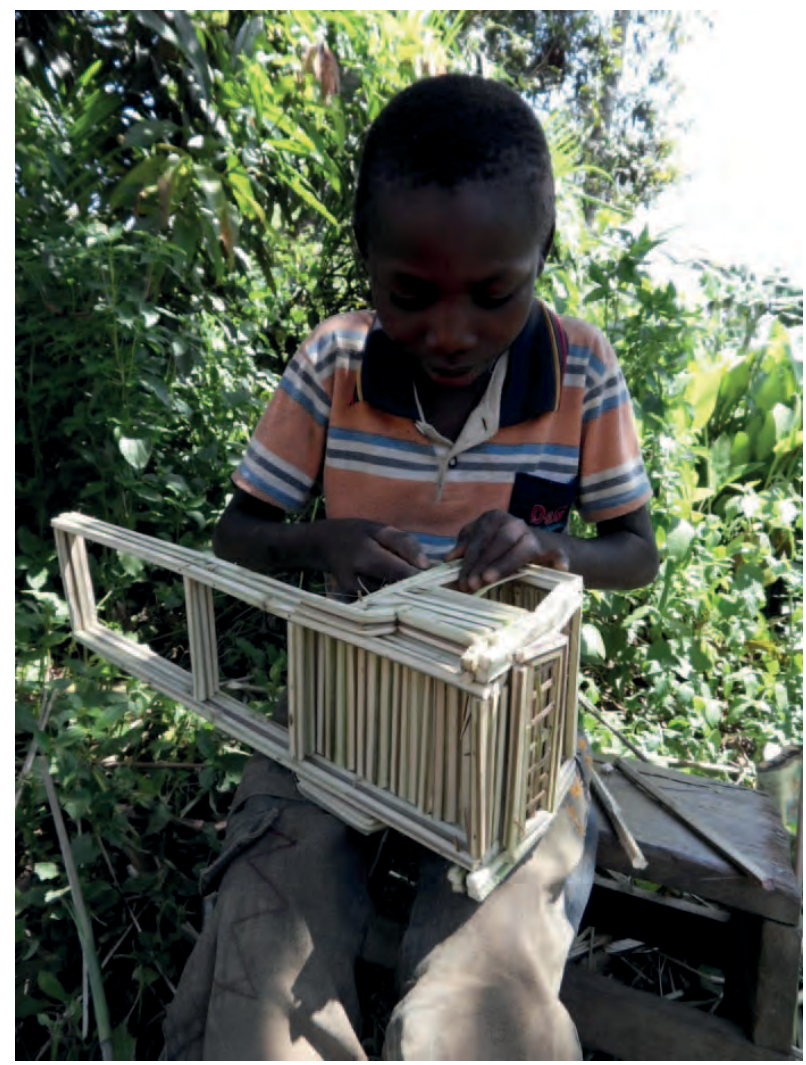


Noms courants :

- Variétés à fruits sucrés : Dinkondo di ngala (Kikongo), bitabe (Lingala), banane fruit (Fr.), dessert banana (Angl.)

- Variétés à fruits à bouillir : ngyoka (Kikongo), makemba (Lingala), banane plantain (Fr.), plantain (Angl.) .

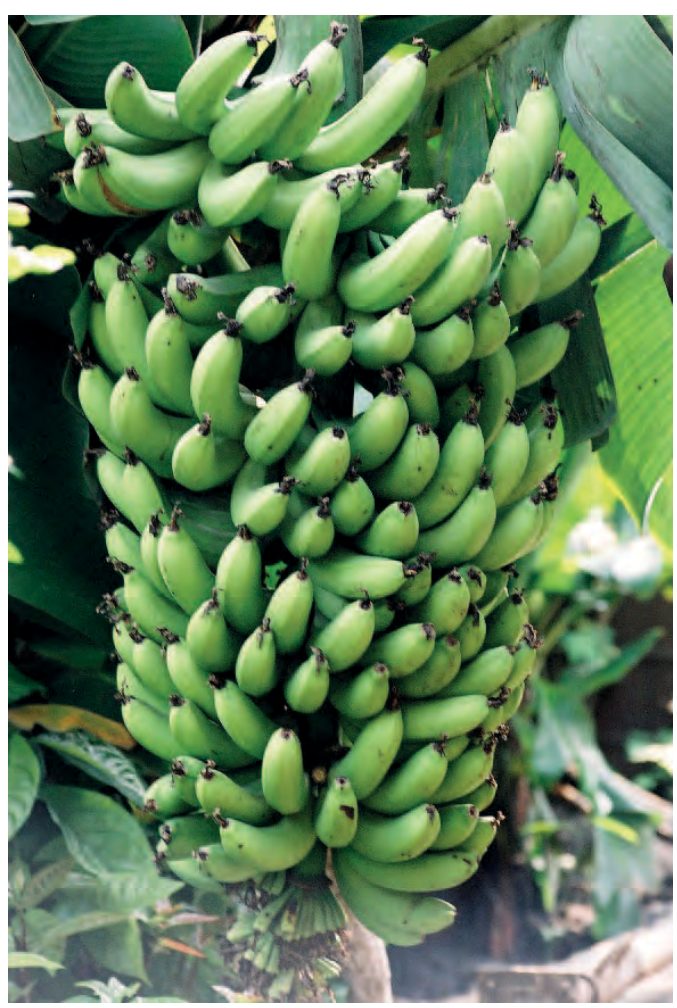

Description: Grande plante herbacée, de 2 à $9 \mathrm{~m}$ de haut, poussant à partir d'un bulbe souterrain. Les bases massives des pétioles, disposées en spirale, se développent en hauteur et s'empilent pour former un stipe ou faux tronc. Les grandes feuilles retombantes et longuement pétiolées ont jusqu'à $3 \mathrm{~m}$ de long et $60 \mathrm{~cm}$ de large. Lorsque le bananier a produit de 25 à 30 feuilles, il développe un bourgeon floral, puis une inflorescence appelée « régime», qui retombe sur le côté. Le régime est formé de spathes disposées en spirale ; il porte à sa base des fleurs femelles qui donneront les bananes, et à son extrémité des fleurs mâles. La floraison se produit sept mois après la plantation, et les fruits mûrissent en quatre mois. Dans la plupart des variétés cultivées, les fleurs mâles sont stériles, et les fruits se développent sans fécondation. Le bananier produit un seul régime et meurt après le développement des fruits. On doit donc le couper après la récolte.

Ecologie : la région d'origine des bananiers comprend l'Inde, I'Indonésie et la Mélanésie; ils sont maintenant largement répandus dans le monde tropical. La domestication des bananes aurait commencé il y a 7.000 ans dans le Sud-Est asiatique, aidée par les migrations humaines et la sélection humaine de variétés à fruits sans graines, qui se reproduisent par voie végétative ; les bananiers auraient été introduits en Afrique à partir de l'Est il y a 2.000 à 3.000 ans. Les bananes fruits proviennent principalement d'un clone issu du croisement de trois variétés de $M$. acuminata. Les bananes plantain sont issues de croisements entre des sous-espèces de $M$. acuminata et l'espèce $M$. balbisiana. Il existe également des bananes à bière, légèrement amères, largement cultivées dans les Provinces du Nord Kivu et du Sud Kivu.

Les bananiers fruits comme les bananiers plantains sont largement cultivés au Kongo Central. Ils préfèrent des limons friables, profonds, et non compactés. La fertilité du sol et sa richesse en matière organique assurent de bons rendements. Les bananiers requièrent de l'eau en quantité convenable.

A droite: Les abeilles visitent les fleurs de bananier toute la journée pour le nectar et le pollen.

Reproduction: Par bulbes. Enlever les racines mortes et les parties abîmées, mettre les bulbes dans un sac, et les tremper dans l'eau bouillante pour contrôler les nématodes et les insectes perforants. Pour la plantation, la meilleure méthode est de creuser un trou de $60 \times 60 \times 60 \mathrm{~cm}$, d'y verser 5 seaux de compost, que l'on mélange au fond du trou avec du sol de surface. Planter le bulbe dans le trou au début de la saison des pluies, et ajouter de temps en temps des restes alimentaires et du fumier.

Gestion : Eliminer toutes les feuilles mortes. Le développement des fruits a besoin de 6 à , 8 feuilles en bonne santé sur la plante. Enlever les bulbes en surnombre. Couper les tiges mortes après la récolte, et couvrir la base de terre pour limiter l'infestation par les perforateurs et les charançons. Couper les tiges mortes en morceaux pour qu'elles puissent sécher ou pourrir rapidement. L'addition de paillage et de compost tous les six mois améliore les rendements de façon significative. 
Utilisations : Les bananes fruits sont l'un des principaux fruits consommés, en RD Congo, dans beaucoup de pays tropicaux, ainsi qu'à l'exportation vers l'Europe et l'Amérique du Nord. Elles contiennent de la vitamine B6 et de la riboflavine; elles se digèrent facilement, surtout quand elles sont bien mûres. On peut aussi en faire une farine, avec de petits fruits verts, qui sont pelés, plongés 4 à 5 minutes dans l'eau chaude, puis séchés au soleil avant d'être moulus en farine.

La banane plantain est couramment consommée en R.D. Congo et dans une grande partie de l'Afrique, dans les Caraïbes, en Amérique Centrale et dans certains pays d'Amérique du Sud. Elle est plus grosse et plus longue que la banane fruit, plus pauvre en sucre mais beaucoup plus riche en amidon, ce qui la rend plus ferme et lui donne une bonne tenue à la cuisson. II est d'usage de consommer les bananes plantain après cuisson, car elles restent fermes et servent de féculent pour accompagner des plats de viande, poulet et poisson. Les bananes plantains bouillies et pilées donnent une pâte appelée lituma en lingala, et « foutou banane » en Côte d'I voire, qui sert également de féculent.

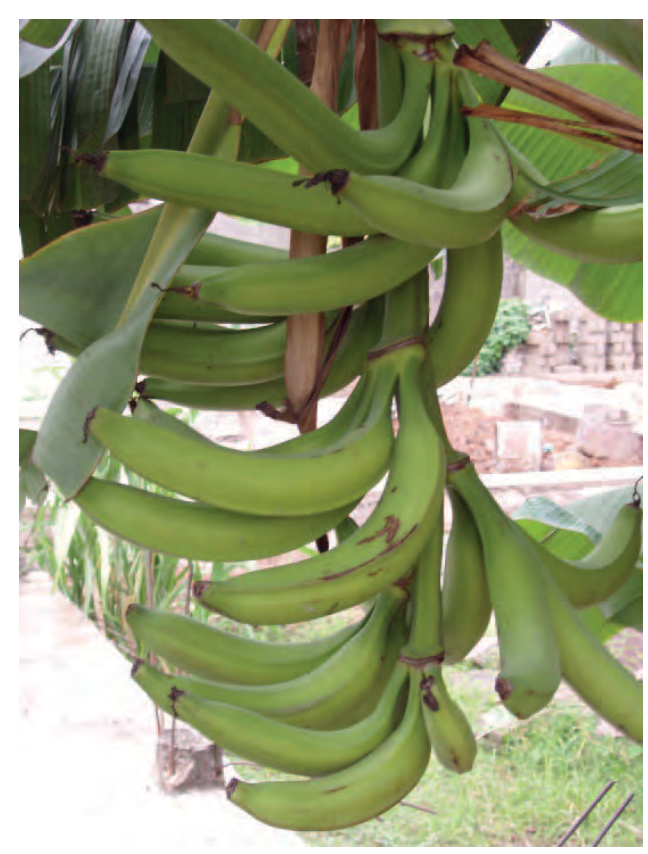

La bière de bananes est largement consommée dans les Provinces du Kivu, ainsi que dans les pays des Grands Lacs, Burundi, Ouganda et Rwanda, où des bananiers à bière sont spécialement cultivés pour cet usage.

Au Kongo Central, on mangeait traditionnellement comme des épinards les jeunes feuilles non ouvertes (nsoko mankondo). On extrait parfois de la tige une fibre fine utilisée comme ficelle. On emploie les bulbes pour traiter les œdèmes et les entorses. On emploie la racine pour expulser les vers intestinaux. Les abeilles récoltent le nectar et le pollen. La pluie et le sol humide accroissent la sécrétion de nectar. Le miel a un goût astringent, comme le tamarin.

Bananes pantains Photo: Luc Pauwels

Références: De Wildeman 1903, Butaye 1909, Gillet et Pâque 1910, Castagné 1983, Daeleman et Pauwels 1983, Crane et al. 1984, Drachoussoff 1993, Nakasone et Paull 1998, Raemaekers 2001 
Noms courants : Nsenga, kimbongo (Kikongo), mobambo (Lingala), parasolier (Fr.), umbrella tree (Angl.)

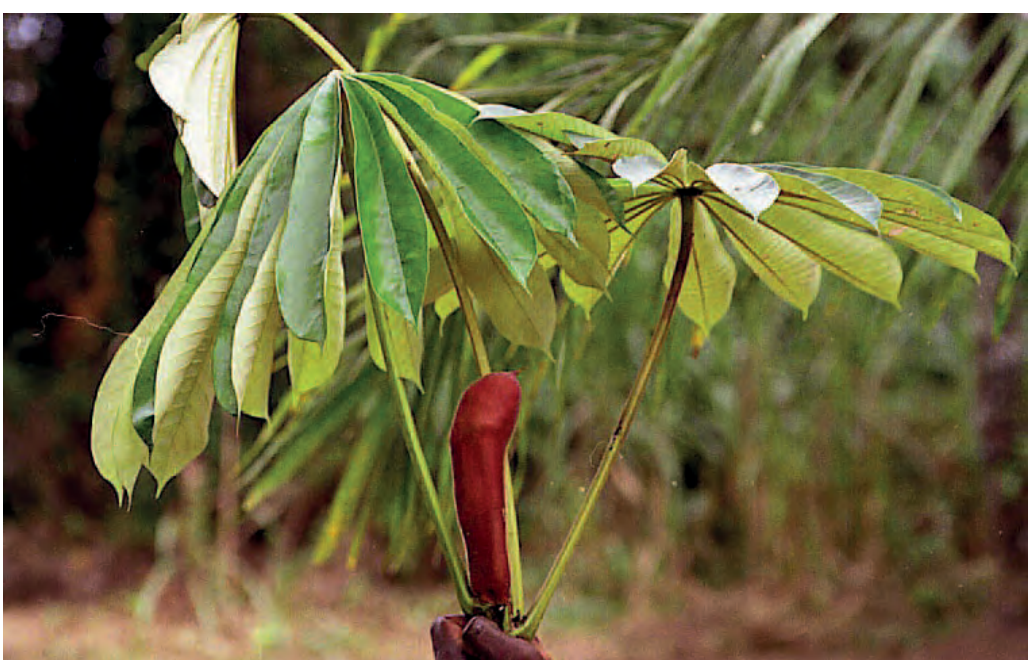

Description : Arbre à tronc droit, à croissance très rapide, pouvant atteindre $20 \mathrm{~m}$ de haut, ayant souvent des racines contreforts. Feuilles composées, brillantes, pouvant avoir 12 à 15 lobes ayant chacun $45 \mathrm{~cm}$, au-dessus d'un pétiole poilu. Les gaines des feuilles sont brun rouge et poilues, jusqu'à $30 \mathrm{~cm}$ de long. Les arbres mâles ont des inflorescences de 15 à $20 \mathrm{~cm}$ de long, dont la moitié pour le pédoncule, et 7 $\mathrm{cm}$ de large, et portent plus de 50 glomérules floraux à étamines roses. Les arbres femelles portent des paires de fleurs succulentes longues de 2 à $3 \mathrm{~cm}$ sur un pédoncule de $12 \mathrm{~cm}$. Le fruit charnu, vert puis jaune, a

environ $12 \mathrm{~cm}$ de long.

Ecologie : Arbre des forêts secondaires, souvent espèce pionnière après abattage de la forêt, sur des sols lourds, humides et fertiles. II ne pousse pas à l'ombre. De la Guinée à l'Angola.

Reproduction: Habituellement par semis direct en plein champ. Les fruits jaunes tombent au sol à maturité. Ecraser le fruit dans l'eau. Les graines flottent et on peut les sécher. On peut les conserver seulement deux mois, au frais.

Usages: Au Kongo Central, on emploie la sève des racines comme désinfectant et pour cicatriser les blessures. Le fruit est comestible. La cendre du bois sert de sel, et de lessive en savonnerie. La canopée donne de l'ombre aux caféiers. Le bois est très léger, tendre et à grain grossier. II sert à faire des radeaux, des palissades, des cloisons grossières et pour l'isolation des toits ; on en fait aussi des tabourets, des instruments de musique, des cannes de marche, des corbeilles et des paniers, etc. On l'emploie comme substitut du liège et pour faire du papier. Les racines aériennes contiennent beaucoup de liquide (environ 2,5 I. chacune), que l'on peut boire comme de l'eau. C'est la plante médicinale la plus utilisée dans les territoires de Kisantu et Mbanza Ngungu pour traiter les hernies. Au Kongo Central et au Gabon, on indique que les fleurs sont un

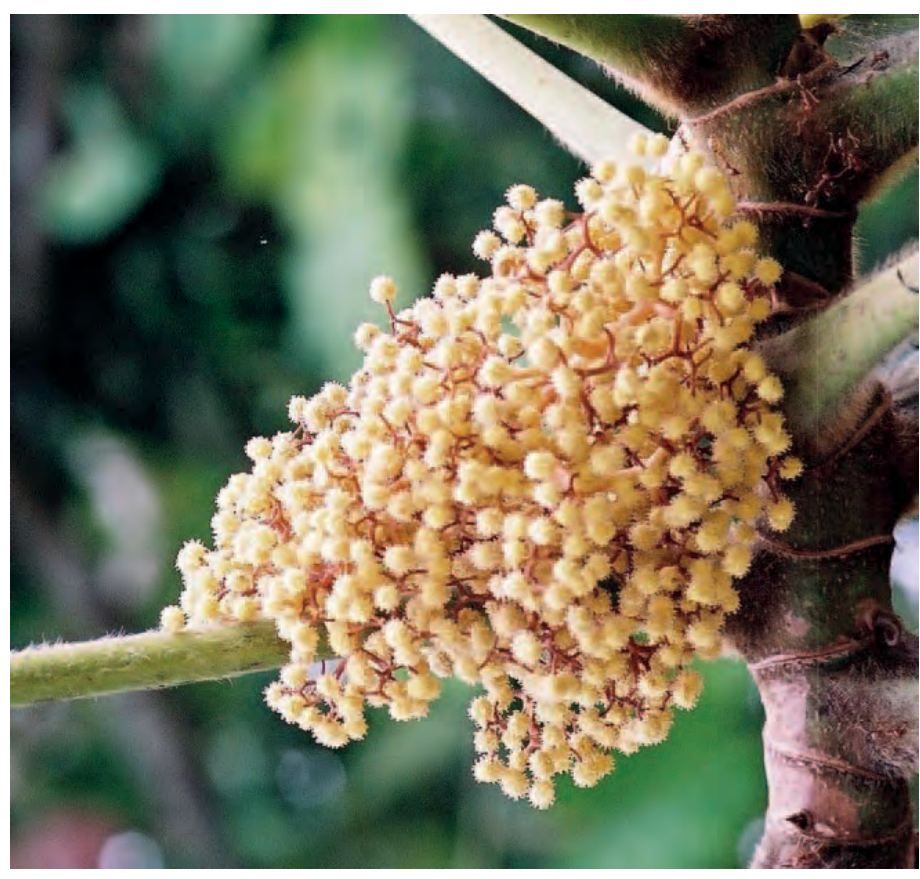

fourrage pour les abeilles. Les chenilles comestibles Nsinga se nourrissent des feuilles.
Les fleurs mâles

Références: De Wildeman 1903, Gillet et Pâque 1910, Hauman 1948, Nsimundele 1966 - 68, Daeleman et Pauwels 1983, Burkill 1985, Lobreau-Callen et al. 1989, Ambougou 1991, Peters et al. 1992, Pauwels 1993, Katende et al. 1995, Kibungu Kembelo 1995, Kibungu Kembelo et al. 2021 


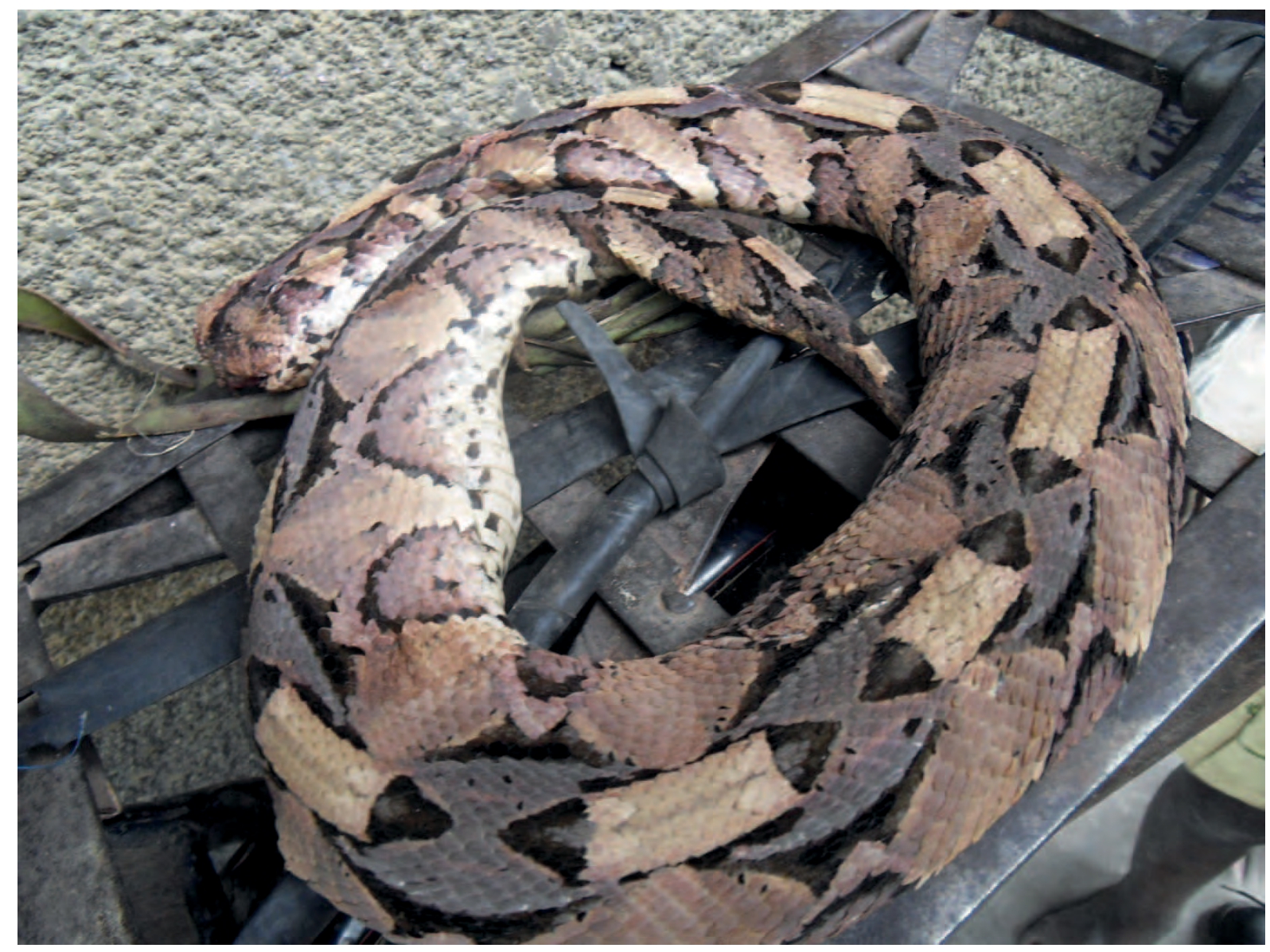

Serpent sur le porte bagage du vélo à Sombala

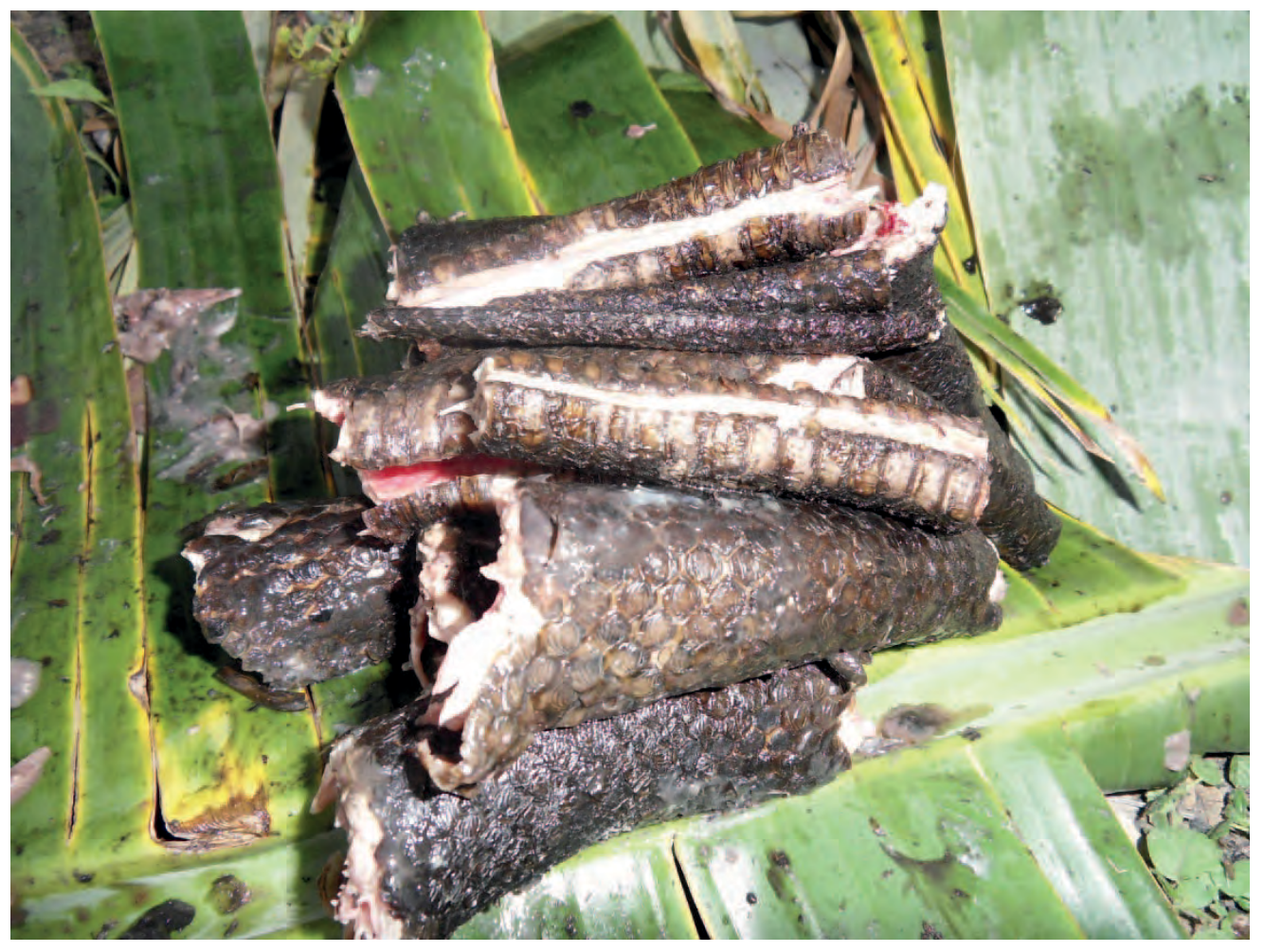

Viande de serpent découpée 
Noms courants : Nsilu nsilu (Kikongo), esobi (Lingala), liane de Kisanji (Fr.), savanna gooseberry (Angl.)

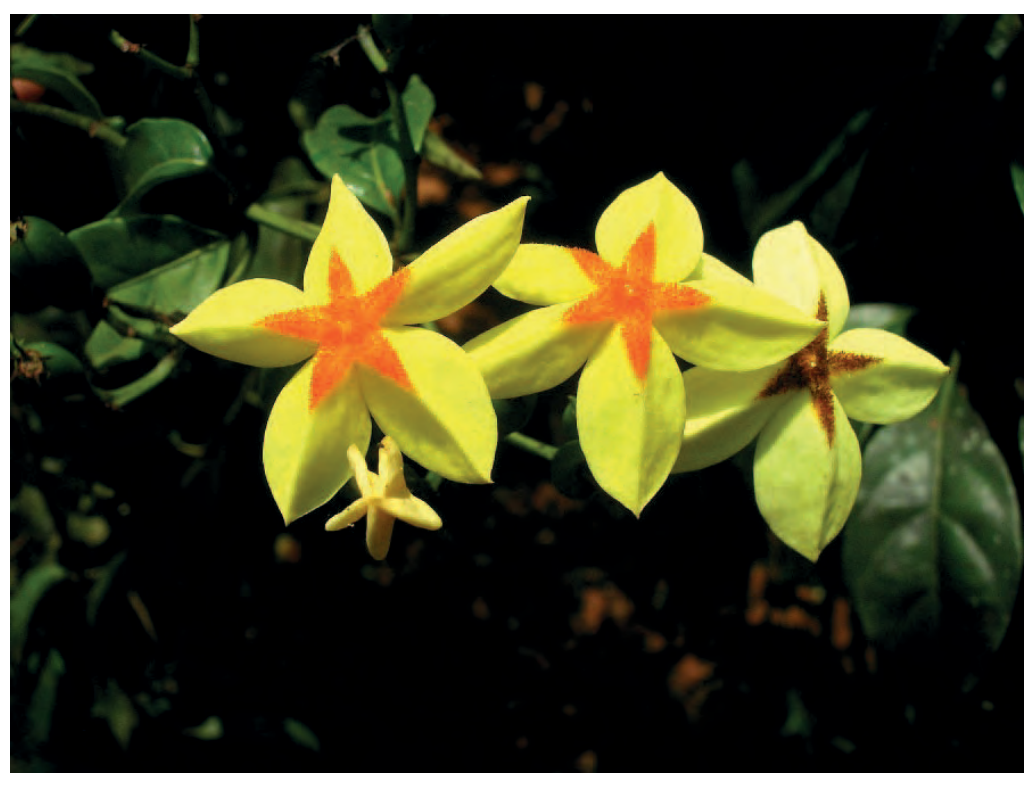

Description : Arbuste de $2 \mathrm{~m}$ de haut, ou liane pouvant atteindre 8 à $10 \mathrm{~m}$ de long là où elle n'est pas sujette aux feux annuels. La tige contient une substance gluante blanche. Feuilles opposées, simples et entières, de 5 à 13 sur 2 à 7,5 cm. Des bouquets de fleurs en forme d'étoiles, de couleur jaune vif, se disposent à l'extrémité des branches. La corolle est jaune, avec une étoile centrale rouge ou brune. Les fruits mûrs sont jaunes, ils mesurent de 1 à 2,5 sur 0,5 à $1 \mathrm{~cm}$, et contiennent beaucoup de petites graines dans une pulpe légèrement sucrée.

Photo: Quentin Luke

Ecologie : Plante des savanes boisées dans toute l'Afrique tropicale. Elle pousse en forêt près des cours d'eau, près des affleurements rocheux, et dans la forêt sempervirente.

Reproduction : Les boutures reprennent bien. Les graines germent bien, mais sont très petites, et difficiles à séparer de la pulpe.

Gestion: La plante fleurit un pu deux ans après la plantation.

Usages : On cueille les fruits quand ils sont jaunes. Les écraser pour faire sortir la pulpe, et jeter la coque. Certains prétendent qu'ils sont insipides, d'autres disent qu'ils ont un goût comme un mélange de kiwis et de figues. On peut en faire des confitures. En Ubangi, on mange parfois les feuilles comme des épinards. Les racines et les feuilles ont des usages médicinaux. En Angola les fruits sont utilisés dans le traitement des maladies sexuellement transmissibles. Les feuilles sont utilisées contre l'arthrite, les rhumatismes, comme médicament pour l'avortement et l'accouchement.

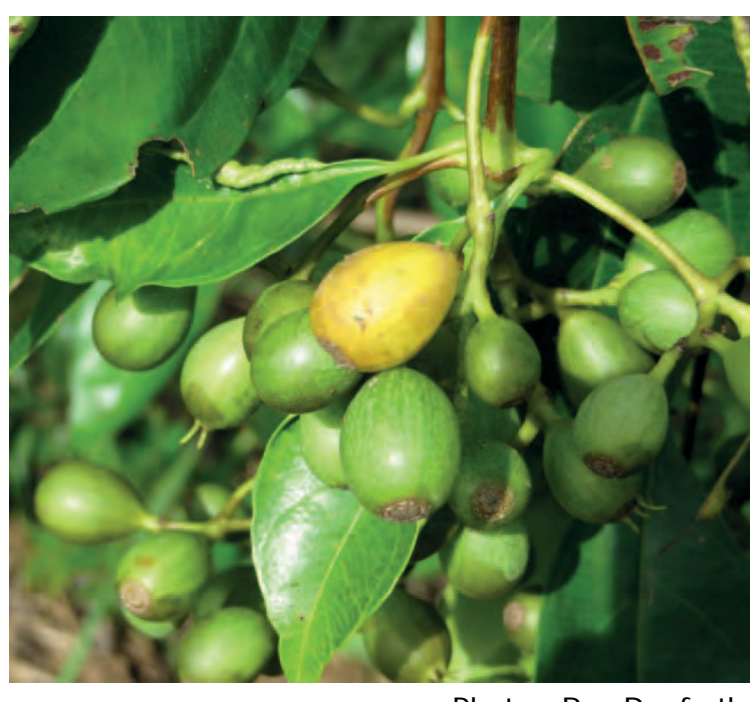

Références : Renier 1948, Hallé 1966, Vivien et Faure 1996, Burkill 1997, Danforth et Noren 1997, Vande weghe 2004, Leyens et Lobin 2009, Göhre et al. 2016 
Noms courants : Muntusu (Kikongo), bokamu (Lingala), arbre à pain indigène (Fr.), giant yellow mulberry (Angl.)

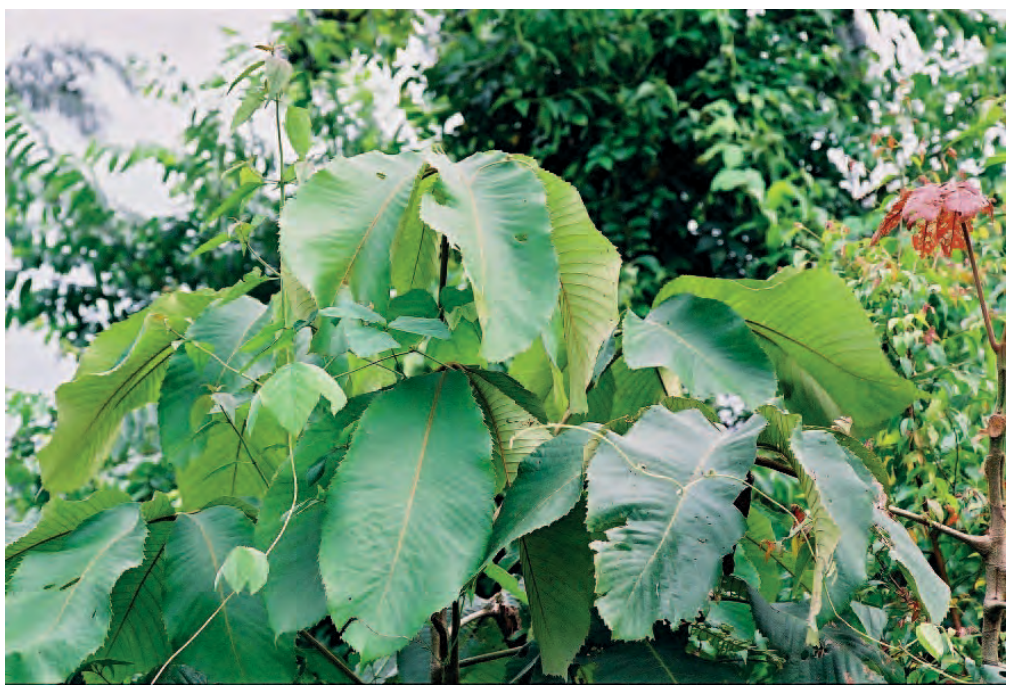

Description : Arbre à tronc court pouvant avoir $20 \mathrm{~m}$ de haut, avec souvent des racines échasses. Feuilles composées disposées en spirales, ayant 5 folioles. Les folioles, de 16 à $30 \mathrm{~cm}$ de long, ont des marges dentées. Les fleurs mâles sont jaunes, les fleurs femelles vertes. Les fruits ont de 6 à 10 $\mathrm{cm}$ de diamètre. Le bois est blanc jaunâtre, tendre et fibreux. En Afrique Centrale, les arbres peuvent fleurir toute l'année.

Ecologie : Arbre des forêts primaires et secondaires, souvent dans des lieux humides, sur des sols lourds, de la Sierra Leone à l'Angola, l'Ouganda et la Tanzanie. II demande une forte pluviosité, et pousse du niveau de la mer jusqu'à $1.200 \mathrm{~m}$.

Reproduction : Extraire les graines du fruit et les sécher. II vaut mieux les tremper avant de les semer. Les graines germent facilement après quatre semaines. On peut aussi prendre des boutures.

Usages : La pulpe du fruit est comestible et légèrement acide. On peut cueillir les fruits mûrs pour les manger, ou verts pour les conserver. Si on laisse les fruits tomber de l'arbre, ils sont généralement pourris. La sève qui coule des racines aériennes peut se boire. Au Kongo Central, on mange parfois les feuilles. On les emploie aussi pour panser les blessures. Le bois est jaune et léger mais difficile à travailler; il sert à fabriquer des ustensiles de cuisine. Il convient comme bois de feu. Les graines se mangent après cuisson; elles sont riches en huile et acides aminés. Au Nigéria, les graines servent à préparer une soupe très populaire. On peut extraire de la cendre de bois une lessive pour la savonnerie. L'arbre a de nombreux usages médicinaux. La sève des feuilles aide à cicatriser les blessures ; on prend une décoction de l'écorce des racines avec les feuilles pour calmer la toux. Les feuilles mortes forment une épaisse couche d'humus, développant la fertilité du sol. Les niveaux d'azote organique sont améliorés par les mycorhizes associés aux racines. On indique qu'au Gabon les fleurs seraient visitées par les abeilles.

Références : Butaye 1909, Gillet 1927, Hauman 1948, Nsimundele 1966 - 68, Burkill 1985, Keay 1989, Ambougou 1991, Pauwels 1993, White et Abernethy 1997, Nsimundele 2004, Okafor 2004, Pousset 2004, Meunier et al. 2010

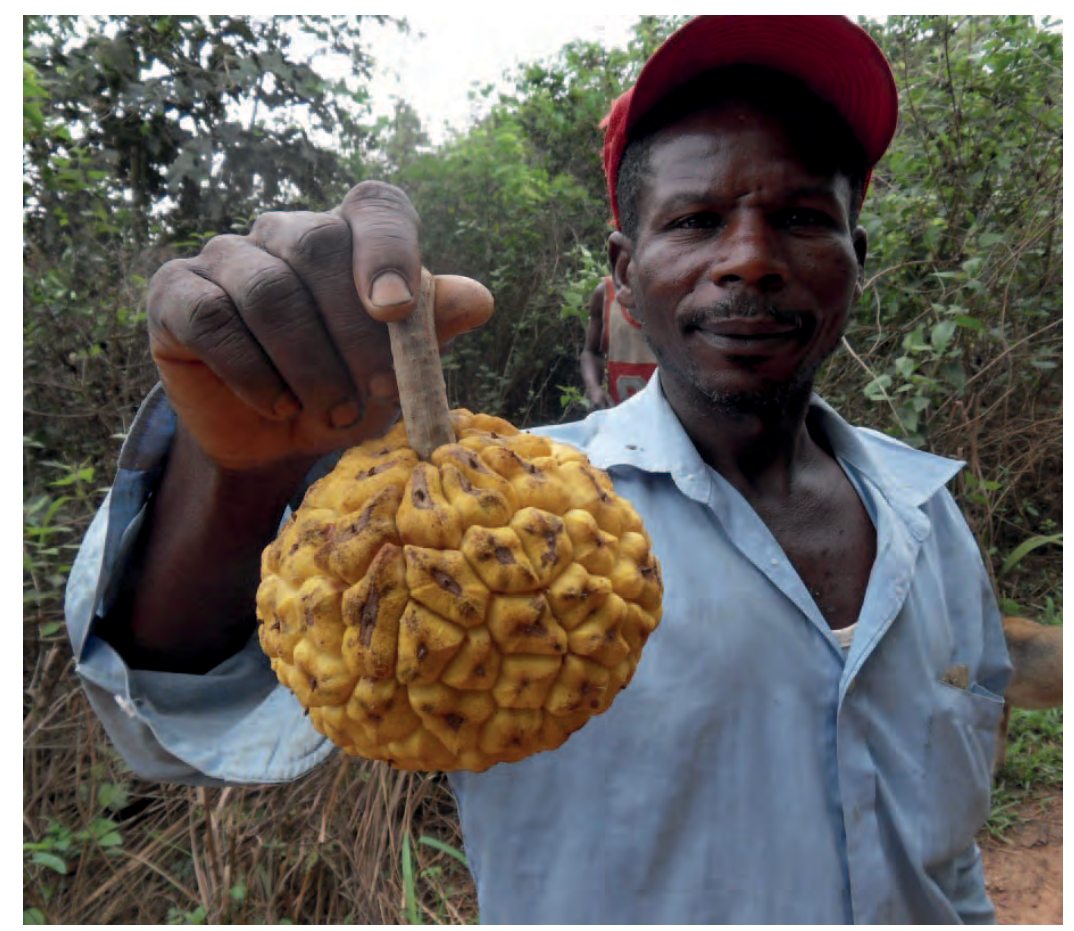




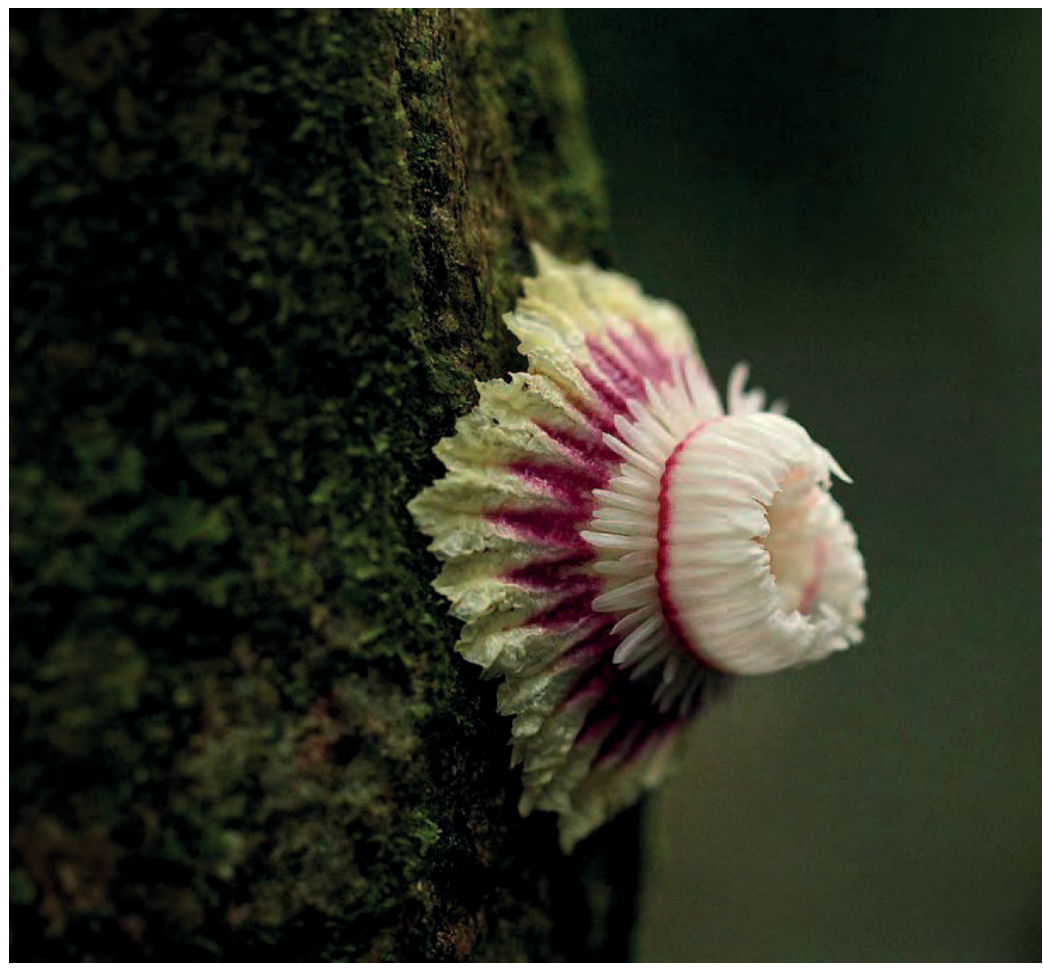

Description : Petit arbre pouvant atteindre $10 \mathrm{~m}$ de haut. L'écorce est pâle, rugueuse et noueuse. Les branches sont tordues. Feuilles alternes d'environ $12 \times 4 \mathrm{~cm}$. Les fleurs, à l'odeur de vanille, poussent parmi les feuilles, sur les branches ou sur le tronc. Les fruits, ligneux, sont brunâtres ou rougeâtres, avec une coque grêlée ; ils contiennent de 4 à 6 graines dans une pulpe gélatineuse.

Napoleonaea vogelii avec des fleurs sur le tronc.

Photo: Bart Wursten

Ecologie : Arbre des sous-bois au Kongo Central. Pousse près des cours d'eau ou de la mer, de la Guinée à l'Angola.

Usages : Le fruit est comestible, et a bon goût. Le bois est dur, jaune clair à brun clair, mais ses petites dimensions limitent son utilité. II prend un beau poli, mais n'est pas durable. On l'emploie pour les manches d'outils ou comme bois de feu. Les rameaux contiennent de la saponine; ils servent de bâtons à mâcher au Ghana et au Nigéria. Au Libéria et en Sierra Leone, on grille l'écorce interne et les racines pour traiter la toux et I'asthme. Au Nigéria, on traite la fièvre avec une décoction des racines; on emploie aussi les feuilles, l'écorce, les graines, les rameaux, les fruits et les racines pour traiter le diabète, la fièvre, les toux et le catarrhe.

Références : Renier 1948, Liben 1971, Pauwels 1993, Burkill 1995, Vivien et Faure 1996, White et Abernethy 1997, Tolu Odugbemi 2006, Harris et Wortley 2008, Fayaz 2011

Napoleonaea imperialis au jardin botanique de Kisantu.

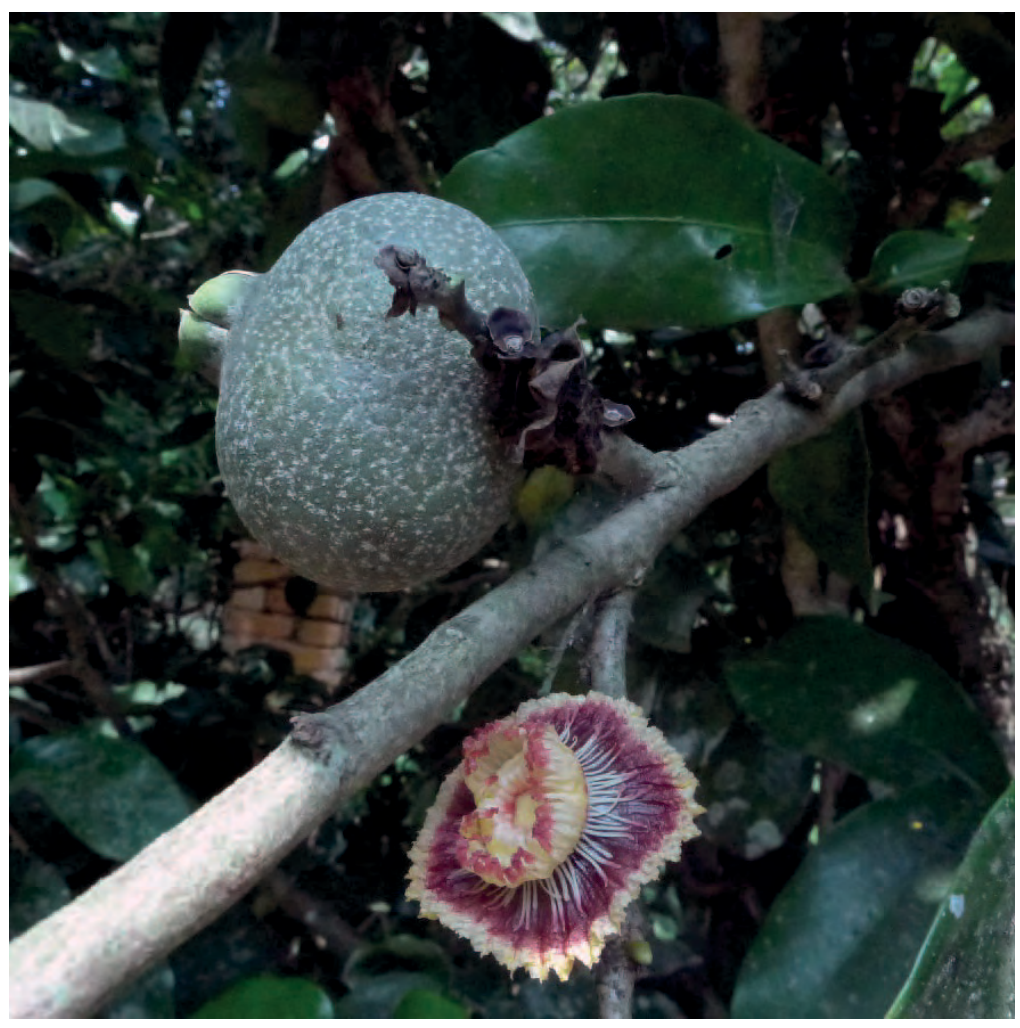


Noms courants : Kienga ki masa, ngulu masa (Kikongo), bois d'or (Fr.), West African boxwood (Angl.) bilinga (commerce)

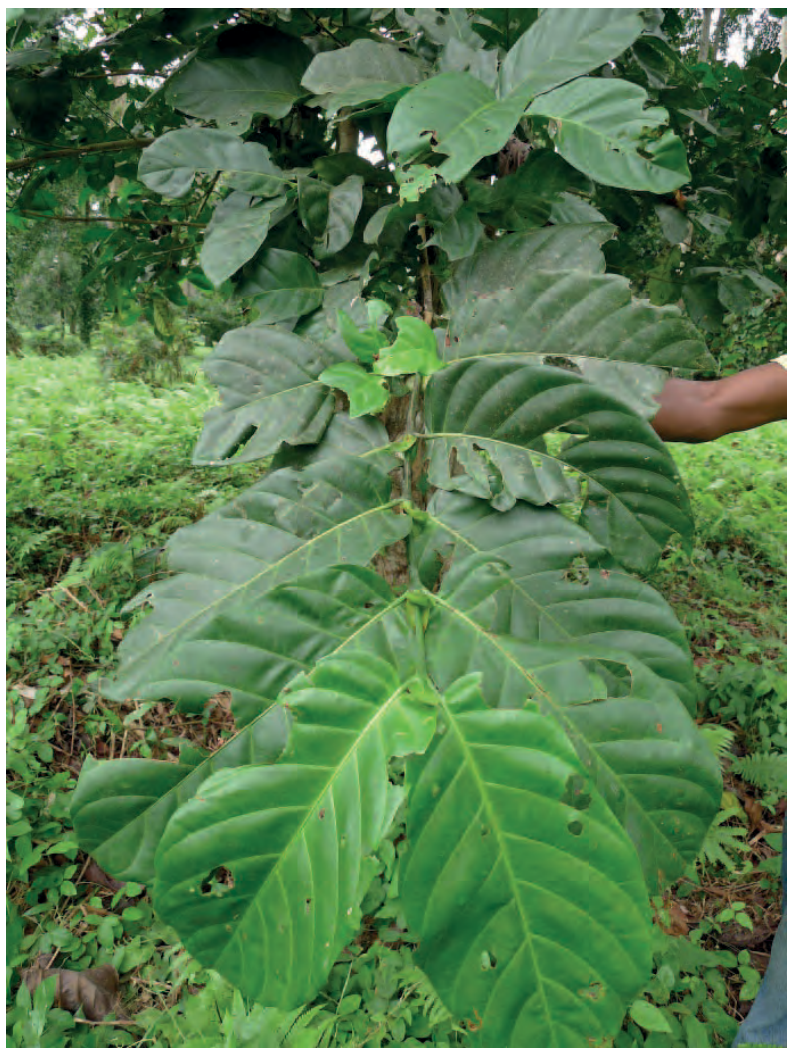

taux de 50 à $75 \%$; elle est meilleure si l'on a trempé les graines. Repiquer les semis dans un germoir après 1,5 à 2 mois, quand ils ont 10 à $15 \mathrm{~cm}$ de haut et 4 à 6 feuilles, espacés de $25 \mathrm{~cm}$, en évitant d'endommager ou de laisser sécher les tiges tendres. Après 12 mois, on réduit les semis en souches et on peut les planter en pleine terre, espacés de $3 \times 3 \mathrm{~m}$. Par ailleurs, la reproduction par boutures est facile. L'arbre se régénère aisément dans les grandes
Description : Grand arbre jusqu'à $40 \mathrm{~m}$ de haut, à racines profondes. Feuilles ovales, brillantes, sur un pétiole de $1 \mathrm{~cm}$ de long, avec une paire de stipules à la base. Inflorescences terminales solitaires, de $3 \mathrm{~cm}$ de diamètre, portant de petites fleurs de couleur blanc verdâtre à jaune. Fruits ronds, gris brun, de $2,5 \mathrm{~cm}$ de diamètre, à l'écorce épineuse, avec beaucoup de petites graines dans une pulpe blanche. Surexploitée, cette espèce est menacée.

Ecologie : Arbre des marécages, et des zones humides de la grande forêt pluviale, de la Sierra Leone au Cameroun, au bassin du Congo, en Ouganda et au Mozambique. Il pousse bien dans les sites ensoleillés.

Reproduction : Par graines en pépinière. Le fruit mur se ramollit ; on l'écrase et on fait sécher la pulpe pour extraire les graines; semer dans les deux mois. La germination intervient dans les 2 à 3 semaines, avec un

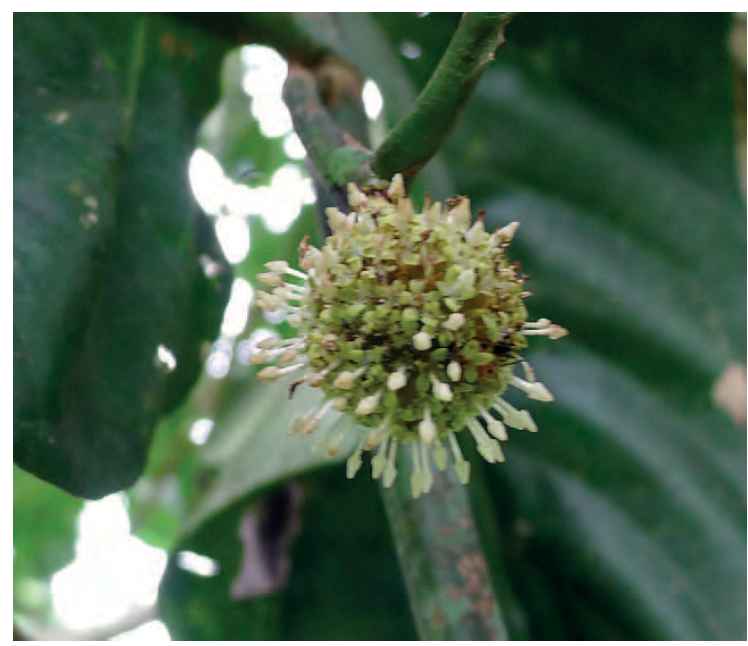

clairières et le long des routes.

Gestion: Arbre à croissance rapide. Les jeunes arbres ont souvent plusieurs tiges: éliminer les tiges secondaires avant qu'elles deviennent trop grosses.

Usages: Le bois de cœur est jaune à brun doré, brunissant exposer à l'air. II a une texture grossière, est dur, résistant, et n'est attaqué ni par la pourriture ni par les termites. II a une valeur commerciale, et sert en construction lourde, pour le mobilier, les mortiers et les embarcations. II est durable en dessous du sol. II sert aussi de bois de feu et pour le charbon de 
bois. La chair du fruit est comestible, mais peu appréciée, et sert plutôt de nourriture de famine. Les racines, l'écorce et le bois servent à faire une teinture jaune. Cet arbre est largement utilisé en médecine traditionnelle. Les racines auraient des propriétés diurétiques, et sont employées pour le traitement des anémies. On boit des décoctions de l'écorce pour traiter l'hépatite, et comme lavement pour chasser les vers intestinaux.

Références : De Wildeman 1903, Butaye 1909, Gillet 1927, Renier 1948, Hallé 1966, Daeleman et Pauwels 1983 , Katende et al. 1995, Vivien et Faure 1996, Burkill 1997, Orwa et al. 2009, Opuni-Frimpong et Opuni-Frimpong 2012

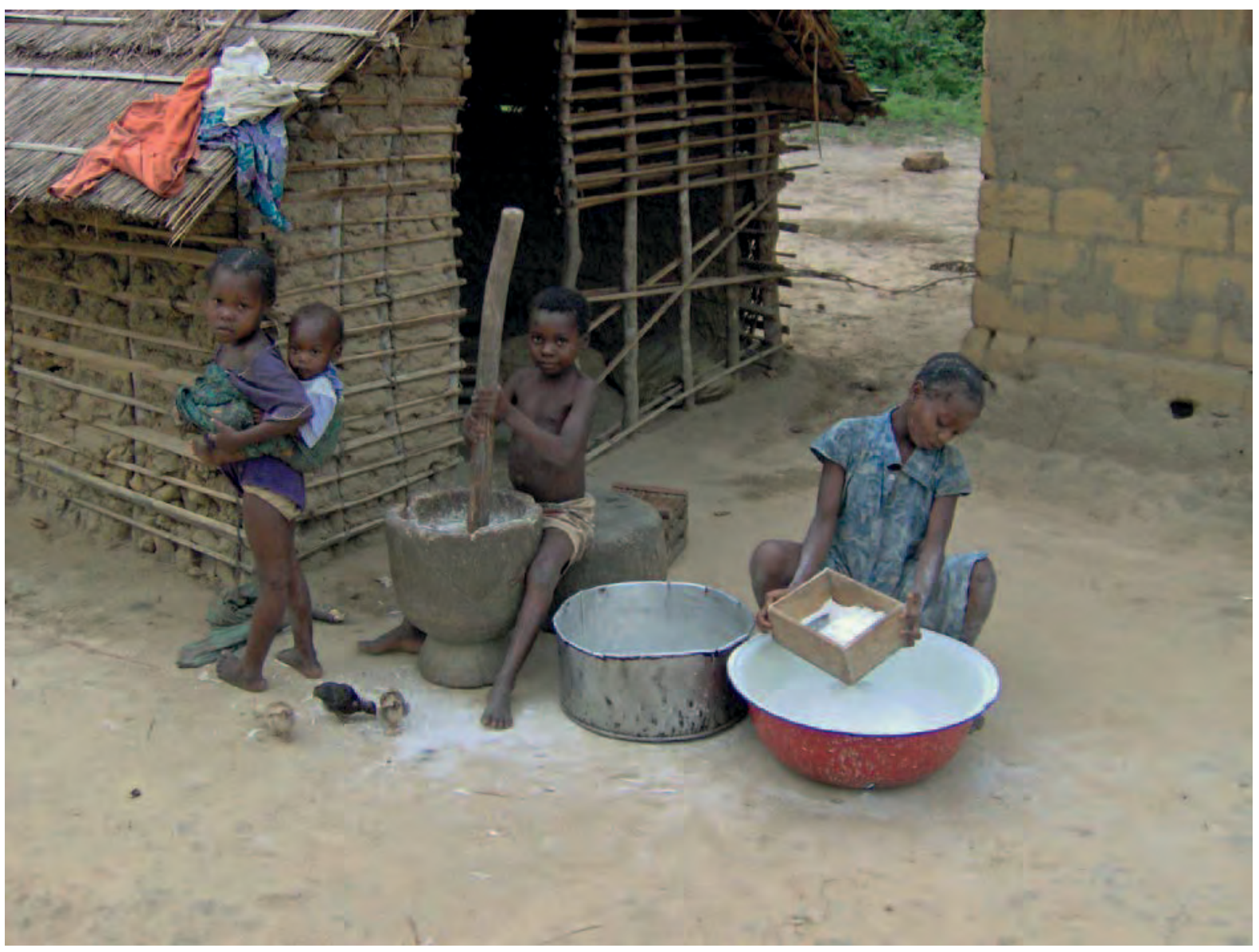

Enfants préparant du manioc pour le repas du jour 


\section{Nelsonia canescens}

Common names Kinzonzi (Kikongo).

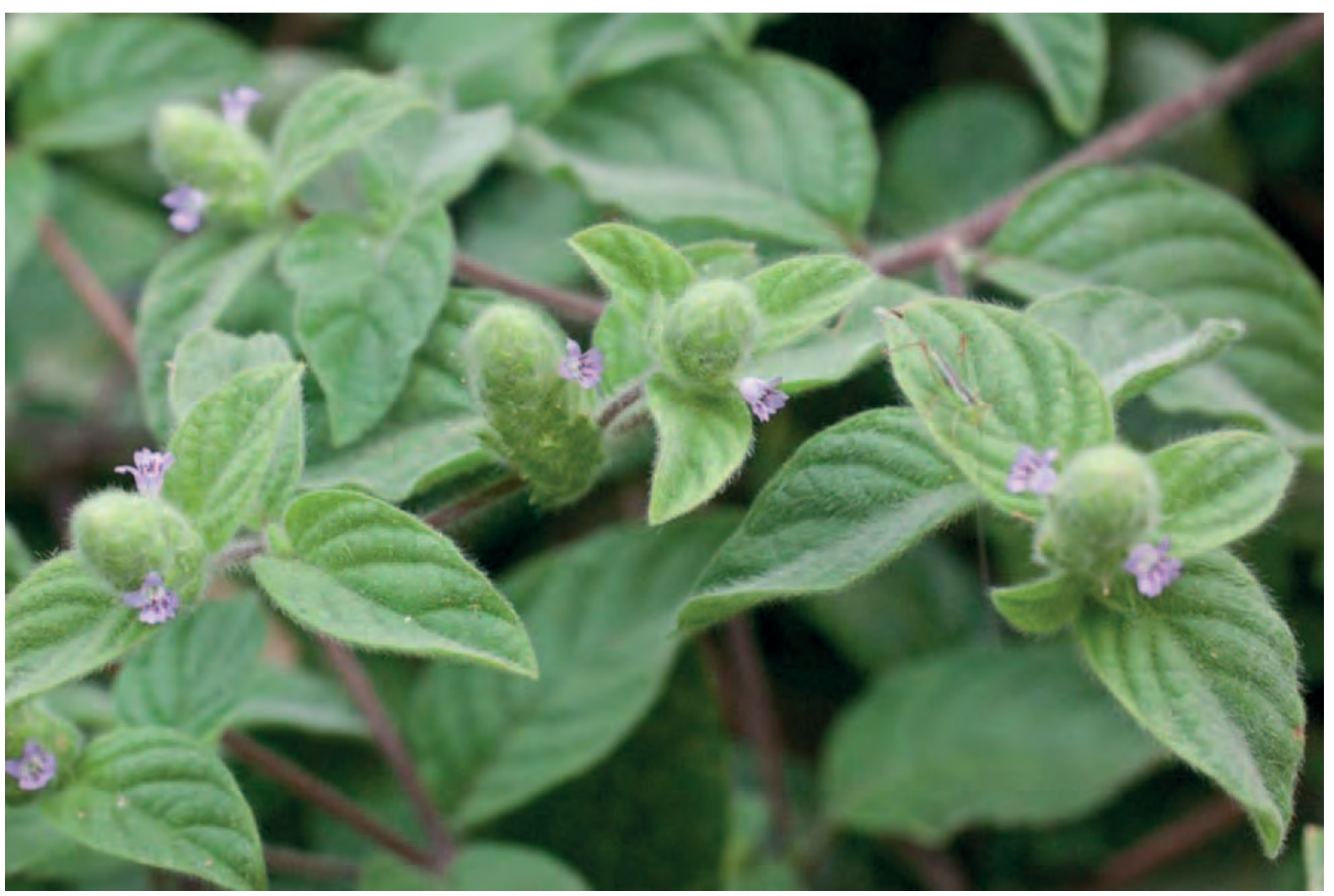

Photo : Andres Hernandez

Description : Plante herbacée retombante, ramifiée, avec des épis dressés de petites fleurs roses ou pourpres terminales. Feuilles opposées de 8 à 10 sur 6 à $7 \mathrm{~cm}$, sur des pétioles de 2 à $4 \mathrm{~cm}$.

Ecologie : Plante des lieux ombragés, souvent dans les lits de cours d'eau dans la savane en Afrique, et largement répandue sous les tropiques.

Usages: Au Kongo Central, on mange les feuilles comme des légumes ; elles ont un goût acide ; on les donne également aux moutons et aux chèvres. La plante est utilisée comme source de sel végétal. Au Ghana, le jus de la plante est instillé dans les yeux pour soigner la fièvre. Au Sud du Nigéria, on sèche la plante et on la réduit en poudre pour l'appliquer sur les blessures; on applique aussi sur les petites blessures la sève fraiche ; on boit comme laxatif une décoction de la plante. En Côte d'Ivoire, on gratte la peau pour y appliquer la sève afin de traiter le ver de Guinée.

Références : Gillet et Pâque 1910, Gillet 1927, Irvine 1930, Dalziel 1937, Renier 1948, Burkill 1985, Peters et al. 1992, Neuwinger 2000 


\section{Nephelium lappaceum}

Noms courants : Ramboutan, poilu, litchi chevelu (Fr.), rambutan (Angl.)

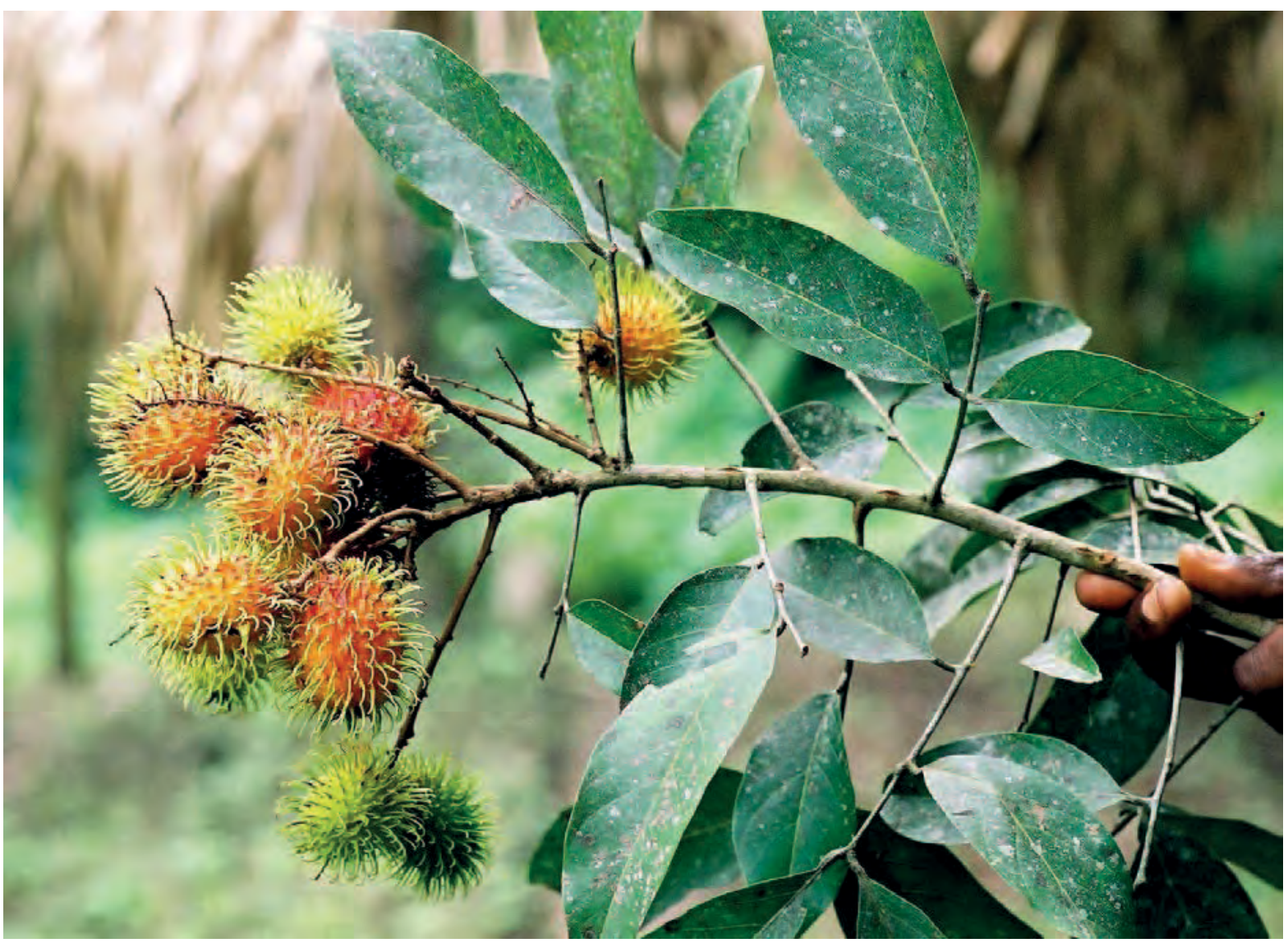

Ramboutan au jardin botanique de Kisantu

Description : Arbre touffu à feuilles persistantes pouvant atteindre $20 \mathrm{~m}$ de haut. Les feuilles vert foncé, ovales, persistantes, mesurent 30 à $40 \mathrm{~cm}$ de long, elles sont coriaces, luisantes, et constituées de 5 à 7 paires de folioles de $10 \mathrm{~cm}$ environ. De forme ovoïde, le fruit mesure de 3 à $6 \mathrm{~cm}$ environ. Sa saveur est douce, légèrement acide. II comprend une coque qui est rougeâtre à orangée avec des épines velues, que l'on enlève pour manger la pulpe qui est riche en vitamines $C$, en fer et en calcium.

Dans les bonnes variétés, la chair est pulpeuse, sucrée et juteuse. Les arbres reproduits par semences peuvent être mâles (40 à $60 \%$ ), ou hermaphrodites; ceux-ci fonctionnent soit comme arbres femelles, soit comme réellement hermaphrodites. Ce dernier type est plus souhaitable, et peut se trouver plus fréquemment dans certaines variétés. Les abeilles jouent un rôle important dans la pollinisation.

Ecologie : Originaire d'Asie (Malaisie, Indonésie, Thaïlande), l'arbre a été introduit en R.D. Congo à partir du jardin botanique de Kisantu. II requiert un climat chaud et humide avec des pluies bien réparties. Une saison sèche d'au moins un mois est nécessaire pour commencer la floraison ; par la suite, une humidité convenable est nécessaire pour l'apparition et la croissance des fruits. L'arbre s'adapte à de nombreux types de sols, y compris ceux qui sont mal drainés, mais préfère un limon profond et bien drainé.

Reproduction : Les semis fructifient en 5 à 6 ans, mais ils donnent une forte proportion d'arbres mâles, et la fructification des arbres femelles est très variable. II vaut donc mieux si possible, reproduire les arbres par voie végétative, marcottage ou greffage. On obtient les porte-greffes à partir des semis.

On lave et sèche les graines, pour les semer en germoirs immédiatement. La germination est réduite si l'on sème plus de deux jours après l'extraction des graines. Transplanter les semis quand ils atteignent environ $15 \mathrm{~cm}$, en dérangeant aussi peu que possible les racines, dans des planches bien garnies de fumier, espacés de $30 \times 30 \mathrm{~cm}$. Les semis sont prêts pour le greffage quand ils ont 12 à $18 \mathrm{~cm}$ de diamètre et produisent de nouveaux bourgeons. Pour les greffons, choisir des arbres ayant donné de beaux fruits, avant qu'ils fructifient dans la saison en cours. Les tiges doivent porter beaucoup de bourgeons dormants. Les meilleurs greffons viennent de bois d'un an ayant 
l'épaisseur d'un doigt. On doit parfois couper à l'avance le limbe des feuilles sur la tige pour faciliter la formation des bourgeons. Mettre le greffon à l'ombre avec le pied dans l'eau. Maintenir le greffon humide si on doit le transporter. Choisir un jour nuageux pour greffer. Ombrager les semis greffés.

Gestion : On peut cultiver les ramboutans en association avec d'autres arbres, arbustes ou plantes herbacées. On recommande une taille précoce conduite pour former un centre ouvert. Couper les branches qui ont donné des fruits, et enlever les rejets. II est important d'assurer un bon paillage. On peut enlever des anneaux d'écorce sur les branches ou sur le tronc en fin de saison des pluies pour améliorer la floraison et la fructification des arbres qui ont eu de faibles floraisons la saison précédente.

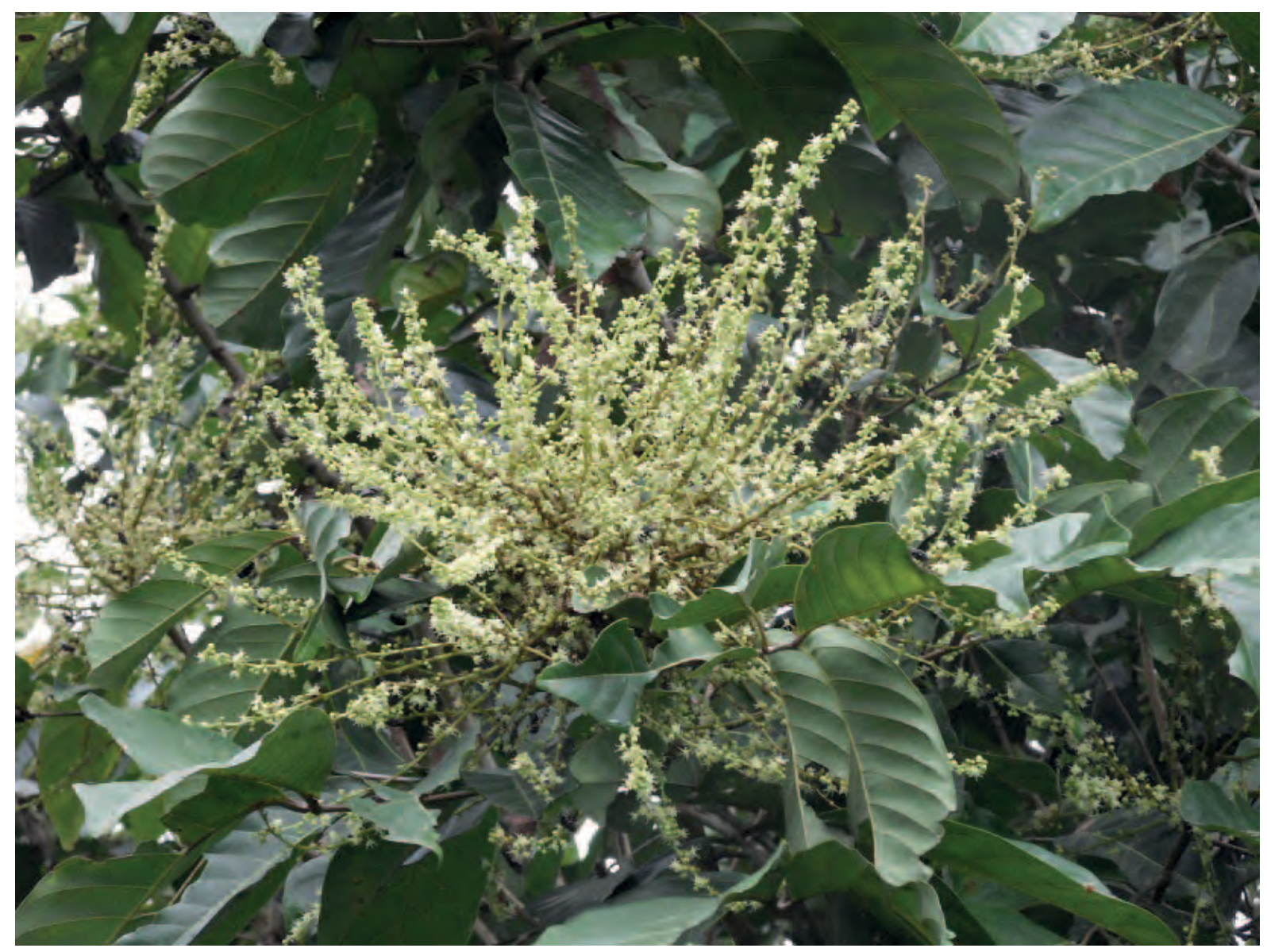

Ramboutan fleuri en novembre

Usages : Les fruits sont parmi les meilleurs. La chair est blanche et juteuse, avec un très bon goût. La graine cuite est comestible ; on peut aussi l'employer pour faire du savon ou des bougies. Le bois tend à se fendre en séchant, mais il est dur, résistant, facile à travailler et se polit bien. II est durable pour les usages en menuiserie intérieure, mais est sujet aux attaques de champignons. On extrait des jeunes pousses une teinture verte pour la soie.

Références : Gillet 1927, Renier 1948, Garner et Chaudhri 1988, Nakasone et Paull 1998 


\section{Nephrolepis biserrata}

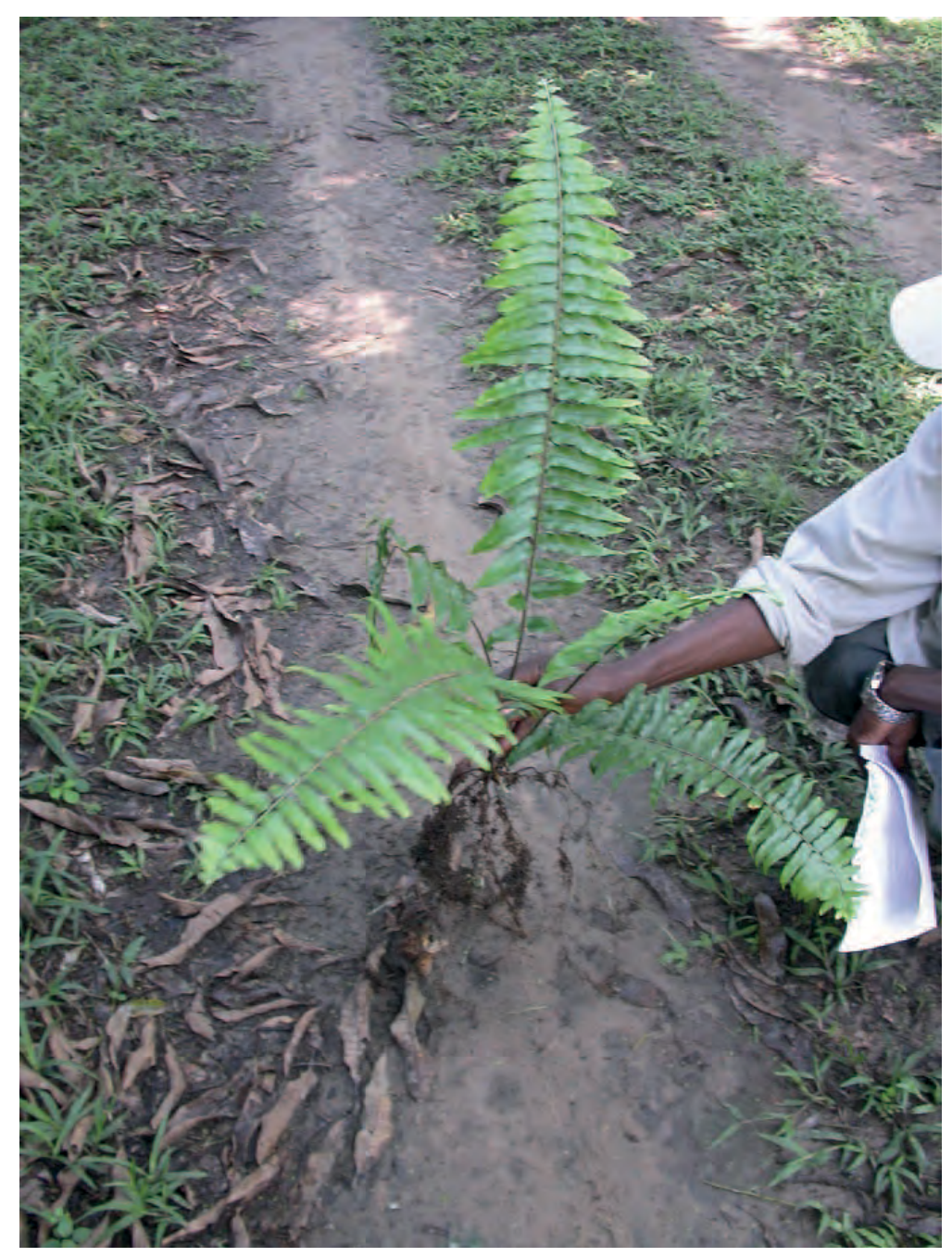

(Nephrolepidaceae)

Noms courants: Bonkenkele, biangala (Lingala), sword or Boston fern (Angl.)

Description : Fougère épiphyte pérenne à feuilles arquées. Pétioles pouvant avoir $40 \mathrm{~cm}$ de long. Les feuilles peuvent atteindre $2,5 \mathrm{~m}$ de long et $30 \mathrm{~cm}$ de large, avec des pennes de $15 \times 2 \mathrm{~cm}$.

Ecologie : Plante pantropicale, présente aussi en Afrique du Sud, dans des sites frais et arrosés, le plus souvent à l'ombre. On trouve cet épiphyte dans les forêts galeries, les forêts secondaires et les plantations, souvent sur les palmiers à huile.

Gestion : Supporte les périodes sèches et la lumière éclatante.

Usages: Au Kongo Central, on découpe les jeunes feuilles enroulées sur elles-mêmes pour les cuire dans I'huile ou dans l'eau et les manger comme légumes. Dans beaucoup de Provinces de la R.D. Congo, on brûle la souche de cette plante pour frotter les pièges avec la cendre. La souche sert aussi à laver les jeunes enfants. Dans l'Equateur, on trempe les feuilles dans I'huile de palme, puis on les applique sur les inflammations; on emploie les feuilles séchées, également trempées dans l'huile de palme, pour faire des massages sur les rhumatismes. Dans la Sangha (Congo Brazzaville), on donne à boire une décoction des frondes pour traiter la dysenterie et pour prévenir les avortements ; on prescrit le jus des frondes contre la gonorrhée. Dans la Province de la Tshopo (autour de Kisangani), la plante sert de légume et de condiment; les feuilles aident à retirer les épines du corps ; les feuilles sont aussi employées comme un savon; et pour sécher le poisson. Au Kivu, les Shi mangent le rhizome.

Références: De Wildeman 1909, Bouquet 1969, Konda Ku Mbuta et al. 1992, Lawalrée 2000, Vande weghe 2004, Termote 2012, Fundiko 2015, Konda Ku Mbuta et al. 2015 a et $2015 b$

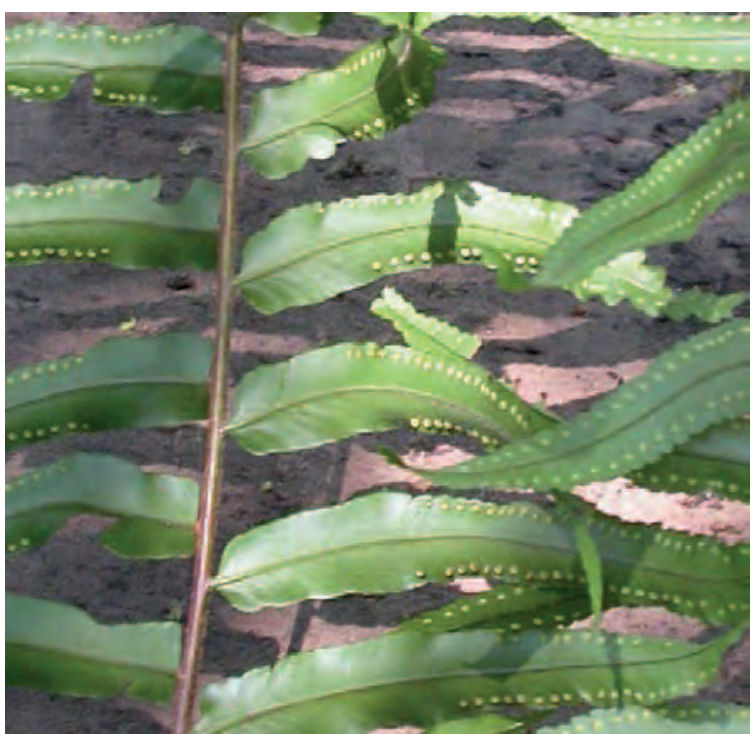




\section{Newbouldia laevis}

Noms courants: Mumpese mpese (Kikongo), boundary tree (Angl.)

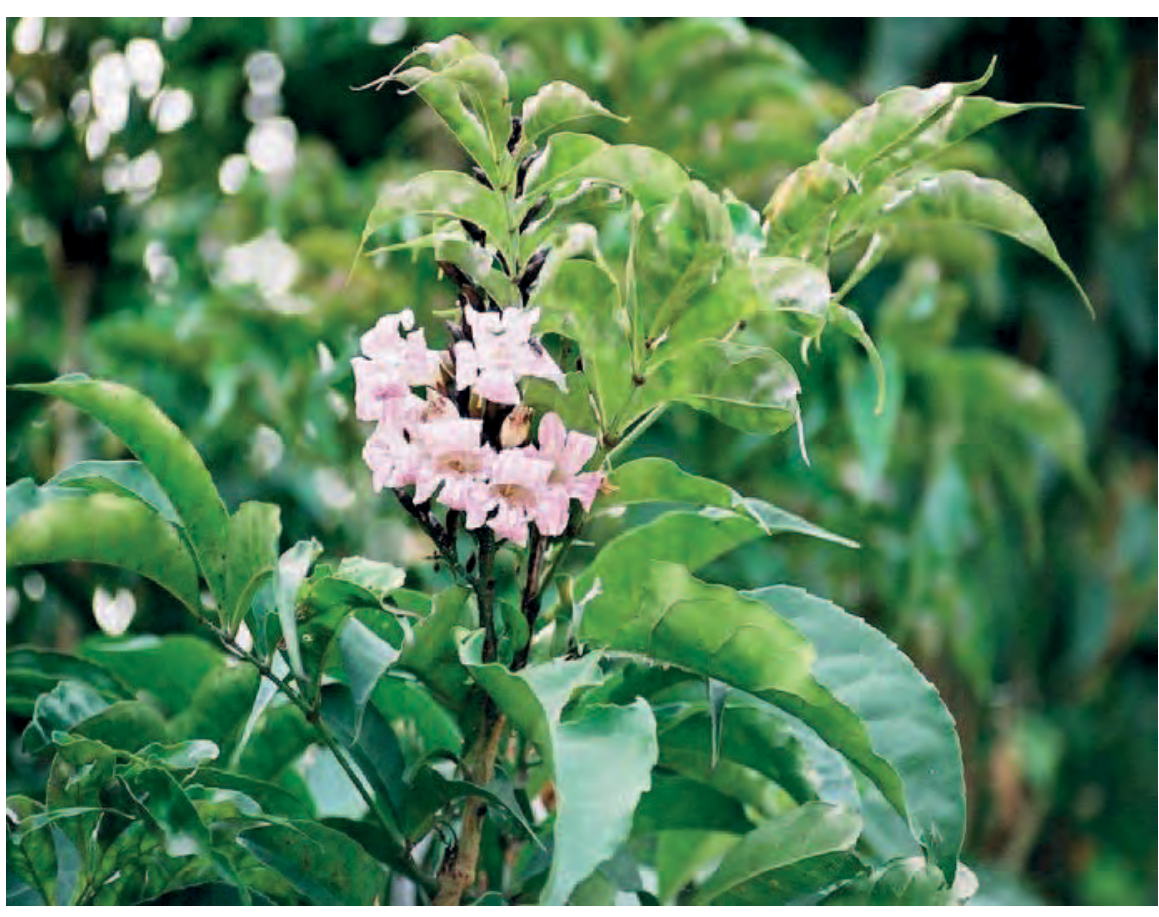

Description : Arbuste ou petit arbre de 3 à $8 \mathrm{~m}$ de haut, avec des branches verticales et de belles fleurs. Inflorescences en panicules terminales de 10 à $15 \mathrm{~cm}$ de long, fleurs de couleur lilas, à corolle d'environ $5 \mathrm{~cm}$ de long. Les fruits sont des capsules de 25 à $35 \mathrm{~cm}$ de long sur 1 à $1,8 \mathrm{~cm}$ de large.

Ecology : Arbre des savanes boisées, du Sénégal à la R.D. Congo.

Reproduction : L'arbre se cultive aisément, à partir des graines ou par boutures.

Usages : Souvent planté comme haie ou pour marquer les limites autour des parcelles. Le bois est régulière et moyennement durable ; on en fait des poteaux et des manches d'outils; il constitue un bon bois de feu. Au Kongo Central, on prend une décoction des racines pour contrôler les vers intestinaux. Cette plante a de nombreux usages médicinaux ; un bain de bouche préparé avec les feuilles peut s'avérer efficace pour combattre les bactéries qui causent la carie dentaire.

Newbouldia laevis planté autour d'une parcelle.

Références : Butaye 1909, Gillet et Pâque 1910, Gillet 1927, Renier 1948, Nsimundele 1966 - 68, Liben 1977, Burkill 1985, Pauwels 1993, Neuwinger 2000, Okeke 2003, Nzuki Bakwaye et al. 2013

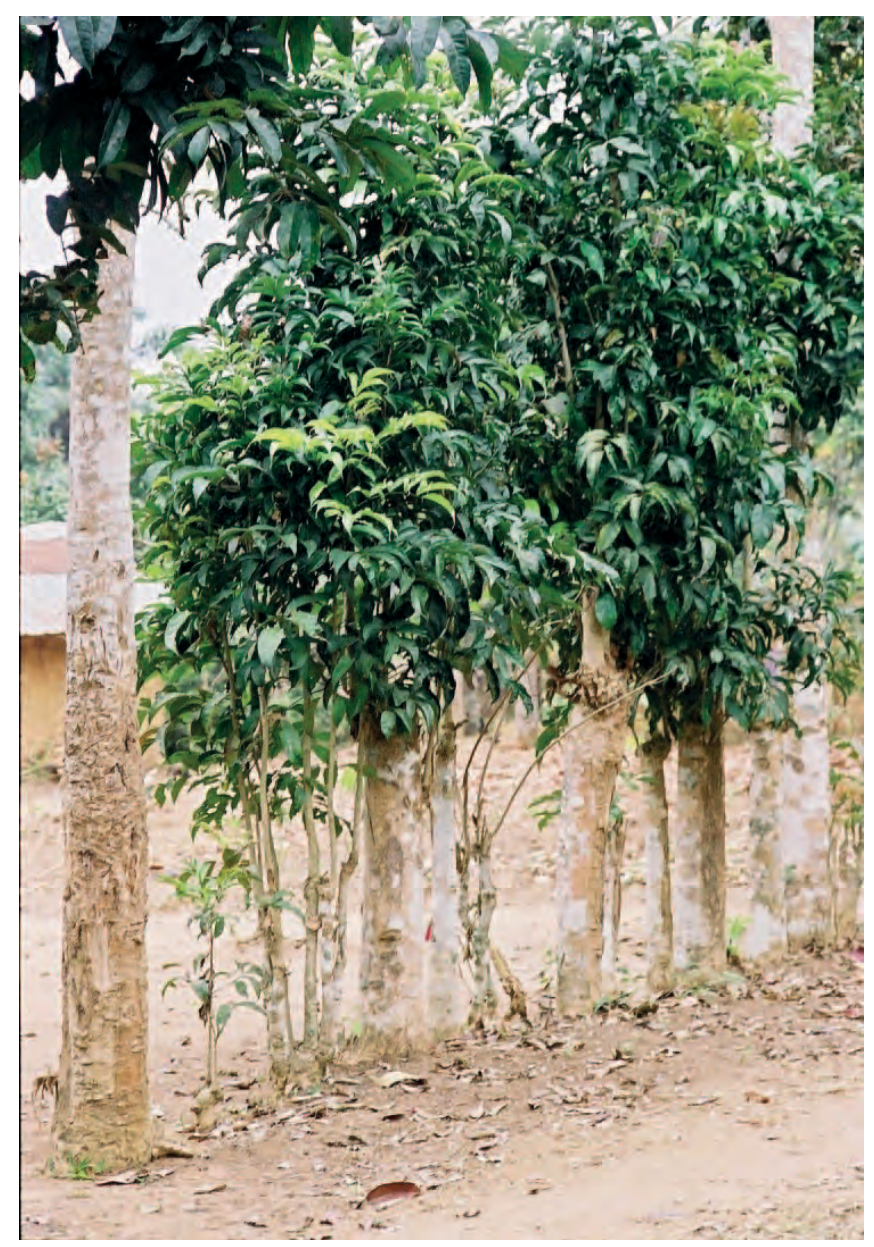


Noms courants : Fumu (Kintandu), tumbaco (Lingala), tabac, herbe à Nicot (Fr.), tobacco (Angl.)

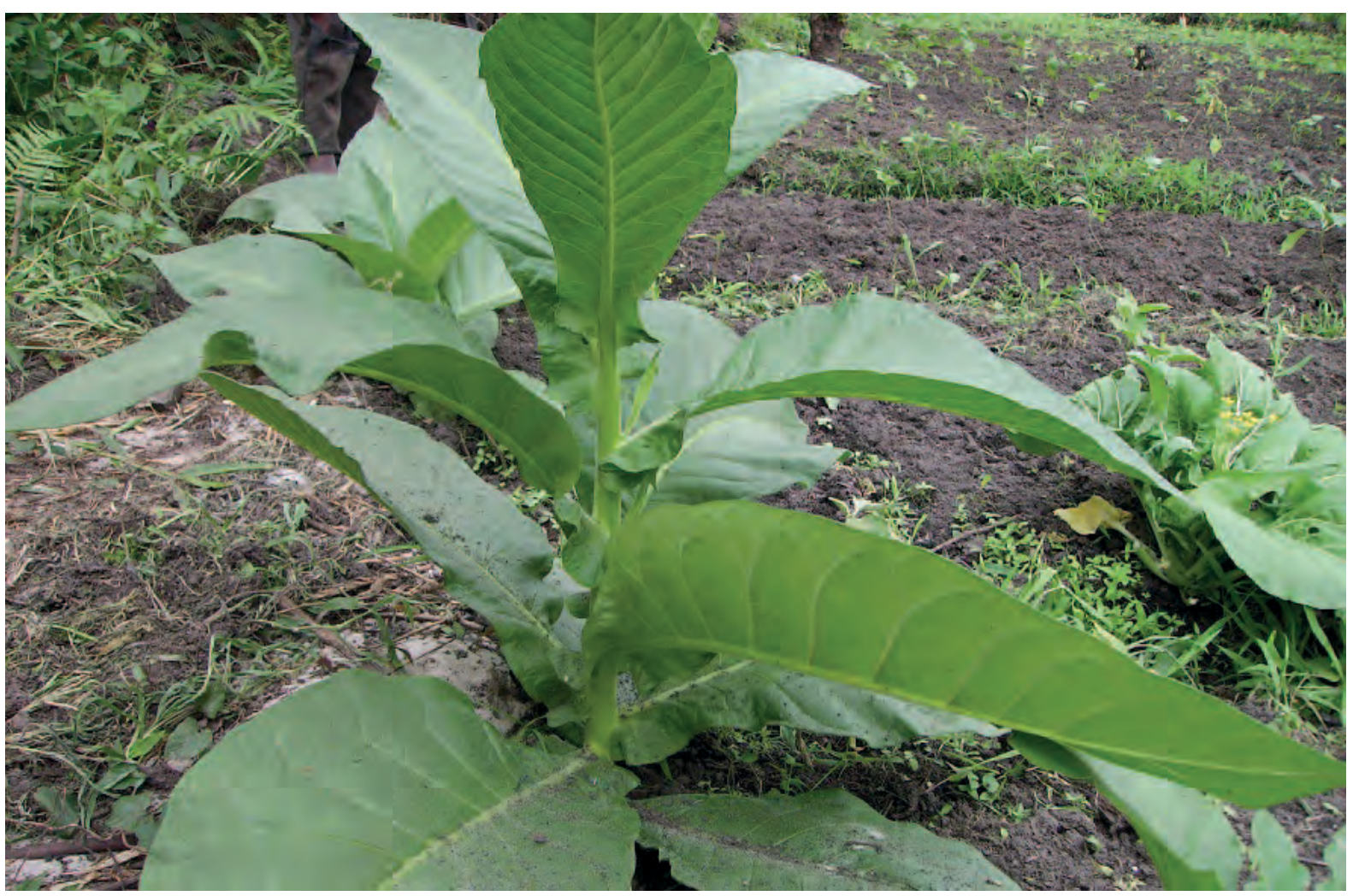

Description : Plante herbacée annuelle de 1 à $3 \mathrm{~m}$ de haut. Les feuilles nombreuses, entières, de 30 à $50 \mathrm{~cm}$ de long sur 10 à $21 \mathrm{~cm}$ de large, fragiles, sont alternes, sessiles, de forme ovale à lancéolée, à pointe aigüe et de couleur vert pâle. Au toucher, elles sont visqueuses comme la tige. Les fleurs sont vert-jaunâtre, blanches ou rosées selon la variété, atteignant $5 \mathrm{~cm}$ de long. Le fruit est une capsule déhiscente qui renferme de nombreuses petites graines.

Ecologie : Plante originaire d'Amérique Centrale, qui prospère en climats chauds, et demande suffisamment de pluie pendant sa croissance. Elle pousse mal sur les sols inondés ou les sols salins.

Reproduction : Les graines sont durables. On doit les semer délicatement sur un germoir bien préparé. Une cuillère à thé suffit pout $30 \mathrm{~m}^{2}$. La meilleure méthode est d'utiliser un arrosoir muni d'un pulvérisateur. Mettre les graines dans l'arrosoir, ajouter l'eau, agiter, puis pulvériser.

Usages : La plante est couramment cultivée pour le tabac à fumer, et aussi à priser ou chiquer. On peut aussi l'utiliser comme insecticide en pulvérisation. Les plus fortes concentrations de nicotine se trouvent dans les tiges et dans les nervures des feuilles. Les pulvérisations sont plus efficaces quand la température dépasse $30^{\circ}$ $C$; elles repoussent également les insectes, et ont des effets fongicides. On ne doit manger les récoltes alimentaires que plus de quatre jours après la pulvérisation. Les pulvérisations de nicotine sont

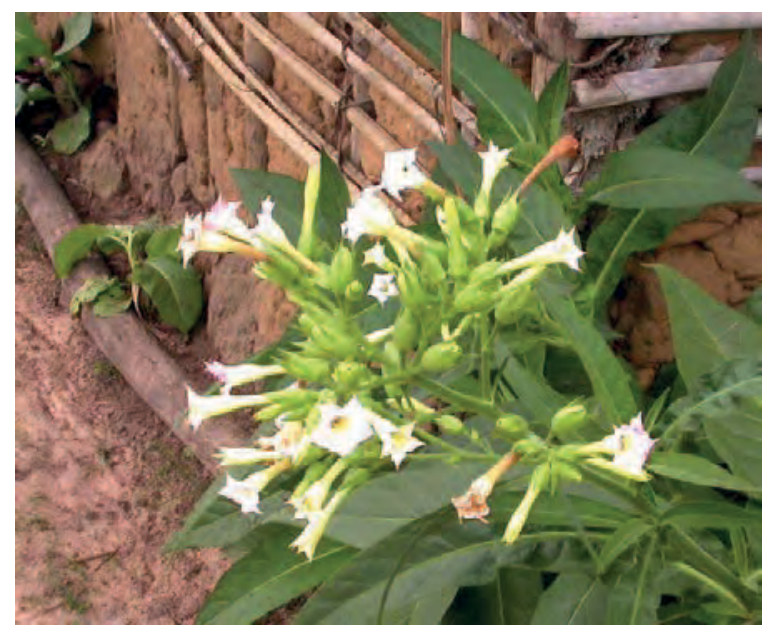
efficaces contre les pucerons, les piérides du chou, les chenilles, les altises, les charançons, la mineuse des feuilles, les mites, les térébrants, et la rouille des haricots. Tremper 24 heures dans 15 litres d'eau $1 \mathrm{Kg}$ de tiges et feuilles de tabac pilées. Ajouter un peu de savon râpé, pour faciliter l'adhésion du spray sur la plante. Filtrer pour éliminer les parties solides. Pulvériser immédiatement. Laver soigneusement tout le matériel après usage. La nicotine est très toxique (dose mortelle entre $\mathbf{3 0}$ et $\mathbf{6 0} \mathbf{~ m g}$ ) et un insecticide très puissant (50 fois plus toxique que le DDT). Il est essentiel d'éviter tout contact avec la peau pendant toute la séquence des opérations. Le tabac est aussi une plante utile pour les abeilles, auxquelles elle fournit du pollen et du nectar. Le miel de tabac 
seul a mauvais goût ; mais ce goût est normalement masqué, le nectar du tabac étant mélangé avec celui d'autres plantes.

Références : Gillet 1927, Purseglove 1968, Daeleman et Pauwels 1983, Crane et al. 1984, Stoll 2000, Bikandu et al. 2020

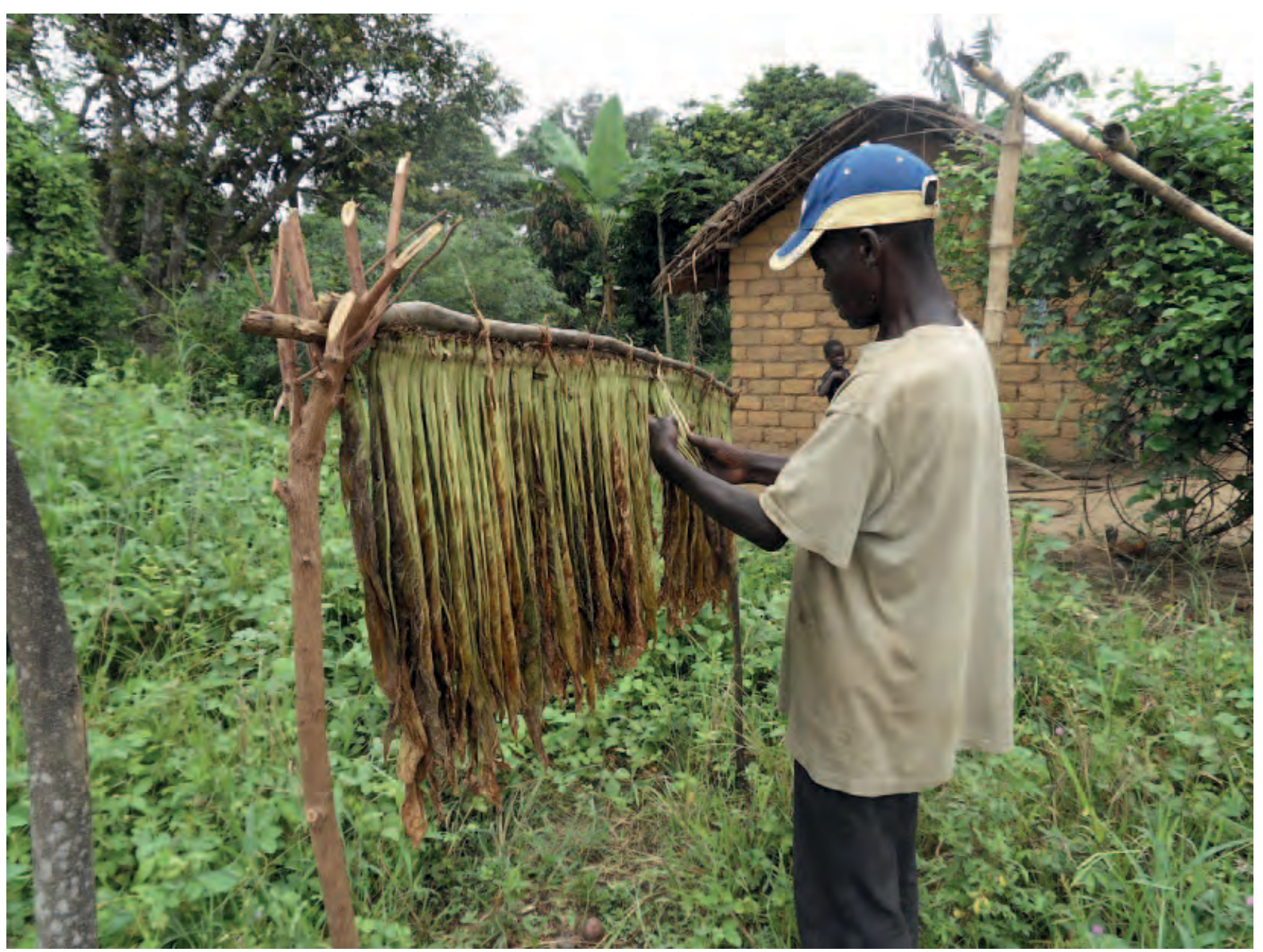




\section{Nymphaea lotus}

Noms courants : Longalonga, kilongalonga (Kikongo). (désigne aussi N. maculata et $N$. nouchall), koto (Lingala), nénuphar ( $F r$.), water-lily (Angl).

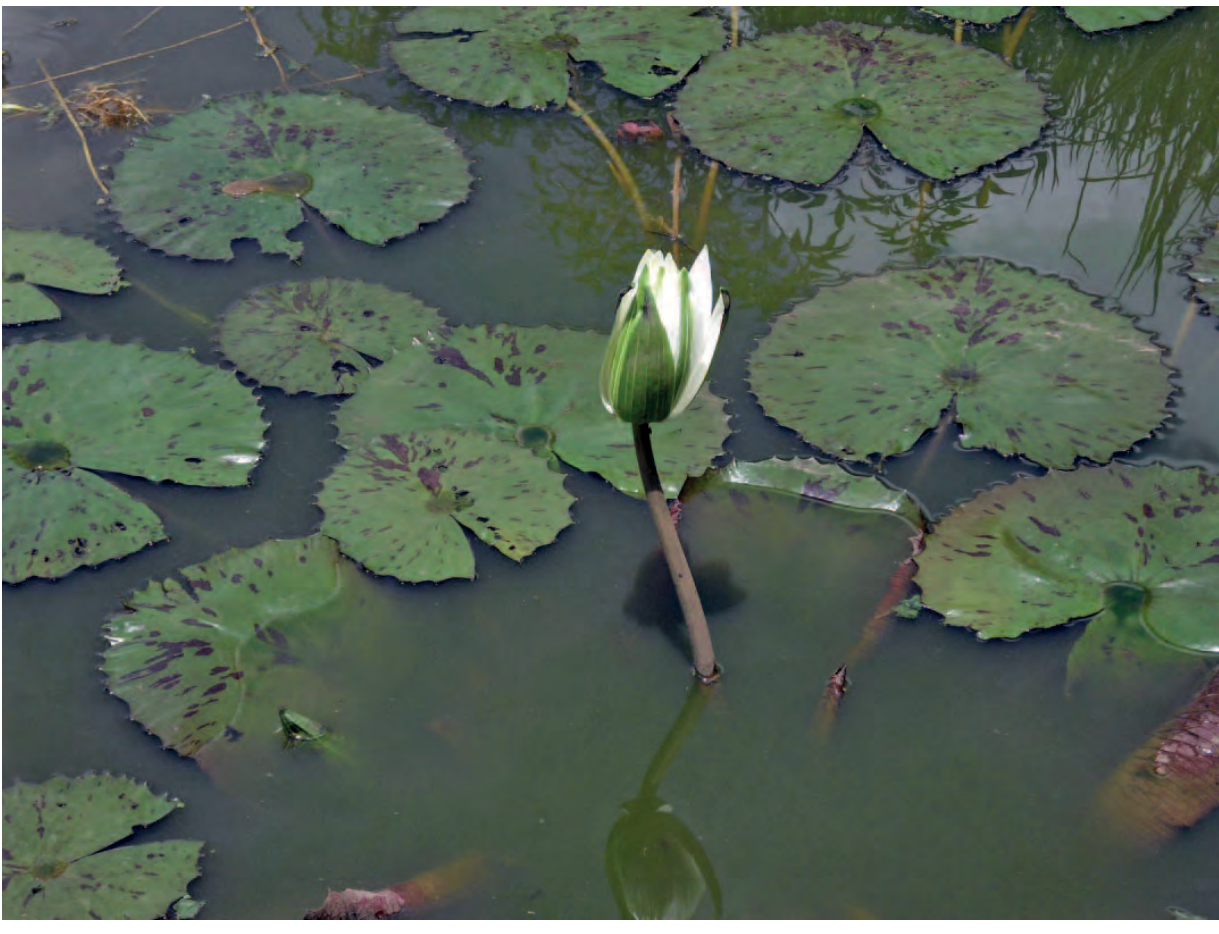

Description : Plante aquatique pérenne avec un long rhizome tubéreux et des racines ancrées dans la vase. Les feuilles flottantes sont rondes, de 12 à 40 $\mathrm{cm}$ de diamètre, vert brillant en dessus, vert pâle souvent striées de pourpre foncé en dessous. Les bords des feuilles sont nettement dentés. Les fleurs solitaires, de couleur blanche, crème ou rose, avec des étamines jaunes, ont jusqu'à $20 \mathrm{~cm}$ de diamètre, au bout de tiges en partie émergentes pouvant atteindre $2 \mathrm{~m}$ de long. Elles fleurissent toute l'année.

Ecologie : Plante des eaux calmes, originaire d'Afrique de l'Est et Asie du Sud. Elle était cultivée dans l'ancienne Egypte, où on lui attribuait une grande valeur comme un symbole de la création, dont les fleurs pouvaient procurer la force et le pouvoir. Elle est maintenant répandue dans tous les continents. Elle est invasive dans les eaux stagnantes.

Reproduction : Se cultive à partir des graines ou du rhizome.

Usages : Le nénuphar est cultivé à titre ornemental dans les bassins et les pièces d'eau. Au Kongo Central, on emploie les feuilles pour traiter les abcès, les démangeaisons, la migraine, l'alcoolisme, l'addiction au tabac, le jaunissement des cheveux, les œdèmes, les rhumatismes, l'épilepsie, les éruptions cutanées, et les troubles mentaux. La cendre a servi à donner du sel. Dans certaines zones, on mange les rhizomes, les réceptacles floraux et les graines. Les rhizomes se mangent crus, en ragouts ou en sauces. On peut aussi les piler pour avoir une farine. Les racines, gluantes, sont diurétiques, narcotiques et sédatives. Les abeilles récoltent le nectar et le pollen des fleurs, comme ceux de $N$. nouchali (à droite).

Références : Gillet et Pâque 1910, De Wildeman 1934, Staner et Boutique 1937, Renier 1948, Hauman 1951, Busson 1965, Arkinstall 1979, Daeleman et Pauwels 1983, Akobundu et Agyakwa 1987, Fichtl et Adi 1994, Burkill 1997, Kibungu Kembelo 2003

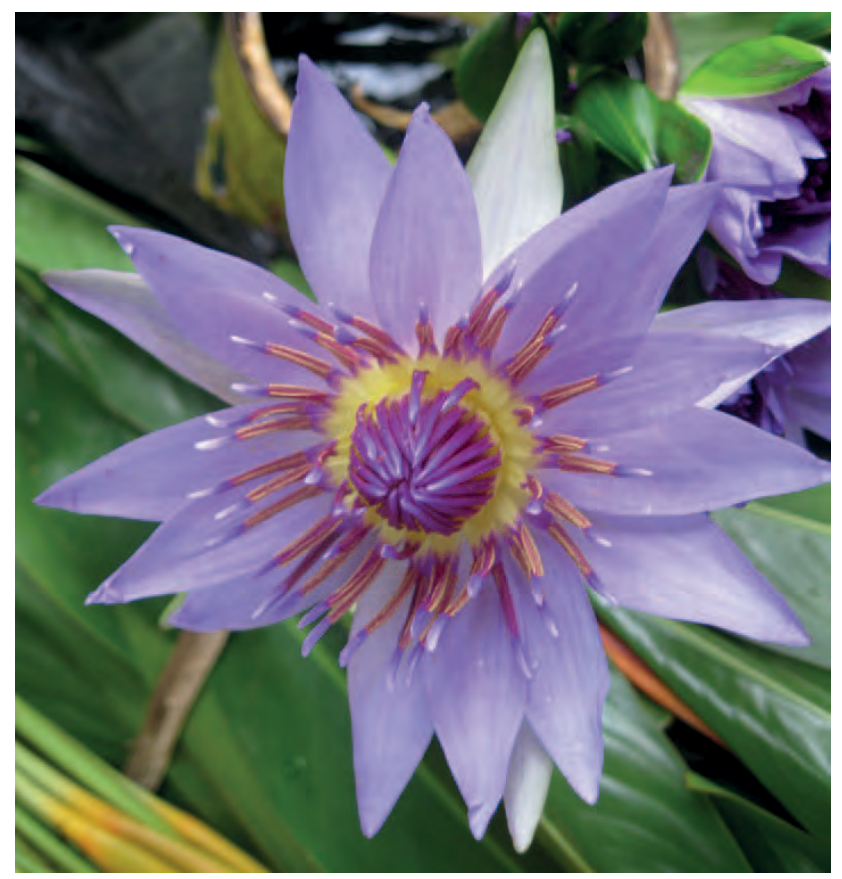


Noms courants : Kidimbi, kidimbi ki nseke, ngo nti (Kikongo)

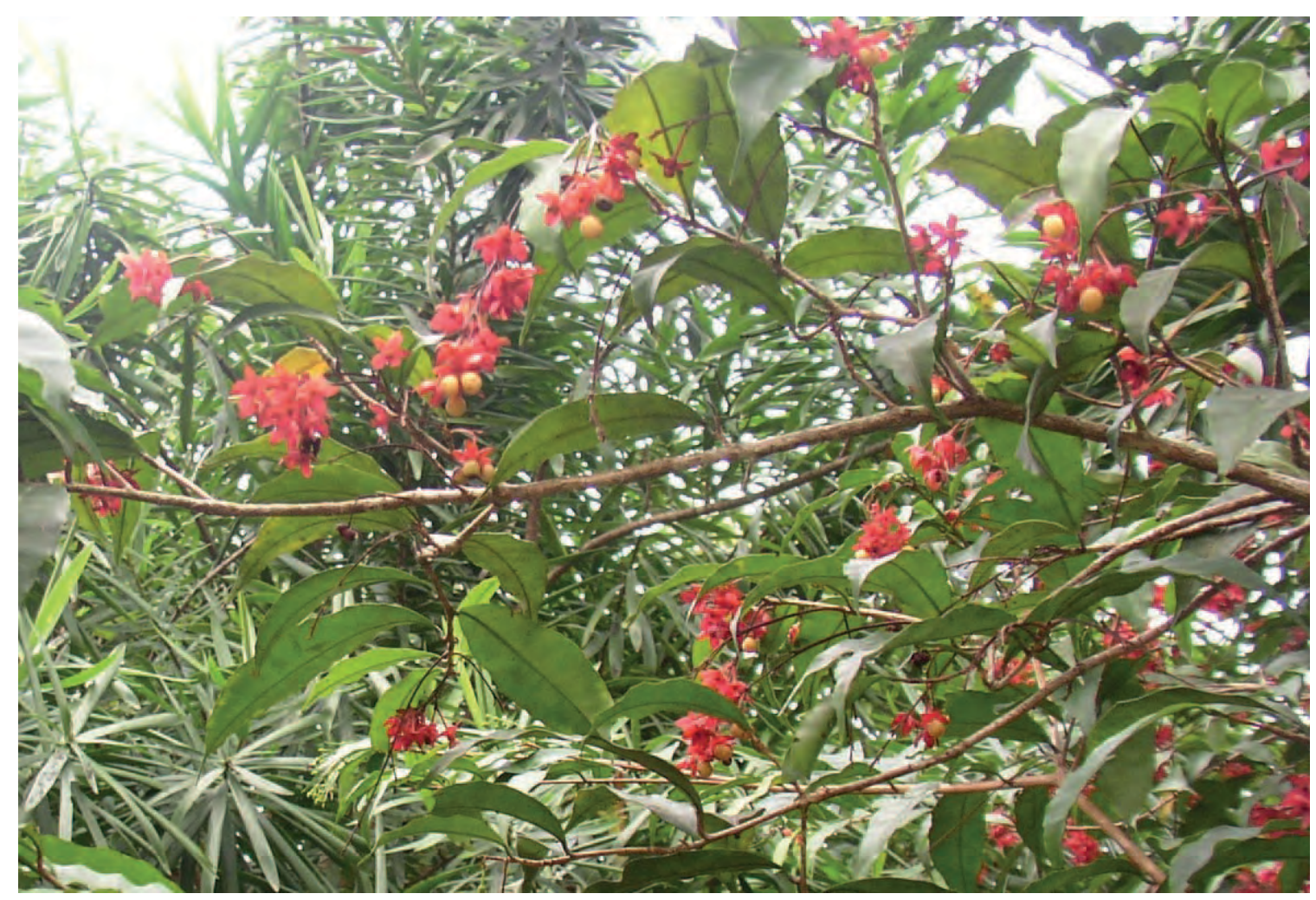

Description : Arbuste de 3 à $8 \mathrm{~m}$ de haut. Les feuilles lancéolées mesurent 3 à 15 sur 1 à $6 \mathrm{~cm}$. Inflorescences en courts racèmes de 2 à 6 fleurs. Les pétales jaunes ont de 5 à $13 \mathrm{~mm}$ de long. Les sépales rouges ont de 4 à 6 $\mathrm{mm}$ de long à la floraison. Ils grandissent jusqu'à $18 \mathrm{~mm}$ et persistent autour des fruits, pouvant donner à l'arbre vu de loin une coloration rouge. Les fruits sont des drupes, jaunes puis noires, de 6 à 9 sur 4 à $7 \mathrm{~mm}$.

Ecologie : Arbuste des savanes boisées et des lisières de forêts. Largement répandu en Afrique tropicale, de la Guinée au Cameroun, au bassin du Congo, au Soudan et en Ouganda.

Reproduction: Les espèces du genre Ochna peuvent se cultiver à partir des graines, ou de boutures prélevées sur de jeunes branches.

Usages : Les feuilles se mangent crues en salade. Elles sont un bon fourrage pour les chèvres et les moutons. Le bois, brun clair, est dur et lourd. On l'emploie pour les manches d'outils et le mobilier. Au Kongo Central, l'écorce s'emploie comme teinture. L'écorce interne sert à traiter l'anémie : on

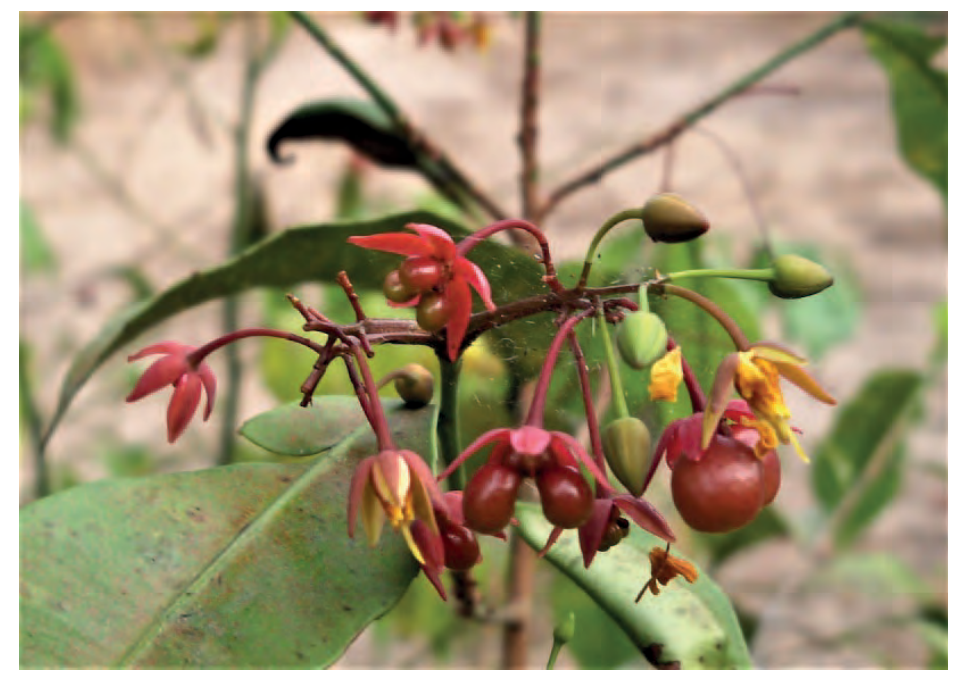
la sèche, la trempe dans l'eau bouillante, puis on administre de petites quantités au patient. Ailleurs en Afrique, on utilise l'écorce de la racine comme celle des tiges pour traiter la toux, la dysenterie, les maladies parasitaires de la peau et I'inflammation des gencives. Les fruits seraient comestibles. Les chenilles comestibles Kwesu (Gonimbrasia eblis) se nourrissent des feuilles.

Références : Gillet et Pâque 1910, Renier 1948, Irvine 1961, Watt et Breyer-Brandwijk 1962, Nsimundele 1966 68, Bamps et Farron 1967, Daeleman et Pauwels 1983, Peters et al. 1992, Pauwels 1993, Burkill 1997 Lautenschläger et al. 2018, 
Noms courants : Boma (Lingala), mukezo a temo (Kipende), mermaid tree (Angl.)

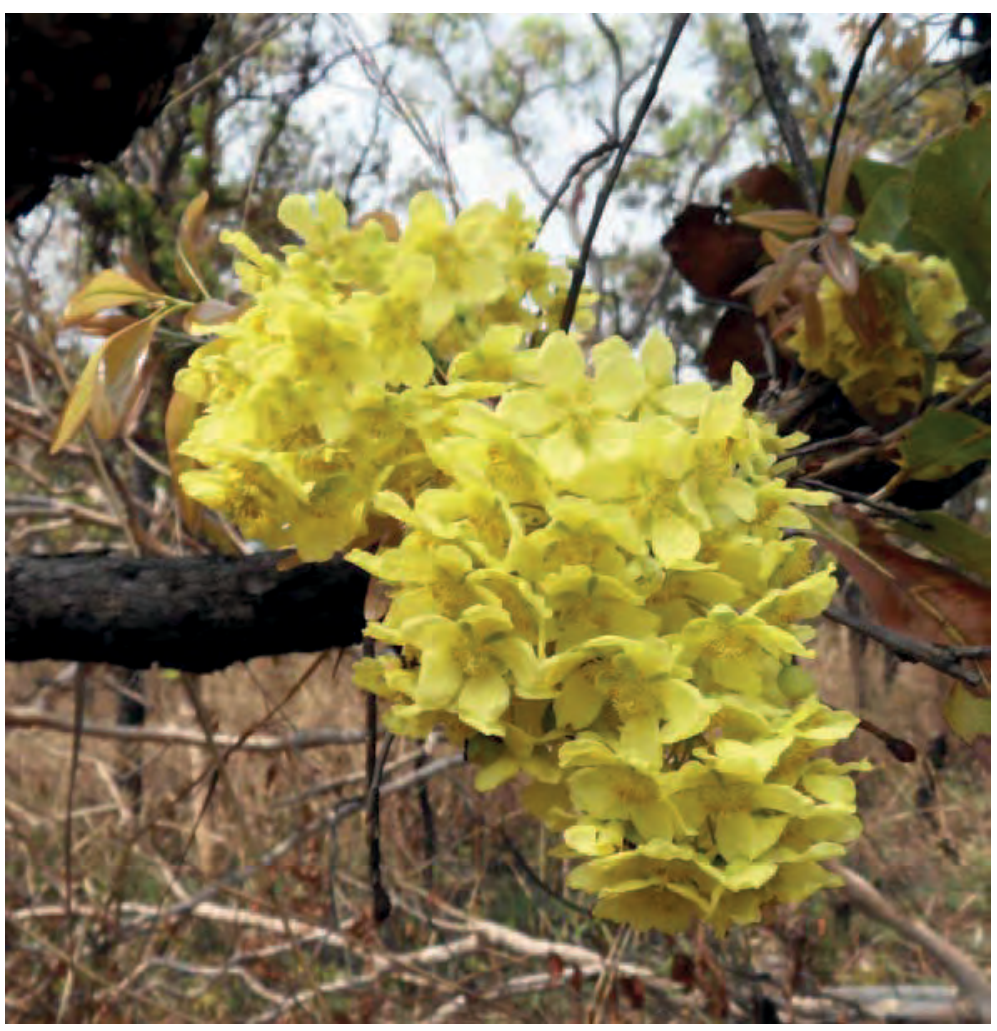

Description : Arbuste à couronne étalée pouvant atteindre $8 \mathrm{~m}$ de haut; l'écorce s'écaille en plaques. Feuilles brillantes, simples, alternes, avec de courts pétioles robustes de 2 à $15 \mathrm{~mm}$ de long. Le limbe a 5 à 16 sur 2 à $6 \mathrm{~cm}$. Les jeunes feuilles sont vert clair, bronzées ou rouges. Les fleurs sont jaunes et parfumées, éphémères, en nombreux racèmes. Les fruits réniformes, de 8 à $12 \mathrm{~mm}$ de long, sont entourés de sépales persistants, roses à rouges.

Ecologie: Arbuste des forêts claires, des savanes boisées, et des brousses sableuses. Présent en R.D. Congo au Kongo Central, au Kasaï et au Katanga. Présent également en Angola, en Zambie, au Botswana et au Transvaal.

Reproduction: La culture de cet arbuste est difficile. Les graines sont souvent parasitées. Récolter des graines avant qu'elles noircissent complètement, les semer immédiatement dans du sol portaient, et les repiquer dès que possible.

Usages: Le bois s'emploie en menuiserie, et pour fabriquer des outils et des ustensiles. Le fruit est comestible mais les graines sont toxiques. La graisse du fruit peut s'employer pour fabrique des bougies et en savonnerie. Les fleurs sont très attirantes pour les abeilles et les autres insectes.

Références : Renier 1948, Watt et Breyer Brandwijk 1962, Bamps et Farron 1967, Malaisse 1997, Behr 2005

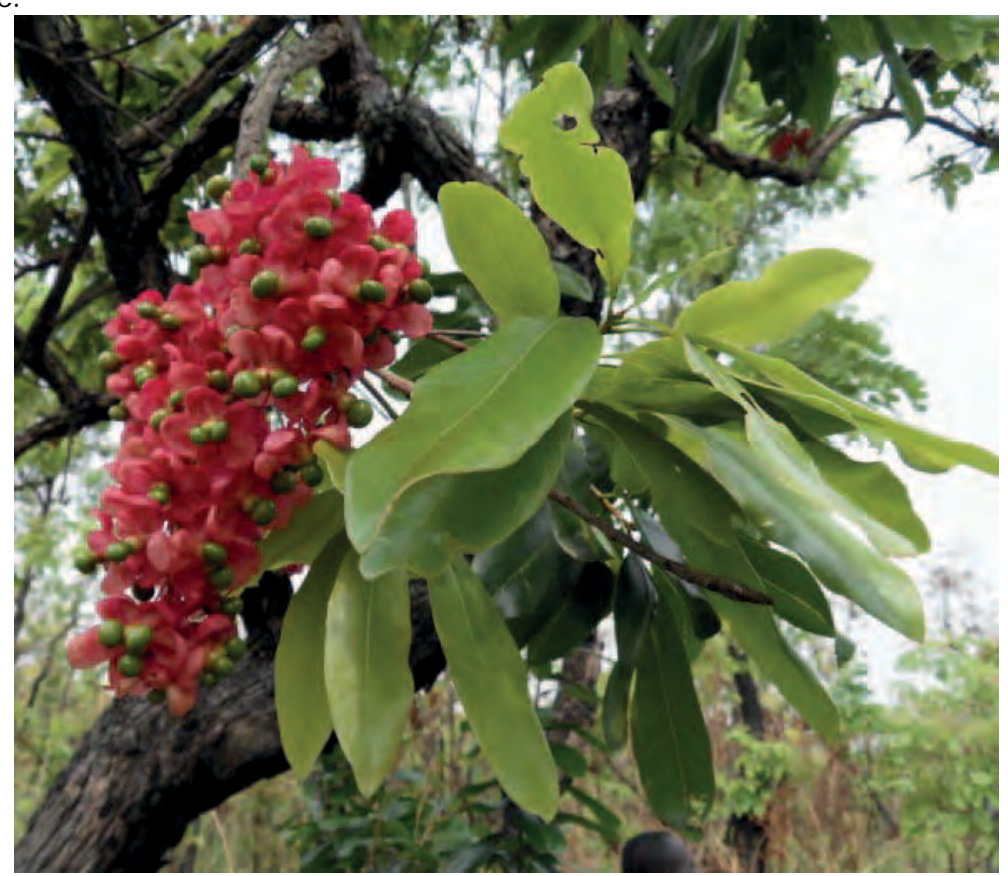




\section{Ocimum americanum}

Synonyme : 0 . canum

Noms courants : Dingwansi (Kikongo), camphor basil (Angl.).

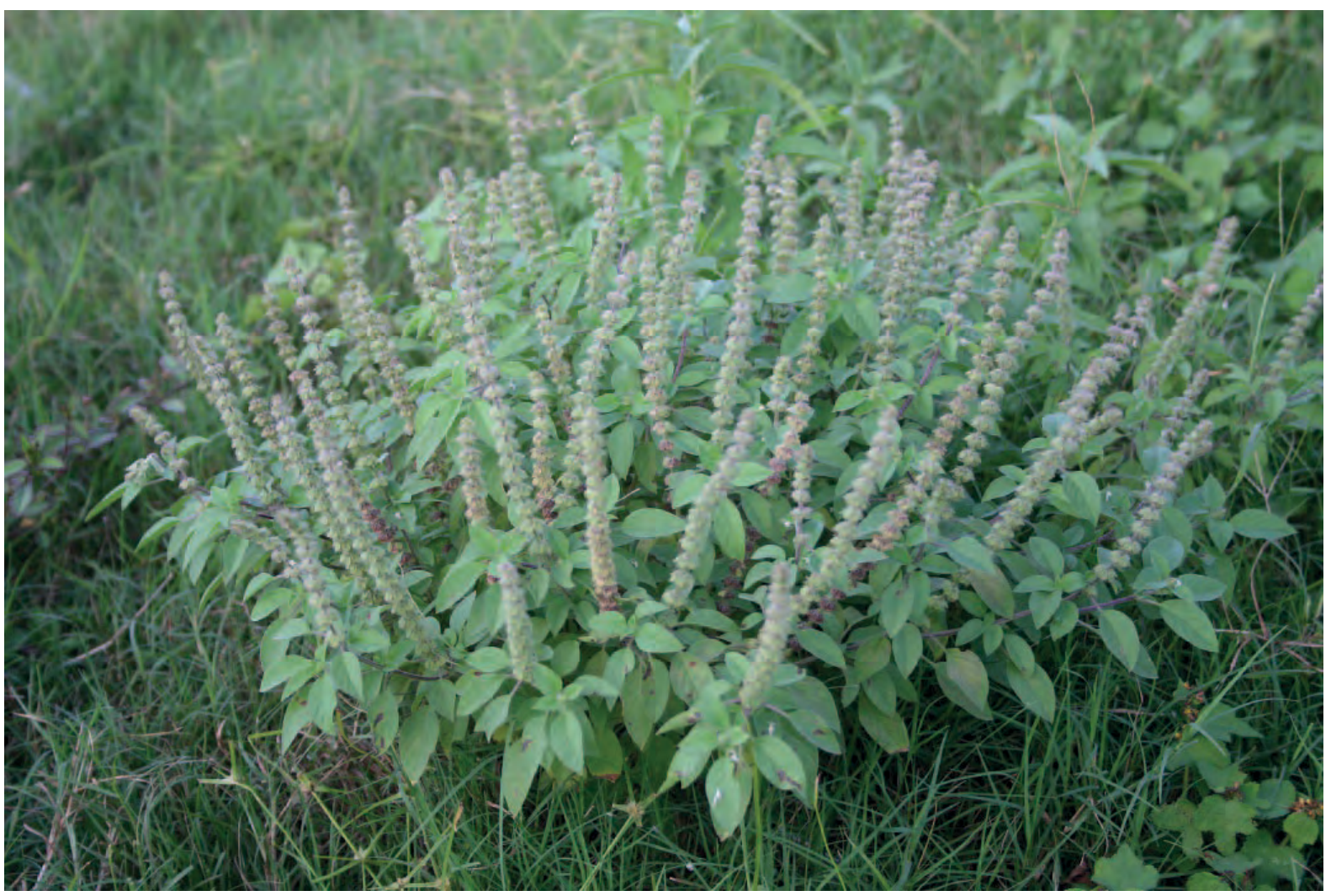

Description : plante herbacée buissonnante, semi-ligneuse, aromatique, pouvant atteindre $40 \mathrm{~cm}$ de haut. Tige et branches quadrangulaires, vert pâle, densément couvertes quand elles sont jeunes de poils blancs dont la densité diminue par la suite. Feuilles simples sur un pétiole jusqu'à $2,5 \mathrm{~cm}$ de long. Le limbe est lancéolé à elliptique, de 2,5 à 5 sur 1 à 2,5 cm, avec des glandes sur les deux faces. L'inflorescence, qui a jusqu'à $15 \mathrm{~cm}$ de long, est composée de trois cymes. Fleurs longues de $5 \mathrm{~mm}$, blanches ou pourpre clair. Le fruit est composé de quatre graines distinctes.

Ecologie : Plante présente et souvent cultivée à Madagascar, en Afrique tropicale, Péninsule Arabique, Asie du Sud, du niveau de la mer à $450 \mathrm{~m}$.

Reproduction : A partir des graines.

Usages: Employée comme condiment, spécialement pour masquer le goût de vase ou la mauvaise odeur de certains poissons. On boit aussi une infusion des feuilles. Leur goût est plus doux que celui de 0 . basilicum ou 0 . gratissimum. On les emploie contre les vers intestinaux. Les espèces du genre Ocimum sont d'importants fourrages pour les abeilles dans les savanes sèches. Leur miel est léger et délicieux.

Références : Gillet et Pâque 1910, Gillet 1927, Staner et Boutique 1937, Renier 1948, Daeleman et Pauwels 1983, Siemonsma et Kasem Piluek 1993, Burkill 1995, Hepburn et Radloff 1998

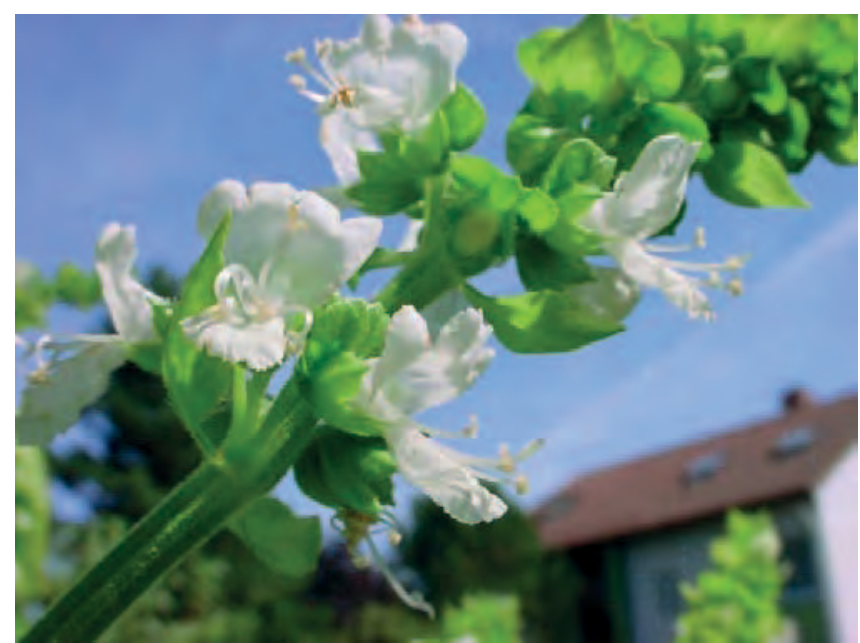

Photo: Christian Bauer 


\section{Ocimum basilicum}

Noms courants : Dizulu (Kikongo), basilic (Fr.), sweet basil (Angl.)

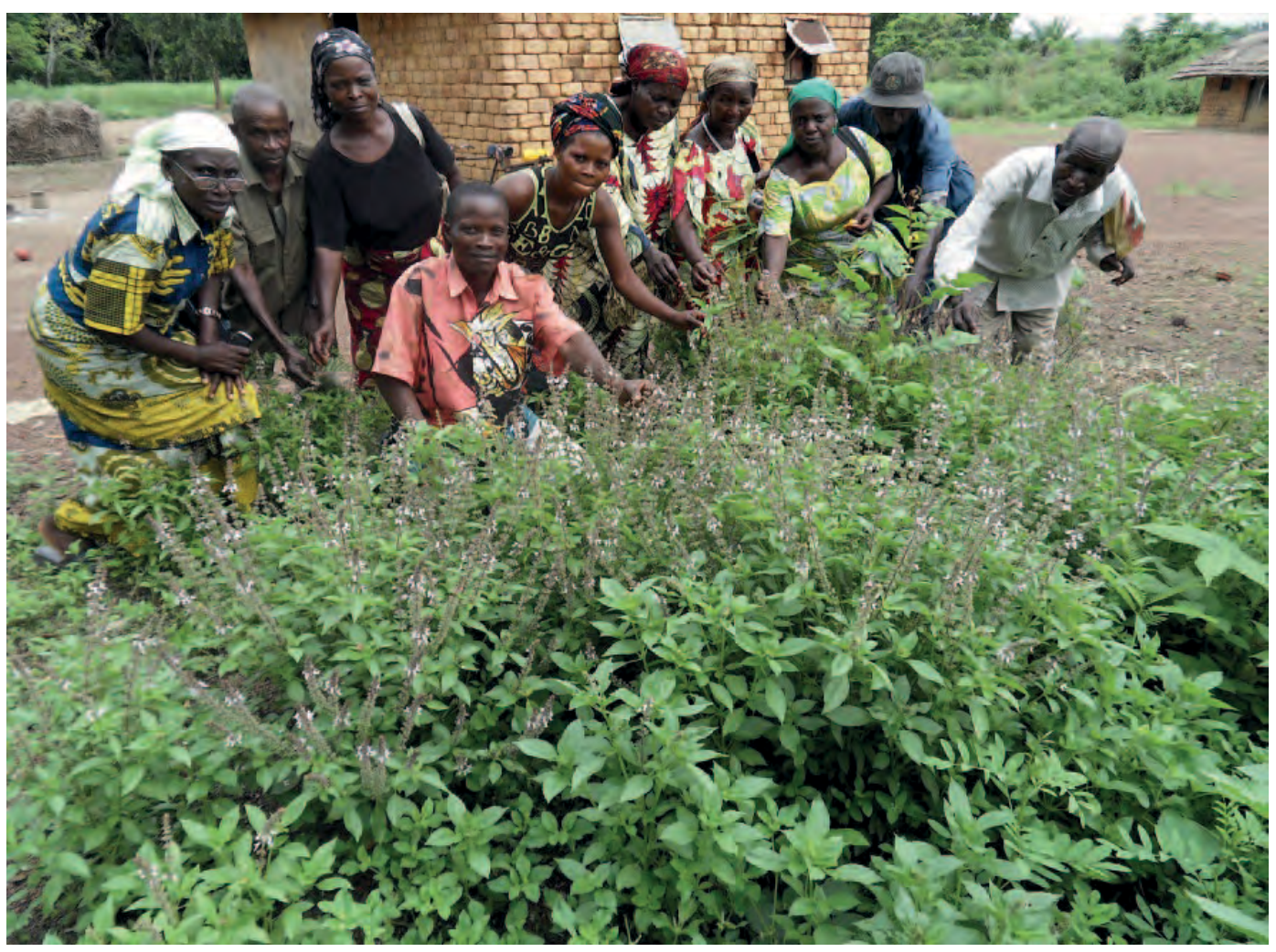

Ocimum basilicum au village de Lufulu

Description : Plante herbacée aromatique pérenne, souvent cultivée comme annuelle, buissonnante, ramifiée, ligneuse à la base, atteignant $1 \mathrm{~m}$ de haut. Les feuilles sont vert clair à vert pourpré, à marges dentées, de 3 à 8 cm de long. Les petites fleurs bleu pâle, mauves ou pourpres, au bout d'inflorescences lâches pouvant avoir $30 \mathrm{~cm}$ de long.

Ecologie : Plante probablement originaire d'Asie du Sud et d'Afrique, cultivée dans l'Egypte ancienne depuis plus de quatre mille ans, largement répandue sous les tropiques et dans le monde méditerranéen. Préfère les limons ou les sables limoneux avec un bon drainage et en pleine lumière, jusqu'à 1.000 m d'altitude.

Reproduction : Semer les graines en poquets ou en germoir, et transplanter les semis à 5 à $8 \mathrm{~cm}$ de haut, espacés de 30 × 30 à $45 \times 45 \mathrm{~cm}$. On peut aussi cultiver le basilic à partir de boutures.

Gestion : Quand la plante atteint 50 à $70 \mathrm{~cm}$, pincer le bourgeon terminal pour faciliter la ramification. Récolter juste avant la floraison. Rabattre à 10 à $15 \mathrm{~cm}$ du sol.

Usages : Les feuilles, très aromatiques, s'emploient fraîches ou séchées comme condiment pour les soupes et les sauces. On les mélange aussi avec le piment fort. Le basilic est une composante essentielle des cuisines méditerranéennes, notamment italienne et provençale. Au Kongo Central, la plante a des usages médicinaux pour traiter les maux d'estomac et les hémorroïdes. On prend couramment une infusion des feuilles pour faciliter la digestion et comme vermifuge. Les feuilles peuvent servir à tuer la mineuse des feuilles sur les avocatiers et autres arbres fruitiers : tremper toute une nuit $100 \mathrm{~g}$ de feuilles dans 1 litre d'eau ; piler et presser les feuilles, et ajouter $1 \mathrm{ml}$ de savon liquide avant pulvérisation. Le basilic fleurit toute l'année, fournissant aux abeilles pollen et nectar.

Références : Gillet 1927, Renier 1948, Daeleman et Pauwels 1983, Tindall 1983, Fichtl et Adi 1994, de Guzman et Siemonsma 1999, Stoll 2000, Kibungu Kembelo 2003, Pousset 2004, van Wyk et Wink 2004 
Synonyme : $O$. suave

Noms courants : Dinsusu, dinsusunsusu, dinkondi (Kikongo), lumba lumba (Lingala), baumier, basilic africain (Fr.), tree basil (Angl.)

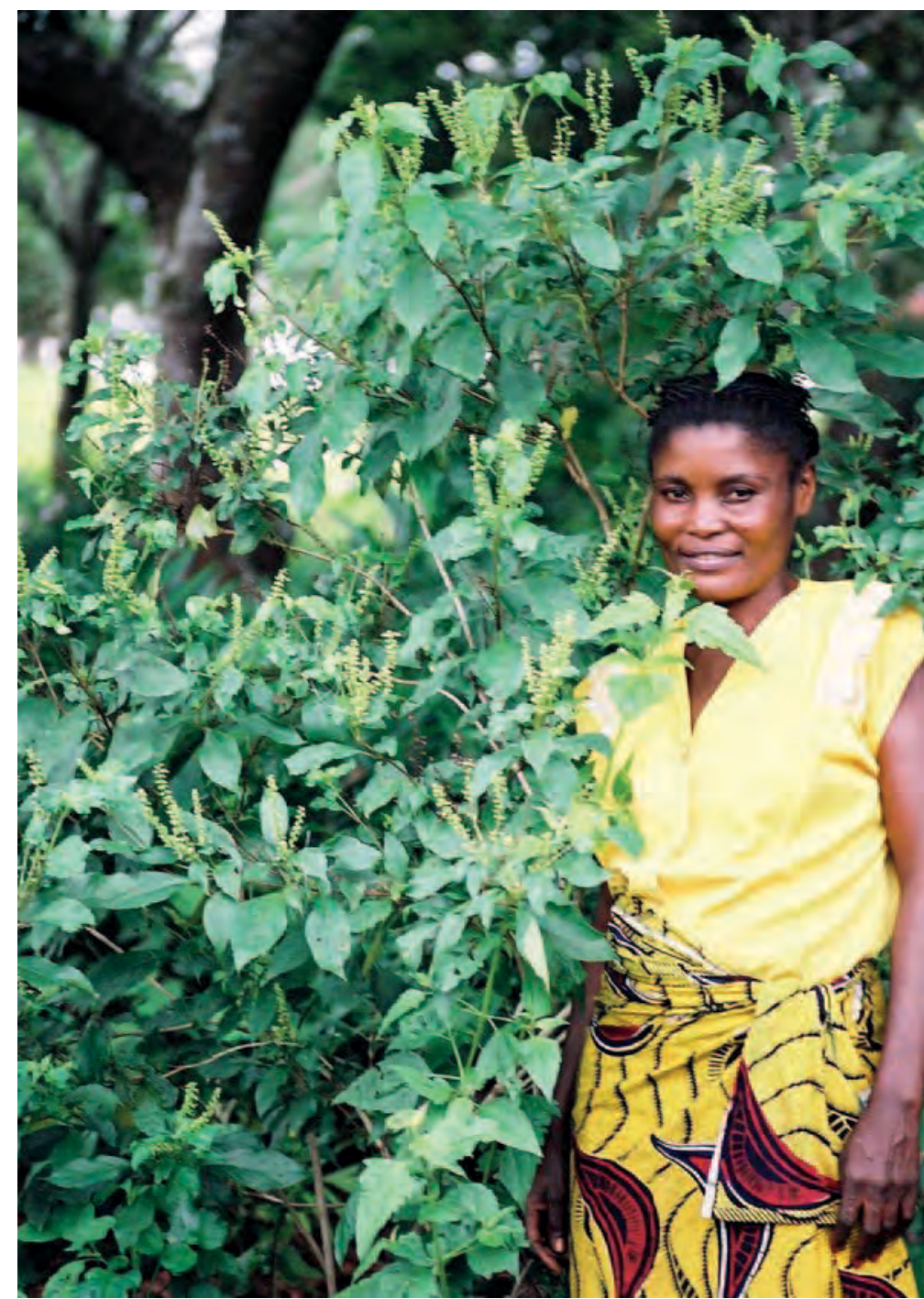

Description : Plante herbacée pérenne, ligneuse à la base, très ramifiée et très aromatique, de 1 à $3 \mathrm{~m}$ de haut. La tige est ronde à quadrangulaire. Feuilles opposées, pétiole de 2 à $4,5 \mathrm{~cm}$, limbe elliptique de 8,5 à 16 sur 1 à $1,5 \mathrm{~cm}$, avec des marges grossièrement dentées, pointu à l'extrémité, pubescent. L'inflorescence est un racème terminal, simple ou ramifié, de 5 à $30 \mathrm{~cm}$ de long. Petites fleurs blanc verdâtre. Les fruits sont de minuscules graines de $1,5 \mathrm{~mm}$ de long enfermées dans le calice persistant.

Ecologie : Plante d'Afrique tropicale et d'Asie du Sud, souvent cultivée avec les planches de légumes et autour des parcelles dans les villages.

Maman Thérèse à côté de 0 . gratissimum derrière chez elle à Kasangulu.

Reproduction : Par graines ou boutures.

Usages : Les feuilles très parfumées sont une épice très appréciée pour assaisonner la viande, notamment le poulet, et les soupes. Les feuilles et les tiges servent, en association avec d'autres plantes, à traiter le diabète, la sciatique, les hémorroïdes, la migraine, les rhumatismes, les caries dentaires, la toux, l'asthme, les problèmes oculaires et les refroidissements. On frotte les feuilles entre les mains pour les inhaler et déboucher les narines. L'huile essentielle de distillation de la plante contient de l'eugénol et du thymol. On l'emploie comme onguent pour traiter l'acné. C'est la troisième plante médicinale la plus utilisée dans les territoires de Kisantu et Mbanza Ngungu. La plante constitue un excellent insecticide. En Afrique du Sud, on la brûle pour chasser les moustiques. Les fleurs, dont la production dure de longs mois, sont importantes pour les abeilles. On frotte souvent cette plante sur les ruches, spécialement autour du seuil, ainsi que les autres espèces d'Ocimum, pour attirer les abeilles.

Références : Gillet et Pâque 1910, De Wildeman 1934, Renier 1948, Watt et Breyer - Brandwijk 1962, Arkinstall 1979, Howes 1979, Fichtl et Adi 1994, Bown 1995, Kibungu Kembelo 2003, Pousset 2004, Göhre et al. 2016, Kibungu et al. 2021 


\section{Odontonema cuspidatum}

\section{Synonyme : $O$. strictum}

Noms courants : Scarlet fire spike (Angl.)

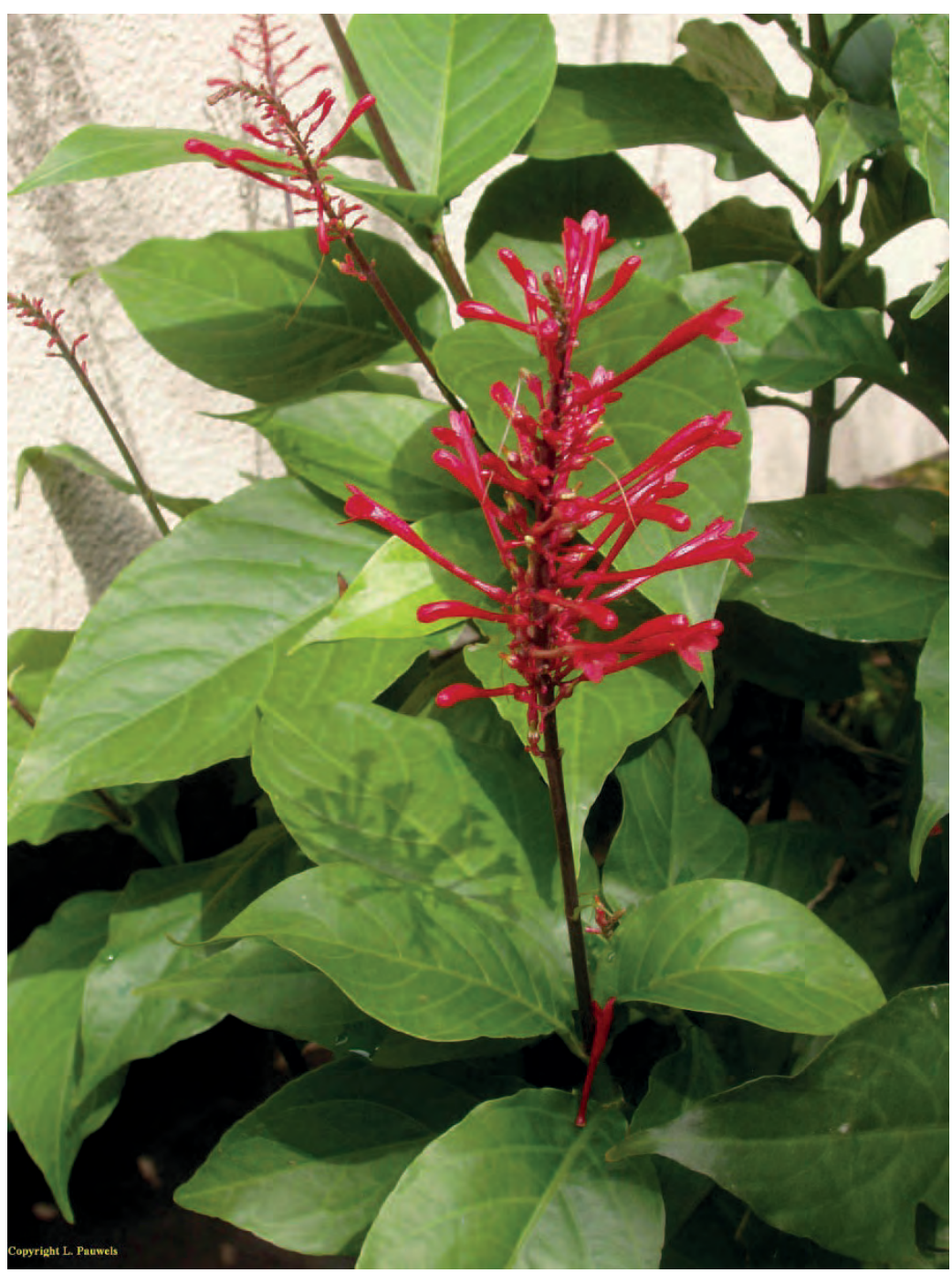

\section{(Acanthaceae)}

Description : Buisson de 2 à $3 \mathrm{~m}$ de haut, à l'odeur caractéristique. Feuilles de 7 à 17 sur 3 à $7 \mathrm{~cm}$ opposées ovoïdes-elliptiques, d'un vert brillant intense, finissant en pointe acérée. Les inflorescences en racèmes terminaux longs de $20 \mathrm{~cm}$, portent plusieurs fleurs tubulaires écarlates, longues de 2,5 à $3 \mathrm{~cm}$. Les fruits sont des capsules, longues de 7 à $10 \mathrm{~mm}$, contenant au plus quatre graines plates.

Ecologie: Plante originaire d'Amérique Centrale, où elle pousse en forêt et au bord des cours d'eau. Demande un sol fertile, riche en humus, partiellement éclairé.

Reproduction: Par graines et boutures.

Usages: Plante ornementale cultivée pour ses fleurs, qui seraient un bon fourrage pour les abeilles.

Photo: Luc Pauwels

Références : Burkill 1985, Pauwels 1993, Phillips et Rix 1997, Llamas 2003, Fayaz 2011 
Noms courants : Kiwaya, kubi (Kikongo)

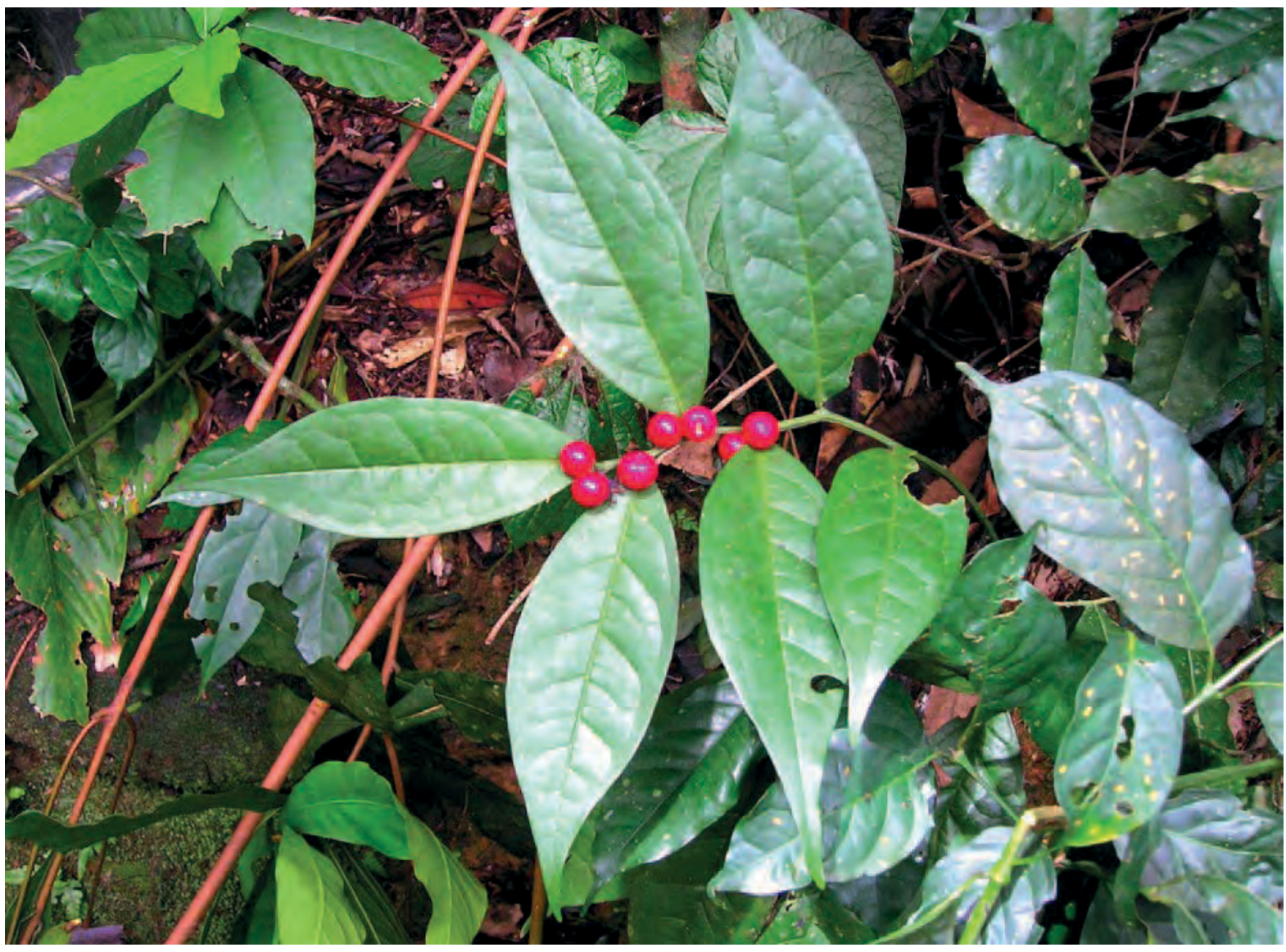

Les deux photos : Quentin Luke

Description : Buisson bas de 1 à $2 \mathrm{~m}$ de haut, à l'odeur caractéristique. Feuilles de 7 à 17 sur 3 à $7 \mathrm{~cm}$. Petites fleurs à cinq pétales blancs, en courts racèmes. Fruits ronds et rouges de 7 à $10 \mathrm{~mm}$ de diamètre, sucrés et comestibles à maturité.

Ecologie : Plante des anciennes forêts isolées et des galeries forestières, de la Sierra Leone à l'Angola, au bassin du Congo et à l'Ouganda.

Usage : La plante est appréciée comme condiment. Les feuilles et le fruit ont un goût d'ail prononcé. On met les graines entières ou râpées dans les plats comme de l'ail. On trempe l'écorce dans l'eau avec le poisson pour enlever le goût de vase. Le fruit est comestible. En R.D. Congo, on emploie la plante pour traiter la pneumonie et la lèpre ; on prend l'écorce réduite en poudre pour traiter les maux d'estomac; on emploie les feuilles pour faciliter l'accouchement.

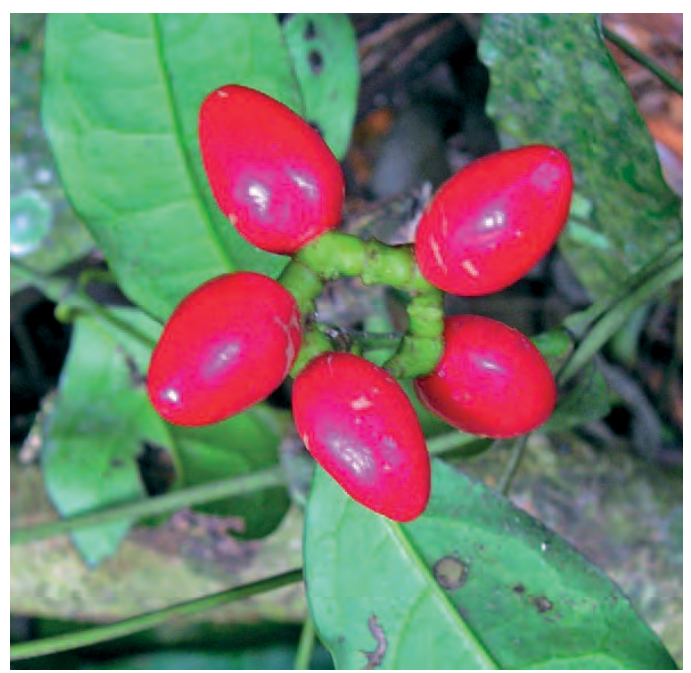

Références : Gillet et Pâque 1910, Gillet 1927, Staner et Boutique 1937, Louis et Léonard 1948, Renier 1948, Daeleman et Pauwels 1983, Pauwels 1993, Burkill 1997, White et Abernethy 1997, Nsimundele 2004, Hawthorne et Jonkind 2006, Biloso 2010 
Nom courant : Mokenamischi (Tshiluba)

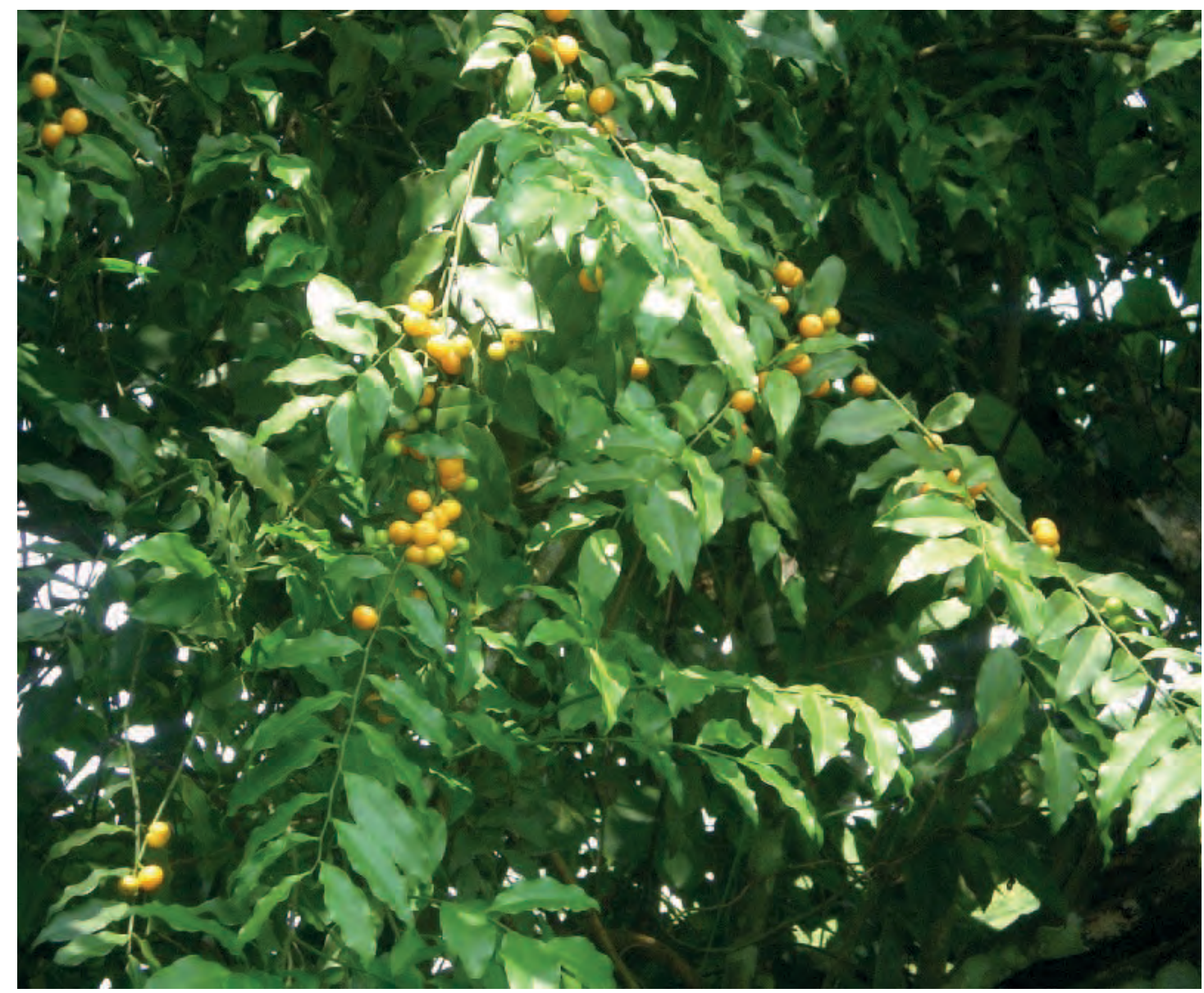

Description : Petit arbre, souvent à plusieurs tiges, jusqu'à $10 \mathrm{~m}$ de haut, avec de longues branches souvent tombantes. Feuilles de 4 à 8 sur 1,5 à 3,5 cm. La plante entière, et spécialement l'écorce, sent l'ail. Fruits ronds de $1 \mathrm{~cm}$ de diamètre, le calice formant une coupe à la base.

Ecologie : Arbre des forêts galeries, des clairières dans la forêt pluviale, et des forêts secondaires.

Usages : Les tiges, l'écorce et les racines ont des usages médicinaux pour traiter une variété de maladies. Les fruits sont comestibles ; les graines s'emploient comme condiment.

Références Louis et Léonard 1948, Irvine 1961, Keay 1989, Vivien et Faure 1996, Burkill 1997, Malaisse 1997, Konda Ku Mbuta et al. 2015b 


\section{Oldenlandia affinis}

Nom courant : Kimbeni (Kimbala)

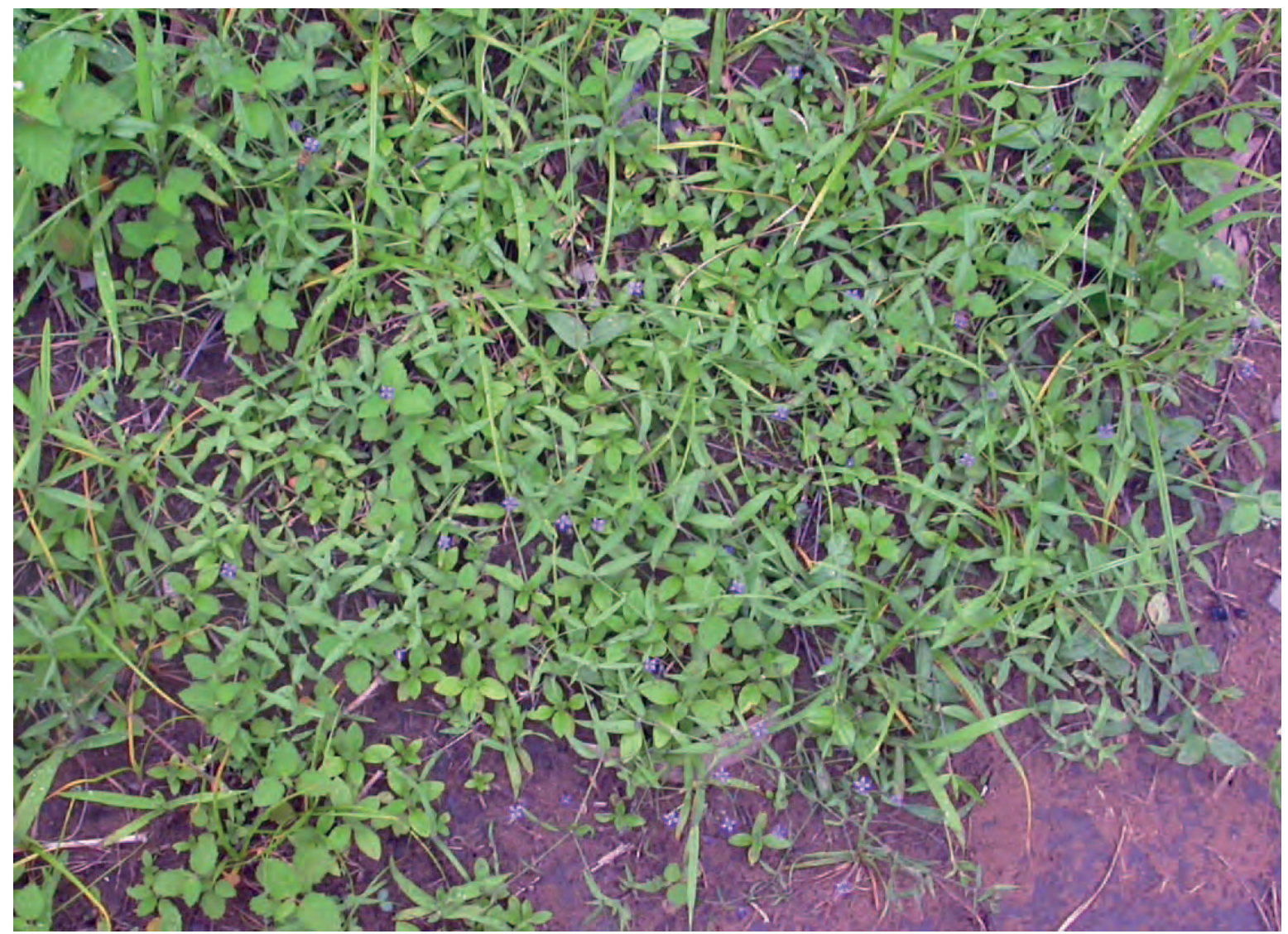

Oldenlandia affinis sur un terrain vague à Kasangulu

Description : Petite herbe rampante de $60 \mathrm{~cm}$ de long. Les tiges sont filiformes avec des stipules à la base des feuilles, qui ont généralement moins d'1 cm de long. La corolle des fleurs a 3 fois la longueur des sépales.

Ecologie : Plante des prairies et des anciennes cultures, largement répandue en Afrique et Asie tropicales.

Usage : On a observé la collecte du nectar par les abeilles à Kasangulu en novembre. On emploie la sève pour traiter les maux de tête au Kongo Central, et pour traiter les ophtalmies au Congo Brazzaville. En R.D. Congo, on emploie les feuilles en médecine traditionnelle pour assister les femmes en travail : I'efficacité de cette pratique a été confirmée scientifiquement. En Afrique du Sud, on prend une décoction des racines pour traiter les essoufflements et les maladies cardiaques. Les tiges séchées servent de cure dents. La plante se mange avec un ancien ennemi en signe de réconciliation.

Photo: Bart Wursten www.zimbabweflora.co.zw

Remarque : On connait huit espèces d'Oldenlandia présentes au Kongo Central.

Références : Staner et Boutique 1937, Renier 1948, Watt et BreyerBrandwijk 1962, Pauwels 1982, Burkill 1997, Neuwinger 2000

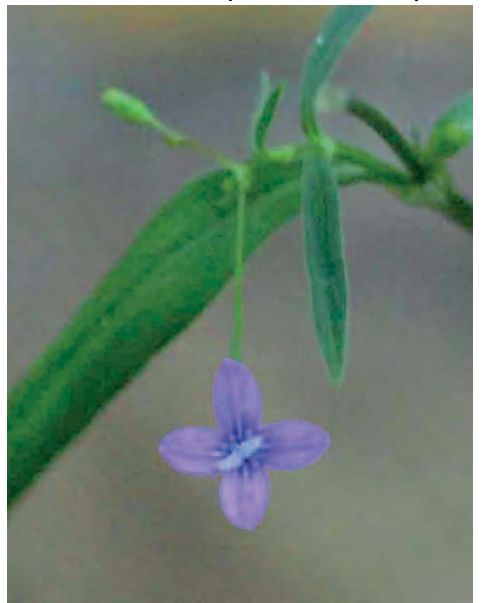


Nom courant : Okekele (Turumbu)

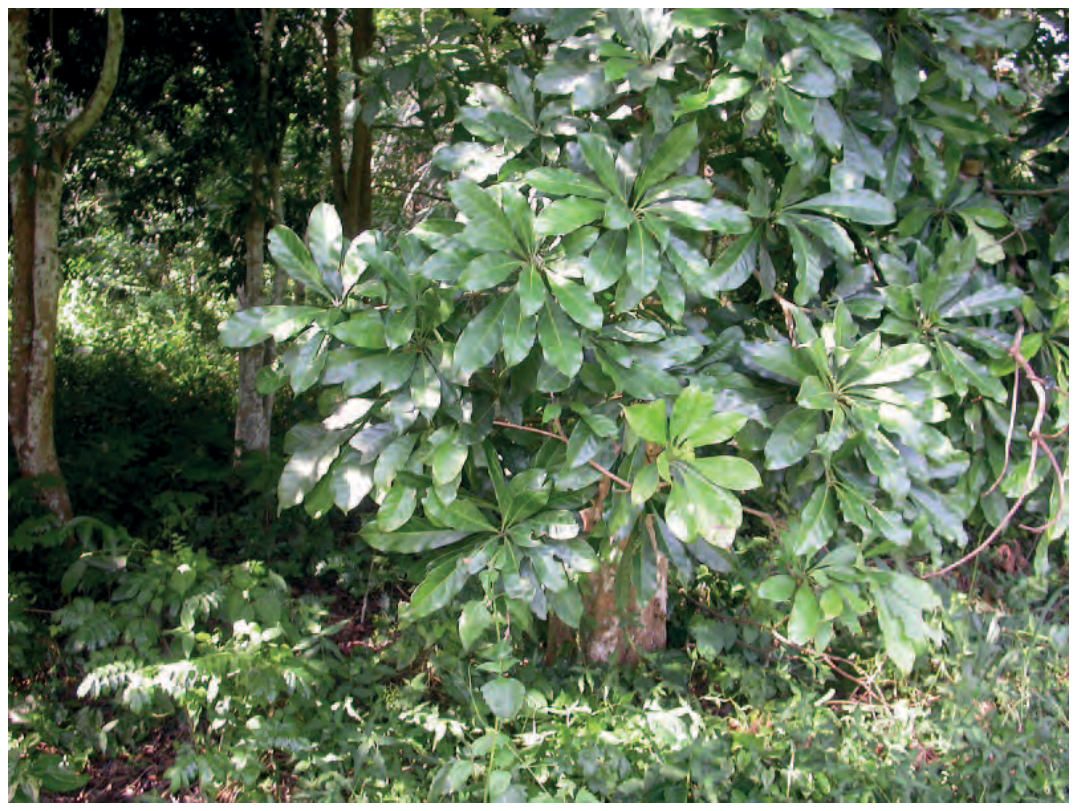

Description : Arbre atteignant 20 $m$ de haut et $30 \mathrm{~cm}$ de diamètre. Le tronc libère un latex blanc gluant. Les fleurs et les fruits poussent sur le tronc. Les fruits ont $9 \mathrm{~cm}$ de diamètre. L'écorce est marquée par des lignes de lenticelles. Les feuilles se groupent en bouquets terminaux.

Ecologie: Arbre de la forêt primaire dans l'Est de la R.D. Congo.

Reproduction: Les seuls animaux capables de casser et ouvrir le fruit sont les éléphants ; les graines germent après avoir traversé leur intestin. Les graines ne peuvent pas germer sans leur aide. Mais, en ce qui concerne 0 .

elatum, on peut extraire la graine du fruit, et elle germe en 3 à 9 semaines.

Ci-dessous : Jeune fruit sur le tronc d'un arbre au jardin botanique de Kisantu.
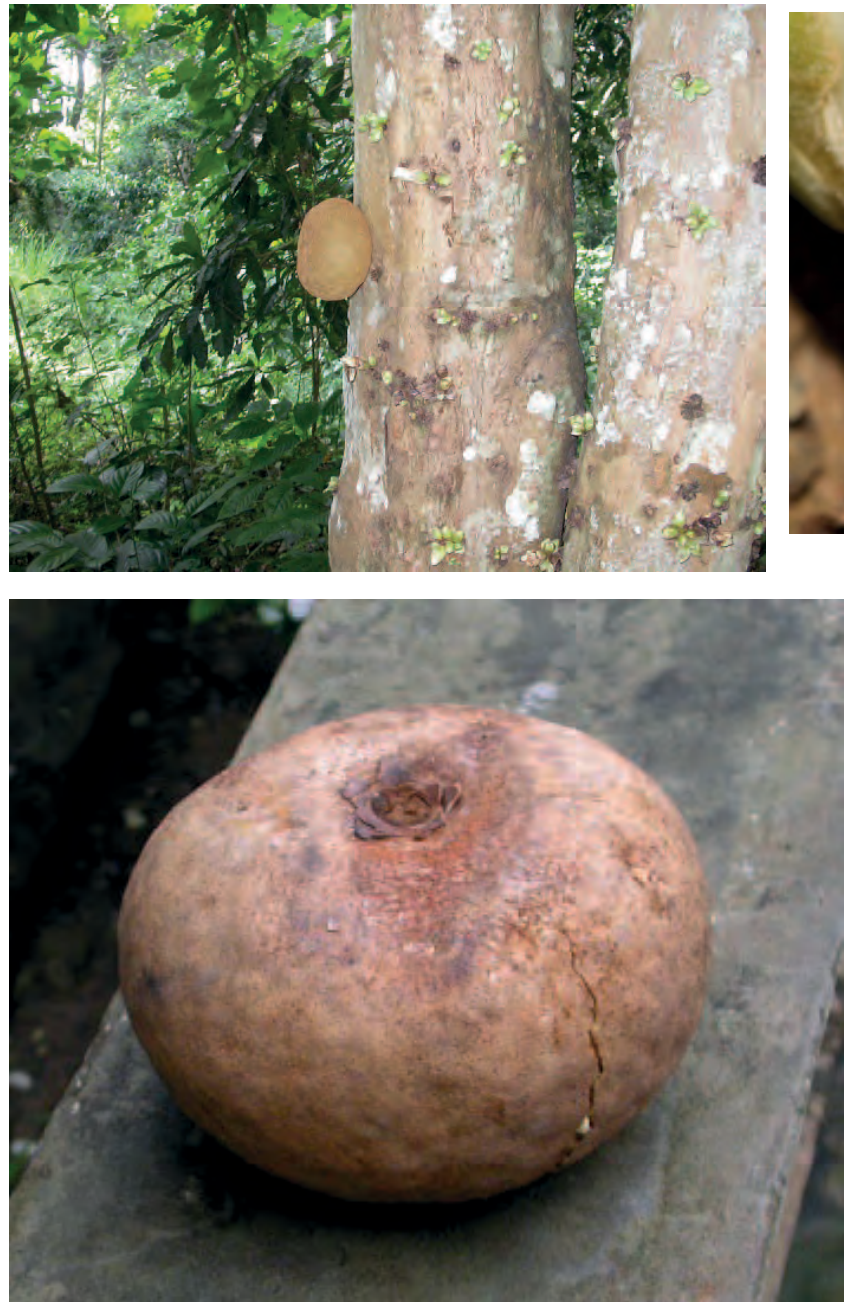

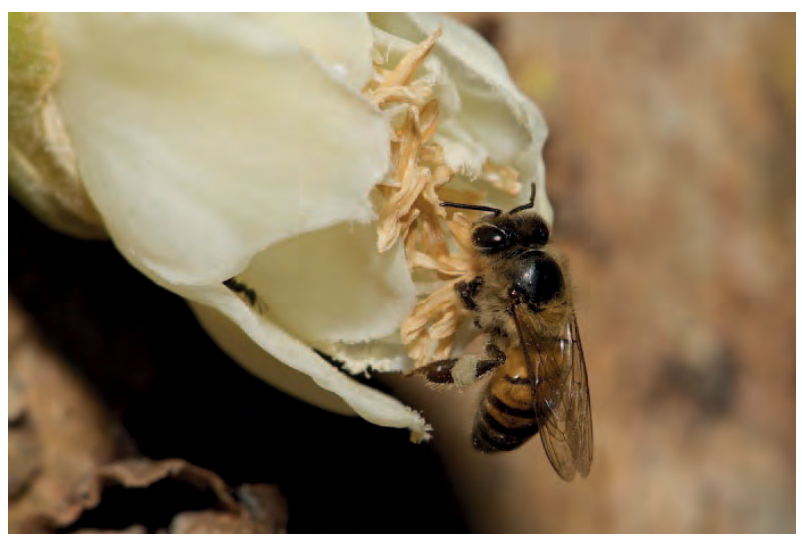

Abeille récoltant le nectar et un peu de pollen sur les fleurs en juin à Kisantu. Photo : Nicolas Vereecken

Usages : D'autres espèces, 0 , ahia, 0 , elatum et 0 . procerum donnent un bois employé pour les planches, les ustensiles, les pirogues, les tambours. Les fruits d'O. procerum sont comestibles ; au Ghana on en fait une soupe.

A gauche : Fruit de O. mortehani tombé à terre

Références : Renier 1948, Irvine 1961, White et Abernethy 1997, Vande weghe 2004, Hawthorne et J ongkind 2006 


\section{Oncinotis tenuiloba}

Noms courants : Nionsinionsi, yonsiyonsi (Kikongo), magic rope (Angl.)

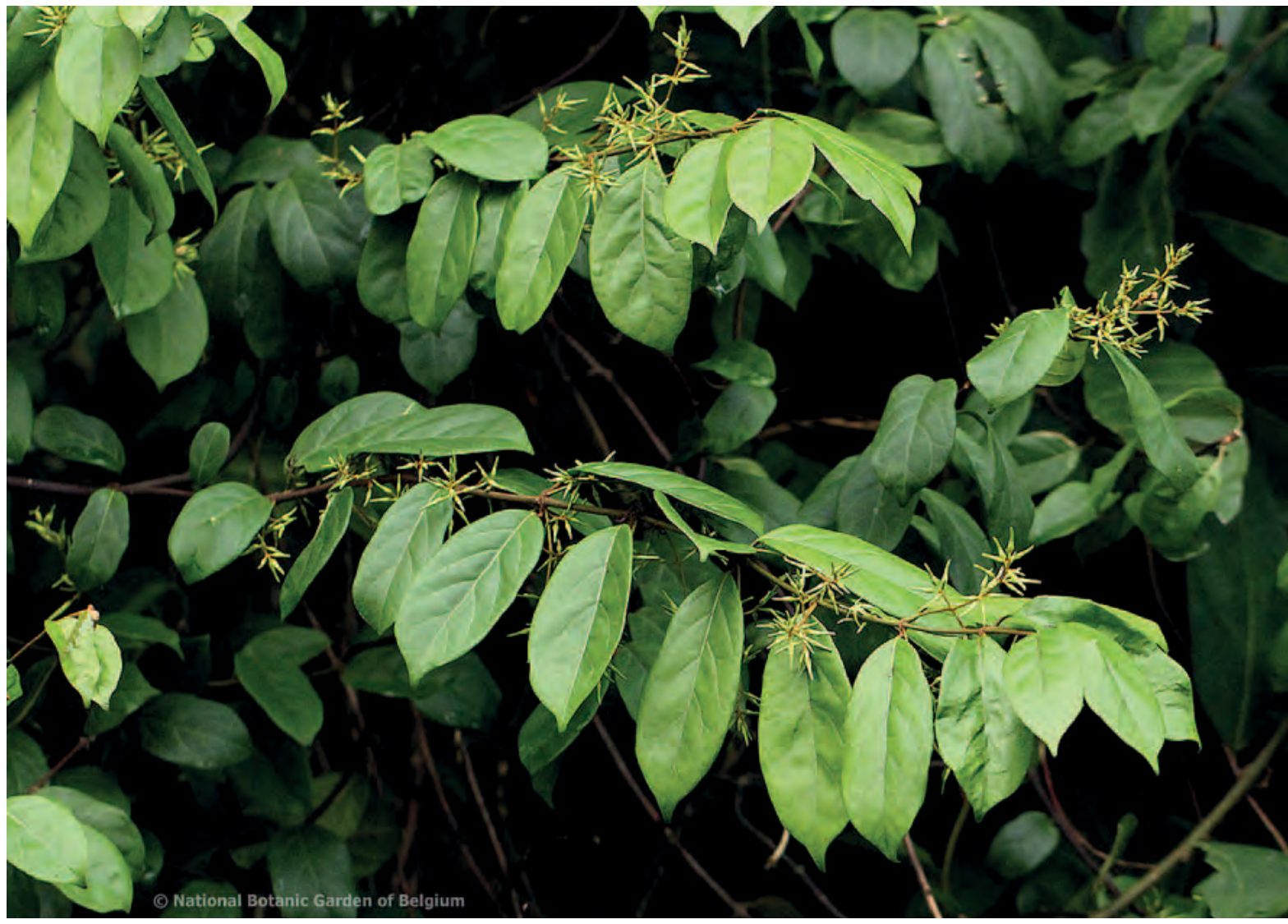

Photos: Bart Wursten Jardin Botanique National de Belgique

Description : Liane forestière grande et vigoureuse, jusqu'à $30 \mathrm{~m}$ de long, à tiges glabres dégageant un latex blanc. Feuilles opposées, brillantes, minces, coriaces, à la base nettement en coin et au bout très pointu, de 6 à 14 sur 2,5 cm. Nombreuses panicules ouvertes de fleurs atteignant $10 \mathrm{~cm}$, à l'aisselle des feuilles. Le calice a $2 \mathrm{~cm}$ de long, et le tube de la corolle $4 \mathrm{~cm}$, avec des pétales recourbés jaune vert jusqu'à $7,5 \mathrm{~cm}$ de long. La graine a 1 $\mathrm{cm}$ de long, et porte des poils blancs de $4 \mathrm{~cm}$.

Ecologie : Liane des forêts dans toute l'Afrique tropicale.

Usages: Au Kongo Central, on dilue le latex dans l'eau pour le faire boire aux femmes qui allaitent afin de stimuler la lactation.

Remarque : On trouve aussi au Kongo Central 0 . glabrata et $O$. hirta.

Références Gillet et Pâque 1910, Renier 1948, Daeleman et Pauwels 1983

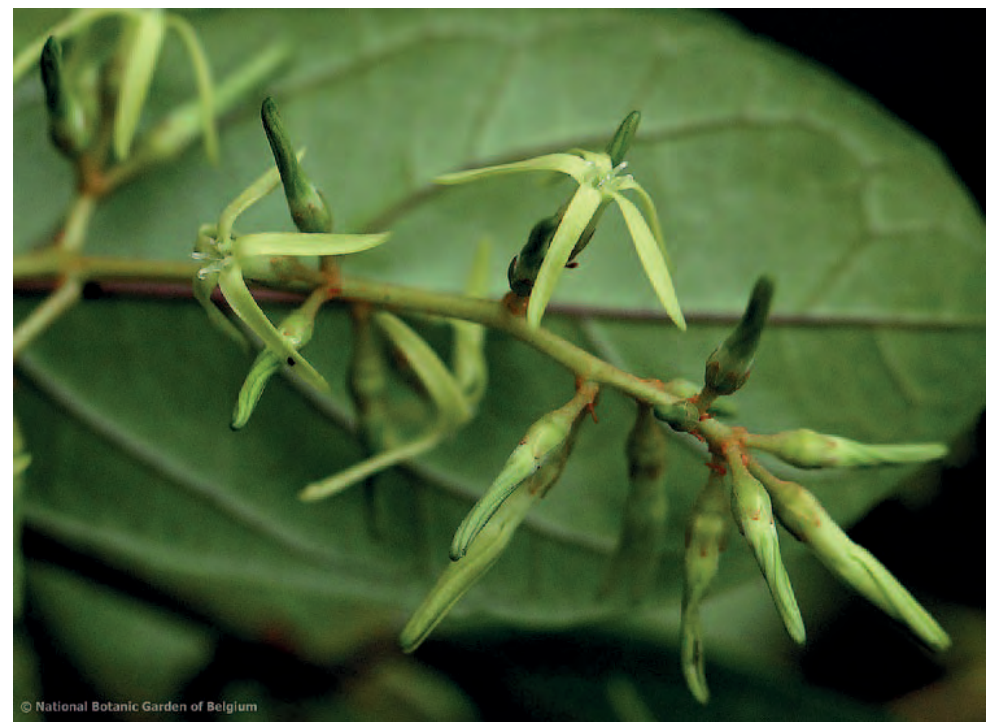




\section{Oncoba dentata}

Synonyme : Lindackeria dentata

Noms courants : Nkaka kisani, mbamba, pangia ya nsania (Kikongo), lompondju (Lingala)

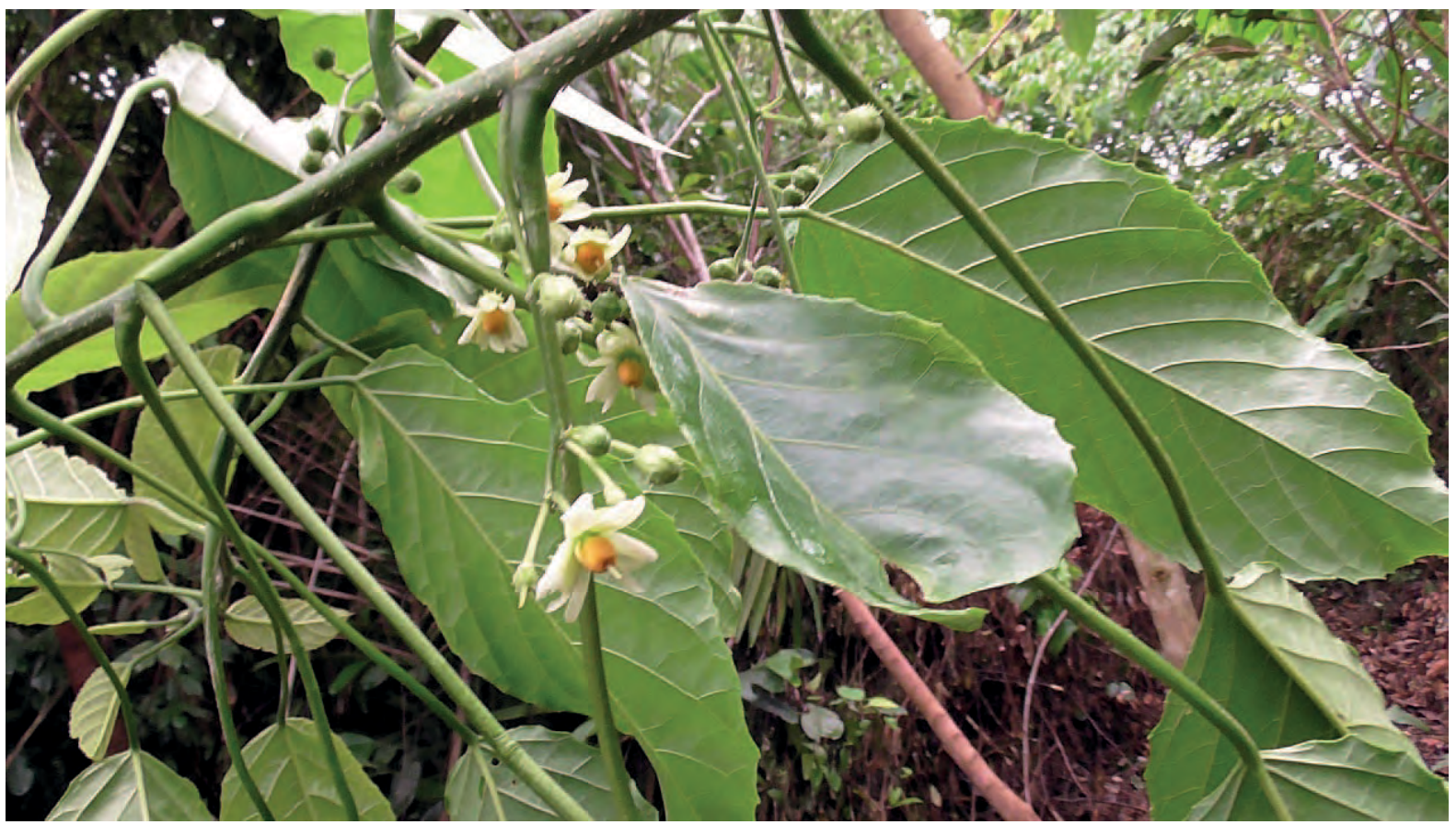

Oncoba dentata fleuri en octobre

Description : Petit arbre de 6 à $10 \mathrm{~m}$ de haut. Les feuilles sont rondes et parfois grossièrement dentées ; elles mesurent 8 à 28 sur 4 à $14 \mathrm{~cm}$, sur des pétioles de 4 à $18 \mathrm{~cm}$. Les fleurs blanches parfumées sont disposées en panicules longs de 7 à $10 \mathrm{~cm}$. Le fruit est une capsule épineuse, orange à maturité, de 2 à $3 \mathrm{~cm}$ de diamètre. II contient quelques graines noires avec un arille rouge.

Ecologie : Arbre des friches et des forêts secondaires, de la Guinée au Cameroun, au Soudan, à la R.D. Congo et à l'Angola.

Usages: Les troncs sont utilisés en construction. Dans la Province de l'Equateur, on emploie une décoction de l'écorce comme antihelminthique ; on utilise une poudre des feuilles pour tuer les poux. Autour de Yangambi, on prend une décoction des feuilles en lavement contre la colique. Dans l'Uele, on prend une macération de l'écorce des racines contre les abcès des gencives. Les graines donnent une huile que l'on emploie en Ubangi pour traiter le pian et la lèpre. En Ubangi, on emploie une décoction des feuilles pour tuer les puces ; pour traiter les œdèmes, on boit une décoction des racines, et on masse l'œdème avec la cendre des racines brûlées. Au Congo Brazzaville, on emploie une décoction des feuilles pour traiter les problèmes mentaux. En Afrique équatoriale, on emploie une décoction des racines pour soulager les maux de tête. On applique l'huile des graines sur les infections cutanées. La plante donne un sel végétal. Les espèces d'Oncoba sont importantes pour le fourrage des abeilles dans toute l'Afrique équatoriale.

Références : Gillet et Pâque 1910, Staner et Boutique 1937, Renier 1948, Bamps 1976, Daeleman et Pauwels 1983, Pauwels 1993, Burkill 1994, White et Abernethy 1997, Hepburn et Radloff 1998, Neuwinger 2000, Vande weghe 2044, Harris et al 2011 


\section{Oncoba glauca}

Nom courant : Mbama (Kikongo)

Description : Arbuste de 5 à $8 \mathrm{~m}$ de haut à tiges cannelées. Les feuilles décidues, brillantes, de 19 à 25 sur 3,5 à 7,5 cm, sont disposées sur des pétioles de 1,5 à $6 \mathrm{~cm}$. On trouve de 1 à 3 fleurs parfumées à l'aisselle des feuilles, presque toute l'année. Les fruits sont des capsules de 6 à 7 sur 5 à $6 \mathrm{~cm}$, disposées sur des tiges de $5 \mathrm{~cm}$. Les fruits sont jaunes à maturité, avec une chair ferme contenant beaucoup de graines.

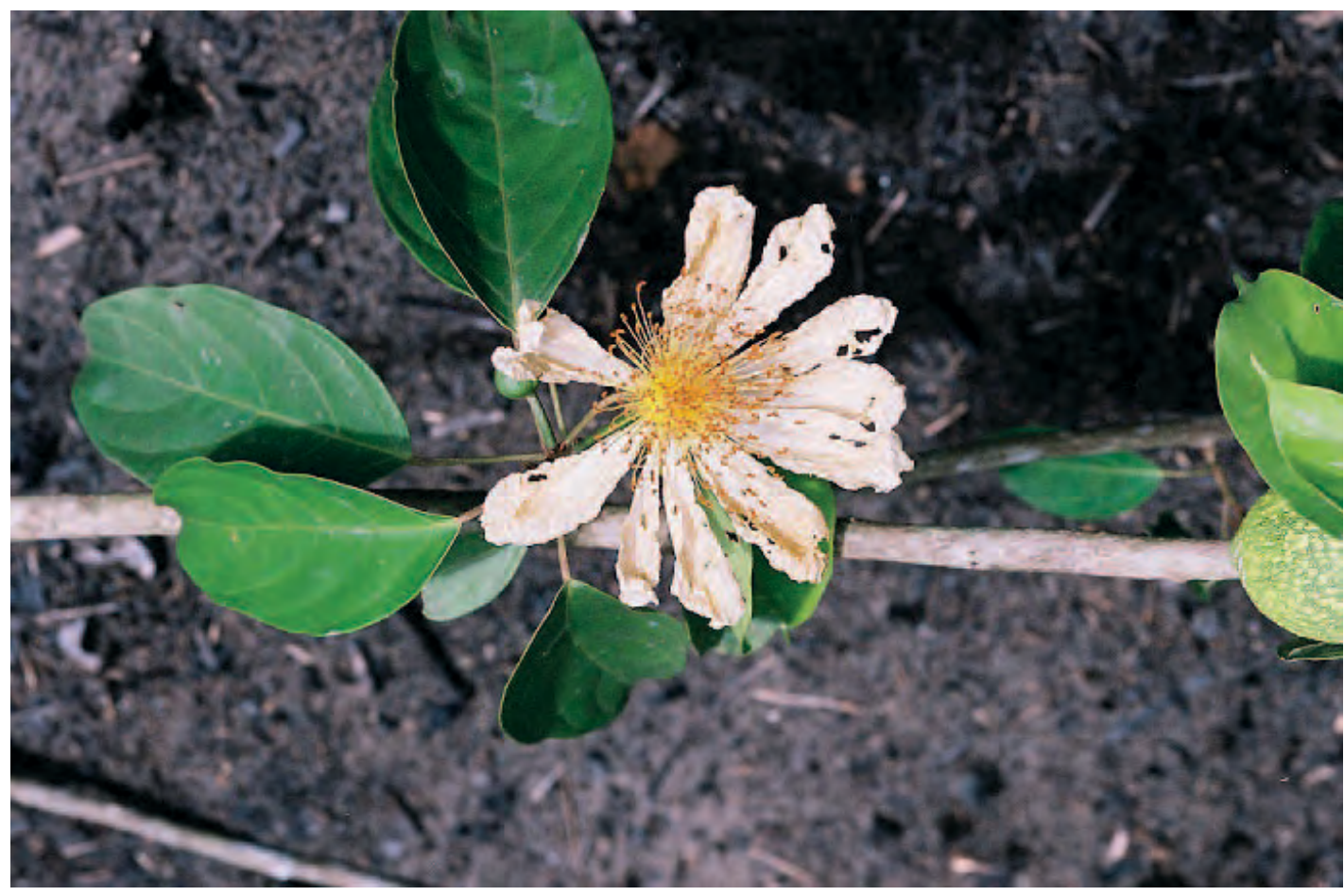

Les deux photos ont été prises en avril près de Bandundu

Ecologie : Se rencontre habituellement en forêt-galerie près de l'eau, en R.D. Congo, au Nigeria, en Guinée équatoriale, au Cameroun et au Gabon.

Usages : Avec l'écorce fibreuse pilée, on bouche les trous occupés par les abeilles dans les arbres ; l'odeur calmerait les abeilles. Les fruits sont comestibles. Les graines contiennent une huile qui a été utilisée autrefois pour traiter la lèpre et la syphilis. En République du Congo, on masse les tempes avec la sève pour soulager la migraine. On emploie aussi la sève pour traiter les morsures de serpents, les lésions cancéreuses de la peau, et les rhumatismes. Le bois est rougeâtre, à grain fin, il convient pour le tournage, les manches d'outils, etc. Au Gabon,

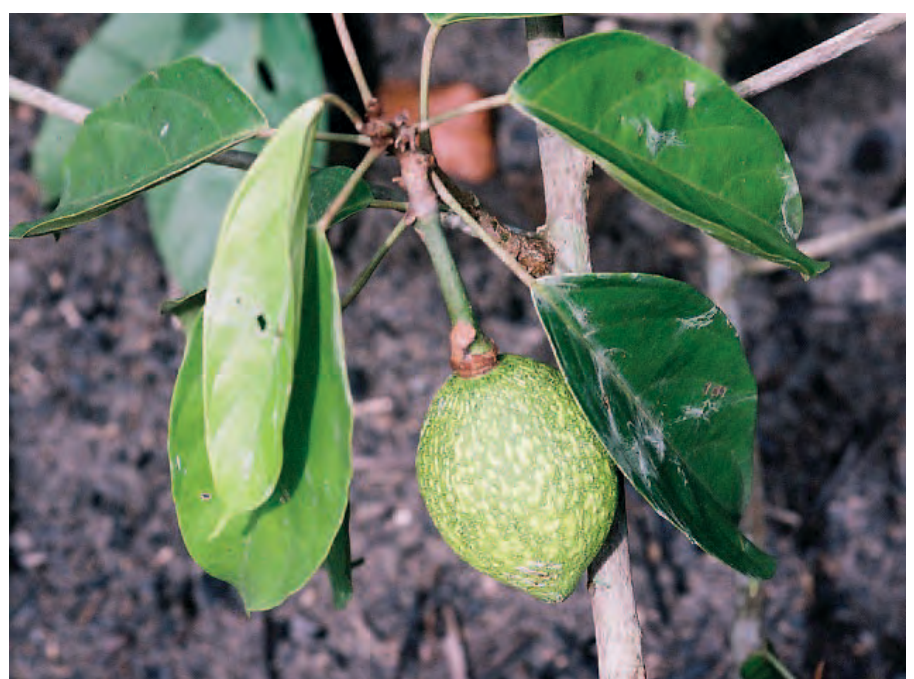
on emploie les graines cuites et pilées comme poison pour les rats. Les diverses espèces d'Oncoba sont d'importants fourrages pour les abeilles en Afrique équatoriale.

Références : Staner et Boutique 1937, Renier 1947, 1948, Irvine 1961, Raponda-Walker et Sillans 1961, Pauwels 1993, Burkill 1994, Abernethy et White 1997, Hepburn et Radloff 1998, Neuwinger 2000 
Noms courants Nsansi, nti nsansi, sansi (Kikongo), arbre à tabatières (Fr.), snuff-box tree (Angl.)

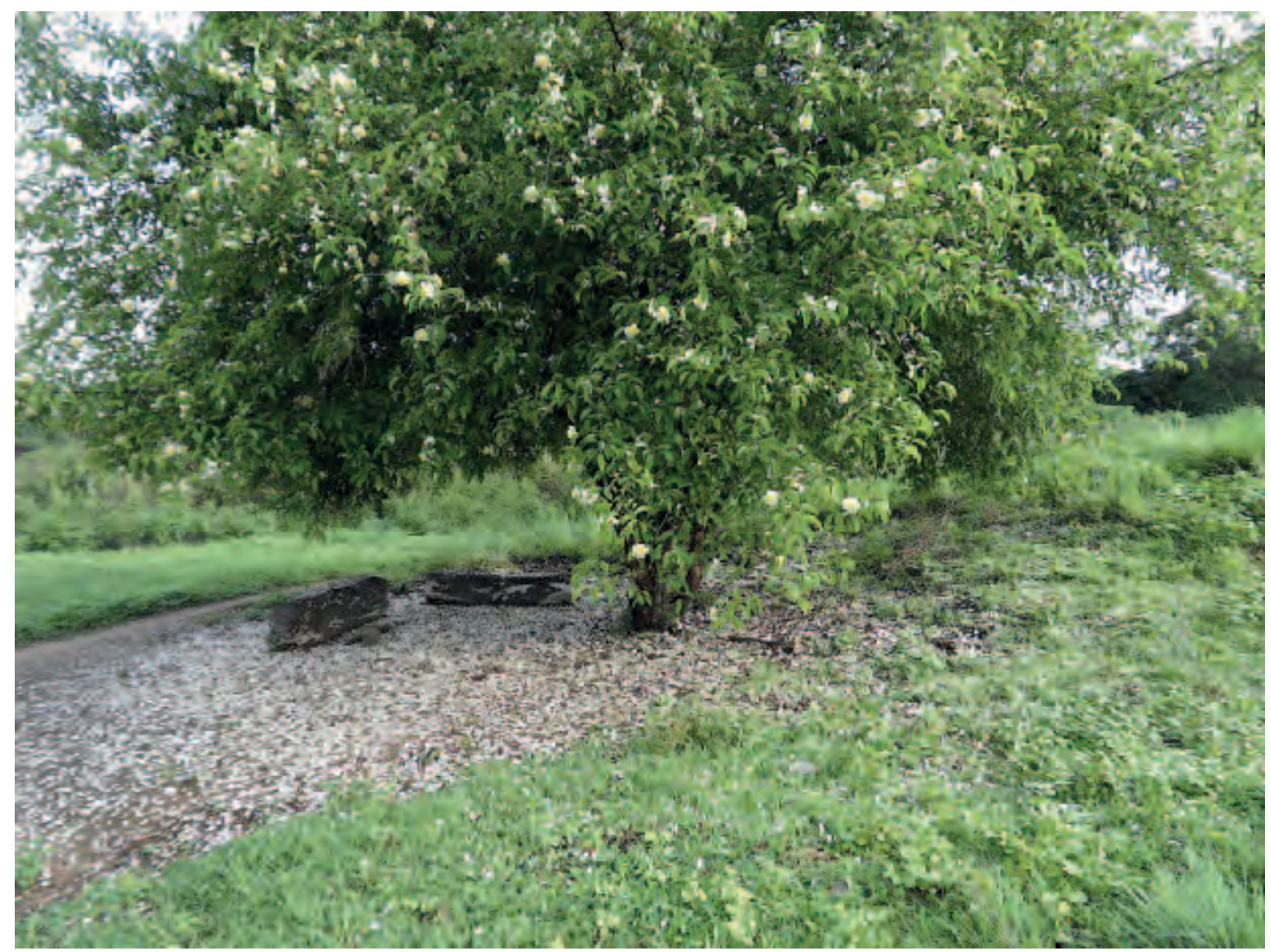

Description : Arbuste épineux haut de 4 à $10 \mathrm{~m}$. Les feuilles ont 3,5 à 12 sur 2 à $6 \mathrm{~cm}$. Les feuilles peuvent être rouges quand elles sont jeunes. Les fleurs solitaires et parfumées, de $5 \mathrm{~cm}$ de diamètre, sont blanches, avec 3 à 4 sépales et 13 pétales en spirale. Les fruits ronds à coque dure ont $5 \mathrm{~cm}$ de diamètre, ils portent parfois des nervures, et contiennent des graines brun brillant.

Ecologie: Arbre des forêts secondaires, forêts galeries et savanes boisées dans toute l'Afrique tropicale, formant parfois des fourrés.

Reproduction : Par graines.

Usages: Les fruits servent traditionnellement de tabatières, et de

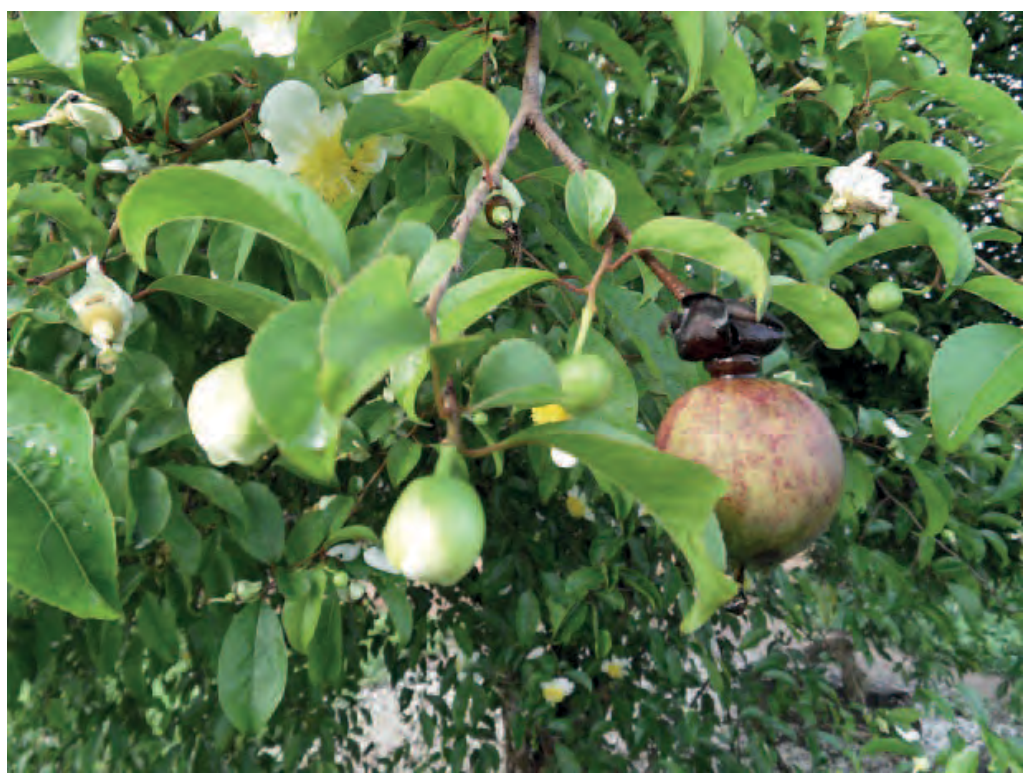
hochets pour les enfants. Leur pulpe brune épaisse est comestible, mais plutôt aigre. Le bois, brun clair et dur, prend un beau poli ; on l'emploie en ébénisterie. Au Congo Brazzaville, cette plante a de nombreux usages médicinaux ; et on considère qu'elle protège des mauvais esprits.

Références : Gillet et Pâque 1910, Eggeling et Dale 1951, Bamps 1976, Daeleman et Pauwels 1983, Keay 1989, Pauwels 1993, Burkill 1994, Malaisse 1997, Ruffo et al. 2002 


\section{Oncoba welwitschii}

Synonyme : Caloncoba welwitschii

Noms courants : Kisani, kisania, n'sani, ntela (Kikongo), bosake (Lingala)

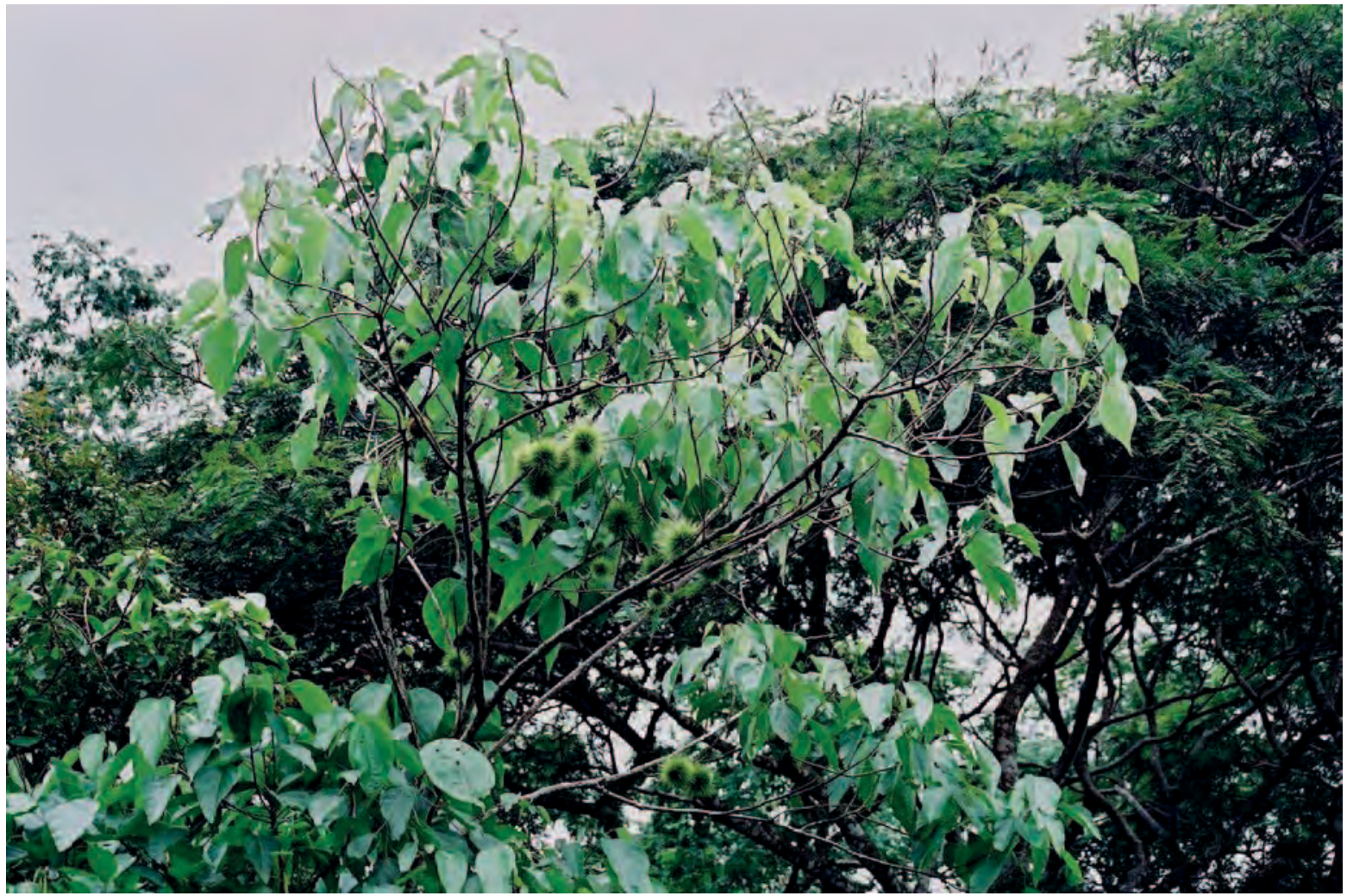

Description : Petit arbre de 5 à $6 \mathrm{~m}$ de haut. Feuilles ovales de 10 à $28 \mathrm{~cm}$ sur 8 à $20 \mathrm{~cm}$, se terminant en une longue pointe, droites ou arrondies à la base. Les fleurs, grandes ( $5 \mathrm{~cm}$ de diamètre) et voyantes, sont disposées sur les branches, et apparaissent dès les premières pluies. Elles ont 3 à 4 sépales, et 5 à 13 pétales blancs. Le fruit

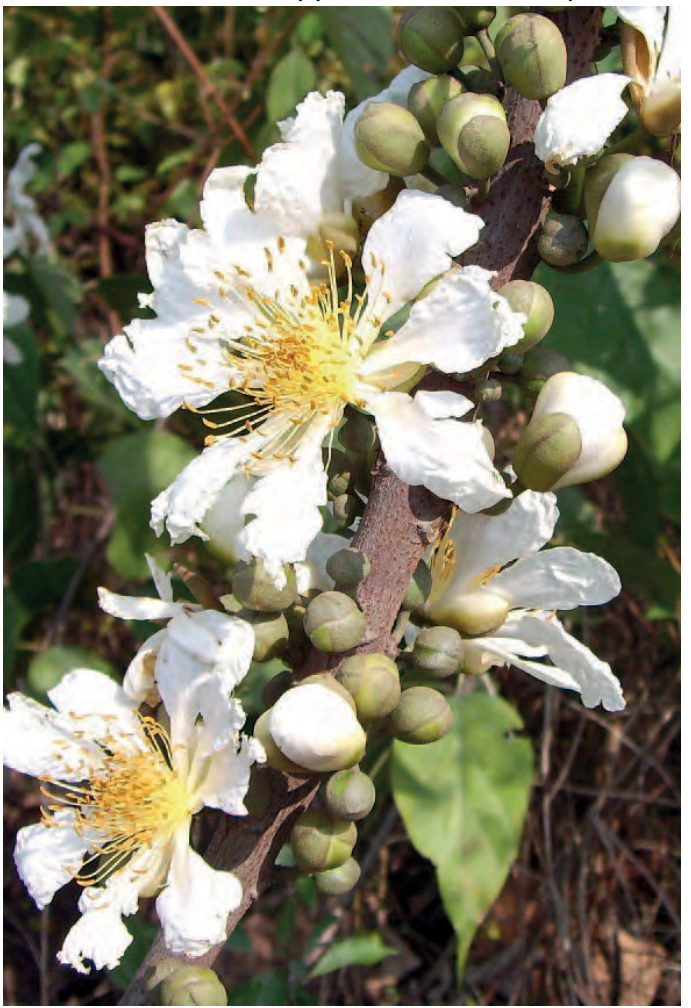
est une capsule de 3 à $4 \mathrm{~cm}$ de diamètre, couvert d'épines souples de 2 à $4 \mathrm{~cm}$, dont la coque s'ouvre en 5 ou 6 parties, laissant apparaître une boule de pulpe gélatineuse de couleur rose violacé, contenant des graines noires et dures, ovoïdes, d'environ $4 \times 3 \times 2 \mathrm{~mm}$.

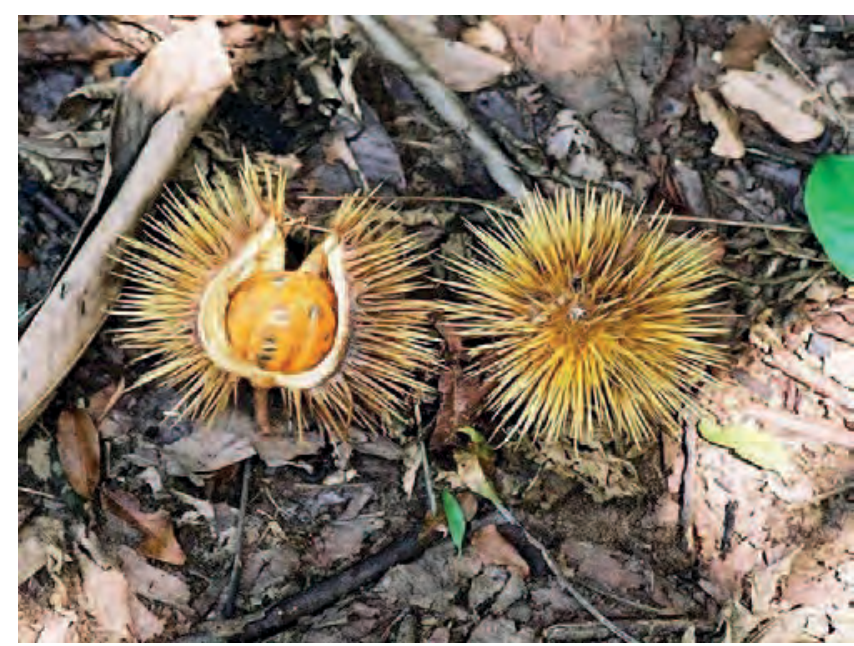

Ecologie: Arbre très commun des forêts secondaires du Kongo Central. Présent également au Nigéria, au Cameroun, au Gabon, en Angola, au Malawi et au Mozambique. 
Reproduction et gestion : On peut cultiver l'arbre à partir des graines ; il recèpe bien.

Usages: Les troncs servent en construction, ainsi que pour le charbon de bois ; la pulpe du fruit est comestible. Les chenilles comestibles Mimpemba, Matambungu et N'sani (Cymothoe caenis) ; celle-ci a un goût un peu amer, mais est disponible en grandes quantités en janvier, et à nouveau à la fin de la saison des pluies. Les abeilles visitent fréquemment les fleurs, mais, selon certains, le nectar donnerait un miel amer. Cette plante a de nombreux usages médicinaux. Au Kongo Central, on emploie les fleurs et les fruits pour traiter les maladies mentales, l'asthme, les calculs biliaires et les vers intestinaux. On fait bouillir les fruits avec du jus d'ananas pour traiter les douleurs abdominales chez les femmes enceintes. Au Congo Brazzaville, on fait avec l'écorce et les feuilles des emplâtres pour faire mûrir les abcès; et des cataplasmes pour traiter les bronchites et les rhumatismes. On applique les feuilles pilées sur les fractures afin de réduire l'enflure avant d'appliquer les attelles. On saupoudre le nombril des nouveaux nés avec la poudre des feuilles après détachement du cordon ombilical. On pile l'écorce dans l'huile de palme, pour appliquer la pâte obtenue sur les démangeaisons ; le jus de l'écorce s'emploie pour expulser les parasites. On frotte sur le corps la râpure de l'écorce pour tuer les poux. L'huile extraite des graines a été employée en R.D. Congo pour traiter la lèpre; elle contient des acides chaulmogrique et hydrocarpique.

\section{Chenille comestible Nsani} (Cymothoe caenis)

\section{Remarque :}

Selon certains, on ne doit pas employer le bois pour construire les ruches ou leur toiture, car il risque de tuer les abeilles. En Centrafrique, on emploie le jus des feuilles pour éloigner les abeilles pendant la récolte du miel.
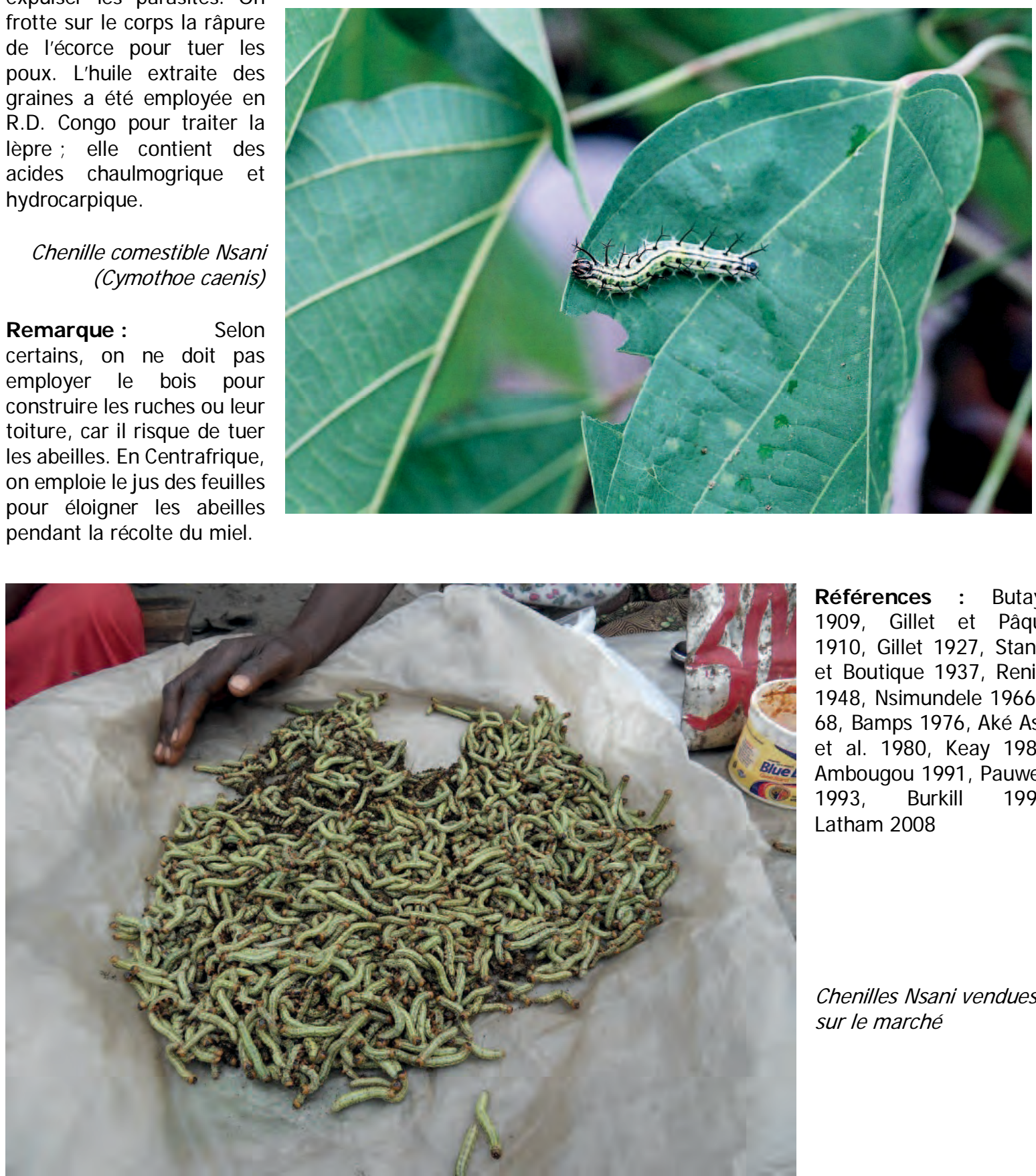

Références : Butaye 1909, Gillet et Pâque 1910, Gillet 1927, Staner et Boutique 1937, Renier 1948, Nsimundele 1966 68, Bamps 1976, Aké Assi et al. 1980, Keay 1989, Ambougou 1991, Pauwels 1993, Burkill 1994, Latham 2008

Chenilles Nsani vendues sur le marché 


\section{Ongokea gore}

Noms courants : Ntuti, ntieti, samu (Kikongo), boléko (Fr.) boleko ou isano oil (Angl.)

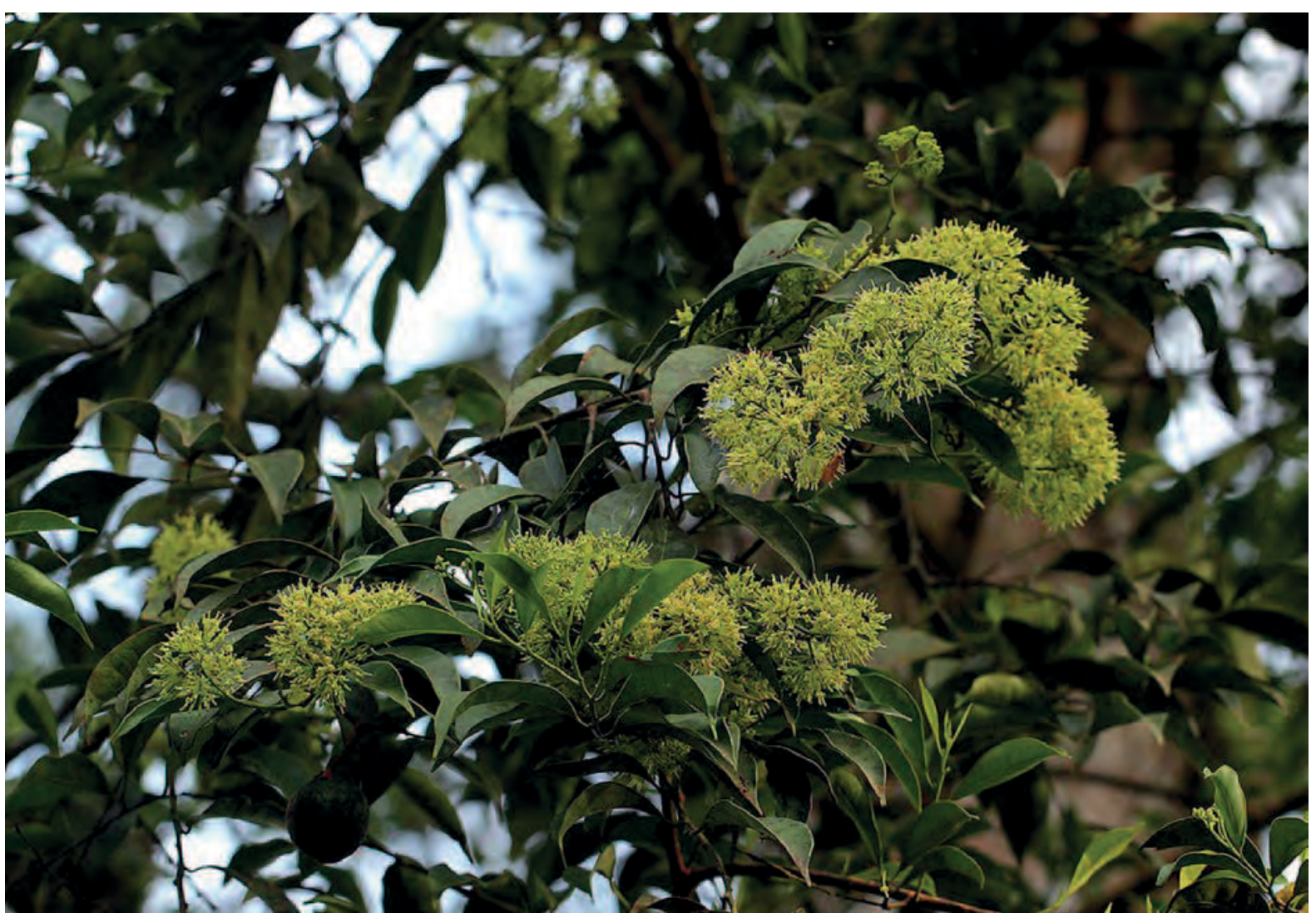

Les deux photos : Bart Wursten

Description : Arbre à tronc droit, cylindrique et sans contrefort pouvant atteindre $40 \mathrm{~m}$ de haut. Feuilles alternes de 4 à 11 sur 2 à $5 \mathrm{~cm}$. Fleurs verdâtres de 3 à $4 \mathrm{~mm}$ de long en panicules de 5 à $15 \mathrm{~cm}$. Les fruits sont contenus dans un calice persistant, vert et coriace, qui se divise en deux à quatre segments ; le fruit est une drupe globuleuse de 2 à $4 \mathrm{~cm}$ de diamètre contenant une seule graine. Au Kongo Central, les fruits sont abondants en septembre.

Ecologie : Arbre des forêts primaires et des forêts inondables. Présent de la Sierra Leone à l'Est de la R.D. Congo et à l'Angola.

Reproduction : Le germination est lente et peut prendre plusieurs mois, parfois plus d'un an.

Usages : Les bois, dur et élastique, s'emploie pour les charpentes et le mobilier, mais seulement après avoir été parfaitement séché. II tend à se fendre facilement. La poudre de graines carbonisées est un maquillage traditionnel. L'huile des graines, connue comme huile de boléko ou d'isano, sert de purgatif et pour expulser les vers intestinaux. Elle sèche vite ; on l'emploie en savonnerie et comme lubrifiant ; elle

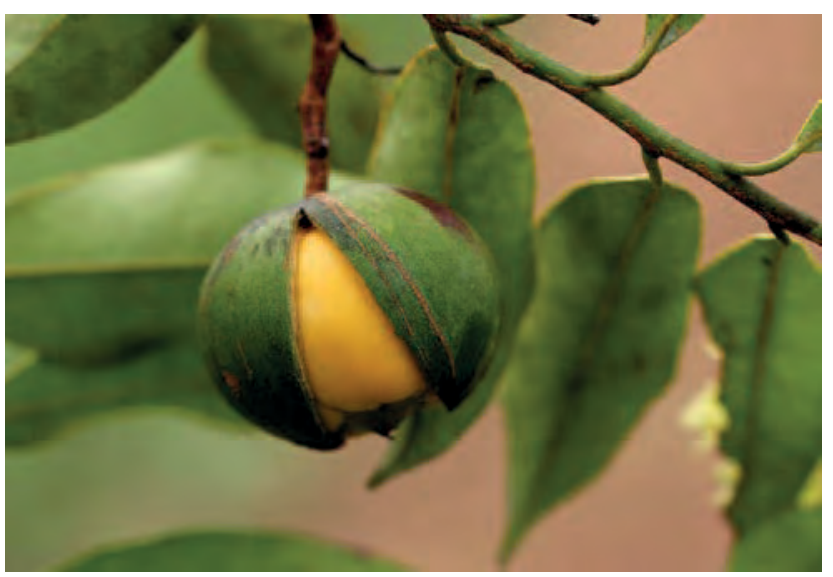
entre dans la composition de peintures et vernis, comme l'huile de lin. Le fruit mûr est comestible ; on l'emploie comme appât pour attraper les rats palmistes. On pulvérise les feuilles réduites en poudre pour faire inhaler la poudre aux enfants atteints de troubles respiratoires. Les fleurs sont attrayantes pour les abeilles, mais le miel n'est pas bon.

Références : Gillet et Pâque 1910, Gillet 1927, Louis et Léonard 1948, Renier 1948, Nsimundele 1966 - 68 , Daeleman et Pauwels 1983, Keay 1989, Pauwels 1993, Burkill 1997, Neuwinger 2000, Louppe 2007 


\section{Oplismenus hirtellus}

(Poaceae)

Noms courants : Tudama dama (Kikongo), Oplismène à poils courts, herbe à paniers (Fr.) basket grass (Angl.)

Description : Herbe rampante des forêts et des lieux humides. Les feuilles mesurent $12 \times 2 \mathrm{~cm}$.

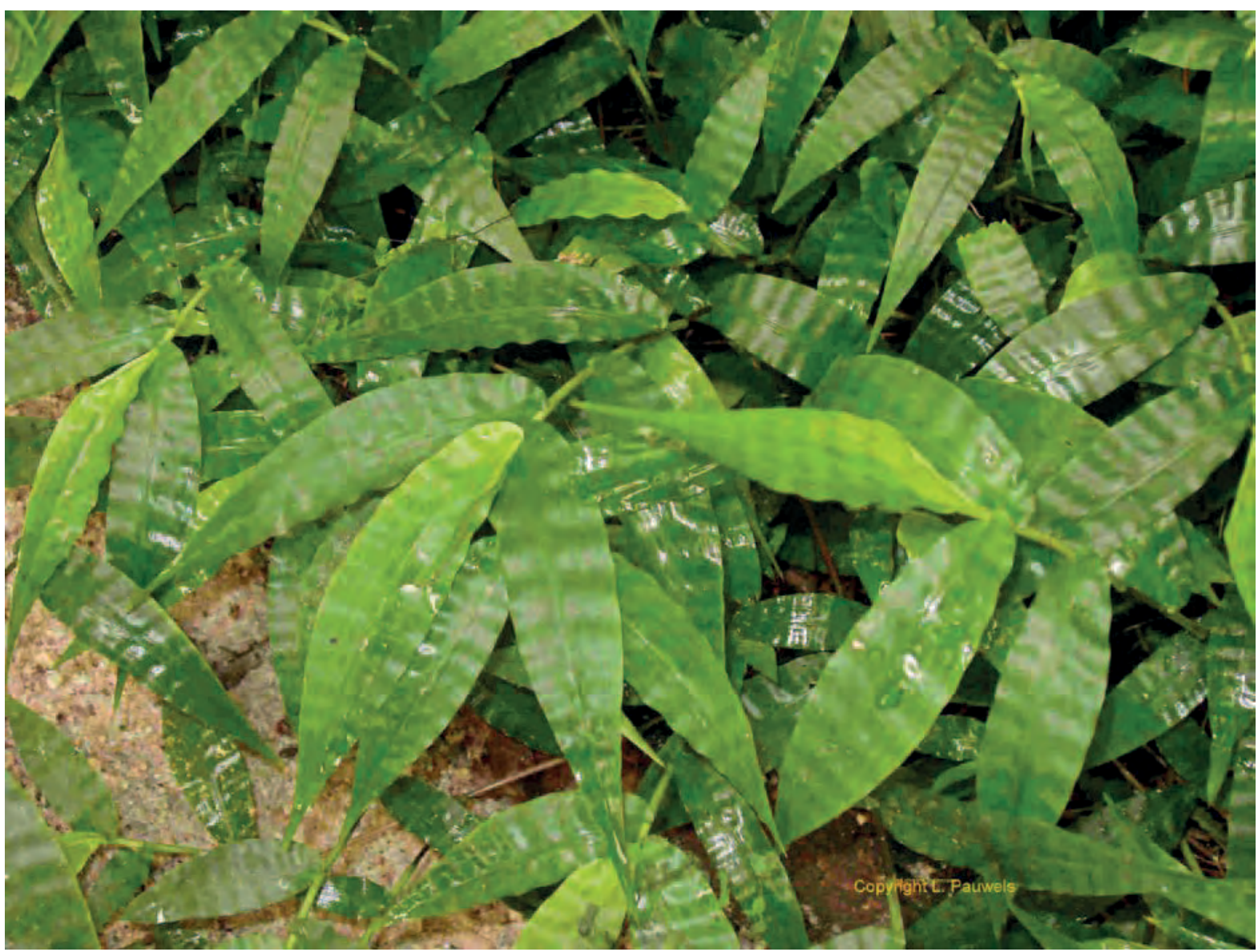

Photo : Luc Pauwels

Ecologie: Plante des sous-bois forestiers, qui tolère l'ombre épaisse, présente sur tous les continents, excepté l'antarctique.

Reproduction : Les graines, collantes, adhèrent au pelage des animaux et aux vêtements. On cultive aussi cette plante à partir des stolons.

Usages: Cette herbe est un pâturage pour le bétail, et une bonne plante de couverture pour les lieux ombragés.

Références : Gillet et Paque 1910, Renier 1948, J ohnson 2005

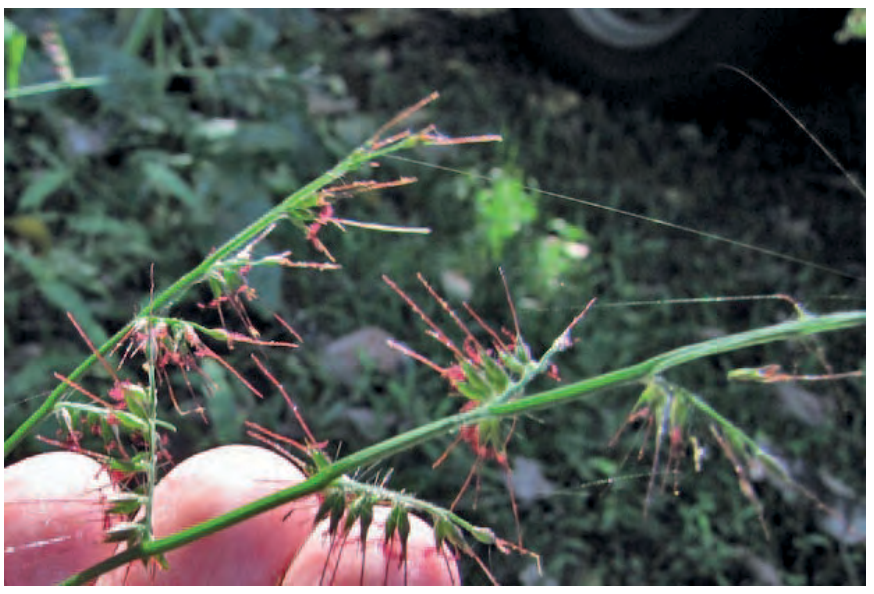

Photo de l'inflorescence : Forest et Kim Starr 


\section{Opuntia ficus-indica}

Noms courants : Figuier de Barbarie (Fr.), prickly pear (Angl.)

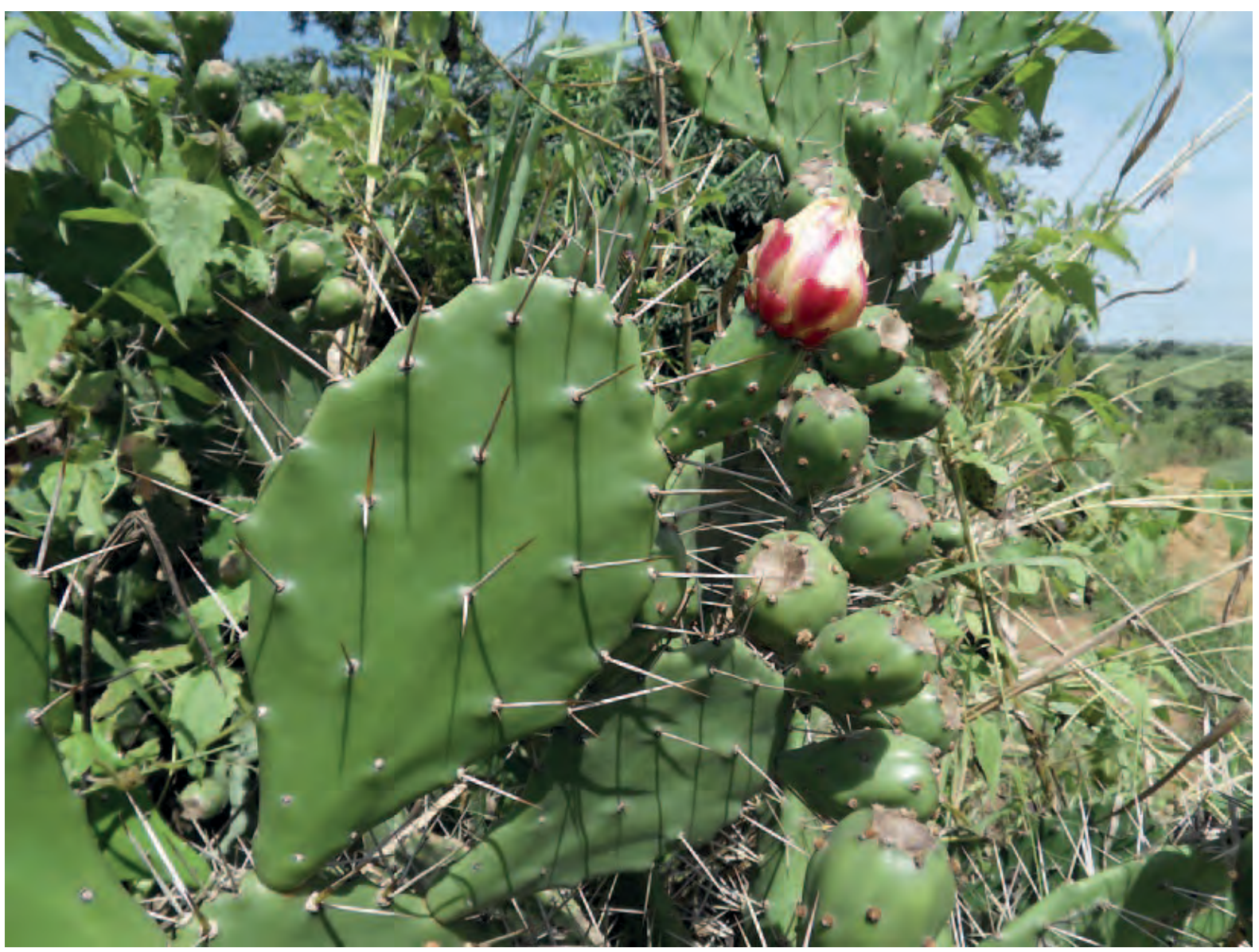

Description : Plante dressée de 4 à $6 \mathrm{~m}$ de haut, organisée en cladodes ou raquettes, qui sont des tiges modifiées, de 25 à $40 \mathrm{~cm}$ de long, 15 à $20 \mathrm{~cm}$ de large et 1,5 à $3 \mathrm{~cm}$ d'épaisseur. Unis les uns aux autres, les cladodes tendent à former des branches. Ceux de la base se lignifient pour former au-delà de la quatrième année de croissance un véritable tronc. Les cladodes peuvent porter des épines. Les fleurs jaunes, de 2 à $8 \mathrm{~cm}$ de diamètre, sont disposées sur le bord supérieur des cladodes, tout au long de l'année. Les fruits sont de couleur brun rouge. A maturité, on peut faire glisser leur peau épineuse pour libérer la pulpe comestible sucrée à l'intérieur.

Ecologie: Originaire d"Amérique tropicale et largement répandu dans les régions subtropicales et méditerranéennes. Parfois cultivé dans les jardins. Peut pousser dans des zones arides chaudes et sèches et sur des sols pauvres. Devient parfois envahissant.

Reproduction : On peut planter les cladodes n'importe

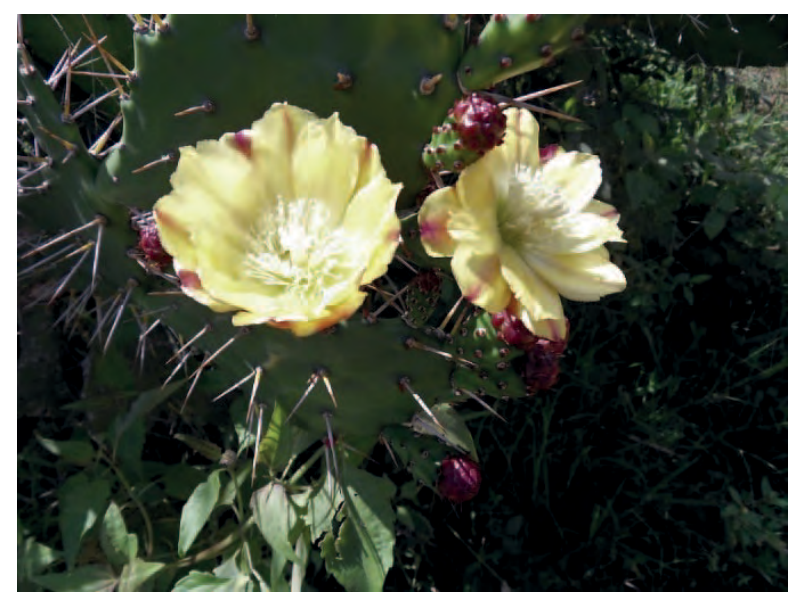
quand. Les détacher de la plante et les laisser deux jours au sec et au soleil jusqu'à ce que la base soit totalement desséchée et soit devenue calleuse.

Usages : Le fruit est sucré et comestible. La plante est largement utilisée comme clôture et pour le contrôle des érosions. Les abeilles visitent les fleurs pour le nectar et le pollen. Le miel est parfumé, blanc, et granule lentement jusqu'à une belle consistance crémeuse.

Références : Renier 1948, Pauwels 1993, van Wyk et Gericke 2000, Ruffo et al 2002 
Noms courants : Loso (Kikongo), riz (Fr.), rice (Angl.)

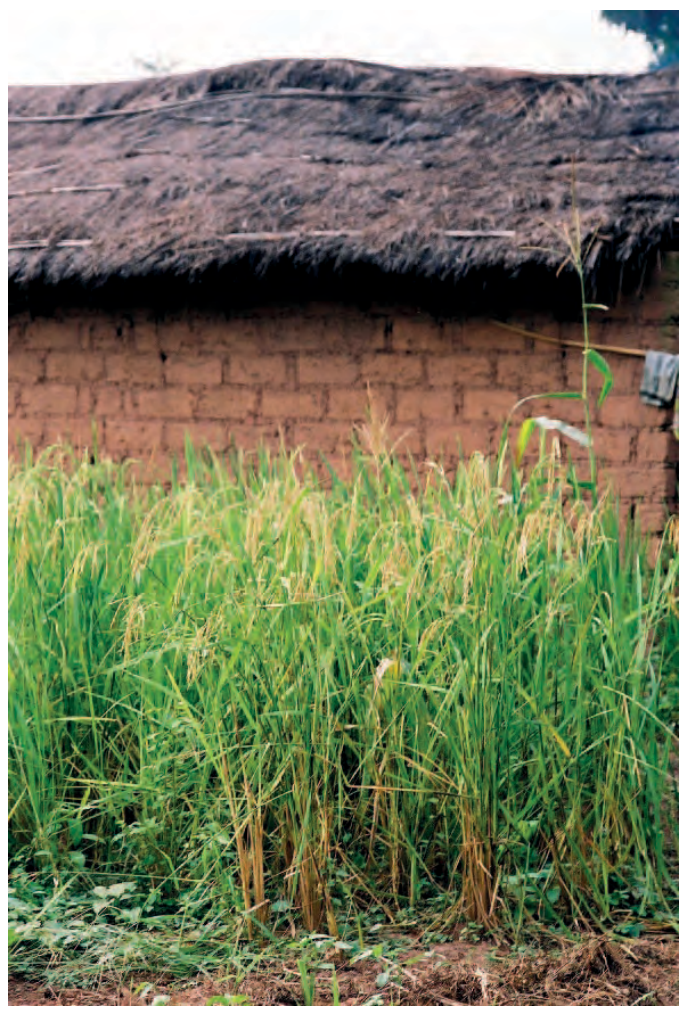

Description : II existe deux types de variétés de riz cultivé, le riz irrigué ou inondé, qui représente l'essentiel des superficies cultivées de la riziculture mondiale, et le riz pluvial qui couvre $12 \%$ des superficies cultivées à l'échelle mondiale, et $40 \%$ des superficies cultivées en Afrique. Au Kongo Central, on cultive le riz pluvial, qui est une herbe à tiges multiples atteignant environ $1 \mathrm{~m}$ de haut, chaque tige portant des grains en panicules lâches. Ecologie : Les variétés de riz cultivées sont originaires d'Asie. Le rendement dépend de l'ensoleillement, le nombre de tiges par plante dépendant d'un nombre suffisant de jours de soleil sans nuages. Sur les sols acides, on observe souvent une déficience en phosphore.

A gauche: Culture de riz au village de Nkondi, district de Manianga

Reproduction: Utiliser des semences stockées depuis 3 à 6 mois. Semer en ligne le long des lignes de niveau pour faciliter le désherbage. Planter de façon à ce que la floraison intervienne pendant les pluies et la récolte après les pluies.

Gestion : Au Kongo Central, et particulièrement dans le district de Manianga, la culture du riz pluvial se faisait

traditionnellement sur les forêts brûlées sur les pentes des collines, en système de culture par rotation. On peut améliorer le système en plantant des bandes horizontales de $3 \mathrm{~m}$ de largeur de légumineuses en cultures de couverture (par exemple Canavalia ensiformis ou Desmodium gangeticum) pour contrôler l'érosion, et en organisant la rotation avec du maïs et des arachides la première année, suivis de manioc la seconde.

En haut et à gauche : Tata Masola Pamba récoltant son riz près de Nkondi

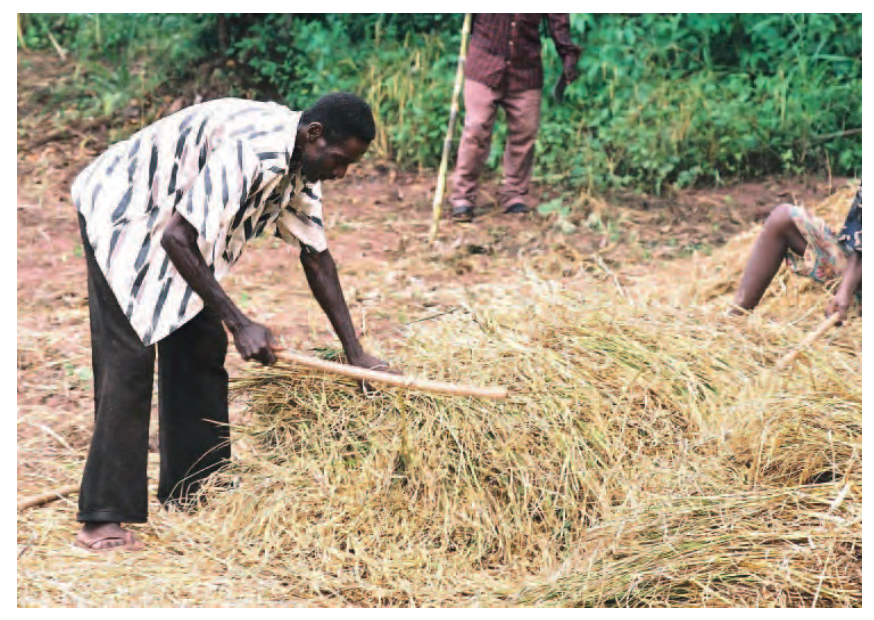

Usages : Le riz permet de nourrir les deux tiers de l'humanité ; il est la base de l'alimentation dans la plupart des pays d'Asie, ainsi que dans plusieurs pays d'Afrique de l'Ouest. En R.D. Congo, des quantités importantes de riz sont consommées dans les villes, principalement importées d'Asie. II y a quelques productions de riz pluvial dans la plupart des Provinces, la production la plus importante étant concentrée à Bumba (Province de la Mongala, Equateur) ; le riz de Bumba est commercialisé à Kinshasa, où il est apprécié pour sa qualité ; on produit également du riz irrigué dans la périphérie de Kinshasa depuis les années 1980. Dans les villages du Kongo Central, on réserve le riz pour les malades et pour les enfants récemment sevrés; on pense qu'il réduit la mortalité infantile. On l'utilise également pour les grandes occasions. On donne une décoction des racines, des feuilles et des enveloppes des grains pour traiter le béribéri et les troubles mentaux. On donne une décoction des grains additionnée de sel pour la réhydratation des patients souffrant de diarrhée.

Remarque : La variété améliorée R-66, développée par l'INEAC, permet d'accroitre les rendements de 50 à $80 \%$.

Références : Gillet 1927, Mukoko Matondo 1991, Drachoussoff 1993, Raemaekers 2001, Pousset 2004 
Noms courants : Nsa Iwasa (Kikongo), yellow sorrel (Angl.)

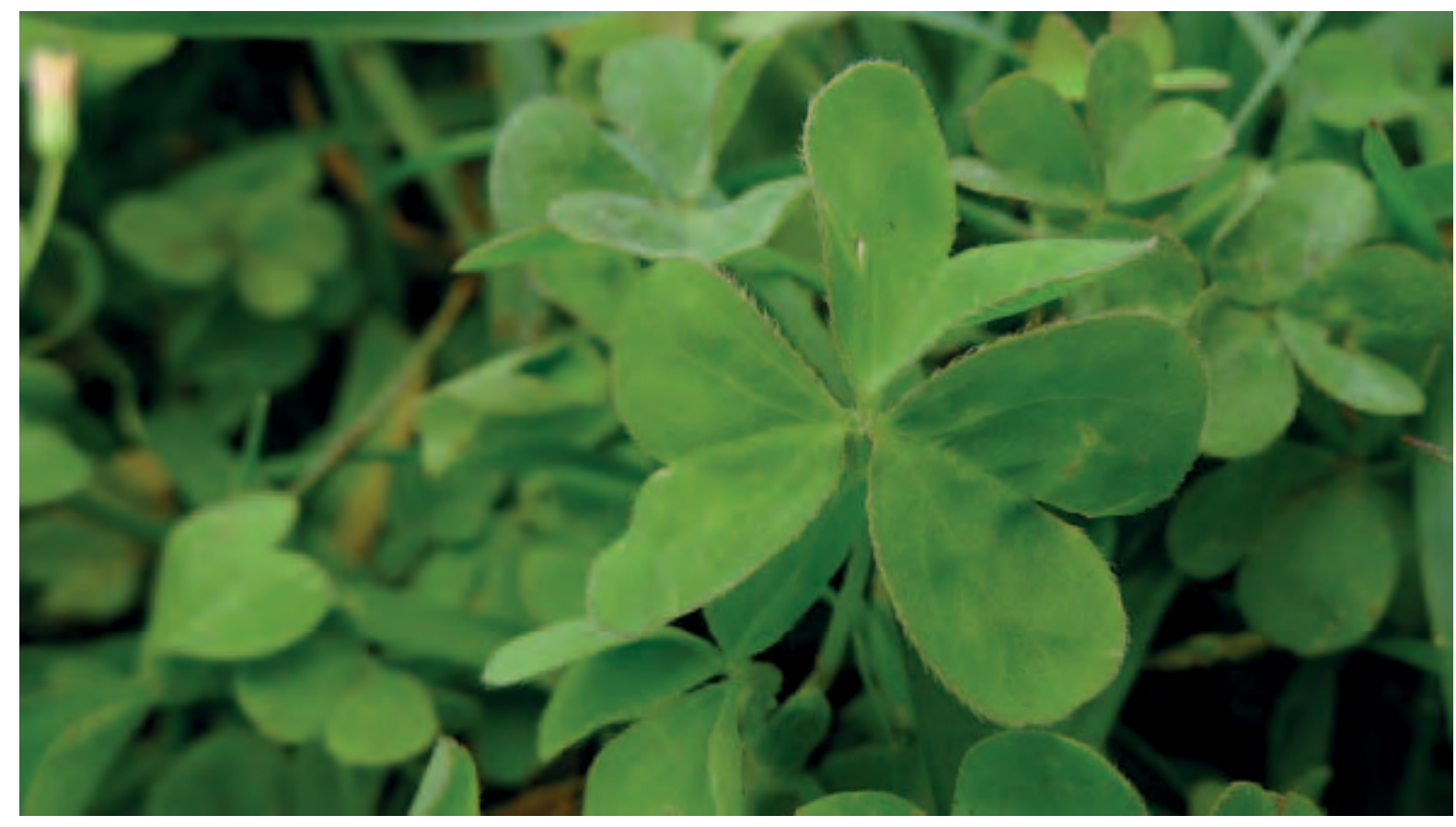

Les deux photos : John Tann

Description : Plante herbacée variable pouvant atteindre $30 \mathrm{~cm}$ de haut. Les racines sont gonflées et couvertes d'une enveloppe lâche, comme un oignon. La plante porte de fines tiges grimpantes qui s'enracinent aux nœuds. Les feuilles sont trifoliées, avec des folioles arrondis. Certaines variétés ont des feuilles pourpres. Le fruit est une étroite capsule cylindrique de 1 à $2 \mathrm{~cm}$ de long, qui s'ouvre en explosant.

Ecologie : Adventice commune des jardins à sol acide et des friches humides, largement répandue dans les climats chauds.

Usages : Au Kongo Central, les feuilles, qui ont le même goût que l'oseille ou le citron, se mangent comme légumes. On en fait aussi une boisson: infuser 10 minutes, sucrer, puis refroidir. La plante est riche en vitamine $C$, on l'emploie pour traiter le scorbut et pour faciliter la digestion. Les feuilles sont rafraichissantes, antiscorbutiques et anti dysentérique. Mangées longtemps et en grandes quantités, les oxalates

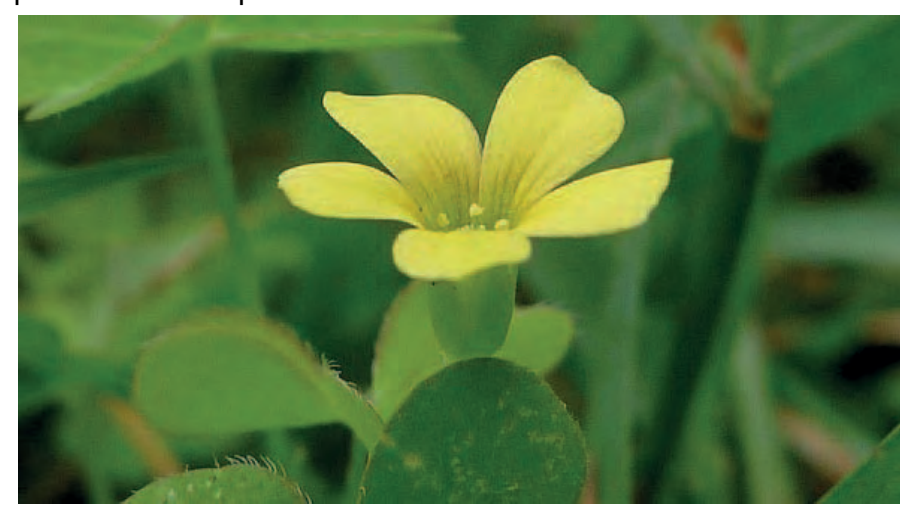
qu'elle contient peuvent inhiber l'absorption de calcium. Ailleurs en R.D. Congo, on emploie aussi cette plante pour réduire la fièvre, pour prévenir les caries dentaires et pour traiter les morsures de serpents. En Tanzanie, on mange les feuilles ainsi que les fruits verts. On a montré l'action positive de cette plante contre Staphlyococcus aureus.

Références : Gillet et Pâque 1910, Gillet 1927, Staner et Boutique 1937, Renier 1948, Wilczek 1958, Nsimundele 1966 - 68, Williamson 1975, Daeleman et Pauwels 1983, Burkill 1997, Wikipedia (Consulté le 22.10.2012) 
Noms courants : Kinsungwa, kinsungu (Kikongo)(de nsunga = bonne odeur), café de brousse (Fr.)

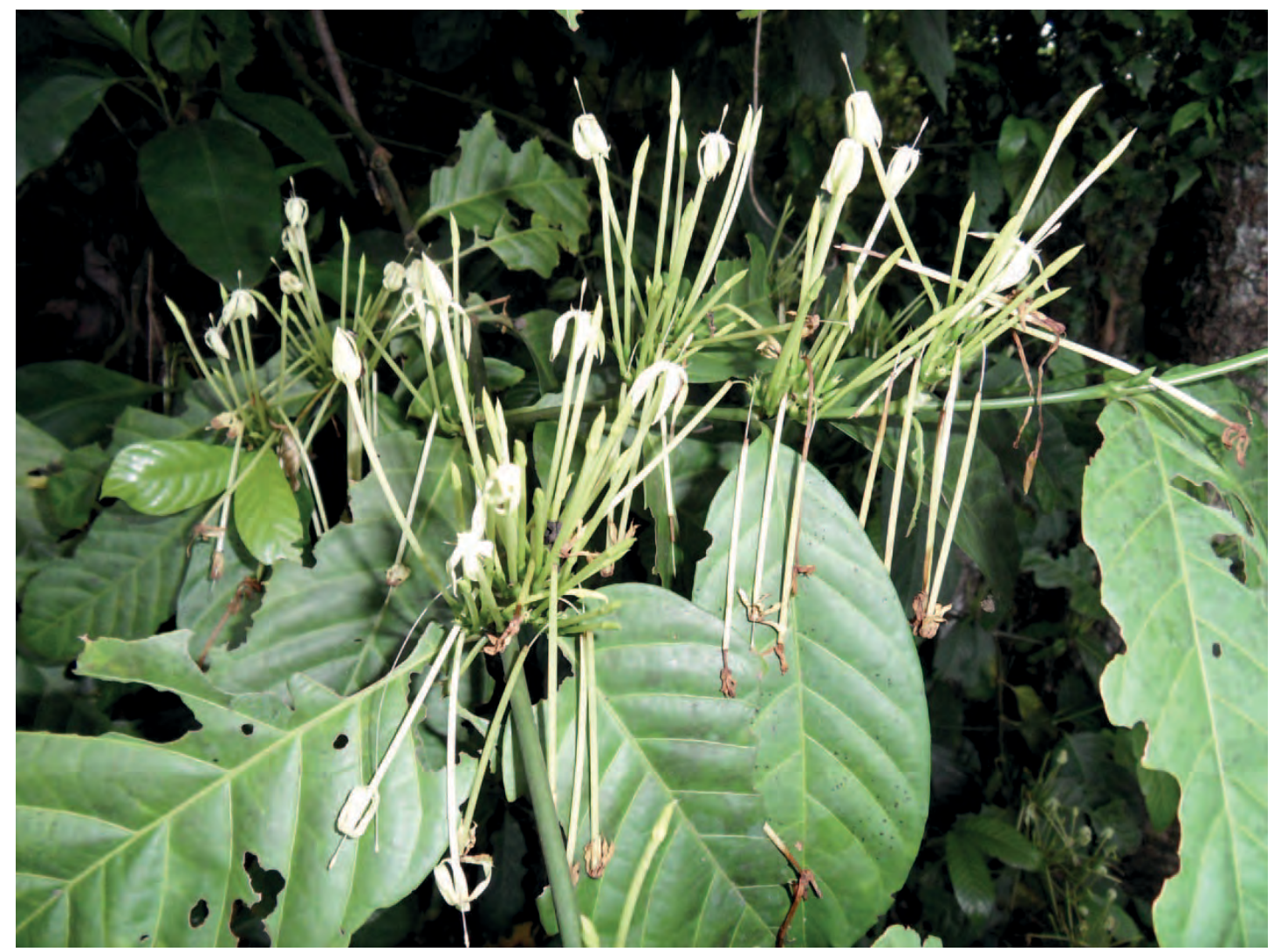

Description : Arbuste semblable au caféier, de 2 à $15 \mathrm{~m}$ de haut. L'écorce est lisse. Les branches sont courbées et pendantes. Feuilles elliptiques à base arrondie et bout pointu, de 8 à 26 sur 2 à $12 \mathrm{~cm}$, avec des stipules triangulaires de 8 à $16 \mathrm{~mm}$ de long. Fleurs blanches et parfumées, jusqu'à $6 \mathrm{~cm}$ de long, étroitement tubulaires, disposées en cymes axillaires denses. Les fruits ont $5 \mathrm{~cm}$ de long. La plante a une odeur agréable, même desséchée. Deux sous espèces sont présentes au Kongo Central.

Ecologie : Plante de sous-bois des forêts, présente du Sénégal au Mozambique, largement répandue dans le bassin du Congo, au Kenya et au Zimbabwe.

Usages : Arbuste à cultiver à titre ornemental. Au Kongo Central, on faisait traditionnellement tremper les feuilles dans le vin de palme pour lui donner une bonne odeur et le rendre plus enivrant. Les chenilles comestibles Nsungu ou Nsuangu se nourrissent des feuilles. Les abeilles visitent les fleurs. En Ubangi, on fait une pâte avec l'écorce et les feuilles pour traiter la toux. A Lulonga, on donne en lavement une macération de l'écorce pour aider l'accouchement. En Tanzanie et au Malawi, on emploie les troncs en construction et comme bois de feu. A Ghana, les rameaux sont populaires comme bâtons à mâcher. En Sierra Leone, l'écorce séchée s'emploie comme parfum.

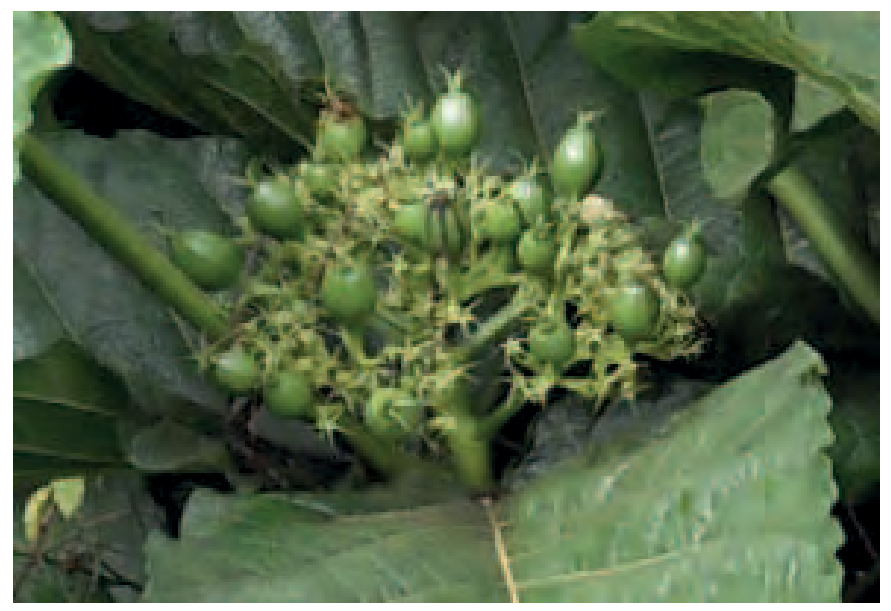

Références : Butaye 1909, Gillet et Pâque 1910, Staner et Boutique 1937, Renier 1948, Irvine 1961, Uphof 1968, Daeleman et Pauwels 1983, Pauwels 1993, Beentje 1994, Burkill 1997 


\section{Oxyanthus unilocularis}

(Rubiaceae)

Noms courants : Bayombolo, tulufu (Ngwaka)

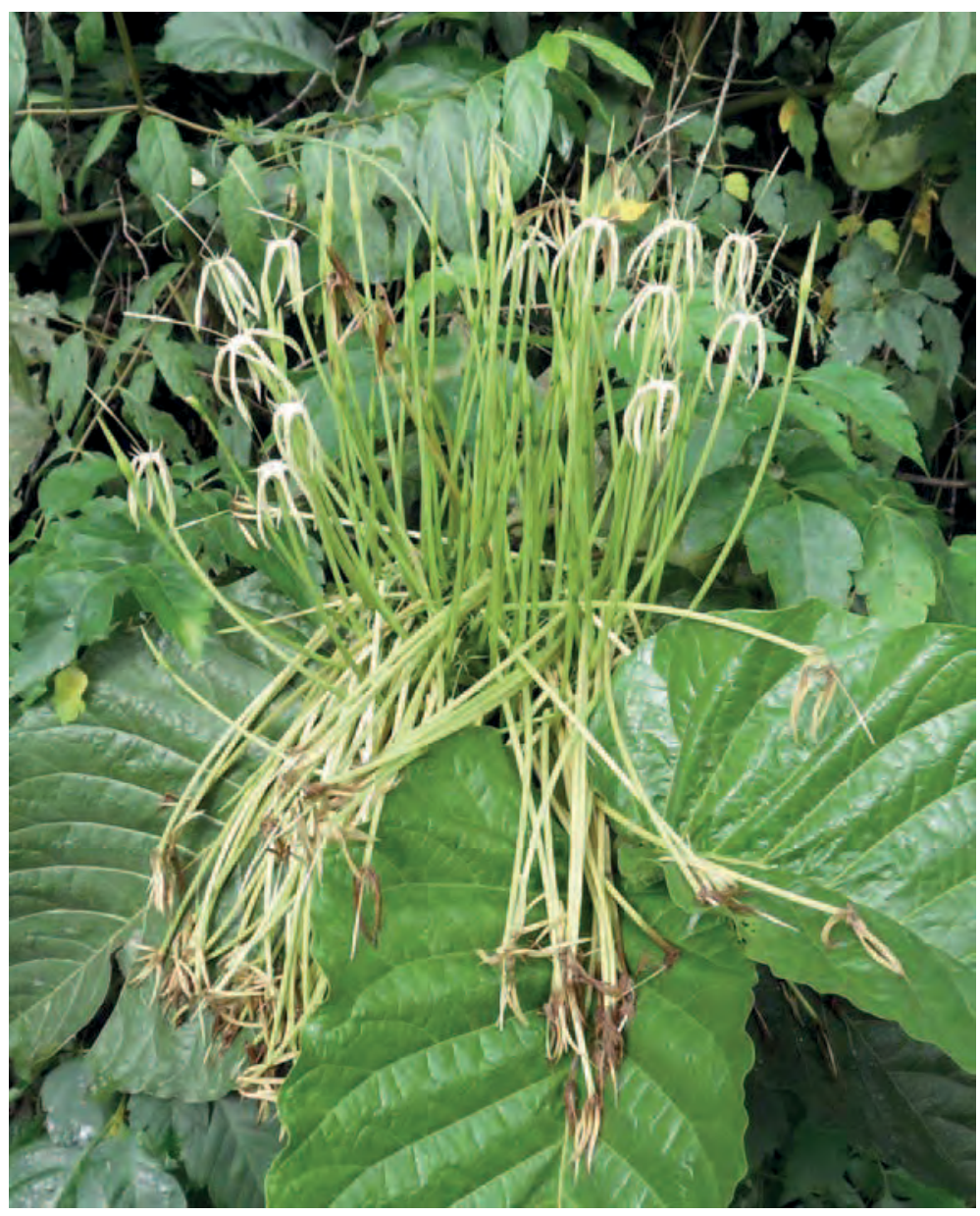

Description : Arbuste atteignant $8 \mathrm{~m}$ de haut, avec de grandes feuilles, mesurant jusqu'à $35 \times 17 \mathrm{~cm}$, asymétriques à la base. La face inférieure des feuilles est couverte de poils abrasifs : au toucher, elle est comme du papier de verre. Les fleurs blanches ont jusqu'à $20 \mathrm{~cm}$ de long ; les fruits, verts, ont jusqu'à $3 \mathrm{~cm}$ de diamètre.

Ecologie : Plante des forêts secondaires et des lisières de forêts, de la Sierra Leone à l'Ouganda.

Usages : Le bois, dur et blanc, constitue un bon bois de feu. Dans les Provinces de l'Equateur, on emploie une décoction des racines avec d'autres plantes pour empêcher les avortements. Au Congo Brazzaville, on met l'écorce dans un bain de vapeur pour traiter la fièvre. Les cendres peuvent s'utiliser en savonnerie.

Références : Irvine 1930, Renier 1948, Eggeling et Dale 1951, Irvine 1961, Bouquet 1969, Pauwels 1993, Burkill 1997, White et Abernethy 1997, Konda Ku Mbuta et al. 2015a

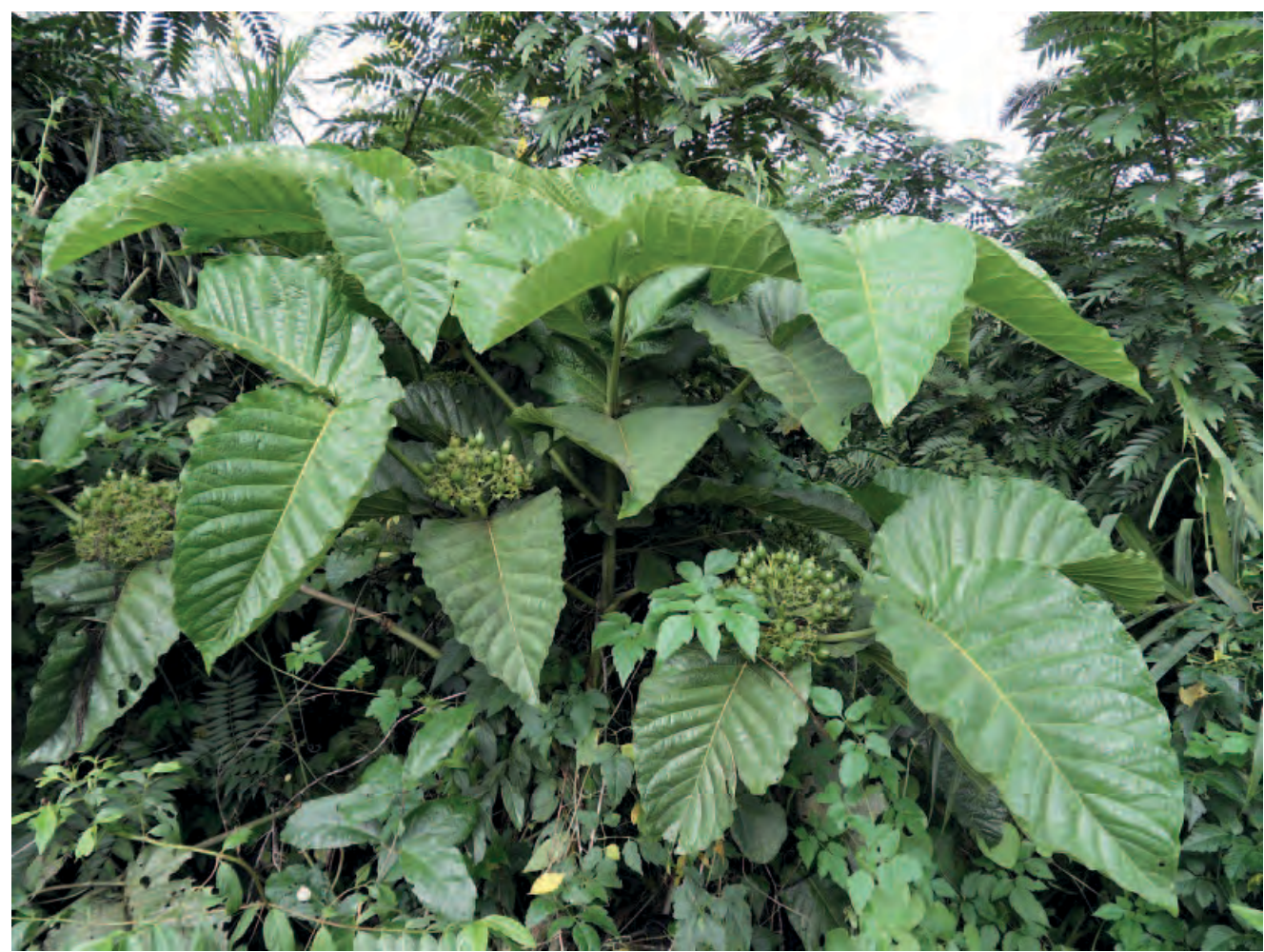


Synonyme : Bombacopsis glabra

Noms courants : Nguba nguela, nguba ya mputu (Kikongo), noyer d'Amérique (Fr.)

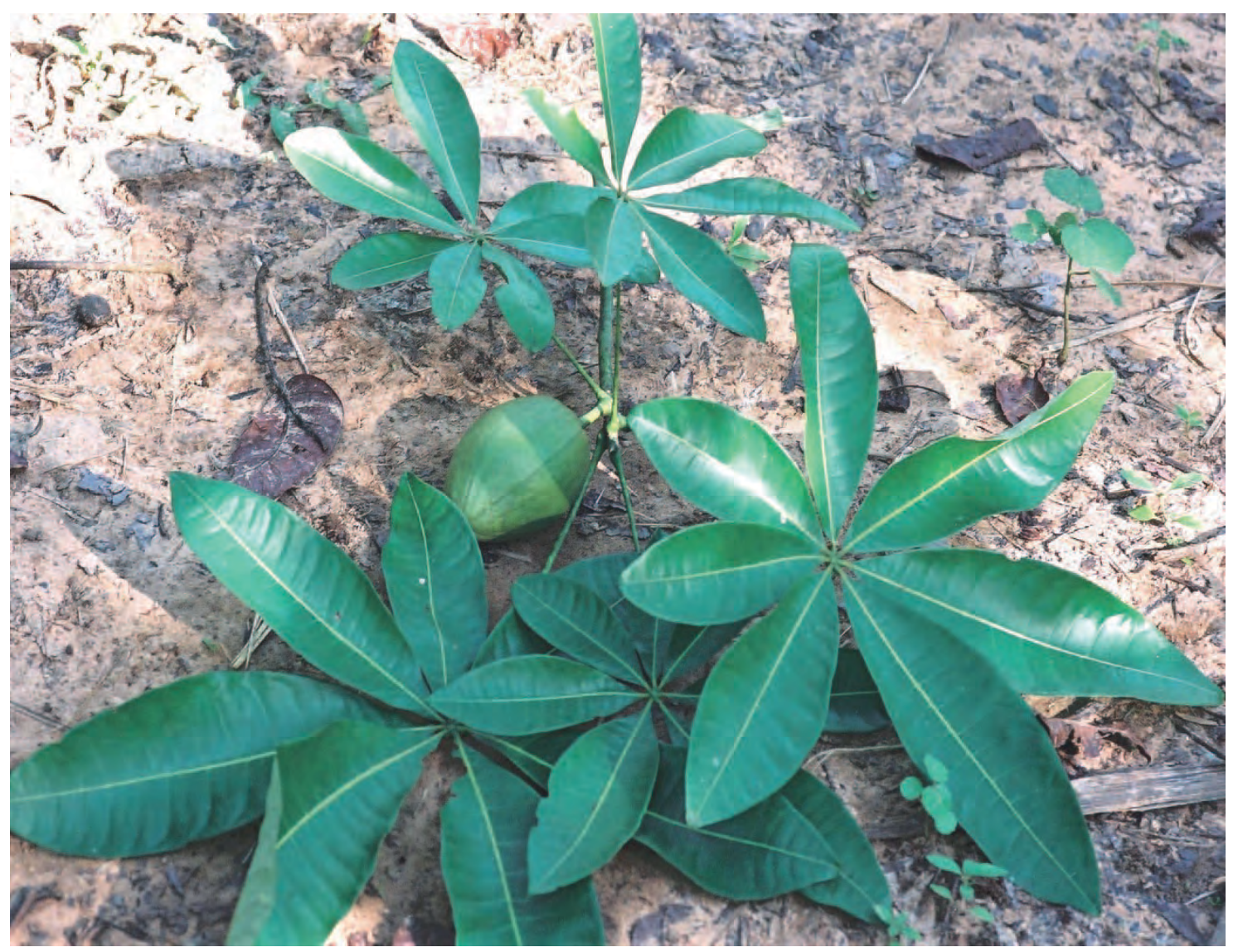

Description : Petit arbre de 6 à $8 \mathrm{~m}$ de haut, à feuilles brillantes en dessus, composées, digitées, avec 5 à 8 folioles, et à grandes fleurs blanches parfumées. Le fruit est une capsule ovoïde de 9 à 13 sur 5 à $6 \mathrm{~cm}$, contenant de 10 à 20 graines pesant chacune $1,8 \mathrm{~g}$ en moyenne.

Ecologie: Arbre originaire d'Amérique centrale, introduit depuis le XVlème siècle et parfaitement acclimaté. Cultivé également en Afrique de l'Ouest, au Soudan et en Zambie. Arbre rustique poussant bien sur sols sableux. Souvent planté comme haie autour des parcelles.

\section{A droite: Graines nouvellement récoltées}

Reproduction : Cultivé par boutures, mais les graines germent bien et les semis se transplantent facilement.

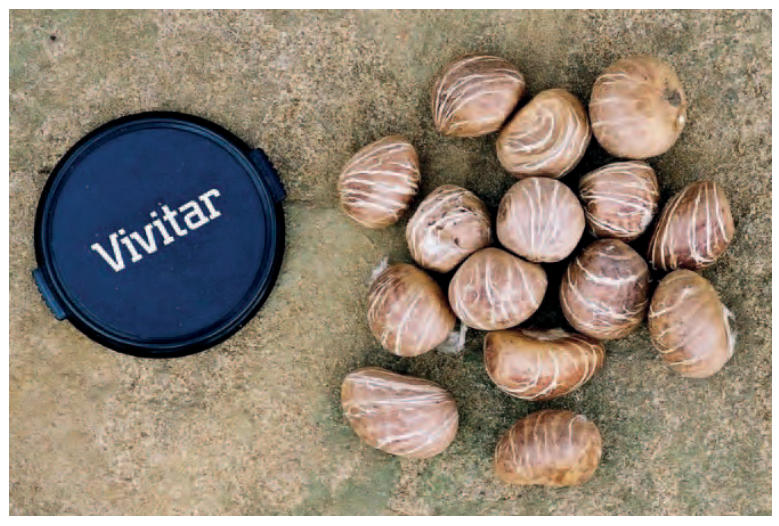

Gestion : Les arbres commencent à porter des fruits la troisième année, et atteignent leur production maximale la septième année. On peut obtenir $4,5 \mathrm{~kg}$ de graines par arbre.

Usages: Les graines se mangent crues ou grillées. Elles ont une haute teneur en huile (45\%) et peuvent s'employer en savonnerie. Au Gabon, on mange les jeunes feuilles. On a observé des abeilles récoltant le nectar en novembre.

Références : Gillet 1927, Robyns 1963, Anton-Smith 1964, Burkill 1985, Pauwels 1993, Nsimundele 2004 


\section{Palisota hirsuta}

Noms courants : Bundabunda (Kikongo)

Description : Plante herbacée vigoureuse à longues feuilles, pouvant atteindre $3 \mathrm{~m}$ de haut.

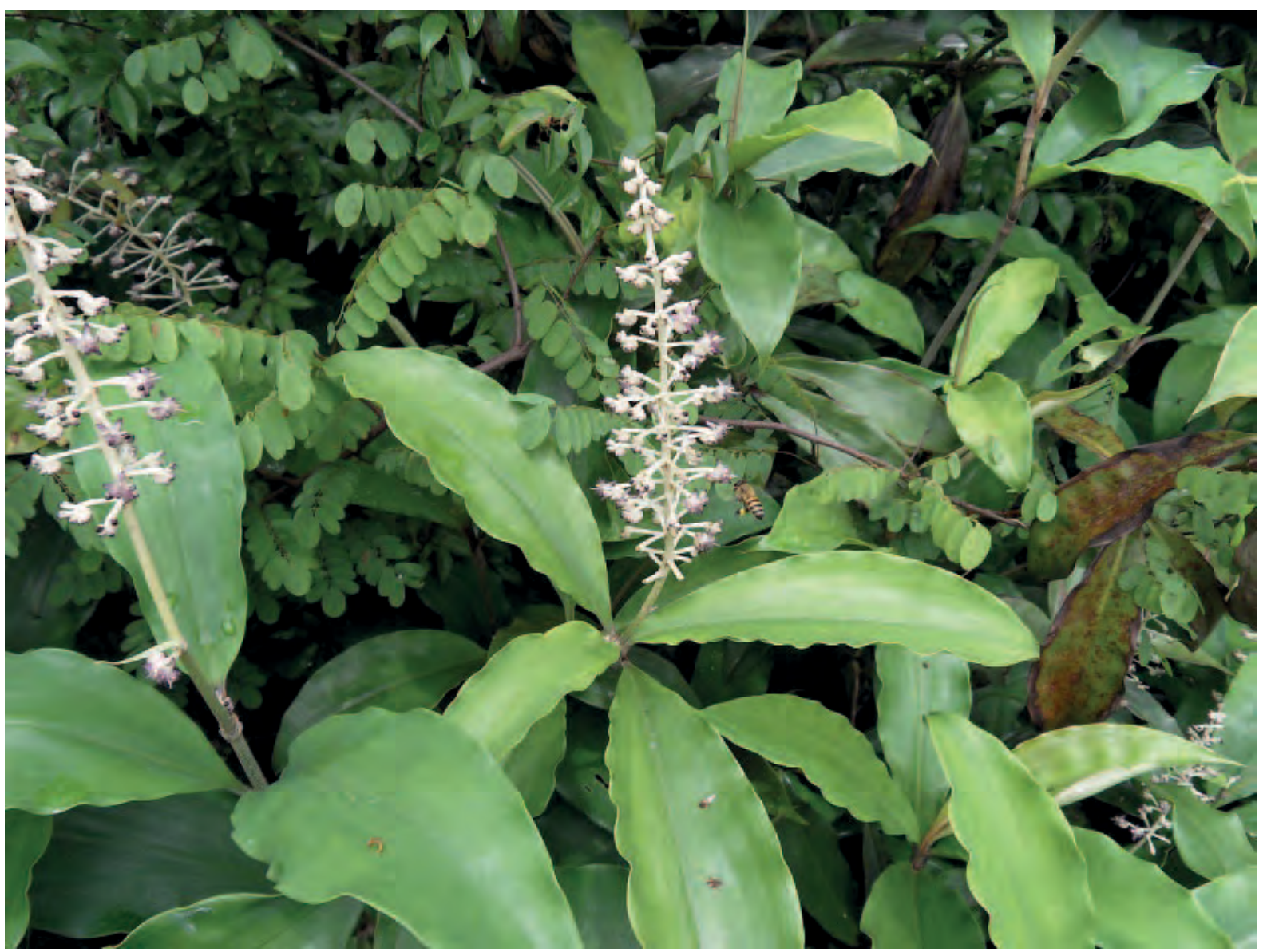

Abeille récoltant le pollen en janvier

Ecologie : Plante commune des jachères et des forêts secondaires, en Afrique de l'Ouest et dans le bassin du Congo.

Usages: Bonne source de pollen pour les abeilles, au Kongo Central et au Gabon. Les espèces de Palisota sont connues comme un bon fourrage pour les abeilles aux USA. La sève ou les tiges écrasées, appliquées en compresses, ont des propriétés analgésiques et antiseptiques. On mâche les tiges pour calmer la toux. On emploie la plante séchée dans la fabrication de savon. La plante est parfois cultivée à titre ornemental. On croyait traditionnellement que, s'il y avait des jumeaux et que l'un mourait, il fallait enterrer les feuilles avec le corps pour protéger le jumeau vivant de la mort.

Remarque : On trouve aussi au Kongo Central $P$. mannii, qui est probablement visité par les abeilles.

Références: Gillet et Pâque 1910, Daeleman et Pauwels 1983, Burkill 1985, Lobreau-Callen et al. 1989, Ambougou 1991 


\section{Palisota pynaertii}

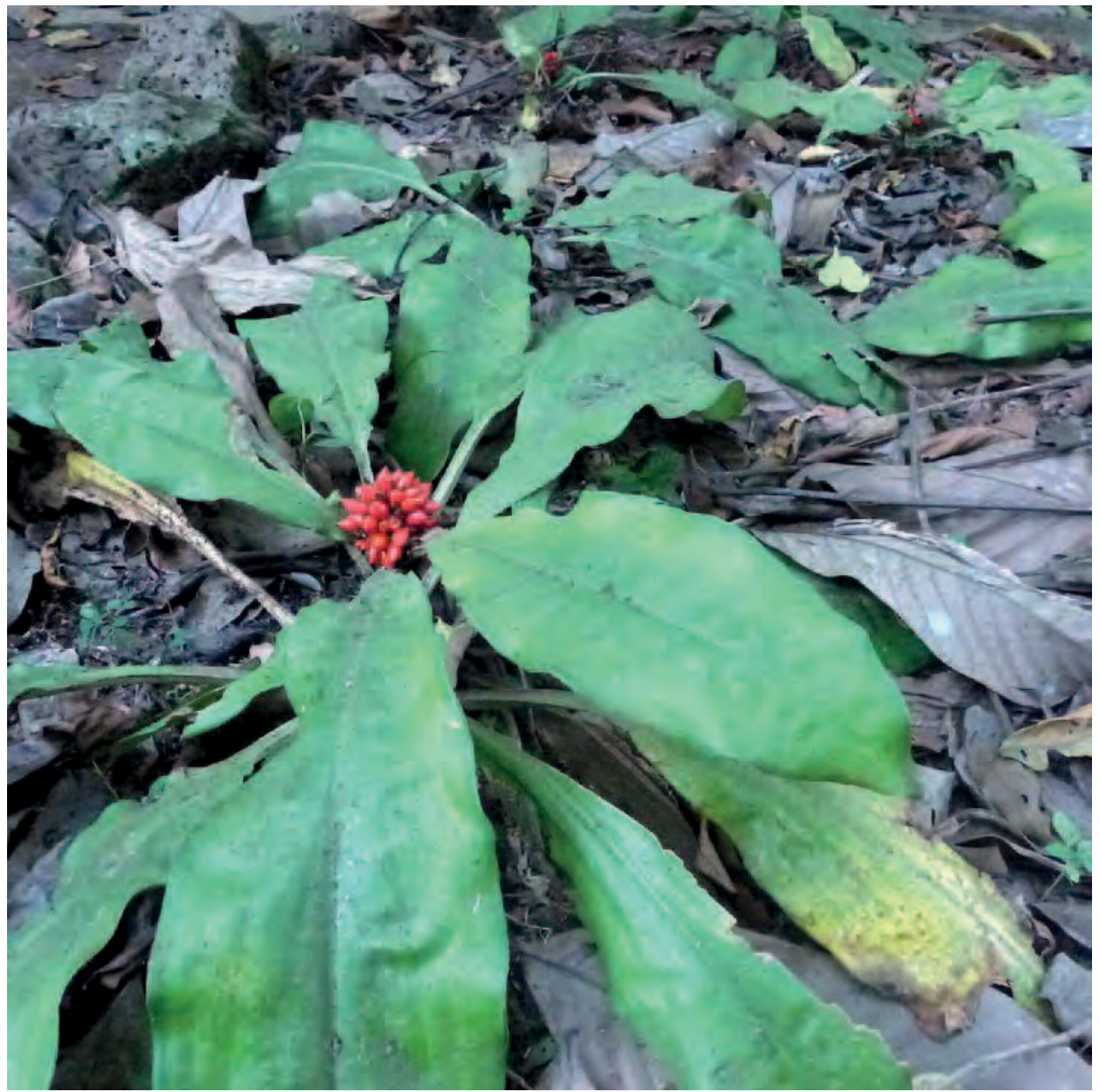

(Commelinaceae)

Description : Plante herbacée à tige très courte et longues feuilles, avec pétiole rainuré. Les fleurs sont blanches, les fruits sont d'abord blancs puis deviennent rouges.

Ecologie : Plante des sous-bois humides, du Gabon à la RD Congo.

Reproduction : Par graines.

Usages : Au Gabon, on applique la plante râpée sur les blessures pour les cicatriser.

\section{Références :}

Raponda-Walker et Sillans 1961, African Plant Database (3.4.0)

(Consulté

19.11.2018)

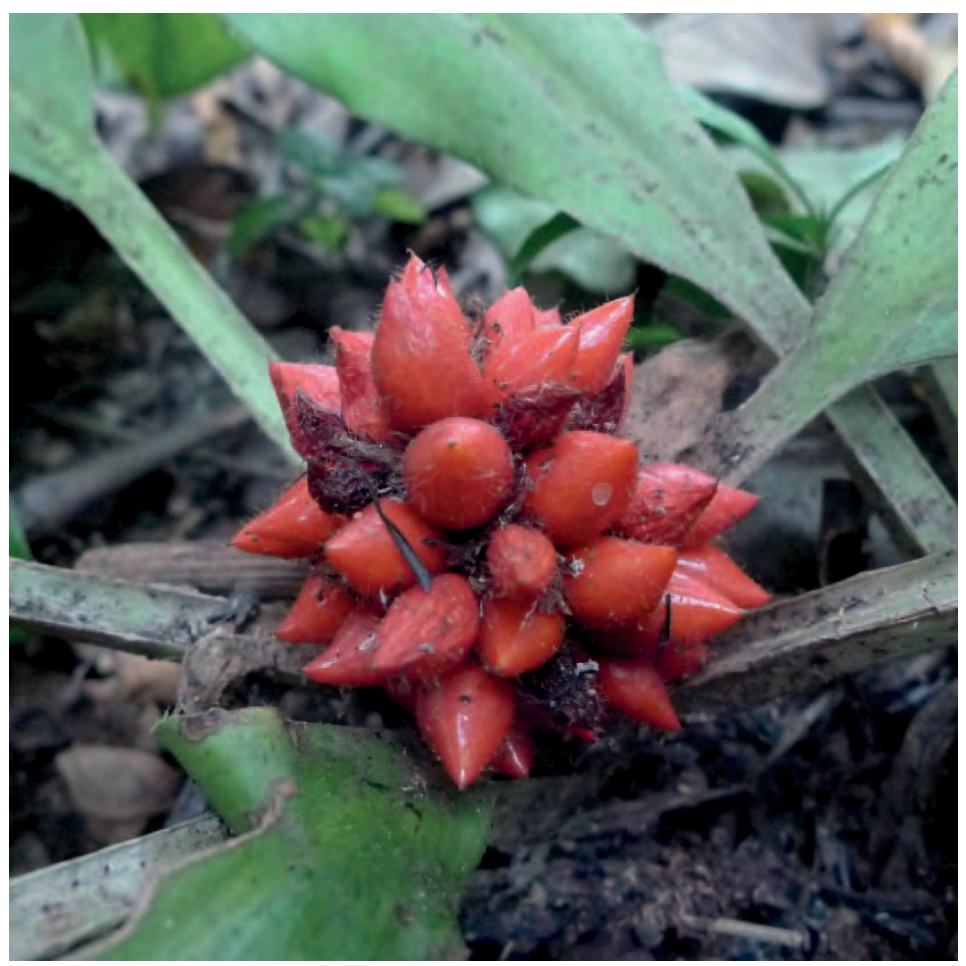




\section{Palisota schweinfurthii}

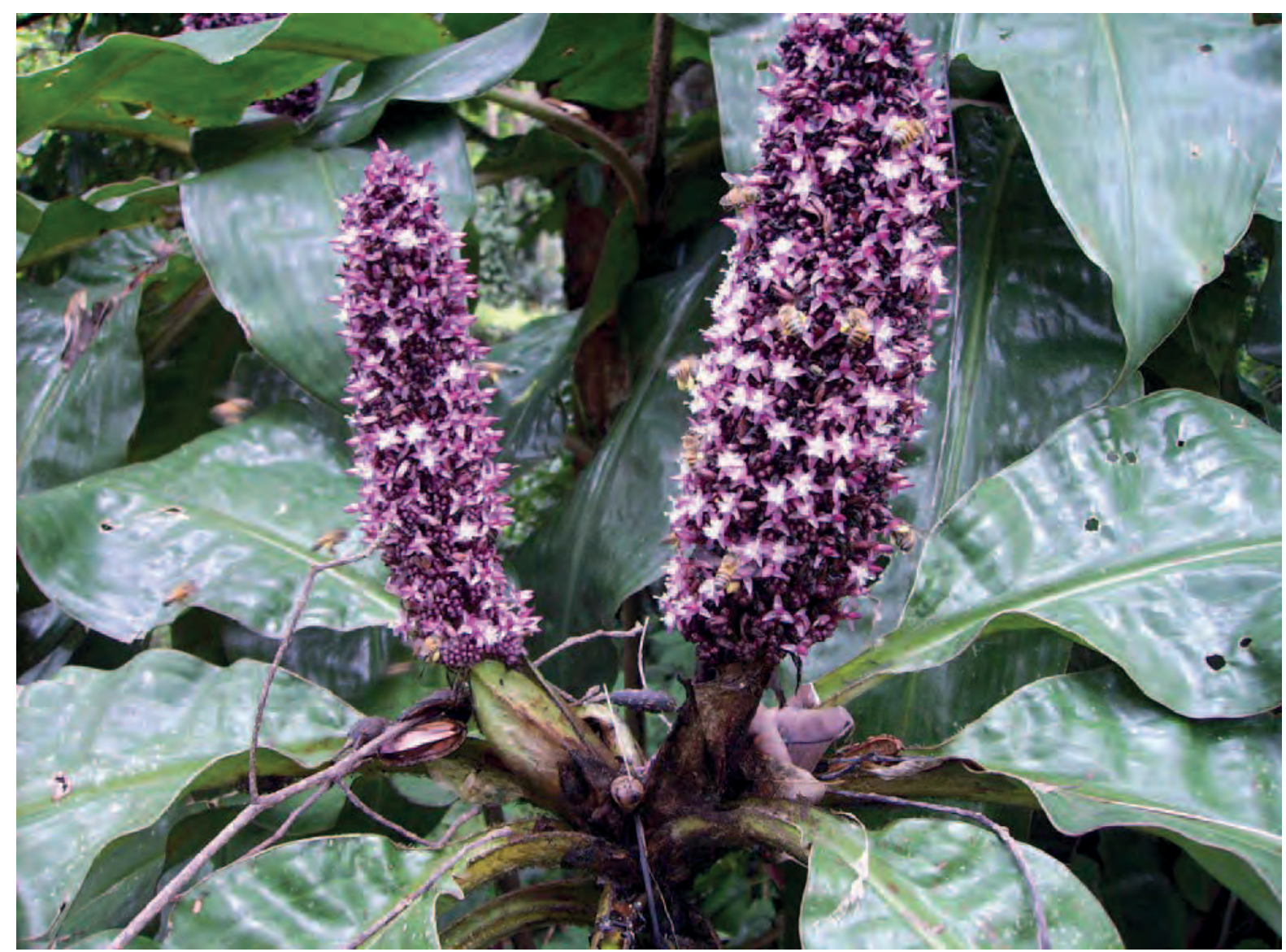

Récolte du nectar par les abeilles en octobre

Description : Plante herbacée vigoureuse, avec des tiges atteignant $1,8 \mathrm{~m}$ de haut. Les feuilles se disposent surtout en rosettes terminales. Les fleurs forment des épis denses, et sont suivies de fruits rouges.

Ecologie: Pante des clairières de la forêt pluviale, des bords de routes et des lisières des champs, du Cameroun au Soudan, à l'Angola, la Zambie et la Tanzanie.

Usages : Les fleurs sont très attractives pour les abeilles, qui collectent le nectar en octobre et novembre. Les espèces de Palisota sont un

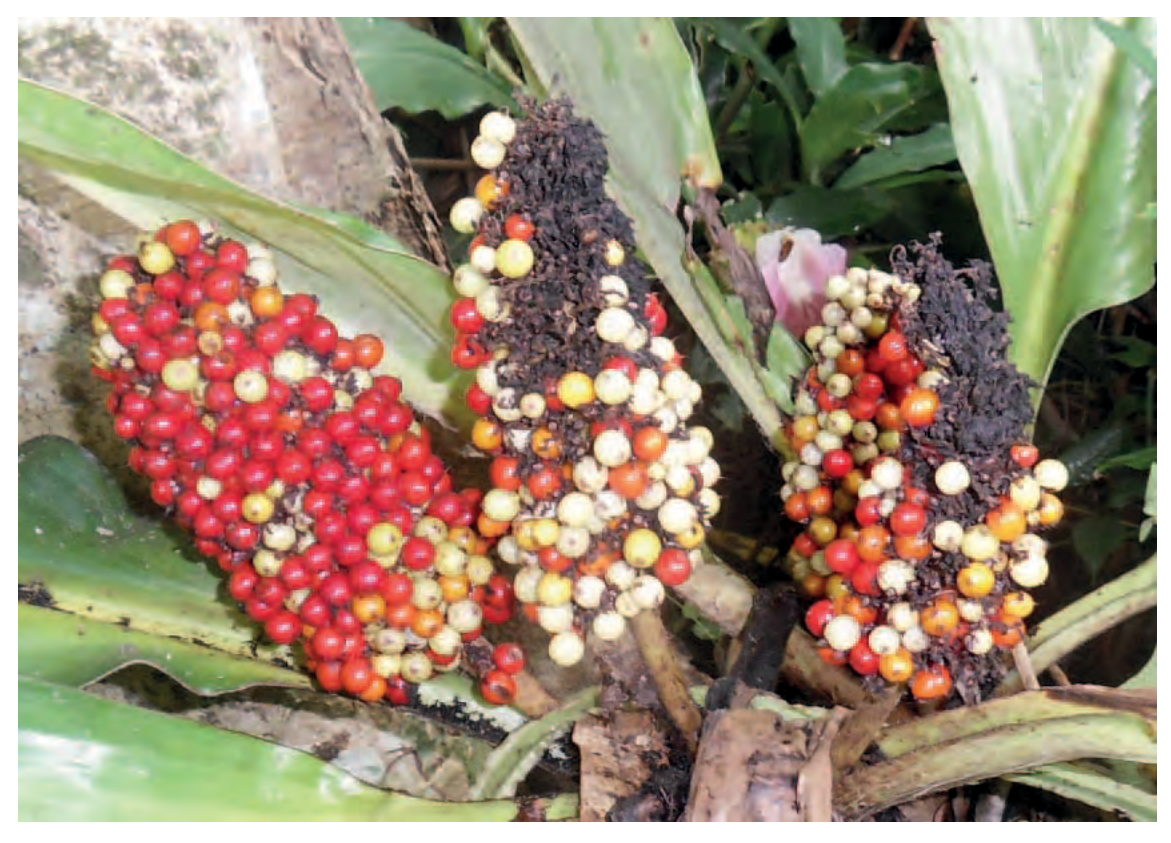
important fourrage pour les abeilles dans les savanes humides de l'Afrique équatoriale. Toutes les parties de la plante ont des usages médicinaux.

Références : Renier 1948, Hepburn et Radloff 1998, Neuwinger 2000 


\section{Pancovia laurentii}

Noms courants : Nkila nkumbi (Kikongo), mutendu, mutindi (Lingala)

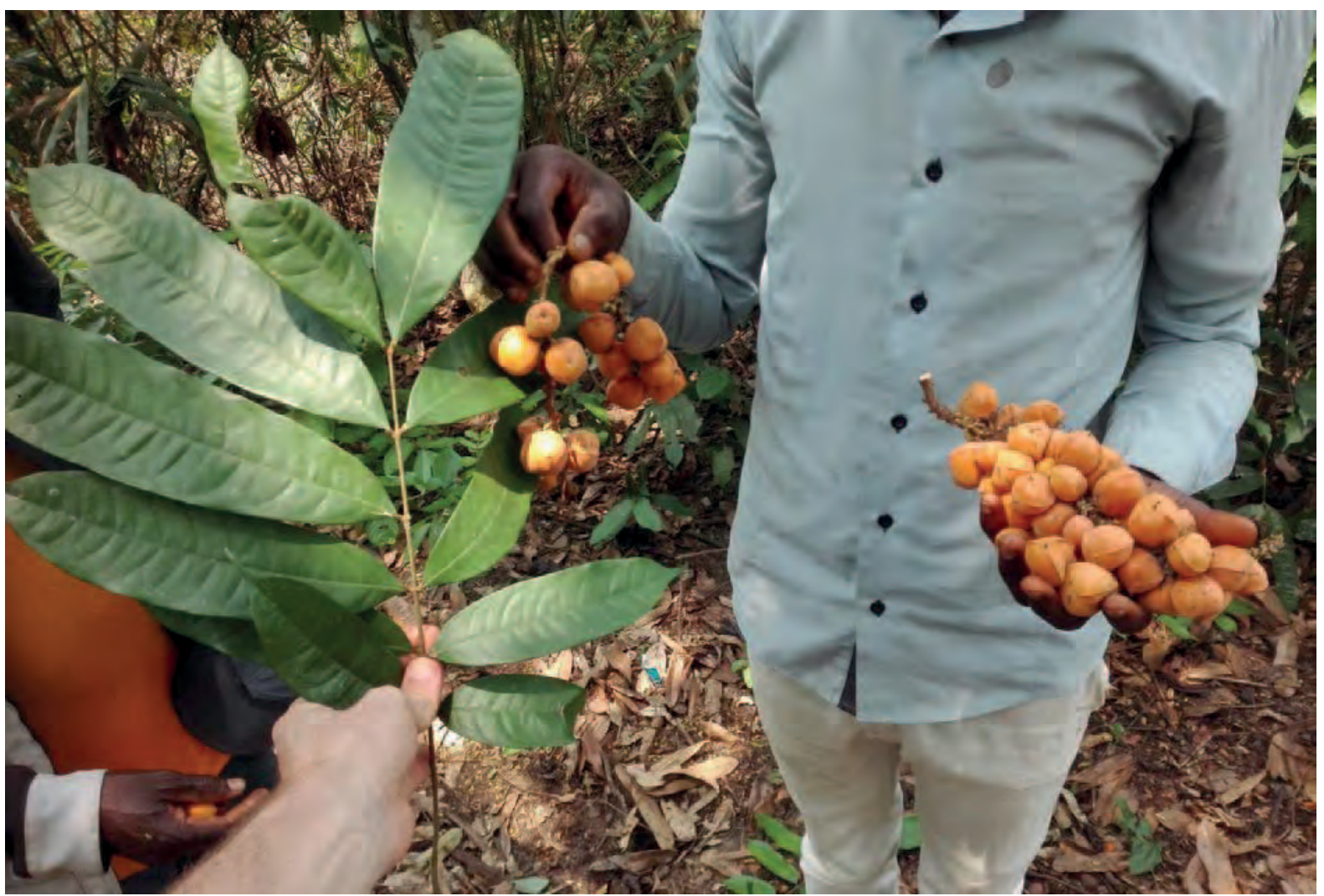

Feuillage et fruits d'un arbre près de Vanda à Bandundu en octobre.

Michael Sthreshley

Description : Un arbre atteignant $20 \mathrm{~m}$ de haut. Les feuilles sont regroupées en rosette aux extrémités des branches. Pétiole de 10 à $18 \mathrm{~cm}$ de long et le rachis mesure de 20 à $40 \mathrm{~cm}$ de long, les folioles sont sous-opposées, 12 à $24 \times 2,5$ à $5 \mathrm{~cm}$. Inflorescence portée sur la tige, jusqu'à $30 \mathrm{~cm}$ de long. Le fruit est une baie ailée à trois côtés, de 2,5 × 3,5 cm, en grappes lourdes tombantes poussant à partir du tronc. La pulpe du fruit est orange avec 3 graines brunes dans chaque fruit.

Ecologie : Forêts primaires et galeries et également présentes au Cameroun, Gabon, Congo (Brazzaville).

Usages: Les fruits sont comestibles et bien triés par la suite, bien que signalés comme acides. Le bois est blanc. La racine et l'écorce sont utilisées dans la province de l'Équateur pour traiter l'impuissance et la stérilité.

Références : Renier 1948, Hauman 1960, Daeleman et Pauwels 1983, Pauwels 1993, Vivien et Faure 1996, Nsimundele 2004, Konda Ku Mbuta et al. 2015a 


\section{Panda oleosa}

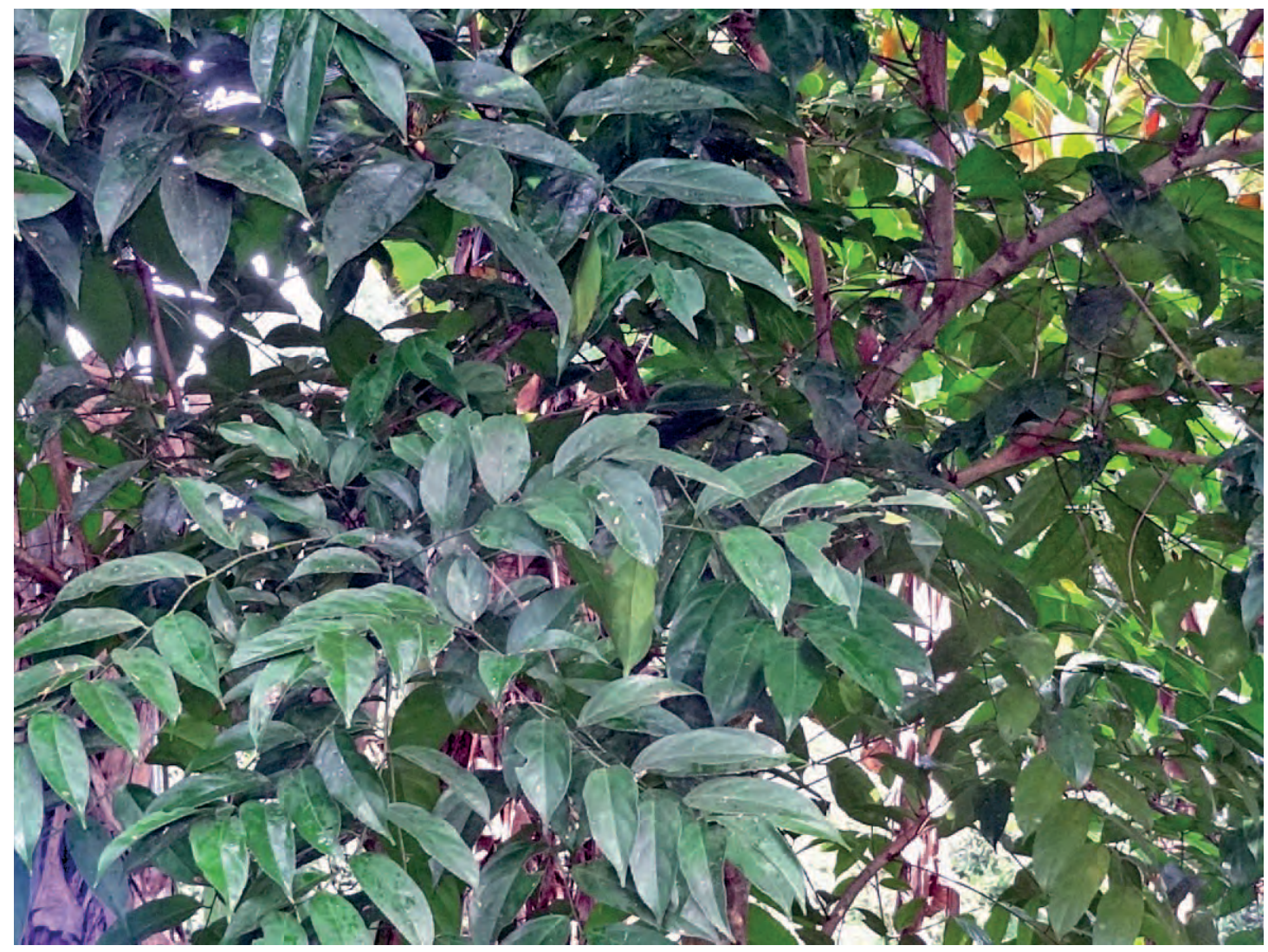

Description : Arbre de 10 à $35 \mathrm{~m}$ de haut. Le tronc, pouvant avoir $1 \mathrm{~m}$ de diamètre à l'âge adulte, est cannelé à la base ou porte de légers contreforts. La couronne est haute et allongée. Les feuilles, alternes, sont de tailles très variables, de 10 à $13 \mathrm{~cm}$ de long et 4 à $13 \mathrm{~cm}$ de large. Les jeunes feuilles sont d'un rose rouge vif. L'inflorescence est un racème de 10 à $13 \mathrm{~cm}$ de long et 4 à $13 \mathrm{~cm}$ de large. Le fruit est rond, dur, vert à jaune pâle, de 5 à $6 \mathrm{~cm}$ de diamètre. Sa chair est d'un orange rouge profond. Le noyau, extrêmement dur, comporte trois ouvertures contenantes chacune une graine triangulaire-ovoïde, concave, d'environ $2 \mathrm{~cm}$ de long, comprimée, d'un brun brillant. La plupart des arbres donnent chaque année des fruits, qui peuvent rester sur l'arbre plusieurs mois.

Ecologie : Arbre des forêts riveraines et des forêts inondables, du Libéria à la République Centrafricaine et à la RD Congo.

Reproduction : La germination peut prendre de 8 mois à 3 ans, avec un taux qui peut n'être que de $5 \%$. Au Gabon, on ramasse les fruits au sol dans la forêt, et on extrait les graines avec un couteau tranchant, ce qui est un travail dangereux!

Photos : Roy Danforth

Usages: Au Mayombe, on emploie le bois en charpentes et menuiserie. Les graines pilées se mettent dans les sauces. L'huile des graines s'emploie pour la cuisine. On peut aussi manger les graines cuites. Différentes parties de la plante s'emploient en médecine traditionnelle. Les abeilles récoltent le nectar des fleurs.

Références Staner et Boutique 1937, Robyns 1958, Busson 1966, Pauwels 1993, Vivien et Faure 1996, Burkill 1997, White et Abernethy 1997, Lemmens 2007, Harris et al. 2011

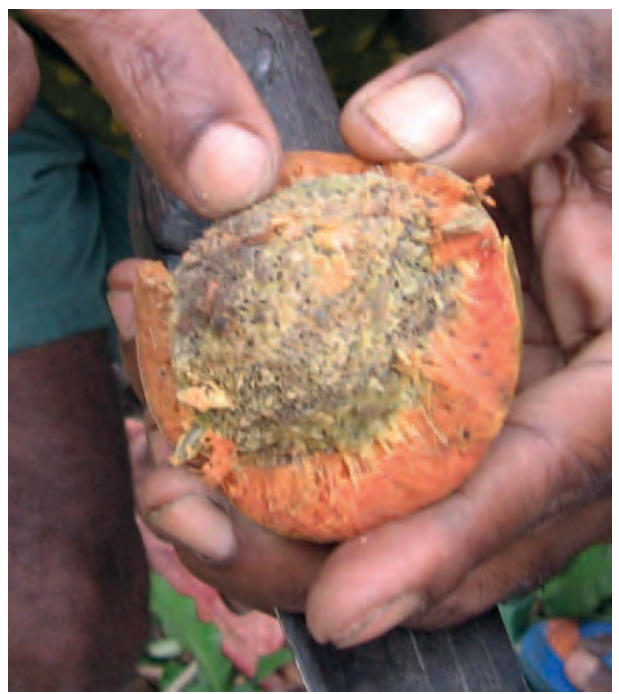




\section{Pandanus candelabrum}

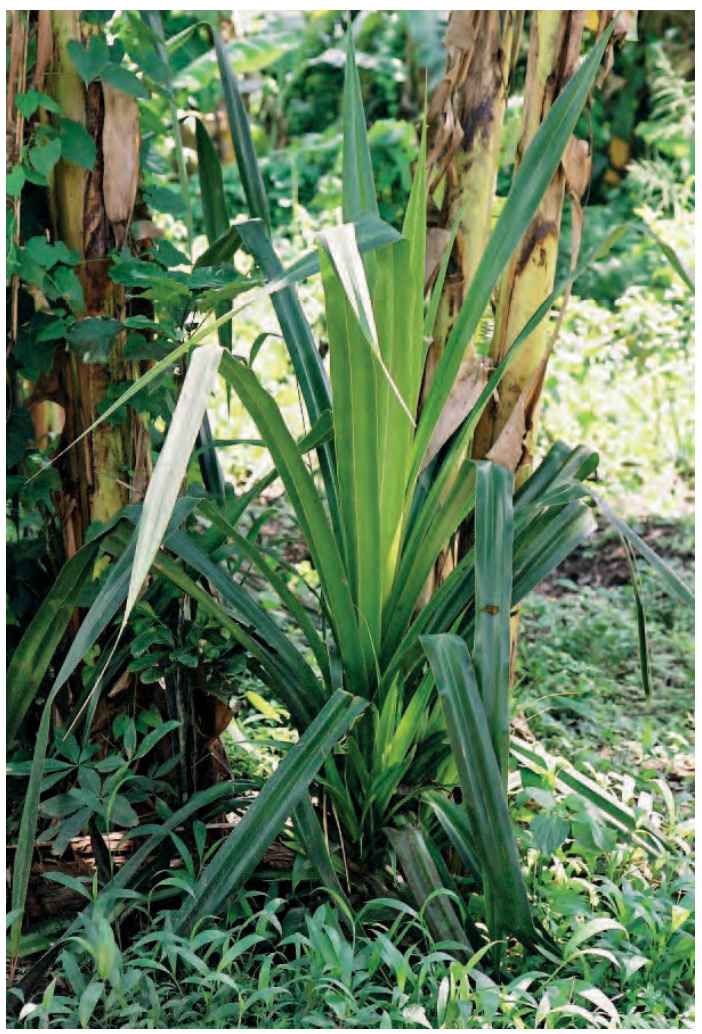

Usages: Les feuilles (makenge) sont coriaces et solides. Après avoir enlevé les épines et la nervure centrale, on les sèche entières ou en lanières. On les emploie à faire des nattes (mfubu) et des paniers. Le bois, jaunâtre et poreux, se brise en morceaux fibreux, est un bois de feu médiocre. La plante a divers usages médicinaux.

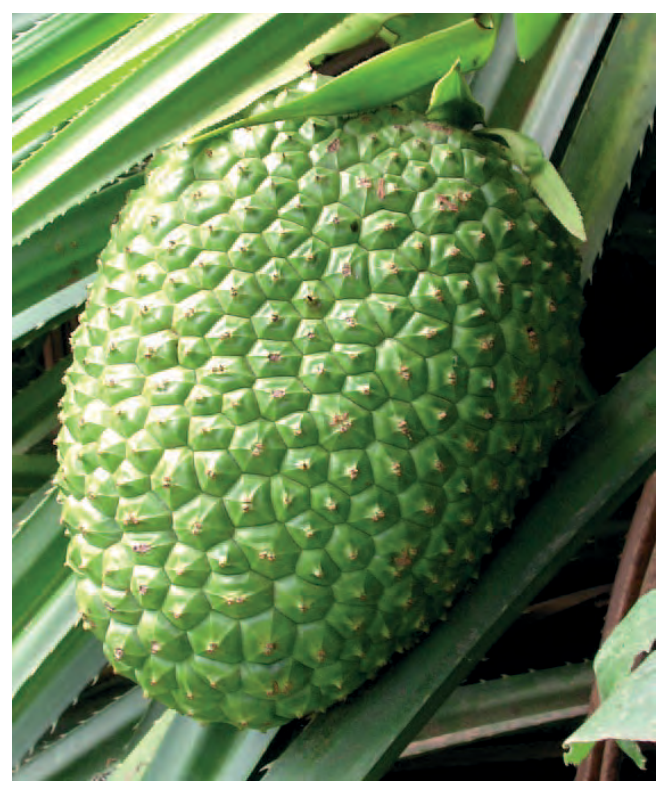

(Pandanaceae)

Nom courant : Kenge (Kikongo)

Description : Arbre atteignant $20 \mathrm{~m}$ de haut. Les tiges portent à la fois des branches et des racines échasses. Les feuilles ont jusqu'à $2,5 \mathrm{~m}$ de long et $8,5 \mathrm{~cm}$ de large : elles se terminent en pointe et portent des aiguilles piquantes sur la nervure centrale et latéralement. Les fleurs sont blanches avec une odeur forte. Les fruits (en bas à gauche) ont de 10,5 à 31 $\mathrm{cm}$ de long.

Ecologie : Plante des bords de cours d'eau, des lits de rivière et des lieux humides, parfois plantée dans les villages. Les espèces de Pandanus sont répandues dans toute l'Afrique.

Reproduction: Les graines ou les boutures poussent facilement sur sols humides.

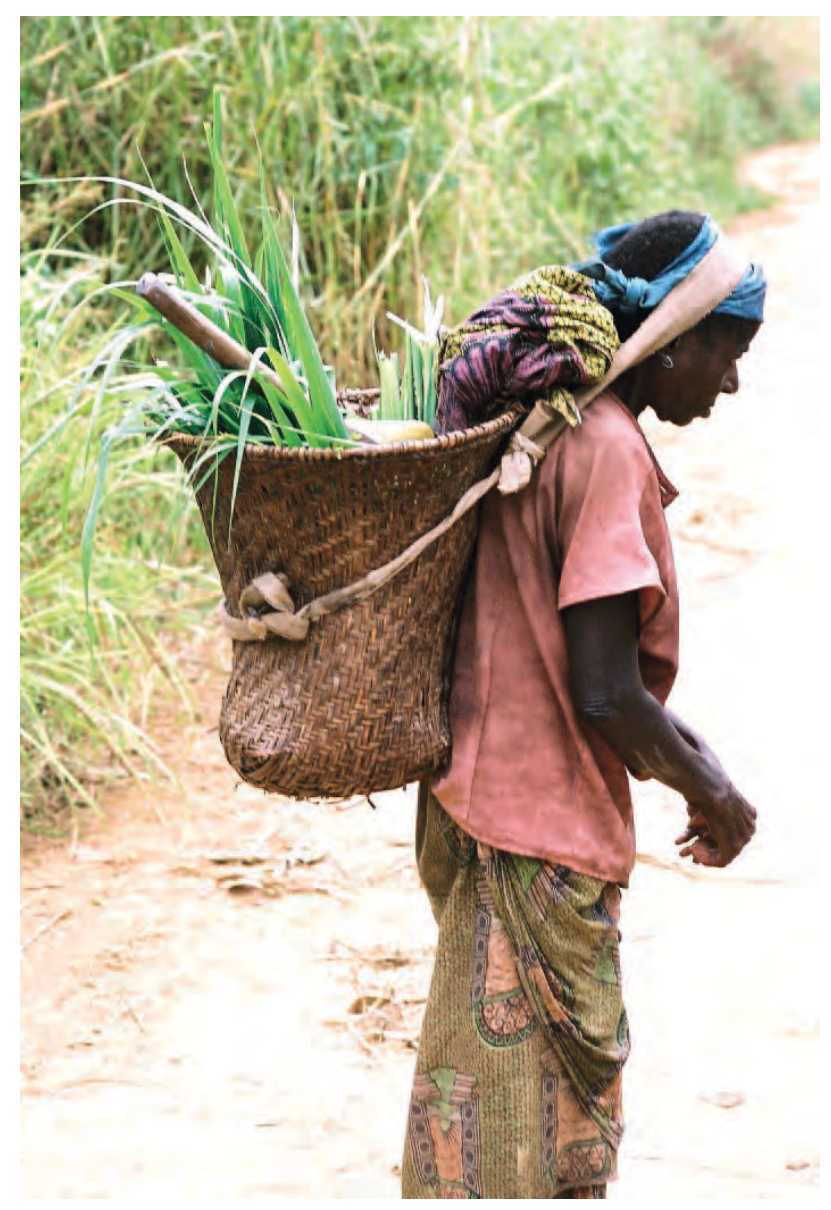

Dame rentrant chez elle avec un panier de feuilles de pandanus. Fabrication d'une natte à Kilueka

Photo : Quentin Luke 


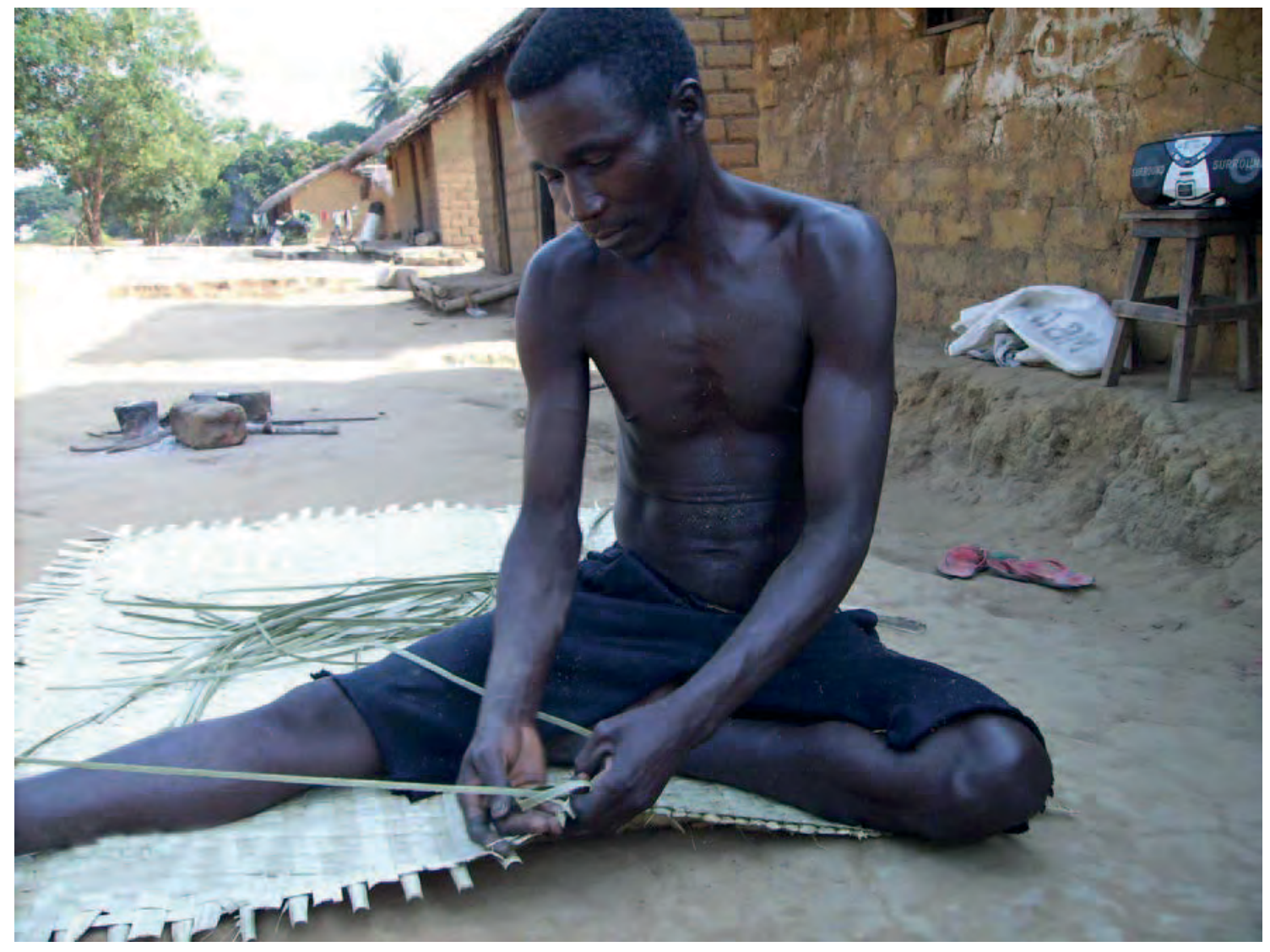

Fabrication d'une natte à Kilueka

References De Wildeman 1903, Gillet et Pâque 1910, Renier 1948, Purseglove 1972, Daeleman et Pauwels 1983, Pauwels 1993, Burkill 1997

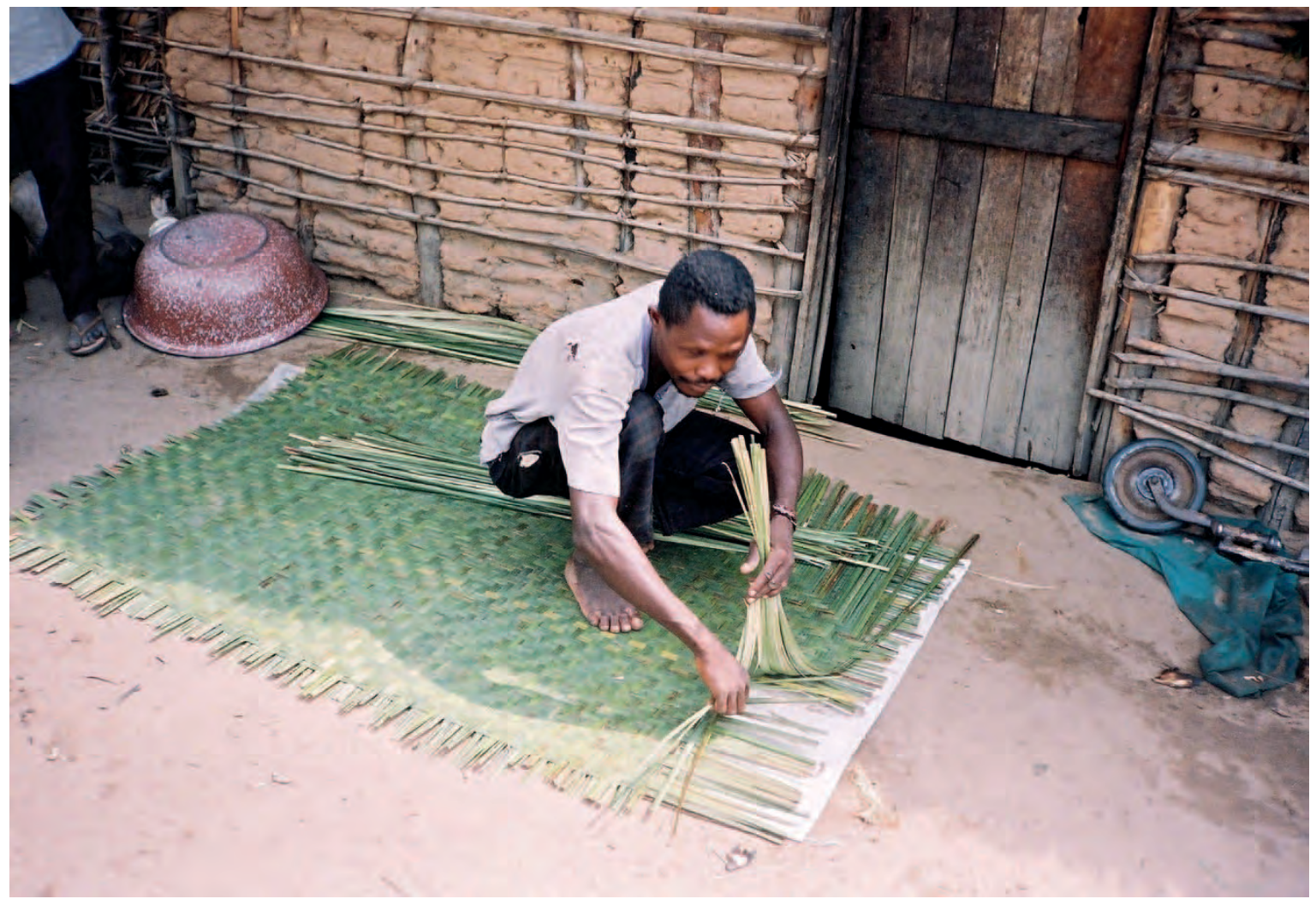


Noms courants : Vacoa, baquois, vaquois (Fr), mkadi (Swahili), common screw pine (Angl.)

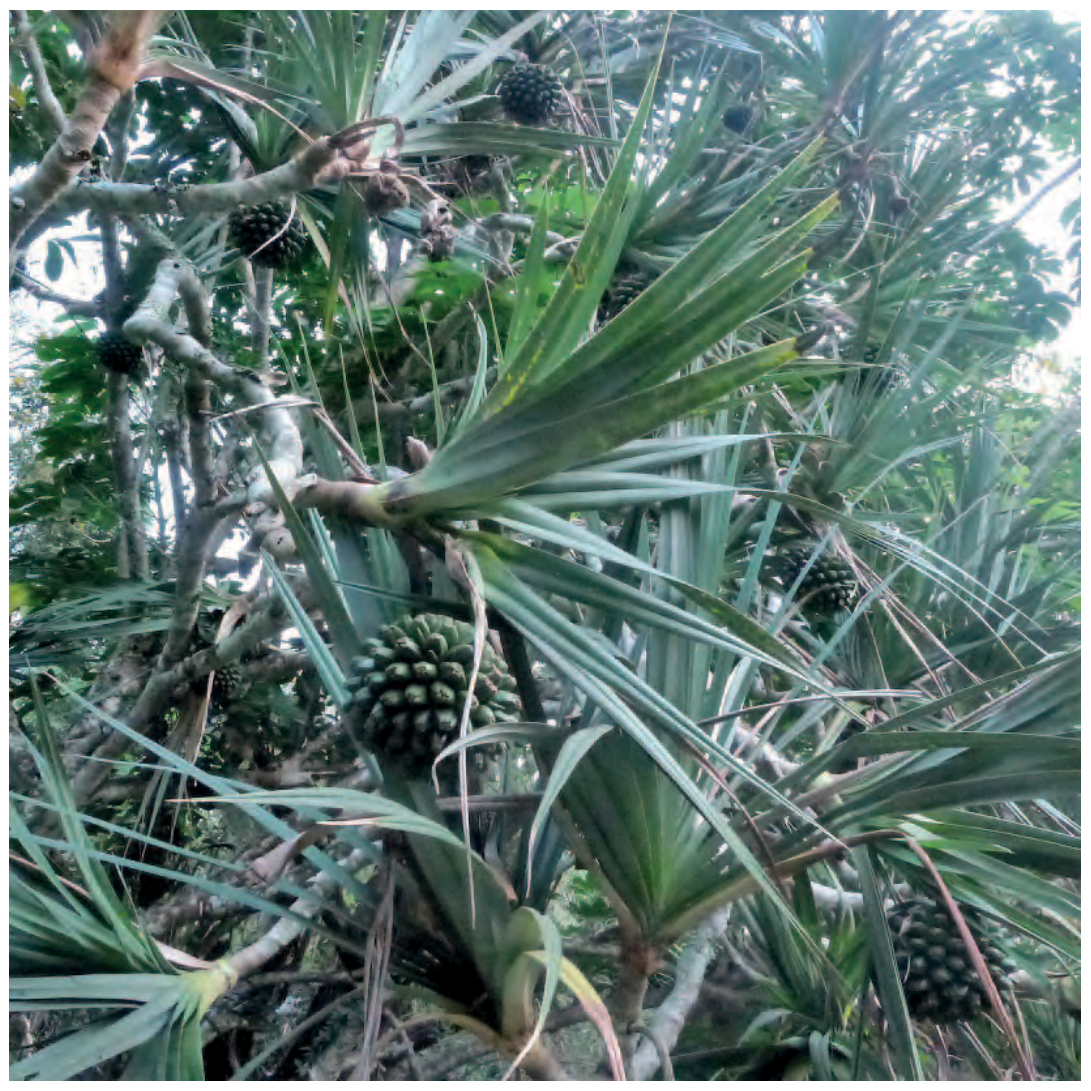

Description : Arbre pouvant atteindre $20 \mathrm{~m}$ de haut, avec un tronc lisse et ramifié possédant de nombreuses grosses racines aériennes de 2 à $8 \mathrm{~cm}$ de diamètre partant des tiges et atteignant le gé et sont légèrement épineuses sur les bords. L'inflorescence mâle est un spadice ramifié de 30 à 80 $\mathrm{cm}$ de long, à l'aisselle d'un spadice blanc crème ; l'inflorescence femelle est un bouquet globuleux d'ovaires serrés. Les fruits sont ovoïdes, de 15 à $25 \mathrm{~cm}$ de long, composés de jusqu'à 200 drupes fibreuses les unes à côté des autres, de couleur jaune à maturité.

Ecologie: Plante originaire des îles Mascareignes, diffusée en Afrique continentale.

Reproduction: Tremper les graines 24 heures avant de les semer. Les semis sortent de terre après 4 mois, avec un taux de germination de plus de $50 \%$. On peut aussi faire des boutures de tiges ou transplanter des rejets.

Usages : On emploie les feuilles, surtout jeunes, pour la couverture des toits et pour produire des cordages, des paniers, des nattes, des chapeaux, des filets. Les fruits cuits sont comestibles. La plante se cultive aussi à titre ornemental.

Références : Gillet 1927, Purseglove 1972, Burkill 1997, Brink 2011

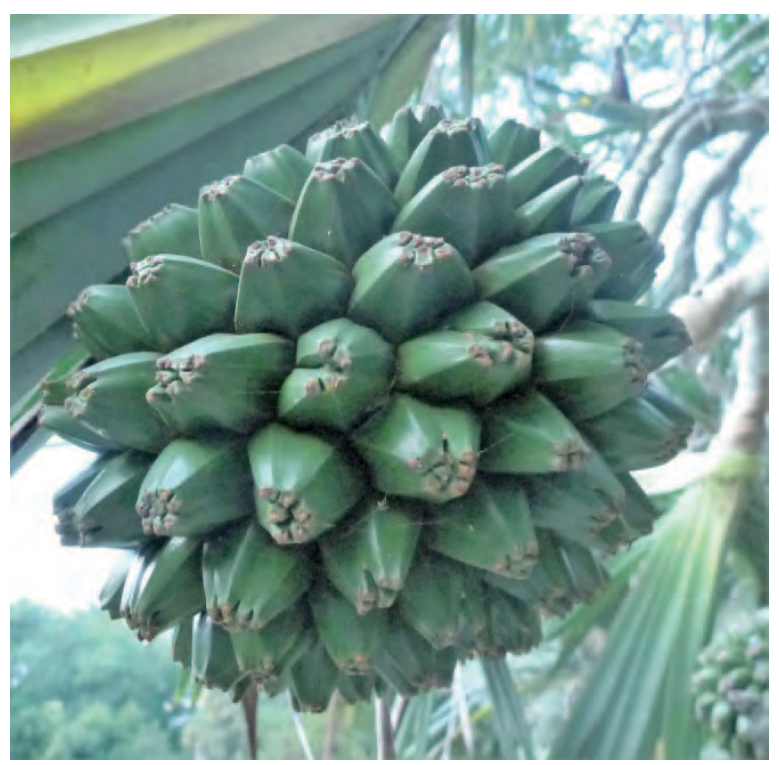


Noms courants : Nkanda diadi (Kikongo), herbe de Guinée (Fr.), buffalo grass, Guinea grass (Angl.)

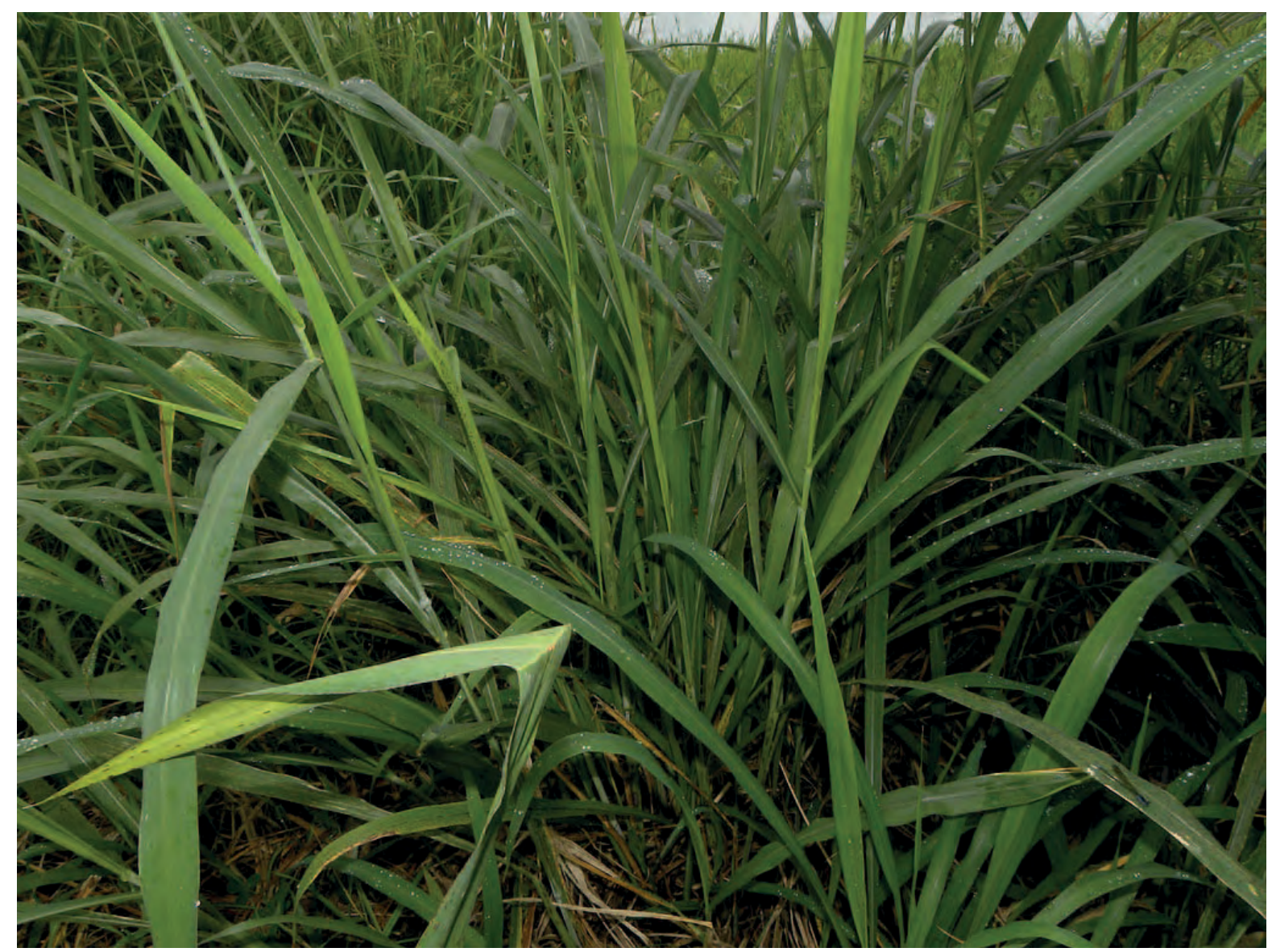

Photo: Reinaldo Aguilar

Description : Herbe pérenne en touffes de 0,5 à 4,5 m de haut. Les feuilles ont 15 à $100 \mathrm{~cm}$ de long et jusqu'à $35 \mathrm{~mm}$ de large. L'inflorescence est une panicule lâche très ramifiée, de 15 à $60 \mathrm{~cm}$ de long, et jusqu'à $25 \mathrm{~cm}$ de large, les branches inférieures étant distinctement en hélice. L'espèce est très variable.

Ecologie : Herbe originaire d'Afrique tropicale et Afrique australe subtropicale. Présente aux lisières des forêts, dans la savane, comme herbe pionnière sur les forêts défrichées et dans les savanes arborées, où elle tend à pousser à l'ombre légère sous les arbres. Résiste à la sécheresse.

Reproduction : Par graines ou division des touffes. Les graines sont souvent difficiles à obtenir. Espacer les plants de 0,5 à $1 \mathrm{~m}$ et planter par temps humide. Les tiges forment des racines facilement à partir des nœuds.

Gestion : Le pâturage par rotation donne de bons résultats sans dommage pour la plante. Celle-ci n'est pas adaptée à un pâturage continu ou fréquent.

Usages : Les tiges servent à faire des balais et des paniers. Les femmes portaient traditionnellement les épis de fleurs en colliers. L'herbe de Guinée, seule ou en mélange, constitue un fourrage de bonne qualité pour les bovins, les chèvres et les moutons, en pâturage ou coupée. Elle conserve sa valeur à maturité. On peut aussi la sécher et la moudre et l'employer en mélange avec des légumes pour la volaille ou les porcs. Elle convient pour être séchée pour faire du foin et pour l'ensilage. Les tiges s'emploient pour couvrir les toits. Les graines s'emploient pour nourrir les oiseaux. Quand on la donne aux cobayes avec Euphorbia heterophylla, cela améliore sensiblement l'ingestion, la digestibilité, la fécondité, le poids à la naissance et le poids au sevrage.

Références : De Wildeman 1903, Gillet et Pâque 1910, Gillet 1927, Renier 1948, Bogdan 1977, Chen et Hutton 1992, Burkill 1994, Kouakou et al. 2015 


\section{Panicum phragmitoides}

Noms courants : Nzamba, zamba (Kikongo).

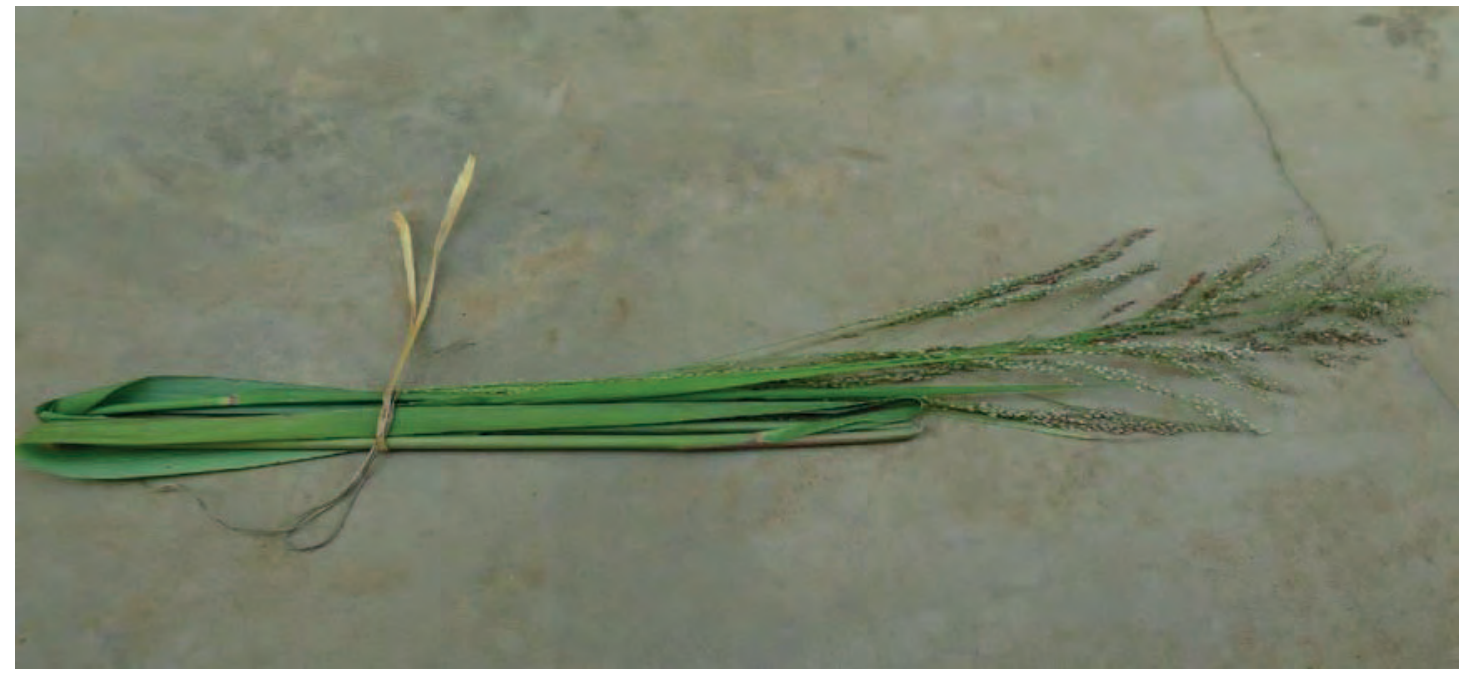

Description : Grande herbe pérenne atteignant $2 \mathrm{~m}$ de haut, avec des feuilles de 50 à $75 \mathrm{sur} 2 \mathrm{~cm}$. Les inflorescences sont de grandes panicules de $70 \mathrm{~cm}$, avec des spirales de $40 \mathrm{~cm}$. Les épillets sont glabres et mesurent 3 à $4 \mathrm{~mm}$. La plante se distingue de $\mathrm{P}$. maximum par ses glumes à 5 à 7 côtes.

Ecologie : Plante des sols fertiles et secs en savane, de la Guinée à la R.D. Congo, à l'Angola et au Malawi.

Usages : S'emploie en R.D. Congo comme chaume pour les toits, appelés nyanga-nzamba. Le bétail broute les feuilles. Au Nigéria, on l'emploie comme clôture; et à Sokoto comme balai. Au Kongo Central, on l'emploie pour récolter les termites Lunsu : le soir, quand ils vont sortir en volant de leur termitière, on place sur celle-ci une couche de tiges en fleurs, difficile à traverser, qui piège en partie les termites. On récupère les termites accumulés dans les couches d'herbe en secouant celles-ci dans un seau muni d'un couvercle, ou dans un sac en jute. On remet rapidement la

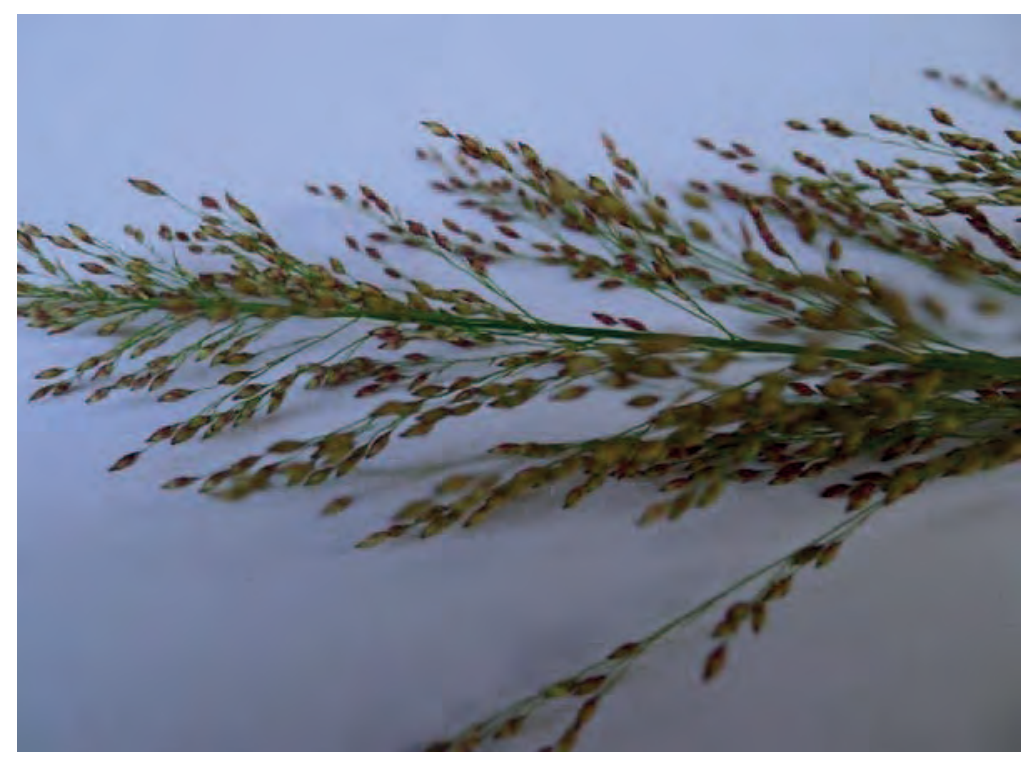
couche d'herbe pour une nouvelle capture, et ainsi de suite. Cette technique ancienne est moins efficace que l'emploi d'une moustiquaire : dans ce cas, on peut récolter plus de $80 \%$ des termites.

Remarque : Nzamba désigne aussi $P$. coloratum (Butaye 1909).

Références : Renier 1948, Daeleman et Pauwels 1983, Burkill 1994, Konda Ku Mbuta et Ambuhl 2019 


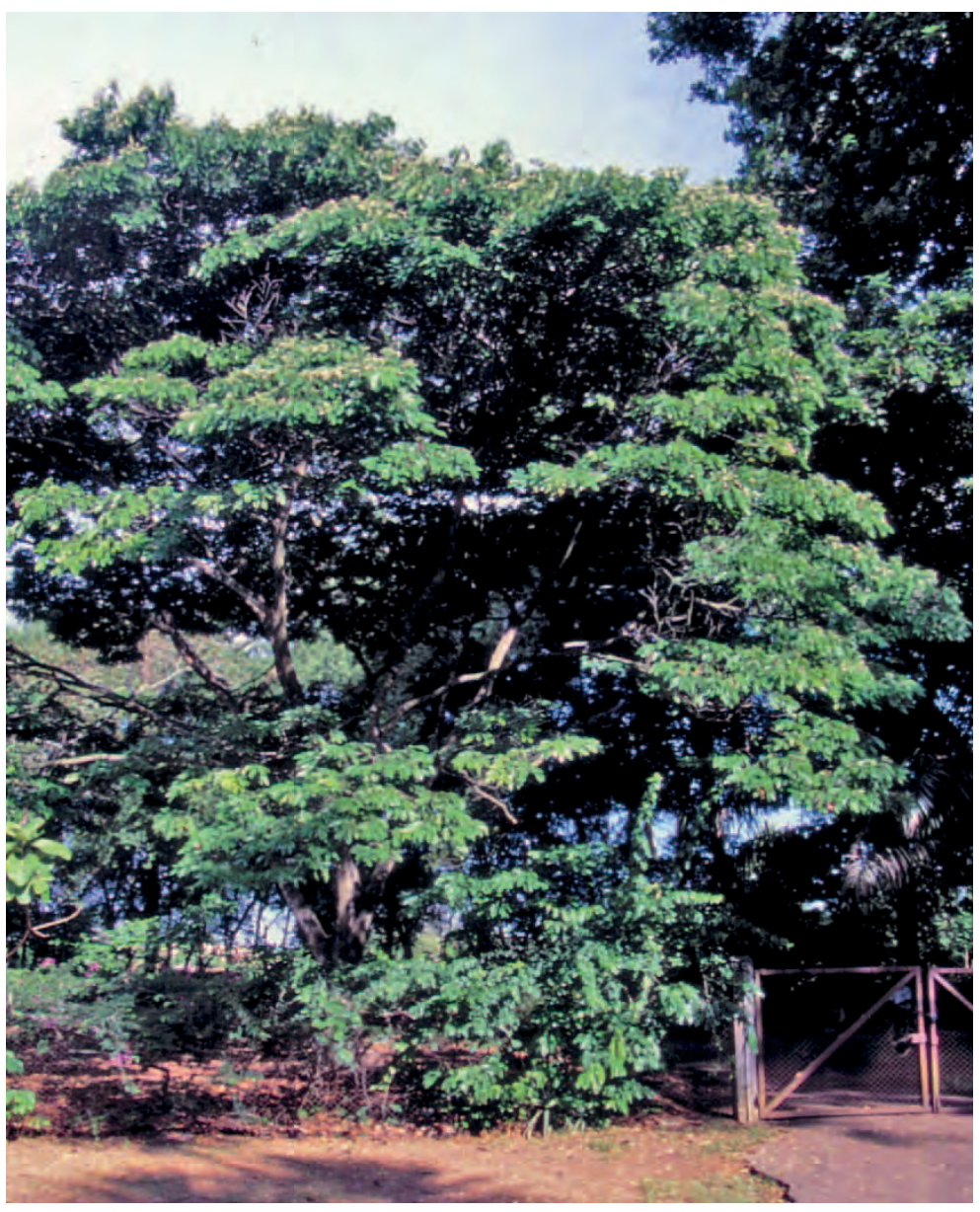

Reproduction : Tremper les graines 1 ou 2 jours dans l'eau froide, ou quelques minutes dans l'eau bouillante pour accélérer la germination. On doit planter les semis sur sol fertile en plein soleil pour avoir une bonne croissance. Les espacer de $3 \times 3 \mathrm{~m}$, en plantations pures ou avec d'autres espèces produisant du bois à croissance modérément rapide.

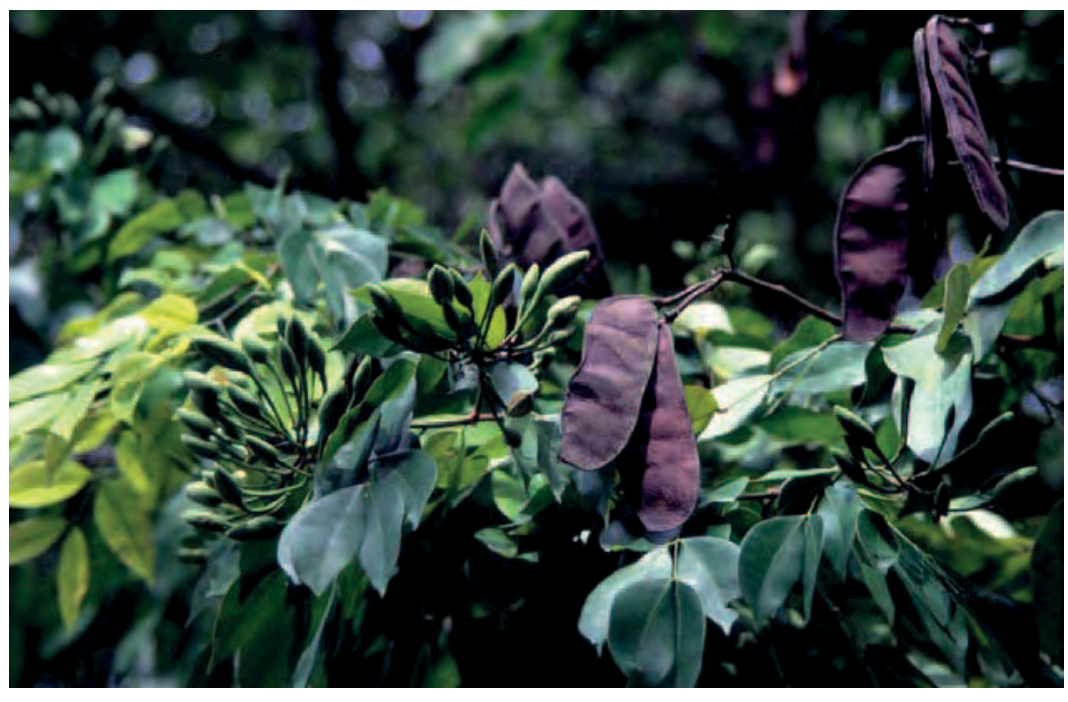

Nom courant : Lubese (Kikongo)( (Mbese $=$ osselet; les graines servent à jouer aux osselets).

Description : Grand arbre forestier sempervirent à contreforts, de 15 à $35 \mathrm{~m}$ de haut. L'écorce est pratiquement lisse. Feuilles alternes, composées à 3 à 5 paires de folioles de 2 à 15 sur 1 à $6 \mathrm{~cm}$. L'inflorescence est une panicule terminale aplatie, avec des fleurs bleuâtres. Le fruit est une gousse oblongue plate, de 10 à 20 sur 3,5 à 6 $\mathrm{cm}$, contenant 3 à 8 graines rectangulaires plates longues de 1,5 à $2,5 \mathrm{~cm}$, brun foncé brillant.

Photos: F.J. Breteler

Ecologie: Arbre des forêts pluviales de plaine et des forêts galeries, de la Guinée au Kenya et au Nord de l'Angola.

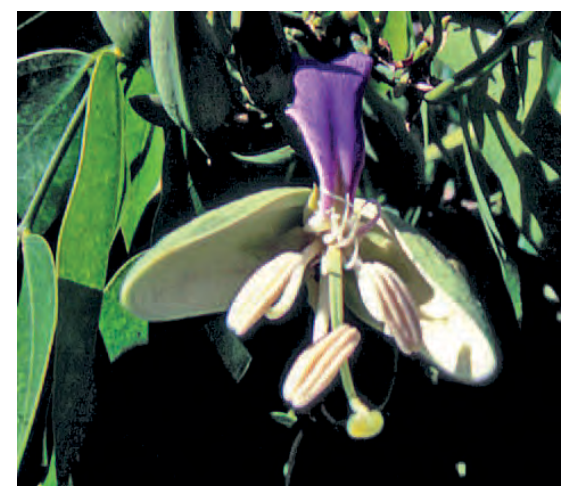

Usages : Le bois est dur, à grain fin, résistant à l'eau et de bonne qualité. On l'emploie pour les menuiseries, le mobilier et les traverses de chemin de fer. II convient pour les parquets, les jouets, le tournage, la sculpture, les placages et le contreplaqué. On garde spécialement les graines pour le jeu de mbese (équivalent des osselets). Au Bas-Uele, la sève de l'écorce mélangée avec le jus de canne à sucre constitue un laxatif. En Sierra Leone, l'arbre a été planté pour donner de l'ombrage aux plantations de cacao.

Références : Butaye 1909, Gillet et Pâque 1910, Staner et Boutique 1937, Renier 1948, Wilczek et al. 1952, Daeleman et Pauwels 1983, Pauwels 1993, Lemmens 2010 


\section{Parinari capensis}

Noms courants : Nsudi n'funi, nsudinsudi, n'funin'funi (Kikongo), dwarf mobola plum (Angl.)

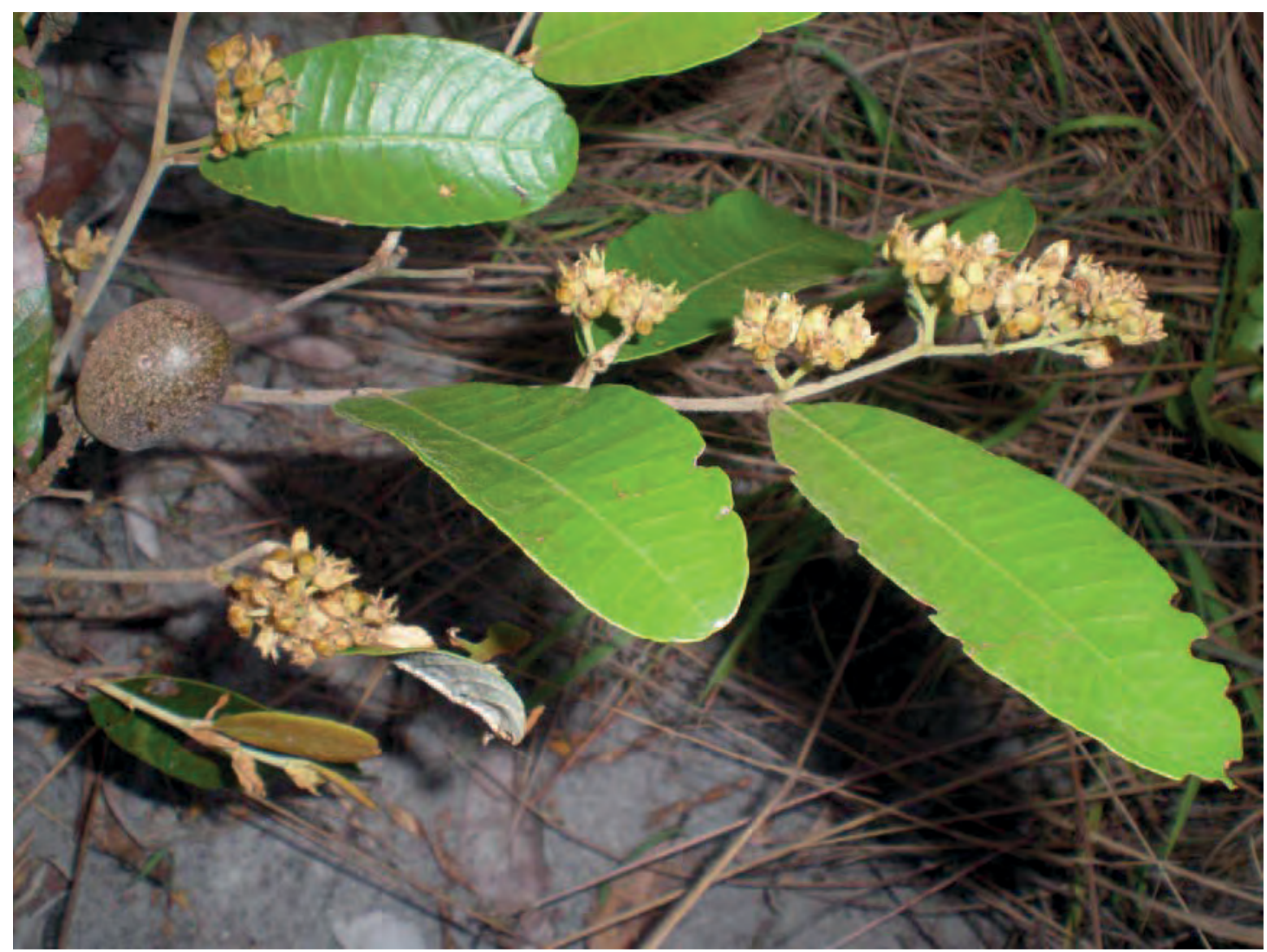

Description : Buisson bas de 20 à $60 \mathrm{~cm}$ de haut, poussant sur des rhizomes ligneux longs, épais et ramifiés. Les tiges ramifiées sont couvertes de poils jaunes ou argentés sur la face supérieure. Les feuilles, très variables, ont 5 à $11 \mathrm{~cm}$ de long sur des pétioles de 2 à $3 \mathrm{~cm}$. L'inflorescence est terminale ou axillaire. Le calice est en forme de coupe. Le fruit est une drupe longue de 2,4 à $2,8 \mathrm{~cm}$, jaune à maturité, qui noircit en séchant en formant des tâches liégeuses brunes.

Ecologie : Pousse sur les sols pauvres de savane. Présente de la R.D. Congo à l'Afrique du Sud et au Mozambique.

Reproduction : Enterrer les fruits mûrs et laisser la chair pourrir. Immerger les graines 15 minutes dans l'eau bouillante, lasser refroidir et tremper 12 heures. Les graines restent viables 2 ans. Semer en pots ou employer des rejets de racines.

Usages: La pulpe du fruit a un goût agréable, et se mange, crue ou cuite. Les graines aussi sont comestibles. Les fleurs sont visitées par les abeilles.

Références : Hauman 1952, Daeleman et Pauwels 1983, Katende et al. 1995, Malaisse 1997, van Wyk et Gericke 2000

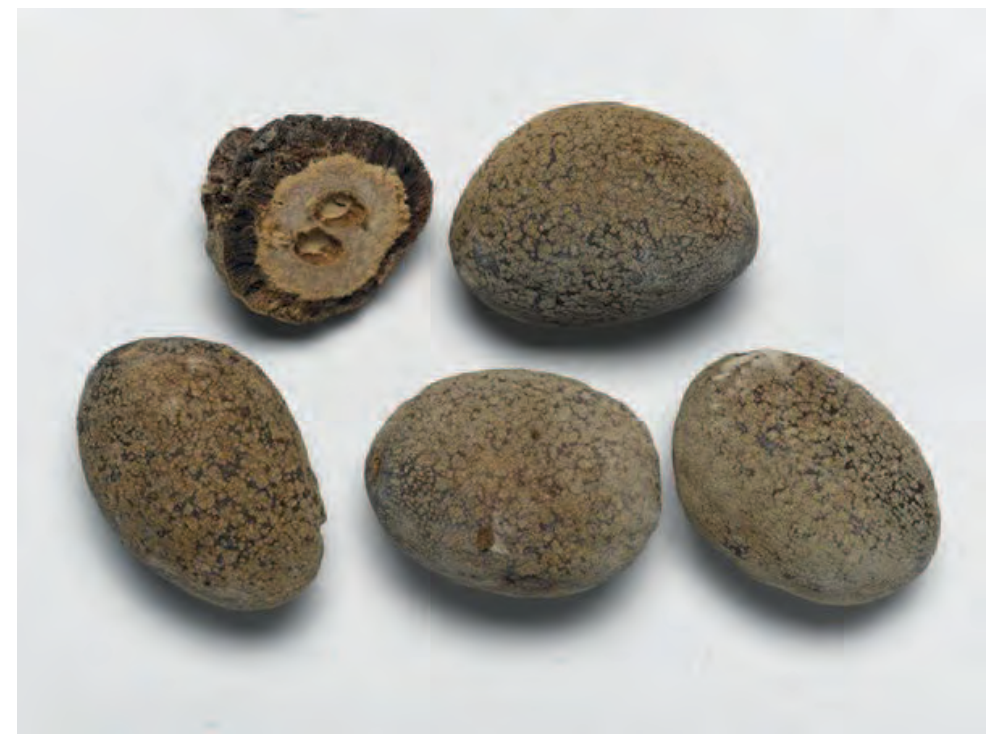

Photo: Aluka 


\section{Parinari excelsa}

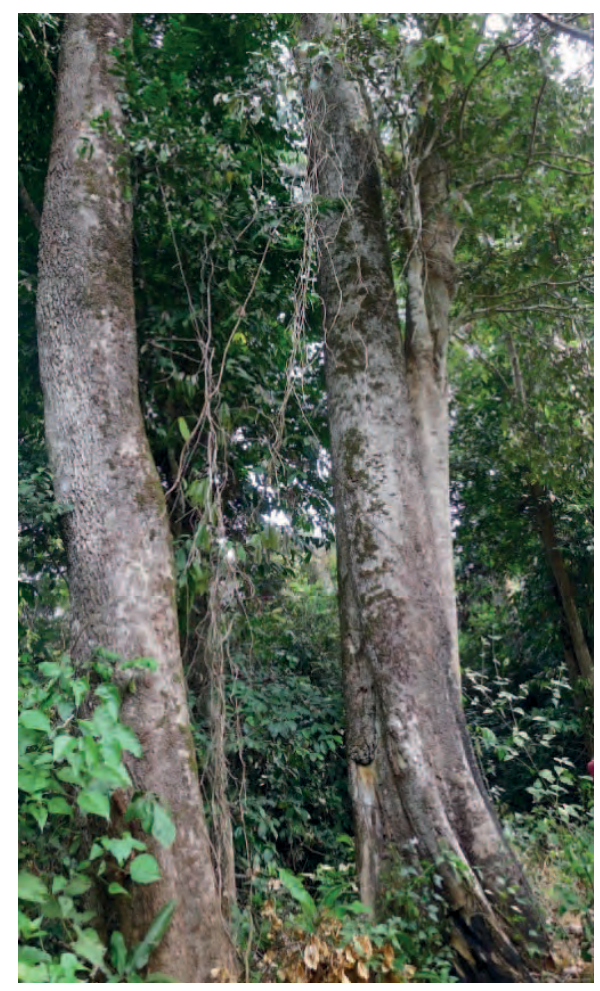

Reproduction Utilisez des jeunes plantes sauvages ou des rejets de racines.

Photos prises à Buma, secteur Kivulu, Kongo Central.
(Chrysobalanaceae)

Noms courants : Banga (Kikongo), manguier sauvage (Fr.), forest mobola plum (Angl.)

Description : Arbre très ramifié pouvant atteindre $40 \mathrm{~m}$ de haut. Le fût peut avoir $1 \mathrm{~m}$ de diamètre. L'écorce est grise, finement rainurée, devenant avec l'âge rugueuse et écaillée. Les rameaux, sombres, sont parsemés de lenticelles pâles. Les jeunes pousses et les tiges basses ont des poils laineux clairs. Feuilles alternes de 6 à $8 \mathrm{~cm}$ de long, en général avec un long bout pointu, se rétrécissant pour devenir vert foncé brillant au-dessus et brun clair velouté en-dessous. Les fleurs terminales sont très reconnaissables. Chacune est très petite, de $4 \mathrm{~mm}$ de diamètre, avec 5 pétales blanc crème, sur des tiges ramifiées à côté des feuilles. Le fruit est une drupe charnue, parfois ronde, jusqu'à $4 \mathrm{~cm}$ de long, vert brun avec des taches claires, contenant 1 ou 2 graines. L'écorce endommagée a une odeur de lait aigre et libère une sève aqueuse. L'arbre est à croissance rapide.

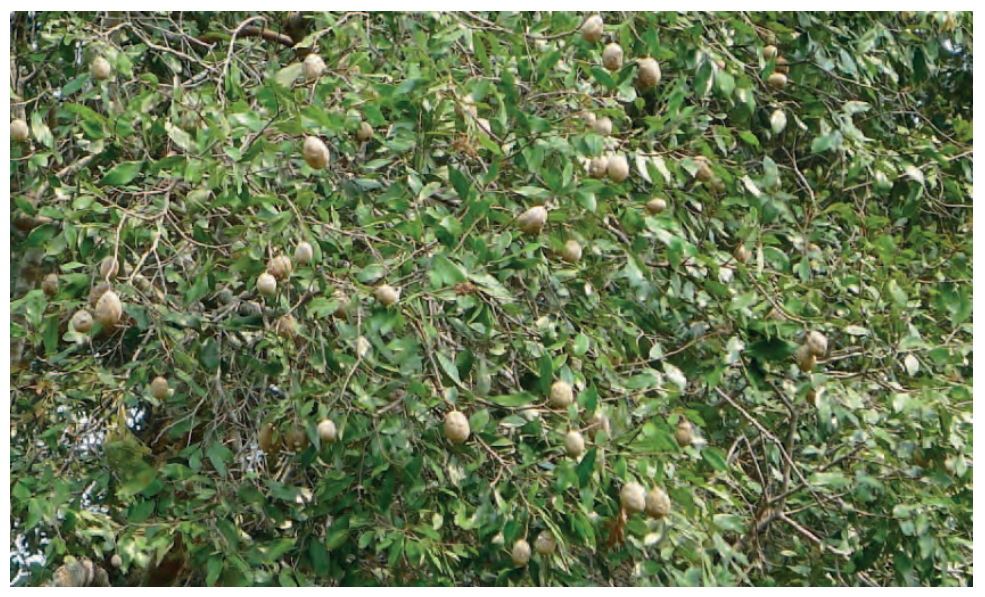

Ecologie: On rencontre cet arbre depuis le Sénégal jusqu'au Soudan et en Ouganda, et vers le sud jusqu'au Mozambique et en Angola, du niveau de la mer à $2.100 \mathrm{~m}$ d'altitude. En Amérique du Sud, on le trouve de la

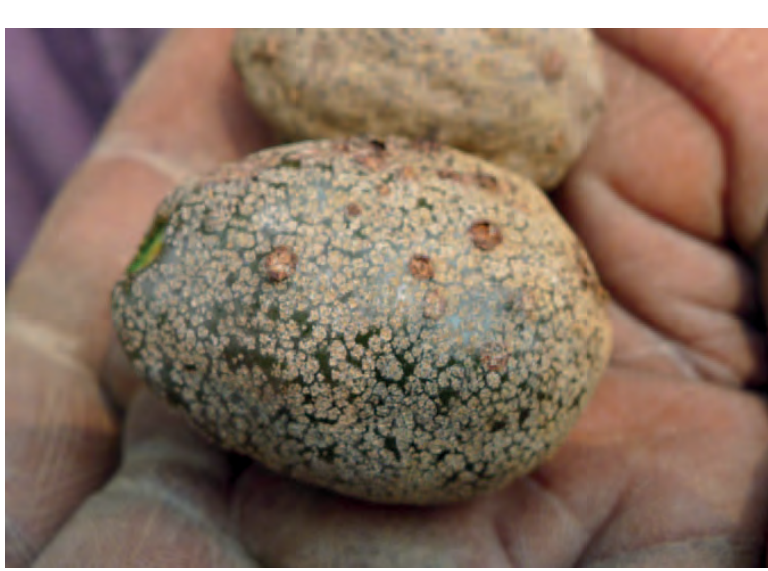
Bolivie, du Pérou et de la Colombie jusqu'à l'Est du Vénézuela, aux Guyanes et au Brésil et vers le nord jusqu'au Costa Rica.

Usages: Les fruits mûrs sont comestibles et très appréciés ; on enlève l'écorce ligneuse pour manger la pulpe charnue, qui a un goût comparable à l'avocat et contient $38 \%$ de sucre. La graine rôtie est également comestible. Le bois, résistant et dur, convient pour la construction lourde, les manches d'outils, le charbon de bois et le bois de feu. Au Kongo Central, l'écorce a des usages médicinaux pour faciliter la cicatrisation des plaies. Comme pour l'espèce précédente, les fleurs sont un important fourrage pour les abeilles.

Références : Gillet et Pâque 1910, De Wildeman 1934, Hauman 1952, Letouzey et White 1978, Burkill 1985, Ambougou 1991, Malaisse 1997, Hepburn et Radloff 1998, Ruffo et al. 2002, Nsimundele 2004, Fichtl 2014 
Nom courant : Kisudi ki nkandi (Kikongo)

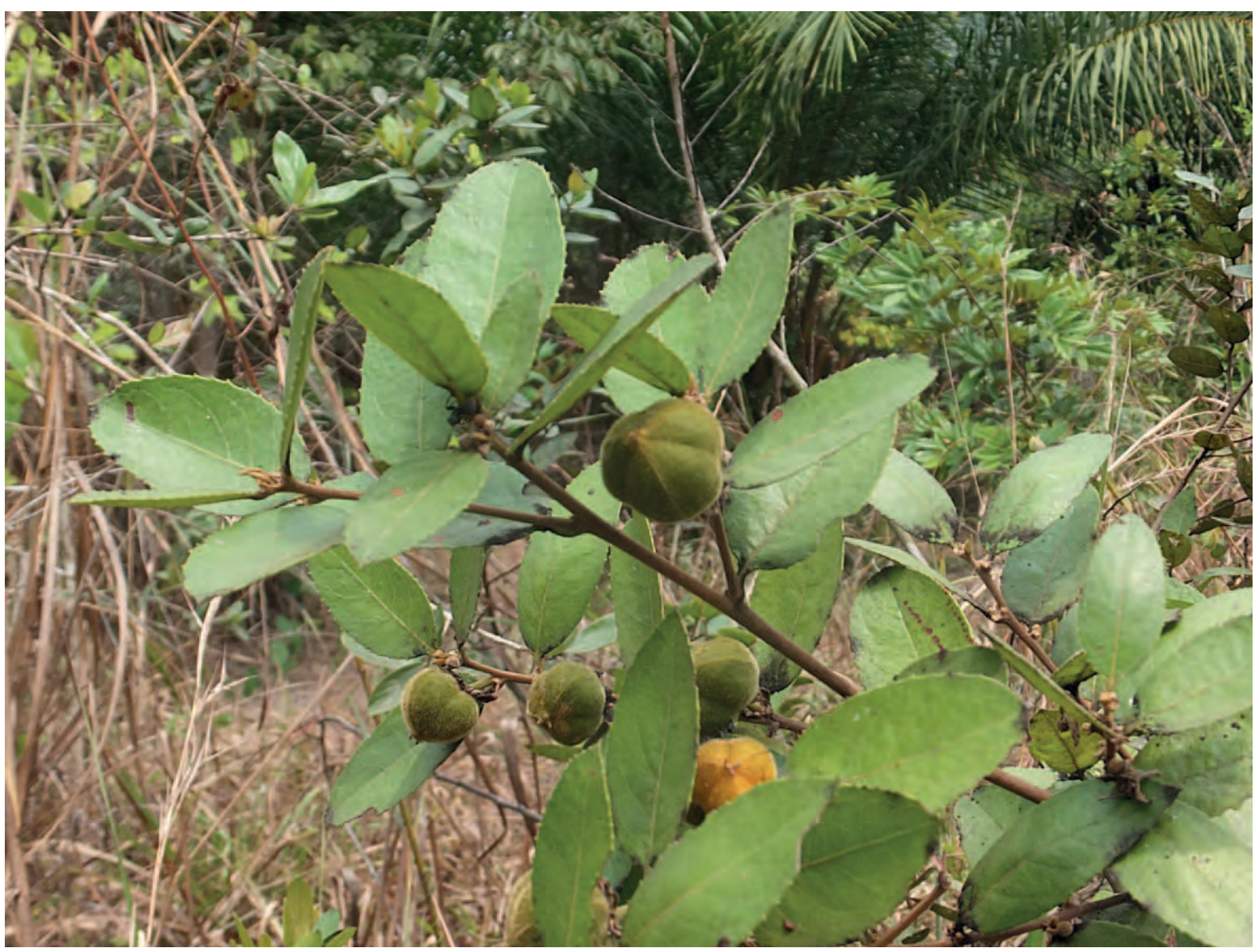

Description : Buisson à nombreuses tiges poussant jusqu'à 1,5 à $3 \mathrm{~m}$ à partir d'un rhizome. Les feuilles, de 6 à 10 sur 2 à $4 \mathrm{~cm}$, sont ovales, alternes avec de courts pétioles, brunâtres, velues, avec des nervures proéminentes en dessous. Les feuilles portent des dents pointues. Fleurs blanches, parfumées, isolées ou groupées par 2 ou 3. Le fruit est une capsule d'environ 1,2 à $1,8 \mathrm{~cm}$ de diamètre, déhiscente et s'ouvrant au sommet en 3 valves. II contient 6 à 7 graines brunes entourées par une gelée orange sucrée.

Ecologie : Plante de la savane et des forêts secondaires. Présente aussi au Cameroun, en Centrafrique, au Congo Brazzaville, en Angola, Zambie, Zimbabwe et Botswana, où on la trouve dans les savanes boisées, les forêts et les fourrés, sur les sables du Kalahari ou sur des sols argileux.

Usages : La décoction de l'écorce des racines serait très efficace contre la dysenterie amibienne. Pour traiter les rhumatismes, on prend la même décoction en bain de vapeur, ou on boit la sève des feuilles. On pile aussi les feuilles pour appliquer la pulpe sur les parties douloureuses affectées par les rhumatismes. En Afrique du Sud, on prend une infusion des feuilles pour traiter la gonorrhée, et en gargarisme contre les maux de dents. Au Gabon, on signale que les abeilles visitent les fleurs de Paropsia grewioides.

\section{A droite : plante en fleurs près de Kimwenza en} septembre

Références : Renier 1948, Watt et Breyer-Brandwijk 1962, Bamps 1976, Ambougou 1991, Pauwels 1993, Neuwinger 2000, De Ruijter 2007

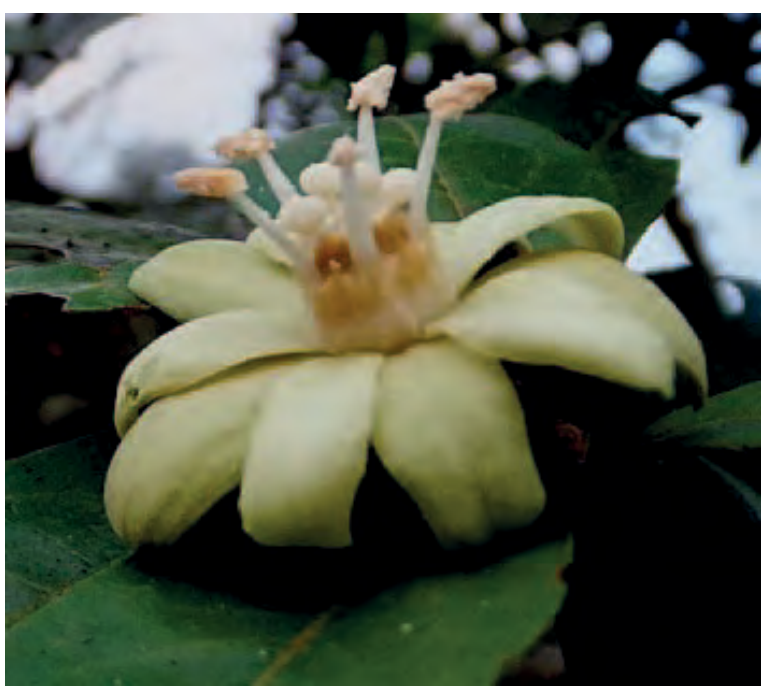




\section{Paspalum notatum}

Noms courants : Pasipolomo (Kikongo), paspalum (Fr.) Bahia grass (Angl.)

Description : Gazon rampant agressif pérenne, formant une pelouse épaisse avec ses stolons et rhizomes. Les stolons s'appliquent fermement sur le sol. Les feuilles de 5 à $20 \mathrm{~cm}$ se terminent en fine pointe.

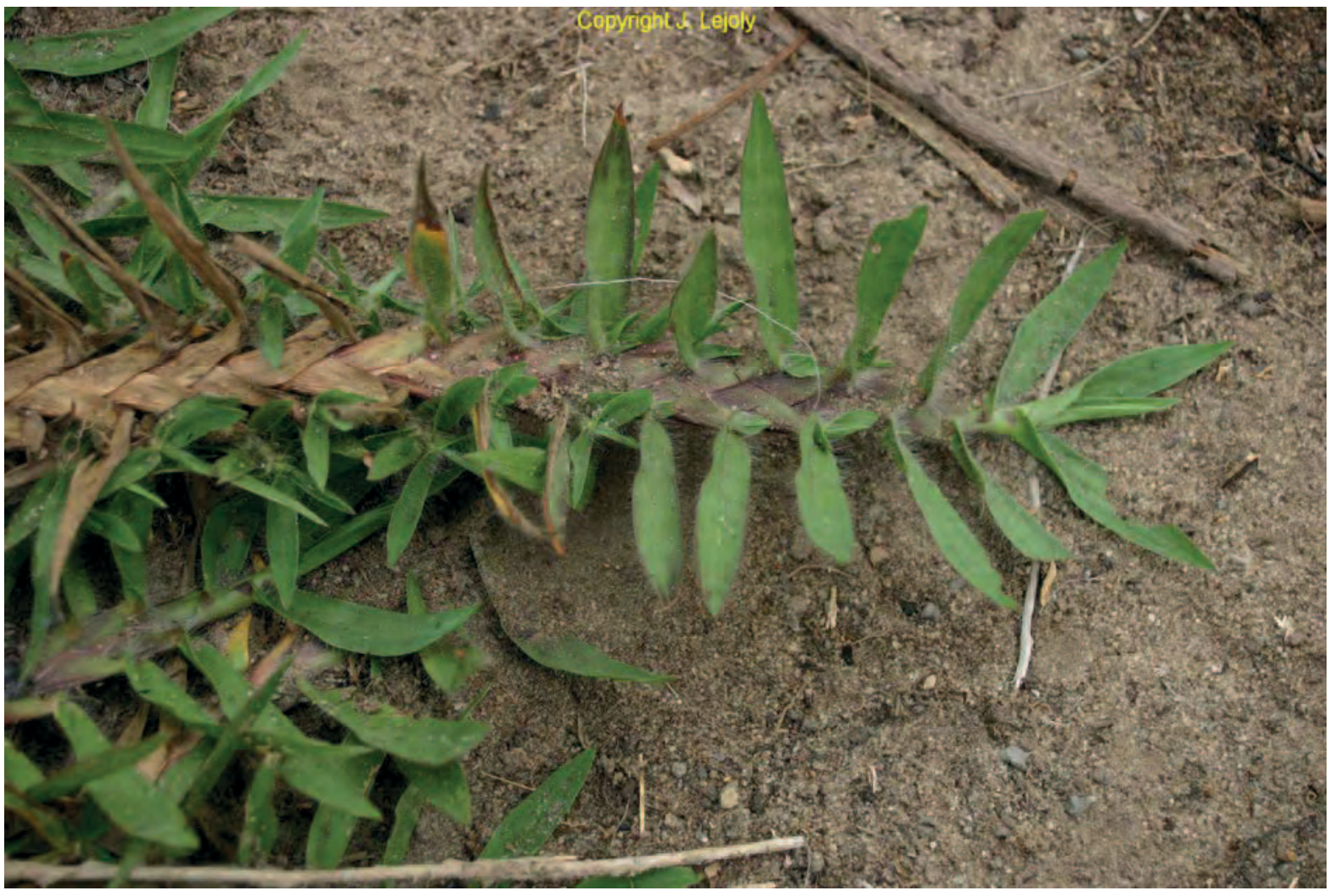

Photo: J ean Lejoly

Ecologie : Gazon introduit depuis le Brésil, maintenant largement cultivé. Pousse bien au soleil ou à l'ombre. Tolérant à la sécheresse comme aux inondations, couvrant le sol rapidement et s'enracinant profondément.

Reproduction : Par graines ou rhizomes. Les rhizomes prennent racine à partir des nœuds. Les planter en carrés tous les 15 ou $25 \mathrm{~cm}$

Gestion : Le paspalum, très résistant et durable, demande peu d'entretien.

Usages : Excellent gazon pour les pelouses. Cultivé aussi pour l'alimentation du bétail, notamment apprécié par les volailles et les lapins. Employé pour contrôler les érosions. En raison de sa croissance au ras du sol, prévient les risques d'incendie quand on le plante autour des habitations. Les chenilles comestibles Makala s'en nourrissent. Donne un bon engrais vert lorsqu'il est composté.

Références : Gillet 1927, Renier 1948, Uphof 1968, Bogdan 1977, Daeleman et Pauwels 1983, Burkill 1994, Kibungu Kembelo 1995 


\section{Passiflora edulis $\mathrm{f}$. flavicarpa}

Noms courants : Goki dimputu (Kikongo), maracuja, grenadille (Fr.), yellow passion fruit (Angl.)

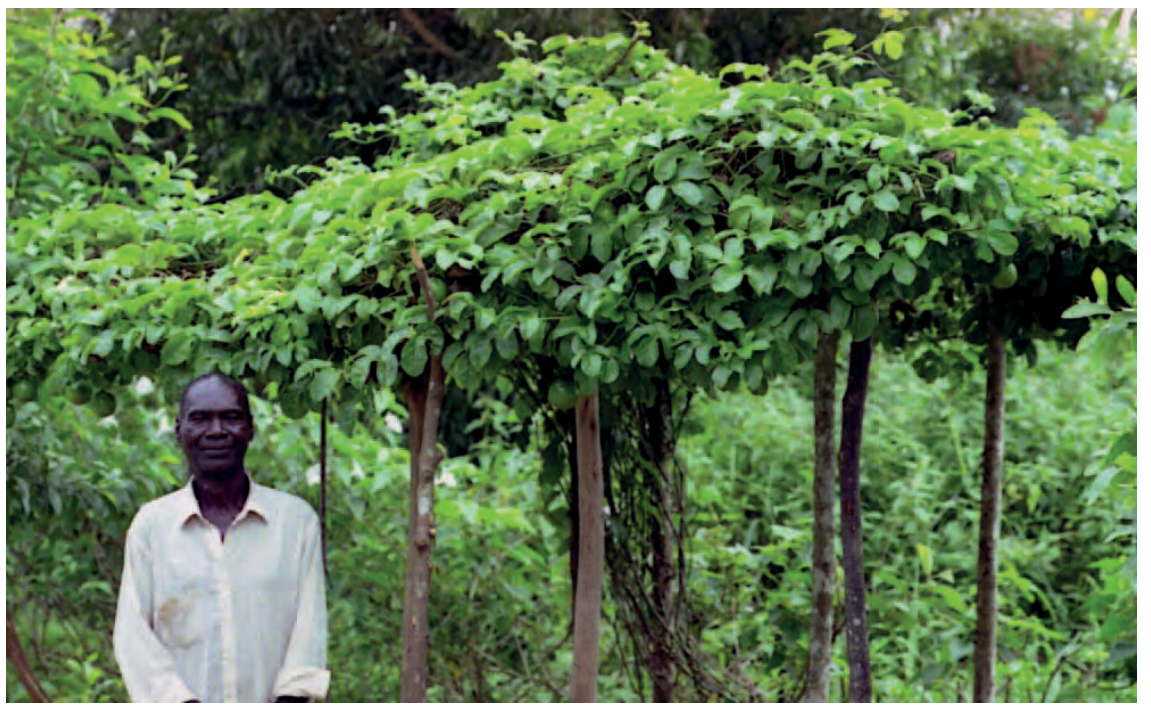

Description : Plante grimpante vigoureuse, à base ligneuse, développant des tiges d'environ $6 \mathrm{~m}$ de long. Les feuilles persistantes, de 6-13 $\times$ 8-13 cm, sont membraneuses profondément trilobées.

Tata Mansita chez lui avec un maracuja sur une treille

La fleur, de 4 à $7 \mathrm{~cm}$ de diamètre, comprend 5 sépales et 5 pétales blancs presqu'entièrement

constituée de filaments pourpres au centre et blancs vers l'extérieur. Elle porte au centre une colonne de 1 à 1,3 $\mathrm{cm}$ de haut portant les 5 étamines terminées par les anthères tournées vers le bas, et un ovaire ovoïde de $8 \mathrm{~mm}$ de haut, surmonté de 3 ou 4 styles blancs unis à la base. Le fruit est une baie, jaune ou pourpre à maturité selon les variétés, de 3 à $4 \mathrm{~cm}$ de diamètre, contenant de nombreuses graines noires, entourées d'un arille comestible de saveur douce. Les abeilles sont les principaux pollinisateurs.

Ecologie : Originaire d'Amérique tropicale et largement répandue dans les pays tropicaux. Demande un sol bien drainé et des pluies régulières. Cependant, les pluies doivent être minimales pendant la floraison, car elles font éclater le pollen et gênent l'activité des insectes pollinisateurs. II existe deux variétés, $P$. edulis flavicarpa, à fruits jaunes, plus gros, et plus acides, cultivée à moins de $600 \mathrm{~m}$ d'altitude, et notamment dans l'Ouest de la R.D. Congo, et $P$. edulis edulis, à fruits pourpres, plus petits, et plus parfumés, cultivée à plus de $600 \mathrm{~m}$ d'altitude, et notamment dans l'Est de la R.D. Congo.

Reproduction : On cultive cette plante à partir des graines. Laver les graines pour éliminer la pulpe, les sécher et semer dans les trois mois. Le taux de germination peut atteindre $85 \%$. Transplanter les semis en poquets quand ils ont 2 à 4 feuilles, et les laisser à l'ombre 1 ou 2 mois. Fournir progressivement plus de lumière. Transplanter quand ils ont 25 à $50 \mathrm{~cm}$ et se sont endurcis 2 mois en plein soleil.

A droite : Concentré de maracuja mis en bouteille en R.D. Congo

Gestion : Fournir à la liane une treille ou un support pour lui permettre de pousser en hauteur. Si les fruits de certains pieds n'ont pas bon goût, il faut arracher les pieds.

Usages : Le jus du fruit à un goût unique ; il est une excellente source de provitamine $A$, et peut-être la meilleure source de vitamine B3

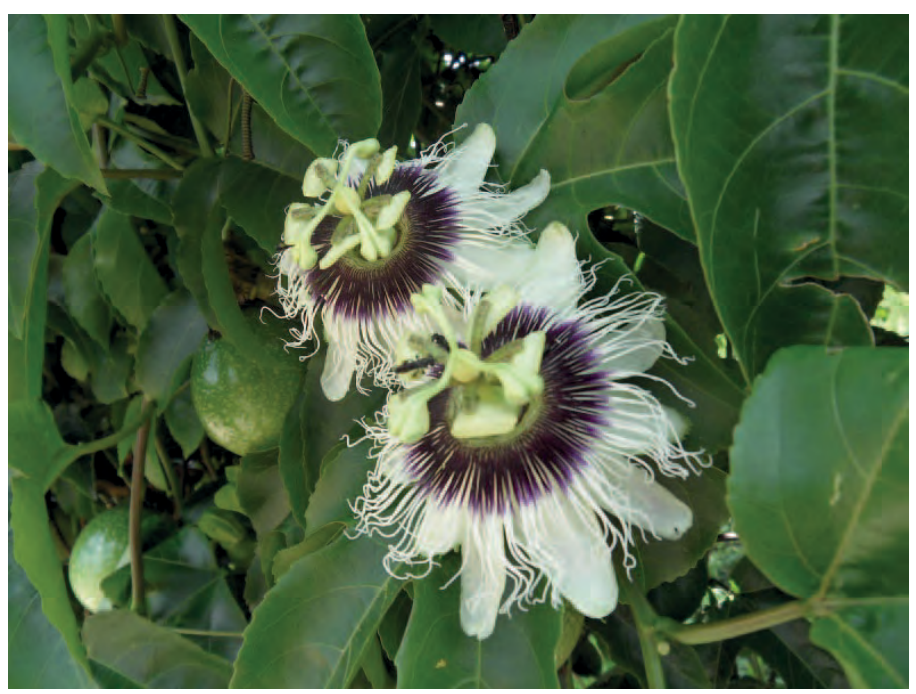
ou niacine. Son contenu en vitamine $C$ est bon.

Références : Gillet 1927, Daeleman et Pauwels 1983, Martin et al. 1987, Robyns 1995, Nakasonne et Paull 1998 


\section{Passiflora quadrangularis}

Nom courant : Barbadine (Fr. et Angl.)

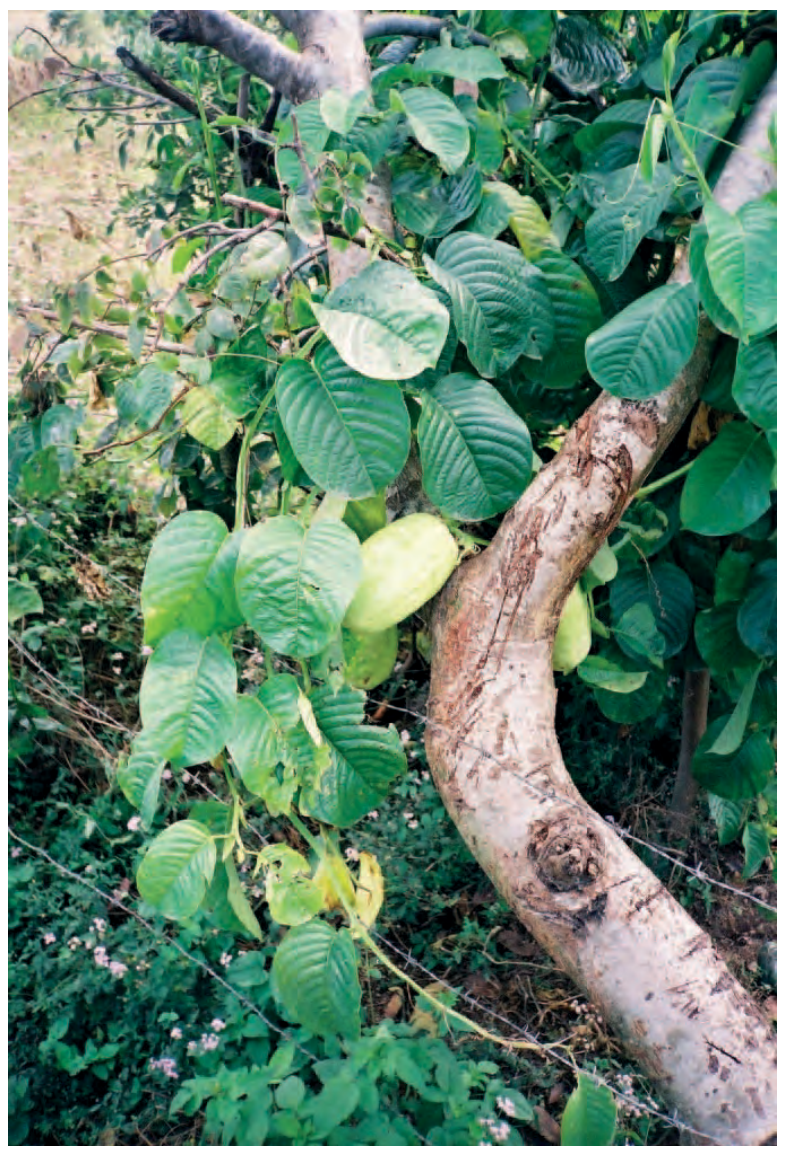

Description: Liane pérenne vigoureuse à racines tubéreuses charnues. Les tiges sont quadrangulaires et ailées. La floraison se produit sur des pousses vigoureuses environ 9 mois après la plantation, et le fruit apparait 60 à 80 jours après. Les grandes fleurs pendantes vers le bas sont odorantes; elles sont formées de 5 sépales et de 5 grands pétales roses, le tout surmonté d'une couronne de filaments blancs, violet pâle et pourpre foncé. Au centre de la fleur se trouvent un pistil à trois styles et cinq étamines. Les fruits sont vert jaune, de 20 à $30 \mathrm{~cm}$ de long et 10 à $15 \mathrm{~cm}$ de diamètre.

Ecologie: Plante originaire d'Amérique du Sud tropicale. Préfère un sol humide, riche en humus. Souvent cultivée sur une treille, donnant un espace ombragé près de la maison.

Reproduction: Par graines ou boutures. Les graines germent en 2 à 4 semaines. Transplanter les semis en sachets au stade de deux feuilles à 4 à $5 \mathrm{~cm}$ de hauteur. Planter en pleine terre après 4 mois, espacés de 4 à $5 \mathrm{~m}$, sur une treille robuste capable de supporter les fruits pendants.

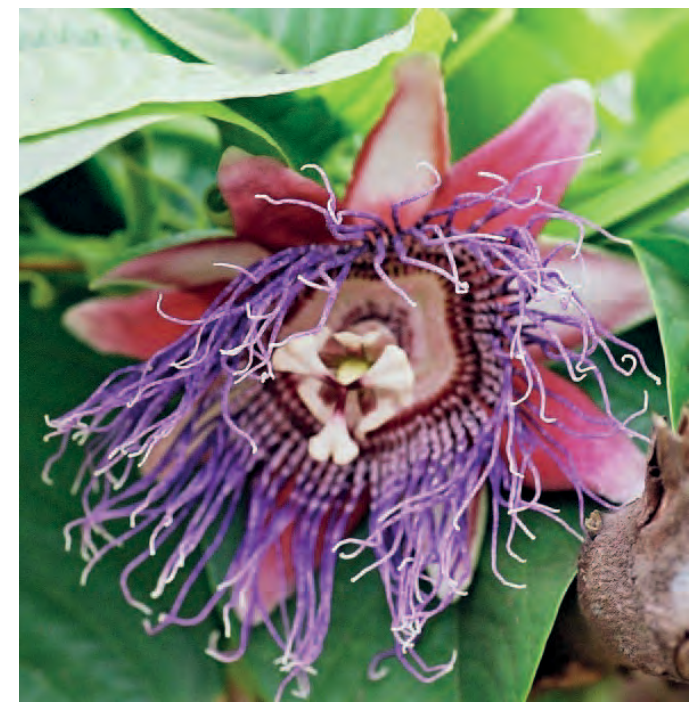

Gestion : Hors de la zone d'origine de la plante, on signale souvent une fructification médiocre. Pour avoir une récolte convenable, on recommande la pollinisation manuelle. II peut être nécessaire de couvrir les fruits pour les protéger des oiseaux, des chauves-souris et des rats. Couper les branches à ras après avoir cueilli les fruits, ne

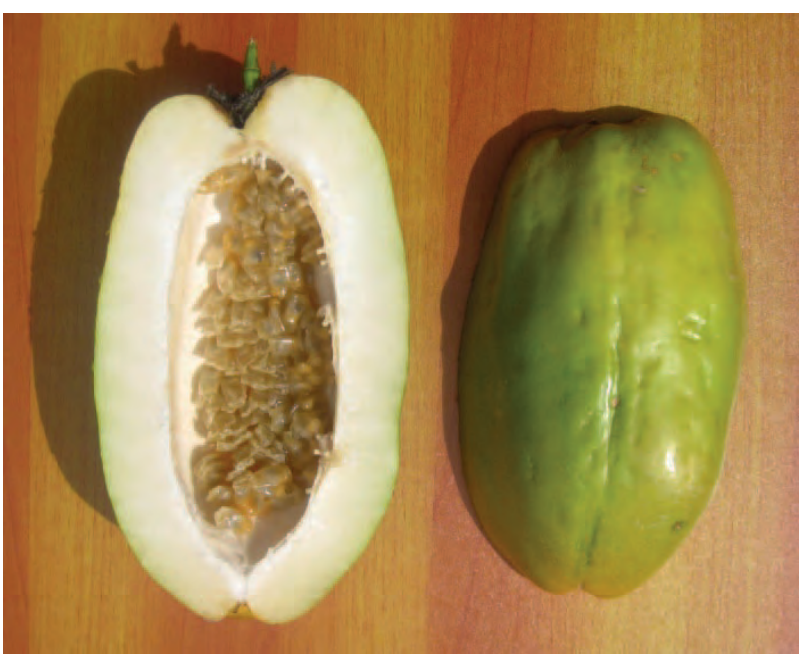

1989, Macmillan 1991, Robyns 1995 conservant que la tige et les branches maitresses. La plante a une vie utile de 5 à 6 ans.

Usages : Le fruit entier et son jus sont comestibles, mais la chair est assez fade et se mange souvent avec d'autres fruits. Le jus peut aussi se mélanger avec du jus d'orange, de papaye ou de goyave. Le fruit vert peut être bouilli et mangé comme légume.

Remarque : On trouve aussi au Kongo Central une troisième espèce de passiflore, Passiflora foetida, également originaire d'Amérique, et dont les fruits sont eux aussi comestibles.

Photo de gauche : Ton Rulkens

Références : Gillet 1927, Renier 1948, Purseglove 1968, Crane et Walker 1984, Dupriez et De Leener 
Noms courants : Ngudi nkayi, ludimi lu mbwa (Kikongo), lukaka, mopumba (Lingala)

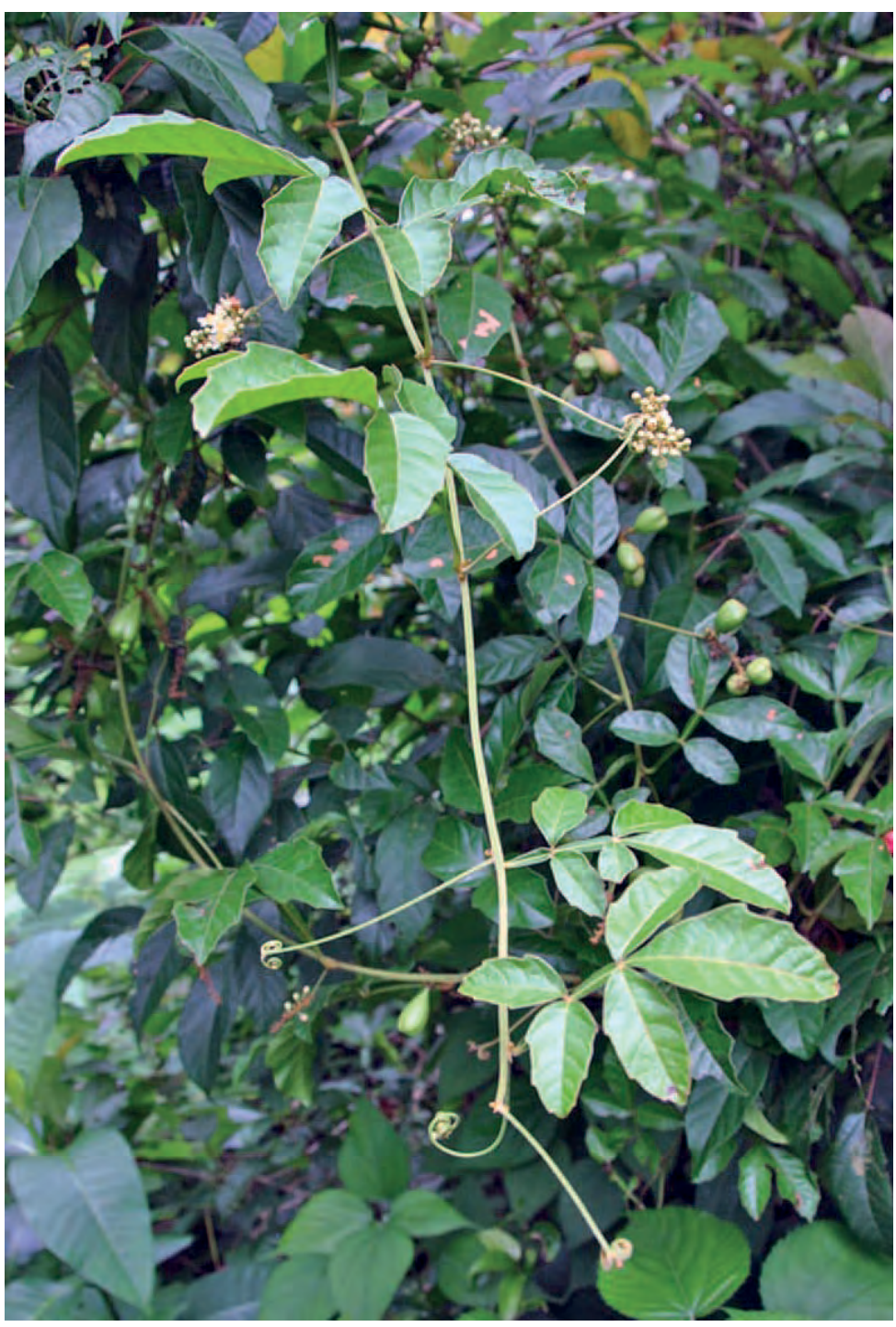

Description : Liane semi ligneuse à tiges striées de 5 à $6 \mathrm{~m}$ de long. Les feuilles sont disposées au bout d'un pétiole ailé, elles sont composées de 5 folioles de 5 à 10 sur 3,5 à $6 \mathrm{~cm}$, la foliole terminale étant la plus grande. II y a des fleurs presque toute l'année, disposées en épis pouvant avoir $10 \mathrm{~cm}$ de long. Fruits trilobés jusqu'à $3 \mathrm{~cm}$ de long, contenant des graines rouge brillant dans une chair pourpre.

Ecologie: Plante très répandue en Afrique tropicale et à Madagascar. Pousse dans les lieux humides des recrus forestiers.

Reproduction : par graines.

Photo: Stefaan Dondeyne

Usages : Le principal usage médicinal de la plante en Afrique est d'arrêter les hémorragies. Au Kongo Central, on emploie la cendre des feuilles pour soigner les blessures. On prend une décoction des feuilles pour traiter la gonorrhée. Les rameaux servent couramment de bâtons à mâcher. Les feuilles sont largement employées pour traiter la colique, la diarrhée et la dysenterie. Dans les Provinces de I'Equateur, on traite les difficultés respiratoires en frottant sur la poitrine un mélange des feuilles réduites en poudre avec des cendres chaudes. La décoction de la racine avec du gruau de maïs se donne à boire pour traiter les diarrhées sanguinolentes et les paralysies, ou en lavement contre les paralysies. On applique les feuilles en cataplasme sur les fractures. Les graines, comestibles, sont connues pour leur taux élevé en amidon. On emploie les tiges comme cordages.

Références: Gillet et Pâque 1910, Staner et Boutique 1937, Renier 1948, Hauman 1960, Irvine 1961, Busson 1965, Nsimundele 1966 - 68, Uphof 1968, Daeleman et Pauwels 1983, Malaisse 1997, Burkill 2000, Konda Ku Mbuta et al. $2015 a$

Photo : H.J. Ndangalasi Tanzanian Plant Collaboration

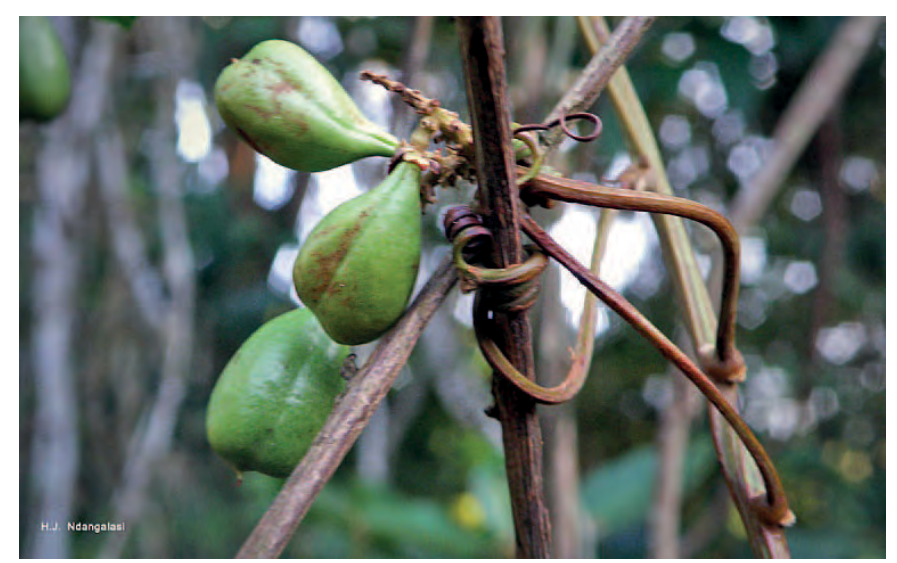




\section{Pauridiantha multiflora subsp. dewevrei}

Noms courants: Zamba dinkanka, papaya mfinda, safi di n'kanka, makaku (Kikongo), mopam-bunga, mopampunga, mpapanya (Lingala).

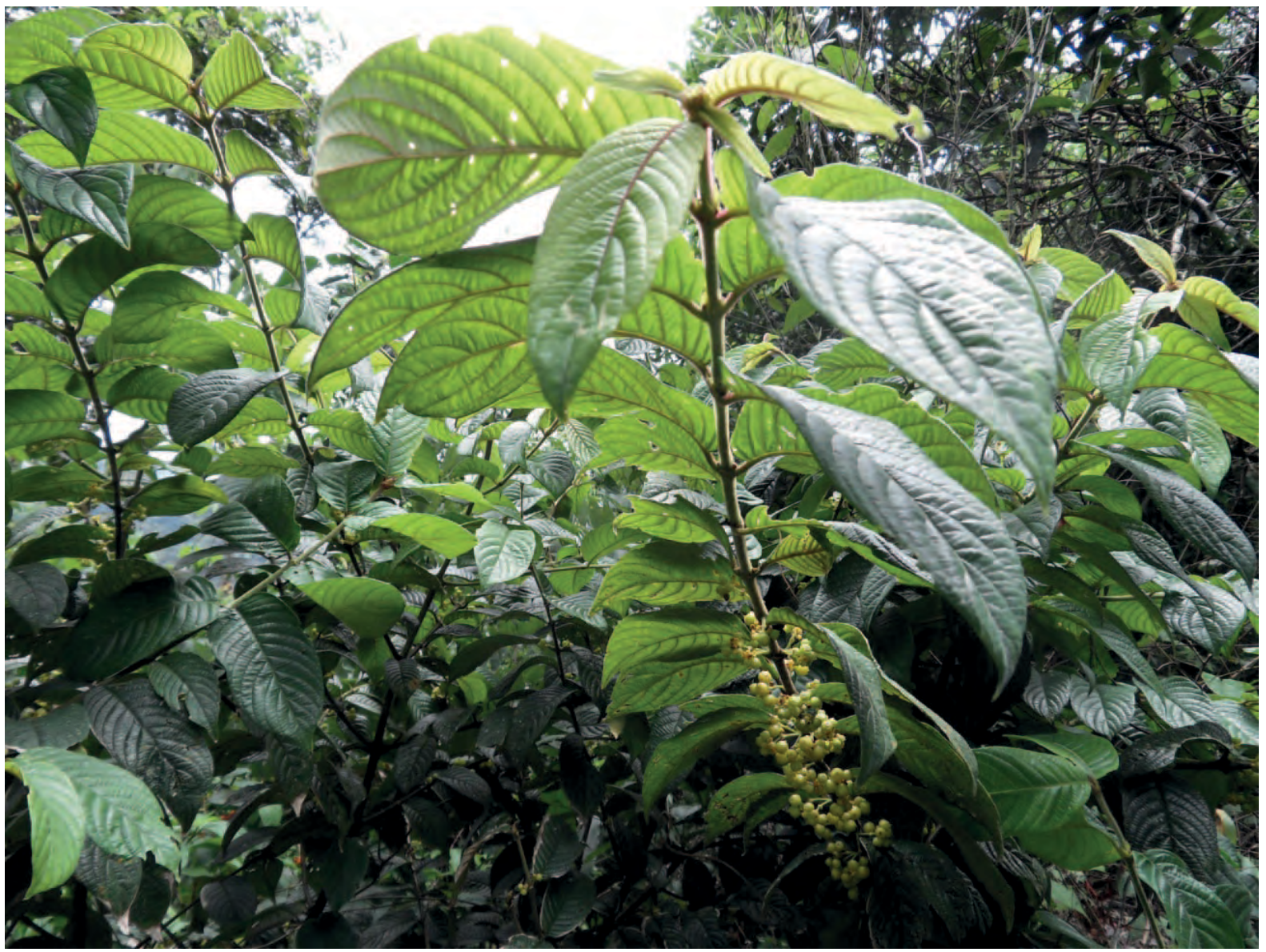

Pauridiantha multiflora subsp. dewevrei portant des fruits en novembre

Description : Buisson de 2 à 8 m de haut. Tiges couvertes d'un tissu de poils fins. Feuilles de 6 à 21 sur 2,6 à 7,7 $\mathrm{cm}$. Très petites fleurs jaune orange groupées, de 6 à 20, à l'aisselle des feuilles. Fruits d'abord jaunes ou rougeâtres, devenant noirs à maturité.

Ecologie: Plante des recrus forestiers et forêts secondaires au Cameroun, en Centrafrique, au Gabon et dans les deux Congo.

Usages: Les branches fines sont employées comme bois de feu. Au Congo Brazzaville, on traite les hernies avec un extrait de l'écorce dans du vin de palme. Chez les Mongo, on fait boire, ou on donne en lavement, de très petites quantités d'un extrait de l'écorce ou des fruits pour traiter la colique. Le fruit serait comestible ; on le broie finement dans l'eau, et on emploie le filtrat comme lavement pour traiter les convulsions des enfants. On a observé à Selu en novembre la récolte du nectar par les abeilles.

Remarques: Le bois n'est pas durable ; on trouve quatre autres espèces au Kongo Central.

Références : Gillet et Pâque 1910, De Wildeman 1934, Renier 1948, Hallé 1966, Bouquet 1969, Pauwels 1993, Burkill 1997, Neuwinger 2000, Ntore et Lachenaud 2020

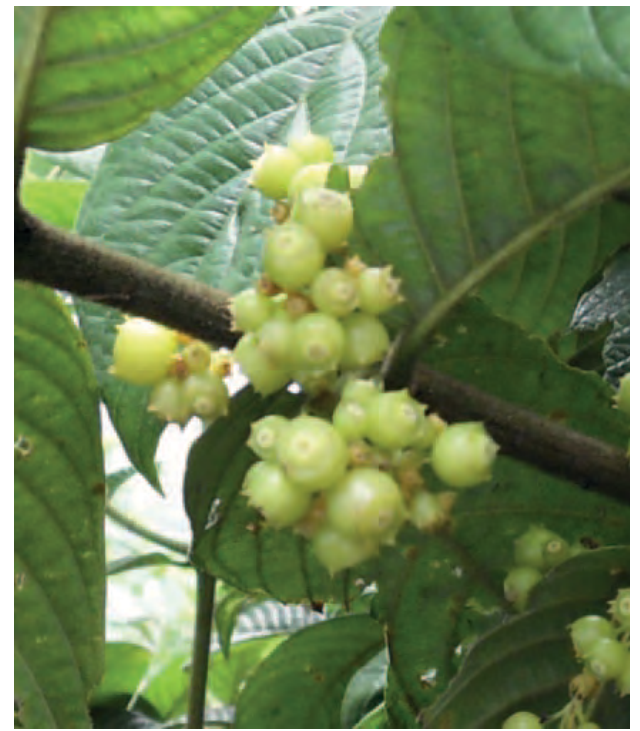


Nom courant : Bolanda mpona, bompiolo (Lingala)

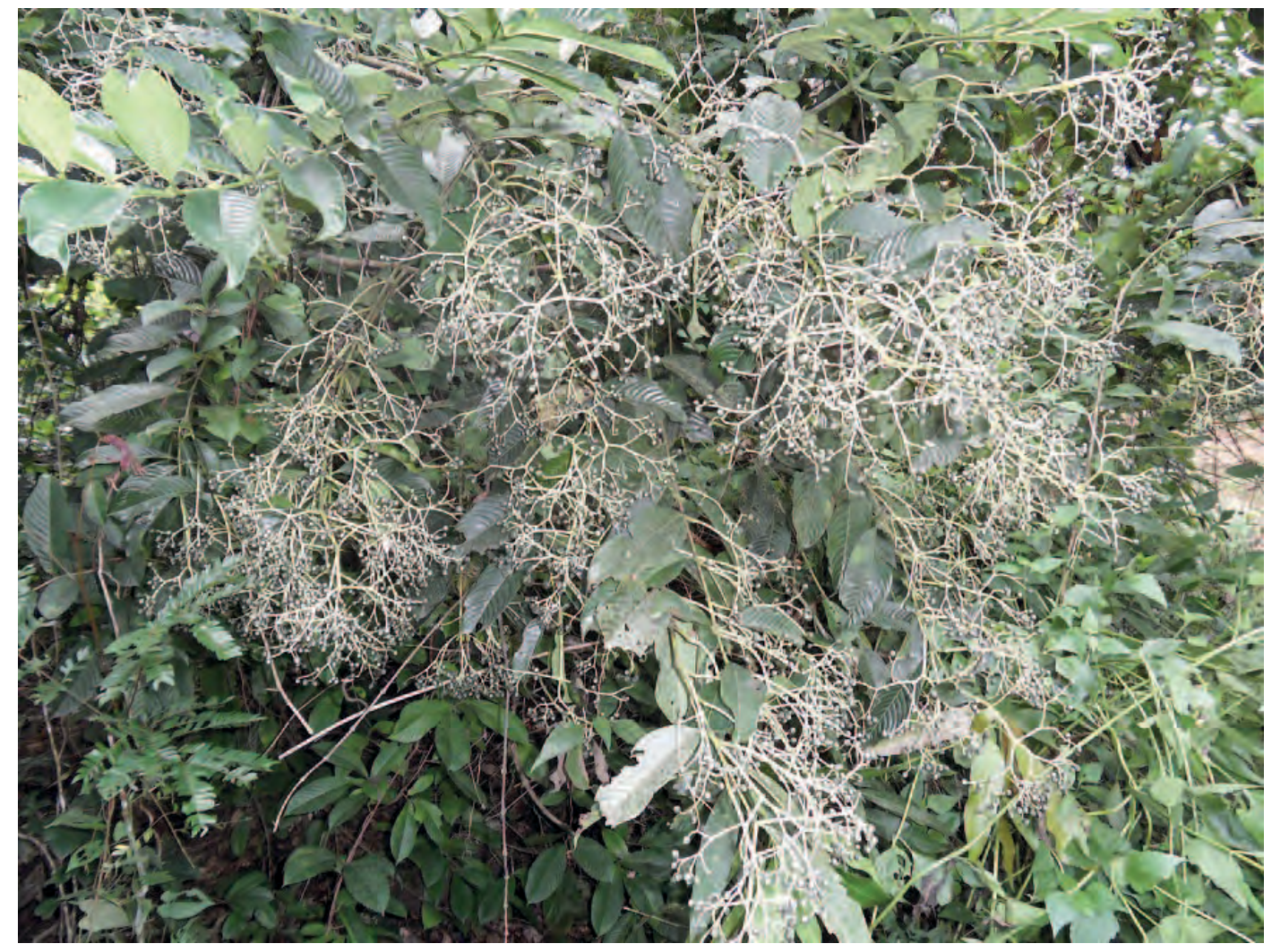

Description : Arbuste de 1,5 à $18 \mathrm{~m}$ de haut. Feuilles vert jaune, profondément plissées, de 8 à 24 sur 4 à $8 \mathrm{~cm}$, sur un pétiole de 0,6 à $1,2 \mathrm{~cm}$. Fleurs disposées en inflorescences terminales de 8 à $24,5 \mathrm{~cm}$ de long, la corolle est pubescente au dehors, verte ou blanc verdâtre. Les fruits sont des baies verdâtres, presque rondes, de 3,7 à 7 $\mathrm{mm}$ de diamètre.

Ecologie : Plante des lisières de forêts dans toute l'Afrique Centrale, très commune dans le Sud-Ouest du Congo.

Usages : Les branches fines s'emploient en construction et comme bois de feu. L'écorce contient une chemique qui a des propriétés comparables à celles de la quinine, et qui est létale pour les protozoaires. Les fleurs sont probablement un fourrage pour les abeilles.

Remarque : La plante se reconnait aisément à son inflorescence terminale. Si I'on jette des morceaux de bois dans un feu de brousse, ils explosent bruyamment.

Références ; Gillet et Pâque 1910, Renier 1948, Bouquet 1972, Pauwels 1993, Burkill 1997, Fundiko 2015, Ntore et Lachenaud 2020

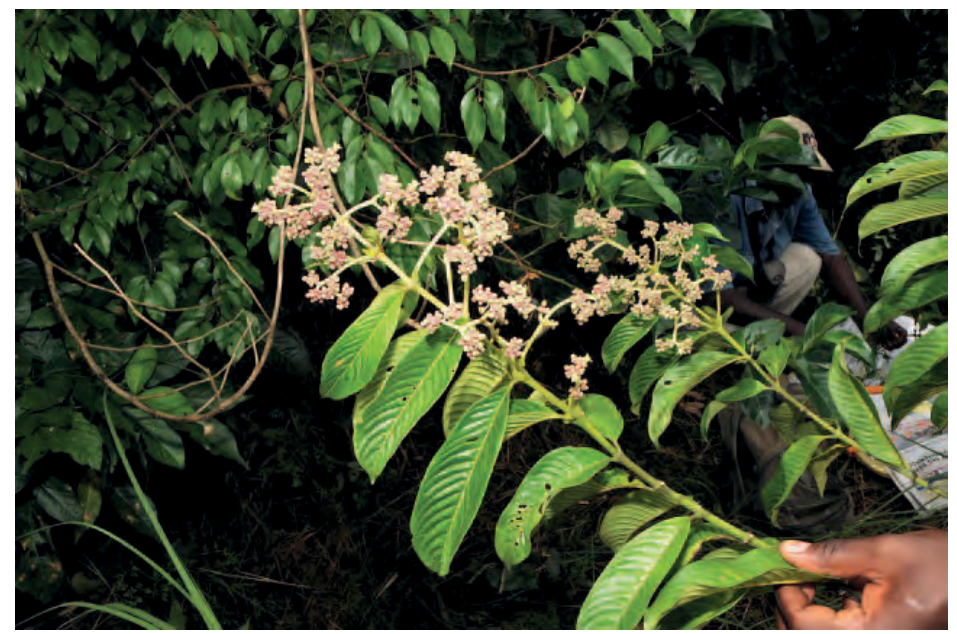

Photo : (c) David Harris, RBG/Edinburgh et www.africanplants.senckenberg.de. 


\section{Pedilanthus tithymaloides}

Synonyme : Euphorbia tithymaloides

Noms courants : Bois de lait, plante zigzag, pantouflier (Fr.), Japanese poinsettia (Angl.)

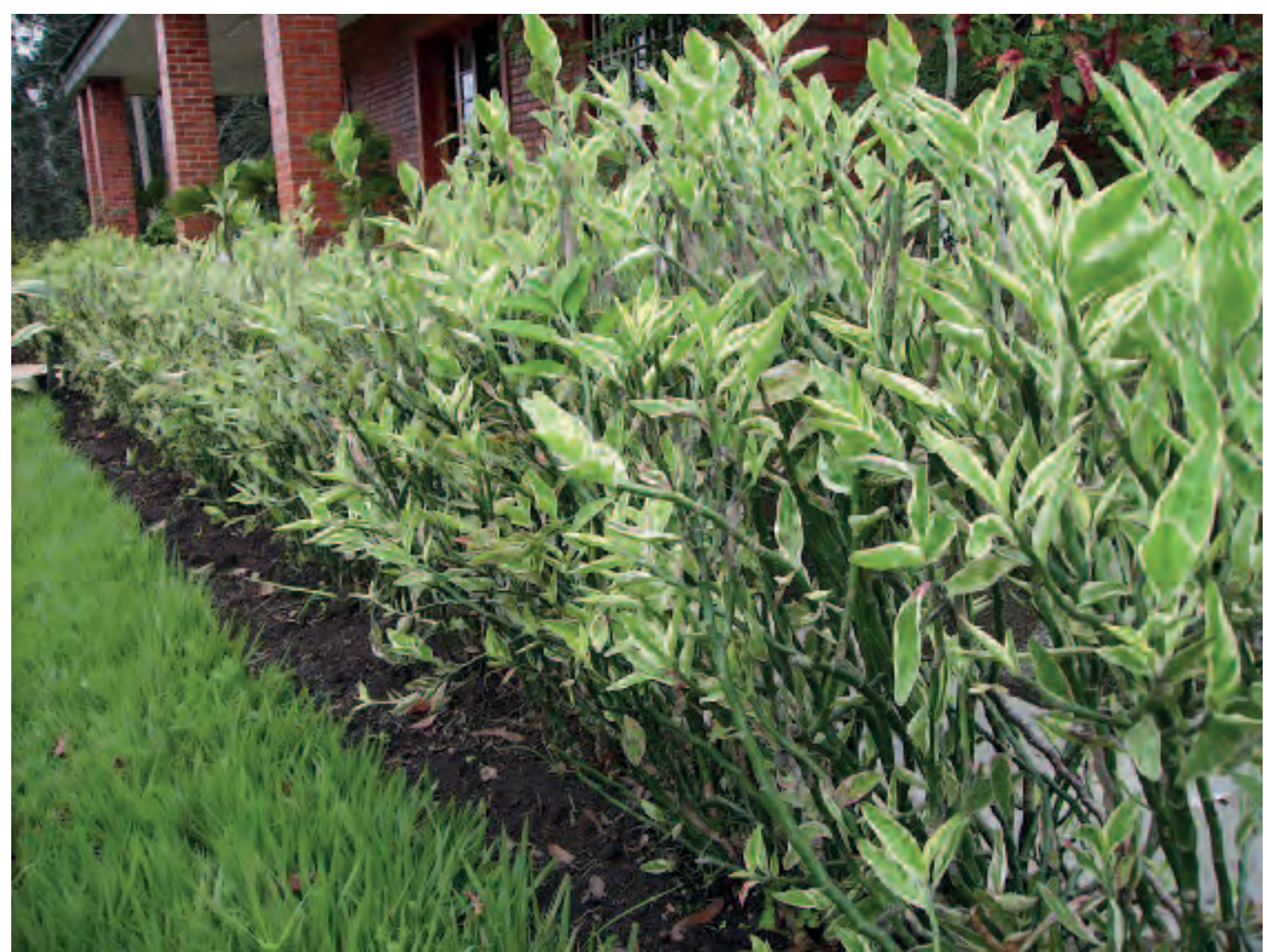

Pedilanthus tithymaloides cultivé comme haie au jardin botanique de Kisantu

Description : Buisson succulent à fortes tiges et branches en zigzag, atteignant $3 \mathrm{~m}$ de haut. Feuilles charnues, souvent panachées de vert jaune et de rose, de 3,5 à 8 sur 2,5 à $5 \mathrm{~cm}$. Fleurs en forme de bec, rouges ou pourpres, en bouquets axillaires ou terminaux.

Ecologie: Plante originaire des Caraïbes, maintenant cultivée partout sous les Tropiques.

Reproduction : Par boutures des tiges.

Usages : Cultivé couramment comme haie en Afrique de I'Ouest. Dans les Provinces de l'Equateur, on traite le zona en appliquant sur la tête une fine poudre des feuilles. On emploie la sève laiteuse pour traiter les verrues. La racine est un émétique puissant. Aux Maldives, on mange les feuilles.

Références : Jex-Blake 1956, Macmillan 1991, Burkill 1994, Philip et Rix 1997, Fayaz 2011, Konda Ku Mbuta et al. 2015a, Cameron et Lowe 2017

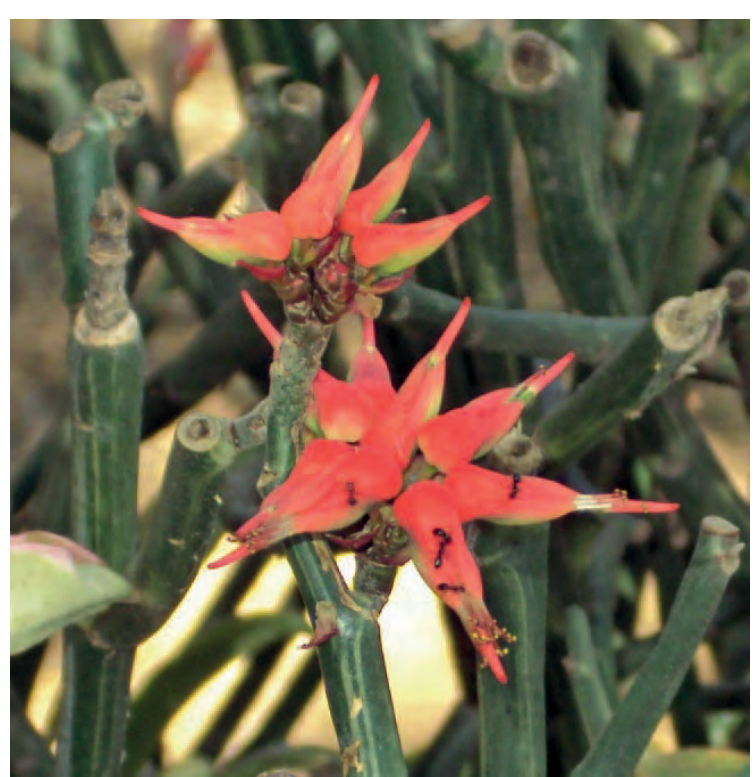

Photo : Anne Njeri Kibughi 


\section{Peltophorum pterocarpum}

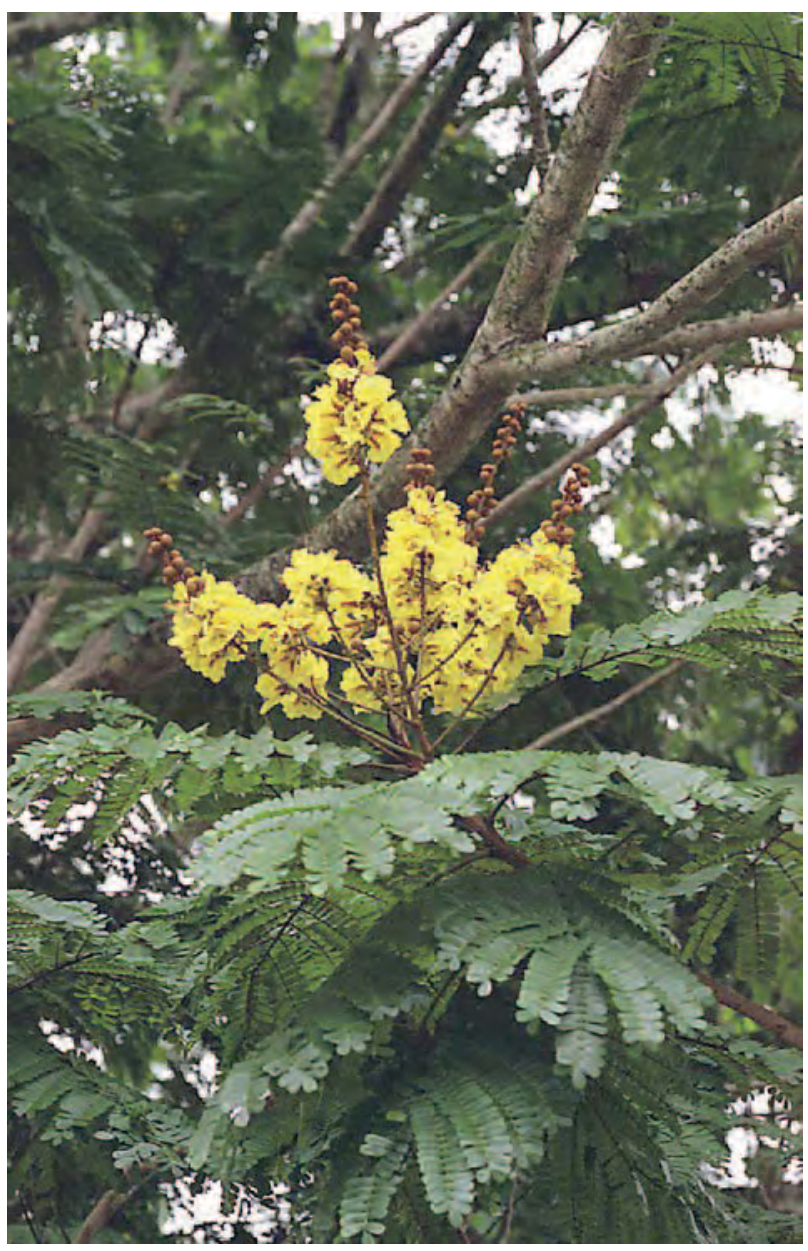

(Fabaceae)

Noms courants : Arbre de feu, flamboyant jaune, flamboyant de I'Inde (Fr.), yellow flame tree (Angl.)

Description : Arbre atteignant $20 \mathrm{~m}$ de haut, à tronc droit, couronne dense et croissance rapide (120 à 180 $\mathrm{cm}$ par an). Feuilles atteignant $35 \mathrm{~cm}$ de long, composées de 8 à 10 pennes portant chacune 10 à 20 folioles de 0,5 à 2,8 sur 0,4 à $0,7 \mathrm{~cm}$. Les fleurs sont jaunes, de 2,5 à $4 \mathrm{~cm}$ de diamètre, regroupées en grandes grappes pouvant mesurer jusqu'à $20 \mathrm{~cm}$ de long. Le fruit est une gousse de 5 à $10 \mathrm{~cm}$ de long et $2,5 \mathrm{~cm}$ de large, rouge au départ, devenant noire à maturité et contentant d'une à quatre graines. L'arbre résiste au vent et n'est pas attaqué par les insectes perforants.

Ecologie: Arbre originaire d'Asie du Sud-Est et Australie du Nord, maintenant couramment cultivé sous les Tropiques. Planté à Kinshasa comme arbre d'avenues et présent au jardin botanique de Kisantu. Pousse bien sur les sols bien drainés, plutôt secs. Pousse sur les sols sablonneux pauvres pourvu que les pluies annuelles dépassent $1.000 \mathrm{~mm}$ d'eau.

Reproduction : Les graines sont difficiles à extraire et ne germent pas facilement. II faut les scarifier avant de les semer. On peut aussi pratiquer le bouturage ou le marcottage.

Gestion : L'arbre recèpe bien.

Usages : Le bois est bon pour le mobilier et comme bois de feu. Selon la documentation, l'arbre serait utile pour restaurer les terres envahies par Imperata cylindrica. A Java, on emploie l'écorce en tannerie pour avoir une teinture brun clair, et en médecine pour traiter les ulcères et la dysenterie. Arbre parfois cultivé comme ombrage dans les plantations de café, comme brise vent ou comme arbre d'avenues. Les racines pénètrent profondément le sol et ne dérangent pas les constructions. Le bétail mange les feuilles, qui sont riches en protéines. On a observé la récolte du pollen par les abeilles à Kisantu en novembre ; on sait qu'elles récoltent aussi le nectar.

Références : Dubois et Collart 1950, Leloup 1956, Uphof 1968, NAS 1979, Macmillan 1991, Pauwels 1993, Burkill 1995

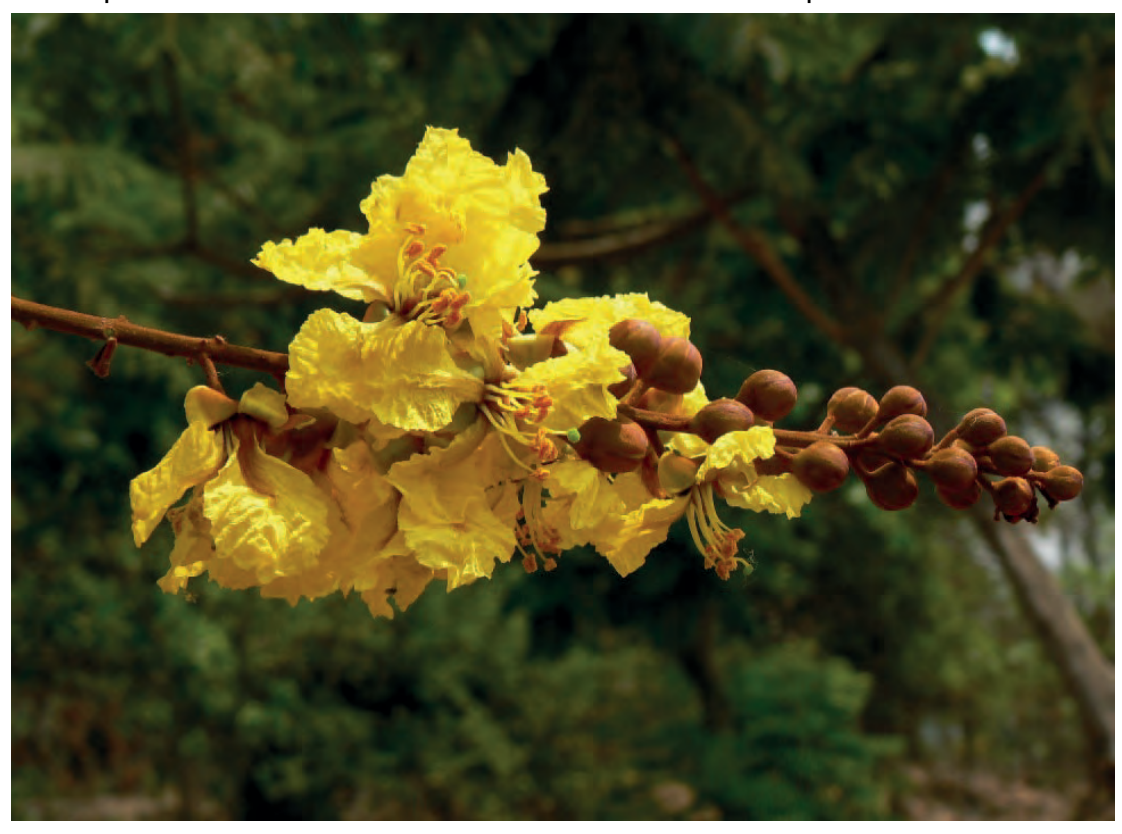

Photo : Dinesh Valke 


\section{Pentaclethra eetveldeana}

Noms courants : Nseka, kiseka, nsombo nseka, nseka mfusila, nsambu, m’vanzi fioti (Kikongo)

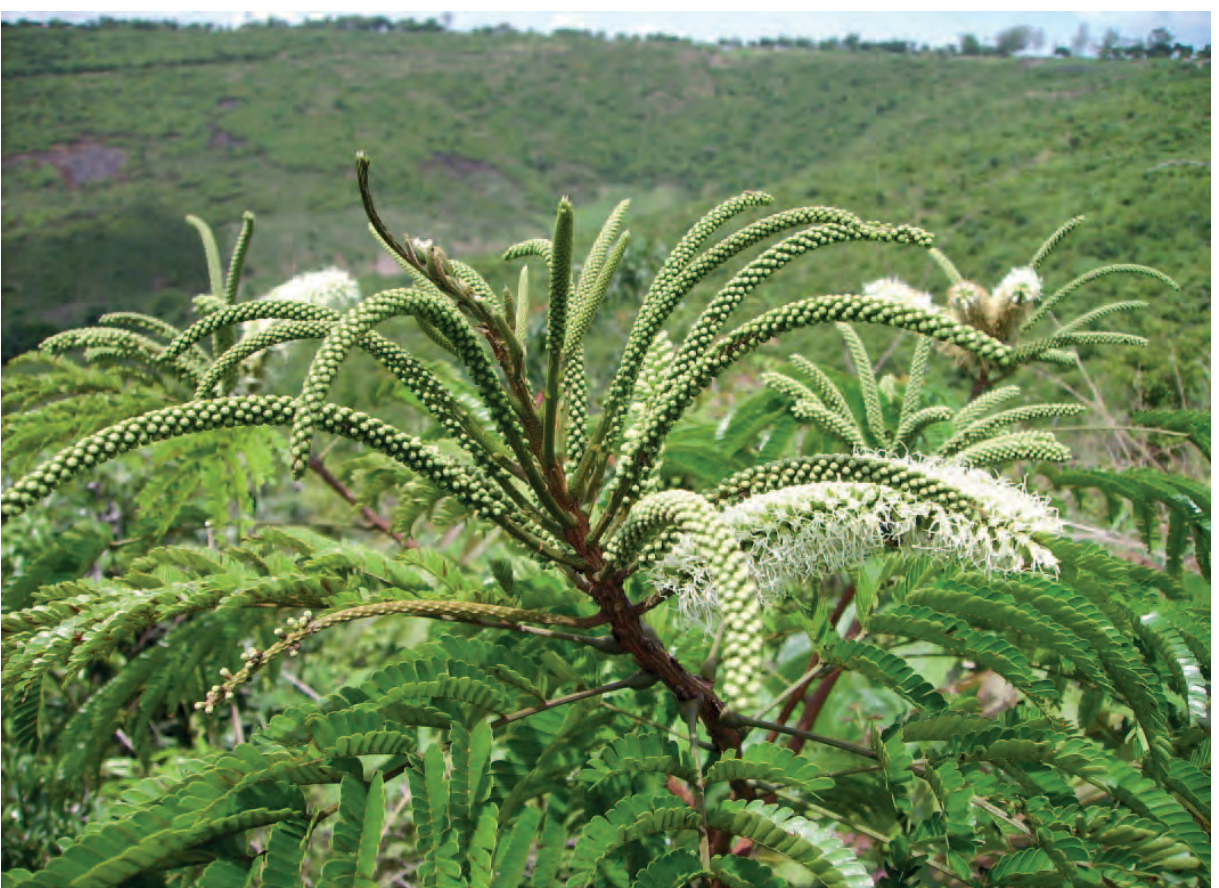

place, puis s'ouvre en explosant et projetant au loin 3 à 8 graines.
Description : Arbre de 15 à $30 \mathrm{~m}$ de haut. La photo ci-dessus a été prise en octobre. Ecorce grise fissurée. Feuilles bipennées pouvant atteindre $40 \mathrm{~cm}$ de long, avec 9 à 18 paires de pennes opposées contenant chacune de 15 à 30 folioles de 8 à 13 sur 2 à $3,5 \mathrm{~mm}$, obliquement rhomboïdes. L'inflorescence est une panicule pouvant atteindre $30 \mathrm{~cm}$ de long et contenant de nombreuses petites fleurs odorantes. Le fruit est une gousse plate, brune ligneuse, pouvant avoir $20 \times 4 \mathrm{~cm}$, qui reste longtemps en

Ecologie : Arbre des forêts secondaires, commun au Kongo Central, présent également au Congo Brazzaville, à Cabinda et au Gabon.

Reproduction : La germination des graines est irrégulière, mais atteint un haut pourcentage. Le mieux est de les semer en pleine terre à faible profondeur, pour ne pas endommager la racine pivotante.

Gestion : L'arbre recèpe bien dans les jachères.

Usages : Les graines contiennent une huile que l'on emploie comme antirouille et pour protéger les pieds contre les chiques (n'tanda Tunga penetrans). L'arbre est une source importante de bois de feu et charbon de bois. Le bois est blanc et dur, mais sujet aux attaques d'insectes et aux déformations. On l'emploie en construction, pour les pilons et les mortiers. Le charbon de bois servait traditionnellement à marquer le visage des femmes en deuil. Au Kongo Central, on soulage les démangeaisons avec un liquide obtenu par trempage de l'écorce. On donne une décoction des feuilles pour traiter les refroidissements et les maux d'estomac. Les chenilles comestibles minsangula (Achaea catocaloides) se nourrissent des feuilles. Les abeilles récoltent le nectar des fleurs. Au Gabon, on signale que le miel serait toxique et donnerait des nausées et la colique ; cependant, ceci n'a pas été observé au Kongo Central.

\section{A droite: Chenilles minsangula en vente dans un marché villageois.}

Références: Gillet et Pâque 1910, Denis 1932, De

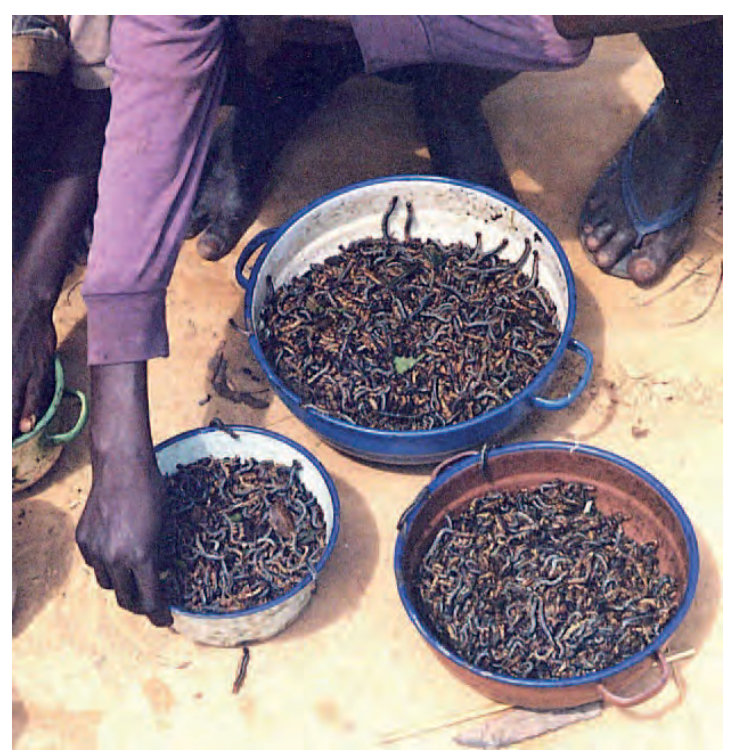

Wildeman 1934, Renier 1948, Gilbert et Boutique 1952, Nsimundele 1966 - 68, Daeleman et Pauwels 1983, Ambougou 1991, Mukoko Matondo 1991, Pauwels 1993, Kibungu Kembelo 1995, Latham 2008 


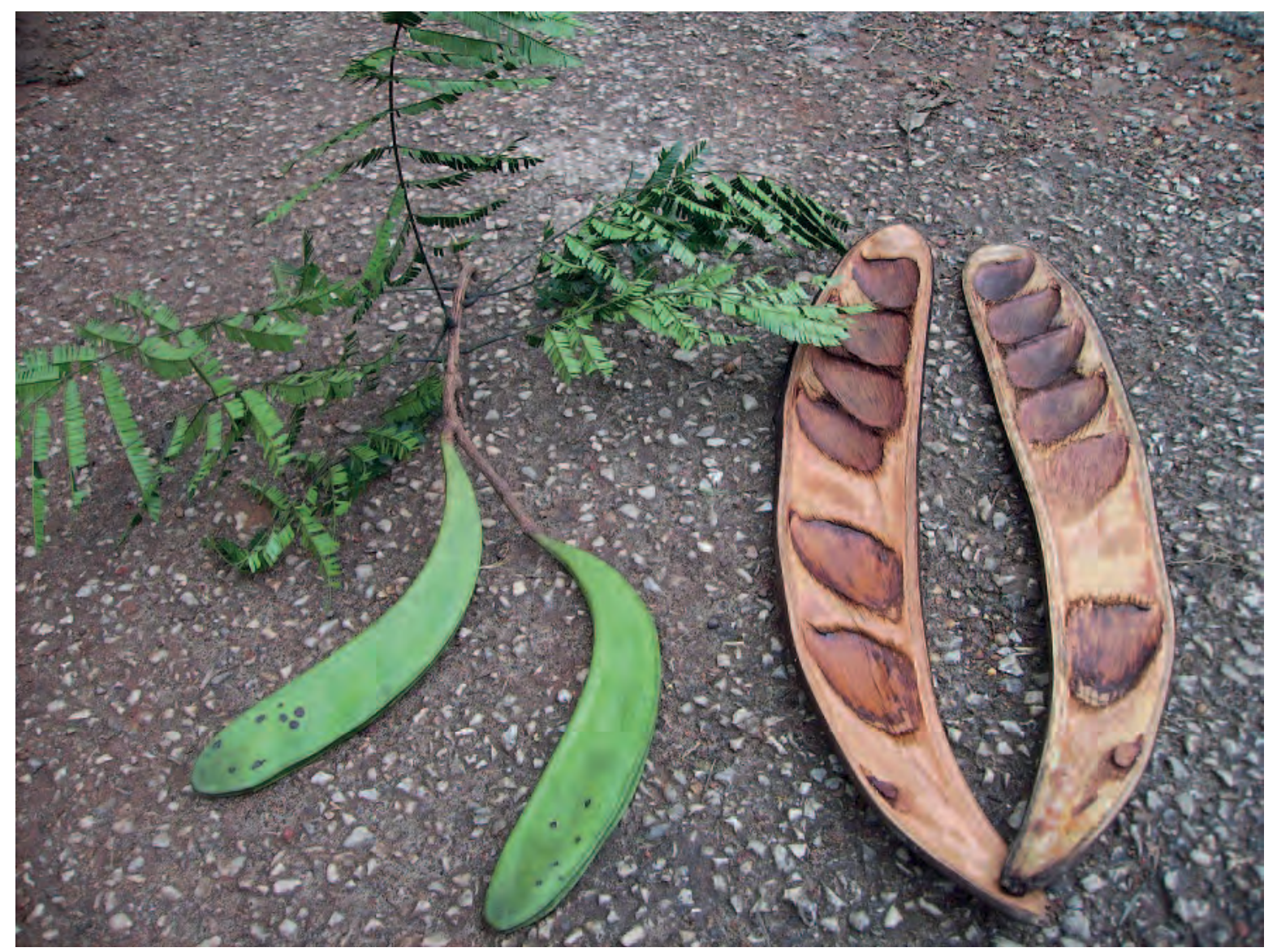

Gousses de Pentaclethra eetveldeana (à gauche) et de P. macrophylla (à droite).

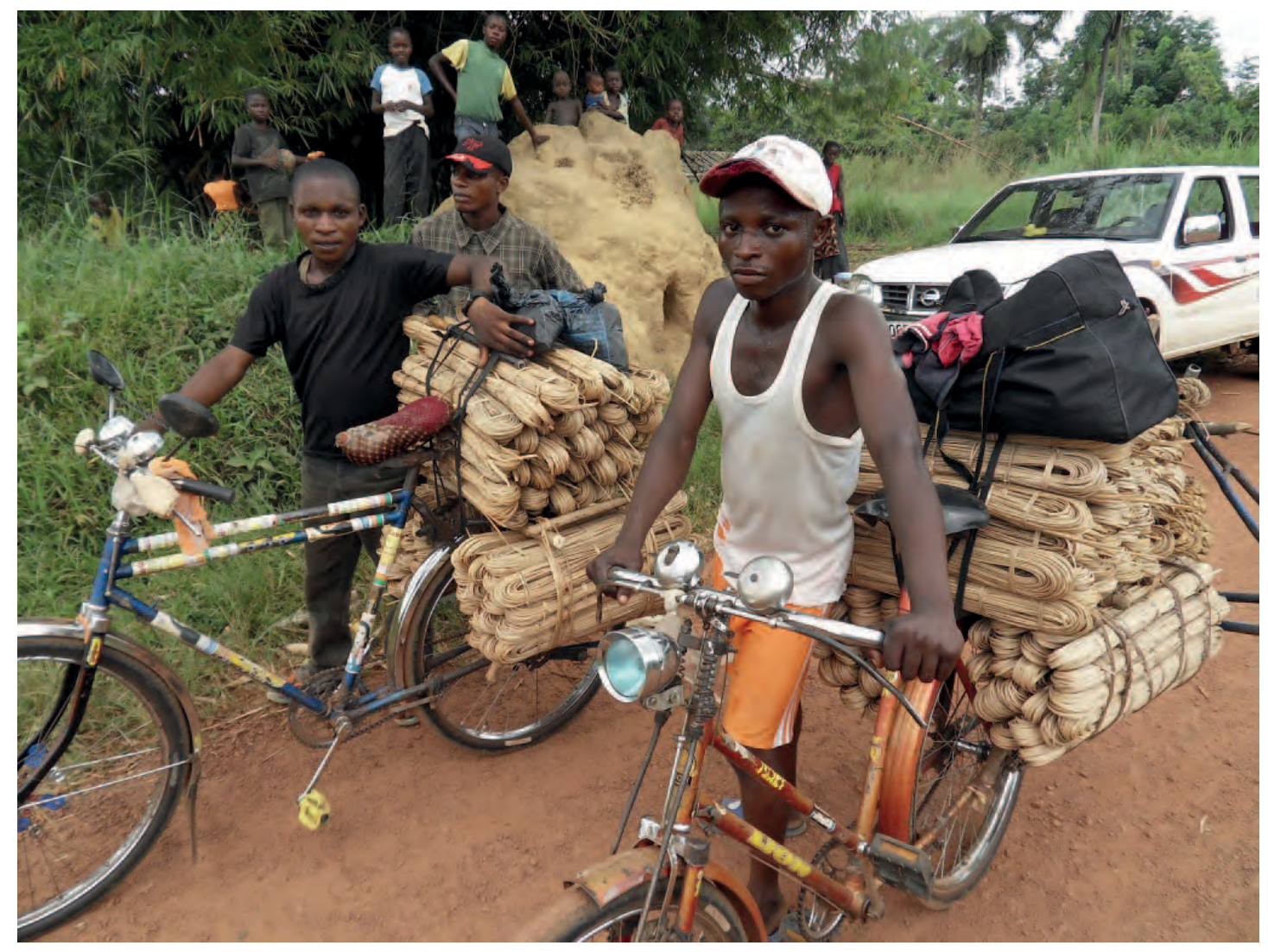

Des paquets d'Eremospatha haullevilleana en route vers le marché (voir page 323) 


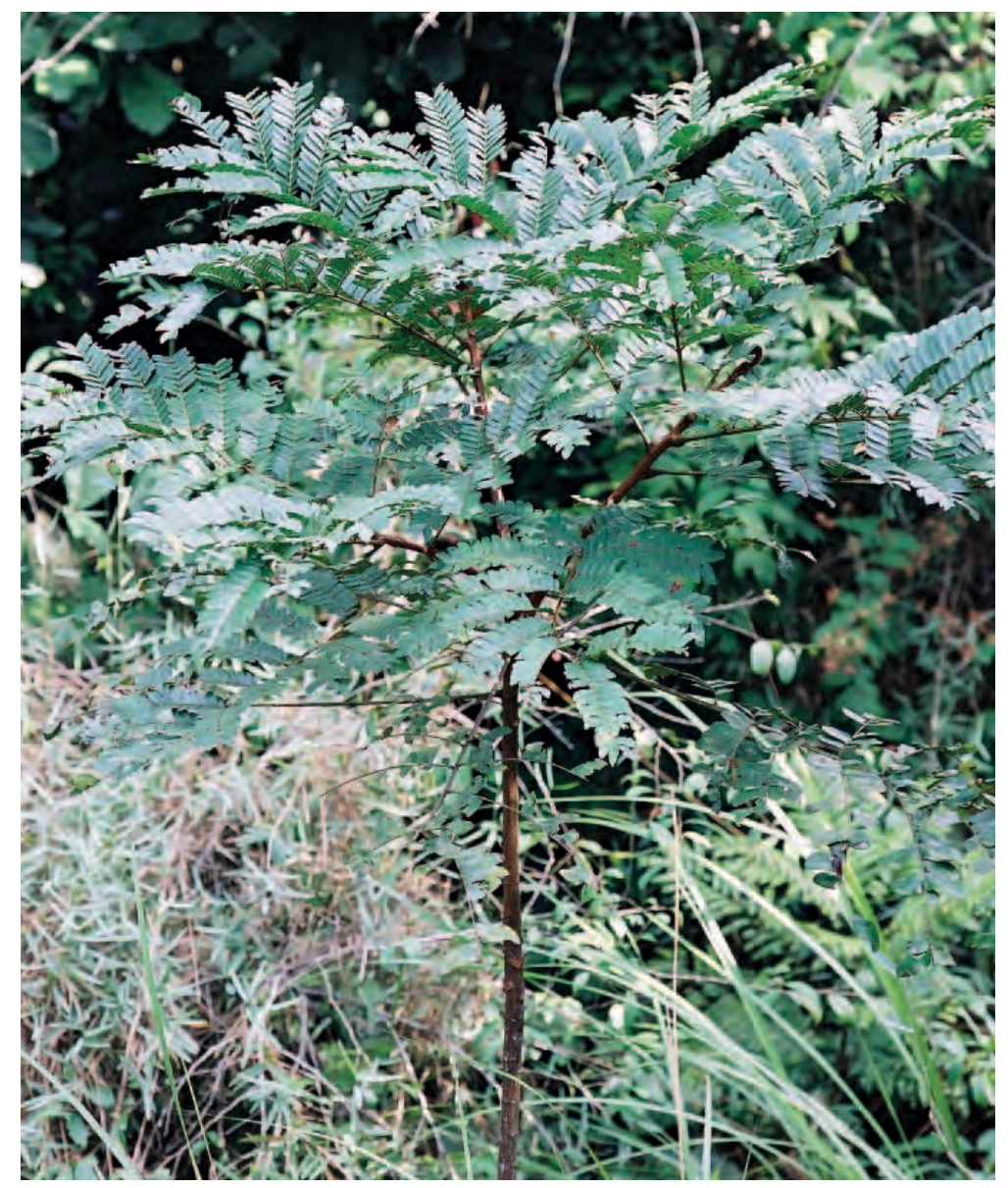

Noms courants : N'gansi, panza (Kikongo), bosanza (Lingala) owala, mubala, arbre à semelles, acacia du Congo ( $\mathrm{Fr}$ ), oil bean tree (Angl.)

Description: Arbre à croissance rapide atteignant $25 \mathrm{~m}$ de haut. Fût atteignant $100 \mathrm{~cm}$ de diamètre ; écorce grisâtre à brun rougeâtre, mince, s'écaillant irrégulièrement. Feuilles alternes, bipennées, de $20-45 \mathrm{~cm}$ de long; pennes opposées, en 9 à 13 paires, de 8 à $14 \mathrm{~cm}$ de long, clairement articulées à la base, avec 6 à 20 paires de folioles ; folioles opposées, sessiles, obliquement oblongues à elliptiques, de 12 à $25 \mathrm{~mm}$ sur 5 à $10 \mathrm{~mm}$. Inflorescence: panicule terminale ou axillaire atteignant $30 \mathrm{~cm}$ de long, composée d'épis, multiflore, densément couverte de poils étoilés brunâtres. Fruit : gousse atteignant $50 \mathrm{~cm} \times 10 \mathrm{~cm}$ $\times 2 \mathrm{~cm}$, persistant longtemps et s'ouvrant de manière explosive sur l'arbre, puis fortement recourbée, contenant 5-8 graines. Graines à contour elliptique, aplaties, de $3,5-7 \mathrm{~cm}$ $\times 2,5-3,5 \mathrm{~cm} \times$ environ $1 \mathrm{~cm}$, lisses, brun pourpre. L'arbre nodule pour fixer l'azote, il a une bonne régénération naturelle après le feu, repousse facilement après l'abattage et résiste

aux termites.

Ecologie: Arbre des forêts secondaires du Sénégal à l'Angola. La croissance peut être bonne quand la pluie est convenable, même sur sol relativement acide. L'arbre tolère les inondations, mais il préfère les sols limoneux bien drainés.

\section{A gauche : Croissance d'un jeune arbre dans la forêt secondaire.}

Gestion : L'arbre recèpe bien. Pentaclethra macrophylla est généralement protégé et souvent entretenu sur les terres agricoles, notamment en R.D. du Congo où il est cultivé dans les exploitations et pour améliorer la jachère arbustive.

Usages : Le bois est dur mais

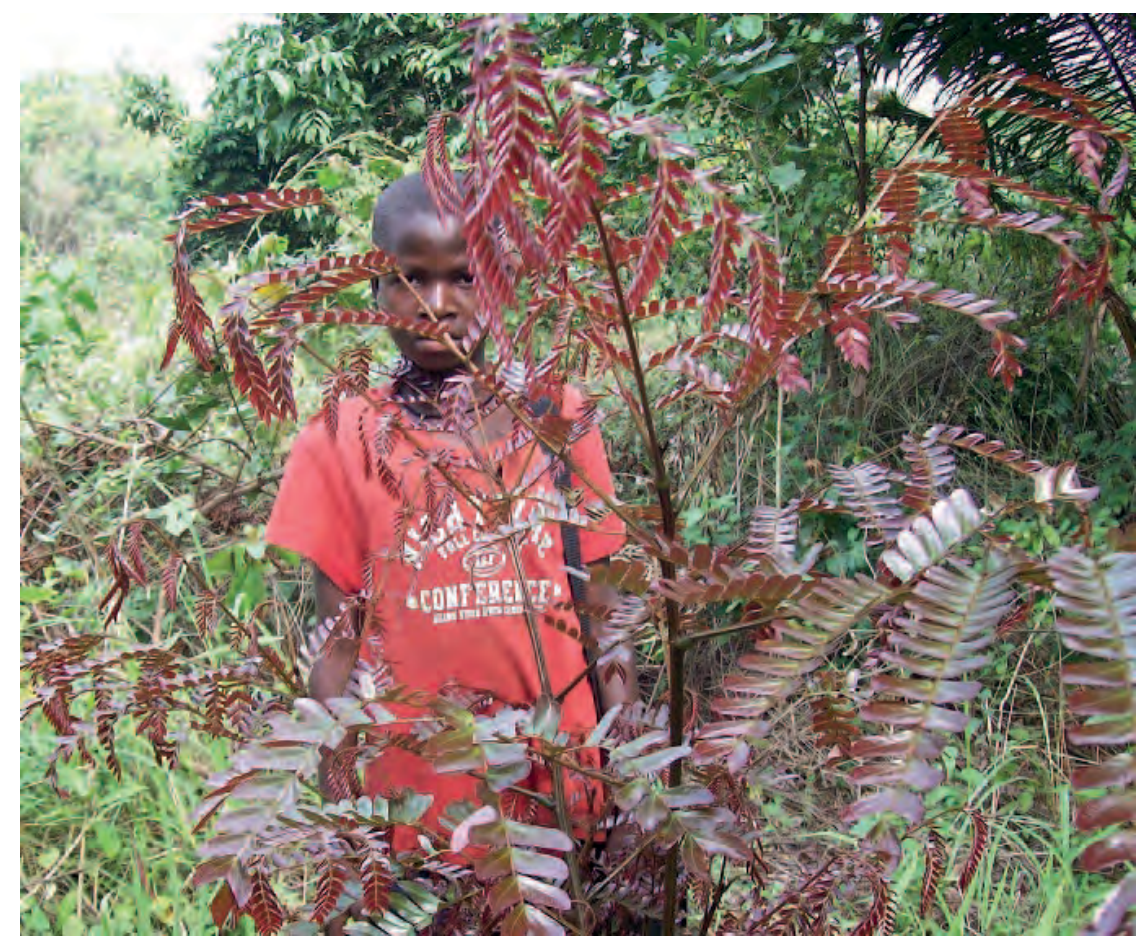

difficile à travailler. On l'emploie pour faire des mortiers et autres ustensiles. II donne un bon charbon de bois et un bon bois de feu, même si celui-ci dégage une odeur désagréable. Le charbon de bois servait traditionnellement à marquer le visage des femmes en deuil. Les graines sont consommées bouillies ou rôties. Elles sont également 
fermentées pour produire un amuse-gueule ou un condiment ayant un goût de viande, très populaire dans le sudouest du Nigeria où il est appelé "ugba". Les graines contiennent une huile qui est comestible, et que l'on emploie comme antirouille et pour protéger les pieds contre les chiques (n'tanda Tunga penetrans). Les gousses servent de combustible; leur cendre donne une lessive employée en savonnerie. Les feuilles tombent pendant la saison sèche et donnent un paillage qui améliore la fertilité du sol. Les fleurs sont une importante source de nectar pour les abeilles, qui les butinent toute la journée. Les chenilles comestibles Minsendi (/mbrasia obscura) et Minsangula (Achaea catocaloides) se nourrissent sur les feuilles. On donne à boire une décoction des feuilles pour traiter la diarrhée.

\section{A droite: Gousses ouvertes avec leurs graines}

Références: Gillet et Pâque

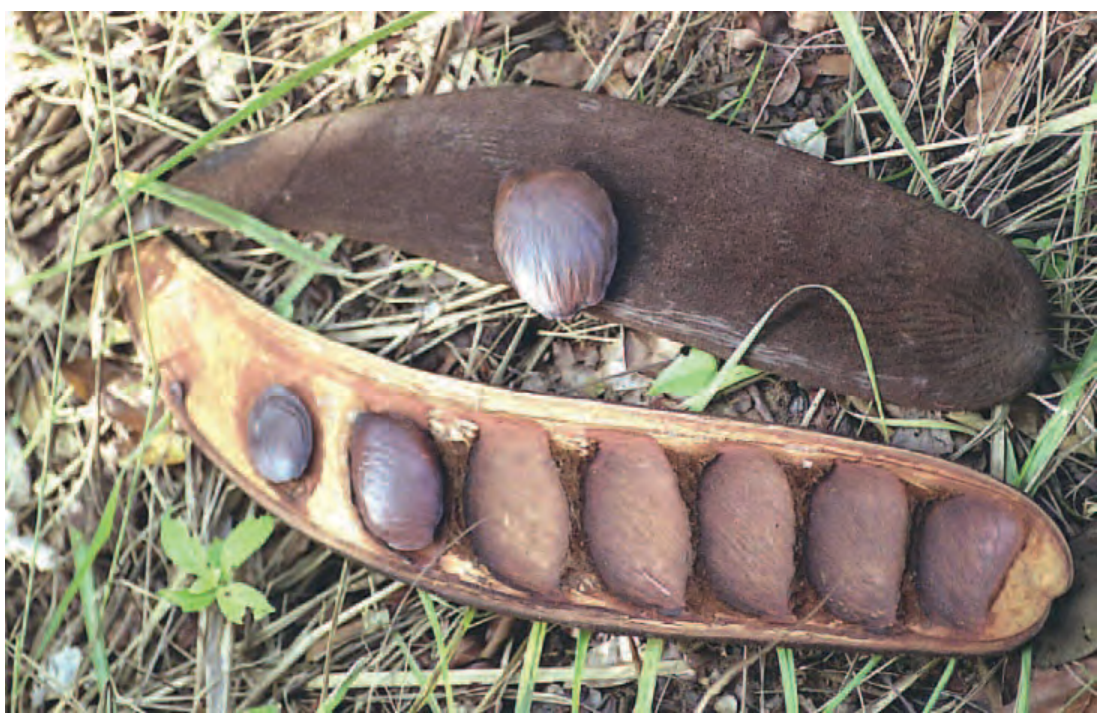

1910, Renier 1948, Gilbert et Boutique 1952, Irvine 1961, Pauwels 1993, Burkill 1995, Kibungu Kembelo 1995, Ladipo et Boland 1995, Pousset 2004, Latham 2008, Orwa et al. 2009

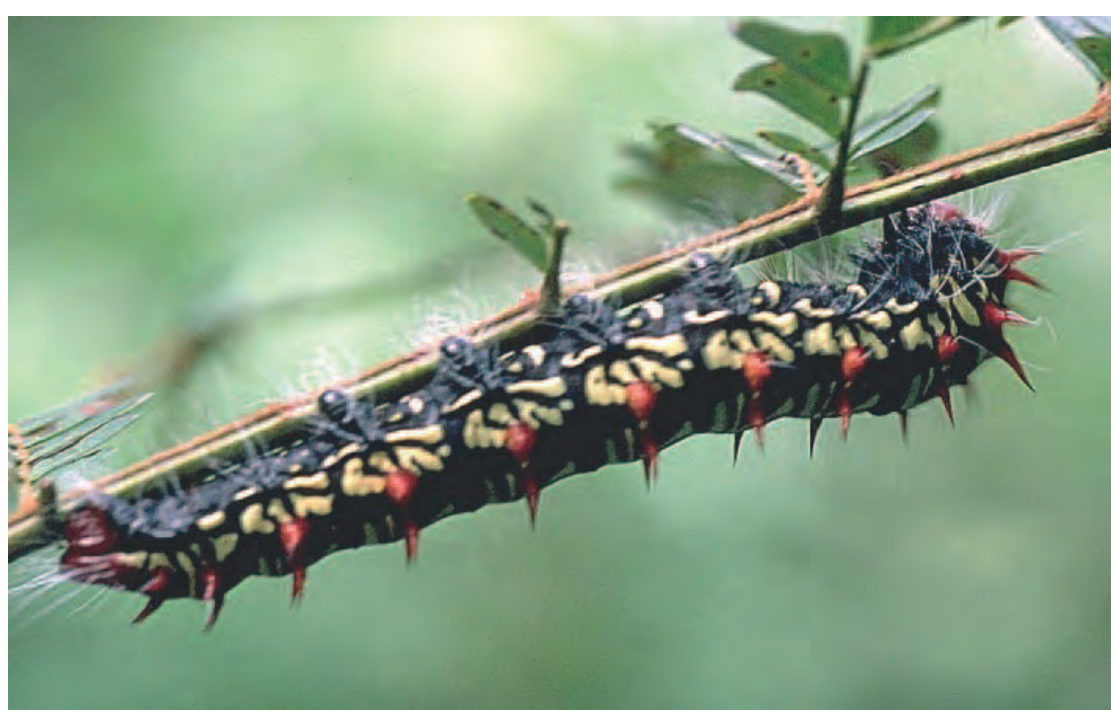

A gauche : Imbrasia obscura mangeant les feuilles de Pentaclethra macrophylla 
Noms courants : Nkenge kiasa, nke kiasa (Kikongo).

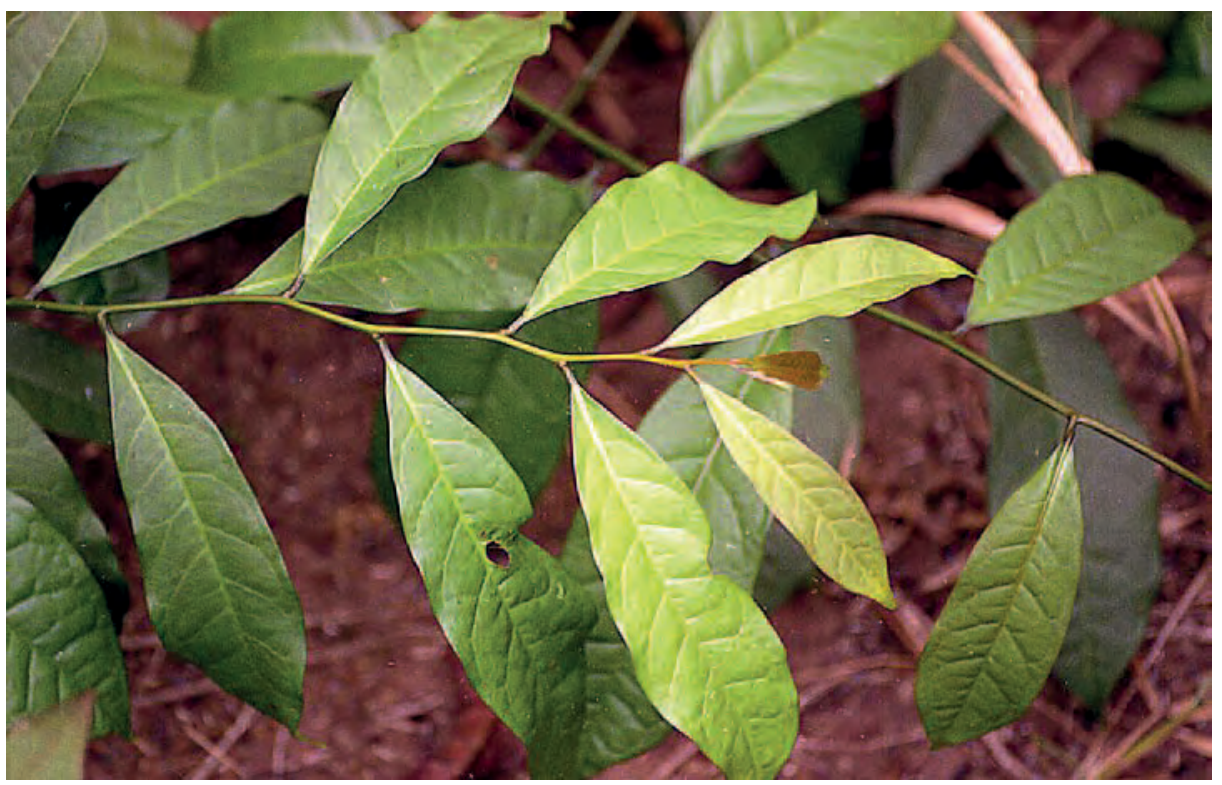

Description : Liane à branches de 3 à $20 \mathrm{~m}$. Feuilles de 5 à 15 sur 1 à $7,5 \mathrm{~cm}$. Fleurs à l'aisselle des feuilles, blanches avec des taches rouges et bleues au bout des pétales. Fruits gris tachetés, de 2 à $4 \mathrm{~cm}$ de diamètre avec une courte stipule. Les grosses racines ont une odeur et un goût semblables à ceux du raifort.

Ecologie: Plante commune des forêts autour des villages du Kongo Central. On la rencontre depuis le

Nigeria jusqu'à la République centrafricaine, et la République démocratique du Congo et l'Angola.

Usages : Fruit comestible, sucré et poivré. Les feuilles et les racines sont également comestibles. Pour soulager les douleurs, on frotte l'écorce des racines sur les parties sensibles. L'écorce sert aussi à traiter diverses maladies, dont l'asthme, le psoriasis, les rhumatismes, l'épilepsie, la colique et les hémorroïdes. La sève permet de réduire les inflammations. La plante sert aussi de médicament contre le lumbago et la diarrhée. C'est la quatrième plante médicinale la plus utilisée dans les territoires de Kisantu et Mbanza Ngungu. On l'emploie contre la gale des chiens.

A droite : Arbre en fleurs en juillet
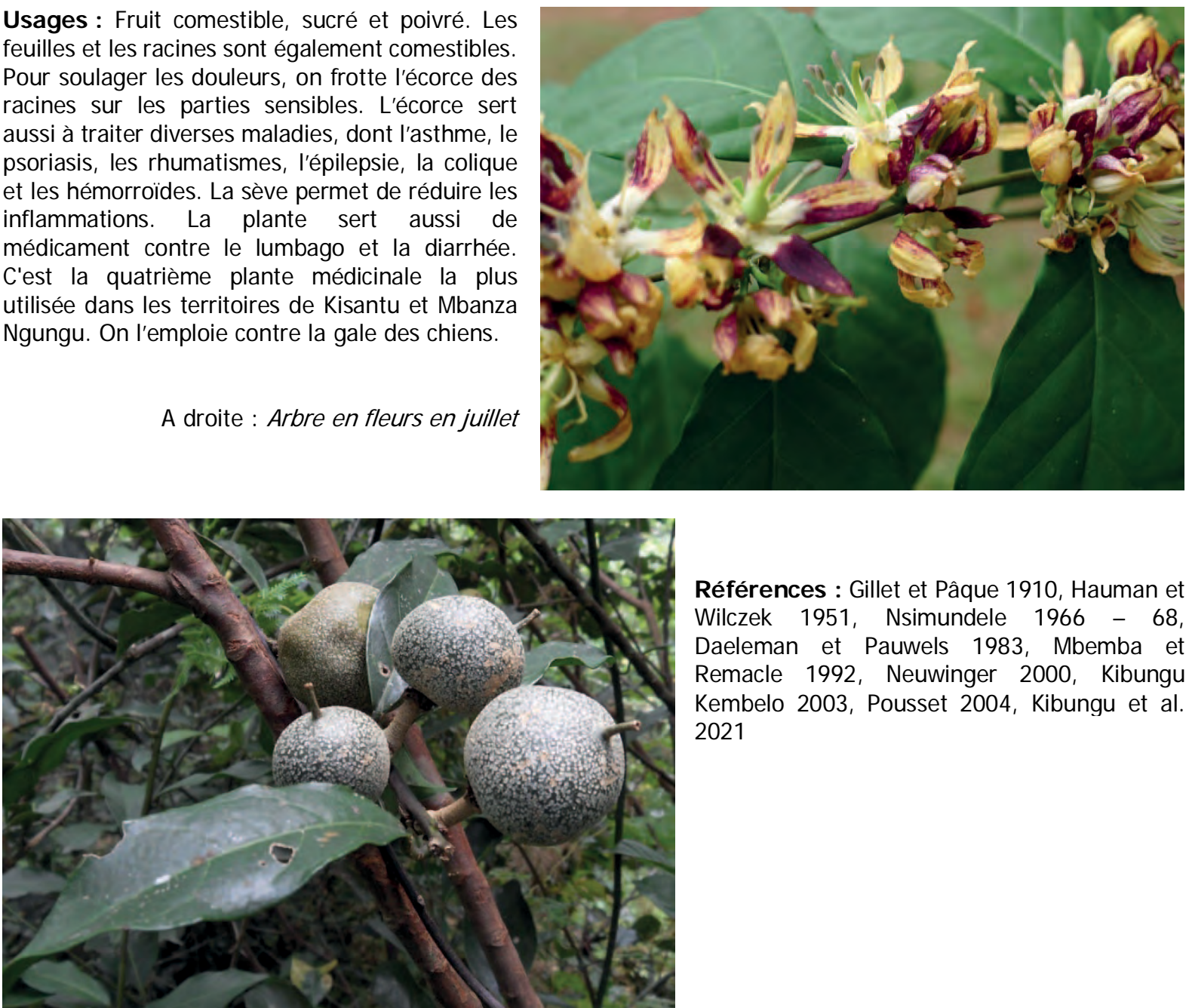

Références : Gillet et Pâque 1910, Hauman et Wilczek 1951, Nsimundele 1966 - 68, Daeleman et Pauwels 1983, Mbemba et Remacle 1992, Neuwinger 2000, Kibungu Kembelo 2003, Pousset 2004, Kibungu et al. 2021 


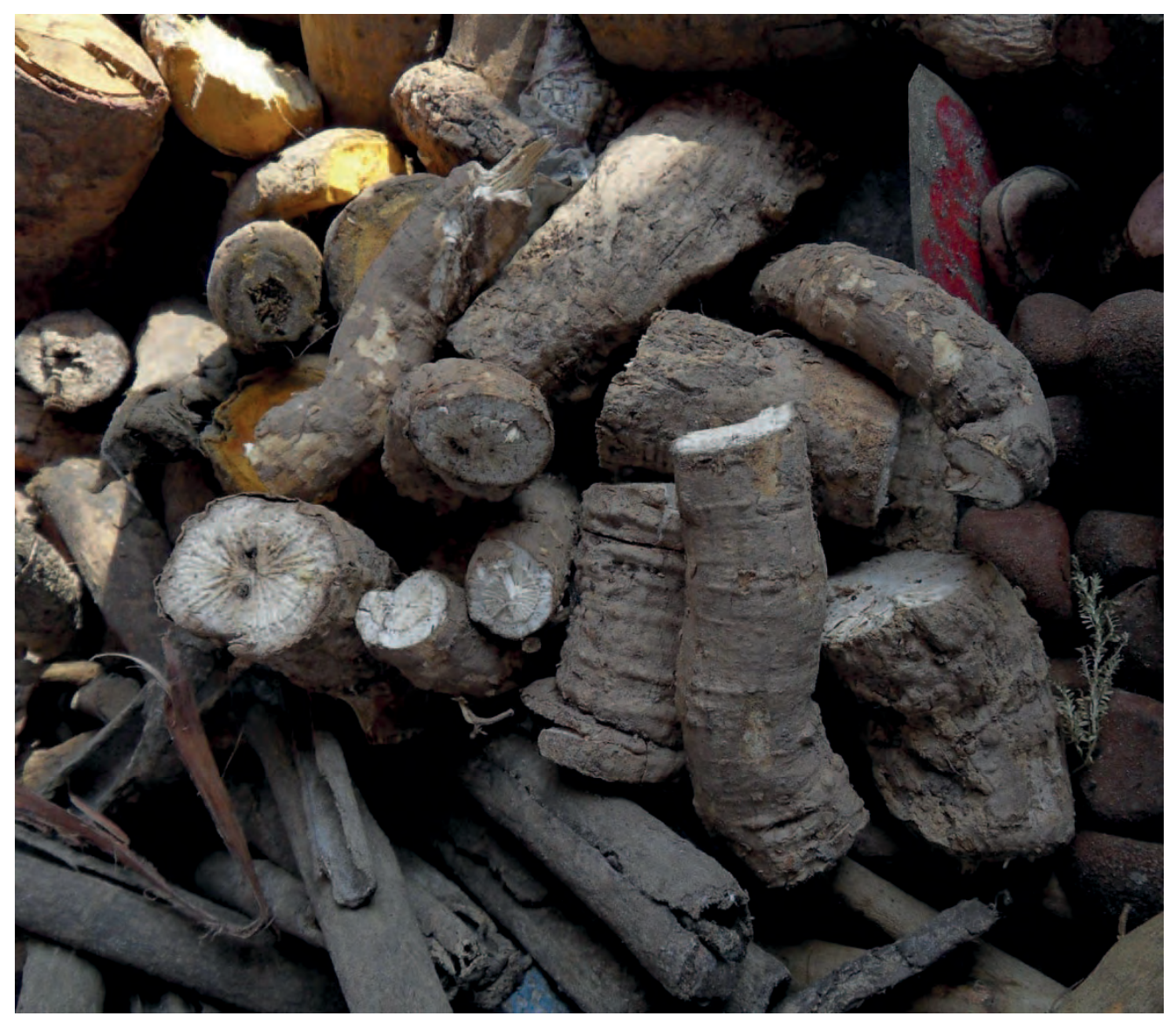

Racines de Pentadiplandra en vente sur un marché

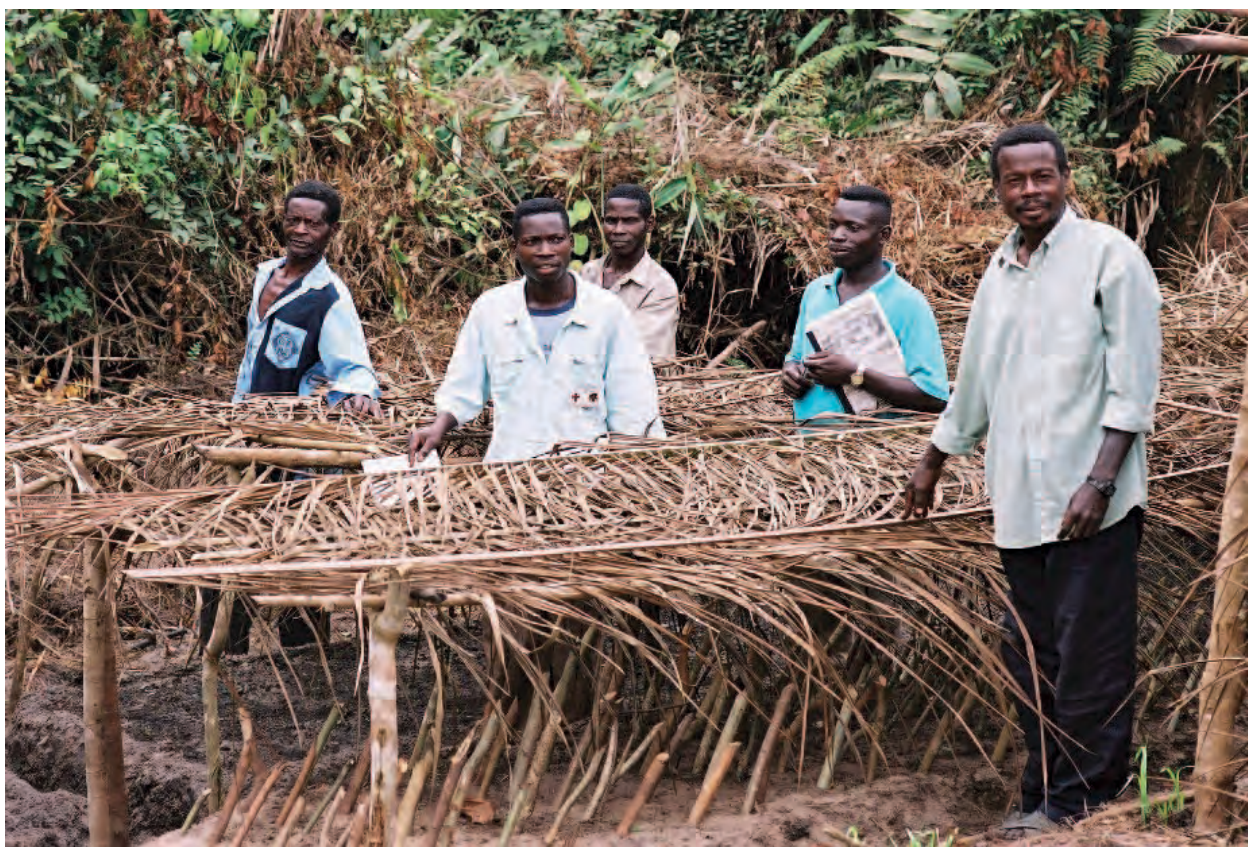

De nombreux arbres indigènes précieux peuvent être cultivés à partir de boutures.

Un groupe d'agriculteurs à Kinseki avec un lit de boutures ombragé 


\section{Synonyme : Piper pellucidum}

Noms courants : Pépéromie, herbe à couleuvre (Fr), pepper elder (Angl.)

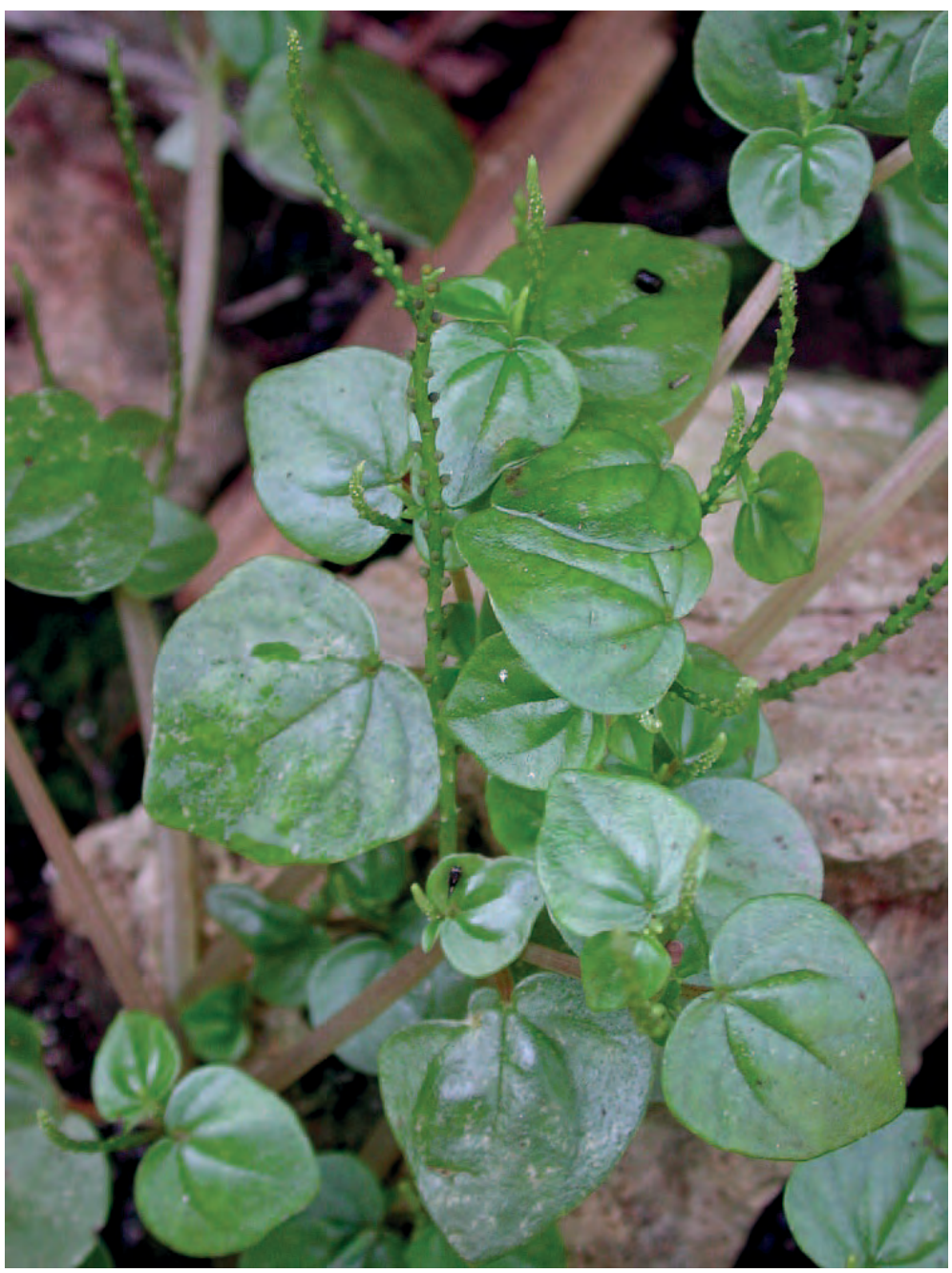

Description: Plante herbacée annuelle, charnue, avec parfois des trainées roses, formant des racines aux nœuds. Feuilles translucides de 1 à $3 \mathrm{~cm}$ de long. Inflorescences en épis souples, de 1 à $6 \mathrm{~cm}$ de long. Fleurs nombreuses, sans pétale, composées de deux étamines et un ovaire. Les fruits sont de minuscules baies à une graine.

Photo: John Hayden

Ecologie : Adventice des cultures, parfois cultivée comme légume. Elle pousse dans les lieux humides et ombragés, près des maisons, au bord des chemins et des routes, au bord des cours d'eau et sur les collines boisées jusqu'à $1100 \mathrm{~m}$ d'altitude. Particulièrement répandue sur les surfaces humides dures, telles que les murs, les toits et les caniveaux. Originaire d'Amérique tropicale, maintenant largement distribuée sous les Tropiques.

Reproduction: Surtout par graines, mais aussi par boutures des tiges ou des feuilles.

Usages: Dans beaucoup de régions tropicales, la plante sert de condiment ou se mange comme légume piquant. On la cultive occasionnellement à cet effet. Elle a beaucoup d'usages médicinaux dans de nombreux pays. Dans les Provinces de l'Equateur, elle traite les névralgies, l'épilepsie et la diarrhée. Ailleurs en R.D. Congo, elle est l'un des ingrédients d'une infusion contre les convulsions. On la cultive aussi parfois à titre ornemental.

Références : Balle 1948, Renier 1948, Raponda-Walker et Sillans 1961, Busson 1965, Akobundu et Agyakwa 1987, Burkill 1997, Neuwinger 2000, Mosango 2008, Termote 2012, Konda Ku Mbuta et al. 2015 
Noms courants : Groseiller des Barbades (Fr.), Barbados cherry (Angl.)

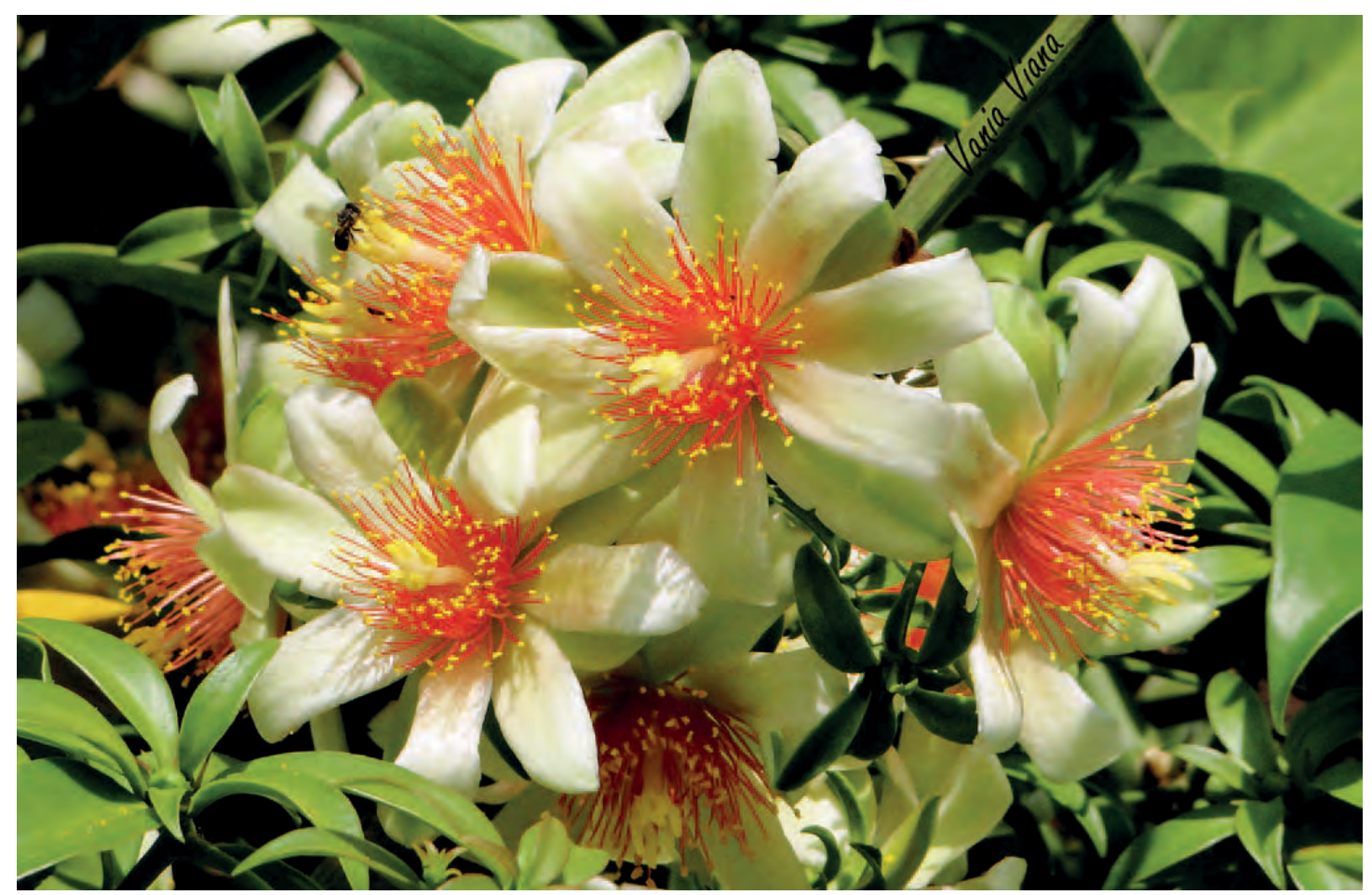

Photo : Vania Viana-Brazil

Description : Buisson grimpant épineux atteignant $10 \mathrm{~m}$ de haut. Feuilles alternes, jaunâtres, succulentes, de 8,5 à 10 sur 3,5 à $4,5 \mathrm{~cm}$. Les épines se forment d'abord à l'aisselle des feuilles, puis au centre d'aréoles quand les feuilles ont disparu. Les nombreuses fleurs, en panicules, sont blanches ou roses, cireuses, et parfumées. Les fruits ont environ $2 \mathrm{~cm}$ de diamètre, ils sont juteux, et portent à la surface des écailles comme des feuilles.

Ecologie: Plante introduite depuis l'Amérique Centrale et les Antilles. Déclarée mauvaise herbe en Afrique du Sud, où elle cause des dommages importants aux forêts en étouffant les arbres.

\section{Photo : Jim West}

Reproduction : Par graines ou boutures.

Gestion : Manipuler la plante avec des pinces ou avec du papier journal enroulé. Elle peut devenir invasive et difficile à éradiquer.

Usages: Les fruits sont comestibles, avec beaucoup de petites graines et un excellent goût de citron. On peut manger les feuilles comme légumes ou en salades. On peut cultiver la plante pour

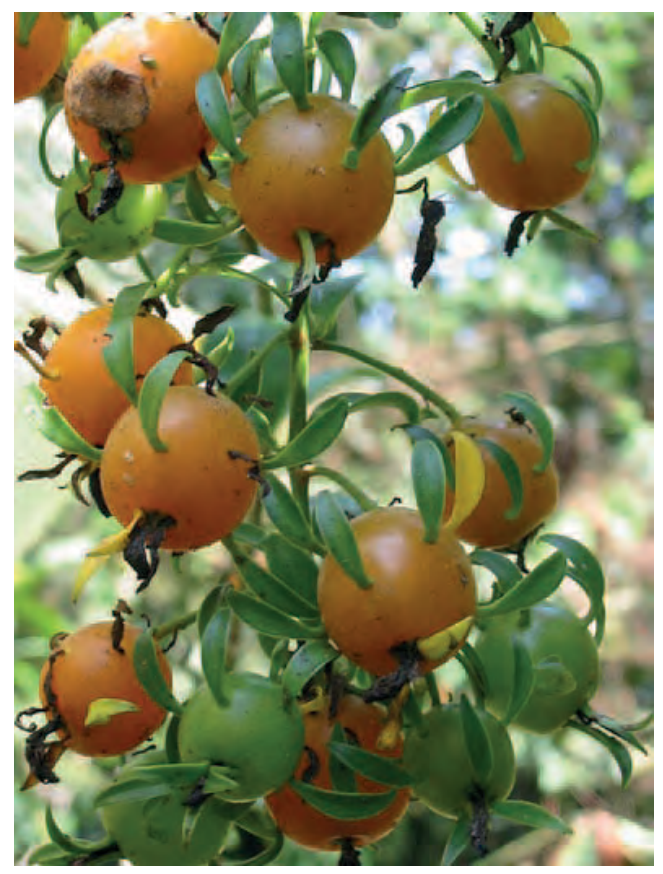
renforcer une haie.

Références : Gillet 1927, Renier 1948, Pauwels 1993, Llamas 2003, Fayaz 2011, Wikipedia (Consulté le 26.12.2012), Witt et Luke 2018 


\section{Pereskia grandifolia}

\section{Noms courants: Rose cactus (Angl.)}

Description : Arbuste de 2 à $10 \mathrm{~m}$. Porte parfois des épines de 1 à $2 \mathrm{~cm}$ au bas de la tige. Feuilles épaisses de 6 à 15 sur 3 à $9 \mathrm{~cm}$. Fleurs spectaculaires, de couleur rose, de 3 à $5 \mathrm{~cm}$ de diamètre, tout au long de l'année. Fruit en forme de poire, de 4 à $10 \mathrm{~cm}$ de long, jaune rouge ou vert, portant des feuilles longues de 4 à $10 \mathrm{~cm}$.

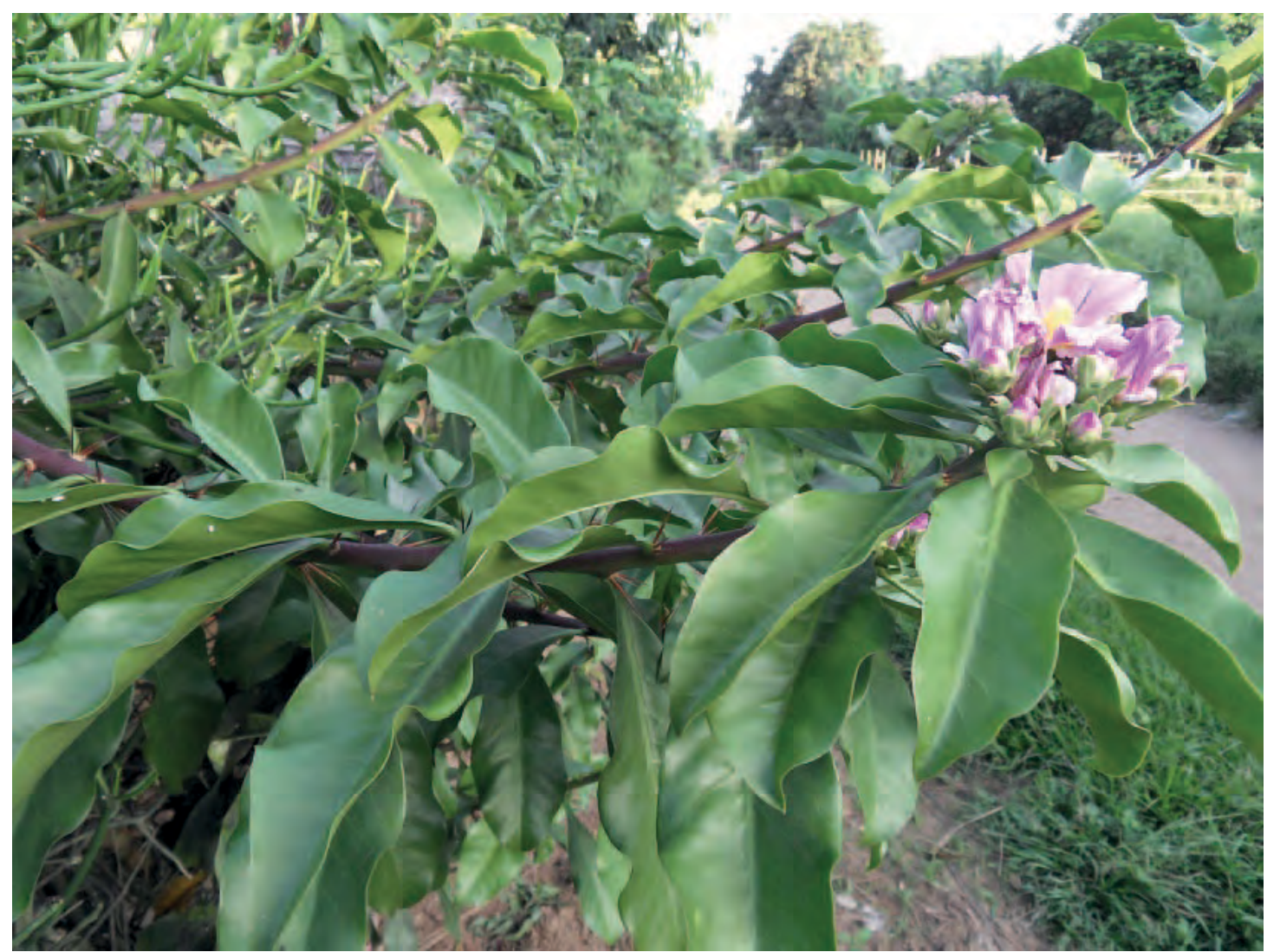

Pereskia grandifolia en fleurs en mars

Ecologie : Originaire du Brésil, maintenant largement cultivé sous les Tropiques.

Reproduction : Facile à cultiver par boutures ou par graines. Il faut planter les boutures avant que sèche la surface coupée.

Usages : Le fruit bien mûr est comestible. Les feuilles se mangent crues ou cuisinées ; elles sont aussi mangées par le bétail.

Références : Fayaz 2011, Llifle Encyclopedia of Living Forms (Consulté le 27.12.2018) 


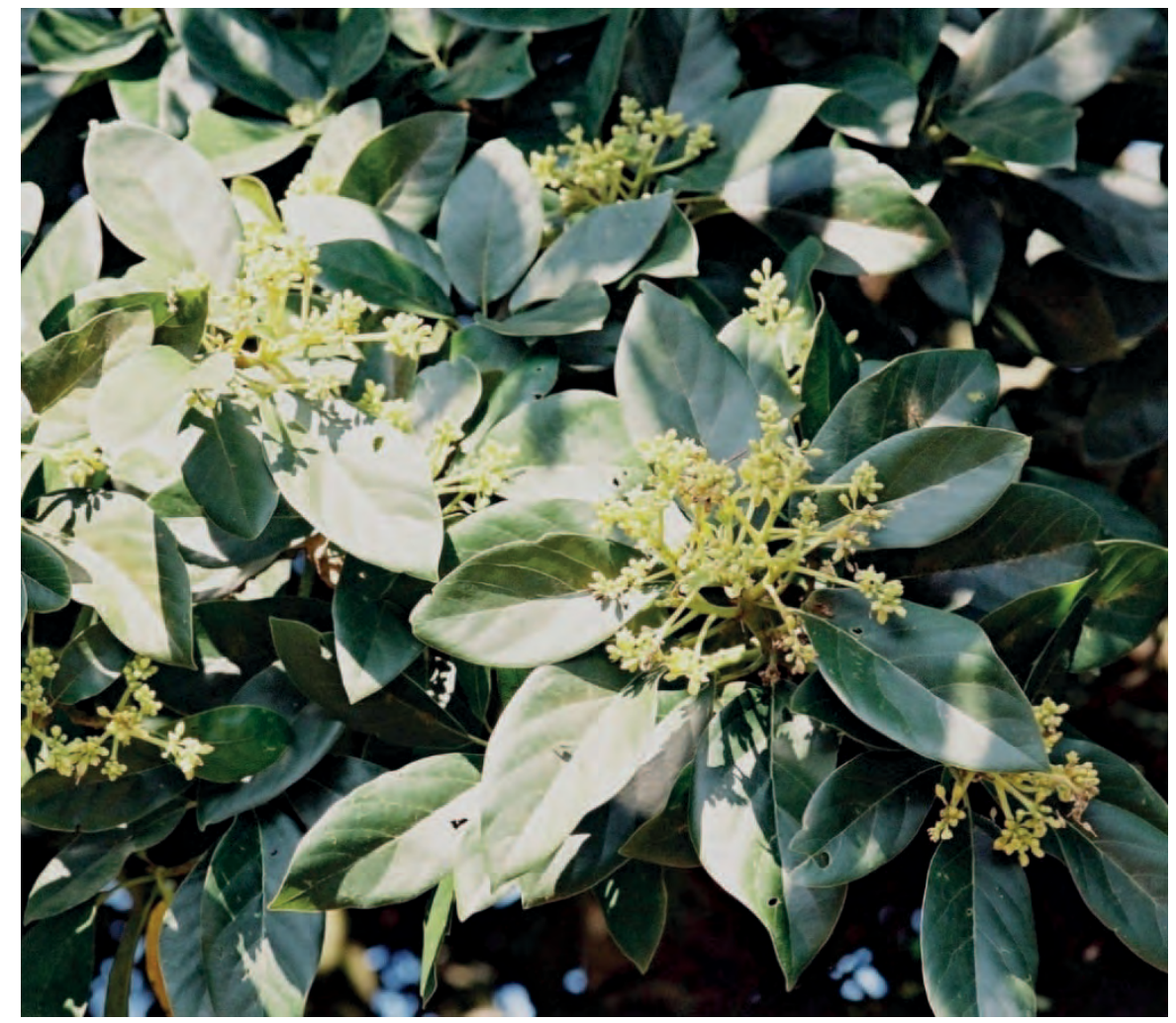

Noms courants : Divoka, savoka (Kikongo), avocatier (Fr.), avocado pear (Angl.)

Description : Arbre de 6 à $15 \mathrm{~m}$ de hauteur, à cime touffue et tronc couvert d'une écorce grisâtre et crevassée. Les feuilles sont alternes, elliptiques, et mesurent 20 à $30 \mathrm{~cm}$ sur 10 à $15 \mathrm{~cm}$ sur un pétiole de 3 à $5 \mathrm{~cm}$, de couleur vert brillant au-dessus et ternes en dessous. Les fleurs mesurent de 5 à $10 \mathrm{~mm}$. Le fruit, l'avocat, est en forme de poire, de 7 à $20 \mathrm{~cm}$ de longueur, pesant de 100 à $1000 \mathrm{~g}$. Il a une chair tendre et une grosse graine centrale ovale de 3 à $5 \mathrm{~cm}$ de long.

Ecologie: Originaire d'Amérique tropicale, et parfaitement naturalisé au Kongo Central. On le cultive sur les limons sablonneux. II demande un bon drainage et ne supporte pas les inondations. Les variétés mexicaines tolèrent mieux l'excès ou le manque d'eau, ainsi qu'un climat chaud ou humide.

Reproduction: L'arbre se reproduit par graine, mais il vaut mieux le greffer. Les graines restent viables 2 ou 3 semaines, ou davantage si on les conserve au sec. Enlever la peau de la graine pour une germination meilleure et plus rapide. Transplanter en gardant une motte de terre autour des racines. Planter les graines en pépinière à l'écartement de $35 \times 35 \mathrm{~cm}$, en les couvrant au maximum d'un $\mathrm{cm}$ de terre. Les porte-greffes peuvent être greffés avec des rameaux terminaux de $6 \mathrm{~cm}$. On peut transplanter les plants greffés après environ 18 mois.

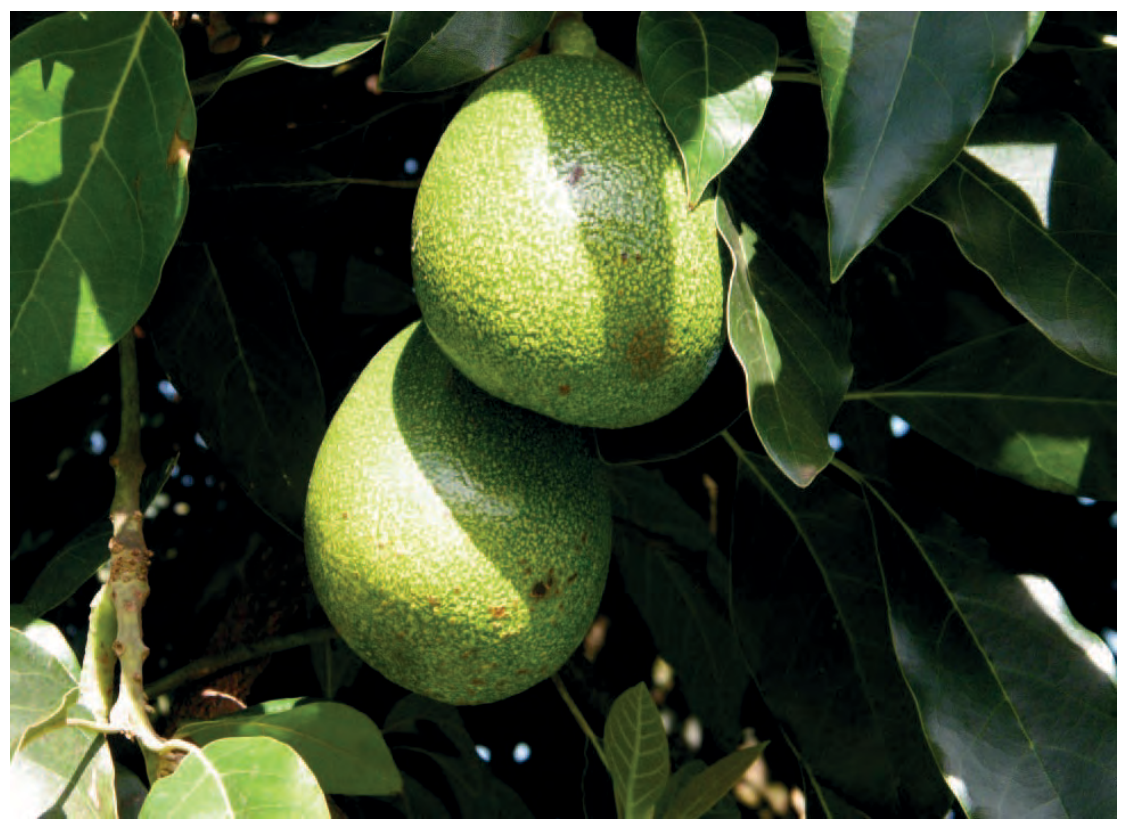

Usages: L'arbre est cultivé principalement pour ses fruits, délicieux, qui sont les plus nourrissants de tous les fruits. L'avocat donne une graisse très digeste, contenant des acides gras insaturés. Certaines variétés sont de bonne source de phosphore et de riboflavine, et d'excellentes sources de vitamine A. D'autres ont un contenu intéressant en protéines. La présence d'abeilles accroit le rendement en fruits. La sécrétion de nectar est abondante quand l'humidité est forte. Le miel d'avocatier est sombre, avec un goût prononcé. L'arbre donne un bel ombrage et son bois dur est utilisé en construction.

Références : Gillet 1927, Robyns et Wilczek 1951, Purseglove 1968, Crane et al. 1984, Martin et al. 1987, Pauwels 1993, Fichtl et Adi 1994, Nakasone et Paull 1998, Jones 1999 


\section{Persicaria decipiens}

Noms courants : Renouée à feuilles de saule (Fr), willow weed (Angl.)

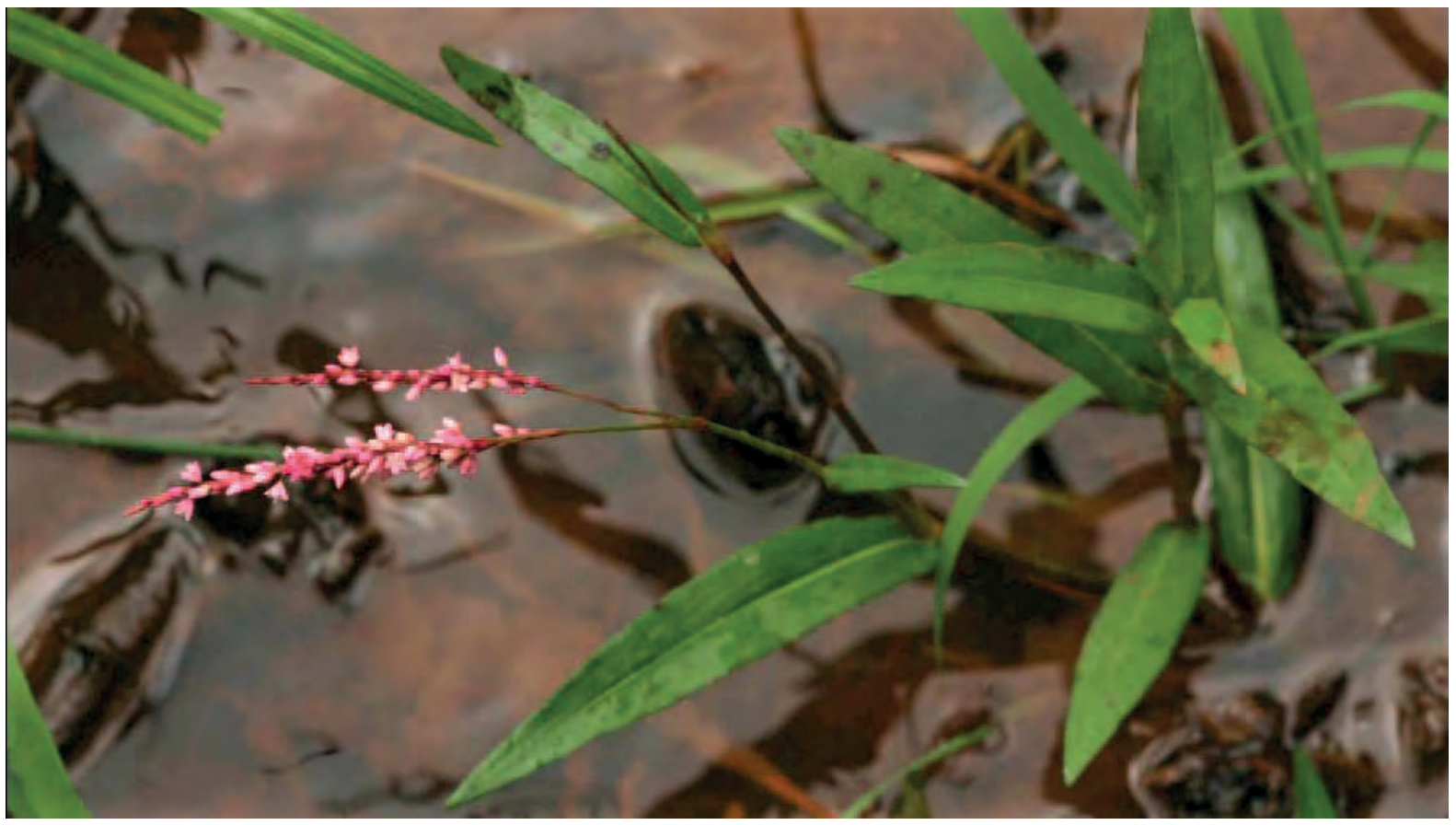

Photo : Bart Wursten

Description : Herbe annuelle légère atteignant $1 \mathrm{~m}$ de haut, habituellement ramifiée, formant des racines à partir des nœuds portant des poils raides. Feuilles étroites engainant la tige, atteignant $11 \mathrm{~cm}$ de long. Petites fleurs avec des sépales blancs, rose pâle ou rouges. Le fruit est une coque indéhiscente à trois faces atteignant $2,5 \mathrm{~mm}$ de long, lisse et brillante, enfermée dans les sépales.

Ecologie: Plante des marais et des argiles noires humides, poussant souvent dans l'eau en association avec Cyperus latifolius. Très répandue de la Méditerranée à l'Afrique du Sud, en Asie du Sud Est et en Australie, largement acclimatée ailleurs. Peut devenir gênante localement en raison de sa nature invasive.

Reproduction : Récoltée dans la nature, n'est pas cultivée.

Usages: Les jeunes feuilles de cette espèce et de $P$. Senegalensis se cuisent pour être mangées comme légumes. IL s'agit d'une nourriture de famine, car les feuilles sont grossières et gluantes. En R.D. Congo, on brûle la plante pour obtenir un sel végétal.

Références : Busson 1965, Katende et al. 1999, Jansen 2004 
Noms courants : Kivinsu (Kikongo), abalé, wulo (Fr.), stinkwood tree (Angl.)

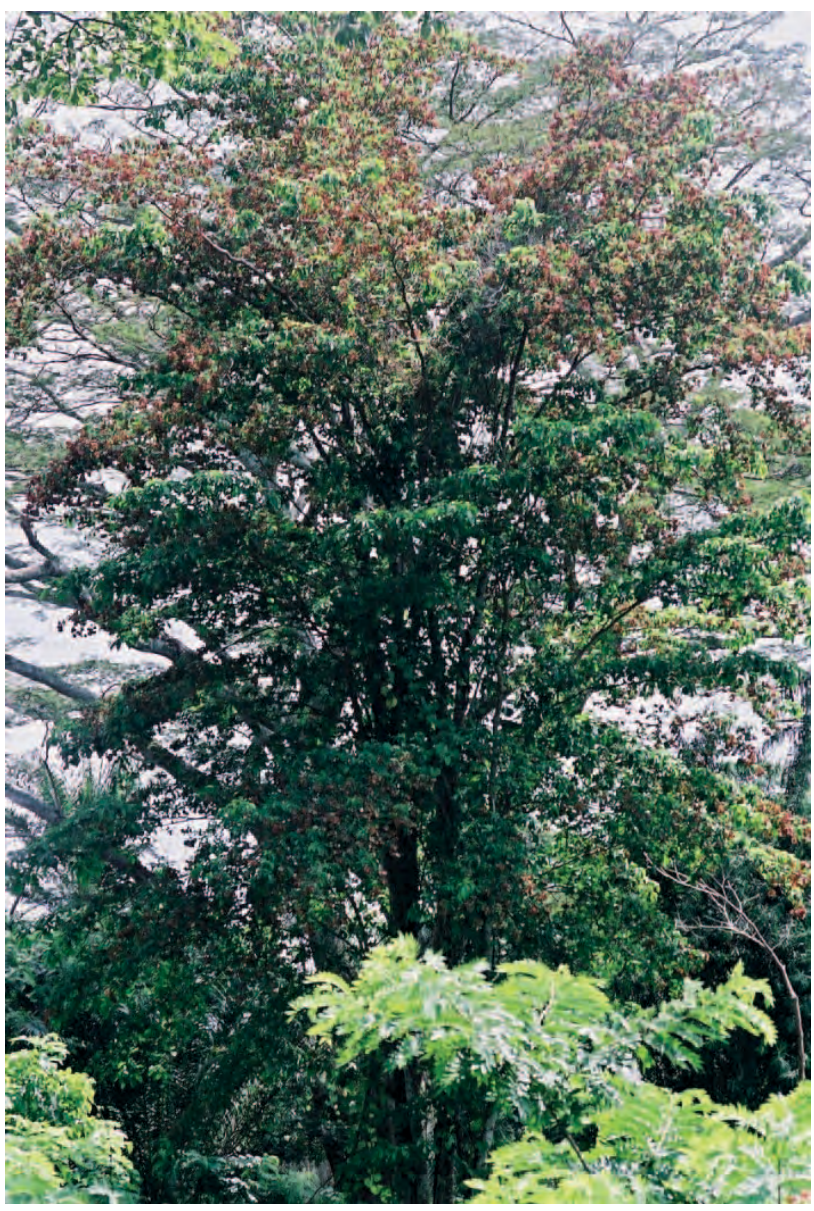

Description : Arbre de 20 à $30 \mathrm{~m}$ de haut, à l'écorce fissurée longitudinalement devenant écailleuse. Feuilles simples de 6 à $16 \mathrm{~cm}$ sur 4 à $7 \mathrm{~cm}$. Fruit en forme de fuseau de $7 \mathrm{~cm}$ de long, indéhiscent, pourvu de 4 ailes caractéristiques de couleur jaune orangé.

Ecologie: Arbre des forêts denses, habituellement forêts secondaires, de la Guinée à l'Angola.

Reproduction : Par graines, qui, selon les rapports, germeraient en environ un mois.

Gestion : L'arbre recèpe bien.

Usages: Le bois de cœur, de couleur rouge brun, résiste aux termites. II est utilisé pour les charpentes lourdes, les mortiers, la construction, la construction navale, les pagaies. Le bois vert a une mauvaise odeur quand on vient de le couper. II constitue un bon bois de feu. Les chenilles comestibles Mvinsu (/mbrasia epimethea), Minsongo, Nsila et Mbambi (/mbrasia truncata) se nourrissent des feuilles. Les Mvinsu sont très recherchées : celui qui trouve une jeune colonie installée sur un arbre marque celui-ci pour se l'approprier et signifier que nul autre ne peut récolter les chenilles. Les racines, le bois, et particulièrement l'écorce, ont des usages médicinaux, comme laxatifs, purgatifs et abortifs. Ailleurs en R.D. Congo, la plante est utilisée comme anti inflammatoire. Les abeilles établissent souvent des colonies sauvages sur cet arbre; la documentation indique qu'au Gabon il constitue un fourrage pour les abeilles.

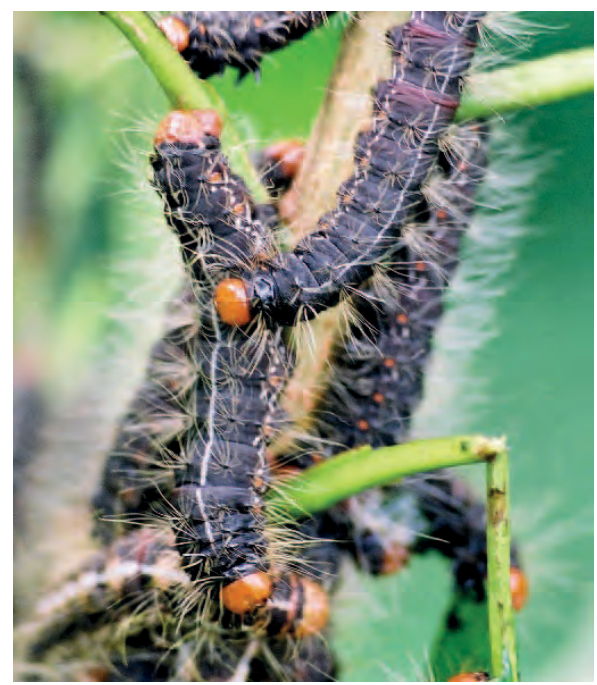

A gauche: Chenilles comestibles Mvinsu

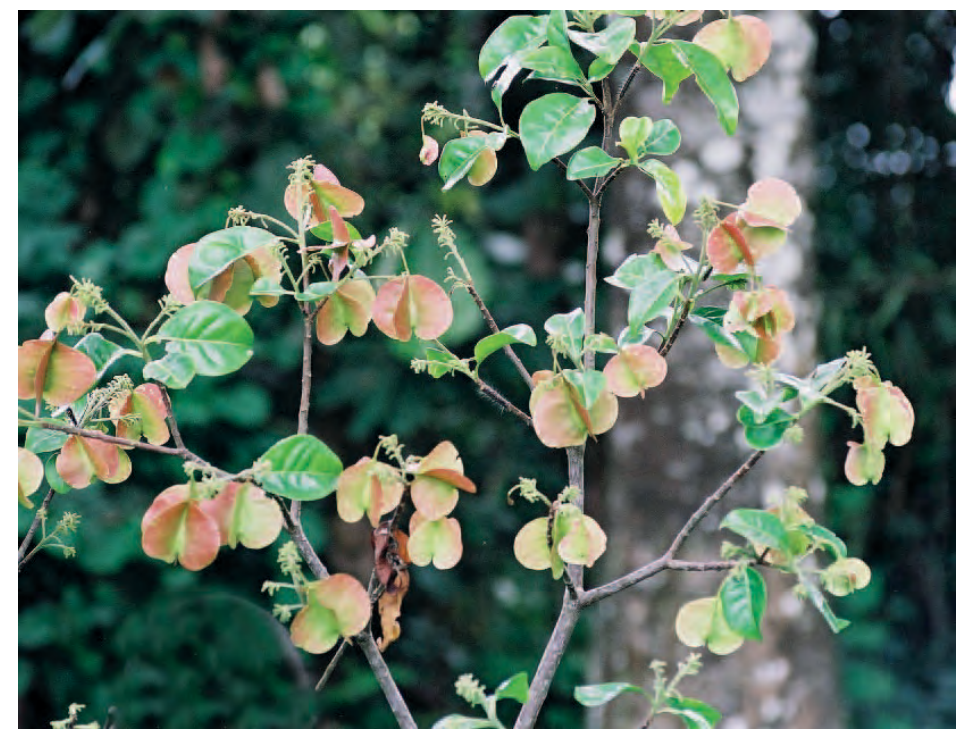
sur une branche à la mission de Ndembo.

Références : Gillet et Pâque 1910, Staner et Boutique 1937, Renier 1948, Irvine 1961, Nsimundele 1966 - 68 , Liben 1971, Ambougou 1991, I wu 1993, Pauwels 1993, Burkill 1995, Kibungu Kembelo 1995, Latham 2008 


\section{Phaseolus lunatus}

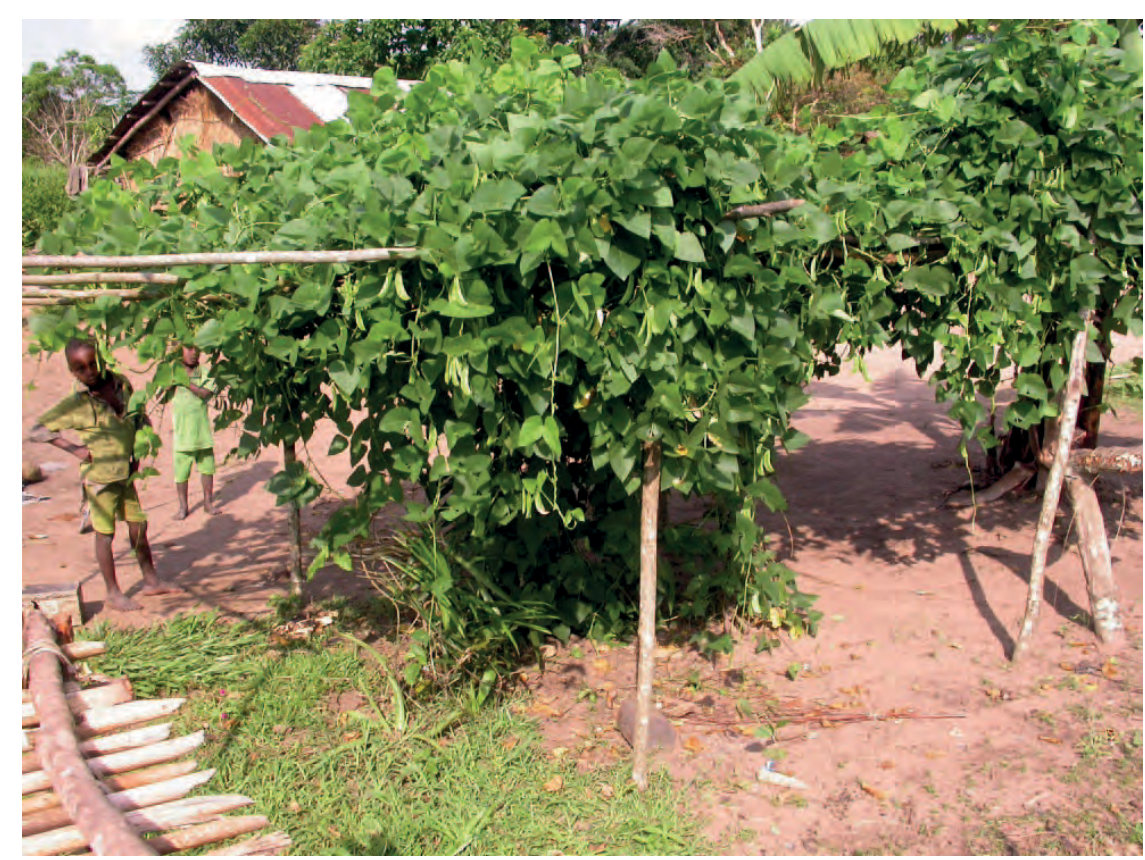

(Fabaceae)

Noms courants : Deso mangongo, mambambi (Kikongo), haricot de Lima (Fr.), lima bean (Angl.)

Description : Plante herbacée annuelle ou pérenne. Les tiges, les gousses et les graines ont des formes très variables. Les variétés grimpantes s'enroulent sur leur support, elles atteignent 1,8 à $4 \mathrm{~m}$ et ont une grosse racine pivotante. Les variétés basses sont généralement annuelles et ont seulement 30 à $90 \mathrm{~cm}$ de haut. Les feuilles sont composées trifoliées, souvent poilues en-dessous. Les fleurs sont blanches, roses ou mauves. La gousse contient 3 ou 4 graines.

Plantes sur une treille à Kimbambu

Ecologie: Plante originaire du Pérou, largement répandue sous les tropiques, cultivée occasionnellement au Kongo Central. Elle prospère aussi bien dans les zones humides ou sèches, mais exige des sols bien drainés. Si les températures sont trop fortes, il peut y avoir de sérieuses pertes de fleurs ou de fruits. Les variétés grimpantes demandent des tuteurs ou des treilles.

Reproduction : Les graines germent dans les 5 ou 6 jours.

Gestion: Cultiver avec tuteurs ou sur treille, et replanter tous les trois ans. Cultiver en rotation avec des céréales pour éviter l'infection par le nématode doré, qui peut affecter très sévèrement les récoltes. La

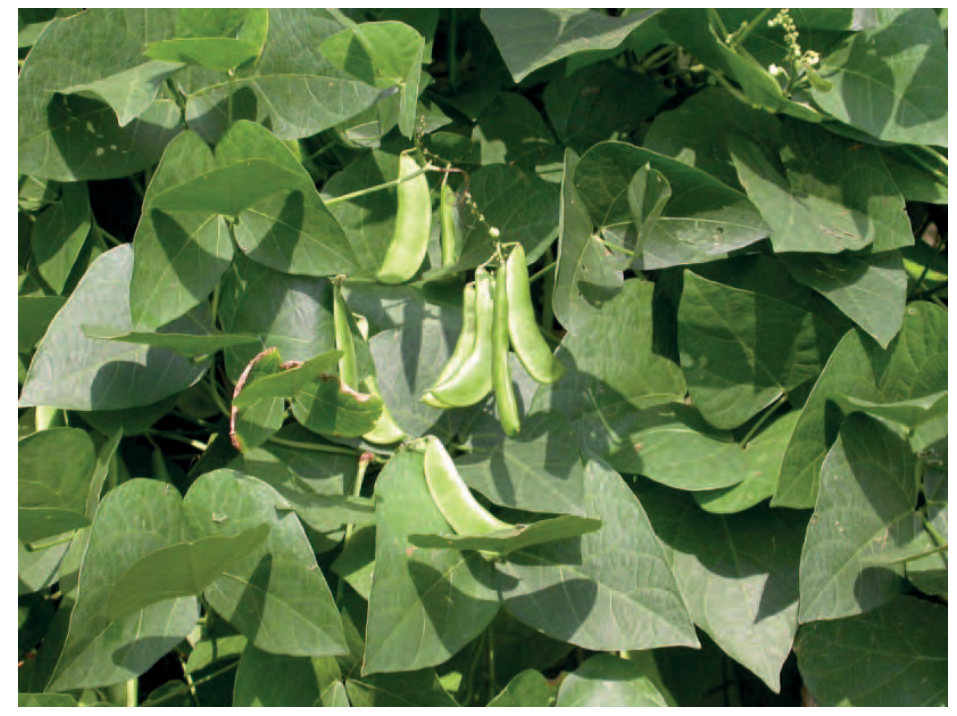
plante donne des graines mûres 90 à 110 jours après le semis.

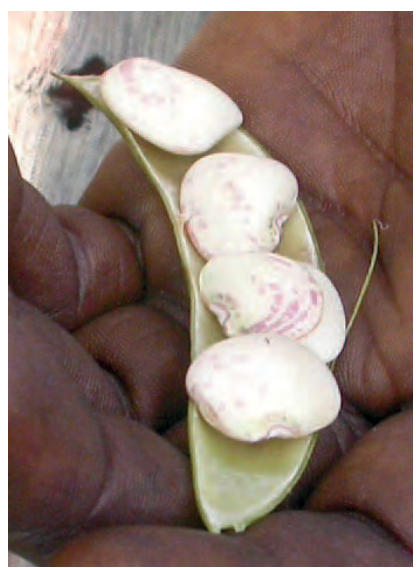

Usages : Les graines se mangent avant maturité : on les prend dans les gousses quand celles-ci commencent à jaunir. Les graines mûres se mangent habituellement bouillies, rôties, ou frites à l'huile. On mange aussi les gousses et les feuilles jeunes et tendres. Quelques variétés (souvent à graines foncées; les variétés à graines blanches sont plus sûres) contiennent des glycosides cyanogénétiques toxiques, ce qui demande une préparation soignée : tremper les graines dans plusieurs eaux, puis les faire bouillir 10 à 15 minutes. Les feuilles tombées contribuent à restaurer la fertilité. La plante peut servir d'aliment du bétail. Au Kongo Central, les femmes boivent une infusion des graines contre les règles douloureuses. Dans les hauts plateaux de l'Angola, les fleurs sont un fourrage important pour les abeilles.

Références : Gillet et Pâque 1910, Staner et Boutique 1937, Renier 1948, Hauman et al. 1954, Portugal-Araújo 1974, Kay 1979, NAS 1979, Smartt 1976, Burkill 1995, Raemaekers 2001 


\section{Phaseolus vulgaris}

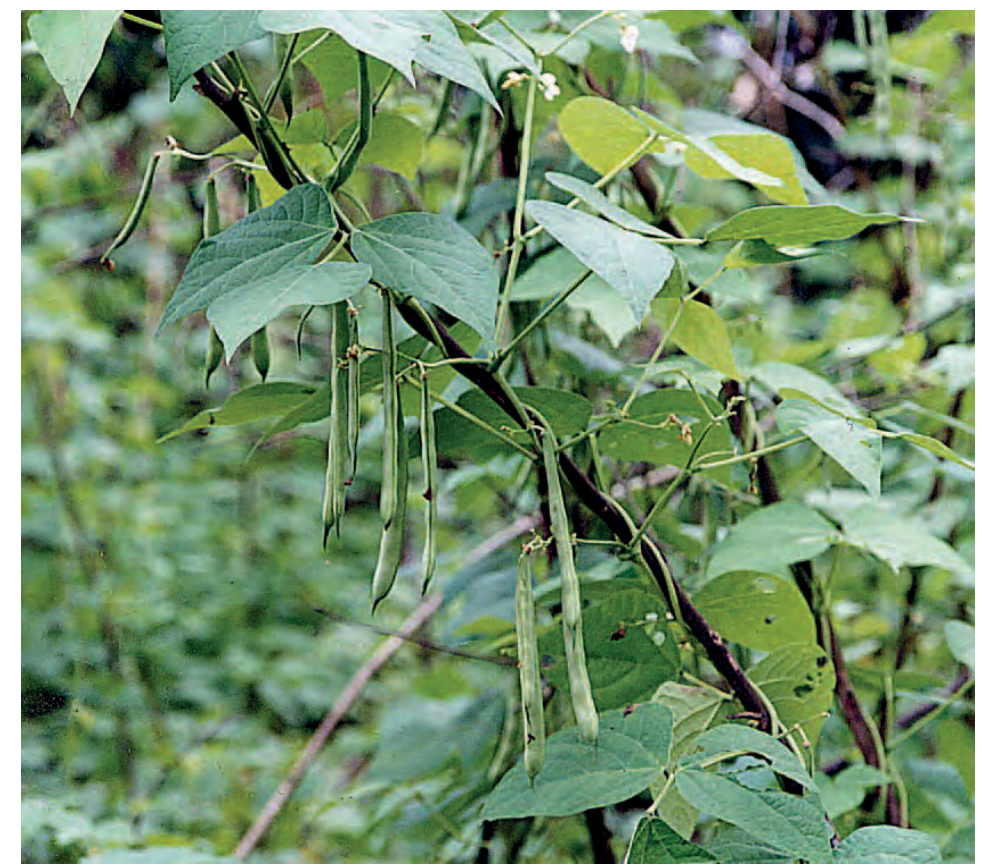

Ecologie: Plante originaire d'Amérique Centrale, maintenant très répandue dans les zones tempérées et chaudes. Les haricots grimpants sont souvent cultivés en saison sèche dans les jardins maraichers en vallées. La plante a une large gamme de tolérance. La plupart des variétés sont adaptées pour des cultures jusqu'à $1.000 \mathrm{~m}$ d'altitude, sur des sols avec des pH de 5,5 à 6,5. On doit éviter les sols acides qui limitent l'activité bactérienne des Rhizobium fixateurs d'azote. Des sols limoneux plutôt lourds conviennent bien. En saison des pluies, les variétés grimpantes donnent de meilleurs résultats que les variétés naines.

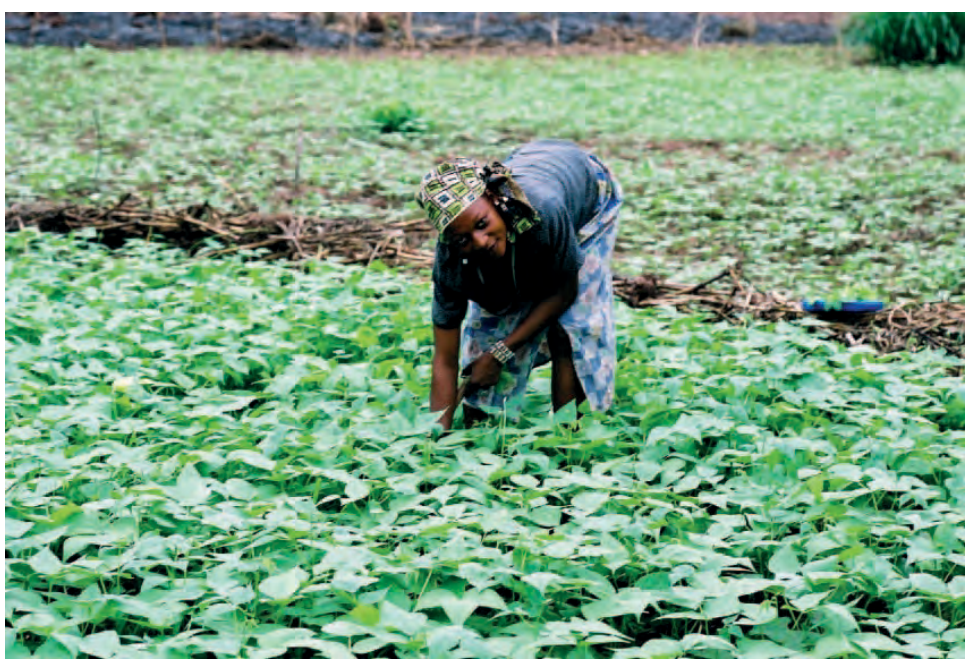

Reproduction : Les haricots grimpants se sèment directement, à 1 à $3 \mathrm{~cm}$ de profondeur. On recommande 4 à 6 graines par trou, espacés de 40 à $50 \mathrm{~cm}$ sur des lignes espacées de 100 à $120 \mathrm{~cm}$. Les haricots nains se sèment habituellement avec des espacements de 15 à $25 \mathrm{~cm}$.

Gestion : II est important de désherber jusqu'à la floraison. Les haricots grimpants se cultivent sur des treilles de $2,5 \mathrm{~m}$ de haut. On doit mettre en place des tuteurs avant la germination des graines. Les haricots se récoltent 70 à 90 jours après le semis. On doit les récolter avant que les gousses s'ouvrent.

Culture de haricots nains dans le district de Manianga

Usages : On consomme soit les gousses entières avant maturité (haricots verts) soit les graines mûres séchées ( haricots secs). Les haricots verts sont principalement cultivés en Europe, et également dans certains pays d'Afrique pour l'exportation, notamment au Sénégal et au Kenya. Les haricots secs constituent une culture importante et une base de l'alimentation dans plusieurs pays d'Afrique, et notamment dans l'Est de la R.D. Congo. Ils sont riches en amidon, et également en protéines. Ils constituent une source importante de protéines pour les populations qui en consomment régulièrement. On peut également manger les jeunes feuilles comme légumes, et les sécher pour conservation.

Références : Purseglove 1968, Daeleman et Pauwels 1983, Tindall 1983, Raemaekers 2001 


\section{Synonyme : Phaulopsis poggei}

Noms courants : Papleaf (Angl., Gambie).

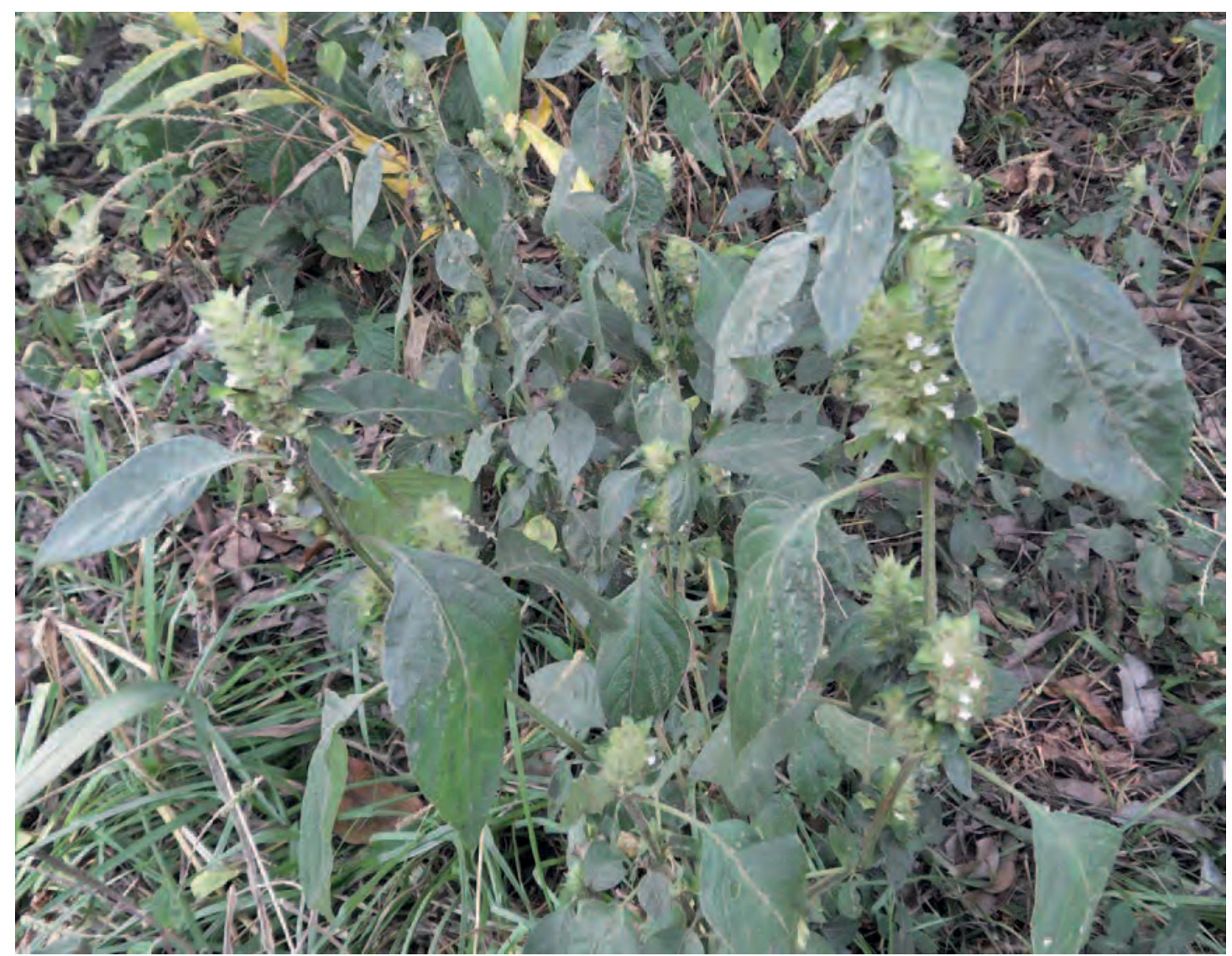

Plante en fleurs en juin

Description : Plante herbacée rampante, annuelle ou pérenne pour quelques années, pubescente, atteignant 60 $\mathrm{cm}$ de haut. Feuilles elliptiques se rétrécissant aux deux extrémités. Petites fleurs toute l'année, formant des épis denses, latéraux ou terminaux, avec des corolles blanches dépassant $8 \mathrm{~mm}$ de long.

Ecologie: L'une des trois espèces présentes au Kongo Central, très commune autour de Kisantu. Présente dans toute l'Afrique tropicale, excepté les zones les plus sèches.

Usages: On sait que les abeilles butinent le pollen et le nectar. On a observé la récolte du nectar en juin. Au Kenya, le bétail broute cette plante. En Tanzanie, on mange les feuilles comme légumes. La plante a aussi des usages médicinaux.

Photo : Bart Wursten www.zimbabweflora.co.zw

Références : Renier 1948, Fichtl et Adi 1984, Burkill 1985, Blundell 1987, Neuwinger 2000

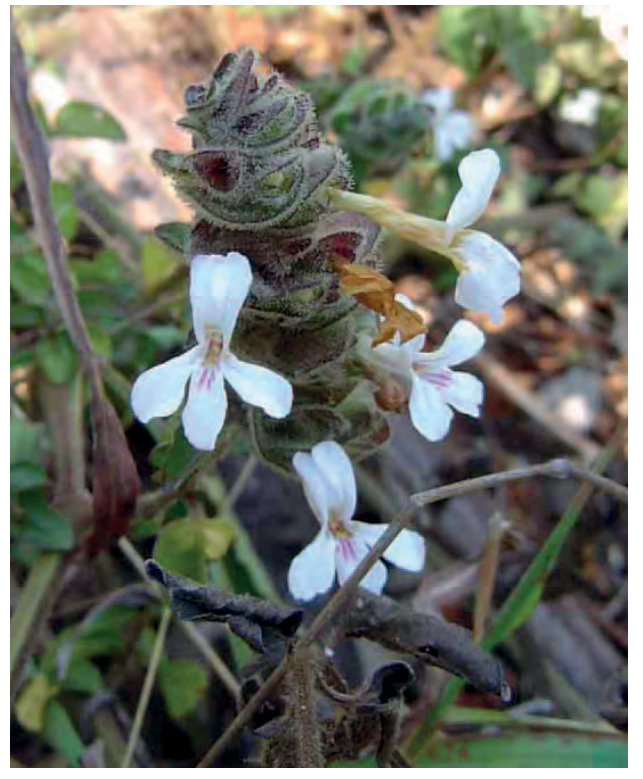




\section{Phoenix reclinata}

Noms courants : Dinsongo, dinsongwa, mpuvu (Kikongo), dattier sauvage (Fr.), wild date palm (Angl.)

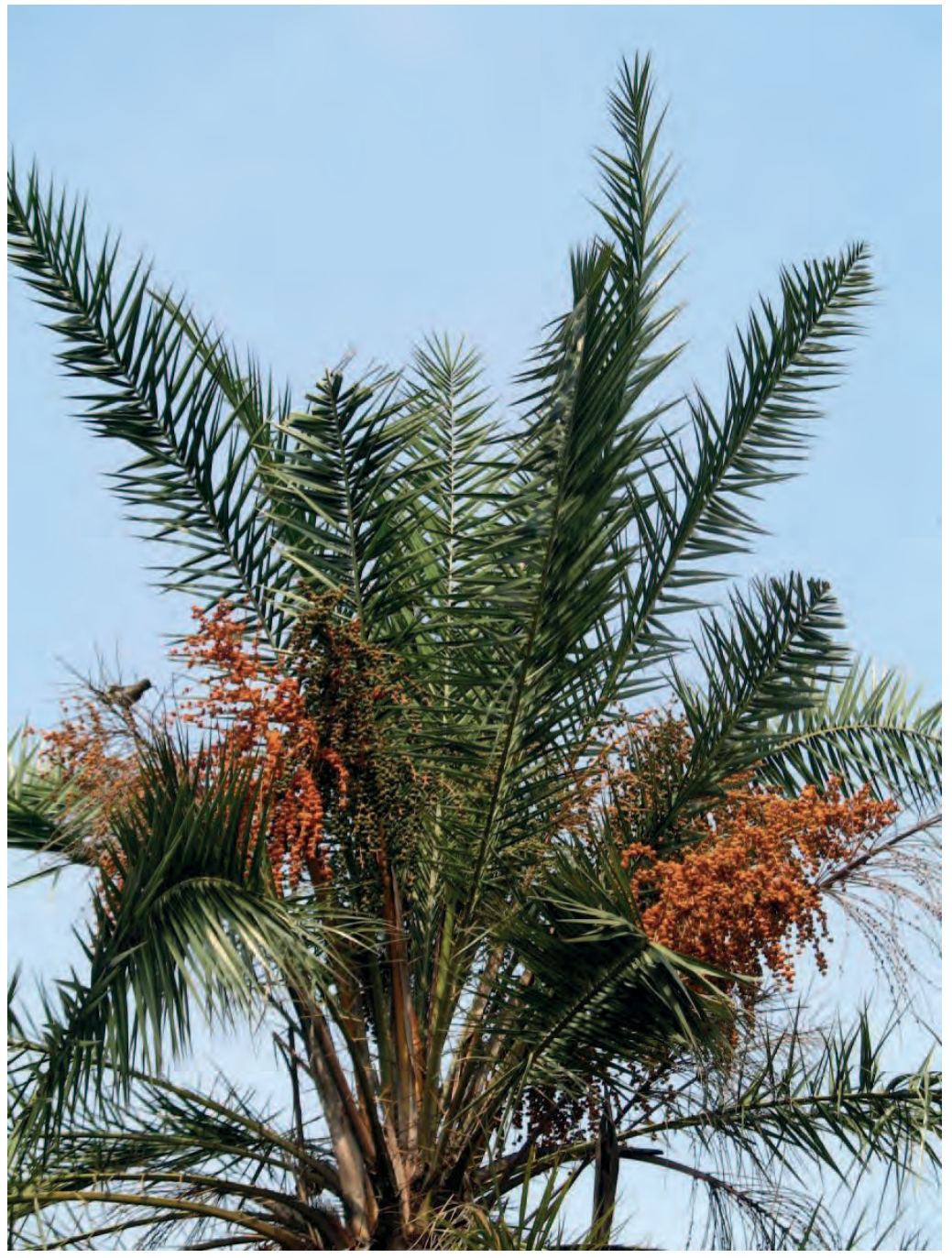

Description : Palmier pouvant atteindre $10 \mathrm{~m}$ de haut. Les vieux troncs se penchent souvent. Les feuilles jusqu'à $3 \mathrm{~m}$ de long sortent d'une gaine fibreuse, elles se disposent en couronne d'environ 25 feuilles formant une voute. Les folioles atteignant $60 \mathrm{~cm}$ de long, sont étroites, brillantes, pliées en deux, rigides et pointues. Les fleurs mâles et femelles sont sur des arbres différents. Le fruit est brun jaunâtre, de 1,3 à $2 \mathrm{~cm}$ de long.

Ecologie: Arbre de l'Afrique tropicale. Au Kongo Central, il est commun dans certains marécages. On le cultive parfois pour des raisons ornementales.

Reproduction: Par graines ou rejets. Enlever la pulpe du fruit et sécher la graine pour la conserver. La germination est bonne avec des graines fraichement récoltées.

Photo: Anny Mandungu

Usages : Les fruits sont comestibles, et très nourrissants bien que la couche de chair soit mince. Avant de les manger, on les trempe quelques instants dans l'eau bouillante. Le bois s'emploie pour confectionner des portes, des lits, des toitures et des fenêtres. II est dur et résistant aux termites. On l'emploie aussi comme bois de feu. On le plante parfois pour protéger les rives des cours d'eau. Les feuilles s'emploient pour couvrir les toits, et pour confectionner des nattes et des paniers. On obtient une teinture à partir des racines. On cuit le « chou » terminal pour le manger, bien que certains le trouvent amer. La sève est très sucrée, on en fait du vin de palme. On peut l'extraire à la base de la tige. On emploie les fruits et les racines pour traiter les hémorroïdes. Autrefois, on disposait les bases épineuses des palmes autour des jardins pour éloigner les voleurs. Les fleurs donnent de grandes quantités de nectar et pollen pour les abeilles.

Références: Gillet et Pâque 1910, Gillet 1927, Renier 1948, Daeleman et Pauwels 1983, Pauwels 1993, Fichtl et Adi 1994, Burkill 1997, Mbandu Luzolawo et al. 2020

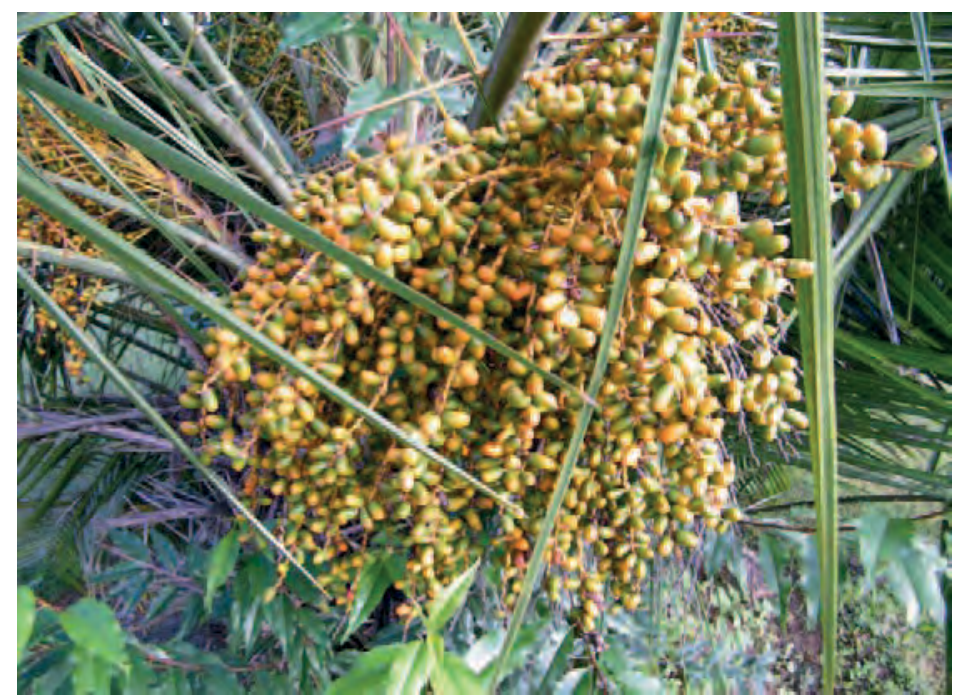

Photo : Karl Gercens 


\section{Phyllanthus amarus}

Noms courants : Ntetanteta (Kikongo), herbe au chagrin (Fr.), black catnip (Angl).

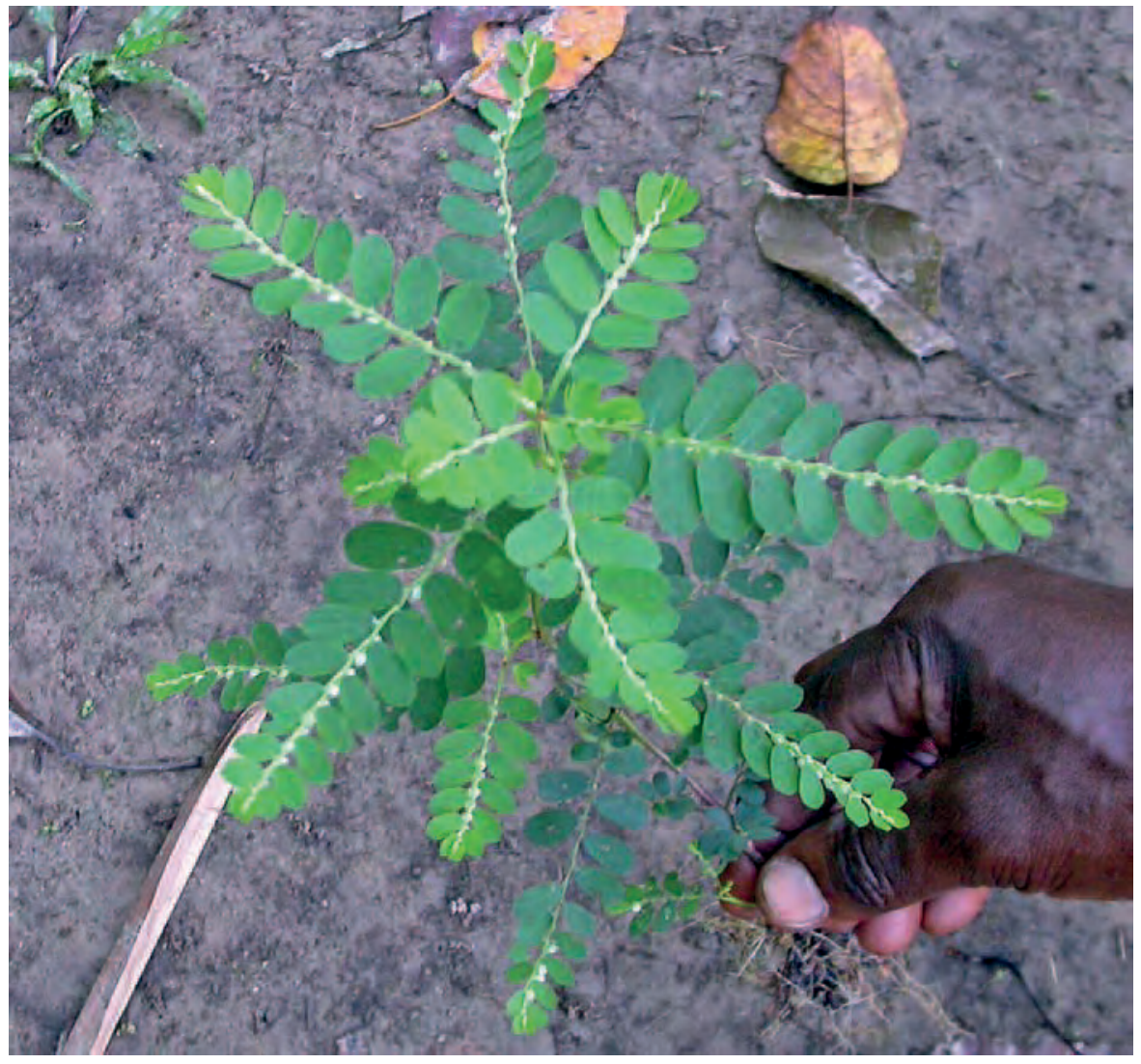

(Phyllanthaceae)

Description : Plante herbacée annuelle dressée atteignant $80 \mathrm{~cm}$ de haut. Les rameaux sont aplatis et souvent légèrement ailés. Feuilles alternes serrées le long des rameaux latéraux. Les fleurs vert pâle, souvent rougeâtres, apparaissent à l'aisselle des feuilles, isolées ou par paire. Le fruit pendant est une capsule à trois lobes, de 1,7 à $2,2 \mathrm{~mm}$ de diamètre.

Ecologie : Plante commune au bord de routes, dans les cultures, dans les friches en forêt ou en savane. Probablement originaire de l'Ouest de I'Inde et du Pakistan, très répandue en Asie et dans les Caraïbes.

Usages: $\mathrm{Au}$ Kongo Central, la plante sert à traiter la dysenterie amibienne. On a montré que les racines étaient très efficaces contre les escargots. Les extraits de la plante sont toxiques pour le poisson et les grenouilles ; cependant, le bétail broute la plante. On extrait de la tige et des feuilles une substance noire, utilisée pour la teinture du coton, et comme encre. La plante sert à calmer les fortes douleurs intestinales. Les feuilles sont riches en potassium, et s'emploie pour faciliter l'urination.

Remarque : On utilise largement les espèces de Phyllanthus pour traiter la jaunisse et comme purgatifs.

Références : Gillet et Pâque 1910, Daeleman et Pauwels 1983, Burkill 1994, van Holthoon 1999, Nsimundele 2004, Oudhia 2008

Photo : Phuong Tran 


\section{Phyllanthus muellerianus}

Nom courant : Nsende (Kikongo)

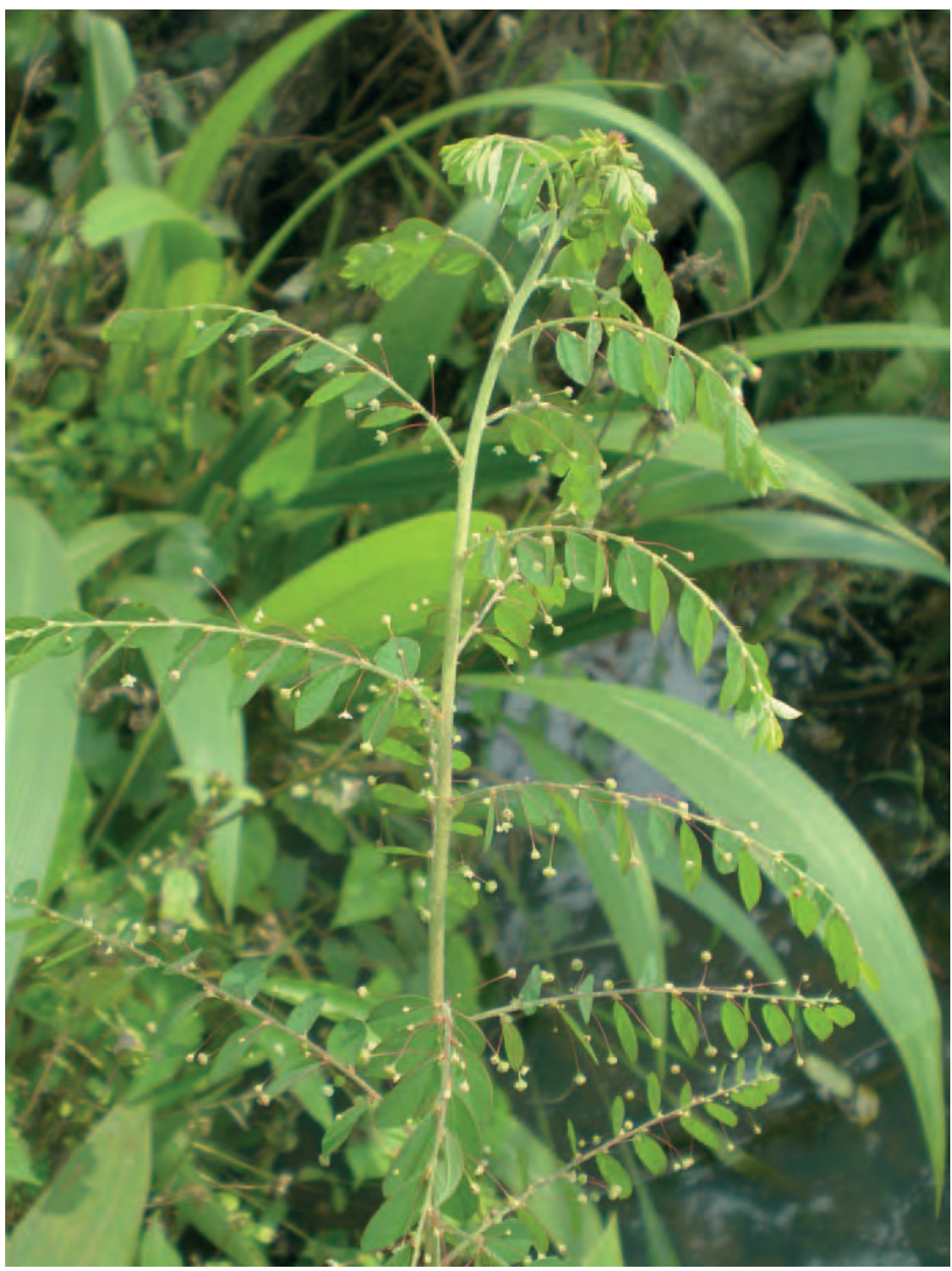

(Phyllanthaceae)

Description : Arbuste, buisson grimpant, occasionnellement arbre atteignant $12 \mathrm{~m}$ de haut. Branches fortes avec 3 épines à la base des jeunes tiges. Feuilles de 3.5 à 6.5 sur 1.8 à $3,5 \mathrm{~cm}$. II peut y avoir une seule ou plusieurs inflorescences longues de 2 à $9 \mathrm{~cm}$, avec des fleurs en bouquets de 2 à 3 fleurs mâles pour 1 fleur femelle. La floraison intervient à la fin de la saison sèche, peu après la formation des jeunes feuilles. Le fruit est une capsule charnue de 3 à 5 $\mathrm{mm}$ de diamètre, habituellement lisse, passant du vert au rouge puis au noir, et contenant 6 graines.

Ecologie: Se trouve de la Guinées Bissau au Soudan, à l'Angola et au Mozambique, dans les forêts riveraines et les savanes boisées, sur des sols profonds et bien drainés.

Reproduction : Par graines ou boutures.

Gestion : Peut se recéper.

Usages: Au Kongo Central, la plante est cultivée pour renforcer les clôtures. Les feuilles servent à assaisonner les soupes. On les emploie aussi comme fourrage pour le bétail.

On fait avec les fleurs une boisson rafraichissante. Les fruits, légèrement acides, sont comestibles. La plante donne une teinture noire utilisée pour colorer les fibres. En Zambie, on utilise le bois en construction. Les tiges sont employées en vannerie et pour les pièges à poisson. En R.D. Congo, on emploie l'écorce finement râpée pour soigner les plaies. La plante sert d'antidote contre les poisons. Elle traite la dysenterie, les rhumatismes et la pneumonie. Selon la documentation, les abeilles visiteraient les fleurs.

Références : Renier 1948, Staner et Boutique 1937, Martin et al. 1987, Burkill 1994, Malaisse 1997, Neuwinger 2000, Arbonnier 2004, Ben-Bala 2008, Abdullahi et al. 2011, Ilunga Wa Ilunga et Meerts 2020 


\section{Phyllanthus niruroides}

(Phyllanthaceae)

Noms courants : Munengena (Kikongo ?), kapunga punga (Tshiluba)

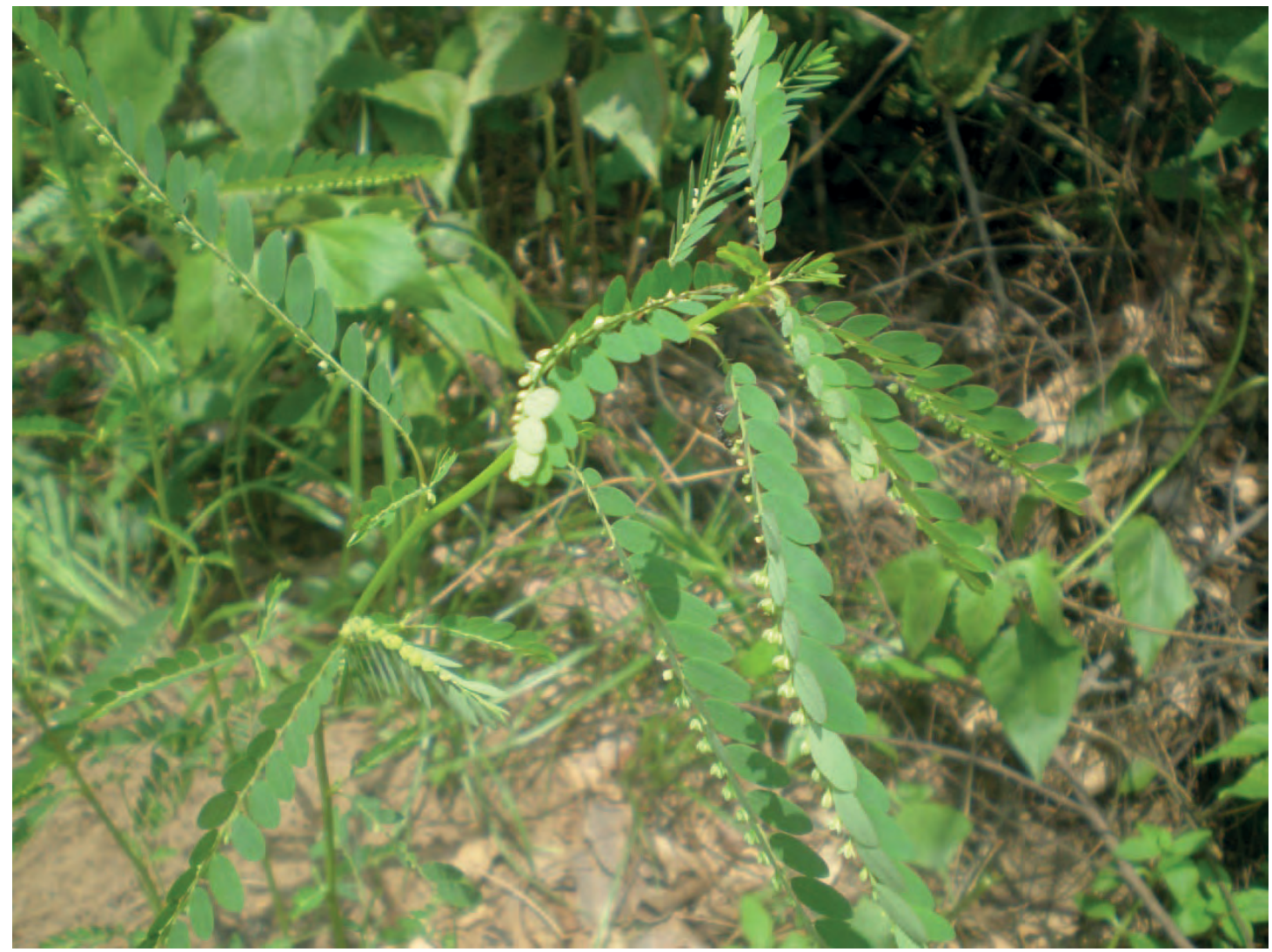

Description : Plante herbacée annuelle de $1 \mathrm{~m}$ de haut. Feuilles alternes, serrées le long des rameaux latéraux, avec des stipules lancéolées rougeâtres. Feuilles oblongues de 2,5 à 12,5 sur 1,5 à 4,5 mm, arrondies à la base et obtuses au sommet. Fleurs axillaires. Fleurs mâles par 2 ou 3 à l'aisselle des branches. Fleurs femelles solitaires vers l'extrémité des branches. Le fruit est une capsule trilobée de 2,2 à 2,8 mm de diamètre contenant jusqu'à 6 graines.

Ecologie: Présente de la Guinée Bissau et à la R.D. Congo, sur les sites perturbés, les prairies et les savanes boisées.

Usages : Les espèces de Phyllanthus sont largement employées à des fins médicinales. A Mbuji-Mayi, on emploie la plante pour traiter la diarrhée et l'épilepsie.

Références : Renier 1948, Burkill 1994, Alvarez Cruz 2008, Konda Ku Mbuta et al. 2015b, Ilunga Wa Ilunga et Meerts 2020 


\section{Phyllocosmus africanus}

Synonyme : Ochthococosmus africanus var puberula

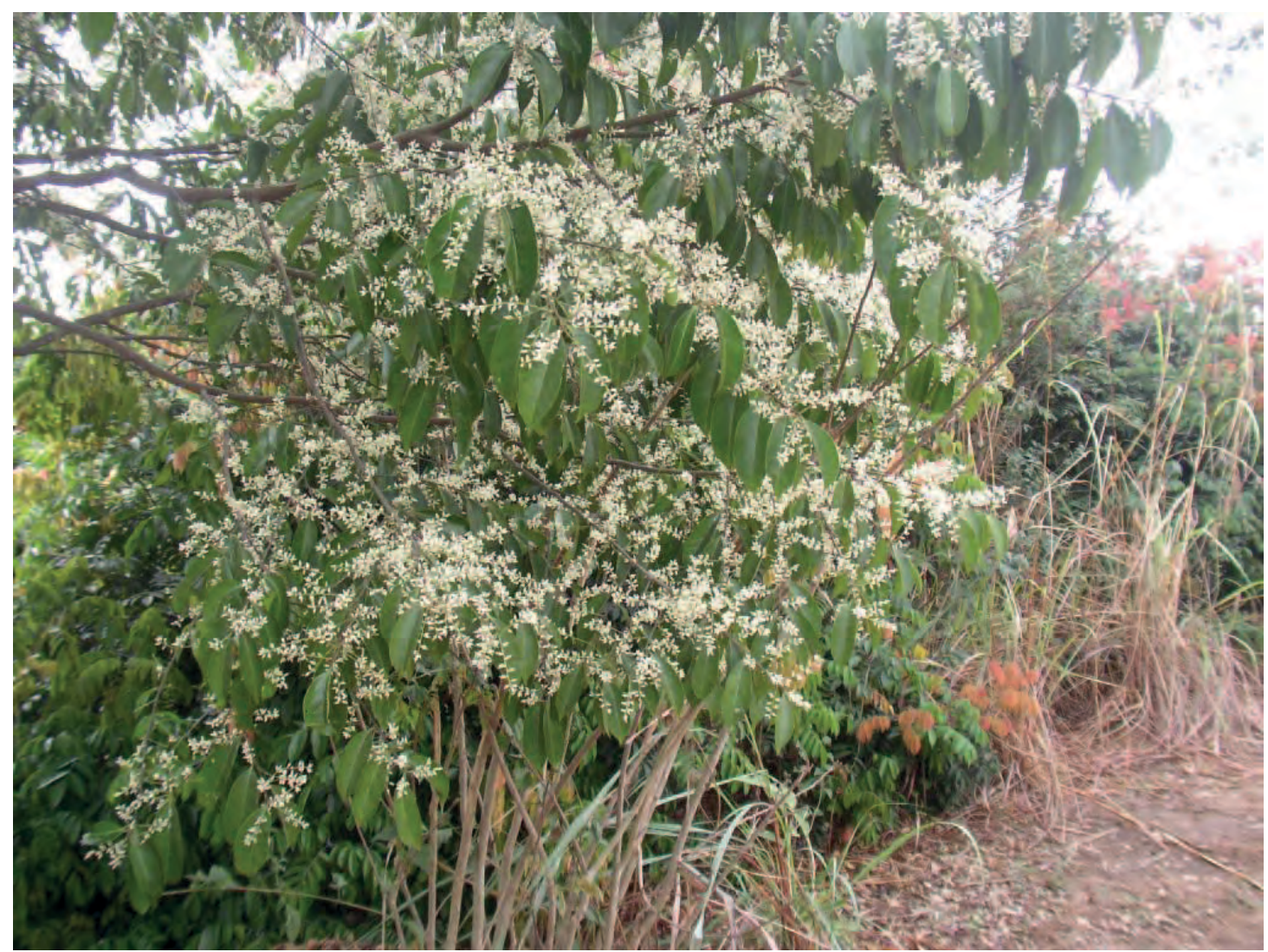

Photos prises en janvier

Description : Arbre atteignant $20 \mathrm{~m}$ de haut. La base de l'arbre est souvent entourée par une masse de tiges adventices. Les feuilles ont 5 à 18 sur 2 à $6,5 \mathrm{~cm}$. Les inflorescences sont des racèmes axillaires. Fleurs blanches et parfumées dont la corolle tubulaire a environ $2 \mathrm{~mm}$ de diamètre et $5 \mathrm{~mm}$ de long. Les nombreuses fleurs d'un même arbre fleurissent toutes en même temps: pendant quelques jours, en octobre ou novembre, l'arbre attire beaucoup d'insectes et apparait vu de loin comme une boule blanche. Ce sont probablement des mouches qui pollinisent les fleurs. Le fruit est une capsule ronde de 4 à 6 $\mathrm{mm}$ de diamètre.

Ecologie : Arbre présent dans des forêts inondables et sur des termitières, de la Guinée Bissau à la Centrafrique et à la R.D. Congo.

Usages: Le bois sert pour des poteaux et des poutres en construction. Les menues branches servent à faire des pièges. Le bois

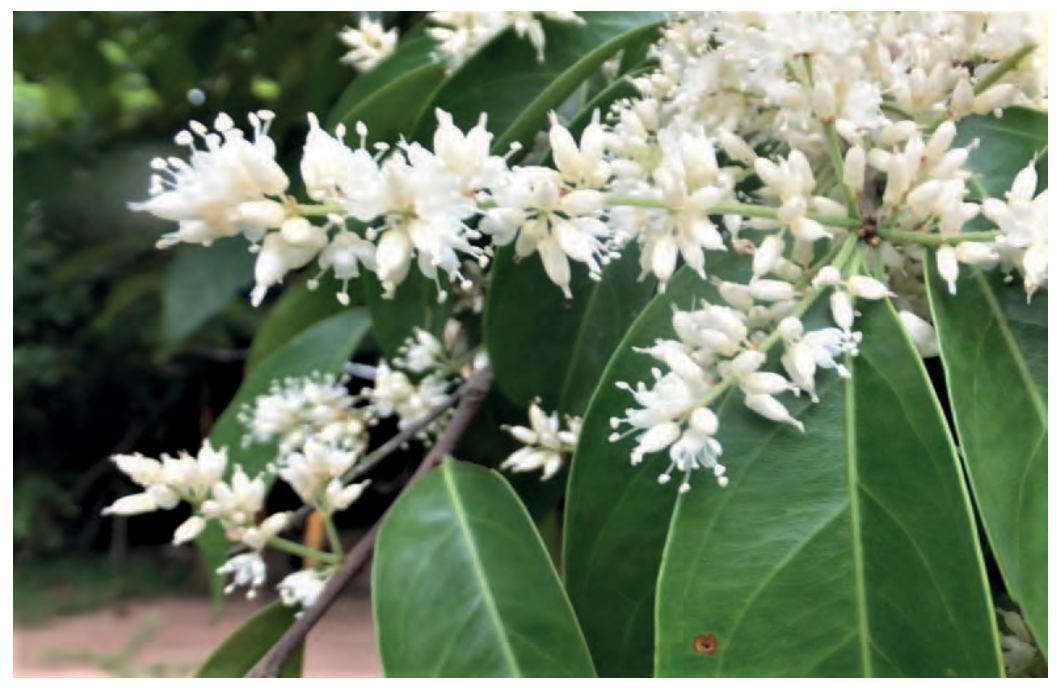
donne un bon charbon de bois. Le bois est souvent de petit diamètre, il est difficile à scier et à sécher. Au Kongo Central, on prend une décoction des feuilles comme expectorant. Ailleurs en Afrique, l'écorce a des usages médicinaux.

Références Renier 1948, Burkill 1994, Neuwinger 2000, Nsimundele 2004, Hawthorne et J onkind 2006, Harris et Wortley 2008, Lemmens 2012 


\section{Physalis angulata}

Noms courants : Bobo, kindokiela (Kikongo), biloka loka (Lingala)

Description : Plante herbacée annuelle très ramifiée, atteignant $1 \mathrm{~m}$ de haut, avec des tiges quadrangulaires et creuses. Feuilles en spirale de 5 à 8 sur 2 à $5 \mathrm{~cm}$ sur des pétioles de 1,5 à $5 \mathrm{~cm}$. Fleurs solitaires aux aisselles des feuilles. Le calice est long de 3 à 4,5 mm avec 5 lobes. Le fruit est une baie jaune de 0,7 à $1,1 \mathrm{~cm}$ de diamètre contenant de nombreuses graines à l'intérieur d'une enveloppe membraneuse.

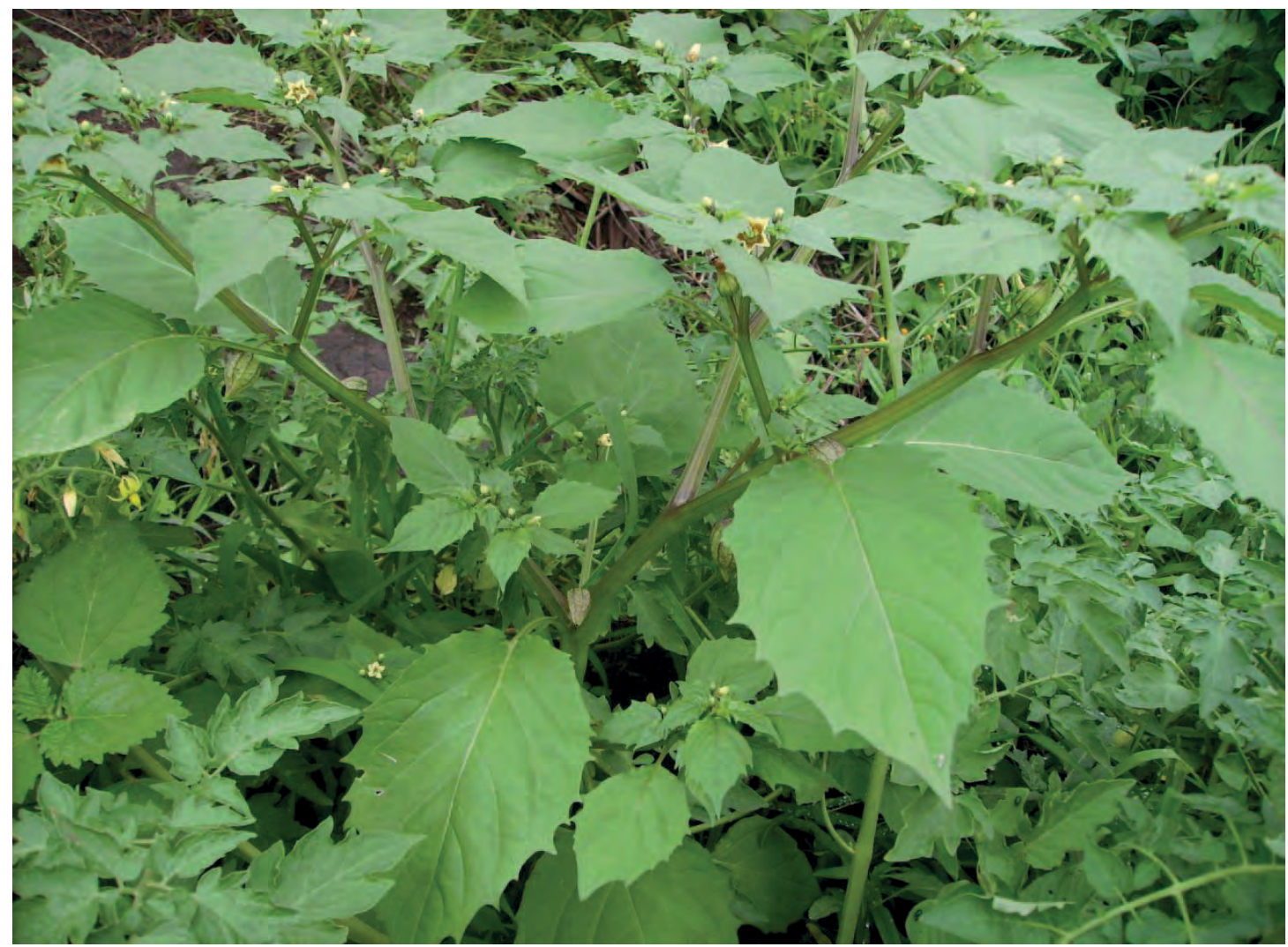

Physalis angulata en fleurs en octobre

Ecologie : Plante originaire d'Amérique tropicale, commune dans toute l'Afrique tropicale. Elle pousse le mieux sur des sols humides et fertiles, et tolère l'ombre partielle. Elle est présente comme adventice des cultures et des pâtures, et dans les friches.

Reproduction : Se reproduit facilement par graines, que l'on sème à faible profondeur.

Usages: Au Kongo Central, on emploie les feuilles pilées avec les fruits pour traiter les démangeaisons, la gale et la variole. On mange parfois les fruits avec des légumes. Les feuilles, bien qu'amères, peuvent se manger en salade. En grande quantités, la plante est toxique pour le gros bétail et les moutons, et donne à la viande une odeur musquée.

Références: Gillet et Pâque 1910, De Wildeman 1934, Staner et Boutique 1937, Renier 1948, Daeleman et Pauwels 1983, Burkill 2000, Mairura 2008, Bikandu et al. 2020 
Noms courants : Groseiller du Cap (Fr.), Cape gooseberry (Angl.)

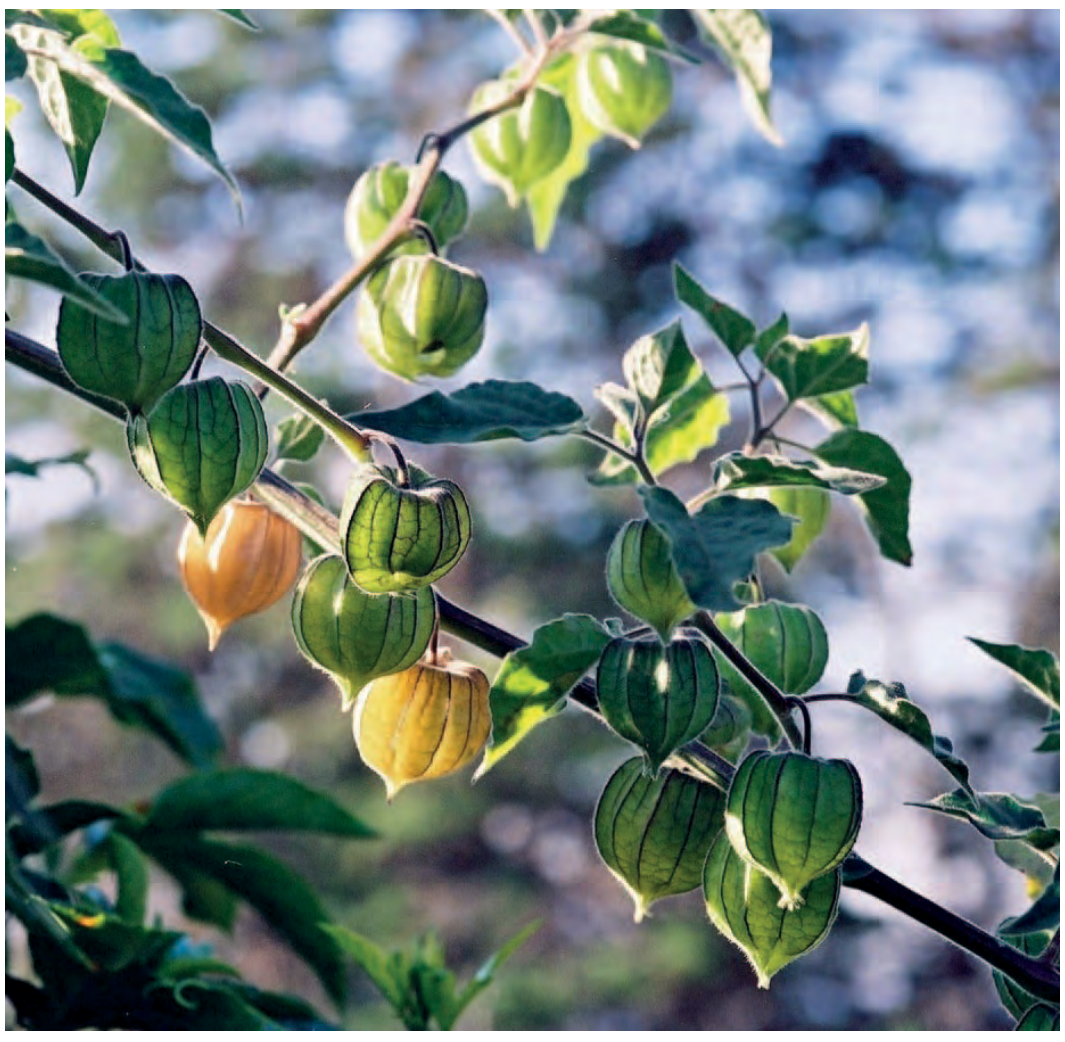

Description : Plante herbacée annuelle ou pérenne, rampante ou droite, atteignant $100 \mathrm{~cm}$ de haut. Petites fleurs jaunes à l'aisselle des feuilles. Les fruits sont des baies rondes orange de 1 à $1,5 \mathrm{~cm}$ de diamètre, à l'intérieur d'un calice membraneux.

Ecologie: Originaire du Pérou, mais maintenant largement cultivée, notamment en Afrique du Sud. Pousse dans les friches et en lisière de forêt. Sa culture peut s'intercaler avec celle du maïs. Prospère en plein soleil, résiste bien à la sécheresse, et n'aime pas les inondations. Ne pas la cultiver dans des champs précédemment occupés par des pommes de terre ou des tomates.

Reproduction: Choisir les gros fruits des plantes vigoureuses. Ecraser les baies, les sécher au soleil, puis extraire les graines. Semer en germoir à $0,5 \mathrm{~cm}$ de profondeur. Semer de préférence en début de saison sèche. Transplanter les semis en pépinière, quand ils ont 2 ou 3 feuilles, espacés en carré de $10 \mathrm{~cm}$. Transplanter en pleine terre après 2 à 3 mois avec une motte de terre autour des racines. Les boutures prennent aussi très bien.

Gestion : Planter avec des écartements de 80 à $100 \mathrm{~cm}$, si possible avec des tuteurs de $1 \mathrm{~m}$ de haut. Si la plante n'a pas fleuri quand elle atteint $30 \mathrm{~cm}$ de haut, pincer le bourgeon terminal pour favoriser la ramification. Cueillir les fruits quand ils tournent au jaune d'or et que la texture du calice devient comme du papier. On peut laisser les fruits mûrs sur la plante 2 ou 3 semaines pour les rendre plus savoureux. La plante demande un bon désherbage. Rabattre la plante au début des pluies, car la pluie fait pourrir les fruits. On peut cultiver la plante 2 ou 3 saisons de suite. II est utile de mettre en place un paillage pour éviter que la pluie éclabousse les fruits les plus bas.

Usages : Le fruit est sucré, avec un goût spécial légèrement acide, et un contenu élevé en vitamine $C$. On peut les manger crus, cuits, ou en conserves. Chaque plante donne

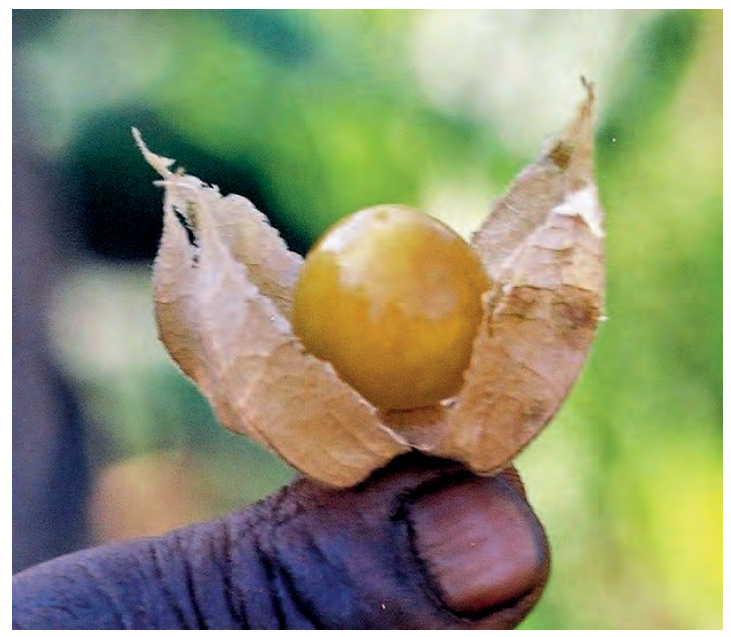
0,5 à $1 \mathrm{~kg}$ de fruits. Ils donnent d'excellentes confitures. Les abeilles butinent le pollen et un peu de nectar pendant la longue période de floraison. Les feuilles se mangent comme légumes; normalement on ne les sèche pas pour les conserver. La plante a divers usages médicinaux.

Références : Renier 1948, Watt et Breyer Brandwijk 1962, FAO 1982, Martin et al. 1987, Dupriez et De Leener 1989, Fichtl et Adi 1994, Katende et al. 1995, Bikandu et al. 2020 
Noms courants : Tidi, tiri, mayoko (Kikongo), épinard sauvage (Fr.)

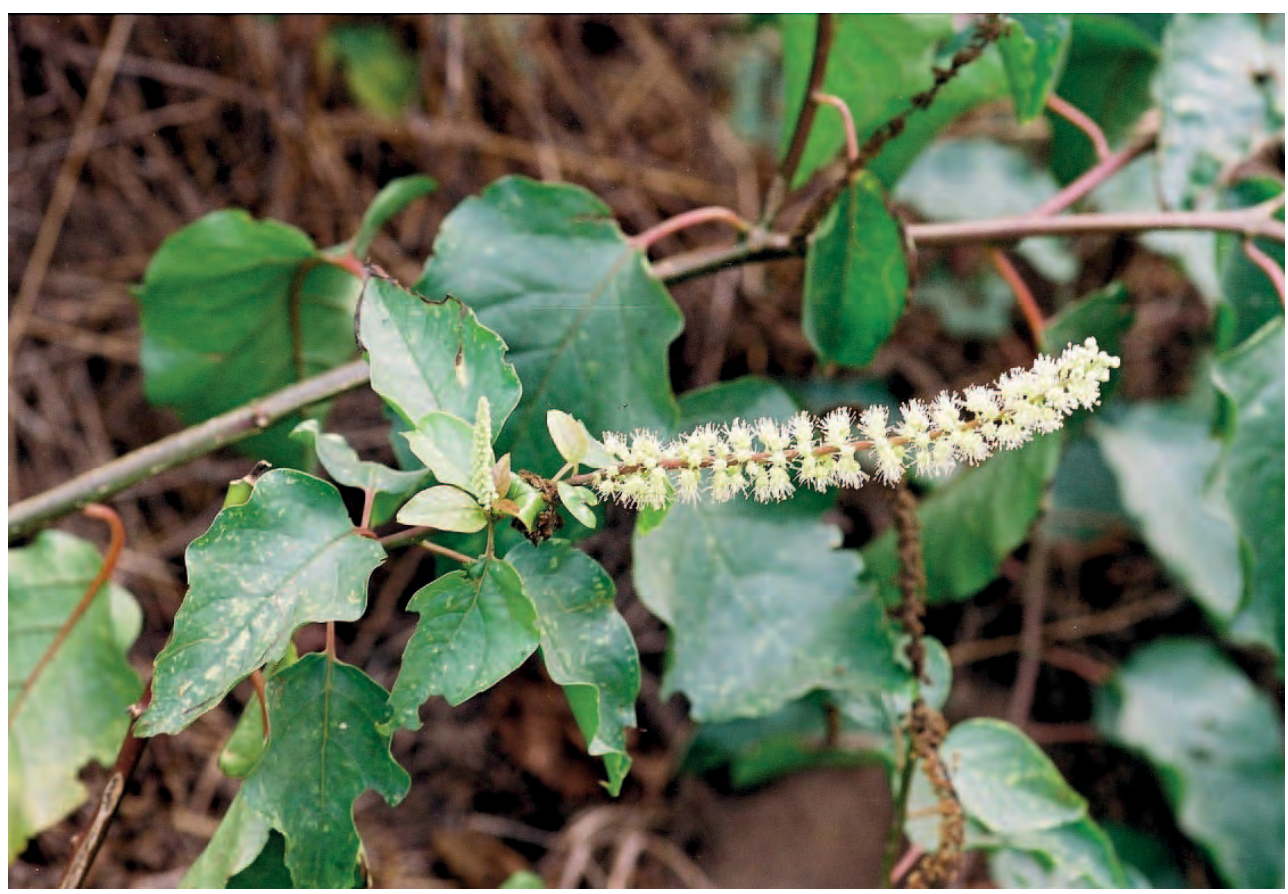

\section{Description :} Plante grimpante buissonnante ou ligneuse croissance rapide, atteignant $7 \mathrm{~m}$ de haut et $15 \mathrm{~m}$ de long. L'espace entre les nœuds peut atteindre 10 $\mathrm{cm}$. Les tiges peuvent avoir 9 $\mathrm{mm}$ de diamètre. Feuilles

habituellement glabres, de 4 à 15 sur 2 à $10 \mathrm{~cm}$, ovales, avec des pétioles tendres de 1 à $5 \mathrm{~cm}$ de long. L'épi floral peut avoir $40 \mathrm{~cm}$ de long, avec des fleurs rouges,

blanches, jaunes ou vertes.

Ecologie : Plante présente en forêts, savanes boisées ou terres cultivées jusqu'à 2.000 m d'altitude. Largement répandue de la Guinée à la R.D. Congo, ainsi qu'à Madagascar et en Afrique du Sud.

Reproduction : à partir des semis spontanés, ou par boutures.

Usages: Plante parfois cultivée comme légume au Kongo Central : on hache les très jeunes feuilles pour les cuire avant de les manger. Mais, en général, on considère la plante comme toxique; on signale que les feuilles seraient toxiques pour le bétail. Les feuilles vertes contiennent jusqu'à $6 \%$ de protéines.

A droite : Plante portant des fruits près de Kilueka en août.

Au Kongo Central, on emploie aussi les feuilles pour traiter la gale. On applique les feuilles séchées sur les coupures et les œdèmes. Les fruits sont employés

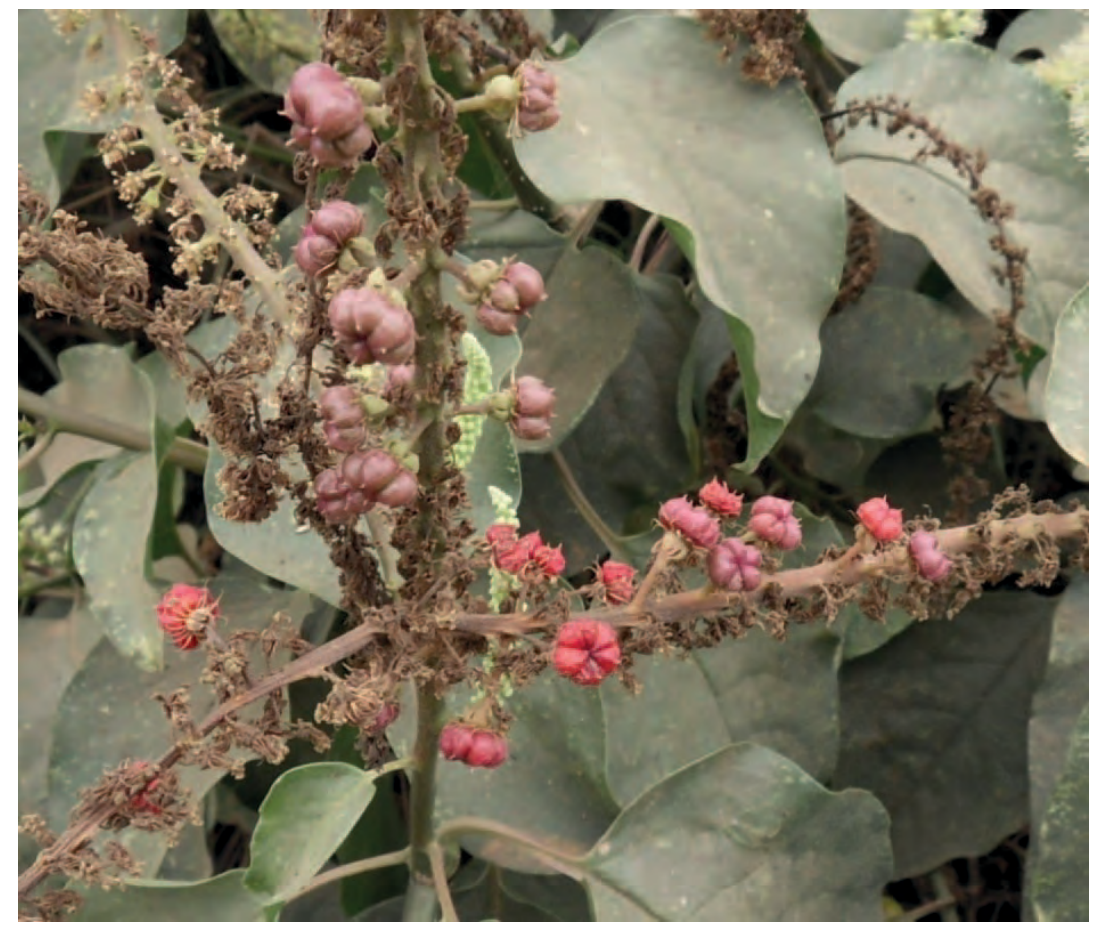
comme savon au Nord du Kenya et en Ethiopie ; on peut récolter les fruits verts et les sécher pour usage ultérieur. Ils contiennent de la saponine et produisent une mousse qui agit comme un poison sur les escargots; on a noté que les escargots vecteurs de bilharziose sont moins nombreux en dessous des bassins où on fait la lessive avec ces fruits. Le jus des fruits peut servir à tuer les larves de moustiques dans les flaques. Le fruit contient une substance rouge qui noircit au soleil et s'utilise comme encre. Les feuilles donnent une teinture jaune. Les racines 
à faible dose sont un médicament contre les ascaris et le ténia. Les abeilles butinent le nectar et le pollen ; la plante est signalée comme fourrage des abeilles en Ethiopie et au Gabon.

\section{Remarque : les feuilles adultes et les fruits sont très toxiques.}

Références : Gillet et Pâque 1910, Gillet 1927, Renier 1948, Balle 1951, Watt et Breyer-Brandwijk 1962, Busson 1965, Kokwaro 1976, Daeleman et Pauwels 1983, Ambougou 1991, Konda Ku Mbuta et al. 1992, Mbemba et Remacle 1992, Bekele-Tesemma et al 1993, Fichtl et Adi 1994, Burkill 1997, Malaisse 1997, Nsimundele 2004

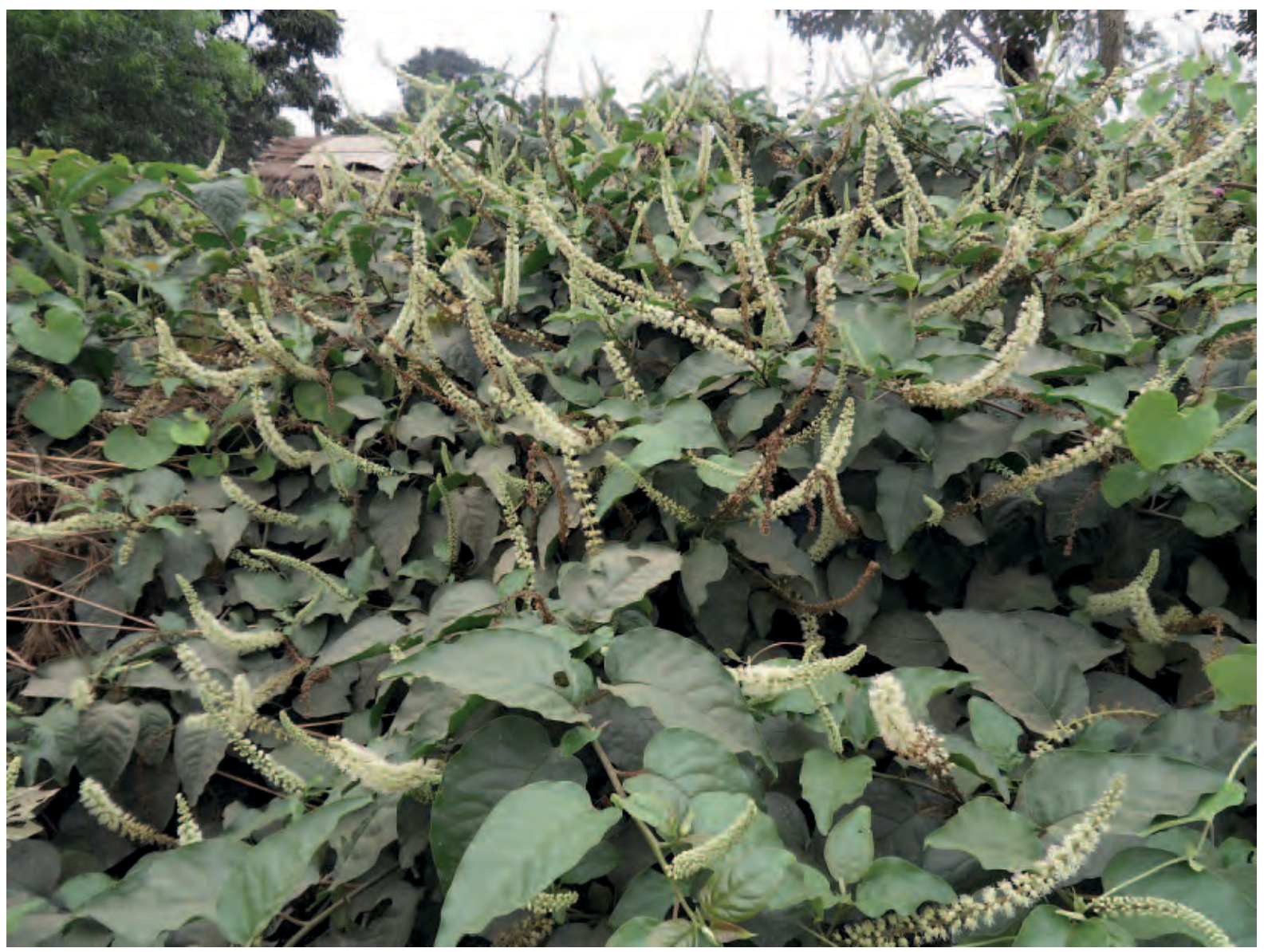

Phytolacca dodecandra en fleurs en août

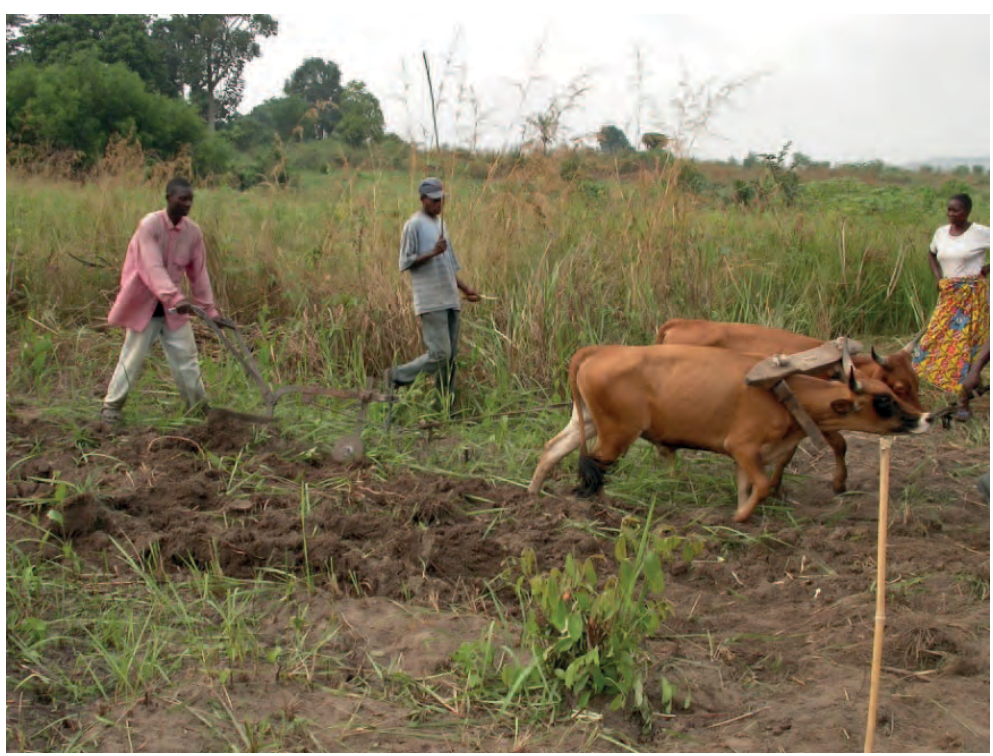

Une charrue de bœuf labourant au Manianga 
Noms courants : Obéro, démoulai à gros fruits, ebam (Fr).

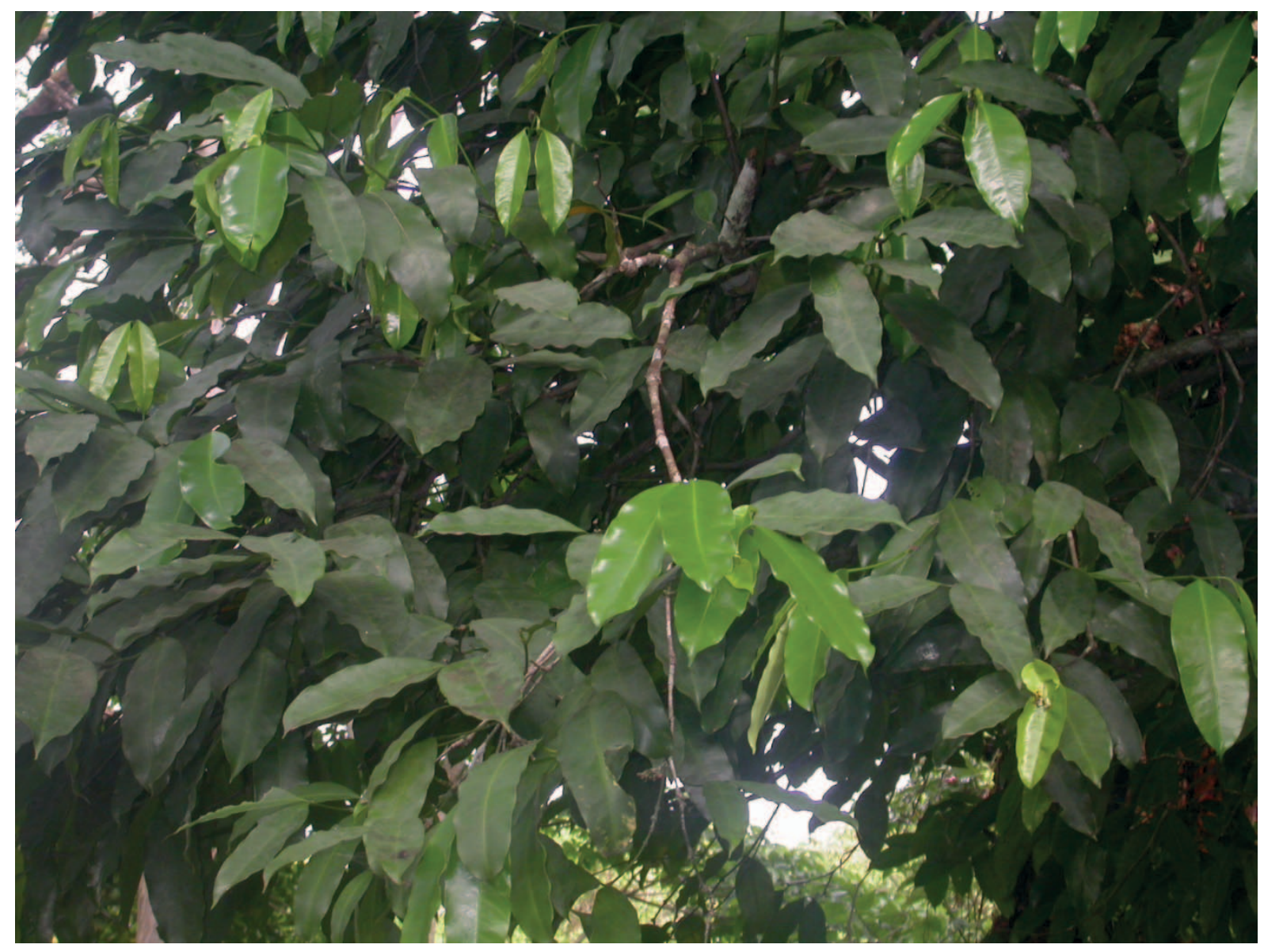

Feuillage d'un arbre au jardin botanique de Kisantu

Description : Arbuste ou arbre pouvant avoir $35 \mathrm{~m}$ mais d'ordinaire plus petit, donnant des fleurs et des fruits toute l'année. Feuilles alternes simples elliptiques jusqu'à $26 \mathrm{~cm}$ de large. Petites fleurs blanches surtout en position terminale. Fruits de couleur verte, jaune ou orange, longs de $20 \mathrm{~cm}$. Graines plates de 2,5 à 4,5 cm de long, à l'intérieur d'une chair blanche à orange.

Ecologie: Arbre de sous-bois des forêts pluviales, de la Côte d'I voire à l'Ouganda et à l'Angola.

Usages : Le bois est jaune pâle, dur et élastique, il prend un beau poli. On l'emploie pour les manches d'outils, les cannes de marche, les pilons et mortiers, la sculpture, les pagaies. On fait aussi des cuillers et des louches avec la coque dure des fruits. On emploie largement les graines, l'écorce et les racines pour diminuer la fièvre et contre la malaria. On prend l'écorce comme laxatif. Les graines contiennent un alcaloïde, l'akuammine, et sont largement employées comme analgésique, et pour traiter les problèmes de poitrine et d'estomac, la pneumonie et les vers intestinaux. A cet effet, on mâche et on mange l'écorce et les graines pilées, ou bien on boit une décoction des racines, de l'écorce et des graines. En R.D. Congo, on emploie l'écorce pour traiter la toux et la fièvre typhoïde.

Références : Gillet 1927, Staner et Boutique 1937, Renier 1948, Burkill 1985, Nyunaï et Njifutié 2006

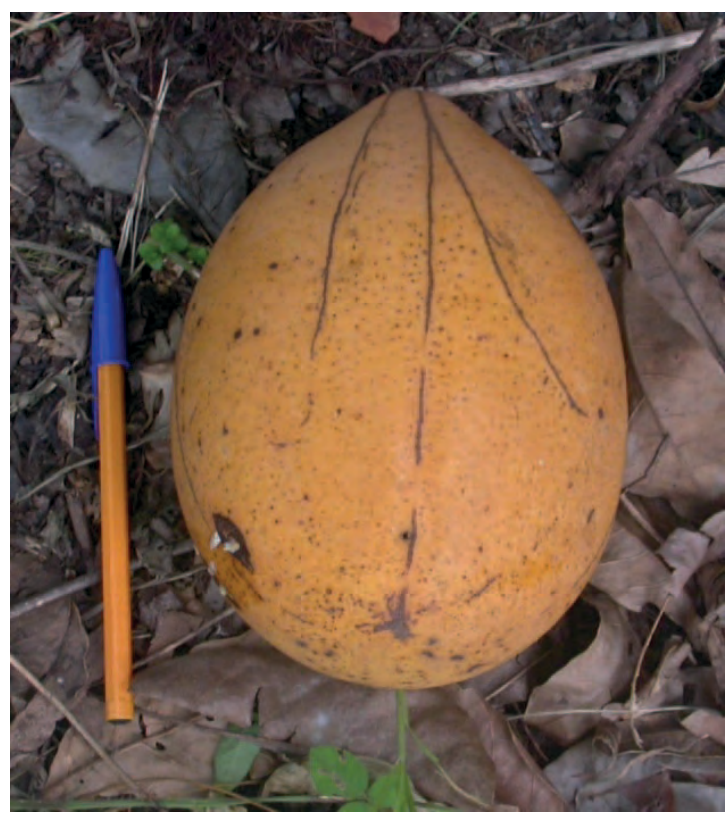




\section{Piliostigma thonningii}

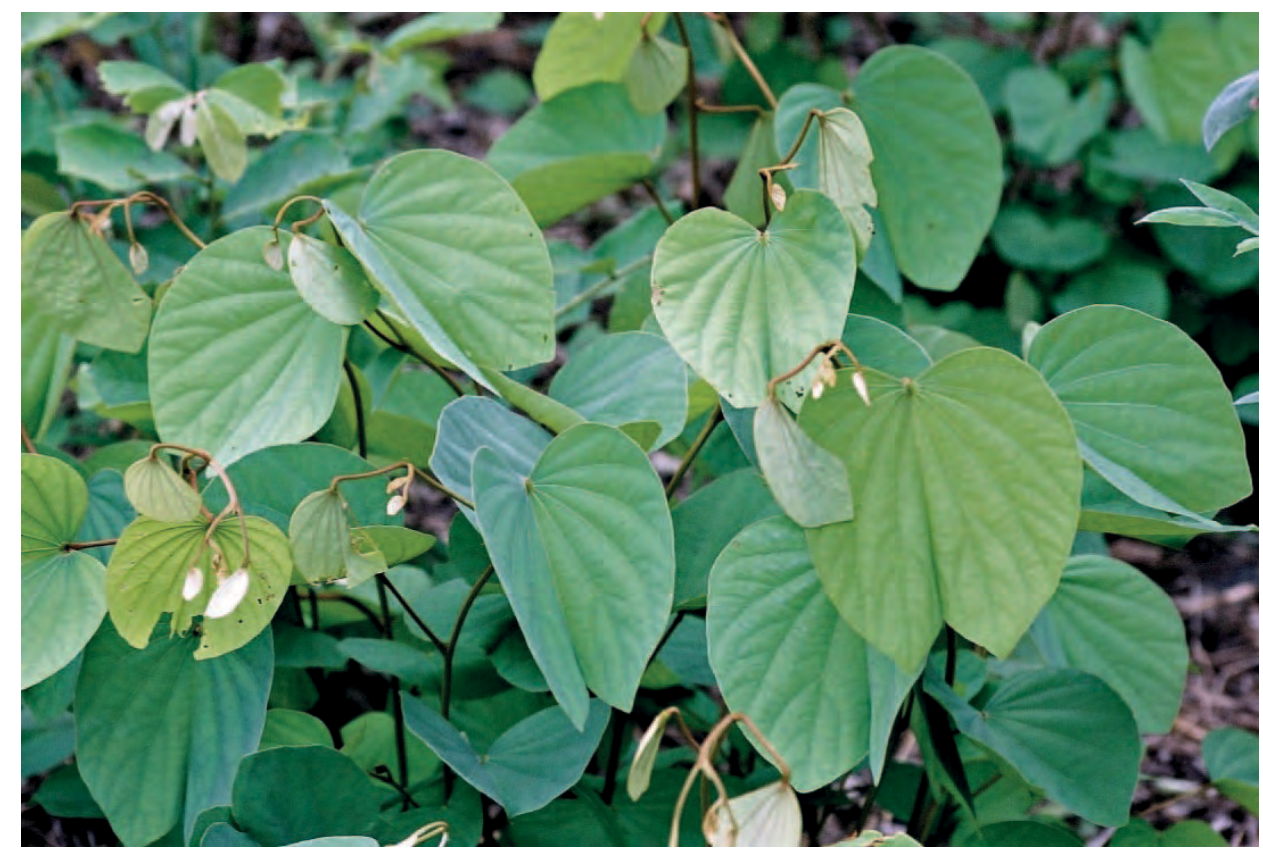

(Fabaceae)

Noms courants : Kialakoko (Kikongo), pied de boeuf (Fr.), camel's foot tree (Angl.)

\section{Description :}

Arbuste de 3 à $6 m$ à troncs et branches courts et tortueux. Les feuilles sont bilobées et velues en dessous. Les fleurs sont blanches et parfumées.

Ecologie : Plante des savanes boisées dans toute l'Afrique tropicale, souvent associée à Annona senegalensis.

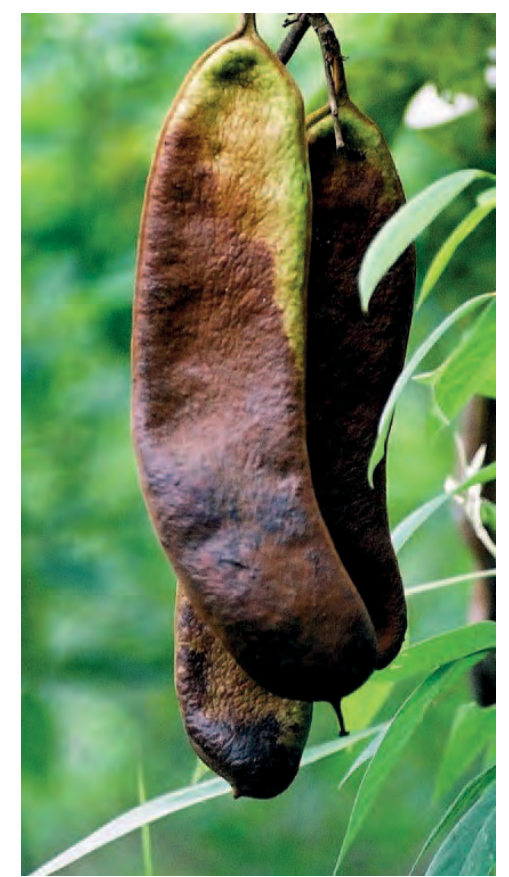

Reproduction : Semer les graines en pleine terre après trempage 24 heures dans l'eau froide. Normalement, le taux de germination est bon. Les graines se gardent plusieurs années si on les garde au frais, au sec, et à l'abri des insectes.

Gestion : Plante à croissance rapide, recèpe bien et se conduit en taillis.

Usages: Le bois est dur, facile à travailler, sujet aux attaques des termites et insectes perforants. On l'emploie en construction, pour les

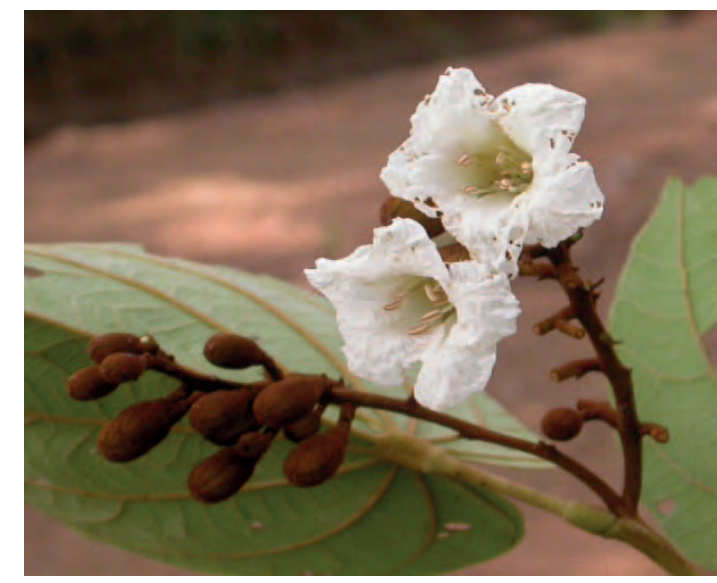
pilons, manches d'outils, mobilier et menuiserie générale ; mais sa petite taille limite son utilité. On emploie les tiges et les racines comme bâtons à mâcher. Le bois brûle bien, et longtemps à partir des braises, avec une flamme chaude et peu de fumée. L'écorce donne des fibres servant de liens.

A gauche : Les fruits restent longtemps sur l'arbre.

Le latex des troncs sert à réparer les bateaux. La plante a de nombreux usages médicinaux. Par exemple, on applique les feuilles fraiches sur les plaies pour les cicatriser. L'écorce s'emploie contre les rhumes er les maux de dents. Les fruits peuvent servir de savon. La chair autour des graines est comestible, semblable à un biscuit ; les enfants la mâchent, et on en mange en temps de famine. On peut aussi manger les feuilles, les gousses pilées et les graines. On mâche les jeunes feuilles pour étancher la soif. Les gousses et les graines donnent une teinture bleue; les graines grillées une teinture noire. Les fleurs seraient butinées par les abeilles, elles sont connues comme fourrage important pour les abeilles sur les hauts plateaux d'Angola.

Références : Wilczek et al. 1952, Portugal-Araújo 1974, Peters et al 1992, Pauwels 1993, Burkill 1995, Katende et al. 1995, Pousset 2004 


\section{Piper guineense}

(Piperaceae)

Noms courants : Kapidi, nkefu (Kikongo), boloko, bololoko (Lingala), West African black pepper (Angl.)

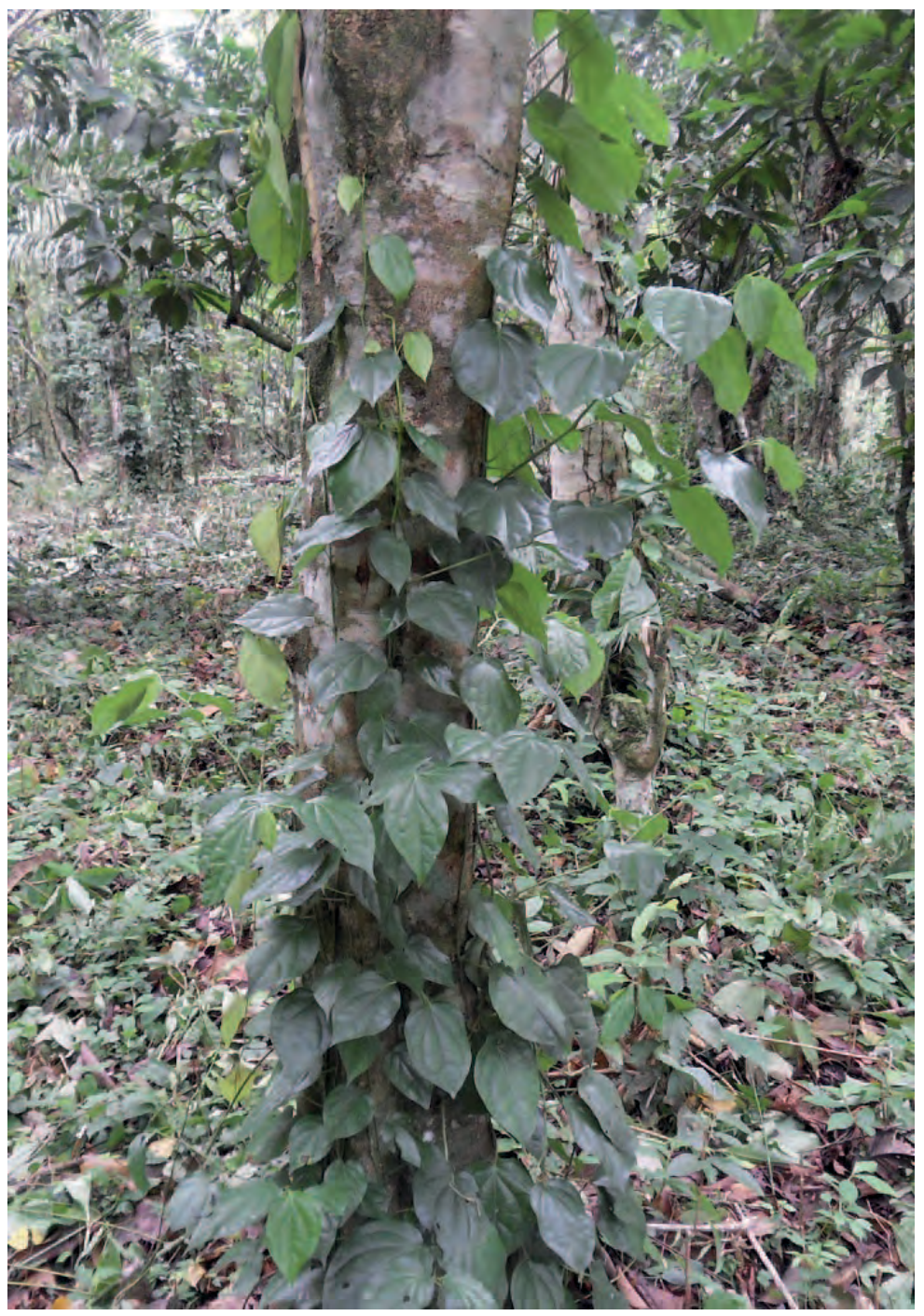

Description : Liane sempervirente atteignant $23 \mathrm{~m}$ de long, qui grimpe à l'aide de racines adventives poussant sur la tige. Les vieilles tiges sont liégeuses. Les feuilles mesurent 4,5 à 16,5 sur 2 à $12 \mathrm{~cm}$, avec un long bout pointu; leur base est rétrécie ou arrondie, souvent de façon inégale. Les fruits rouges, jaune orangé ou bruns, se disposent en courts épis.

Ecologie: Plante présente de la Guinée à l'Ouganda et à l'Angola, dans les sites humides et les fonds de vallées. On la cultive parfois, ou on la laisse grimper aux arbres.

Reproduction: par graines ou par boutures.

Usages: Les grappes de fruits, aromatiques, s'emploient abondamment comme épices et condiments, comme le poivre noir, mais moins fort. On mange les fruits crus pour leur goût épicé et pour traiter les rhumes. On pile et on tamise les fruits séchés pour les ajouter aux sauces. On ajoute aussi cette poudre au café et au thé. Les feuilles aussi servent de condiment. La plante a des usages médicinaux pour aider la digestion. Les racines servent à traiter la bronchite. On donne une décoction de l'écorce en lavement pour traiter les problèmes intestinaux. Les fruits s'emploient comme onguent sur la peau, notamment pour calmer les rhumatismes. La plante a des propriétés antimicrobiennes et insecticides. La cendre peut s'employer comme sel végétal.

Références : Gillet et Pâque 1910, De Wildeman 1934, Balle 1948, Renier 1948, Busson 1965, Uphof 1968, Burkill 1997, Ruffo et al. 2002, Kibungu Kembelo 2003, Nsimundele 2004, Biloso et Lejoly 2006

A droite : Fruits de poivre en vente au marché

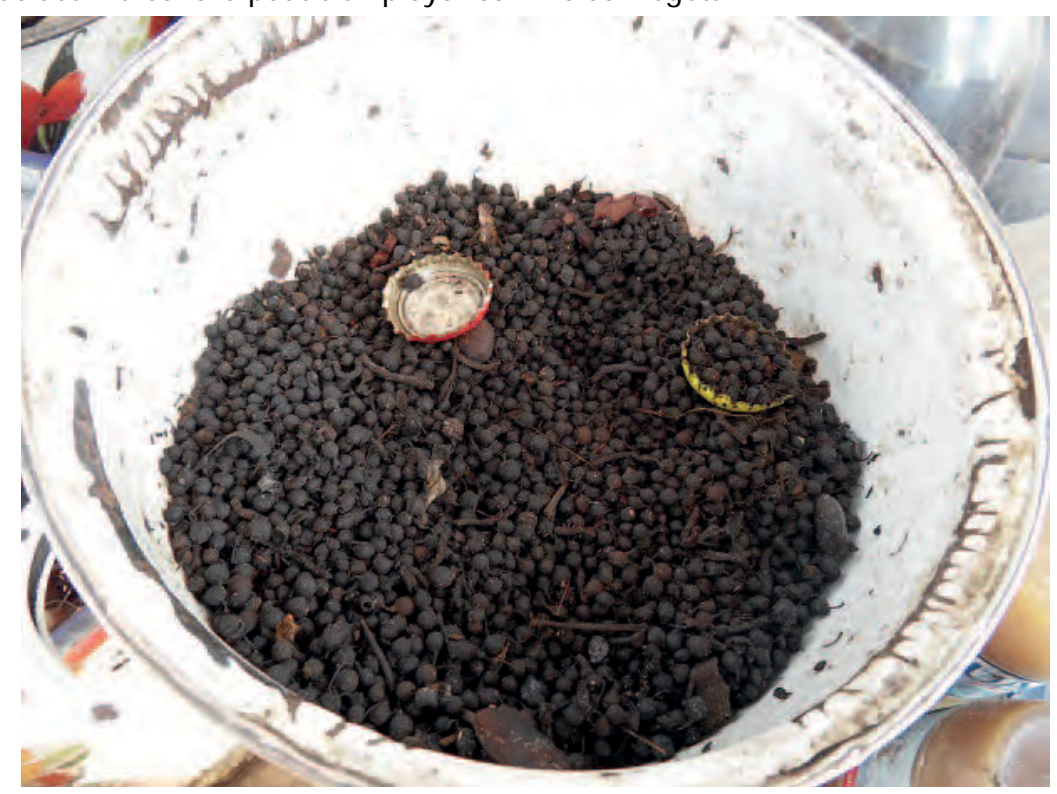


Noms courants : Kapidi, kupidi (Kikongo), poivrier (Fr.), pepper (Angl.)

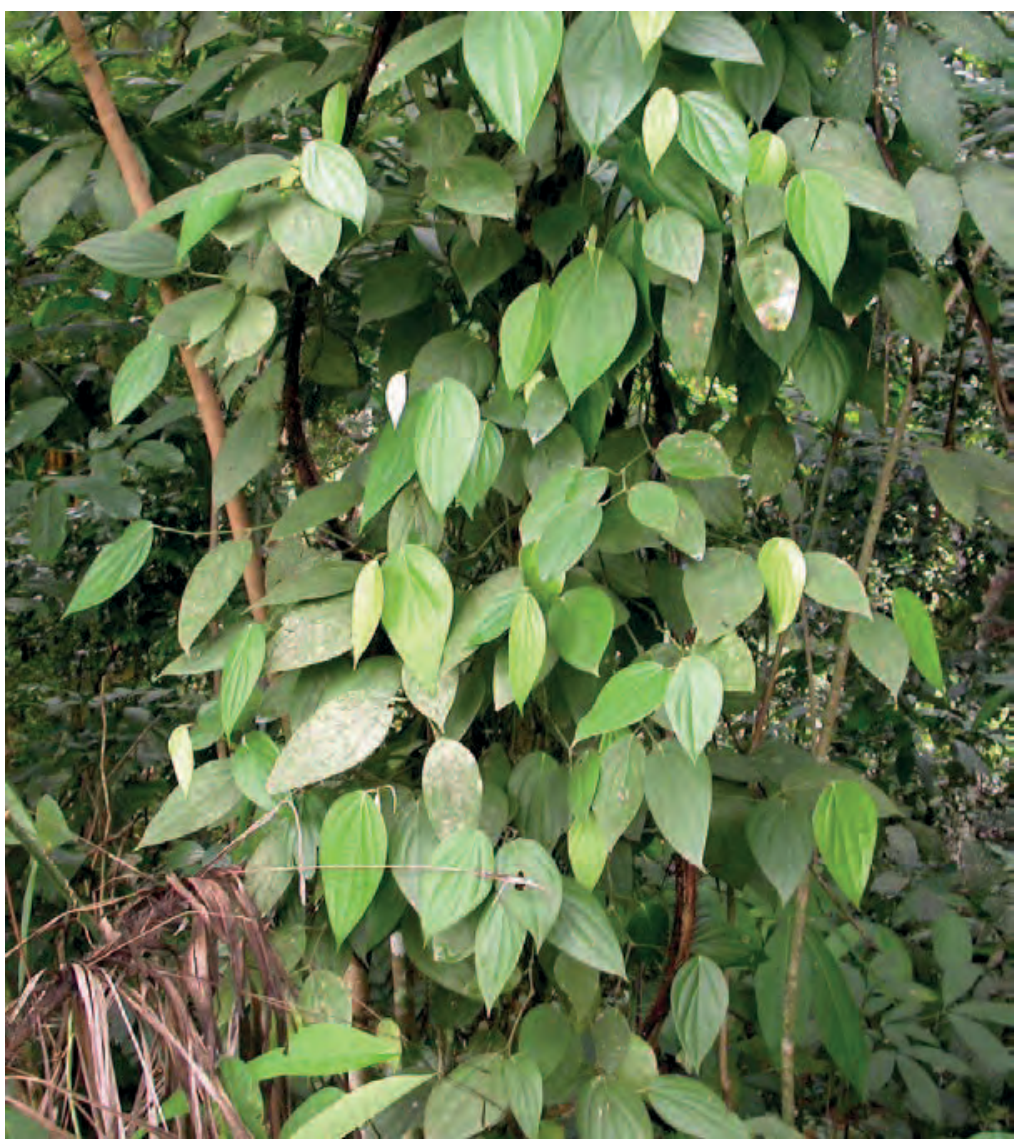

Description : Liane grimpante pouvant atteindre $10 \mathrm{~m}$, mais normalement taillée vers $4 \mathrm{~m}$. Feuilles de 8 à $20 \mathrm{~cm}$ de long, alternes, ovales et pointues. Les fleurs sont le plus souvent bisexuelles. Les fruits, de 3 à $6 \mathrm{~mm}$, rouges à maturité, noircissent en séchant. Piper nigrum se distingue de piper guineense par des feuilles et des épis floraux plus longs, et une ramification moins abondante. II y a de nombreuses variétés améliorées.

Ecologie : Originaire d'Inde du Sud et largement répandu sous les tropiques. Demande un climat chaud et humide, mais ne supporte pas l'inondation. La plante demande de l'ombrage et un sol fertile, riche en matière organique. Elle supporte très mal la sécheresse.

Reproduction : Se cultive normalement à partir de boutures prélevées sur de jeunes tiges ou des tronçons de tiges d'environ $50 \mathrm{~cm}$ de long. On les plante dans un sol humide et ombragé, elles donnent des racines après deux mois. On peut aussi semer des graines fraichement récoltées.

Usages: Les graines fraiches ou séchées, entières ou pilées, sont partout dans le monde l'épice forte essentielle pour la cuisine. Le poivre est connu pour stimuler la digestion en augmentant les sécrétions de salive et sucs gastriques. Dans le passé, on employait aussi le poivre comme vermifuge. Pour préparer le poivre noir, on laisse les fruits en tas une nuit, puis on les sèche au soleil sur des nattes les jours suivants. II faut les retourner régulièrement au râteau, et ils sont prêts après 4 ou 5 jours. L'huile de poivre distillée à partir des fruits s'emploie en parfumerie.

Références Gillet 1927, Purseglove 1968, Daeleman et Pauwels 1983, Dupriez et De Leener 1989, de Guzman et Siemonsma 1999

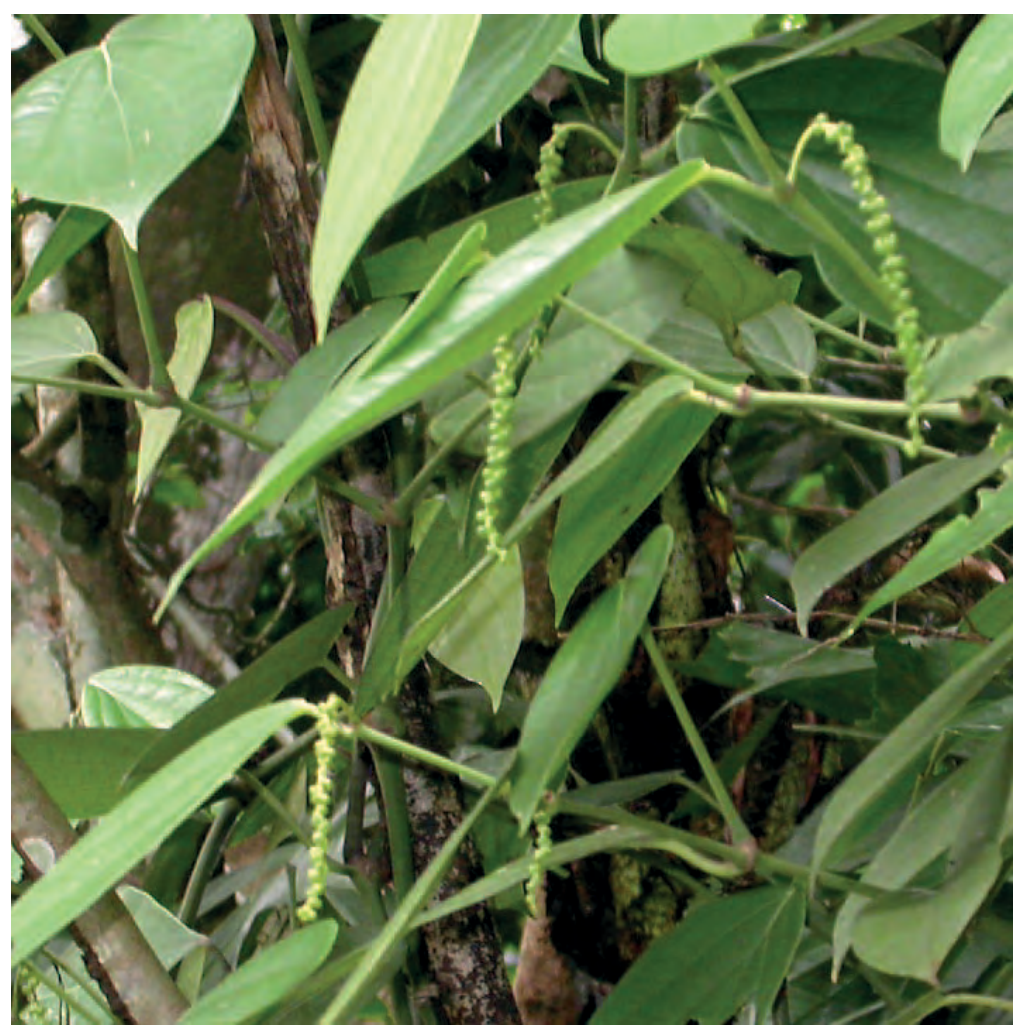




\section{Piper umbellatum}

Noms courants : Kilemba kimfinda (Kikongo), itolombo (Lingala), cow foot leaf (Angl.)

Description : Plante herbacée pérenne rampante, jusqu'à $1,50 \mathrm{~m}$ de haut, se ramifiant à la base. Les tiges poussent sur une souche ligneuse. Feuilles alternes, presque circulaires, jusqu'à $36 \mathrm{~cm}$ de part en part. Inflorescence composée de 2 à 8 épis, pouvant atteindre ensemble $15 \mathrm{~cm}$ de long. Le fruit est une drupe brunâtre de section triangulaire, contenant une seule graine.

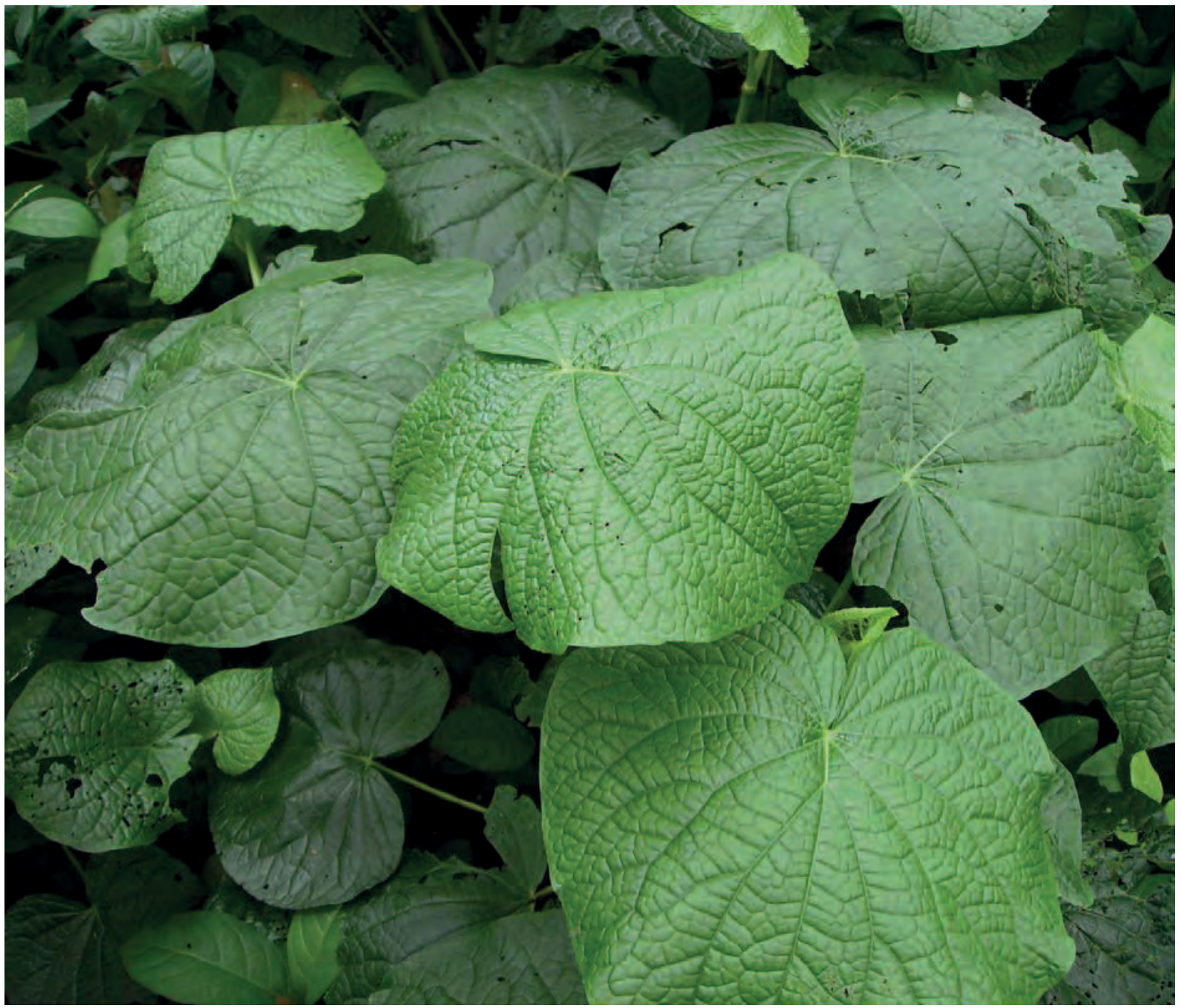

Ecologie : Plante très répandue sous les tropiques, dans les lieux ombragés à l'ombre. Souvent plantée près des habitations.

Reproduction : Par bouture des tiges ; donne des racines à partir des nœuds.

Usages: Les feuilles au goût poivré se mangent comme légumes. Les feuilles fraiches pilées dégagent une odeur de céleri. La cendre de la plante donne un sel végétal. Les feuilles trempées dans l'eau s'emploient pour traiter les maux de dents. En Afrique tropicale, les feuilles ont beaucoup d'usages médicinaux, pour assouplir la peau, pour traiter les blessures et comme antiseptique. On les emploie en cataplasmes sur les abcès et les brûlures. La décoction des feuilles traite la jaunisse, la malaria, les problèmes urinaires et rénaux, la syphilis, les problèmes menstruels, les maux d'estomac; on l'applique également sur les blessures et les tumeurs infectées.

Références : Gillet et Pâque 1910, Staner et Boutique 1937, Balle 1948, Renier 1948, Busson 1965, Daeleman et Pauwels 1983, Mbemba et Remacle 1992, Burkill 1997, Domis et Oyen 2008 


\section{Piptadeniastrum africanum}

Synonyme : Piptadenia africana

Noms courants : Singasinga (Kikongo), African greenheart, dabema (commerce)

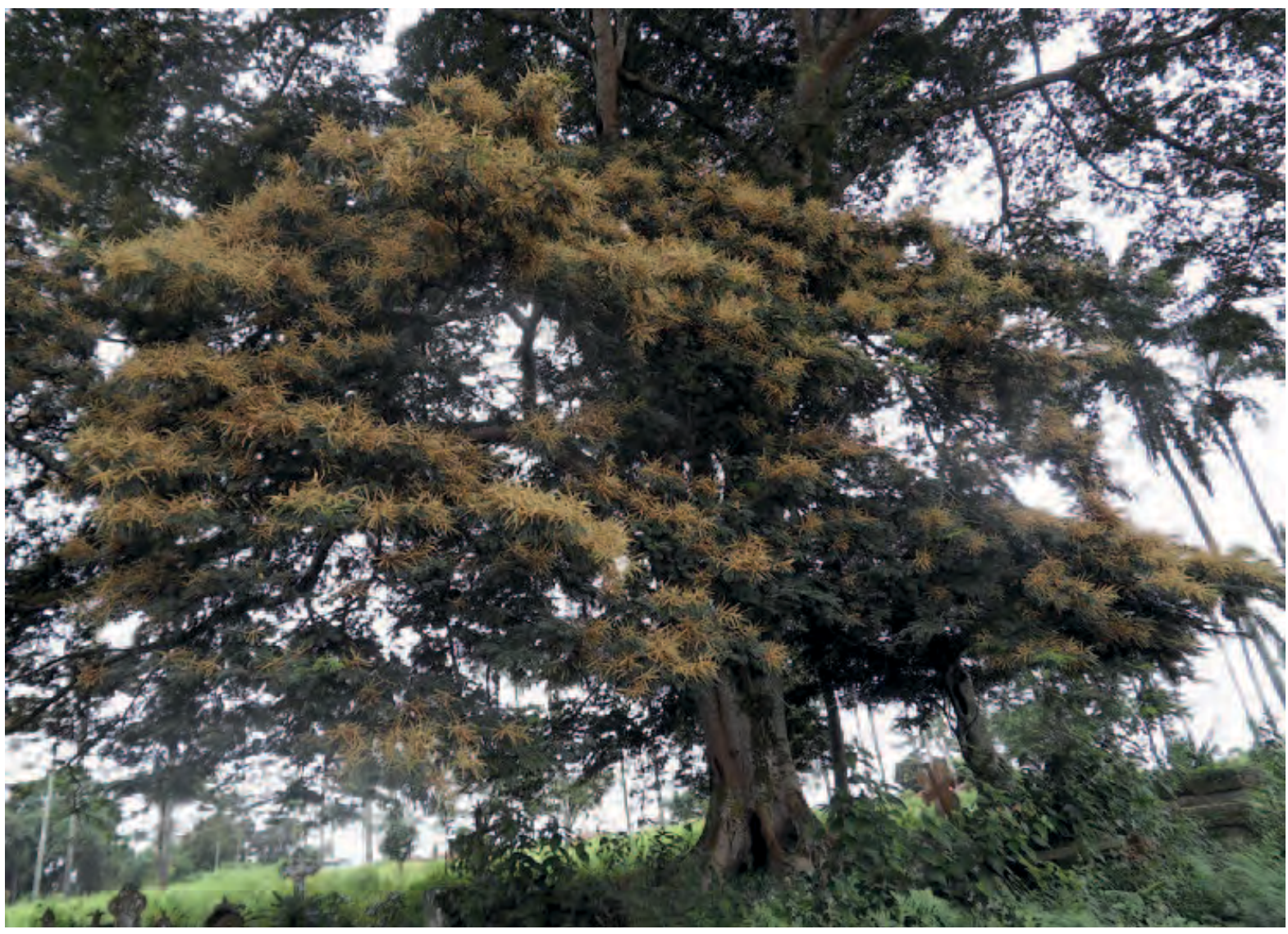

Arbre en fleurs en février au cimetière de Lemfu

Description : Arbre atteignant $45 \mathrm{~m}$ de haut, avec de grands contreforts hauts de $5 \mathrm{~m}$. Jeunes branches couvertes d'une toison épaisse de poils bruns. Feuilles composées de 12 à 14 paires de pennes sur des pétioles rouges. Fleurs de couleur crème, sur des épis ramifiés de 4 à $11 \mathrm{~cm}$, à tiges couvertes de poils bruns. Gousses plates, brun foncé, de $12,5 \mathrm{~cm}$ de long.

Ecologie : Arbre des forêts de basse altitude, de la Sierra Leone à l'Angola et à l'Ouganda.

Reproduction: Par graines ou boutures. On récolte les graines ailées au pied des arbres. Elles germent en une ou deux semaines, mais perdent leur viabilité très vite. Les semis poussent lentement ; on les transplante après 6 à 12 mois.

Usages: Le bois est de bonne qualité, durable même exposé à l'eau, et assez résistant aux termites; mais il a mauvaise odeur, et sa sciure irrite la gorge et les gencives. Très bon pour faire des pirogues, pour la construction lourde et pour les parquets. On emploie l'écorce comme savon; la

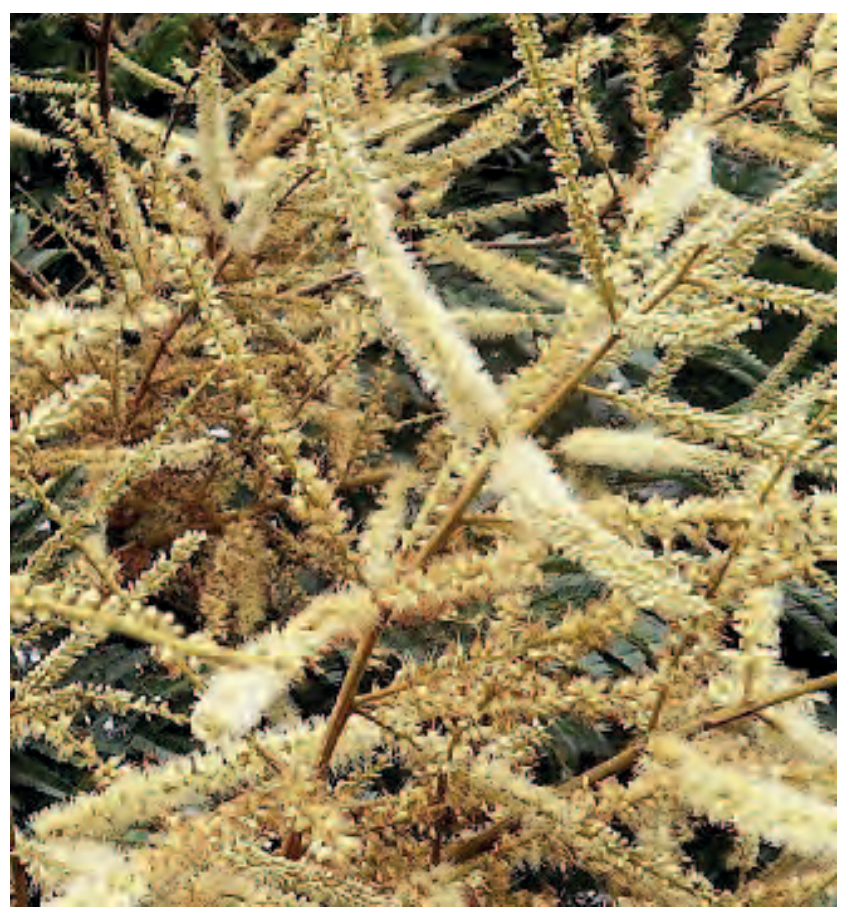


cendre des gousses et de l'écorce s'emploie en savonnerie. La racine contient beaucoup de saponine. Les chenilles comestibles Minsendi et Nsinga se nourrissent des feuilles. Les abeilles butinent les fleurs.

Remarque : L'arbre a d'autres usages médicinaux en Afrique, mais on doit employer chacune de ses parties avec beaucoup de précautions.

Références : Laman 1936, Renier 1948, Gilbert et Boutique 1952, Nsimundele 1966 - 68, Allen et Allen 1981, Ambougou 1991, Pauwels 1993, Burkill 1995, Katende et al. 1995, Kibungu Kembelo 1995, Neuwinger 2000, Meunier et al. 2010

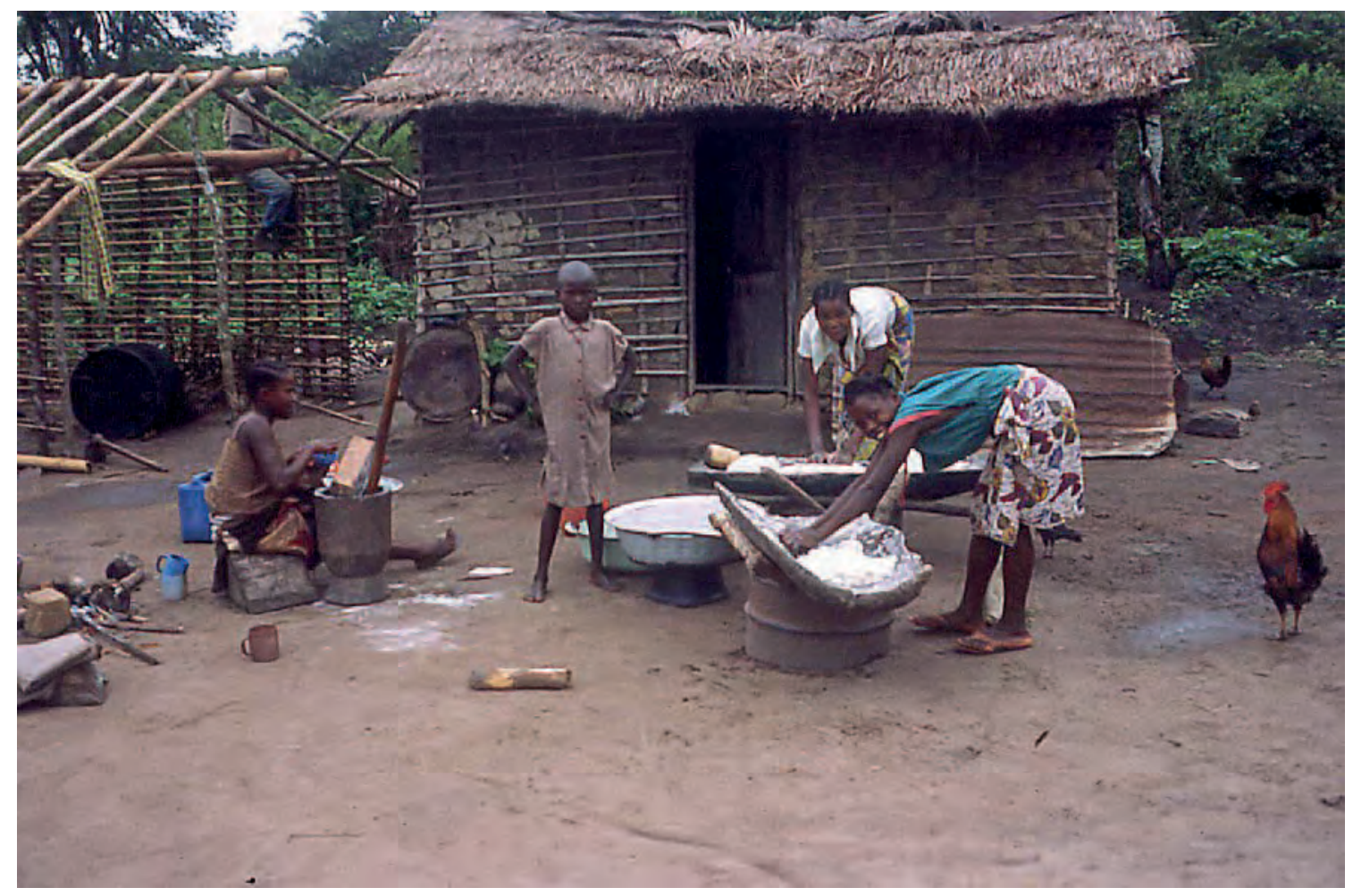

Préparation de la « chikwangue » à partir du manioc frais ayant subi le rouissage dans l'eau 


\section{Pithecellobium dulce}

Noms courants : Mkwaju wa kihindi (Swahili), Madras thorn (Angl.)

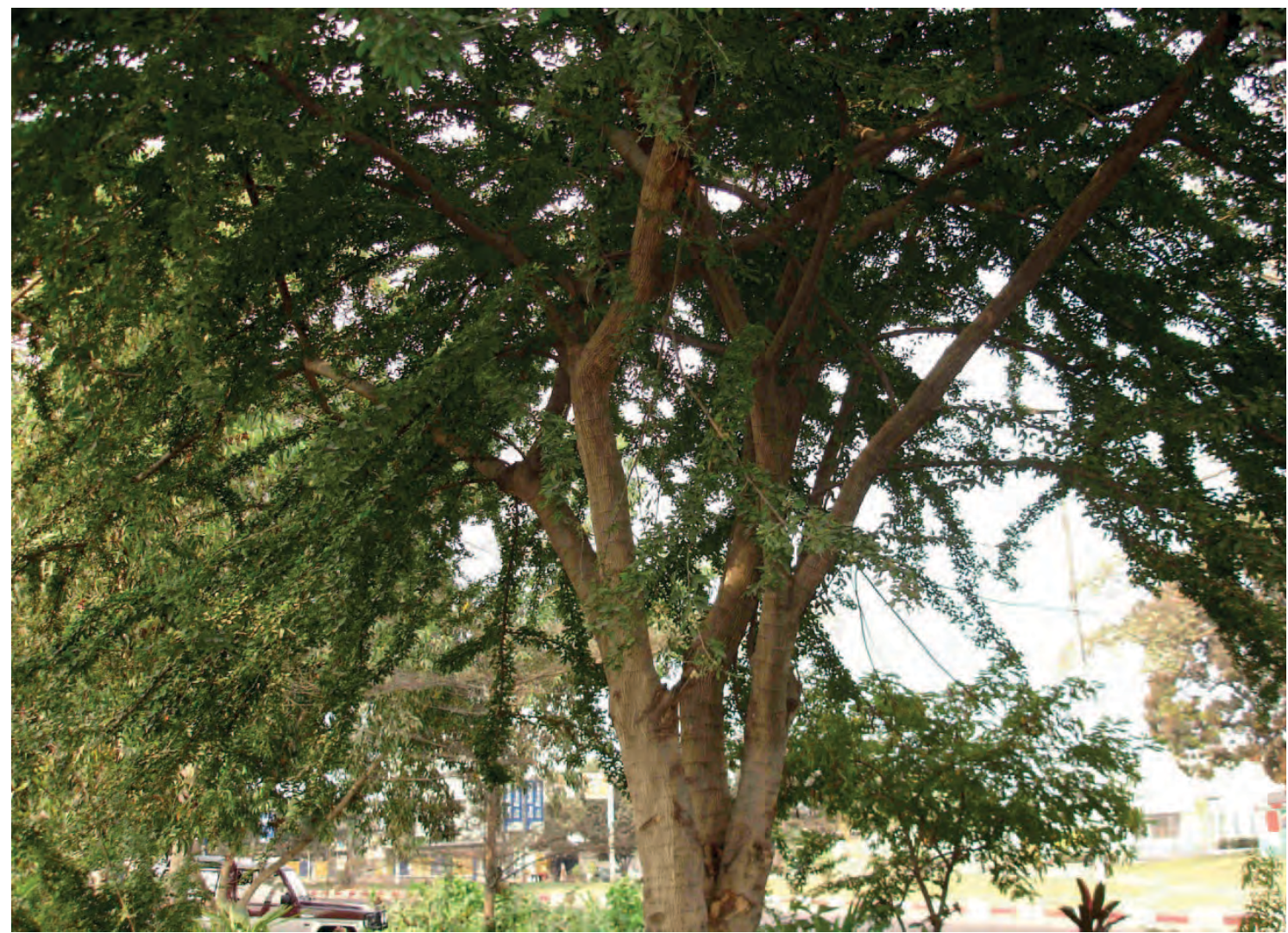

Description : Arbuste informe et touffu de 4 à $15 \mathrm{~m}$ de haut, armé de courtes épines à la base de chaque paire de feuilles. Ecorce claire et lisse, avec des marques horizontales, jeunes branches tortueuses. Feuilles disposées sur des pétioles épais, avec deux paires de folioles ovales asymétriques atteignant chacune $5 \mathrm{~cm}$ de long, à l'extrémité arrondie. Petites fleurs crème, avec des bouquets d'étamines vert pâle. Gousses d'environ $12 \mathrm{~cm}$ de long, enroulées en spirale et étranglées entre les graines. Les gousses sont rouges à maturité ; elles se divisent pour libérer des graines noires brillantes, presqu'entièrement recouvertes par un arille charnu, rouge et blanc, sucré et comestible.

Les deux photos sur cette page : Luc Pauwels

Ecologie : Plante originaire d'Amérique Centrale, largement cultivée sous les tropiques. Accepte la plupart des sols, y compris les sables pauvres et les sols humides salés. Très résistante à la sécheresse. Supporte un pâturage intensif ou la coupe pour le fourrage.

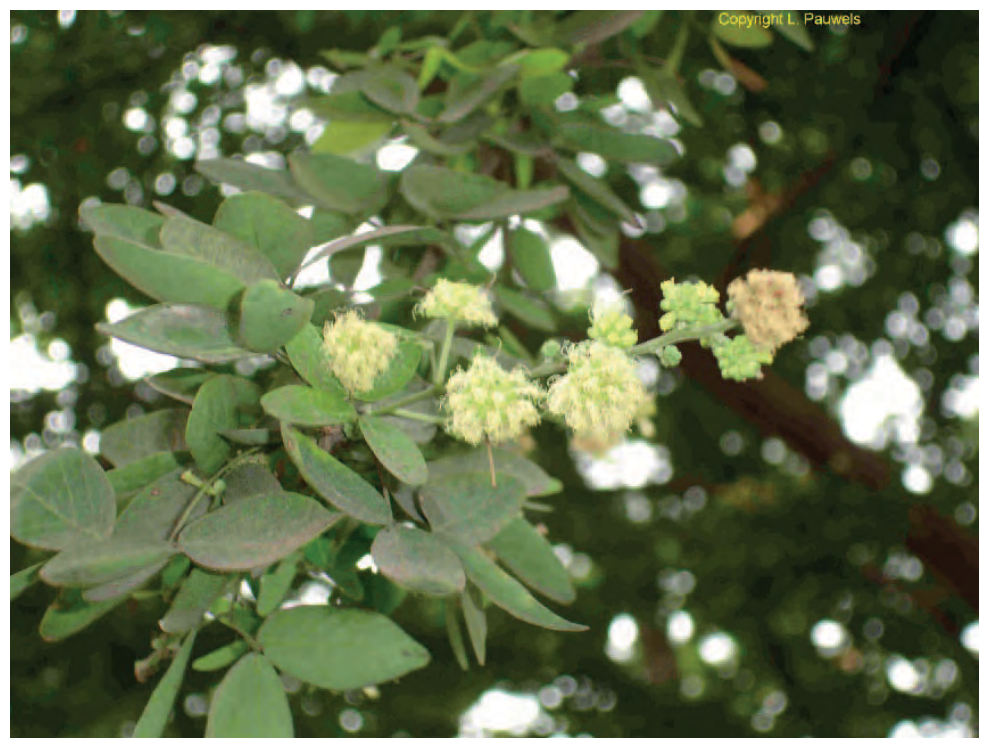

Reproduction : A partir des semis spontanés, par semis direct ou par boutures. La germination des graines atteint $95 \%$ en deux semaines. On cultive des plantes améliorées par marcottage ou greffage.

Gestion : Plante à croissance rapide, recèpe bien, et peut se tailler pour donner des haies. Supporte la taille intensive et le pâturage par des chèvres. 
Usages : Le bois est brun rouge, à texture fine, dur, lourd, mais fragile. II constitue un combustible médiocre, avec beaucoup de fumée et peu de chaleur. Les arilles des fruits sont comestibles, et la plante a des usages médicinaux. Elle est utile comme fourrage pour les abeilles, donnant du nectar et du pollen, qui donnent un miel blanc léger. Au Ghana, la plante a été introduite pour faire des haies. L'écorce s'emploie en tannerie. Les gousses et les feuilles sont broutées par le bétail.

Références : Irvine 1961, Allen et Allen 1981, Little 1983, Rochelau et al. 1988, Hendro-Sunarjono et Coronel 1991, Mbuya et al. 1994, Burkill 1995, Leo 2007, Orwa et al. 2009, Pauwels (communication personnelle 9.6.2015)
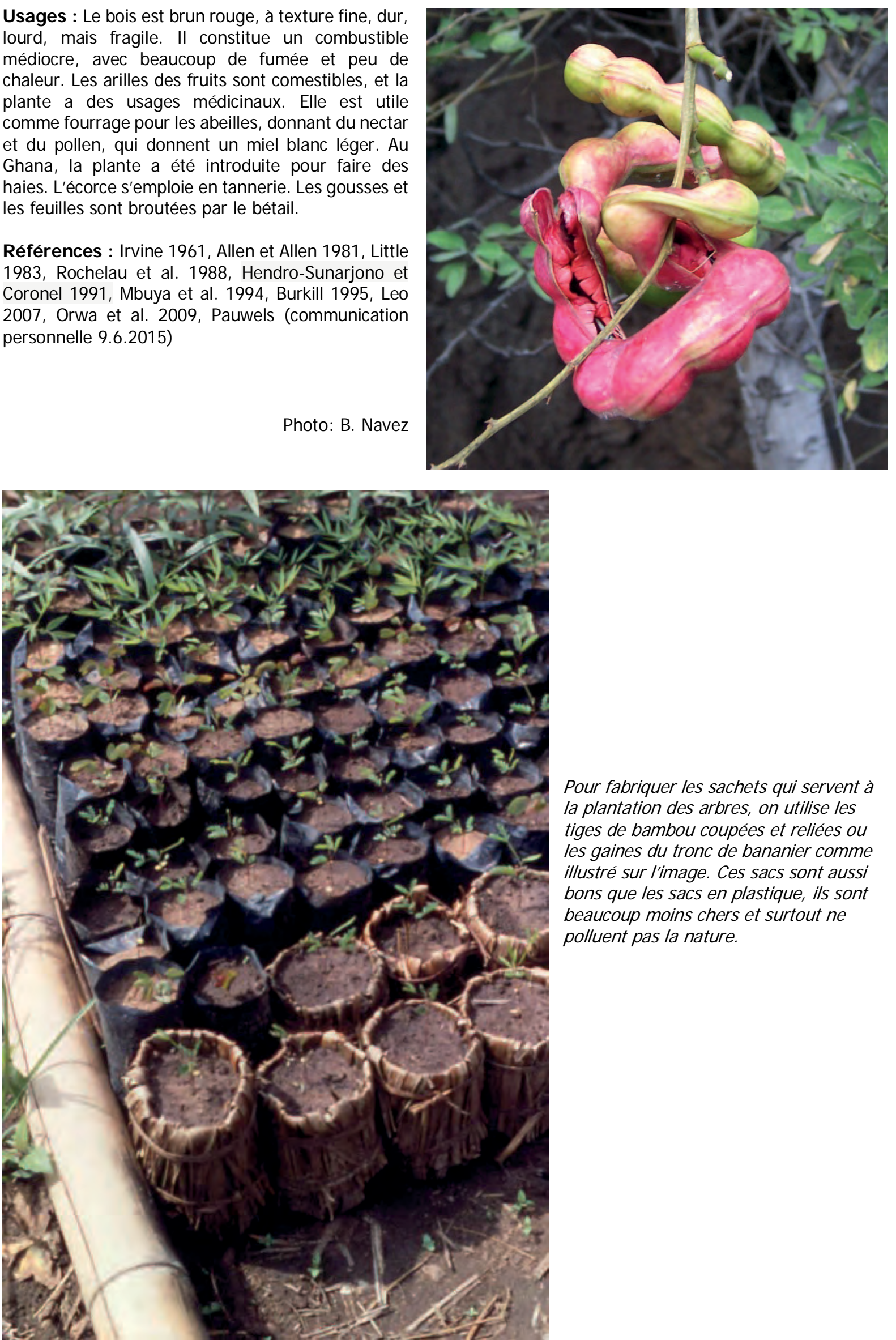

Pour fabriquer les sachets qui servent à la plantation des arbres, on utilise les tiges de bambou coupées et reliées ou les gaines du tronc de bananier comme illustré sur l'image. Ces sacs sont aussi bons que les sacs en plastique, ils sont beaucoup moins chers et surtout ne polluent pas la nature. 


\section{Plagiostyles africana}

Noms courants : Kasua, vamu (Kikongo)

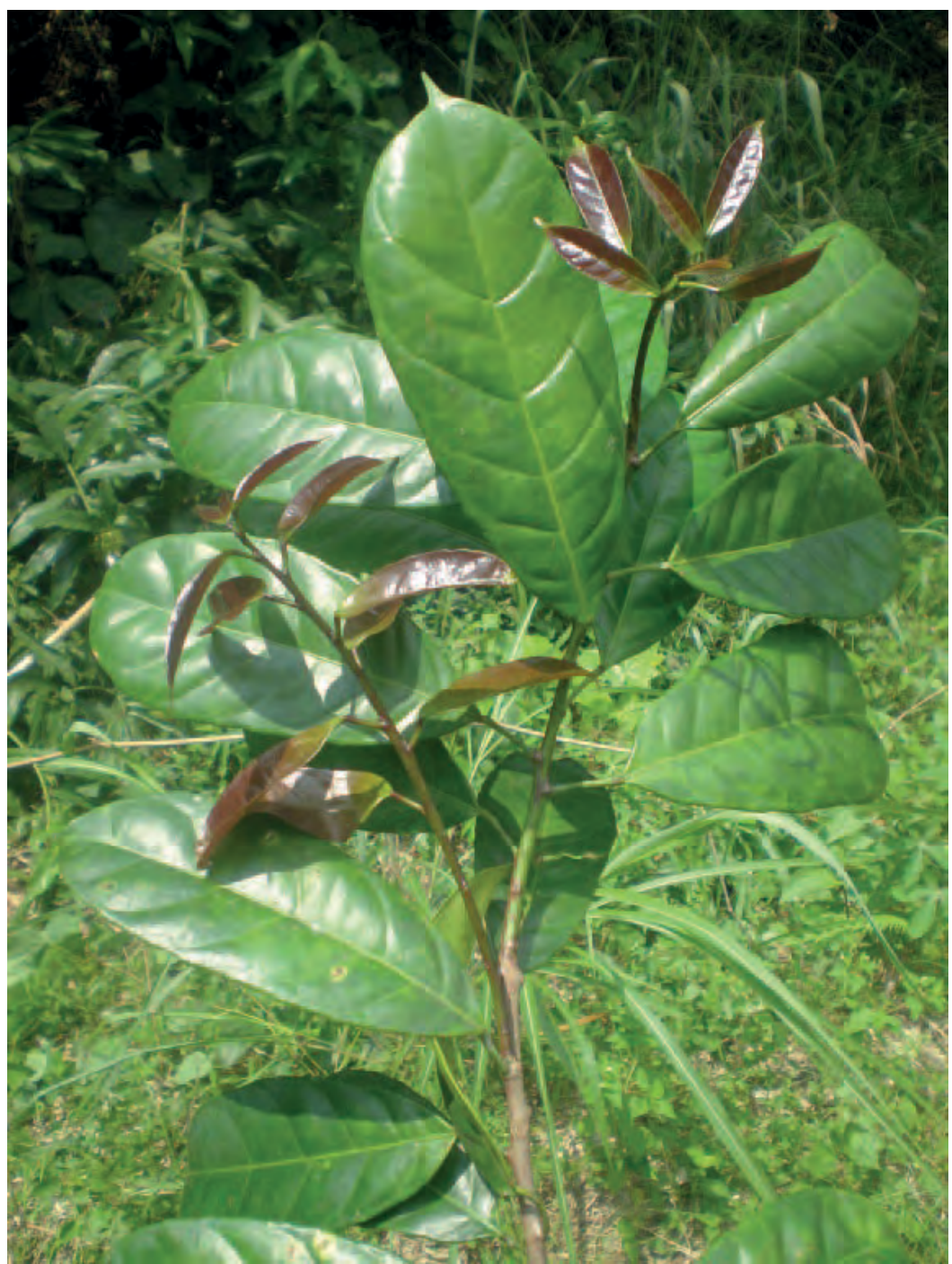

(Euphorbiaceae)

Description : Arbre de 3 à $25 \mathrm{~m}$ donnant un latex blanc. Feuilles brillantes de 8 à 20 sur 2,5 à $9 \mathrm{~cm}$, virant au jaune avant de tomber. Fleurs diö̈ques. Fruits rouges et sucrés, de 1,8 à 2,4 sur 1 à 1,2 cm.

Ecologie : Arbre des forêts galeries et forêts secondaires, du Sud du Nigéria aux deux Congo.

A gauche : Jeune arbre à Kilueka

Usages : Le bois est blanc jaunâtre. Au Gabon, on en fait des cuillers, des peignes et des épingles à cheveux. Au Kongo Central, on emploie une macération du cambium pour traiter les problèmes auditifs et la surdité. Dans toute l'Afrique Centrale, on boit une décoction de l'écorce pour traiter les douleurs pulmonaires et les courbatures fiévreuses. Les abeilles visitent les fleurs.

Références : Renier 1948, Bouquet 1969, Vivien et Faure 1985, Ambougou 1991, Pauwels 1993, Burkill 1994, White et Abernethy 1997, Nsimundele 2004, Schmelzer et Lemmens 2008 
Synonyme: Coleus esculentus

Noms courants : Bigondie (Kongo), viazi maji (Swahili), Livingstone potato (Angl.)

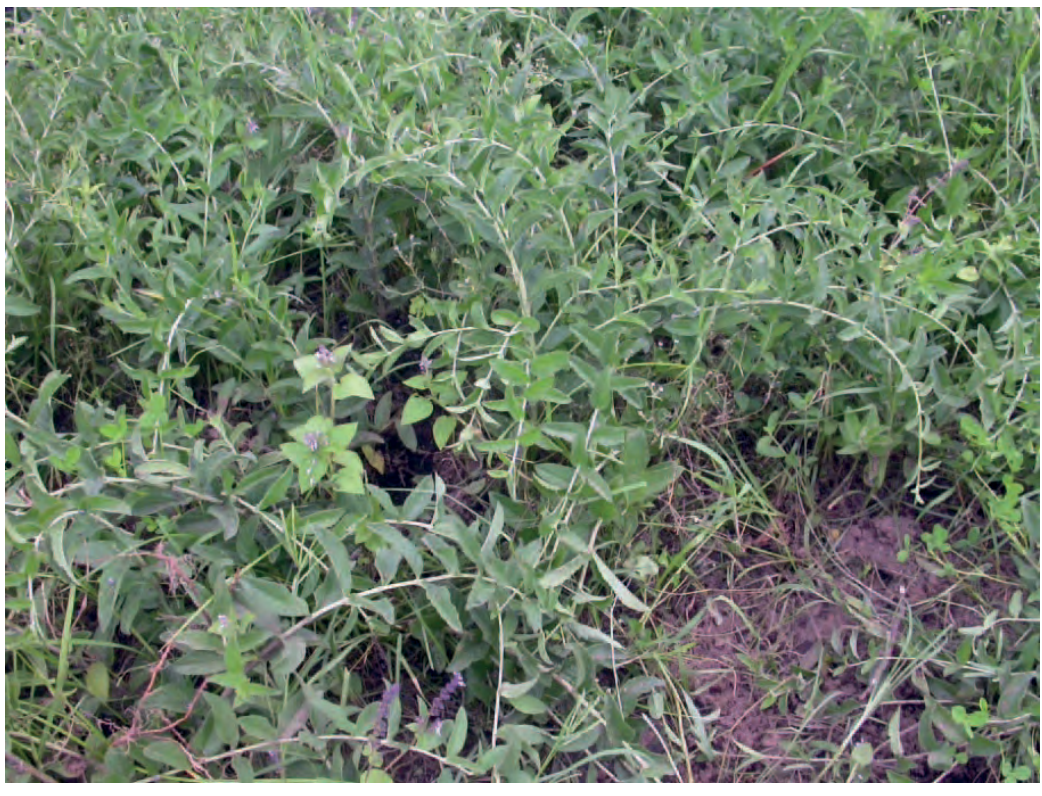

Description : Plante pérenne à tiges atteignant $90 \mathrm{~cm}$ poussant sur des racines tubéreuses. Tiges quadrangulaires velues, portant des paires de feuilles opposées presque sessiles, allongées et dentées. Les fleurs jaunes en bouquets dressés apparaissent avant les feuilles. Les tubercules forment des grappes à la base de la tige ; ils sont velus, sucrés, et parfois ramifiés. Ils ont jusqu'à 10 $\mathrm{cm}$ de long et $2 \mathrm{~cm}$ de diamètre.

Ecologie : Plante originaire d'Afrique tropicale, très adaptable, qui pousse dans diverses zones climatiques, pourvu que la pluie soit régulière pendant la saison de croissance, et le sol bien drainé.

contiennent à la récolte $29,3 \%$ d'hydrates de carbone et $7,7 \%$ de protéines. On les mange normalement crus, mais certains les font cuire sous la cendre pour réduire leur amertume. Autrefois, on donnait aux enfants au

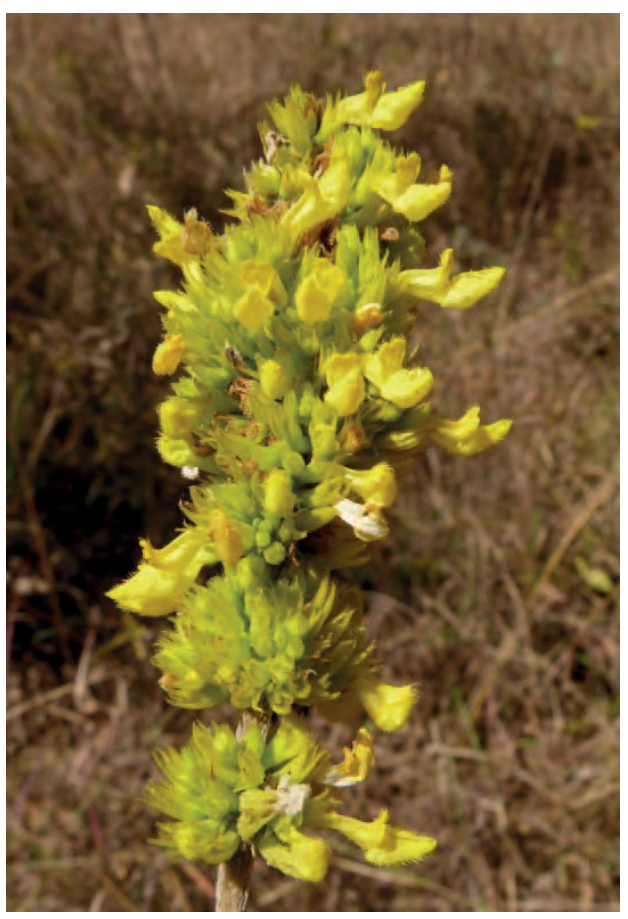
sevrage des tubercules bouillis et très doux; ceux-ci sont aussi appréciés par les malades incapables de manger autre chose. On peut sécher les tubercules pour les conserver. Certaines variétés ont des feuilles comestibles.

Reproduction : Par boutures de tiges de 10 à $20 \mathrm{~cm}$, ou par tubercules germés. On peut aussi employer des graines, mais elles germent lentement. On conserve de petits tubercules au frais jusqu'à germination, puis on les plante à plat à $5 \mathrm{~cm}$ de profondeur sur des buttes ou des billons espacées de 50 à $100 \mathrm{~cm}$, avec distances des

ligne de 30 à $100 \mathrm{~cm}$.

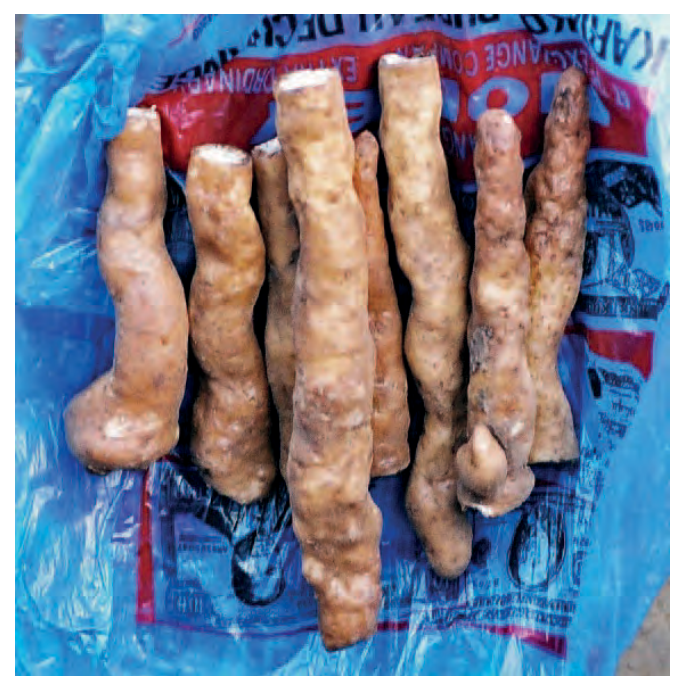

A gauche : Plante en fleurs. Photo: Warren McLeland www.africanplants.senckenberg.de

Gestion : Butter les plantes pour éviter le verdissement. La récolte a lieu 180 à 200 jours après la plantation. Les rendements varient de 2 à 25 tonnes à l'hectare.

Références : Renier 1948, Watt et Breyer-Brandwijk 1962, Busson 1965, Kay 1973, Harlan et al 1976, Tindall 1983, Tredgold 1986, Burkill 1995, Malaisse 1997, van Wyk et Gericke 2000, Dhliwayo 2002, Schippers 2002 
Noms courants : Dimpemba mpemba, lumpokopoko, lunwumu lu nseke (Kikongo)

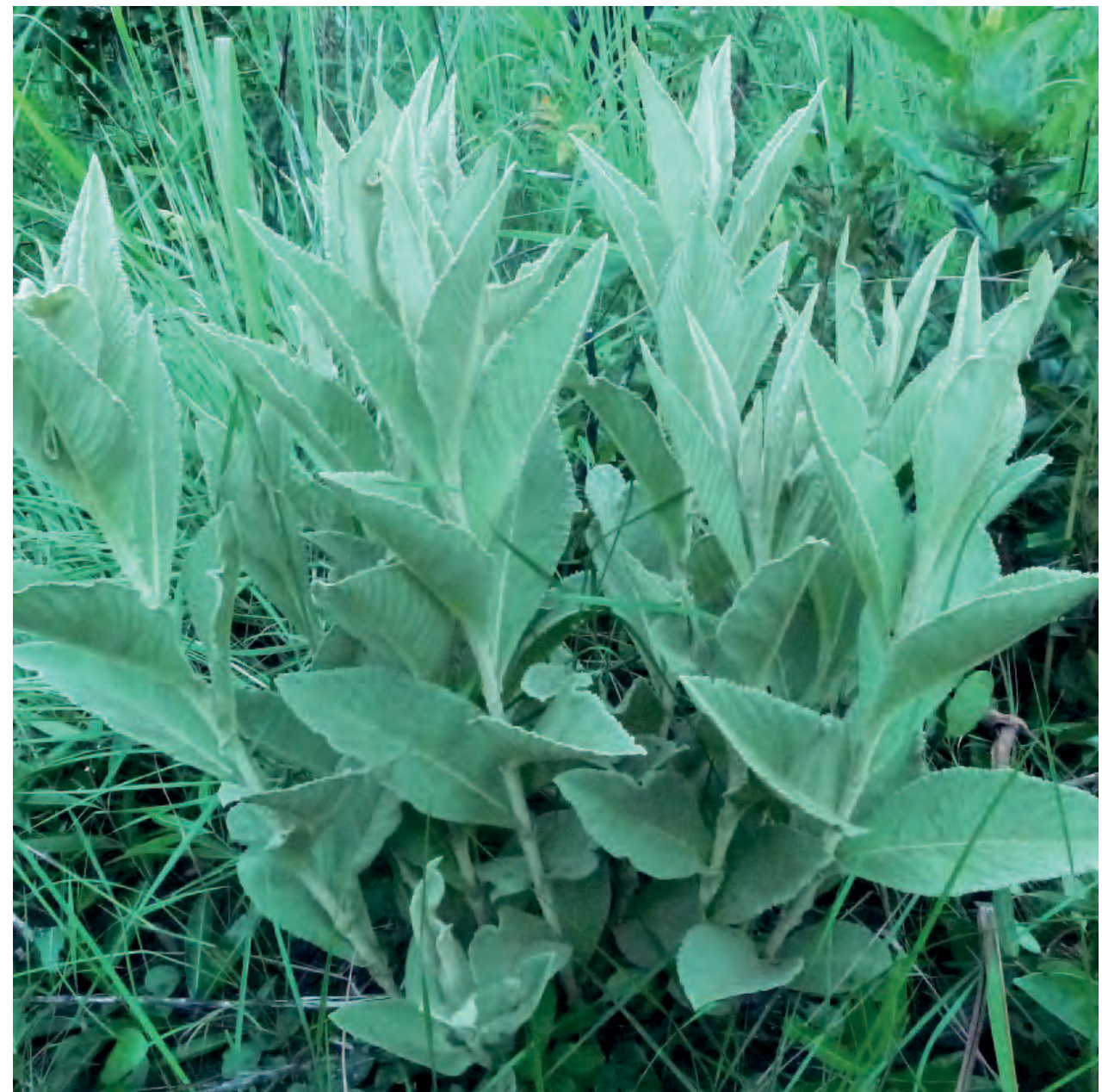

Description : Buisson de 25 à $130 \mathrm{~cm}$ de haut, donnant des feuilles chaque année à partir d'une souche ligneuse souterraine. Les tiges sont solitaires ou en touffes, cylindriques, grises, laineuses et densément feuillues. Les feuilles mesurent 10 à 15 sur 3 à $9 \mathrm{~cm}$, sur un pétiole de 1,5 $\mathrm{cm}$. Têtes florales terminales solitaires à pétales rouges, sur un pédoncule de 1 à 8 $\mathrm{cm}$.

Ecologie : Plante des savanes herbeuses et boisées en R.D. Congo, Angola, Tanzanie et Zimbabwe.

Usages : Les feuilles et les racines ont des usages médicinaux, pour traiter les blessures et les plaies, et les douleurs des veines et des artères.

Références : Lisowski 1989, Neuwinger 2000, Konda Ku Mbuta et al. 2015b

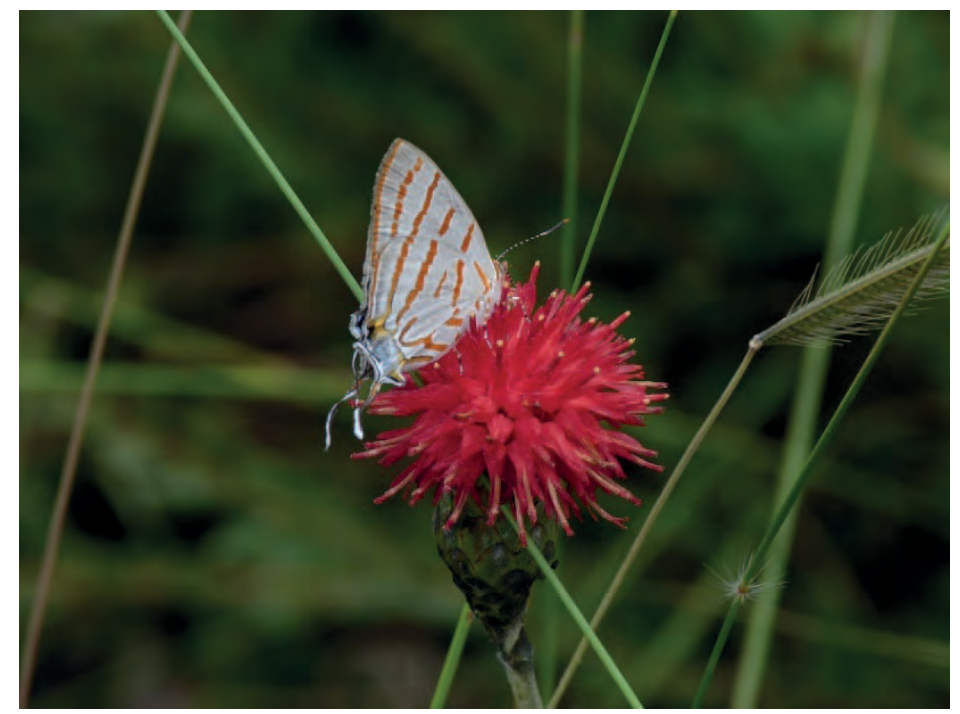

Photo : Warren McLeleand 


\section{Pleiotaxis pulcherrima}

Noms courants : Kasal-kangai (Kiluba), feu de Dieu (Fr.)

Description : Buisson de $25 \mathrm{~cm}$ à $1 \mathrm{~m}$ de haut, poussant sur une souche ligneuse. Les feuilles ont jusqu'à $20 \mathrm{x}$ $6,5 \mathrm{~cm}$. Le limbe porte en dessous un velours dense de fins poils blancs. Fleurs terminales, corolle écarlate à pourpre, jusqu'à $3 \mathrm{~cm}$ de long.

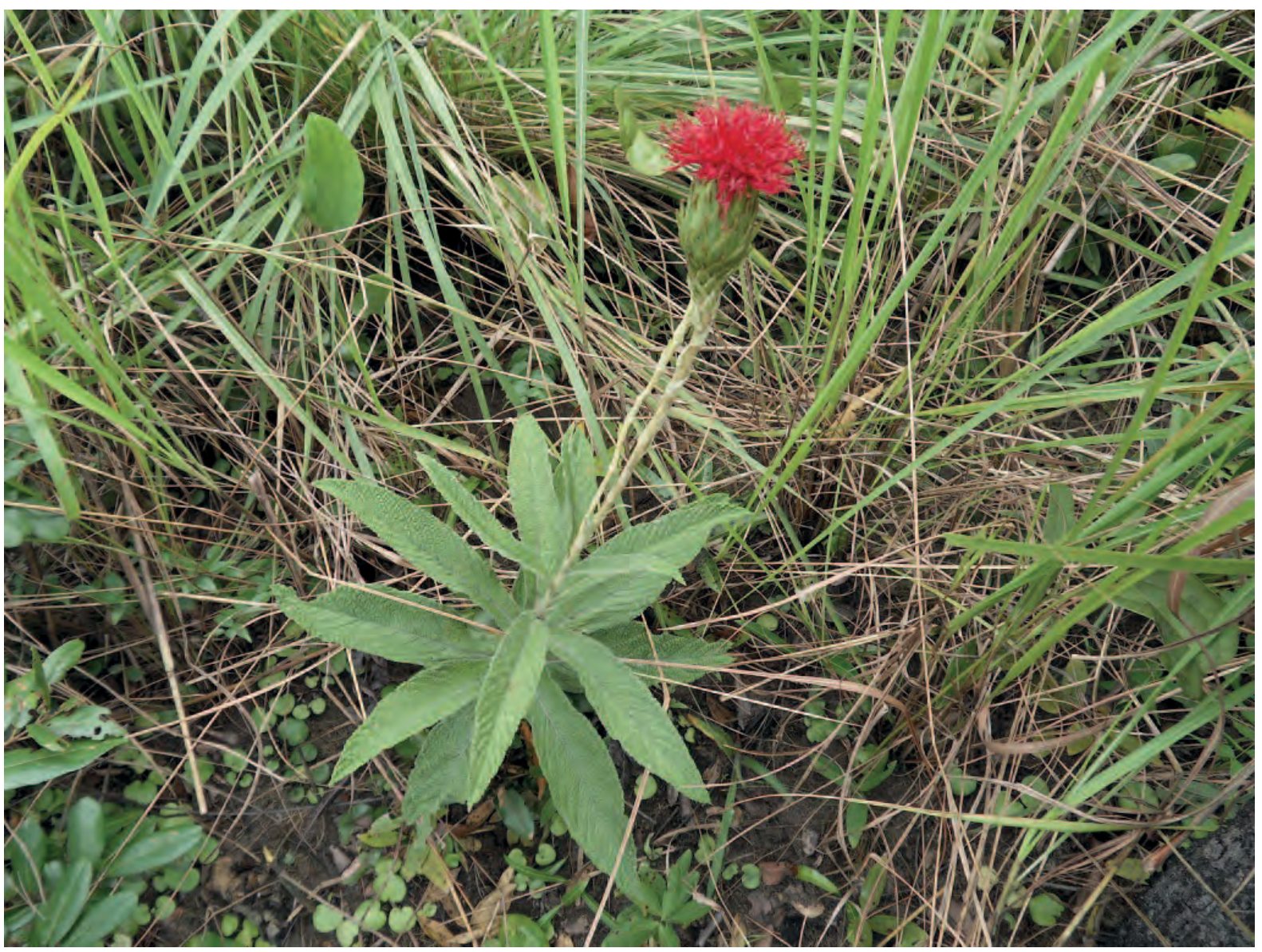

Pleiotaxis pulcherrima sur le plateau Bateke en février

Ecologie : Plante présente en savane herbeuse et boisée de l'Angola et la R.D. Congo à la Tanzanie et au Mozambique.

Usages : Les feuilles et les racines ont des usages médicinaux dans l'Est de la R.D. Congo. Culture possible comme plante ornementale.

Remarque: Dans le Nord de l'Angola, on mange les racines et les feuilles de $P$. rugosa (Ntelamakatexe ou kakatiana - Kikongo) pour traiter les douleurs abdominales et la diarrhée.

Références : Lisowski 1991, Neuwinger 2000, Baumann 2005, Stevens 2011, Göhre et al. 2016 


\section{Plumbago auriculata}

Noms courants : Plumbago (Fr. et Angl.).

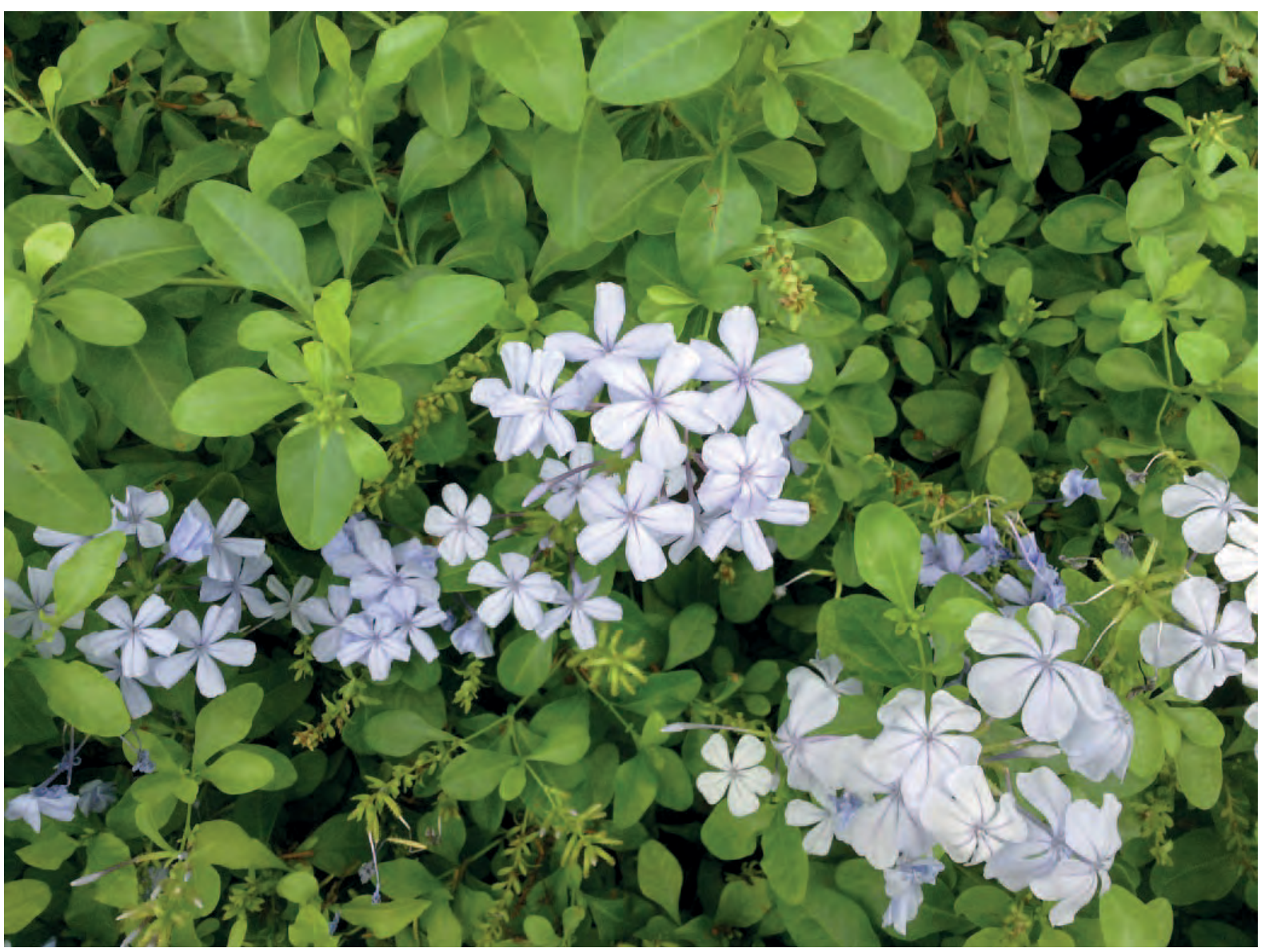

\section{Plumbago auriculata en fleurs à Kinshasa en mai}

Description : Buisson semi grimpant atteignant 3m de haut, glabre excepté l'inflorescence. Feuilles disposées en bouquets alternés. Feuilles de 3 à $7 \mathrm{~cm}$ de long sur de courts pétioles, marges des feuilles ondulées. Inflorescences en panicules compacts de nombreuses fleurs bleu pâle.

Ecologie : Plante originaire d'Afrique du Sud, maintenant largement cultivée en zones tropicales et subtropicales.

Reproduction : Par graines, boutures ou rejets. Semer les graines sous une légère couche de terre. Ne pas les laisser sécher. La meilleure méthode de reproduction est de prendre sur la plante mère des rejets portant des racines.

Gestion : On peut cultiver cette plante comme haie, mais il faut la rabattre et la contrôler, car elle produit de nombreux rejets. Elle répond bien à la taille. Elle fleurit abondamment après avoir été rabattue, ou après une poussée de croissance, les fleurs apparaissant sur le bois nouveau.

Usages : Cultivée comme haie et plante ornementale. Employée traditionnellement pour traiter les verrues, les fractures et les blessures. Reniflée comme du tabac à priser contre les maux de tête.

Références : Jex-Blake 1956, Aubrey 2001, Fayaz 2011, Cameron et Lowe 2017 


\section{Plumbago zeylanica}

(Plumbaginaceae)

Noms courants : Mwambula (Swahili), dentelaire de Ceylan (Fr.), white plumbago (Angl.)

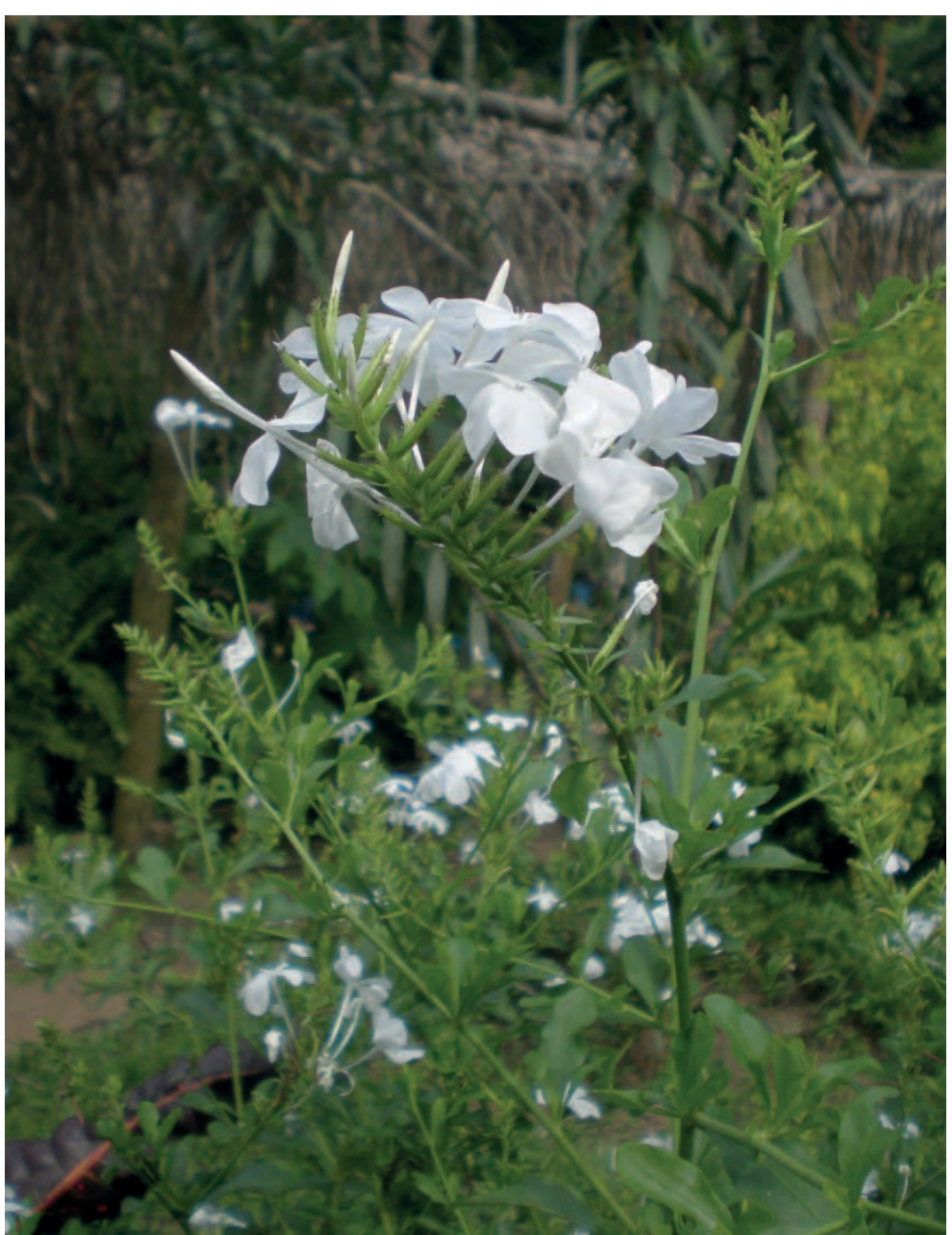

Description : Buisson rampant de 1 à 2 $\mathrm{m}$ de haut, grimpant occasionnellement à $4 \mathrm{~m}$. Feuilles alternes, de $70 \times 25 \mathrm{~mm}$, élargies vers le milieu ou en-dessous. Fleurs terminales, blanches ou parfois mauves. Le calice des fleurs est cylindrique, long de plus de $10 \mathrm{~mm}$ et couvert de longs poils glandulaires. Quand le fruit est mûr, les glandes deviennent très collantes, le calice se brise aisément, et s'attache au pelage des animaux, aux vêtements, et même à la peau.

Ecologie: Plante originaire d'Asie du Sud-Est, répandue sous les Tropiques. Elle pousse bien en plein soleil ou sous ombre partielle sur des sols acides.

A gauche: Plumbago zeylanica en fleurs en janvier.

Reproduction : Par graines, boutures, ou rejets portant de racines prélevés au bas de la plante.

Usages: Plante parfois cultivée, à titre médicinal ou ornemental. La substance active est la plumbagine, un antispasmodique et antibiotique, qui contient de la vitamine K. On l'emploie au Kongo Central pour traiter la gale. On l'emploie aussi parfois contre la tuberculose et la lèpre, mais elle est difficile à manipuler en raison de sa haute toxicité. En Angola la racine est utilisee pour soigner les plaies. Les fleurs seraient visitées par les abeilles.

Références : Renier 1948, Watt et BreyerBrandwijk 1962, Kokwaro 1976, Burkill 1997, van Wyk et al. 1997, Neuwinger 2000, Mungwini 2006, Leyens et Lobin 2009, Heinze et al. 2016

Photo de droite : Colin Reid

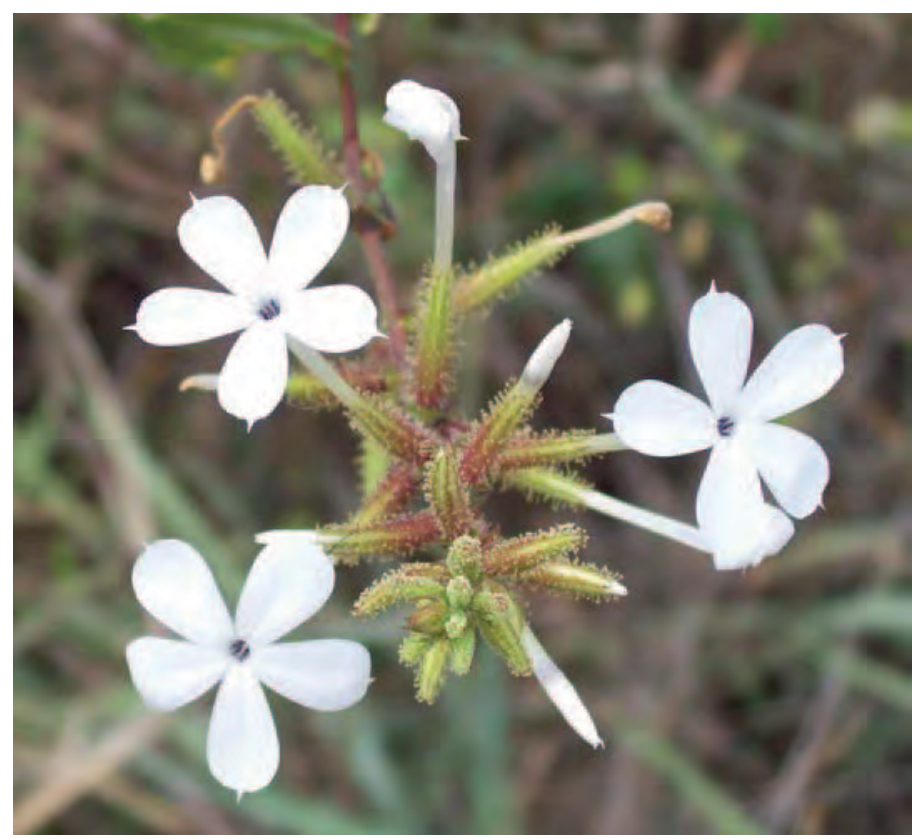




\section{Plumeria rubra}

Noms courants : Frangipanier (Fr), frangipani (Angl.)

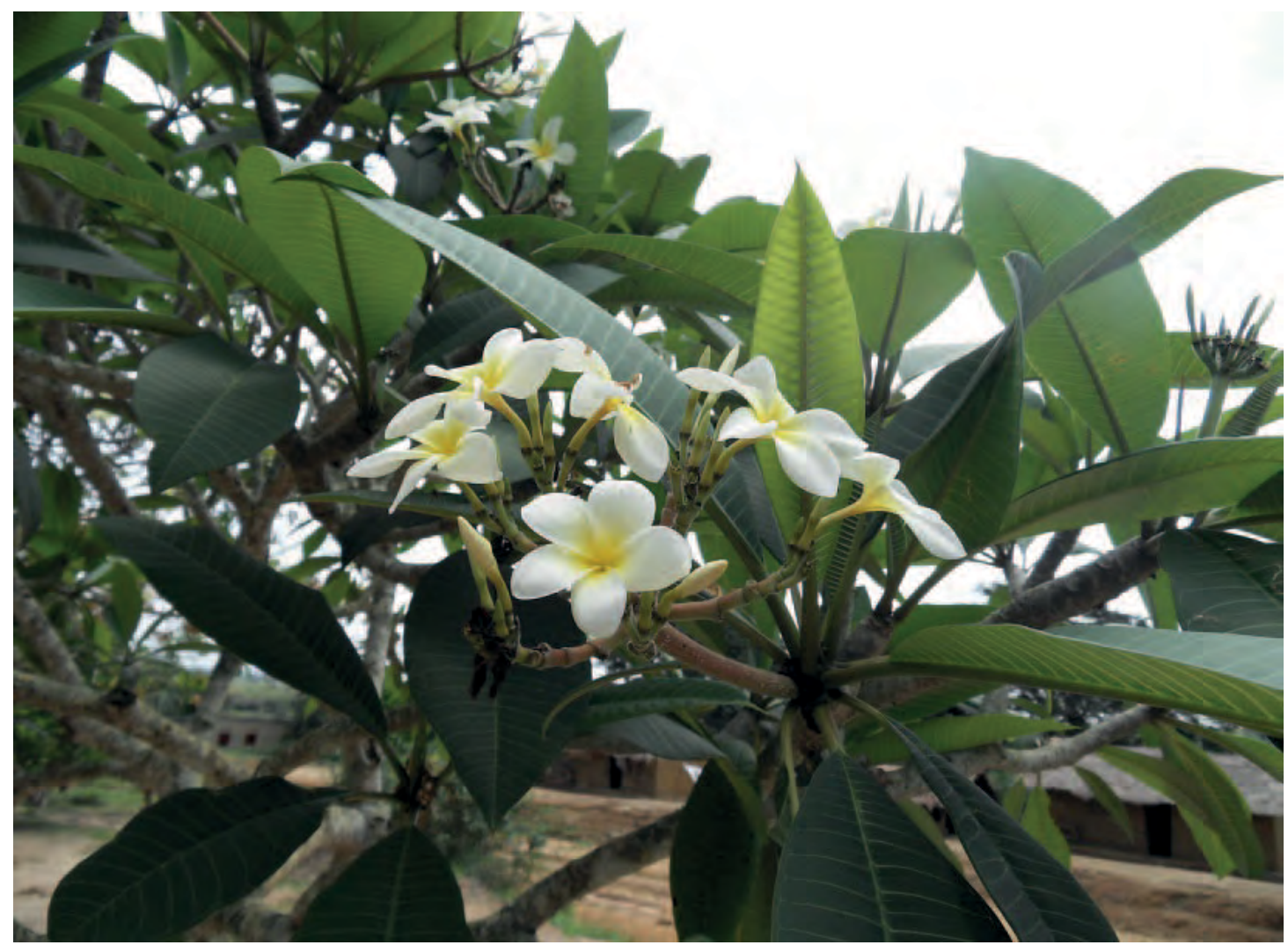

Description : Arbuste de 2 à $5 \mathrm{~m}$ de haut, à branches charnues, épaisses, fragiles, pourvues d'un abondant latex. Feuilles disposées en spirales en bouquets à l'extrémité des branches, sur des pétioles d'environ $6 \mathrm{~cm}$ de long. La feuille oblongue, pointue au bout, mesure 22 à 28 sur 7 à $9 \mathrm{~cm}$. Fleurs très parfumées, blanches, roses ou rouge pourpre.

Ecologie: Plante originaire d'Amérique Centrale, largement cultivée dans les parcs et jardins en climats tropicaux et subtropicaux.

Reproduction: Par boutures. Laisser la base sécher plusieurs jours avant de planter. Planter de sorte que la base reste juste en-dessous de la surface, sans être enterrée profondément.

Usages : Plante ornementale populaire dans les jardins. Le latex est fortement purgatif, et l'écorce est diurétique. Les fleurs ont un potentiel en parfumerie.

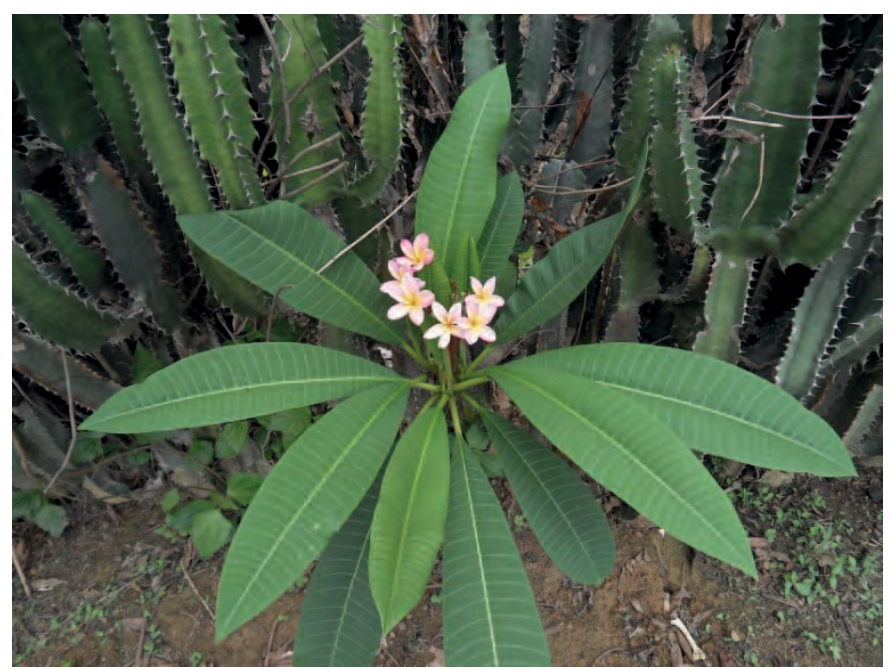

Remarque : On cultive aussi $P$. alba au Kongo Central.

Références ; Jex-Blake 1956, Burkill 1985, Pauwels 1993, Llamas 2003, Fayaz 2011, Cameron et Lowe 2017, Wikipedia (Consulté le 29.12.2018). 


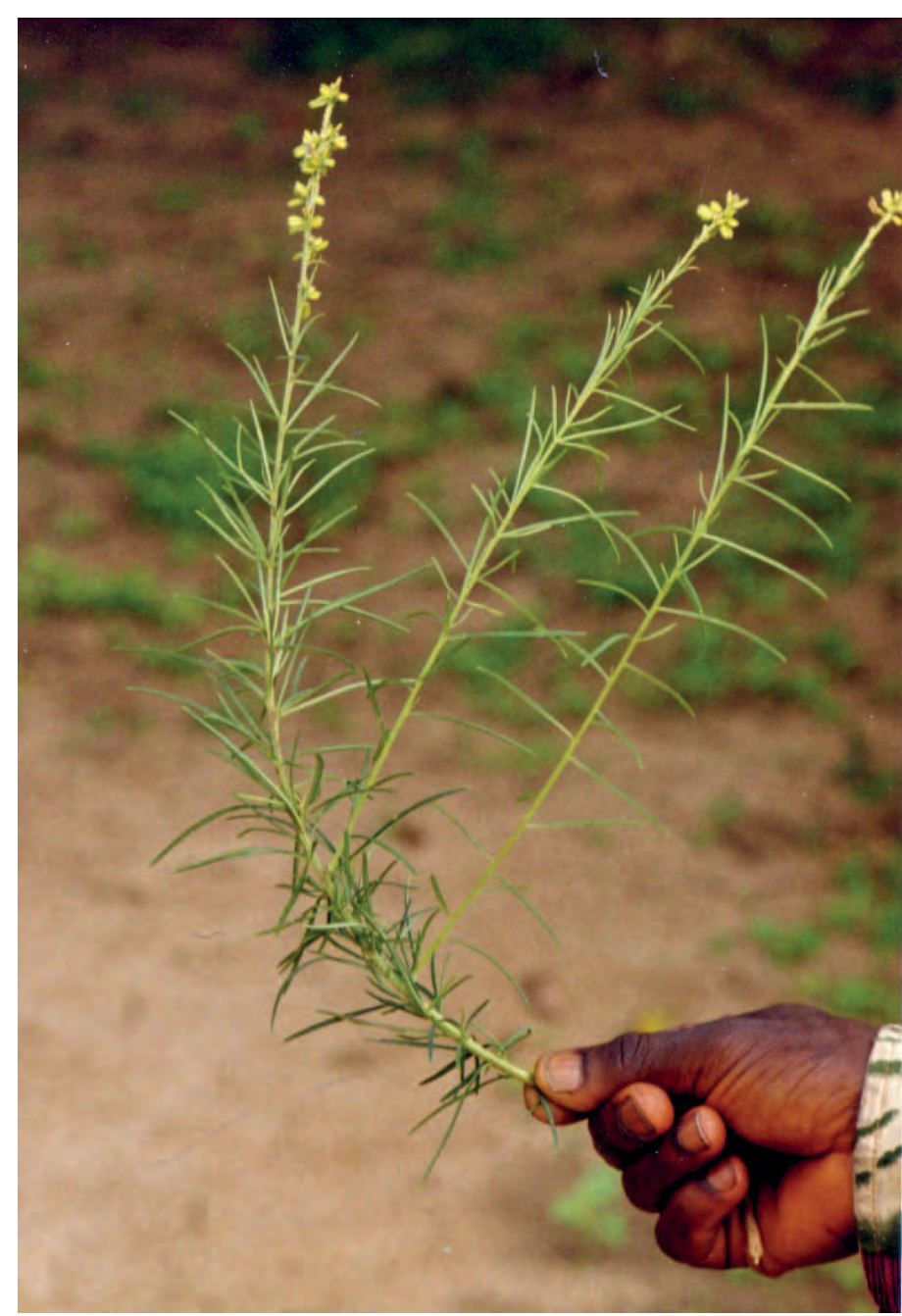

Noms courants : Lunsambinsambi (Kikongo), bosasobe (Lingala)

Description : Plante herbacée annuelle atteignant $1,5 \mathrm{~m}$ de haut, souvent ligneuse à la base. Feuilles de 1 à $6 \mathrm{~cm}$ de long. Nombreuses fleurs bleues terminales en janvier.

Ecologie : Plante des vallées près de l'eau en Afrique tropicale, en savanes, marécages, et terres cultivées. Altitude de 350 à $1600 \mathrm{~m}$. Présente au Nord du Nigéria, au Soudan, en Ouganda et en Angola.

Reproduction : par graines.

Usages: $\mathrm{Au}$ Kongo Central, on utilise les feuilles, les tiges et les racines pour traiter le diabète, les désordres mentaux, les hémorroïdes, la gastrite, l'épilepsie, les vers intestinaux et la toux. On fait bouillir les racines, et on fait boire le liquide contre les maux d'estomac. La poudre des racines est réputée efficace contre les maux de gorge. On applique l'écorce fraiche ou en poudre sur les plaies infectées. Les espèces de Polygala sont d'importants fourrages pour les abeilles en Afrique du Nord.

Références : Gillet et Pâque 1910, Petit 1958, Daeleman et Pauwels 1983, Burkill 1997, Hepburn et Radloff 1998, Neuwinger 2000, Kibungu Kembelo 2003 


\section{Portulaca oleracea}

Noms courants: N'dia ngulu, n'labanlaba (Kikongo), pourpier (Fr.), purslane (Angl.)

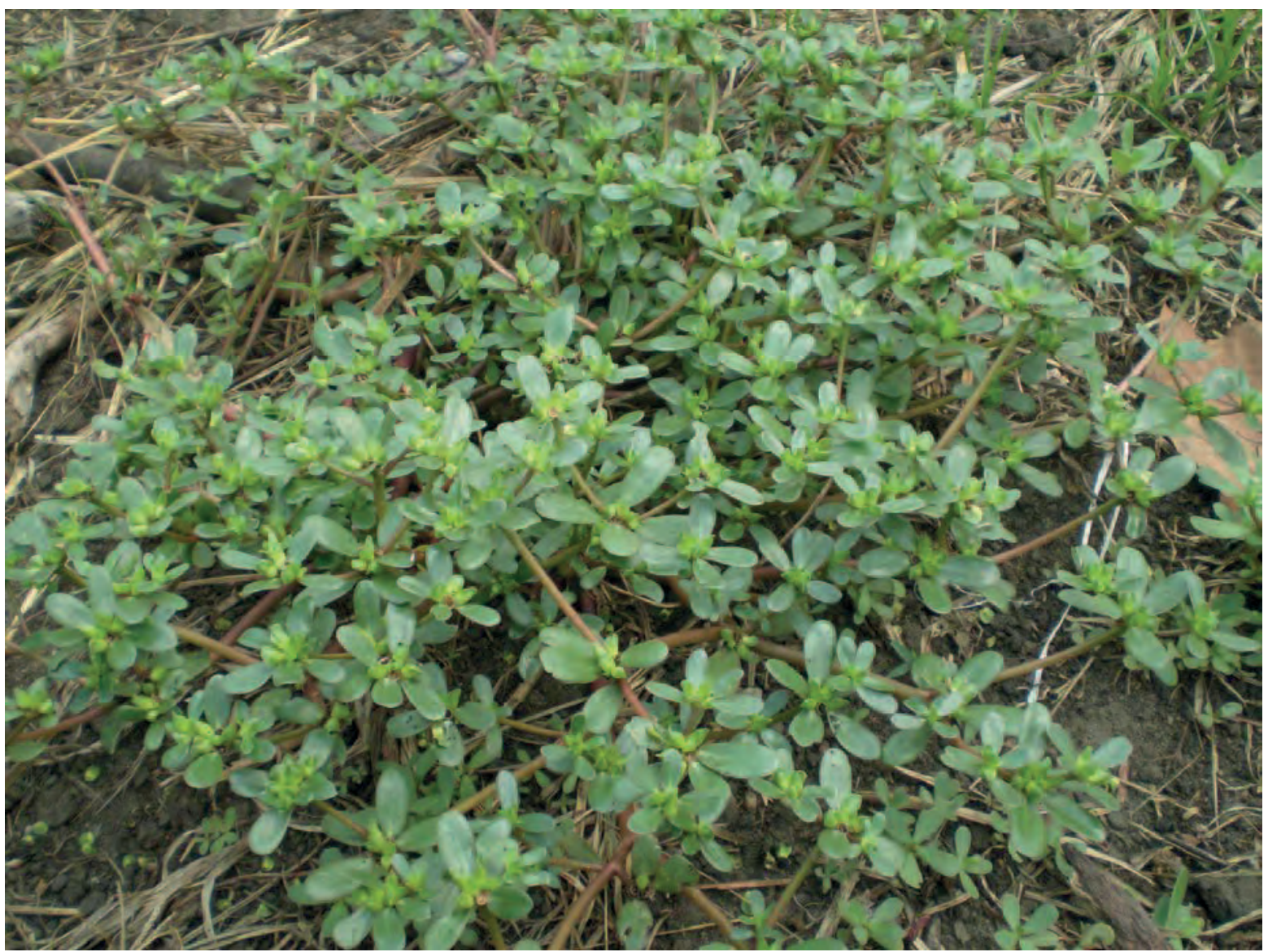

Description : Herbe annuelle charnue, très ramifiée, avec des tiges atteignant $30 \mathrm{~cm}$ de long. Les feuilles sont sessiles alternes, plus ou moins opposées, ou en spirale. Elles ont 10 à $30 \mathrm{~mm}$ sur 3 à $12 \mathrm{~mm}$. Les fleurs jaunes sessiles ont de 4 à $6 \mathrm{~mm}$ de long.

Pollinisation : Les fleurs bisexuelles s'ouvrent très brièvement, les abeilles butinent le pollen et sont supposées contribuer à la pollinisation.

Ecologie: Plante originaire d'Asie, mais devenue commune dans les friches tropicales et subtropicales. Longtemps cultivée comme légume dans le Sud de l'Europe, peut devenir envahissante, car elle résiste à l'arrachage.

Usages : On mange les feuilles succulentes, crues ou cuisinées, seules ou avec d'autres aliments. Elles sont également pâturées par le bétail. Elles sont riches en acide ascorbique, fer et calcium. Elles ont de nombreux usages médicinaux en Afrique. Au Kongo Central, ont fait bouillir les feuilles et les tiges, et on les donne aux femmes enceintes pour soulager les douleurs abdominales. On les emploie aussi comme diurétique, pour traiter les rhumatismes, la fièvre, les troubles du conduit urinaire, comme sédatif, et contre les vers intestinaux.

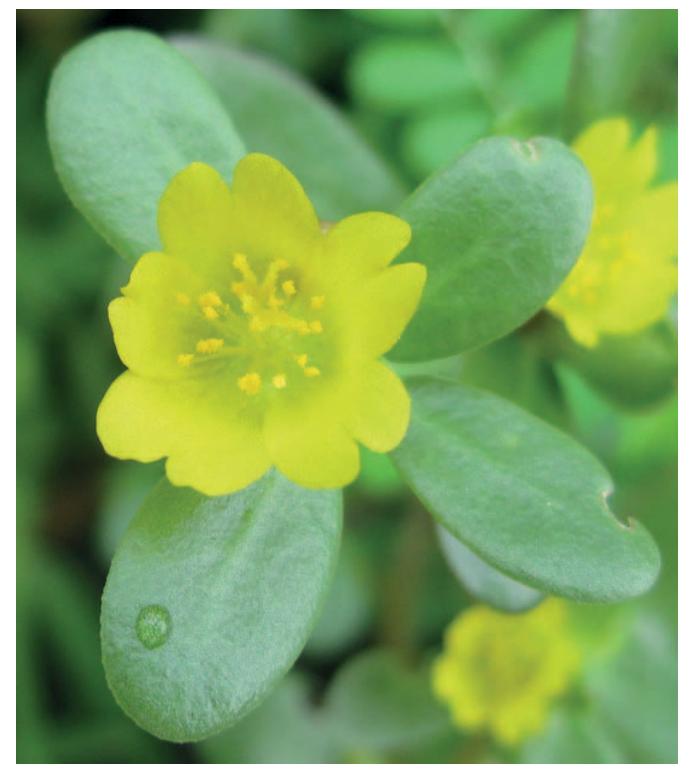

Photo: Ton Rulkens

Références : Gillet 1927, Renier 1948, Hauman 1951, Busson 1965, Nsimundele 1966 - 68, Daeleman et Pauwels 1983, Crane et Walker 1984, Burkill 1997, Malaisse 1997, El Jack 2004 
Noms courants : Bokana (Kikongo)

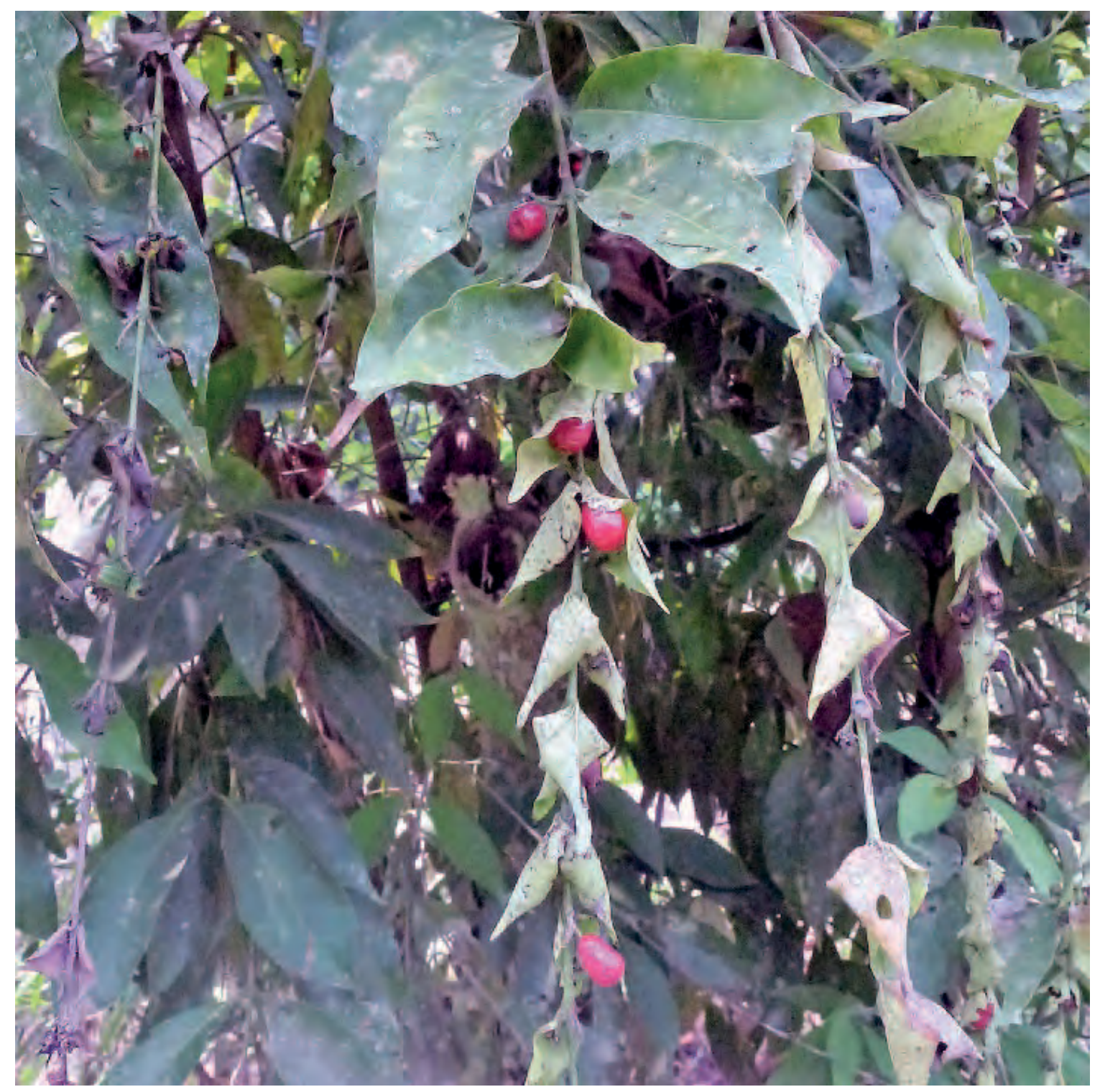

Pouchetia baumanniana portant des fruits au jardin botanique de Kisantu en août

Description : Plante buissonnante atteignant $3 \mathrm{~m}$ de haut, avec des fleurs pendulaires de couleur crème et des baies rouge foncé.

Ecologie : Se rencontre en forêt et savane du Nigéria à l'Angola.

Usages: Les fruits seraient comestibles. Au Sénégal on emploie une décoction des feuilles pour soulager les douleurs.

Remarques : La plante s'associe souvent avec des fourmis.

Références : Renier 1948, Martin et al. 1987, Burkill 1997, White et Abernethy 1997, Kew Science (Consulté le 10.11.2018) 


\section{Premna matadiensis}

\section{Synonyme : $P$. congolensis}

Description : Arbuste ou plante grimpante atteignant $3 \mathrm{~m}$ de haut. Feuilles opposées, ovales à elliptiques, pétiole de 1 à $2 \mathrm{~cm}$ de long, de 4 à $11 \mathrm{~cm}$ de long et de 3,2 à $5,5 \mathrm{~cm}$ de large. Fleurs blanc verdâtre. Fruits noirs, $5 \times 5$ $\mathrm{mm}$.

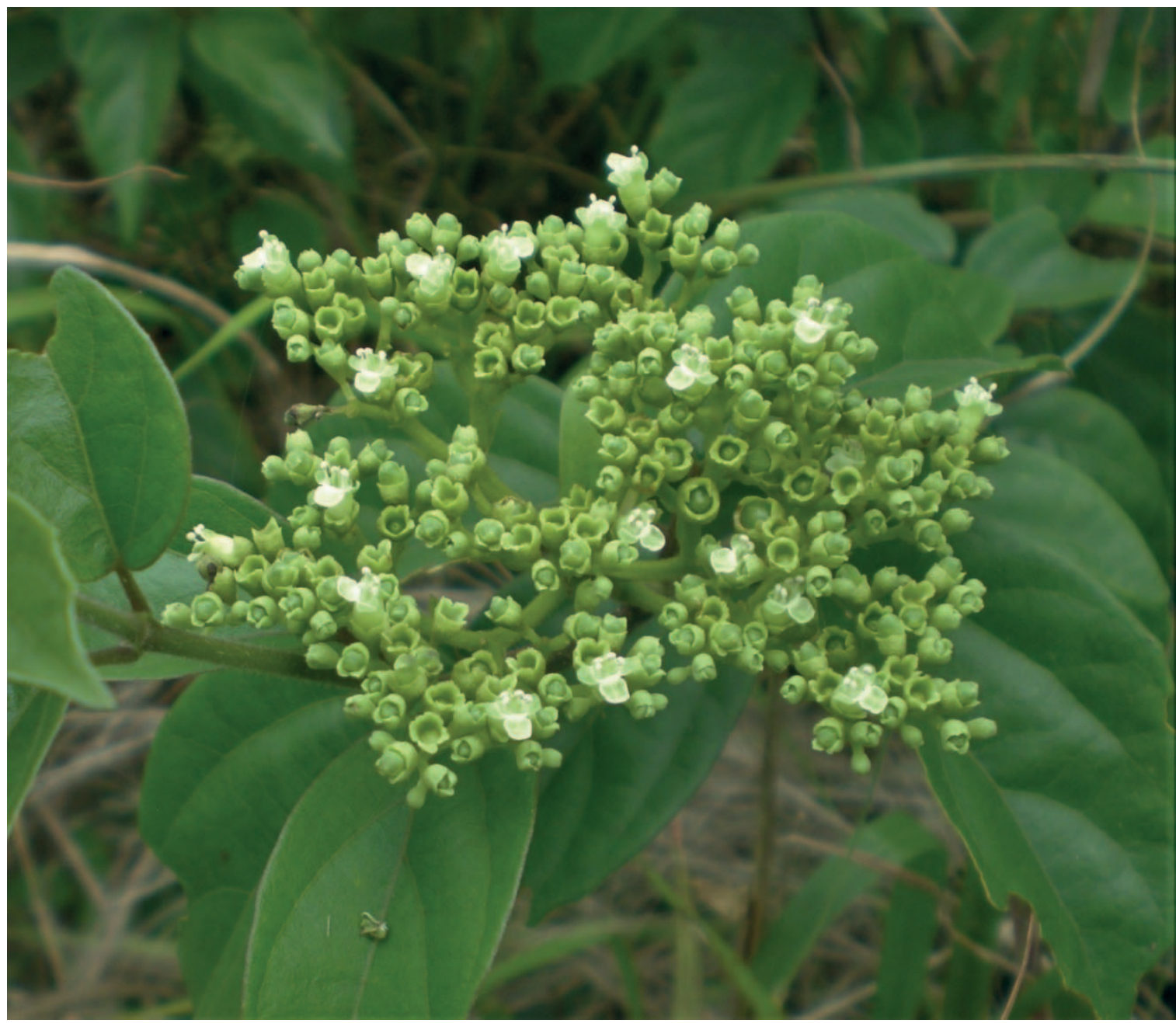

Les deux photos ont été prises à Sombala en décembre

Ecologie : Présent dans la savane, galeries forestières et les jachères de l'ouest de la R.D. Congo et Angola.

Usages: On utilise pour le bois plusieurs espèces de Premna

Remarque: On trouve aussi $P$. angolensis et $P$. congolensis au Kongo Central. $P$. angolensis est un arbre des forêts de terre ferme. $P$. quadrifolia a des fleurs de couleur lilas à bleu et se cultive à titre ornemental.

Références : Gillet 1927, Pauwels 1993, Paton

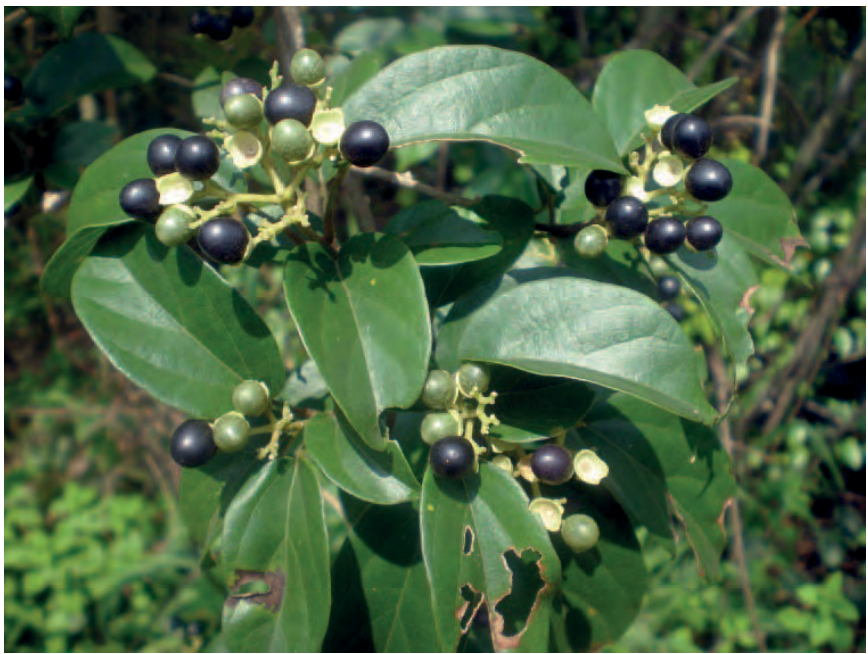
et Meerts 2020 
Synonyme : Mussaenda stenocarpa

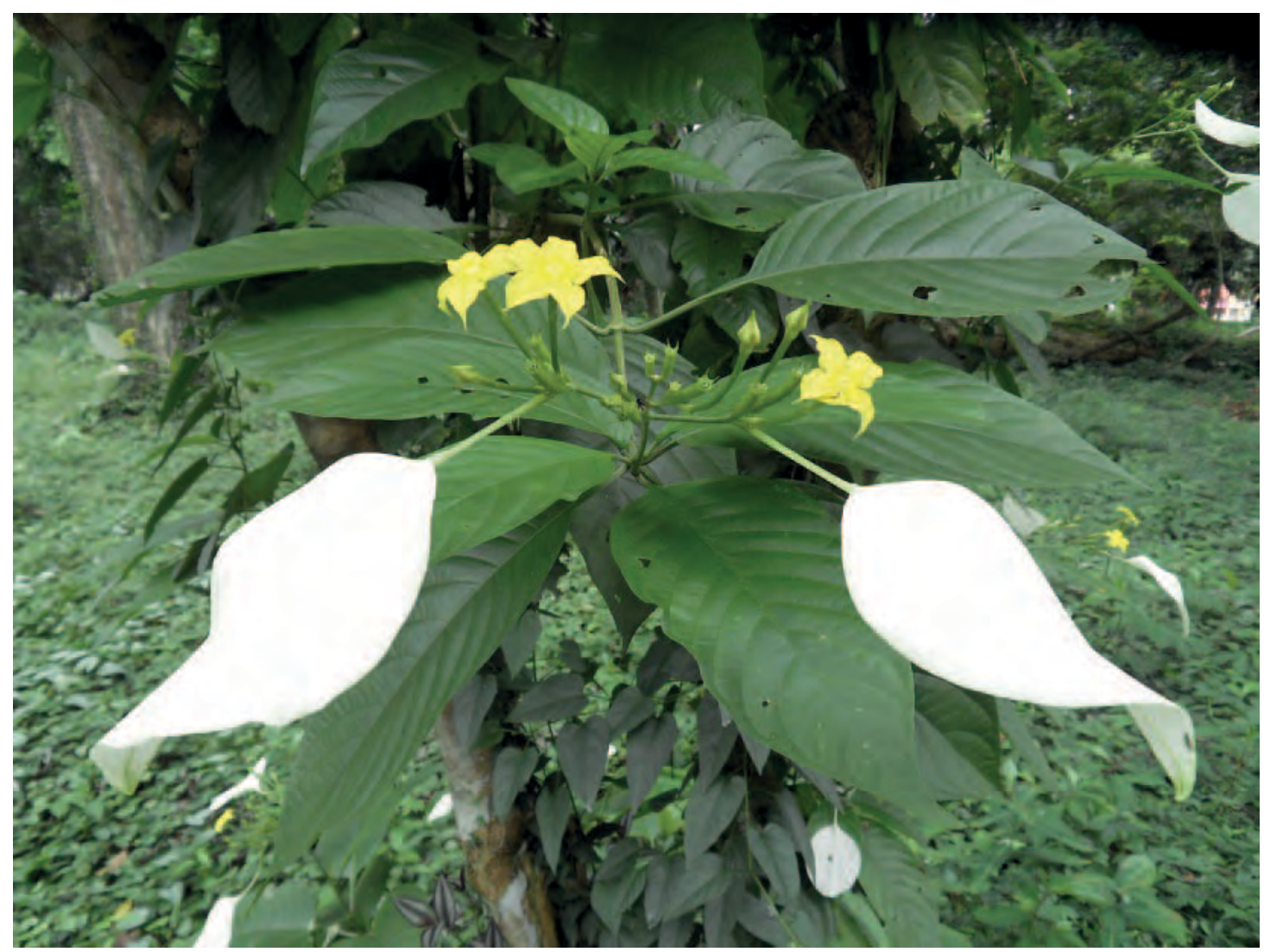

Pseudomussaenda stenocarpa en fleurs en mai

Description : Buisson d'un à quelques mètres de haut. Feuilles elliptiques en coin à la base et pointues au bout, de 9 à 17 sur 4 à $6 \mathrm{~cm}$. Inflorescences terminales lâches, dans lesquelles quelques fleurs sur les bords ont un lobe blanc élargi, qui agit comme un organe d'attraction visuelle. Fruit cylindrique indéhiscent jusqu'à $2 \mathrm{~cm}$ de long. Fleurs en janvier, mars, mai et décembre.

Ecologie : Forêts secondaires au Cameroun, en Centrafrique, au Congo Brazzaville et en R.D. Congo.

Usages: Au Congo Brazzaville, on emploie une décoction de cette plante, avec d'autres, en bain de vapeur pour traiter les troubles cardiaques, la fièvre et la toux. A Turumbu, R.D. Congo, on fait une poudre avec l'écorce des racines pour la mettre en gouttes dans les narines contre la malaria.

Références : Pauwels 1993, Neuwinger 2000 


\section{Pseudospondias microcarpa}

Nom courant : Nyibu (Kikongo)

Description : Arbre de 6 à $20 \mathrm{~m}$ de haut, avec un tronc de 3 à $18 \mathrm{~m}$, tordu, avec de grands contreforts. L'écorce se détache en grandes écailles. Feuilles composées de 5 à 21 folioles dissymétriques, chacune de 5 à 17 sur 2,4 à $6 \mathrm{~cm}$. Fleurs mâles et femelles distinctes. Inflorescences longues de 10 à $60 \mathrm{~cm}$ de couleur blanc verdâtre. Fruits ellipsoïdes, de 3 à 3,5 cm de long, bleu noir à maturité, à l'odeur assez prononcée.

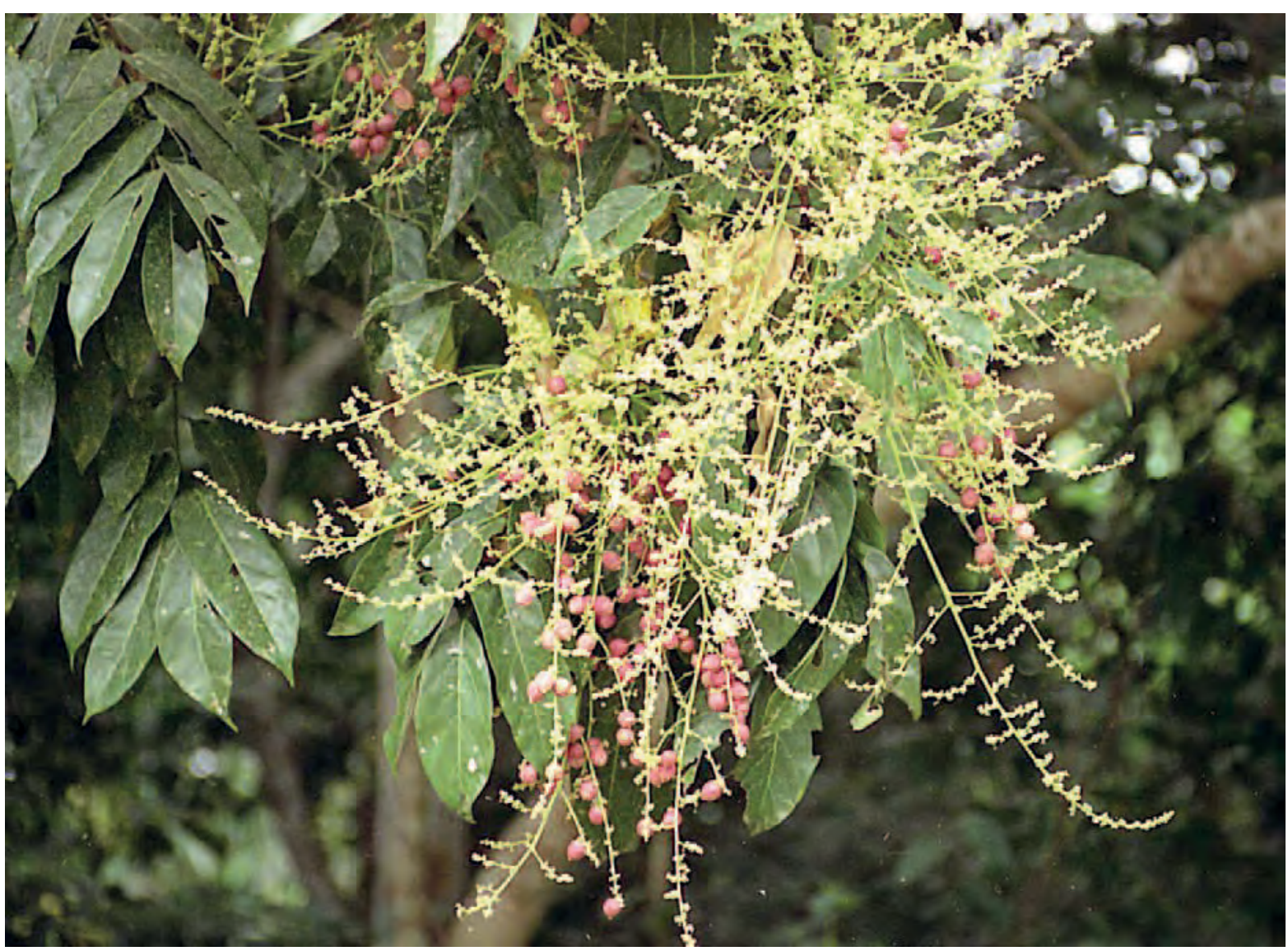

Arbre portant des fleurs et des fruits au jardin botanique de Kisantu en août

Ecologie : Arbre des lisières de forêts et des forêts secondaires, dans les sites humides et les berges de cours d'eau, en Afrique de l'Ouest, jusqu'en Angola, Ouganda et Malawi.

Reproduction : L'arbre peut se cultiver à partir des graines, que l'on trempe 12 heures dans l'eau avant de les semer. Les graines se conservent 5 mois, le mieux étant de les garder dans le fruit séché entier. On peut aussi planter les semis spontanés ou faire des boutures. Les jeunes arbres doivent se planter dans des lieux humides.

Gestion : Arbre à croissance rapide, qui recèpe bien et se conduit en taillis.

Usages : Fruits comestibles sucrés au goût de térébenthine. Le bois est tendre ou assez dur, gris ou verdâtre, déformable, peu durable et sujets aux attaques d'insectes. II arrive qu'on l'emploie pour des poteaux ou des planches. Au Kongo Central, on emploie l'écorce pour traiter la dysenterie et les douleurs abdominales. Les feuilles comme l'écorce donnent du tannin. Les abeilles butinent les fleurs en janvier et en août. Au Gabon, les espèces de Pseudospondias sont connues comme fourrage des abeilles. L'arbre donne une ombre épaisse.

Références : Gillet et Pâque 1910, Gillet 1927, Van Der Veken 1960, Nsimundele 1966 - 68, Burkill 1985, LobreauCallen et al. 1989, Ambougou 1991, Peters et al. 1992, Pauwels 1993, Katende et al. 1995, Nsimundele 2004, Harris et al. 2011, Latham et Konda Ku Mbuta 2017 


\section{Psidium guajava}

Noms courants : Fulunta, difuelenta, dipela (Kikongo), goyavier (Fr.), guava (Angl.)

Description : Arbuste de 6 à $10 \mathrm{~m}$ de haut. L'arbre donne des magnifiques fleurs blanches aux étamines dorées. Le fruit est une grosse baie arrondie, d'environ $8 \mathrm{~cm}$ de diamètre jaune avec une chair rose.

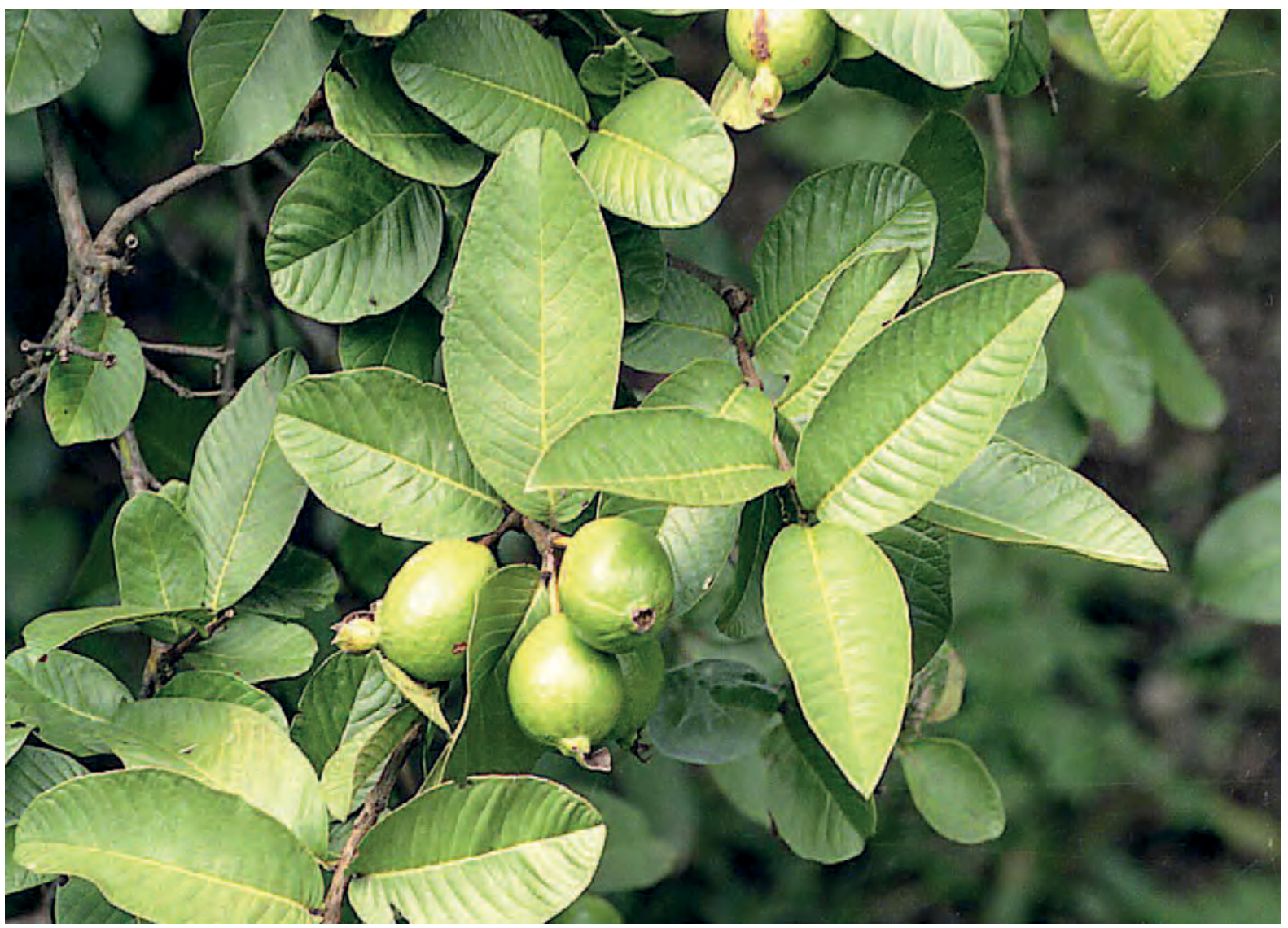

Ecologie : Originaire des Caraïbes et de l'Amérique centrale cultivé maintenant partout sous les tropiques, peut devenir sérieusement envahissant. Tolère les inondations temporaires et les fortes chaleurs.

Reproduction : Sélectionner une bonne variété et la reproduire par marcottage. On peut aussi cultiver l'arbre à partir de rejets, que l'on peut provoquer en coupant la racine 60 à $90 \mathrm{~cm}$ en dessous du tronc.

Gestion : L'arbre est productif entre 2 et 8 ans après plantation.

Usages: Les fruits comestibles sont variables en forme et en goût, allant du sucré à l'aigre. Les fruits mûrs se mangent crus, ou en compote. La goyave contient 2 à 5 fois plus de vitamines que le jus d'orange. Elle est une source importante de vitamine $C$, et une bonne source de vitamine $A$, fer, calcium et phosphore. La consommation du fruit mûr protège du scorbut. Les bois, dur, s'emploie pour les manches d'outils. Au Kongo Central, on boit une infusion des feuilles contre les vers intestinaux, la colique et la fièvre. La consommation des fruits verts, ainsi que l'infusion des feuilles, sont efficaces contre la diarrhée. Les abeilles butinent les fleurs, elles récoltent beaucoup de pollen et un peu de nectar. Le miel produit est jaune pâle, faiblement visqueux, et agréable au goût. Dans certains pays, les feuilles s'emploient en teinturerie et tannerie.

Références : Gillet et Pâque 1910, Renier 1948, Purseglove 1968, Daeleman et Pauwels 1983, Ambougou 1991, Bekele-Tesemma et al. 1993, I wu 1993, Pauwels 1993, Lakshmi et Mohana Rao 1998, Hirt et M'pia 2001, Nsimundele 2004, Pousset 2004, van Wyk et Wink 2004, Lautenschläger et al. 2018 
Noms courants : N'kisu (Kikongo), faux goyavier, goyavier acide (Fr.), Guinea guava (Angl.)

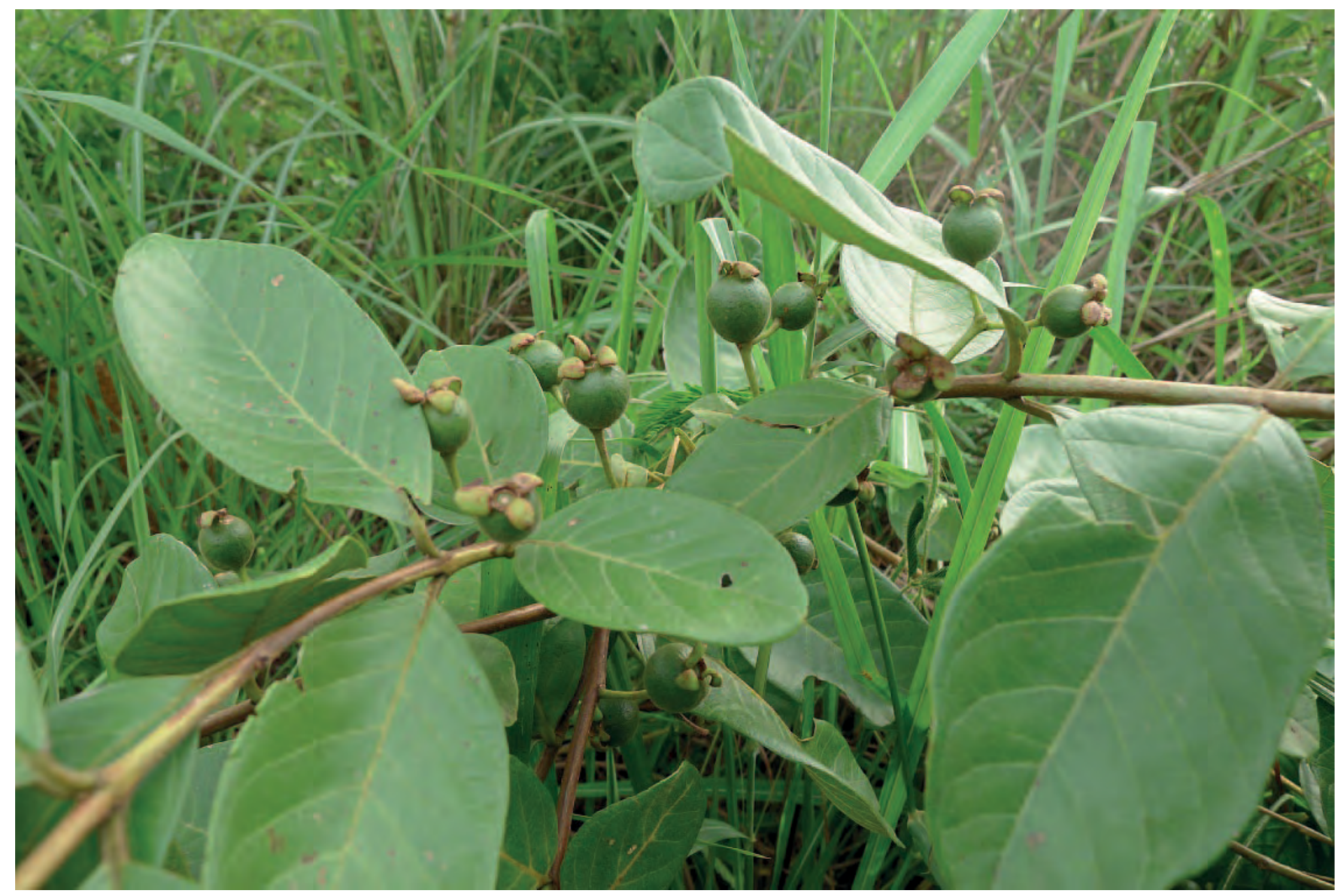

Description : Arbrisseau de 1,5 à $4 \mathrm{~m}$ de haut. Il se distingue de $P$. guajava par de jeunes branches pubescentes de section circulaire, et des feuilles ayant de 7 à 10 paires de nervures secondaires. Feuilles de 10 à 12 sur 6 à 7,5 cm, recourbées au bout et pubescentes en-dessous. L'inflorescence est composée de 1 à 3 fleurs blanches. Le fruit est une baie globulaire à ovoïde de 3 à $4 \mathrm{~cm}$ de diamètre. Espèce très variable, se croisant très facilement avec $P$. guajava.

Ecologie: Plante originaire d'Amérique tropicale, cultivée au Kongo Central, spécialement autour de Kisantu, mais pousse mal sur les sols sablonneux.

Usages: Le fruit a un goût aigre et acide agréable, on en fait des gelées. Le bois est dur, et sert pour les manches d'outils et les instruments agricoles. L'écorce, riche en tannins,

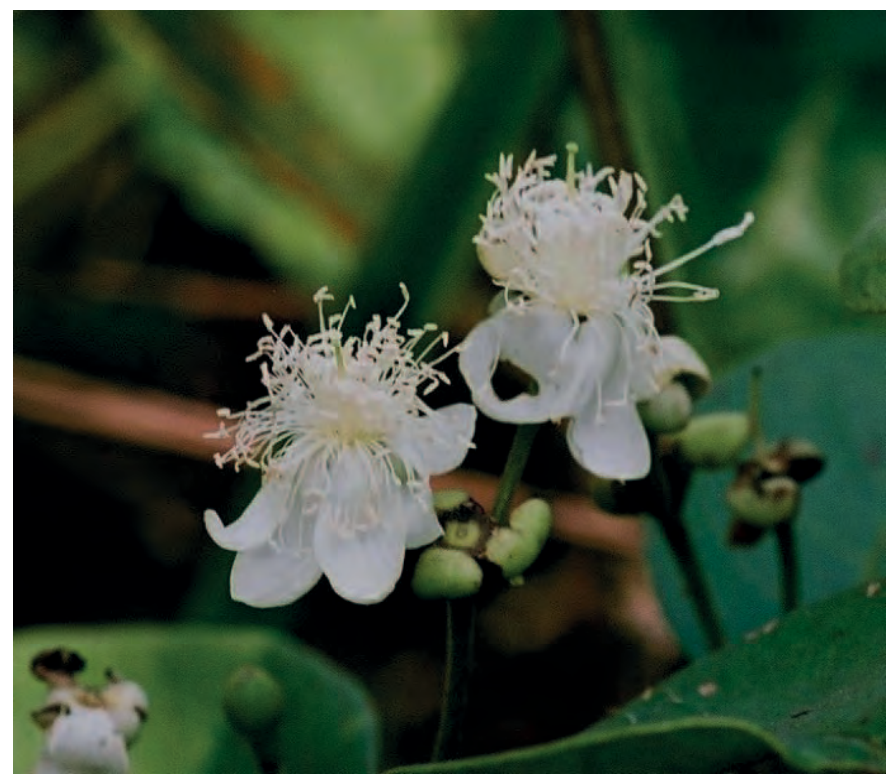

s'emploie pour tanner les peaux. On emploie une décoction de l'écorce ou des racines pour traiter les désordres urinaires, la diarrhée et la dysenterie. Au Costa Rica, on dit qu'elle réduit les varices et ulcères sur les jambes. On prend une décoction des feuilles contre les refroidissements et les bronchites.

Références : Boutique 1968, Uphof 1968, Martin et al. 1987, Verheij et Coronel 1991, Pauwels 1993, Roubik 1995, Wikipedia (Consulté le 1.11.2018) 
Noms courants : Kikalakasa (Kikongo), bangassu, boonga, boussaka (Lingala), African winged bean (Angl.)

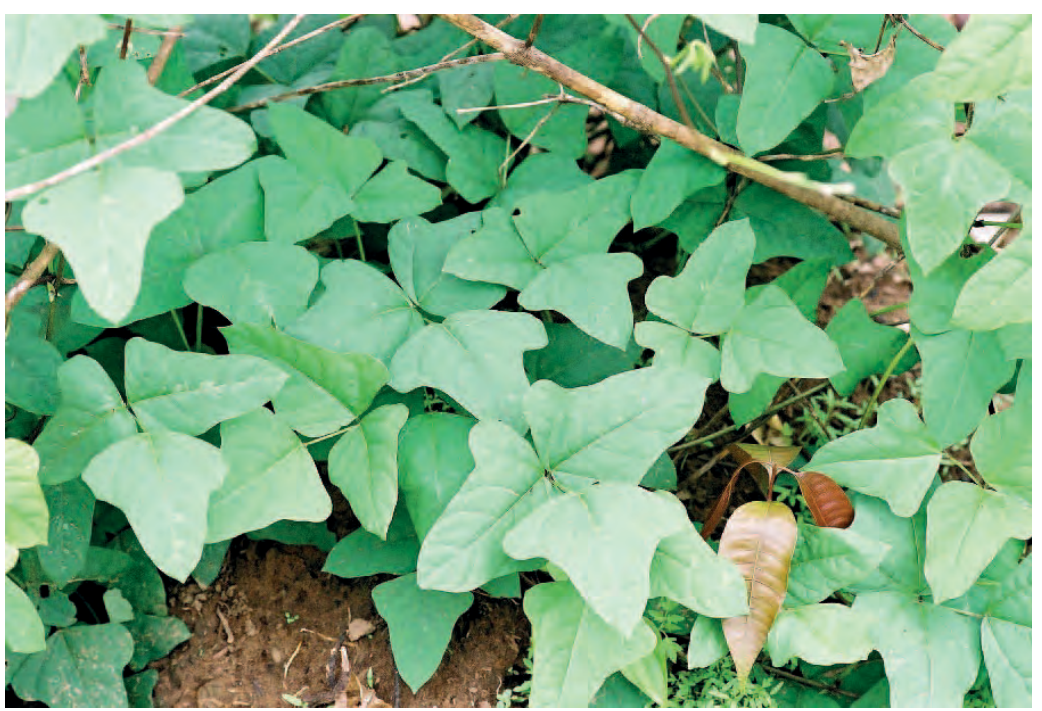

Description : Liane pérenne ligneuse pouvant avoir $6 \mathrm{~m}$ de long. Feuilles composées de 3 folioles de 2,5 à 12 sur 1,8 à $10 \mathrm{~cm}$ sur un pétiole de 5 à $18 \mathrm{~cm}$. Fleurs bleues ou violacées, de 1,6 à $2,4 \mathrm{~cm}$ de long. Les fruits ailés, de section rectangulaire, ont de 3,5 à 8 sur 1 à $2 \mathrm{~cm}$ et contiennent de 5 à 8 graines.

Ecologie: Plante présente en savane et forêts galeries; dans les friches et autour des marais, dans toute l'Afrique Centrale, du Cameroun à I'Angola, en Tanzanie, au Mozambique et à Maurice.

Reproduction: II faut gratter ou scarifier les graines avant semis pour faciliter la germination. Les graines se conservent durablement. Semer directement à des espacements de $50 \times 50$ $\mathrm{cm}$.

Gestion : Peut se cultiver en treillis; dans ce cas, semer une ou deux graines près du pied de chaque support. La culture pousse bien en association avec la patate douce. Un désherbage précoce est important. On enlève habituellement les feuilles avant l'apparition des fruits ; on peut alors les sécher et les mettre en poudre pour utilisation ultérieure.

Usages : Légume intéressant. Les feuilles, les gousses, les germes, les graines et les tubercules sont tous comestibles. Les feuilles fraîches contiennent $7 \%$ de protéines, les feuilles sèches $39 \%$. On peut en faire une farine que l'on mélange avec d'autres farines. Les graines rôties donnent une excellente farine contenante $33 \%$ de protéines. On sait que les feuilles stimulent la lactation des mères. En Ubangi, on traite le lumbago en appliquant un cataplasme fait avec une pâte de feuilles fraiches. La sève s'emploie pour traiter les douleurs; avec Lannea welwitschii, on en fait un bain de bouche contre les infections.

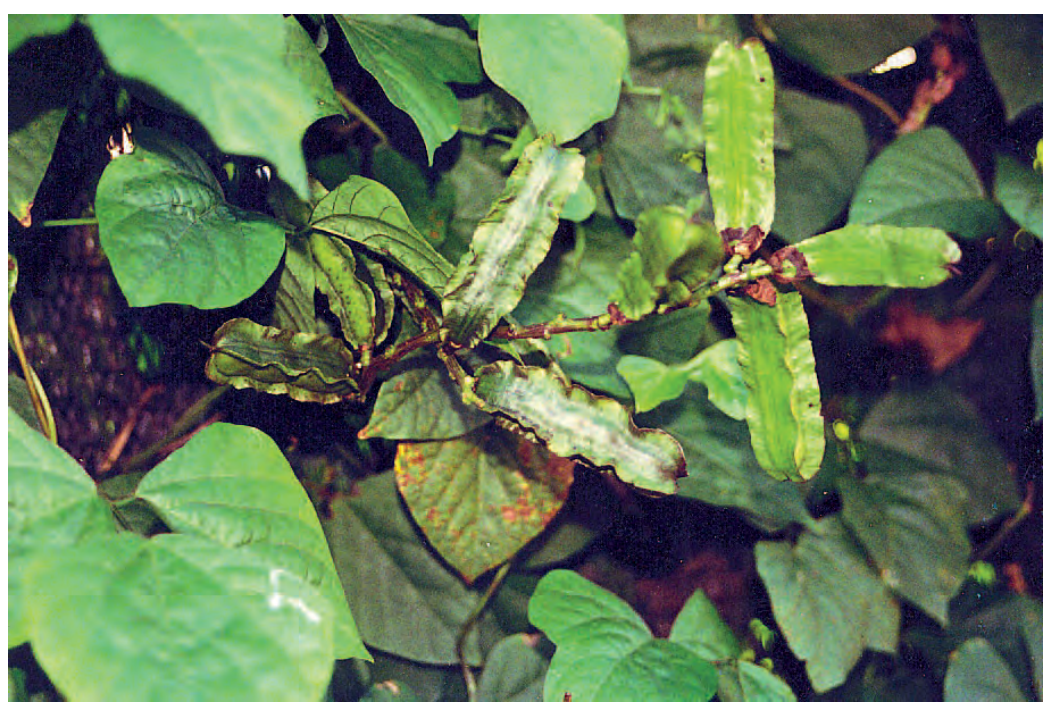

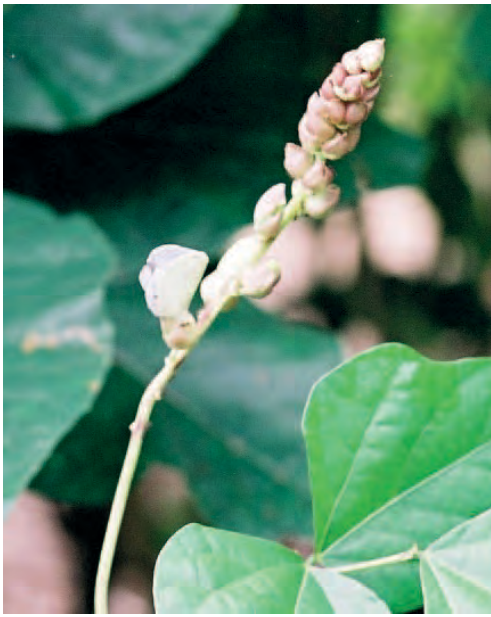

Remarque: La culture de ce légume est encouragée en $\mathrm{RD}$ Congo, spécialement à Kinshasa et dans les environs, pour sa valeur dans la promotion de la lactation des mères allaitantes.

Références : Renier 1948, Hauman et al. 1954, Mbemba et Remacle 1992, Burkill 1995, Paulus 1997, Nsimundele 2004, Schippers 2004

Photo: Rudy Schippers 
Nom courant : Kisokosoko (Kikongo)

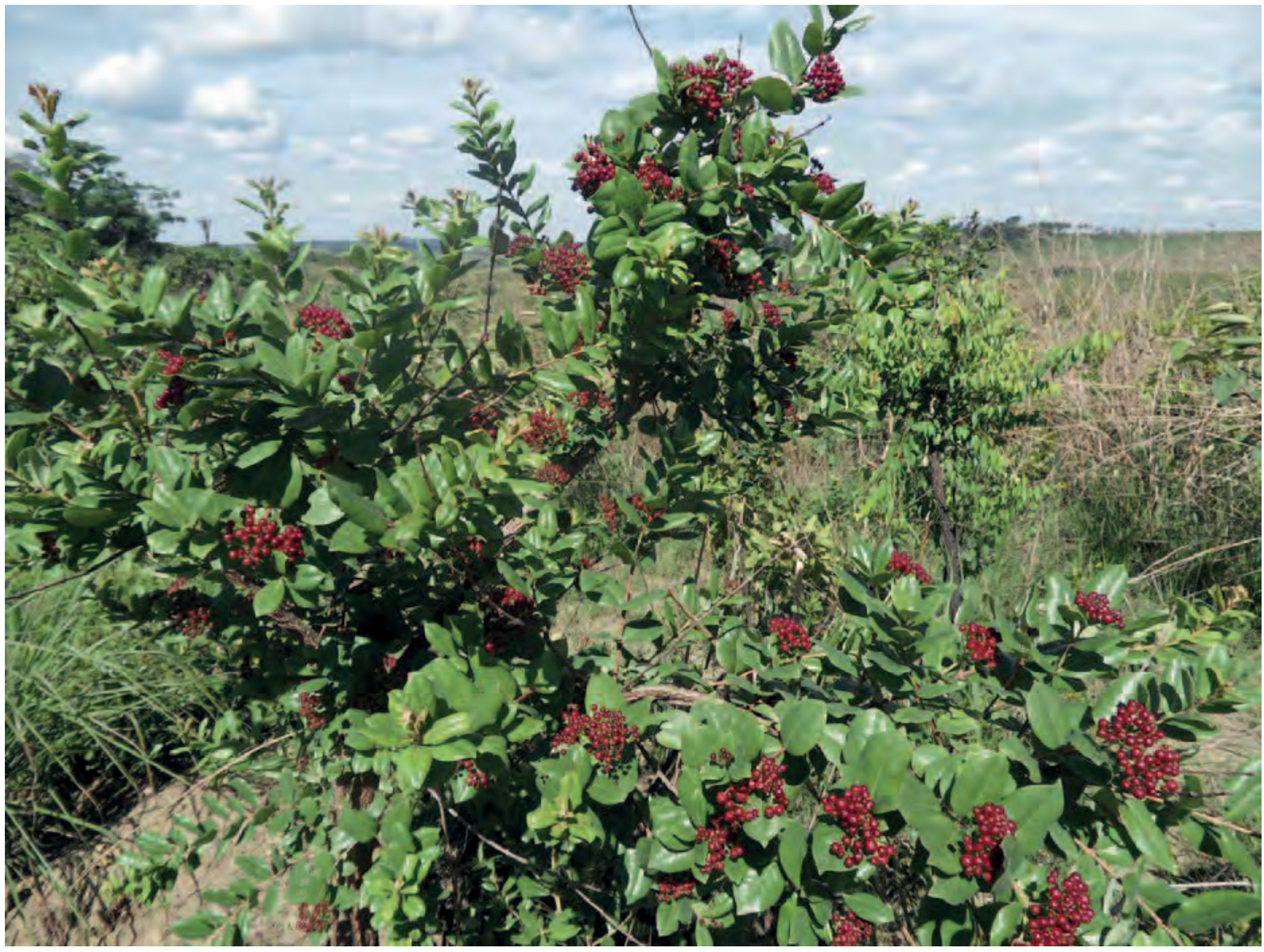

Description : Arbuste atteignant $6 \mathrm{~m}$ de haut. Ecorce grise à brune, rugueuse et plutôt liégeuse, se détachant en plaques ou en bandes. Petites feuilles elliptiques, coriaces, vert clair dessous. Tiges couvertes de poils roux. Fleurs blanc crème, parfumées, d'environ $8 \mathrm{~mm}$ de diamètre. Fruits rouges de 8 à $10 \mathrm{~mm}$ de diamètre.

Ecologie: Arbuste commun de la savane, de la Guinée à l'Ethiopie et au Mozambique.

Usages: On prend l'écorce, spécialement celles des racines, pour la piler, et en faire une pâte avec de l'eau ou de l'huile de palme, que l'on applique en massage sur la gale. La résine sert à éloigner les mites. On l'emploie aussi pour traiter les maladies des lapins domestiques et les tiques du bétail. En Afrique de l'Est, on donne une décoction des racines et des feuilles pour soigner la lèpre. Les abeilles butinent le nectar. L'écorce peut s'employer comme insecticide. En Haut Katanga, on mange les fruits.

Références: Butaye 1909, Gillet et Pâque 1910, Renier 1948, Bamps 1970, Kokwaro 1976, Coates Palgrave 1983, Dupriez et De Leener 1993, Pauwels 1993, Burkill 1994, Malaisse 1997, Göhre et al. 2016, Latham et Konda Ku Mbuta 2017, Lautenschläger et al. 2018

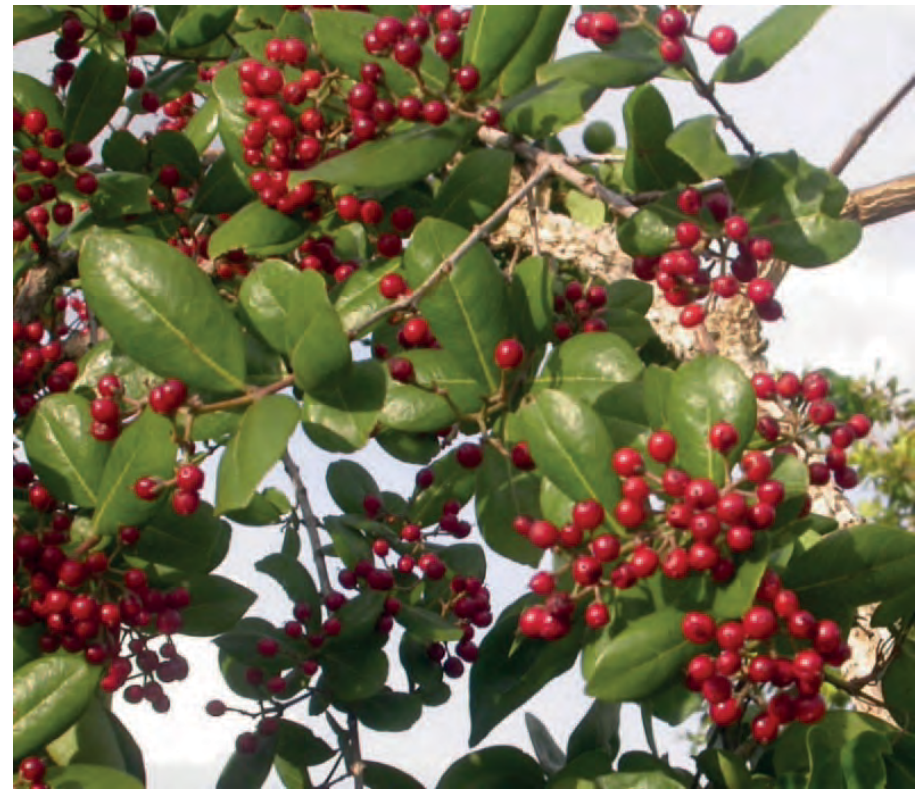




\section{Psychotria calva}

Noms courants : Kibofula, kimbafuela (Kikongo), faux Ipéca (Fr.)

Description : Arbuste à tronc lisse, irrégulier, au feuillage épais, pouvant atteindre $8 \mathrm{~m}$ de haut.

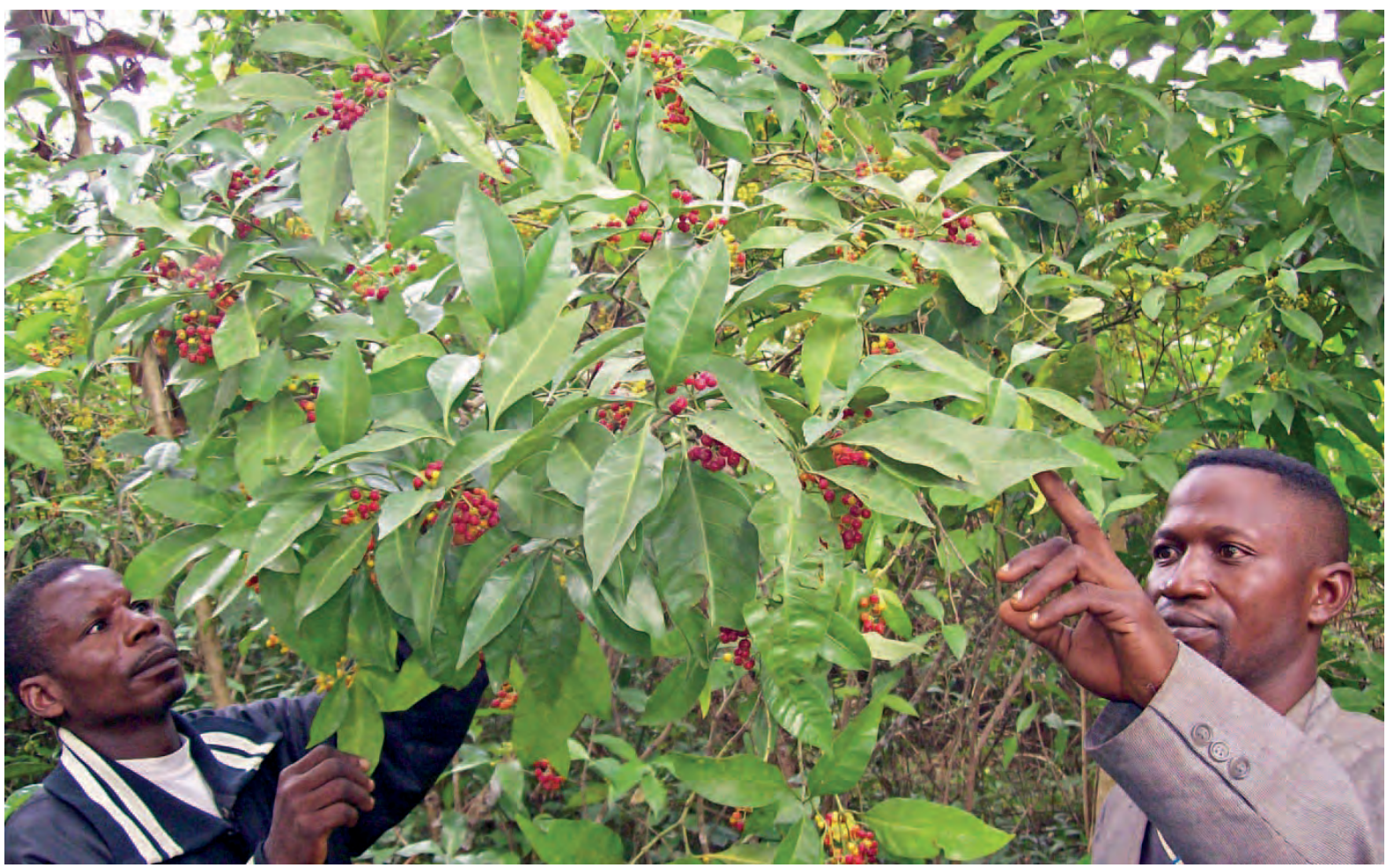

Psychotria calva en lisière de forêt vers Sombala

Ecologie : Pousse au bord de l'eau, en lisière de forêts ou en savane arbustive, du Sénégal à la R.D. Congo.

Reproduction : A partir des graines, collectées à terre après leur chute.

Usages : Les feuilles se mangent comme légumes. L'écorce s'emploie comme émétique. On frotte sur la peau, ou on boit, une macération des feuilles contre les maux de tête et la dépression. Ailleurs en Afrique, on fait avec les racines, en mélange avec les racines de Phyllanthus muellerianus and Harrisonia abyssinica, une décoction que l'on prend contre la toux et contre la coqueluche.

Références : Butaye 1909, Gillet et Pâque 1910, Gillet 1927, De Wildeman 1934, Renier 1948, Nsimundele 1966

- 68, Daeleman et Pauwels 1983, Burkill 1997, Neuwinger 2000 


\section{Psychotria vogeliana}

Noms courants: Mupwimu (Kimbala), fuba (Kiyansi), mumfiti (Kipindi).

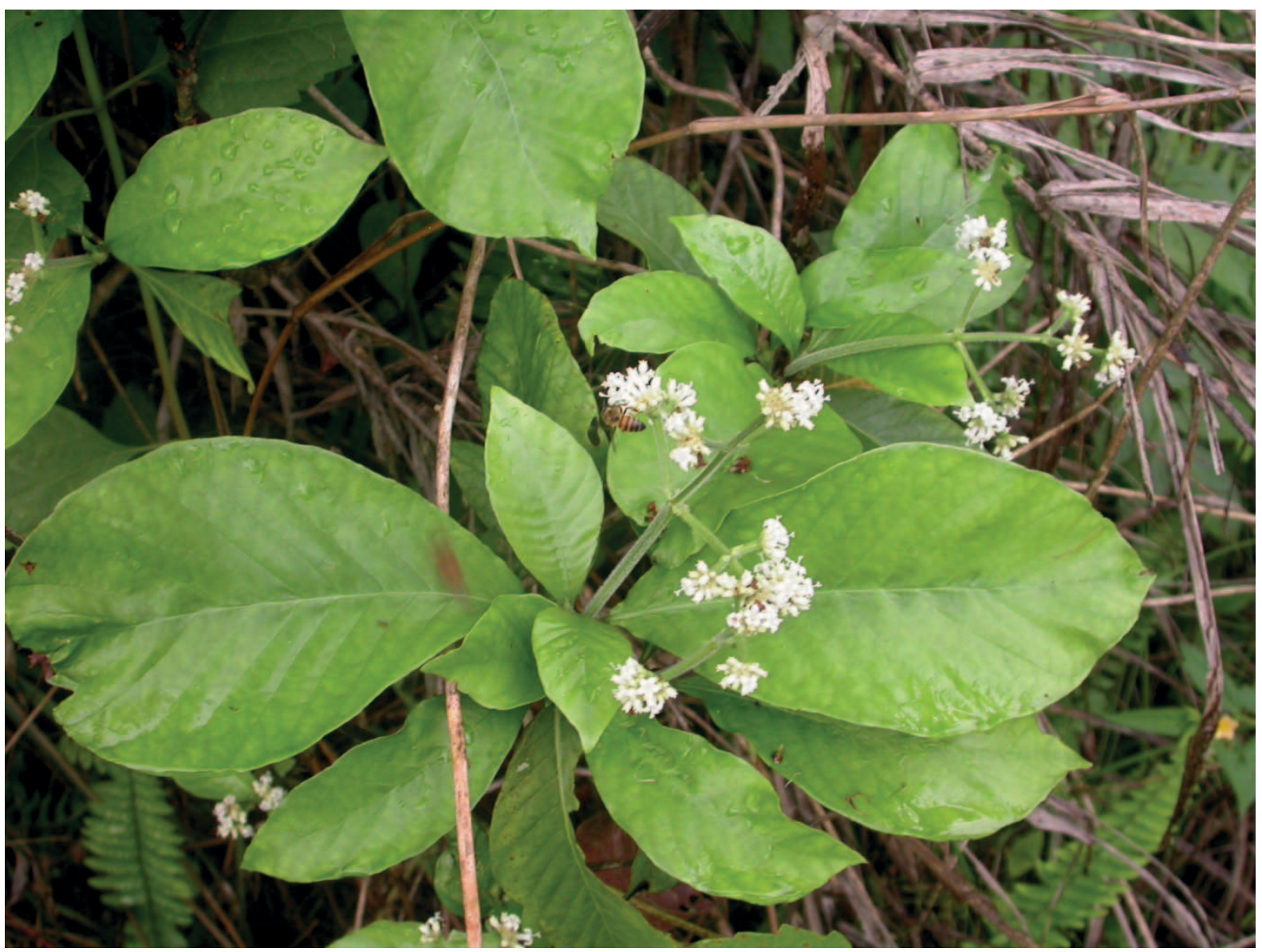

Description : Buisson atteignant $2 \mathrm{~m}$ de haut. Les feuilles ont 18 à 20 sur 8 à $10 \mathrm{~cm}$. Pétioles velus de 1 à $2 \mathrm{~cm}$. Fleurs parfumées. Fruits bleus de $7 \mathrm{~mm}$ de diamètre (cf. cidessous).

Ecologie: Plante commune dans les forêts humides. Présente aussi dans les forêts décidues, les savanes boisées et les sites humides, du Mali au Cameroun et à la R.D. Congo.

Usages: On a observé les abeilles butinant les fleurs en novembre et décembre. Au Ghana, les menues branches servent de bâtons à mâcher. Au Congo Brazzaville, la plante est employée pour traiter le rachitisme. Les femmes emploient les feuilles odorantes comme cosmétiques. Les racines et les feuilles s'emploient pour traiter la fièvre.

Références : Renier 1948, Ambougou 1991, Pauwels 1993, Burkill 1997, White et Abernethy 1997, Hepburn et Radloff 1998

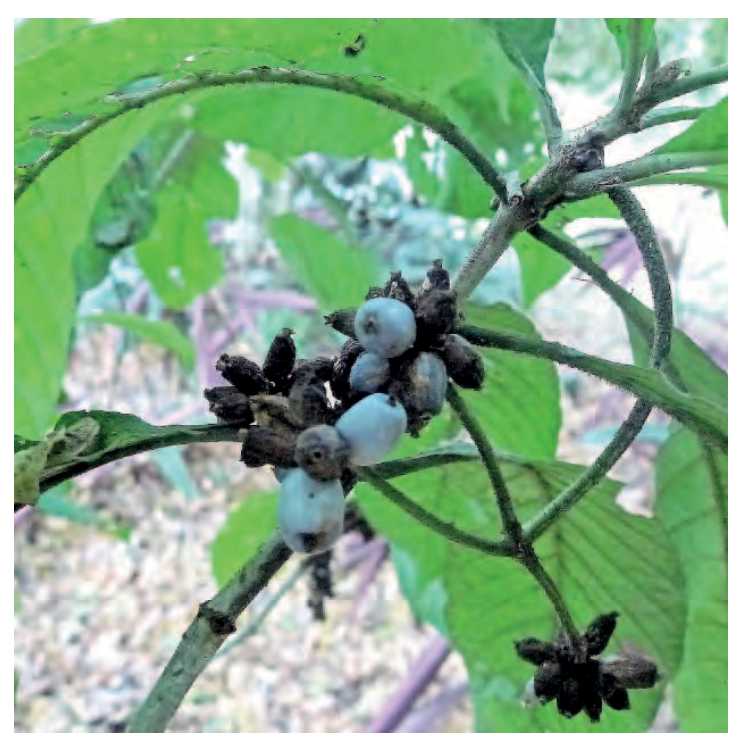




\section{Psydrax subcordata var. subcordata}

Noms courants : Nsudi bandumba (Kiyombe)

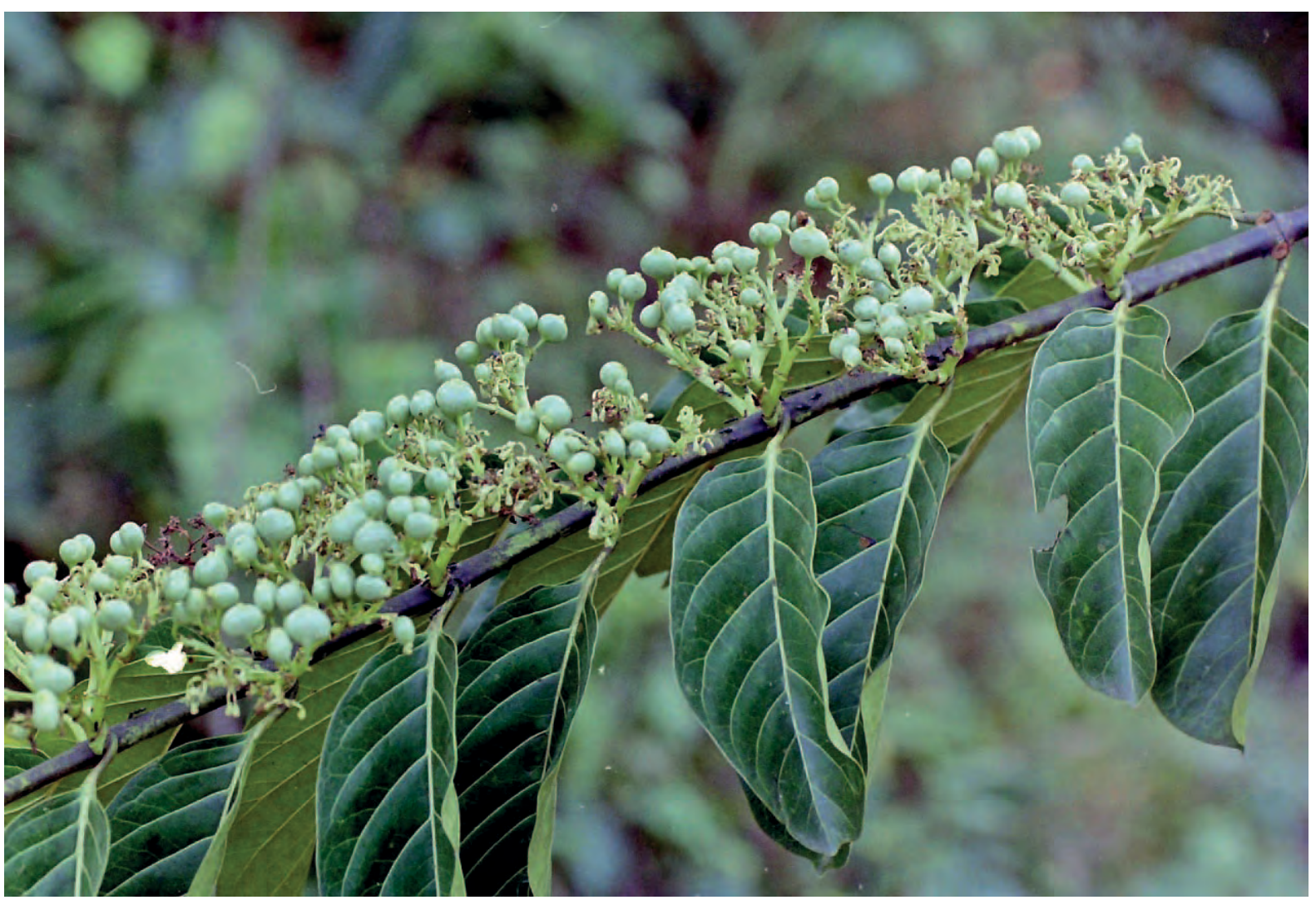

Description : Arbre à croissance rapide mais vie brève, pouvant atteindre $15 \mathrm{~m}$ de haut, avec un tronc dégagé et des branches horizontales. Feuilles opposées pouvant avoir $15 \mathrm{~m}$ de long avec des nervures proéminentes, sur un pétiole atteignant $2 \mathrm{~cm}$. Fleurs en bouquets au-dessus des feuilles, à l'odeur forte, fétide, désagréable.

Ecologie : Plante des clairières dans les forêts primaires et secondaires, de la Gambie au Rwanda et à l'Angola. Devient invasive quand la forêt a été coupée, au bord des routes et sur les anciennes cultures.

Reproduction : Les graines sont répandues par les oiseaux qui ont mangé les fruits.

Usages: Le bois aurait un grain fin. En Sierra Leone, on en fait des cannes ornementales. Ailleurs, il sert essentiellement de bois de feu. Diverses parties de la plante ont des usages médicinaux.

Remarques: Des fourmis, probablement une espèce de Crematogaster, font leurs nids dans le tronc et à la base des branches, qu'elles creusent dedans et gonflent dehors. La relation entre les fourmis et leur hôte n'est pas élucidée.

Références : Holland 1922, Renier 1948, Irvine 1961, Keay 1989, Burkill 1997, Hawthorne et Jonkind 2006 


\section{Pteridium aquilinum subsp. centraliafricanum (Dennstaedtiaceae)}

Noms courants : Kisielele, biteko, ntekwa tekwa, nkungambwa (Kikongo), misili (Kwango), fougère (Fr.), bracken (Angl.)

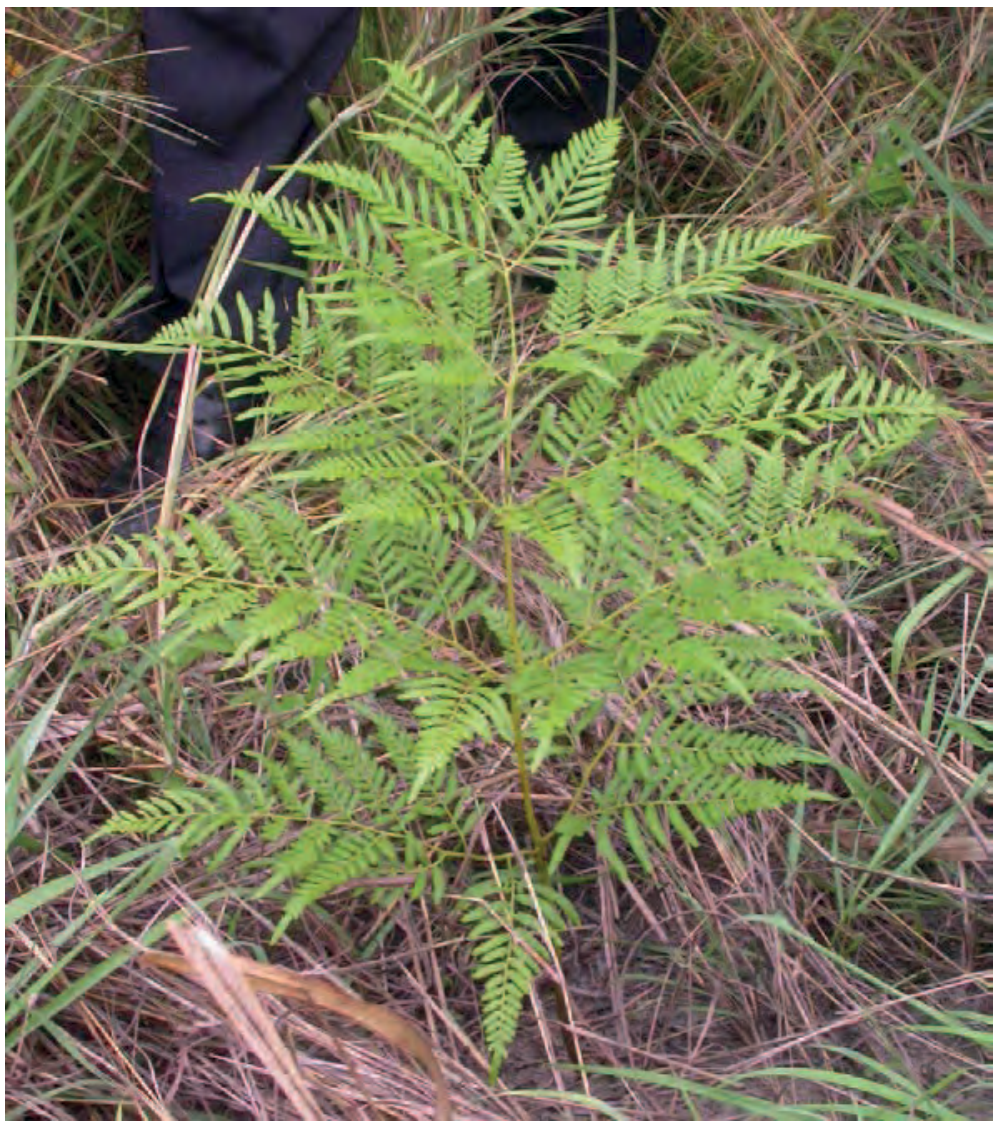

Description : Fougère de 1 à $3 \mathrm{~m}$, poussant sur de longs rhizomes souterrains, se reproduisant par les rhizomes ou par spores. Tige ronde, épaisse et velue. Feuille composée jusqu'à $45 \mathrm{~cm}$ de long, à silhouette triangulaire et profondément divisée. Chaque foliole a environ $12 \mathrm{~cm}$ de long avec environ 21 paires de foliolules.

Ecologie : Pteridium aquilinum est une espèce cosmopolite ayant de nombreuses sous espèces. La sous espèce d'Afrique Centrale est une plante des forêts secondaires, et adventice commune des cultures en zone forestière, souvent en concentration dense en bordure des pentes en terrain argileux.

Usages: Les jeunes pousses se cuisinent comme légumes, avec des oignons etc. Elles ont aussi des usages médicinaux contre les douleurs de la poitrine et des articulations, et les hémorroïdes. Au Nord de I'Angola, on emploie les feuilles et les rhizomes pour traiter l'épilepsie. Les rhizomes se mangent parfois, et constituent une nourriture importante chez les Maoris de

Nouvelle Zélande. On l'a aussi employée contre le ver solitaire. Aux USA, on a obtenu un caoutchouc à partir de fougères. Les jeunes pousses peuvent être pâturées par le bétail, mais elles deviennent toxiques pour les bêtes qui en mangent plus de 3 semaines d'affilée. Les chenilles comestibles Minsuka (Nudaurelia anthina) et N'teku se nourrissent des feuilles. Au Katanga, la plante nourrit aussi les chenilles comestibles Nyodes prasinodes.

Remarques: L'espèce se distingue de $P$, aquilinum qui a des tiges glabres et des feuilles moins dentées.

A droite: crosses fraiches en vente sur un marché.

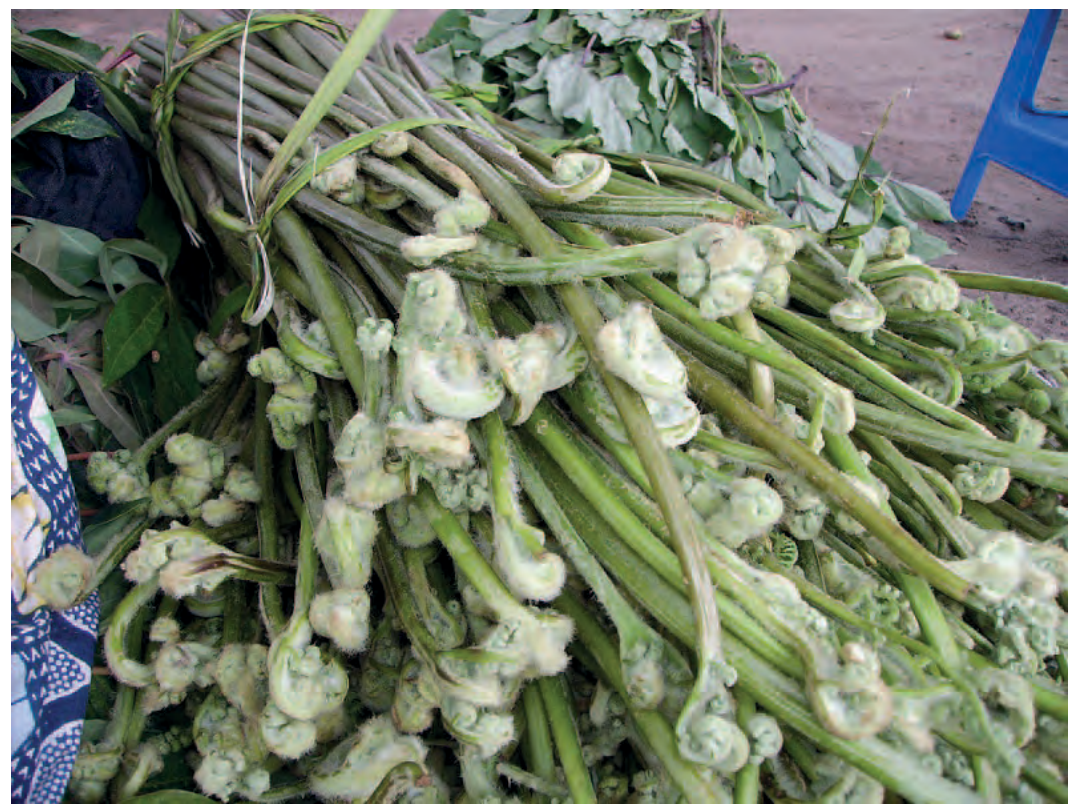

\section{Avertissement : La plante est carcinogène et pourrait aussi provoquer le béribéri.}

Références : Renier 1948, Watt et Breyer-Brandwijk 1962, Uphof 1968, Arkinstall 1979, Malaisse et Parent 1980, Daeleman et Pauwels 1983, Akobundu et Agyakwa 1987, Konda Ku Mbuta et al. 1992, Kibungu Kembelo 1995, Biloso et Lejoly 2006, Latham 2008, Göhre et al. 2016 
Noms courants : Nkoso, lukungu nseke (Kikongo et Yaka), bloodwood (Angl.)

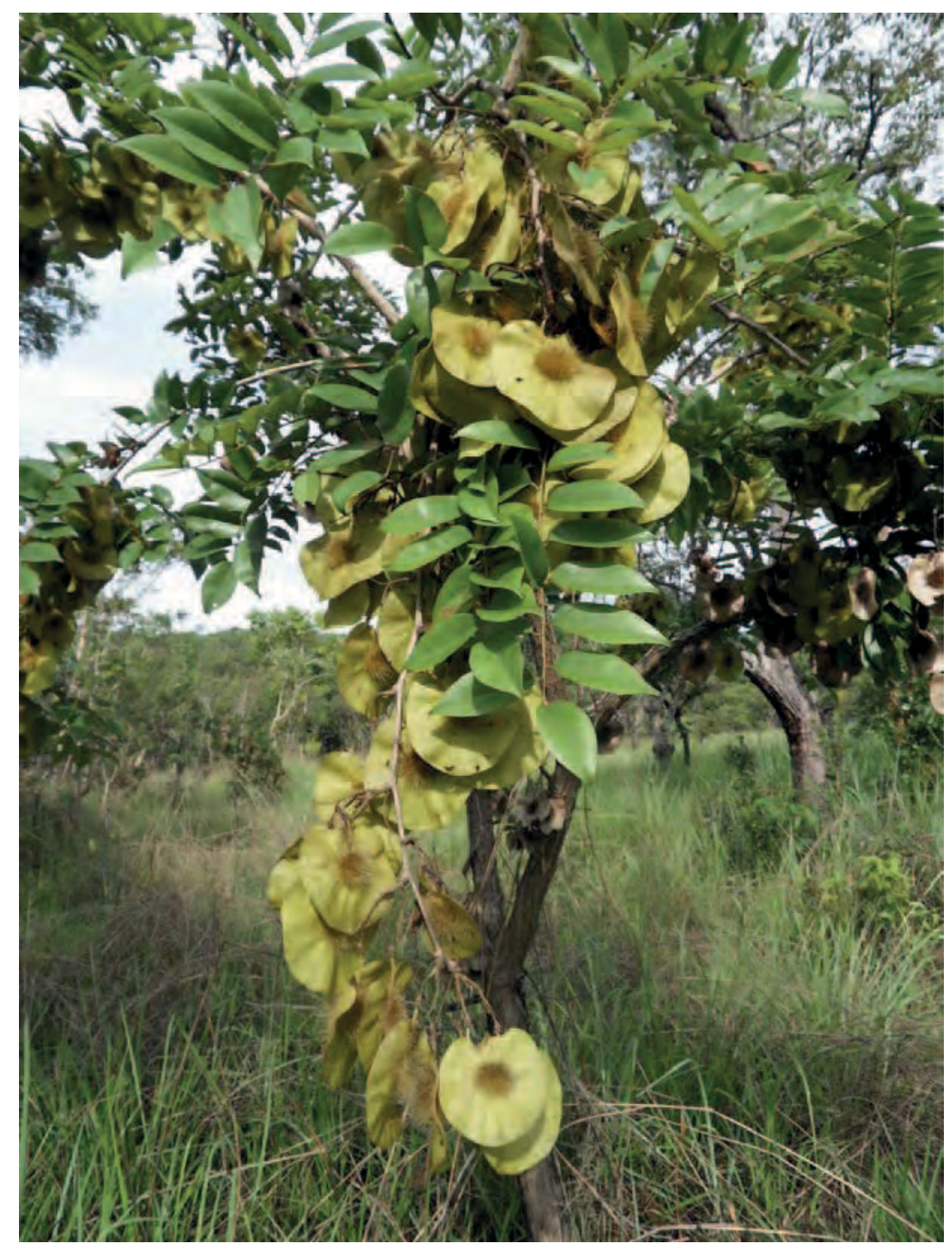

Description : Arbuste de 4 à $5 \mathrm{~m}$ de haut. Feuilles composées à 12 à 20 folioles, ayant chacune 4,5 à 7 sur 2,5 à $3,8 \mathrm{~cm}$. Les entailles libèrent une sève rouge, qui sèche en masse. Les fleurs jaune orange, parfumées, se développent avant les feuilles en grands bouquets ramifiés. Fruits circulaires remarquables, de 5 à 10 $\mathrm{cm}$ de diamètre, densément couverts de poils raides bruns. La gousse contient une graine unique, qui porte une aile ondulée.

Ecologie: Arbre de la savane. Préfère les sols sablonneux bien drainés. Largement répandue dans la savane boisée dans toute l'Afrique centrale et australe.

Reproduction: Par graines. Récolter les gousses et sortir les graines. Les tremper dans l'eau 1 à 2 jours, puis les semer directement, étant donné la longue racine pivotante. La germination demande 20 à 30 jours. La croissance est lente d'abord, mais s'améliore par la suite. Le taux de germination est de 30 à 70 $\%$. On peut aussi planter de grandes boutures.

Gestion : La lumière est importante pour la croissance. L'arbre peut se recéper et résiste au feu.

Usages : Le bois de cœur a une belle couleur brun rouge doré. II est très durable, se travaille aisément et prend un beau poli. On l'emploie pour la construction et le mobilier, la sculpture, les manches d'outils, les poteaux, les ruches, le bois de feu et le charbon de bois. L'arbre fixe l'azote et peut se planter pour la conservation des sols. L'écorce intérieure, fibreuse, s'emploie pour fabriquer des paniers. L'écorce s'emploie aussi en teinturerie. En Namibie et au Zimbabwe, le bois de cœur des racines est réduit en poudre ; celle-ci sert de teinture rouge pour les fibres de feuilles de palmier employée pour tresser des paniers. Les arbres en fleurs sont une importante source de miel. Les espèces de Pterocarpus sont une importante source de miel dans les savanes de l'Afrique équatoriale. A Lindi, Tanzanie, on protège ces arbres comme fourrage des abeilles.

Références : Renier 1948, Hauman et al. 1954, Smith 1957, Williamson 1975, Pauwels 1993, Mbuya et al. 1994, Venter et Venter 1996, Malaisse 1997, Hepburn et Radloff 1998, Aubrey 2003, Takawira - Nyenya 2005, Lalika et Machangu 2008 


\section{Pueraria phaseoloides var. javanica}

Noms courants : Kudzu tropicale (Fr.), tropical kudzu (Angl.)

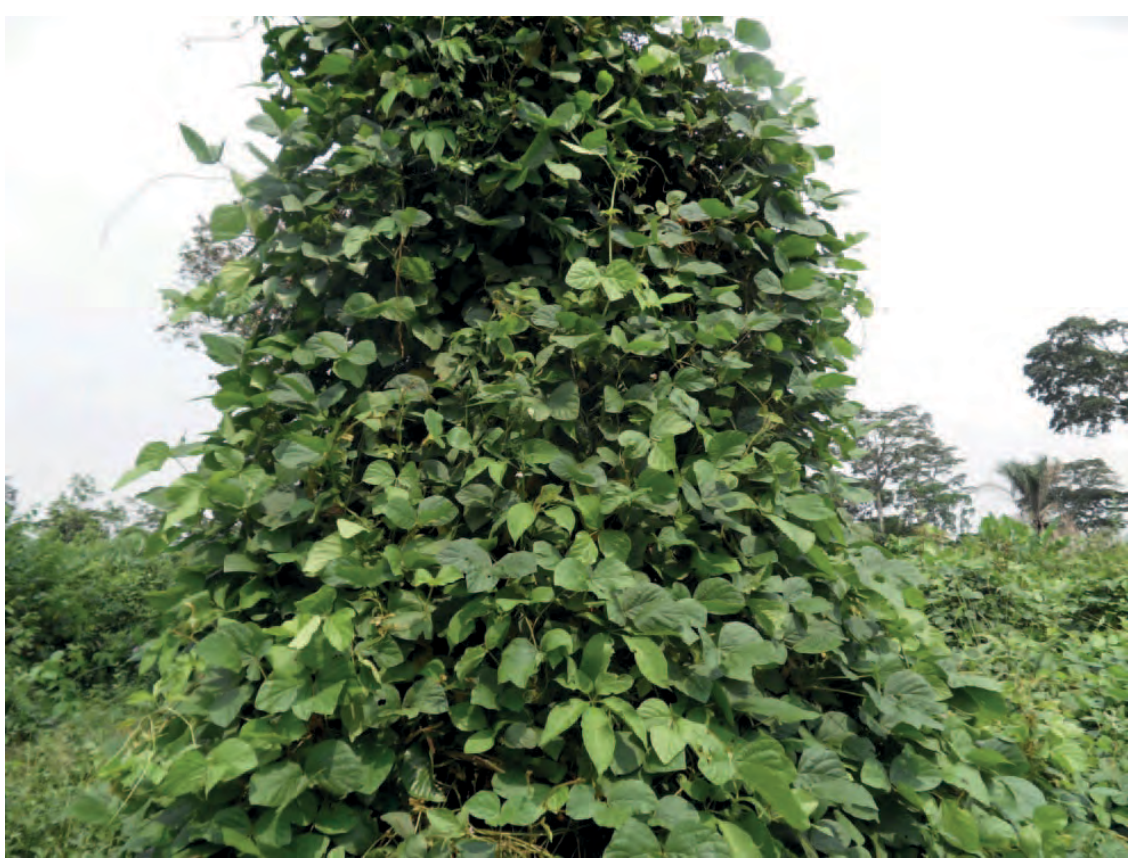

Description : Plante herbacée robuste, grimpante ou rampante, poussant jusqu'à $10 \mathrm{~m}$ de long sur une racine pivotante profonde. Tiges couvertes de poils bruns. Feuilles trifoliées. La plante s'enracine aux nœuds. Les folioles ont 5 à 12 sur $11 \mathrm{~cm}$. Fleurs disposées en longs racèmes axillaires, corolles atteignant $2 \mathrm{~cm}$ de long, blanchâtres avec une tache mauve. Gousses linéaires aplaties, droites ou légèrement courbées, jusqu'à $11 \mathrm{~cm}$ de long, avec 10 à 20 graines brun foncé.

Ecologie: Originaire d'Asie du Sud Est tropicale, naturalisée dans de nombreux pays tropicaux. Pousse avec des pluies supérieures à 1500 mm, et supporte une saison sèche de 2 à 3 mois. Tolère les sols acides, préfère les sols lourds aux sols sableux. Supporte les inondations pendant 2 à 3 mois. Tolère l'ombre.

Reproduction : A partir de plantes enracinées ou en divisant les souches. On peut aussi semer des graines, mais leur collecte peut être un problème dans certaines zones. Les tremper 24 heures dans l'eau chaude. Les plantes qu'on laisse grimper sur les arbres donnent davantage de graines. La souche de rhizobium du niébé CP 756 est requise pour une inoculation réussie. Planter à de grands espacements ou sur des buttes.

Gestion : Plante à croissance lente les 2 à 4 premiers mois, demandant un bon désherbage. Après 4 à 5 mois, les plantes forment une masse dense de 60 à $80 \mathrm{~cm}$ de haut. On peut les cultiver en association avec Panicum maximum.

Usages: Introduite en R.D. Congo comme plante de couverture pour les plantations de palmier à huile. Bon fourrage pour le bétail, et aussi pour les lapins, restant vert en saison sèche, mais pouvant demander une accoutumance assez longue des bêtes. On peut en faire des haies. Cultivée comme plante de couverture, engrais vert, et contrôle des érosions, bien adaptée à l'Afrique tropicale. La

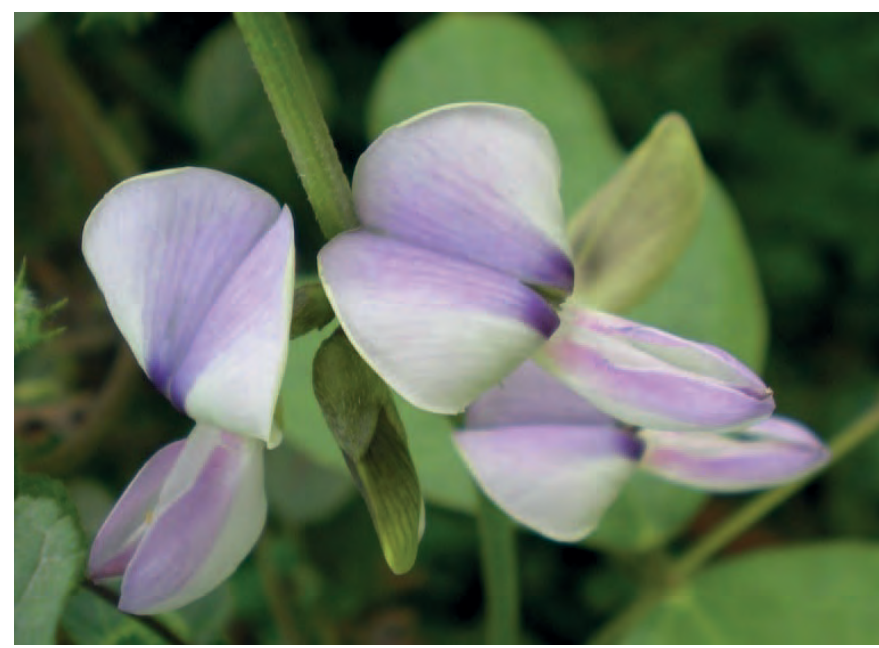
racine tubéreuse est comestible, bien que rarement mangée. La tige donne des fibres utilisables comme ficelles ou cordages. Les abeilles seraient le principal pollinisateur ; au Kongo Central, elles butinent le nectar en mai.

Références : Renier 1948, Bogdan 1977, NAS 1979, Allen et Allen 1981, Crane et Walker 1984, Halim 1992, Burkill 1995, Bakenga et al. 2000, Raemaekers 2001 
Noms courants: Mukomamanga (Swahili), grenadier (Fr.), pomegranate (Angl.)

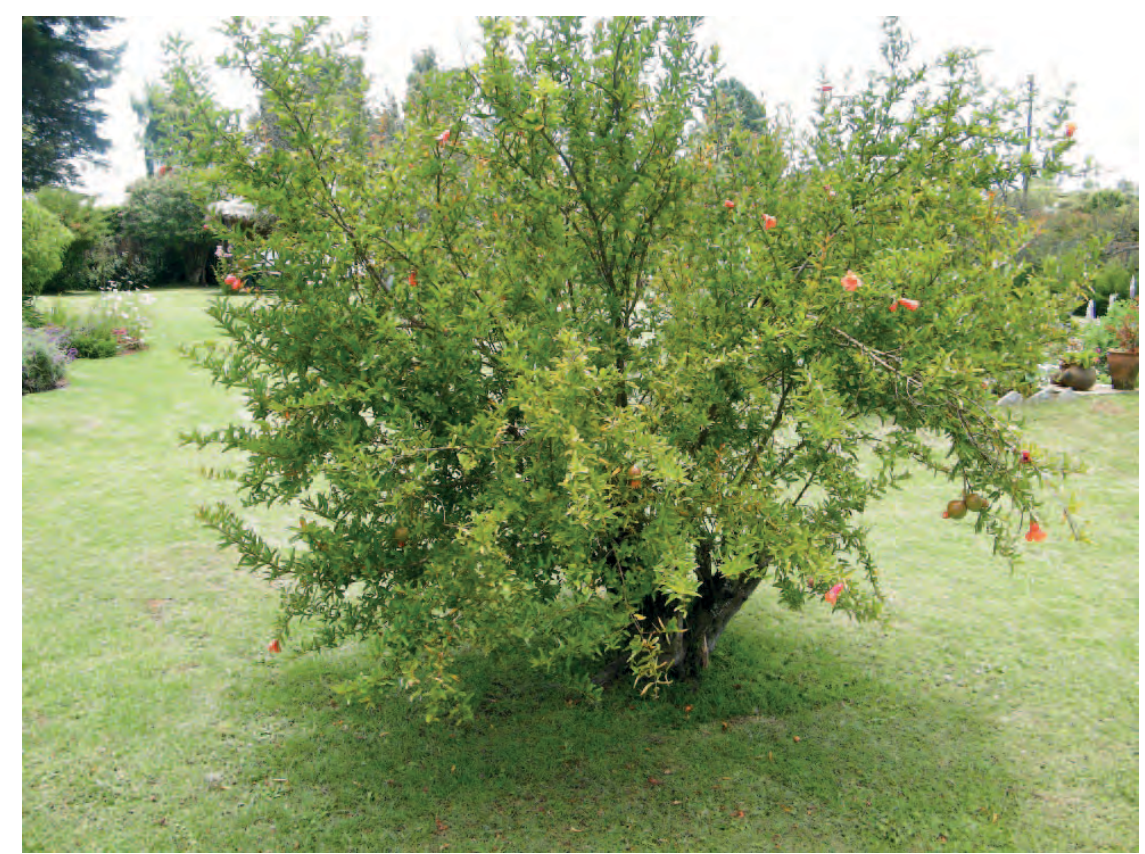

Description : Arbuste tortueux décidu, jusqu'à $6 \mathrm{~m}$ de haut, souvent très ramifié à la base. Les branches se terminent souvent en épines et portent aussi des épines axillaires. Fleurs cireuses, rouges ou jaune pâle, au bout des rameaux. Les fruits ont 6 à $12 \mathrm{~cm}$ de diamètre, leur couleur varie du vert jaune au violet noir, leur peau est coriace. Chaque fruit contient de nombreuses graines rouges juteuses.

Ecologie: Plante originaire d'Asie Centrale, cultivée autour de la Méditerranée depuis l'antiquité. Facile à cultiver, préfère les sols fertiles bien drainés, au soleil et à l'abri du vent. Fructifie mal en conditions humides. Les meilleurs fruits se produisent lorsqu'une période fraiche est suivie par une saison chaude et sèche.

Reproduction : Faire des boutures avec du bois dur ou des racines. Les boutures doivent avoir l'épaisseur d'un crayon, avec du bois de plus de six mois et moins de deux ans. On les prélève sur des rejets à la base de la tige principale, de préférence sur des arbres améliorés. Débarrasser les boutures des feuilles. Planter presque toute dans le sol, en laissant dehors le bourgeon terminal. Planter après 9 mois en pépinière. On pratique aussi le marcottage aérien, en séparant les marcottes de la branche mère après 3 à 4 mois, une fois qu'elles ont de bonnes racines.

Usages: Le fruit se mange frais, ou bien on en fait un jus qui donne une boisson rafraîchissante, la grenadine. En Asie, on concentre le jus pour l'employer comme sauce. La tige, la racine et la peau du fruit ont des emplois médicinaux pour

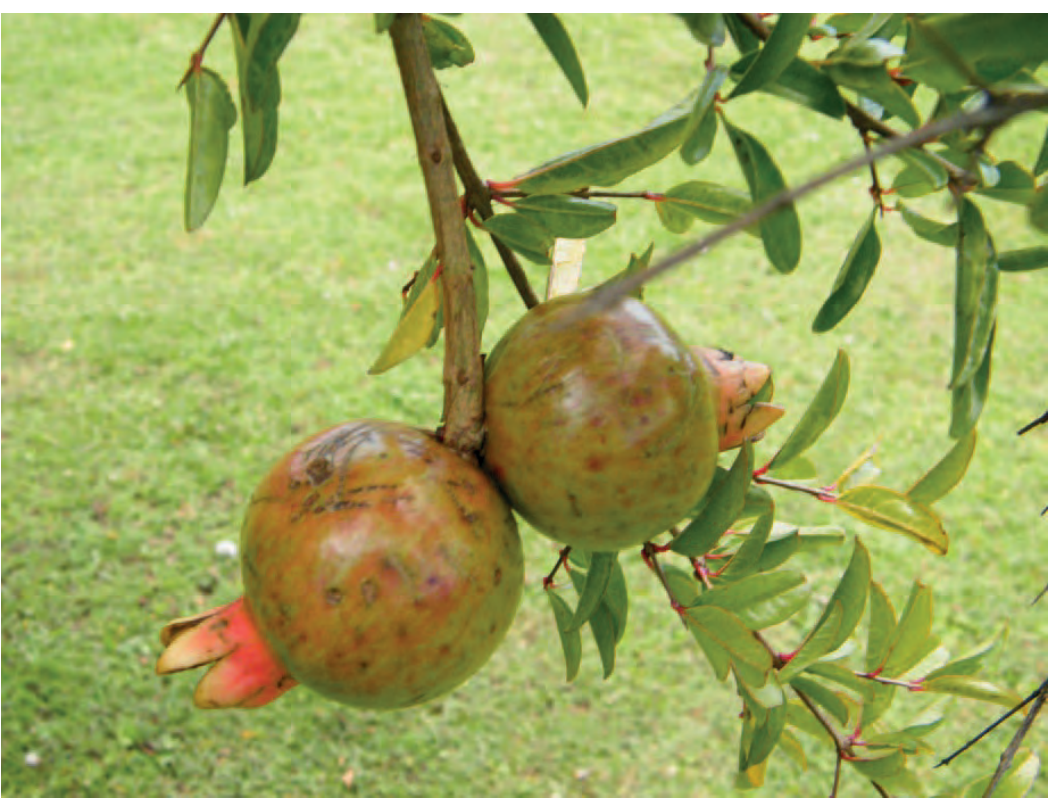
traiter la diarrhée et comme antihelminthique.

Références : Sudiarto et Rifai 1991, van Wyk et Wink 2004, Wikipedia (consulté le 8.11.2011), SEPASAL (consulté le 8.11.2011) 


\section{Pycnanthus angolensis}

Noms courants : Kilomba, nlomba, kunda mavondu (Kikongo), faux muscadier (Fr.), false nutmeg (Angl.)

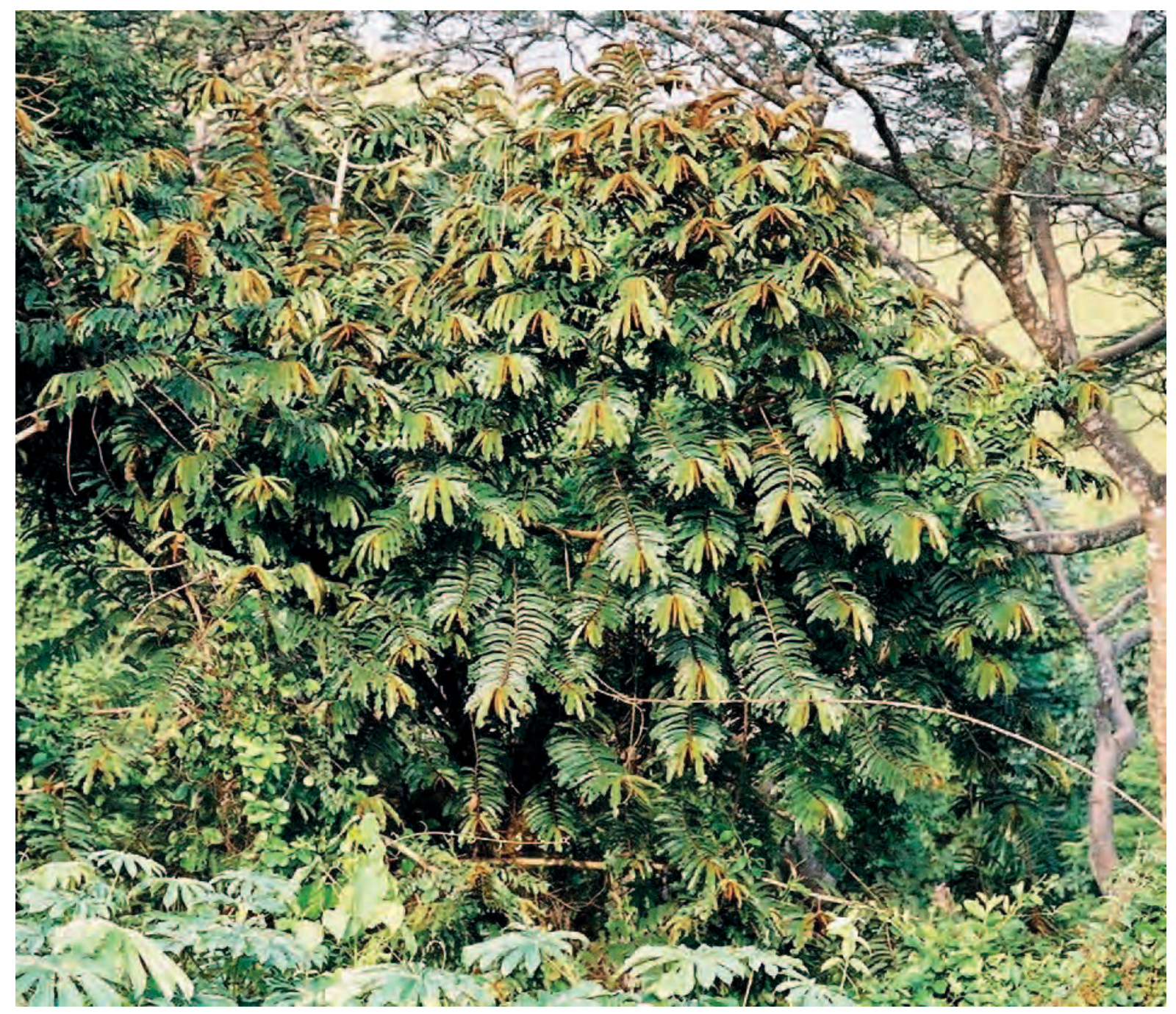

Description : Arbre jusqu'à $30 \mathrm{~m}$ de haut. Branches groupées à la cime et pendantes. L'écorce externe est de couleur brun grisâtre. Les ramilles sont minces et tombantes, couvertes de poils roux. Les feuilles, souvent mangées par les insectes, sont rarement entières. Les fleurs sont unisexuées, régulières, avec une taille très petite. Le fruit est une drupe de 3-4,5 cm sur 2-4 $\mathrm{cm}$, de couleur orange jaunâtre quand il est mûr. La graine qu'il contient est ellipsoïde et de couleur brun foncé.

Ecologie: Arbre des forêts secondaires, sur sols argileux ou dans les vallées; de la Guinée à l'Angola, à l'Ouganda et à la Tanzanie.

Reproduction: Collecter les graines sous les arbres, et les semer en pots après trempage de 24 heures dans l'eau froide.

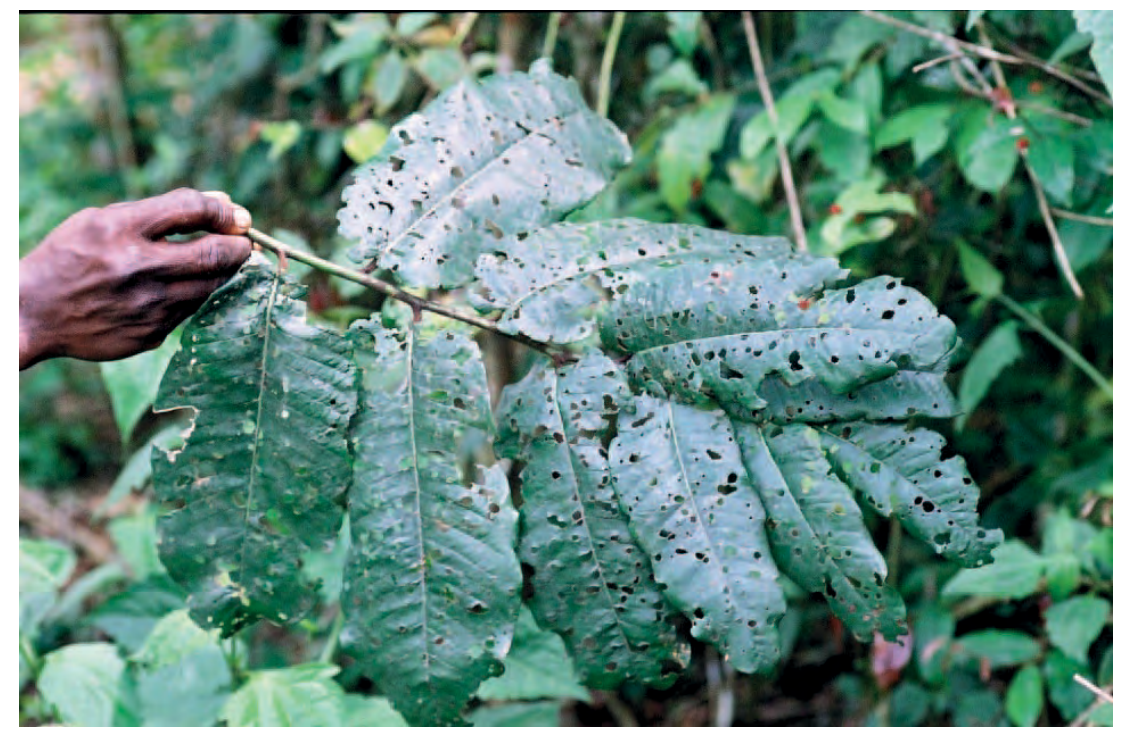




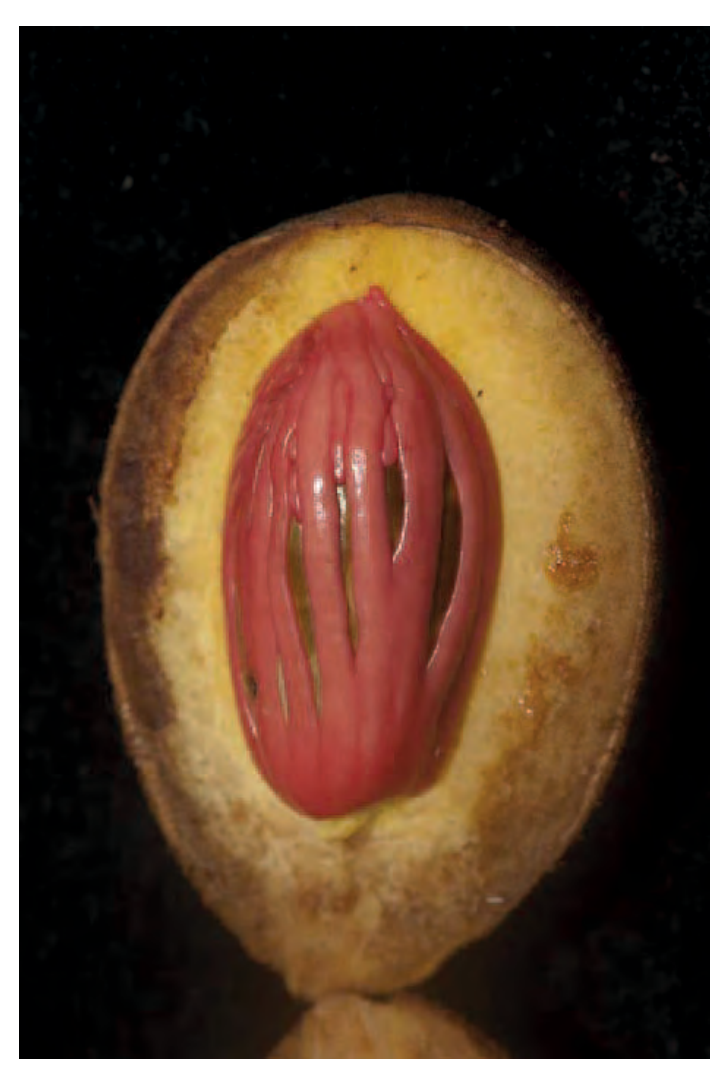

Usages : Le bois est blanc grisâtre à rosâtre, léger et tendre. II se scie et se rabote aisément, se polit et se colle bien. On l'emploie largement en construction, pour les cloisons, portes et fenêtres. Il est sensible aux attaques de champignons, insectes perforants et termites. II donne un bon bois de feu. Au Kongo Central, le latex de l'écorce s'emploie pour traiter les blessures et pour stimuler la lactation. Les rameaux, racines, graines et feuilles ont aussi des usages médicinaux. Les graines sont une importante source de graisse et ont été utilisées pour l'éclairage et pour donner du savon. Les chenilles comestibles N'lombela, qui se nourrissent des feuilles, sont une réserve spéciale de nourriture pour les vieillards.

Remarques : L'arbre croit rapidement ; il est invasif.

Références : Butaye 1909, Renier 1948, Gilbert et Troupin 1951, Nsimundele 1966 - 68, Pauwels 1993, Katende et al. 1995, Burkill 1997, Harris et al. 2011

Fruit montrant un arille comparable à la noix muscade.

Photo: David Harris/Royal Botanic Garden Edinburgh

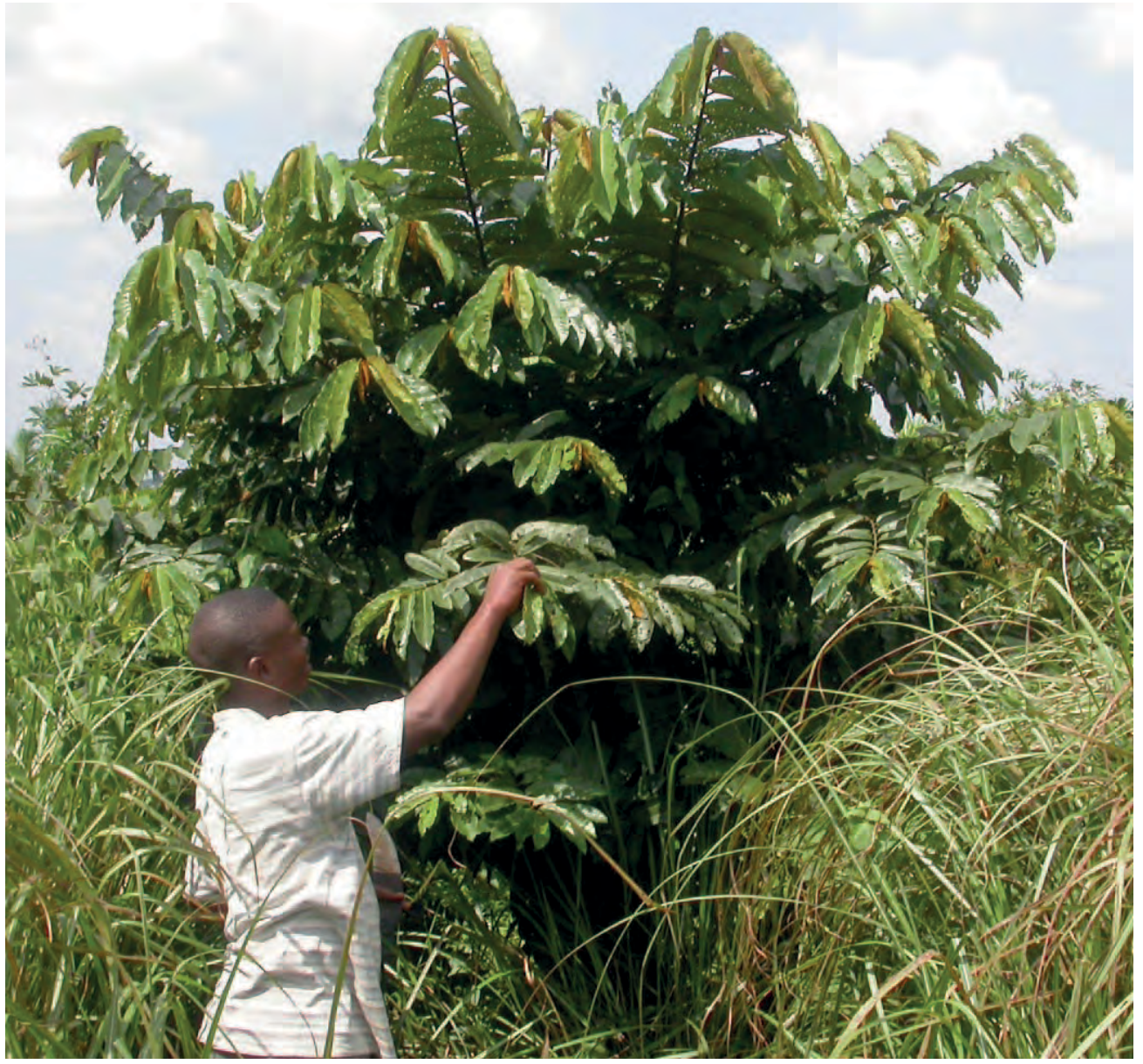

Jeune arbre à Kingudi 


\section{Pyrostegia venusta}

Noms courants : Liane aurore, pluie d'or (Fr.), golden shower (Angl.)

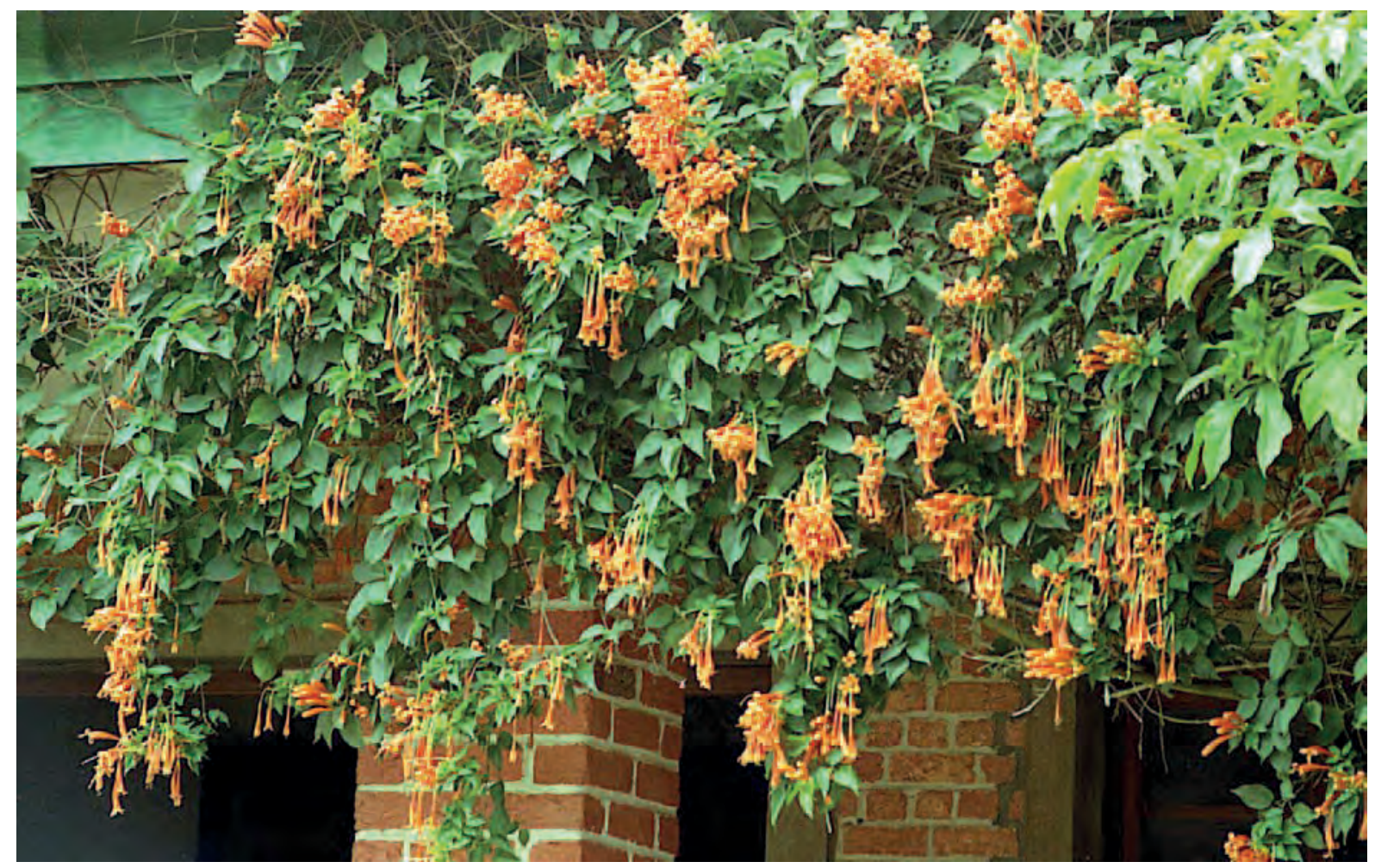

Description : Liane sempervirente vigoureuse, atteignant $30 \mathrm{~m}$ de long. Feuilles composées à 2 ou 3 folioles oblongues de 5 à $8 \mathrm{~cm}$ de long. La plante fleurit longuement avec des fleurs tubulaires orange, en bouquets axillaires ou terminaux pendants.

Ecologie: Plante ornementale originaire du Brésil, plantée occasionnellement sur les clôtures et autour des maisons. Tolère bien la sécheresse et la chaleur.

Reproduction: Par boutures, mais c'est lent et ne réussit pas toujours.

Gestion : Reprend bien après la taille qui suit la floraison.

Usages : Plante ornementale. Les abeilles butinent très activement le nectar des fleurs durant la saison sèche, malgré les difficultés causées par l'étroitesse de la corolle.

Références : Jex-Blake 1957, Morton 1964, Portugal-Araújo 1974, Macmillan 1991

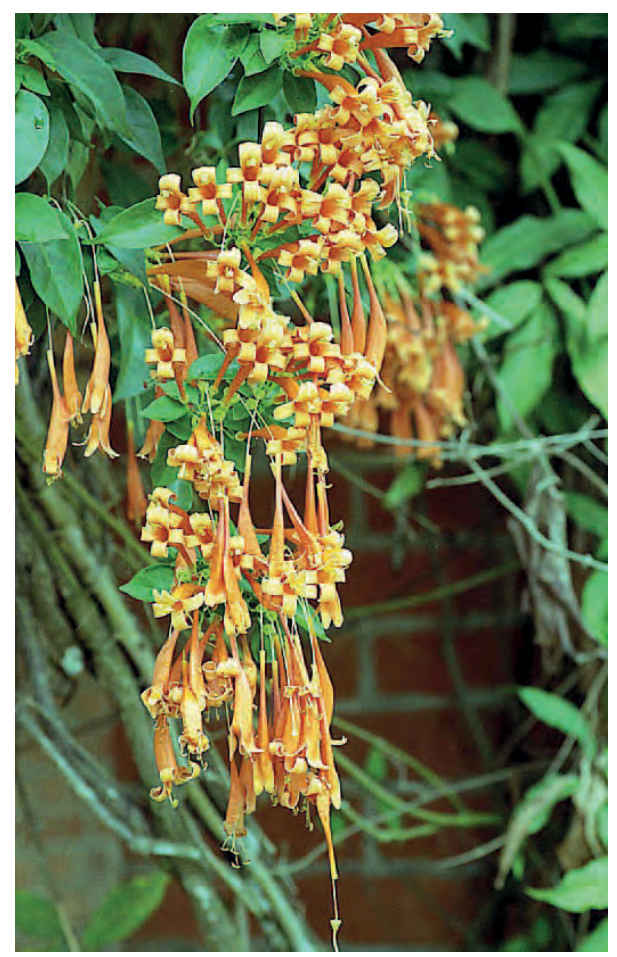




\section{Quassia africana}

Noms courants : Minkadi nkadi, munkadi nkadi, yombo, nkari nkari (Kikongo)

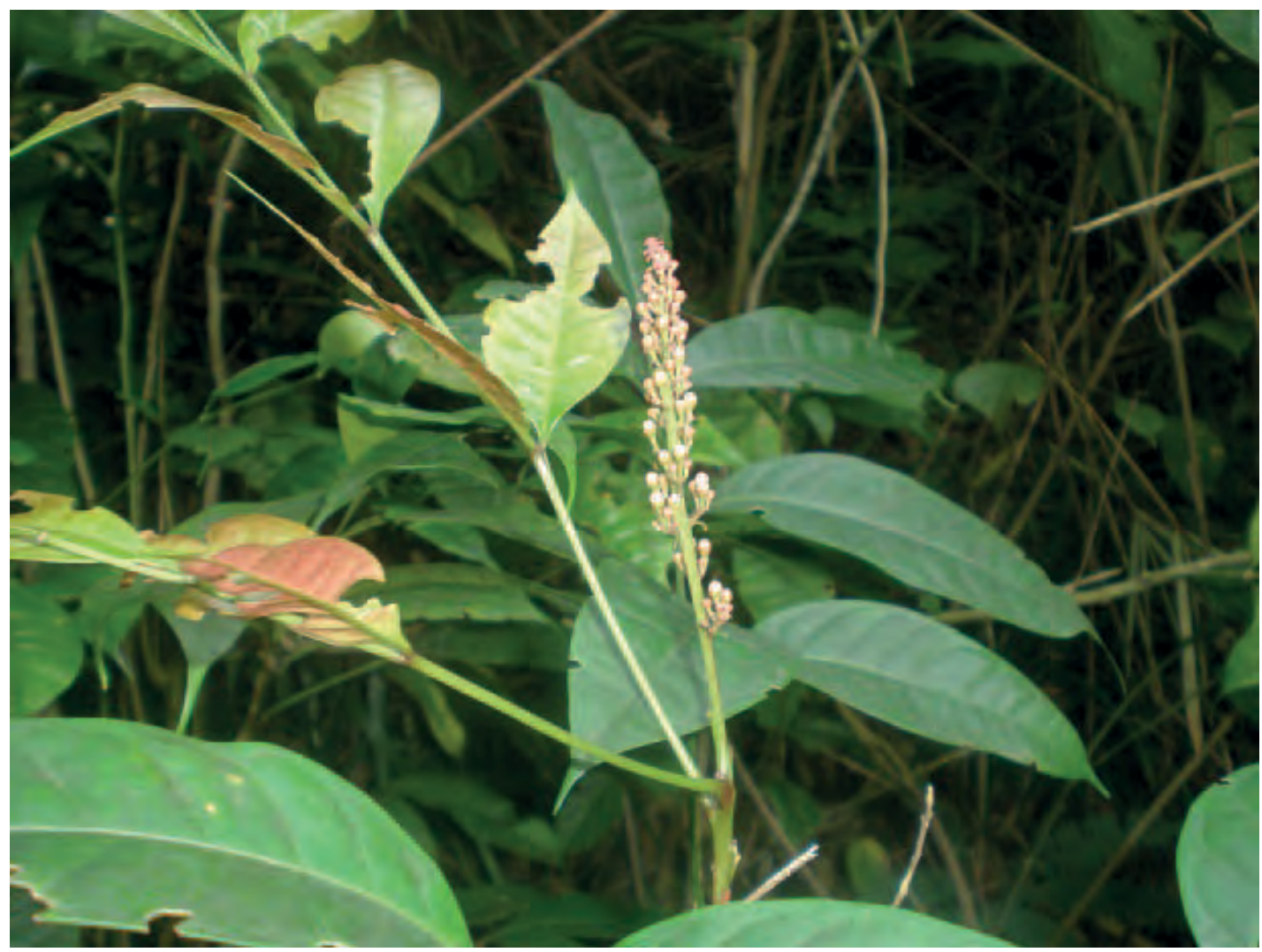

Description : Arbuste pouvant atteindre $4 \mathrm{~m}$ de haut. Ecorce vert grisâtre. Branches et rameaux glabres. Feuilles alternes composées avec 5 à 7 folioles opposées de 5 à 20 sur 2 à $8 \mathrm{~cm}$ sur des pétioles de 4 à $10 \mathrm{~cm}$. La foliole terminale est légèrement plus grande que les folioles latérales. Inflorescence terminale de 12 à $20 \mathrm{~cm}$ de long. Pétales blancs ou roses, avec des reflets jaunes. La plante fleurit toute l'année.

Ecologie: Arbuste présent dans les forêts pluviales de basse altitude, dans les zones de transition entre forêts sempervirentes et semi-décidues, de l'Ouest du Cameroun à la R.D. Congo et à l'Angola.

\section{Racines en vente sur un marché}

Usages: Toutes les parties de la plante sont très amères. Au Kongo Central, on emploie une décoction de la plante pour tuer les poux. On en fait aussi une lotion pour traiter les œdèmes. La poudre de bois sert comme tonique et pour faire baisser la fièvre. Au Manianga, les feuilles et les racines servent à traiter les hernies. Dans l'Equateur, on emploie les racines pour combattre les vers intestinaux et pour traiter les douleurs menstruelles sévères. On donne une infusion des racines pour traiter les

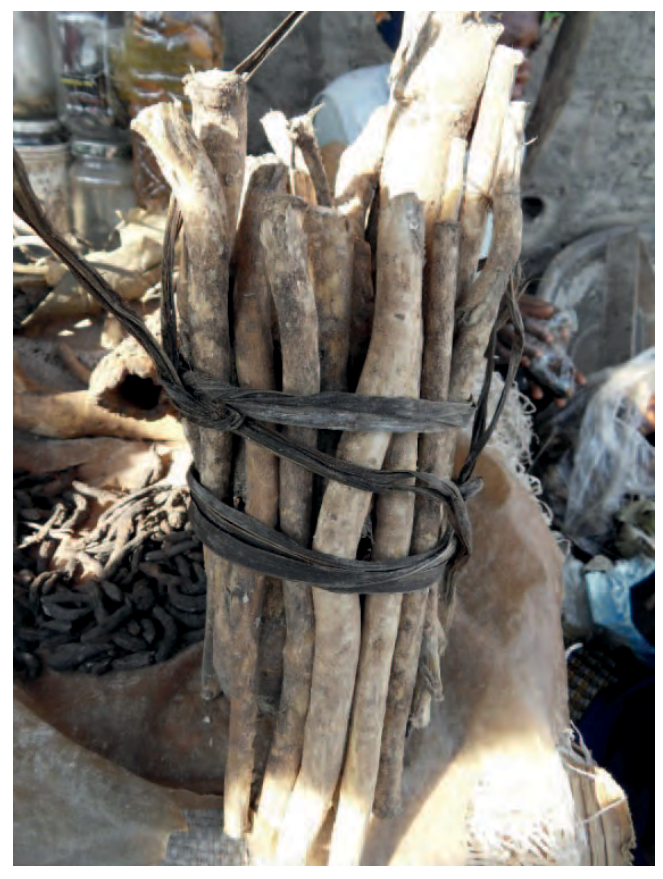
bronchites et pour faire baisser la fièvre. La plante sert à traiter les chancres syphilitiques. Pour chasser les poux, on fait une pommade avec l'écorce des racines et de I'huile de palme. On emploie comme insecticide dans I'horticulture des extraits des espèces de Quassia.

Références : Gillet et Pâque 1910, Staner et Boutique 1937, Renier 1948, Gilbert 1958, Nsimundele 1966 - 68 , Arkinstall 1979, Daeleman et Pauwels 1983, FAO 1986, Burkill 2000, Konda Ku Mbuta et al. 2015a 
Noms courants : Quinine de Cayenne, bois de Suriname, bois de Quassia, bois amer (Fr.), Quassia wood (Angl.)
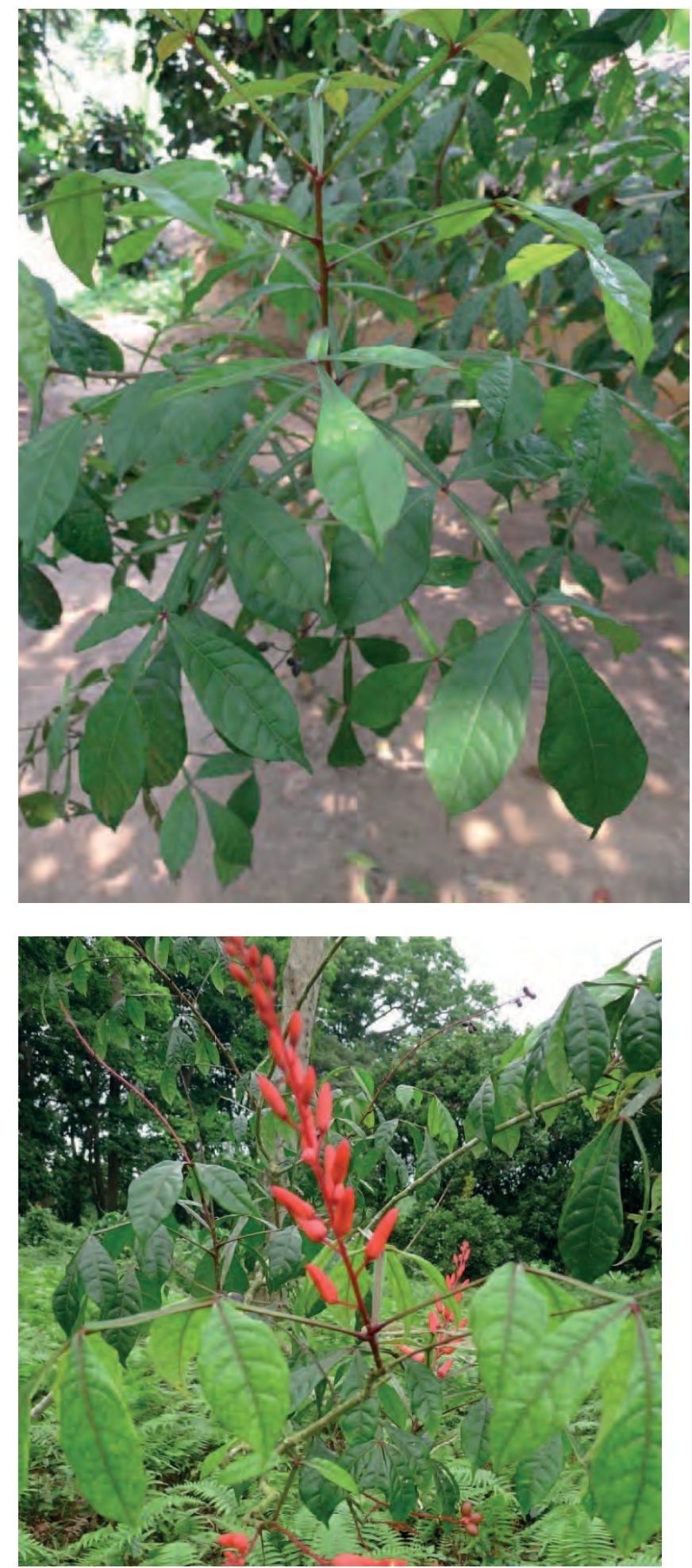

Description: Arbrisseau de 2 à $3 \mathrm{~m}$ de haut. Feuilles composées imparipennées jusqu'à 5 folioles, avec un rachis ailé de 5 à $16 \mathrm{~cm}$. Fleurs disposées en racèmes de 10 à $25 \mathrm{~cm}$ de long, bisexuelles, rouge vif à l'extérieur, blanches à l'intérieur, avec étamines et pistil saillants.

Ecologie : Plante originaire du Brésil, maintenant largement cultivée sous les tropiques.

Reproduction : Par graines, ou boutures de bois semi mûr, dans une petite serre fermée humide sur sol sableux.

Usages : La poudre du bois amer stimule l'appétit et facilite la digestion; elle a des propriétés antimicrobiennes ; elle peut servir à traiter les poux et comme insecticide contre les pucerons. La plante est souvent cultivée comme plante ornementale.

Références : Gillet 1927, Renier 1948, RHS 1999, Burkill 2000, van Valkenburg et Bunyapraphatsara 2001, van Wyk et Wink 2004, Fayaz 2011.

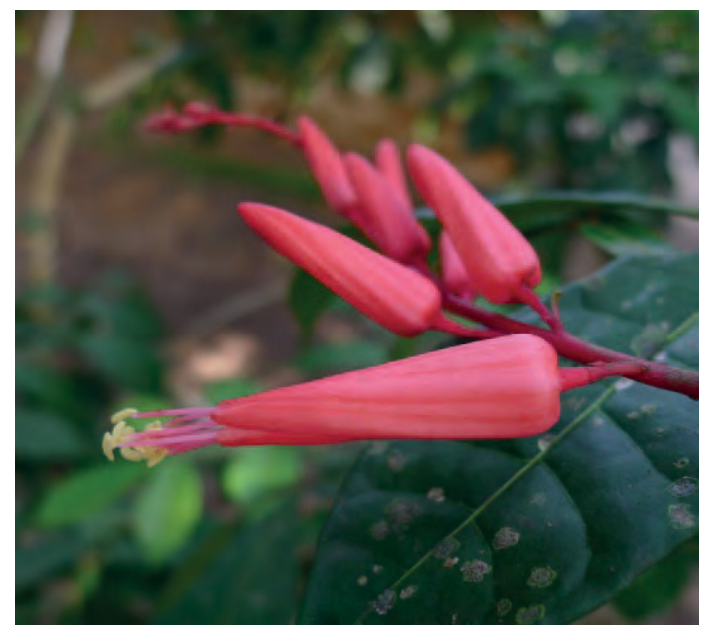




\section{Raphia gentiliana}

Synonyme : $R$. gilletii

Noms courants : Koko, ba di magusu, mawusu (Kikongo), palmier raphia (Fr.), raffia palm (Angl.),

Description : Palmier pouvant atteindre $8 \mathrm{~m}$ de haut avec des palmes jusqu'à $10 \mathrm{~m}$ de long. L'inflorescence peut avoir $2.1 \mathrm{~m}$ de long, et contient des fruits ronds ou allongés.

Usages: Les tiges des feuilles servent à faire des hamacs, des lits, et divers articles de mobilier. Traditionnellement, on tissait avec les fibres de raphia des jeunes feuilles un tissu, le «mbari », que l'on enroulait autour des reins pour les danses. On exploite l'arbre pour le vin de palme. Les abeilles butinent le nectar; elles
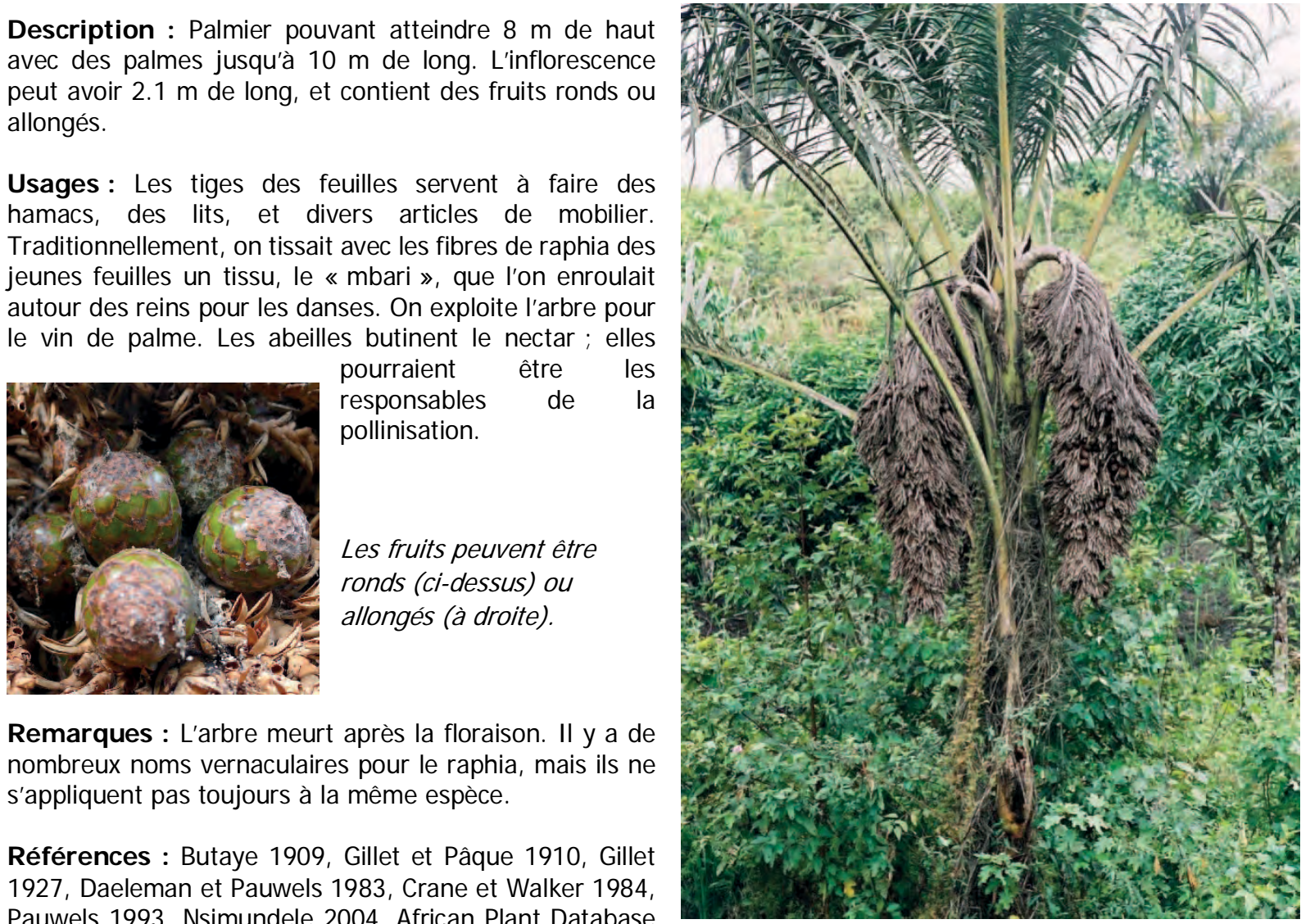

Remarques: L'arbre meurt après la floraison. II y a de nombreux noms vernaculaires pour le raphia, mais ils ne s'appliquent pas toujours à la même espèce.

Références : Butaye 1909, Gillet et Pâque 1910, Gillet 1927, Daeleman et Pauwels 1983, Crane et Walker 1984, Pauwels 1993, Nsimundele 2004, African Plant Database (3.4.0.) (Consultée le 8.9.18), Mbandu Luzolawo et al. 2020

Koko en fleurs à la ferme de Matolo près de Kasangulu et (ci-dessous) dans la forêt secondaire vers Kintudi

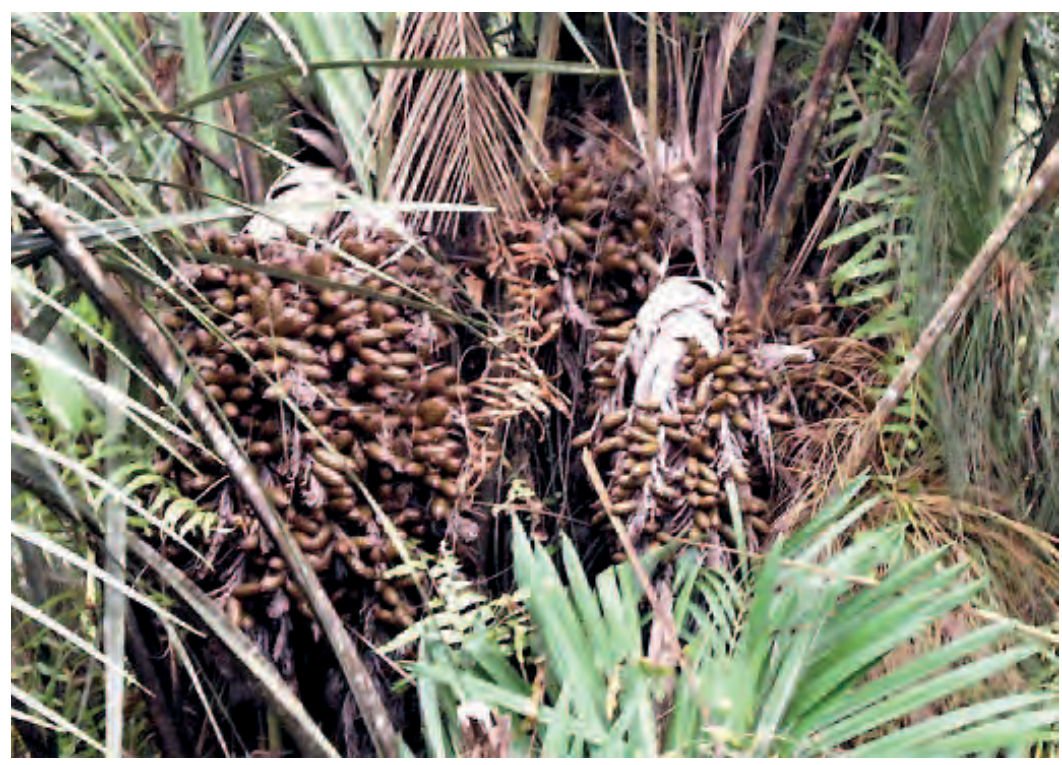




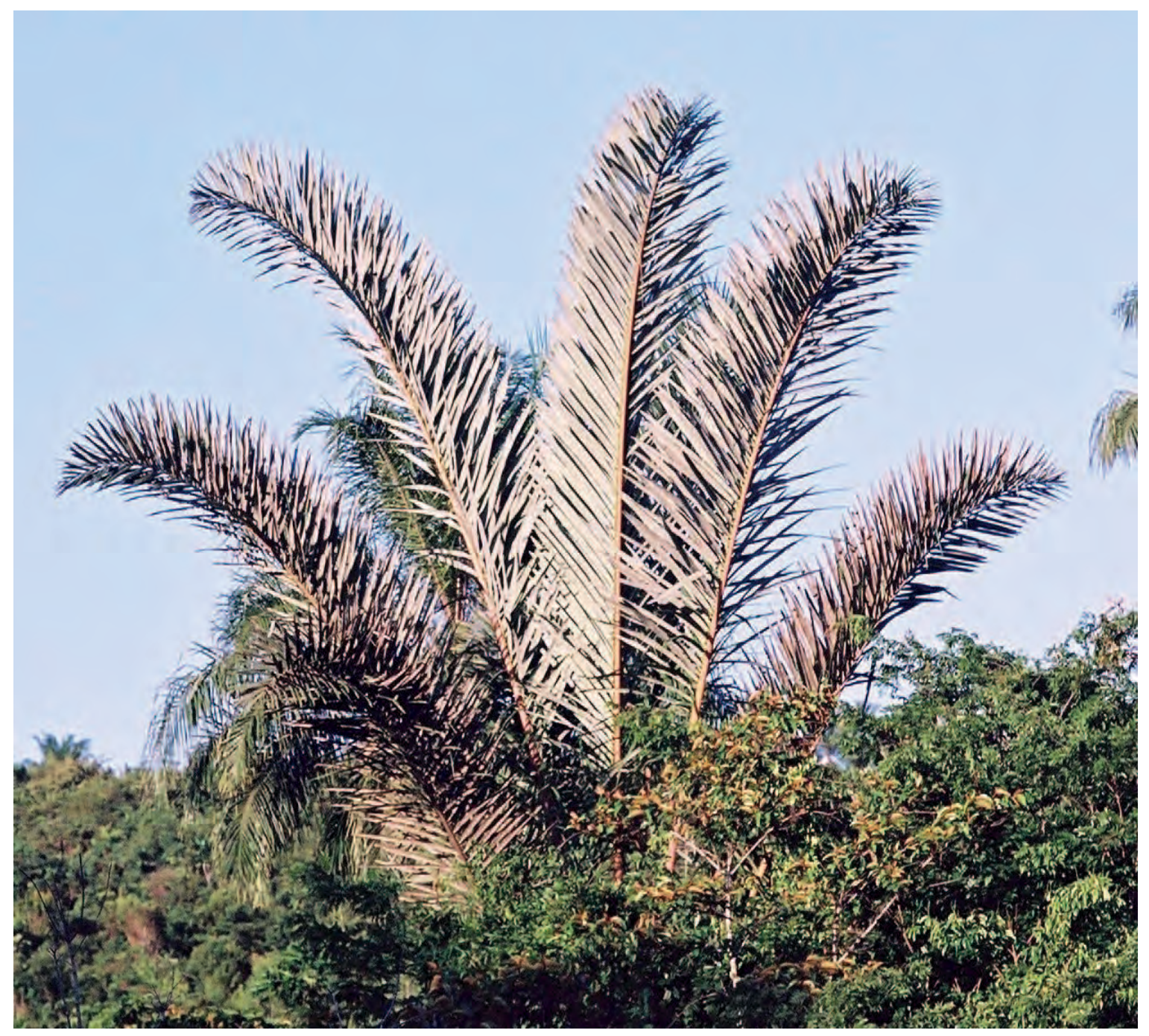

Raphia gentiliana dans une forêt secondaire à Kibombo

A droite: Un jeune mécanicien avec son camion Isuzu fait de tiges de palme de Koko.

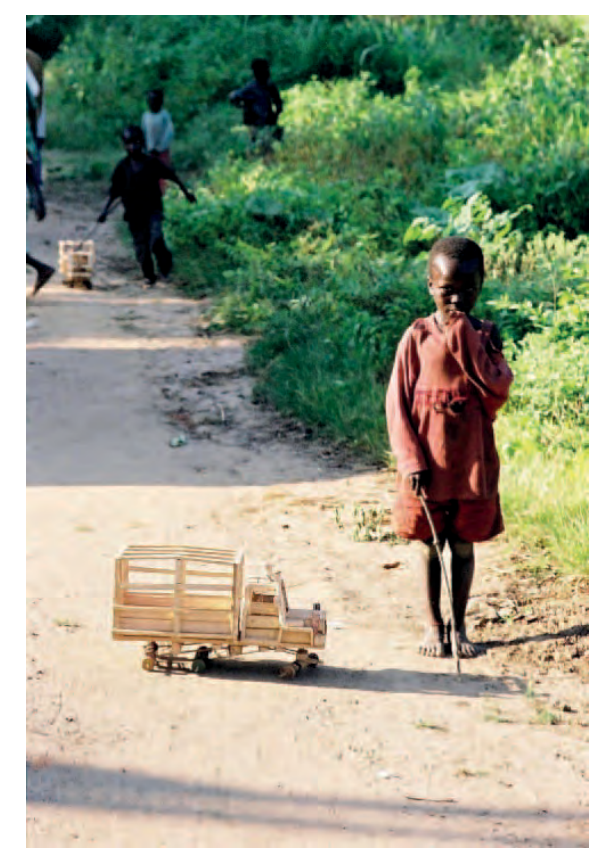




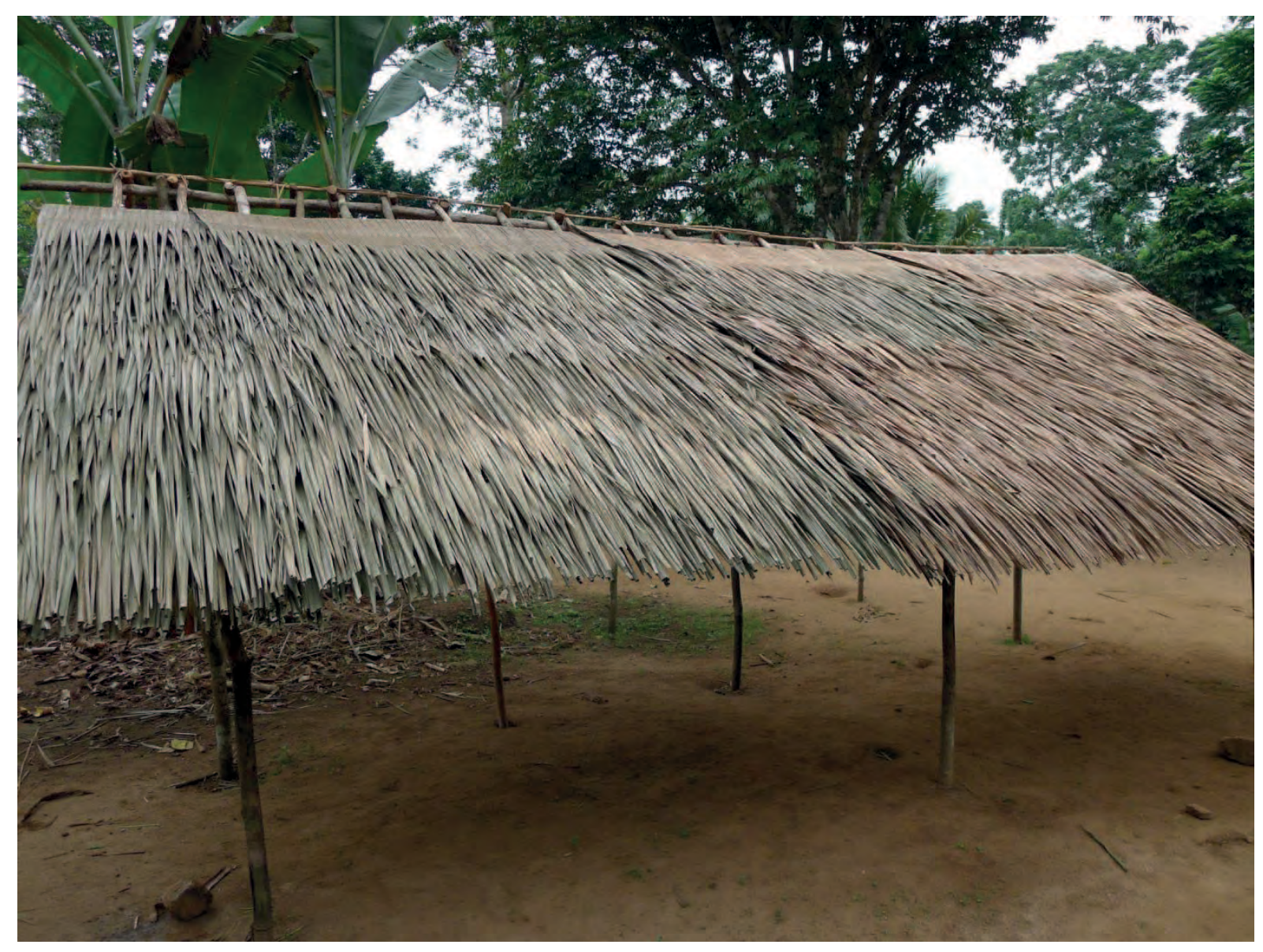

Toit en feuilles de palmier raphia

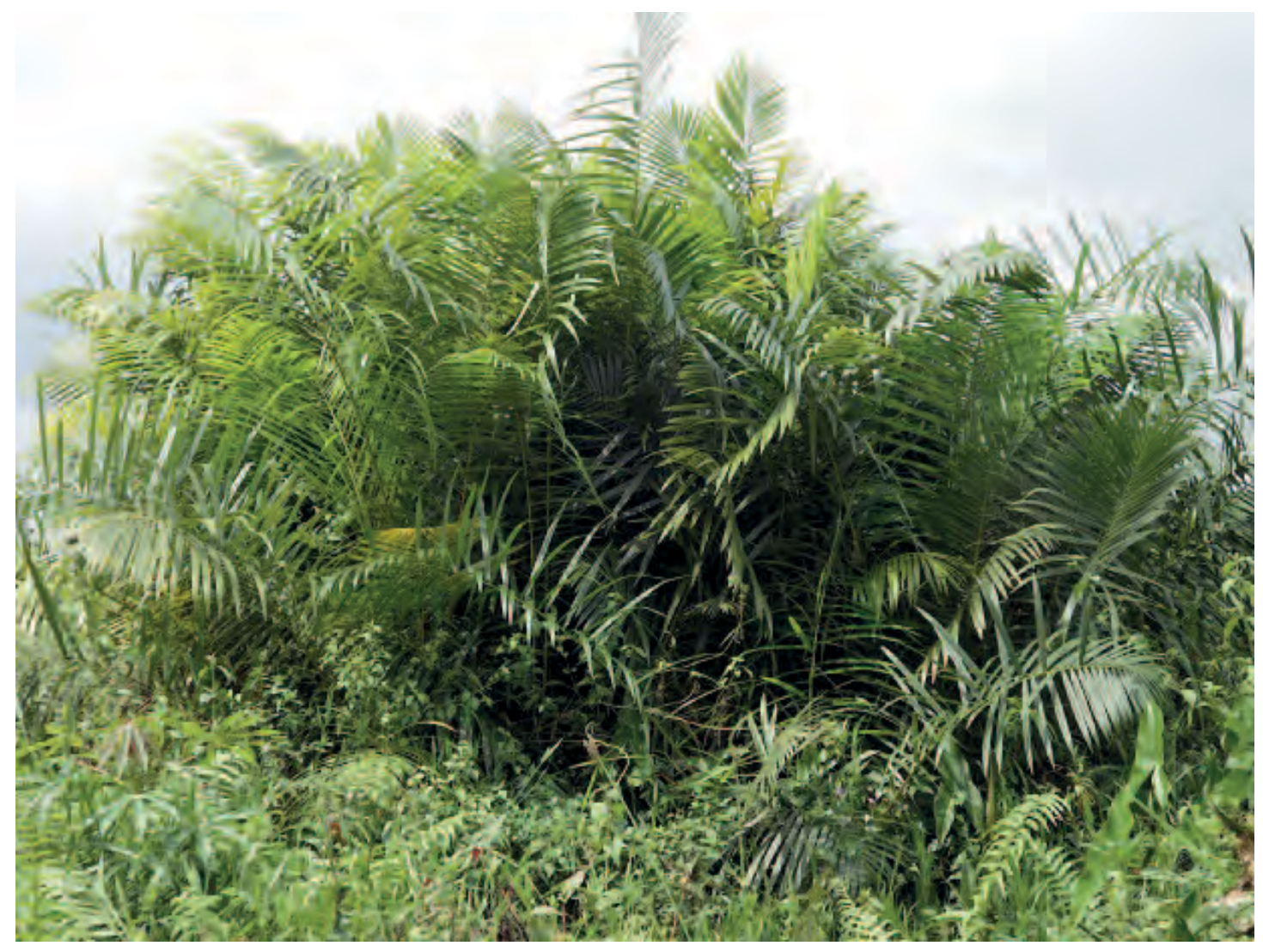

Un jeune plant de palmier raphia 


\section{Raphia matombe}

Noms courants: Tombe, ba di matombe (Kikongo), palmier raphia (Fr.), raffia palm (Angl.),

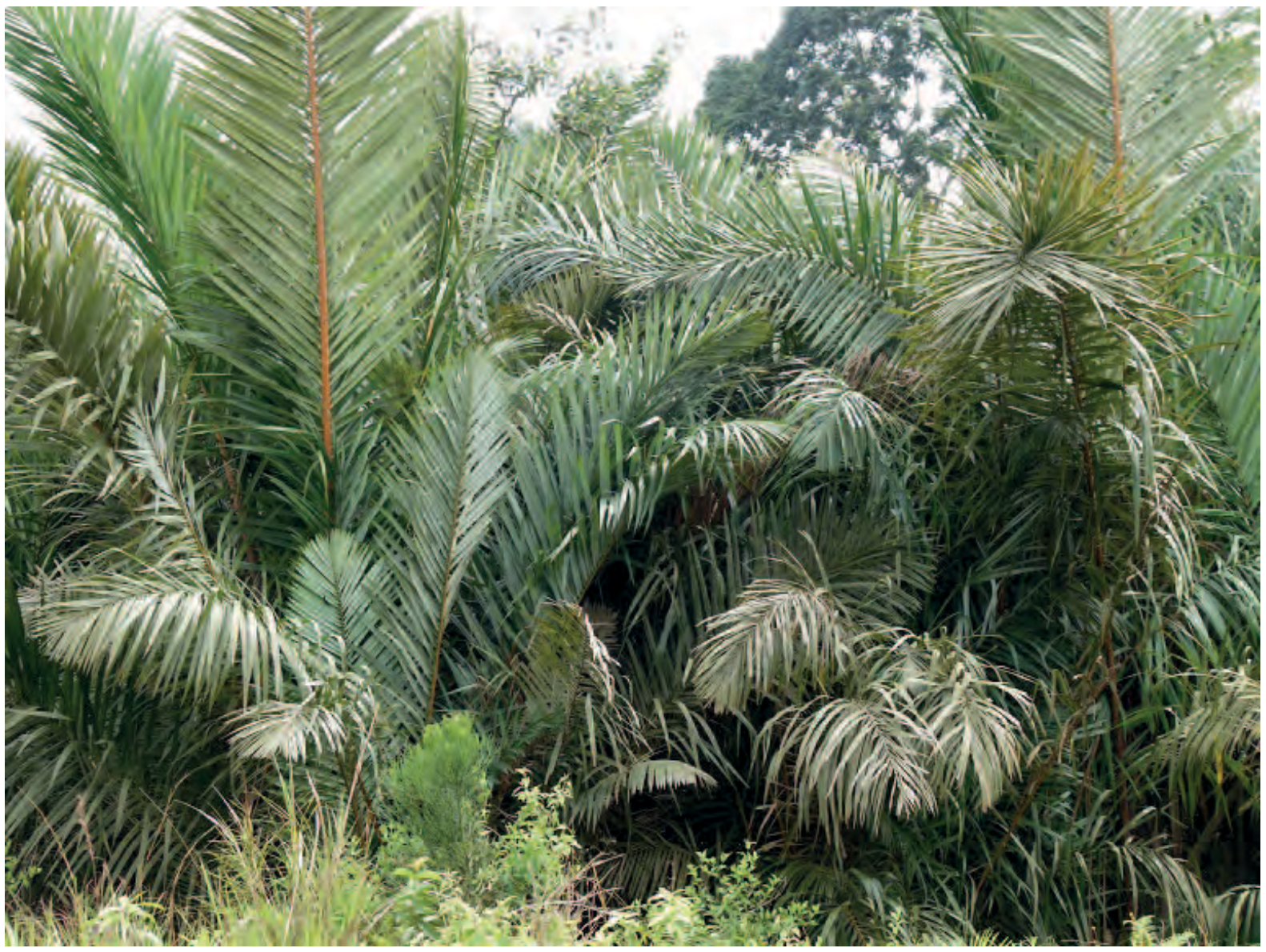

Ecologie : Petit palmier des sites humides et des marais.

Photo : Thea Lautenschläger

Usages : Avec les tiges des palmes, on produit du mobilier de village; l'arbre est exploité pour le vin de palme. Les fibres extraites des jeunes feuilles servent à faire des nattes, des tissus, des ficelles. Le cœur du tronc peut se manger en période de disette (Communication personnelle - Gracia Matondo). Les abeilles butinent le nectar, et pourraient être responsables de la pollinisation.

Remarque : On trouve aussi au Kongo Central $R$. laurentii.

Références : Gillet et Pâque 1910, Purseglove 1972, Daeleman et Pauwels 1983, Crane et Walker 1984, Pauwels 1993, Nsimundele 2004, Lautenschläger et al. 2019, Mbandu Luzolawo et al. 2020

Right: Lit fabriqué par Papa Antoine près de Mbanza Nzundu

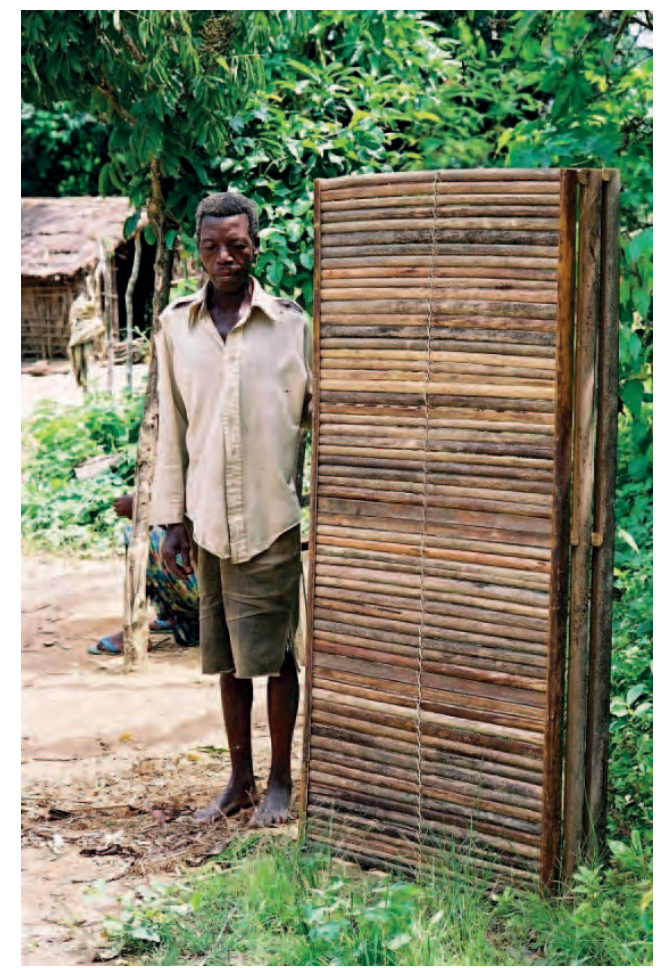




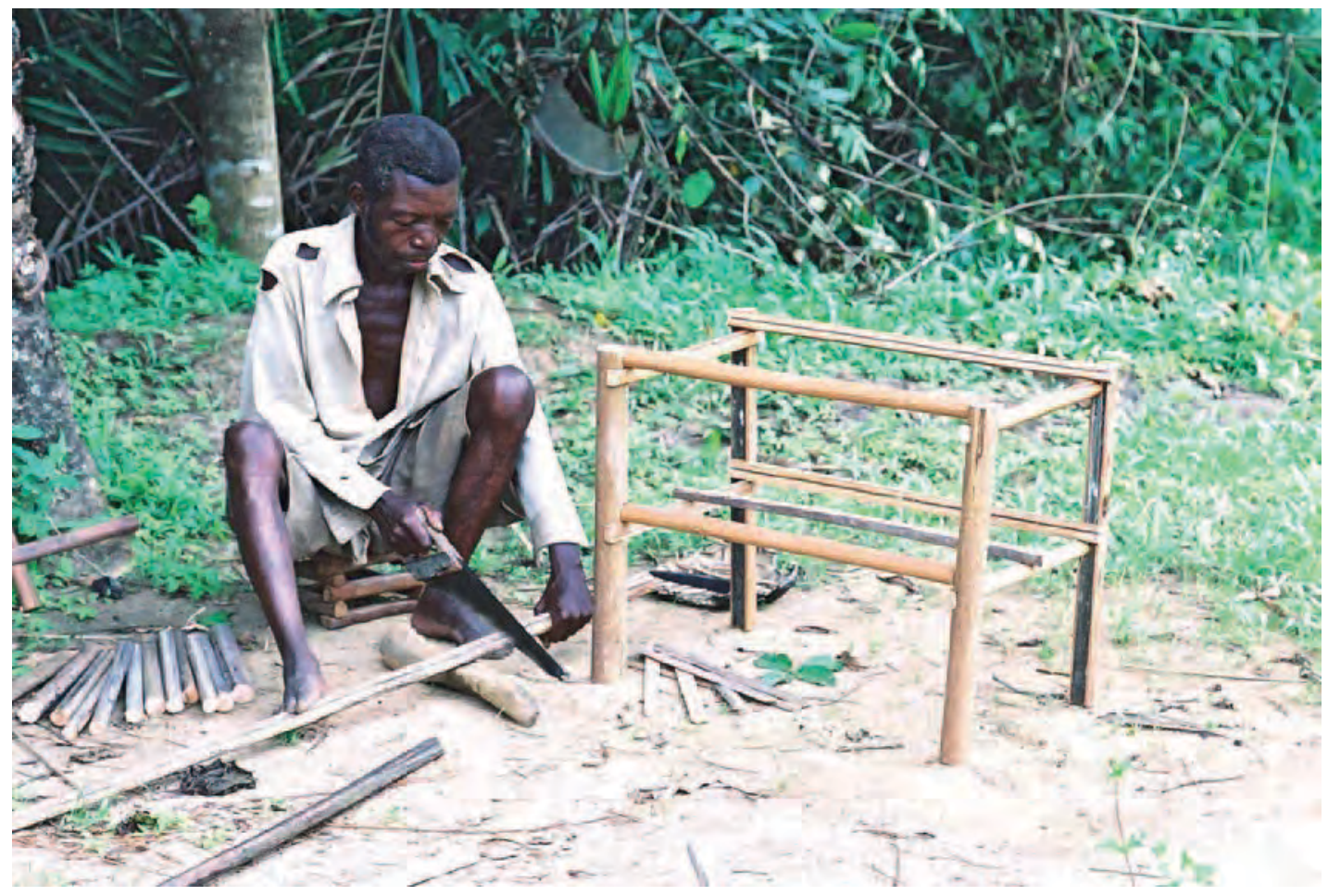

Papa Antoine fabriquant un placard

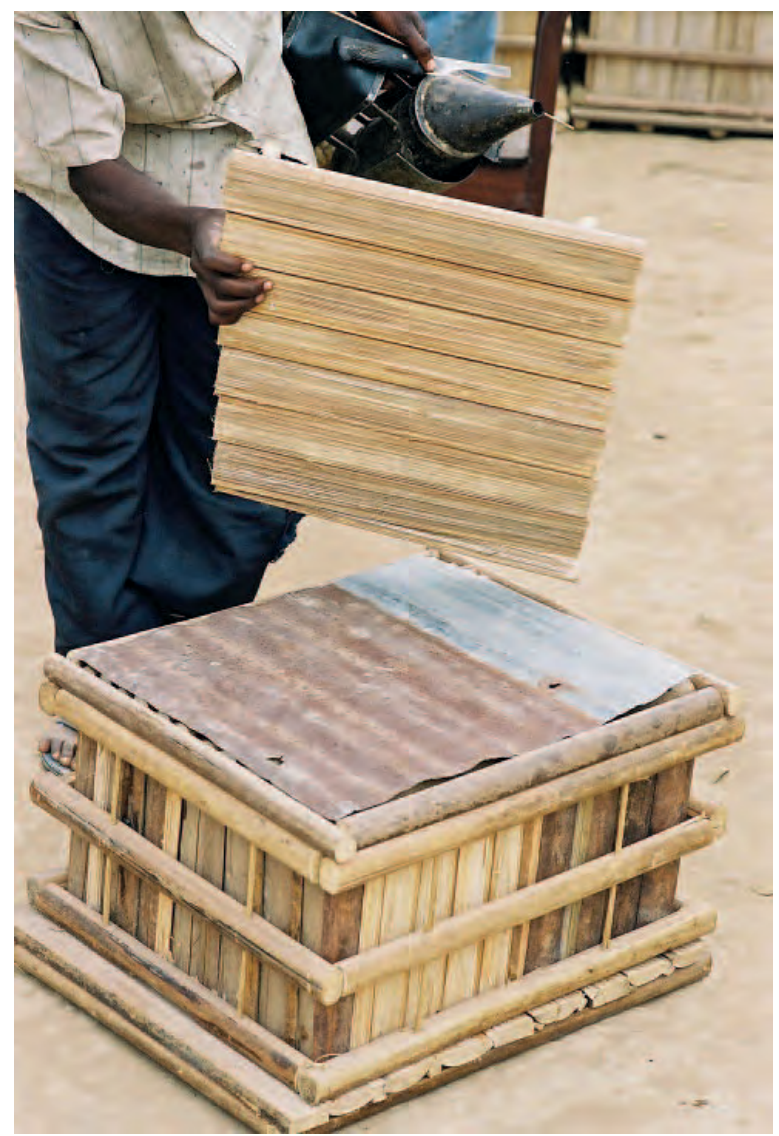

Ruche confectionnée par un apiculteur du Congo Brazzaville à Mbanza Nzundu. 
Noms courants: Nsaku (Kikongo = couteau à longue lame), ba di magangu (Kikongo).

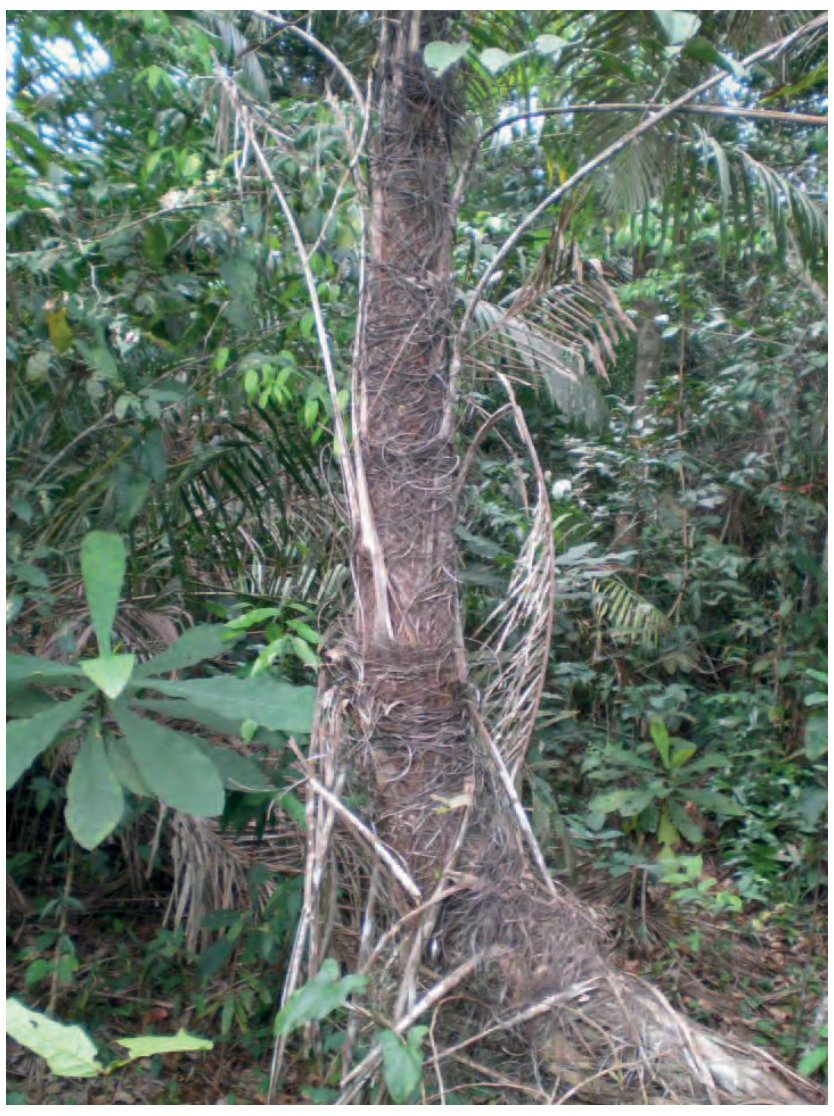

Description : Palmier qui pousse en touffes serrées jusqu'à $10 \mathrm{~m}$ de haut. Les fleurs femelles se trouvent à la base de l'inflorescence, et les fleurs mâles plus haut.

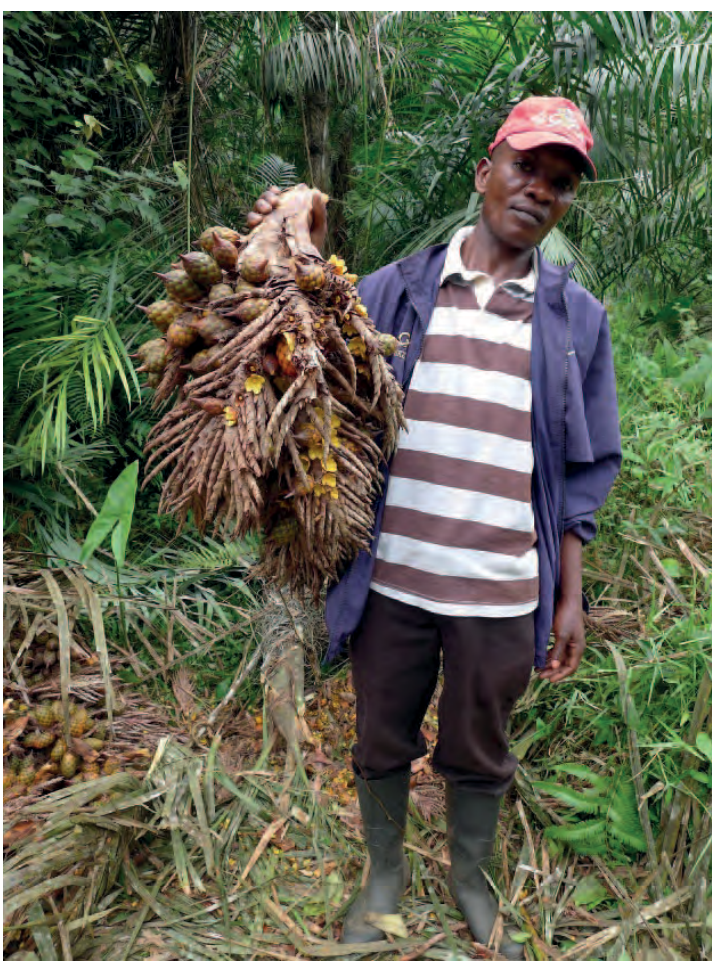

Ecologie : Se rencontre dans certains sites marécageux. Présent dans la zone forestière centrale de la R.D. Congo.

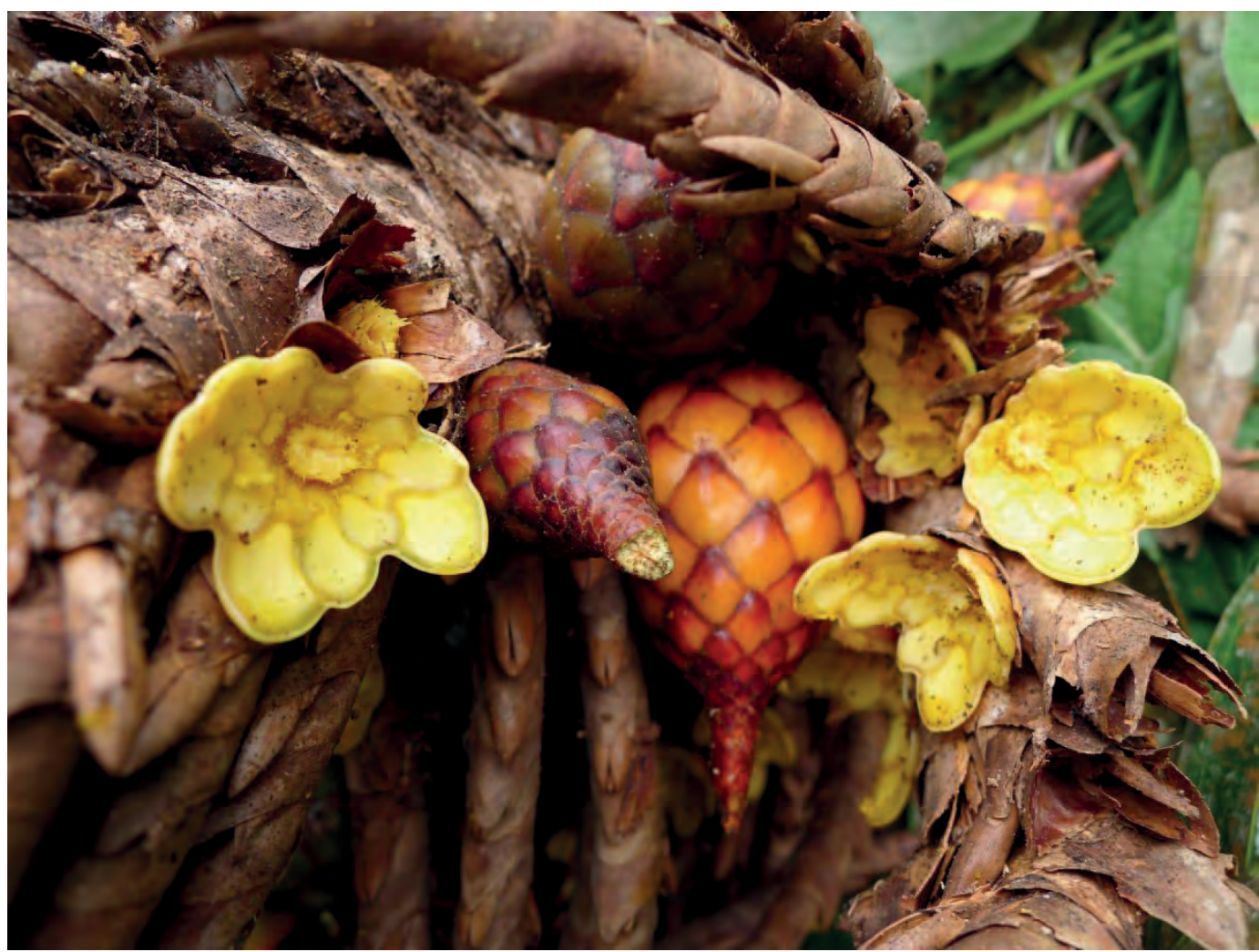


Usages: La pulpe autour des graines est comestible ; elle contient une huile jaune orange composée de plus de $70 \%$ d'acides gras insaturés (contre $55 \%$ pour l'huile de palme). On empile les fruits, et on les couvre de branches et feuillage jusqu'à maturité. On fait alors tremper ou bouillir les fruits dans l'eau pour enlever les écailles qui

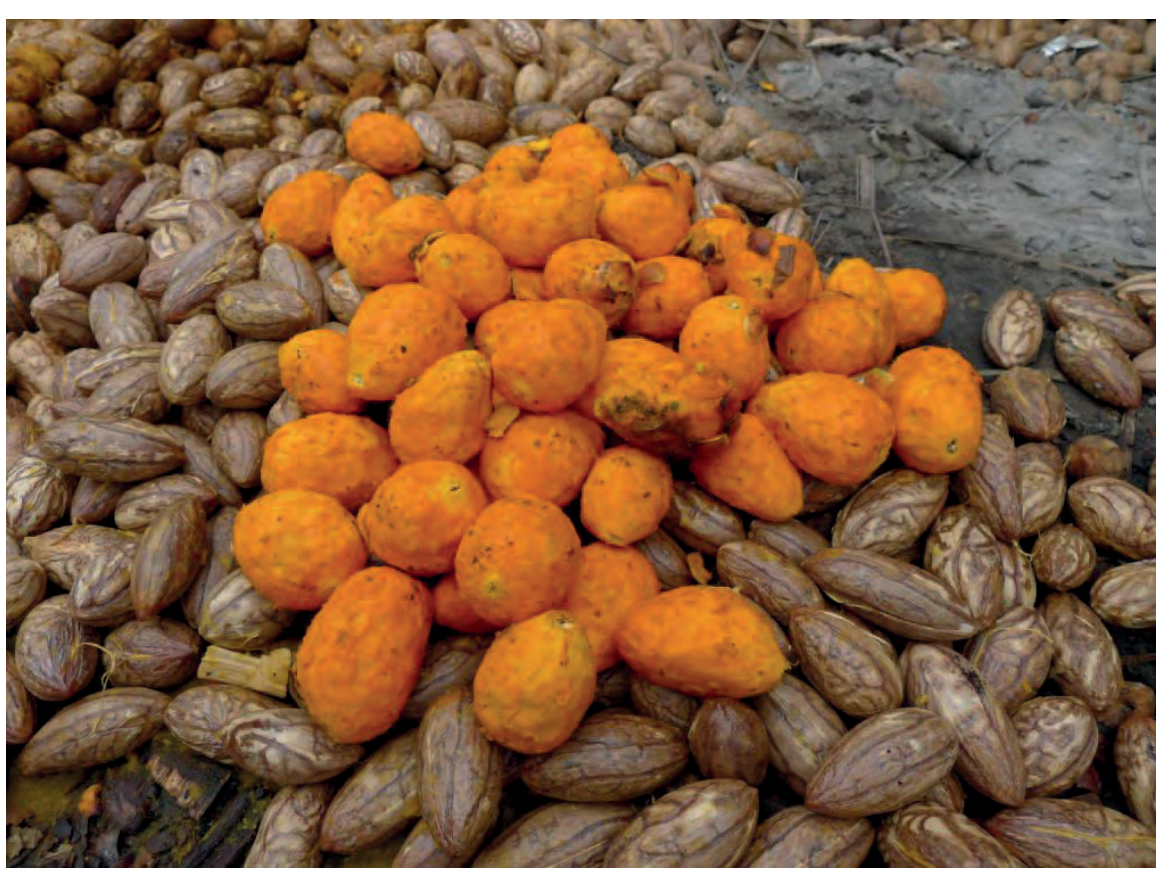
entourent la chair. Le fruit se mange comme condiment ; il permet de contrôler la consommation de sucre en cas de diabète. Les tiges des feuilles servaient traditionnellement à faire un couteau à longue lame nommé nsaku. On retire des troncs du vin de palme. Les abeilles collectent le nectar et pourraient être les responsables de la pollinisation.

A gauche: Fruits épluchés et noix

Références : Gillet et Pâque 1910, Renier 1948, Crane et Walker 1984, Pauwels 1993, Kanika et al. 2004, Biloso et Lejoly 2006

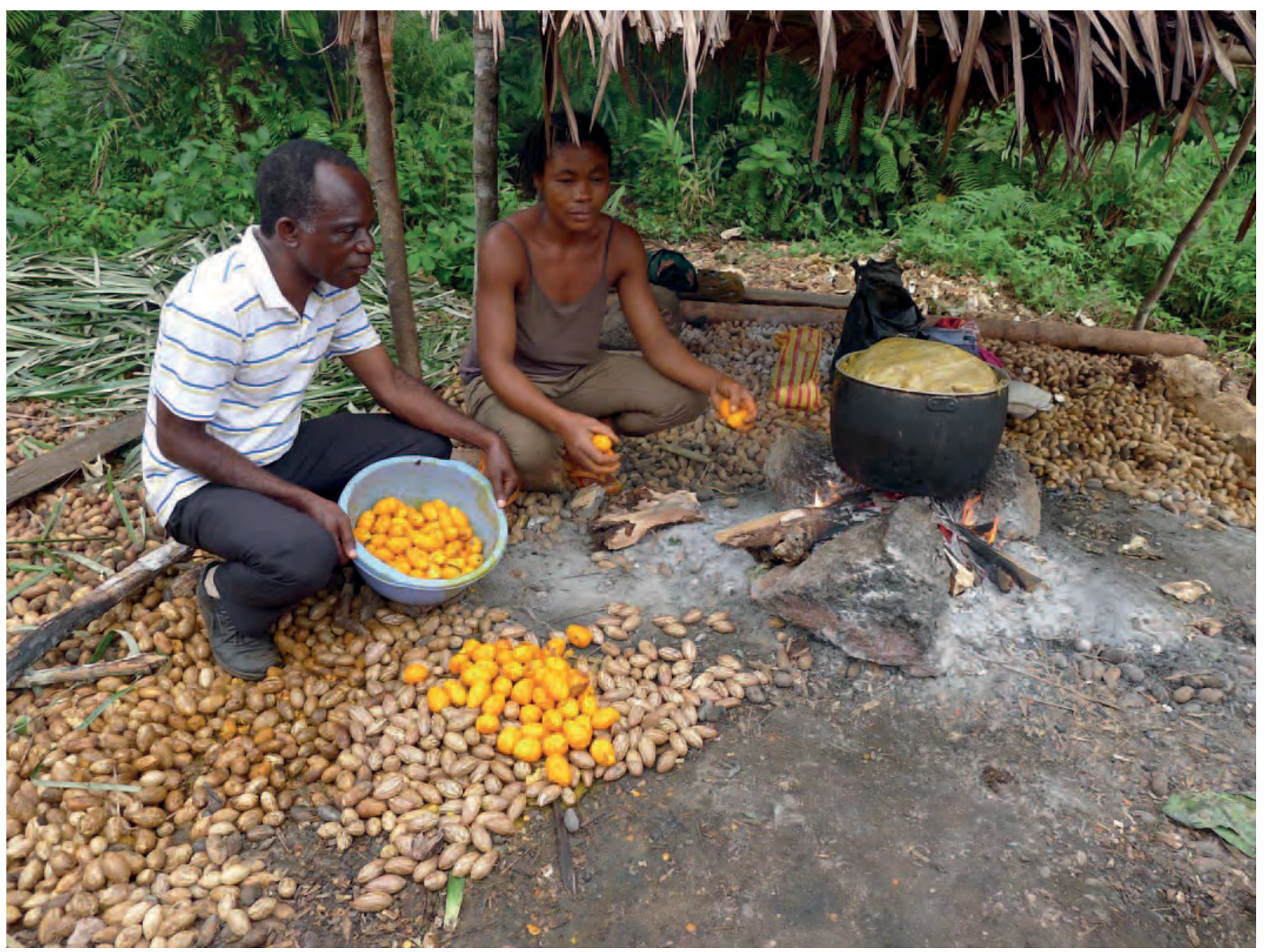

Konda Ku Mbuta (à gauche) avec des fruits épluchés. La chair se mange avec du manioc. On jette les noix. 
Synonyme : $R$. obscura

Noms courants : Kilungu, ndungu zi matebo, ndungu zi misitu (Kikongo), zumbu (Yaka), musitu (Manianga).

Description : Buisson de 1 à $2 \mathrm{~m}$ de haut. Feuilles de 4,5 à 9 sur 1,5 à $3 \mathrm{~cm}$. Fleurs parfumées. Fruits rouges en forme de cœur de 6 à $10 \mathrm{~mm}$ de long.

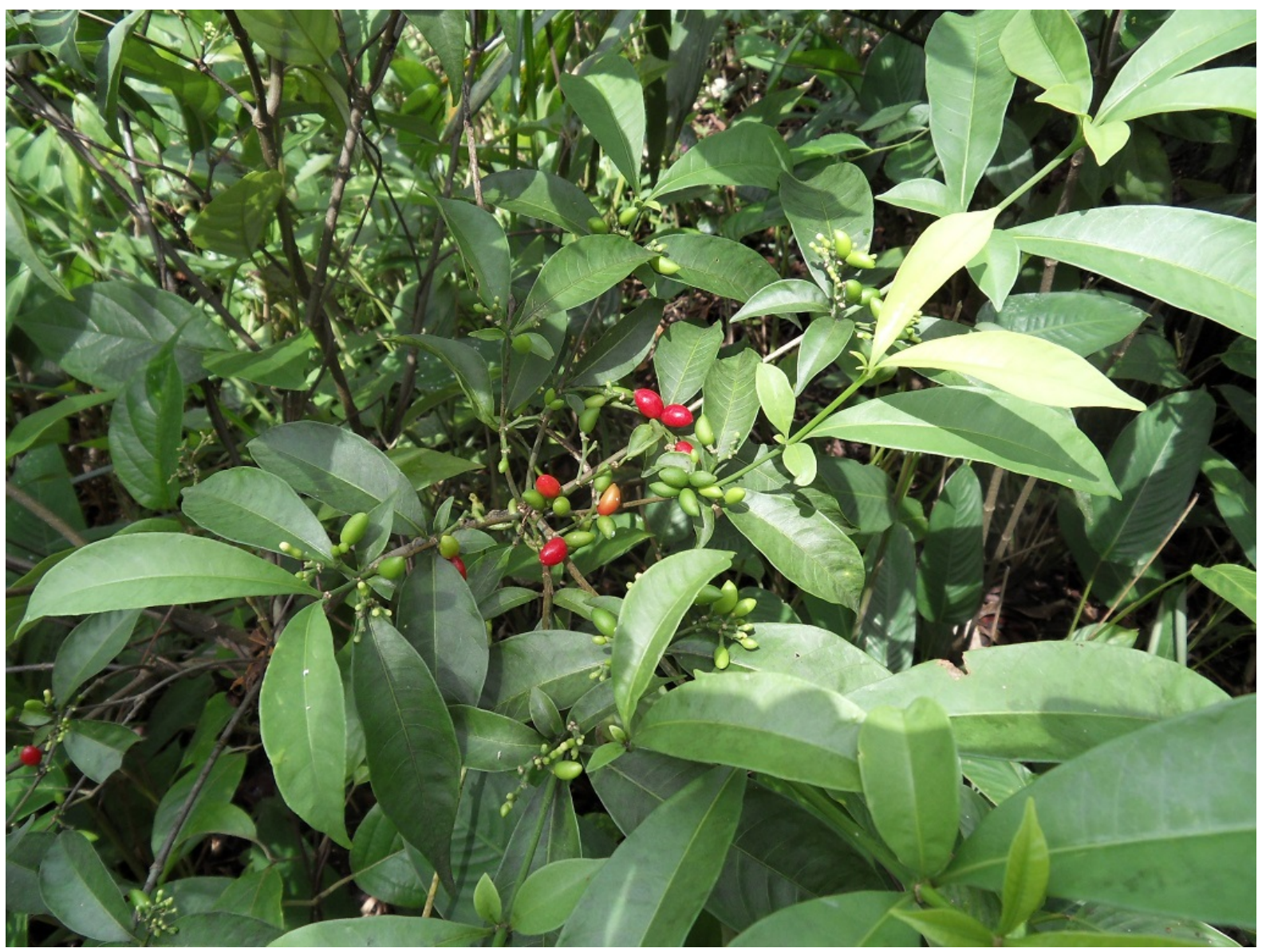

Ecologie : Plante commune des forêts secondaires, du Libéria au Kenya, à l'Ouganda et au Malawi.

Usages: Au Manianga, on traite les douleurs abdominales avec des racines bouillies dans l'eau. Ailleurs en R.D. Congo, on prend des feuilles fraiches ou séchées, dans du vin de palme ou de l'eau, pour traiter les désordres gastro-intestinaux, les empoisonnements, la jaunisse, la gonorrhée, la stérilité féminine. On applique la poudre des racines sur les blessures pour les cicatriser. On frotte la poudre des racines, la chair des fruits, ou les graines pilées, sur la tête pour tuer les poux, et ailleurs pour tuer les parasites de la peau. On prend une décoction des racines pour traiter la fièvre et le diabète. Les espèces de Rauvolfia sont des fourrages importants pour les abeilles dans les savanes humides et les zones équatoriales de l'Afrique.

Références : Renier 1948, Arkinstall 1979, Pauwelss 1993, Hepburn et Radloff 1998, Schmelzer 2007 
Noms courants : Kilungu (Kikongo), zumbu (Yaka)

Description : Arbuste de 4 à $6 \mathrm{~m}$ de haut, à branches et rameaux verticillés. Les feuilles simples sont groupées au bout des rameaux. Le fruit orange ou rouge est une drupe ovoïde de 8 à $14 \mathrm{~mm}$ de long. Chaque fruit porte une graine comprimée.

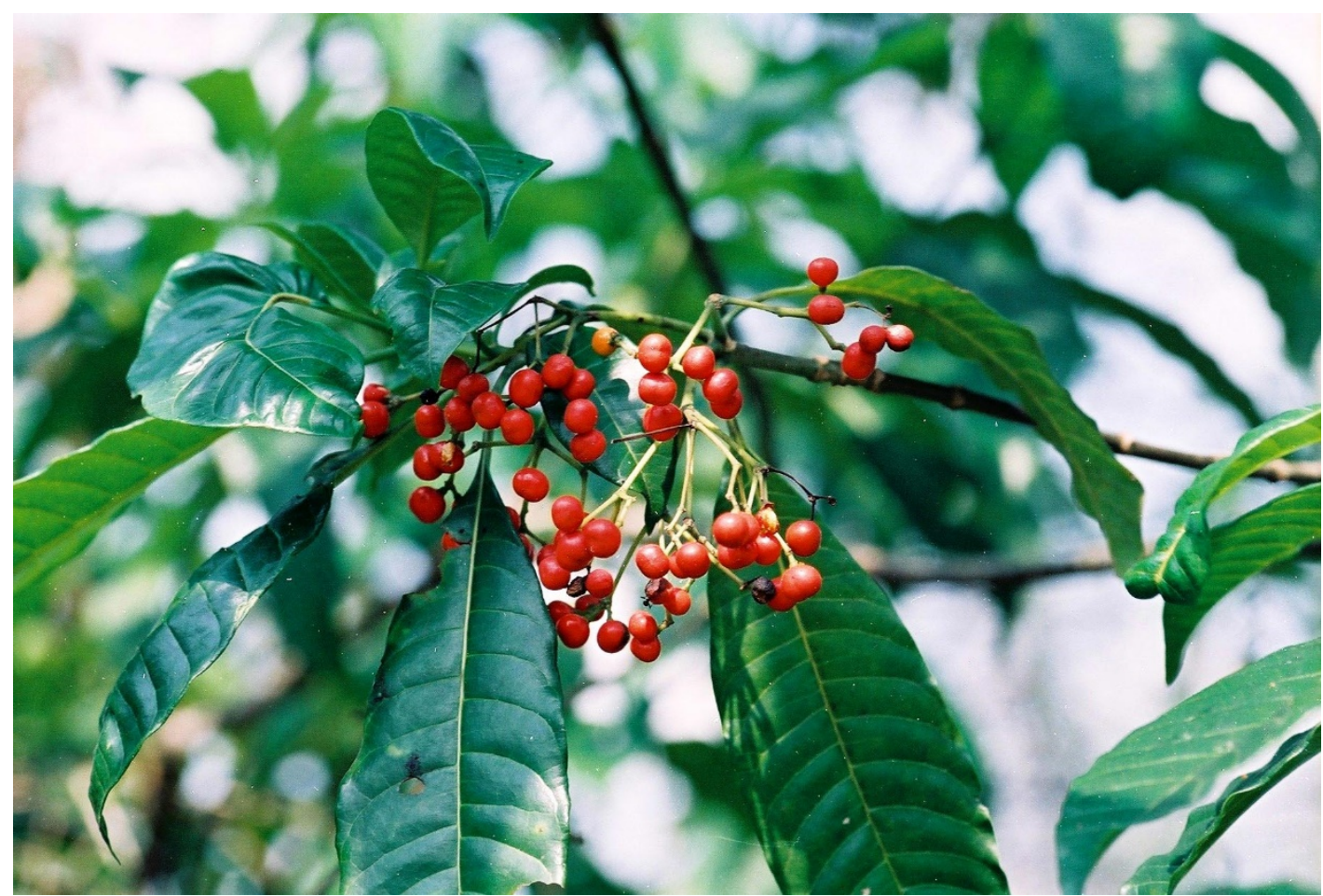

Ecologie : Plante des forêts secondaires et de la savane, de la Guinée au Soudan, à l'Angola et au Mozambique.

Reproduction : Récolter les fruits mûrs et les sécher. Semer directement les graines, qui restent viables environ un mois. On peut aussi faire des boutures.

Gestion: Les semis se transplantent aisément et poussent vite. On peut cultiver la plante en haie. L'arbre recèpe bien et peut se conduire en taillis.

Usages: Plante médicinale importante. La poudre de l'écorce des racines a été traditionnellement exportée du Congo pour traiter I'hypertension. La racine contient de la réserpine, qui donne une longue réaction sédative. Maintenant, on emploie l'écorce des racines au Kongo Central pour traiter les vers intestinaux et les maladies mentales. Le latex des jeunes feuilles s'emploie contre les maux d'estomac. La décoction de l'écorce des racines peut servir d'insecticide. La plante a beaucoup d'autres usages médicinaux en Afrique: l'écorce des racines traite aussi les maux de dents, les abcès et les parasites cutanés; les racines et les feuilles bouillies servent à

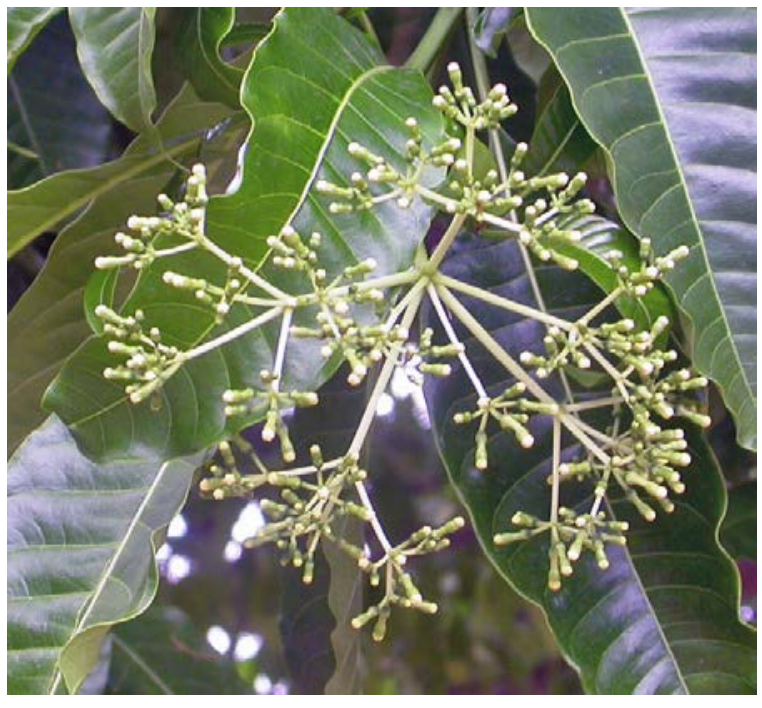
traiter les vers intestinaux, et comme purgatif. L'arbuste est largement planté à titre ornemental. Le bois est blanc à grain fin ; il a peu d'importance économique, sauf comme bois de feu. On peut obtenir une teinture jaune à partir de l'écorce. Les abeilles butinent intensément les fleurs et récoltent le nectar. Les chenilles comestibles Kaba ( Lobobunaea phaedusa) et Kindengula (Daphnis neri) se nourrissent des feuilles.

Références : Gillet 1927, Renier 1948, Watt et Breyer-Brandwijk 1962, Nsimundele 1966 - 68, Daeleman et Pauwels 1983, Ambougou 1991, Mukoko Matondo 1991, Pauwels 1993, Mbuya et al. 1994, Katende et al. 1995, White et Abernethy 1997, Neuwinger 2000, Raemaekers 2001, Schmelzer 2007, Lautenschläger et al. 2018 


\section{Renealmia africana}

Noms courants : Susa (Kikongo)

Description : Plante herbacée pérenne avec des tiges feuillues de 1 à 1,5 m sur un rhizome. Fleurs blanches, fruits rouges, puis noirs à maturité. La plante a une odeur d'urine.

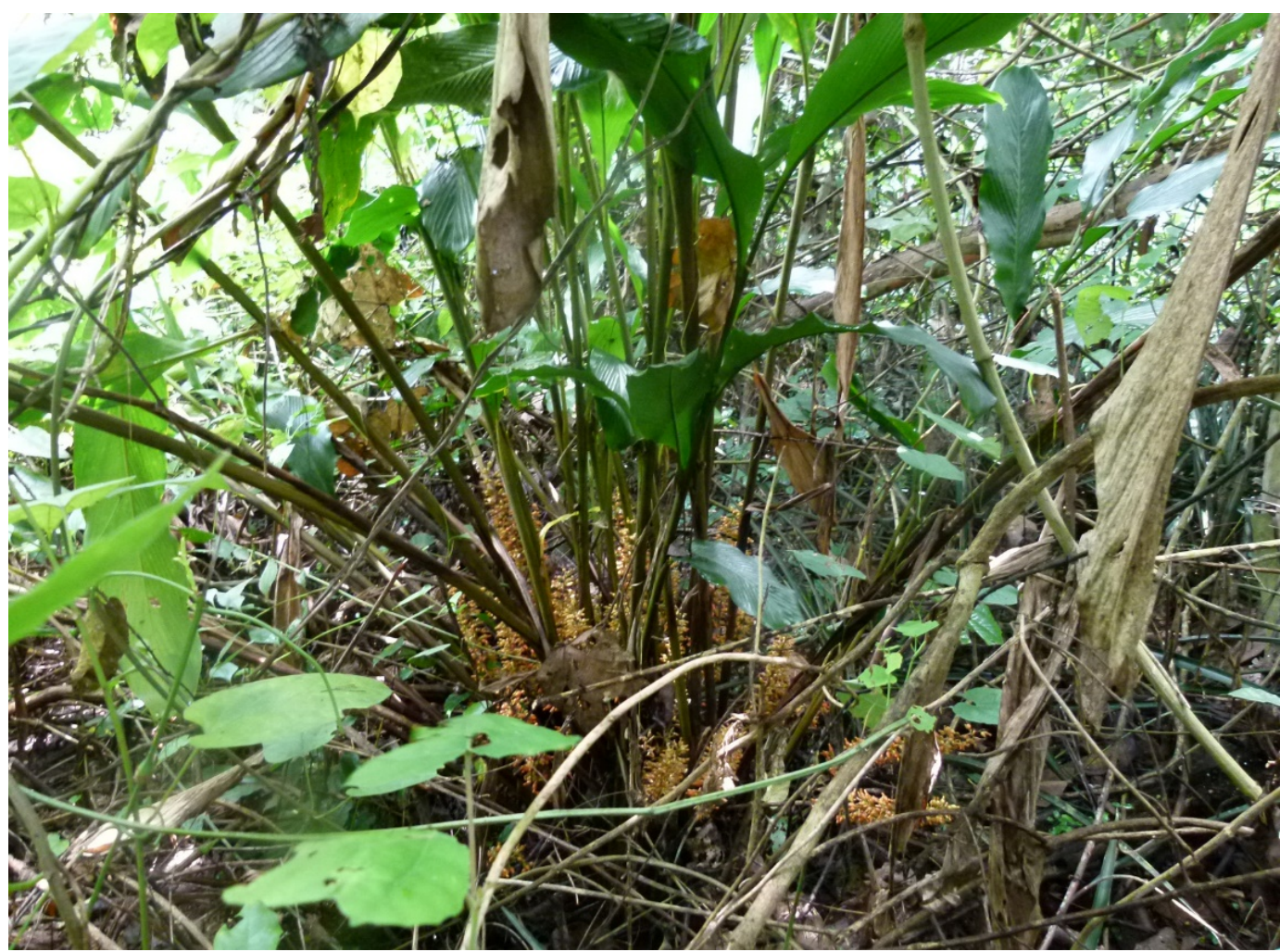

Photos en haut et à gauche : Thea Lautenschläger

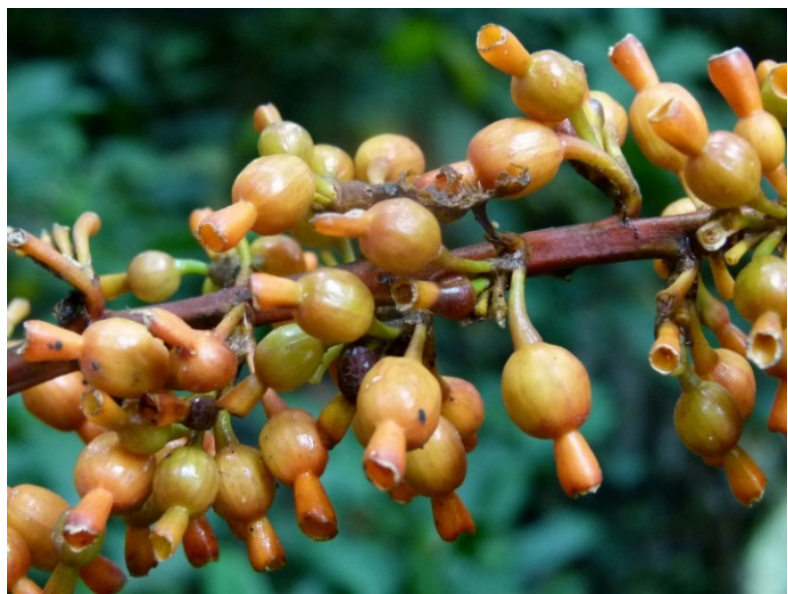

Photo de droite : fruits séchés au marché de Kisantu

Usages : La plante et ses graines, au goût piquant, ont des usages médicinaux. On pile les feuilles trempées dans l'eau pour obtenir une lotion qui traite l'urticaire et les fièvres subites. La plante sert aussi à traiter la scoliose. Une espèce de chenilles comestible se nourrit sur la plante. On la cultive parfois comme plante ornementale.

References Gillet et Paque 1910, Gillet 1927, Renier 1948, Daeleman et Pauwels 1983, Burkill 2000, Neuwinger 2000, Konda Ku Mbuta et al. 2015a
Ecologie : Plante des forêts humides, au Sud du Nigéria, à l'Ouest du Cameroun, à Fernando Po et dans le bassin du Congo. Localement commune.

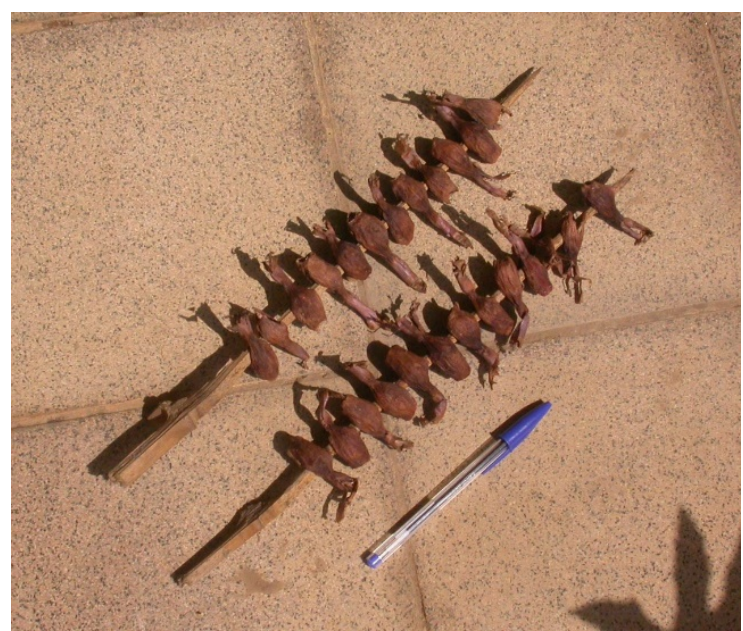


Noms courants : Kikomba, mpakasa, mukubi, mvuma, (Kikongo), linuku, lopanzanzoko (Lingala)

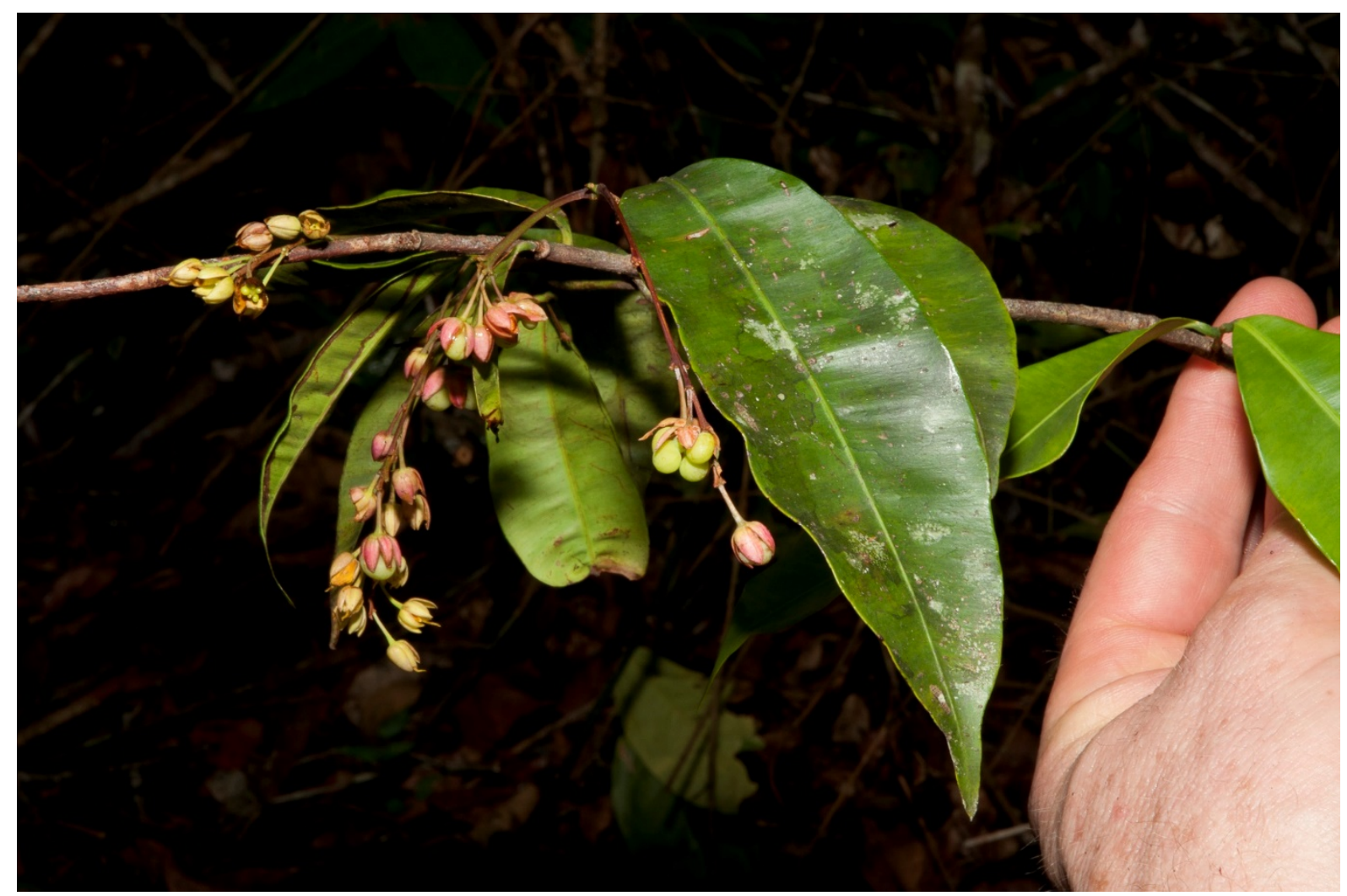

Les deux photos : David Harris/Royal Botanic Garden, Edinburgh

Description : Arbuste haut de 3 à $10 \mathrm{~m}$. Le tronc, souvent cannelé, a un diamètre irrégulier. L'écorce est rougeâtre et fibreuse. Les feuilles ont 7,5 à 13 sur 2,5 à $4 \mathrm{~cm}$. L'inflorescence est un racème de 8 à $18 \mathrm{~cm}$ composé de 20 fleurs jaunes ou davantage. Les fruits ont 6 à $9 \mathrm{~mm}$ de long. En fructifiant, le calice devient rose à rouge : à distance, l'arbre parait couvert de fleurs rouges, comme les espèces du genre Ochna.

Ecologie: Plante des forêts secondaires et forêts marécageuses, au Cameroun, au Soudan, au Gabon et dans les deux Congo.

Usages : Le bois, très dur et résistant aux termites, s'emploie en construction et pour fabriquer des houes en bois. On fait des brosses avec les rameaux. Le charbon de bois est particulièrement apprécié des forgerons. Les jeunes feuilles sont comestibles, et se vendaient traditionnellement sur les marchés au Kongo Central.

Références : Gillet et Pâque 1910, Renier 1948, Bamps et Farron 1967, Pauwels 1993, Harris et Wortley 2008, Harris et al. 2011 


\section{Rhabdophyllum welwitschii}

(Ochnaceae)

Noms courants : Mpakasa, kikomba (Kikongo), lofandia ndiukumoke (Lingala)

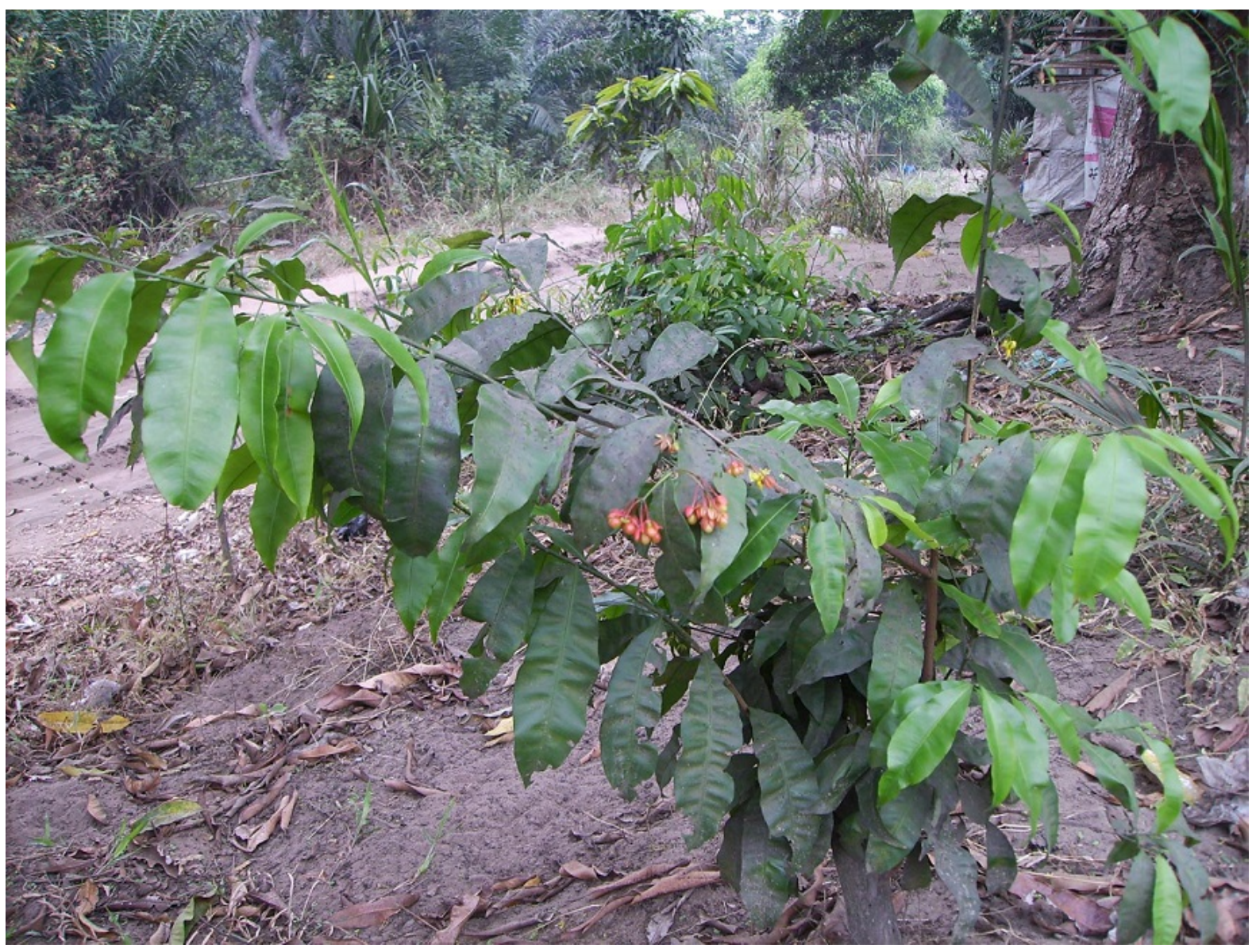

Description : Arbuste de 2 à $10 \mathrm{~m}$, dont le tronc dépasse rarement $5 \mathrm{~cm}$ de diamètre. Feuilles de 6 à 12 sur 2 à $5 \mathrm{~cm}$ sur un pétiole de 2 à $4 \mathrm{~mm}$. Les fleurs ont un bouton franchement conique, arrondi à la base, pointu au sommet, de $5 \mathrm{~mm}$ de long sur 2 à $3 \mathrm{~mm}$ de diamètre. Les fruits, de 4 à $5 \mathrm{~mm}$ de diamètre, rouges puis noirs, ont des sépales rouges.

Ecologie : Plante des forêts secondaires, des forêts galeries et des savanes arbustives, du Gabon à l'Angola et à la Zambie.

Usages: Les tiges servent à faire des balais et s'emploient en construction. Dans l'Equateur, la racine traite la stérilité féminine, avec Impatiens invingii, Diospyros gabunensis et Eriocoelum kerstingii.

Références : Renier 1948, Bamps et Farron 1967, Daeleman et Pauwels 1983, Pauwels 1993, Biloso et Lejoly 2006, Harris et Wortley 2008, Konda ku Mbuta et al. 2015a 


\section{Rhynchosia mannii}

(Fabaceae)

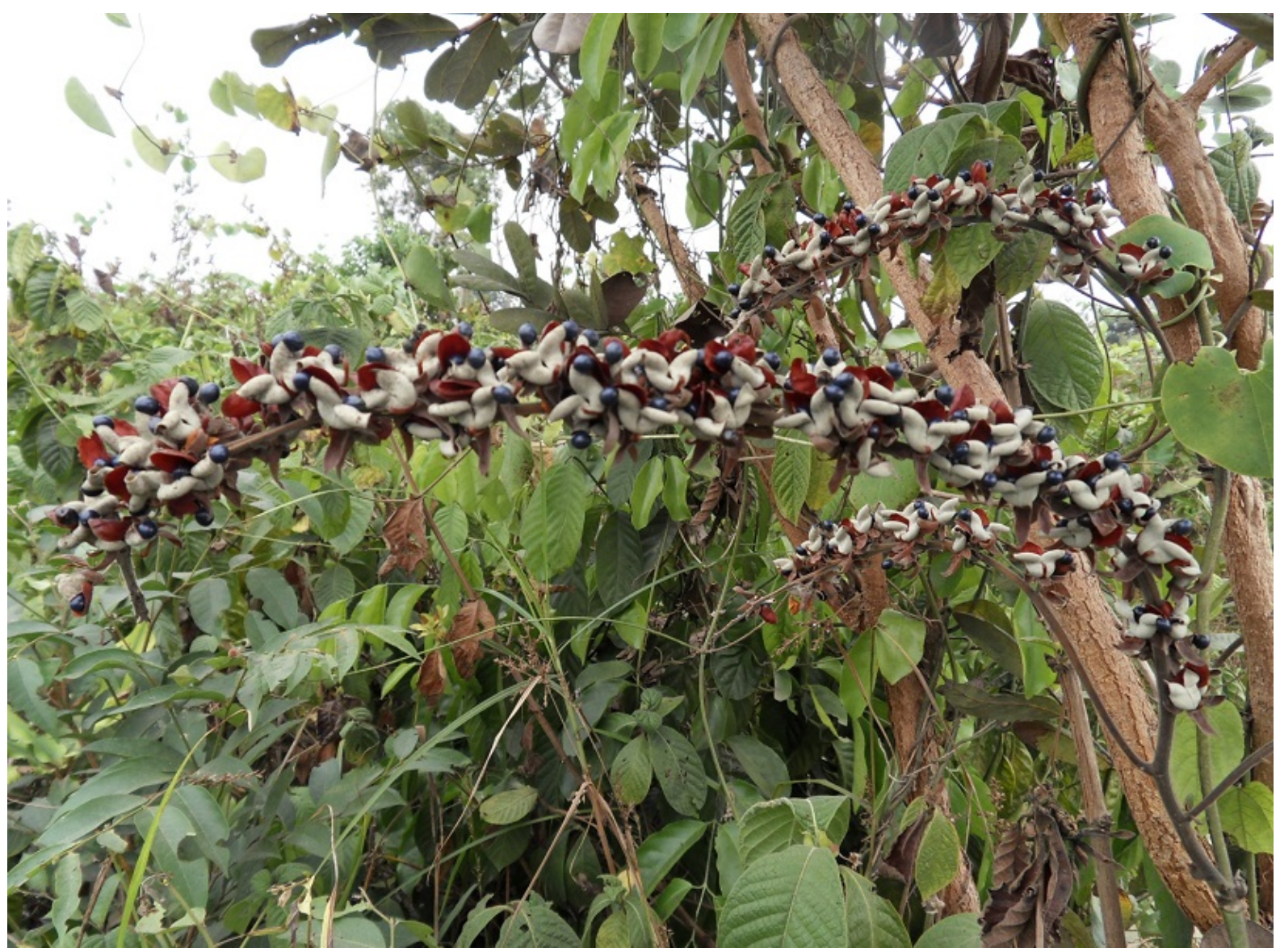

Rhynchosia mannii portant des fruits en août.

Description : Liane volubile de 4 à 8 m de haut. Feuilles trifoliées, sur un pétiole de 6 à 12 cm ; la foliole centrale est ronde ; les autres mesurant 8 à 16 sur 5 à $14 \mathrm{~cm}$, sont asymétriques et très coriaces. Inflorescences terminales de $40 \mathrm{~cm}$, portant 3 à 6 branches de 10 à $20 \mathrm{~cm}$. La corolle est d'abord verte rayée de rouge, puis jaune rayée de pourpre, puis mauve. Les gousses sont oblongues, couvertes d'un tissu gris clair ou brun de poils courts. Les gousses s'ouvrent pour montrer des graines brillantes bleu foncé, adhérentes aux gousses.

Ecologie : Plante des sous-bois des forêts secondaires et des forêts galeries, présente aussi dans les champs de manioc, du Nigéria à l'Angola et à l'Ouganda.

Usages : Au Gabon, les jeunes mères mangent des feuilles cuites pour calmer les douleurs suivant l'accouchement; on donne également ces feuilles aux enfants pour traiter les coliques. Toutes les espèces de Rhynchosia sont utiles pour couvrir le sol et contrôler les érosions. Dans le bassin du Congo, on consomme comme légumes les feuilles de $R$. goetzei. D'autres espèces ont des usages médicinaux et servent de liens. Certaines peuvent se cultiver comme

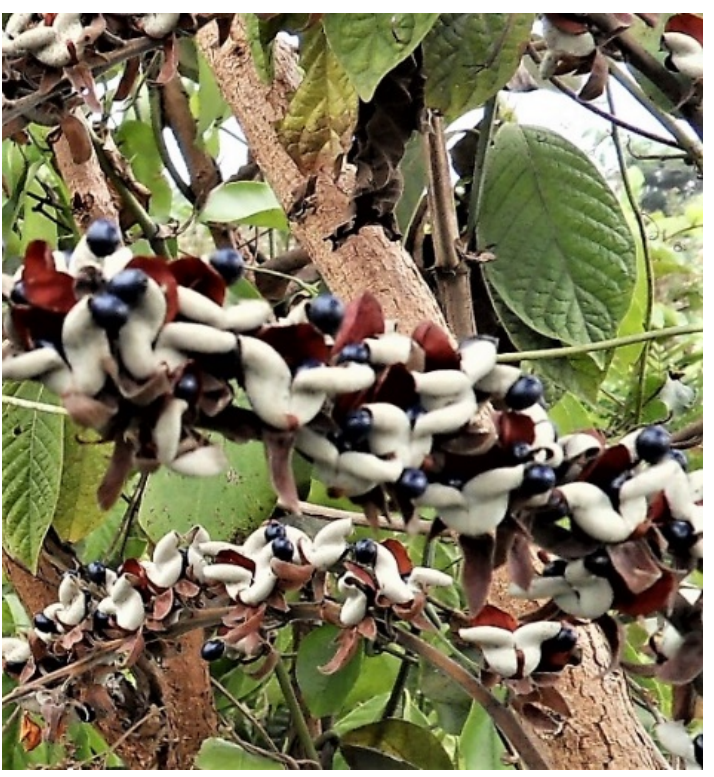
plantes ornementales.

Références : Hauman et al. 1954, Raponda-Walker et Silans 1961, Burkill 1995, Neuwinger 2000, Harris 2002, Bongers et al. 2005 


\section{Rhynchospora corymbosa}

\section{(Cypericaceae)}

Noms courants : Kiwenga ndumbu (Kikwese), herbe à couteau (Fr.), knife grass (Angl.)

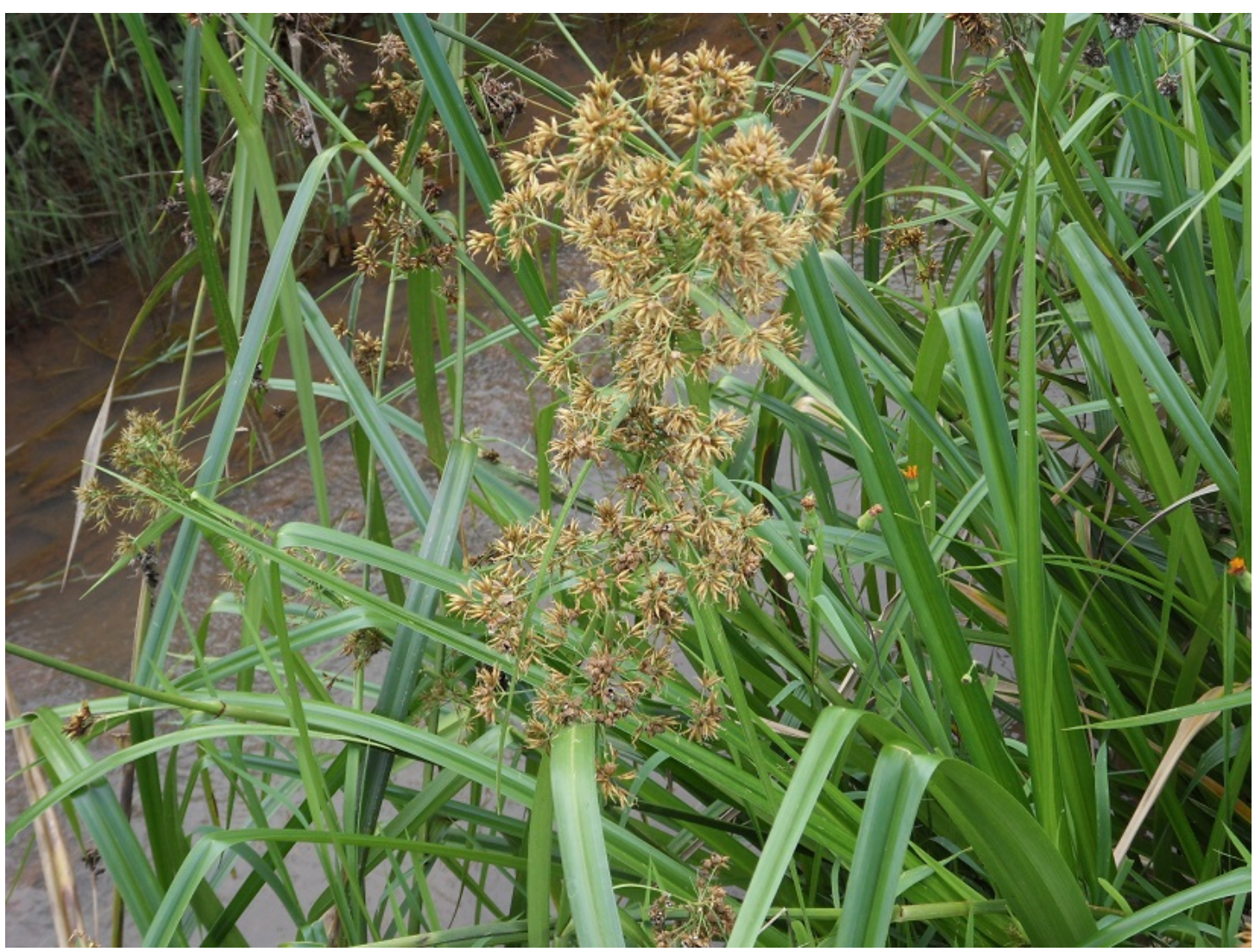

Description : Plante haute de $1 \mathrm{~m}$ ou davantage, dont les feuilles, de 50 sur $3 \mathrm{~cm}$, ont des bords coupants. Tiges à section triangulaire. Fleurs en grands panicules terminaux ou axillaires. L'inflorescence se compose d'une succession de corymbes d'épillets bruns groupés en faisceaux, étagés et sous-tendu par une grande bractée foliaire. Le fruit est un akène de couleur brun-jaune. II est surmonté d'un élément conique plus large et aussi long que lui.

Ecologie : Espèce pantropicale, formant des stations denses dans les marais de la savane, et occasionnellement de la forêt. Adventice causant de sérieux problèmes dans les rizières.

Usages : Les tiges servent occasionnellement à faire des paniers. La plante permet de contrôler la mouche tsétsé car la couverture dense qu'elle produits au-dessus de l'eau empêche la mouche de se reproduire.

Références : Renier 1948, Burkill 1985, Akobundu et Agyakwa 1987, White et Abernethy 1997 


\section{Ricinodendron heudelotii}

Noms courants : Kingela (Kikongo), cork wood tree (Angl.)

\section{(Euphorbiaceae)}

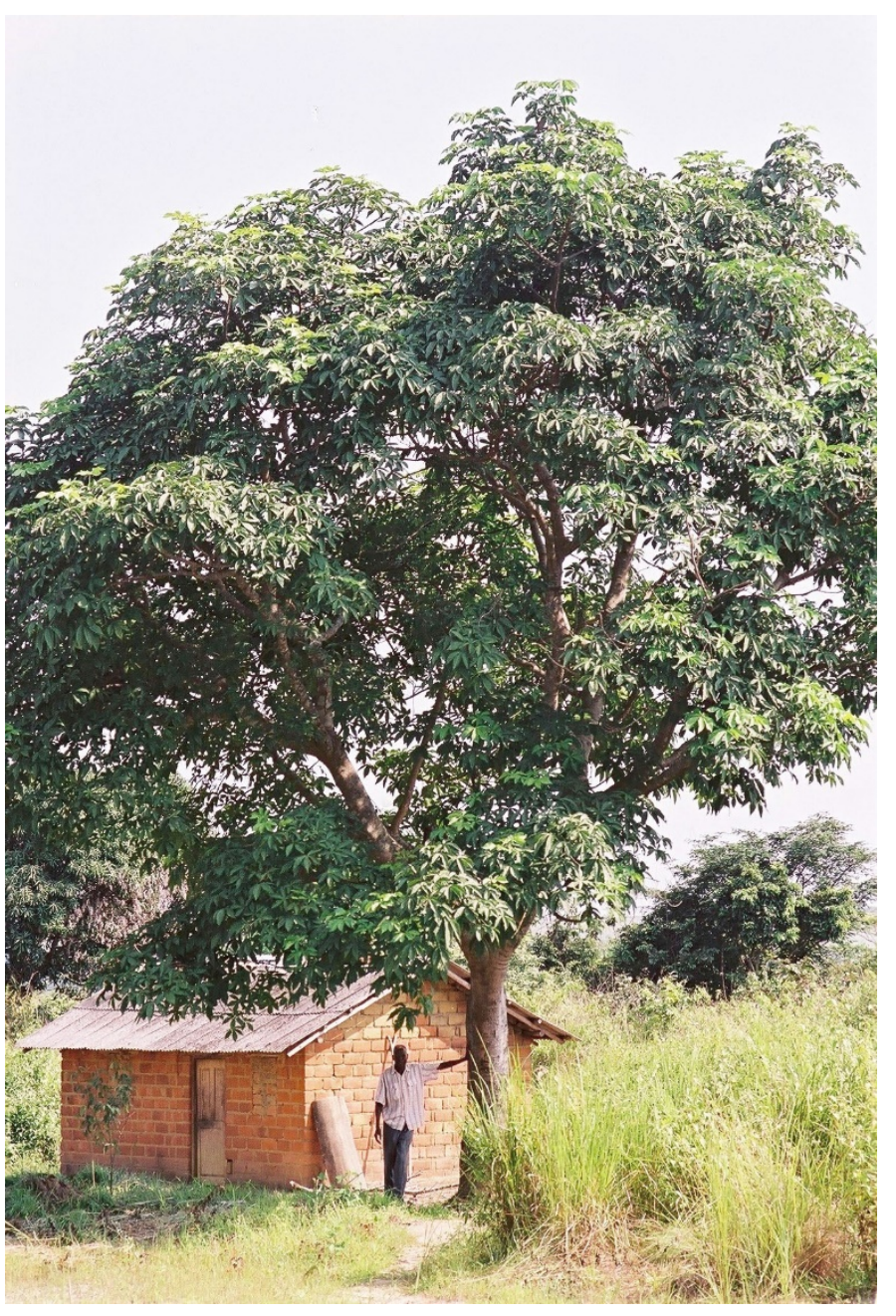

Description : Arbre à croissance rapide avec un tronc droit de 20 à $35 \mathrm{~m}$ de haut. Les jeunes rameaux sont couverts d'un dense duvet brun. Les feuilles sont alternes avec 5 à 7 folioles de 6 à 20 sur 3 à $12 \mathrm{~cm}$ (foliole centrale plus grande avec 10 à $30 \mathrm{~cm}$. Inflorescence mâle en panicules de 25 à $40 \mathrm{~cm}$, inflorescence femelle plus courte. Fleurs mâles blanc verdâtre à vert jaune, fleurs femelles blanches. Fruits comprimés de 2,5 à 3,5 sur $4,5 \mathrm{~cm}$. L'arbre commence à donner des fruits après 7 à 10 ans. II a des racines profondes et une durée de vie supérieure à 200 ans.

Ecologie : Arbre commun en lisière des forêts décidues et forêts secondaires en Afrique tropicale, de la Guinée à l'Angola à l'Afrique orientale et au Soudan. Pousse sur des sols acides et bien drainés. II prospère en climat chaud et humide, mais supporte la sécheresse. S'il n'est pas soumis à une forte compétition pour la lumière, il pousse bien dans une gamme de sols, d'humidité et de conditions de drainage. Parfois planté pour faire des clôtures.

Reproduction: Se cultive bien à partir de boutures de $1 \mathrm{~m}$ de long, et aussi par graines. On sort les graines des fruits pournis pour les semer en pépinières ombragées. La coque des graines étant très dure, la germination prend de longs mois, mais ensuite la croissance est rapide. On peut aussi transplanter les semis spontanés, qui poussent bien. Les transplanter quand ils ont $50 \mathrm{~cm}$. Les jeunes plants sont sujets aux attaques d'insectes.

Gestion : L'arbre recèpe bien et peut se conduire en taillis. On peut l'associer à d'autres cultures vivrières (bananiers, palmiers, plantes annuelles), étant donné ses racines profondes qui ne concurrencent pas les cultures.

Usags: Le bois est blanc, tendre, léger et périssable. On en fait des planches, des tambours, des mortiers, des cercueils. La cendre du bois sert de sel de cuisine, pour la savonnerie, et pour l'industrie de l'indigo. On peut faire bouillir les noyaux des graines pour les manger, ou les préparer en sauce comme les arachides. Le noyau contient 15 à $45 \%$ d'huile comestible, l'arbre pourrait être une source importante d'huile de

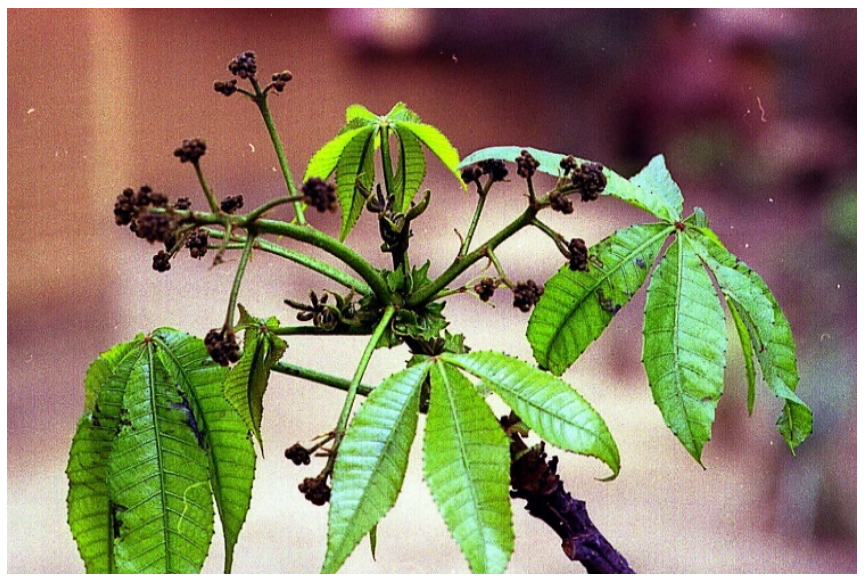
cuisine. La sève de l'écorce permet de traiter la diarrhée ; on donne une infusion de l'écorce comme lavement. Les feuilles et les tiges constituent un fourrage de qualité pour les chèvres et moutons, avec $16 \%$ de protéines et sans toxicité connue. Au Kongo Central, traditionnellement, on plantait cet arbre pour attirer les chenilles comestibles Mvinsu (/mbrasia epimethea). Les chenilles Minsendi, Mimpemba, Kaba (Lobobunaea phaedusa) et Bisu ( Nudaurelia petiveri) se nourrissent aussi des feuilles. Si l'on trouve des Imbrasia epimethea sur un arbre planté dans un village, elles appartiennent au propriétaire de l'arbre. Au Kongo Central, il était coutume de planter cet arbre sur les tombes ou à proximité. Les feuilles servent à emballer les produits ; on les emploie également comme paillage. Etant donné ses racines profondes, l'arbre est utile pour contrôler les érosions et améliorer les sols. II y a 
communément des champignons comestibles au pied de l'arbre. Les abeilles butinent les fleurs tôt le matin, probablement pour le nectar.

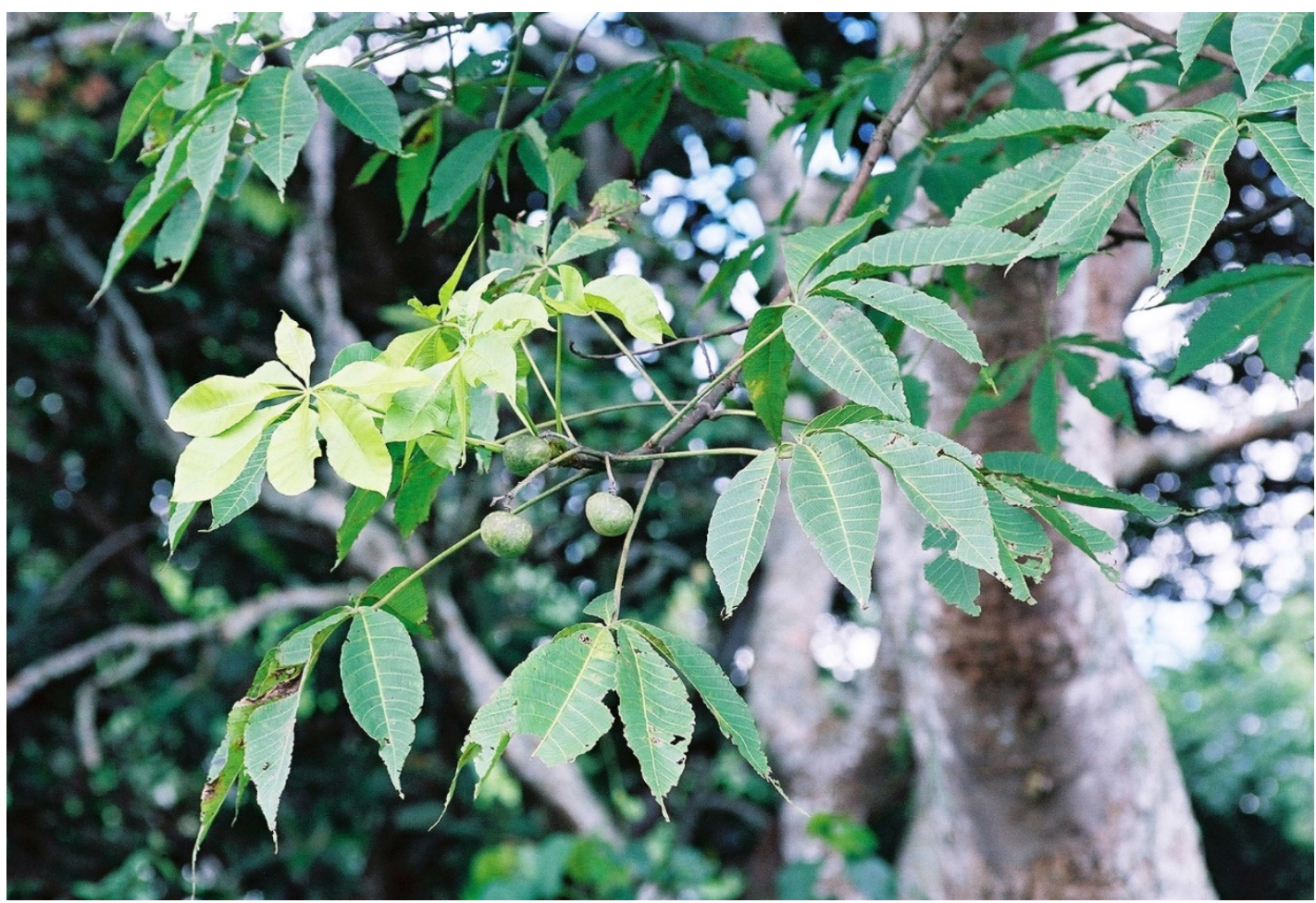

Remarque : Pour conserver les graines, on récolte d'abord les fruits tombés des arbres, dont on extrait les noix. On met celles-ci dans l'eau bouillante une heure et 15 minutes pour ramollir les coques. On ouvre les coques dont on sort les noyaux, puis on les fume : on peut alors les conserver plusieurs années.

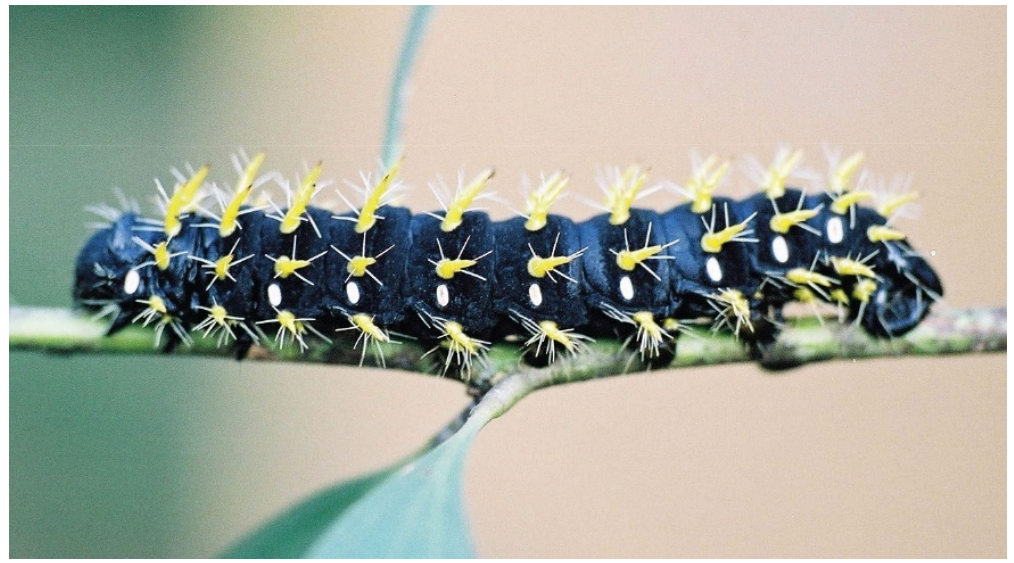

Références: Butaye 1909, Gillet et Pâque 1910, Gillet 1927, De Wildeman 1934, Renier 1948, Léonard 1962, Busson 1965, Nsimundele 1966 - 68, Dupriez et De Leener 1989, Kibungu Kembelo 1995, Anigbogu 1996, Mapongmetsem et Tshiegang 1996, Shiembo et al. 1997, Sunderland et al. 1999, Neuwinger 2000, Latham 2008, Meunier et al. 2010

Photo : Nudaurelia petiveri 


\section{Ricinus communis}

Noms courants : Mpuluka (Kikongo), ricin (Fr.), castor oil plant (Angl.)

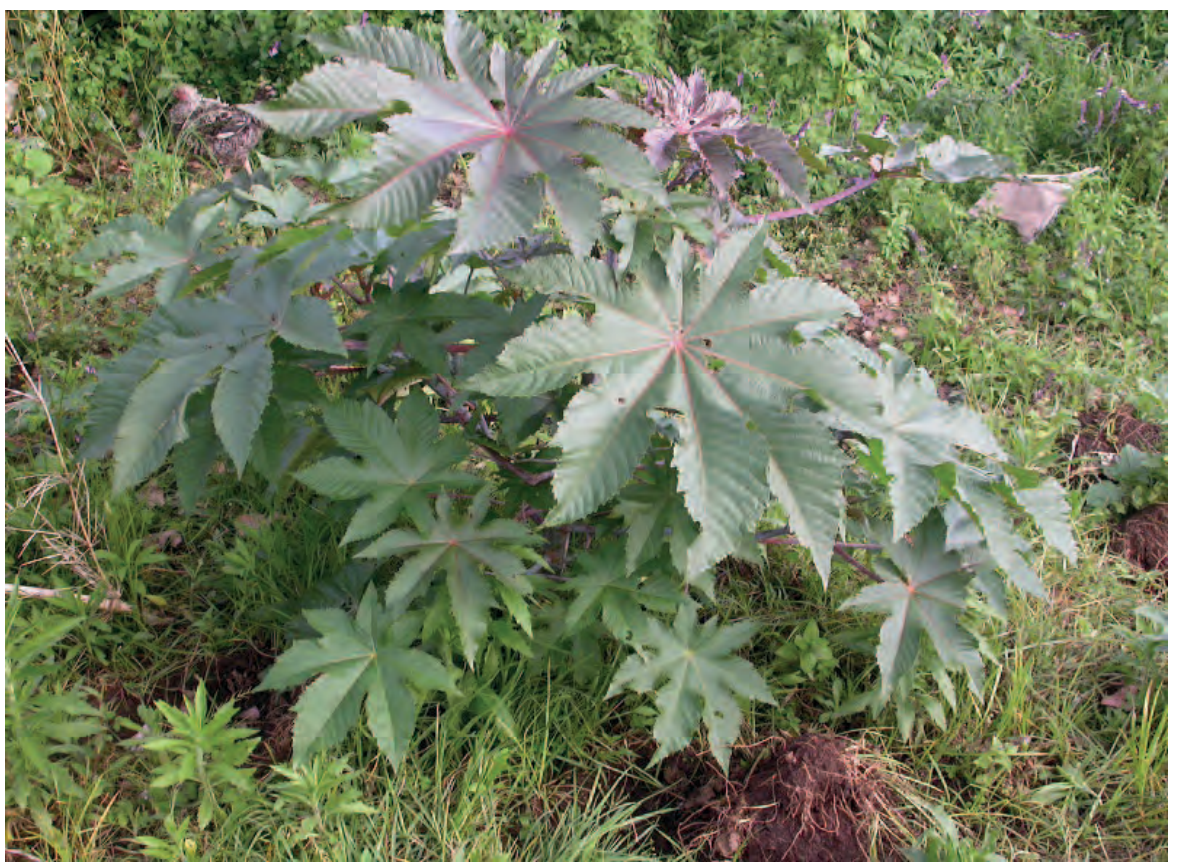

(Euphorbiaceae)

Description : Buisson de 2 à $3 \mathrm{~m}$ de haut, souvent ramifié à la base. Feuilles alternes, vert sombre ou rouges, sur de longs pétioles. Inflorescences en panicules terminales de 25 à $50 \mathrm{~cm}$ de long. Fleurs sans pétales; fleurs mâles dans la partie inférieure de l'inflorescence, à très nombreuses étamines ; fleurs femelles à style rouge plumeux. Le fruit est une capsule épineuse contenant trois graines.

\section{Ecologie :}

Plante originaire d'Afrique de l'Est et du Nord, présente partout sous les tropiques et largement cultivée.
Reproduction : Les graines restent viables 2 à 3 ans. Pour avoir une germination régulière, leur verser dessus de l'eau bouillante, puis les laisser tremper 24 heures.

Usages : L'huile de ricin, extraite des graines, sert parfois comme purgatif radical, mais cette pratique n'est pas recommandée. On l'emploie pour traiter les parasites de la peau. Les femmes s'appliquent sur les seins les feuilles bouillies pour arrêter la lactation. Au Nord de l'Angola, on emploie les feuilles pilées pour traiter la nausée, et on les applique en compresses contre les maux de tête. On grille les graines pour faire une poudre, que, traditionnellement, on s'appliquait sur la peau pour prendre le deuil d'un défunt. L'huile de ricin brûle avec une lumière claire. On l'emploie comme insecticide, pour la protection du bois, et pour des pulvérisations contre la malaria. L'huile de ricin s'emploie commercialement pour les peintures, vernis, lubrifiants, graisse, fluide hydraulique, savonnerie, encre d'imprimerie, et divers produits chimiques. Après extraction de l'huile, le toun

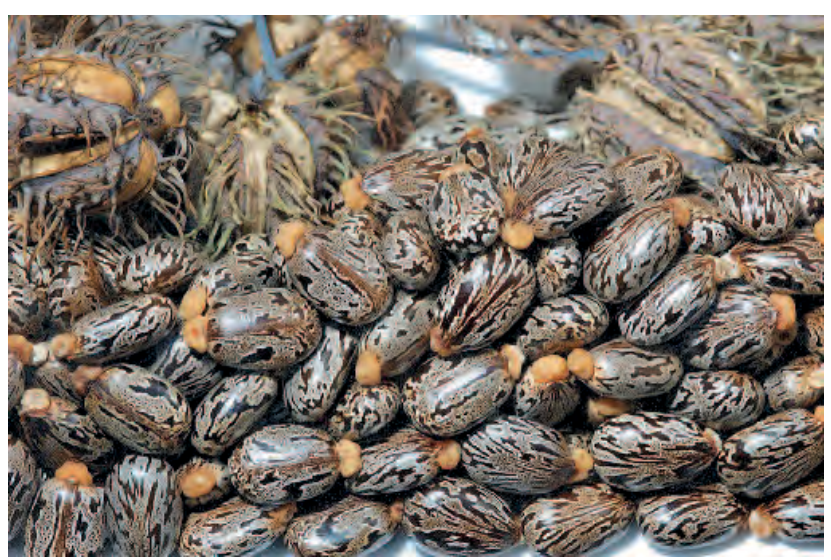

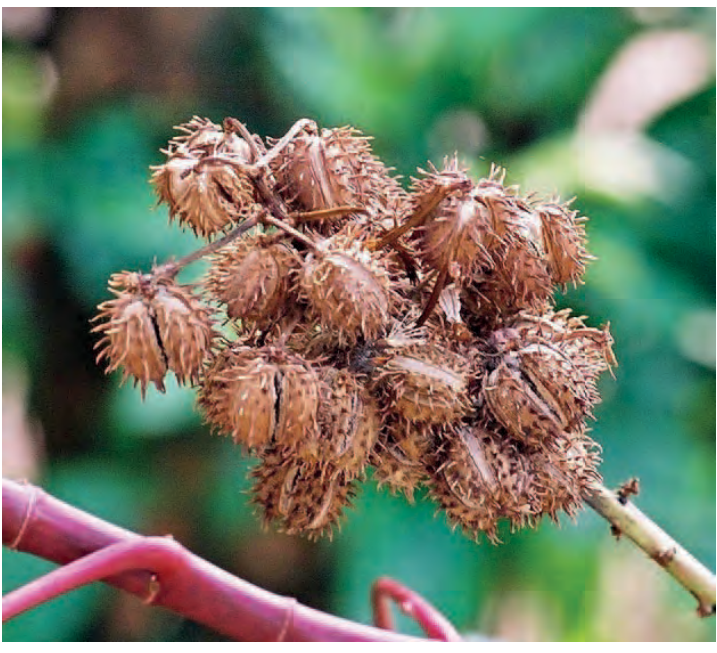

ourteau peut servir de fertilisant. Les abeilles butinent occasionnellement le nectar des glandes présentes sur les jeunes feuilles. A Kilueka, les feuilles sont une nourriture importante pour l'élevage de la chenille comestible Samia ricini (N'sani gata - Kikongo).

\section{Avertissement : tenir les graines éloignées des enfants. Elles contiennent de la ricine, une toxine létale.}

Références: Gillet et Pâque 1910, Gillet 1927, Renier 1948, Crane et Walker 1984, Iwu 1993, Pauwels 1993, Burkill 1994, van Wyk et al. 1997, Göhre et al. 2016 


\section{Rinorea oblongifolia}

Nom courant : Nkuta kani (Kikongo)

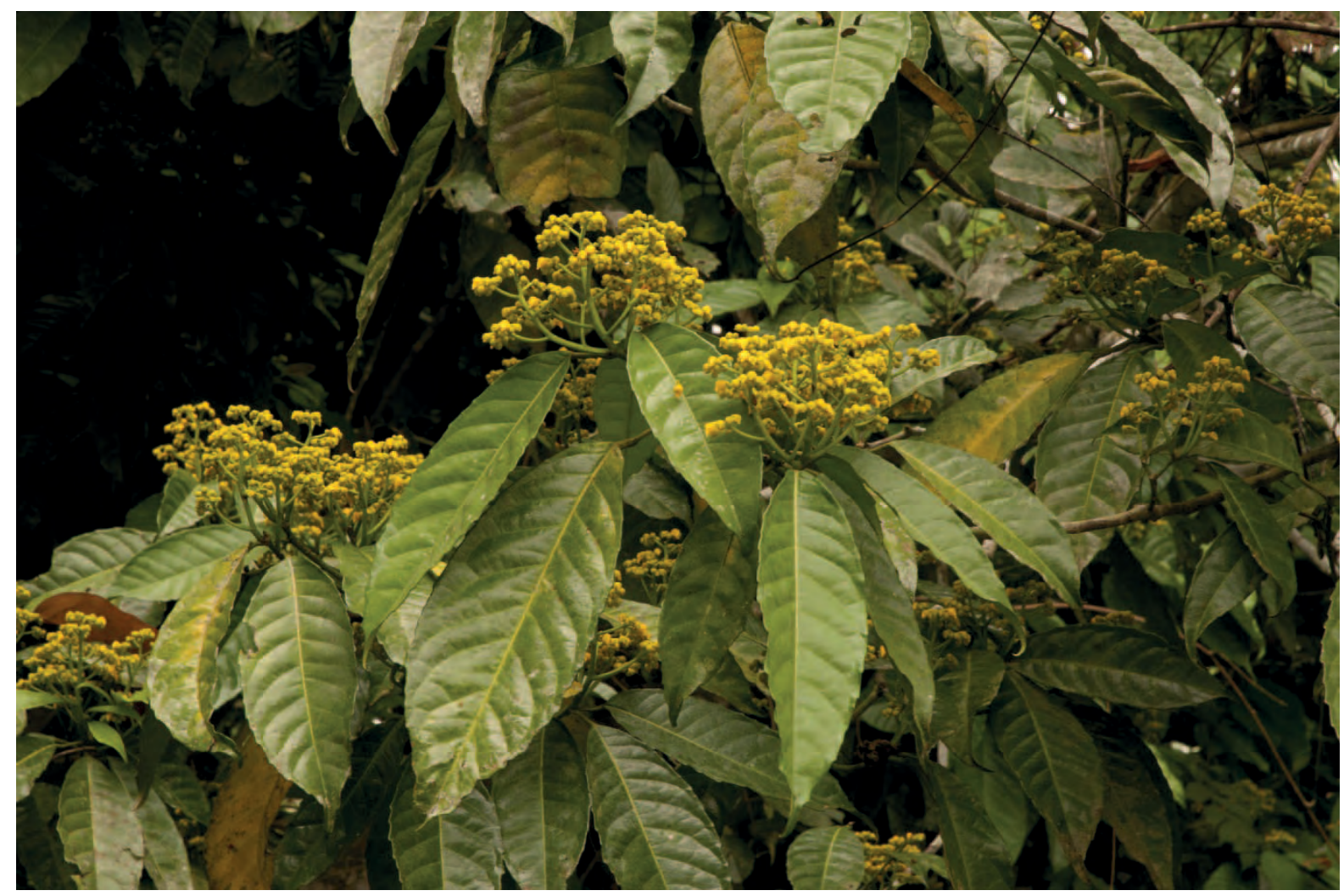

Photo: David Harris/Royal Botanic Garden Edinburgh

Description : Arbuste pouvant atteindre $13 \mathrm{~m}$ de haut. Grandes feuilles de 14 à 28 sur 4 à $10 \mathrm{~cm}$, sur des pétioles de 1,5 à $5 \mathrm{~cm}$. Fleurs cireuses jaune verdâtre de 5 à $7 \mathrm{~mm}$, en inflorescences terminales de 5 à $10 \mathrm{~cm}$, avec des sépales mauves ou bruns. Fruits ovales de 2,3 sur $1,6 \mathrm{~cm}$.

Ecologie : Plante des sous-bois de la forêt pluviale de plaine, et des forêts saisonnièrement inondées. Les arbustes se trouvent souvent groupés près de l'eau. De la Sierra Leone au Gabon et à la R.D. Congo, au Soudan et en Ouganda.

Usages: Le bois jaune, grossier, est utilisé en construction. On en fait des cannes de marche, des cuillers, des peignes. En Centrafrique, on boit un extrait des racines comme purgatif. En R.D Congo, autrefois, on pilait les fruits dans l'eau, puis on passait la pâte dans les cheveux pour éloigner les animaux sauvages.

Références: Irvine 1961, Taton 1969, Pauwels 1993, Burkill 2000, Neuwinger 2000, Harris et al. 2011 
Noms courants : Pigeonberry (Angl.)

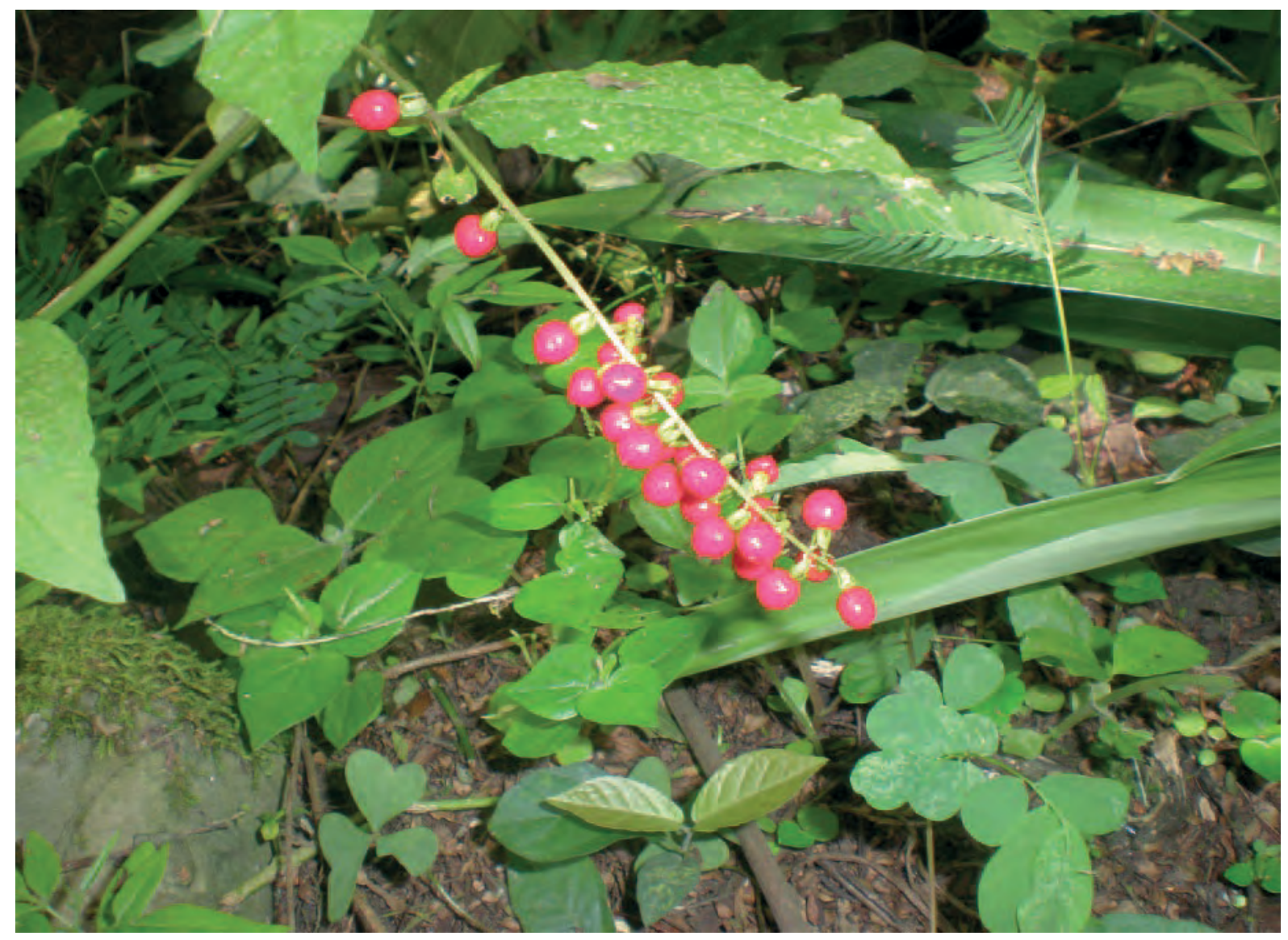

Description : Plante pérenne dressée, irrégulière, de 0,4 à $2 \mathrm{~m}$ de haut. Feuilles lancéolées, elliptiques ou oblongues, pouvant atteindre 15 sur $9 \mathrm{~cm}$. Petites fleurs blanc rosé en racèmes pendants ou bouquets longs de 4 à $15 \mathrm{~cm}$. Petites baies rouges, comparables aux groseilles, de 2,5 à $5 \mathrm{~mm}$ de diamètre, qui restent longtemps sur la plante.

Ecologie : Plante originaire du Sud des Etats Unis, et d'Amérique centrale et méridionale, maintenant répandue partout sous les Tropiques. Commune autour de Kisantu.

Reproduction: Par graines, en sol humide bien drainé, à l'ombre ou au soleil.

Usages: Parfois cultivée comme plante ornementale, à l'ombre. On employait traditionnellement le jus des fruits comme teinture et comme encre. Les fruits pourraient être mangés sans risque.

Références : Gillet 1927, Renier 1948, Williams 1949, Jex-Blake 1957, Fayaz 2011, Wikipedia (Consulté le 15.3.2016)

Photo: Hannes Oehm www. africanplants. senckenberg.de

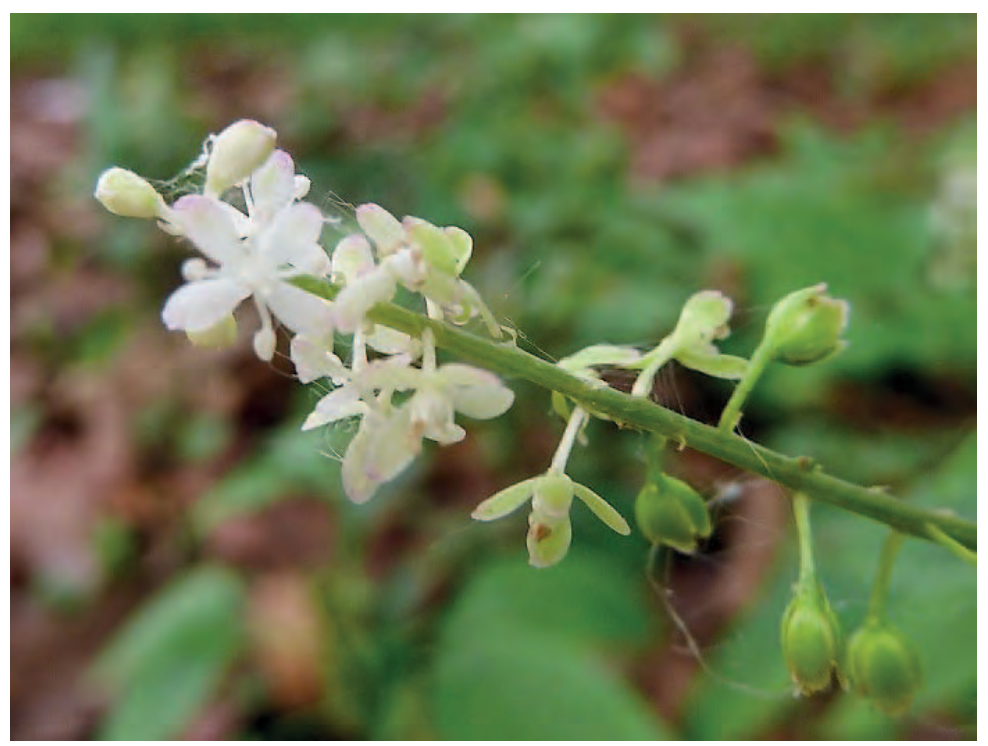




\section{Rothmannia octomera}

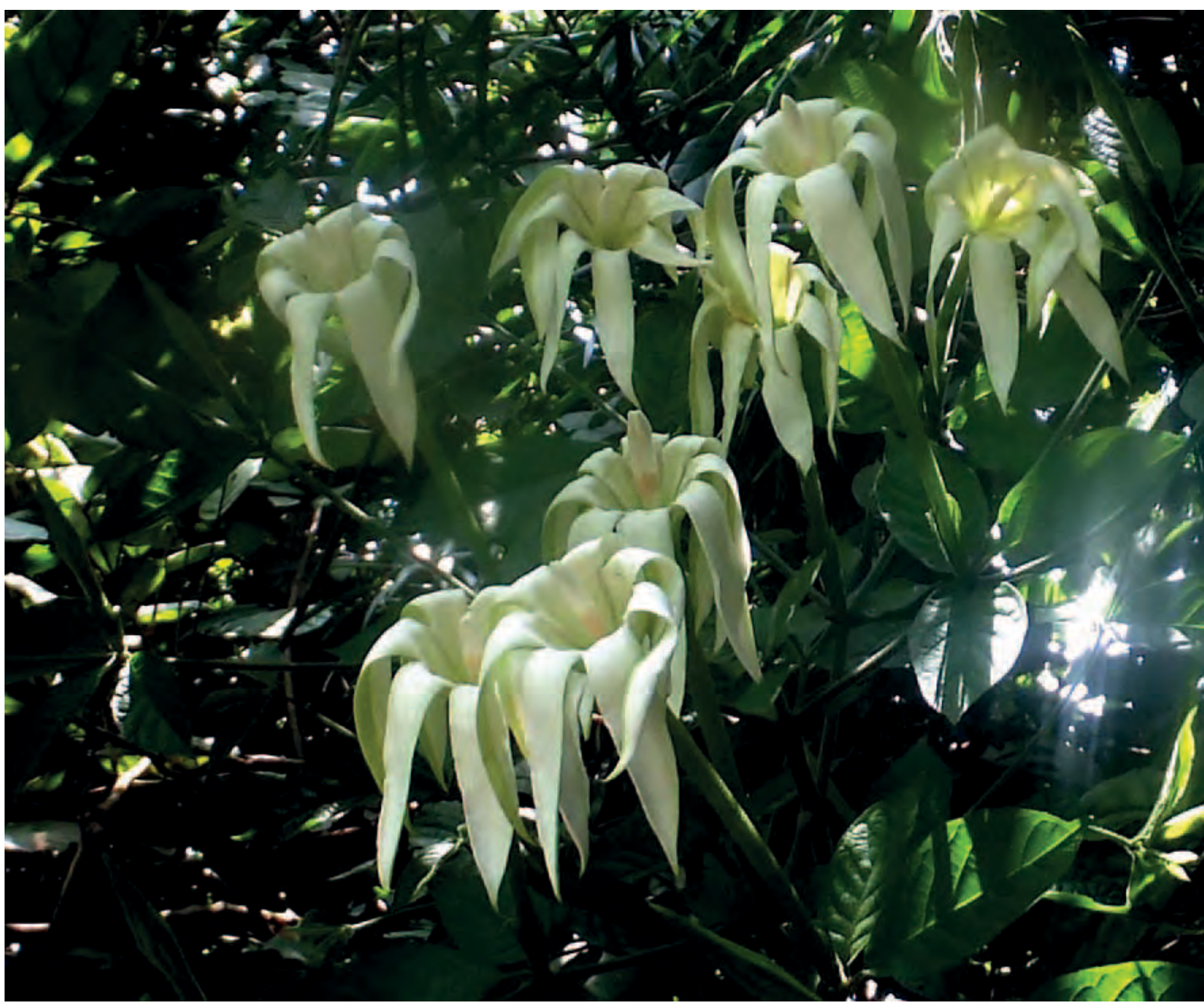

Description : Plante buissonnante jusqu'à 5 à $6 \mathrm{~m}$ de haut. Feuilles de 9 à 29 sur 5 à $11 \mathrm{~cm}$. Feuilles et tiges couvertes de poils légers. Fleurs blanches dressées avec une corolle en tube jaune de 14 à $19 \mathrm{~cm}$ prolongée par des lobes de 2,5 à $7 \mathrm{~cm}$. Les fleurs s'ouvrent la nuit après les premières grandes pluies de novembre, et restent ouvertes umr grande partie de la journée qui suit. Fruits longs jusqu'à $11 \mathrm{~cm}$, vert sombre avec des marques blanches.

Ecologie: Plante des forêts secondaires et recrus forestiers. Se trouve aussi au Cameroun, en Centrafrique et au Gabon.

Reproduction: Par graines, boutures de tiges semi-durcies, ou marcottage aérien.

Usages : Les racines pilées s'emploient pour traiter les bronchites et les affections pulmonaires. On mélange la poudre des feuilles avec des bananes pour faire un tonique pour les femmes après l'accouchement. Les Igbo du Nigéria emploient le fruit pour colorer la peau en noir. Plante cultivée à titre ornemental.

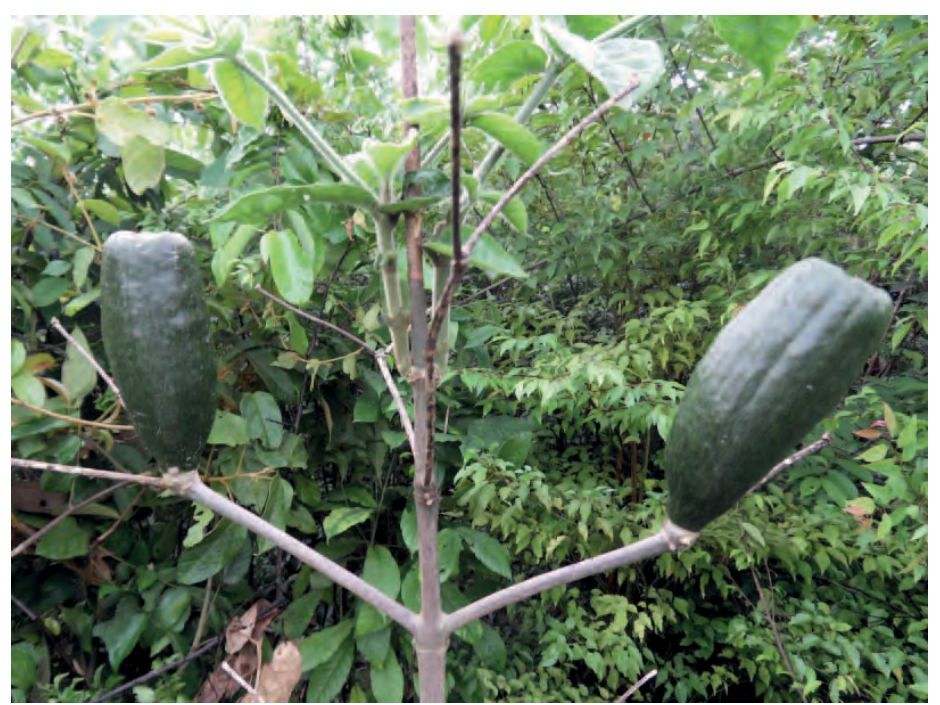

Références : Sillans 1953, Bouquet 1969, Burkill 1997, Pauwels 1993, Neuwinger 2000, Fayaz 2011, Harris et al. 2011 
Rourea coccinea subsp. coccinea

(Connaraceae)

Synonyme : Byrsocarpus coccineus

Noms courants : Yamuntu (Kikongo).

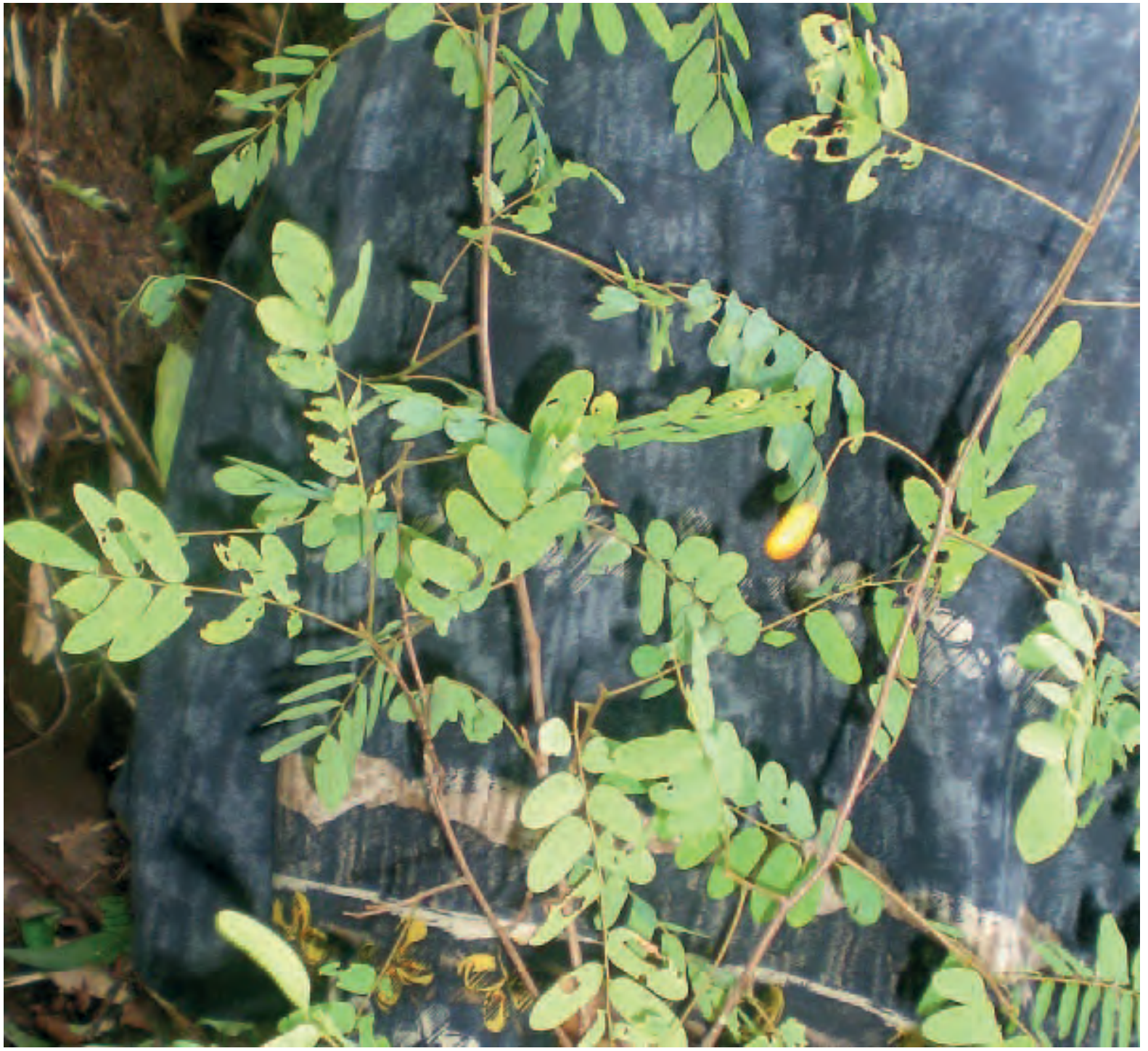

Description : Buisson grimpant commun. Feuilles composées de 11 à 13 paires de petites folioles, généralement asymétriques, longues de 0,5 à $4,5 \mathrm{~cm}$. J eunes folioles rouge rosé. Fleurs parfumées, apparaissant aux nœuds avant les feuilles; pétales jaune pâle rayés de rouge. Fruits de plus de $1,5 \mathrm{~cm}$ de long, s'ouvrant en bas sur un côté pour faire apparaitre une graine noire entourée par un grand arille brillant, jaune ou orange.

Ecologie : Plante de l'Afrique tropicale, dans des forêts pluviales, sèches ou inondables, des forêts galeries, des savanes en cours de reforestation.

Usages : Les feuilles pilées servent d'émétique au Kongo Central. Ailleurs en Afrique, la plante a de nombreux usages médicinaux.

Références : Staner et Boutique 1937, De Wildeman 1938, Renier 1948, Troupin 1952, Irvine 1961, Burkill 1985, Neuwinger 2000, Nsimundele 2004 


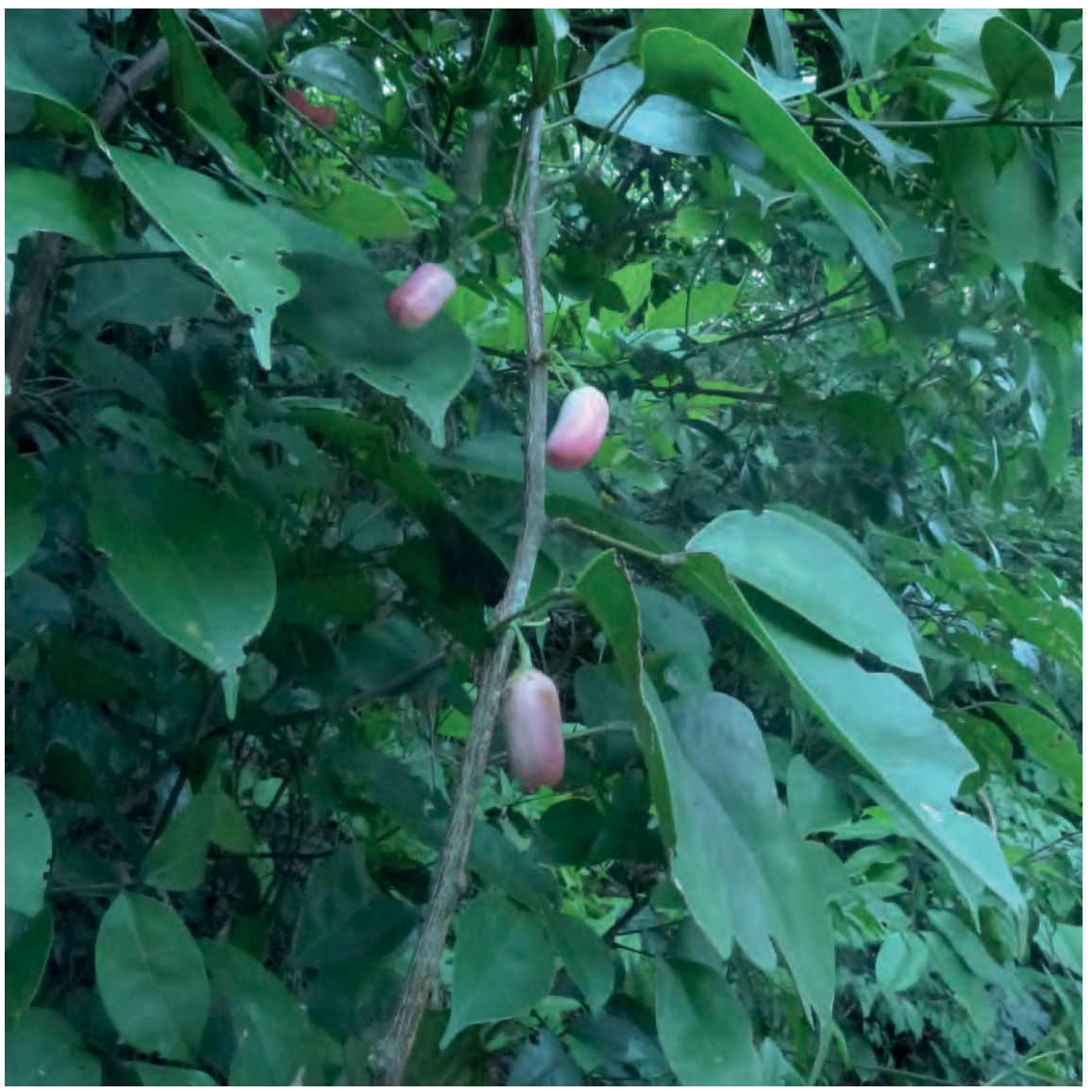

\section{Synonyme :}

viridis

Noms courants: Botuko (Lingala).

Description : Buisson bas ou liane ligneuse atteignant $20 \mathrm{~m}$ de long. Feuilles généralement à 3 à 5 folioles, mais parfois une seule. Pétiole et rachis de 1 à $13 \mathrm{~cm}$ de long. Folioles acuminées au sommet, de 2,5 à 17 sur 1,5 à $8 \mathrm{~cm}$. Fleurs jaunes. Fruits légèrement courbes, longs de 1,5 à $2 \mathrm{~cm}$, blanc rosé. Graines entourées par un arille charnu brillant, rouge à orange.

Ecologie: Plante présente du Cameroun à l'Angola, dans la forêt pluviale équatoriale et les forêts galeries.

Usages : On emploie l'infusion des feuilles pour de gorge, certaines éruptions et les douleurs intestinales. On la donne aussi comme émétique.

Références : Staner et Boutique 1937, Renier 1948, Troupin 1952

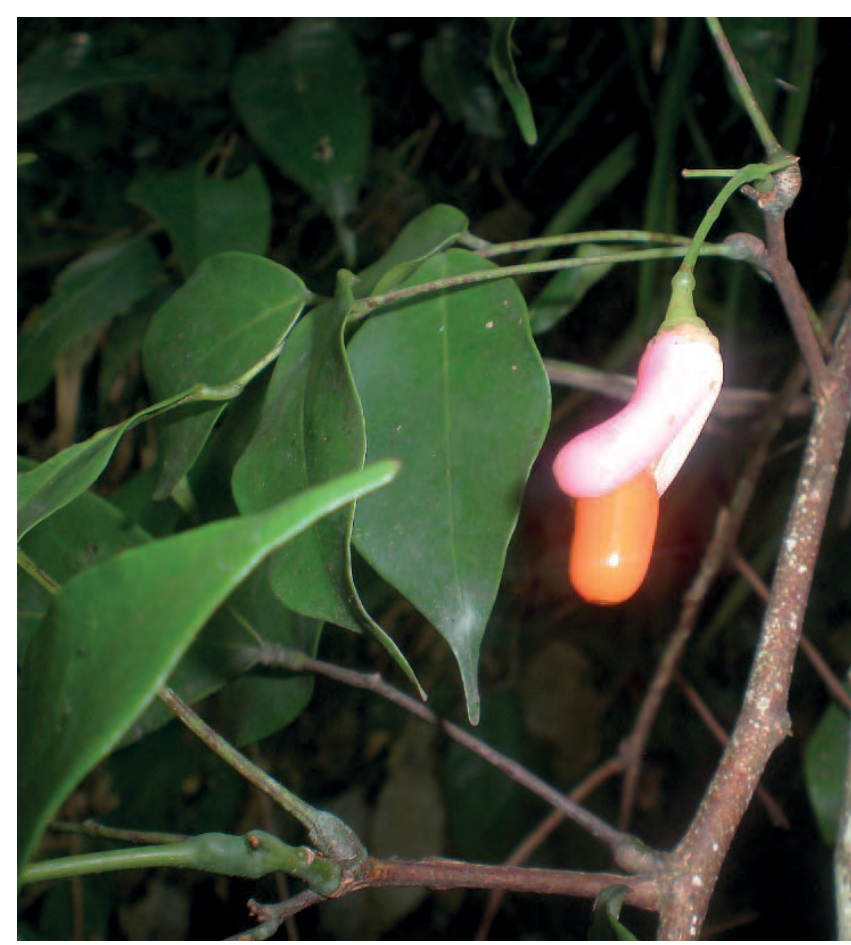
traiter la bronchite, les maux

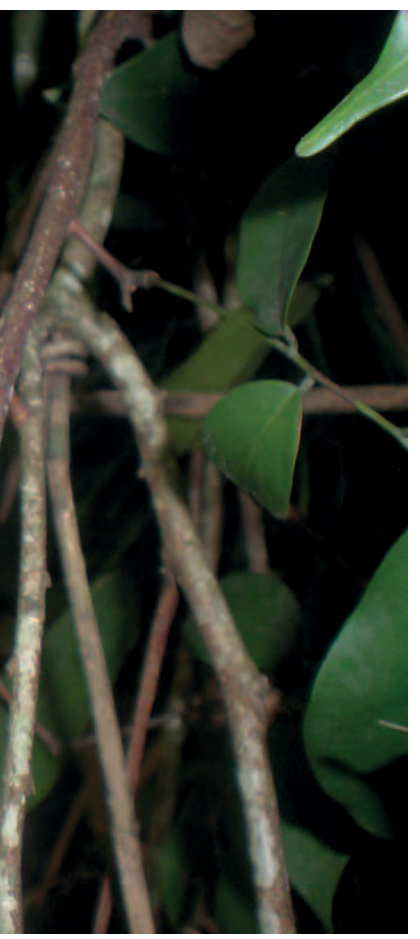



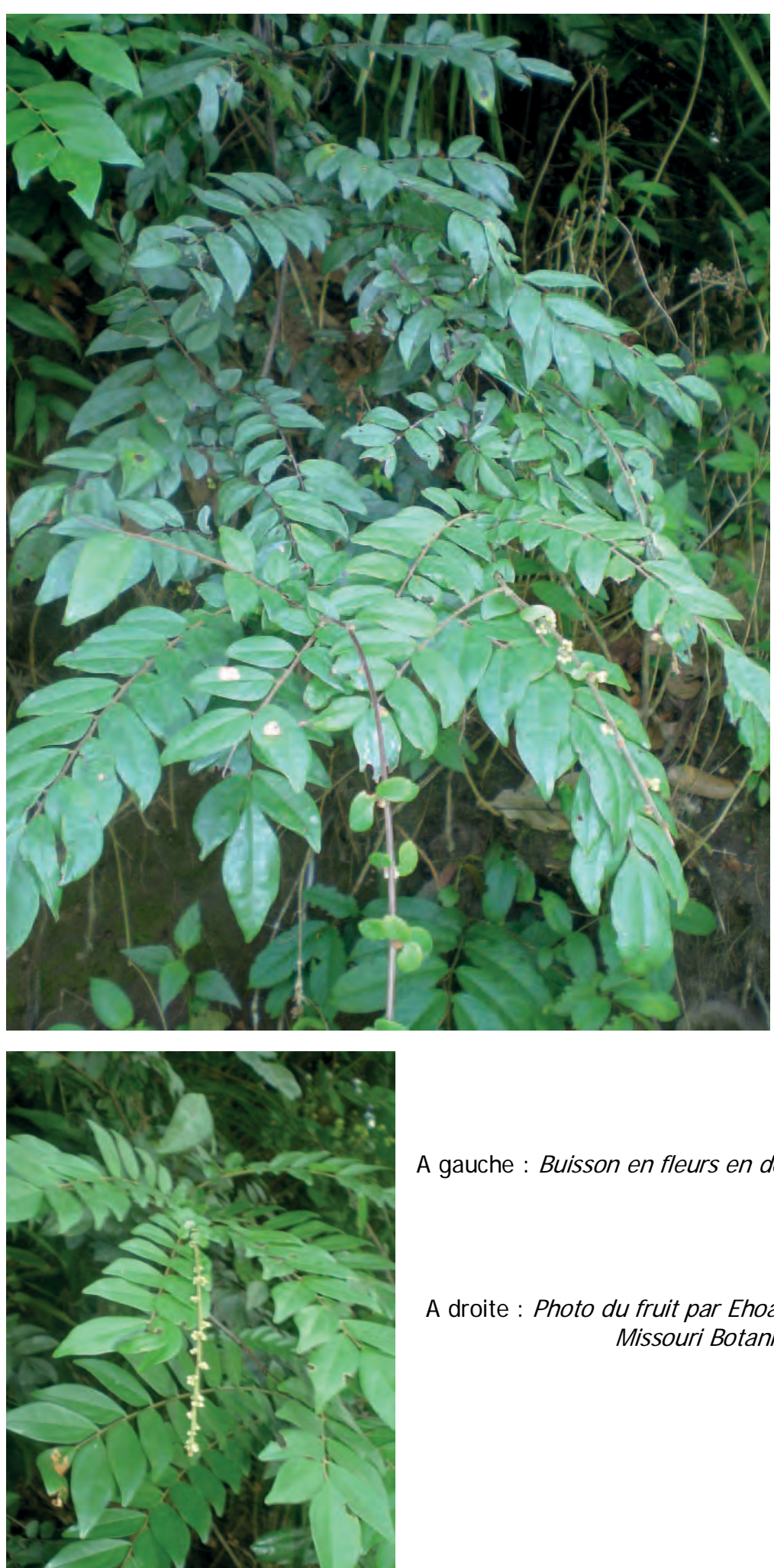

Description : Plante buissonnante ou grimpante. Les rameaux portent parfois des vrilles. Feuilles rhomboïdales, à pétiole et rachis de 7 à $28 \mathrm{~cm}$, portant 17 à 41 folioles, variables en taille et en forme, de 2,5 à 7,5 sur 1 à $3,3 \mathrm{~cm}$. Fleurs blanches parfumées, à l'odeur de muguet. Graine noir brillant, d'environ $1,8 \mathrm{~cm}$ de long, entourées d'un arille charnu orange de $0,8 \mathrm{~cm}$ de long.

Ecologie: Plante des sous-bois forestiers du Nigéria à l'Angola. Commune dans les forêts secondaires, les bords de route, et parfois sur les termitières. Très commune dans les formations secondaires et recrus forestiers, plus rare en savane.

Usages: L'écorce et les racines sont appliquées en cataplasmes sur l'éléphantiasis. On applique les feuilles pilées sur les blessures comme hémostatique et pour la cicatrisation. La plante s'emploie aussi pour traiter les maux de dents. Dans l'Est du Congo, les Ndasa indiquent que le jus des feuilles, pulvérisé sur un essaim d'abeilles, les calme, facilitant ainsi la récolte du miel.

Références Renier 1948, Troupin 1952, Bouquet 1969

A gauche : Buisson en fleurs en décembre

A droite: Photo du fruit par Ehoarn Bidault, Missouri Botanical Garden

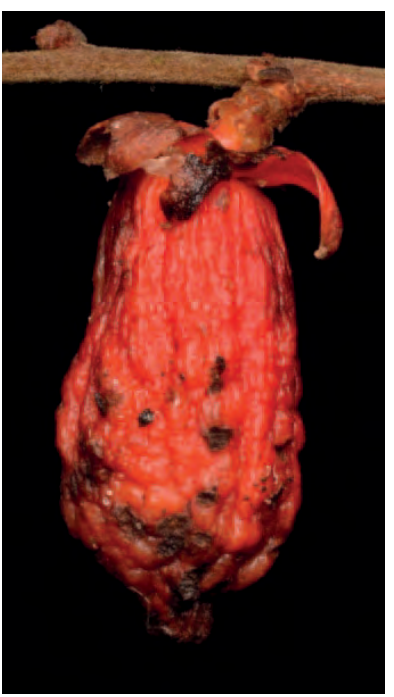




\section{Rumex usambarensis}

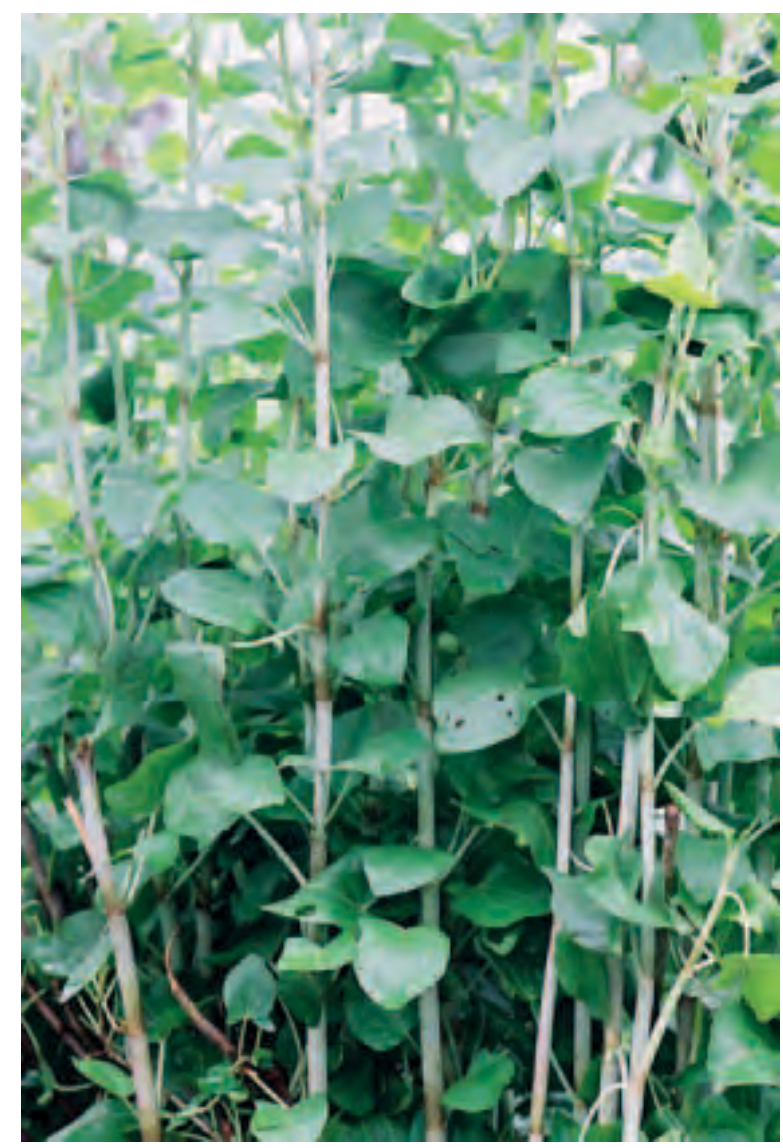

Usages: Les feuilles se mangent, crues ou cuites, comme légumes. Les tiges se mâchent pour leur goût aigre et salé. Au Kenya, on grille les tiges, pelées et lavées, pour les manger sucrées ou salées. Au Kenya, les racines s'emploient pour traiter les abcès. En Ouganda, elles donnent une teinture. Les feuilles fraiches, la sève et les racines ont des usages médicinaux pour traiter le diabète, la conjonctivite, la fièvre, les refroidissements, la toux, la diarrhée, la bilharziose et l'asthme, et pour faciliter la digestion.

Références: Goode 1974, Katende et al. 1999, Maundu et al. 1999, Neuwinger 2000
(Polygonaceae)

Nom courant : Oseille chinoise

Description : Petite plante buissonnante, parfois presque grimpante avec des feuilles oblongues aux bouts pointus, avec à la base des lobes pointés vers l'extérieur. Les fleurs composent une panicule rouge complexe, d'environ $7,5 \mathrm{~cm}$ de diamètre.

A gauche: Rumex usambarensis cultivé dans une parcelle au village de Teki près de Kisantu

Ecologie : Plante présente en Afrique Centrale, orientale et méridionale. Parfois cultivée, pousse mieux sur les sols riches en humus. Plante commune en Afrique orientale, dans les savanes herbeuses er boisées entre 900 et 2.400 $\mathrm{m}$ d'altitude.

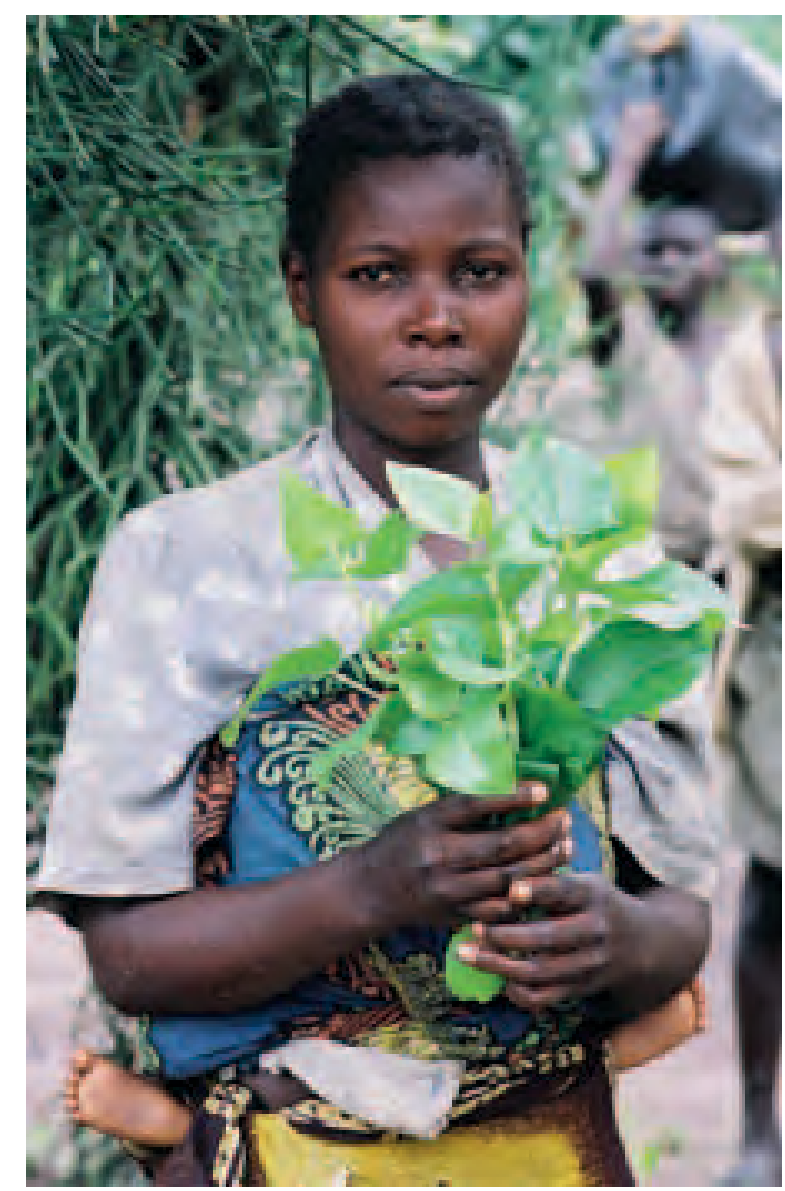


Nom courant: Kinzonzi (Kikongo)

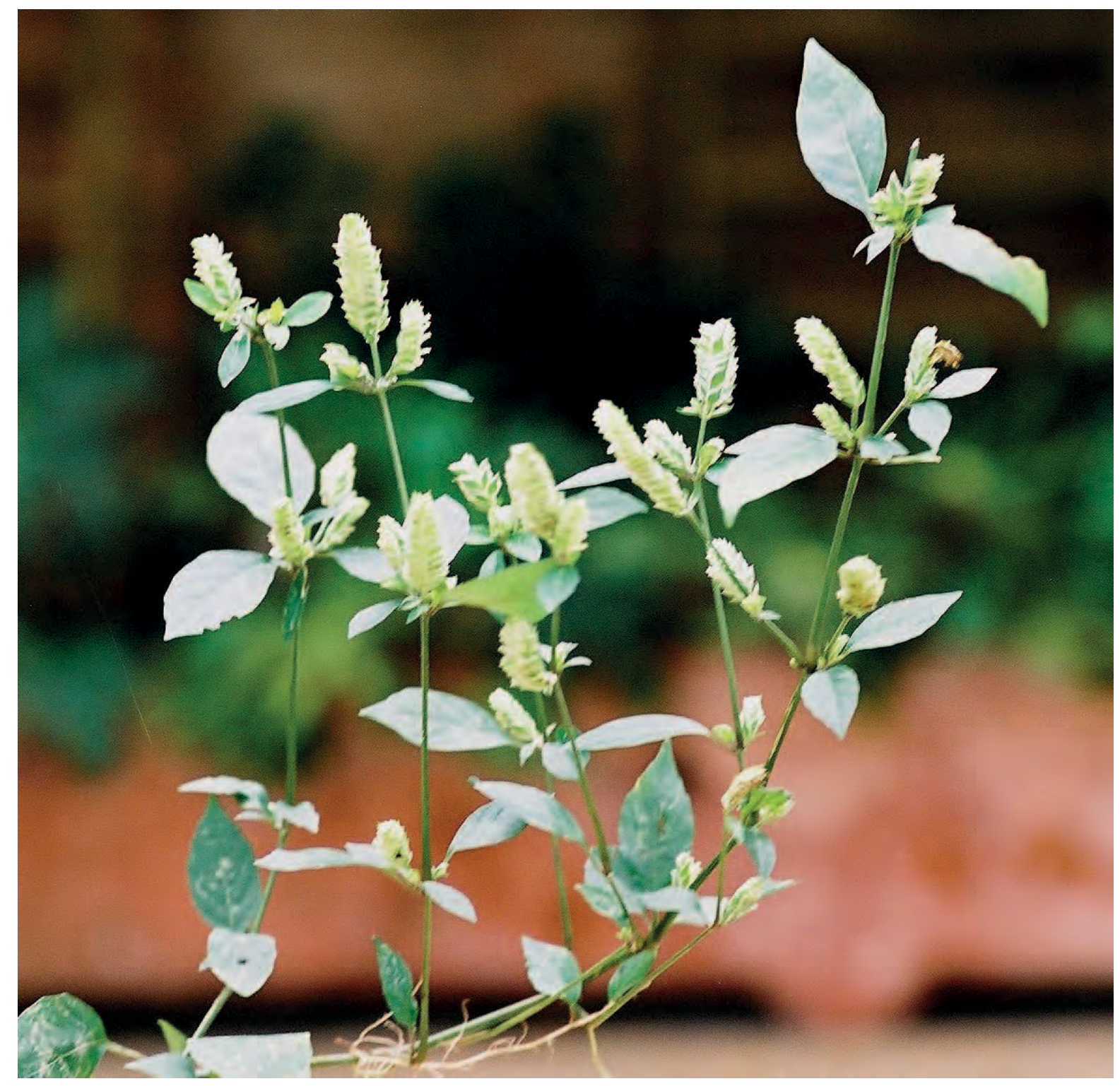

Description : Petite plante herbacée de $20 \mathrm{~cm}$ de haut, avec des tiges finement pubescentes de $30 \mathrm{~cm}$ de long. Entre nœuds de 2 à $4 \mathrm{~cm}$. Feuilles de 2,5 à 4 sur 1,5 à $2 \mathrm{~cm}$, glabres, opposées; pétioles de 1 à $3 \mathrm{~cm}$, en coins à la base. Fleurs de 1,5 à $4 \mathrm{~cm}$, axillaires ou terminales. Fruits finement pubescents longs de $5 \mathrm{~mm}$.

Ecologie : Plante des sites frais ombragés. Présente aussi an Nigéria, au Cameroun et au Gabon.

Usages : Au Kongo Central, les feuilles se mangent comme légumes. On pile aussi les feuilles séchées pour les mélanger comme Ocimum gratissimum avec la semoule pour se manger avec la viande et les haricots.

Références : Renier 1948, Heine 1966, Terra 1966, Daeleman et Pauwels 1983 


\section{Rutidea smithii}

(Rubiaceae)

\section{Nom courant : Kisu (Kikongo)}

Description : Plante grimpante atteignant $6 \mathrm{~m}$ de long.

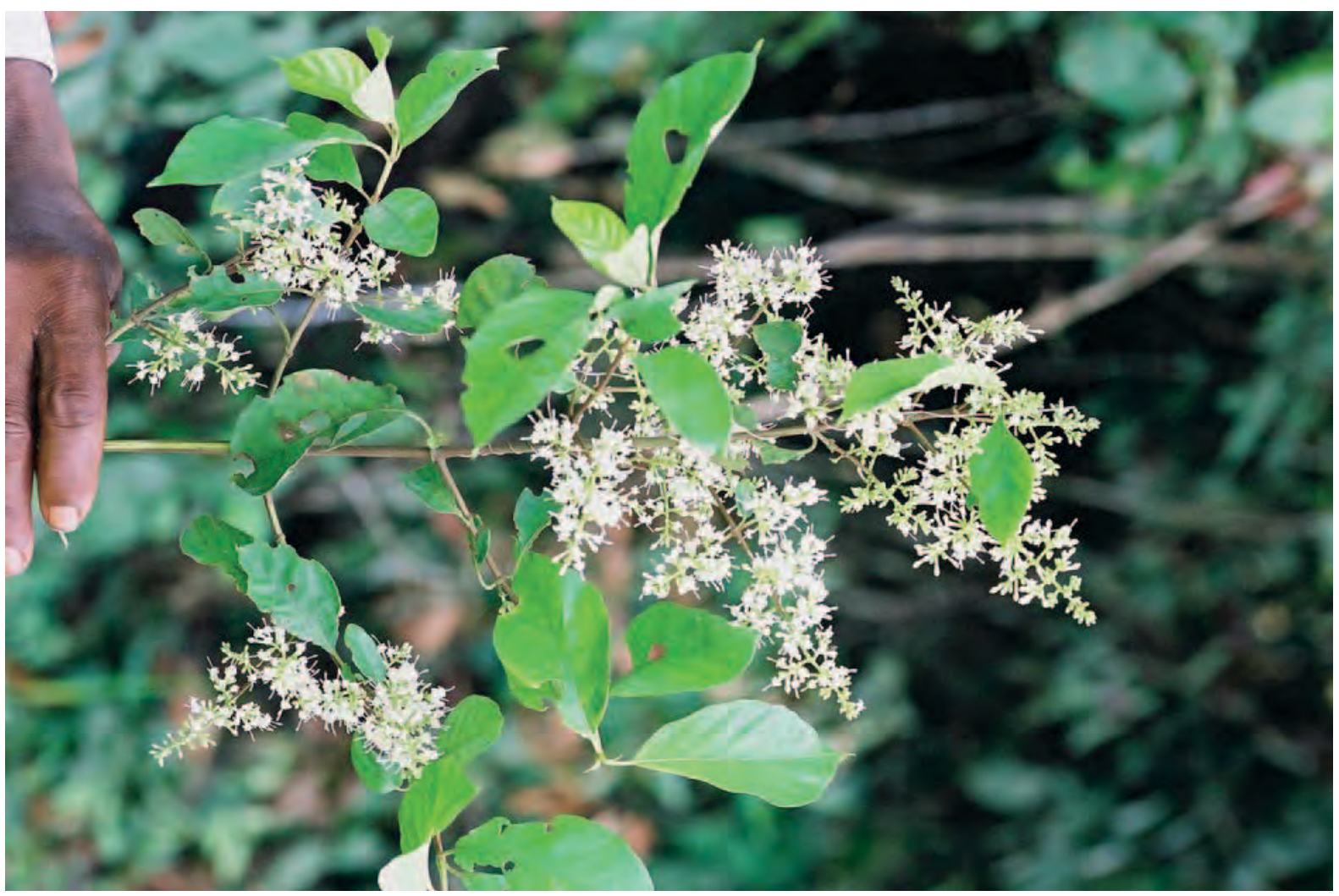

Rutidea smithii en fleurs en janvier près de Kikola

Ecologie : Plante des forêts secondaires et marges forestières, de la Sierra Leone au Soudan, à la Zambie et à l'Angola.

Usages : On a observé des abeilles butinant le nectar à midi. Les fines tiges sont creuses et peuvent servir de pailles pour boire. Les feuilles ont une odeur piquante. Séchées et mises en poudre, on les inhale pour décongestionner les sinus et soulager les maux de tête. Les I gbo du Nigéria appliquent les racines pilées sur les blessures.

Références : Gillet et Pâque 1910, Burkill 1997, Neuwinger 2000

A droite : $R$. olenotricha devrait être aussi une source de nectar pour les abeilles. Voici cette plante en fleurs en janvier.

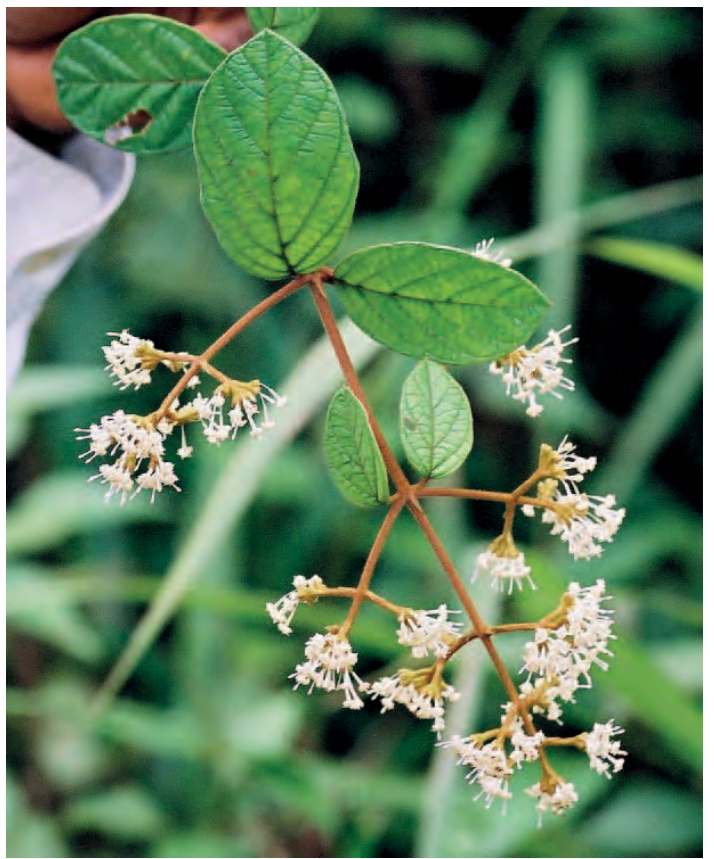




\section{Synonyme : S. florida}

Noms courants : Dimputu (Kikongo) $\left(\right.$ Mputu = Europe $=$ quelque chose qui est mieux $\left.{ }^{1}\right)$, bungo (Swahili), vigne en caoutchouc (Fr.)

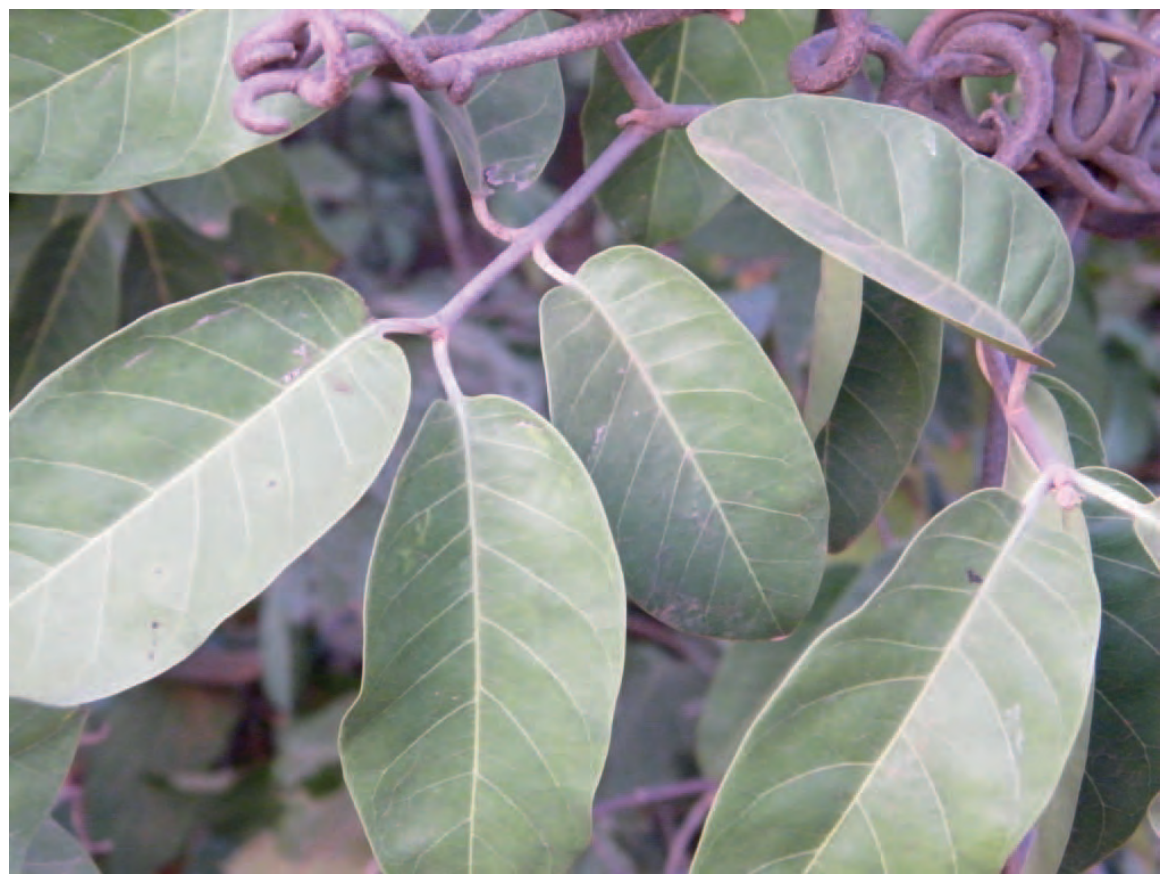

Description : Grande liane forestière de 20 à $50 \mathrm{~m}$ de long, grimpant sur les arbres et les buissons en lisière de forêt. Toutes les parties dégagent un latex blanc quand on les coupe. L'écorce est lisse et brune. La plante porte des vrilles brunes pouvant avoir $12 \mathrm{~cm}$ de long. Les feuilles sont grandes, ovales, coriaces, brillantes, cordifomes à la base et pointues au sommet, de 7 à 16 sur 4 à $8,5 \mathrm{~cm}$. Les fleurs sont en grappes terminales denses, blanches avec une gorge jaune, parfumées, de 3,5 $\mathrm{cm}$ de long. Les fruits sont des baies rondes de 2,5 à 7 $\mathrm{cm}$ avec une peau verte épaisse qui devient jaune ou orange à maturité, contenant une pulpe aigre-douce et de nombreuses graines. La peau du fruit se dessèche jusqu'à former une coque dure et brune.

Ecologie : Liane commune en lisière de forêt et dans les fourrés des forêts fluviales et de la forêt tropicale. Largement répandue en Afrique de l'Ouest, centrale et orientale vers l'Éthiopie et le sud de la Somalie et également présente au Mozambique et dans les îles de I'Océan Indien. On le trouve souvent sur l'argile sablonneuse alluviale ou sur un sol rocheux.

Reproduction : Retirer les graines de la pulpe et les laver. Les graines germent facilement après 12 jours.

Usages : Le latex est dur et résineux et parfois utilisé pour falsifier celui de Landolphia owariensis. Les enfants l'emploient pour faire des balles. Les

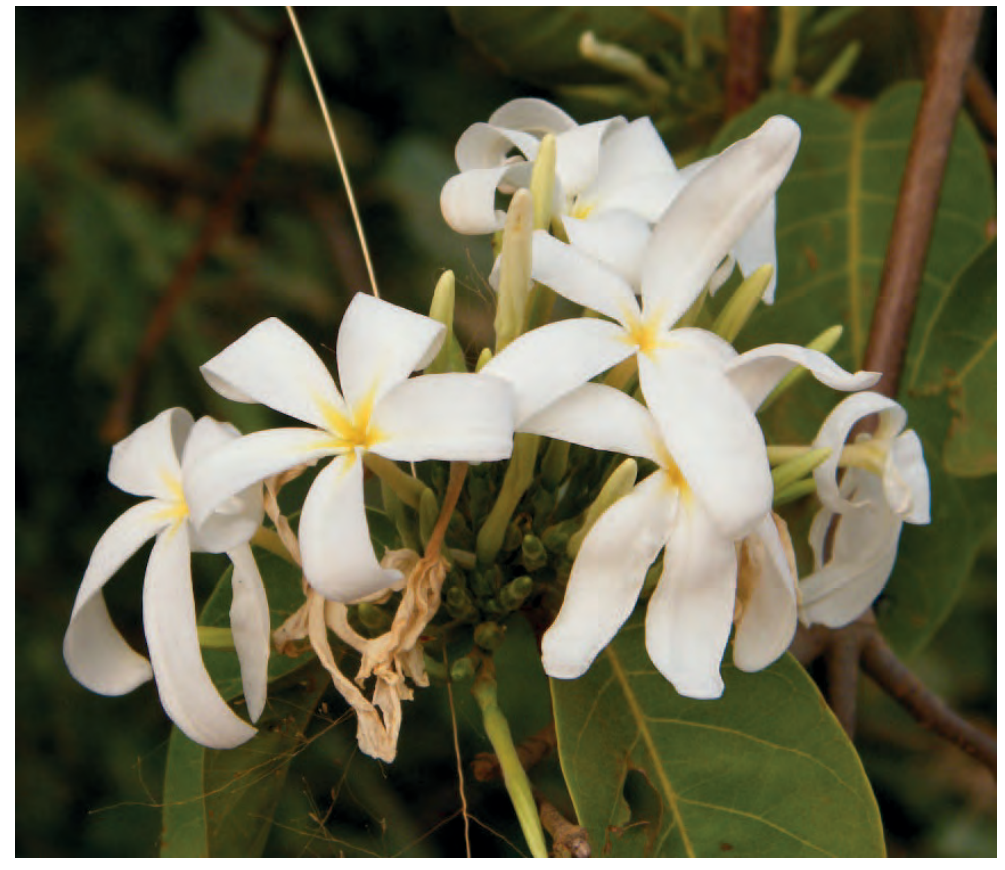
fruits comestibles sont très populaires. On les ouvre pour extraire les graines et manger la pulpe, qui a un goût similaire au tamarin. On soulage les maux de dos et l'hypertension avec une infusion de feuilles. On fait boire une

\footnotetext{
${ }^{1}$ Nous enregistrons cette façon de parler ; mais si elle signifie que ce qui est meilleur ne peut pas venir du Congo, elle n'est évidemment pas la nôtre. Tout le travail de ce livre consiste au contraire à identifier ce qui est excellent dans les plantes originaires du Kongo Central, aussi bien que dans celles qui peuvent venir d'ailleurs.
} 


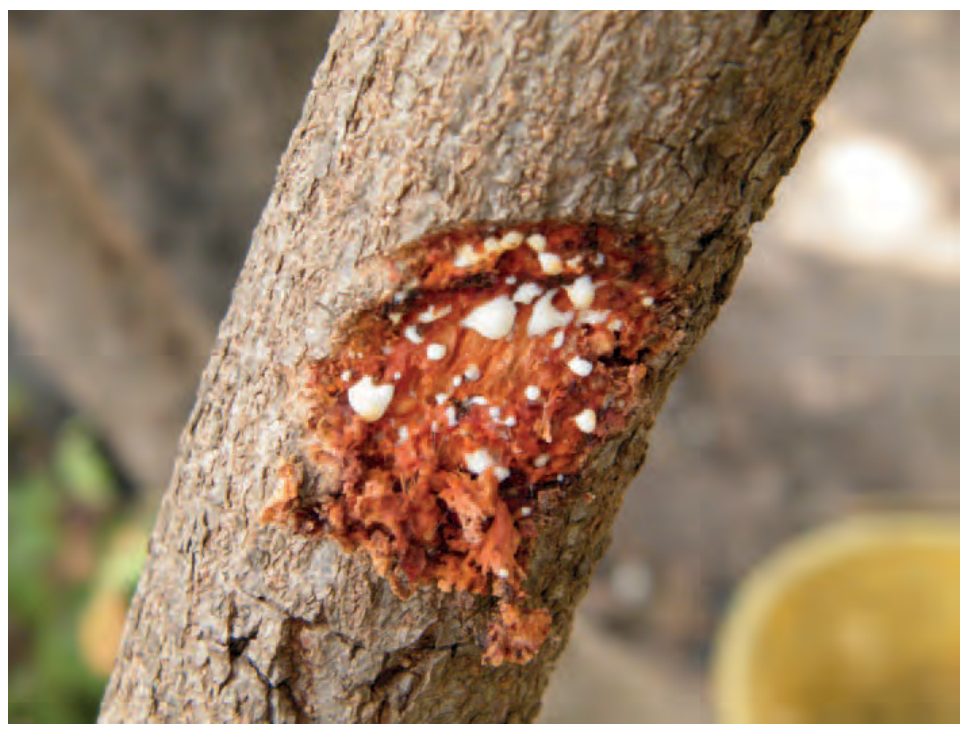

décoction des racines pour traiter les rhumatismes et l'infertilité chez les femmes. Les fleurs seraient visitées par les abeilles. On a extrait du caoutchouc de cette plante pendant la guerre 1939 - 45.

A gauche : Latex suintant d'une coupure dans la tige.

Références : Gillet et Pâque 1910, Gillet 1927, Renier 1948, Daeleman et Pauwels 1983, Beentje 1994, Katende et al. 1999, Maundu 1999, Neuwinger 2000, Ruffo et al. 2002

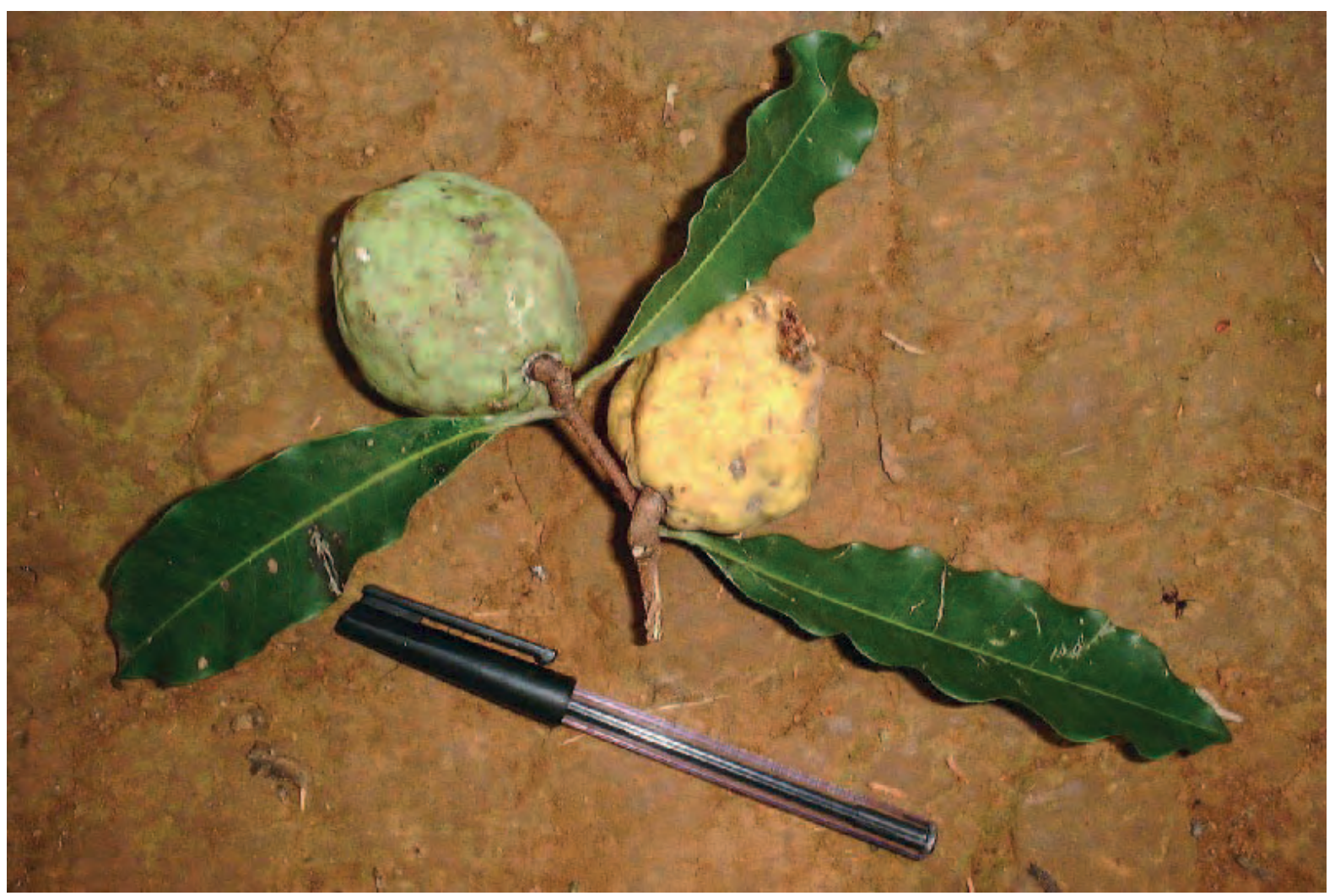

Photo : Robert Copeland 
Sabicea africana

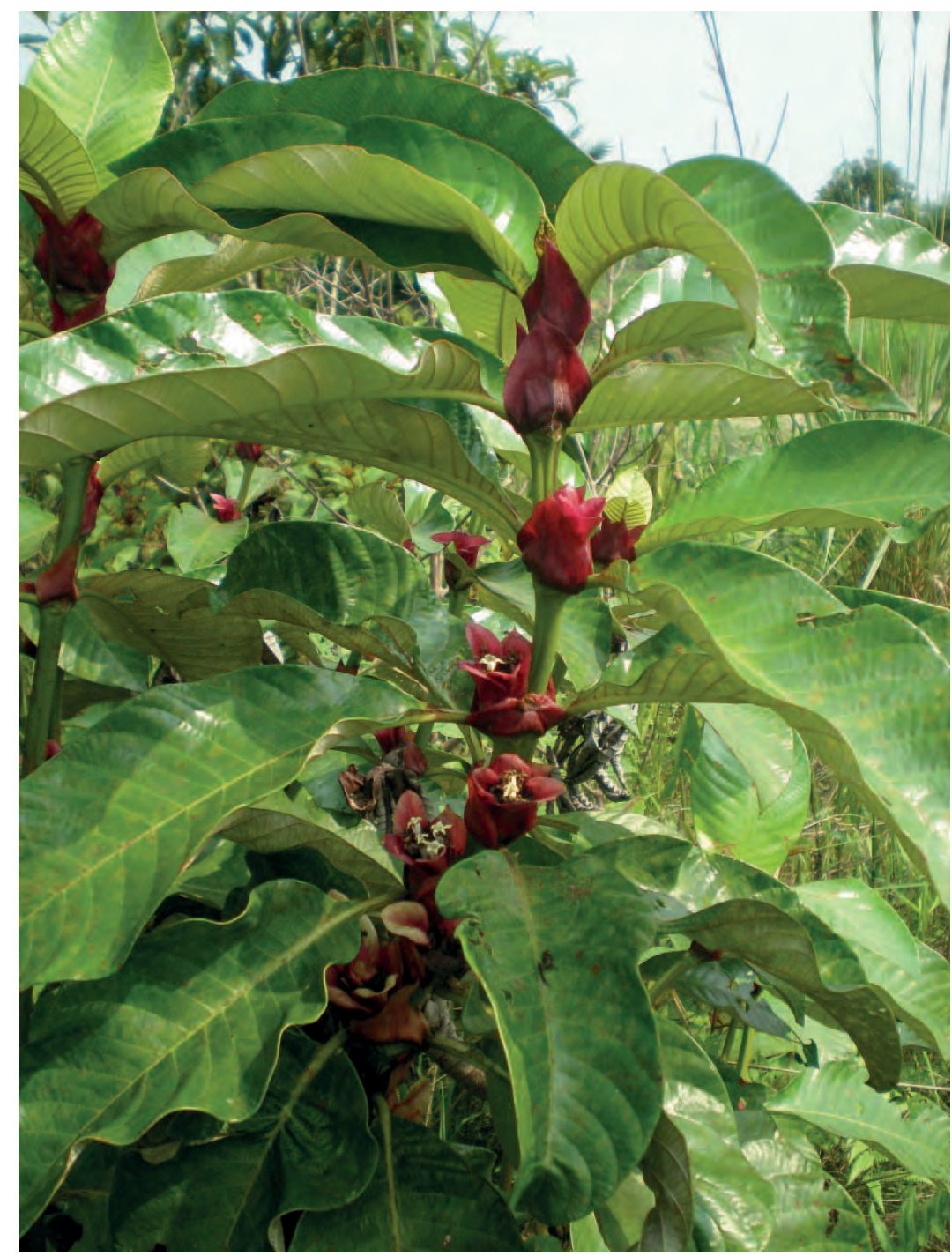

(Rubiaceae)

Synonyme : Stipularia africana

Nom courant : Tungwa (Kikongo)

Description : Arbuste de 0,5 à 4 $\mathrm{m}$ de haut. Les feuilles sont grandes, jusqu'à $20 \mathrm{~cm}$ de long et $11 \mathrm{~cm}$ de large, densément poilues dessous. Le fruit est charnu, jusqu'à 1,5 à $1,7 \mathrm{~cm}$ de long et 1,3 à $1,4 \mathrm{~cm}$ de diamètre.

Ecologie: Plante des marais et des lieux humides, de la Sierra Leone à la RD Congo.

Usages: La chair du fruit est comestible. Au Congo (Brazzaville), on fait boire une décoction de la plante entière pour arrêter les saignements graves. La plante est une source de sel végétal en Ubangi. Elle est parfois cultivée comme plante ornementale.

Références : Renier 1948, Irvine 1961, Pauwels 1993, Burkill 1997, Neuwinger 2000

Photo: Bart Wursten

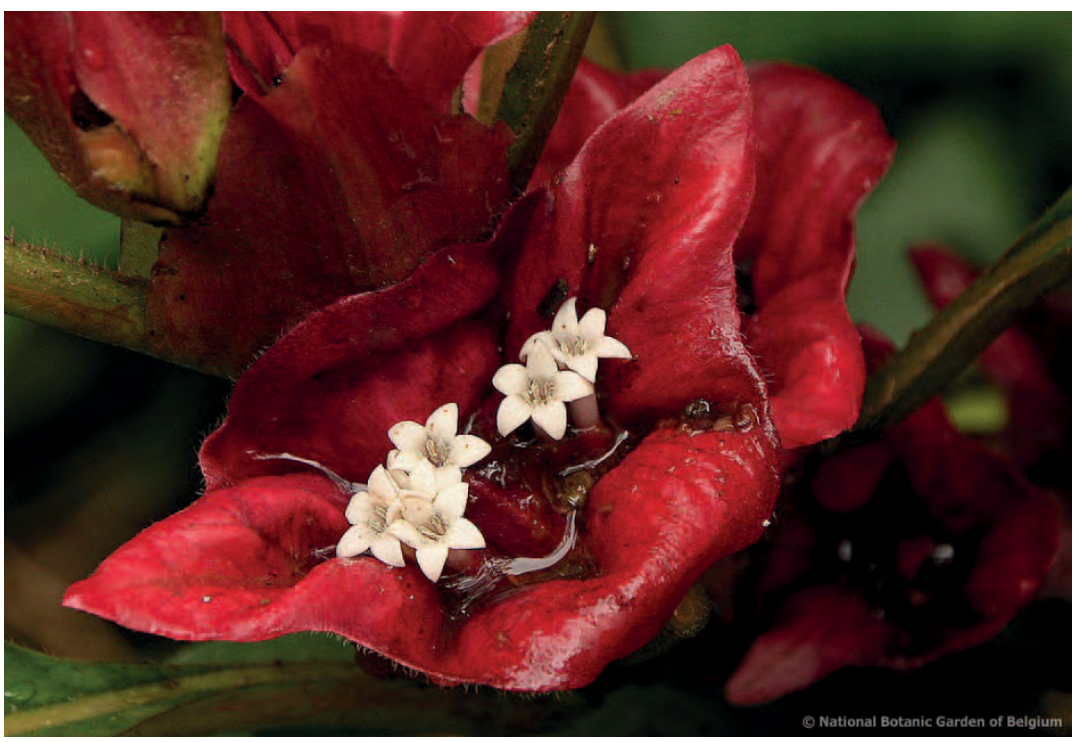


Nom courant : Lukaya lu tiba muana (Kimputu)

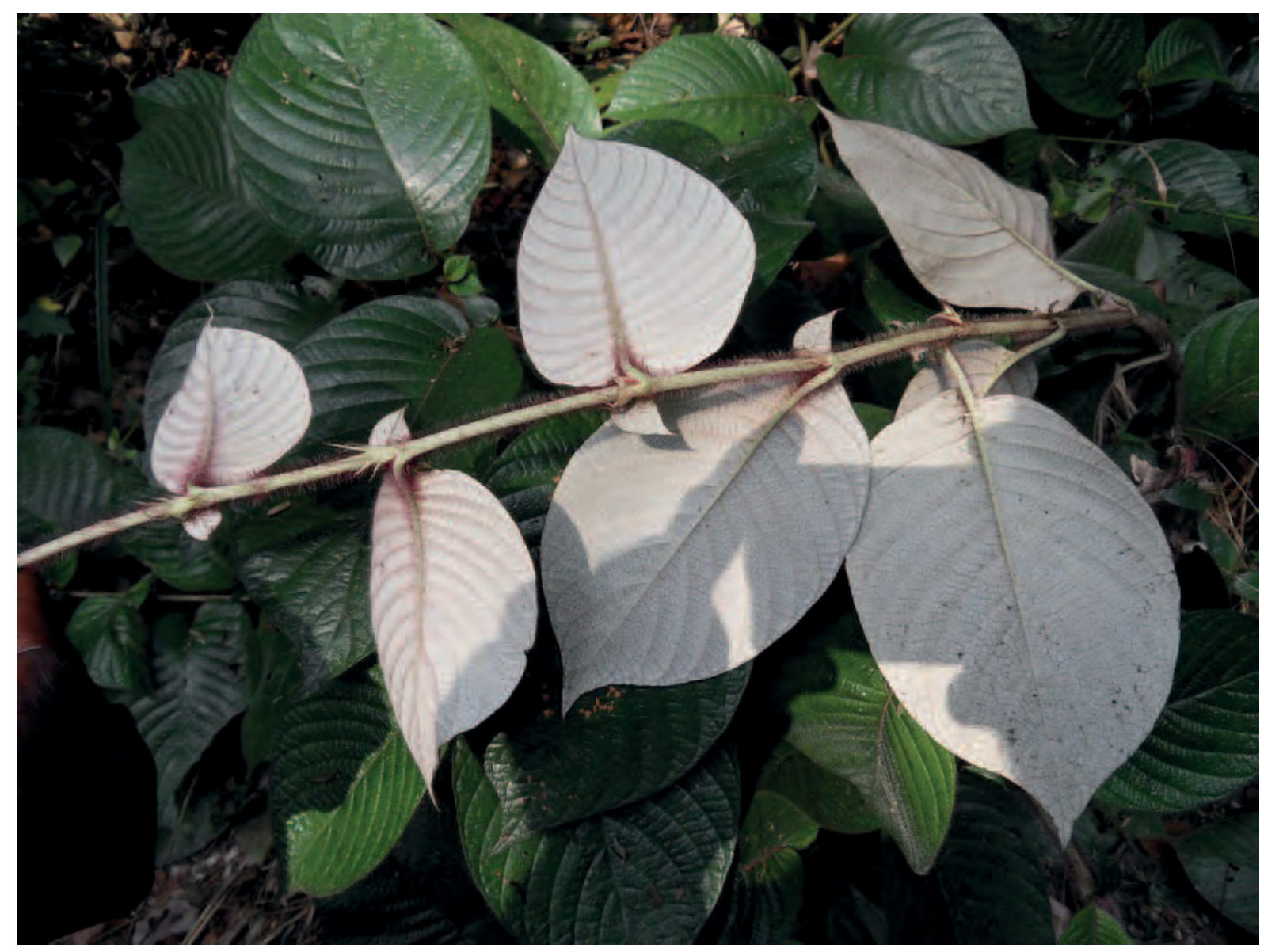

Description Une liane rampante, inhabituelle pour ses feuilles opposées dissemblables, I'une de 10 à $15 \mathrm{~cm}$ de long et de 4 à $8 \mathrm{~cm}$ de large, l'autre feuille de seulement 1 à $2 \mathrm{~cm}$ de long. Les fleurs blanches se disposent en bouquets subsessiles

Ecologie: Plante commune dans le sud-ouest de la RD Congo en particulier dans les forêts humides.

Usages: le nom Kimputu signifie que les feuilles sont utilisées pour frictionner les nourrissons

Références : Renier 1948, Lachenaud (communication personnelle 16.12.2013)

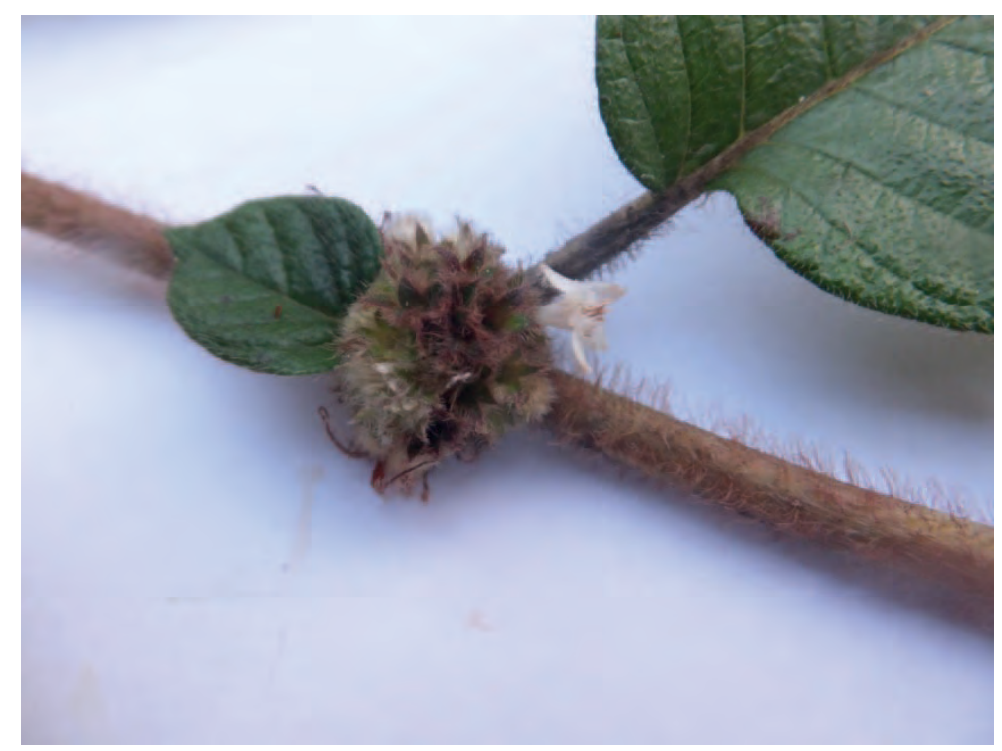




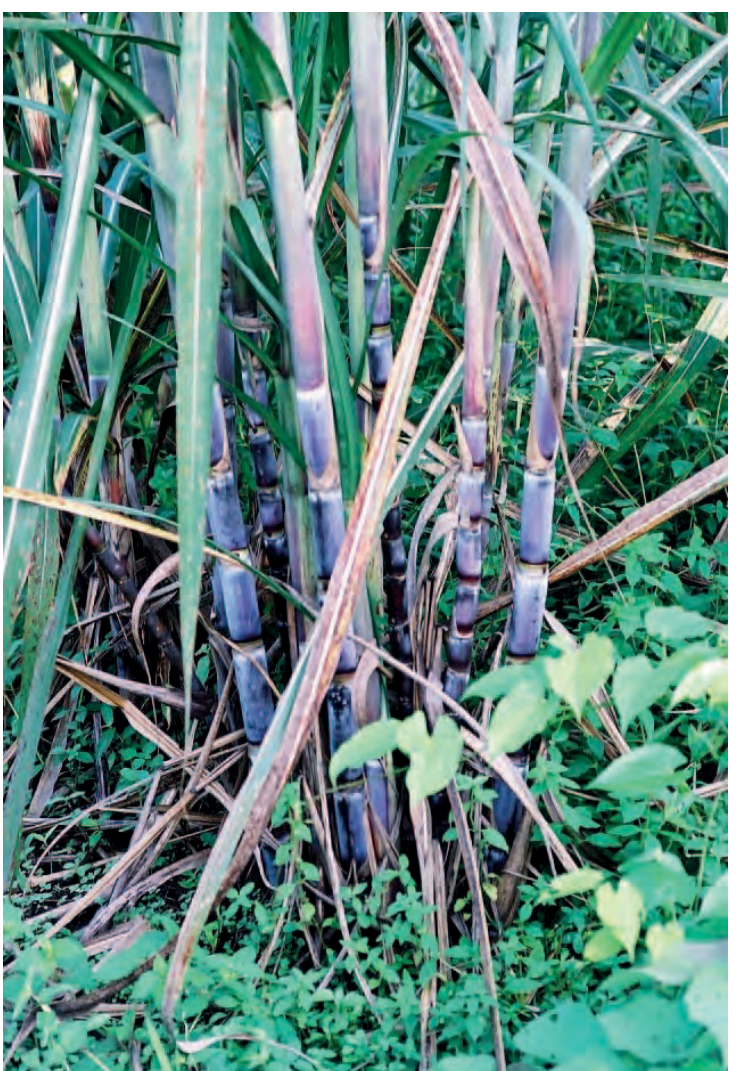

Noms communs: Munsie, mukuku (Kikongo), canne à sucre (Fr.), sugar cane (Angl.),

Ecologie: Cultivée en Inde depuis plus de 4000 ans, la canne à sucre était connue en Afrique et en Occident au Moyen Age, A partir du XVème siècle, la culture de la canne à sucre a été introduite dans de nombreux pays tropicaux, et a joué un rôle important dans I'histoire économique du monde. Les cultivars modernes forment un ensemble d'hybrides complexes issus principalement de croisements entre Saccharum officinarum et d'autres variétés. La canne à sucre est fréquemment cultivée au Kongo Central dans de petites parcelles, en particulier autour des maisons. Elle est cultivée également dans une grande plantation de plus de 11000 hectares à Kwilu Ngongo, par la Compagnie Sucrière, qui a produit 90000 tonnes de sucre en 2018. La canne à sucre nécessite des températures élevées, des sols fertiles et si possible lourds, avec des précipitations élevées. Une fumure adéquate est nécessaire.

Reproduction : A partir de boutures de tiges de cannes immatures, âgées de 8 à 12 mois. Pour une meilleure production, il faut couper la partie haute des cannes une semaine avant de prélever les boutures ; puis la bouture à planter n'est constituée que du tiers supérieur de la canne qui reste. Chaque bouture doit avoir 3 bourgeons. Les espacer de $60 \mathrm{~cm}$ sur des lignes distantes de 1,5 à 1,8 m. Planter à un angle de $45^{\circ}$ ou à plat à la base d'un sillon.

Planter au début de la saison des pluies.

Gestion : La canne à sucre est une culture vivace. La première récolte demande de 15 à 16 mois pour mûrir. Après la récolte, on laisse les souches en terre pour produire deux à quatre autres récoltes, chacune prenant environ un an pour mûrir.

Extraction du jus de petits morceaux de canne avec une presse à main.

Usages : En cultures familiales, la canne à sucre est principalement cultivée pour en mâcher les morceaux, ce qui est

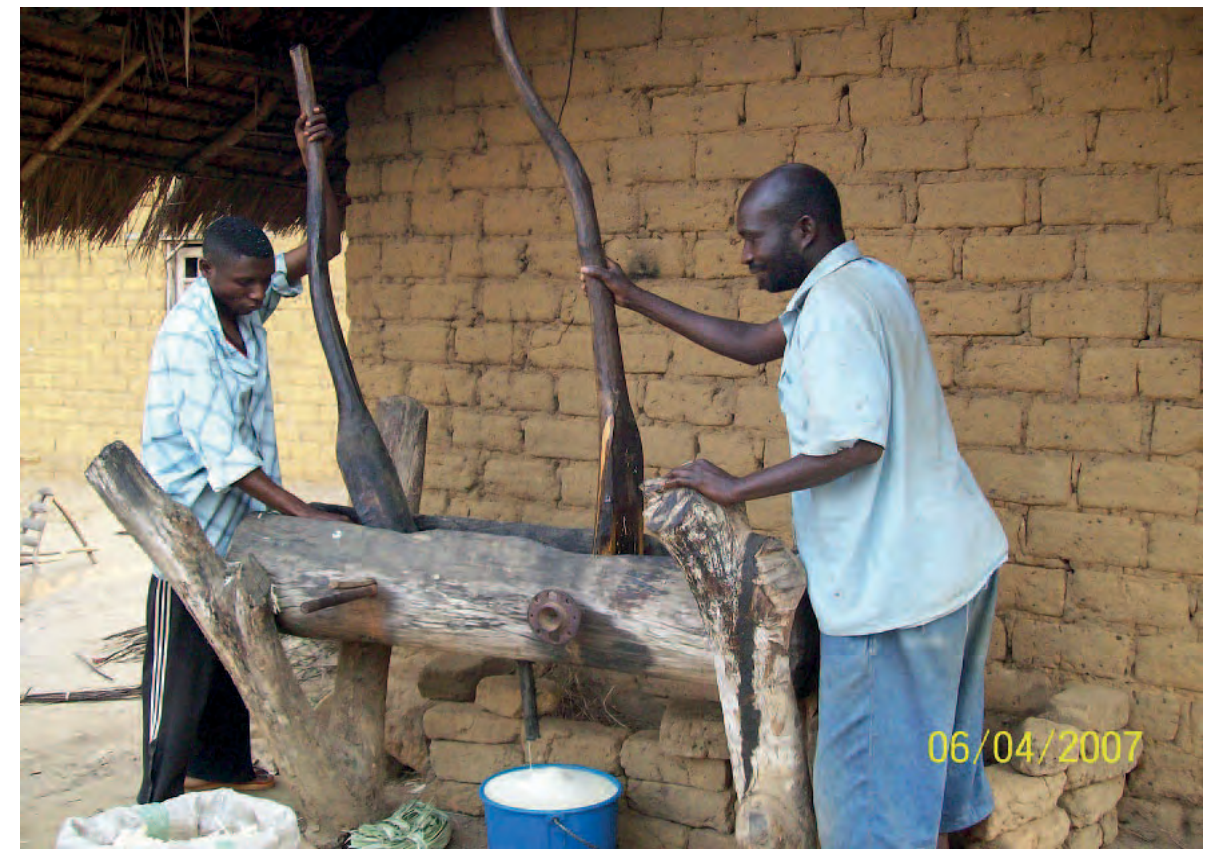
agréable au goût, favorise la salivation, et contribue à nettoyer les dents. On extrait également le jus, pour préparer le malafu ou lungwila, une bière laiteuse et capiteuse.

À leur entrée dans la sucrerie, les cannes des plantations industrielles sont découpées en petits morceaux puis pressées et broyées dans plusieurs moulins, pour obtenir un jus qui contient 80 à $85 \%$ d'eau, 10 à $20 \%$ de sucre et 0,7 à $3 \%$ de composés organiques et minéraux. Ce jus est séparé de la bagasse, résidu fibreux brûlé pour assurer les besoins en énergie de la sucrerie (mais que l'on pourrait employer aussi pour fabriquer des papiers et cartons). Une partie du jus peut servir à la fabrication de rhum. Pour l'essentiel, il sert à produire du sucre : il est 
filtré et porté à ébullition pour traverser plusieurs chaudières et subir une concentration par évaporation. A l'issue du processus, le sucre cristallise, et le résidu, qui est encore sucré, constitue la mélasse. Le sucre cristallisé peut être commercialisé comme sucre roux, ou raffiné pour donner du sucre blanc. La production mondiale de sucre de canne pendant la campagne 2018-2019 a été de 144845 millions de tonnes, les deux principaux pays producteurs étant l'Inde et le Brésil. La consommation de sucre dans le monde est en moyenne de 25,5 $\mathrm{kg}$ par habitant et par an. La mélasse permet de produire de l'alcool et de la levure ; on l'emploie comme aliment du bétail. Dans certaines conditions, le traitement de la mélasse avec de l'urée convertit les sucres en un substitut protéique qui peut être consommé par les ruminants. Les abeilles butinent la sève exsudant des tiges coupées et des cannes brûlées.

Remarque : Une variété de canne à sucre, appelée Minsengo, est préférée pour faire une bière dite minsanga.

Références : Gillet et Pâque 1910, Purseglove 1972, Daeleman et Pauwels 1983, Crane et al. 1984, Burkill 1994

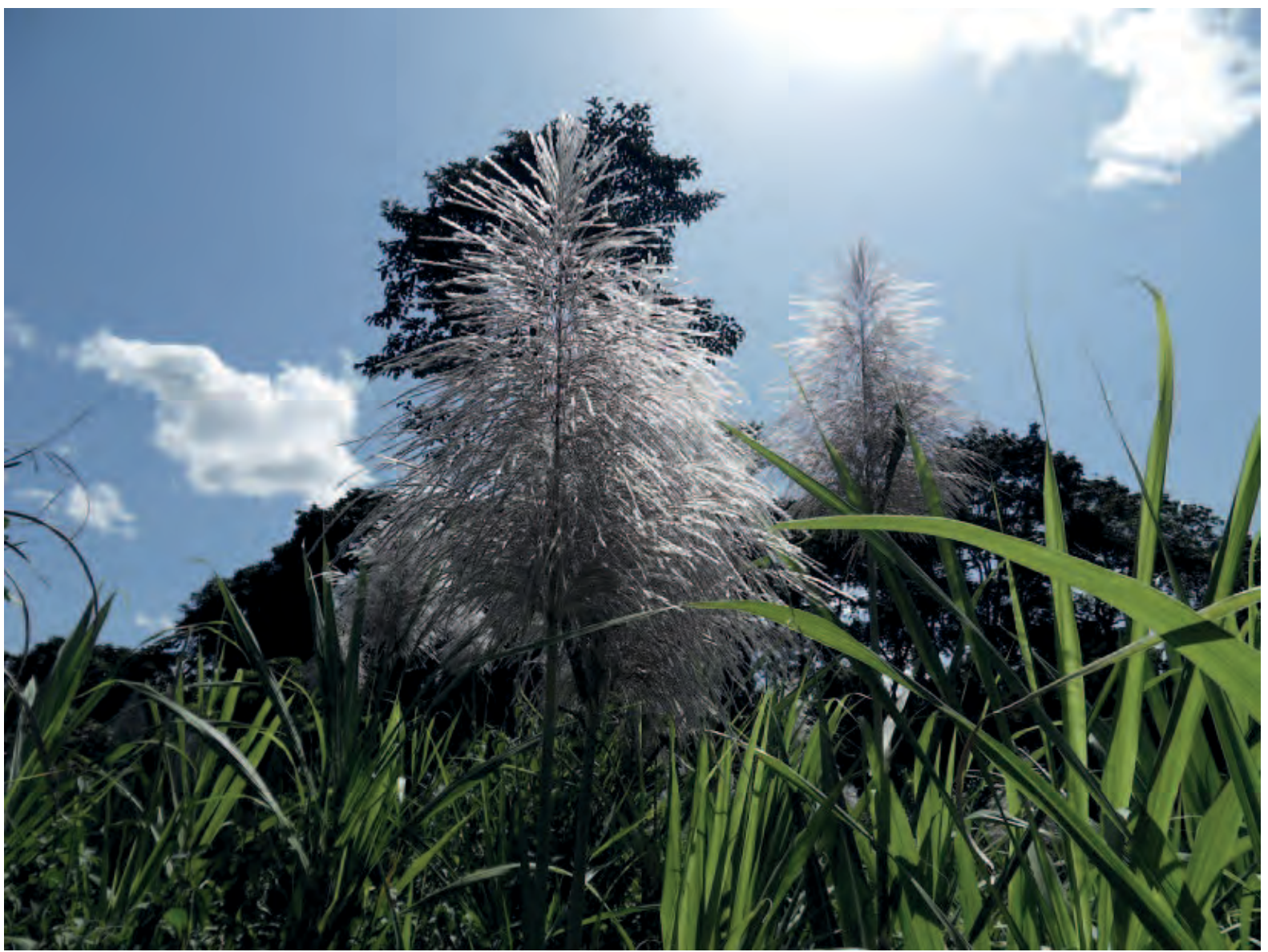

Floraison de la canne à sucre en mars 
Nom courant : Mbondi (Kikongo).

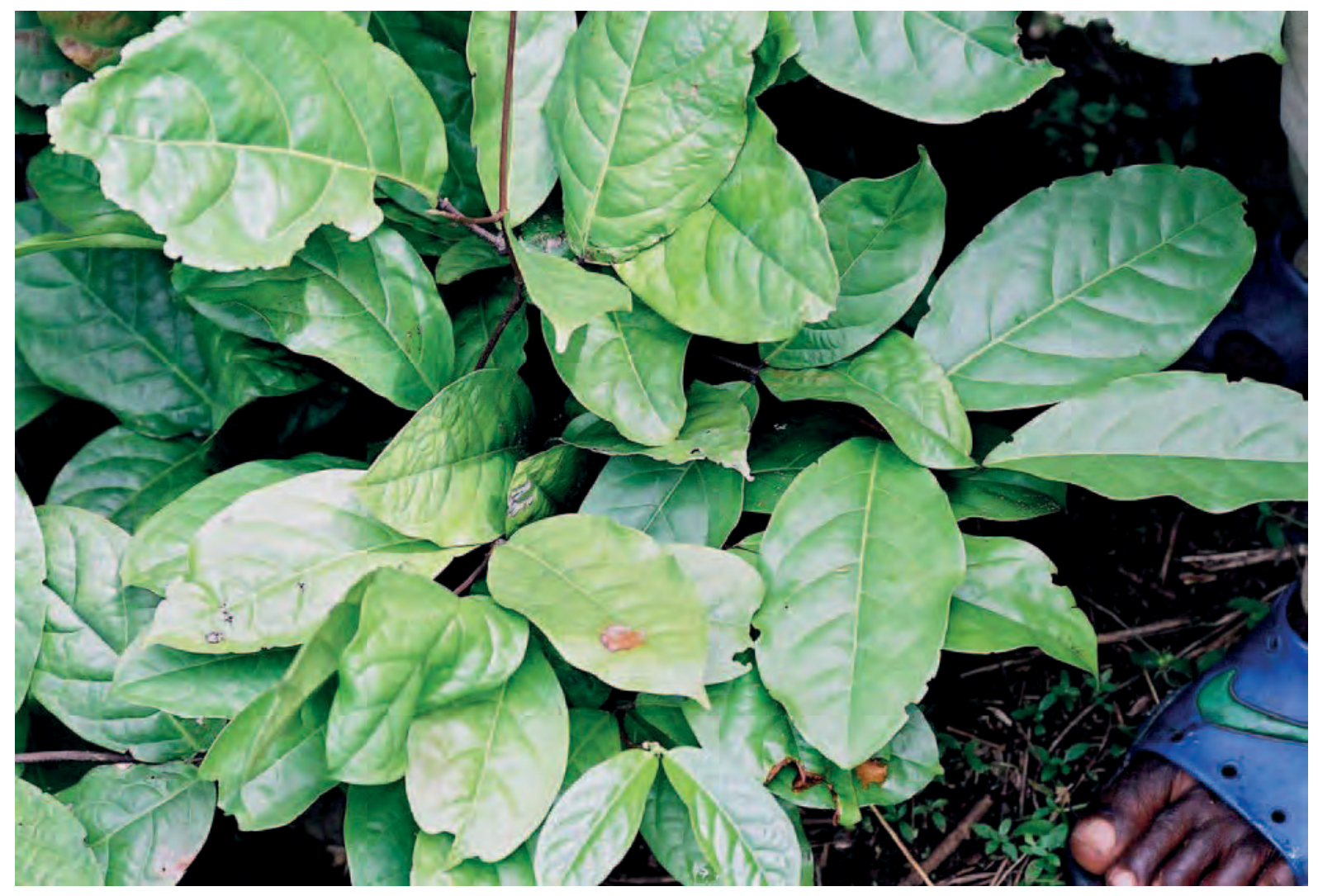

Salacia pynaertii dans la forêt défrichée près du village de Kintudi

Description : Liane vigoureuse de 2 à $40 \mathrm{~m}$ de long. Les feuilles, opposées, ont de 3,5 à $18 \mathrm{~cm}$ de long et de 1,5 à $8 \mathrm{~cm}$ de large, avec des pétioles courts de 2 à $12 \mathrm{~mm}$ de long. Les fleurs sont jaunes à brunes de 3 à $4 \mathrm{~mm}$ de diamètre. Les fruits sont globulaires, de 1,5 à $3 \mathrm{~cm}$ de diamètre.

Ecologie : Plante des forêts secondaires et forêts marécageuses. Avec la réduction de la longueur de la jachère forestière et la surexploitation possible, cette plante est devenue rare dans certaines parties du Kongo Central.

Reproduction : La plante peut être cultivée à partir de boutures.

Photo des fruits : Ehoarn Bidault, Missouri Botanical Garden

Usages: Se mange comme légume au Kongo Central. II y avait un marché important pour cette plante à Kinzala, sur la route de Kimvula. Les feuilles fraîches contiennent plus de $3 \%$ de protéines et sont généralement pilées et cuites avec des arachides (avec des chenilles ou des champignons et des tomates) ou avec des graines de courge (avec des

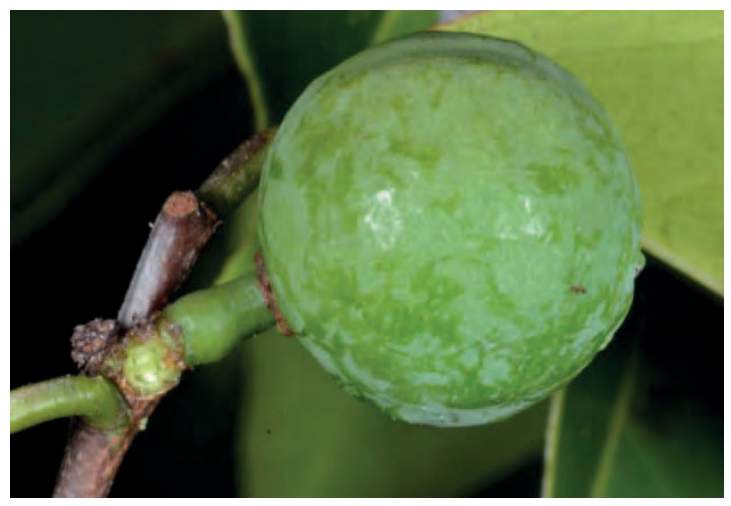
champignons, des chenilles ou des fourmis volantes). On mange les fruits de cette espèce et de plusieurs autres espèces apparentées.

Références: Renier 1948, Adriaens 1951, Wilczek 1960, Mbemba et Remacle 1992, Peters et al. 1992, Nsimundele 2004 
Noms courants : Sureau, grand sureau, sureau noir (Fr.), elderberry (Angl.)

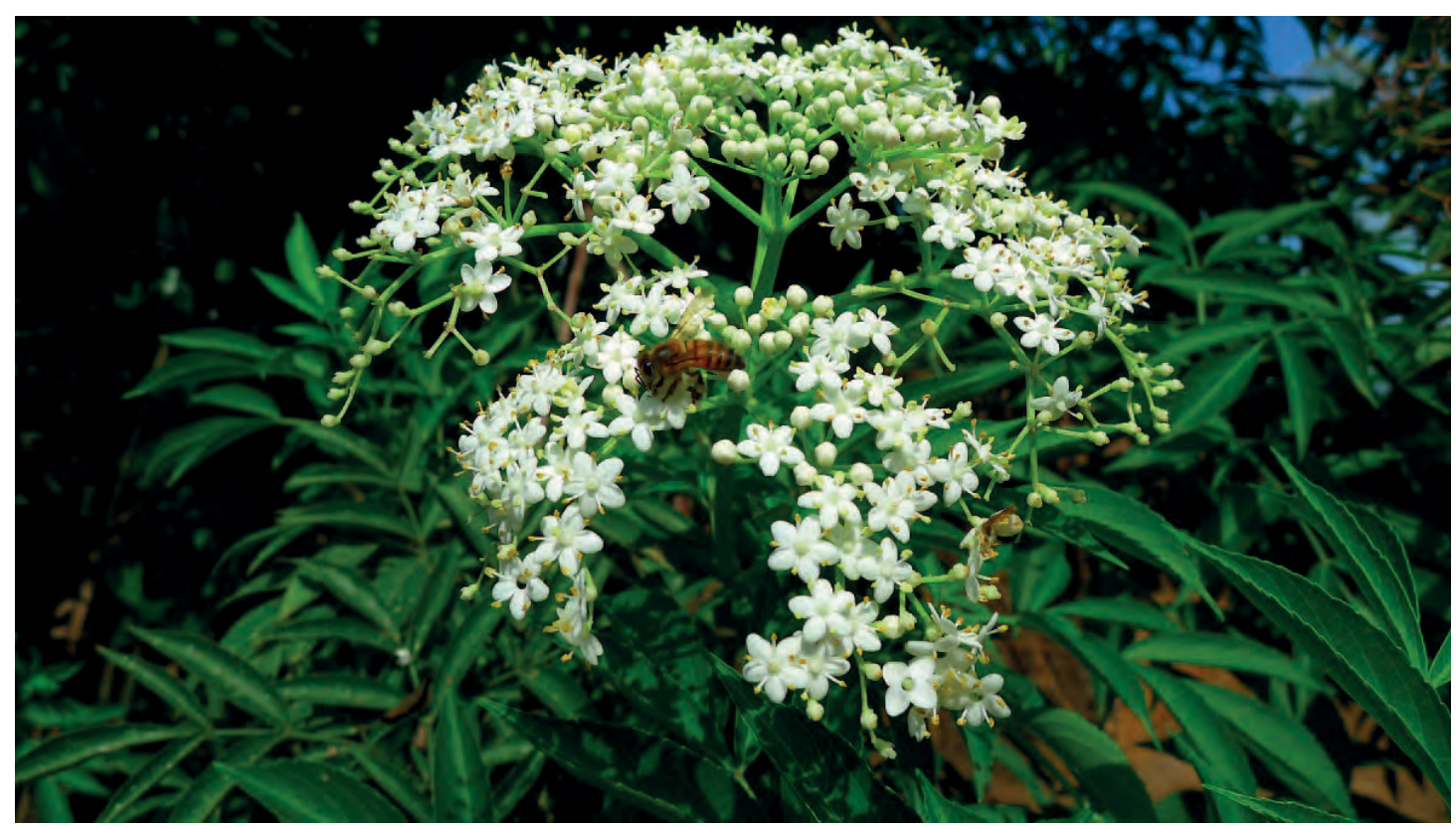

Abeilles butinant le nectar et le pollen d'un buisson près de Kilueka en février

Description: Arbuste à l'odeur désagréable, ayant jusqu'à $4 \mathrm{~m}$ de haut. Feuilles composées de folioles dentées, de 5 à $11 \mathrm{~cm}$ de long et de 2 à 3 $\mathrm{cm}$ de large. Inflorescence terminale aux nombreuses fleurs, ayant jusqu'à $20 \mathrm{~cm}$ de diamètre. Fruits noirs contenant 3 à 5 graines.

Ecologie: Plante originaire du Mexique, maintenant répandue en Afrique. Introduite en RD Congo par le jardin botanique de Kisantu en 1901.

Usages : Plante cultivée à des fins ornementales ou médicinales. On a observé la récolte du pollen et du nectar par les abeilles en février à Kilueka.

Références : Gillet 1927, Pauwels 1993

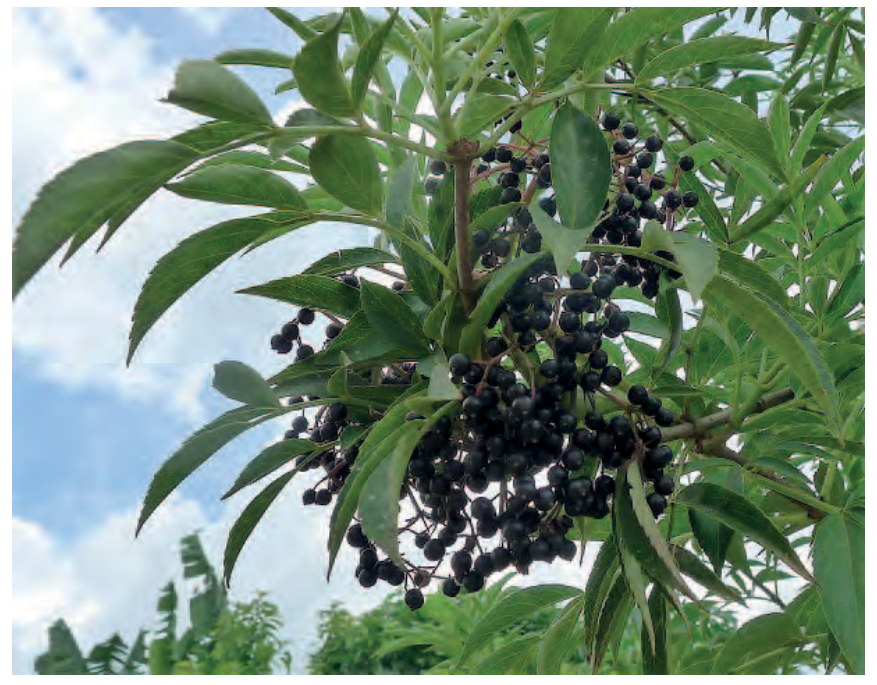


Noms communs : Sansevière (Fr.), mother-in-laws tongue (Angl.)

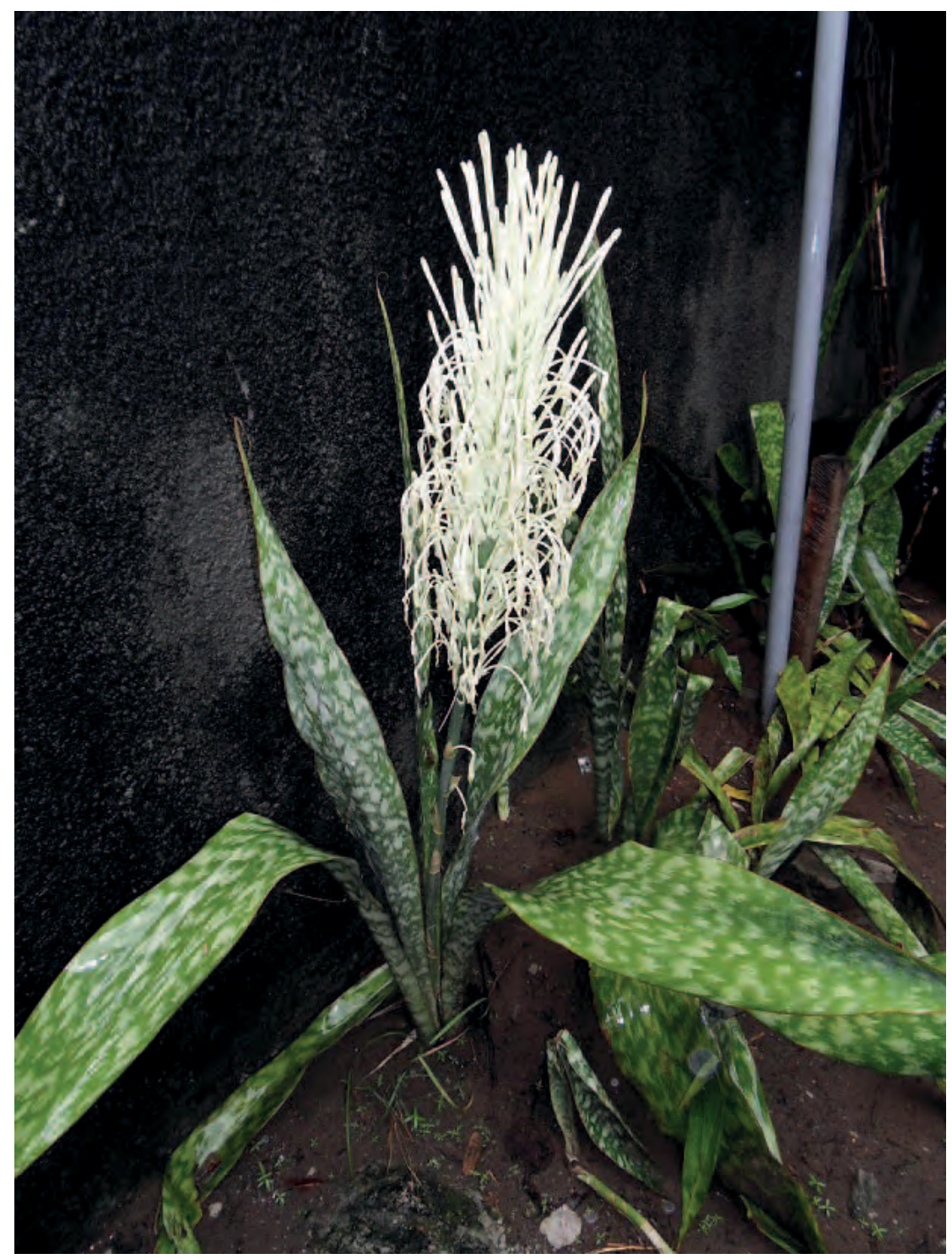

Description :

Plante

succulente vivace poussant en rosette à partir d'un rhizome rampant. Feuilles jusqu'à $60 \mathrm{~cm}$ de long avec des marques blanches ou blanc verdâtre et une fine ligne brun rouge sur les bords. Inflorescence au bout d'une tige de 30 à $70 \mathrm{~cm}$ de long. Les fleurs parfumées s'ouvrent le soir, produisant un liquide sucré gluant.

Ecologie: Plante de l'Afrique équatoriale, dans les savanes boisées sur sol pierreux ou sablonneux, généralement à l'ombre.

Reproduction: Par division des rhizomes.

Usages : Cultivée comme plante ornementale. On a cultivé cette plante aux ÉtatsUnis pour sa fibre, qui est de bonne qualité, brillante, résistante et convenable pour fabriquer des cordages.

Références Dodge 1897, Baumann 2005, African Plant Database (3.4.0.) (consulté 1.1.2019) 
Noms courants : Lunioka nioka, kula nyoka (nioka = serpent ; les ondulations des feuilles évoquent le mouvement des serpents) (Kikongo), sansevière (Fr.), bowstring hemp (Angl.).

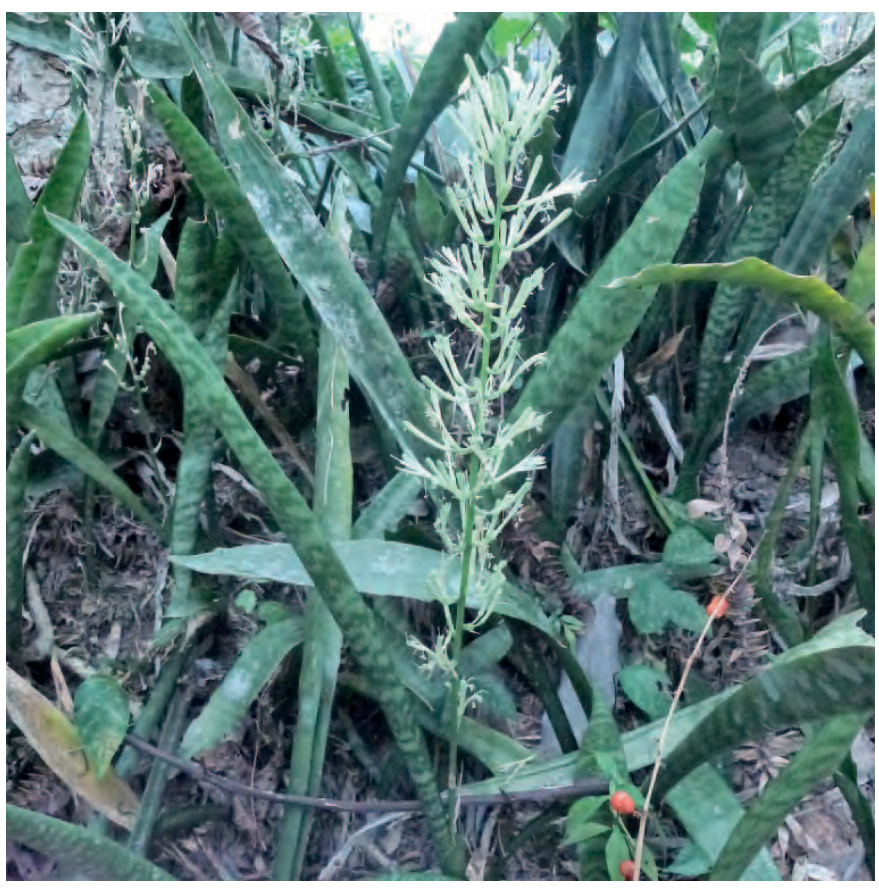

Description: Les feuilles, de 50 à $80 \mathrm{~cm}$, à texture densément fibreuse, poussent en rosette sur un gros rhizome souterrain. Elles ont une forme d'épée, sont enroulées à la base et pointues au sommet. Elles sont souvent divisées verticalement en trois bandes: une bande centrale vert clair ponctuée de lignes horizontales constituées de motifs irréguliers vert foncé ; et, de part et d'autre, des marges semi transparentes de couleur jaune ou rosâtre. Elles sont souvent ondulées, de sorte que les marges évoquent le mouvement d'un serpent. Les fleurs de couleur crème sont disposées en petits bouquets formant un épi. Les fleurs sont parfumées et tombent rapidement. Les fruits sont légèrement lobés, ronds, rouges ou oranges.

Ecologie : Pousse en touffes à l'ombre, le long des ruisseaux, sur des affleurements rocheux et sur des termitières dans les savanes et les forêts du Sénégal à la République Centrafricaine et au

sud jusqu'à la R.D. Congo.

Reproduction : par division des rhizomes ou par boutures de feuilles.

Usages : Les feuilles contiennent environ $2 \%$ de fibres qui sont parfois extraites pour fabriquer des cordes ou des cordes à arcs. En Inde, on obtient jusqu'à 1500 kg de fibres blanches fines. À MbanzaNgungu, on frictionne les articulations douloureuses avec la feuille. En Afrique du Sud, les espèces de Sansevieria sont également utilisées pour traiter les hémorroïdes. La plante est souvent cultivée comme ornementale ; en Europe, elle est très répandue comme plante d'appartement et pour la décoration des bureaux.

Remarque : Un certain nombre d'espèces ont été décrites en Afrique de l'Ouest, mais elles sont toutes assez similaires en apparence. $S$. liberica est peutêtre l'espèce la plus commune et la plus répandue.

Références: Morton 1961, Purseglove 1972, Daeleman et Pauwels 1983, Macmillan 1991, Burkill 1995, van Wyk et al. 1997, Nzuki Bakwaye et al. 2013

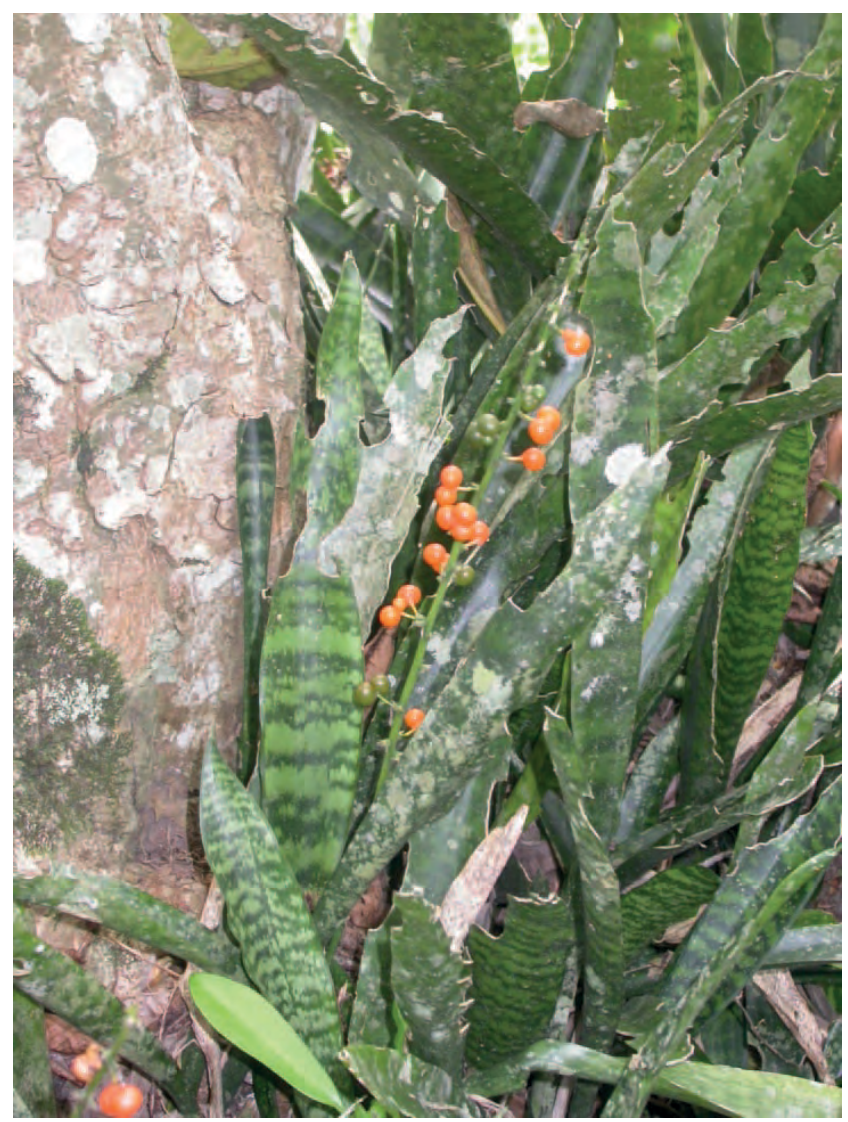


Noms communs : Mpangi nsafu, nkaka nsafu (Kikongo).

Description : Arbre forestier de taille moyenne jusqu'à $26 \mathrm{~m}$ de haut avec des contreforts ailés ou des racines échasses. Les feuilles composées ont 7 à 9 folioles, 15 à $19 \mathrm{~cm}$ de long et 5 à $7 \mathrm{~cm}$ de large. L'écorce est normalement assez lisse. Les fleurs sont jaunes. Les fruits ronds, d'environ $2 \mathrm{~cm}$ de diamètre, vont du noir violacé au noir.

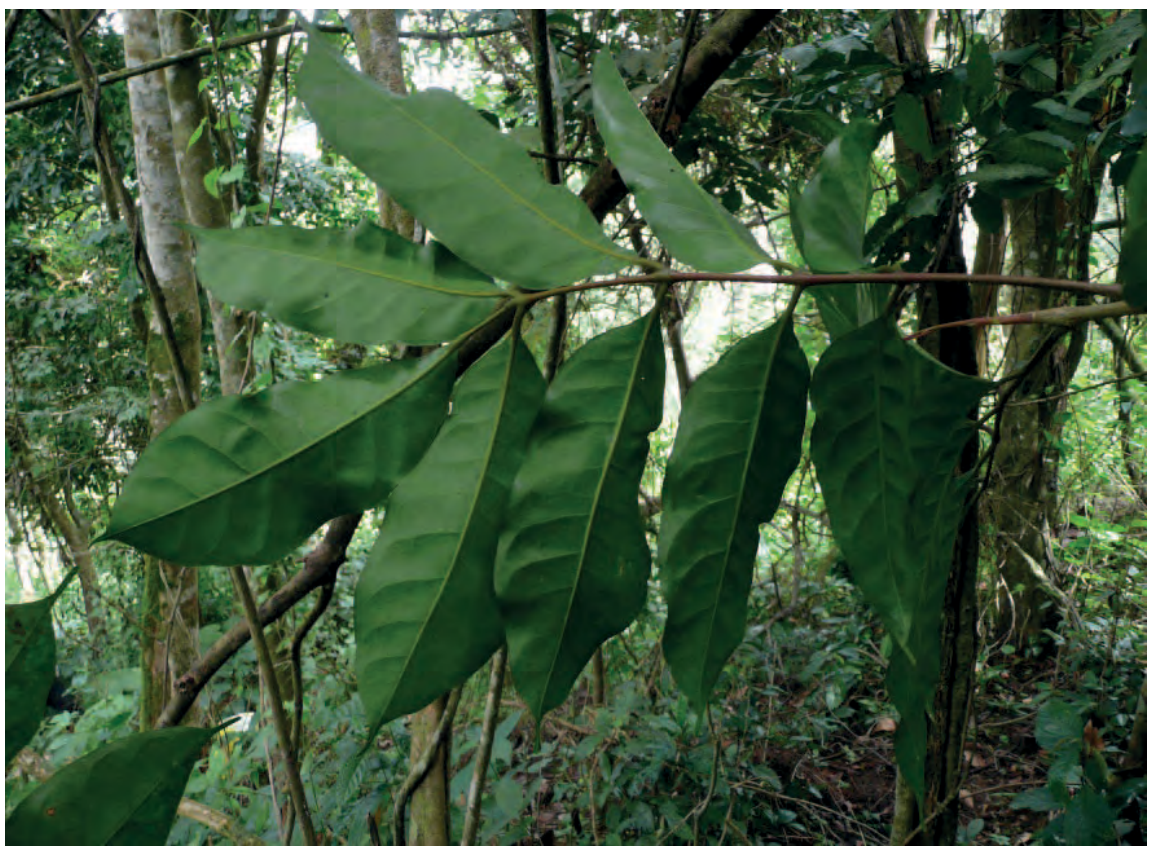

Ecologie: Arbre présent dans l'étage inférieur des forêts fermées de la Sierra Leone à la R.D. Congo (Mayombe, Kongo Central et forêt centrale).

Les deux photos : Carel Jongkind/Fauna et Flora International

Usages : Le bois, grisâtre à brun jaunâtre, a un grain fin et une texture régulière. On l'emploie pour la sculpture et les articles domestiques. Au Gabon, on décore les manches de hache et les arcs avec les racines aériennes. L'écorce aromatique, à l'odeur de baumier contient une oléo résine. Au Kongo

Central, on donne une décoction des feuilles pour traiter l'asthme, les problèmes de foie et la toux. Avec la résine on traite les rhumatismes. Au Congo Brazzaville, on donne aux enfants de la poudre de l'écorce avec du sel et de I'huile de palme contre la coqueluche, ainsi que pour expulser les vers intestinaux. On emploie des décoctions de l'écorce en massages ou bains de vapeur contre la fièvre et contre l'eczéma. On mange les fruits dans certains pays, mais ils ont le goût et l'odeur de la térébenthine.

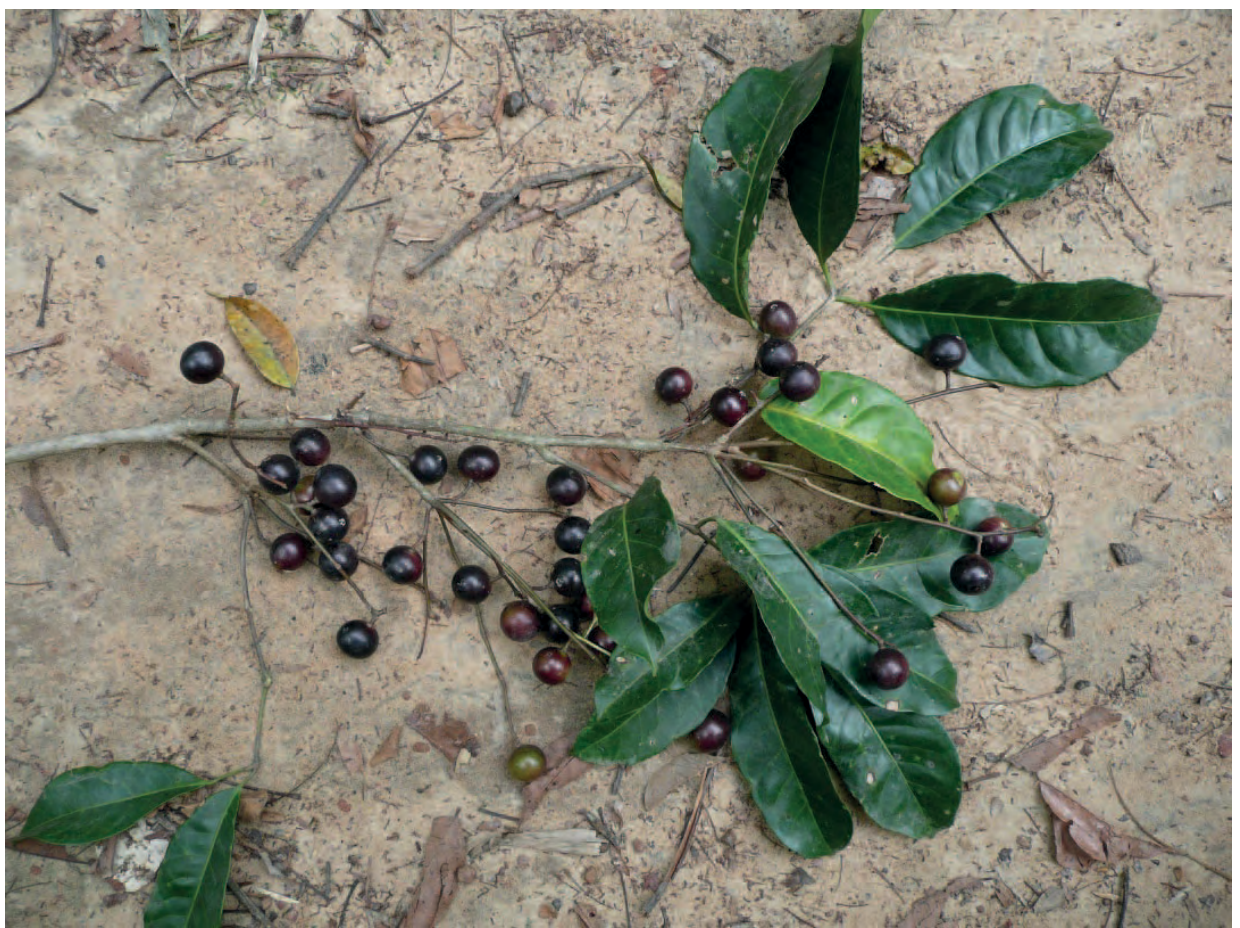

Références : Troupin 1958, Nsimundele 1966 - 68, Burkill 1985, Pauwels 1993 
Sarcocephalus latifolius

(Rubiaceae)

Noms courants : Kienga, kilolo ki kienga (Kikongo)

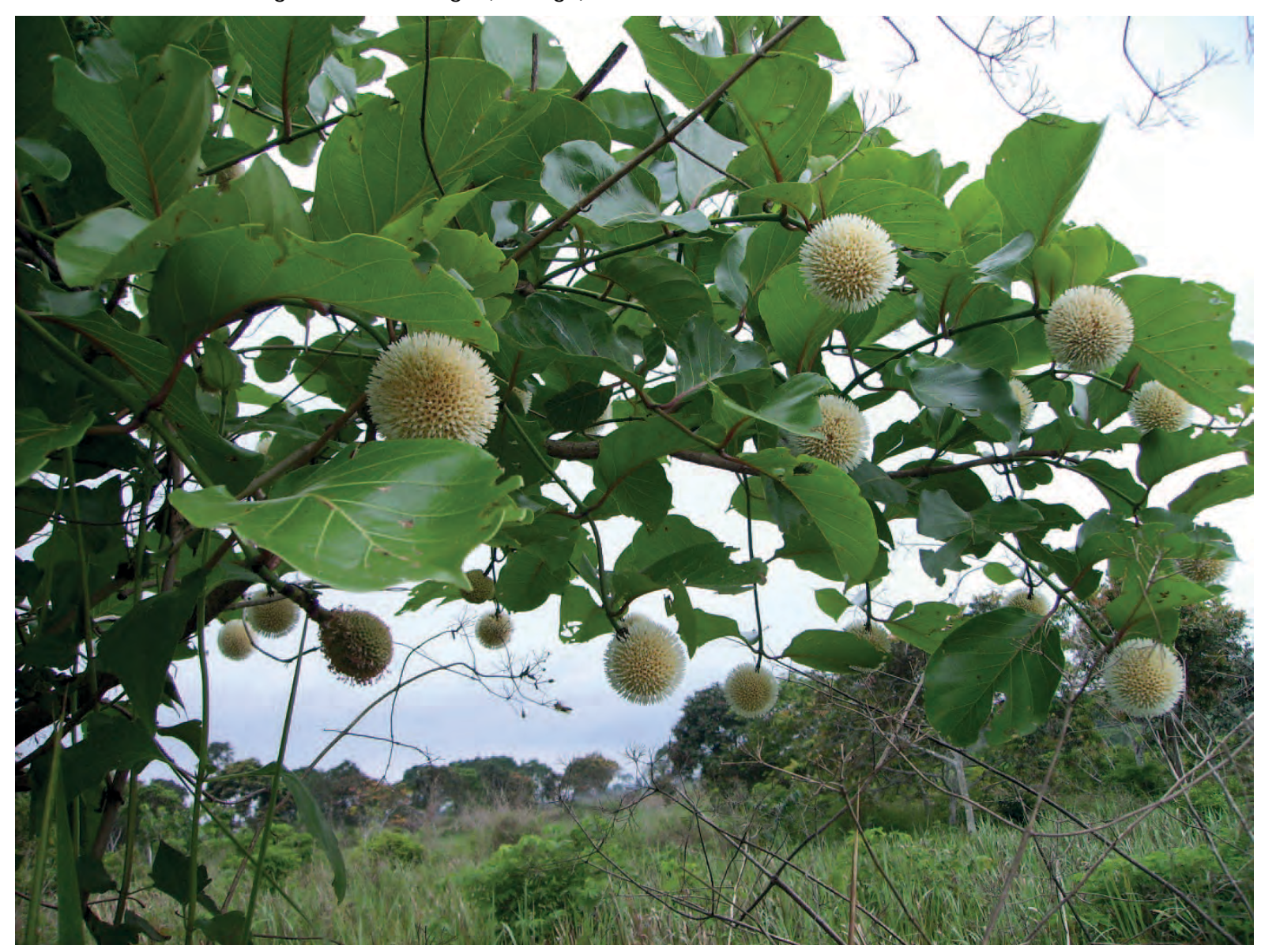

Sarcocephalus latifolius en fleurs en octobre

Description : Buisson grimpant ou arbuste de 1 à $5 \mathrm{~m}$ de haut, ayant des racines profondes. Feuilles elliptiques de 7 à 19 sur 6 à $14 \mathrm{~cm}$. Inflorescences terminales en capitules sphériques très denses composés de nombreuses fleurs blanches soudées par leurs ovaires, et donnant l'apparence d'une boule blanche. Fruits composés globuleux pouvant avoir la taille d'une orange.

Ecologie : L'arbuste pousse bien sur des sols moyennement limoneux, acides et bien drainés. II y en a deux formes, l'une de savane et l'autre de forêt. II est commun en Afrique occidentale, dans le bassin du Congo et en Ouganda.

Reproduction : L'arbuste peut se reproduire par graines ou boutures, mais les graines sont minuscules, plus petites même que celles des Eucalyptus. Le fruit mûr tombe au sol. Rassembler les fruits et laisser leur écorce se décomposer, ou bien écraser les fruits et faire flotter la pulpe dans une bassine d'eau. Les graines se séparent et tombent au fond; les récolter et les sécher. Les garder au sec dans une boîte fermée pour les semer dans les deux mois. Avant de semer, tremper les graines dans l'eau chaude, laisser refroidir et tremper 24 heures. On peut aussi transplanter les semis spontanés.

A droite : Bunaea alcinoe broutant les feuilles.

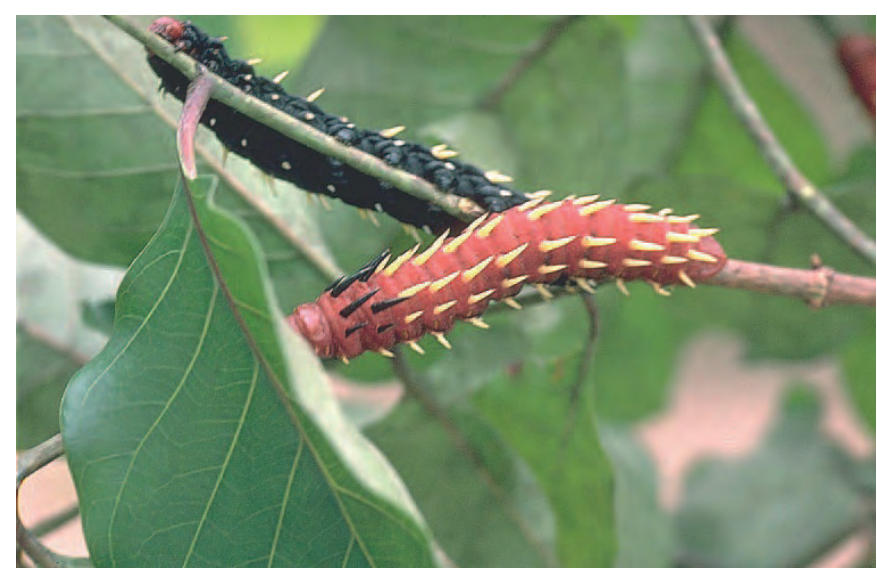


Usages : Le bois, jaune, convient pour la sculpture, le mobilier et les placages. On l'emploie aussi comme bois de chauffage et pour le charbon de bois. On plante l'arbuste pour les clôtures. L'écorce est un vermifuge efficace. Au Kongo Central, on emploie les racines pour le traitement des douleurs abdominales et de la diarrhée. On a montré qu'elles contiennent une substance semblable au tramadol analgésique. Ailleurs, on emploie les racines pour traiter les fièvres. Les fruits, comestibles, ne sont pas très appréciés. Les abeilles visitent les fleurs d'octobre à décembre. Les chenilles comestibles Makedi kedi (Bunaea alcinoe) et Munsona (Platysphinx stigmatica) broutent les feuilles pour se nourrir.

Références : Butaye 1909, Gillet et Pâque 1910, Renier 1948, Nsimundele 1966 - 68, Arkinstall 1979, Katende et al. 1995, Kibungu Kembelo 1995, Burkill 1997, Latham 2008, Boumendjel et al. 2013, Lautenschläger et al. 2018

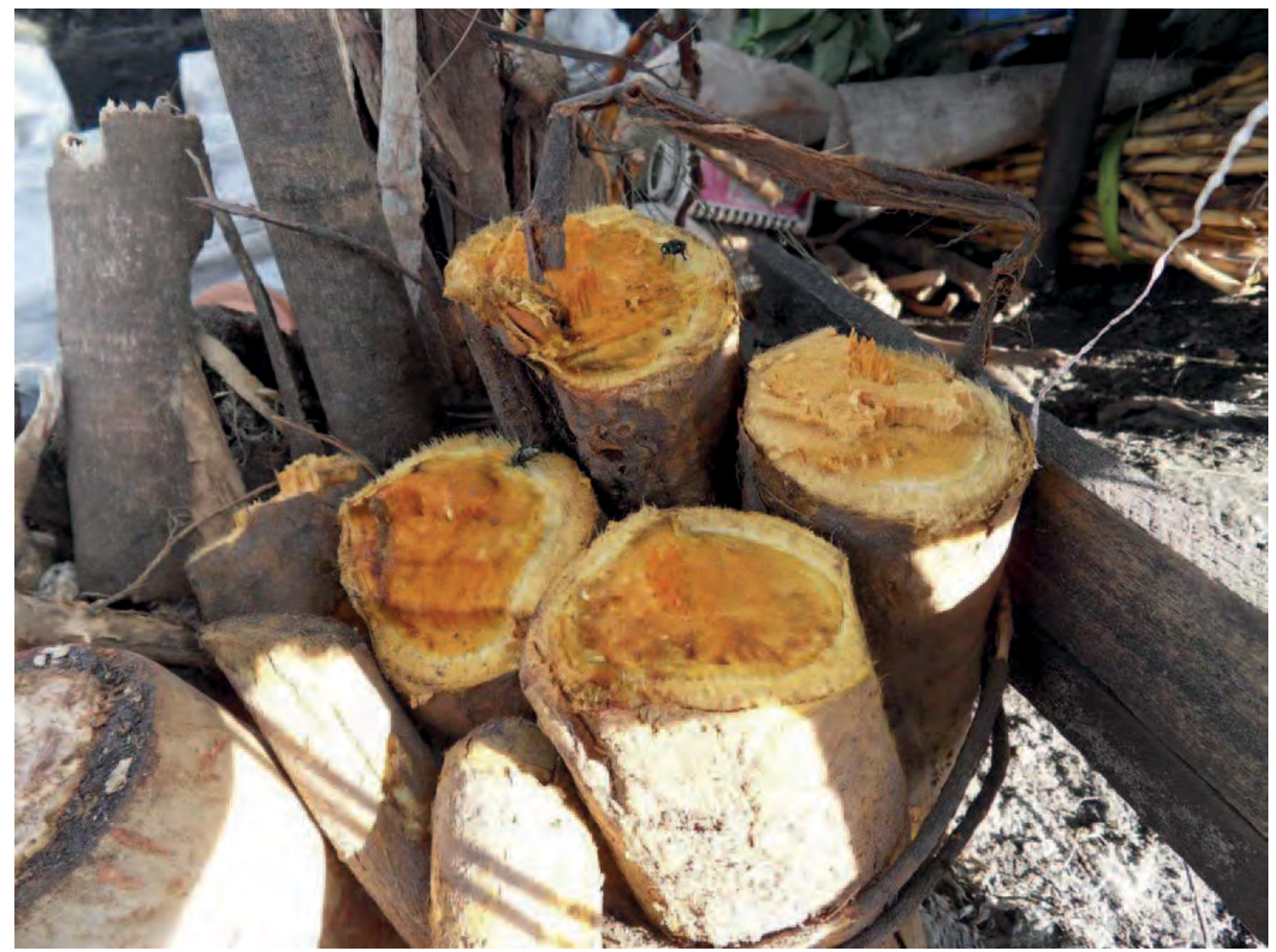

Morceaux de racines en vente sur un marché 
Nom courant : Nkaka kizionzi (Kikongo)

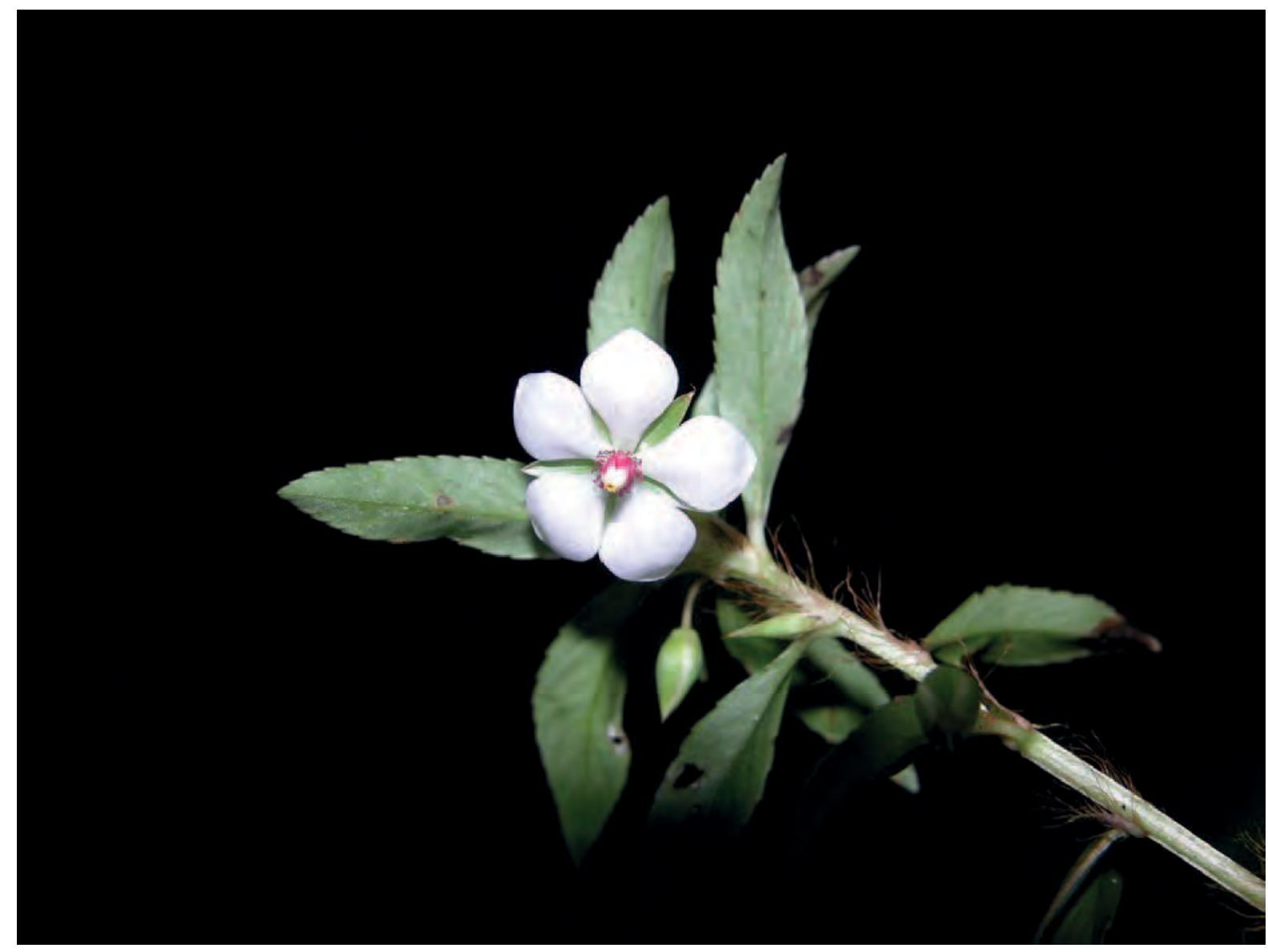

Photo: D. Solano, INBio 'Darwin I nitiative Project 162/12/020'

Description : Plante herbacée rampante annuelle ou vivace, de 5 à $60 \mathrm{~cm}$ de haut, souvent avec de longues tiges partant près de la base. Les tiges, raides et anguleuses, sont rouges ou teintées de violet. Les feuilles sont dentées, de 1 à $6 \mathrm{~cm}$ de long. Les fleurs sont axillaires, généralement solitaires, avec des pétales blancs à rosés. Le fruit est une capsule de 3,5 à $7 \mathrm{~mm}$ de long.

Ecologie : Plante des sites humides dans les régions arrosées de l'Afrique tropicale, souvent comme adventice dans les champs de riz.

Usages : On met dans la soupe les feuilles et les jeunes pousses. L'ensemble de la plante, mucilagineux, est utilisé en médecine au Gabon et au Nigeria pour son effet diurétique. On l'emploie également au Nigeria pour traiter l'ophtalmie.

Références : Gillet et Paque 1910, Renier 1948, Bamps et Farron 1967, Burkill 1997, Neuwinger 2000 


\section{Scadoxus multiflorus}

Noms courants : Boule de feu (Fr.), fireball lily (Angl.)

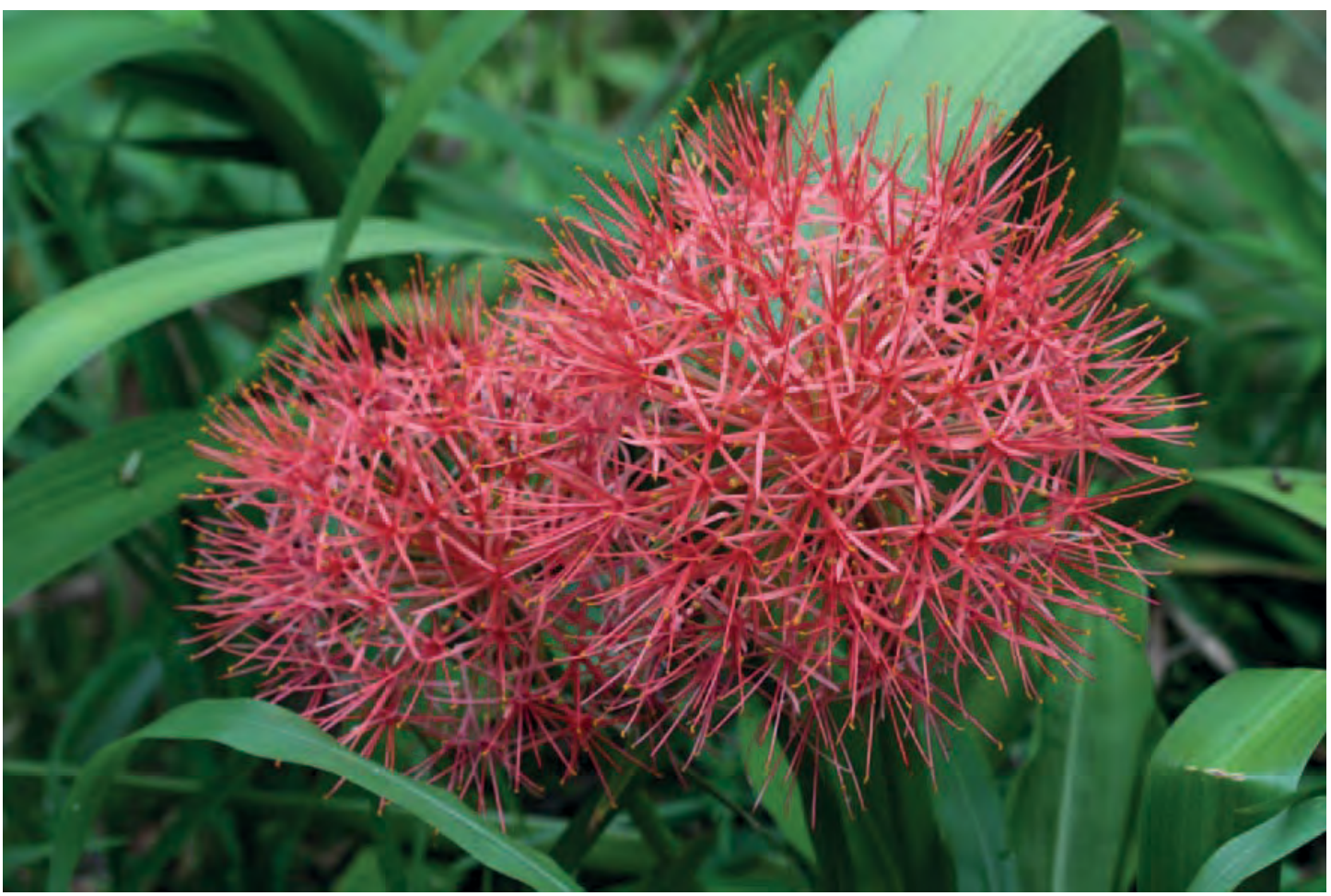

Photo : Marissa Rose

Description: Plante herbacée charnue poussant sur un gros bulbe de $6,5 \mathrm{~cm}$ de diamètre. Les feuilles sont disposées en hélice à la base ; elles ont $25 \mathrm{~cm}$ de long sur $8 \mathrm{~cm}$ de large. Elles apparaissent à la saison des pluies. L'inflorescence est une ombelle de fleurs rouges de $15 \mathrm{~cm}$ de diamètre, sur une tige tachetée de 20 à $40 \mathrm{~cm}$ de haut. Elle apparaît en saison sèche, alors que le bulbe est encore sans feuilles. Les fruits sont orange, de 5 à $8 \mathrm{~mm}$ de diamètre.

Ecologie : Plante des savanes boisées, des lisières forestières et des forêts secondaires à travers l'Afrique tropicale. Egalement présente dans la péninsule arabique. La plante pousse bien même sous ombre épaisse. Le sol doit être bien drainé, riche et léger, avec beaucoup de feuilles pilées ou de compost bien fermenté.

Reproduction : Par graines ou par rejets. La graine doit être semée dès qu'elle est mûre. Nettoyez la pulpe, avec soin car la graine en dessous est molle et charnue. Appuyez doucement sur la graine dans le sol, ne la couvrez pas, mais laissez le haut juste visible ou de niveau avec la surface du sol. Les rejets doivent être prélevés après la floraison et replantés immédiatement. On peut aussi planter les rhizomes juste en dessous du sol ; le mieux est de les laisser en place sans y toucher pendant de nombreuses années.

Gestion : C'est une belle plante d'ornement pour les jardins ombragés ; on peut la cultiver dans de grands pots à l'ombre. Elle ne semble pas craindre la concurrence des racines des arbres. Maintenez l'humidité mais sans la gorger d'eau.

Usages: Au Kongo Central, on emploie les bulbes pilés pour traiter la gale. Les abeilles récoltent sur les fleurs un pollen abondant. Ailleurs en Afrique, on emploie le bulbe pour traiter l'hydropisie et soigner les blessures. Plante ornementale souvent cultivée.

Remarque : Cette plante est toxique. Le genre Scadoxus contient des alcaloïdes très toxiques.

Références : Renier 1948, Nsimundele 1966 - 68, Burkill 1985, Fichtl et Adi 1994, Roodt 1998, Llamas 2003, Baumann 2005, Fayaz 2011 


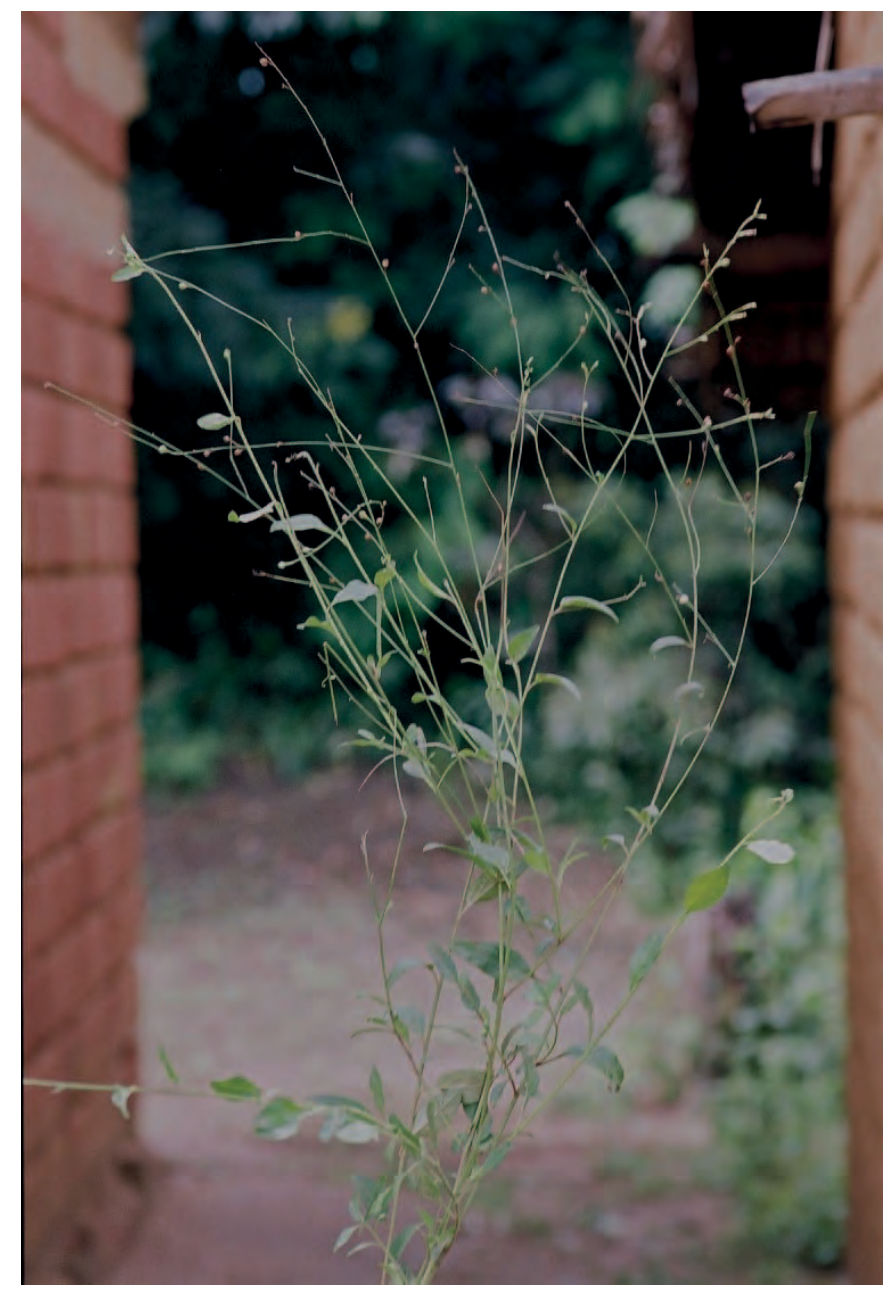

Noms communs : Lunzila nzila (Kikongo), tumpu di nkombo (Kintandu)

Description : Herbe annuelle ou pérenne légère mince, dressée, ligneuse à la base, très ramifiée, de $1 \mathrm{~m}$ de haut. Les feuilles sont alternes, les feuilles inférieures étant plus grandes avec des pétioles jusqu'à $5 \mathrm{~mm}$ de long. Les limbes des feuilles sont ovales, de $2.4 \mathrm{~cm}$ de long et $0.8 \mathrm{~cm}$ de large avec une pointe émoussée. Les feuilles supérieures sont petites et sans pétiole. Les fleurs blanches sont disposées au sommet des tiges.

Ecologie: Plante commune des friches et adventice des cultures, du Sénégal au Cameroun et ailleurs en Afrique. On la trouve aussi en Amérique tropicale.

\section{Reproduction : Par graines.}

Usages: Importante plante médicinale. Au Kongo Central, on emploie la racine et les feuilles pour traiter le diabète, la malnutrition protéique chez les jeunes enfants, la sciatique, les douleurs thoraciques, la gastrite, les hernies, les rhumatismes et l'asthme. On donne une décoction des feuilles pour soulager les douleurs chez les femmes enceintes et comme purgatif pour les enfants. Ailleurs en Afrique, la plante est utilisée comme purgatif et pour traiter l'anxiété, les coliques, la constipation, la conjonctivite, les convulsions fiévreuses, la rougeole, la varicelle, l'œdème et les maladies respiratoires chez les

enfants.

\section{Avertissement :} signale que toutes les parties de la plante pourraient causer la destruction des globules rouges.

Références : Gillet et Pâque 1910, Renier 1948, Delaude et al. 1971, Arkinstall 1979, Akobundu et Agyakwa 1987, Burkill 2000, Neuwinger 2000, Kibungu Kembelo 2003, Bikandu et al. 2020

A droite : Paquets de plantes séchées en vente sur un marché.

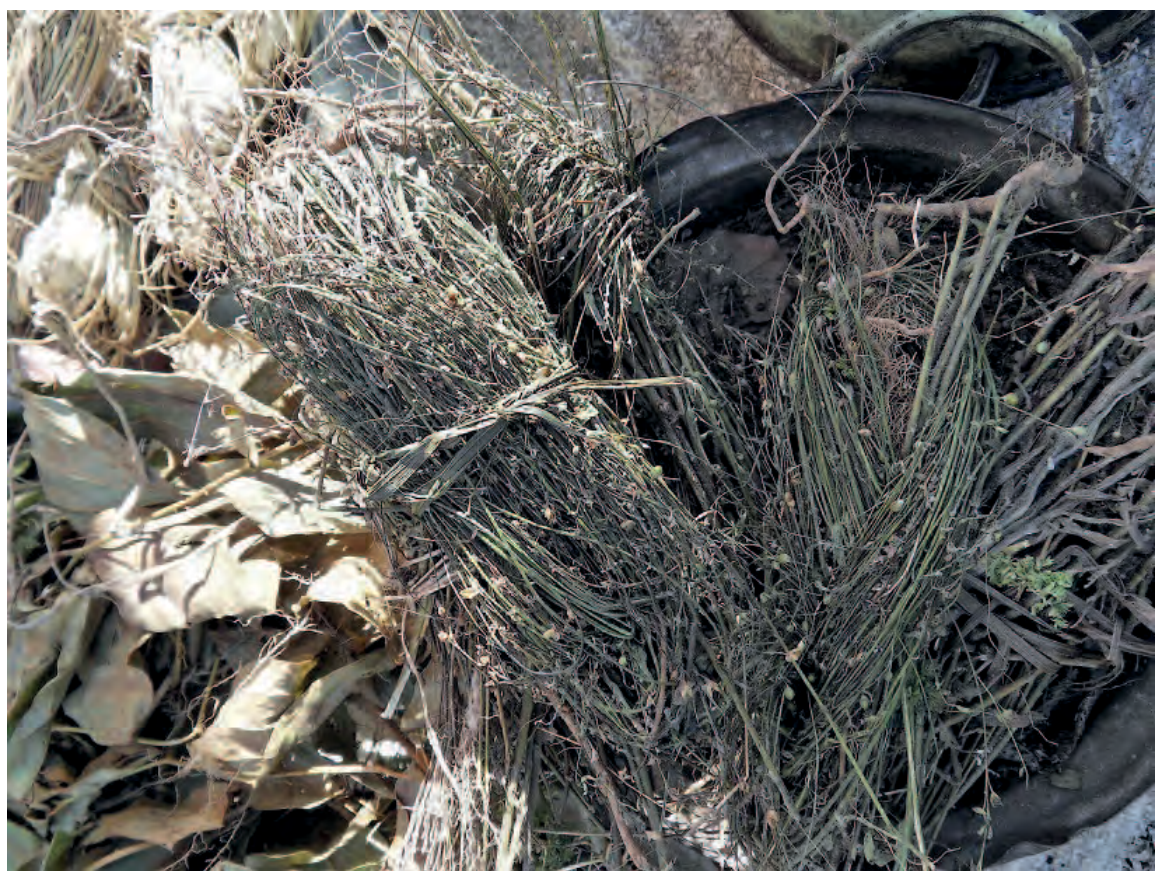




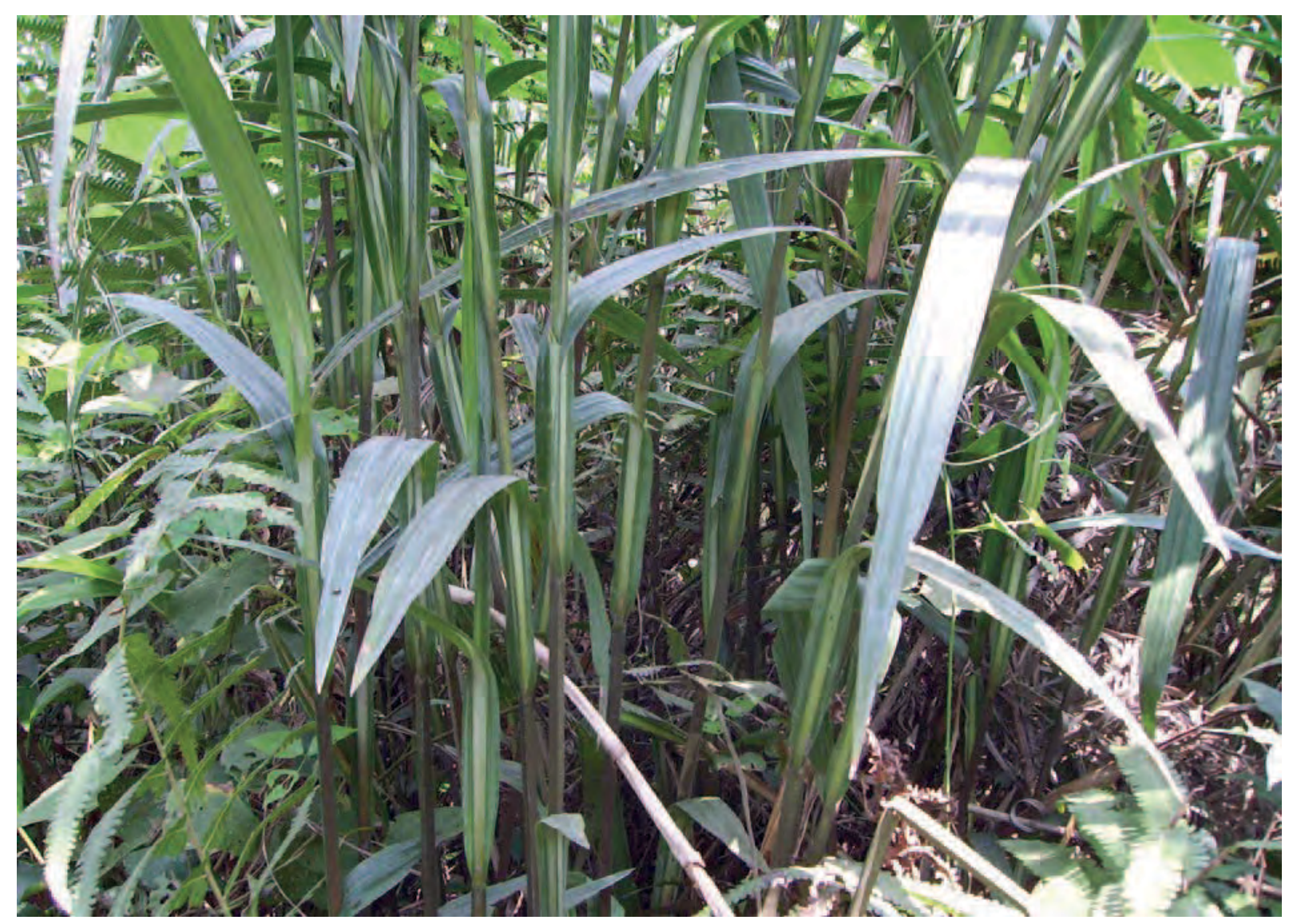

Noms courants : Nkengisi (Kikongo), herbe rasoir, couteau de singe (Fr.)

Description : Herbe rampante vivace avec une tige triangulaire et des feuilles très tranchantes

Ecologie: Herbe des marais ou des forêts, que l'on trouve de l'Afrique de l'Ouest jusqu'en Afrique de l'Est.

Utilisations : La plante est utilisée en médecine pour traiter une grande variété de maladies, y compris la lèpre, et les morsures de serpents, et pour faciliter la transpiration.

Remarque : Les feuilles dures et tranchantes peuvent causer des blessures, parfois mortelles, aux animaux qui en mangent en grandes quantités.

Références : Gillet et Paque 1910, Raponda-Walker et Sillans 1961, Daeleman et Pauwels 1983, Burkill 1985, Neuwinger 2000, Konda Ku Mbuta et al. 2015a 


\section{Synonyme : Sapium cornutum}

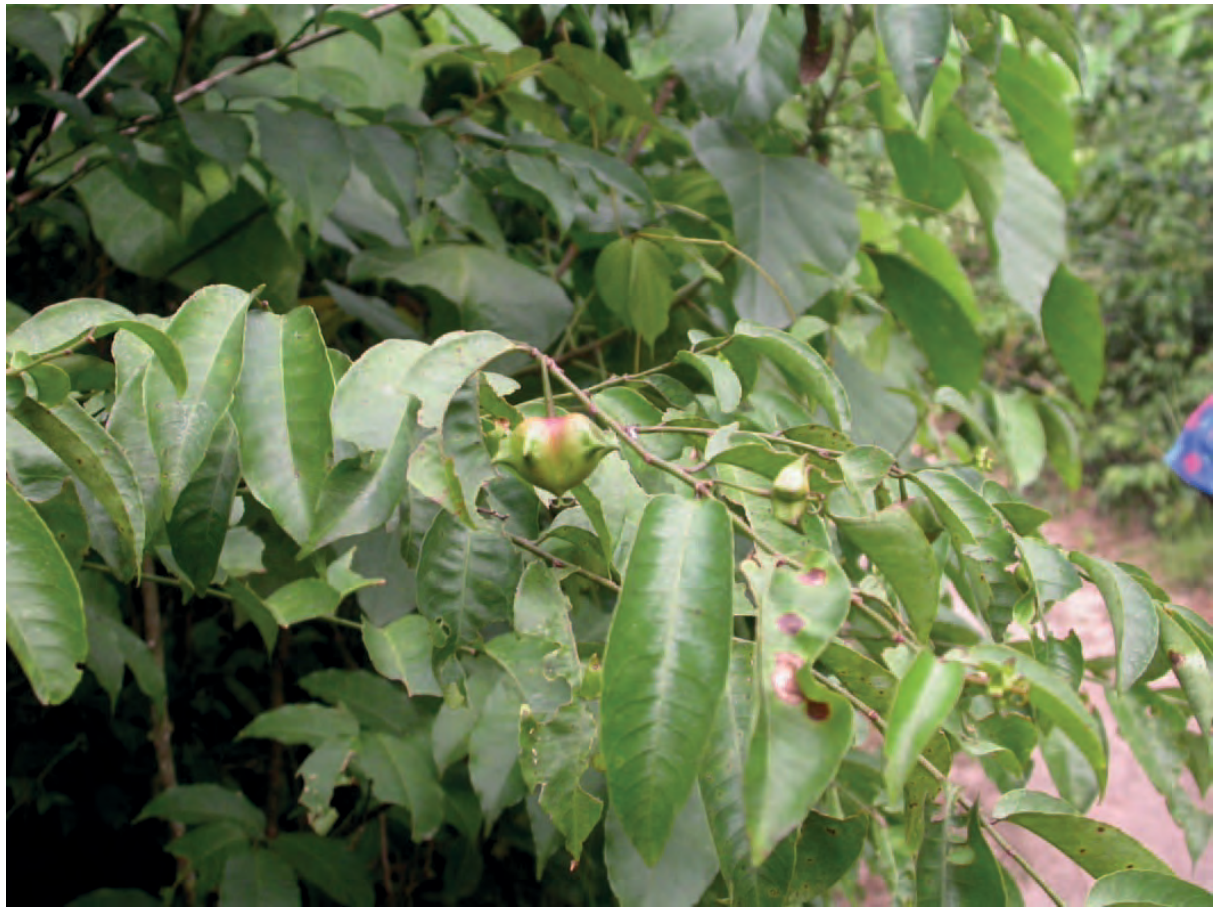

Noms courants : Ntiti, kititi, ntiti mbwela (Kikongo)

Sclerocroton cornutus portant des fruits à Mbanza Nzundu

Description : Arbuste ou petit arbre de 1,5 à $12 \mathrm{~m}$ de haut. Feuilles de 10 à $13 \mathrm{~cm}$ de long et de 4,5 à $6 \mathrm{~cm}$ de large. Les fleurs mâles ont de 3 à $16 \mathrm{~cm}$ de long, disposées à plusieurs dans chaque bractée. Les fleurs femelles sont de $1 \mathrm{~mm}$. Les fruits côtelés et cornés jaunissent puis deviennent rouges en mûrissant.

Ecologie : Cet arbuste se trouve couramment dans les forêts secondaires, les forêts fermées et la savane boisée, en particulier sur les sols sablonneux. Présent de la Sierra Leone au Libéria et du Cameroun à l'Angola. La plante préfère les sols bien drainés. C'est une espèce utile pour la reforestation.

Reproduction : Par graines.

Gestion : L'arbre recèpe bien.

A droite : Fleurs mâles

Usages: Au Kongo Central, on donne une décoction des feuilles pour la toux et la cécité des rivières. On applique les feuilles pilées sur les piqûres d'insectes ou les morsures de serpents. Plante hôte des chenilles comestibles Ntiti, Nsatiti, Nsila et Kaba (Lobobunaea phaedusa). Les abeilles récoltent le nectar des fleurs mâles tout au long de la journée.

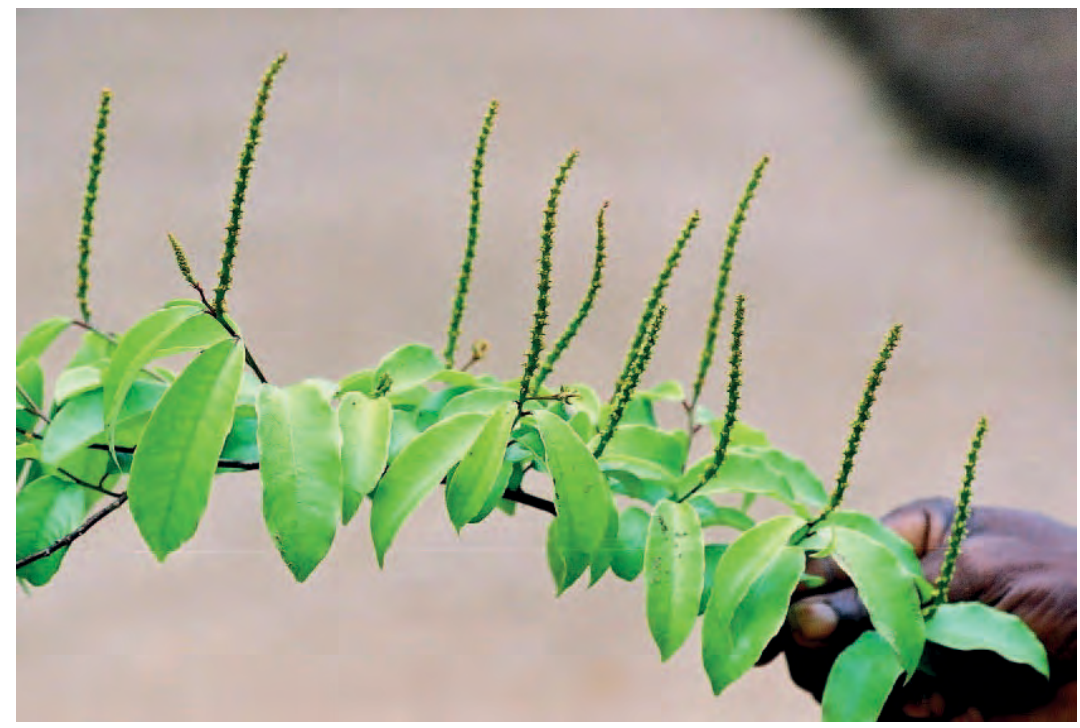

Références : Renier 1948, Léonard 1962, Mukoko Matondo 1991, Pauwels 1993, Latham et Konda Ku Mbuta 2017 
Noms courants: Mabondo (feuilles comme des plumes), ba di mabondo, gangu, ba di magangu, mahangu, mamia, manga (Kikongo), ivoire végétal ( $F r$. )

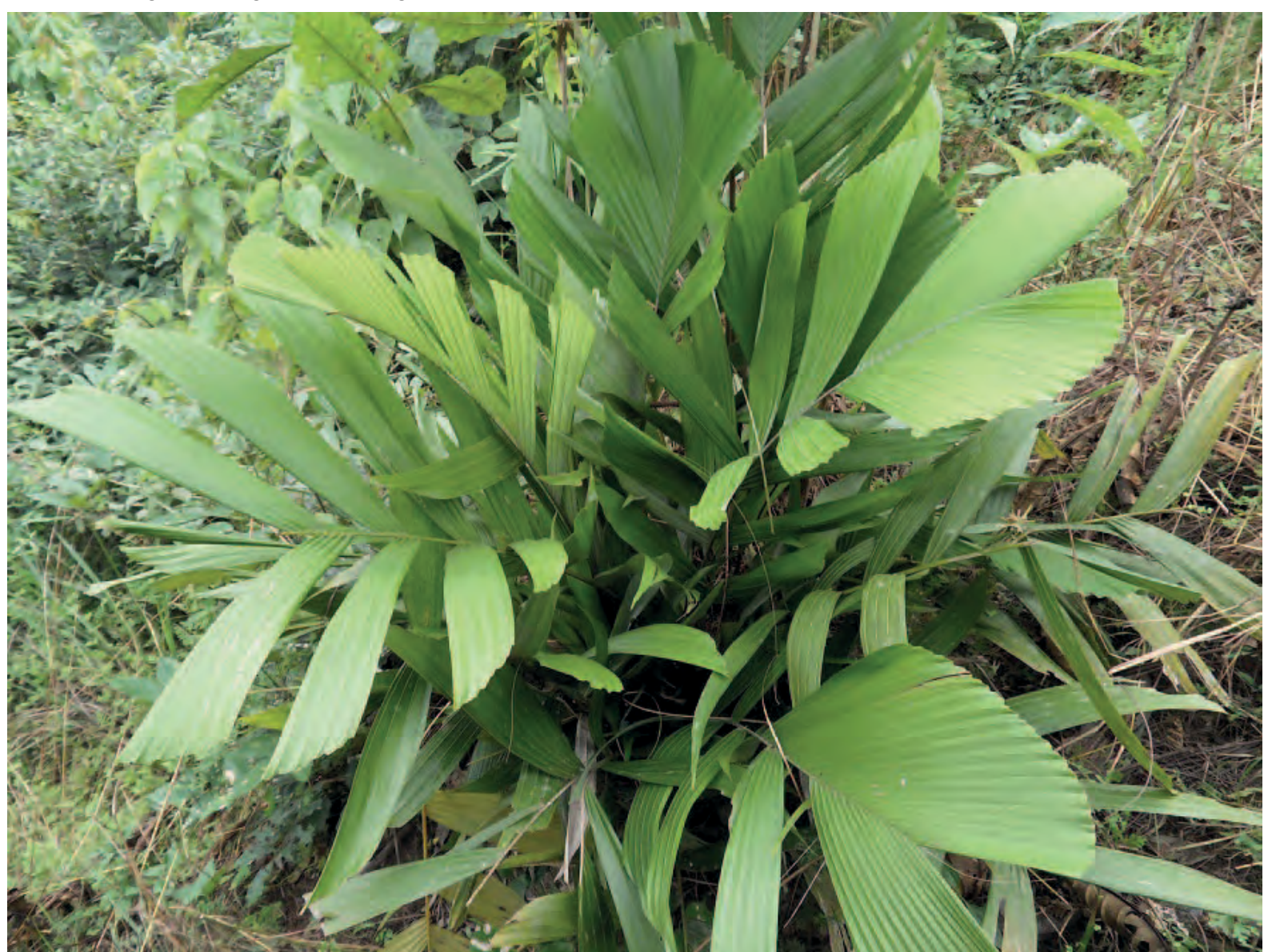

Description : Palmier pratiquement sans tige, donnant des feuilles arquées jusqu'à $4 \mathrm{~m}$ de long, et produisant des rejets.

Ecologie : Pousse près des rivières et dans des lieux humides, du Ghana au Cameroun, au Gabon et à l'Angola.

Reproduction : A partir de rejets séparés de la plante mère.

Usages : On emploie les feuilles soit pour les toitures (voir cidessous), les nattes et les murs des paillotes. Les fruits non mûrs sont doux et gélatineux ; on peut les manger, mais ils deviennent durs en mûrissant. On applique sur la paupière la cendre de feuilles pour traiter la filariose oculaire à loa loa.

Références Gillet et Pâque 1910, Renier 1948, Daeleman et Pauwels 1983, Tereshima et al. 1991, Pauwels 1993, Burkill 1997, Nsimundele 2004, Brink 2011, Mbandu Luzolawo et al. 2020

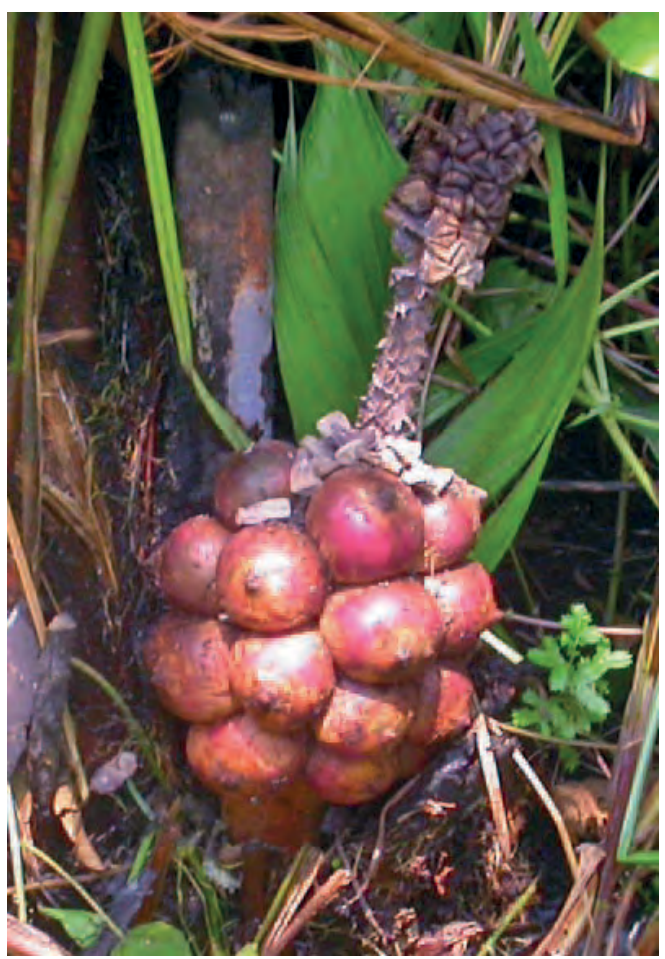




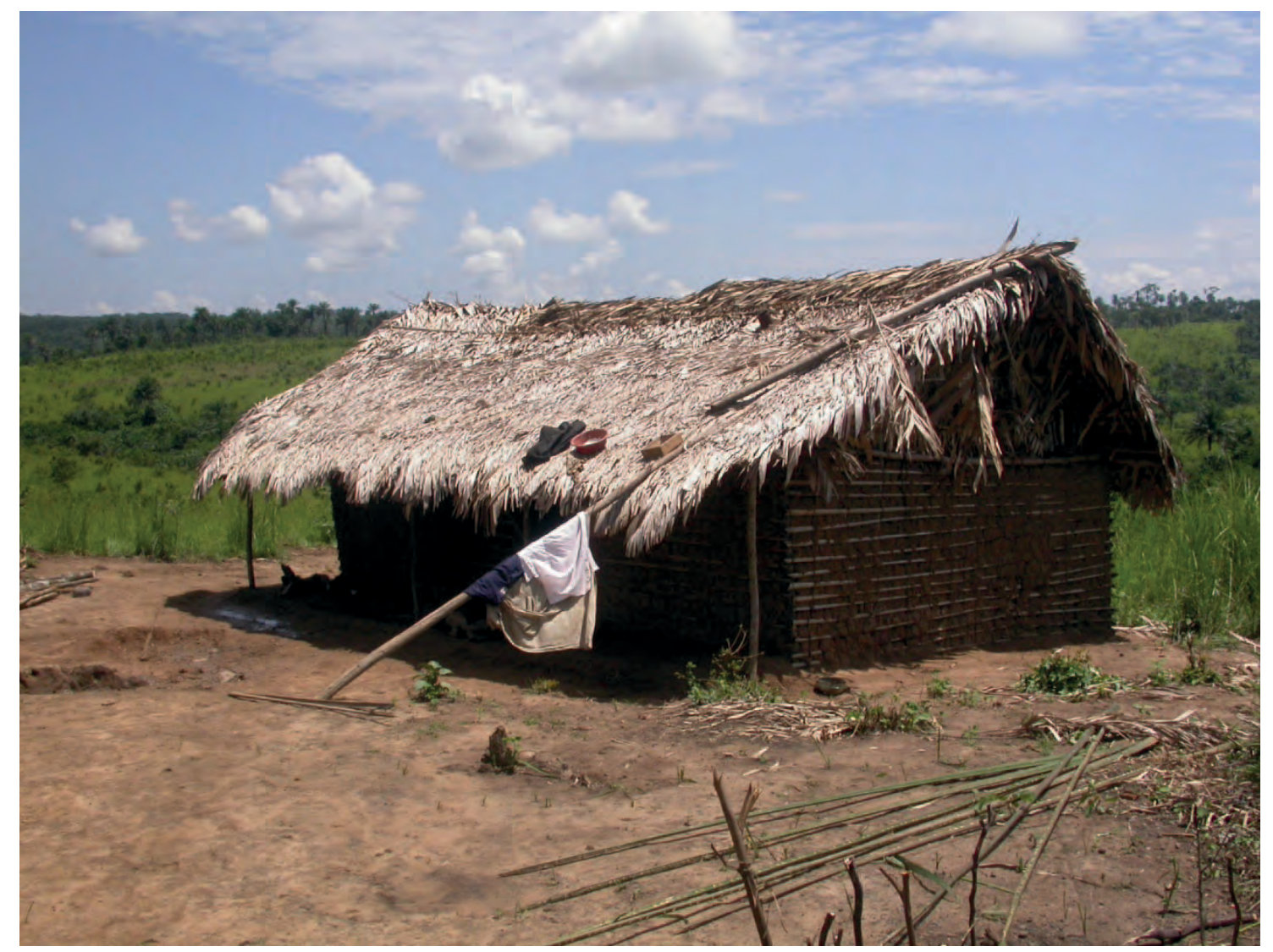

Maison près de Madimba couverte de feuilles de Sclerosperma mannii

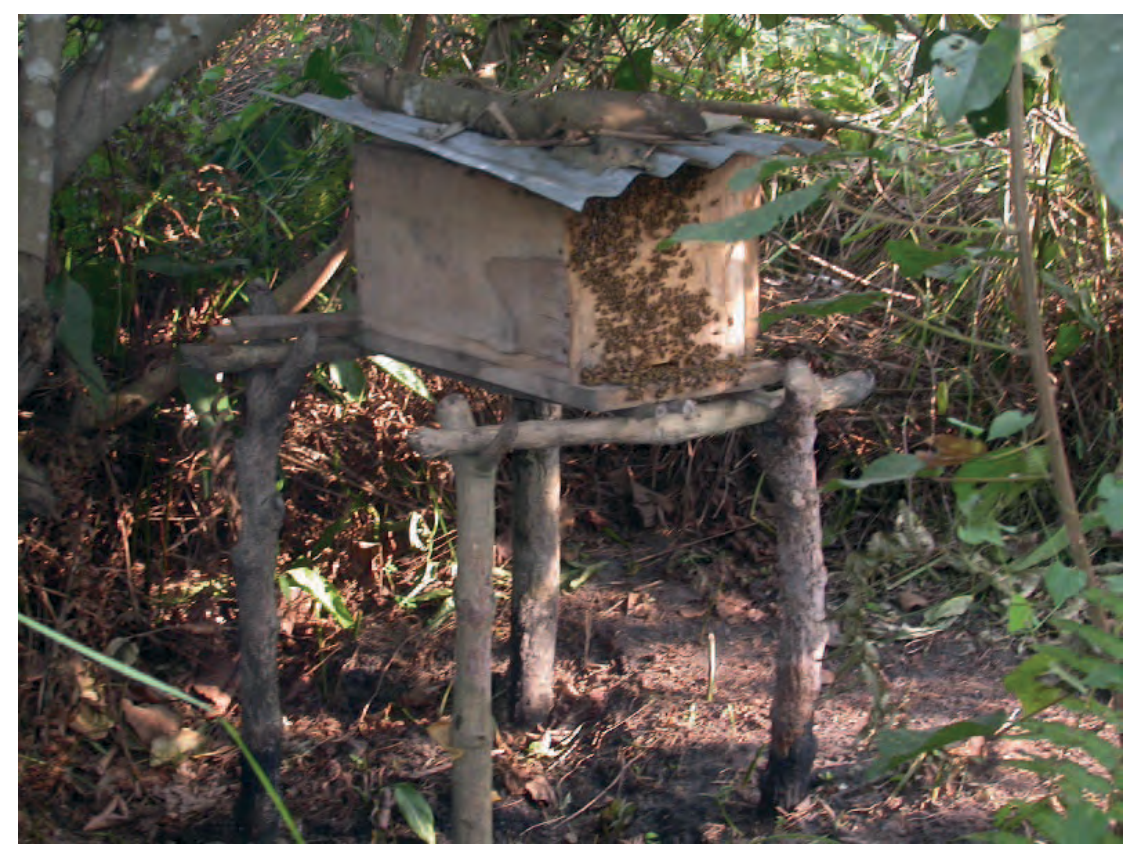

Boite de capture avec un nouvel colonie d'abeilles. Un bon site est près de l'eau dans un endroit calme et ombragé. 


\section{Scoparia dulcis}

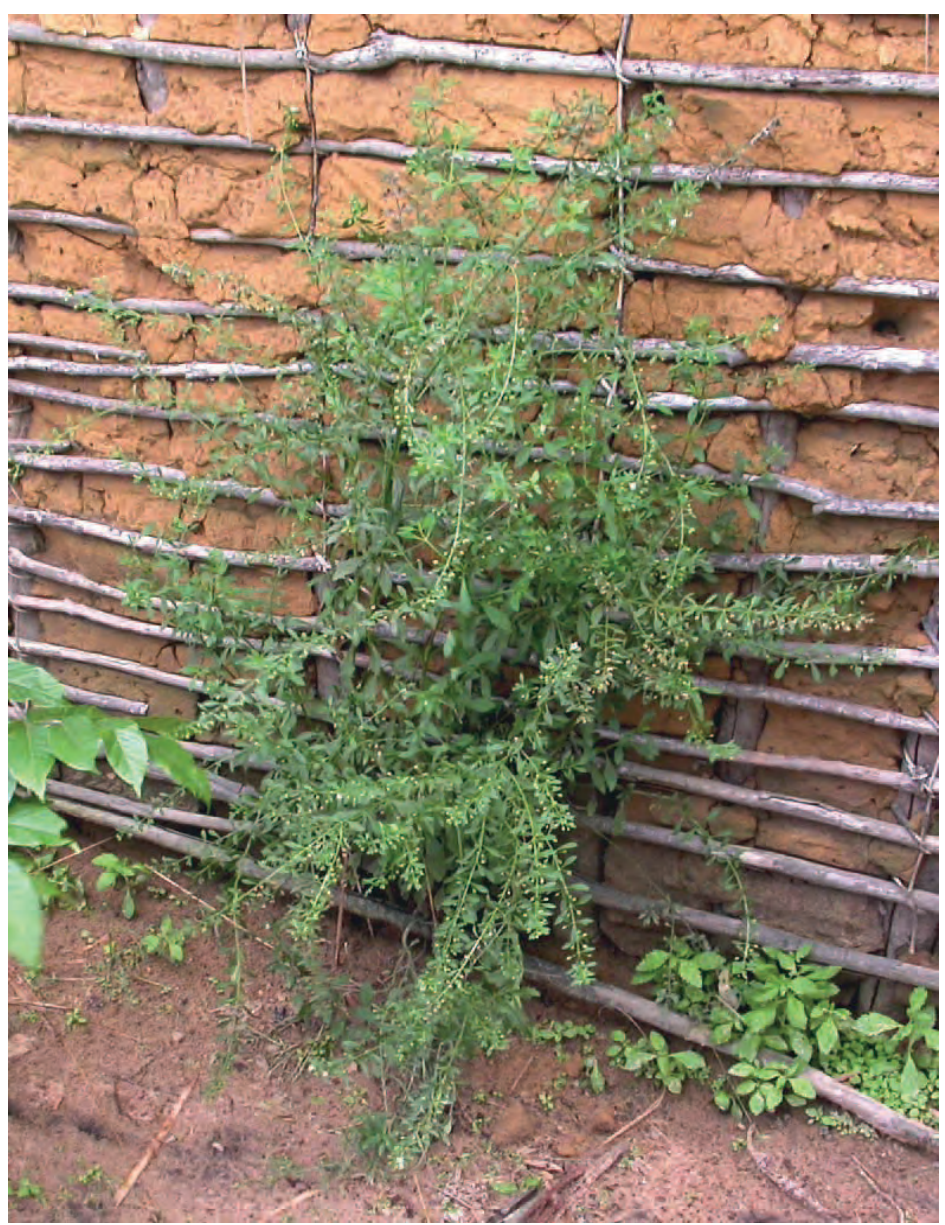

(Plantaginaceae)

Noms courants : Kiese kiese (kiese $=$ joie, bonheur) (Kikongo), balai doux (Fr.), sweet broom weed (Angl.)

Description : Herbe dure, dressée, feuillue, très ramifiée et buissonnante, jusqu'à $60 \mathrm{~cm}$ de haut. La tige est plus ou moins ligneuse, côtelée et glabre. Les feuilles sont opposées, ou à trois par nœud, ovales ou lancéolées, de 1,2 à $4,5 \mathrm{~cm}$ de long et 0,2 à $0,9 \mathrm{~cm}$ de large, la moitié supérieure largement dentée, avec un coin à la base. Le limbe de la feuille a une surface lisse; la surface inférieure a quelques points glandulaires. Les fleurs sont blanches ou teintées de bleu, disposées isolément ou par deux à l'aisselle des feuilles supérieures. Le fruit est une capsule ronde.

\section{A gauche: Scoparia dulcis à côté d'une} maison dans le village de Nsumba

Ecologie: Plante originaire d'Amérique centrale, maintenant fréquente dans les friches et les lieux humides partout sous les tropiques.

\section{Reproduction : A partir de graines.}

Usages : Plante médicinale employée pour traiter les maux de dents. On administre le jus en lavement contre les vers intestinaux. Quand on mâche les feuilles, elles sont d'abord amères puis deviennent douces. On les emploie comme adoucissant pour prendre les médicaments ayant un gout désagréable. Cette plante a de nombreux autres usages médicinaux en Afrique, ainsi par exemple on donne une décoction des feuilles pour traiter les ulcères d'estomac, ou on la met en gouttes dans les oreilles pour traiter leur inflammation. On l'emploie aussi pour traiter la diarrhée et la colique chez les enfants. La plante sert parfois de balai. Les abeilles visitant les fleurs pour leur nectar.

Remarque : Kiesekiese signifie joie en Kikongo probablement en référence au goût agréable des feuilles.

Références: Renier 1948, Akobundu et Agyakwa 1987, Fischer 1999, Burkill 2000, Neuwinger 2000, Pousset 2004

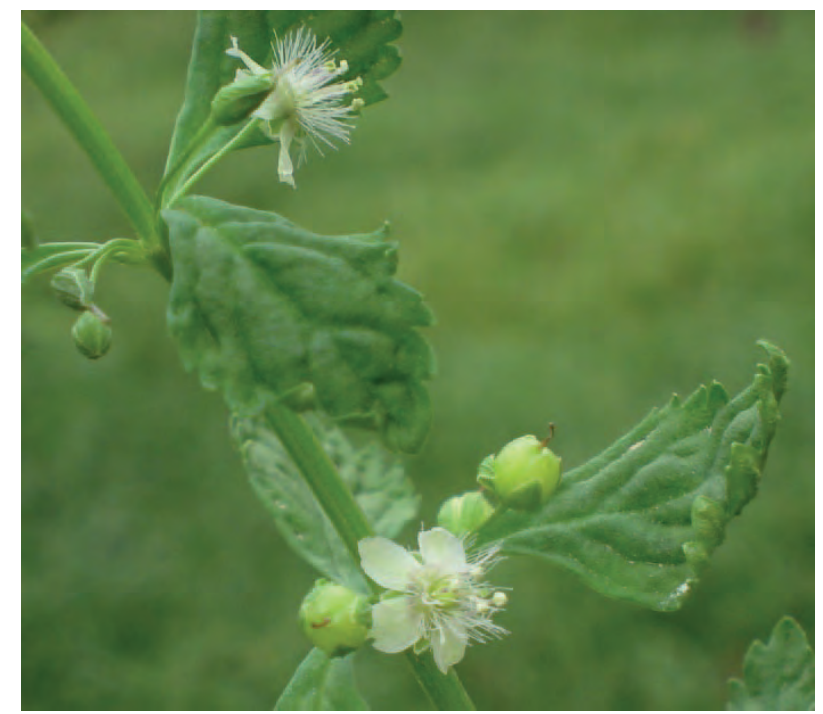

Photo : Phuong Tran 


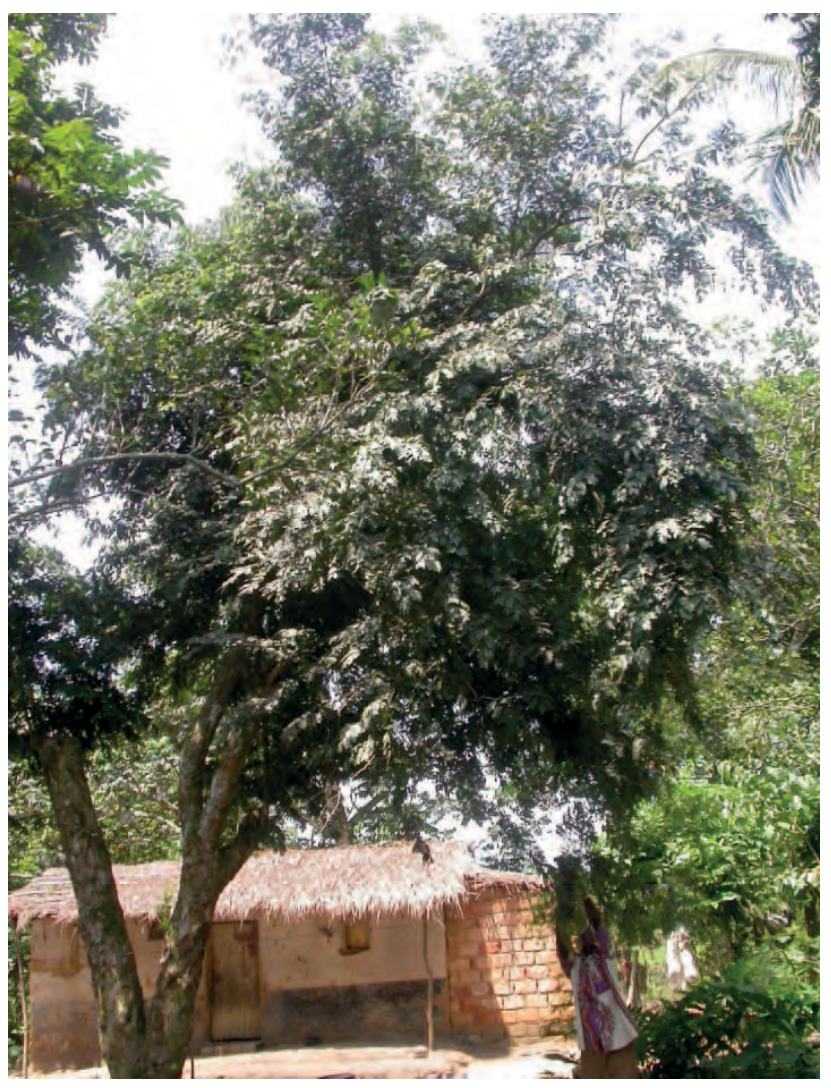

Noms courants : Kiwaya, ngakala (Kikongo), edembe (Lingala), arbre à ail (Fr.). Kiwaya désigne aussi Olax gambecola et Hua gabonii.

Description : Arbre de 25 à $40 \mathrm{~m}$ de haut avec un diamètre allant jusqu'à $80 \mathrm{~cm}$. L'arbre entier, mais surtout l'écorce, a l'odeur d'ail, en particulier après la pluie. L'écorce des jeunes arbres est lisse, jaune pâle à gris, et devient écaillée plus tard. Les arbres peuvent avoir une base légèrement cannelée. Les feuilles sont composées de 5 à 10 paires de folioles alternes. Les folioles individuelles, de 3,5 à 4,5 de long et de 1,3 à $2 \mathrm{~cm}$ de large, sont sessiles et arrondies en haut, inégales à la base. Les fleurs sont disposées en grappes serrées de 5 à $8 \mathrm{~cm}$ de long. Les fruits sont de petites gousses vert pâle de 7,5 à 13,5 sur 3 à $5 \mathrm{~cm}$.

Ecologie: L'arbre est présent au Cameroun, au Gabon et en R.D. Congo au Kongo Central, au Kasaï et dans la cuvette centrale. Les arbres se trouvent en forêts sur des sols fermes et sont souvent grégaires.

Usages: L'écorce (voir ci-dessous) a une saveur d'ail et s'emploie largement comme condiment. Les feuilles sont également comestibles ; on les découpe sommairement, puis on les cuit comme légume. Au Kongo Central, on emploie l'écorce, avec Aframomum

melegueta, dans le traitement des hémorroïdes. L'écorce sert également à traiter la perte de poids et le diabète en combinaison avec d'autres plantes. Les graines sont utilisées pour traiter l'infection par les ankylostomes, ainsi que les règles douloureuses et prolongées. Le peuple Mongo utilise également l'écorce, les tiges, les brindilles et le tronc à des fins médicinales. Au Gabon, on donne une infusion de l'écorce pour traiter la constipation; et on traite les maux de
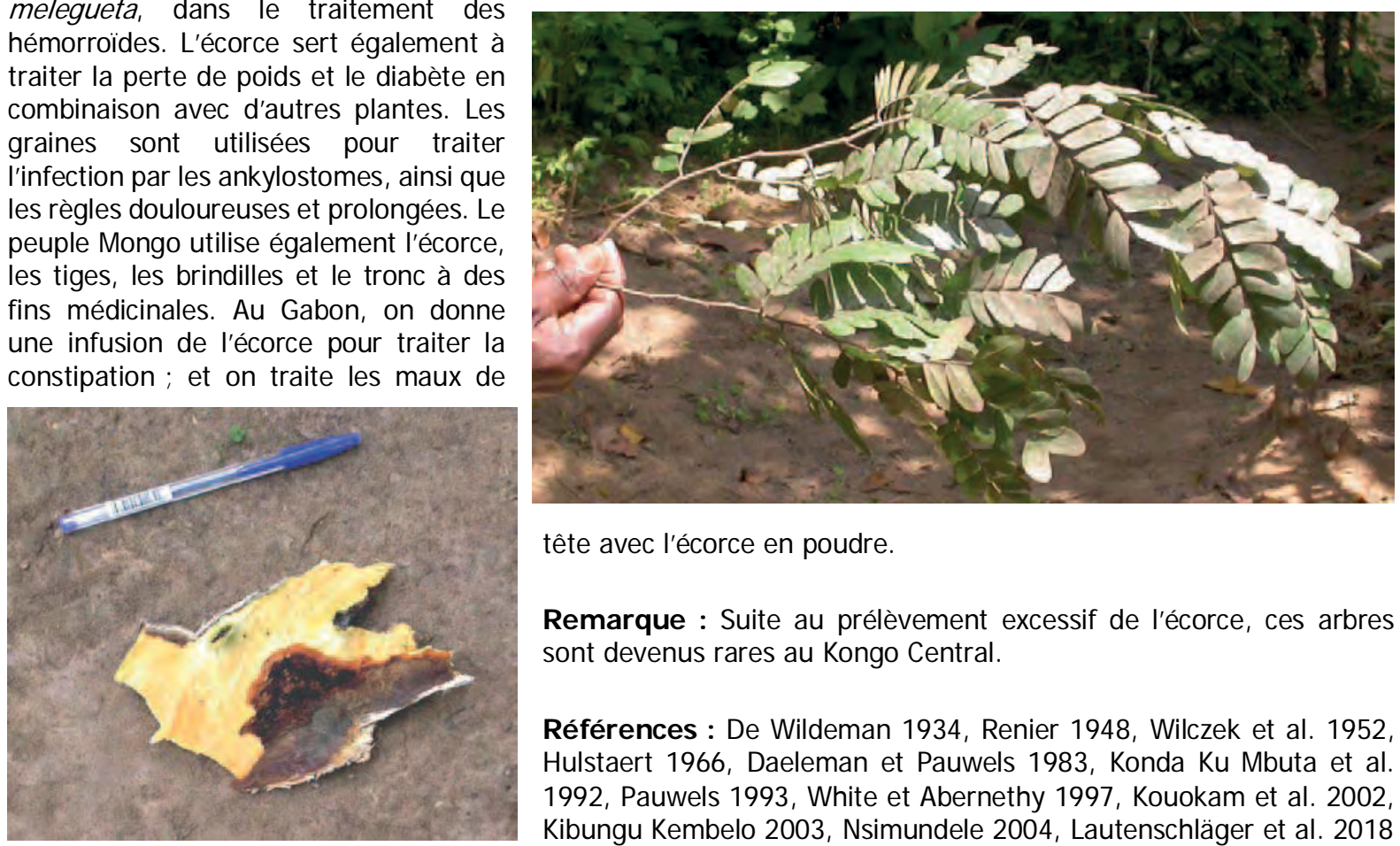

tête avec l'écorce en poudre.

Remarque : Suite au prélèvement excessif de l'écorce, ces arbres sont devenus rares au Kongo Central.

Références : De Wildeman 1934, Renier 1948, Wilczek et al. 1952, Hulstaert 1966, Daeleman et Pauwels 1983, Konda Ku Mbuta et al. 1992, Pauwels 1993, White et Abernethy 1997, Kouokam et al. 2002, Kibungu Kembelo 2003, Nsimundele 2004, Lautenschläger et al. 2018 
Noms courants : Mfuki (Kikongo)

Description : Buisson grimpant. Les branches sont couvertes de poils roux. Les limbes de feuilles mesurent de 7 à $9 \mathrm{~cm}$ de long de 2 à $2,7 \mathrm{~cm}$ de large sur un pétiole court. Les fleurs délicates, agréablement parfumées, blanches à jaunâtres ou verdâtres sont disposées en cymes lâches.

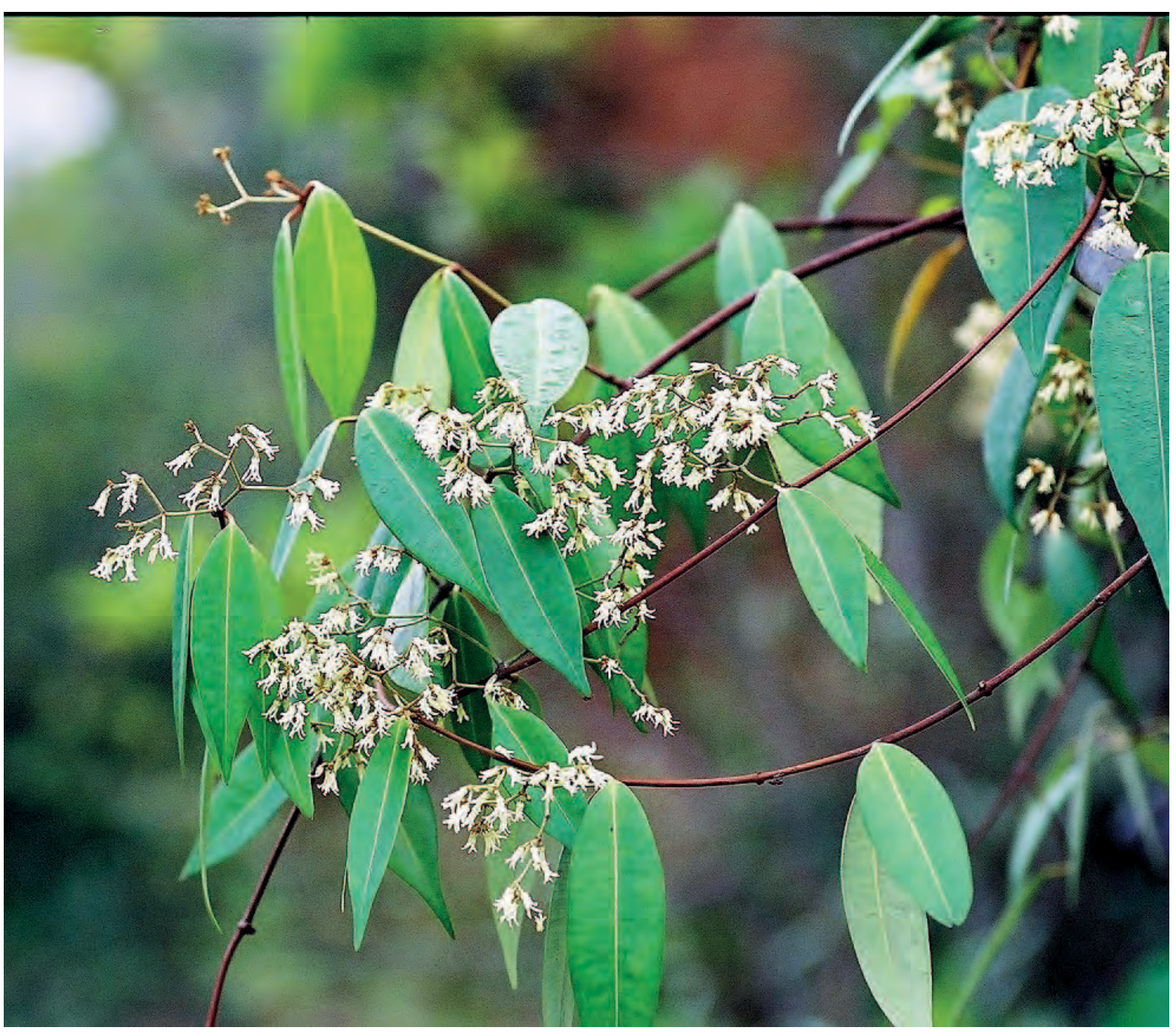

Secamone letouzeyana en fleur près du village de Kubana, Kongo Central

Écologie : Plante de la savane, du Cameroun à l'ouest de la R.D. Congo.

Usages : Une espèce non identifiée de Secamone sert à faire des cordes dans le sud de la Tanzanie. S. afzelii est consommé comme légume au Bénin.

Références : Klackenberg 2001, Achigan-Dako et al. 2009 


\section{Sechium edule}

Noms courants : Christophine, chouchoute (Fr.), chayote, vegetable pear (Angl.)

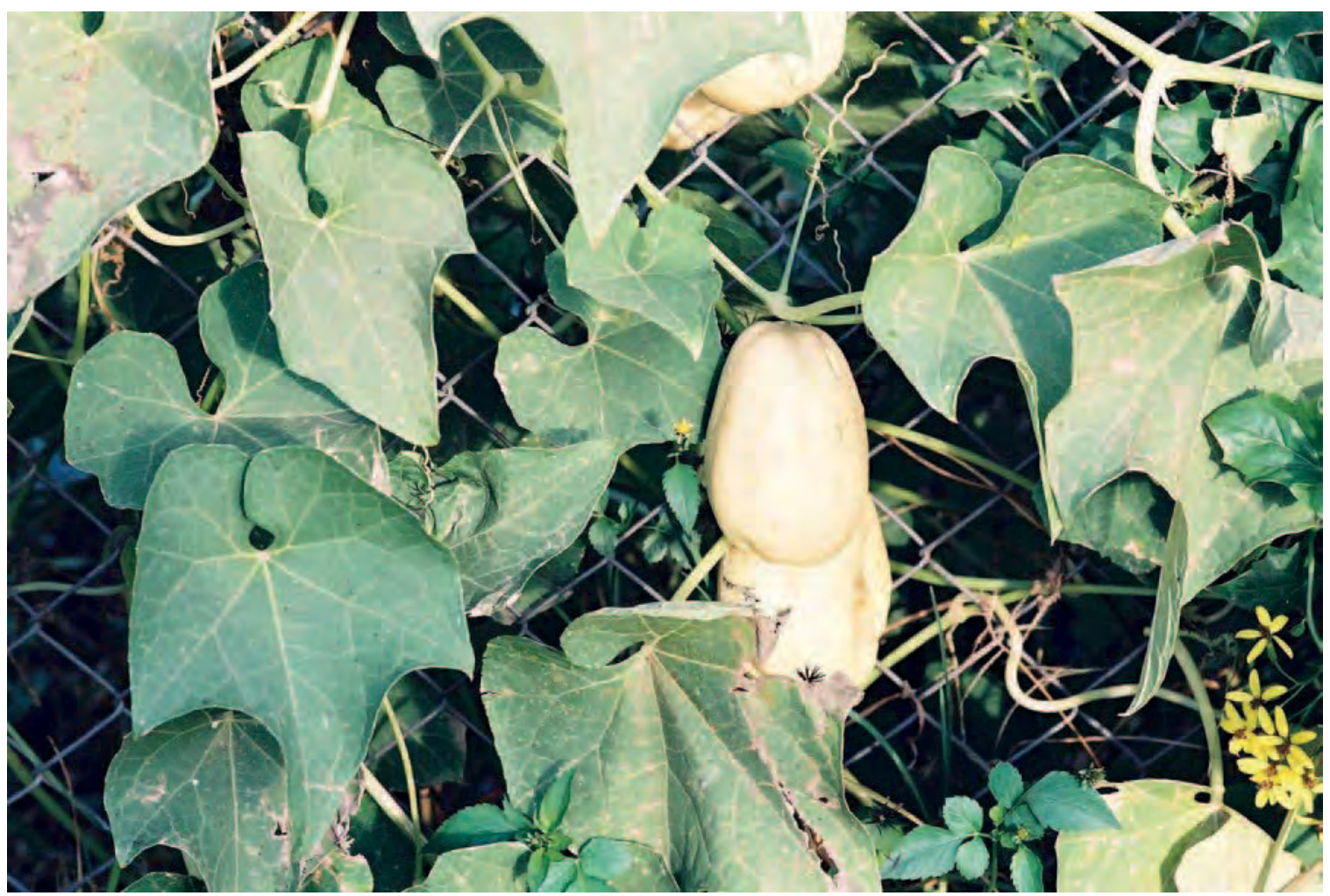

Description : Plante herbacée vivace vigoureuse, grimpante, sur une grande racine tubéreuse. La plante peut pousser de 10 à $15 \mathrm{~m}$ en une saison. Le fruit est une baie charnue à une seule graine, généralement en forme de poire, plissée, jaune-vert, de 7 à $20 \mathrm{~cm}$ de long. Les fleurs mâles et femelles sont séparées mais sur la même plante. Les fruits exposés au soleil sont jaune clair, ceux qui sont à l'ombre deviennent vert foncé.

Ecologie : Plante originaire du sud du Mexique et d'Amérique centrale, cultivée maintenant partout sous les tropiques, bien que pas très répandue en Afrique. Elle prospère dans des sols riches et bien drainés, sous ombre légère, et ne tolère pas les inondations. Elle est sensible à la sécheresse et aux vents violents. Elle tolère les hautes températures, mais il semble que des nuits fraîches favorisent le développement des fruits.

Reproduction : Planter un fruit mûr dans un trou préparé à l'avance, à une profondeur égale aux deux tiers de sa longueur, avec la partie la plus large en bas ou sur le côté. Planter en lignes espacées de 100 à $120 \mathrm{~cm}$, les plantes étant espacées de 60 à $75 \mathrm{~cm}$ le long des lignes. On peut aussi faire des boutures de tiges de 15 à $20 \mathrm{~cm}$, qu'il faut ombrager et maintenir humides. Les plantes requièrent des tuteurs ou une treille. Les tubercules ne se développent pas avant la deuxième année.

Gestion : Les fruits sont prêts pour la récolte 100 à 120 jours après la plantation, et la période de récolte dure longtemps. Remplacer les plantes après trois ans pour prévenir les risques de maladie. Si on déterre un tubercule, la plante continue à pousser et produit de nouveaux tubercules.

Usages: Les jeunes feuilles se mangent comme légumes. Elles sont riches en vitamines $A$ et $C$, vitamines $B$, calcium et fer. Ailleurs, on mange aussi les fruits immatures, les pousses, et les racines tubéreuses. Les fruits varient en saveur de fade à sucré ou farineux. On peut faire cuire les racines tubéreuses comme aliment de base : elles sont une bonne source d'amidon facilement digestible. Les fleurs sont très attrayantes pour les abeilles; on en trouve toute l'année.

Références : Gillet 1927, Renier 1948, Portugal-Arajo 1974, Tindall 1983, Crane et al. 1984, Dupriez et De Leener 1989, Siemonsma et Kasem Piluek 1993, Robinson et Decker-Walters 1997 


\section{Securidaca longipedunculata}

Noms courants : Nsunda, nkama nsunda (Kikongo), violet tree (Angl.)

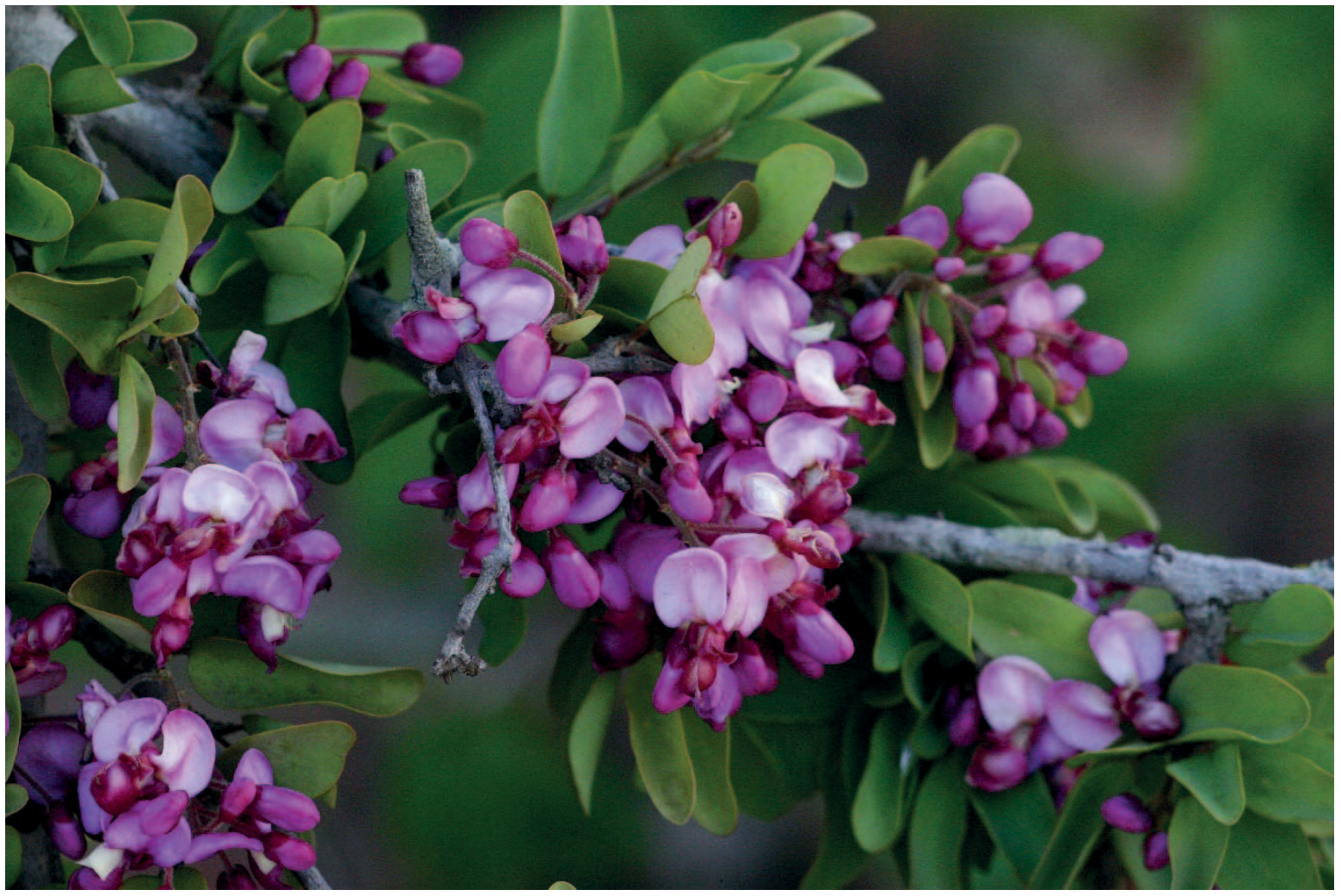

Photo: Bart Wursten www.zimbabweflora.co.zw

Description : Bel arbre de 4 à $5 \mathrm{~m}$ de haut. L'écorce de la racine est fortement parfumée. Les fruits sont des noix plus ou moins arrondies, généralement veinées, parfois lisses, portant une aile oblongue, plutôt courbée, jusqu'à $4 \mathrm{~cm}$ de long. L'aile est vert violacé quand elle est jeune, puis pâlit et prend une couleur paille à maturité.

Ecologie : Habituellement un arbuste de savane sur les sols sablonneux ou pierreux, mais parfois trouvé en forêt. Présent du Sénégal au Soudan et à l'Afrique du Sud.

Reproduction : Tremper les graines dans l'eau froide pendant 24 heures. Semez directement sur le site final de plantation. Les graines peuvent être stockées pendant de longues périodes à température ambiante si elles sont maintenues au sec. Les semis spontanés ne se transplantent pas facilement. L'arbre peut se reproduire à partir de rejets poussant sur les racines.

Gestion : Cet arbre pousse lentement.

Usages: Le nom Kikongo signifie que cette plante a cent usages. On fait bouillir les racines et on inhale la vapeur pour traiter la fièvre. On frictionne la racine sur la peau pour traiter les rhumatismes. On indique également que les racines dans l'eau chaude en cataplasme soulagent les symptômes des rhumatismes. On fait une boisson ou une décoction avec les racines pour traiter les douleurs de poitrine. On mâche les racines pour soulager les maux de dents. L'huile des racines, volatile, contient de grandes quantités de méthyl salicylate, connu sous le nom d'« essence de gaulthérie couchée » ou «wintergreen». Les graines contiennent une huile employée pour repousser les serpents, que l'on applique sur les bracelets aux bras et aux chevilles. Les branches donnent une fibre d'excellente qualité, que l'on emploie pour faire des cordages. Les troncs résistent à la pourriture et aux termites. Le bois sert de bois de feu et pour le charbon de bois. En Ethiopie, on connait les fleurs comme source importante de pollen et nectar pour les abeilles. Au Malawi, on mange les jeunes feuilles. 
Remarque : Il y a deux variétés dans la Province, var. longepedunculata and et var. parvifolia.

Avertissement : on doit prendre les plus grandes précautions avec les usages médicinaux de cette plante, car elle peut être hautement toxique.

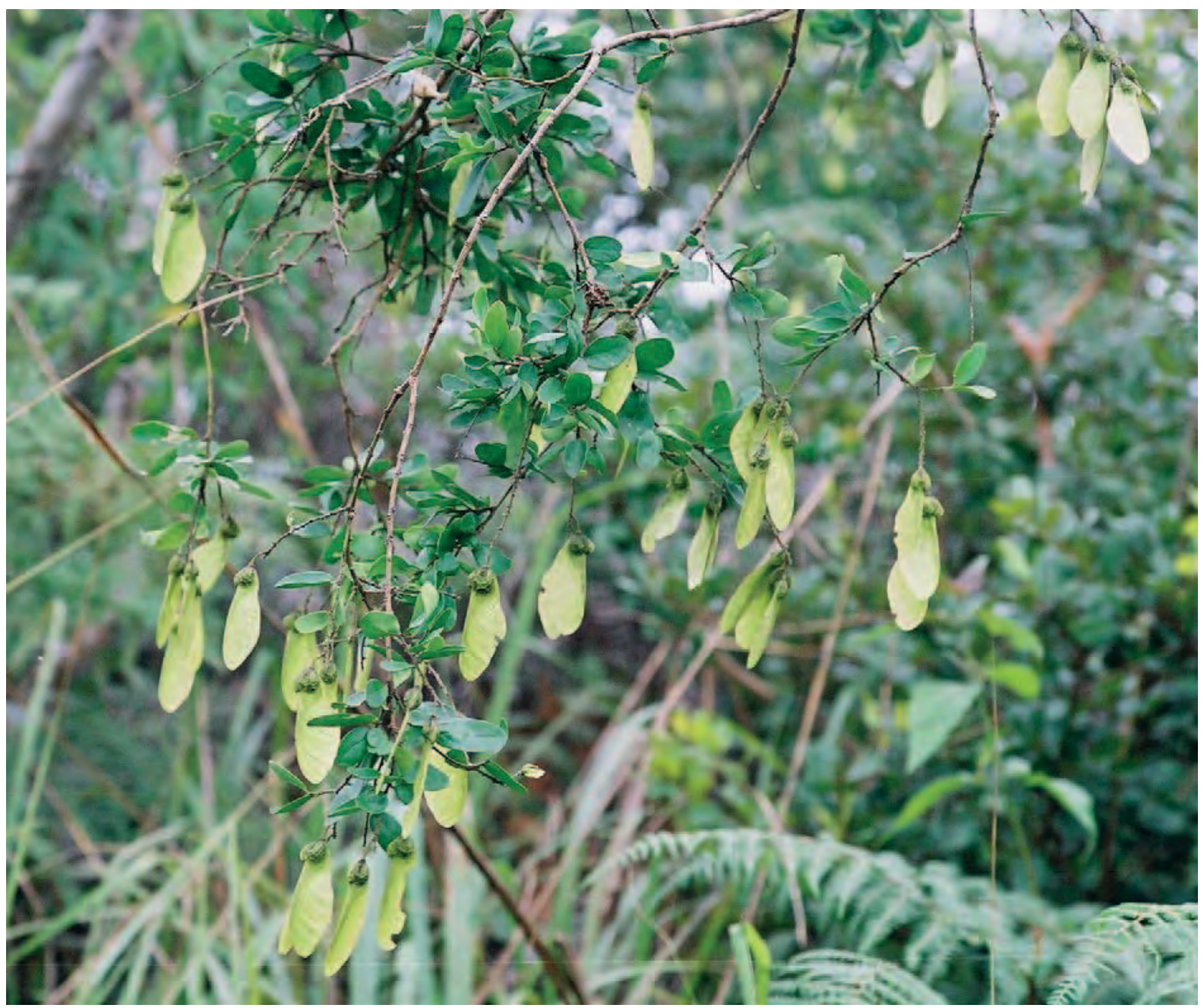

Arbre portant des fruits en mars

A gauche : Racine et branche de Securidaca longipedunculata

Références : Renier 1948, Petit 1958, Watt et Breyer-Branwijk 1962, Nsimundele 1966 - 68, Delaude et Breyne 1971, Williamson 1975, Coates Palgrave 1983, Daeleman et Pauwels 1983, Pauwels 1993, Fichtl et Adi 1994, Mbuya et al. 1994, Malaisse 1997, van Wyk et al. 1997, Dery et Otsyina 2001, Kibungu Kembelo 2003, van Wyk et Wink 2004, Pousset 2004, Fichtl 2013

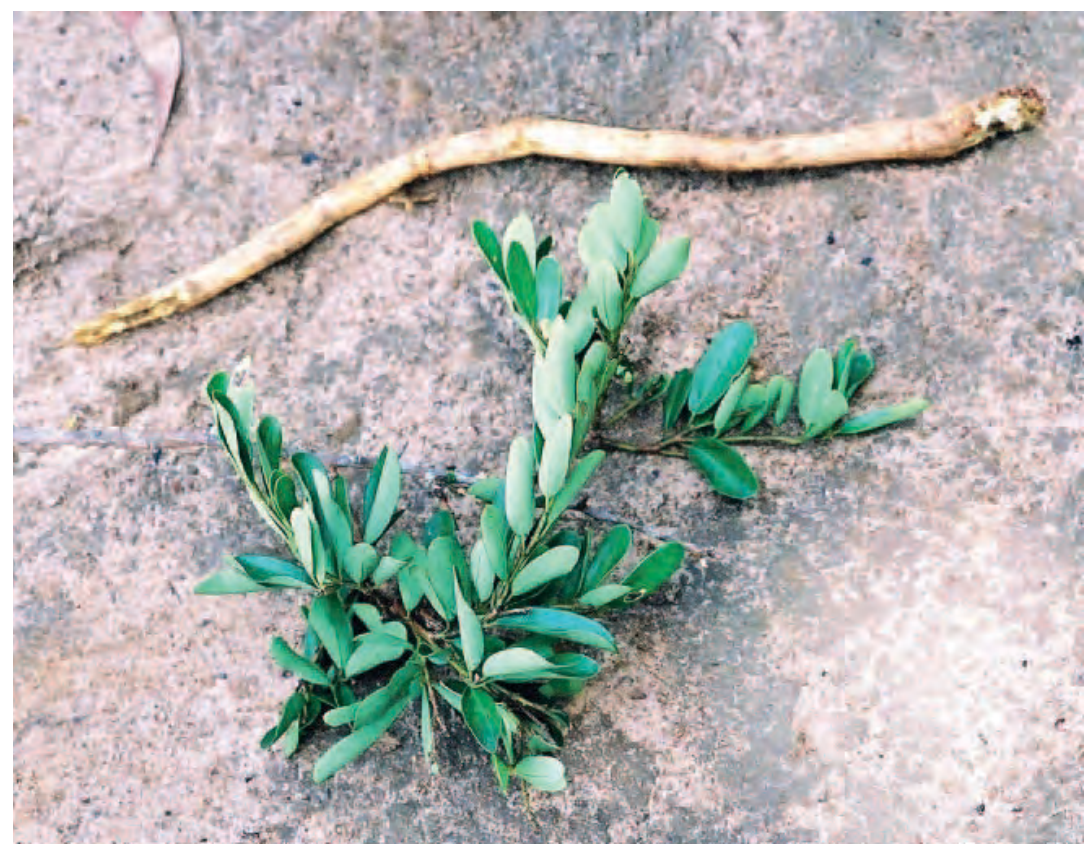


Synonyme : Cassia alata

Noms courants : Bwalu, bawu bawu (Kikongo), dartrier (Fr.), ring-worm bush (Angl.)

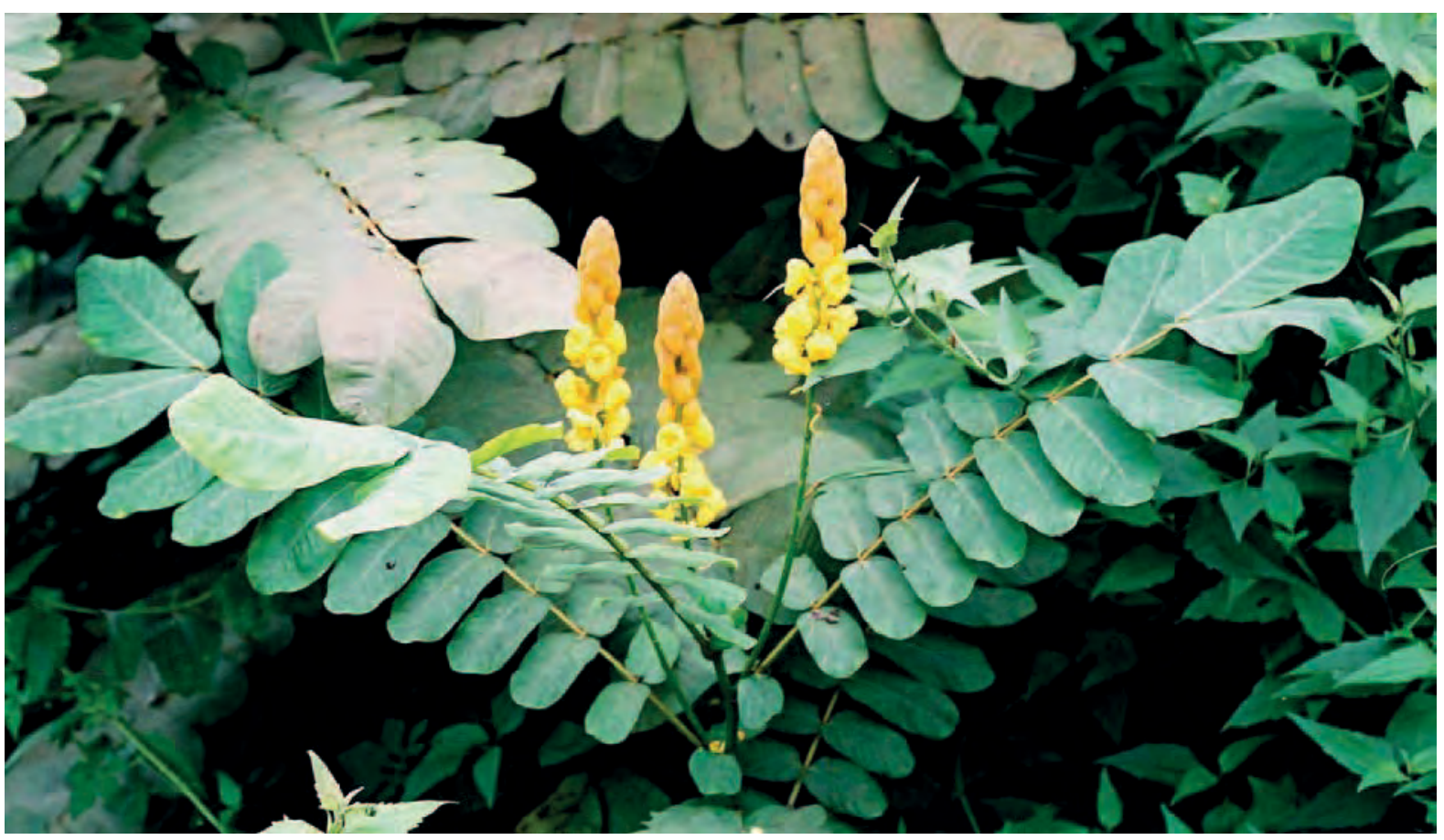

Senna alata au village de Mbanza Ntadi au Manianga

Description : Arbuste de 1,2 à $2 \mathrm{~m}$ de haut, avec de grandes feuilles composées de 8 à 14 paires de folioles chacune de 10 à $15 \mathrm{~cm}$ de long et de 4 à $6 \mathrm{~cm}$ de large. Les fleurs jaune doré sont disposées en nombreux épis verticaux denses jusqu'à $20 \mathrm{~cm}$ de long. Les fruits sont des gousses droites portant quatre ailes, de couleur brun foncé, contenant de nombreuses graines noires plates et triangulaires.

Ecologie : Arbuste originaire de l'Amérique tropicale où il pousse sur les flancs de colline rocheux. On le trouve dans toute l'Afrique tropicale et l'Asie du Sud-Est. Présent dans les villages et les clairières dans la zone forestière, presque toujours échappé des cultures.

Reproduction : Semer les graines directement sur le site de plantation final.

Usages: Le jus des feuilles, qui contient de l'acide chrysophanique, est traditionnellement utilisé pour traiter les inflammations des ganglions lymphatiques de l'aisselle ou de l'aine, les plaies pustuleuses, les pellicules et d'autres maladies de la peau. On applique les feuilles pilées sur les infections fongiques de la peau, pour soulager la constipation et comme désinfectant des blessures. On applique une compresse de feuilles sur le front pour soulager les maux de tête. On emploie la racine bouillie avec du jus de canne à sucre pour traiter les maux d'estomac. La plante est également utilisée pour traiter la fièvre. En Angola, la plante est utilisée pour traiter les vers intestinaux. En Tanzanie, on cultive la plante autour des habitations pour repousser les fourmis. On la cultive parfois comme plante ornementale.

Références : Gillet 1927, Staner et Boutique 1937, Renier 1948, Wilczek et al. 1952, Daeleman et Pauwels 1983, Burkill 1995, Phillips et Rix 1997, Hirt et M'Pia 2001, Pousset 2004, Leyens et Lobin 2009, Göhre et al. 2016 


\section{Senna didymobotrya}

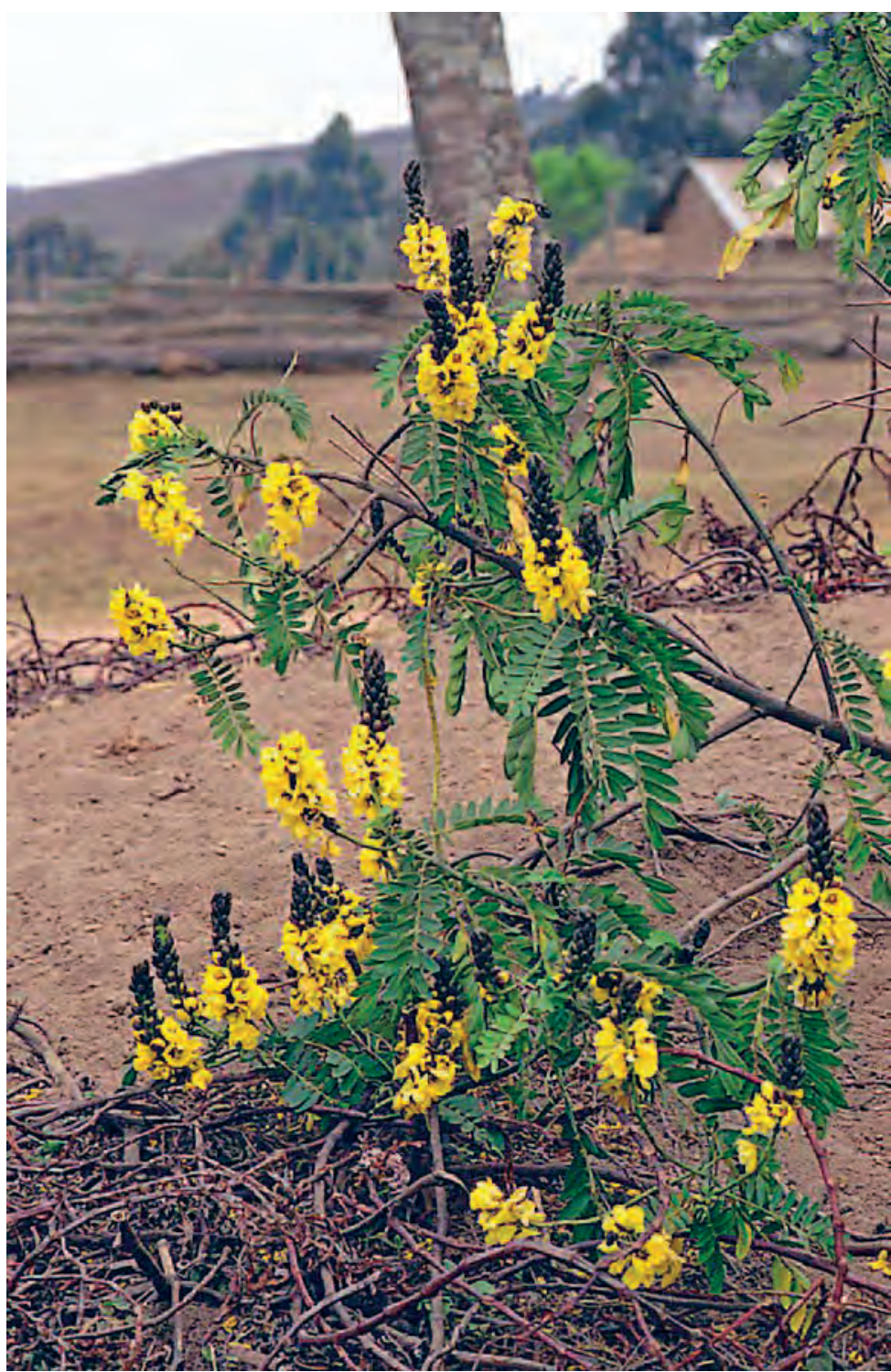

repousse les abeilles. On les emploie en Tanzanie pour enfumer des abeilles lors de la récolte du miel. Les espèces de Cassia et de Senna fixent l'azote et peuvent également être utilisées comme engrais vert. Espèce parfois cultivée comme plante ornementale.

Remarque: Toutes les parties de la plante sont connues pour être très toxiques.

Références : Wilczek et al. 1952, Watt et Breyer-Brandwijk 1962, Kokwaro 1976, Pauwels 1993, Coates Palgrave 1996, Neuwinger 2000, Llamas 2003
(Fabaceae)

\section{Synonyme : Cassia didymobotrya}

Noms courants: Séné africain, arbre candélabre (Fr.) popcorn senna (Angl.)

Description: Arbuste à croissance rapide de 2 à $5 \mathrm{~m}$ de haut, se ramifiant de la base. Feuilles alternes, de 15 à $30 \mathrm{~cm}$ de long avec 8 à 15 paires de folioles chacune de 3 à 5 sur 1,1 à $1,5 \mathrm{~cm}$. Des groupes compacts de fleurs apparaissent à l'aisselle des feuilles supérieures. Les fleurs en forme de coupe sont jaune doré. Les fleurs non ouvertes sont recouvertes de bractées brun foncé à bronze. Gousses de fruits plates, 9 à 12 sur 1,5 à $2,3 \mathrm{~cm}$.

Ecologie: Plante originaire d'Afrique tropicale. Elle est commune dans toute l'Afrique de l'Est jusqu'à 2100 m, en particulier le long des fossés et des bords de routes. On la trouve également en Éthiopie, au Soudan, en Zambie, au Zimbabwe, au Malawi, en Afrique du Sud et au Mozambique.

Reproduction : A partir de graines.

Usages : Une décoction des feuilles, des tiges et des racines est largement utilisée en Afrique de l'Est comme purgatif. En Tanzanie, on emploie une décoction des racines pour traiter les maladies mentales. Les racines fournissent un antidote à l'empoisonnement causé par la tige et les feuilles. Les feuilles ont une forte odeur, comme celle du beurre d'arachide, qui

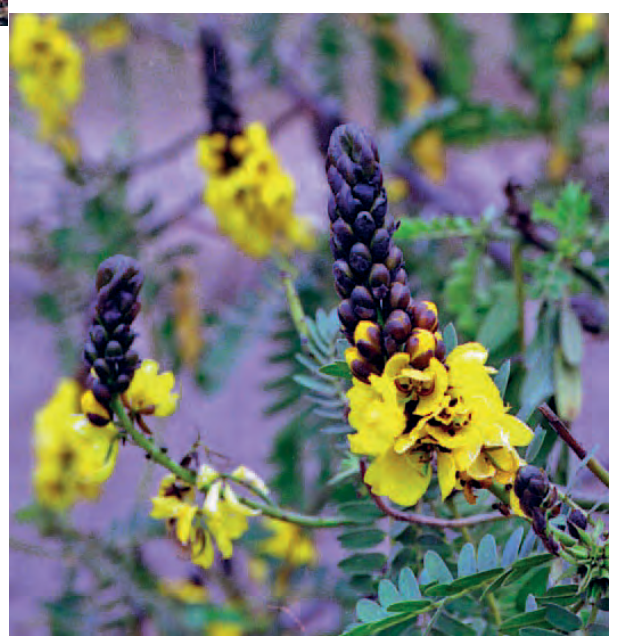




\section{Synonyme : Cassia occidentalis}

Noms communs Mansambi nsambi, linuaka nuaka, n'zungu n'tu, tete bwangila, zekeke (Kikongo), fula (à Manianga), lembe, okasa (Lingala), café puant (Fr.), coffee senna (Angl.)

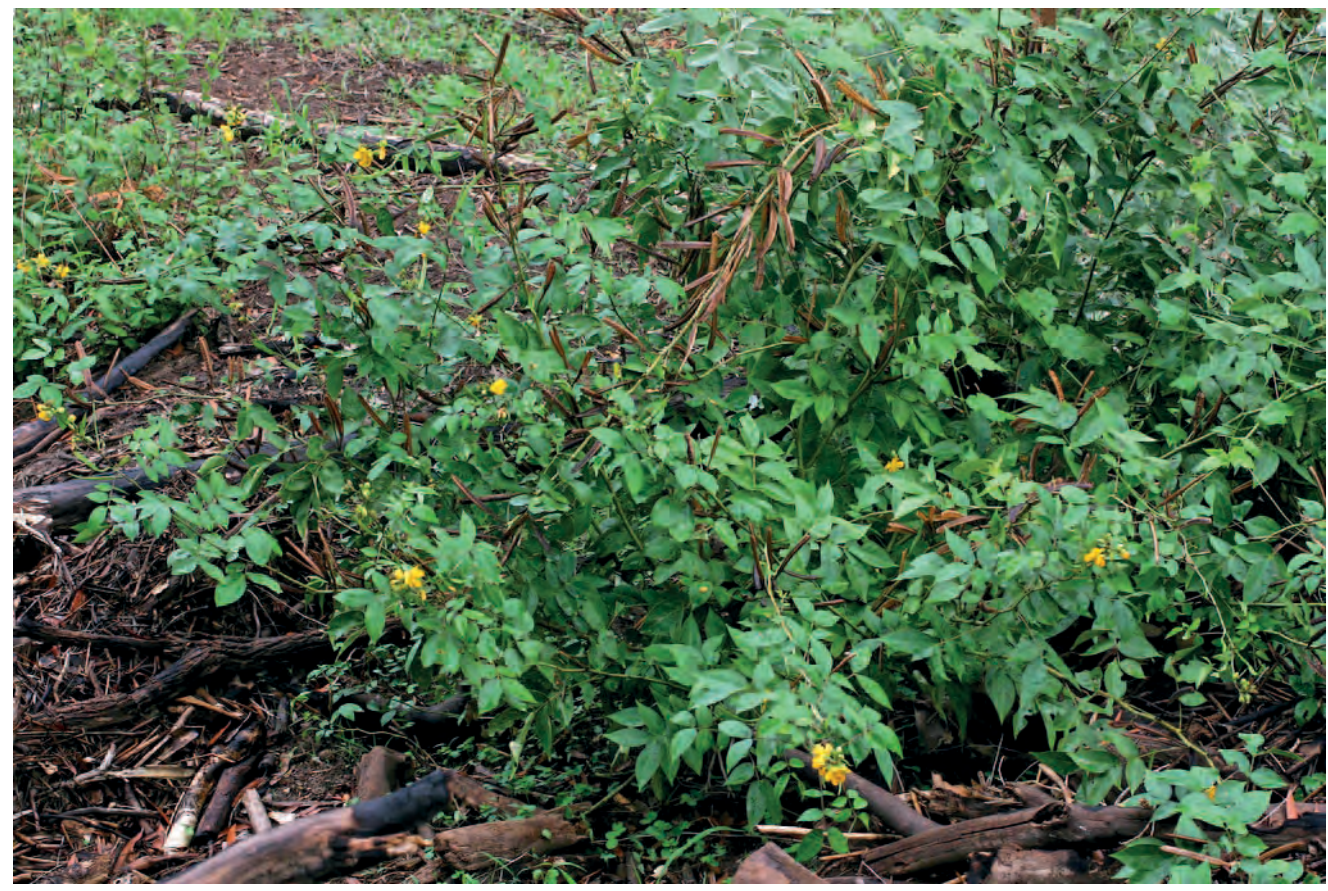

Description : arbrisseau glabre, annuel ou vivace quelques années, pouvant atteindre $1 \mathrm{~m}$ de haut. Toutes les parties de la plante, et surtout les feuilles écrasées, émettent une odeur forte. Les feuilles ont de 12 à $20 \mathrm{~cm}$ de long avec 3 à 5 folioles opposées. On trouve une glande isolée près de la base du pétiole.

Ecologie: Plante commune autour des villages, adventice des friches et des savanes pauvres dans toute l'Afrique tropicale.

Reproduction : par graines.

Usages: Au Kongo Central, on fait chauffer la plante pour l'appliquer sur la zone affectée par les rhumatismes ou sur le front pour les maux de tête. On emploie les racines, trempées dans l'eau, comme purgatif pour les enfants et pour traiter la gonorrhée et ses complications. Au Manianga, la plante sert à traiter les douleurs abdominales et les vers intestinaux. Dans le nord de l'Angola, on traite les douleurs abdominales avec la racine et les feuilles; on applique le liquide des feuilles écrasées pour traiter les infections oculaires. Au Kongo Central, on mange les feuilles comme légumes. On les coupe sommairement pour les cuire dans l'eau ou dans l'huile. Ailleurs, la plante est largement utilisée pour traiter les hématuries (sang dans l'urine). Elle permettrait de contrôler l'envahissement par les herbes parasites Striga, et d'améliorer la fertilité des sols épuisés par la culture des arachides. La graine torréfiée est parfois utilisée comme substitut de café.

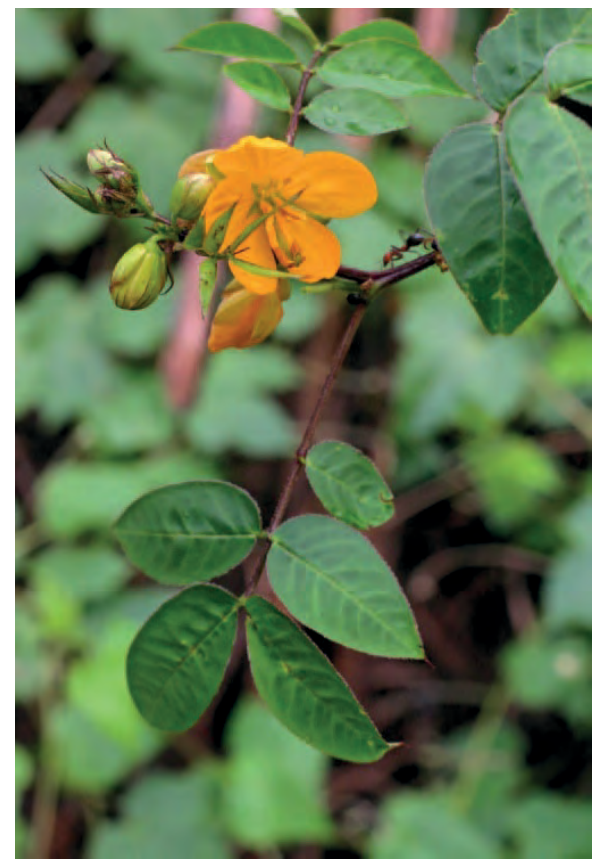

Les deux photos : Tony Rodd

Références : Gillet et Pâque 1910, Gillet 1927, Staner et Boutique 1937, Wilczek et al. 1952, Arkinstall 1979, Konda Ku Mbuta et al. 1992, Burkill 1995, Neuwinger 2000, Tolu Odugbemi 2006, Konda Ku Mbuta et al 2015a, Göhre et al. 2016, Lautenschläger et al. 2018 


\section{Senna siamea}

Synonyme : Cassia siamea

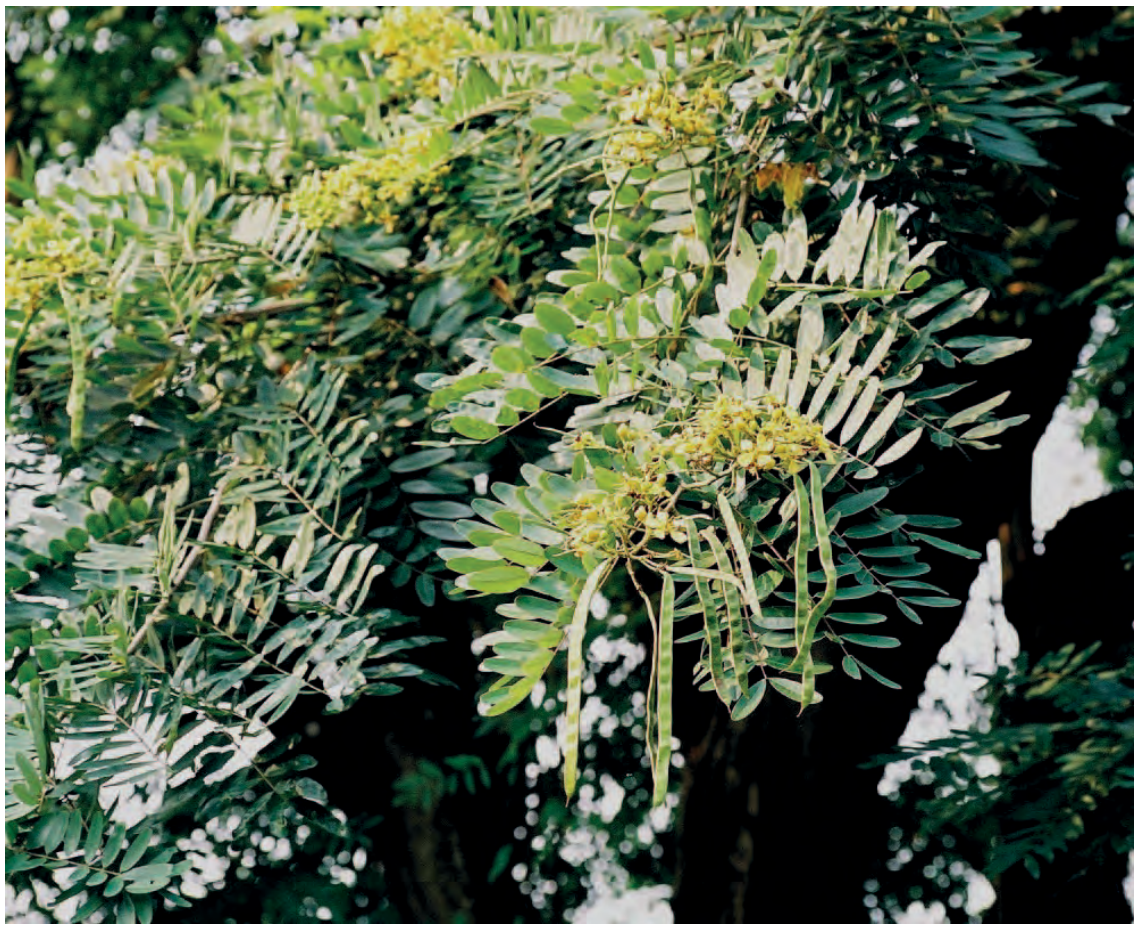

Noms courants : Casse du Siam (Fr.), Siamese cassia (Angl.)

Description : Arbre jusqu'à $10 \mathrm{~m}$ de haut. Feuilles alternes composées de 23 à $33 \mathrm{~cm}$ de long, avec 6 à 12 paires de folioles sur de courts pétioles. Fleurs en bouquets dressés au bout des rameaux, très ramifiés, avec beaucoup de fleurs jaune vif de $3 \mathrm{~cm}$ de diamètre. L'arbre commence à fleurir après 2 à 3 ans et porte des fleurs toute de l'année. Le fruit est une gousse allongée de 5 à $25 \mathrm{~cm}$ de long sur 12 à $20 \mathrm{~mm}$ de large.

Ecologie: Arbre originaire de I'Asie du Sud-Est, mais maintenant largement cultivé sous les tropiques. II préfère un sol profond bien drainé,

mais se développera sur des sols de latérite dégradés tant que le drainage est bon.

Reproduction: Normalement par graines qui restent viable pendant 2 à 3 ans. Retirer les graines des gousses mûres pendant qu'elles sont encore sur l'arbre. On peut semer les graines fraichement récoltées sans prétraitement. II faut les semer dans un site au plein soleil, car l'ombre le plus léger réduit beaucoup la germination. La germination peut atteindre 75\% après 4 à 29 jours. On doit tremper les graines plus anciennes dans l'eau bouillante et laisser refroidir. Les semis se développent lentement, mais sont prêts à être plantés après 5 mois. Souvent, les semis sont cultivés jusqu'à ce qu'ils soient bien établis, puis réduits à des souches avant la plantation. Les jeunes plantes sont sensibles au feu.

Gestion : Planter à 1 - 3 m d'espacement pour la production de bois de feu et à $25-50 \mathrm{~cm}$ d'espacement pour les brise-vent. Une fois établis, les arbres poussent rapidement, même sur des sols infertiles. L'arbre recèpe facilement et dans de bonnes conditions peut donner du bois dans des rotations de 4 à 7 ans.

Usages : On plante parfois cet arbre autour des pâturages comme coupe-feu ; et comme arbre de sous-bois dans les projets de reforestation pour encourager les arbres à bois à développer des troncs droits. II produit un bon charbon de bois, mais donne trop de fumée comme bois de feu. Cultivé comme arbre d'ombrage le long des routes, et dans les plantations de café et de cacao. II est cultivé comme brise-vent. L'arbre est intéressant pour le reboisement des sols érodés et infertiles ; il fixerait l'azote. Le bois est dur, résistant aux termites, durable et prend un bon poli, mais il est difficile à travailler. Le bois de cœur est attrayant et sert en menuiserie. Les jeunes troncs servent de poteaux de construction, etc. Les fleurs sont une source importante de nectar pour les abeilles au Venezuela ; on les connait également au Gabon pour être visitées par les abeilles.

Remarques: Eviter d'associer cet arbre avec d'autres cultures, en raison de la concurrence des racines. Les graines, les gousses et les feuilles sont très toxiques pour les porcs.

Références: Gillet 1927, Renier 1948, NAS 1980, Little 1983, Crane et al. 1984, Lobreau-Callen et al. 1989, Pauwels 1993, Mbuya et al 1994, Vande weghe 2004, Orwa et al. 2009 
Synonyme : Cassia spectabilis

Noms courants : Mbwenge mputu (Kikongo), yellow cassia (Angl.)

Description : Arbre à feuilles caduques de 3 à $9 \mathrm{~m}$ de haut. Feuilles paripennées de 20 à $30 \mathrm{~cm}$ de long, avec 9 à 13 paires de folioles aigües au sommet de 4 à 8 sur 1,5 à $2 \mathrm{~cm}$. Inflorescence en panicules ; fleurs jaunes; les fruits sont des gousses à section rectangulaire, de 20 à $30 \mathrm{~cm}$ de long, à cloisons transversales avec deux séries de graines disposés transversalement. Cet arbre serait plus facile à cultiver, moins sensible aux ravageurs et aux maladies et plus résistant à la sécheresse que $S$. siamea.

Ecologie: Arbre originaire de l'Amérique tropicale. Au Kongo Central, cet arbre est souvent présent près des villages ou des sites d'anciens villages, couvrant une vaste zone et excluant presque tout le reste. II pousse bien sur des limons sablonneux profonds, humides, et acides. II peut pousser jusqu'à $2000 \mathrm{~m}$ d'altitude.

Reproduction : Utiliser des semis spontanés, ou semer directement en plein champ. Verser de l'eau bouillante sur les graines et les faire tremper 24 heures avant de les semer. Les graines peuvent être stockées jusqu'à 2 ans. Cet arbre se reproduit aussi facilement par boutures.

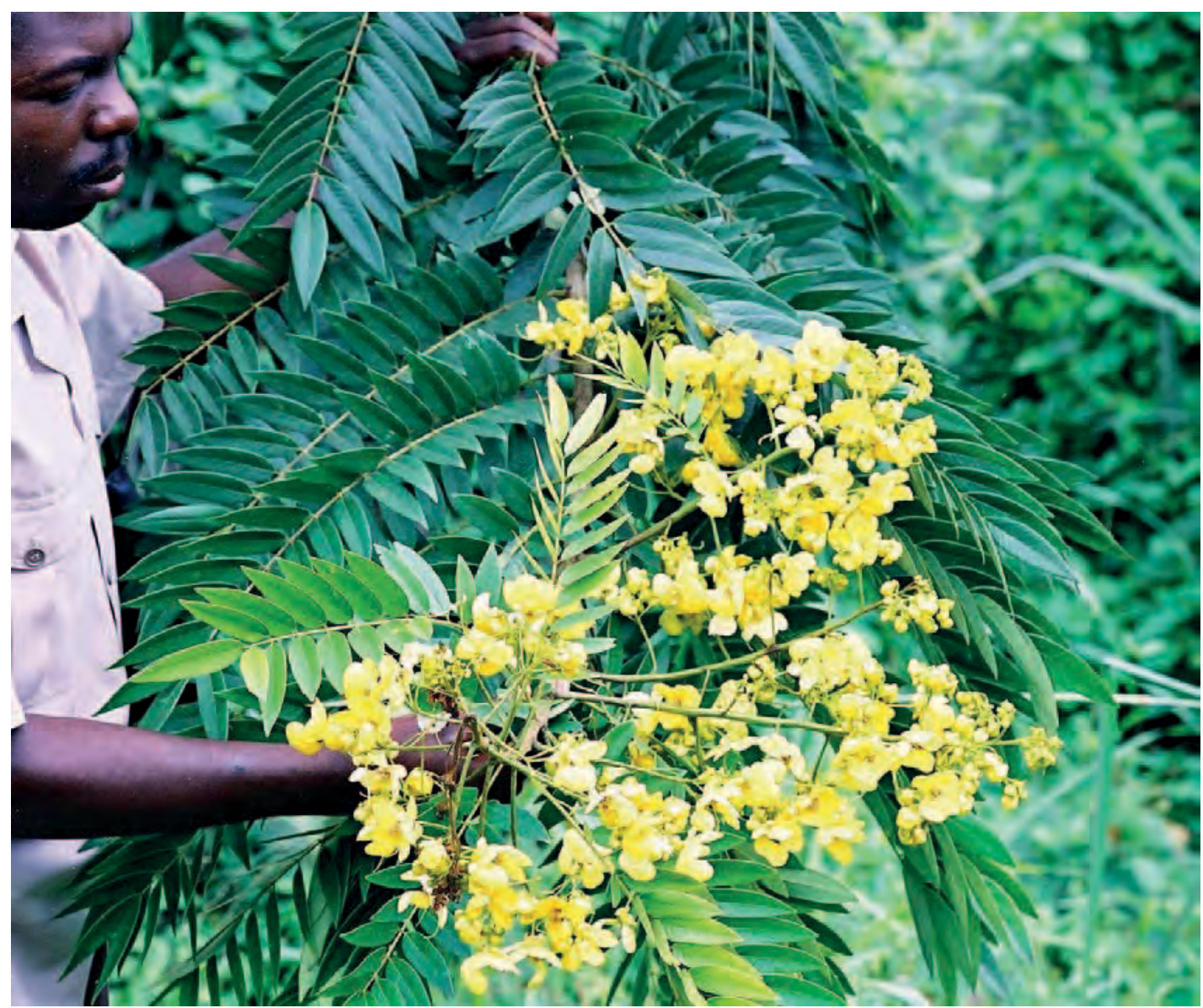

Senna spectabilis en fleurs à Mbanza Nzundu en janvier

Gestion : L'arbre est à croissance rapide sur de bons sites ; on peut le recéper.

Usages : Le bois est largement utilisé comme bois de feu et pour le charbon de bois. Au Kongo Central, l'arbre améliorerait la fertilité du sol, bien qu'il s'agisse d'une plante envahissante dans les terres cultivables. Les feuilles sont connues pour produire un paillis riche en azote. Souvent utilisé comme haie et comme coupe-feu. II peut donner de l'ombre aux plantations de café ; on l'emploie comme coupe-vent. Le bois est dur, lourd, durable et résistant aux termites. On peut en faire des manches d'outils. Les abeilles visiteraient les fleurs ; en Argentine, on dit que les fleurs seraient toxiques pour les abeilles.

Références: Renier 1948, Wilczek et al. 1952, IITA 1978, Daeleman et Pauwels 1983, Pauwels 1993, Burkill 1995, Orwa et al. 2009 
Synonyme : $S$. orientale

Noms courants : Wangila (Kikongo), sésame (Fr.), simsim (Angl.)

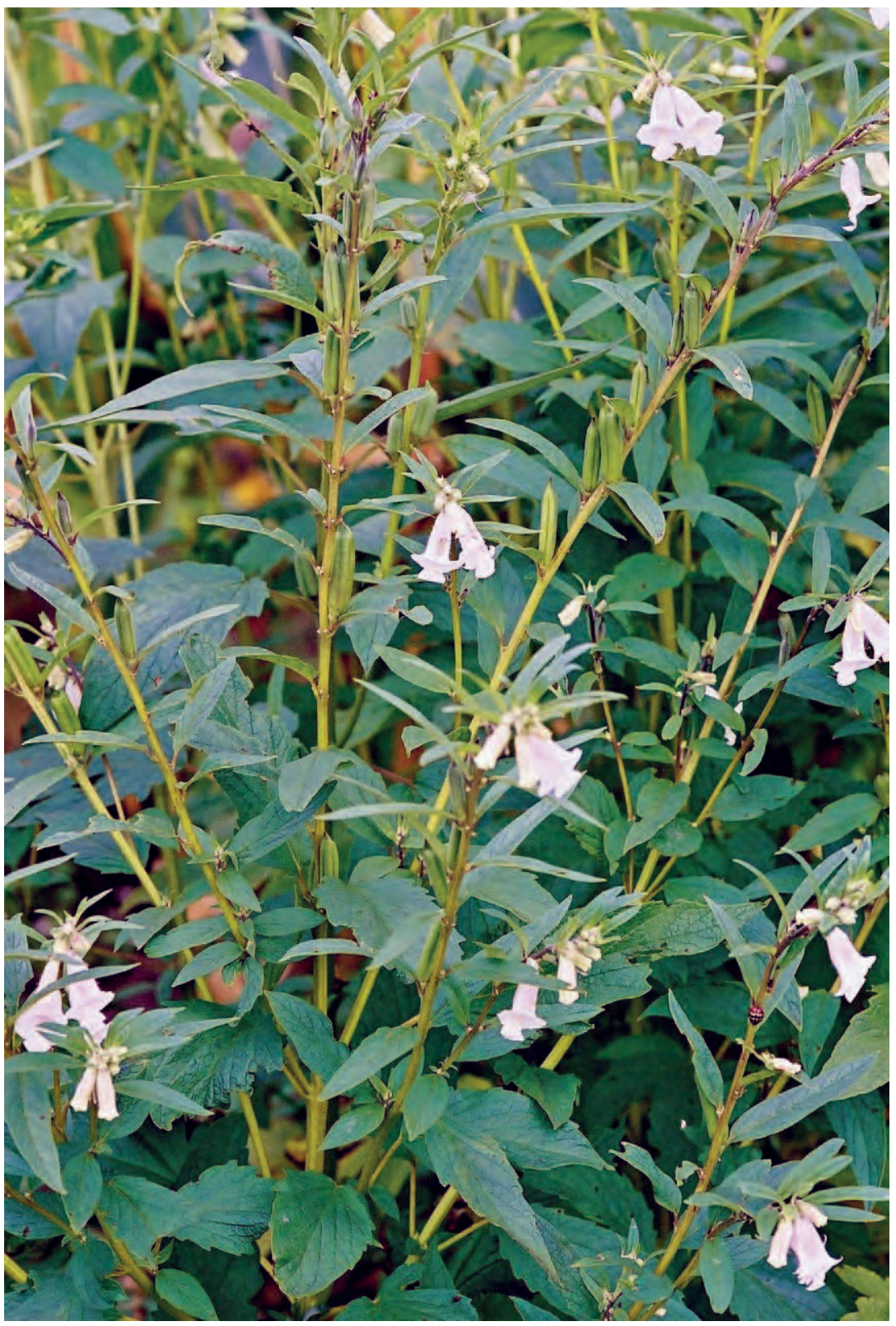

Description: Plante herbacée annuelle pouvant atteindre $1,5 \mathrm{~m}$ de haut. Feuilles lancéolées de 4 à $14 \mathrm{~cm}$ de long, larges de $5 \mathrm{~cm}$ à la base de la plante et se réduisant à seulement $1 \mathrm{~cm}$ de large sur la hampe florale. Les fleurs sont de couleur jaune (mais certains cultivars ont des fleurs blanches, bleues ou violettes), tubulaires, de 3 à $5 \mathrm{~cm}$ de long. Le fruit est une capsule oblongue-quadrangulaire de 1,5 à $3 \mathrm{~cm}$ de long, poilue, surmontée d'un court bec triangulaire, contenant de nombreuses graines. Les graines mesurent quelques millimètres, et leur couleur peut varier du blanc crème au brun jusqu'au noir. Certaines variétés ont des gousses qui n'éclatent pas à maturité.

Ecologie: Plante originaire d'Afrique et d'Inde, souvent cultivée comme culture de rente dans les zones à courte saison sèche. Elle est modérément résistante à la sécheresse une fois établie. Le désherbage est important lorsque les plantes sont jeunes. On peut la cultiver jusqu'à une altitude de $1500 \mathrm{~m}$. Elle préfère les sols limoneux fertiles et ne tolère pas l'inondation.

Reproduction: Se cultive à partir de graines semées à la volée sur une terre bien travaillée. Le semis en lignes espacées de 50 $\mathrm{cm}$ facilite le désherbage. Les plantes doivent être éclaircies à 10 $\mathrm{cm}$ l'une de l'autre dans la ligne. Plantez les graines de 2 à $5 \mathrm{~cm}$ de profondeur.

Gestion : La culture prend normalement de 3 à 4 mois pour mûrir. On récolte la plante lorsque les capsules les plus basses de la tige commencent à s'ouvrir et avant qu'elle soit entièrement mûre. Si on tarde à récolter, on peut perdre beaucoup de graines. II peut y avoir de sérieux problèmes avec les ravageurs.

Usages: On peut moudre la graine et en faire une farine que l'on cuit pour la manger ; on peut également en extraire une huile comestible. La graine, riche en calcium et en phosphore, est donc un aliment précieux pour les enfants. Les jeunes feuilles de cette espèce, de $S$. alatum et de $S$. radiatum se mangent comme légumes, ou servent à épaissir la soupe. On les emploie pour soigner la toux et les douleurs oculaires. Les cendres des tiges ont des usages médicinaux ; on en fait du sel végétal. La plante contient de la sésamine, substance connue pour avoir des propriétés insecticides. Les fleurs fournissent aux abeilles du nectar et du pollen. La sécrétion de nectar est plus élevée les lendemains de pluie. La plante est une source importante de miel ; il peut être intéressant de la cultiver à cette fin.

Références : Renier 1948, Godin et Spensley 1971, Daeleman et Pauwels 1983, Crane et al. 1984, I wu 1993, Fichtl et Adi 1994, Burkill 1997, Martin et al. 1998, Raemaekers 2001 
Noms courants : Wangila matebo, wanguila (Kikongo), black benniseed (Angl.)

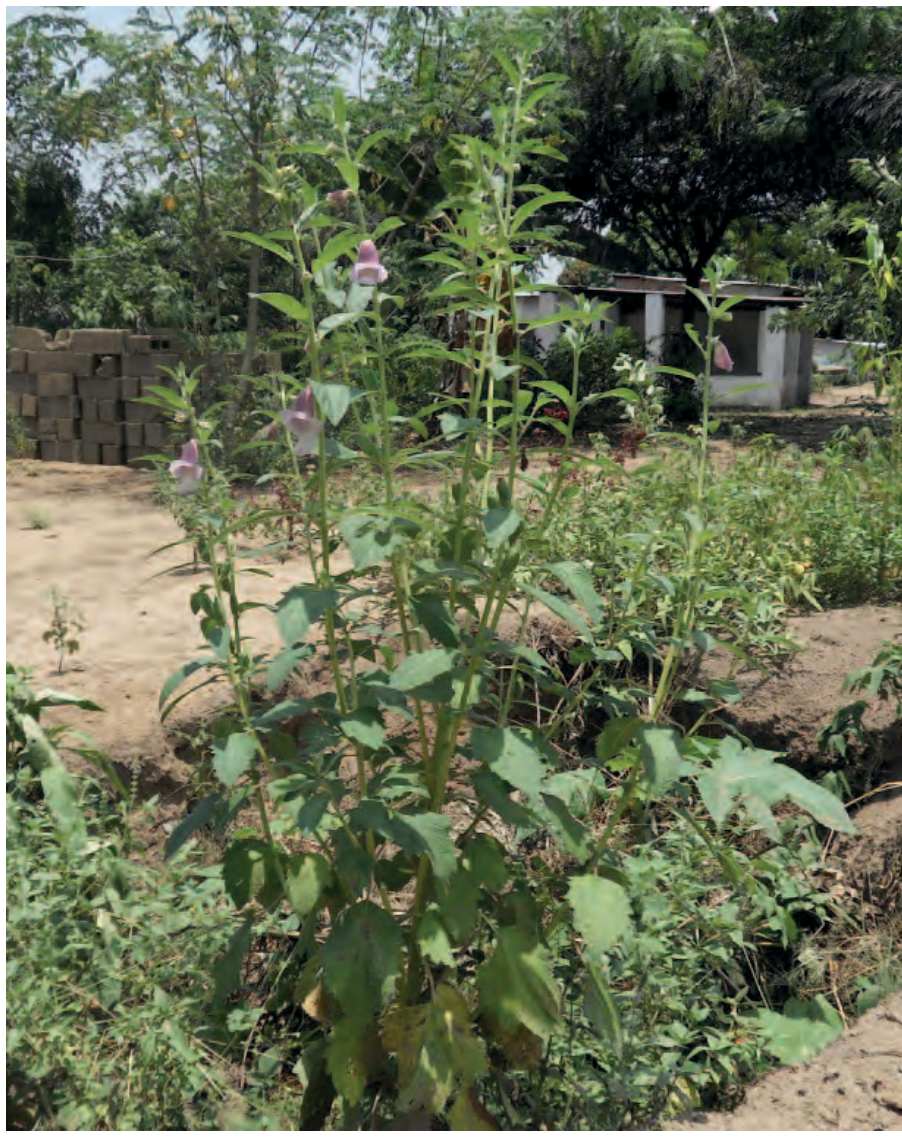

Usages : Les feuilles fraîches se mangent comme des épinards. Elles sont importantes sur le plan nutritionnel en particulier pour les enfants. Les feuilles cuites ont une texture gluante; elles se mangent de la même manière que celles de $S$. orientale. Sesamum radiatum est parfois cultivée pour ses graines. Celles-ci se mangent entières, grillées ou pilées. Une huile comestible peut être extraite de la graine. La plante a plusieurs utilisations médicinales et cosmétiques. Dans le nord de l'Angola, les feuilles sont utilisées pour traiter les problèmes de peau et la typhoïde. Les fleurs sont visitées par les abeilles et la plante est une source importante de nectar dans la savane sèche.

Références : Busson 1965, Stevels 1990, Burkill 1997, Hepburn et Radloff 1998, Schippers 2002, Bedijian 2004, Schippers 2004, Achigan-Dako et al. 2009
Description: Plante herbacée annuelle à l'odeur désagréable, dressée jusqu'à $120 \mathrm{~cm}$ de haut. Feuilles de 3 à $10 \mathrm{~cm}$ de long et de 1,5 à $5 \mathrm{~cm}$ de large. Le pétiole des feuilles inférieures mesure jusqu'à $2,5 \mathrm{~cm}$ de long, mais il est plus court dans les feuilles supérieures. Fleurs solitaires à l'aisselle des feuilles, corolle longue de 2,5 à $5 \mathrm{~cm}$, pubescente, rose à violaçée, parfois blanche. Le fruit est une capsule oblongue-quadrangulaire de 2 à $3,5 \mathrm{~cm}$ de long contenant de nombreuses graines.

Ecologie : La plante est parfois cultivée, mais on la trouve souvent à l'état naturel autour des villages et des champs cultivés au Kongo Central. Elle tolère bien la chaleur et la sécheresse, et continue de pousser et de fleurir pendant la saison sèche.

Reproduction : On peut semer les graines en germoirs, ou directement en place avec 2 à 3 graines par trou. La germination prend 6 à 10 jours. Les semis sont transplantés à l'espacement d'environ $15 \mathrm{~cm}$. On doit récolter les graines alors que les gousses sont encore immatures pour éviter les pertes.

Gestion: La plante pousse bien dans des endroits fertiles. Pour la production de feuilles, on pince le haut des plantes pour favoriser la croissance de nouvelles feuilles à la base, où l'on peut récolter de plus grandes feuilles.

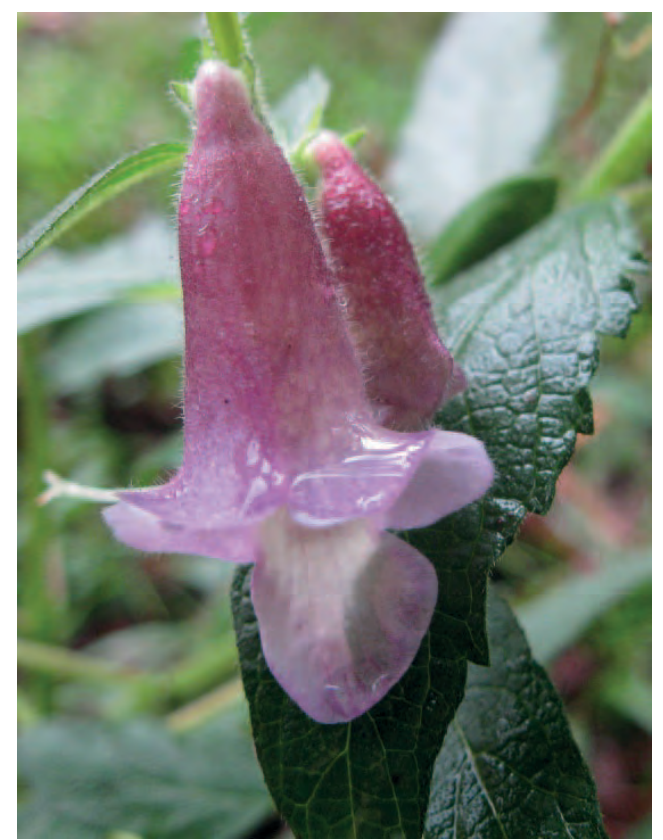


Noms courants :Nongu nongu, mangamba (Kikongo), river bean (Angl.)

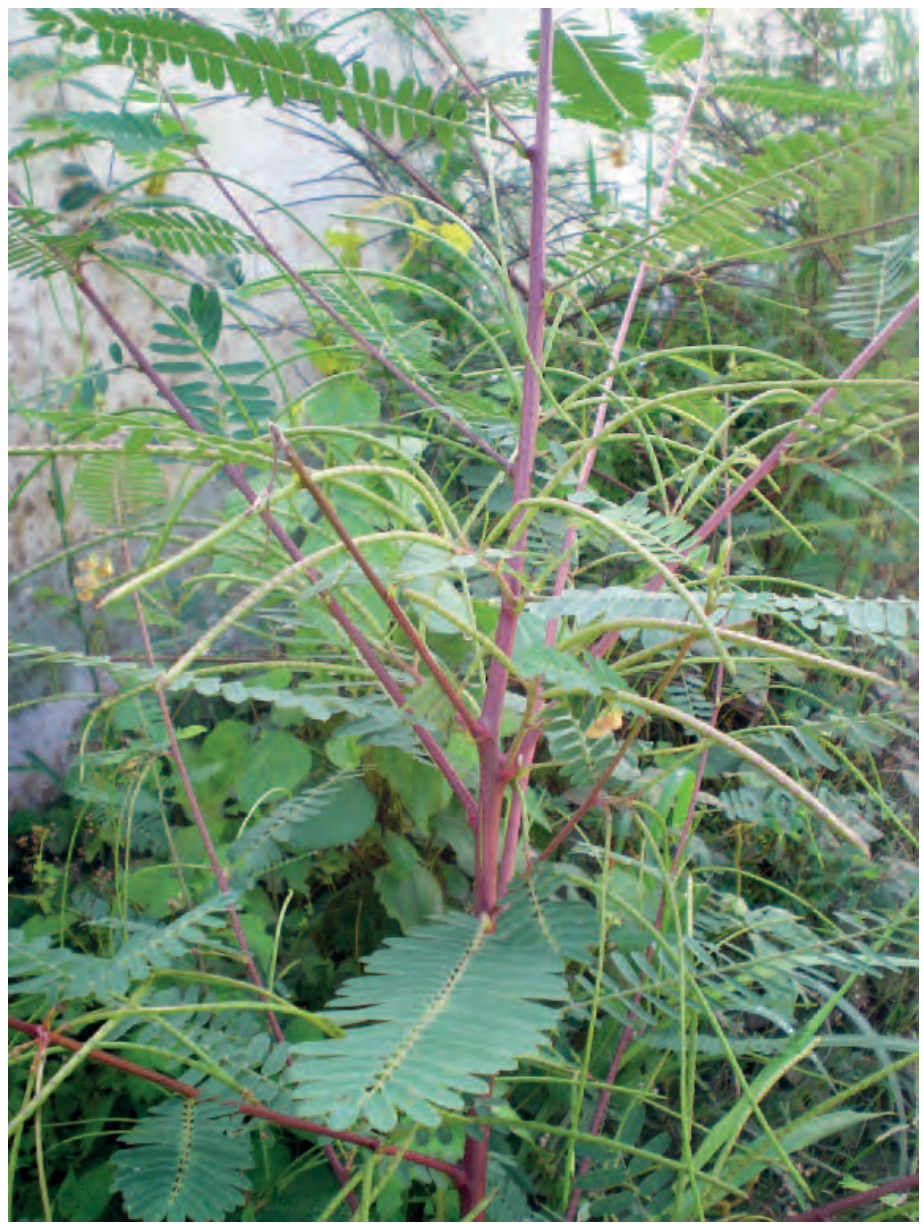

Description : Arbuste très ramifié à bois mou de 1 à $6 \mathrm{~m}$ de haut. Chaque feuille a 10 à 40 paires de folioles, chacune ayant jusqu'à 2,7 cm de long. II y a jusqu'à 20 fleurs jaunes avec des taches violettes dans un racème de $15 \mathrm{~cm}$ de long. Les fruits sont disposés en bouquets de gousses brunes minces de $25 \mathrm{~cm}$ de long.

Ecologie : Plante commune le long des cours d'eau et des marais. Tolère l'engorgement et les sols salins. Certaines variétés tolèrent les sols acides. Largement distribuée et cultivée en Afrique tropicale.

Reroduction: Transplantation des semis spontanés, ou de préférence semis direct. Cette espèce est prolifique pour les graines, avec un taux de germination de $65 \%$ en 16 jours. Aucun traitement n'est nécessaire, mais l'immersion des graines dans l'eau chaude, puis le trempage pendant 24 heures peut augmenter le taux de germination. On peut conserver les graines longtemps si on les garde au frais et au sec. Semer en lignes espacées de 2 à $10 \mathrm{~m}$ l'une de l'autre avec un espacement en ligne de 25 à $50 \mathrm{~cm}$. II peut être nécessaire d'inoculer avec une souche appropriée de rhizobium si la nodulation normale n'a pas lieu.

Gestion : Plante à croissance très rapide, que I'on peut tailler ou recéper quand elle est jeune. Ne doit pas être plantée avec des cultures sensibles aux nématodes comme les

bananiers.

Usages : Le bois est tendre, léger et non durable. Les tiges écorcées servent de lattes pour les toits légers. Les tiges plus épaisses sont utilisées pour la construction ou comme bois de chauffage. II s'agit d'une excellente plante fourragère et d'un bon engrais vert. On peut la cultiver comme haie touffue. Les feuilles contiennent une saponine, si bien que la plante peut être utilisée comme insecticide. La plante fixe l'azote dans le sol. On la cultive comme plante d'ombrage et tuteur pour les poivriers, ou comme brise-vent. Les feuilles et les fleurs sont comestibles.

Remarques: Certaines variétés tolèrent les sols acides. L'arbre peut abriter des nématodes dans les nœuds des racines.

Références : Gillet et Pâque 1910, Hauman et al. 1954, Skerman 1977, Allen et Allen 1981, Pauwels 1993, Beentje 1994, Mbuya et al. 1994, Burkill 1995, Katende et al. 1995, Maundu et Tengnas 2005

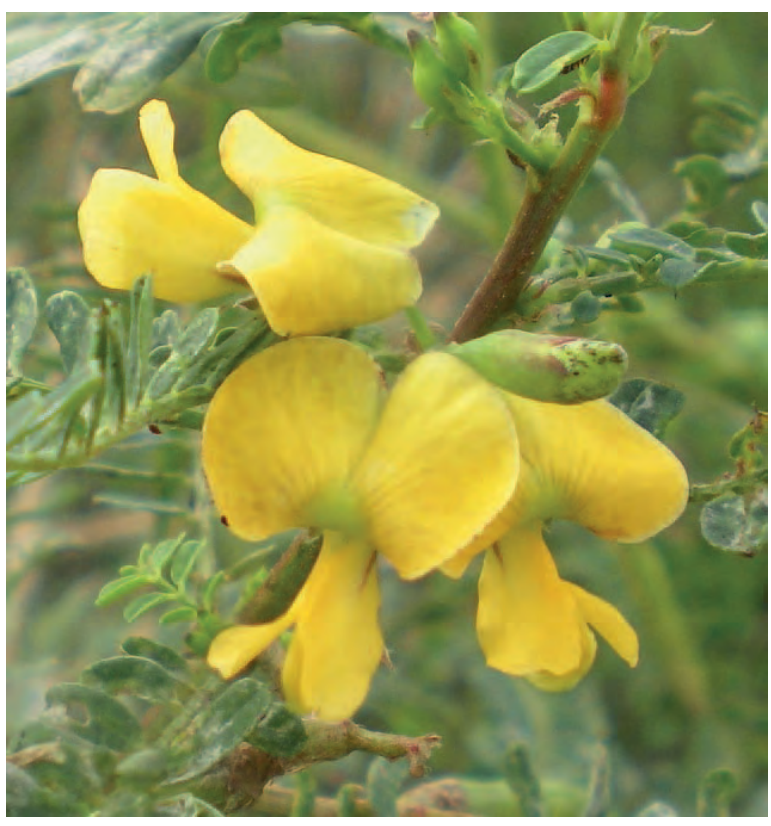

Photo : Phuong Tran 


\section{Setaria megaphylla}

Synonyme : S. macrophylla

Noms courants : Kangeni, kangiya (Kikongo), buffel grass (Angl.)

Description : Herbe vivace drue, dressée et robuste, qui pousse en touffes jusqu'à $3 \mathrm{~m}$ de haut, se reproduisant par graines. Les tiges sont robustes, ce sont des cannes, avec des racines très fortes. Les feuilles sont grandes et fortement plissées, généralement d'environ $1 \mathrm{~m}$ de long et $10 \mathrm{~cm}$ de large. L'inflorescence est dense, raide, avec des branches horizontales poilues portant des épillets densément serrés.

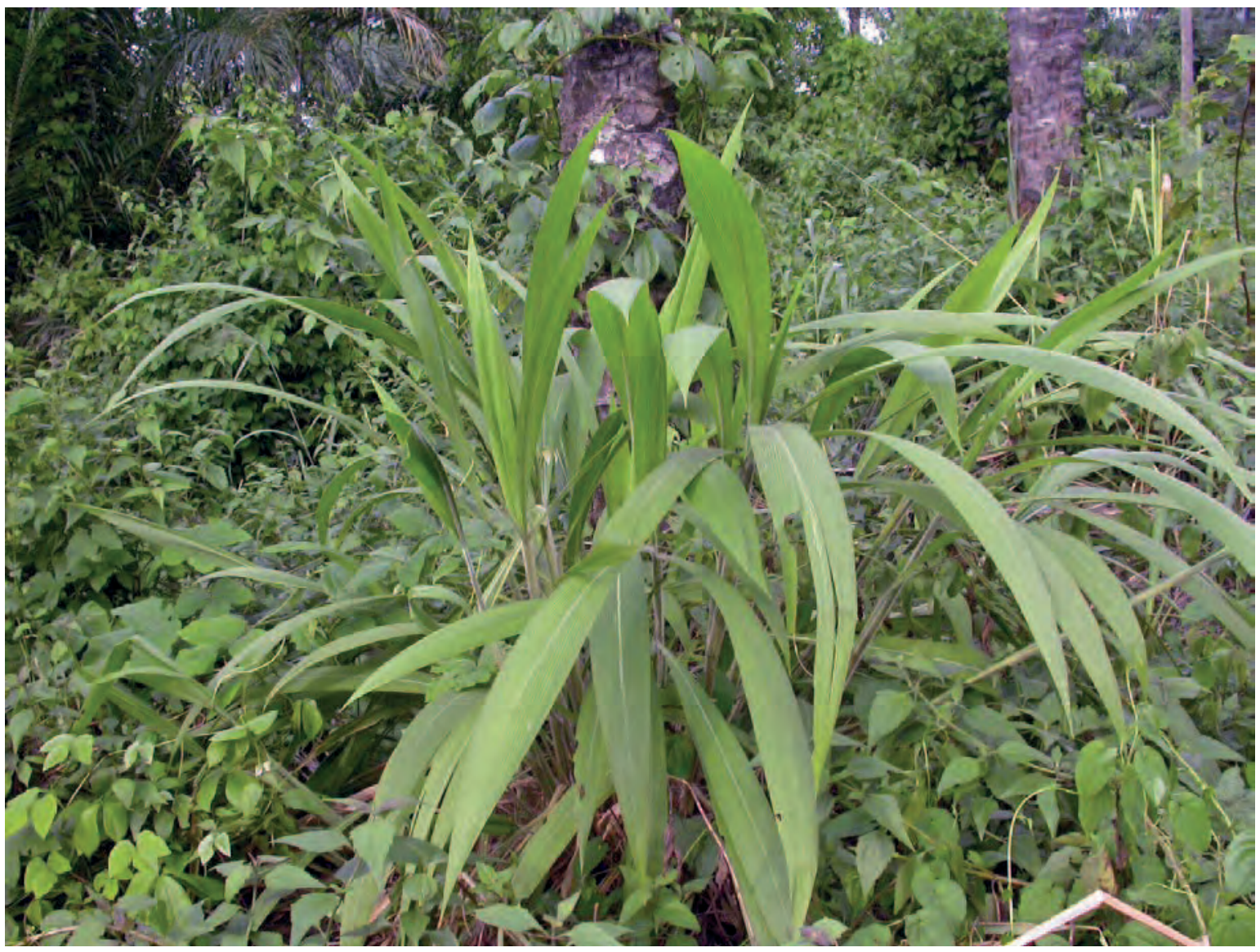

Ecologie : Plante des lieux humides ombragés en lisière de forêt, le long des cours d'eau, dans les zones basses de la forêt et de la savane arbustive où il y a beaucoup d'humidité. Adventice indésirable des cultures dans la zone forestière de l'Afrique de l'Ouest. Se rencontre dans les zones à fortes précipitations de l'Afrique tropicale et subtropicale, ainsi qu'en Amérique et en Inde.

Reproduction : Par division des touffes ou par graines. Une fois les fleurs séchées, retirer les têtes et les secouer dans un sac en papier pour extraire les graines.

Usages : Les feuilles sont parfois utilisées pour envelopper la chikwangue. Elles sont également utilisées pour nourrir les lapins et les porcs. C'est un bon fourrage apprécié par tous les types de bétail, mais si on le récolte pour l'alimentation en étable, éviter de lui permettre de flétrir, car il y a risque de produire de l'acide hydrocyanique toxique. L'herbe pour le fourrage doit être coupée ou broutée lorsqu'elle est jeune. Les tiges sont parfois utilisées dans la construction d'habitations. On peut brûler la plante entière pour produire un sel végétal. Les feuilles et les racines sont utilisées en médecine pour soulager la douleur causée par la morsure de serpent et les ecchymoses, pour traiter l'épilepsie, la gonorrhée et les maladies circulatoires; on donne une décoction de la racine aux femmes enceintes pour faciliter l'accouchement. On emploie également cette plante pour traiter la diarrhée, la migraine, la toux et la somnolence. Cette herbe peut servir au contrôle des érosions, et pour la colonisation des sols déposé par l'érosion. Parfois cultivée comme plante ornementale.

Références : Renier 1948, Daeleman et Pauwels 1983, Akobundu et Agyakwa 1987, Burkill 1994, Neuwinger 2000, Hankey et Mashinini 2002, Nzuki Bakwaye et al. 2013. 
Synonyme : Sapium ellipticum

Noms courants : Kiaka, kingelumi, nkuzi, muaza (Kikongo)

Description : Arbuste ou arbre jusqu'à $25 \mathrm{~m}$ de haut produisant du latex blanc. Feuilles de 3 à $19 \mathrm{~cm}$ de long et de 2 à 6,5 cm de large avec des marges légèrement dentées. Les fleurs, de couleur vert pâle (fleurs mâles) ou jaunâtres (fleurs femelles) sont disposées en épis de 4 à $17 \mathrm{~cm}$ de long. Le fruit est une drupe bilobée comprimée latéralement, de 8 à $15 \mathrm{~mm}$ sur 6 à $8 \mathrm{~mm}$, surmontée par les styles, lisse, verte, virant au jaunâtre puis au violet ou au noir, légèrement charnue, à 2 graines. Graines ellipsoïdes à presque globuleuses, de 5,5 mm de diamètre, lisses, brun jaunâtre.

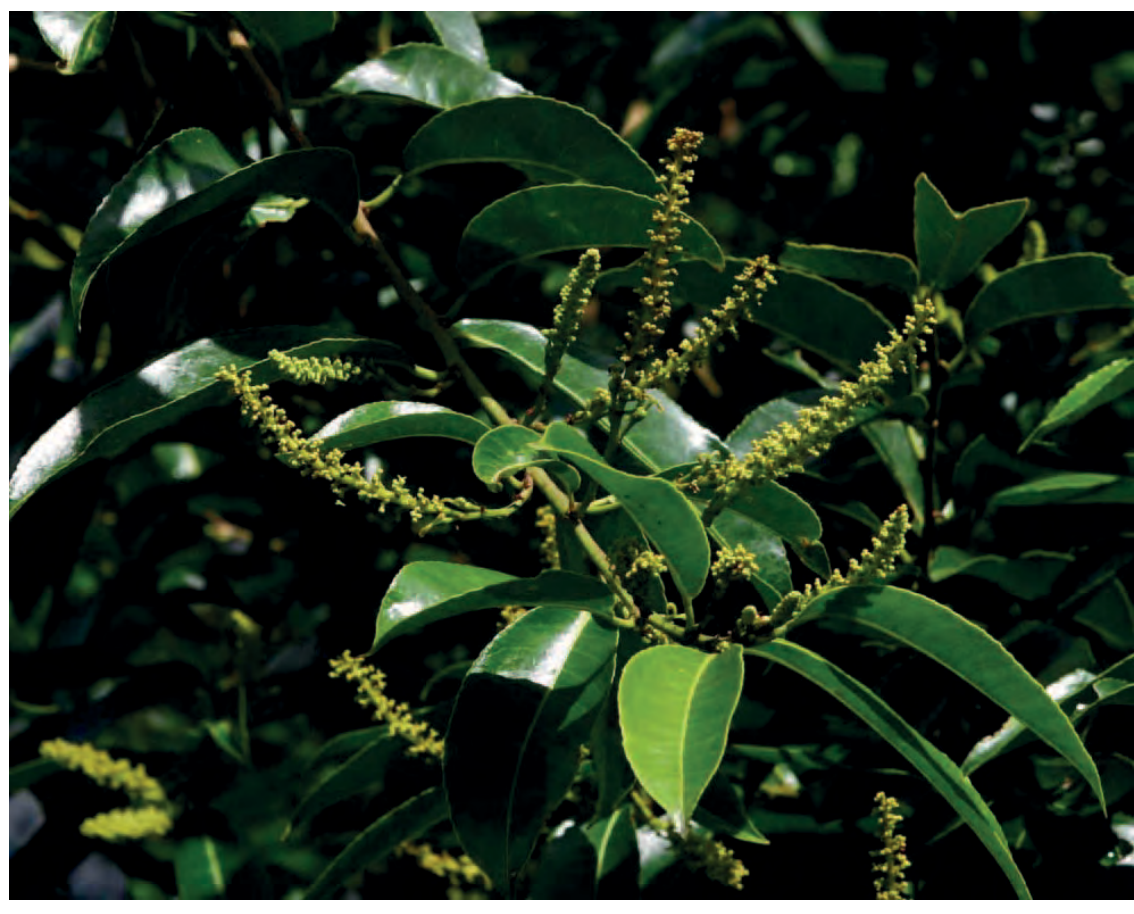

Ecologie: Arbre des forêts secondaires, et des forêts périodiquement inondées. De la Guinée à l'Éthiopie et au sud jusqu'au Cap en Afrique du Sud.

Reproduction: A partir de graines extraites des capsules, ou de semis spontanés. Les graines sont souvent attaquées par des insectes, on doit donc les récolter dès qu'elles sont mûres.

Gestion: L'arbre peut être recépé et taillé

Photos : Bart Wursten

Usages : Cet arbre donne un bois blanc de bonne qualité que l'on peut débiter en planches. Le bois est modérément résistant et dur, mais grossier et fibreux et ne dure pas au contact du sol. II est sensible aux attaques des insectes perforants. On l'emploie pour la fabrication d'outils et de meubles. Le latex peut servir de colle. On donne une infusion de l'écorce pour traiter la gale et les démangeaisons. On donne une émulsion faite à partir des racines pilées contre le bégaiement. On expulse les vers intestinaux avec la racine, les feuilles et de l'eau. Les fleurs sont très attrayantes pour les abeilles qui récoltent le pollen comme le nectar. Plante nourricière des chenilles nommées Kaba (Lobobunaea phaedusa, Pseudobunaea sp.).

Références : Gillet et Pâque 1910, Gillet 1927, Renier 1948, Léonard 1962, Nsimundele 1966 - 68, Kokwaro 1976, Coates Palgrave 1983, Pauwels 1993, Burkill 1994, Fichtl et Adi 1994, Katende et al. 1995, Neuwinger 2000, Schmelzer 2007.

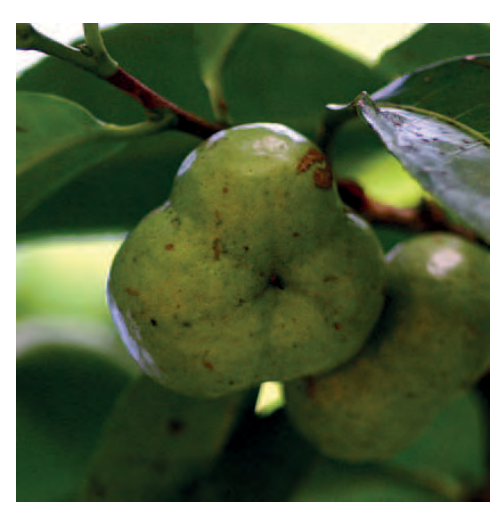


Sida acuta

Noms courants : Lumvumvu (Kikongo), broomweed (Angl.)

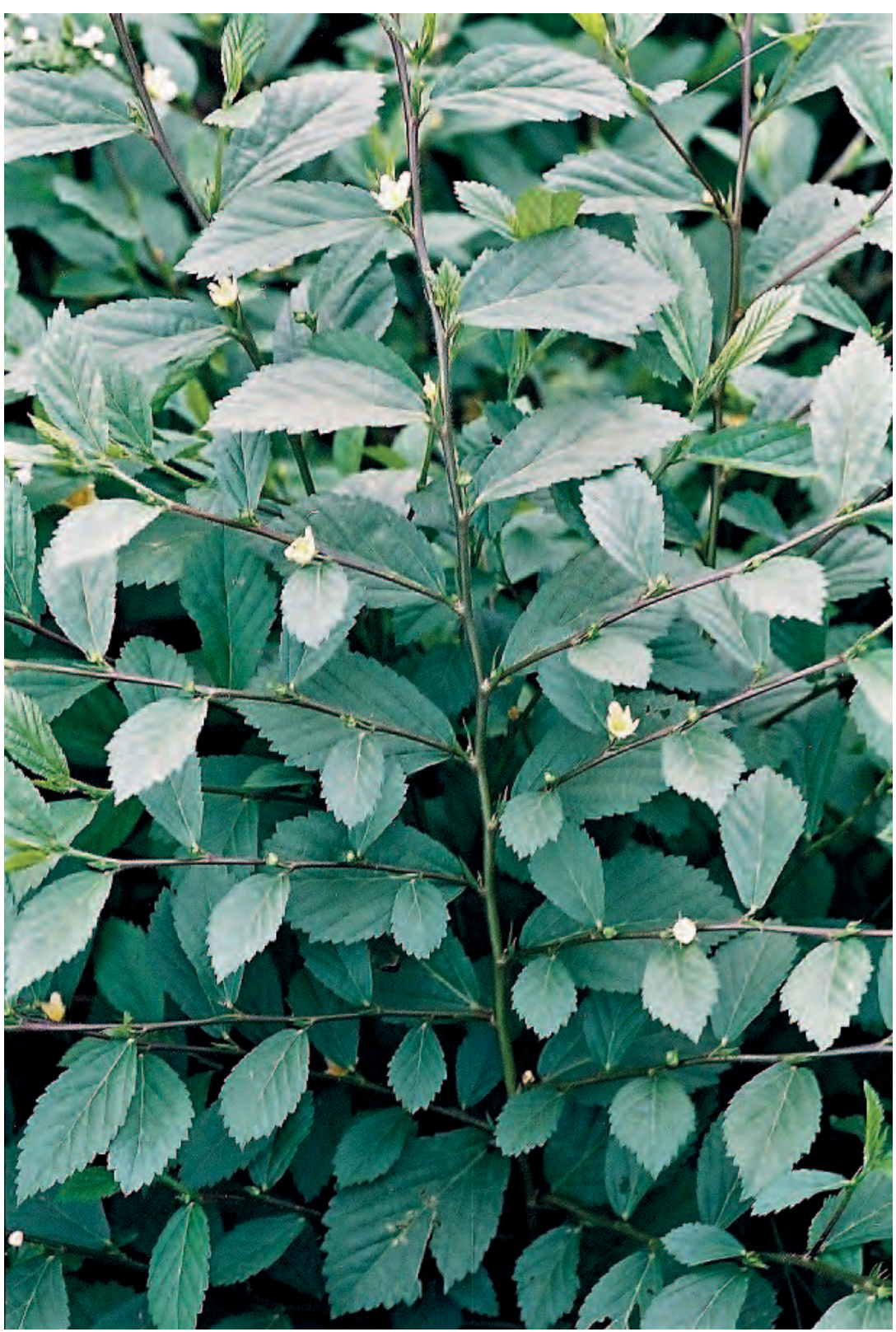

(Malvaceae)

Description :

Plante

buissonnante variable, dressée, vivace de courte durée, jusqu'à 1 $m$ de haut. Les feuilles ont jusqu'à 3 à $5 \mathrm{~cm}$ de long et 1 à $1,5 \mathrm{~cm}$ de large, et sont aigües à l'extrémité, avec des marges finement dentées. Les fleurs jaunes à orange apparaissent en février et mars. La fleur est souvent sessile, ou disposée sur un pédoncule court de moins d'1 cm, alors que les fleurs de $S$. rhombifolia sont d'ordinaire sur des pédoncules de 1 à $4 \mathrm{~cm}$.

Ecologie: Plante commune, en particulier dans les terres remaniées autour des villages et sur les bords des routes.

Usages : Les abeilles butinent occasionnellement le nectar et le pollen en mars. La tige contient une fibre jaune, douce et brillante qui peut être filée comme la soie, mais qui n'a qu'une résistance moyenne. La plante entière sert à faire des balais. Au Kongo Central, on mâche les feuilles pour traiter la gonorrhée.

Références : Portugal-Arajo 1974, Arkinstall 1979, Daeleman et Pauwels 1983, Akobundu et Agyakwa 1987, Blundell 1987, Fichtl et Adi 1994, Burkill 1997, Kibungu Kembelo 2003, Nsimundele 2004 


\section{Sida cordifolia}

(Malvaceae)

Noms courants: Balai poilu, herbe à paniers, sida à feuilles en cœur (Fr). heart-leaf Sida (Angl.)

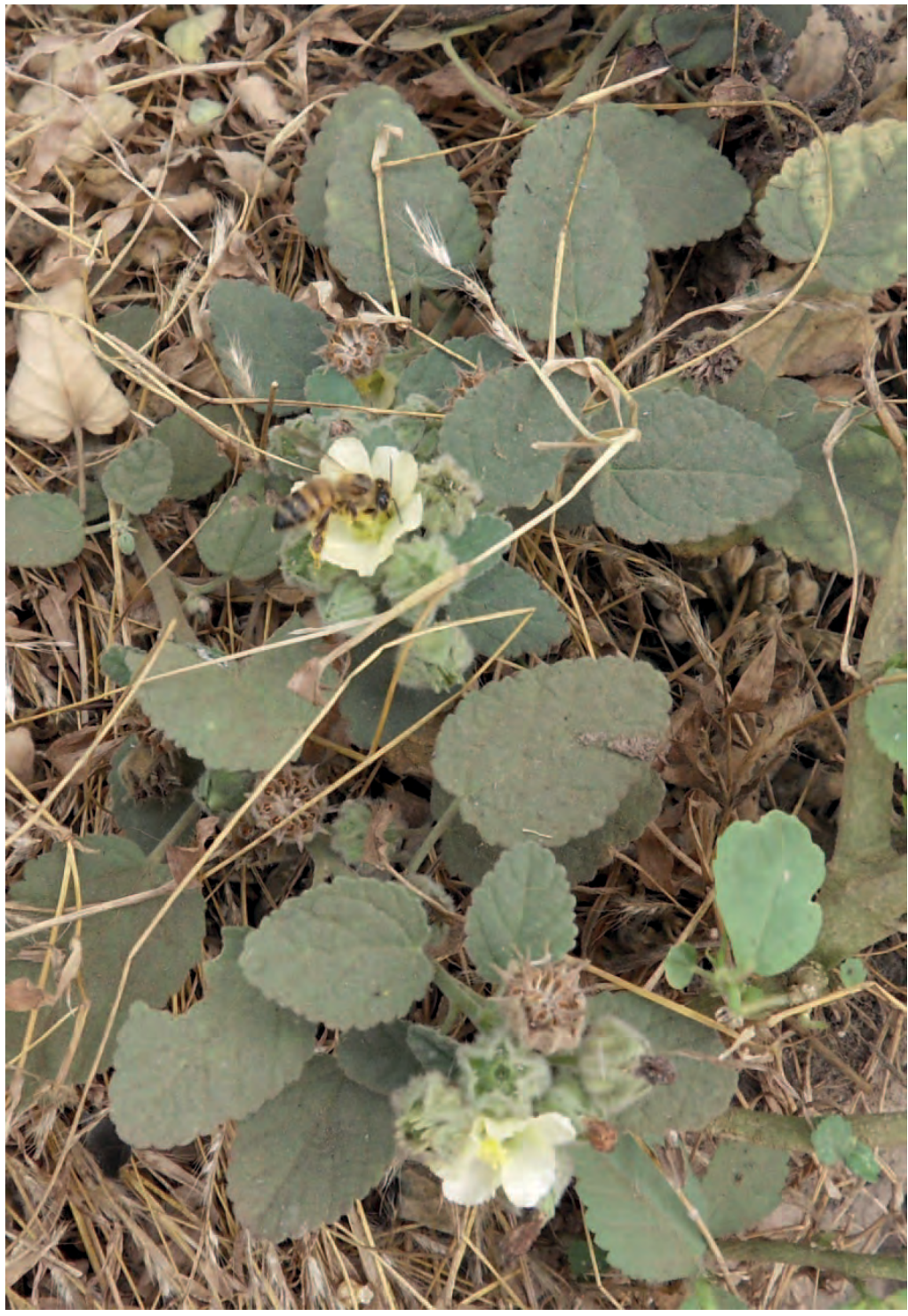

Description : Plante vivace dressée de 50 à $150 \mathrm{~cm}$. La plante est recouverte de poils feutrés blancs et doux. Les tiges sont jaune-vert, poilues, longues et fines. Les feuilles alternes, jaune-vert, ont de 3,5 à 7,5 $\mathrm{cm}$ de long et de 2,5 à $6 \mathrm{~cm}$ de large. Les marges des feuilles sont dentées. Pétiole de $4,5 \mathrm{~cm}$ de long. Les fleurs sont jaune foncé, parfois avec un centre orange plus foncé, un calice couvert de poils à 5 lobes, et une corolle à 5 lobes. Le fruit est une capsule ayant 10 carpelles, chacun avec une paire d'arêtes de 3 à $6 \mathrm{~mm}$ de long.

Ecologie : Plante originaire de l'Inde, mais maintenant largement répandue. Considérée comme envahissante en Afrique, en Australie, dans le sud des États-Unis, à Hawaï et en NouvelleGuinée. Elle envahit les champs cultivés et surpâturés, en concurrence avec les espèces souhaitées.

Usages: Les abeilles butinent le nectar et le pollen des fleurs en Juin. Elles visiteraient également les fleurs en Angola. En Afrique, la plante est importante en médecine, en particulier pour les problèmes respiratoires.

Remarques: $S$. linifolia et $S$. urens sont également présentes au Kongo Central.

Références : Pauwels 1982, Akobundu et Agyakwa 1987, Kokwaro 2009 


\section{Sida rhombifolia}

(Malvaceae)

Noms courants: Kembela, lumvumvu (Kikongo), ikoluonda (Lingala), chanvre du Queensland, herbe dure (Fr), Queensland hemp (Angl.)

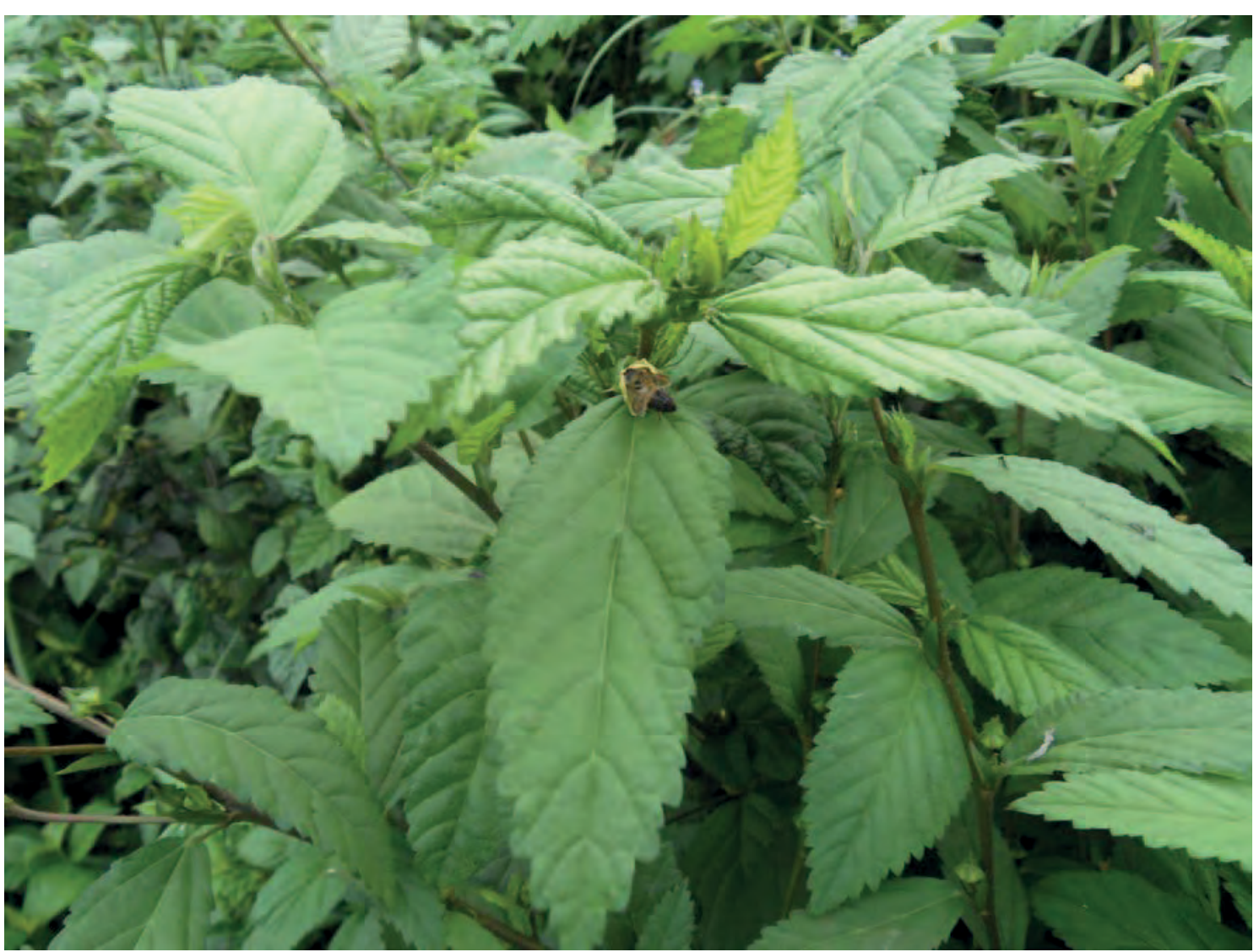

Description : Plante buissonnante variable, pérenne à courte vie, pâle dressée, jusqu'à 1,5 m de haut. Feuilles jusqu'à $8 \mathrm{~cm}$ de long et $5 \mathrm{~cm}$ de large, pétioles jusqu'à $0,5 \mathrm{~cm}$. Fleurs blanches à jaunes à l'aisselle des feuilles. Les fruits est une capsule à 8 à 10 carpelles. Le bec de la capsule est courbe, ni raide ni pointu.

Ecologie : Plante commune sous les tropiques, spécialement dans les terrains remaniés autour des villages, et au bord des routes.

Reproduction : Par graines.

Usages: Traditionnellement, on prenait la sève gluante des feuilles écrasées pour réparer les pots d'argile. La sève est également utilisée pour traiter les brûlures. La plante entière et surtout les feuilles et les racines s'emploient avec d'autres plantes pour traiter la diarrhée, l'énurésie, les douleurs thoraciques, les crampes des doigts ou des bras et la gonorrhée. On emploie largement les feuilles comme pansement pour guérir les plaies, les ulcères, les coupures et les bosses. La plante entière sert à faire des balais. Si on carbonise la plante, il s'en dégage un goudron qui peut servir de colorant noir. La fibre extraite de la tige est de bonne qualité, douce, brillante et de texture uniforme. On peut soit la filer avec de la soie, soit en faire des liens ou pour le jute. On a observé des abeilles butinant le nectar et le pollen en mars.

Références : Gillet et Pâque 1910, Renier 1948, Hauman 1963, Nsimundele 1966 - 68, Akobundu et Agyakwa 1987, Fichtl et Adi 1994, Burkill 1997, Kibungu Kembelo 2003 


\section{Smilax anceps}

Synonyme : S. kraussiana

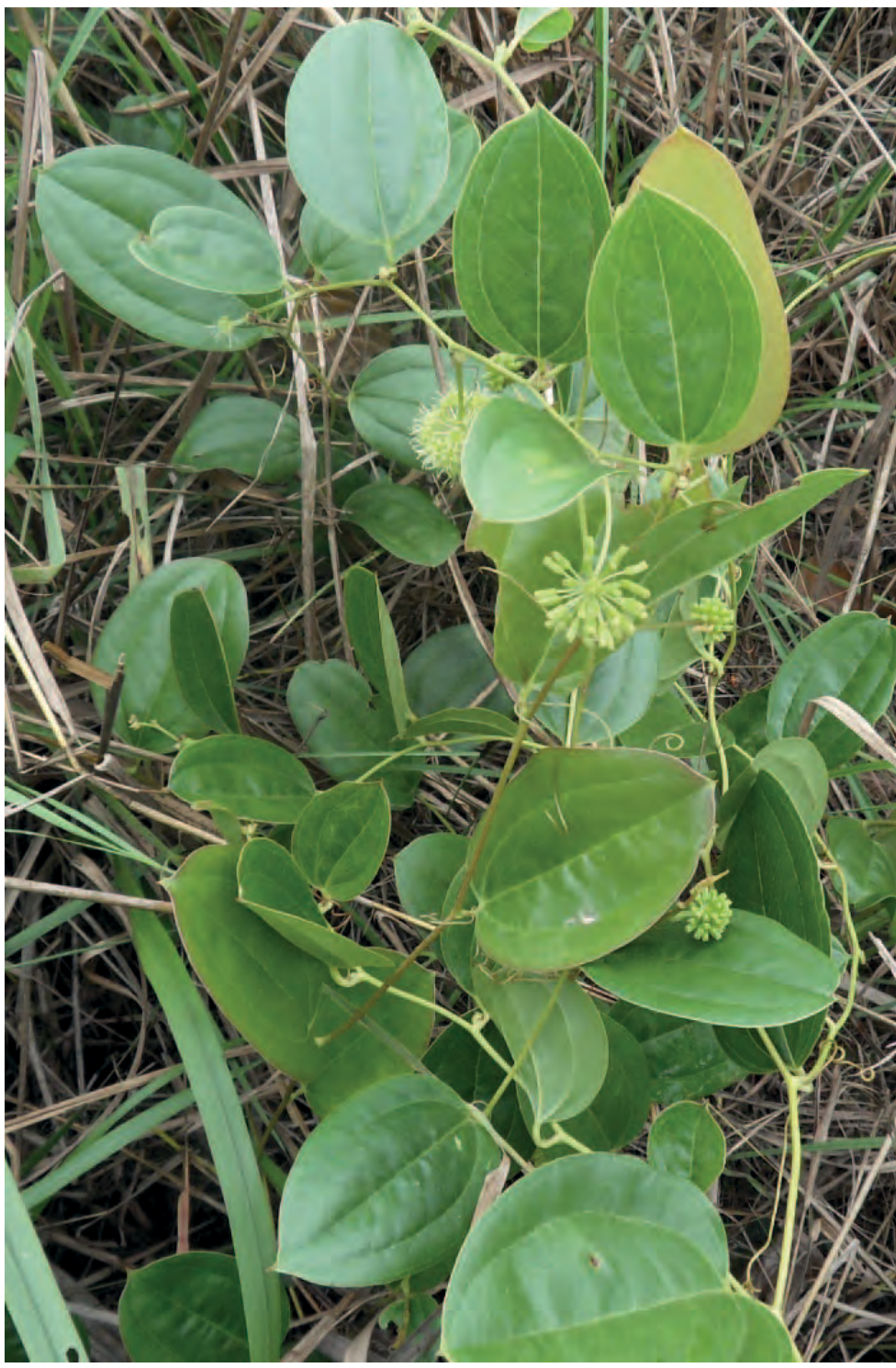

permettrait de parler peu de temps après. Ailleurs en Afrique, les feuilles et le rhizome ont de nombreuses utilisations médicinales, y compris les pansements de plaies et d'abcès. Au Nigéria, les feuilles se mangent. Les rhizomes sont également comestibles. La plante a des propriétés similaires à la salsepareille (Smilax officinalis), une plante médicinale d'Europe du sud. En Afrique centrale, les tiges sont largement utilisées comme liens. La plante est résistante à l'attaque de termites.

Références: Gillet et Pâque 1910, Renier 1948, Morton 1961, Daeleman et Pauwels 1983, Akobundu et Agyakwa 1987, Burkill 2000, Neuwinger 2000, Vande weghe 2004
Noms communs : Kikalala, baka nlele (=prendre le ligne, l'habit) (Kikongo), croc de chien (Fr.), West African sarsaparilla (Angl.).

Description : Liane grimpante épineuse vivace poussant sur un rhizome souterrain ayant jusqu'à $5 \mathrm{~cm}$ de diamètre. La plante est similaire à une plante d'igname, mais a de longues vrilles volubiles. La tige est résistante, fibreuse et recouverte d'épines courtes et courbées. Les feuilles sont alternes, d'environ $12 \mathrm{~cm}$ de long et de $7 \mathrm{~cm}$ de large et fortement pointues. Les feuilles sont lisses sur les deux faces avec 3 nervures visibles qui rayonnent de la base. L'inflorescence est en forme d'ombrelle sur une tige courte avec beaucoup de petites fleurs individuelles verdâtres-blanches. Le fruit est une petite baie ronde pourpre ou noire.

Ecologie: Herbe dure agressive qui pousse souvent dans les champs de manioc. Elle déchire les vêtements des travailleurs dans des terres infestées par cette plante. Largement répandue en Afrique tropicale et en Afrique du Sud.

Usages : Au Kongo Central, on emploie la feuille pour guérir les ulcères buccaux en particulier après une longue maladie. On pose la jeune feuille sur la langue et on la garde dans la bouche aussi longtemps que possible (environ une heure), puis on la remplace par une nouvelle feuille. Traditionnellement, on disait qu'en donnant aux enfants n'ayant pas encore appris à parler quelque chose à boire sur une feuille de Kikalala, on leur

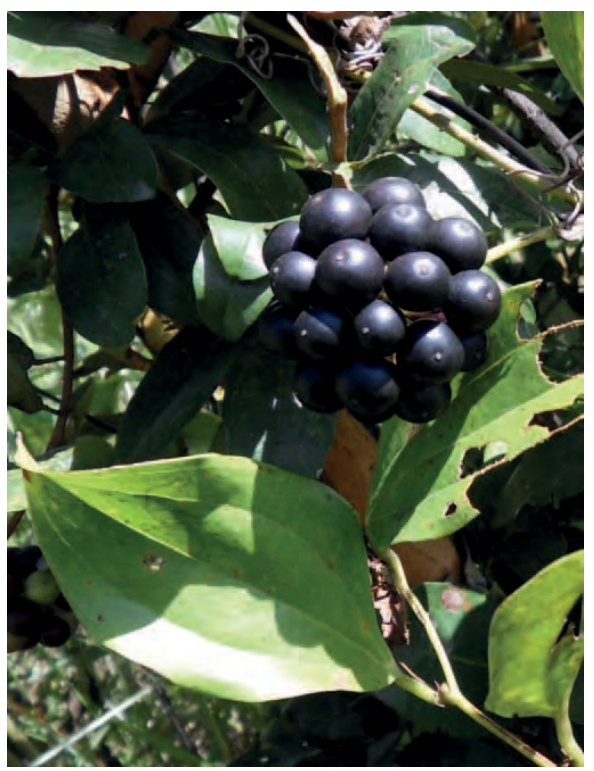




\section{Solanecio angulatus}

Synonyme : Crassocephalum bojeri

Noms courants : Lulaka lu ngombi (= langue de vache), ngondi longo (= ce qui détruit le mariage), kimandi nsusu (Kikongo)

Description : Liane pouvant atteindre $3 \mathrm{~m}$ de long.

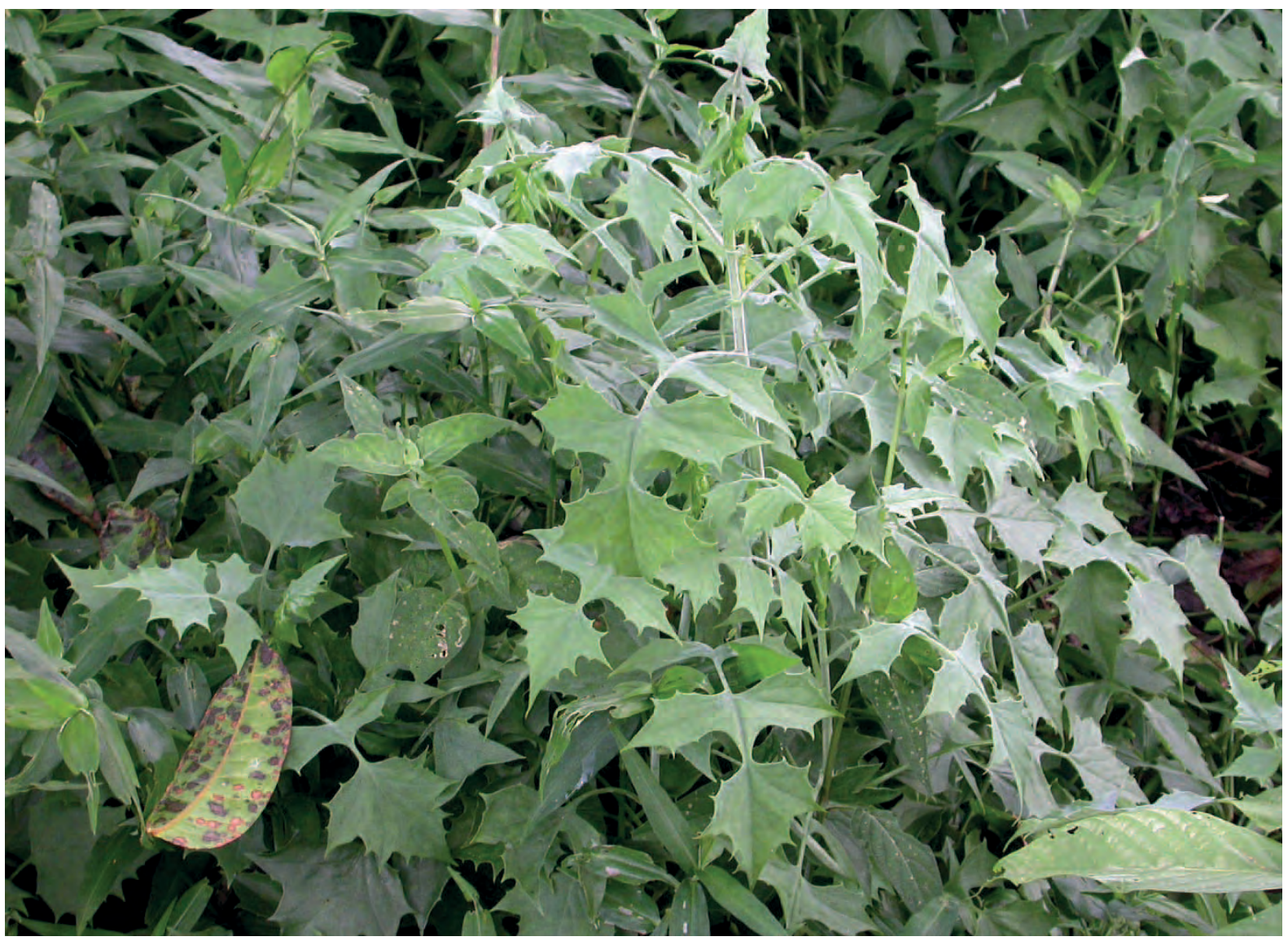

Ecologie : Adventice des cultures. Les espèces comestibles de Solanecio et Crassocephalum poussent normalement à l'état spontané, ou sont occasionnellement cultivées. Elles poussent bien à l'ombre, contrairement à presque tous les légumes à feuilles. On trouve particulièrement $C$. crepidoides dans les zones les plus humides.

Usages: On découpe les feuilles pour les cuire dans l'eau ou l'huile de palme et les manger comme légumes. Pour $C$. crepidoides, la jeune plante entière, et les feuilles semi-succulentes, qui sont gluantes, se mangent comme légumes, ou dans les sauces et les soupes. II en est de même ailleurs pour $C$. rubens. On emploie la plante pour faire baisser la fièvre. Les abeilles butinent le pollen et le nectar de cette plante et des autres espèces de Crassocephalum. Là où la récolte est abondante, et en raison de la longue floraison, ces plantes contribuent probablement utilement à la santé des essaims et à l'abondance du miel.

Références: Renier 1948, Goode 1974, Grubben 1977, Burkill 1985, Dupriez et De Leener 1989, Stevels 1990, Lisowski 1991, Konda Ku Mbuta et al. 1992, Peters et al. 1992, Fichtl et Adi 1994, Schippers 2002

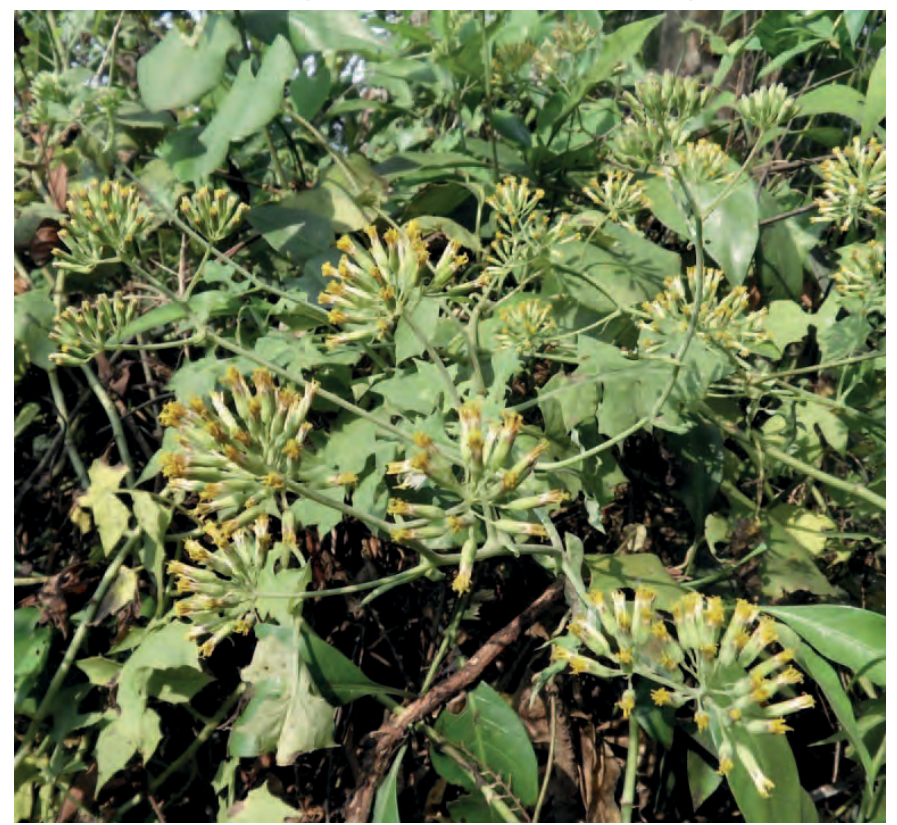




\section{Solanum aethiopicum}

Noms courants : Binsukula, biwansi (groupe binsukula), kinsumba, musoso (Kikongo), bilolo (Lingala) (groupe kinsumba), tomate amère (Fr.), scarlet eggplant (Angl.)

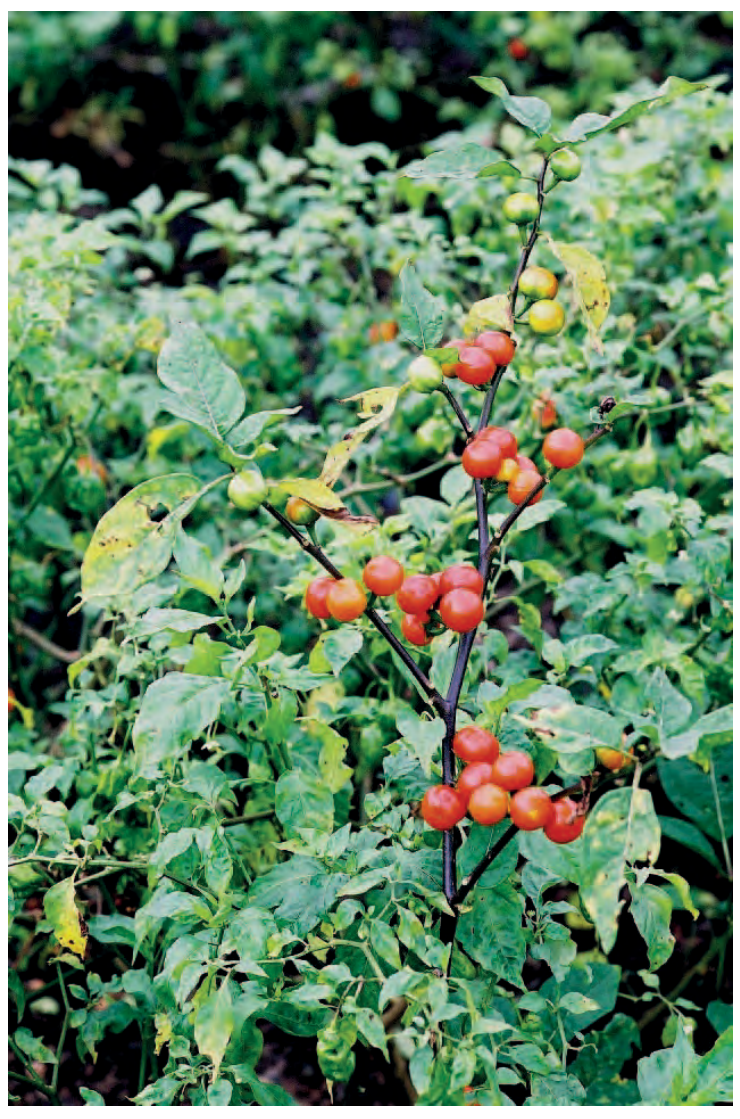

Description: Plante herbacée annuelle ou vivace, atteignent $1 \mathrm{~m}$ de haut, souvent très ramifiée. Une plante du groupe Binsukula porte normalement 1 à 3 fruits de 2,5 à $12 \mathrm{~cm}$, d'abord blancs à verts, puis orange à rouge à maturité. II y en a trois variétés présentes au Kongo Central, avec des fruits longs, courts, en forme de prunes ou ronds. Le groupe Kinsumba a de petits fruits ronds, de 1 à $3 \mathrm{~cm}$ de diamètre, solitaires ou en grappes. II y a des variétés à gros fruits ( $30 \mathrm{~mm}$ de diamètre), dont on mange les fruits et les feuilles, et des variétés à petits fruits ( $20 \mathrm{~mm}$ de diamètre) dont on mange seulement les feuilles. La plante est pollinisée par les abeilles.

A gauche : Kinsumba cultivée en fond de vallée à Kavwaya

Ecologie: Plante largement cultivée dans les fonds de vallées en saison sèche. Elle demande des sols fertiles, profonds et bien drainés., avec du compost si possible. La variété Binsukula prospère en plein soleil. La variété Kinsumba pousse mieux en conditions chaudes et humides ; elle perd ses feuilles en périodes sèches.

Reproduction : Récolter les graines de fruits bien mûrs, les laver et les sécher sur un linge ou sur du papier, mais pas en plein soleil. Semer en germoir et transplanter au bout d'environ 5 semaines. Planter Binsukula tous les 50 à 100 $\mathrm{cm}$ en lignes espacées de 75 à $100 \mathrm{~cm}$; Kinsumba tous les 20 à $30 \mathrm{~cm}$ en lignes espacées de 60 à $75 \mathrm{~cm}$.

Gestion : La culture a besoin de paillage en saison sèche. Les abeilles sont importantes pour la pollinisation.

Usages : On mange aussi bien les fruits que les feuilles de certaines variétés de Kinsumba. Pour les autres, on mange seulement les feuilles. Le contenu en protéines des feuilles fraiches dépasse légèrement $4 \%$, ce sont de bonnes sources de vitamines. On peut sécher et mettre en poudre les feuilles pour un usage ultérieur en sauces ou avec de la pâte d'arachides. On mange seulement les fruits de Binsukula. On les sèche au soleil et on les réduit en poudre pour les sauces ou comme médicament contre I'hypertension.

A droite : Binsukula cultivée à Ladi

Références : Renier 1948, Daeleman et

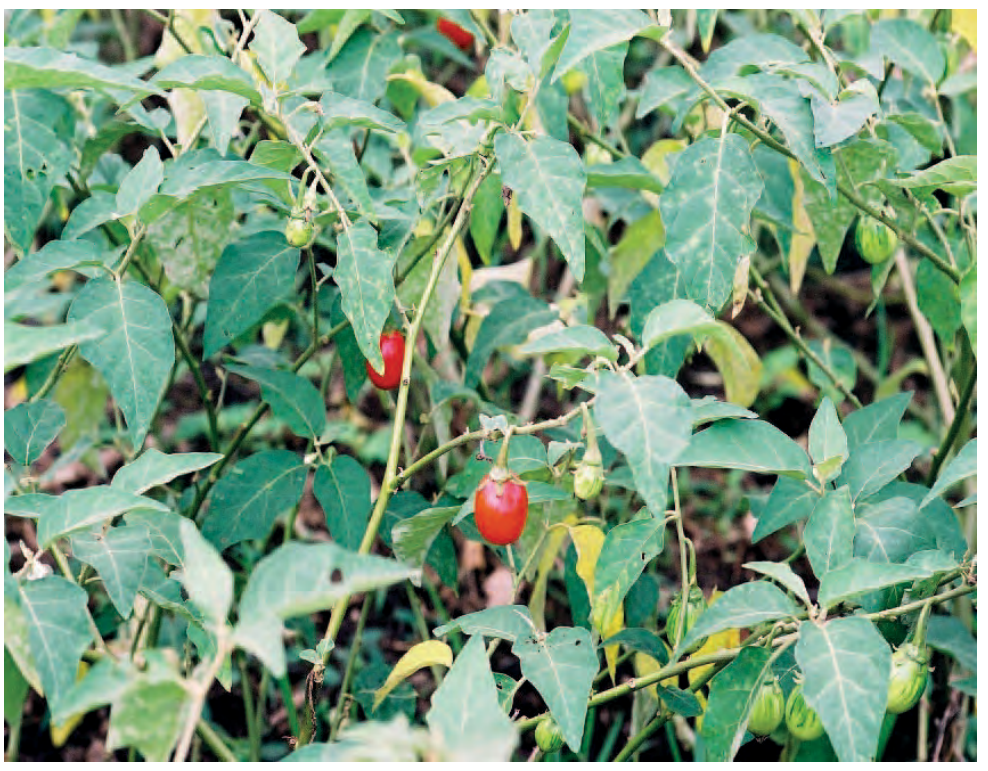
Pauwels 1983, Mbemba et Remacle 1992, Schippers 2002, Bikandu et al. 2020 


\section{Solanum lycopersicum}

Synonyme : Lycopersicon esculentum

Noms courants : Lumantu (Kikongo), tomate (Fr.), tomato (Angl.)

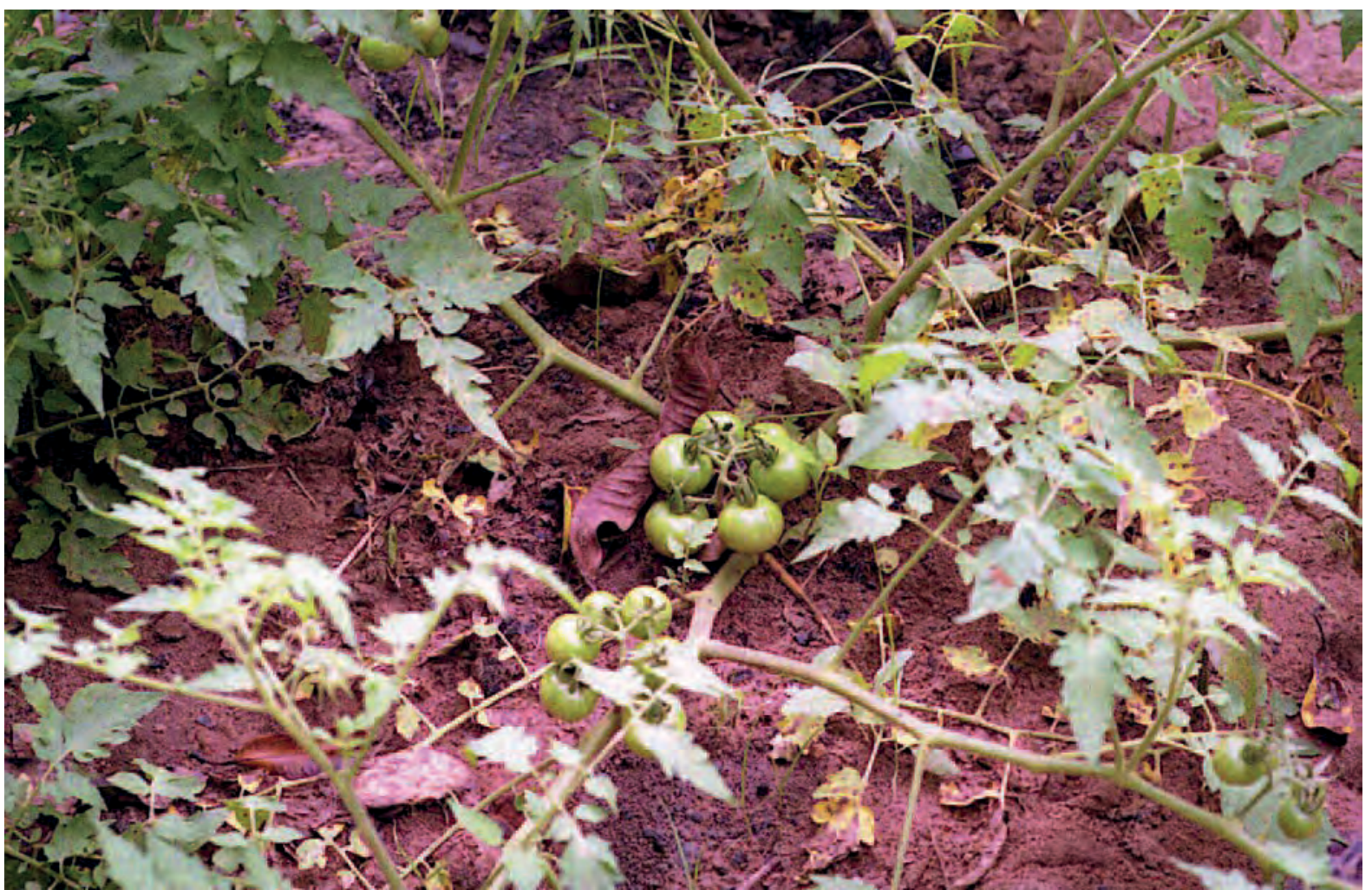

Description : Le plant de tomates est une plante herbacée sensible au froid, vivace en climat chaud, généralement annuelle. Son port dressé en début de croissance, devient retombant ou semi-retombant au fil de la croissance et de la ramification des tiges, nécessitant des supports selon les types de culture. Son système racinaire est de type pivotant à tendance fasciculée. Très dense et ramifié sur les trente premiers centimètres, il peut atteindre un mètre de profondeur. La tige est anguleuse, épaisse aux entrenœuds, pubescente. La tige et les feuilles portent des poils glanduleux contenant une huile essentielle qui donne son odeur caractéristique à la plante. Les feuilles, alternes, longues de 9 à $31 \mathrm{~cm}$, sont composées, imparipennées, et comprennent de 5 à 7 folioles aux lobes très découpés. Le bord du limbe est denté. Le calice compte cinq sépales verts. Ce calice est persistant après la fécondation et subsiste sur le fruit. La corolle compte cinq pétales jaune vif, soudés à la base, souvent réfléchis en arrière, et formant une étoile à cinq pointes. Les fruits charnus sont des baies normalement à deux loges, parfois trois ou plus, à graines très nombreuses. Ils sont très variés par la taille, la forme et la couleur. Leur taille va de quelques grammes (tomate groseille, tomate cerise) à près de deux kilogrammes. Leur forme est généralement sphérique, plus ou moins aplatie, plus ou moins côtelée, mais il en existe en forme de cœur ou de poire. Leur couleur, d'abord verdâtre, tourne généralement au rouge à maturité.

Ecologie : La première domestication de la tomate à gros fruits est vraisemblablement intervenue dans le Mexique actuel, où l'ont trouvée les conquérants en 1519. L'espèce Solanum lycopersicum compte plusieurs variétés botaniques, dont: Solanum lycopersicum var. esculentum à gros fruits, c'est la tomate cultivée de laquelle découlent presque toutes les variétés (cultivars) disponibles; et solanum lycopersicum var. cerasiforme, la tomate cerise. Au Kongo Central, la tomate est devenue subspontanée, les plantes étant des dérivées lointaines de diverses variétés améliorées, avec souvent de petits fruits ; on peut cependant se procurer des semences de bonne qualité auprès des fermes semencières (par exemple Seprosem). La tomate demande un sol fertile et bien drainé. II lui faut une fumure adéquate pour avoir une bonne récolte. Les tomates poussent bien sur des sols légèrement acides. On les cultive couramment dans les potagers en fonds de vallées en saison sèche ; pendant les pluies, elles sont sujettes à la brunissure et à d'autres maladies. Eviter autant que possible les sols où l'on a déjà cultivé des tomates.

Reproduction : Les tomates s'auto-pollinisent à $25 \%$. Sélectionner des graines de plantes qui poussent bien et donnent des fruits précoces de bonne forme et belle couleur. Enfermer les graines trois jours dans un sachet en plastique pour laisser fermenter la gelée qui les entoure. Tamiser, laver, et sécher. Semer les graines en pépinière à la fin de la saison des pluies et transplanter les semis à 8 à $10 \mathrm{~cm}$. N'arrosez pas les semis dans la semaine avant la transplantation, sauf 12 heures avant de les enlever. Planter en lignes espacées de 70 à $90 \mathrm{~cm}$, avec des 
écartements de 30 à $38 \mathrm{~cm}$ le long des lignes. La pépinière doit également être située sur un sol où l'on n'a pas cultivé de tomates auparavant, pour éviter les dommages dus aux nématodes.

Gestion : Arroser à la base de la plante, et jamais sur les feuilles, pour éviter la brunissure et d'autres maladies des feuilles. En désherbant, ne bêchez pas profondément, pour éviter d'endommager les racines nourricières superficielles de la plante. Espacer les plantes pour permettre à l'air de circuler. Pour réduire les infections dues aux nématodes des nodosités des racines (Meloidogyne), un traitement efficace est d'appliquer au sol une décoction des feuilles de Tabernanthe iboga.

Usages: La tomate est un légume important. Les fruits mûrs sont légèrement acides, ils se mangent crus en salade, ou cuits dans de très nombreuses préparations culinaires, seuls ou avec d'autres aliments, poisson, viande ou autres légumes. Les tomates sont une bonne source de vitamines $A$ et $C$, particulièrement quand les fruits ont mûri sur la plante. La tomate est, selon la FAO, le premier légume au niveau mondial en termes de volume de production, devant la pastèque et le chou, mais derrière la pomme de terre et la patate douce, ces deux dernières étant toutefois plutôt considérées comme des féculents. La production de tomates connait deux grandes filières : la tomate de marché pour la consommation en frais, et la tomate d'industrie pour les conserves, concentrés, ketchup et diverses préparations. On pile parfois les feuilles pour les appliquer sur les blessures.

Références : Gillet 1927, Daeleman et Pauwels 1983, Tindall 1983, Mukoko Matondo 1991, Siemonsma et Kasem Piluek 1993, Tabula et al. 2005, Bikandu et al. 2020

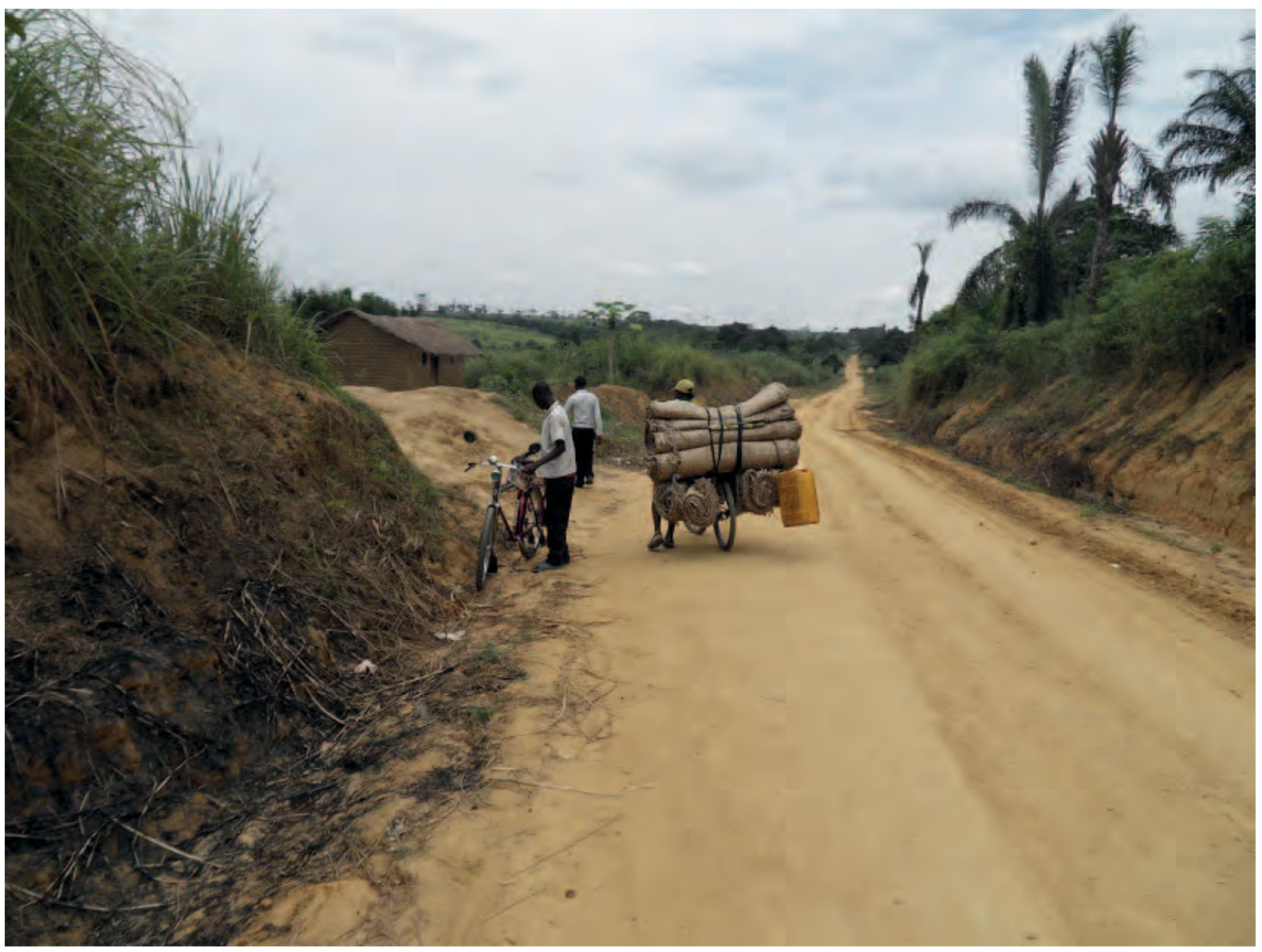

Un commerçant transportant des tapis de couchage fabriqués à partir de Pandanus candelabrum 
Noms courants : Nkeka (Kikongo), fausse tomate, aubergine africaine, gboma (Fr.), Gboma egg plant (Angl.)

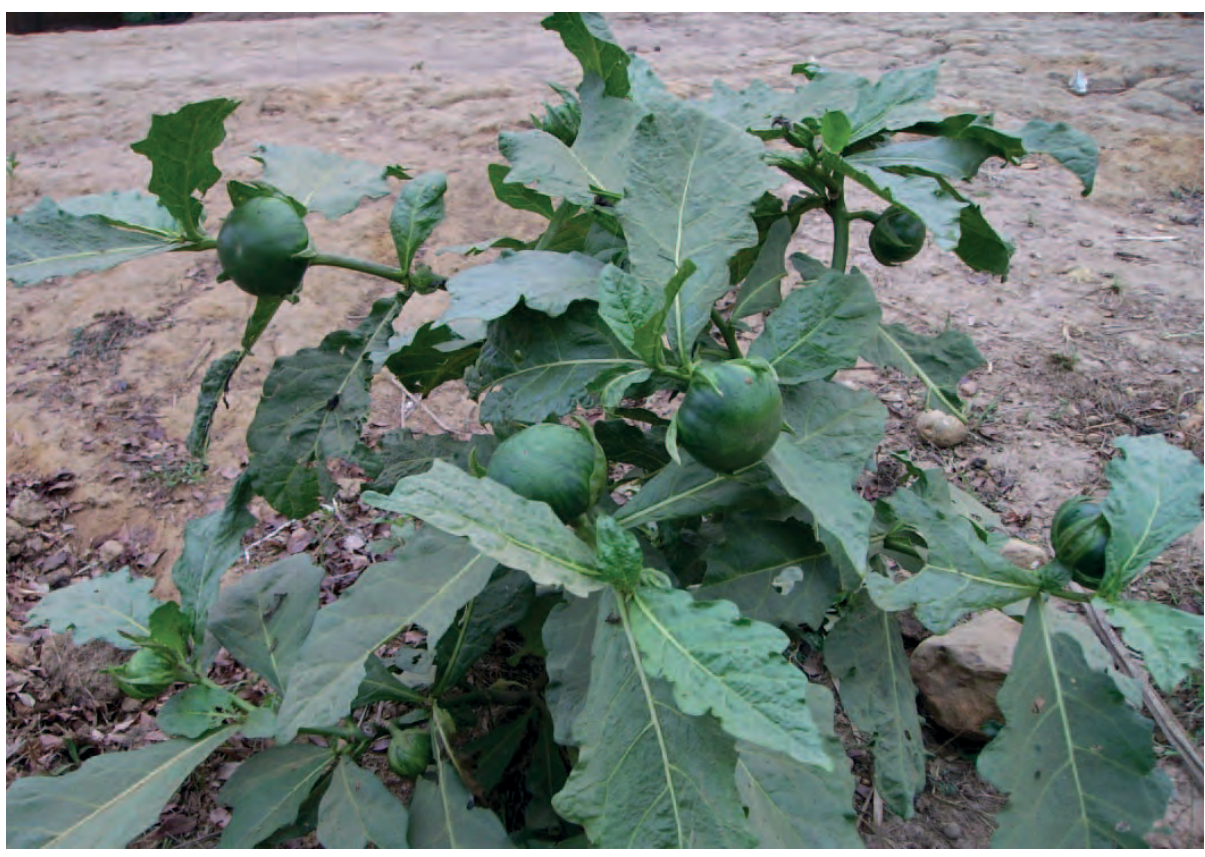

Description : Plante herbacée vivace ramifiée pouvant atteindre $2 \mathrm{~m}$ de haut. Feuilles alternes, ovales et lobées à marge ondulée, de 10 à 35 sur 6 à $20 \mathrm{~cm}$, poilues et parfois épineuses. Fleurs d'un diamètre de 3.5 à $5 \mathrm{~cm}$, sur une courte inflorescence pédonculée regroupant de 1 à 10 fleurs. Les fleurs ont une longueur de 2 à $5 \mathrm{~cm}$ et sont généralement pourpre ou pourpre pâle, rarement blanches. Fruits arrondis, aplatis, et présentant des portions rainurées, 4 à 6 $\mathrm{cm}$ de diamètre. Jeune, le fruit est vert, puis ivoire ou pourpre et blanc avec des rayures sombres. Mûr, il vire au jaune ou brun-jaune. II contient de nombreuses graines et est partiellement couvert par les lobes du calice.

Ecologie: Plante originaire d'Afrique de l'Ouest où elle est largement cultivée, maintenant cultivée également dans de nombreuses zones tropicales. La plante résiste bien à la sécheresse, il lui faut le plein soleil et un sol bien fumé.

Reproduction : Récolter le fruit bien mûr et le laisser fermenter dans l'eau 24 ou 36 heures. Laver et sécher les graines. Semer en pépinière puis transplanter les semis à $6-8 \mathrm{~cm}$ de haut espacés de $50 \times 50 \mathrm{~cm}$. II est important de semer sur un sol fertile.

Gestion: La récolte des feuilles commence une semaine après l'apparition des fleurs. On récolte la tige entière y compris le bourgeon terminal. Les récoltes fréquentes entrainent une croissance lente. Pour de meilleurs rendements, choisir des variétés qui reprennent rapidement.

A droite: On coupe le fruit mûr en morceaux puis on le sèche une semaine. On peut alors le tremper dans l'eau puis le cuire comme légume.

Usages: On mange les jeunes feuilles et les fruits, le

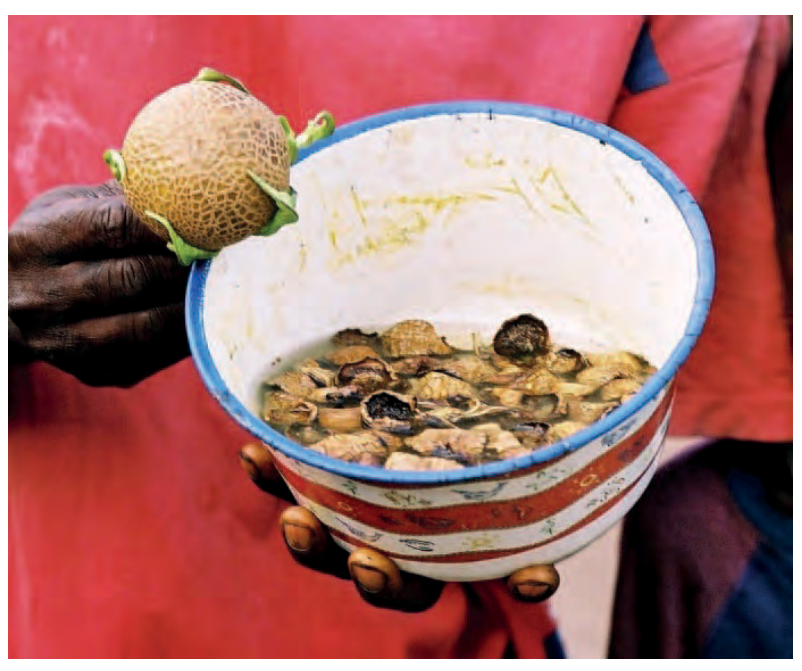
fruit pouvant remplacer la viande. C'est un légume important commercialement en Afrique de l'Ouest. Les fruits se vendent en Côte d'Ivoire et au Ghana, mais ailleurs on apprécie et on emploie surtout les jeunes feuilles, particulièrement celles des variétés de couleur sombre. On peut les récolter sur une longue période. On peut manger les fruits crus, mais plus souvent bouillis ou frits. On ajoute les feuilles aux soupes et aux sauces. Les fleurs aussi sont comestibles. Les feuilles sont riches en calcium. Cependant, il ne faut pas en manger trop souvent, surtout pour les variétés amères ; il faut bien les cuire et jeter l'eau de cuisson. La chenille Munsona sona, le sphinx tête de mort (Acherontia atropus), broute la plante ; certains la mangent, mais elle est nuisible pour les apiculteurs, détruisant les rayons pour manger le miel.

Références : Gillet 1927, De Wildeman 1934, Renier 1948, Grubben 1977, Daeleman et Pauwels 1983, Tindall 1983, Schippers 2002, Bikandu et al. 2020 
Noms courants : Tête de cochon (Fr.), nipple fruit (Angl.)

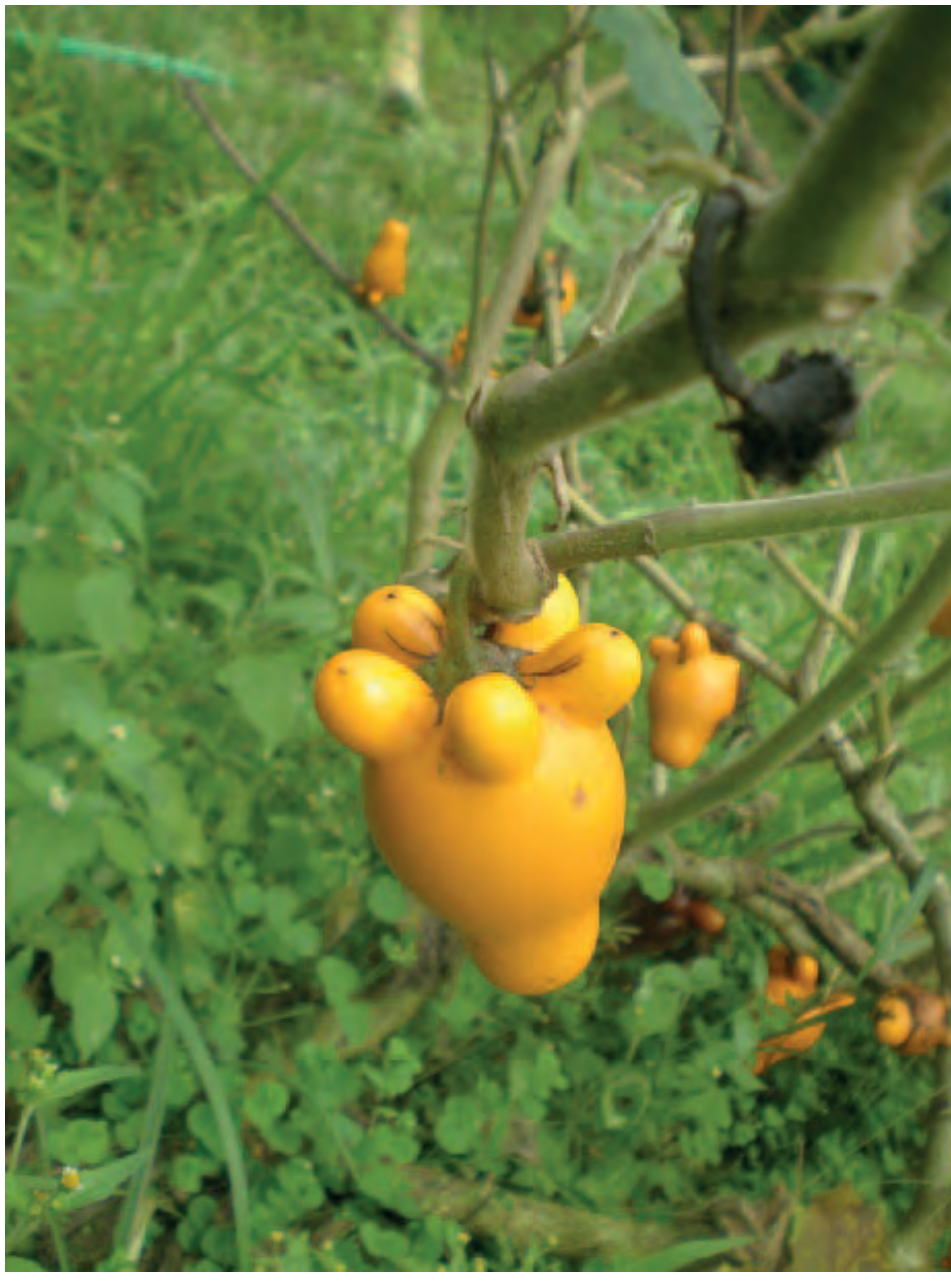

Description : Plante herbacée ou buissonnante pouvant avoir $2 \mathrm{~m}$ de haut. Feuilles longues de 8 à $17 \mathrm{~cm}$, ovales, armée d'épines aplaties jusqu'à $3 \mathrm{~cm}$ de long ; pétioles de 5 à $12 \mathrm{~cm}$. L'inflorescence est un court racème à plusieurs fleurs. Les fleurs sont profondément lobées, avec une corolle mauve 2 à 3 fois plus grande que le calice. Fruit orange ou jaune, jusqu'à 5,5 $\mathrm{cm}$ de diamètre, souvent muni d'une excroissance de $2 \mathrm{~cm}$ en forme de téton; et portant parfois à la base une ou plusieurs parties saillantes comme des tétons. L'intérieur du fruit est spongieux.

Ecologie: Plante originaire d'Amérique centrale et méridionale. Présente dans les savanes herbeuses, les bords de routes, les friches et les terres cultivées là où il pleut beaucoup. Cultivée comme plante ornementale dans les jardins.

A gauche et en dessous: Fruits et feuilles au jardin botanique de Kisantu.

Reproduction : Par graines

Usages : Plante employée traditionnellement pour le traitement de l'asthme, et pour prendre soin des pieds des athlètes. On peut prendre le jus des fruits en guise de savon pour laver les vêtements. En Colombie et en Equateur, on emploie la plante pour éloigner les cafards. Le fruit mûr est toxique; mais, vert, on peut le cuire et le manger ; il constitue une

bonne source de calcium, phosphore, fer et vitamine $B$. En Amérique centrale et du Sud, cette plante sert à attraper les poissons.

Remarque: A Cuba, cette plante est devenue envahissante.

Références : Bikandu et al. 2020, CABI Invasive Species Compendium (consulté le 22.8.2018), Wikipedia (consulté le 22.8.2018), Bikandu et al. 2020

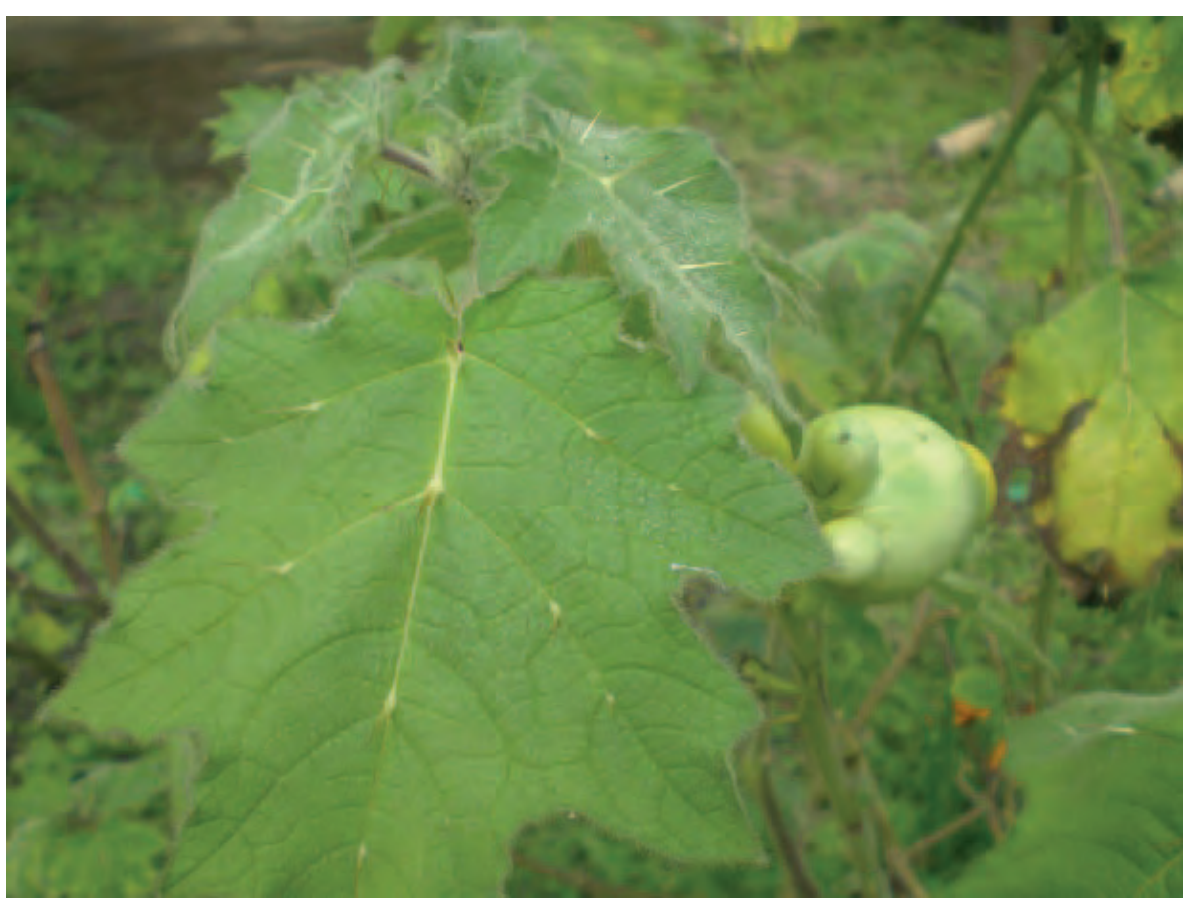




\section{Solanum melongena}

Noms courants : Mbolongo (Kikongo), solo (lingala), aubergine (Fr.), egg plant (Angl.)

Description: Plante herbacée vivace à courte durée de vie, ramifiée, de 0,2 à $0,5 \mathrm{~m}$ de haut. Elle est pourvue d'une racine pivotante vigoureuse à croissance rapide. On la cultive habituellement comme plante annuelle. Tiges et feuilles avec ou sans épines et densément couvertes de poils étoilés. Feuilles alternes, pétiole de 1 à $10 \mathrm{~cm}$ de long ; limbe ovale de 10 à $23 \mathrm{~cm}$ sur 9 à $15 \mathrm{~cm}$. Fleurs souvent solitaires, ou en cymes par groupes de 1 à 8 . Fleurs avec pédicelle de 2 à 3,5 mm de long, atteignant $8 \mathrm{~cm}$ chez le fruit ; calice campanulé, lobes d'environ 1,5 cm de long, fortement élargi et se fendant chez le fruit ; corolle campanulée à lobes largement triangulaires, de 3 à $4 \mathrm{~cm}$ de diamètre, bleu-violet pâle, rarement blanche. Fruit ovoïde contenant de nombreuses graines, de 3 à $20 \mathrm{~cm}$ de long sur 3 à $7 \mathrm{~cm}$ de large, généralement lisse et brillant, de couleur variable. II y a deux principaux types de variétés cultivés au Kongo Central, l'une à fruits violet foncé d'environ $15 \mathrm{~cm}$ de long, et l'autre à fruits verts d'environ $8 \mathrm{~cm}$ de long.

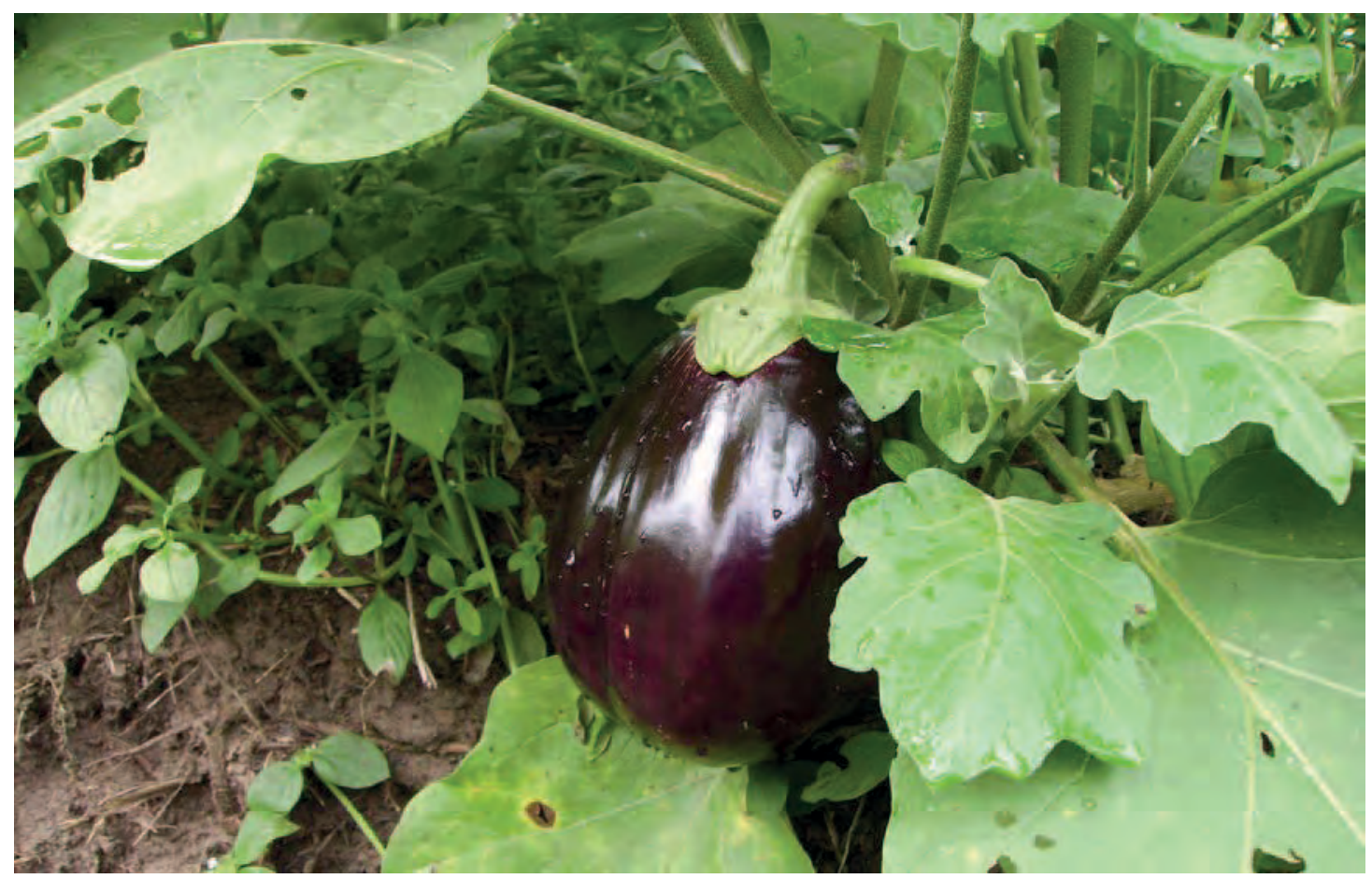

Aubergine cultivée dans un potager en fond de vallée

Ecologie: Plante originaire de l'Inde, cultivée partout sous les climats tropicaux et tempérés chauds (méditerranéens). Demande un sol bien drainé, de préférence sablonneux, mais retenant bien l'humidité. La terre doit être travaillée en profondeur à l'avance. Le paillage est avantageux. Les pluies excessives gênent la croissance et la production des fleurs. On peut cultiver la plante jusqu'à $1200 \mathrm{~m}$ d'altitude.

Reproduction : On trempe souvent les graines 24 heures dans l'eau avant de les semer. Semer dans un germoir ombragé et abrité, et transplanter à $8-10 \mathrm{~cm}$ de hauteur. Planter à des écartements de 50 à $60 \mathrm{~cm}$ en lignes et entre lignes.

Gestion : On peut pincer les pousses terminales quand la plante est établie pour encourager la ramification latérale. Certaines plantes ont besoin de tuteurs.

Usages: On mange les fruits, verts ou mûrs, coupés en tranches ou en morceaux, trempés dans l'eau salée (que l'on jette ensuite), puis cuits. La plupart du temps les fruits sont consommés grillés, frits ou cuits à la vapeur, ou en ragoûts avec d'autres légumes, la viande ou le poisson, ou rôtis, braisés dans des cendres et assaisonnés avec de l'ail, de l'oignon, des épices, du sucre, de l'huile, de la sauce de soja, etc.

Références : Gillet 1927, Daeleman et Pauwels 1983, Tindall 1983, Bikandu et al. 2020 
Noms courants : Kinsumba, ndumbu, nkunga makiadi (Kikongo), morelle noire (Fr.), African nightshade (Angl.)

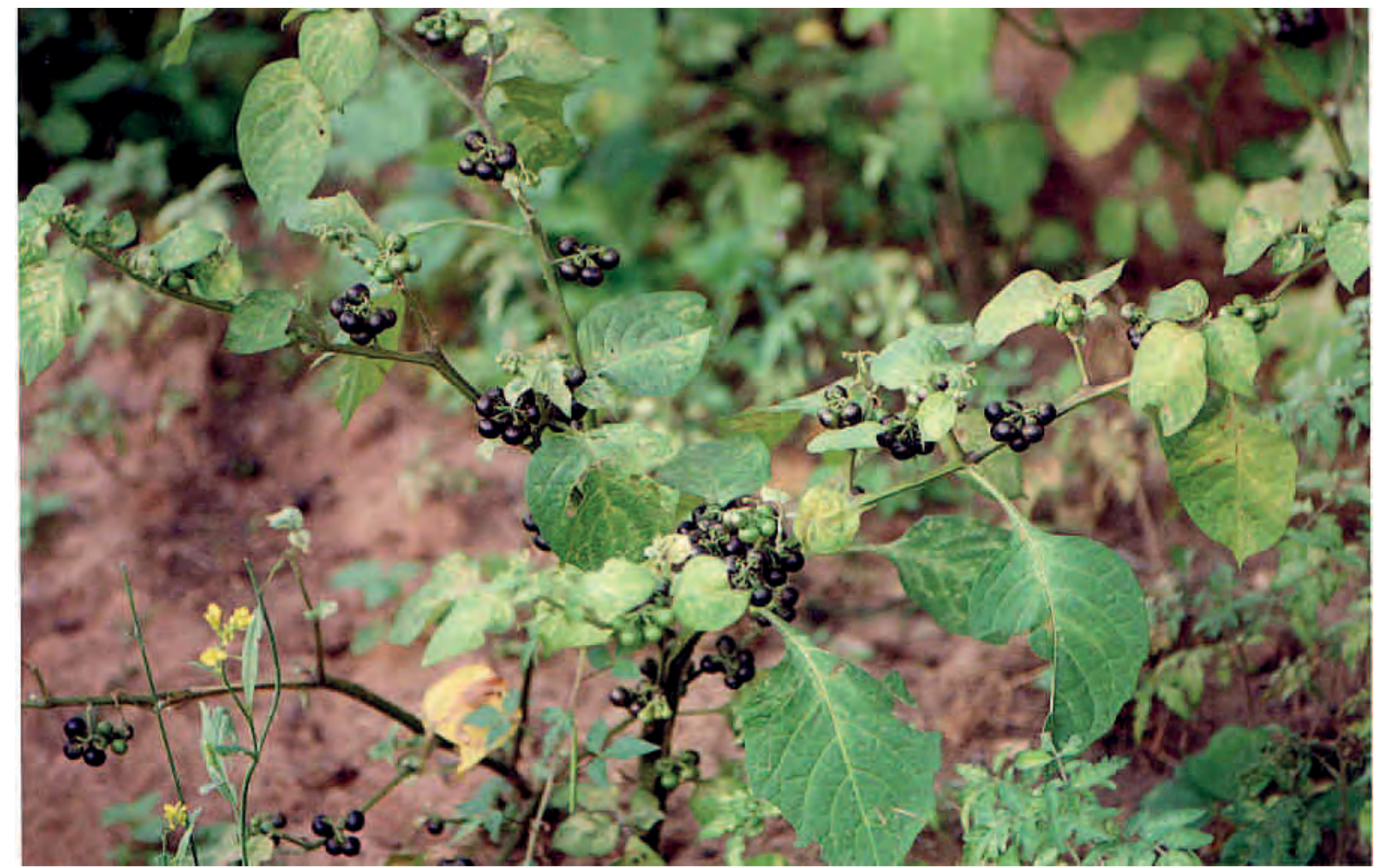

Description : Plante herbacée ligneuse à tiges vertes ou pourpres, portant des ailes plus ou moins dentées. Habituellement d'environ $60 \mathrm{~cm}$ de haut, mais pouvant atteindre $150 \mathrm{~cm}$ ou plus. II y a des cultivars à petites et grandes feuilles, avec différentes formes de feuilles; la couleur des feuilles peut être verte ou pourpre foncé. Les feuilles varient de 4 à $15 \mathrm{~cm}$ de long et 3 à $10 \mathrm{~cm}$ de large. Fleurs à corolle étoilée, de 7-12 mm de diamètre, blanche ou lavée de violet avec une étoile jaune-vert à la base, à lobes ovales-elliptiques, de 3- $6 \mathrm{~mm}$ de long. C'est la seule espèce de solanum dont les fruits demeurent sur la plante à maturité. Les fruits, pourpre foncé, de 10 à $20 \mathrm{~mm}$ de diamètre, sont veloutés quand ils sont jeunes et deviennent brillants à maturité.

Ecologie : Plante probablement originaire de la forêt tropicale humide d'Afrique. Connue comme légume cultivé dans toute l'Afrique tropicale humide, spécialement aux altitudes moyennes et élevées. On connait de nombreuses variétés cultivées, souvent d'importance seulement locale. Cultivée occasionnellement au Kongo Central.

Reproduction : Par graines ou boutures. On peut semer les graines directement, ou en pépinière avant de les transplanter. Pour une bonne germination, fertiliser le sol avec du fumier ou des cendres.

Usages: On cuit les feuilles et les jeunes pousses pour les manger comme légumes. On peut réduire leur amertume en changeant une fois l'eau de cuisson. On peut sécher les feuilles pour les mettre dans les soupes. Si on les sèche à l'ombre, la perte de produits nutritifs sera minimale. Les fruits ne se mangent pas.

Références Martin et al. 1998, Burkill 2000, Fontem et Schippers 2004, Bikandu et al. 2020 
Noms courants: Kinsukulu, ngindu ngindu (Kikongo), aubergine du diable, morelle-diable, mélongène-diable, bellangère bâtarde, aubergine pois ( $\mathrm{Fr}$ ), pea eggplant (Angl.)

Description: Buisson rampant ou grimpant pouvant avoir $3 \mathrm{~m}$ de haut. Les tiges et les branches ont

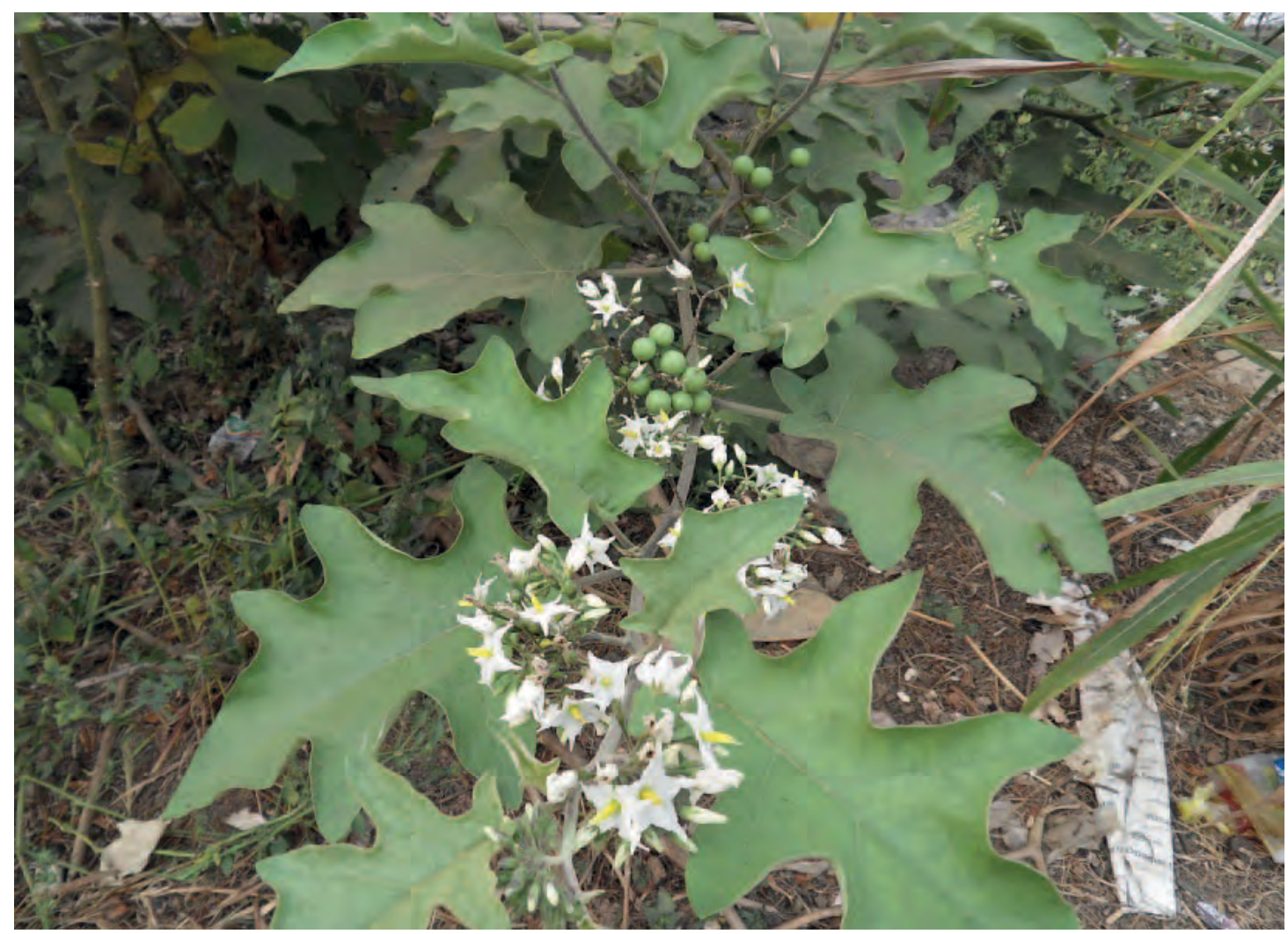

habituellement quelques épines. Feuilles alternes à 7 lobes, de 5.5 à 17 sur 4 à $12 \mathrm{~cm}$, sur un pétiole de 1,5 à 4 $\mathrm{cm}$. Inflorescence pouvant avoir 10 fleurs. Fleurs bisexuées blanches, commençant à fleurir après 3 à 4 mois, et continuant tout au long de la vie de la plante, jusqu'à 5 ans. Le fruit est une baie de 1 à $1,3 \mathrm{~cm}$ de diamètre, jaune à maturité, contenant beaucoup de graines.

Ecologie : Plante originaire d'Amérique centrale et méridionale. En Afrique de l'Ouest et du centre, on la cultive localement dans des jardins de case. On la trouve sur des sols remaniés, au bord des routes et dans les friches, où elle devient souvent une adventice difficile à contrôler. Les graines ont besoin du plein soleil pour germer, de sorte que l'ombrage peut contrôler la diffusion de cette plante.

Reproduction : Habituellement par graines en pépinière ; on transplante les semis après 5 à 6 semaines, espacés d'1 mètre. On emploie aussi des boutures de branches prélevées sur des plantes à haut rendement. Des boutures de bois semi lignifié, prélevées sur de jeunes tiges, et dont on ôte les feuilles, donneront des racines et de nouvelles pousses en 3 à 4 semaines.

Usages: Au Kongo Central, on récolte habituellement les fruits dans la brousse pour les manger. Ils sont particulièrement appréciés par les anciens; on les met en sauces ou en soupes, ou on les hache avec des aubergines et des tomates. La plante a aussi des usages en médecine traditionnelle. S'ils sont employés avec discernement, les feuilles et les fruits peuvent contrôler une large gamme d'affections microbiennes. On peut utiliser Solanum Torvum come porte greffe pour les aubergines, et éventuellement les tomates, sur les sols infesté par les nématodes Meloidogyne. Pour les tomates, Solanum aethiopicum, cultivar 'lizuka' donne de meilleurs résultats. Au Cameroun et au Nigéria, les fleurs sont un fourrage pour les abeilles et une bonne source de pollen.

Références : Bouquet 1969, Burkill 2000, Schippers 2002 et 2004, Abdullahi et al. 2011, Ingram et al. 2011, Witt et Luke 2018, Bikandu et al. 2020 


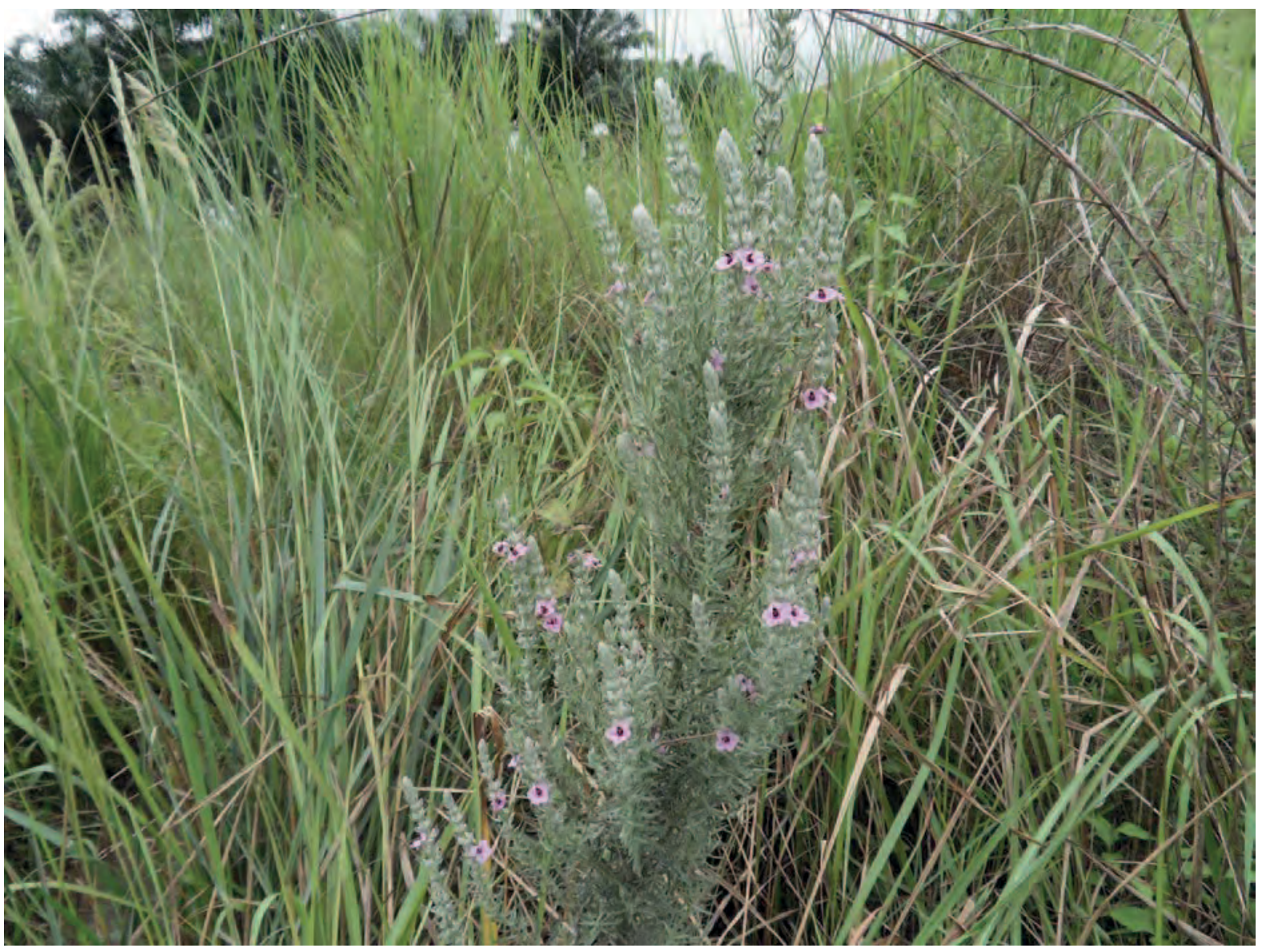

Description : Plante buissonnante pérenne jusqu'à 1 $\mathrm{m}$ de haut, très ramifiée à partir d'une base ligneuse. Feuilles grises à argentées, jusqu'à $4 \mathrm{~cm}$ de long, avec une nervure centrale proéminente en dessous. Nombreuses fleurs, roses à mauves, avec une gorge plus sombre. Le fruit est une capsule de 4 à $5 \mathrm{~cm}$ de long.

Ecologie : Plante des savanes ouvertes, herbeuses ou boisées, sur sols sableux. On la trouve de l'Angola au Rwanda et à la Zambie.

Usages : On a observé les abeilles visitant les fleurs en mars.

Références : Renier 1948, Pauwels 1982

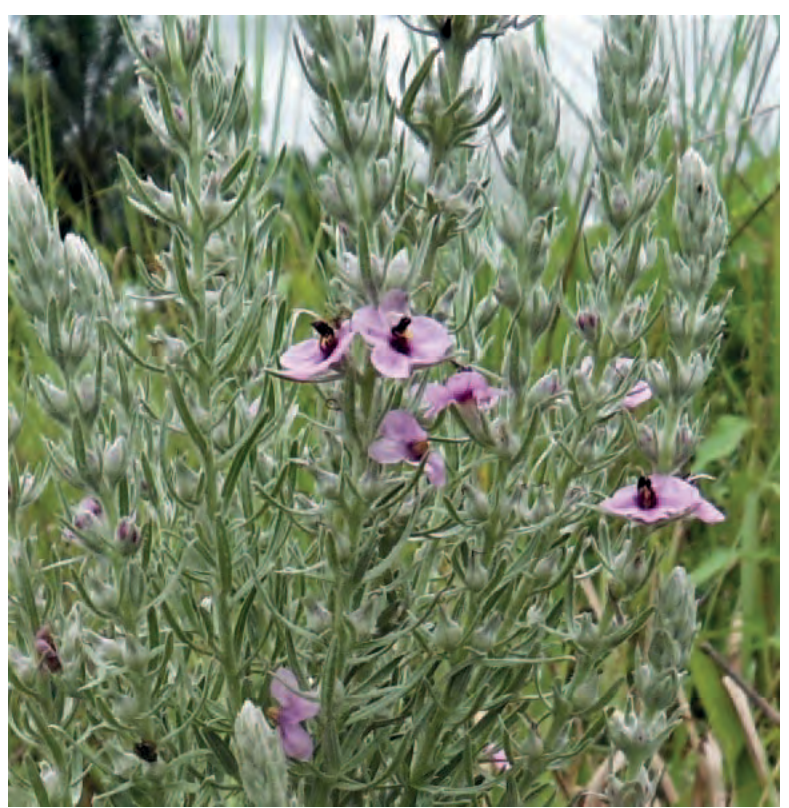


Noms courants : Ntidi, masasi mantidi (Kikongo), sorgho (Fr.), sorghum (Angl.)

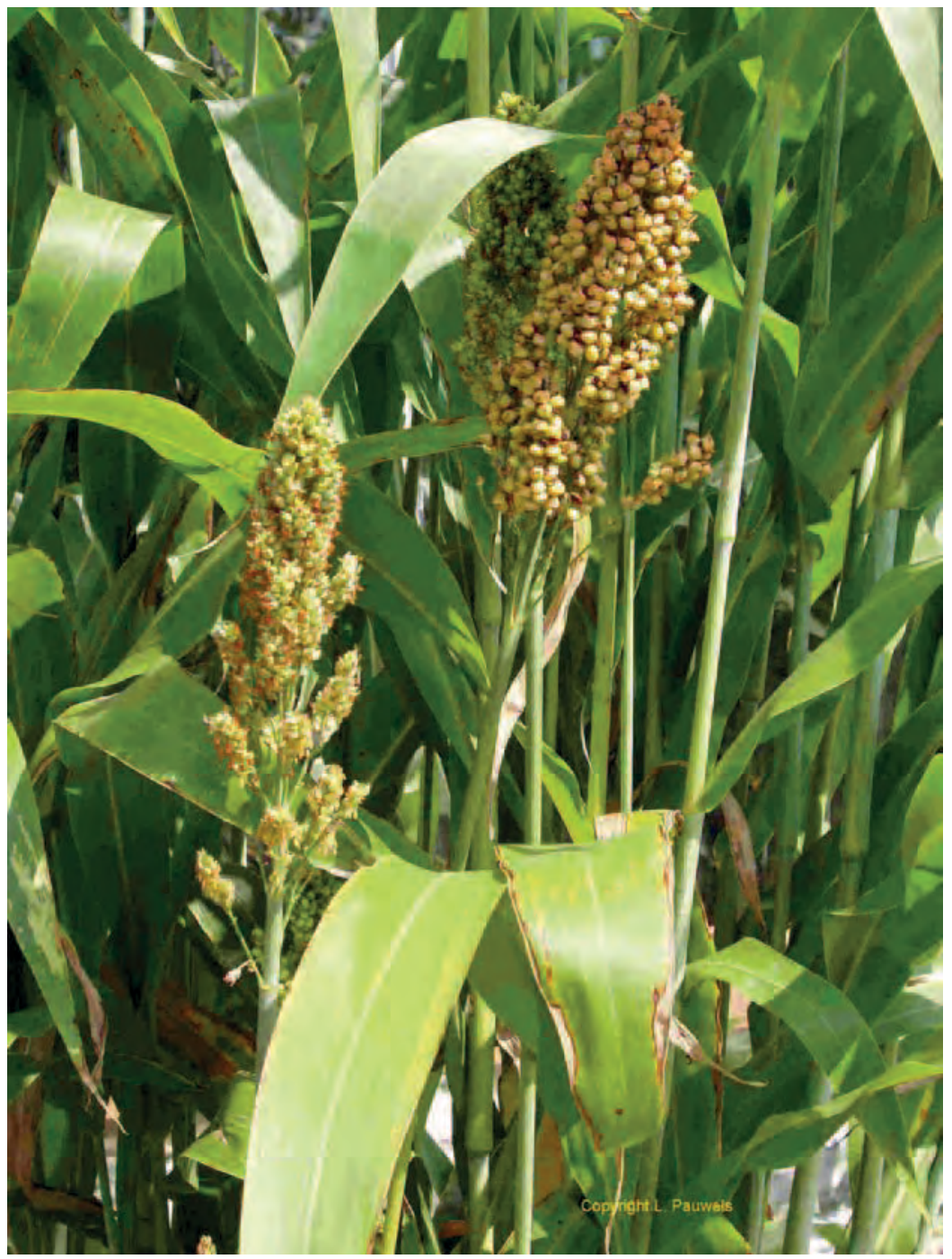

Description : Plante annuelle de 1 à $4 \mathrm{~m}$ de haut, qui ressemble au maïs et à la canne à sucre. Les tiges peuvent atteindre 50 à $300 \mathrm{~mm}$ de diamètre. Le système racinaire peut atteindre une profondeur de 1,5 à $2,4 \mathrm{~m}$. Les feuilles, alternes, ont un limbe de 30 à $100 \mathrm{~cm}$ de long sur 5 à $10 \mathrm{~mm}$ de large. Elles présentent en surface des dépôts de silice qui agissent comme une barrière physique atténuant le stress hydrique en diminuant la transpiration et contrariant la pénétration des ravageurs. L'inflorescence est une panicule de 4 à $50 \mathrm{~cm}$ de long sur 2 à $20 \mathrm{~cm}$ de large, compacte, cylindrique et dressée. Le fruit est un grain blanc crayeux de $4 \mathrm{~mm}$ environ, qui tend à se briser à maturité, et se conserve difficilement. Son taux d'humidité à maturité est encore relativement élevé ( 25 à $30 \%$ ) et la récolte doit être séchée rapidement.

Pollinisation: Les épillets de la panicule contiennent une fleur stérile et une fleur bisexuelle. L'autopollinisation, ou la pollinisation croisée, se fait normalement par le vent.

Photo: Luc Pauwels

Ecologie : Plante cultivée au nordest de l'Afrique, probablement en Ethiopie, depuis plus de 3000 ans, rapidement répandue depuis dans toute l'Afrique, puis dans les autres pays tropicaux. Pousse sur une grande variété de sols, y compris les sols temporairement inondés et dans les sols craquelés en profondeur.

Reproduction : Les graines germent en 7 jours environ.

Usages : Le sorgho est un aliment de base important, surtout dans les régions tropicales semi-arides d'Afrique et d'Asie, et c'est aussi un important aliment du bétail, tant en grain qu'en fourrage, dans les Amériques et en Australie. Dans les préparations culinaires les plus simples, on fait cuire le grain entier à l'eau (pour produire un aliment qui ressemble au riz), on le fait griller (en général au stade pâteux), ou on le fait éclater (comme le maïs). Mais le plus souvent, on moud le grain ou on le pile pour le réduire en farine, souvent après décorticage. La farine de sorgho sert à faire des bouillies épaisses ou liquides, des crêpes, des boulettes ou du couscous, des bières opaques ou troubles et des boissons fermentées sans alcool. En Afrique, on fait germer le grain de sorgho, puis on le met à sécher et on le moud pour faire du malt, que l'on utilise comme substrat de fermentation dans la production de bières locales. Au Kongo Central, on cultive rarement le sorgho comme plante alimentaire. Avec les grains, on fait une bière épaisse, capiteuse et amère. On mélange les graines de certaines espèces avec de la farine de froment pour produire un bon pain bien levé. Les grains servent aussi d'aliments pour les volailles, et les tiges comme fourrage pour le bétail.

Références : Gillet et Pâque 1910, De Wildeman 1934, Staner et Boutique 1937, Renier 1948, Purseglove 1968, Daeleman et Pauwels 1983, Crane et Walker 1984, Burkill 1994 
Noms courants : Munsasa, nsasa mpwatu, masamasa, zowa zowa (Kikongo), tulipier du Gabon (Fr.), tulip tree (Angl.)

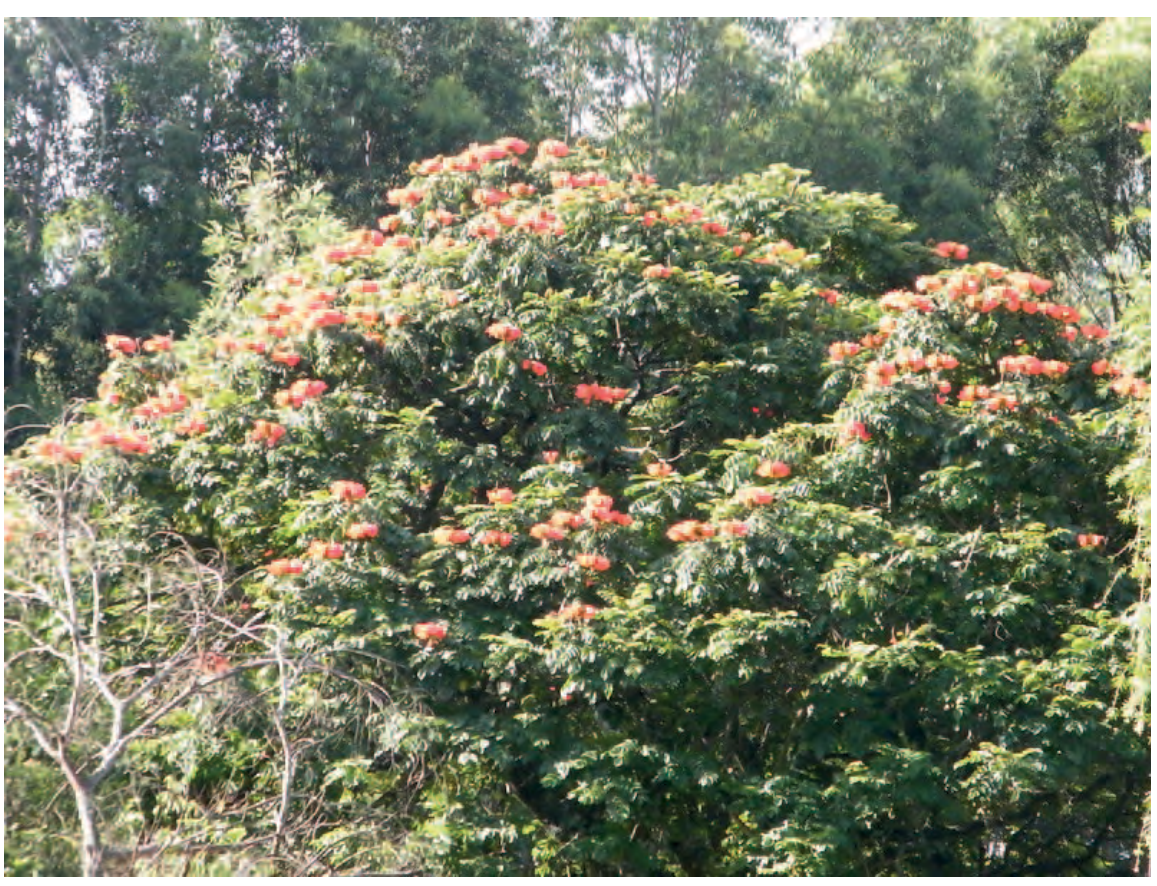

Description : Arbre jusqu'à $20 \mathrm{~m}$ avec un tronc cannelé, de courtes branches et une couronne compacte. Les feuilles caduques, opposées ou verticillées par 3, sont composées imparipennées et comptent de 9 à 15 folioles sessiles ou brièvement pétiolées. Le limbe des folioles est elliptique à ovale, acuminé, mesurant de 7 à 16 $\mathrm{cm}$ de long sur 3 à $7 \mathrm{~cm}$ de large. Les fleurs, grandes et voyantes, sont rougeécarlate, jaune-orange à l'intérieur, regroupées en racème terminal. Le fruit est une capsule déhiscente, de 15 à $27 \mathrm{~cm}$ sur 3,5 à $7 \mathrm{~cm}$. II s'ouvre par deux valves, libérant de nombreuses graines aplaties, ayant environ $2 \mathrm{~cm}$ de diamètre, entourées d'une aile translucide. La floraison commence après 3 ou 4 ans, et dure de 5 à 6 mois chaque année, voire toute l'année dans des conditions favorables. L'arbre a des racines superficielles et résiste mal aux vents violents. Les graines sont dispersées par le vent.

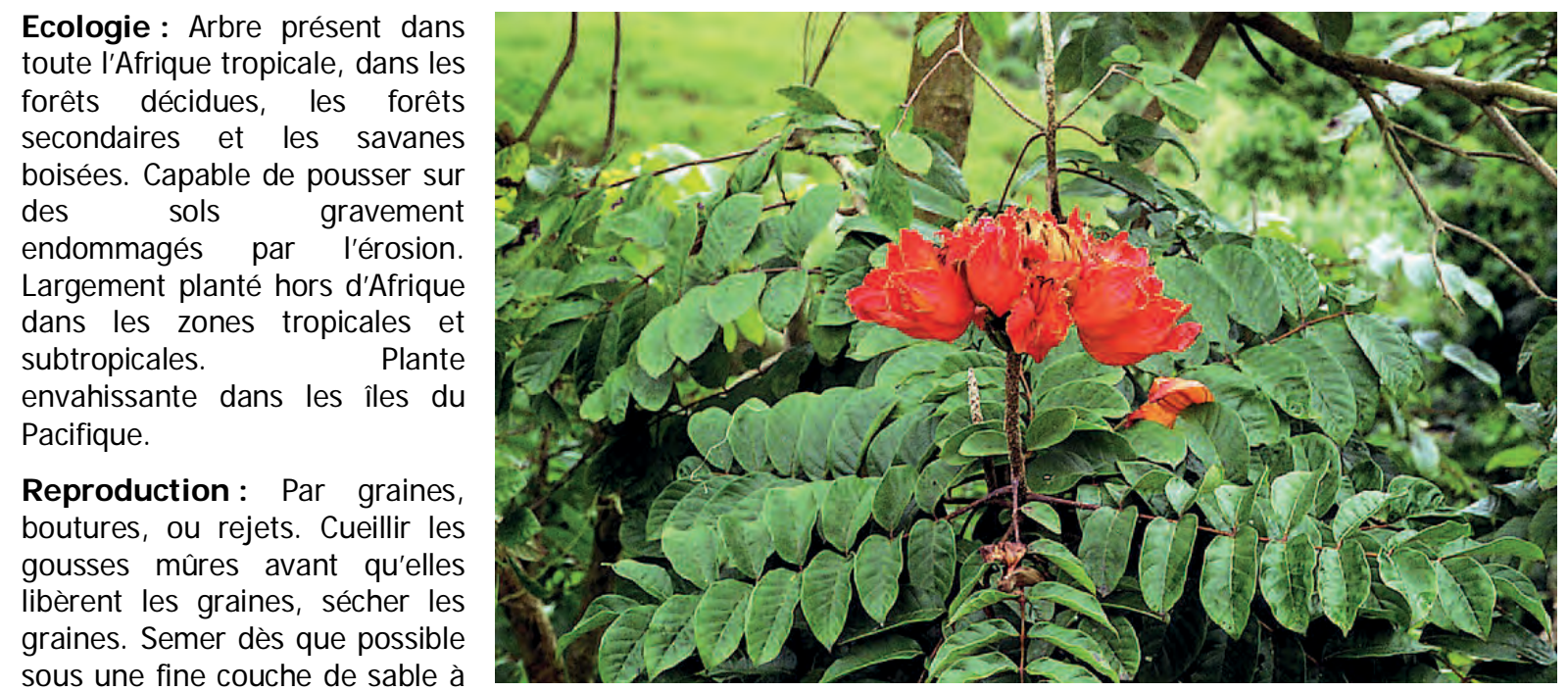
l'abri des fortes pluies. Les boutures de gros diamètre (plus de $10 \mathrm{~cm}$ ) donnent les meilleurs résultats.

Gestion : L'arbre recèpe bien, et sa croissance est très bonne.

Usages: On plante cet arbre comme arbre d'ornement et arbre d'ombrage, pour la reforestation, le contrôle des érosions, la réhabilitation des sols, et comme barrière. Le bois sert en sculpture et pour faire des tambours, mais il est de qualité médiocre, et sujet à la pourriture ; il est médiocre comme bois de feu. Au Kongo Central, on traite l'urétrite avec les feuilles trempées dans l'eau. L'écorce a des propriétés laxatives et antiseptiques. Les graines se mangent dans une grande partie de l'Afrique. L'arbre a de nombreux usages médicinaux, dans sa terre d'origine comme ailleurs. La recherche médicale étudie notamment ses effets sur le diabète, la malaria, et la schistosomiase.

Références Gillet et Pâque 1910, Renier 1948, Nsimundele 1966 - 68, Portugal-Araujo 1974, Liben 1977, Daeleman et Pauwels 1983, Burkill 1985, Bekele-Tesemma 1993, Hepburn et Radloff 1998, Msanga 1998, Bosch 2002, Orwa et al. 2009, Meunier et al. 2010 


\section{Spermacoce latifolia}

(Rubiaceae)

Noms courants: Tekasala, kimbuena, kimbundi, kisadila, kizimatiya (Kikongo, Tekasala signifie « vous devez travailler avant de manger ») ; herbe à marconnet (Fr.)

Description : Plante herbacée annuelle, de couleur vert-jaune, retombante, pouvant atteindre $1 \mathrm{~m}$ de hauteur. Tige épaisse, quadrangulaire, ailée. Feuilles opposées simples, entières ; limbe ové à nervures latérales très marquées. Inflorescence en verticille axillaire ; fleur blanche à petite corolle tubulaire.

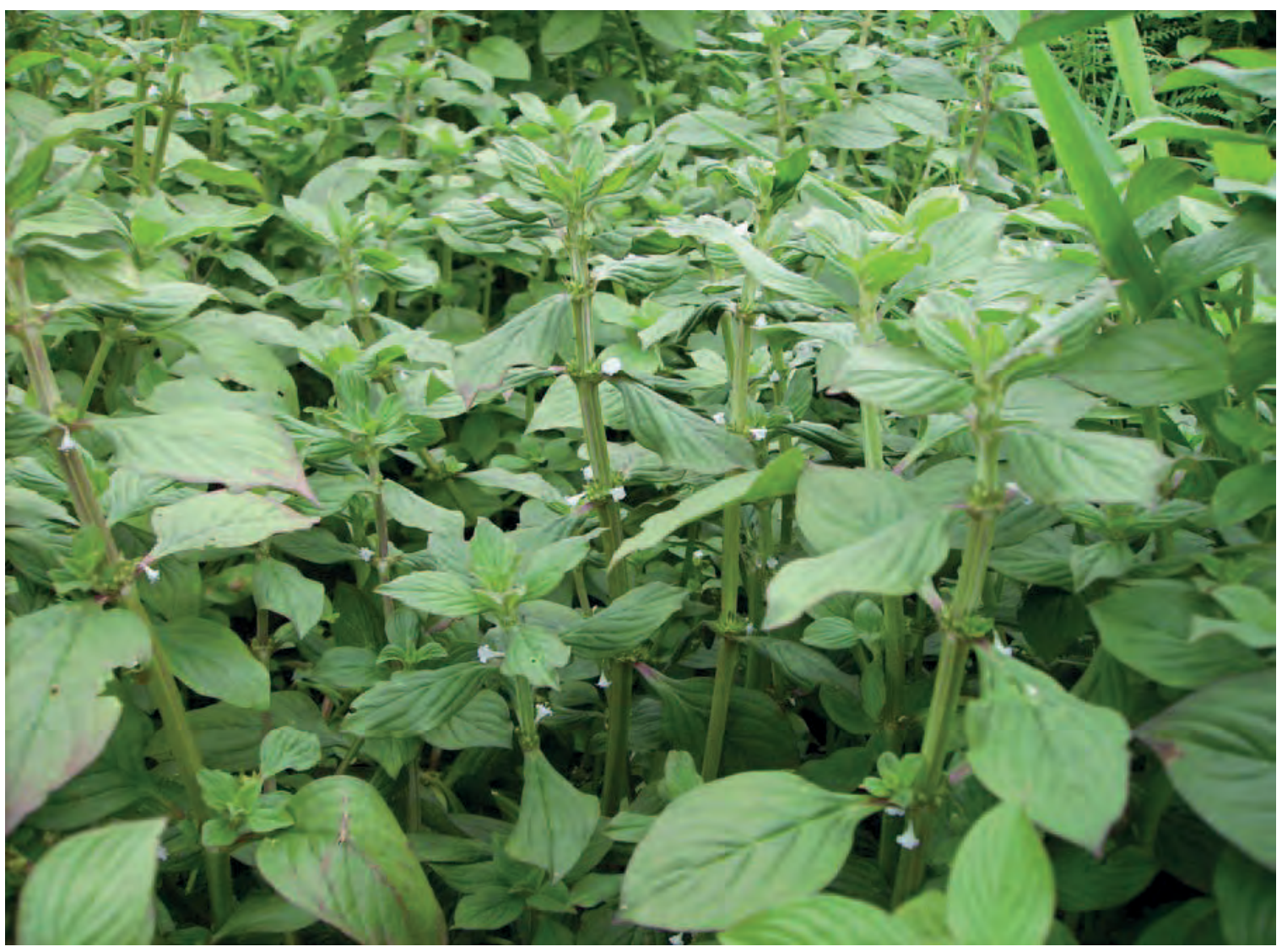

Spermacoce latifolia dans un champ de manioc en janvier

Ecologie : Herbe indésirable originaire d'Amérique du sud, commune maintenant dans plusieurs pays d'Afrique tropicale de la Sierrra Leone au Ghana; en Somalie; et notamment au Kongo Central. On la trouve dans les champs cultivés et dans les friches.

Usages : Les abeilles butinent souvent le nectar et le pollen de novembre à mars, notamment tôt le matin après les fortes pluies. C'est la plante nourricière de la chenille comestible Mimbata.

Remarque: On trouve cinq autres espèces de Spermacoce au Kongo Central.

Référence : Burkill 1997, Latham et Konda Ku Mbuta 2017

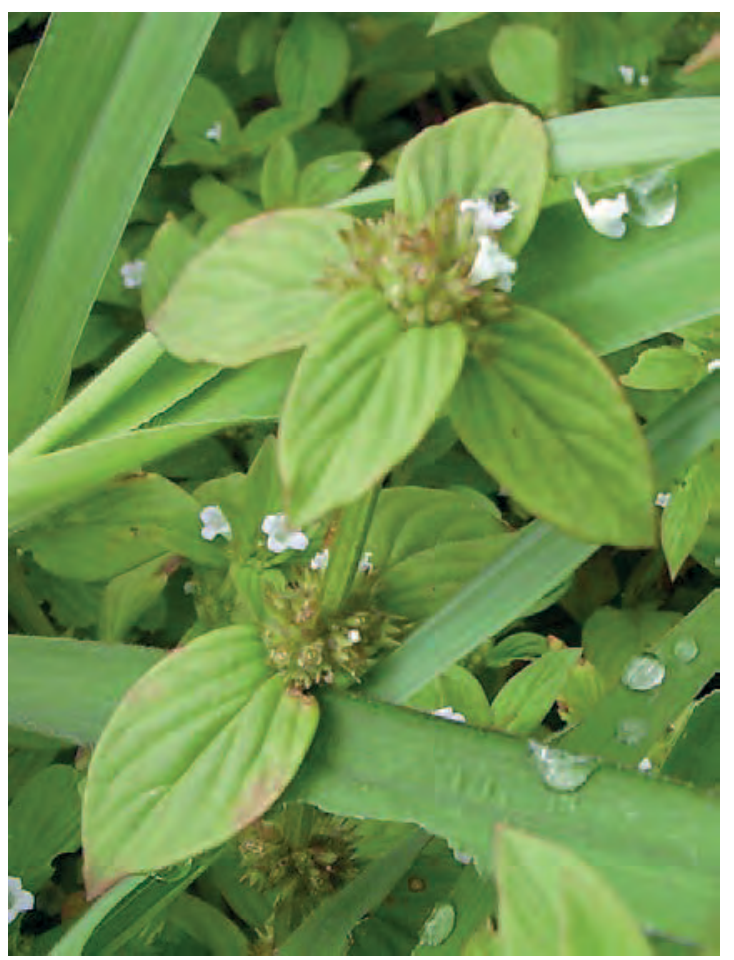




\section{Sphagneticola trilobata}

Synonyme : Wedelia trilobata

Noms courants : Creeping ox-eye (Angl.)

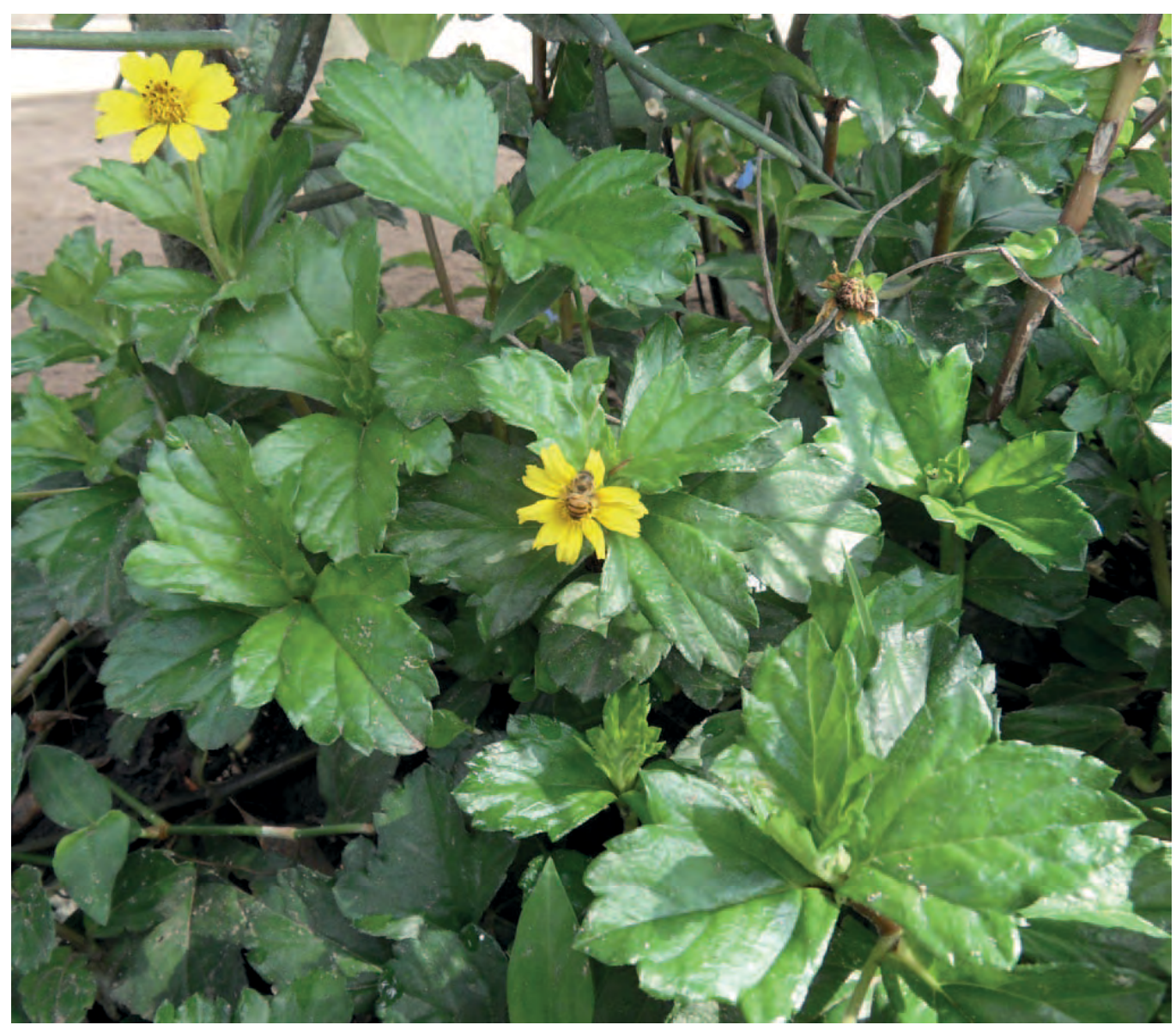

Abeille butinant le nectar en mars

Description : Plante herbacée rampante retombante portant des tiges fleuries pouvant avoir $30 \mathrm{~cm}$ de haut. Elle peut couvrir de grandes surfaces. Les feuilles sont charnues, de 4 à $9 \mathrm{~cm}$ de long sur $2,5 \mathrm{~cm}$ de large, à peu près trilobées, avec des marges dentées. Les fleurs, composées, sont jaunes et mesurent $2,5 \mathrm{~cm}$ de diamètre.

Ecologie : Plante originaire d'Amérique tropicale, largement naturalisée sous les tropiques, notamment en Guinée et Sierra Leone. Pousse aussi bien sur sols secs ou humides. Préfère l'exposition au soleil, mais survit très bien à l'ombre. Dans les plantations, elle est en compétition avec les plantes cultivées pour les nutriments, la lumière et l'eau, ce qui réduit le rendement des récoltes.

Reproduction : Se reproduit à partir des stolons, dont même de petites sections reprennent facilement. Donne peu de graines fertiles.

Usages : Cultivée comme plante ornementale au Kongo Central. Les abeilles récoltent le nectar en mars. Ailleurs, on la cultive parfois comme couverture du sol, mais elle risque de devenir invasive.

Remarque : Le nom accepté de cette plante est Sphagneticola trilobata; cependant, on la connait souvent comme Wedelia trilobata.

Références : Burkill 1985, Llamas 2003, Global Invasive Species Database (consulté le 510.2018) 


\section{Sphenostylis stenocarpa}

(Fabaceae)

Noms courants : Mpempo, mpempu (Kikongo), haricot igname africain (Fr.), African yam bean (Angl.)

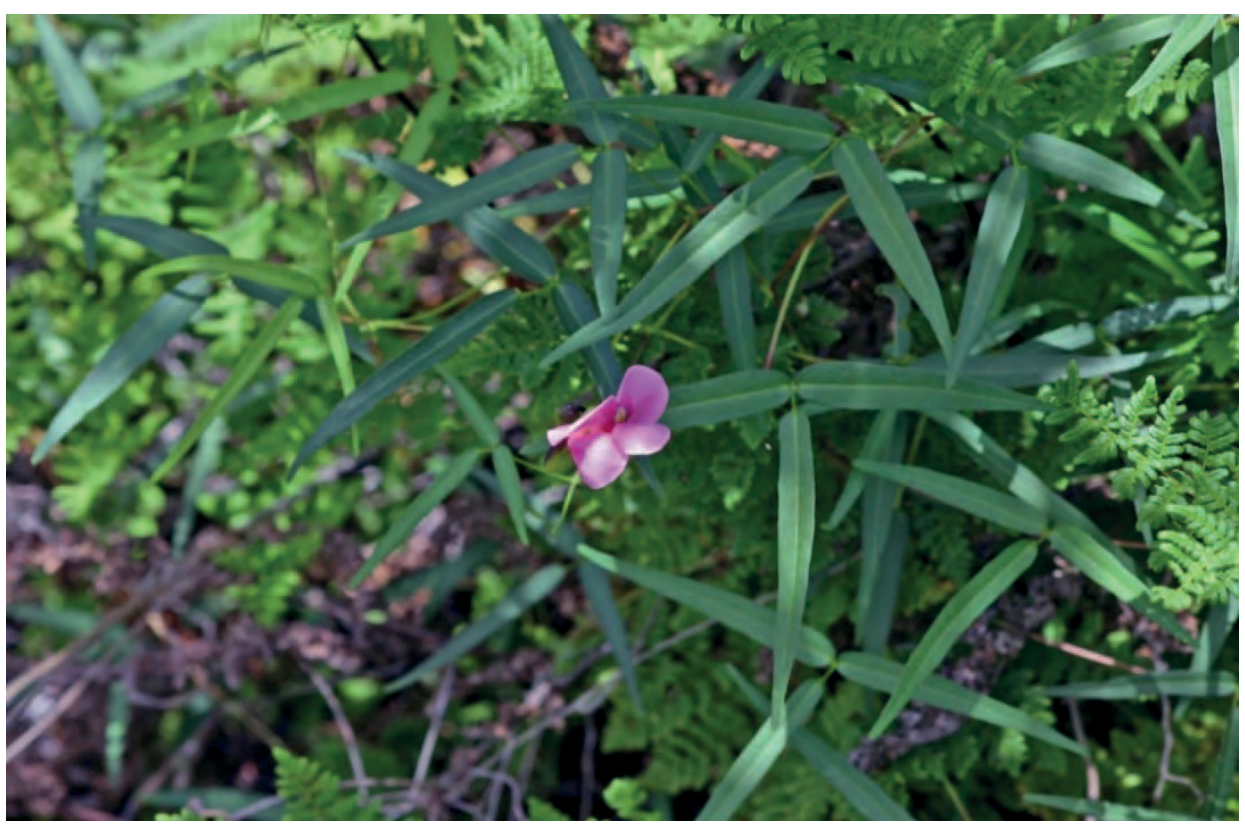

Description : Liane pérenne grimpante vigoureuse atteignant $3 \mathrm{~m}$ de long, avec des feuilles trifoliées, dont les folioles mesurent 3 à 12 sur 0,8 à $5 \mathrm{~cm}$. Fleurs très visibles, rose mauve, pourpres, ou blanc verdâtre, de 1,6 à $4 \mathrm{~cm}$ de long. Les graines sont dans des gousses linéaires plates de 10 à 20 sur 0,5 à $0,8 \mathrm{~cm}$, contenant 20 à 30 graines. La plante donne de petits tubercules en fuseau, de 5 à $7,5 \mathrm{~cm}$ de long. Elle donne des graines des tubercules après 8 mois. après 4 à 5 mois, et

Ecologie: Pante originaire d'Ethiopie. II y a des types naturels ou cultivés partout en Afrique tropicale, au sud jusqu'au Zimbabwe. Elle pousse sur des sols fertiles d'altitude, ou sur des sols sableux pauvres de plaine, ou des sols marécageux, pourvu que soit présent les Bradyrhizobia pour aider à la fixation d'azote. On la trouve en savane herbeuse ou boisée, et aussi sur des sols marécageux et des sols remaniés, de 200 à 1950 m d'altitude.

Reproduction: Par graines ou tubercules. Souvent associée avec des ignames ou des haricots, en utilisant les mêmes tuteurs que les ignames, ou en la laissant ramper sur le sol. Certains prétendent que la plante donne de meilleurs résultats en association que cultivée seule.

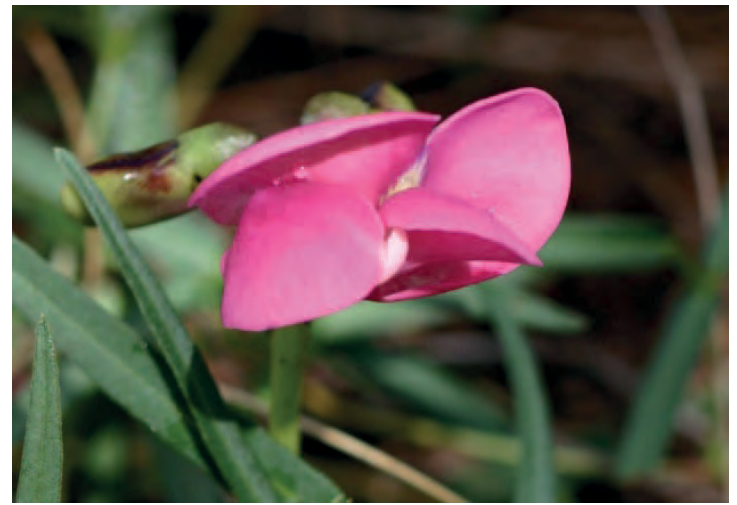

Les deux photos : Bart Wursten

Usages: Au Kongo Central, 0, mange les graines et les racines tubéreuses. II faut tremper les graines 12 heures dans l'eau, puis les cuire de 4 à 6 heures pour les manger sans risque. On peut les manger en bouillie, ou bien entières avec de l'huile de palme et des épices, ou encore mélangées avec du maïs ou des ignames. Elles contiennent de 26 à $29 \%$ de protéines et plusieurs acides aminés. Les feuilles sont comestibles, mais rarement mangées. Les tubercules contiennent de 11 à $19 \%$ de protéines. Ils peuvent peser jusqu'à $500 \mathrm{~g}$, et sont succulents, sucrés, de saveur délicate et croustillants. On peut les manger crus, les cuire à la vapeur ou les bouillir. Les tubercules et les graines se conservent bien.

Références : Gillet 1927, Greenway 1944, Renier 1948, Hauman et al. 1954, Terra 1966, Kay 1973, Duke 1981, Daeleman et Pauwels 1983, Burkill 1995, Malaisse 1997, Amoatey et al. 2000, Schippers 2002, NAS 2006 


\section{Spondias dulcis}

Synonyme : S. cytherea

Noms communs : Manga zi nsende (Kikongo), pomme de Cythère (Fr.), Otaheiti apple (Angl.)

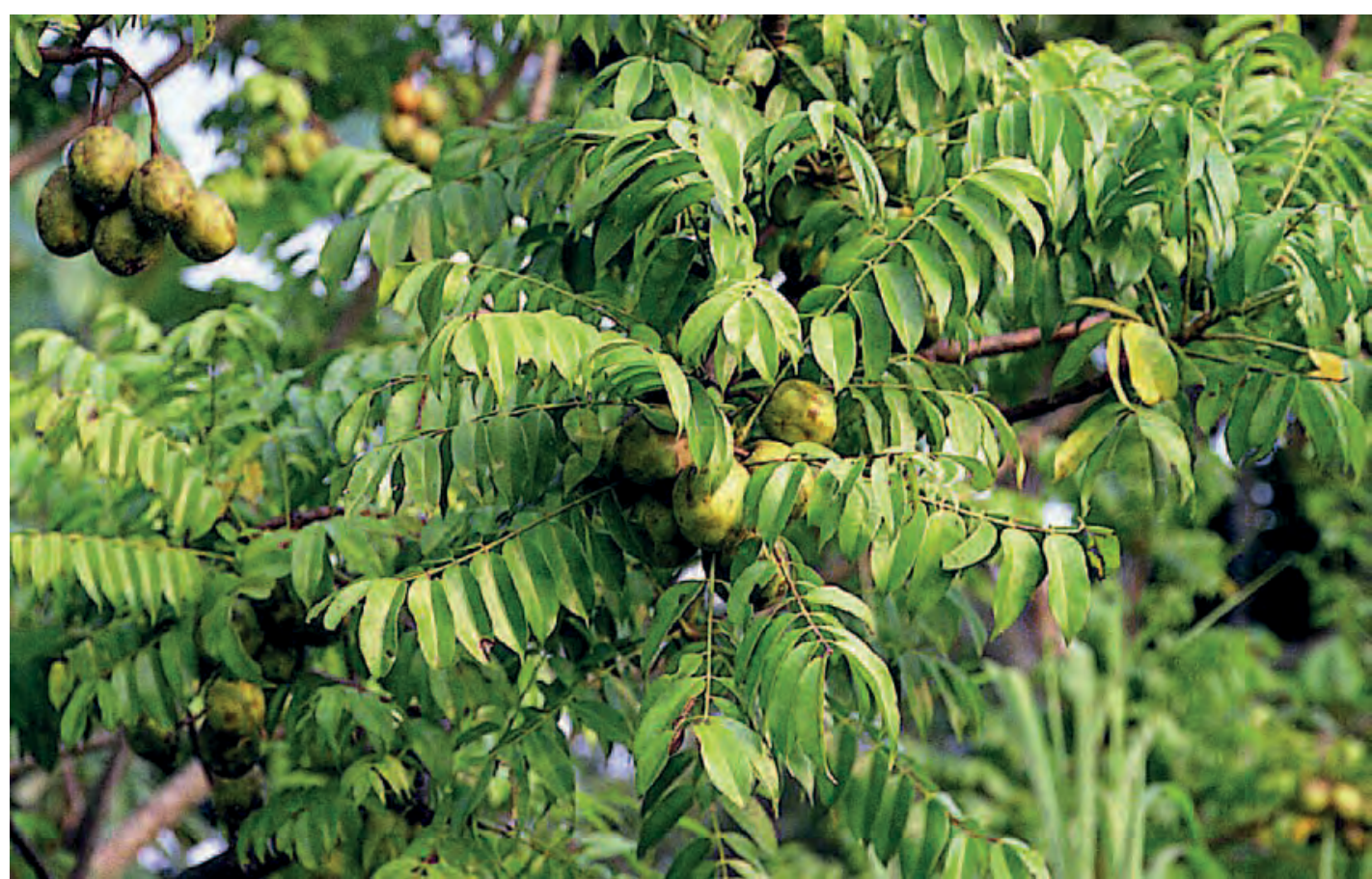

Spondias cytherea, la pomme de Cythère, portant des fruits en janvier.

Description : Arbre décidu à croissance rapide de 9 à $20 \mathrm{~m}$ de haut. Les feuilles, longues de 20 à $60 \mathrm{~cm}$, serrées à l'extrémité des branches, sont composées de 9 à 25 folioles. Les fleurs blanches sont disposées en bouquets regroupant des fleurs mâles et femelles. Les semis peuvent commencer à porter des fruits à l'âge de 4 ans. Les fruits, de 5 à 7 sur 3,5 à $5 \mathrm{~cm}$ contiennent une seule grosse graine portant quelques épines. Ils sont d'abord vert brillant, puis jaunes à maturité.

Ecologie: Arbre originaire d'Asie du sud ou du sud-est, cultivé dans d'autres pays tropicaux. Introduit en RD Congo à partir du jardin botanique de Kisantu. Préfère les sols bien drainés et ensoleillés.

Reproduction : Les graines mettent deux mois à germer. On peut aussi faire des boutures de bois dur, ou des marcottes.

Usages : Le fruit est comestible, la chair a un goût aigre doux évoquant la mangue ou l'ananas ; elle est légèrement fibreuse. On peut la cuire, mais elle prend un léger goût de térébenthine. Au Gabon, on mange les jeunes pousses. On emploie l'infusion des feuilles pour traiter les maux de gorge. On peut faire cuire les feuilles avec la viande pour attendrir celle-ci. On récolte normalement les fruits verts, et on les mange avec un peu de sel. Les fleurs devraient être une source de miel.

Les fruits peuvent être gros comme des mangues.

Références : Burkill 1985, Pauwels 1993, Roubik 1995, Hepburn et Radloff 1998, van Wyk 2005, Orwa et al. 2009

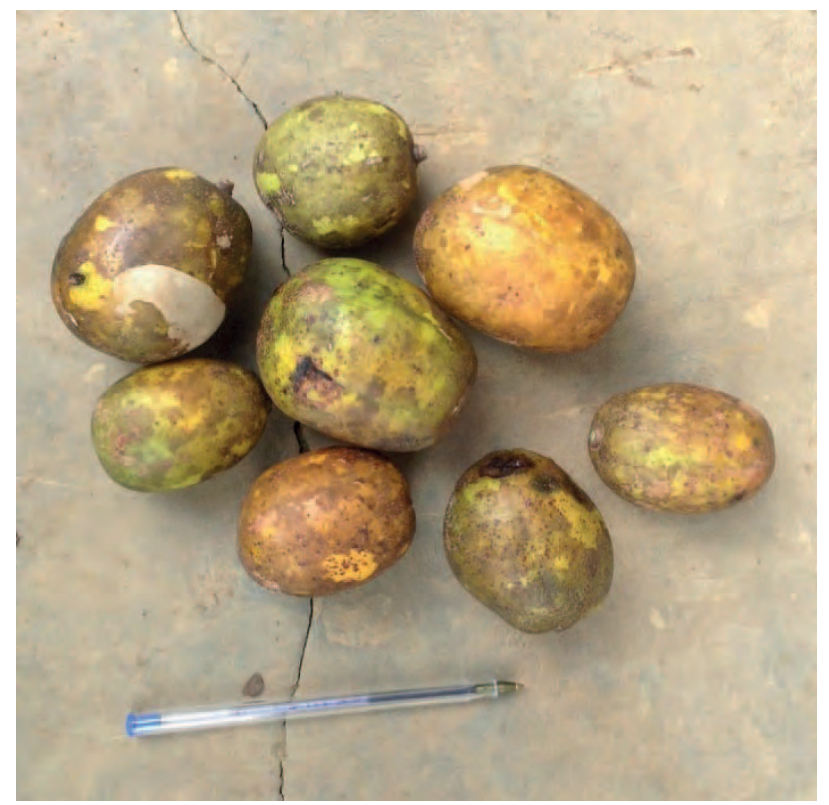


Noms courants : Mungiengie (Kikongo), prunier Mombin (Fr.), hog plum (Angl.)

Description : Arbre pouvant atteindre $25 \mathrm{~m}$ de haut. Son écorce est épaisse, liégeuse, et profondément fissurée.

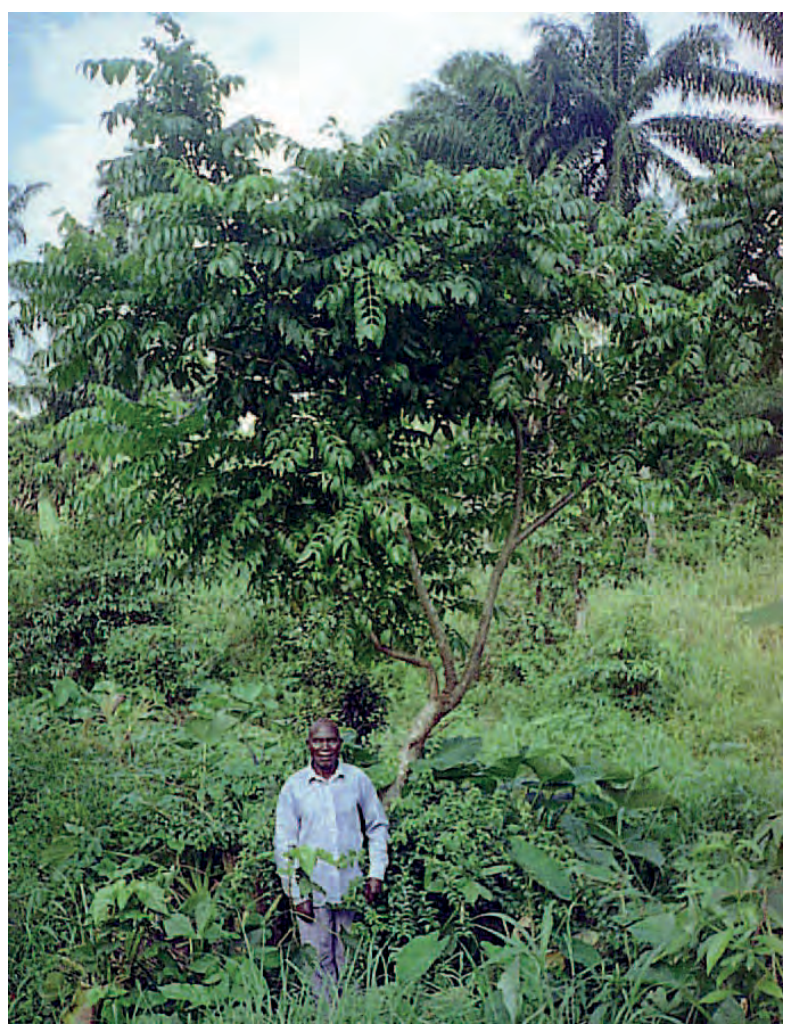
Les feuilles sont imparipennées, avec 5 à 8 paires de folioles opposées, de $10 \times 5$ centimètres, oblongues, acuminées. La floraison massive et parfumée a lieu pendant la saison sèche. Elle se compose de grosses panicules terminales lâches composées de petites fleurs blanches. Les fruits jaunes, de forme ovoïde, mesurent près de 4 centimètres, devenant ridés en séchant. Comestibles leur goût est un peu acide avec un arôme puissant. La chair entoure un unique noyau fibreux. Les fruits apparaissent après 5 ans, ou plus tôt sur les plants issus de boutures. Sur les sites les plus secs, l'arbre se comporte comme un buisson.

Ecologie: Originaire d'Afrique occidentale ou d'Amérique tropicale, présent maintenant du Sénégal à I'Angola. Dans l'ouest de la R.D. Congo, on trouve souvent cet arbre sur les sites d'anciens villages. II se comporte bien sur des sols variés, y compris sur des sables superficiels, du gravier ou des argiles lourdes, mais pousse vraiment bien sur des sols riches, humides, et relativement lourds.

\section{A gauche : Jeune arbre près de Kasangulu}

Reproduction: Ramasser les fruits mûrs dès qu'ils sont tombés au sol, avant qu'ils pourrissent ou soient mangés par les animaux. La graine germe normalement après 35 à75 jours. Des boutures longues de 50 à 70 $\mathrm{cm}$ poussent plus facilement et donnent des fruits plus tôt. Prendre les boutures sur du bois de la saison précédente ou plus ancien. Les planter à $30 \mathrm{~cm}$ de profondeur à leur position finale. Les meilleures variétés se multiplient par greffage. Pour la culture en haies, on peut prendre des boutures de 1,5 à $2 \mathrm{~m}$ de long.

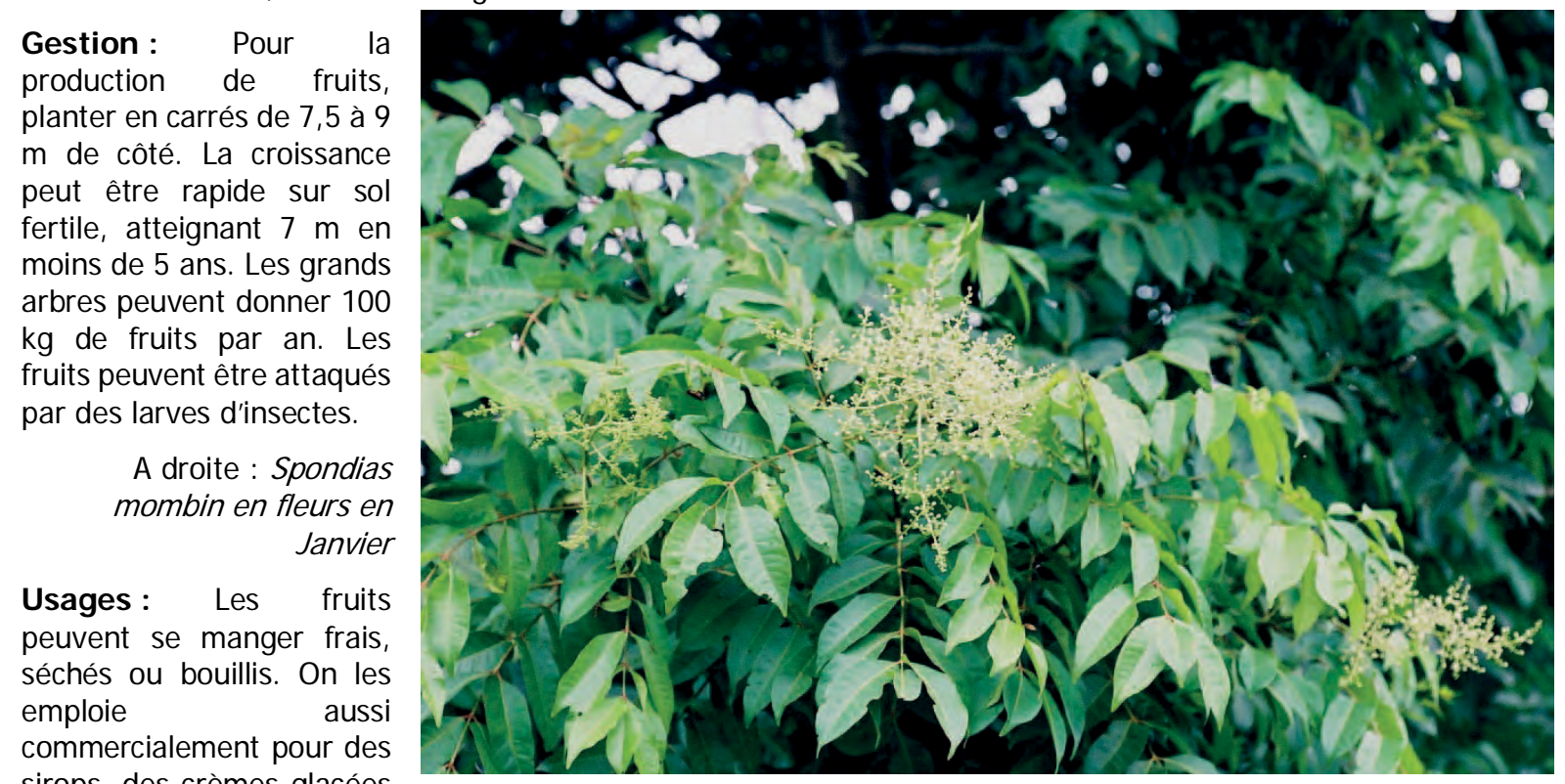
sirops, des crèmes glacées et des gelées. Ils ont un goût acide et de térébenthine, très variable. On peut faire une boisson avec le jus des fruits frais, dont l'acidité diminue si on le laisse reposer une nuit. Le fruit est riche en vitamines $\mathrm{A}$ et $\mathrm{C}$. Les graines aussi sont comestibles. Les feuilles peuvent servir de fourrage pour le bétail ; et les fruits tombés de nourriture pour les porcs. L'arbre constitue un bon arbre d'ombrage. On peut le cultiver comme barrière. Les fleurs seraient une source de miel au Gabon et en Amérique centrale. 


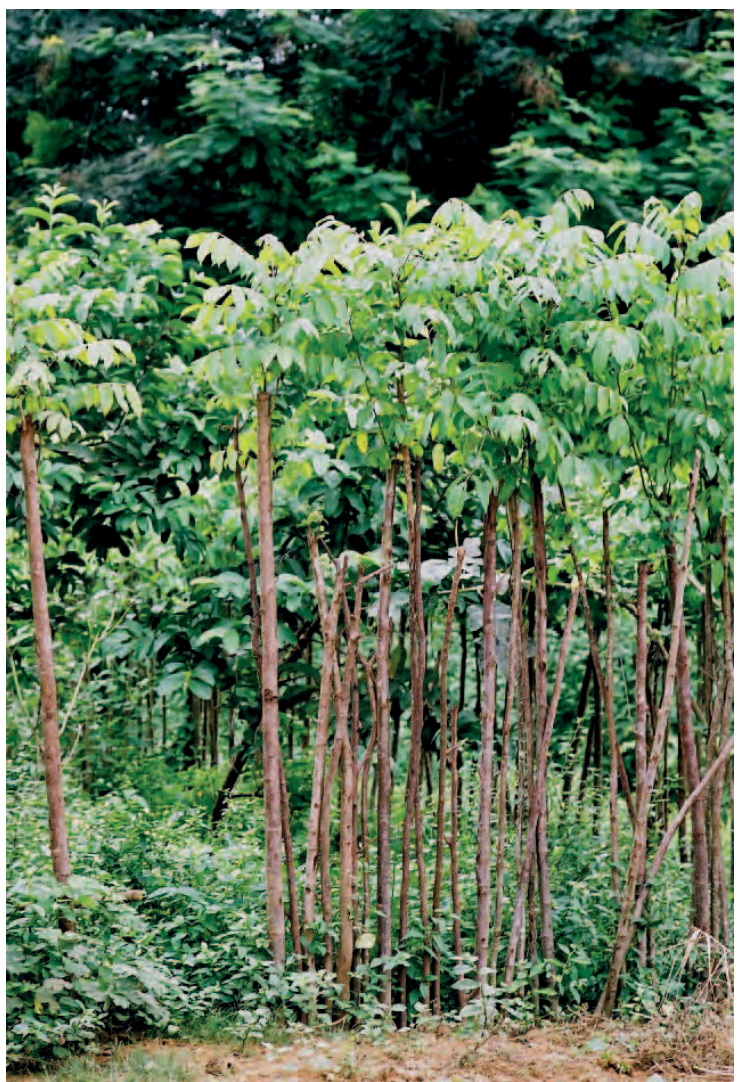

Le bois, blanc à gris, sert essentiellement de bois de feu. II est filandreux, difficile à travailler, et attaqué par les termites. Les troncs peuvent servir de poteaux, et les branches de manches d'outils. Les extraits de cette plante ont des propriétés antibactériennes. Au Kongo Central, on traite les rhumatismes avec une décoction des feuilles. On emploie les feuilles pilées et trempées dans l'eau pour traiter l'asthme. La plante a beaucoup d'usages médicinaux ailleurs en Afrique.

Remarque : Les fruits étant très variables, sélectionner ceux qui sont sucrés avec beaucoup de chair.

Références: Butaye 1909, Gillet et Paque 1910, Renier 1948, Van Der Veken 1960, FAO 1982, Daeleman et Pauwels 1983, Crane et al. 1984, Burkill 1985, Aumeeruddy et Pinglo 1988, Dupriez et De Leener 1989, Lobreau-Callen et al. 1989, Mukoko Matondo 1991, Pauwels 1993, Burkill 2000, Nsimundele 2004, Orwa et al. 2009

A gauche : Tiges de Spondias mombin plantées come haie autour d'une maison au village de Kihungu.

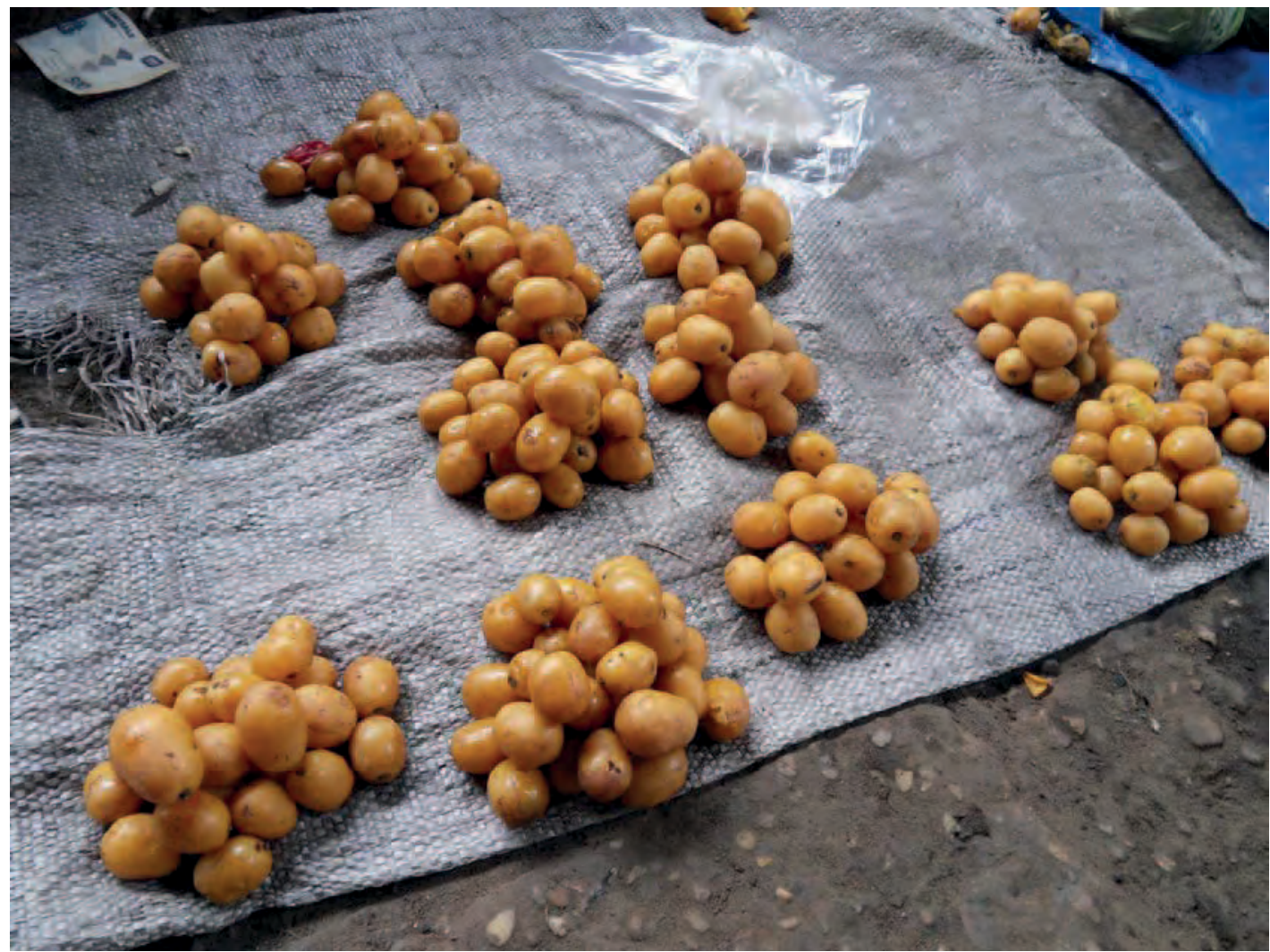

Spondias mombin en vente sur un marché 


\section{Stachytarpheta indica}

Synonyme : $S$. angustifolia

Noms courants : Rat's tail (Angl.).

Description : Les plantes de l'espèce Stachytarpheta sont des herbes annuelles ou des buissons désordonnés.

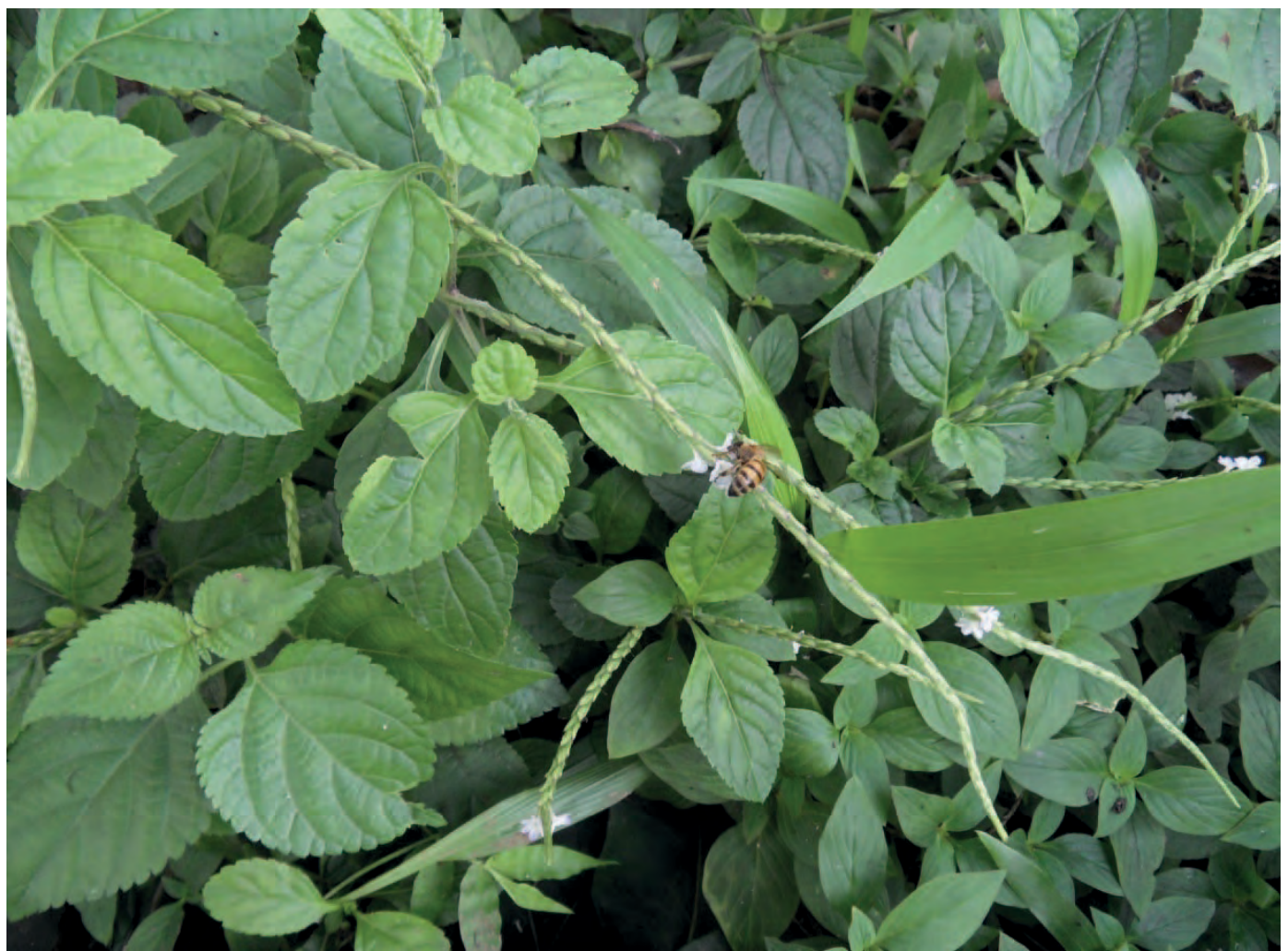

Stachytarpheta indica dans un jardin à Kinshasa

Ecologie : Plante présente dans toute l'Afrique de l'Ouest, souvent rencontrée le long des sentiers ou des routes. Les espèces de Stachytarpheta sont adaptées à la plupart des sols.

Reproduction : Les boutures de tiges tendres prennent racine dans un mélange de sable et de fumier. On peut aussi prendre des graines, à semer à la surface du sol. Après une ou deux années, il vaut mieux replanter.

Gestion : On peut pincer les jeunes pousses pour avoir des plantes buissonnantes.

Usages: Les abeilles récoltent occasionnellement le nectar. D'autres espèces se cultivent comme plantes ornementales. Au Gabon, $S$. indica serait un fourrage pour les abeilles et des espèces de Dactylurina (un autre hyménoptère pollinisateur) de septembre à novembre. On emploie parfois les racines pour faire une pommade pour les yeux.

Références : J ex-Blake 1957, Uphof 1968, Villières 1987a, Ambougou 1991 
Synonyme : S. gabonensis

Nom courant : Nsusu menga, mundi (Kikongo), arbre à pagaies (Fr.)

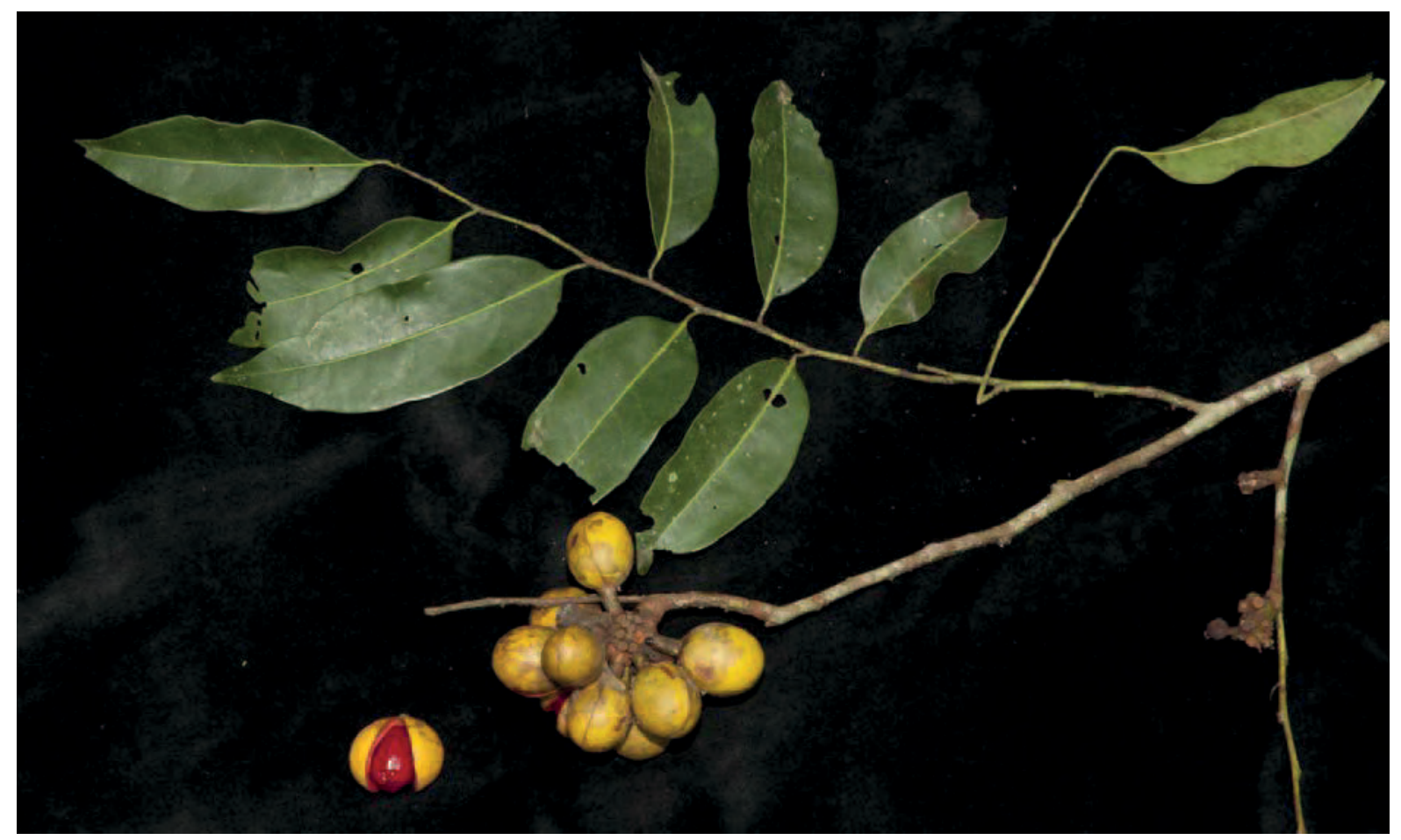

Photos: David Harris/Royal Botanic Garden Edinburgh

Description : Arbre atteignant $30 \mathrm{~m}$ de haut. Tronc brun clair souvent cannelé. L'écorce coupée dégage un jus rouge sang. Feuilles alternes de 8 à 16 sur 2 à $5 \mathrm{~cm}$. L'inflorescence est une tête globuleuse de 0,5 à $1 \mathrm{~cm}$ de diamètre, normalement à pubescence courte brun rougeâtre, contenant 10 à 50 fleurs. Les fruits sont des drupes ellipsoïdes de 2 à 3,5 cm de long, groupés par bouquets jusqu'à 20, parfois charnus à maturité, jaunâtres, contenant une seule graine. Graines ellipsoïdes ou ovoïdes, de 1-2 cm de long, brun foncé, munies d'un arille finement charnu, rouge ou rosé, enveloppant presque complètement la graine, lobé à l'apex.

Ecologie: Arbre des forêts primaires sur sols fermes et des forêts galeries. Se trouve aussi au Cameroun, au Gabon, en Guinée Equatoriale et au Congo Brazzaville.

Reproduction : Selon des essais, les graines commencent à germer 60 à 80 jours après avoir été semées, avec un taux de germination de 48 à 64 $\%$. L'arbre est à croissance lente ; le mieux pour le reproduire est de le planter en forêt secondaire.

Usages: L'arbre donne un bon bois pour tous usages résistant aux intempéries, dur mais assez facile à travailler, employé en construction et pour le mobilier. Il sert aussi de bois de feu. Son principal inconvénient est sa croissance lente, conduisant à des cycles de production très longs. Au Kongo Central, on emploie l'écorce pour arrêter les hémorragies. Ailleurs en RD Congo, on traite les problèmes de peau des enfants, les œdèmes et les blessures avec des décoctions d'écorces qu'on leur fait boire, ou dont on fait des cataplasmes à frictionner. Ces décoctions s'emploient en gargarismes contre les infections buccales. On applique la sève du bois sur les morsures de serpents ; diluée dans l'eau, on la prend contre la diarrhée. On l'emploie aussi pour cicatriser les blessures et pour traiter les douleurs oculaires. Contre la toux, les enfants mâchent les racines et avalent la sève. On extrait des graines une huile aromatique employée comme pommade contre la gale. Les graines servent d'appât pour les porc-épic et les rats palmistes. L'arille des graines est comestible.

Références : Renier 1948, Gilbert et Troupin 1951, Nsimundele 1966 - 68, Pauwels 1993, Burkill 1997, White et Abernethy 1997, Harris et al. 2011, Oyen et Louppe 2012 
Noms courants : Mumvumbi mvumbi, kula mvumbi, kula ndosi (Kikongo) (Mvumbi = cadavre, produit pour embaumer), pop-gun tree (Angl.)

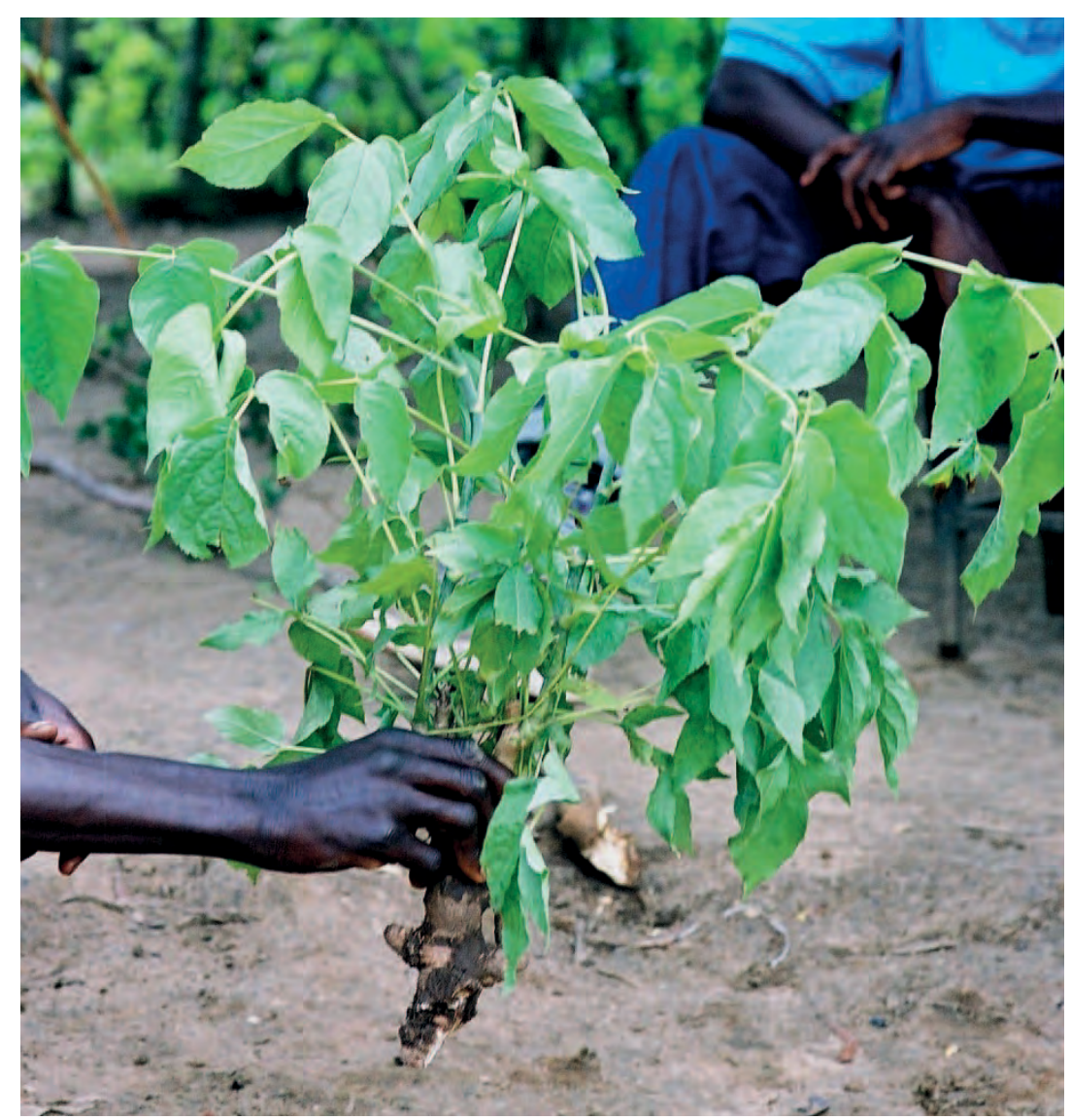

Description : Arbuste de 5 à $8 \mathrm{~m}$ de haut. Le tronc est tortueux et les branches robustes. L'écorce est épaisse et liégeuse. Les feuilles sont disposées sur des branches de 15 à $40 \mathrm{~cm}$ de long, dont la base gonflée entoure le tronc. Les feuilles sont groupées par 5 à 9 au bout des branches. Les fleurs blanches, disposées en têtes composées, apparaissent avant les feuilles.

Ecologie: Plante des savanes boisées dans toute l'Afrique tropicale, spécialement aux basses altitudes et sur les affleurements rocheux.

Reproduction: On part des semis spontanés ou de boutures. Les graines sont difficiles à récolter.

Gestion : Arbuste à croissance rapide, qui recèpe bien et supporte bien la taille.

Usages : Au Kongo Central, on emploie les feuilles, les jeunes pousses, et les racines pour traiter les douleurs post natales, les problèmes rénaux, les douleurs et les hernies. On met les feuilles sur le lit des gens souffrant de lumbago. C'est la plante médicinale la plus utilisée dans les territoires de Kisantu et Mbanza Ngungu pour traiter l'éléphantiasis. Traditionnellement, on brûlait le bois sous un cadavre pour l'embaumer. Le bois, tendre et cassant, sert principalement comme bois de feu, pour la sculpture ou pour des outils agricoles. La plante est odorante, comme le fenouil ou la carotte ; on s'en sert pour parfumer les vêtements. La plante est fortement émétique. Dans le Nord de l'Angola, on emploie une décoction des feuilles pour traiter les thromboses; et une décoction de l'écorce et des racines pour stimuler la fécondité. Les abeilles butineraient le pollen et le nectar. Les enfants prennent les tiges évidées pour lancer des billes.

A droite: Inflorescence en septembre

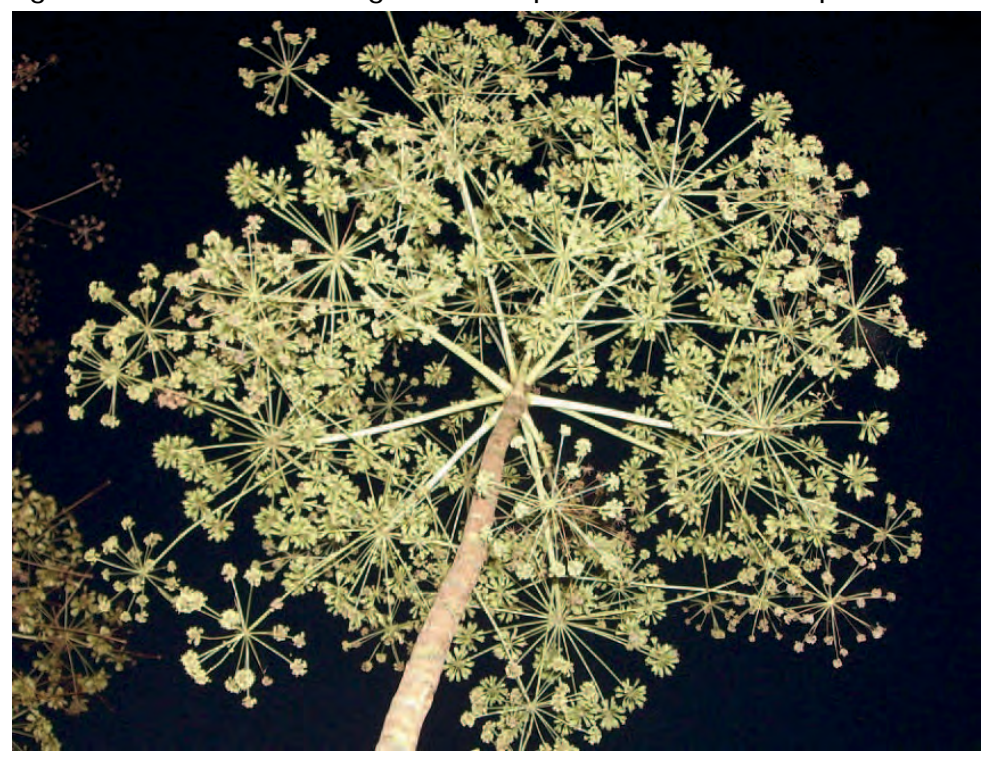

Références : Gillet et Paque 1910, Renier 1948, Daeleman et Pauwels 1983, Pauwels 1993, Fichtl et Adi 1994, Katende et al. 1995, Burkill 2000, Neuwinger 2000, van Wyk et Gericke 2000, Kibungu Kembelo 2003, Göhre et al. 2016, Kibungu et al. 2021 


\section{Sterculia tragacantha}

Noms courants : Nkondo mfinda (Kikongo), African tragacanth (Angl.)

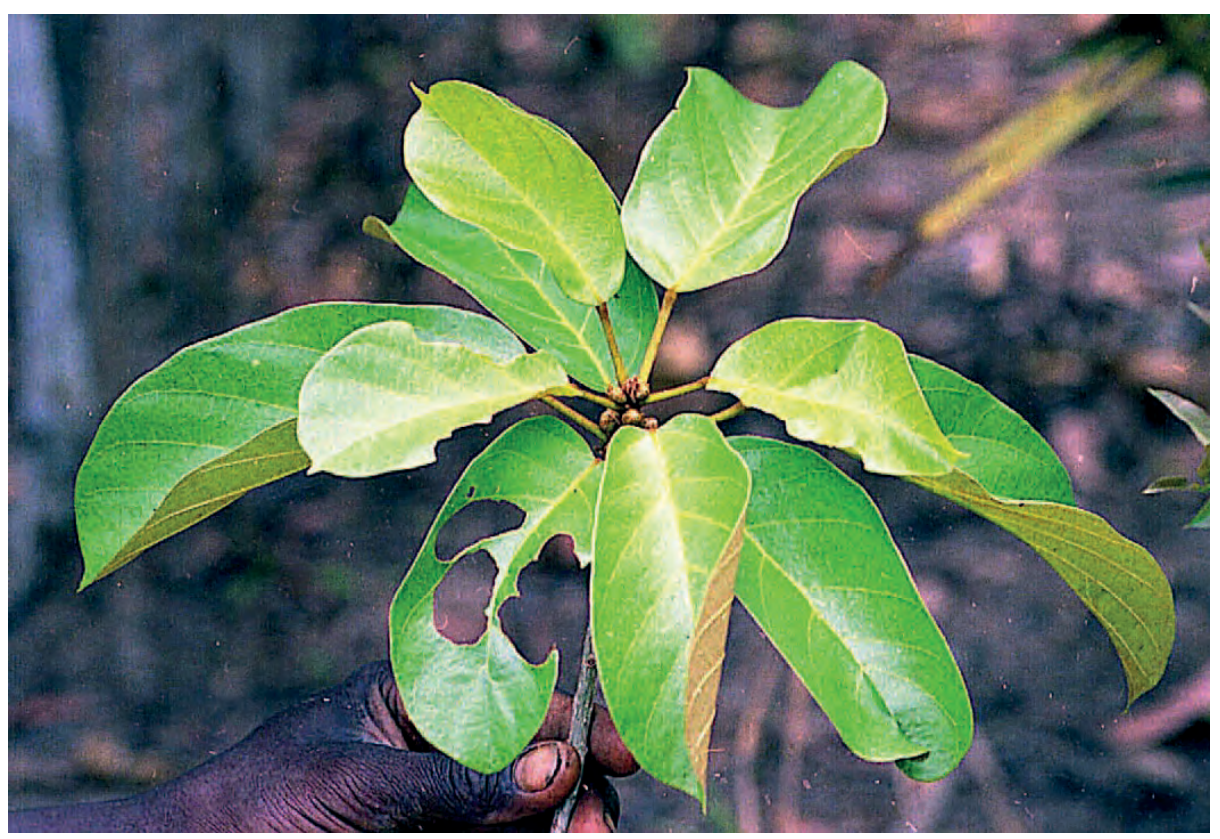

Description : Arbuste de 5 à $6 \mathrm{~m}$ ou arbre jusqu'à $25 \mathrm{~m}$. Tronc ayant parfois des contreforts, avec un long fût droit, sans branche presque jusqu'au sommet. Les jeunes pousses portent des poils étoilés denses. L'écorce est liégeuse et

Pousse venant d'une tige plantée dans une haie dans le district de Manianga.

profondément fissurée avec des motifs en diamant. Feuilles simples, alternes, variables, de 10 à 20 sur 5 à $12 \mathrm{~cm}$, lisses et brillantes dessus, avec des poils orangés en dessous. Fleurs rouge pourpré à rose, en panicules lâches Fruits disposés par groupes de gousses ligneuses brun clair ayant jusqu'à 8 graines.

Ecologie : Arbre des forêts denses humides, des forêts galeries et des jachères. Très répandu en Afrique tropicale, de la Guinée à l'Angola, à la Zambie et à la Tanzanie.

Reproduction : On peut récolter les graines et les conserver quelques semaines. On peut aussi cultiver l'arbre à partir de grandes boutures.

Gestion : L'arbre reprend facilement après avoir été abattu.

Photo: (c) W.D. Hawthorne

Usages : Le bois sert en construction, pour faire des poteaux, du mobilier et des barrières. Les graines se mangent rôties entières, ou pilées et cuites avec

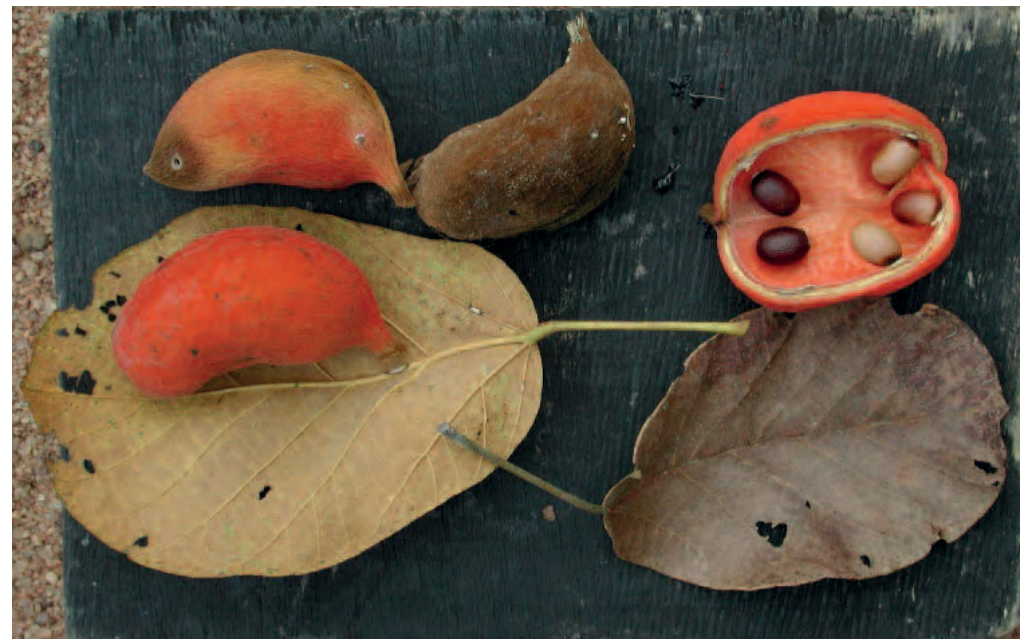
des légumes comme les pois ou la courge. L'écorce donne une résine dite gomme adragante, employée par les forgerons dans la fusion du fer et pour réparer les ustensiles. Au Katanga et au Ghana, on mange les jeunes feuilles. Les fibres de l'écorce, du tronc et des branches peuvent servir de cordages. On emploie l'écorce et les feuilles pour traiter la toux et les rhumes, la gonorrhée, la fièvre, le ver solitaire, les ulcères, les panaris et les morsures de serpents. On emploie les feuilles pour faciliter l'accouchement. On donne une décoction de l'écorce comme émétique et expectorant. Au Manianga, et au Gabon, les abeilles butineraient les fleurs.

Références : Gillet 1927, Dalziel 1937, Renier 1948, Irvine 1961, Germain 1963, Ambougou 1991, Pauwels 1993 , Malaisse 1997, Burkill 2000, Neuwinger 2000, Ruffo et al. 2002 


\section{Streptogyna crinita}

Noms courants : Nkansu ngo (= griffe de léopard), nzefo za ngo, kansingo (Kikongo)

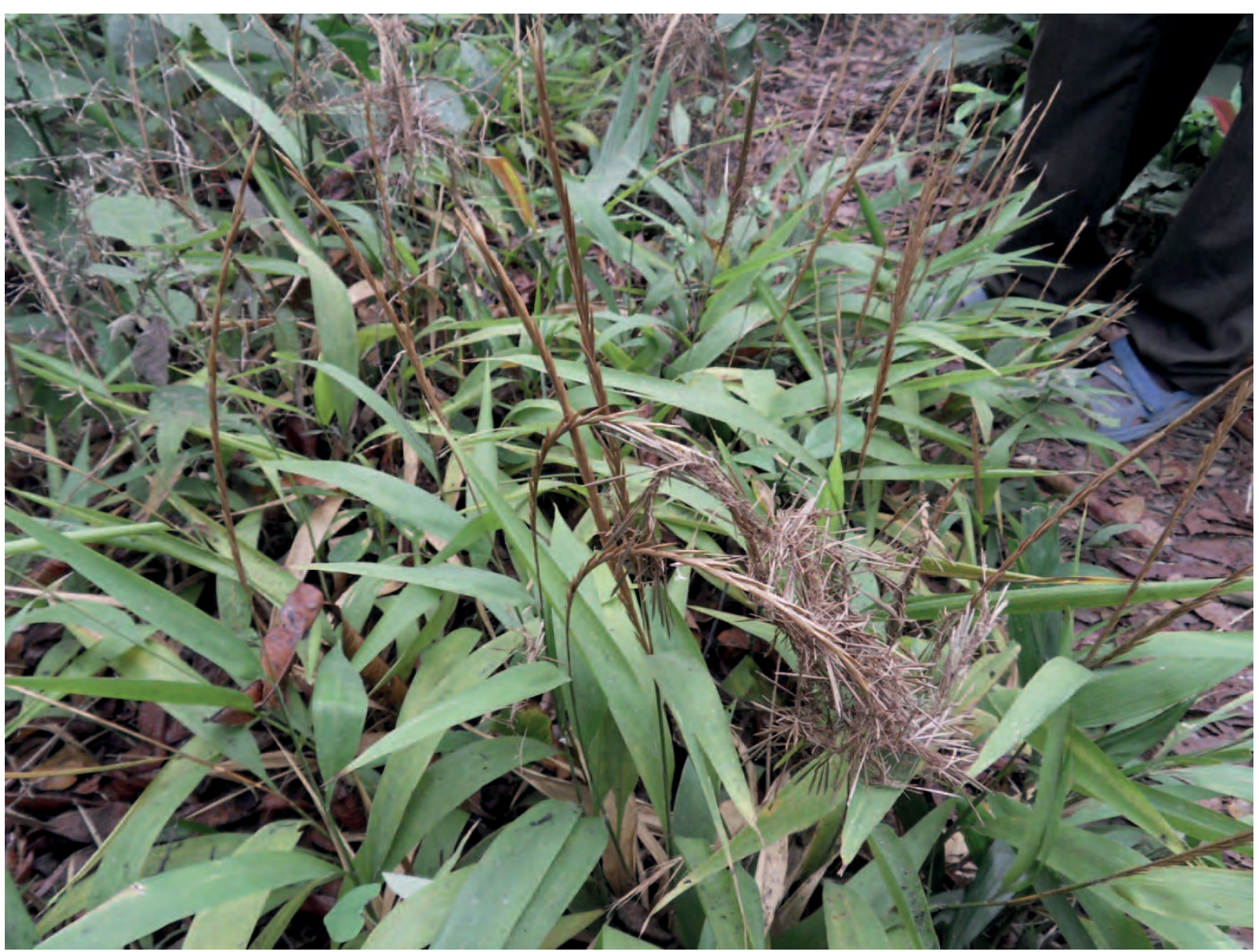

Description : Herbe vivace donnant des tiges de 0 à $150 \mathrm{~cm}$ de haut sur des rhizomes écailleux. Les feuilles sont en forme de lance, de 10 à 40 sur 1 à $3,5 \mathrm{~cm}$. L'épi floral a jusqu'à $20 \mathrm{~cm}$ de long, avec des épillets imbriqués vert sombre à brun, de 20 à $3 \mathrm{~mm}$, prolongés par des piques dures ayant jusqu'à $25 \mathrm{~mm}$ de long.

Ecologie : Plante poussant sur le sol de la forêt. Du Sénégal à Bioko et dans toute l'Afrique tropicale, ainsi qu'en Inde et au Sri Lanka. On la trouve parfois dans les cultures ombragées. Herbe nuisible, particulièrement quand elle donne des fruits, dont les piques se prennent dans les vêtements, les poils des jambes, et le pelage des animaux, d'où il est difficile et douloureux de les extraire.

Usages: Communément employée pour attraper les souris et les rats. On enroule ensemble des tiges fleuries pour les mettre dans les trous des rongeurs.

Remarque : Les graines forment des balles qui se cramponnent aux vêtements. Les oiseaux qui y sont pris sont incapables de s'en sortir, et meurent souvent.

Références Gillet et Pâque 1910, Renier 1948, Daeleman et Pauwels 1983, Burkill 1994 


\section{Strombosia grandifolia}

Noms courants : Bota masa ( bota = bois dur, masa = eau) (Kikongo).

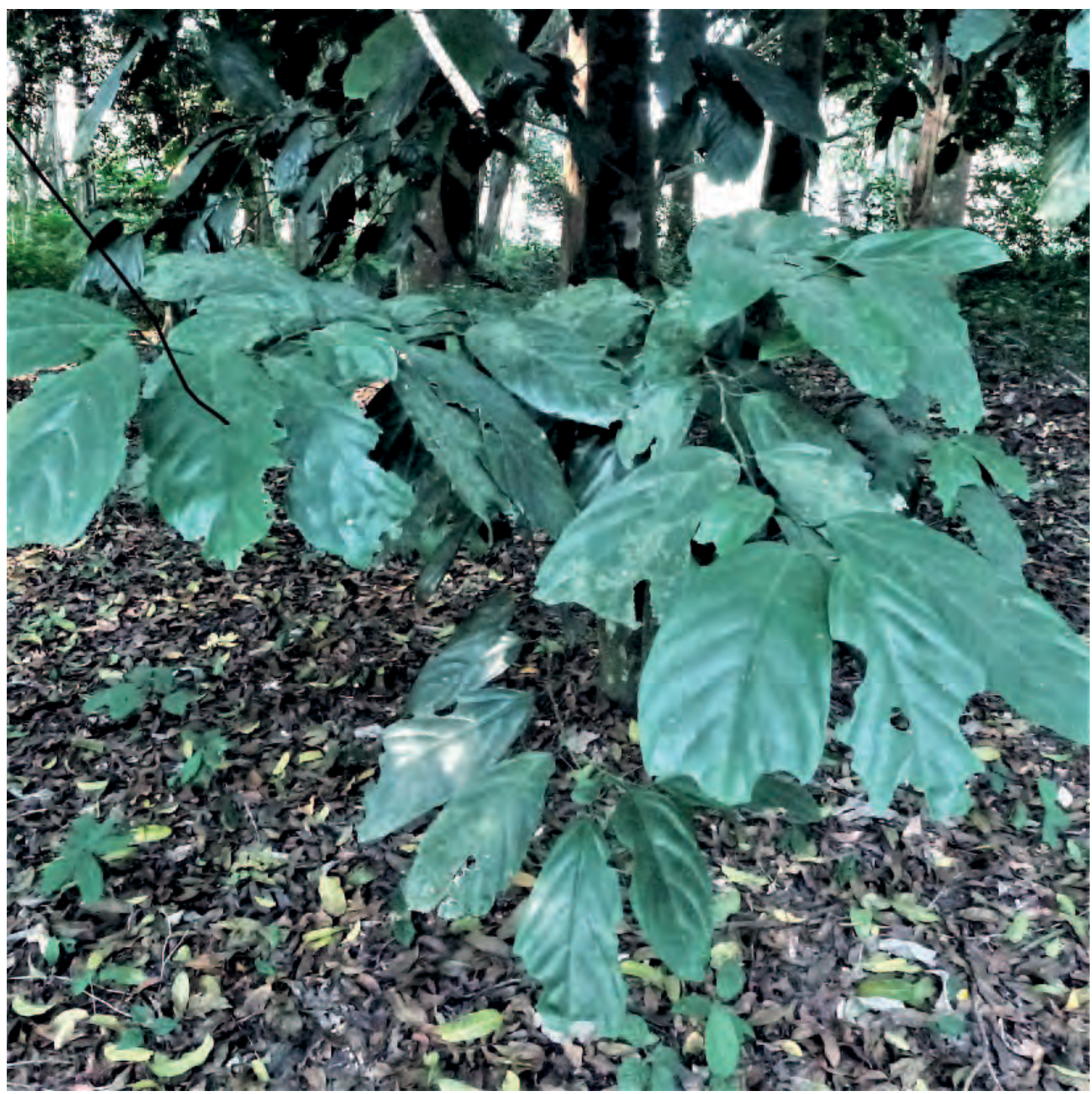

Description : Arbuste de sous-bois, ou arbre de 7 à $25 \mathrm{~m}$, qui ramifie dès la base. Feuilles de 7 à 30 sur 3 à 16 $\mathrm{cm}$ sur un pétiole de 1 à $3 \mathrm{~cm}$. Inflorescence axillaire. Fleurs jaune verdâtre ou blanchâtres, jusqu'à $3 \mathrm{~mm}$ de long. Fruit ovoïde ou ellipsoïde, de 1,7 sur 1,2 cm, complètement entouré, sauf au bout, par un réceptacle lisse et charnu. Graines blanches.

Ecologie : Forêt dense sur terre ferme, ou forêts inondables. Du Bénin à la R.D.C.

Usages : Le bois est rouge violet. C'est un bon bois de construction, facile à scier et à travailler. Moyennement durable, ou très durable ; employé pour creuser des pirogues, pour les manches d'outils et pour la sculpture. Au Congo Brazzaville, il donne une teinture employée pour noircir les poteries.

Remarque : Espèce que l'on confond facilement avec S. tetrandra, S. nigropunctata and S. pustulata. S. tetrandra porte aussi le nom de Mbota masa.

Références Gillet et Paque 1910, Louis et Léonard 1948, Renier 1948, Keay 1989, Pauwels 1993, Burkill 1997, Harris et Wortley 2008, Harris et al. 2011 


\section{Strophanthus sarmentosus}

Noms courants : Kuku kinia, bikuku bi kiula (Kikongo), spider tresses (Angl.)

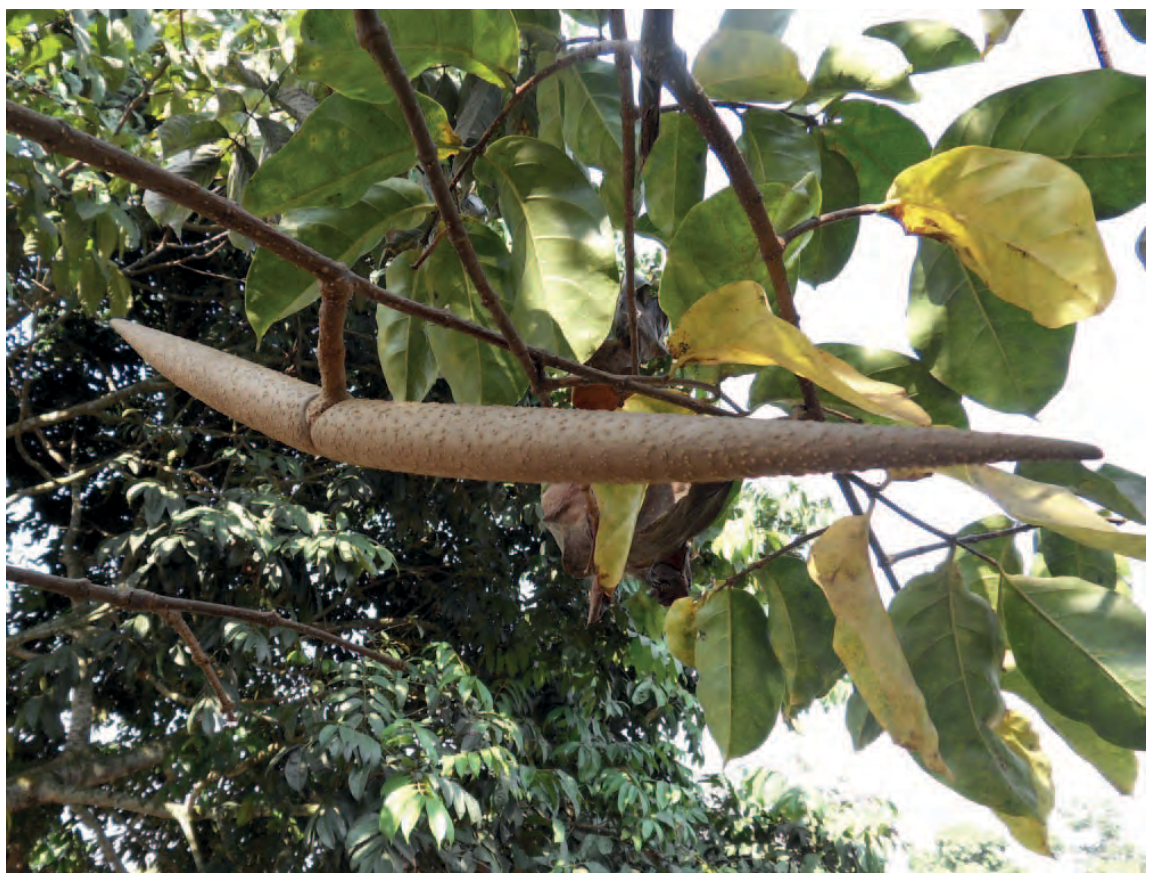

(Apocynaceae)

Description : Grande liane décidue de forêt, jusqu'à 40 $m$ de long, donnant un latex transparent ou blanc. Feuilles elliptiques ou ovées, de 2 à 15 sur 1,5 à $7 \mathrm{~cm}$, opposées et pointues au bout. Grandes fleurs parfumées violet pourpre. Fruit composé de deux gousses, de 10 à 28 sur 1,5 à $4,5 \mathrm{~cm}$, s'effilant en pointe, avec une écorce dure contenant de nombreuses graines. On connaît celles-ci comme toxiques.

Fruit d'une espèce de Strophanthus

Ecologie : Liane des forêts pluviales, des forêts galeries et des taillis, présente du Sénégal à la Centrafrique, à l'Ouganda et à l'Angola (Cabinda), du niveau de la mer à 1400 m d'altitude.

Reproduction : La plante pousse difficilement à partir des tiges portant des racines ; cultivée, elle donne moins de fruits qu'à l'état naturel.

Usages: Avec les tiges, on fabrique les harnais en cerceau employés pour grimper aux palmiers et récolter les régimes de noix de palme ou le vin de palme. Les graines servaient traditionnellement à préparer un poison dont on enduisait les flèches. La sève sert à coaguler le caoutchouc de Funtumia. Les tiges servent à faire des cloisons dans les habitations. La plante a des utilisations en médecine traditionnelle dans toute l'Afrique de l'Ouest. Au Congo Brazzaville, la tige et les feuilles servent à faire des bains de vapeur pour traiter les rhumatismes. Dans les années 1950, on a employé en Europe et aux Etats Unis un extrait des graines pour combattre l'arthrite rhumatoïde et produire de la cortisone, mais on a mis au point d'autres méthodes et la demande de graines s'est effondrée. Au Nigéria, les tiges servent à faire des arcs, des cordages et des nattes.

Photo: Karl Gercens www.KarlGercens.com

Références : Gillet et Pâque 1910, Irvine 1930, Renier 1948, Irvine 1961, Nsimundele 1966 - 68, Beentje 1982, Daeleman et Pauwels 1983, Burkill 1985, Bongers et al. 2005, Beentje 2006, Fayaz 2011

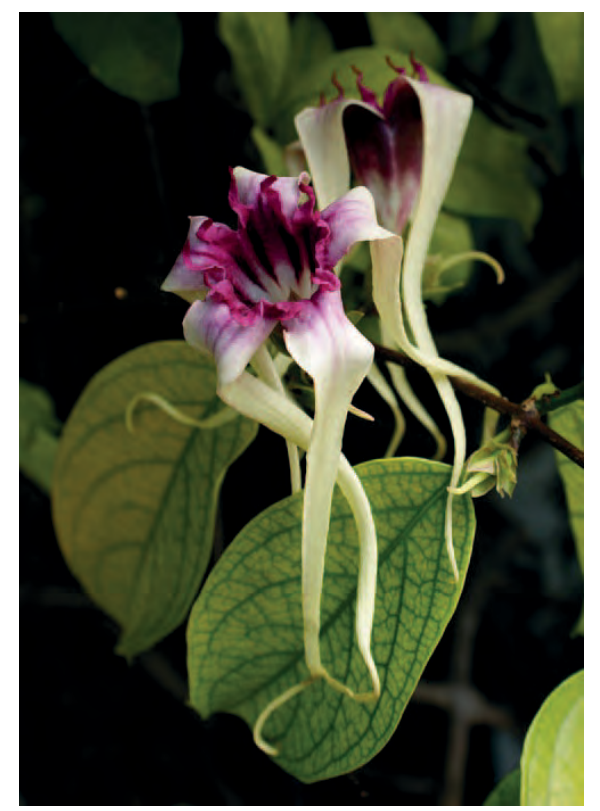




\section{Strophanthus welwitschii}

Noms courants : Bulembe, mulembelembe (Tshiluba), mubula kondo (Kipindi).

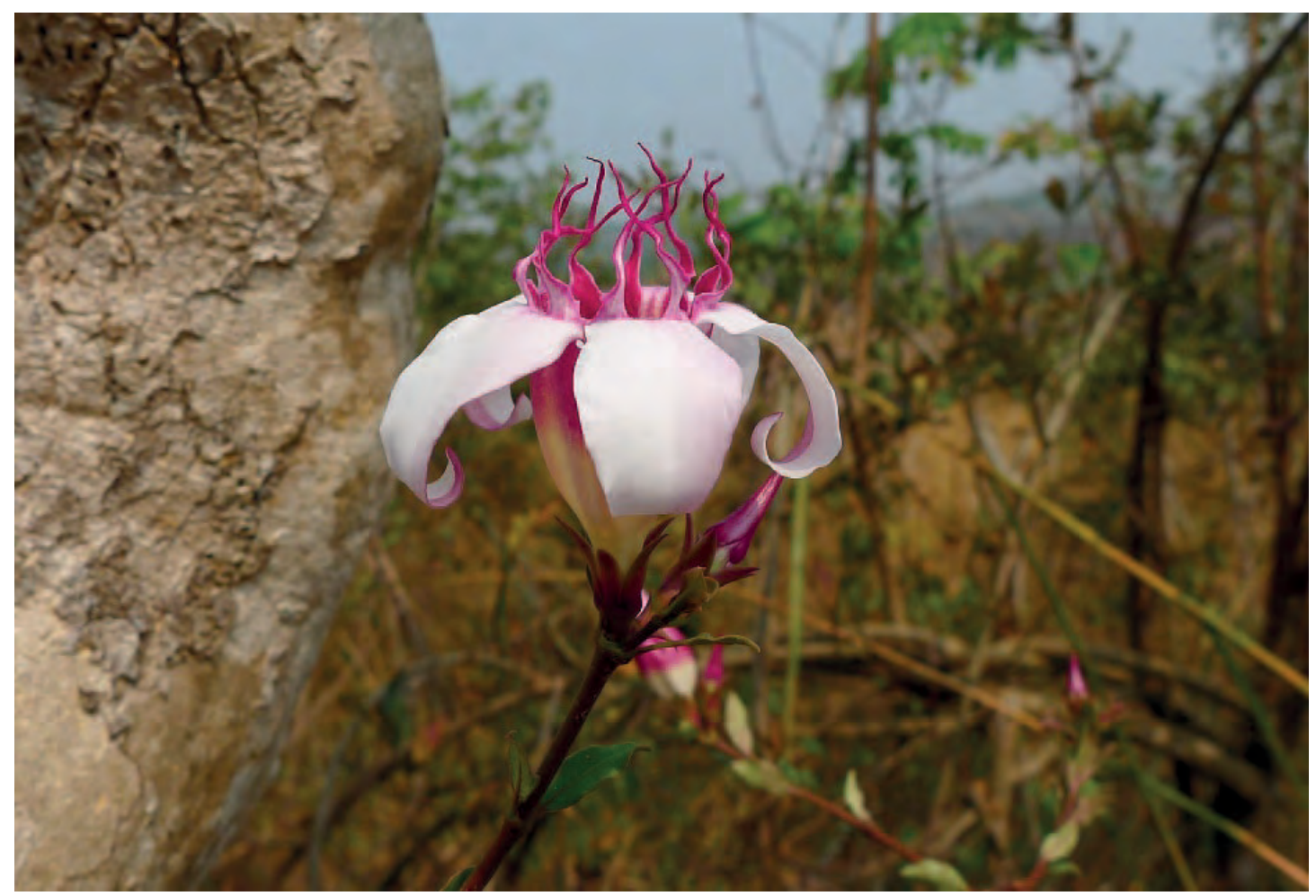

Strophanthus welwitschii en fleurs à Buma, secteur de Kivulu, en juillet.

Description : Arbuste grimpant de 0,6 à $5 \mathrm{~m}$ de haut : rameaux brun foncé avec de nombreuses lenticelles. Feuilles opposées, mesurant 4 à 9 sur 2,5 à $3 \mathrm{~cm}$, ondulées et glabres. L'inflorescence porte de 1 à 3 fleurs. Corolle en tube évasé, blanche et pourpre, de 17 à $38 \mathrm{~mm}$ de long. Fruit composé de deux follicules divergeant à un angle de 160 à $240^{\circ}$, de 10,5 à 28 sur 1,5 à 2,5 cm; graines striées et couvertes de longs poils soyeux.

Ecologie : Plante de la savane et des forêts ouvertes, souvent sur des sites rocheux, en R.D. Congo, de l'Angola à la Zambie et à la Tanzanie.

Reproduction : Par boutures de bois tendre ou par graines.

Usages : Les graines, hautement toxiques, contiennent de la strophantine et de l'oubaïne, des tonicardiaques. En R.D. Congo, on donne aux enfants par voie orale une décoction des graines pour traiter les maladies respiratoires. On frictionne les parties affectées par la gale avec un mélange de poudre de racines et d'huile.

Références : Renier 1948, Watt et Breyer-Brandwijk 1962, Verdcourt et Trump 1969, Beentje 1982, Pauwels 1993, Nsimundele 2004, de Ruitjer 2006, Stevens 2011 


\section{Strychnos cocculoides}

Noms courants : Kalakonki, nkonki (Kikongo), monkey orange (Angl.)

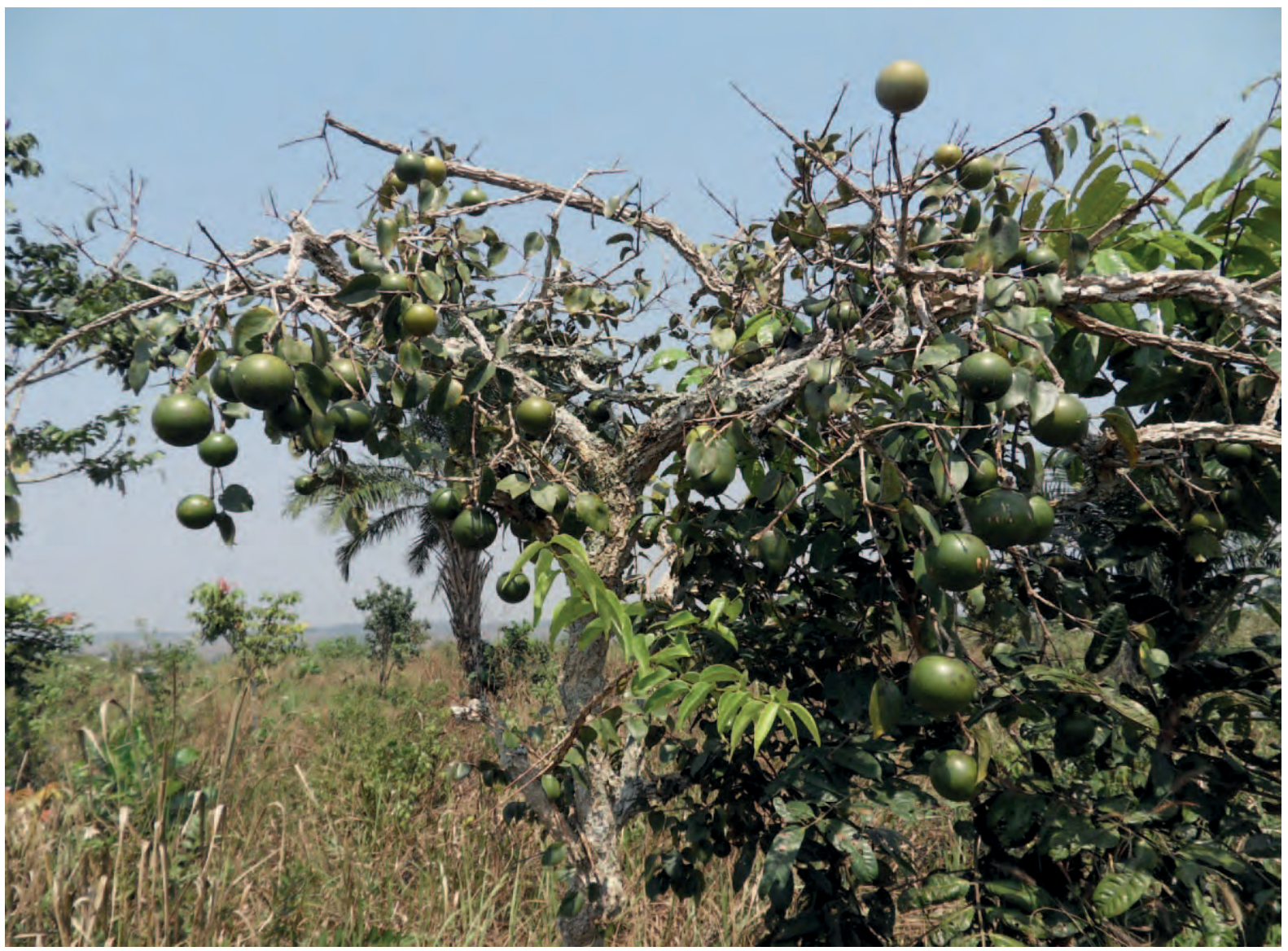

Description : Arbuste pouvant atteindre $6 \mathrm{~m}$ de haut aux branches retombantes. Les branches et les rameaux sont couverts d'épines. Ecorce gris pâle, épaisse, liégeuse avec de profondes fissures longitudinales. Petites fleurs blanc verdâtre. Fruit sphérique de 6 à $11 \mathrm{~cm}$ de diamètre, brun ou jaune orangé, avec une écorce ligneuse dure. Nombreuses graines ovales plates d'environ $2 \mathrm{~mm}$ d'épaisseur et $8 \mathrm{~mm}$ de diamètre. La pulpe attachée aux graines est comestible, avec un goût aigre doux très apprécié.

Ecologie: Arbuste présent du Gabon à l'Afrique orientale et australe dans les savanes et les forêts ouvertes, spécialement dans les zones sèches sur les collines rocheuses de 0 à $2000 \mathrm{~m}$ d'altitude.

Reproduction: Par graines ou rejets de racines. On extrait les graines de la pulpe et on les trempe dans l'eau. Les graines infertiles et la pulpe flottent, et on les jette. On sèche les graines, qui demeurent viables 6 mois. Tremper 24 heures dans l'eau froide pour hâter la germination. La germination est bonne mais lente, atteignant $75 \%$ après 8 semaines. Les rejets de racine se développent là où la racine a été endommagée.

Usages : La pulpe du fruit est comestible, et on en fait une boisson aigre douce non alcoolique. Traditionnellement, on faisait des pipes avec les jeunes tiges évidées. Le bois sert de bois de feu. Blanc, dur et souple, il convient pour les manches d'outils. Avec le fruit on fait une teinture qui fournit aussi une protection contre les insectes. On plante parfois cet arbuste comme barrière autour des parcelles. L'écorce, les feuilles, les racines et les fruits ont de usages médicinaux. On a observé la récolte de nectar par les abeilles sur cette plante et d'autres espèces de Strychnos.

Remarque: On trouve aussi présents au Kongo Central Strychnos pungens (nbumi), S. spinosa (nbumi, kala konki) et $S$. variabilis.

Références : Butaye 1909, Gillet et Pâque 1910, Renier 1948, Watt et Breyer-Brandwijk 1962, Kokwaro 1976, Leeuwenberg et Bamps 1979, FAO 1983, Pauwels 1993, Mbuya et al. 1994, Malaisse 1997, Msanga 1998, Nsimundele 2004, Orwa et al. 2009 


\section{Strychnos icaja}

Nom courants : Mbondo, mbondo bololo (Lingala), Kikwenge a mfinda (Kimbala), curare (English)

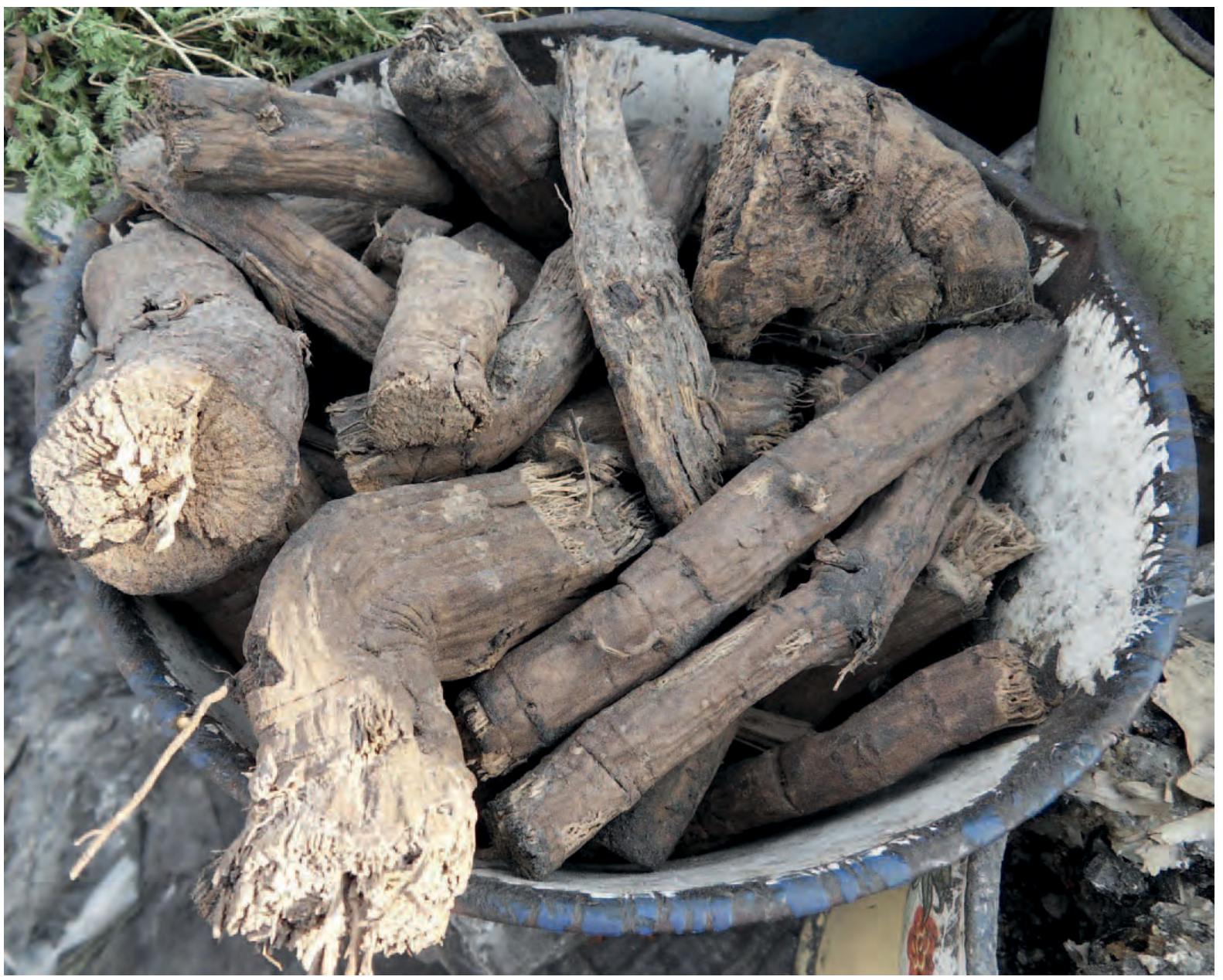

Racines de Strychnos icaja envente sur un marché dans la Province de l'Equateur

Description : Liane de 20 à $100 \mathrm{~m}$ de long grimpant avec des vrilles. Tige de 4 à a $15 \mathrm{~cm}$ de diamètre. Ecorce de gris clair à brun foncé, assez fine, avec de grandes lenticelles. Feuilles de 5 à 15 sur 2 à $7 \mathrm{~cm}$, opposées, simples et entières, sur un pétiole de 4 à $12 \mathrm{~mm}$. Inflorescences axillaires de 3 à 7 sur 2 à $6 \mathrm{~cm}$. Fleurs vert-jaune ou blanc-jaune. Fruits globulaires jaunes de 2,5 à $3 \mathrm{~cm}$ de diamètre, mous à maturité, avec un fin péricarpe entourant une graine ellipsoïde unique.

Ecologie : Liane des forêts denses, forêts galeries et forêts marécageuses dans toute l'Afrique de l'Ouest, et au Sud jusqu'en Angola.

Reproduction : Par graines ou rejets.

Usages: La pulpe du fruit se mange au Kongo Central. Selon la tradition, on faisait un poison d'ordalie appelé Mbundu avec les racines pilées d'une jeune plante macérées une nuit dans l'eau. En R.D. Congo, la poudre des racines mélangée à l'huile de palme sert à traiter les maladies de la peau et les démangeaisons. Ailleurs, la plante a de nombreux usages médicinaux.

Références : Renier 1948, Bouquet 1969, Leeuwenberg et Bamps 1979, Burkill 1995, Hepburn et Radloff 1998, Nsimundele 2004, Mosango 2007, Konda Ku Mbuta et al. 2015a 


\section{Stylosanthes guianensis}

(Fabaceae)

Noms courants : Stylo (Angl.)

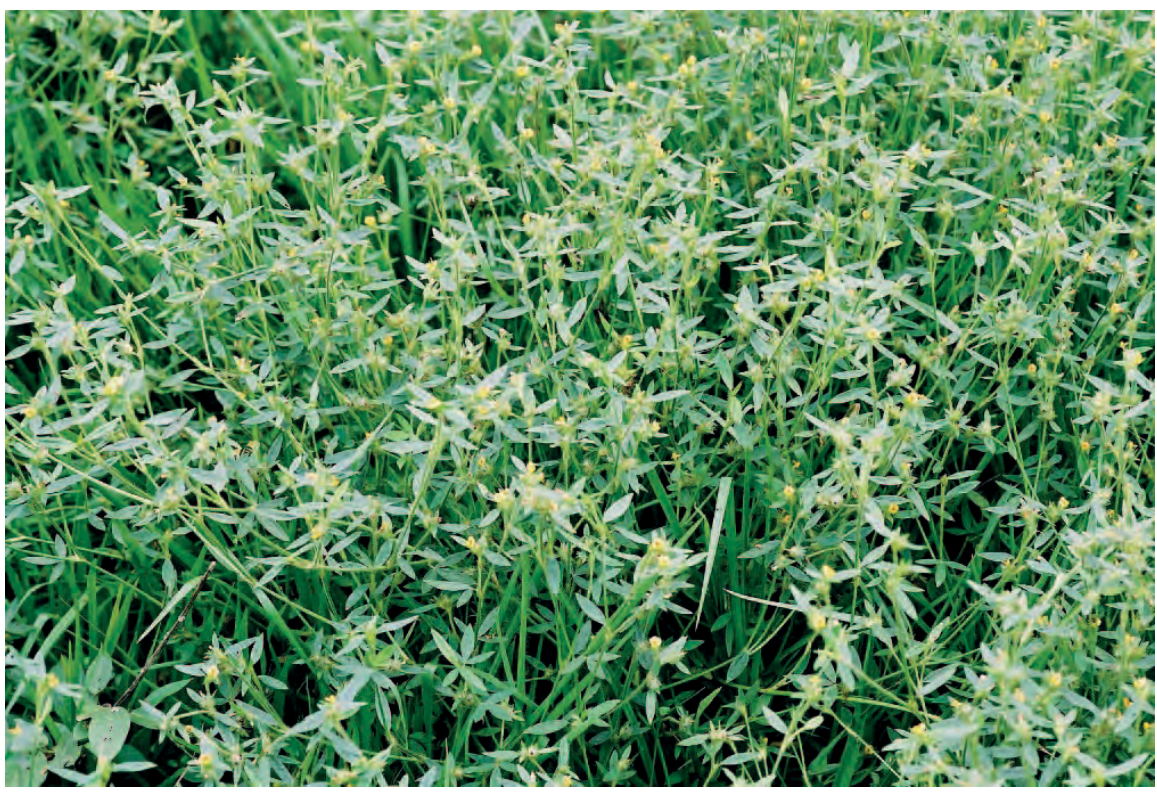

Description : Herbe vivace ramifiée, dressée ou semidressée, de 20 à $120 \mathrm{~cm}$ de haut, devenant ligneuse en vieillissant. Feuilles composées de 3 folioles ovales, glabres ou légèrement poilues, de 0,5 à 4 sur 0,2 à $1,5 \mathrm{~cm}$. Fleurs rougeâtre à jaune orangé en groupes compacts de plus de 40 fleurs. Petites gousses plates, brun clair, terminées par un bec en spirale contenant chacune une seule graine brun clair de 1 à $2 \mathrm{~mm}$.

Ecologie: Plante originaire d'Amérique centrale et méridionale, introduite en Afrique Centrale vers 1947.

Elle supporte bien les sécheresses et les inondations temporaires. On doit la cultiver en plein soleil. Elle préfère les sols grossiers, et pousse bien dans des conditions très acides.

Reproduction: Tremper les graines 10 secondes dans l'eau bouillante, puis les semer à la volée à 3 à $5 \mathrm{~kg}$ par hectare, en ratissant légèrement. On peut la cultiver en rangées alternées avec du maïs, mais il faut la semer en premier car elle germe lentement. On a prouvé que le « stylo » est la meilleure plante à établir sur des terres infestées par Imperata. Brûler d'abord I'Imperata puis semer les graines, si possible avec du superphosphate. Une autre méthode est de donner les graines à manger au bétail, et de le laisser alors brouter les jeunes pousses d'/mperata, appétissantes après le feu.

Usages : Le stylosanthes est un bon fourrage, mais est parfois peu appétissant pour le bétail. Les abeilles récoltent le nectar à la fin de la saison des pluies.

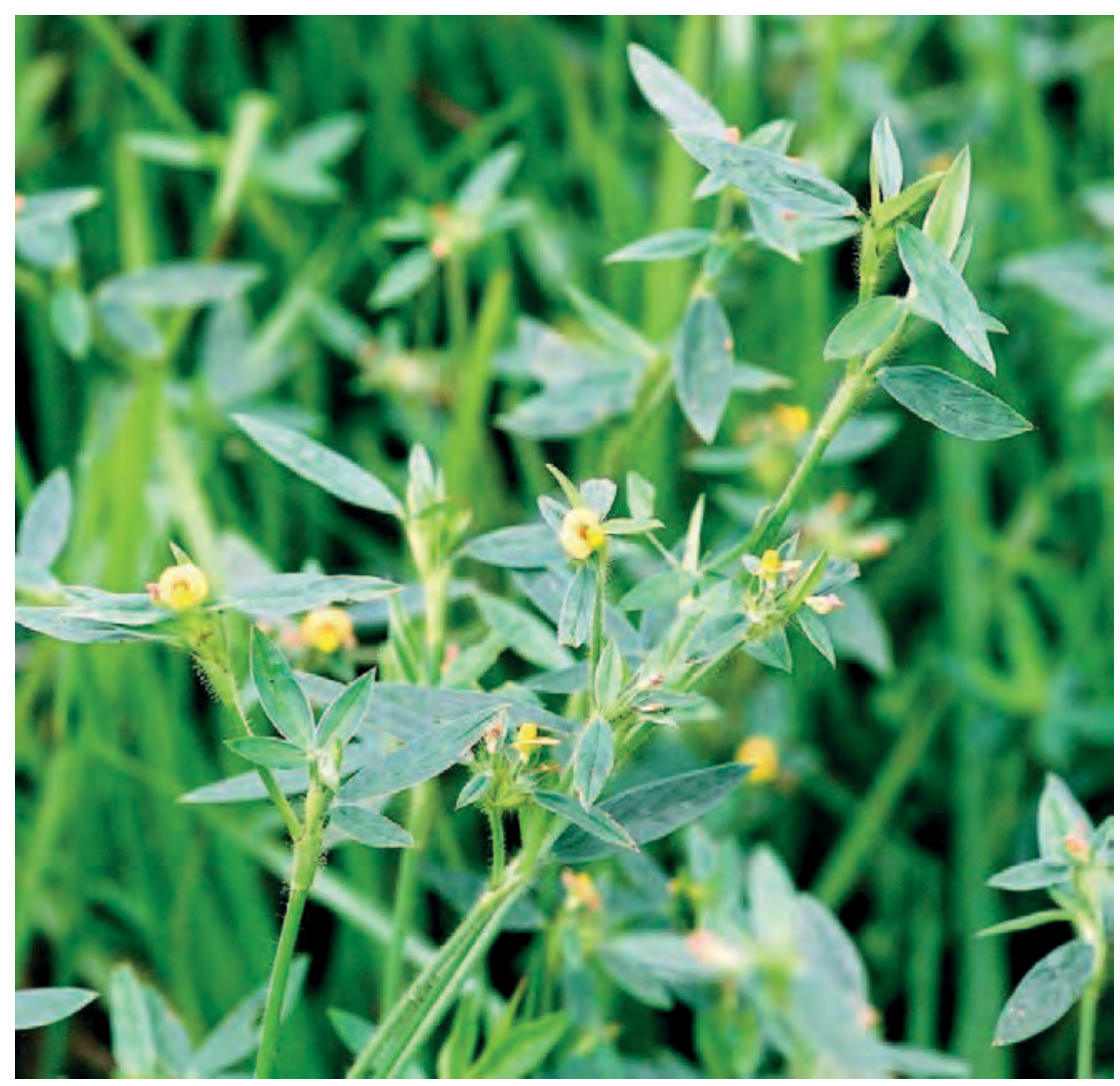

Remarque : Utiliser des cultivars résistants à l'anthracnose causée par Colletotrichum gloeosporioides

Références : Renier 1948, Bogdan 1977, Skerman 1977, Fichtl et Adi 1994, Raemaekers 2001 


\section{Symphonia globulifera}

Noms courants : Kisongi, nsongi, nsempe (Kikongo), mani, manil marécage (Fr.), Karamanni wax (Angl.)

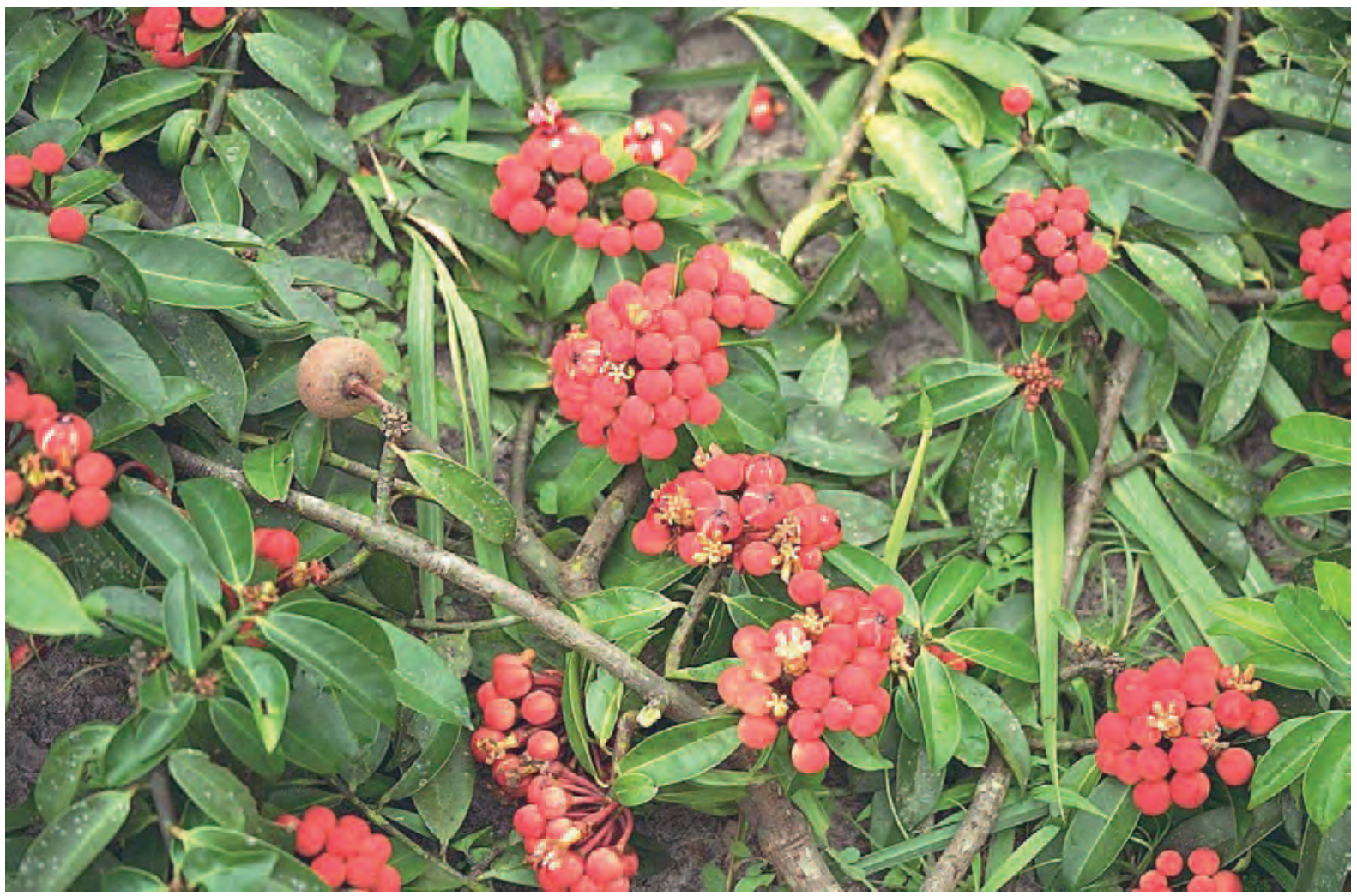

Description : Arbre atteignant 25 à $40 \mathrm{~m}$ de hauteur, à latex jaunâtre visqueux ; fût droit, sans branches jusqu'à $21 \mathrm{~m}$, présentant des racines échasses ou des pneumatophores dans les stations marécageuses. Feuilles opposées, simples, de 5 à 12,5 sur 1 à $5 \mathrm{~cm}$. Inflorescence sessile ombelliforme, à nombreuses fleurs, terminale sur de courts rameaux latéraux. Fleurs pourpres ou écarlates d'environ $4 \mathrm{~cm}$ de diamètre. Fruit de 1,5 à 4,5 sur 2 à $3,5 \mathrm{~cm}$, renfermant 1 à 3 graines. L'arbre en fleurs est très spectaculaire : les courts rameaux horizontaux, tout en haut de l'arbre, sont couverts sur toute leur longueur par une multitude de fleurs.

Ecologie : Arbre poussant au bord des cours d'eau et dans les zones marécageuses de la forêt pluviale, de la Guinée Bissau et la Sierra Leone à la Tanzanie et à l'Angola. Arbre également présent en Amérique tropicale.

Reproduction : Récolter les graines au sol ; les tremper dans l'eau chaude, et laisser refroidir une nuit avant de semer. Semer en pots ou en pleine terre ; transplanter les semis spontanés. Les graines perdent leur viabilité rapidement. Les semis développent rapidement une longue racine pivotante, et sont donc difficiles à transplanter.

Gestion : On peut cultiver cet arbre en culture pure, sans autre espèce, pour protéger les sources, les marais et les rives de cours d'eau. On peut le tailler.

Usages : Le bois, lourd, est comparable à l'acajou et s'emploie pour le mobilier, la construction navale, les ustensiles de ménage, les pagaies. Il résiste bien à l'immersion dans l'eau, et aux attaques d'insectes et de champignons. L'écorce contient une résine jaune très adhésive et résistant à l'eau, dite cire de karamanni, employée comme colle à bois, pour le calfatage des bateaux, pour fixer les couteaux à leurs manches, pour réparer les calebasses, etc. On l'emploie aussi pour protéger les pieds contre les chiques. On applique la sève sur les abcès et les blessures. Au Kongo Central, on mange la pulpe du fruit pour chasser les vers intestinaux; on emploie l'écorce pour traiter la toux chez les enfants. L'arbre est souvent écorcé pour les usages médicinaux, et de ce fait devient rare. C'est une plante nourricière des chenilles comestibles Nsongi ( Rhypopteryx poecilanthes) ; les abeilles butineraient les fleurs, et sont aussi attirées par la résine.

Remarques : Les abeilles récoltent souvent la résine. Selon un proverbe Kisoongi go kifudidi bituuntu, kisiwu kikyeele $=$ Quand le kisongi fleurit, c'est le début de la saison sèche.

Références : Gillet et Pâque 1910, De Wildeman 1938, Renier 1948, Irvine 1961, Nsimundele 1966 - 68, Uphof 1968, Bamps 1970, Daeleman et Pauwels 1983, Keay 1989, Burkill 1994, Katende et al. 1995, Latham 2008 


\section{Synedrella nodiflora}

Noms courants : Madia ma nlumba (Kikongo)(= nourriture des lapins), nodeweed (Angl.)

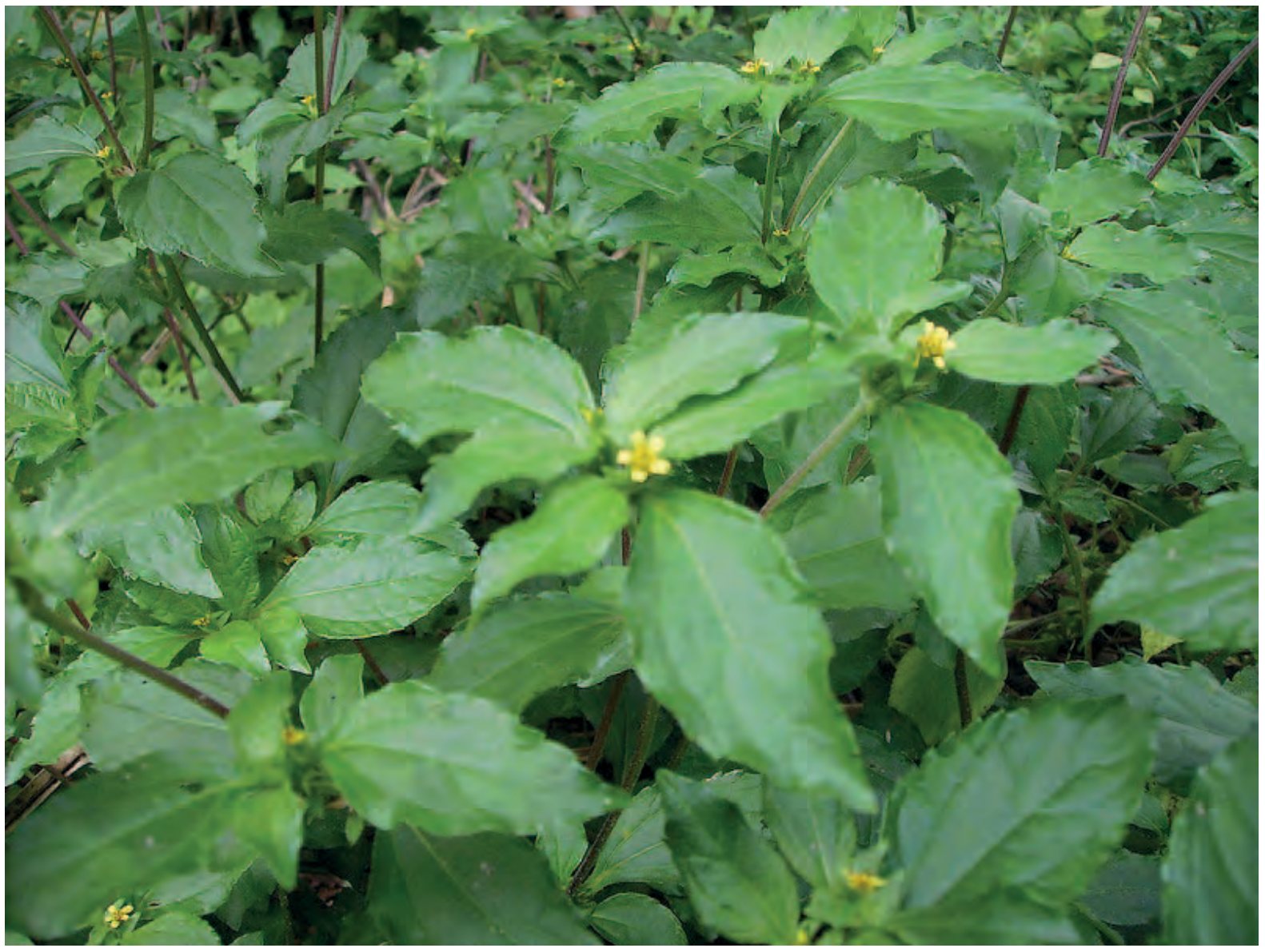

Synedrella nodiflora en fleurs en janvier

Description: Herbe annuelle désordonnée, semi-ligneuse, atteignant $50 \mathrm{~cm}$ ou $1 \mathrm{~m}$ de haut, à partir d'une souche ligneuse. Feuilles simples opposées, de 2 à 6 sur 1 à $4 \mathrm{~cm}$, pubescentes sur les deux faces, râpeuses au toucher, vert foncé, bord crénelé, base atténuée. Fleurs assemblées en petits bouquets axillaires ou terminaux, de $5 \mathrm{~mm}$ de long, jaunes. Graine linéaire de $5 \mathrm{~mm}$ de long portant à l'extrémité deux pointes divergentes de 2 à $3 \mathrm{~mm}$ de long.

Ecologie : Adventice indésirable commune des cultures, des friches et des bords de route, partout sous les Tropiques.

Gestion : Difficile à supprimer une fois établie, émousse même les couteaux tranchants.

Usages : Le bétail, et notamment les lapins, mange les feuilles ; en Indonésie, on mange les jeunes feuilles comme légumes. On donne une décoction des feuilles comme laxatif et pour traiter les problèmes cardiaques. Diverses parties de la plante sont employées pour traiter la conjonctivite, la diarrhée, les blessures, les œdèmes, la lèpre, les règles douloureuses, les ulcères, la toux, les troubles auditifs, les plaies de la bouche et les maux d'estomac. Pour les femmes prêtes à accoucher, il faudrait manger des feuilles pour faciliter le travail, spécialement pour un premier né.

Références : Renier 1948, Abbiw 1980, Daeleman et Pauwels 1983, Burkill 1985, Akobundu et Agyakwa 1987, Neuwinger 2000 


\section{Synsepalum dulcificum}

Noms courants : Punga (Kikongo), fruit miracle (Fr.)

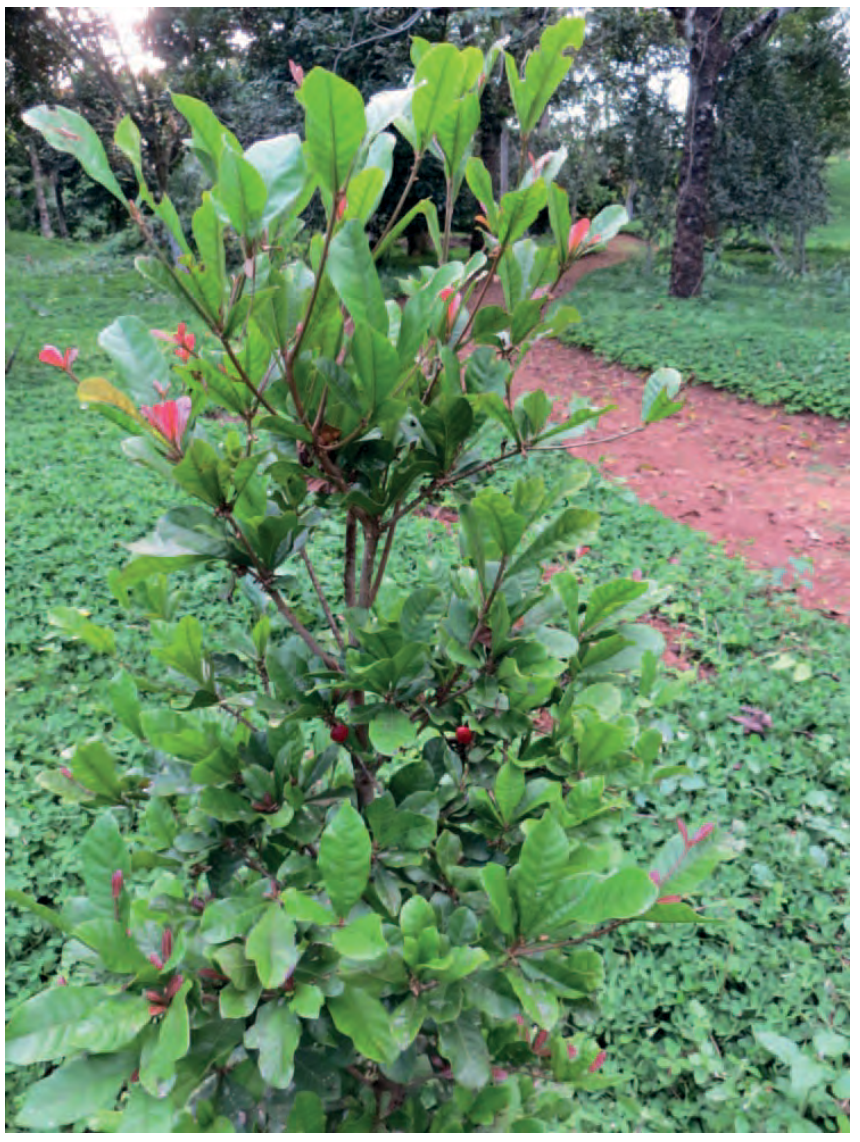

Description : Arbuste de 2 à $3 \mathrm{~m}$ de haut. Ses feuilles mesurent 8 à 15 sur 4 à $6 \mathrm{~cm}$. Ses petites fleurs blanches donnent naissance à de très nombreux fruits rouges de forme ovale longs de 2 à $3 \mathrm{~cm}$. Leur pulpe blanche et acidulée contient une seule graine.

Ecologie : Arbuste présent en lisière de forêts et dans les lieux humides, en Afrique de l'Ouest jusqu'en RD Congo. Il lui faut un sol acide et une humidité convenable.

Reproduction : par graines.

Gestion : Arbuste à croissance lente.

Usages: Les fruits sont comestibles. La pulpe du «fruit miracle » a un goût légèrement sucré, mais elle a la propriété de recouvrir les papilles gustatives de la langue ce qui neutralise l'acidité de tout autre aliment, citron par exemple, durant environ une heure, car il contient une glycoprotéine nommée miraculine. On peut aussi l'employer pour masquer le goût des aliments avariés. Le bois sert comme bois de feu. Au Ghana, les tiges servent de bâtons à mâcher.

Références : Renier 1948, Burkill 2000, Nsimundele 2004

\section{Photo: Roy Danforth}

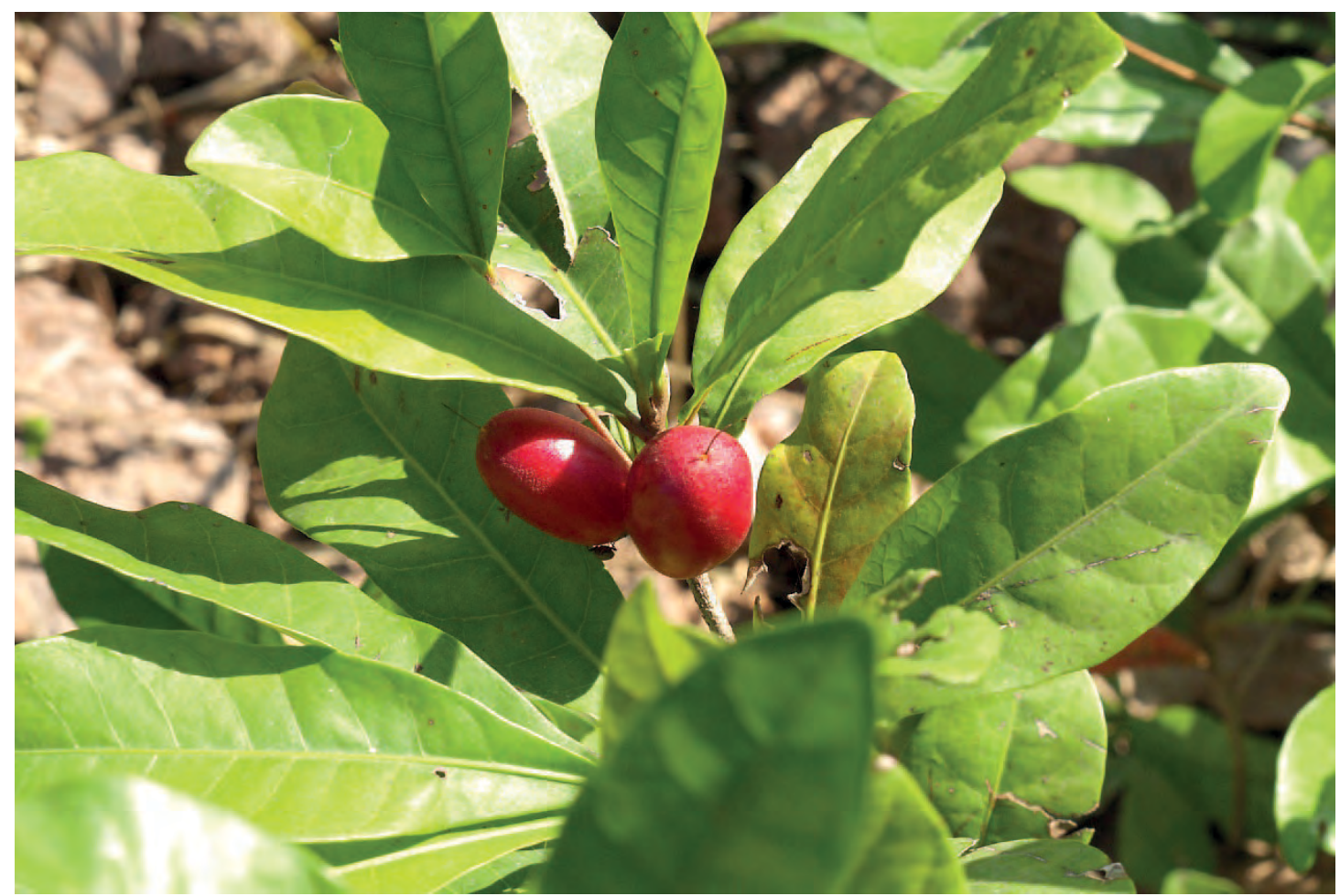

Photo : Tony Rodd 
Noms courants : Mza mbarau (Swahili), jamelonier (Fr.), jambolan (Angl.)

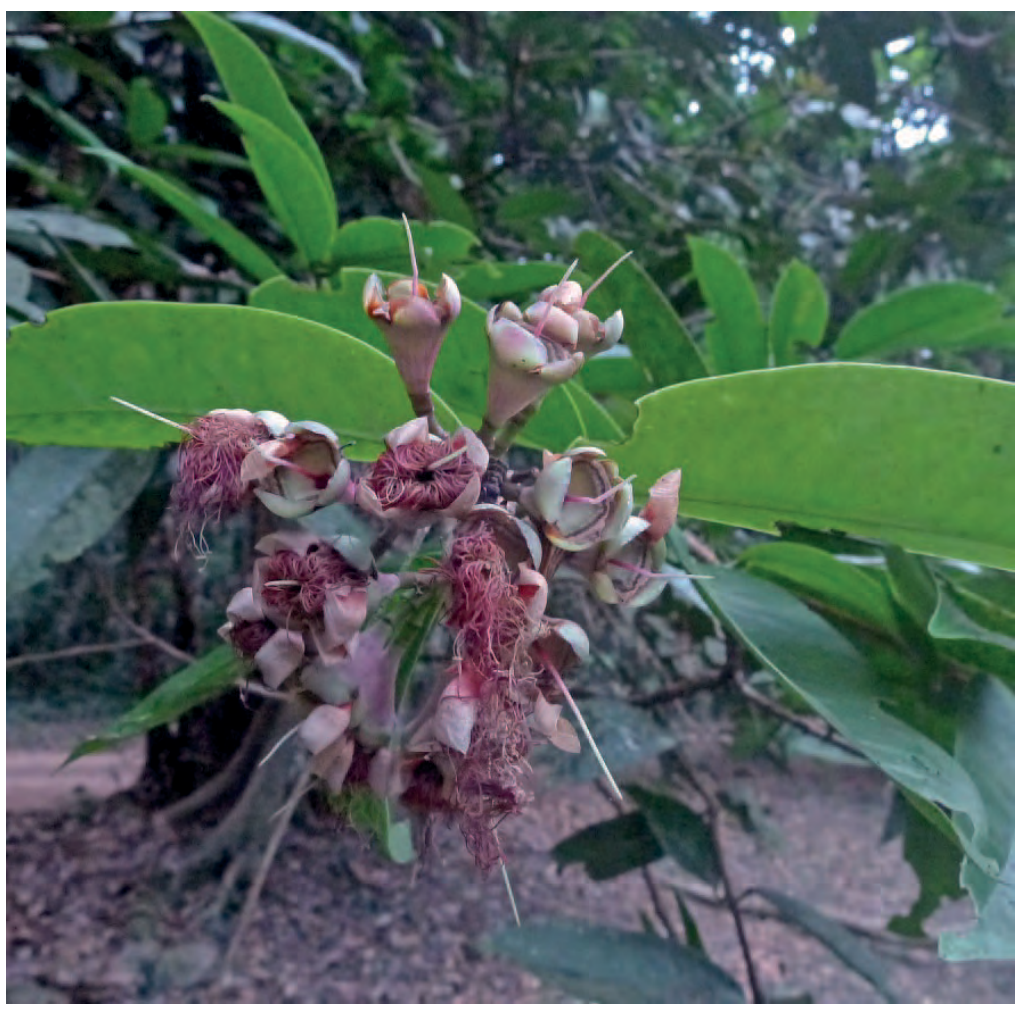

Description: Grand arbre pouvant atteindre $30 \mathrm{~m}$ de haut, mais souvent plus petit. Couronne ramifiée à feuillage tombant dense. Ecorce rugueuse et sombre sur le tronc, lisse et plus pâle sur les jeunes branches. Feuilles jusqu'à $20 \mathrm{~cm}$ de long, fortement aromatiques quand on les écrase. Jeunes feuilles de couleur rougeâtre. Fleurs parfumées attirant beaucoup d'insectes. Le fruit est une baie pourprée, sphérique ou ovoïde de $2,5 \mathrm{~cm}$ de long sur $2 \mathrm{~cm}$ de diamètre. La pulpe blanche, mauve pâle ou jaune, contient de 1 à 5 graines.

Ecologie: Arbre originaire d'Inde, Philippines, Sri Lanka et péninsule malaise, naturalisé dans quelques lieux, peut devenir invasif.

Reproduction: Semer les graines directement sur le site de plantation, ou en pots, après avoir retiré la pulpe et les avoir lavées. La germination intervient après une à deux semaines ; elle est bonne si la graine est fraîche. $\mathrm{Si}$ le fruit tombe au sol, le semis prend

rapidement. Les graines perdent rapidement leur viabilité.

Gestion: Arbre à croissance rapide, qui tolère l'ombre quand il est jeune. Peut-être taillé, rabattu et recépé.

Usages : Le fruit est comestible quand il devient noir. Le bois sert pour des usages généraux, poteaux, manches d'outils et bois de feu. II donne un excellent charbon de bois. Le jus du fruit tend à assécher la bouche. Les abeilles visitent les fleurs, mais le miel aurait un goût très amer.

Remarque: Deux photos prises au jardin botanique de Kisantu.

Références: Beentje 1994, Mbuya et al. 1994, Katende et al. 1995, Maundu et Tengnas 2005,

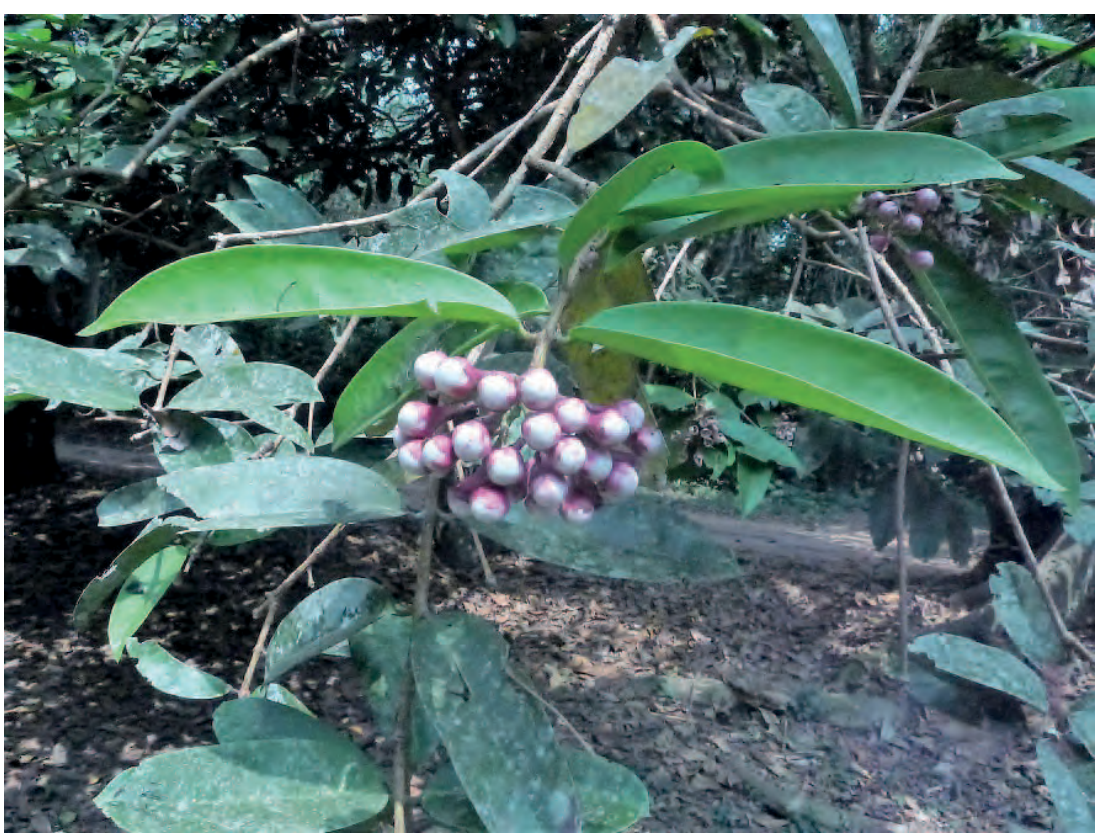
NAS 1980, Witt et Luke 2018 
Noms courants : Kikulu, nkulu (Kikongo), water-berry (Angl.)

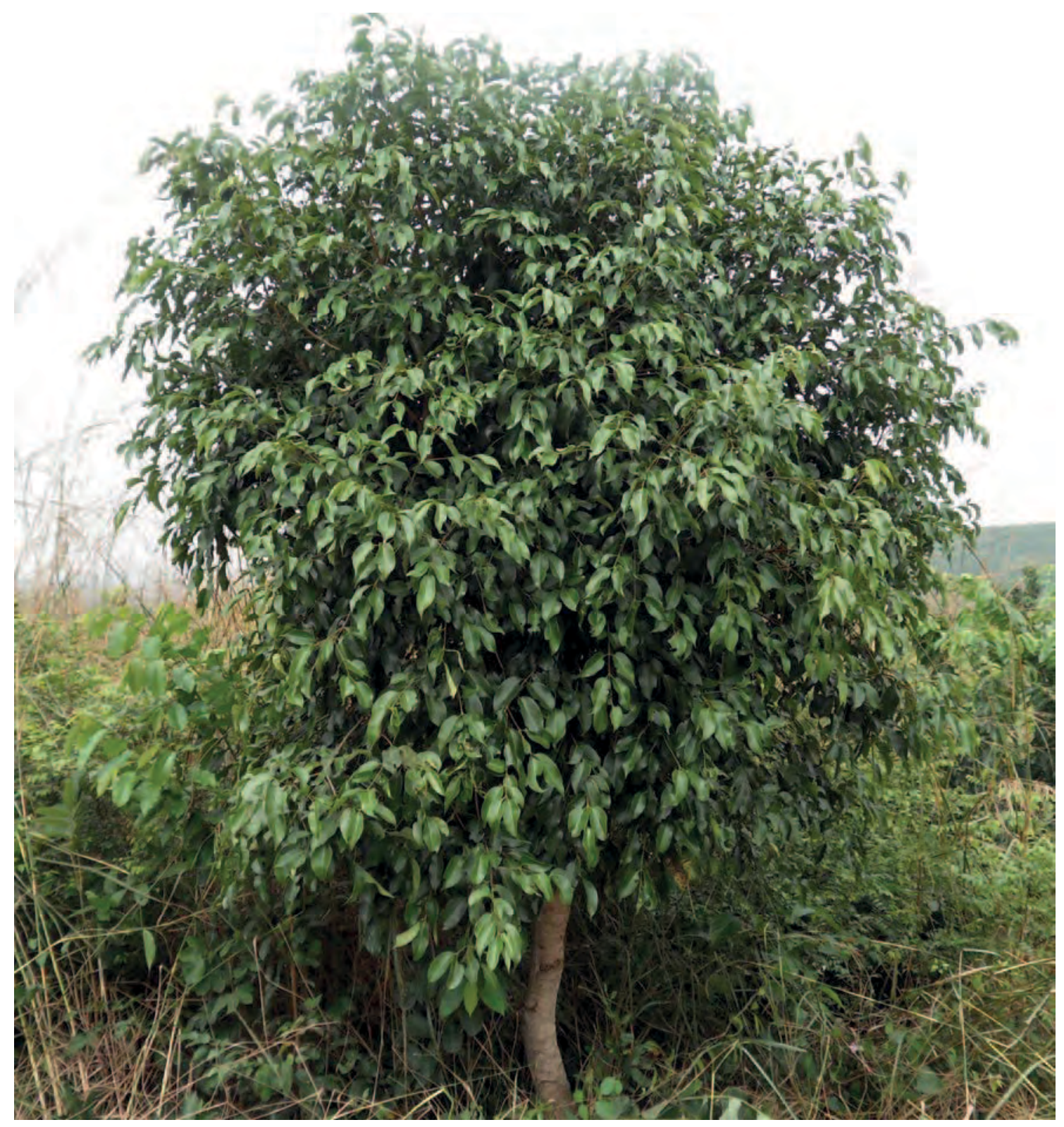

Description : Arbre atteignant $20 \mathrm{~m}$ de haut. L'écorce est lisse et gris clair quand l'arbre est jeune, mais devient noire et rugueuse avec l'âge. Elle donne à la coupure une sève liquide rouge. Les jeunes feuilles sont pourpres. Feuilles elliptiques acuminées au sommet de 3,7 à $12 \mathrm{~cm}$ sur $1,5 \mathrm{~cm}$. Les fleurs blanches ont une odeur de miel attirant de nombreux insectes. Le fruit, noir à maturité, contient un noyau dur entouré d'une pulpe sucrée ; il a de 8 à $12 \mathrm{~mm}$ de diamètre.

Ecologie : Cet arbre est largement répandu en Afrique tropicale. II préfère le bord des cours d'eau et les zones marécageuses, mais il pousse aussi sur les sols bien drainés.

Gestion : Cet arbre peut se tailler et se recéper.

Usages: Le bois est rouge, dur, facile à travailler et très durable, mais se fend facilement. On l'emploie pour le mobilier et la construction générale, les poteaux, les manches d'outil et la sculpture. II sert aussi de bois de feu et pour le charbon de bois. Les fruits très mûrs sont comestibles ; on les récolte sur l'arbre ou tombés au sol. L'écorce s'emploie en tannerie ; on en fait une teinture noire. L'écorce, les racines et les feuilles ont des usages médicinaux, en particulier pour traiter la diarrhée. C'est l'arbre nourricier des chenilles comestibles Nkulu (Mfinda), Makuakua (Micragone cana) et Bubuta. Les abeilles récoltent le nectar des fleurs. 
Références : Irvine 1961, Boutique 1968, Portugal-Araújo 1974, FAO 1983, Lobreau-Callen et al. 1989, Penge et al. 1988, Pauwels 1993, Beentje 1994, Mbuya et al. 1994, Katende et al. 1995, Kibungu Kembelo 1995, Biloso et Lejoly 2006, Orwa et al. 2009, Meunier et al. 2010, Lautenschläger et al. 2018

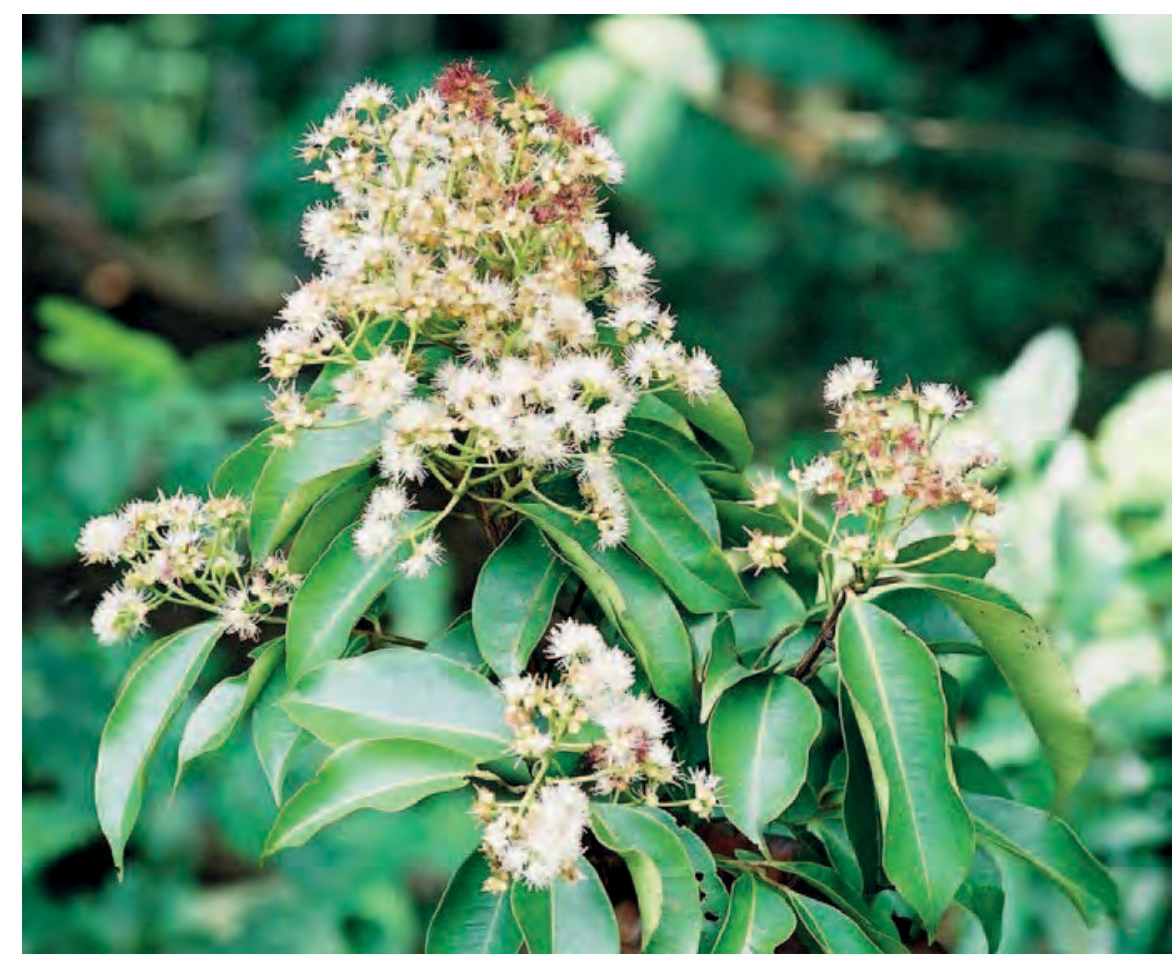

Arbre en fleurs en février près de Luzumu

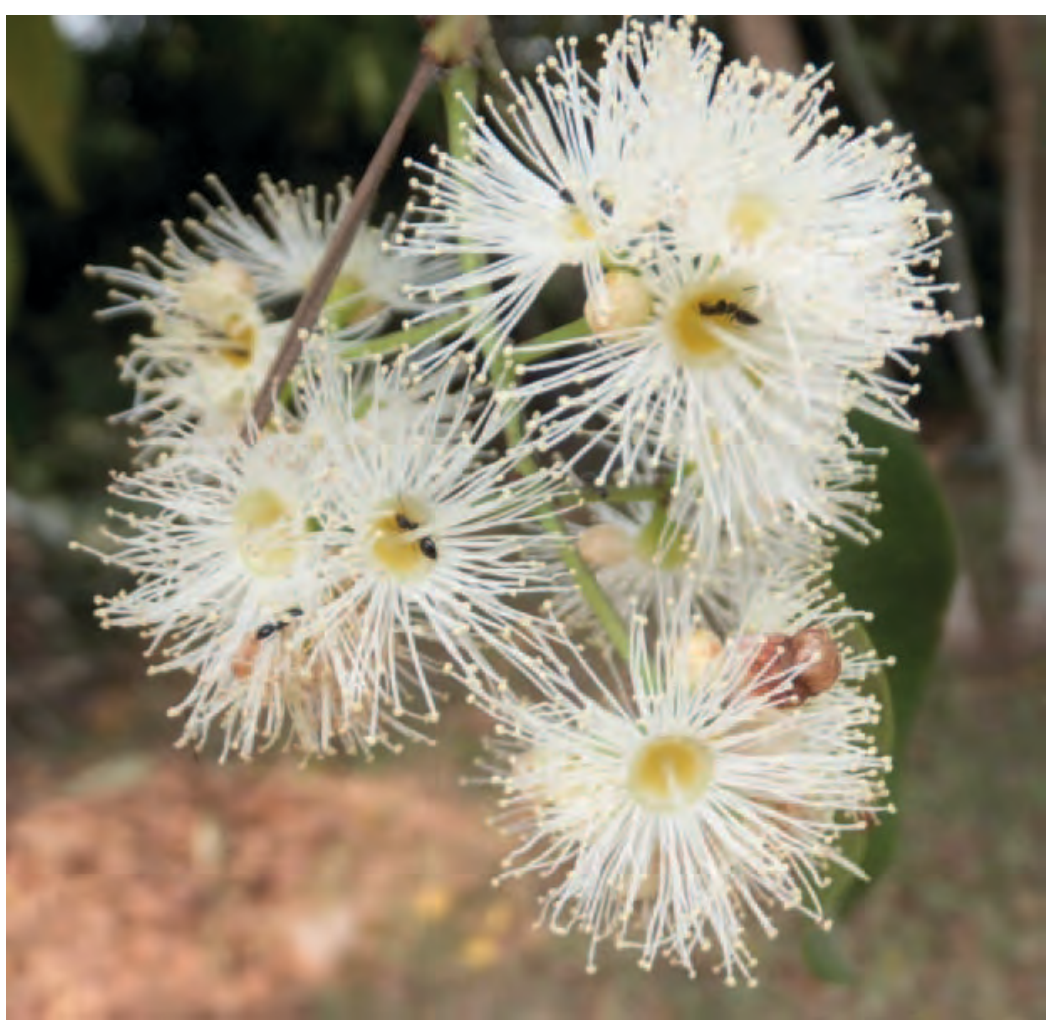




\section{Syzygium guineense subsp. macrocarpum}

Noms courants : Nkisu (Kikongo)

Description : Arbuste ou petit arbre. Les feuilles, ovales à elliptiques, mesurent 7,5 à 15 sur 3,5 à 7,5 cm, sur des pétioles de $38 \mathrm{~mm}$ de long. La principale différence entre cette sous espèce et la variété guineense est le fruit plus grand, de 12 à $30 \mathrm{~cm}$ de diamètre, qui devient pourpre à maturité.

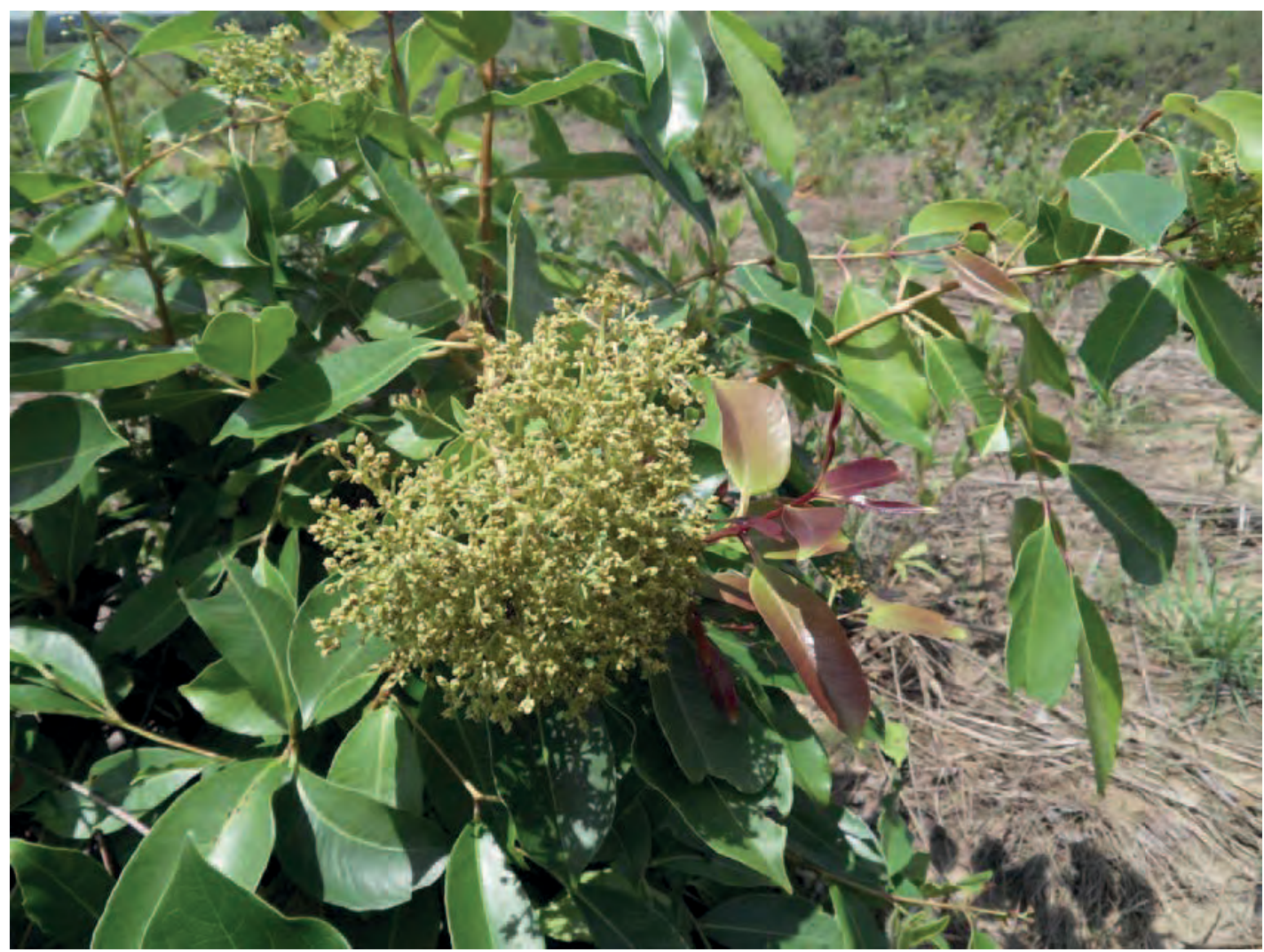

Les fleurs, ici photographiées en novembre, sont très attractives pour les abeilles.

Ecologie : Arbuste des régions de savane soumises aux feux annuels. Très répandu en Afrique tropicale.

Reproduction : Comme S. guineense subsp. guineense.

Usages : Le fruit, comestible, a très bon goût. On donne parfois les fruits à manger aux roussettes pendant leur transport au marché. Les fleurs seraient visitées par les abeilles ; l'arbre est connu comme fourrage des abeilles au Gabon et dans les hautes terres d'Angola. Plante nourricière des chenilles comestibles Bubuta et Nkulu (Nseke) au Kongo Central, et Lobobunaea saturnus Gonimbrasia richelmanni au Katanga.

Références: Boutique 1968, Portugal-Araújo 1974, Malaisse et Parent 1980, Keay 1989, Lobreau-Callen et al. 1989, Pauwels 1993, Kibungu Kembelo 1995, Nsimundele 2004

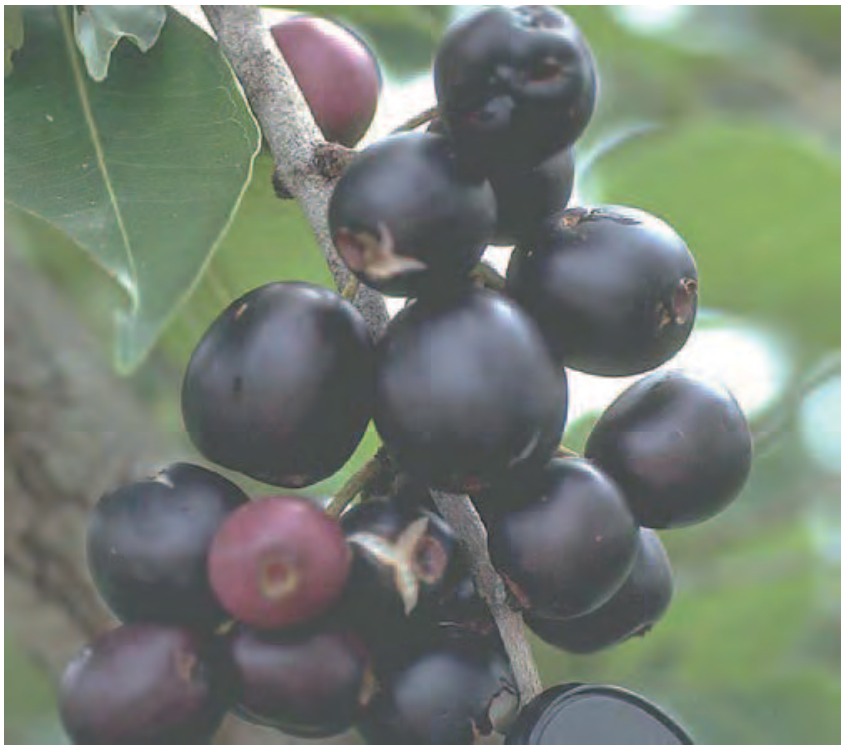




\section{Syzygium jambos}

Noms courants : J ambosier, pommier-rose (Fr.)

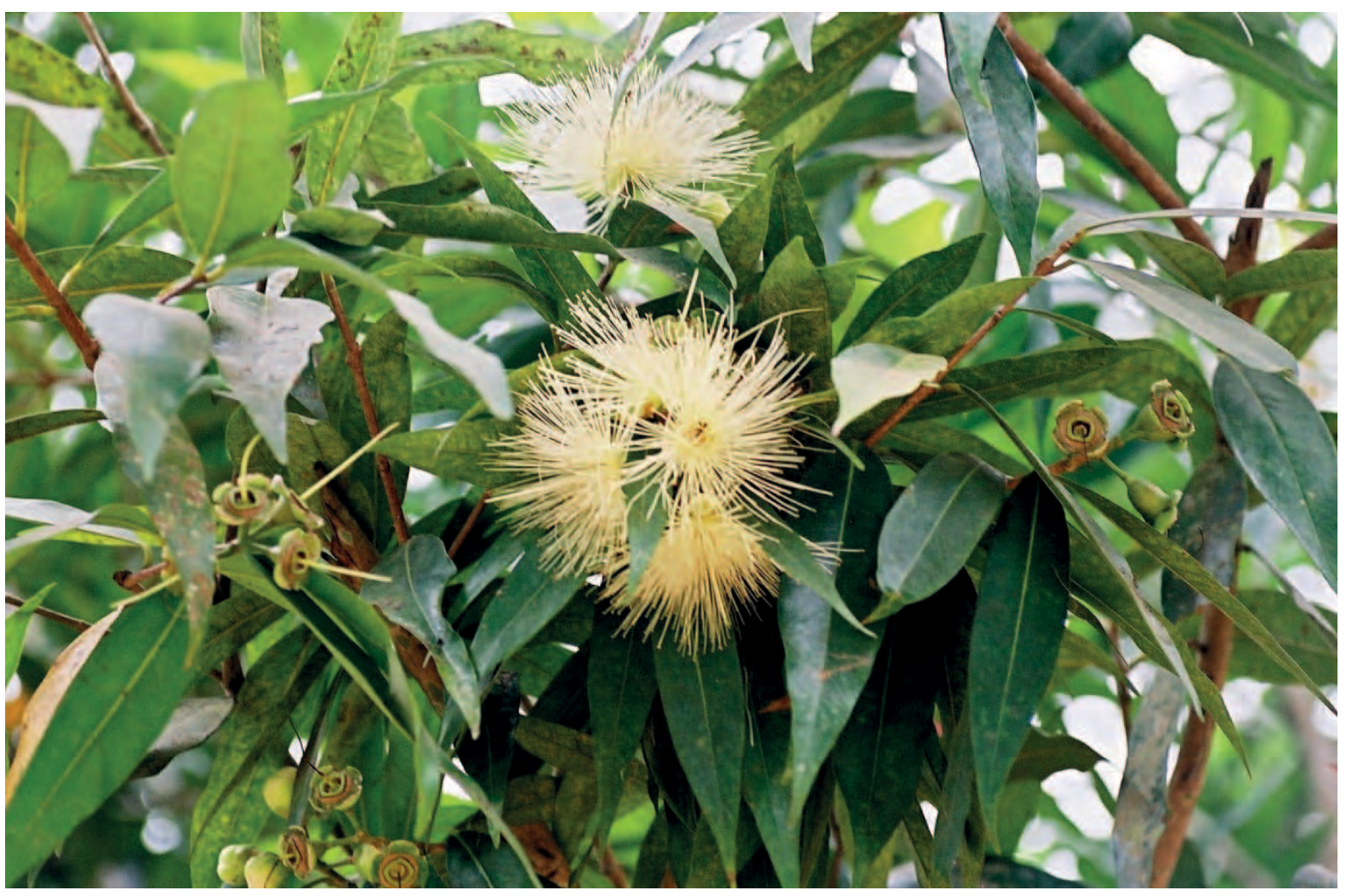

Description : Arbre pouvant atteindre une quinzaine de mètres de hauteur. Les feuilles, opposées, sont lancéolées et longuement acuminées. Elles mesurent 10 à 23 sur 2,5 à $5 \mathrm{~cm}$. Le fruit est une baie de 3 à $5 \mathrm{~cm}$ de diamètre, pouvant aller du jaune pâle au rouge foncé, dont les tissus internes se distendent formant ainsi un fruit « creux » contenant souvent une graine unique devenue libre comme dans un grelot. La chair blanche du fruit est faiblement acide, sucrée et croquante à maturité.

Ecologie : Arbre originaire de la région indo - malaise. Pousse bien sur des sols humides, aussi longtemps qu'ils ne sont pas saturés d'eau. Les arbres établis sont robustes, mais résistent mal à la sécheresse.

Reproduction : L'arbre pousse bien à partir des graines, si elles sont fraîchement récoltées. On le reproduit aussi à partir de marcottes ou boutures. Sur les arbres marcottés, les racines apparaissent après six mois; les marcottes plantées portent des fruits après 3 à 5 ans, alors qu'il faut 3 à 7 ans aux arbres obtenus à partir de semis.

Gestion : Les fruit ne se conservent pas bien, et s'abîment aisément au transport.

Usages: L'arbre fait une bonne plante pour les haies. Les fruits à l'odeur de rose peuvent se manger crus, mais il vaut mieux les cuire. Ils ont une teneur élevée en pectine, de sorte qu'on peut les mélanger avec d'autres fruits au goût plus prononcé pour faire des confitures. Le

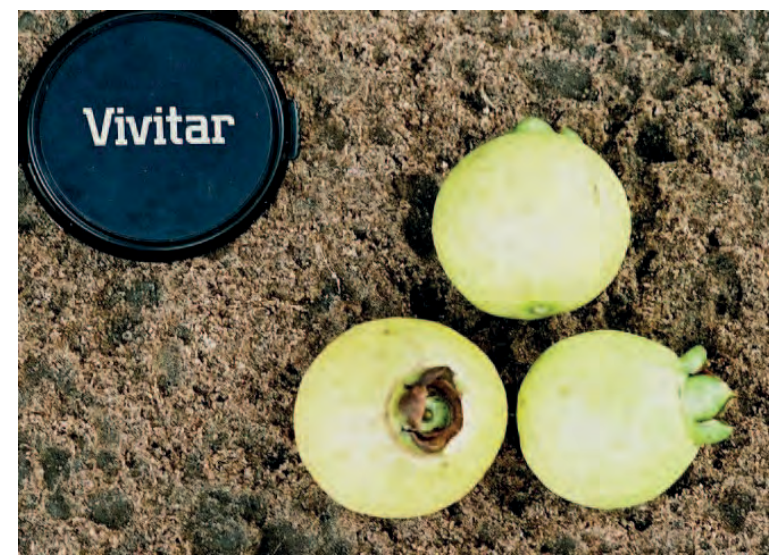
bétail broute les feuilles. Le bois est dur, mais non durable au contact du sol, et facilement attaqué par les termites. II donne un bon charbon de bois, et sert comme bois de feu. Les fleurs fournissent un bon fourrage pour les abeilles, pouvant fournir en grandes quantités un miel ambré au goût léger.

Références : Irvine 1961, FAO 1982, Crane et al 1984, Garner et Chaudhri 1988, Veheij et Coronel 1991, Nakasone et Paull 1998 


\section{Syzygium malaccense}

(Myrtaceae)

Noms courants : Mazenya (Kikongo), jambosier rouge, pommier de Malaisie (Fr.), Malay apple (Angl.)

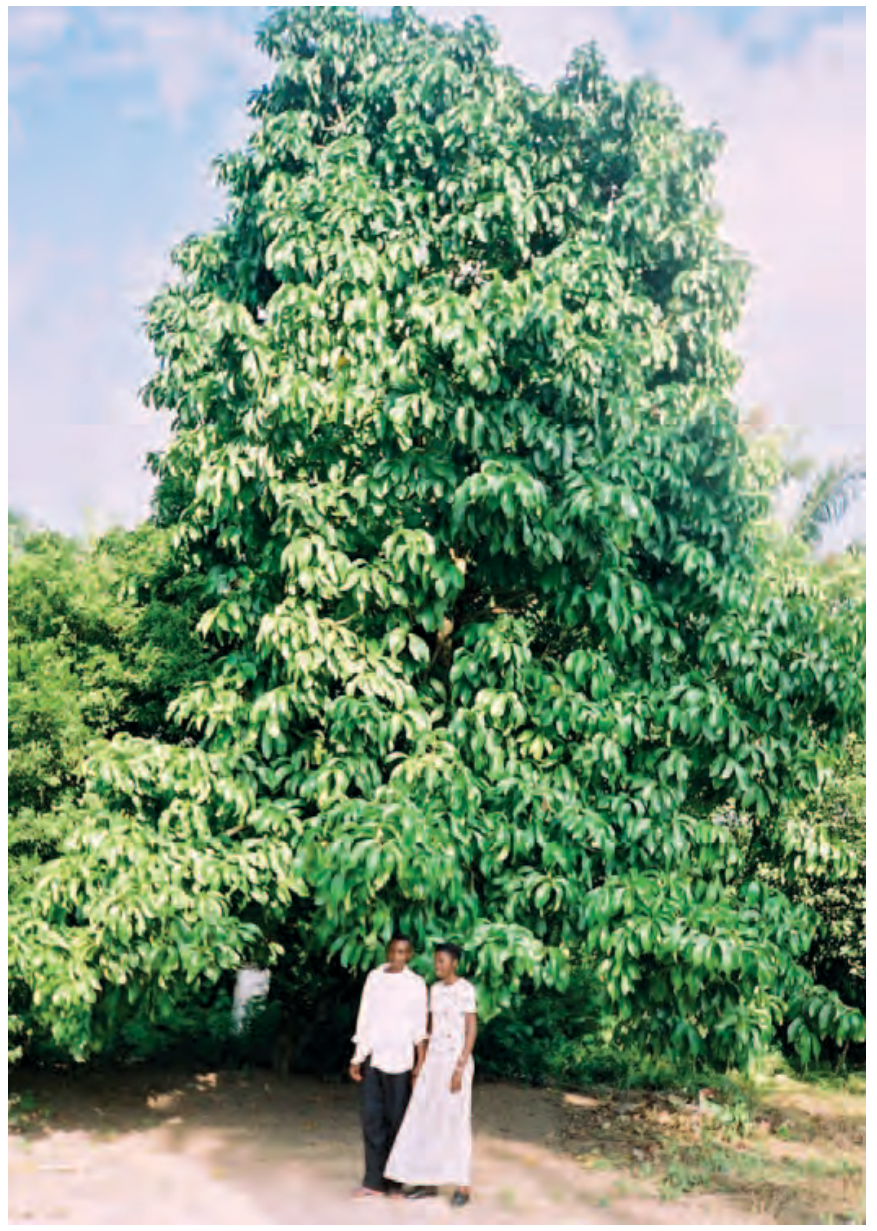

Ecologie: Originaire de Malaisie. Souvent cultivé dans les villages. Ne tolère pas les longues sécheresses, ni les fortes variations de température.

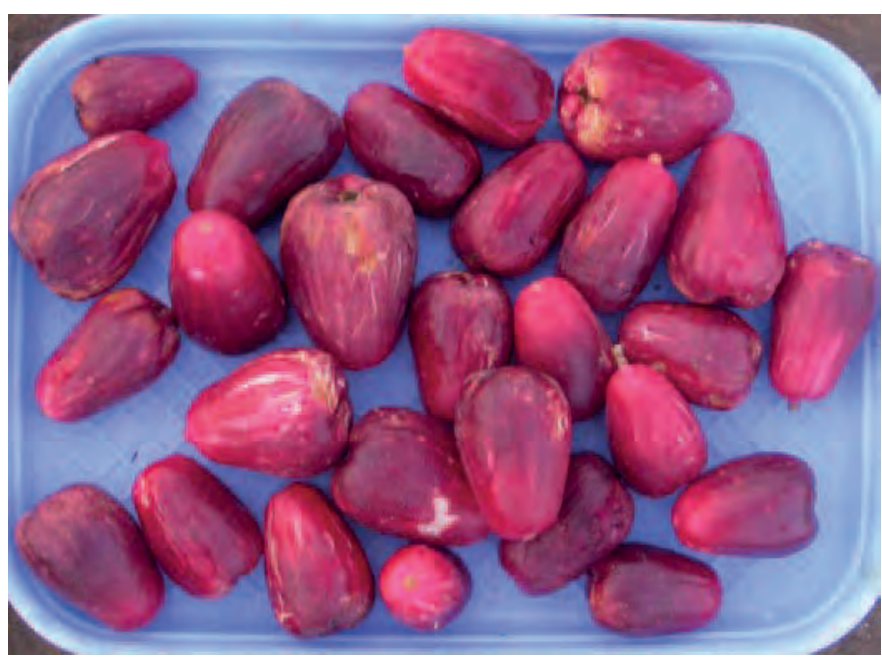

Description : Arbre de 6 à $8 \mathrm{~m}$ de haut. Feuilles ovales, oblongues-lancéolées, un peu pendantes et de grande taille, $15-35 \times 8-18 \mathrm{~cm}$, coriaces, vernissées. Les inflorescences sont des racèmes axillaires, à axe court de $10-15 \mathrm{~mm}$, portant de 4 à 10 fleurs. Les pétales sont roses à rouges, de 10 -15 mm. La fleur comporte un très grand nombre d'étamines rouges (environ 500). A la chute des étamines, elles forment un tapis rouge en dessous de l'arbre. Les fruits, d'abord blancs, puis virant au rouge à maturité, ont 5 à 7 sur 3 à $5 \mathrm{~cm}$. Leur peau mince recouvre une chair blanche, sucrée, juteuse, à l'odeur de rose et de pomme. L'arbre donne souvent des fleurs et des fruits toute l'année.

\section{A gauche: Syzygium malaccense dans une} propriété à Kasangulu

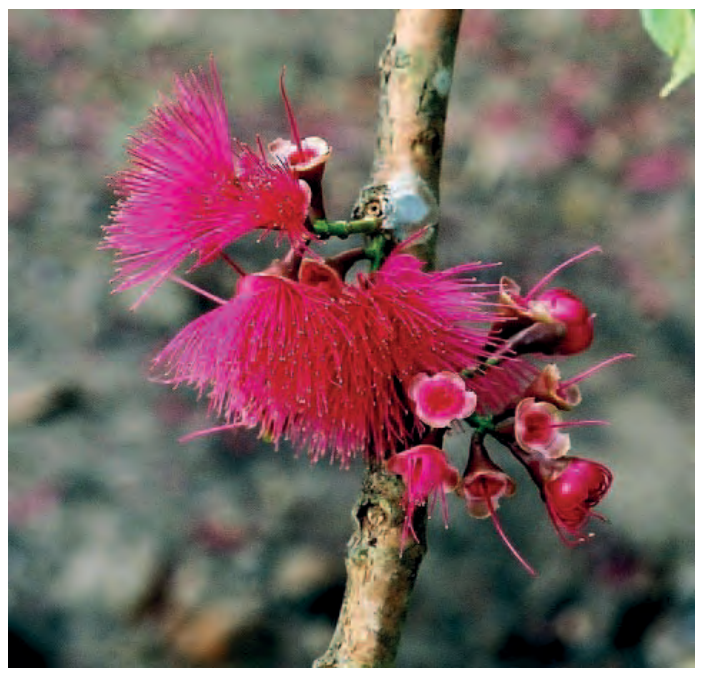

Reproduction : On cultive facilement l'arbre à partir des graines. Cependant, les meilleurs résultats s'obtiennent par greffage sur souche de semis. Espacer tous les 8 à $10 \mathrm{~m}$.

Usages: On cultive l'arbre surtout pour ses fruits, et aussi comme arbre d'ombrage et ornemental. Le fruit peut se manger cru, cuit ou en conserves. Le bois de cœur est dur, lourd et difficile à travailler, mais sert à fabriquer du mobilier. Le bois donne un bon charbon de bois. Les fleurs sont très attractives pour les abeilles. Plante nourricière de la chenille comestible Makedikedi (Bunaea alcinoe).

Remarque : L'arbre est souvent attaqué par les termites.

Références : FAO 1982, Pauwels 1993 


\section{Tabernaemontana crassa}

Noms courants : Munkodi nkodi, mpoki (Kikongo).

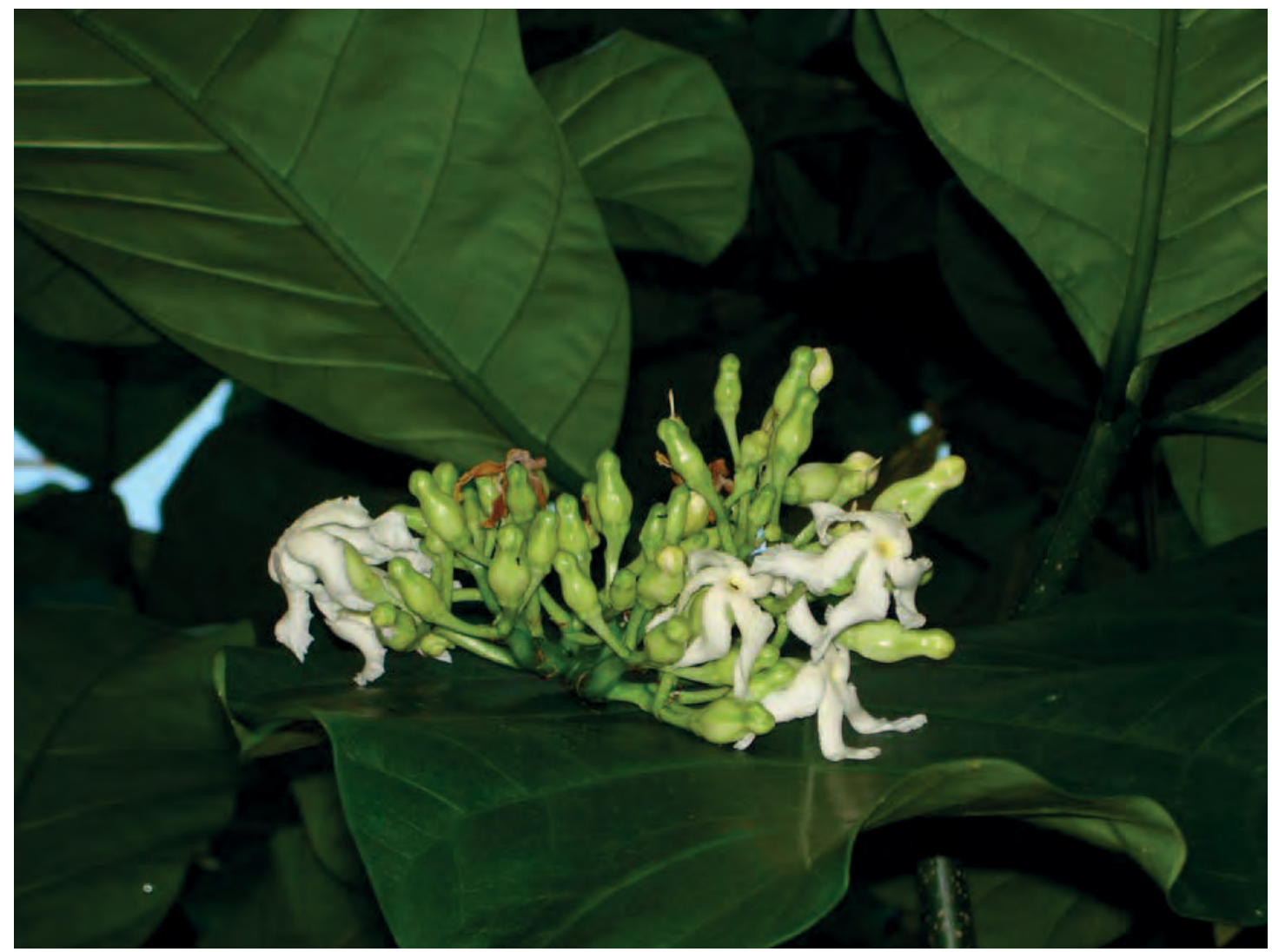

Photo: Museum of Life and Science in Durham, North Carolina, USAC

Description : Petit arbre pouvant atteindre $10 \mathrm{~m}$ de haut. Feuilles opposées, simples et entières de 13 à 40 sur 6 à $20 \mathrm{~cm}$. Fleurs délicatement parfumées, de couleur jaune pâle, aux fourches des branches. Le fruit est composé de deux baies sphériques déhiscentes, vert pâle ou glauques, soudées à la base, chacune contenant de quelques à beaucoup de graines.

Ecologie : Arbre des galeries forestières, des recrus forestiers et des forêts marécageuses, présent de la Sierra Leone, à la Centrafrique et au bassin du Congo.

Reproduction : Par graines, et aussi probablement par boutures de bois semi mûr.

Usages : Le bois convient pour la menuiserie générale, le contreplaqué et la confection de boîtes. Au Libéria, on l'emploie occasionnellement pour faire des mortiers pour piler le riz. Comme pour beaucoup de plantes donnant du latex, on pense dans le bassin du Congo qu'il encourage la lactation. On emploie en lavement une décoction ou une macération des fruits pour traiter les grosseurs des testicules. On donne une décoction de l'écorce des tiges pour traiter la diarrhée. Le latex de l'écorce donne un caoutchouc médiocre, qui reste collant et que l'on emploie occasionnellement. En raison de la beauté et du parfum de ses fleurs, la plante est cultivée à titre ornemental. Les feuilles sont broutées par l'escargot géant africain Achatina achatina, comestible et dont on fait l'élevage.

Remarque : Le latex est extrêmement caustique : une seule goutte dans l'œil peut entraîner la cécité.

Références : Renier 1948, Daeleman et Pauwels 1983, Burkill 1985, Pauwels 1993, Neuwinger 2000, Mairura et Schmelzer 2006 


\section{Tabernanthe elliptica}

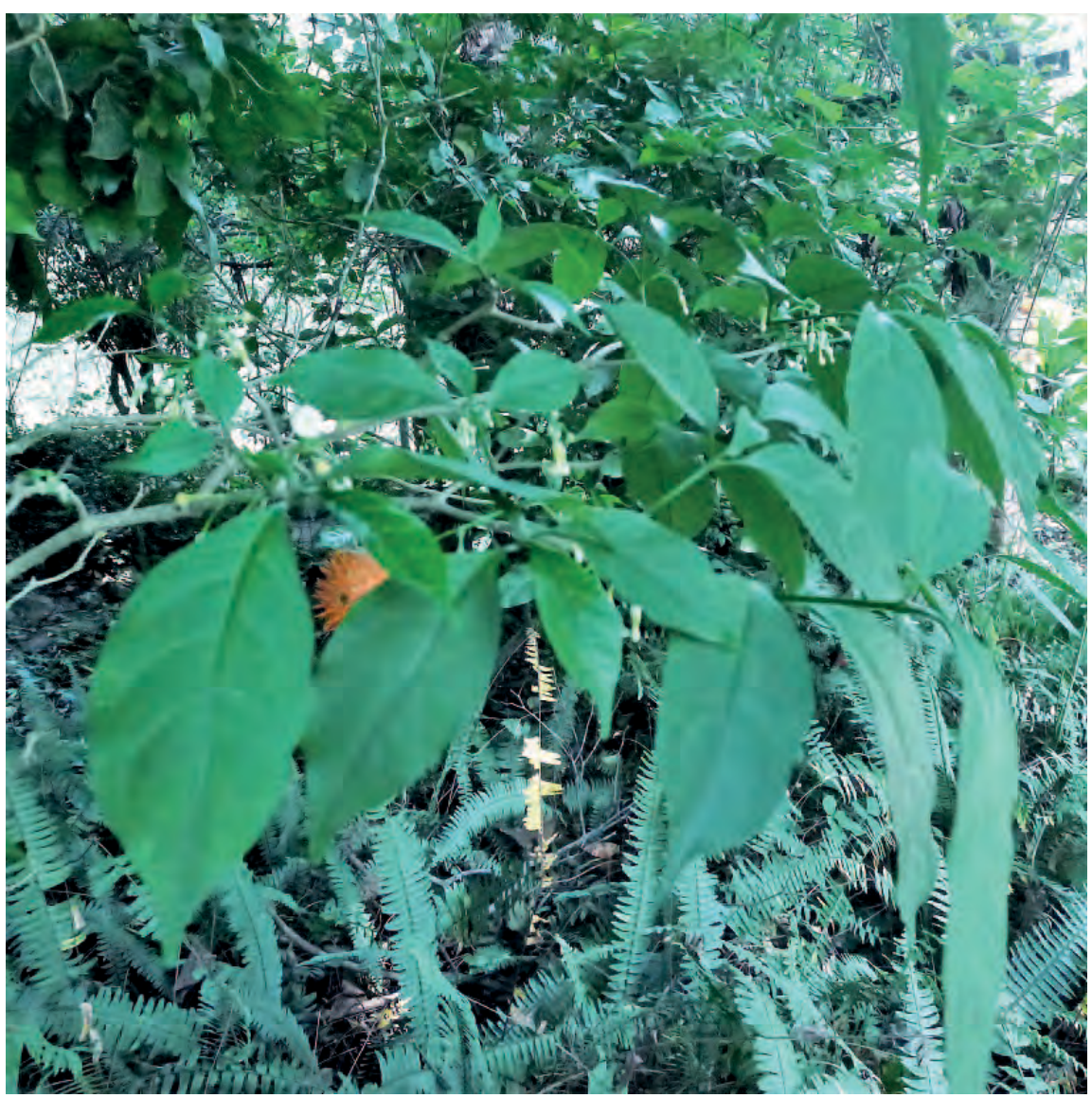

(Apocynaceae)

Ecologie : Plante présente au Congo Brazzaville, en R.D. Congo et en Angola.

Usages : Le fruit est comestible ; il est une source d'alcaloïdes du type de l'iboga.

Références : Malaisse 1997

Tabernanthe elliptica au jardin botanique de Kisantu

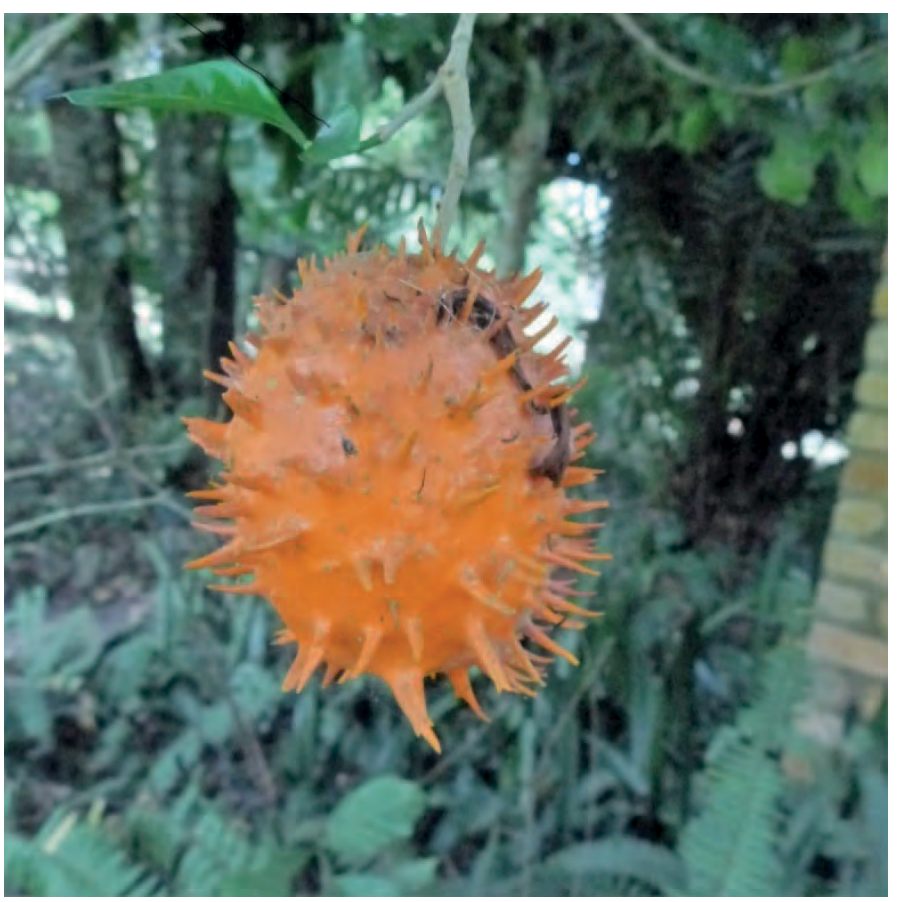




\section{Tabernanthe iboga}

Noms courants : I boga, bois sacré, bois amer (Fr.), sacred wood (Angl.)

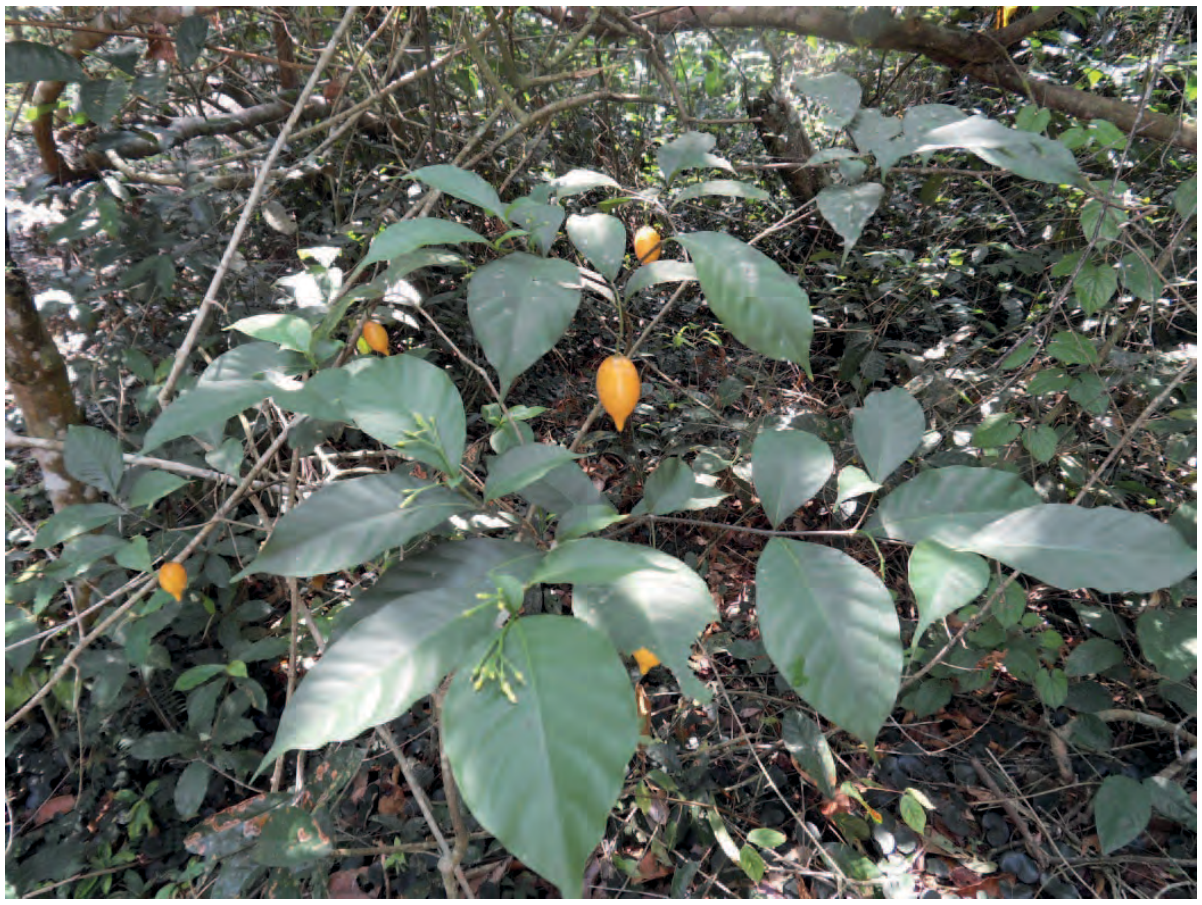

Description : Arbuste de 2 à $5 \mathrm{~m}$ de haut, avec des tiges jusqu'à $10 \mathrm{~cm}$ de diamètre. Il y a du latex blanc dans toutes les parties de la plante. Feuilles opposées de 10 à 18 sur 4 à $8 \mathrm{~cm}$. Petites fleurs avec des marques pourpres à la gorge. Le fruit est une baie ovoïde de 5 à 6 sur $1 \mathrm{~cm}$, contenant les graines dans une pulpe blanche spongieuse.

Ecologie : Arbuste des forêts galeries et des recrus forestiers en Afrique Centrale. Cultivé aussi dans plusieurs pays ouest africains.

Reproduction : Par graines nouvellement récoltées, ou boutures. La scarification des graines augmente beaucoup le taux de germination.

Usages : Les racines et les pousses contiennent un hallucinogène, l'ibogaïne; on les prend comme tonique et aphrodisiaque. A l'échelle internationale, la plante est employée pour traiter l'addiction à la drogue. Elle a cependant des effets nocifs en affectant la coordination musculaire, l'équilibre et la marche; l'ibogaïne a été catégorisée comme une substance hallucinogène dangereuse aux Etats-Unis et dans plusieurs autres pays, où il est par conséquent illégal d'en acheter, d'en vendre ou d'en posséder sans licence d'exploitation. Cependant, l'intérêt qu'elle suscite et les recherches à son sujet continuent. Au Gabon, la racine est très importante dans les cérémonies d'initiation; celles-ci se sont répandues au Sud du Cameroun, en Guinée Equatoriale, au Congo Brazzaville et en R.D. Congo. L'écorce de la racine se mange entière, ou en poudre, ou en boulettes, parfois mélangée avec d'autres ingrédients. On prend une décoction des

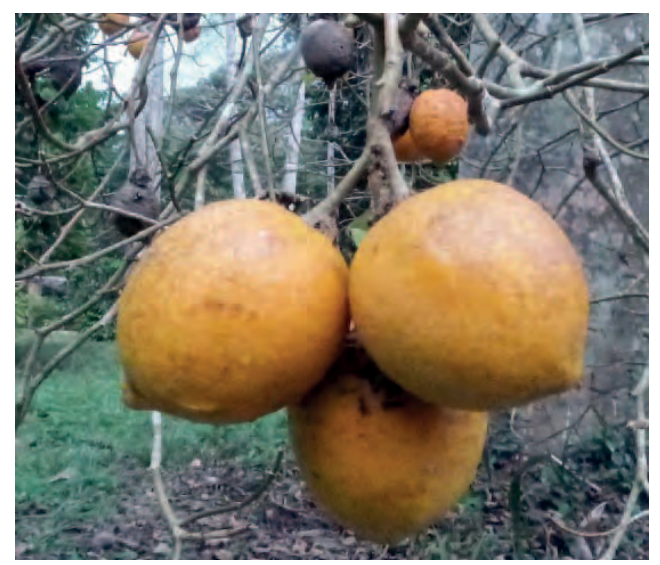
racines comme tonique pour combattre la fatigue, la faim et la soif, quant il faut surmonter un choc physique. Au Congo Brazzaville, on prend la racine macérée dans I'huile de palme pour soulager la toux ; on boit une décoction pour traiter les infections urinaires. On prend le latex comme antihelminthique ; on passe les feuilles chauffées sur les gencives pour calmer les maux de dents. L'application sur le sol d'une décoction des feuilles est efficace pour contrôler l'infection des nœuds des racines par le nématode Meloidogyne.

Références : Gillet 1927, Renier 1948, Nsimundele 1966 - 68, Pauwels 1993, Vande weghe 2004, Tabula et al. 2005, Bourobou Bourobou 2006 
Noms courants : Ngoma kiula (= tambour de crapaud) (Kikongo), African arrowroot lily (Angl.)

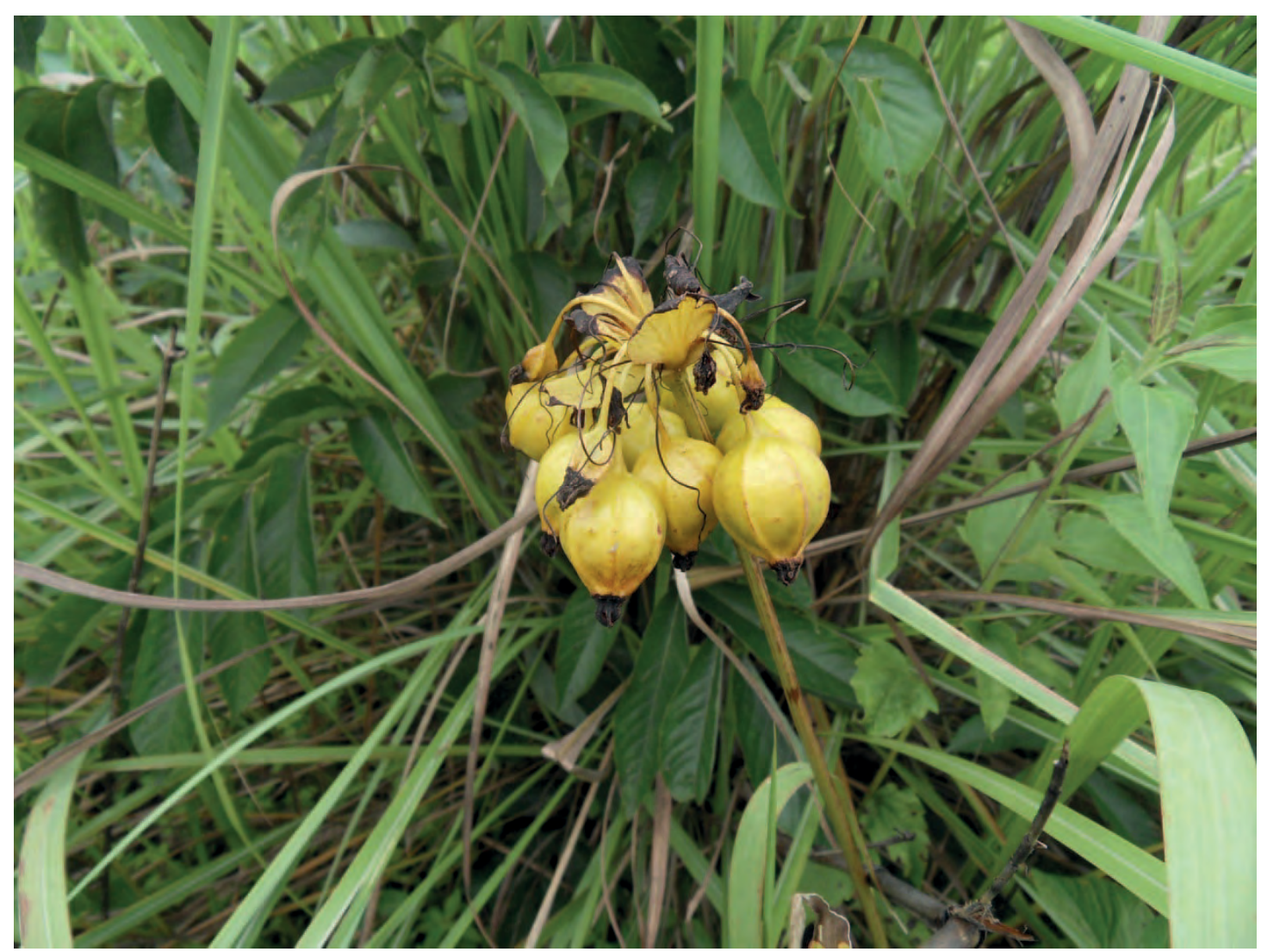

Description : Plante herbacée pérenne de 1,5 m de haut à rhizome tubéreux. Le tubercule est rond, jusqu'à 12 $\mathrm{cm}$ de diamètre, et peut peser de 200 à $700 \mathrm{~g}$. La plante a de 1 à 3 très grandes feuilles, profondément divisées, ayant jusqu'à $90 \mathrm{~cm}$ de long sur $60 \mathrm{~cm}$ de large, sur une tige verte légèrement tachetée de 25 à $130 \mathrm{~cm}$ de haut. Les fleurs sont disposées sur une tige droite, intercalées avec de longs filaments. Les fruits ovales, striés, de 3,5 sur $2,5 \mathrm{~cm}$, contiennent de nombreuses graines brun clair.

Ecologie : Cette plante pousse sur des sols légers et friables en savane herbeuse et dans des taillis sans ombre, en Afrique tropicale, en Asie et dans les îles du Pacifique. On la cultive parfois dans le Pacifique Sud.

Usages : Les tubercules sont très amers et toxiques, mais deviennent comestibles après une préparation soignée. Ils se conservent longtemps. Ils contiennent de 21 à $30 \%$ d'amidon que l'on peut extraire à l'état presque pur. On déterre les tubercules quand les feuilles sont tombées; ils sont lavés, râpés, et la râpure mélangée avec de l'eau, et est nettoyée plusieurs fois par filtration en renouvelant l'eau. Une autre méthode est de tremper la pulpe râpée dans l'eau courante de ruisseau pendant une semaine pour éliminer l'amertume et les produits toxiques. On sèche alors l'amidon au soleil pour faire des bouillies en temps de famine. L'amidon séché se conserve plusieurs mois. Pour préparer l'amidon, mélanger dans l'eau et chauffer dans une marmite jusqu'à avoir une bouillie consistante. L'amidon cuit est aisément digestible et convient aux patients souffrant de problèmes digestifs. Les feuilles servent parfois de légumes. En médecine traditionnelle, les tubercules et leur amidon sont employés contre la dysenterie, la diarrhée et les œdèmes.

Remarque: La préparation de la plante doit être extrêmement soignée, car elle peut être très toxique.

Références : Gillet 1927, Greenway 1944, Williams 1949, Morton 1961, Busson 1965, Nsimundele 1966 - 68 , Purseglove 1972, Williamson 1975, Lisowski et al. 1976, Peters et al. 1992, Burkill 2000, Ruffo et al. 2002, Kokwaro 2009, Wikipedia (consulté le 13.9.2012). 
Noms courants : Sansa banzenza, guele guele, mulembwa (Kikongo), lipopi (Lingala), grassé (Fr.), waterleaf (Angl.)

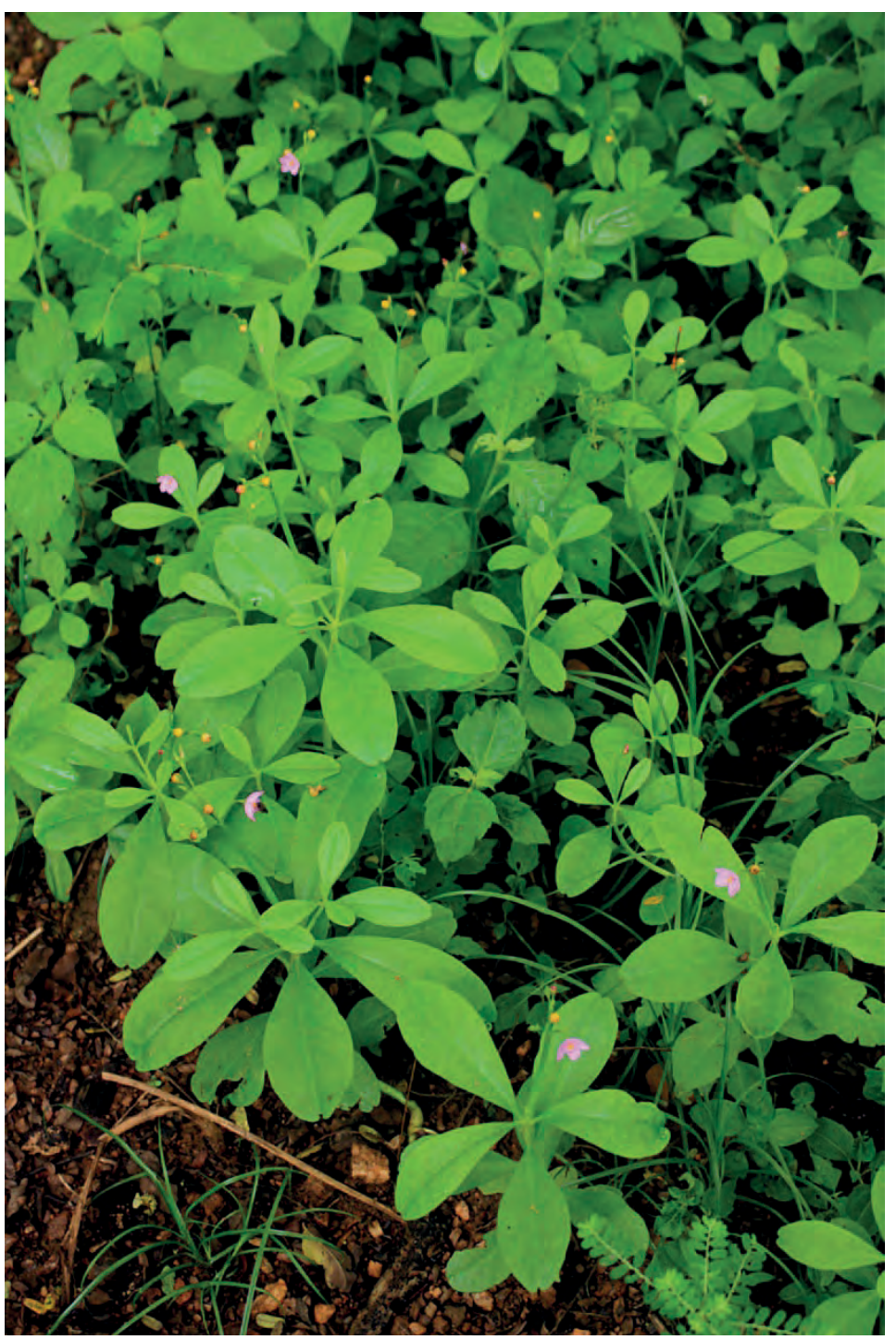

Description : Plante herbacée pérenne, érigée, glabre, atteignant $80 \mathrm{~cm}$ de haut, habituellement fortement ramifiée ; racines gonflées et charnues; tige succulente. Feuilles alternes, simples, succulentes, de 3 à $15 \mathrm{~cm}$ sur 1 à $6 \mathrm{~cm}$, base en longue pointe, apex arrondi à émarginé. Fleurs roses à étamines nombreuses. Le fruit est une capsule de 4 à $7 \mathrm{~mm}$ de long, à 3 valves, déhiscente, contenant de nombreuses graines. Graines comprimées d'environ $1 \mathrm{~mm}$ de long, noir brillant.

Ecologie: Adventice commune sous les Tropiques. L'humidité favorise l'optimum de croissance et développement. La plante pousse bien à l'ombre ou par temps nuageux. Elle préfère un sol fertile bien drainé, mais pousse aussi sur les sols non fertiles. Pousse bien dans les terrains ouverts, sur les bords de route dans les villages, et dans les clairières en forêt. On la cultive occasionnellement.

Reproduction : Se cultive aisément avec des boutures de $10 \mathrm{~cm}$ de long, plantées normalement en saison sèche, à ombrager jusqu'à ce qu'elles aient pris. On doit enlever la paire de feuilles inférieure. On peut aussi utiliser les graines. On les mélange avec du sable pour les semer dans un germoir bien préparé. On transplante les semis à 5 à $8 \mathrm{~cm}$ de haut, espacés de $15 \mathrm{x}$ $15 \mathrm{~cm}$. Un arrosage quotidien est nécessaire la première semaine.

Photo : IITA Image Library

Gestion : La plante demande de 21 à 45 jours entre le semis et la première récolte. Il peut y avoir d'autres récoltes, tous les 8 ou 15 jours, pendant 2 mois. Couper les tiges juste au-dessus du niveau du sol. II ne faut pas pincer les fleurs; La plante a peu d'ennemis ou de maladies, bien qu'elle soit une plante hôte pour les nématodes.

Usages : Légume feuille que l'on trouve souvent en vente sur les marchés. On le mange parfois cru, généralement cuit, dans les soupes et les sauces. II est riche en protéines et sels minéraux. On sèche souvent la plante avant de la cuire. En blanchissant ou cuisant ce légume dans une eau abondante, on élimine presque la moitié de son contenu en acide oxalique soluble, qui risquent autrement de causer des calculs rénaux. Cette eau doit être jetée. Les feuilles fraiches ont un contenu en protéines de 1,9\%. Cette plante contient aussi de l'acide hydrocyanique, et on ne doit en manger qu'en petites quantités. On l'emploie aussi comme laxatif.

Références : Gillet 1927, Hauman 1951, Watt et Breyer-Brandwijk 1962, Busson 1965, Tindall 1983, Dupriez et De Leener 1989, Mbemba et Remacle 1992, Burkill 1997, Martin et al. 1998, Schippers 2002, Nsimundele 2004, Biloso 2010 


\section{Tamarindus indica}

Noms courants : Mukwaya (Swahili), tamarinier (Fr.), tamarind (Angl.)

Description : Arbre de 6 à $12 \mathrm{~m}$ de haut avec une écorce grise rugueuse et une couronne arrondie. Son feuillage est persistant à feuilles alternes, paripennées, jusqu'à douze paires de folioles oblongues de 12 à 32 sur 3 à 11 $\mathrm{mm}$. Fleurs jaune pâle ou rosâtres et striées de rouge sombre ou brun. Les fruits sont des gousses de 5 à $16 \mathrm{~cm}$ de long sur $4 \mathrm{~cm}$ de large, ; la coque est cassante, et contient de 3 à 10 graines enveloppées dans une pulpe brune gluante, au goût aigre ou sucré. L'arbre grandit lentement mais vit longtemps. II commence à donner des fruits après 10 ans, et peut continuer 150 ans. On a développé des variétés améliorées.

Ecologie : Arbre originaire d'Afrique, très adaptable. Largement cultivé en sites ouverts de basse altitude sous les Tropiques. Tolère les sols pauvres légèrement acides pourvu qu'ils soient bien drainés. L'arbre résiste à la sécheresse ; il préfère une longue saison sèche et donne davantage de fruits dans ces conditions.

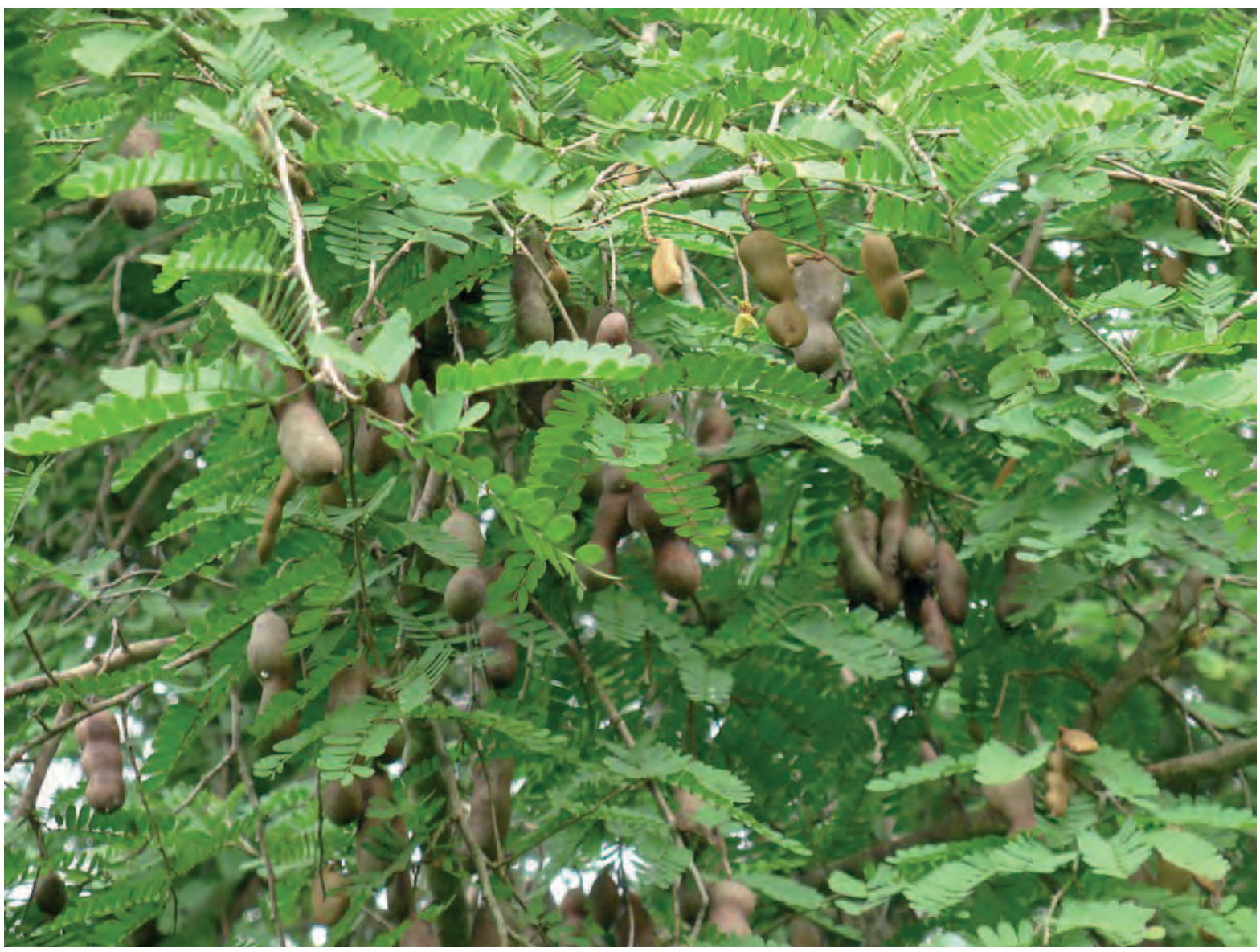

Photo: Mike Bush

Reproduction : Par graines ou transplantation de semis spontanés. Le taux de germination atteint normalement $90 \%$ en 40 ou 50 jours. Récolter les graines sur l'arbre dès que les gousses sont mûres (les graines de gousses sèches ne germent pas bien). Frotter les graines sur un treillis métallique pour enlever la pulpe, séparer par flottaison dans l'eau les graines lourdes. Les sécher au soleil ; on peut les conserver jusqu'à deux ans. Avant de semer, tremper 12 heures dans l'eau, ou frotter avec du papier de verre. II vaut mieux les semer directement en place, car elles développent vite une longue racine pivotante; on peut aussi les semer en pots. Eviter de transplanter à racines nues. On peut aussi reproduire cet arbre par boutures ou par greffage : ces méthodes assurent une meilleure production.

Gestion : Croissance lente. Peut se tailler ou se recéper. Laisser les fruits mûrir sur l'arbre, car les fruits verts ont une pulpe très acide et fibreuse.

Usages: Les fruits aigres/doux se mangent crus, spécialement par les enfants. La pulpe préviendrait le scorbut. Un arbre donne de 10 à $50 \mathrm{~kg}$ de fruits par an. La pulpe est une très bonne source de calcium et phosphore, et aussi une très bonne source de riboflavine. En mélangeant la pulpe avec une bouillie légère de maïs, on obtient une boisson rafraichissante. On peut faire aussi une boisson agréable (mais laxative) avec la pulpe et du sucre, trempés dans l'eau froide, puis agités, et qu'on laisse mûrir au frais quelques jours. L'effet purgatif du fruit se 
perdrait après cuisson. Le fruit noircit avec le temps ; alors, mélangé avec du sucre, il a le goût de dattes sèches. En Tanzanie, on emploie le fruit ayant dépassé la maturité pour nettoyer le cuivre. Les graines pilées peuvent s'employer comme fourrage.

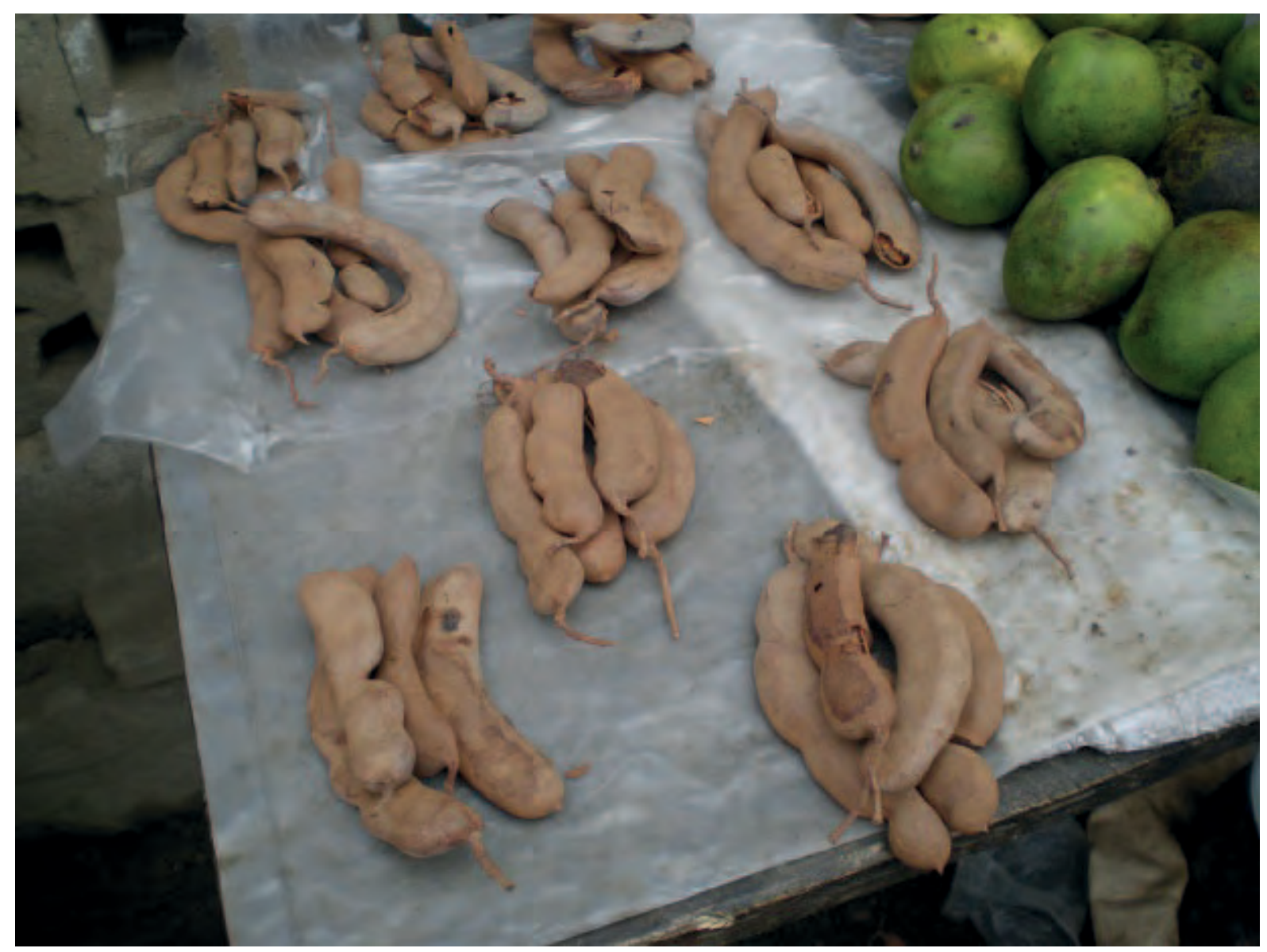

Fruits de tamarin en vente sur un marché.

Les fleurs, les jeunes feuilles et les graines pilées sont aussi comestibles, et sont cuisinés dans une variété de préparations gourmandes. Le bois est élastique ; il convient pour les manches d'outils. L'aubier est jaune pâle. Le bois de cœur est brun sombre, dur, à grain croisé, difficile à travailler, et peut se fendre en séchant. Le bois donne un bon charbon de bois produisant beaucoup de chaleur. On l'emploie aussi comme bois de feu. Les tiges servent de bâtons à mâcher. Les abeilles butinent le nectar et le pollen, et l'arbre est une importante source de miel. Le miel est brun sombre, légèrement visqueux, avec un goût légèrement acide. Arbre utile pour l'ombrage et comme arbre d'avenues. Intéressant comme coupe-feu, car d'autres plantes ne poussent pas à son ombre. II y a une croyance selon laquelle si l'on donne à manger aux poules un morceau d'écorce trempé dans l'eau avec des grains de maïs, cela les incite à ne pas s'éloigner trop loin.

Références : Gillet 1927, Renier 1948, Wilczek et al. 1952, Williamson 1975, Skerman 1977, FAO 1982, Espina et Ordetx 1983, Crane et Walker 1984, Fichtl et Adi 1994, Mbuya et al. 1994, Burkill 1995, Hepburn et Radloff 1998, Msanga 1998, Ruffo et al. 2002, van Wyk et Wink 2004, van Wyk 2005 
Tecoma stans

Noms courants : Yellow trumpet tree (Angl.).

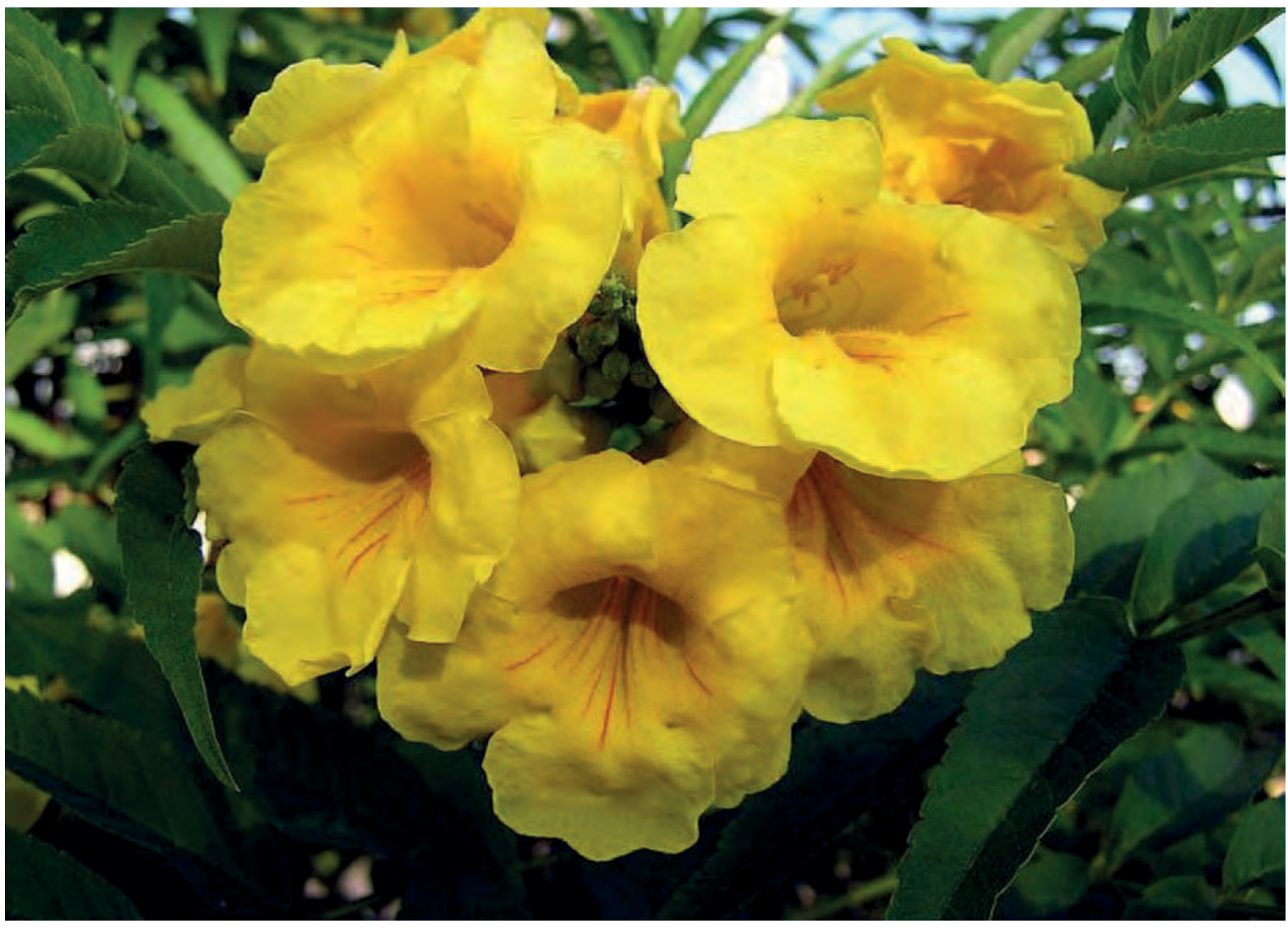

Photo : Linda de Volder

Description : Arbuste variable jusqu'à $7 \mathrm{~m}$ de haut. Ecorce gris brun devenant rugueuse avec l'âge. Les feuilles sont composées de 2 à 5 paires de folioles dentées, avec une foliole terminale plus grande. Les folioles mesurent 6 à 8 sur 1,5 à $3 \mathrm{~cm}$. Les fleurs jaunes, à l'odeur de vanilles, sont disposées en grappes au bout des branches. La corolle mesure 3,5 sur $1,5 \mathrm{~cm}$. La plante fleurit toute l'année, spécialement après les pluies. Les fruits sont de longues capsules de 15 à 17 sur 0,6 à 0,7 cm, qui demeurent attachées à l'arbre.

Ecologie : Plante originaire d'Amérique tropicale.

Reproduction : Par graines, ou boutures ligneuses.

Usages : Habituellement cultivée comme plante ornementale. Bonne source de nectar et pollen pour les abeilles, particulièrement intéressante quand celles-ci n'ont pratiquement rien d'autre à butiner.

Références : Fichtl et Adi 1994, Pauwels 1993, Llamas 2003 


\section{Tephrosia vogelii}

Noms courants : Bwalu, mbaka, walu (Kikongo), mpanga (Lingala), fish poison bean (Angl.).

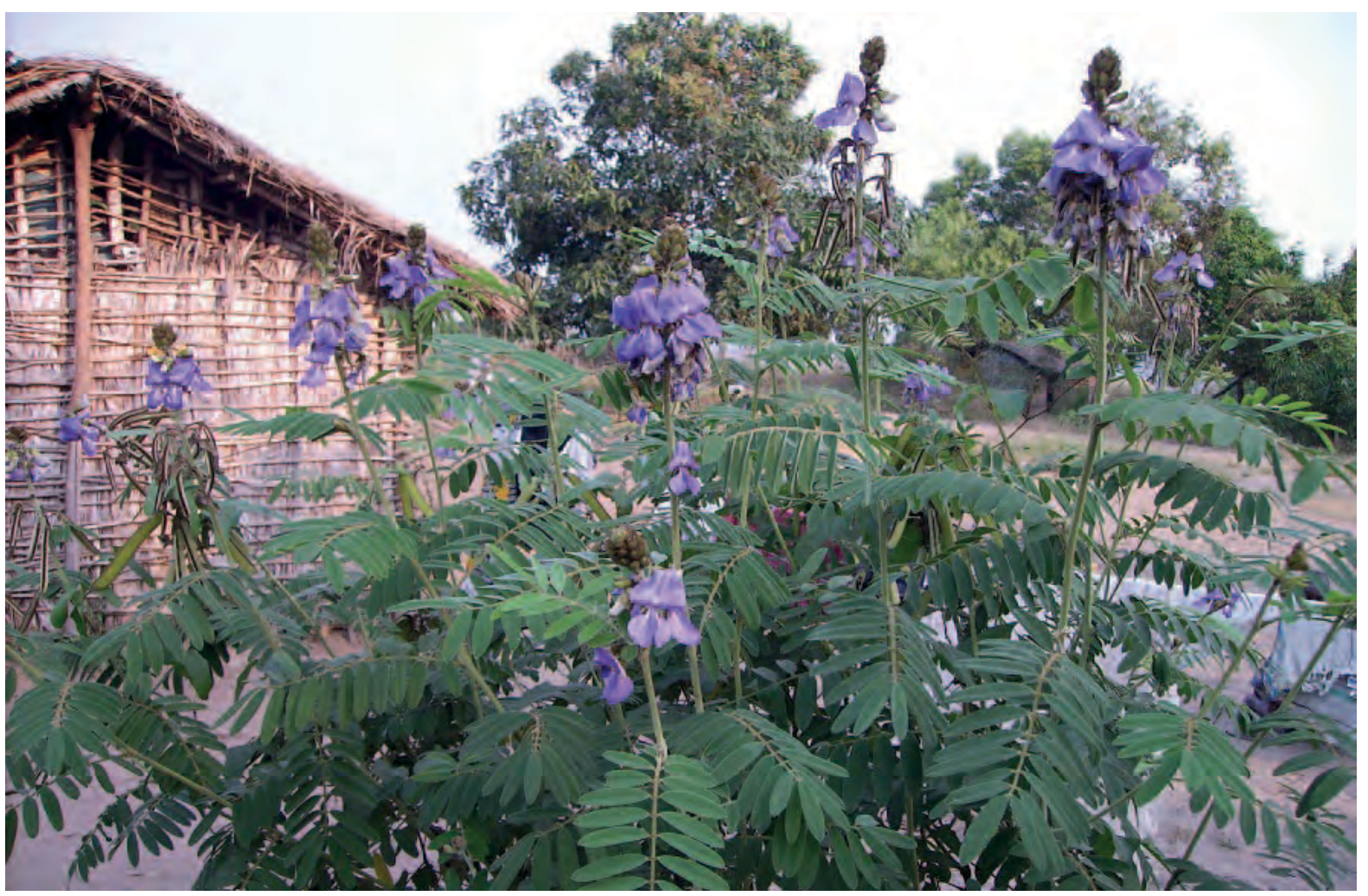

Description : Arbuste très ramifié de 1 à $4 \mathrm{~m}$ de haut. Feuilles composées de 12 à 18 folioles elliptiques de 4,5 à 7 sur 2,5 à 3,8 cm. Les fleurs peuvent être blanches ou bleues. Les gousses sont longues de 5 à $10 \mathrm{~cm}$.

Ecologie : Arbuste présent dans toute l'Afrique tropicale, dans les jachères forestières et les forêts secondaires. Souvent planté dans les villages, autour des champs, parmi les bananiers et dans les sites marécageux. Bien adapté aux sols sableux.

Reproduction: Peut se cultiver en semant en pleine terre des graines nouvellement récoltées, le taux de germination est alors de $80 \%$ après une semaine. Si l'on garde les graines, il faudra les tremper dans l'eau chaude avant de les semer.

Gestion : Cette plante recèpe facilement.

Usages : La plante fixe l'azote sans inoculation préalable. Elle produit une litière abondante à haut contenu en azote.

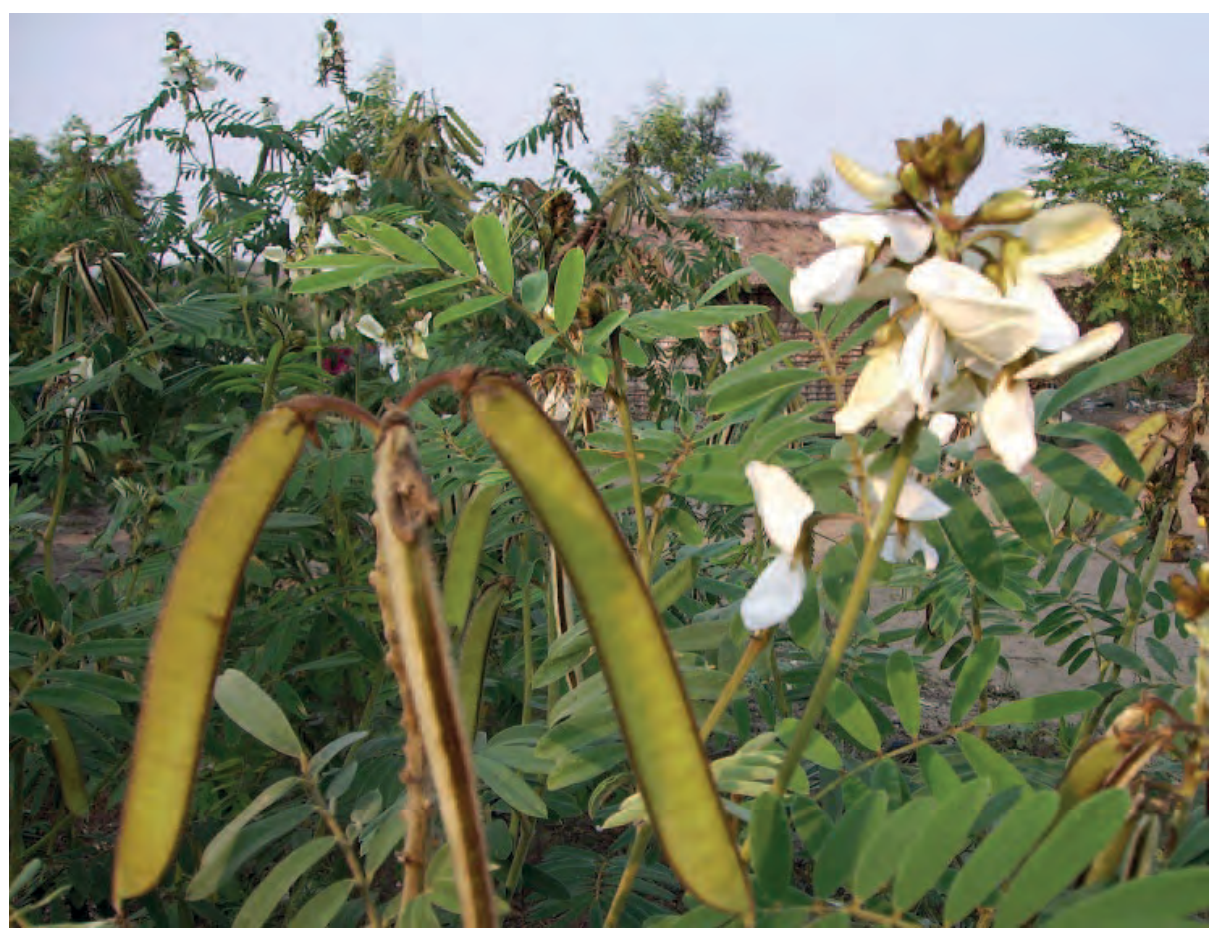

En Zambie, on cultive la plante trois années de suite comme jachère courte, et il en résulte des rendements sensiblement améliorés. Au Malawi, même après une année de jachère à Tephrosia, les rendements en maïs ont augmenté de $20 \%$; et de $41 \%$ après une jachère de 2 ans (communication personnelle - Stephen Carr). Une 
autre étude au Kenya a montré que l'érosion du sol était aussi fortement réduite sous jachère à Tephrosia. Les feuilles et les graines sont efficaces comme insecticides contre les pucerons, et perceurs de tiges du maïs. Elles contiennent de la roténone, avec des concentrations variables selon chaque plante. On pile $100 \mathrm{~g}$ de feuilles pour avoir une pulpe que l'on trempe dans 1 litre d'eau avec $100 \mathrm{~g}$ de savon; on laisse reposer le mélange 1 jour ; on filtre le liquide et on introduit une petite quantité dans l'intérieur de la tige du maïs, avec une pipette ou une éponge, quand elle atteint la hauteur du genou. On répète l'application tous les 7 à 10 jours. On peut aussi employer ce liquide pour contrôler les poux dans la tête et les tiques des chiens. On a montré que les feuilles séchées réduites en poudre avaient une efficacité de $87,5 \%$ pour repousser le parasite Sitophilus zeamais dans le maïs en conservation. On emploie aussi cette poudre contre les tiques. Les tiges peuvent servir de tuteurs pour les haricots ou les ignames. On peut faire des balais avec la plante. Les feuilles ont des usages médicinaux.

Références : Gillet 1927, Renier 1948, Hauman et al. 1954, Watt et Breyer-Brandwijk 1962, Allen et Allen 1981, Daeleman et Pauwels 1983, Egli et Kalinganire 1988, Mukoko Matondo 1991, Pauwels 1993, Msanga 1998, Stoll 2002, Pousset 2004, Orwa et al. 2009

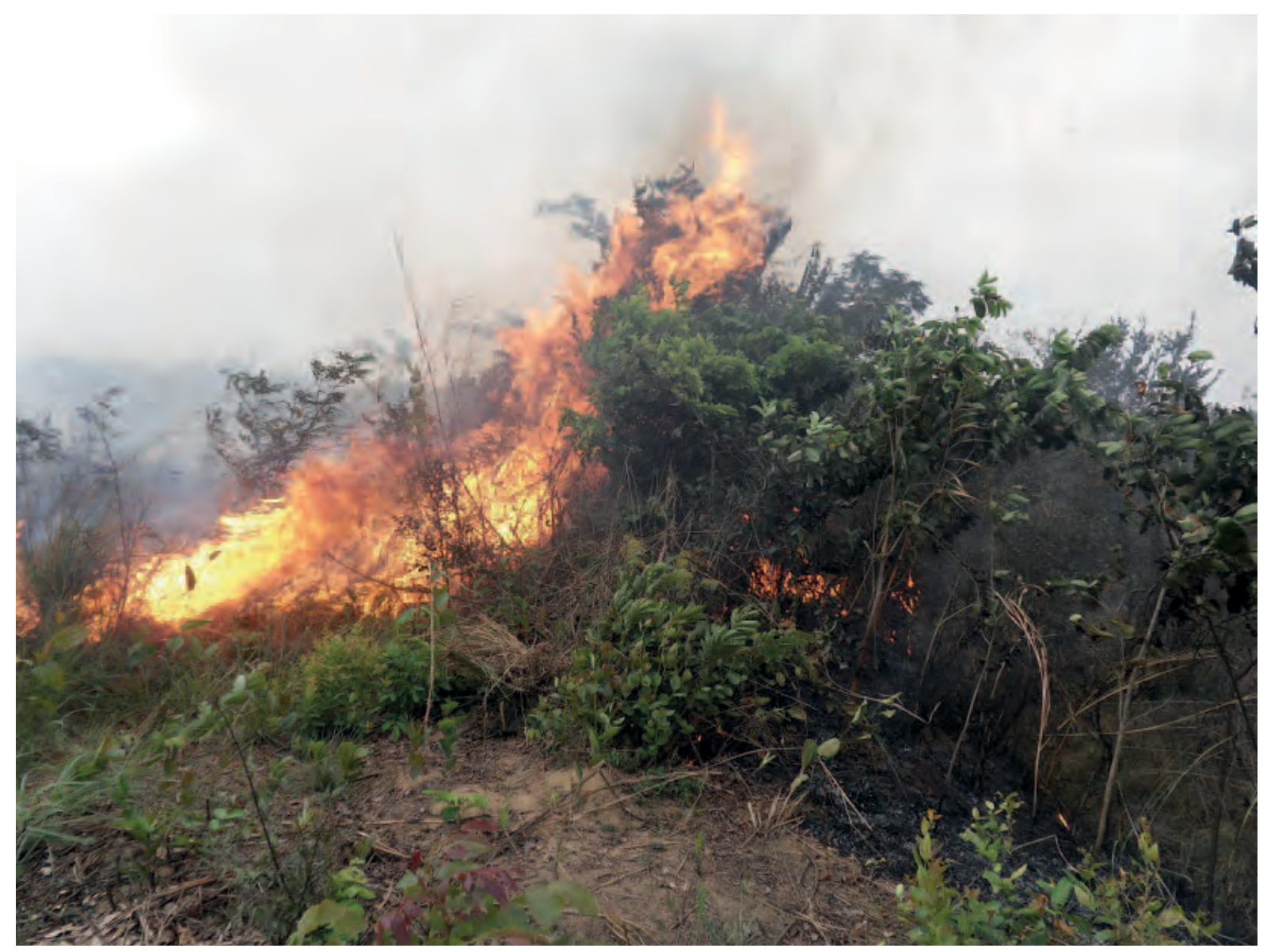

La menace des feux de brousse. 


\section{Terminalia catappa}

Noms courants : Madamé (Lingala), badamier (Fr.), Indian almond (Angl.)

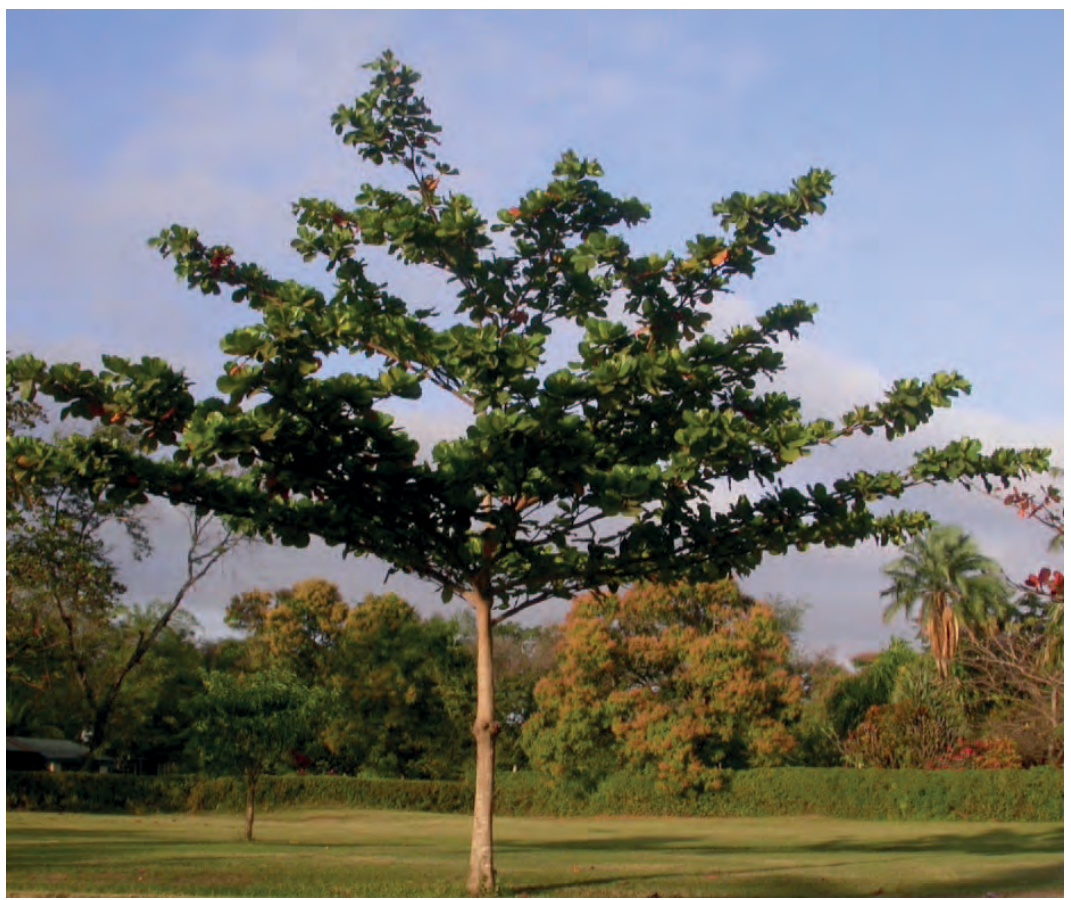

\section{(Combretaceae)}

Description : Arbre caduc à croissance rapide, de 10 à $35 \mathrm{~m}$ de haut, à branches horizontales disposées en étages. Les grandes feuilles, de 15 à 32 sur 10 à $18 \mathrm{~cm}$, tombent à la fin de la saison des pluies. Petites fleurs blanches. Le fruit est une drupe mauve à maturité, en forme d'amande, de 5 à $6 \mathrm{~cm}$ de long ; il est composé d'un péricarpe charnu et fibreux peu épais, entourant une coque dure qui contient le noyau. Le système racinaire étendu fixe et stabilise les sols pauvres et peu consistants.

Ecologie: Arbre originaire d'Asie du Sud-Est. Pousse dans toute l'Afrique de l'Ouest dans les zones fortement arrosées. Tolère les sécheresses modérées. Planté comme arbre d'ornement et d'ombrage dans les villages et au bord des routes.

Reproduction : Par graines. La germination est bonne mais peut prendre deux mois. Tremper les graines 24 heures avant de semer. Les graines restent viables seulement quelques mois.

Gestion: Arbre à croissance moyenne à rapide. Peut se tailler mais ne recèpe pas. Les vieux arbres reprennent mal si on les taille trop bas.

Usages: La graine pressée donne 50 à 60 $\%$ d'une huile comestible comparable à I'huile d'arachides. Bien que comestible, elle est difficile à séparer de la coque dure. La pulpe extérieure du fruit est aussi comestible, mais souvent fibreuse et plutôt fade. Le tronc sert à faire des tambours; le bois est un bon bois de feu. Les feuilles et l'écorce donnent une teinture noire. L'écorce est riche en tanin. Le bois est moyennement dur et lourd; on l'emploie pour la construction de maisons et d'embarcations, les boîtes et le contreplaqué ; il est très exposé aux attaques de termites.

Références: Gillet 1927, Liben 1968, Burkill 1985, Pauwels 1993, Mbuya et al. 1994, Vande weghe 2004, Orwa et al. 2009

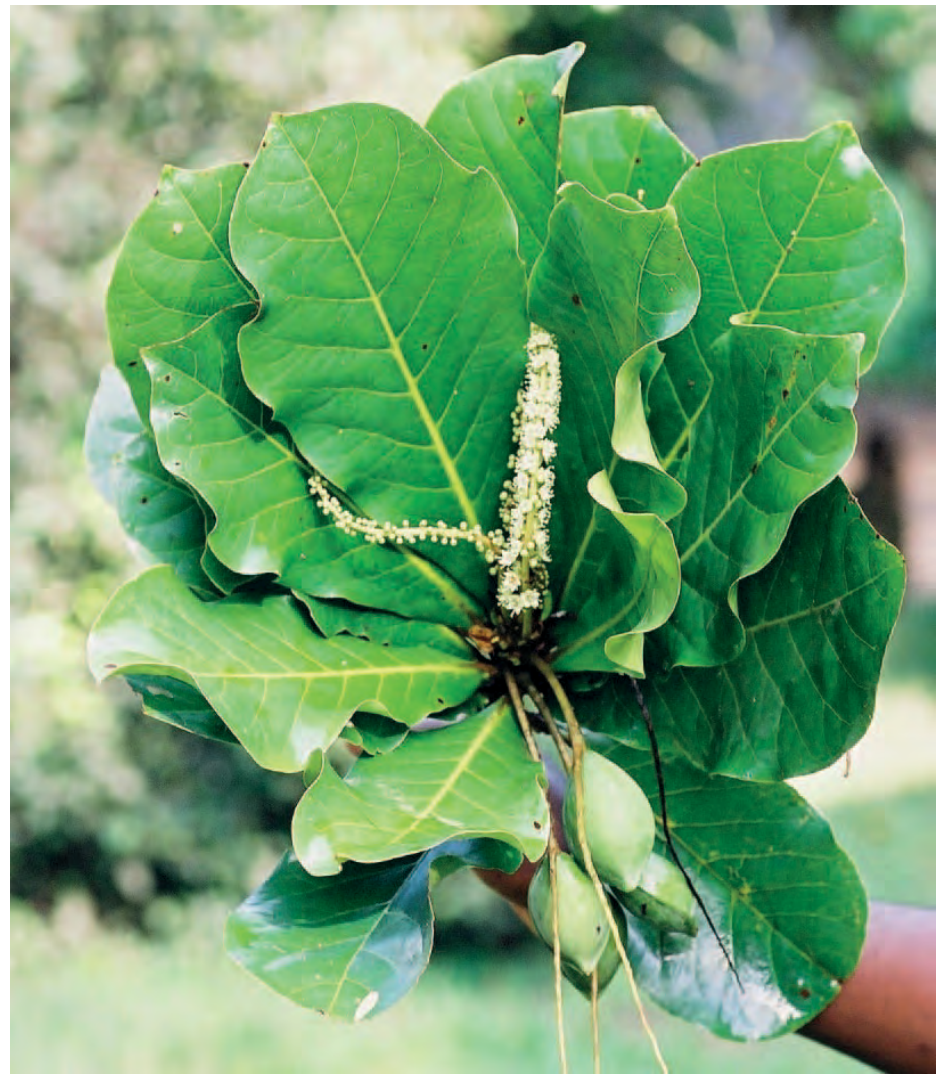




\section{Terminalia superba}

Noms courants : Ndimba (Kikongo), limba, fraké (noms commerciaux)

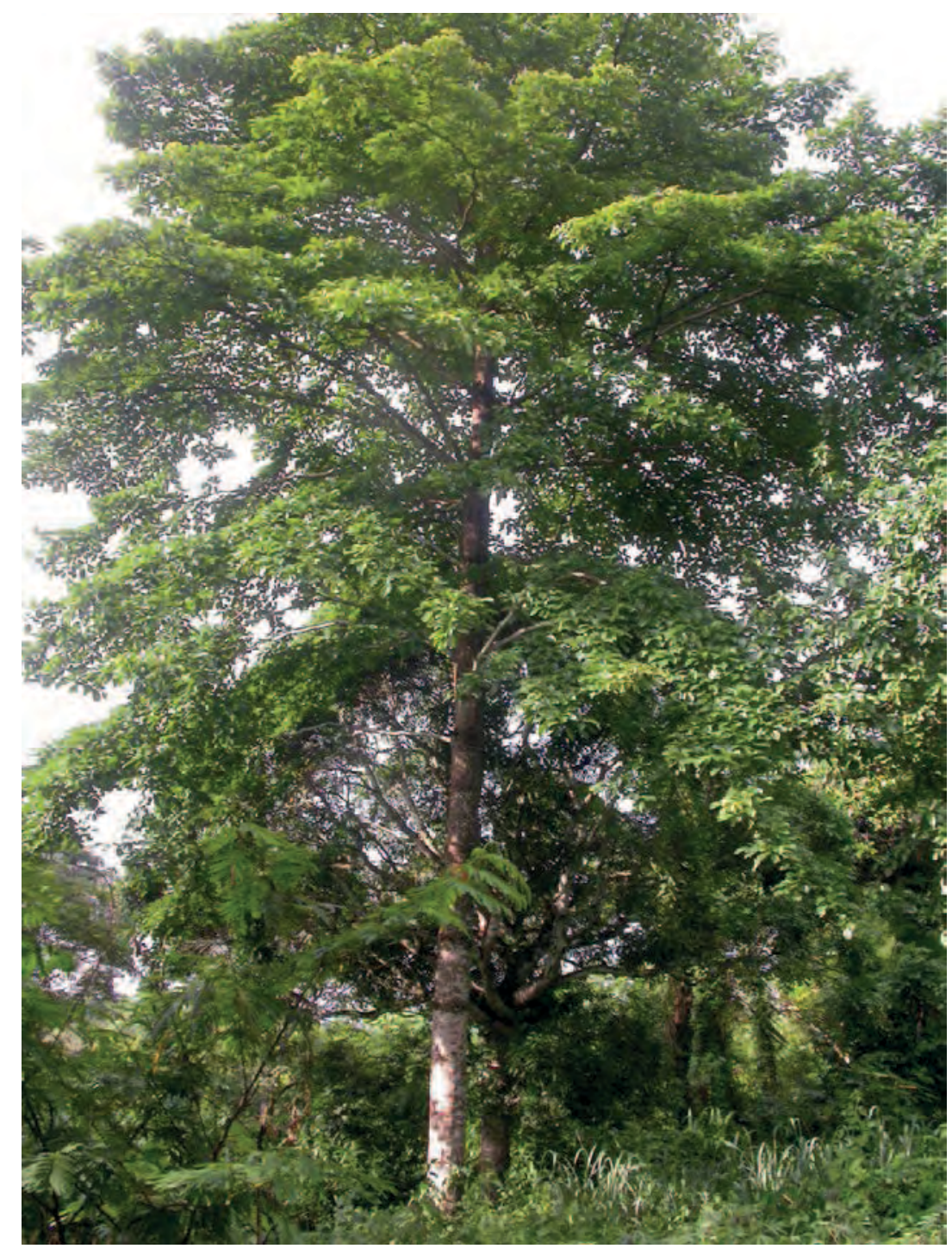

Description : Arbre de 30 à $40 \mathrm{~m}$ de haut avec un long tronc doit, des contreforts ailés, et une couronne ouverte étendue. Les feuilles, de 5 à 16 sur 4 à $9 \mathrm{~cm}$. Les fruits, oblongs elliptiques, mesurent 20 à 22 sur 50 à $60 \mathrm{~mm}$, et portent deux ailes

Ecologie: Arbre présent dans toute l'Afrique occidentale, de la Guinée à la Centrafrique et à l'Angola, dans les forêts secondaires, les savanes boisées, et les terres agricoles, là où le sol n'est pas inondé. Se trouve parfois en peuplements purs. Planté comme arbre d'avenues. Pousse en pleine lumière.

Reproduction: Habituellement à partir des graines, qui germent en deux ou trois semaines. Aucun pré-traitement n'est nécessaire. Les semis sont rabattus en souches après 15 mois, puis transplantés en place. On peut aussi semer les graines en lignes sous ombre légère. Dans les peuplements abattus, les semis reprennent bien. L'arbre produit de grandes quantités de graines, et les semis poussent librement sur les champs en friche.

Gestion : L'arbre peut atteindre 5 $\mathrm{m}$ la seconde année sur les bons sols, et se compare bien de ce point de vue aux conifères à croissance rapide. Cet arbre

recèpe bien.

Usages : Le bois est brun clair, résistant, moyennement dur, et se travaille facilement. On l'emploie pour shingles, les pagaies, les menuiseries d'intérieur, les cercueils, les embarcations, les boîtes et les bols, mais il résiste mal à la pourriture, aux termites et insectes perforants. En utilisant un filler, il est facile à teindre et à polir. II se colle aisément, mais se fend facilement. Le limba se prête particulièrement bien au déroulage et à la fabrication de contreplaqués. Il a constitué jusqu'aux années 1980 l'un des principaux bois exportés d'Afrique, notamment de la RD Congo, de la Côte d'I voire, du Ghana, du Cameroun et du Congo Brazzaville ; mais par la suite la production et les exportations ont diminué à la suite de la surexploitation des peuplements naturels. II donne un bon bois de feu. On peut faire avec l'écorce une teinture jaune. Diverses parties de la plante ont des usages médicinaux. Les chenilles comestibles Bisu (Nudaurelia petiveri) et Minsendi broutent les feuilles.

Remarque : Les coléoptères attaquent l'aubier et le bois de cœur.

Références : Renier 1948, Leloup 1956, Irvine 1961, Liben 1968, Uphof 1968, Burkill 1985, Pauwels 1993 , Kibungu Kembelo 1995 


\section{Tetracarpidium conophorum}

Noms courants : Makasu nsinga (Kikongo), conophor nut (Angl.)

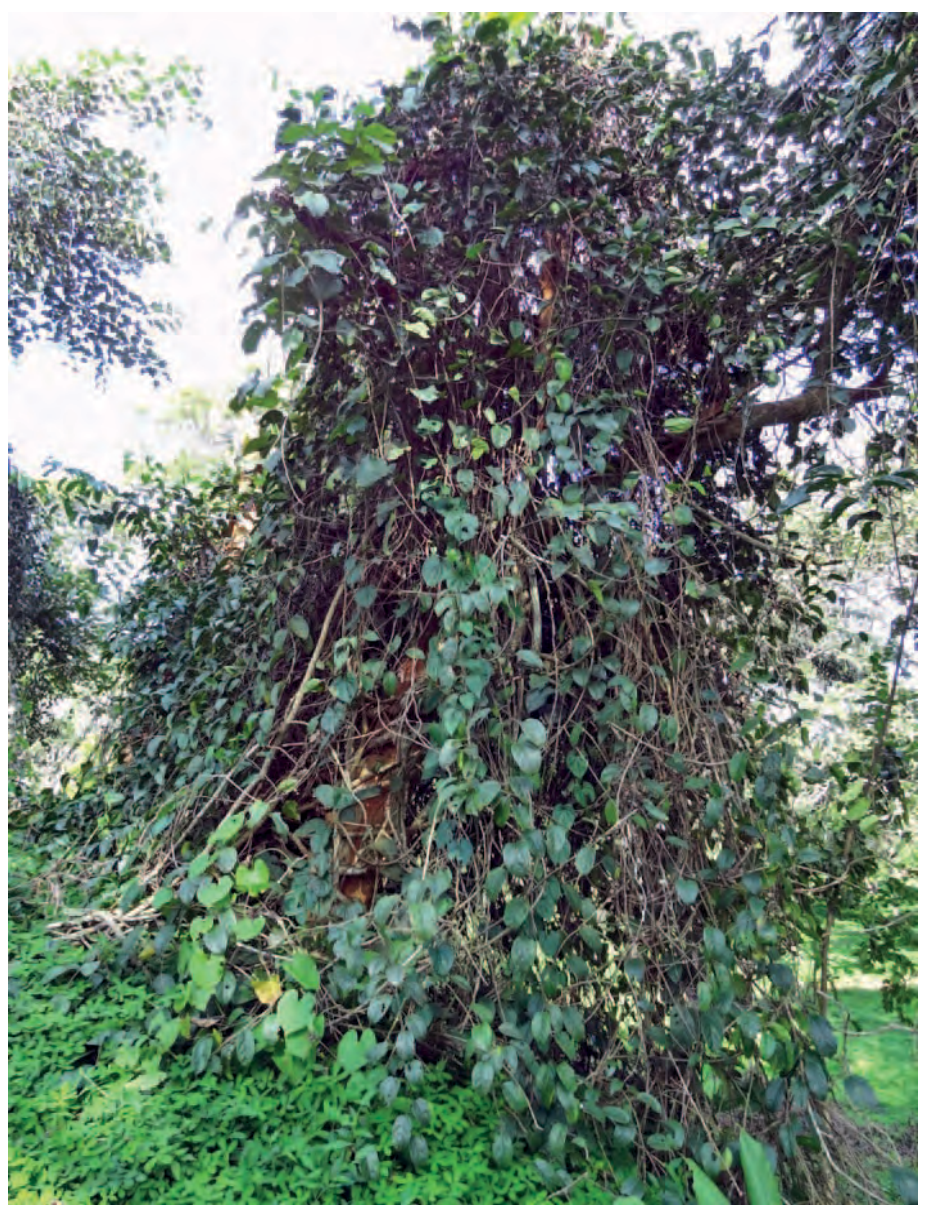

Description : Liane grimpante vigoureuse de 3 à $6 \mathrm{~m}$ de long, se ramifiant librement et pouvant recouvrir l'arbre qui la supporte. Feuilles pointues, vert brillant, de 18 sur 10 $\mathrm{cm}$. Grappes de très petites fleurs blanches. Les fruits (ci-dessous à droite) sont une gousse à 4 ou 5 lobes, partiellement ailée, contenant 4 ou 5 grosses graines (ci-dessous à gauche).

Toutes les photos : Roy Danforth

Ecologie : Plante des forêts secondaires de la Sierra Leone à la R.D. Congo, cultivée en Sierra Leone, au Nigéria et au Cameroun. Pousse bien sur sols forestiers sous pleine ombre.

Reproduction : Par graines.

Gestion : Faire monter les lianes en haut des arbres supports. Elles sont productives après 5 ans.

Usages: Les noix se mangent, habituellement bouillies ou rôties pour ôter leur amertume. On peut aussi les manger crues comme tonique. Elles donnent une huile siccative employée en cuisine et pour des usages médicinaux, à raison de 40 à $60 \%$ de leur poids. Les jeunes feuilles sont aussi comestibles, et se mangent avec du riz. Le tourteau peut servir d'aliment pour animaux.

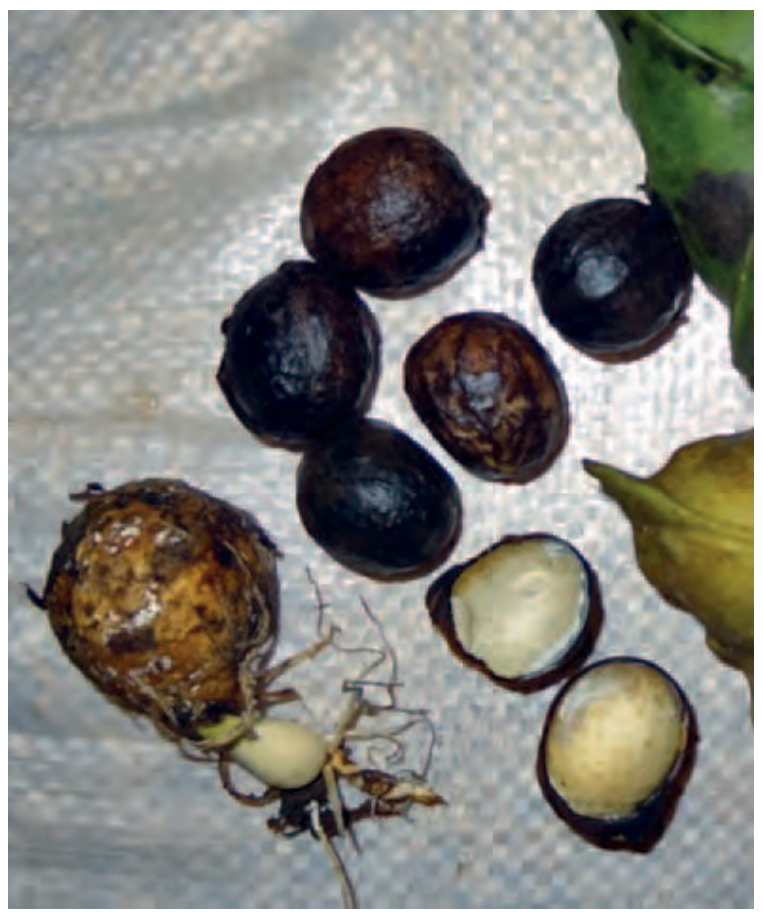

Remarque: Le fruit demeure en bon état

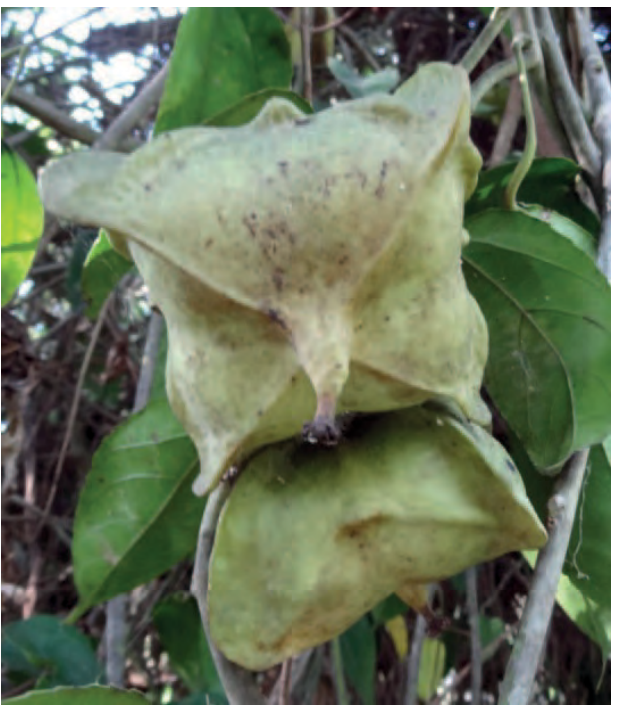

après récolte, et se transporte bien, de sorte qu'il a un potentiel pour des marchés lointains.

Références: Renier 1948, Busson 1965, Danforth et Noren 1997, Nsimundele 2004, Termote 2012, Ayeni et Aliyu 2018 


\section{Tetracera alnifolia}

Noms courants : Kiziazi, nziazi, nziazia (Kikongo), liane à eau (Fr.), water tree (Angl.)

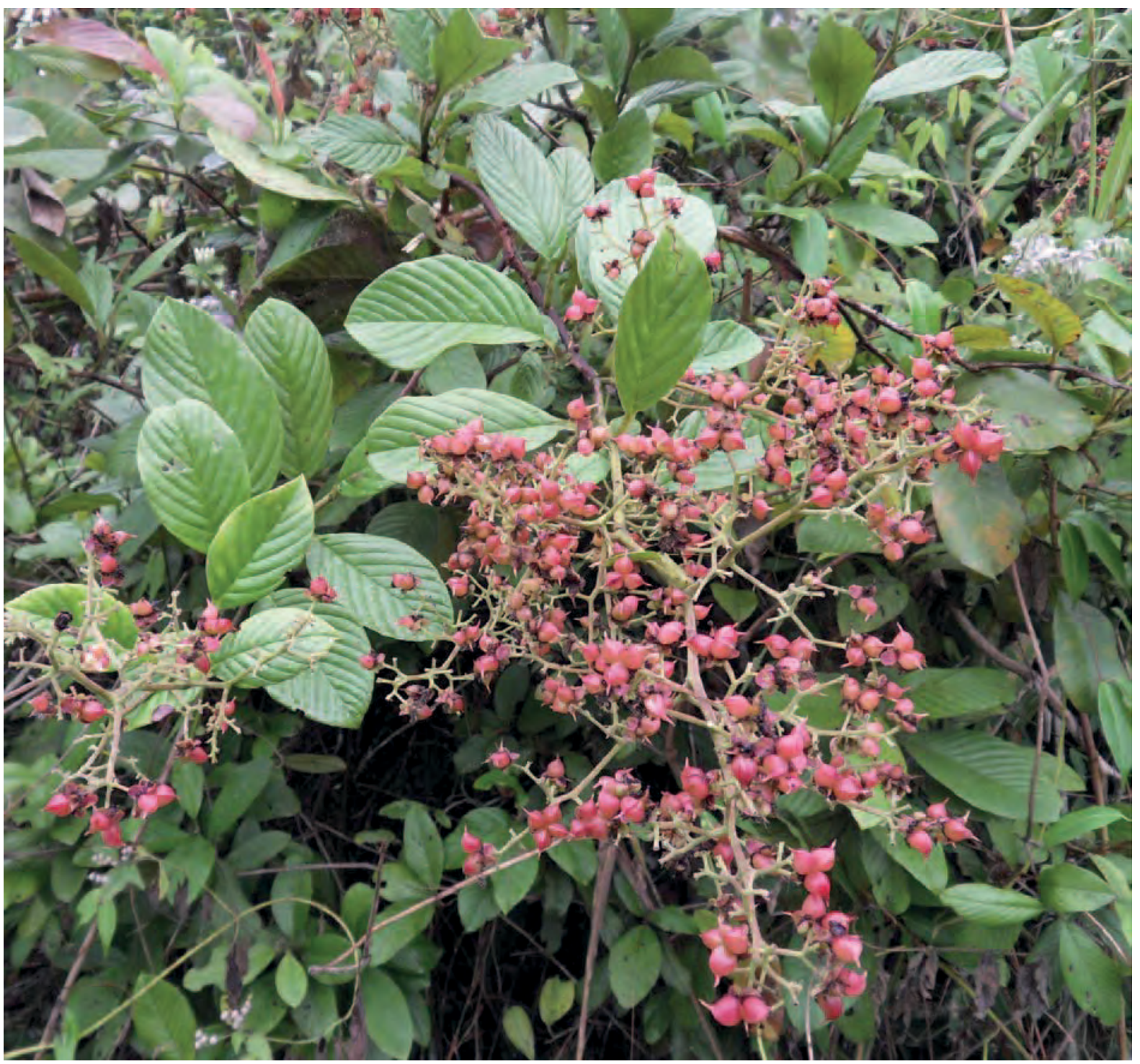

Description : Liane ligneuse pouvant avoir $20 \mathrm{~m}$ de long et $10 \mathrm{~cm}$ de diamètre. Feuilles souvent recourbées, mesurant de 4 à 16 sur 3 à $8 \mathrm{~cm}$, sur un pétiole jusqu'à $2 \mathrm{~cm}$. Fleurs blanches en grands panicules longs de 15 à $25 \mathrm{~cm}$. Fruits ovales ligneux rouge sombre. Quelques graines noir brillant enveloppées dans un arille orange. On trouve quatre autres espèces de Tetracera au Kongo Central.

Ecologie : Liane des savanes boisées et des forêts, en terrain marécageux et sur terre ferme. Parfois rampante en savane herbeuse, fourrés ou lisières forestières. Présente du Sénégal au Cameroun et à l'Angola.

Usages : Les tiges donnent en abondance une sève buvable. Traditionnellement, au Gabon, on en plantait dans la savane pour l'employer en temps de pénurie d'eau. Au Kongo Central, on l'emploie pour les tatouages. Les chenilles comestibles Nyazi broutent les feuilles. Au Manianga, on emploie la sève pour « purifier » le lait maternel, et pour traiter les douleurs abdominales. On la donne aux enfants immédiatement après la naissance, et plus longtemps aux jumeaux, pour les fortifier. On mange parfois les jeunes feuilles comme légumes. Les espèces de Tetracera sont d'importants fourrages des abeilles en Afrique équatoriale.

Références : Renier 1948, Boutique 1967, Arkinstall 1979, Daeleman et Pauwels 1983, Burkill 1985, Hepburn et Radloff 1998, Burkill 2000 


\section{Tetracera poggei}

Noms courants : Kikuya ki nseke, nsingu nkayi (Kikongo)

Description : Grande liane ou buisson rampant. La tige peut atteindre $7 \mathrm{~cm}$ de diamètre. Feuilles variables, de 4 à 13 sur 1,5 à $6 \mathrm{~cm}$. La plante produit de nombreuses fleurs blanches parfumées en inflorescences de 3 à 10 fleurs à anthères jaunes.

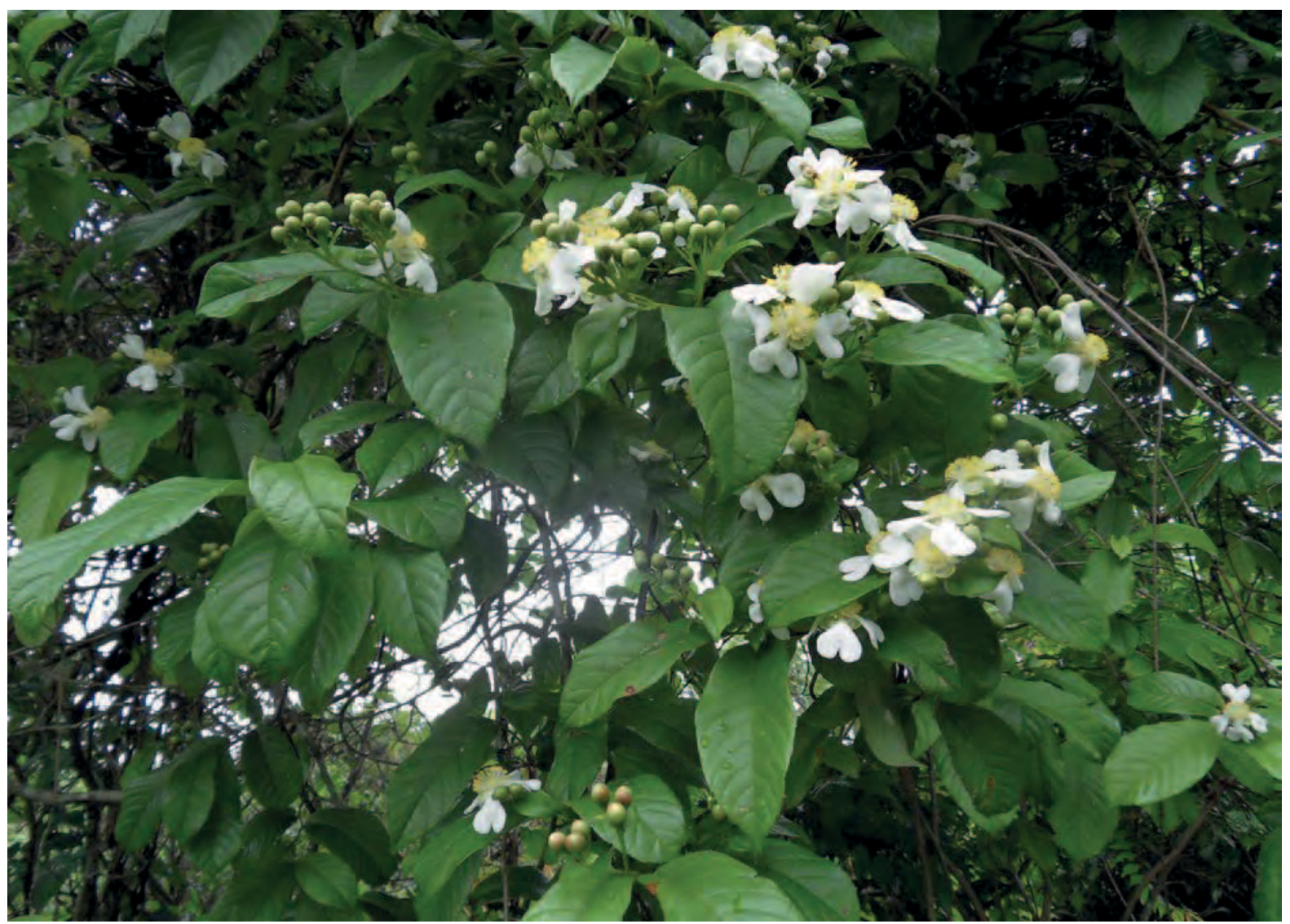

Tetracera poggei en fleurs en décembre

Ecologie : Grimpe sur les arbres ou buissons en lisière de forêt ; présente en savanes boisées et jachères. Plante présente en R.D. Congo et en Angola.

Usages: Au Kongo Central, on emploie les racines pour traiter les problèmes de peau. II y a cinq espèces de Tetracera au Kongo Central, connues comme importants fourrage des abeilles en Afrique équatoriale. On a observé des abeilles butinant le pollen de cette espèce et de $T$. rosiflora. T. alnifolia (Kiziazi, nziazi) serait un fourrage des abeilles au Gabon. Les feuilles de certaines espèces s'emploient comme papier de verre, et les tiges servent à faire des cordages.

Références : Boutique 1967, Daeleman et Pauwels 1983, Mandango et al. 1990, Ambougou 1991, Hepburn et Radloff 1998, Neuwinger 2000, Lebrun et Stork 2003, Nsimundele 2004, Latham et Konda Ku Mbuta 2017

Tetracera poggei portant des fruits à Mingadi en décembre

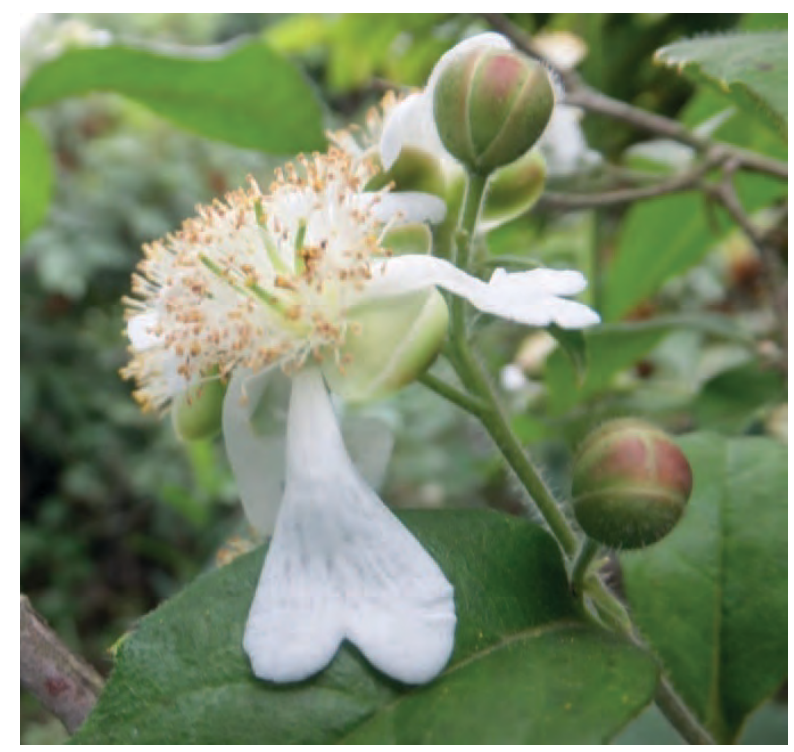




\section{Tetracera rosiflora}

\section{(Dilleniaceae)}

Noms courants : Kiziazia, nziazia (Kikongo)

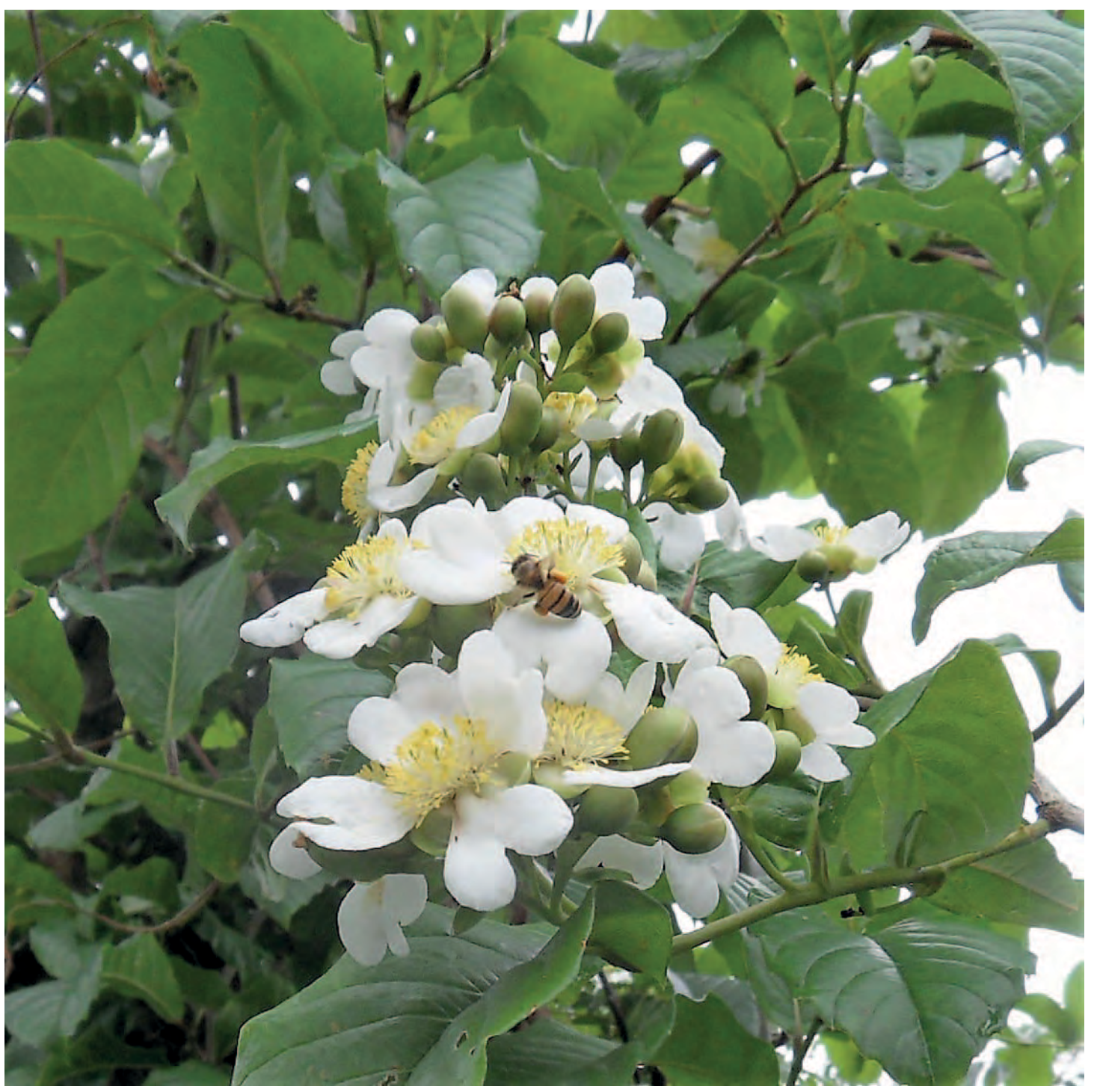

Tetracera rosiflora en fleurs en décembre

Description : Liane avec un diamètre pouvant atteindre $6 \mathrm{~cm}$. Les feuilles mesurent 5,5 à 17,5 sur 2,5 à $8 \mathrm{~cm}$ sur un pétiole de 3 à $10 \mathrm{~mm}$. Les fleurs de couleur rose sont disposées en cymes axillaires ou terminaux à 5 ou 10 fleurs.

Ecologie : Liane des forêts primaires et secondaires, et des savanes en cours de reforestation, du Gabon à la RD Congo.

Usages: On a observé des abeilles butinant le pollen en décembre. Les lianes de plusieurs espèces de Tetracera donnent quand on les coupe de grandes quantités de liquide, que l'on peut boire à la place de l'eau.

Références : Boutique 1967, White et Abernethy 1997, Bongers et al. 2005 


\section{Tetradenia urticifolia}

Noms courants : Mutizo (Kikongo), ginger bush (Angl.)

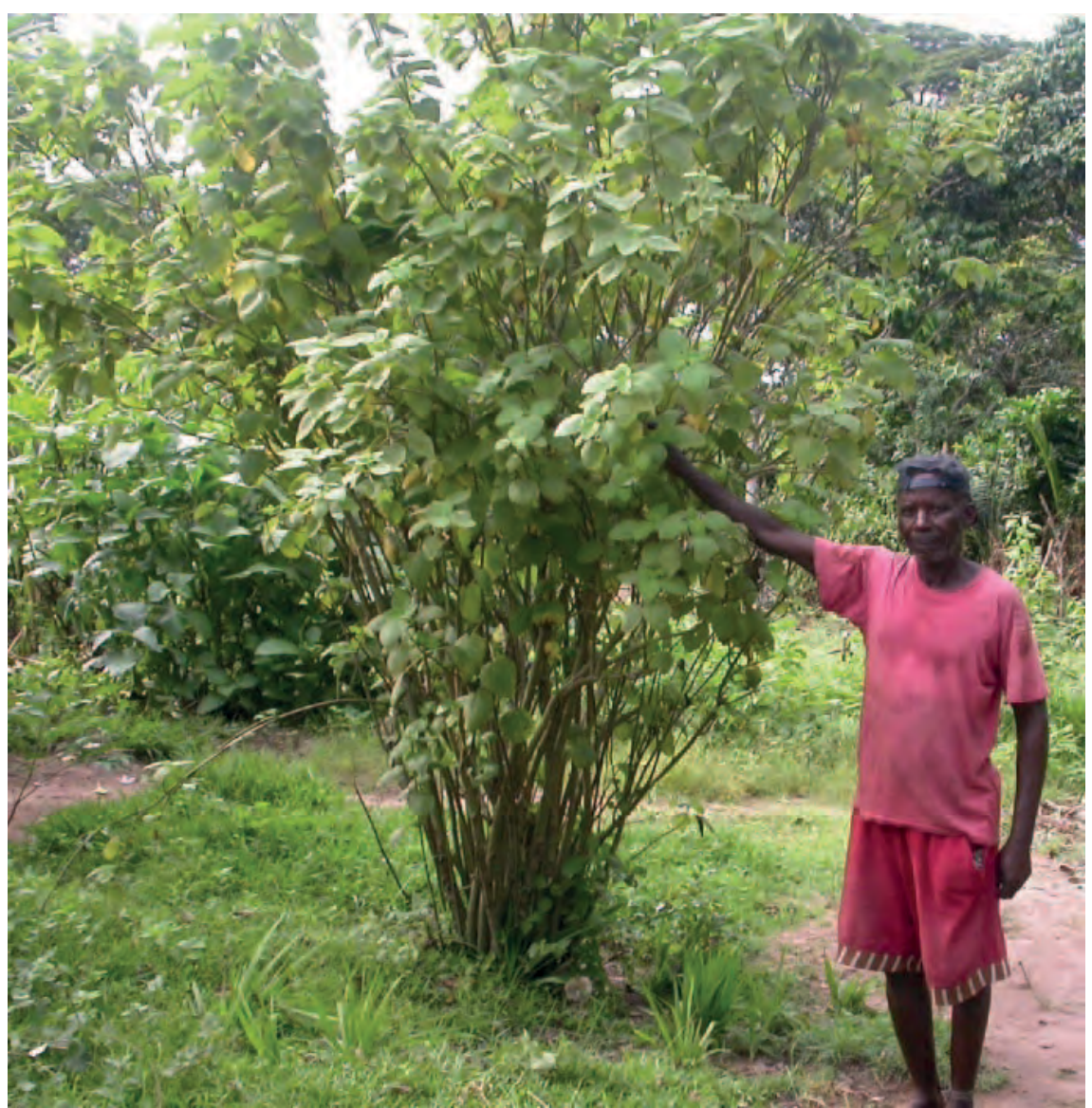

Description : Buisson ou arbuste de 1 à $3 \mathrm{~m}$ de haut. L'écorce est brun clair, lisse avec parfois quelques écailles en vieillissant. Les feuilles, douces au toucher, sont opposées, très odorantes, mesurent 3,5 à 8 sur 3,5 à 7 $\mathrm{cm}$, et sont couvertes d'un fin duvet de poils denses sur les deux faces. Le bord des feuilles est denté. Les fleurs, minuscules, mauves, roses ou blanches, se disposent en racèmes très ramifiées de 20 à $30 \mathrm{~cm}$ de long. Le fleurs mâles et femelles sont sur des plantes différentes. La plante pousse rapidement.

A gauche : Tata Mteka avec un pied de mutizo au village de Mbamba.

Ecologie : Cette espèce se rencontre en lisière de forêt, en savane boisée ou arbustive, surtout près des affleurements rocheux, et aussi près des habitations et des terres cultivées, de

l'Afrique du Sud à l'Angola et à l'Afrique orientale. On la plante parfois comme haie autour des parcelles. Elle préfère les sols profonds et bien drainés.

Reproduction : Par boutures de 20 à $50 \mathrm{~cm}$ de long.

Usages : En RD Congo, on se sert des feuilles comme antiseptique pour traiter les blessures et les piqûres d'insectes. Ailleurs, on l'emploie largement comme insecticide, et pour le paillage des cultures. Au Rwanda, on cultive parfois cette plante comme brisevent, et pour contrôler les érosions en la plantant le long des lignes de niveau. Au Malawi, cette plante serait un puissant remède contre les vers intestinaux. Au Kenya, les Pokot emploient les feuilles pilées contre la cataracte. Cette plante a beaucoup d'usages médicinaux en Afrique.

Remarque : Selon une étude récente, cette plante s'identifie comme T. urticifolia (Email

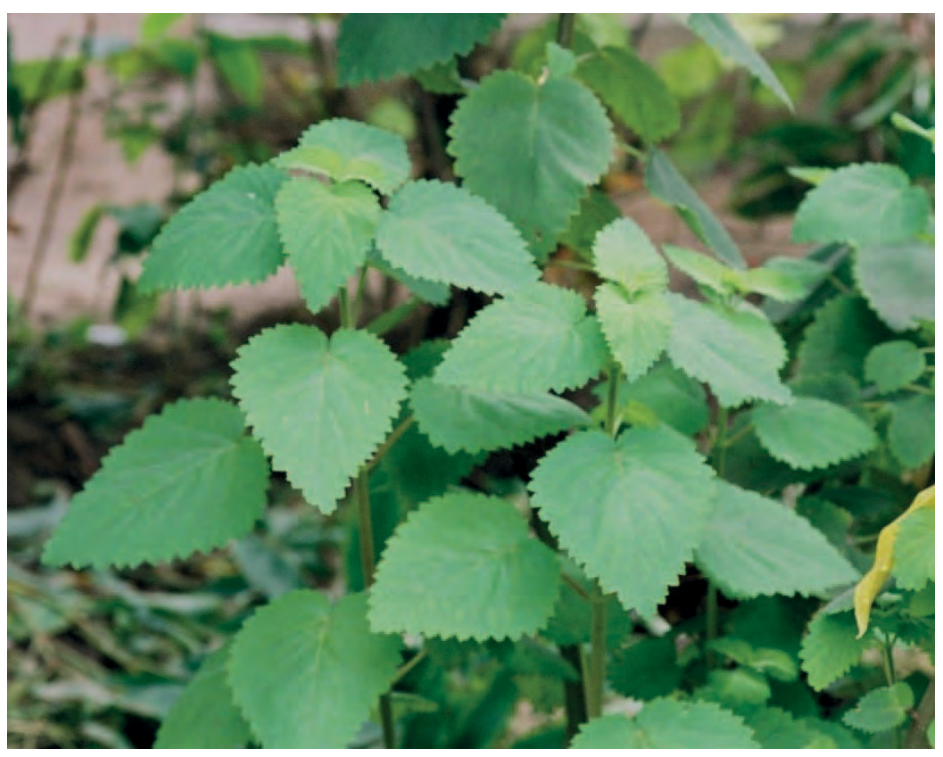
de Pauwels 17.12.2015).

Références : Watt et Breyer - Brandwijk 1962, Williamson 1975, Egli et Kalinganire 1988, Beentje 1994, Phillipson et Steyn 2008 


\section{Tetrapleura tetraptera}

Noms courants : Mbaka (Kikongo), Aidan tree (Angl.)

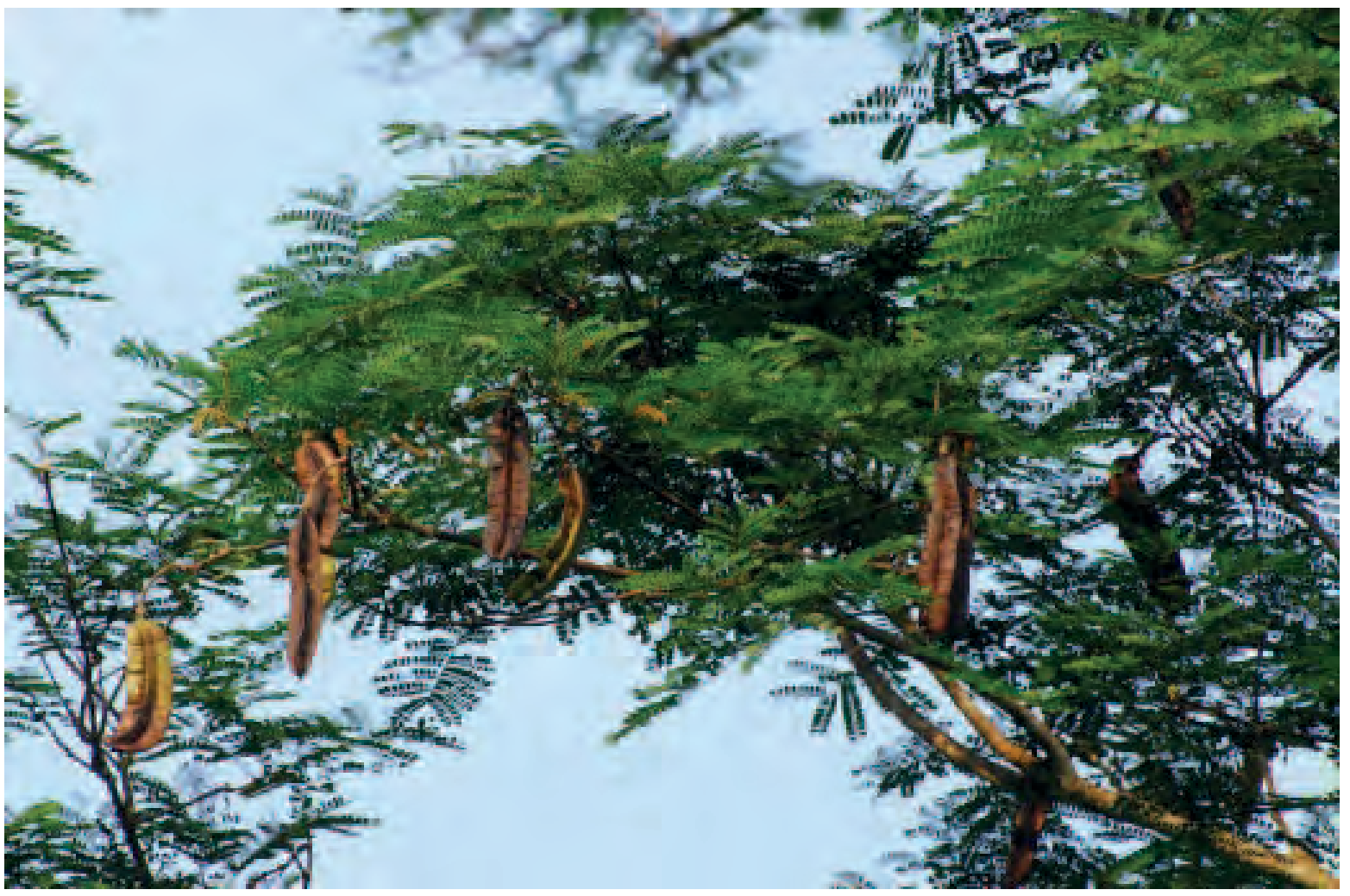

Toutes les photos : Quentin Meunier

Description : Arbre décidu atteignant $25 \mathrm{~m}$ de haut et $1 \mathrm{~m}$ de diamètre, à couronne légère. L'écorce est fine, de couleur gris brun, avec des fissures verticales étroites. Les feuilles sont composées, de 25 à $30 \mathrm{~cm}$ de long, avec 6 à 13 paires de folioles. Les petites fleurs, jaunes, roses ou brunes, sont disposées en épi. Le fruit est une gousse ligneuse, brun rouge sombre ou noire ; il porte 4 ailes, dont deux sont ligneuses, et deux sont creuses et remplies d'une chair sucrée. Les fruits ont une odeur de caramel, particulièrement après être tombés au pied de l'arbre. Les graines sont libérées quand les gousses pourrissent; elles sont dures, brun foncé, et ont $9 \mathrm{~mm}$ de long.

Ecologie: Arbre présent dans les forêts secondaires et en lisière de forêt. Son aire de répartition s'étend du Sénégal à la Tanzanie vers l'Est et à l'Angola et Zimbabwe vers le Sud en passant par le Cameroun et le Gabon

Reproduction : Extraire les graines des fruits à la main. Les

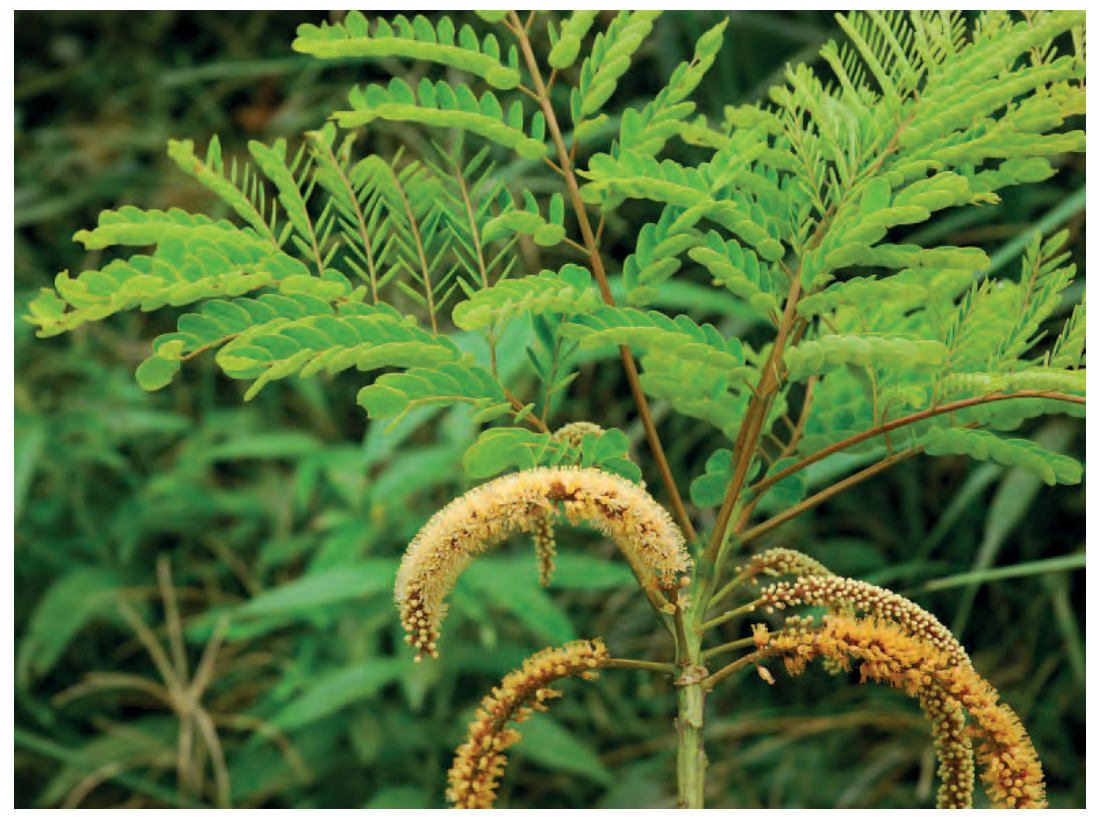
conserver dans la cendre pour limiter les attaques d'insectes. Les tremper quelques heures dans l'eau froide avant de les semer. La germination est généralement bonne, en une à quatre semaines. Les semis restent faibles jusqu'à ce qu'ils soient bien établis; on doit les garder en pépinière 6 mois à un an avant de les planter. On peut aussi planter des semis spontanés. 
Gestion : L'arbre supporte la taille et peut recéper.

Usages: L'aubier est blanc avec des marques ondulées. Le bois de cœur est rouge clair, puis vire au brun rouge ; il est durable, facile à travailler, mais sujet aux fentes. Le bois fraîchement coupé a une mauvaise odeur. On l'emploie pour les poteaux, les portes et fenêtres, la menuiserie générale, et parfois les pirogues et pagaies II sert aussi comme bois de feu et pour le charbon de bois. Le fruit a des usages alimentaires (épice pour les sauces au

Cameroun, fabrication de bonbons au Ghana), et cosmétiques. Des expériences ont montré qu'il donne de bons résultats pour contrôler les escargots hôtes de la schistosomiase. Toutes les parties de la plante connaissent de très nombreuses utilisations médicinales, mais les fruits, réputés antiarthritiques, antiinflammatoires

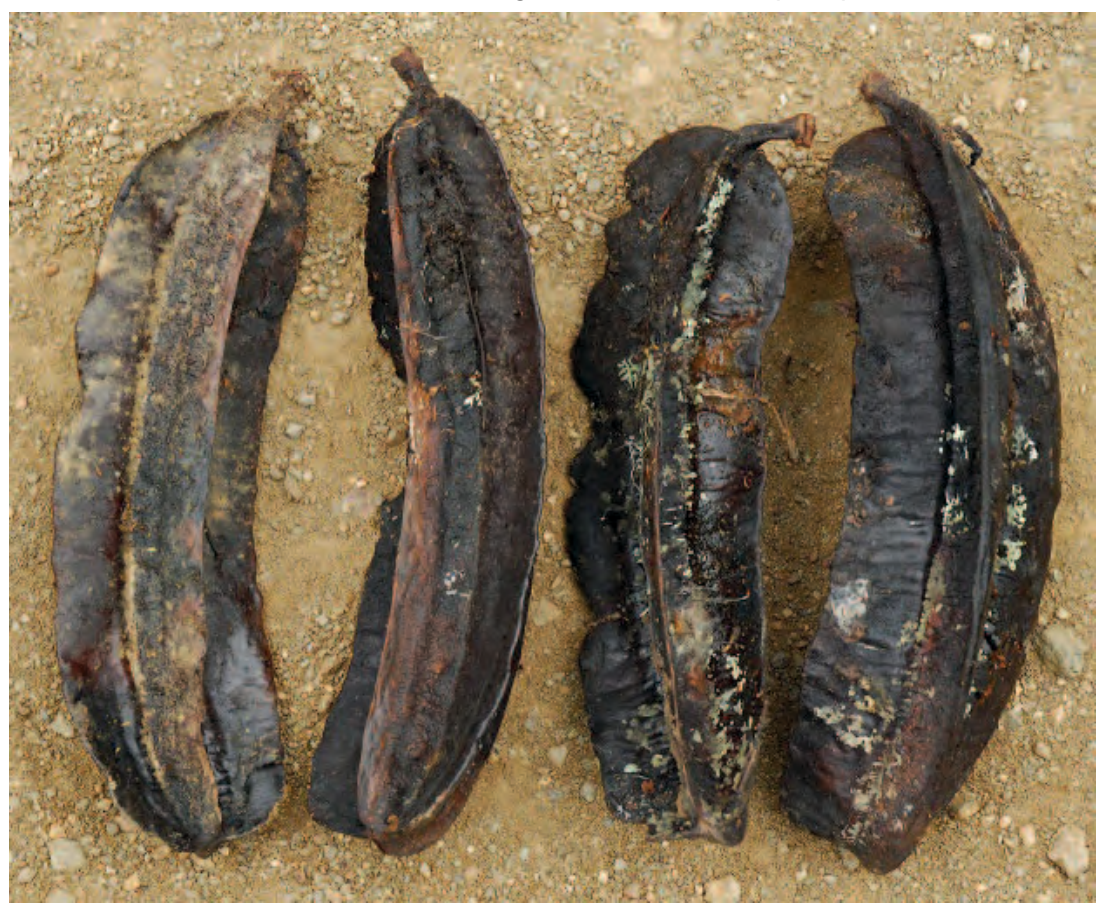
antidiabétiques, sont les plus employés. Le tronc donne une gomme soluble, semblable à la gomme arabique. Les fleurs sont une bonne source de miel.

Références: Gilbert et Boutique 1952, Ambougou 1991, Pauwels 1993, Burkill 1995, Katende et al. 1995, Vivien et Faure 1996, Vande weghe 2004, Meunier et al. 2010, Harris et al. 2011 


\section{Tetrorchidium didymostemon}

Noms courants : Nsusa (Kikongo), uenge (Lingala), arbre à savon du Gabon (Fr.)

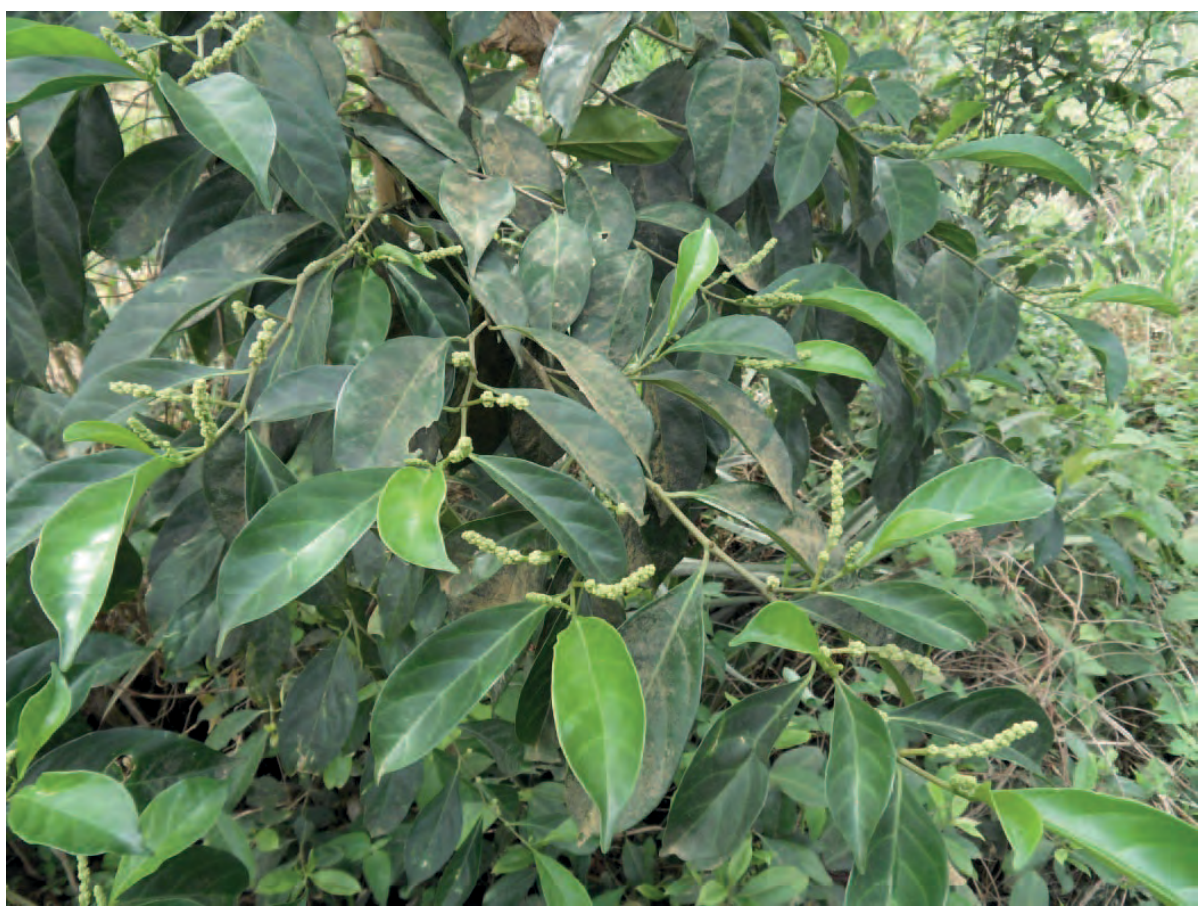

(Euphorbiaceae)

Description : Arbre ou arbuste de 4 à $25 \mathrm{~m}$ de haut, avec des rameaux en zigzags ; écorce lisse ou finement fissurée, brune; l'écorce coupée libère un latex habituellement blanc, parfois rougeâtre ou incolore ; feuilles alternes sur les pousses fleuries, opposées sur les autres rameaux ; limbe elliptique, de 7 à 12 sur 3 à $6 \mathrm{~cm}$, base cunéiforme, apex brusquement acuminé, bords entiers ou parfois dentés. Inflorescence mâle caractéristique, constituée d'un épi dense de fleurs jaunes, de 2,5 à $8 \mathrm{~cm}$ de long, inflorescence femelle constituée d'une fausse ombelle de 1 à 1,5 cm de long à 3-5 fleurs. Le fruit est une capsule verte trilobée, de $5 \times 6$ $\mathrm{mm}$, contenant trois graines rouge orangé.

Ecologie : Arbre commun des forêts secondaires, du Sénégal à la Tanzanie et à l'Angola.

Usages : Le bois, dur et résistant, est employé en construction. Cependant, il n'est pas durable dans le sol ou à I'humidité. L'écorce éloignerait les insectes. Au Kongo Central, on mangeait traditionnellement les feuilles comme légumes. On les emploie pour traiter les enflures, notamment aux jambes. On prend le jus des feuilles contre les maux d'estomac. On emploie le latex contre les nématodes et contre la lèpre. On donne une pommade d'écorce râpée pour traiter les

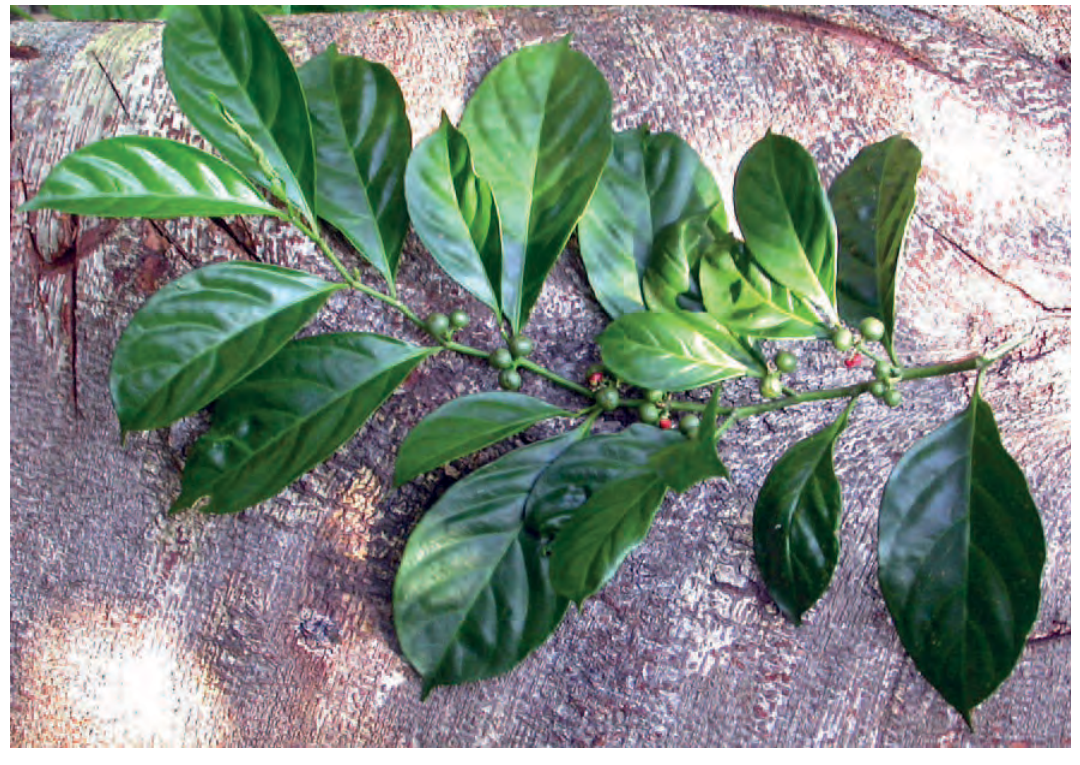
rhumatismes et pour chasser les poux. Les tiges savent de bâtons à mâcher ; on les suce pour avoir la sève sucrée de l'écorce. Le latex est un purgatif puissant.

Références : Gillet et Pâque 1910, Renier 1948, Léonard 1962, Nsimundele 1966 - 68, Keay 1989, Peters et al. 1992, Burkill 1994, Pauwels 1993, Neuwinger 2000 
Noms courants : Cacaoyer (Fr.), cocoa (Angl)

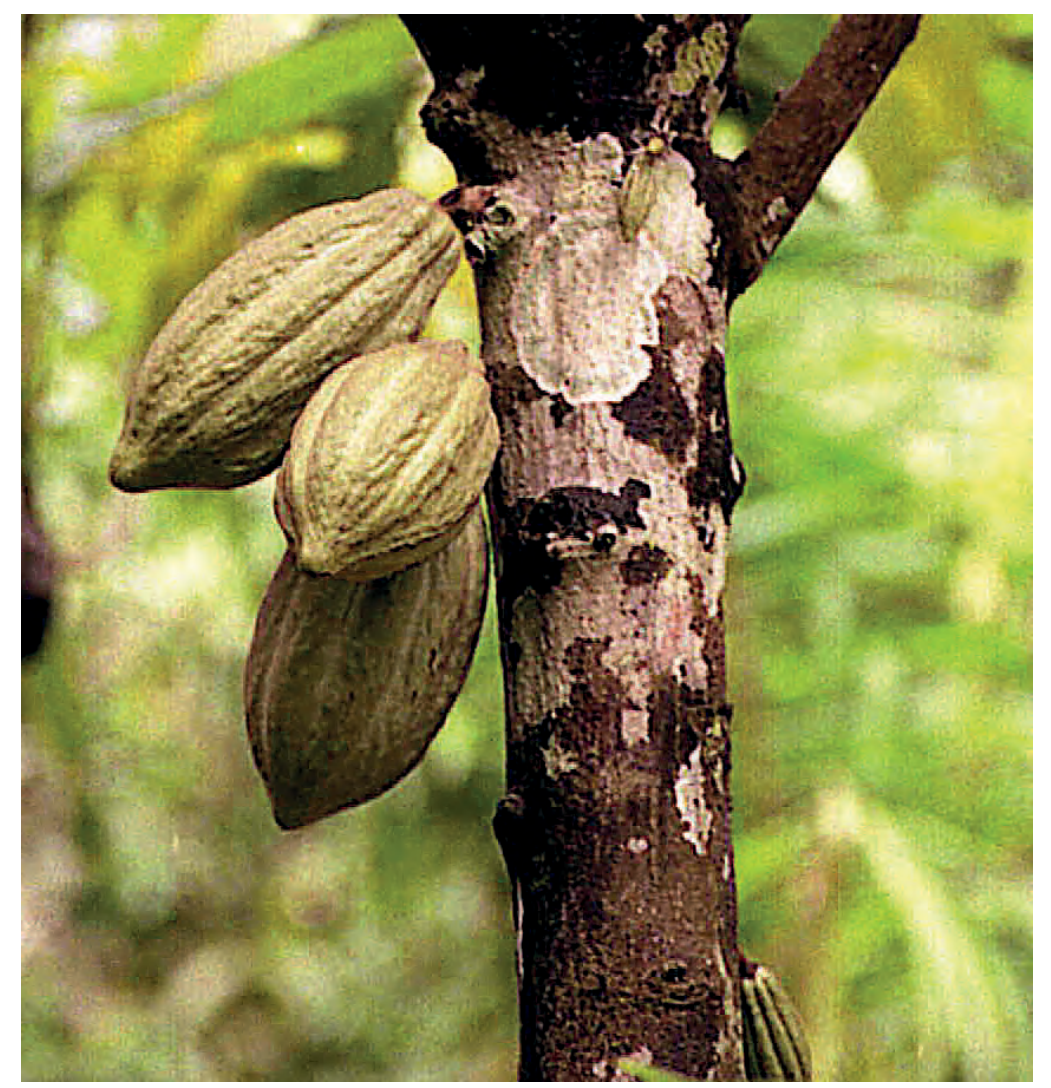

Description : Arbre de 5 à $10 \mathrm{~m}$ de haut. Son tronc est vertical et ses branches sont étagées d'une manière horizontale. Les feuilles du cacaoyer sont persistantes, grandes (jusqu'à 30 $\mathrm{cm}$ ou parfois $35 \mathrm{~cm}$ ), ovales et pointues à leur extrémité. Les fleurs du cacaoyer sont sessiles, de petite taille $(1 \mathrm{~cm})$ et de couleur blanchâtre, poussant directement sur les branches ou le tronc. Les fruits, appelés cabosses, sont charnus et coriaces. Ils ont la forme de ballons de rugby longs d'une vingtaine de centimètres sur des branches ou directement sur le tronc. Chaque fruit peut contenir, dans une pulpe blanche jaunâtre, jusqu'à 40 fèves.

Ecologie : Le cacaoyer est une espèce tropicale originaire du Mexique domestiquée il y a environ 3000 ans, Il a été introduit en Afrique dans les années 1880. En RD Congo, on le cultive fréquemment dans les villages. Et il existe des plantations de cacao, dans le Kongo Central (Mayumbe), les provinces de l'ouest et du nord du pays (Mai-Ndombe, Équateur, Tshuapa, Mongala, Sud et Nord-Ubangui), la Tshopo et le Nord-Kivu, II demande un sol bien drainé, bien aéré, profond, disposant de bonnes réserves de matière organique et nutriments.

Reproduction : On recommande de planter les boutures de la variété Forastero dans des paniers, ou dans des sacs de polyéthylène remplis de sciure de bois fermentée et couverts d'une feuille de polyéthylène. II faut limiter la surface des feuilles et placer les boutures à l'ombre. Les jeunes plants doivent rester à l'ombre jusqu'à ce qu'ils soient établis. On peut réduire l'ombre progressivement, et la supprimer la troisième année.

Gestion : Mettre en place les arbres à des espacements de $3 \times 2.5 \mathrm{~m}$. Il faut bien désherber les jeunes arbres. On peut les tailler pour obtenir un cône inversé à trois ou quatre branches maitresses. Dans les plantations qui commercialisent les fèves, on doit cueillir les cabosses exactement à maturité. Ceci commence d'ordinaire à la fin des pluies et se prolonge environ trois mois. On fait fermenter les fèves après les avoir retirées des cabosses. On les met en tas, ou dans des paniers, en les couvrant de feuilles de bananiers et on les laisse fermenter de quatre à sept jours. La fermentation se poursuit dans deux boîtes successives, chaque fois deux ou trois jours.

Usages : Le fruit se mange frais avant pleine maturité. Les fèves fermentées commercialisées par les plantations constituent la matière première pour la production de chocolat, traditionnellement dans les pays importateurs, mais de plus en plus dans les pays producteurs (Côte d'Ivoire, Ghana, Madagascar).

References : Germain 1963, Purseglove 1968, Drachousssoff 1993, Pauwels 1993, Raemaekers 2001 


\section{Thonningia sanguinea}

Noms courants: Sasabu ( = médicament) (Kikongo), m’bila-na-mabele (Lingala), ground pineapple (Angl.)

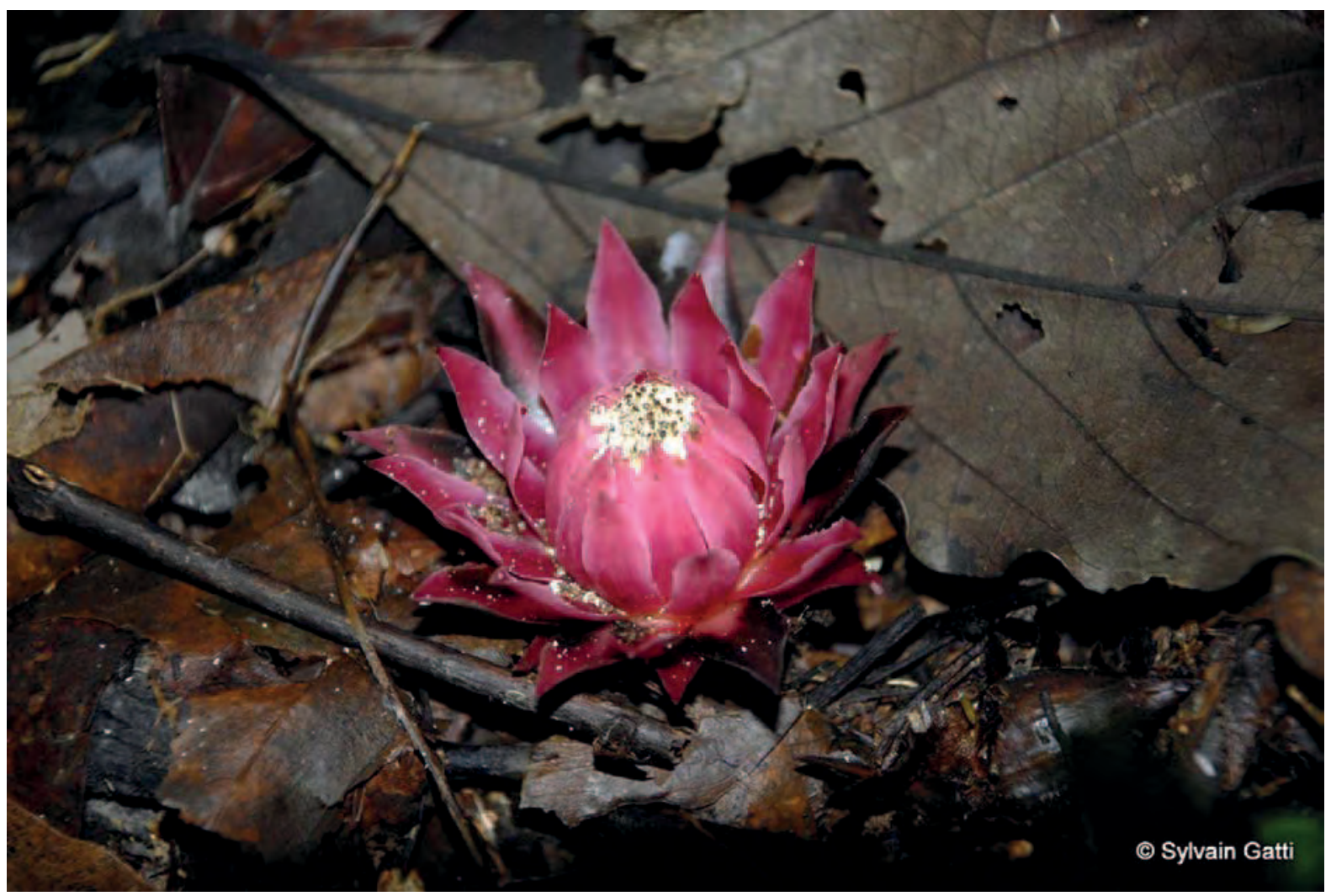

Photo : Sylvain Gatti

Description : Plante parasite des arbres et autres plantes ligneuses pérennes, donnant d'abord un tubercule jaunâtre de 4 à $7 \mathrm{~mm}$ au point d'attache du parasite sur les racines de l'hôte, puis un bulbe de 20 à $35 \mathrm{~mm}$ de diamètre. Seules les fleurs apparaissent au-dessus du sol, les fleurs mâles longues de 8 à 16 mm, les fleurs femelles d'environ 3,5 mm.

Ecologie: Parasite largement présent en Afrique tropicale.

Usages : Au Kongo Central, on touche avec les boutons écailleux l'un des côtés de l'abdomen pour traiter I'incontinence nocturne. Ailleurs en R.D. Congo, on emploie la plante pour traiter la dysenterie et la gonorrhée. En République du Congo, on fait avec la plante un emplâtre pour faire mûrir les abcès; on dissout dans l'eau la plante pilée pour en faire un bain de bouche contre les caries dentaires, les gingivites et les infections de la bouche. On soigne les enfants fiévreux en leur piquant l'estomac avec les écailles des fleurs, puis en y appliquant la sève. Avec le rhizome, on fait une infusion contre les rhumatismes; on emploie aussi cette plante contre les paralysies. On instille la sève des fleurs dans les yeux des enfants atteints de rickettsiose.

Remarque : Cette plante parasite les plantations telles que l'hévéa, le palmier à huile ou le cacao. Normalement, la plante hôte ne meurt pas, mais est affaiblie.

Références : Gillet et Pâque 1910, Renier 1948, Staner 1948, Burkill 1985, Vande weghe 2004, Wikipédia (consulté le 29.10.2016) 


\section{Thunbergia grandiflora}

Noms courants : Blue trumpet vine (Angl.)

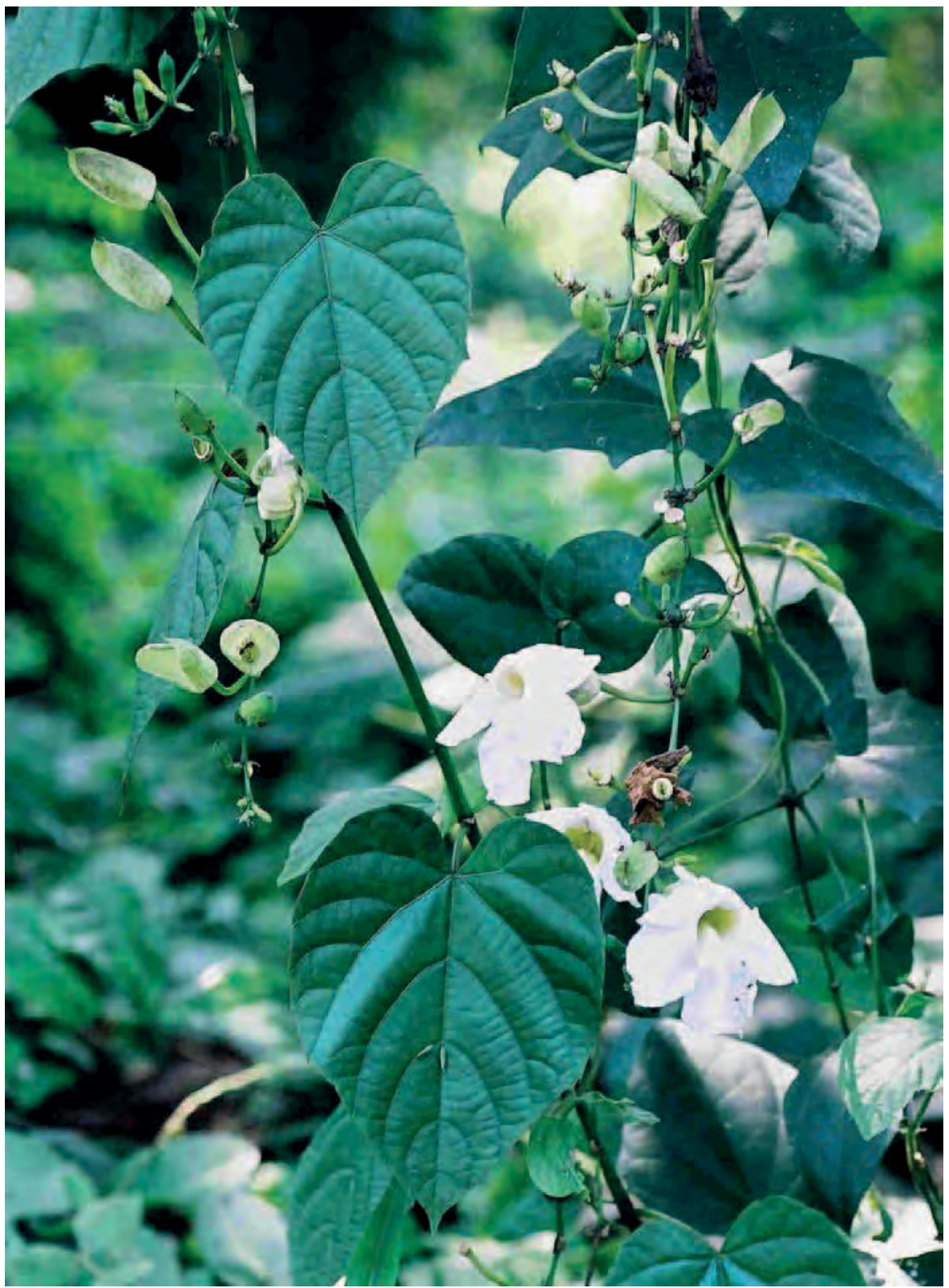

(Acanthaceae)

Description : Belle plante grimpante vigoureuse, à tige quadrangulaire, atteignant $20 \mathrm{~m}$ de long sur un gros tubercule. Les feuilles sont variables, habituellement en forme de cœur, et peuvent avoir 7,5 $\mathrm{cm}$ de long. Cing ou six fleurs, d'ordinaire bleu pâle à gorge jaune, se succèdent le long d'un racème pendant atteignant $12 \mathrm{~cm}$ de long. La variété présente au Kongo Central a des fleurs blanches.

Photo prise en mai au jardin botanique de Kisantu.

Ecologie : Plante originaire de l'Assam en Inde, de la Chine et du Myanmar. Introduite dans la plupart des pays tropicaux humides, elle requiert de l'espace et un support robuste.

Reproduction : A partir des tubercules, par graines, boutures ou marcottes.

Gestion : Guider les tiges sur une charpente ou sur des arbres. Leur feuillage abondant donne un bon ombrage. Cette plante peut devenir très invasive.

Usages : Liane ornementale. En Assam, les feuilles servent de nourriture pour les lapins, et ont des usages médicinaux. Aux Philippines, les fleurs seraient une importante source de nectar pour les abeilles. Quelques espèces de Thunbergia seraient de bonnes plantes pour le miel en Afrique sahélienne.

Références: Gillet 1927, Irvine 1930, Jex-Blake 1957, Crane et al. 1984, Burkill 1985, Phillips et Rix 1997, Hepburn et Radloff 1998, Llamas 2003, Fayaz 2011, Cameron et Lowe 2017 


\section{Tithonia diversifolia}

Noms courants : Kituntu ki nkadi, nkadi nkadi (Kikongo), engrais vert, tournesol mexicain (Fr.), Mexican sunflower (Angl.)

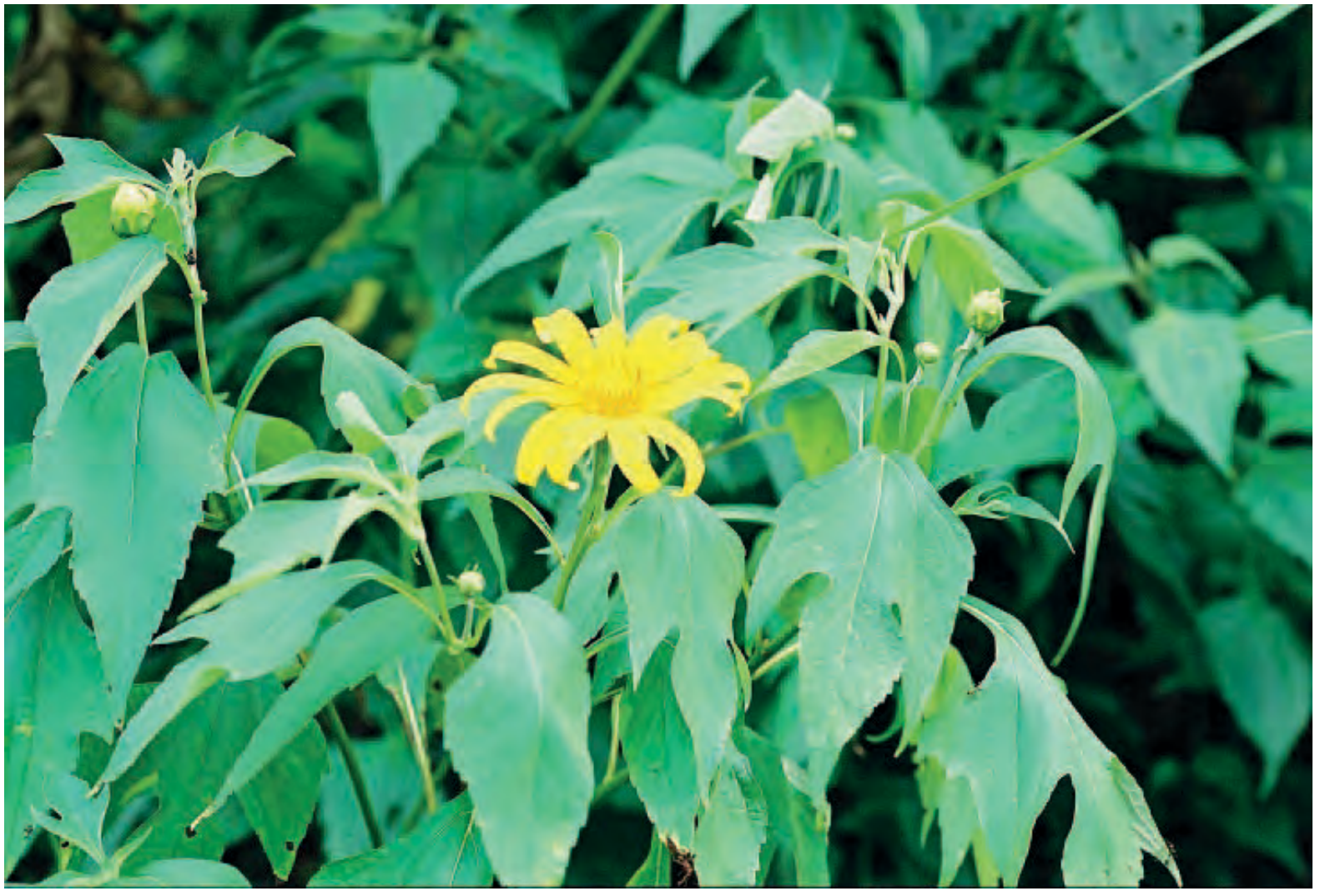

Description : Herbe pérenne dressée pouvant atteindre 2,5 à 3 mètres de haut, qui présente des feuilles alternes dont le limbe comporte 3 à 5 lobes. Elle pousse souvent en massif. Les grandes fleurs voyantes sont jaunes à orange et de 5 à $15 \mathrm{~cm}$ de diamètre. Les graines sont des akènes à 4 angles de $5 \mathrm{~mm}$ de long. Elles sont propagées par le vent.

Ecologie : Plante originaire d'Amérique centrale, parfois abondante au bord des routes. Employée comme haie autour des parcelles dans les villages, se diffuse dans les champs, les friches et les bords de routes.

Reproduction : Le plus facile est la division des touffes. On peut semer les graines en surface sous un paillage d'herbe. On peut aussi faire des boutures de 20 à $30 \mathrm{~cm}$.

Gestion : Pour les haies, tailler la plante à 1 à $1,5 \mathrm{~m}$ de hauteur, pour éviter qu'elle tombe à terre en fin de saison.

Usages : Plante cultivée comme haie. On rapporte que les feuilles et tiges enfouies dans le sol améliorent sa fertilité, surtout en combinaison avec des engrais phosphatés; on a montré un accroissement des

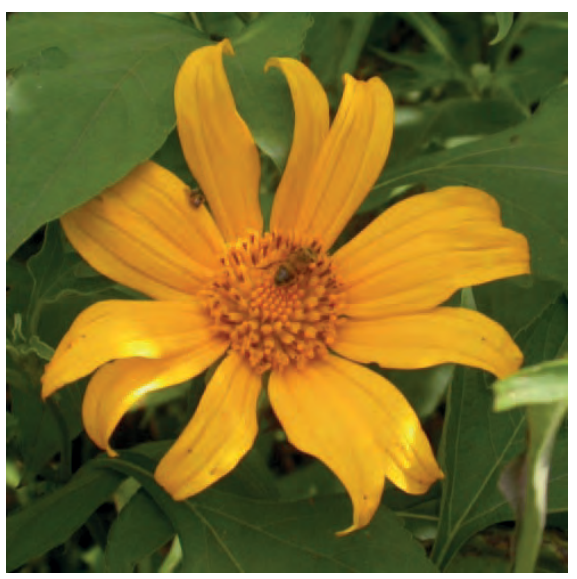
rendements pour le maïs et pour les diverses espèces de Brassica (choux). Au Kenya, une jachère plantée 6 mois de Tithonia diversifolia a accumulé de grandes quantités d'azote, potasse et calcium. On a aussi utilisé cette plante comme fourrage pour le bétail ; elle peut constituer jusqu'à $25 \%$ de la ration des cobayes nourris avec Cenchrus purpureus. On rapporte que si l'on fait bouillir les feuilles, le liquide obtenu peut être appliqué sur les arbres ou versé dans les trous pour contrôler les termites. A Mbanza-Ngungu, on donne une décoction des feuilles pour traiter les douleurs des articulations et les problèmes digestifs. Les abeilles récoltent le nectar des fleurs, mais la sécrétion de nectar est variable selon l'altitude et le type de sols. Le miel est léger, ambré, et cristallise rapidement.

Références: Crane et al 1984, Akobundu et Agyakwa 1987, Ambougou 1991, Lisowski 1991, Roothaert et al 1997, Orwa et al. 2009, Nzuki Bakwaye et al. 2013, Noumbissi et al. 2014, Latham et Konda Ku Mbuta 2017 


\section{Trachyphrynium braunianum}

Noms courants : Kulu ntete (Ntete = long panier utilisé par les porteurs), ngididi (Kikongo), arrow grass (Angl.).

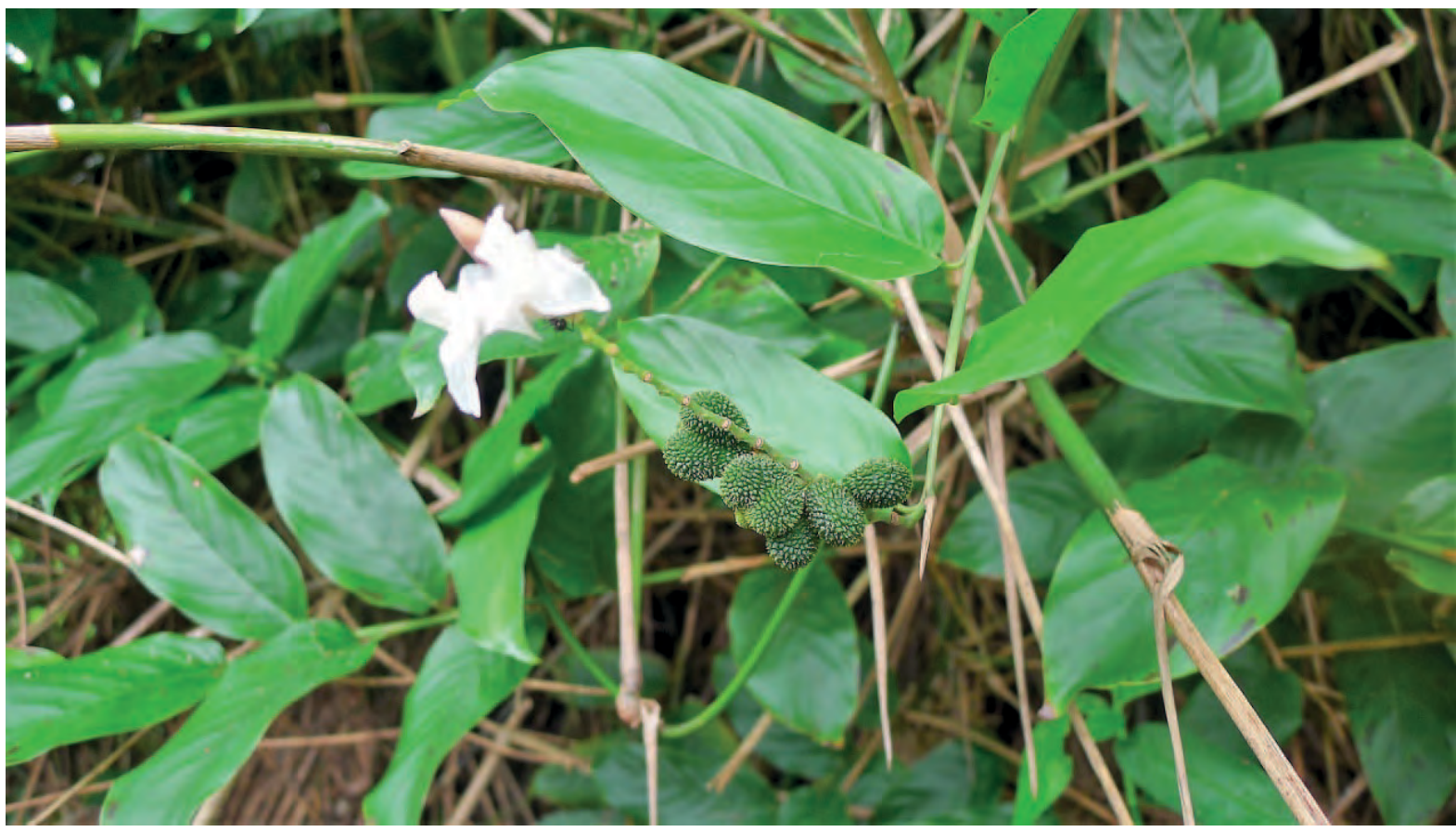

Description : Plante herbacée ligneuse pérenne à rhizomes rampants et tiges semblables aux bambous de 2 - 6 $\mathrm{m}$ de longueur, formant des touffes. Feuilles de tailles très variables, de 5 à 13,5 sur 4 à $8 \mathrm{~cm}$. L'inflorescence est terminale, en épi simple ou parfois ramifiée à la base, et peut avoir $20 \mathrm{~cm}$ de long. Les fleurs blanches, parfois teintées de rose ou de pourpre, ont 2 à $3 \mathrm{~cm}$ de long. Le fruit est une capsule jaune orangé, d'environ 1,5 cm de diamètre ; il contient une à trois graines brillantes, noires ou brunes, avec un arille beige clair.

Ecologie : Plante présente en forêt galerie, ou en savane près de l'eau, commune de la Guinée au Soudan et à l'Ouganda, du niveau de la mer à 1.200 m d'altitude.

Reproduction : Cette plante se reproduit naturellement par graines ou rejets.

Usages: On emploie les feuilles pour emballer la chikwangue, et aussi le sel de mer. Les tiges fendues servent à confectionner des paniers, et des attaches pour la construction. Les tiges servent aussi de chevrons pour fixer le chaume. On les emploie largement pour tresser des nattes, des passoires, des ruches, et des pièges pour le poisson et pour les rats. Les fruits sont comestibles. On boit une décoction des tiges contre les hernies et les maux d'estomac. On fait un cataplasme de feuilles pilées et chauffées que l'on applique sur la plante des pieds durcie et fendillée. On donne la sève des racines, souvent en mélange avec celle d'autres Marantacées, comme traitement de la folie. Avec la racine rôtie et réduite en poudre, additionnée de sel et de grains d'Aframomum melegueta; on fait une pâte que l'on frotte dans des scarifications pour le traitement des rhumatismes. En R.D. Congo, on applique les feuilles en cataplasme sur les inflammations. Les fleurs sont pollinisées par les abeilles visitent

Références : Gillet et Pâque 1910, Daeleman et Pauwels 1983, Burkill 1997, White et Abernethy 1997, Kémeuzé 2010, Dhetchuvi et Ley 2017 


\section{Treculia africana}

Noms courants : Nsungi, nzaza (Kikongo), baimi, bolimbo (Lingala), arbre à pain d'Afrique (Fr. ), African breadfruit (Angl.)

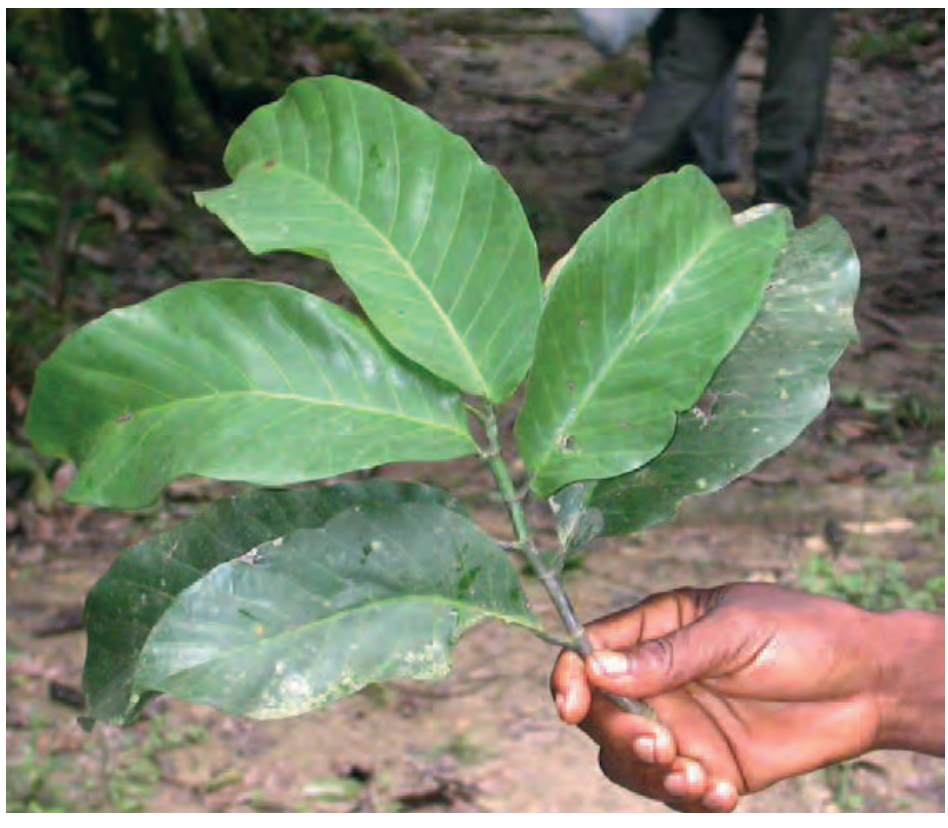

Description : Arbre à croissance rapide jusqu'à $35 \mathrm{~m}$ de haut. Feuilles ovales ou elliptiques, coriaces, de 12 à 40 sur 7 à 20 $\mathrm{cm}$. Inflorescences sphériques ; l'inflorescence femelle se développe pour donner un fruit jaune de $35 \mathrm{~cm}$ de diamètre pouvant peser $12 \mathrm{~kg}$, hérissé de stigmates noirs durcis de $8 \mathrm{~mm}$ de long ; elle contient alors les fruits, qui sont des akènes de 12 à $15 \mathrm{~mm}$ de long.

Ecologie : Arbre des forêts primaires près de l'eau et des forêts galeries, du niveau de la mer à $1.200 \mathrm{~m}$ d'altitude, du Sénégal en Angola. Présent aussi au Mozambique et au Soudan. Parfois planté.

Reproduction : Extraire les grains du fruit pourrissant. Les semer le plus vite possible en pots ou en plein champ.

Usages : Les graines, comestibles, sont très appréciées. On laisse pourrir le fruit, ou on le trempe dans l'eau, pour pouvoir extraire les grains. Leur goût rappelle celui des arachides, on les mange crues, rôties, bouillies, ou frites. On peut aussi les piler pour les ajouter aux sauces ou en faire des soupes. Elles contiennent $73 \%$ d'hydrates de carbone, $16 \%$ de protéines, et $6 \%$ d'huile. Le bois est blanc à jaune clair, et à grain fin. On l'emploie pour le mobilier, la sculpture, le tournage ou la marqueterie. On peut aussi l'employer pour faire du papier. II convient comme bois de feu et pour le charbon de bois. L'arbre protège le sol, en conservant l'humidité pendant la saison sèche. Au Kongo Central, on emploie les feuilles pour traiter les caries dentaires.

Remarque : Les qualités nutritives de la graine sont particulièrement bonnes. La composition des graisses est équilibrée, les protéines sont appropriées pour la nutrition des enfants comme des adultes, et la part d'hydrates de

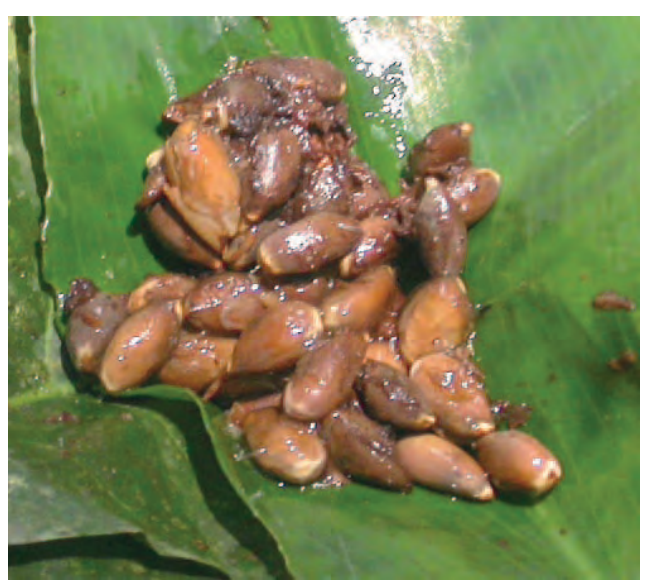

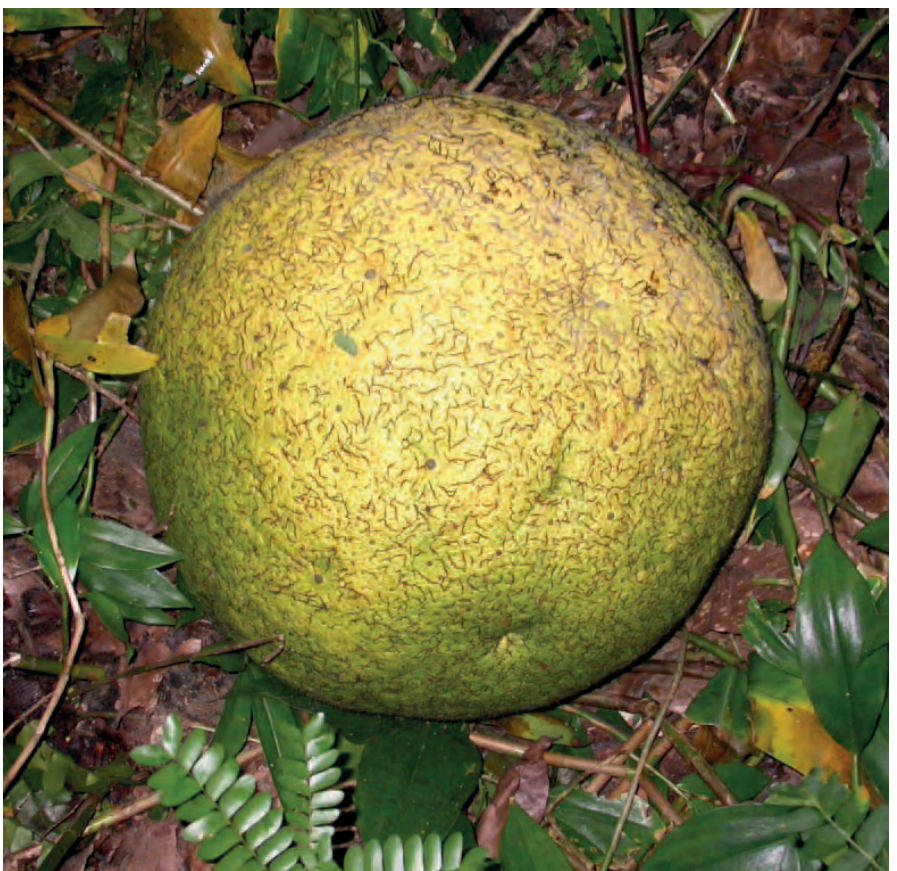

carbone est aussi de bonne composition.

Références : Gillet 1927, Hauman 1948, Renier 1948, Bijttebier 1981, Pauwels 1993, Burkill 1997, Katende et al. 2000, Burrows et Burrows 2003, Nsimundele 2004, Meunier et al. 2010

A gauche: Graines extraites d'un fruit tombé 

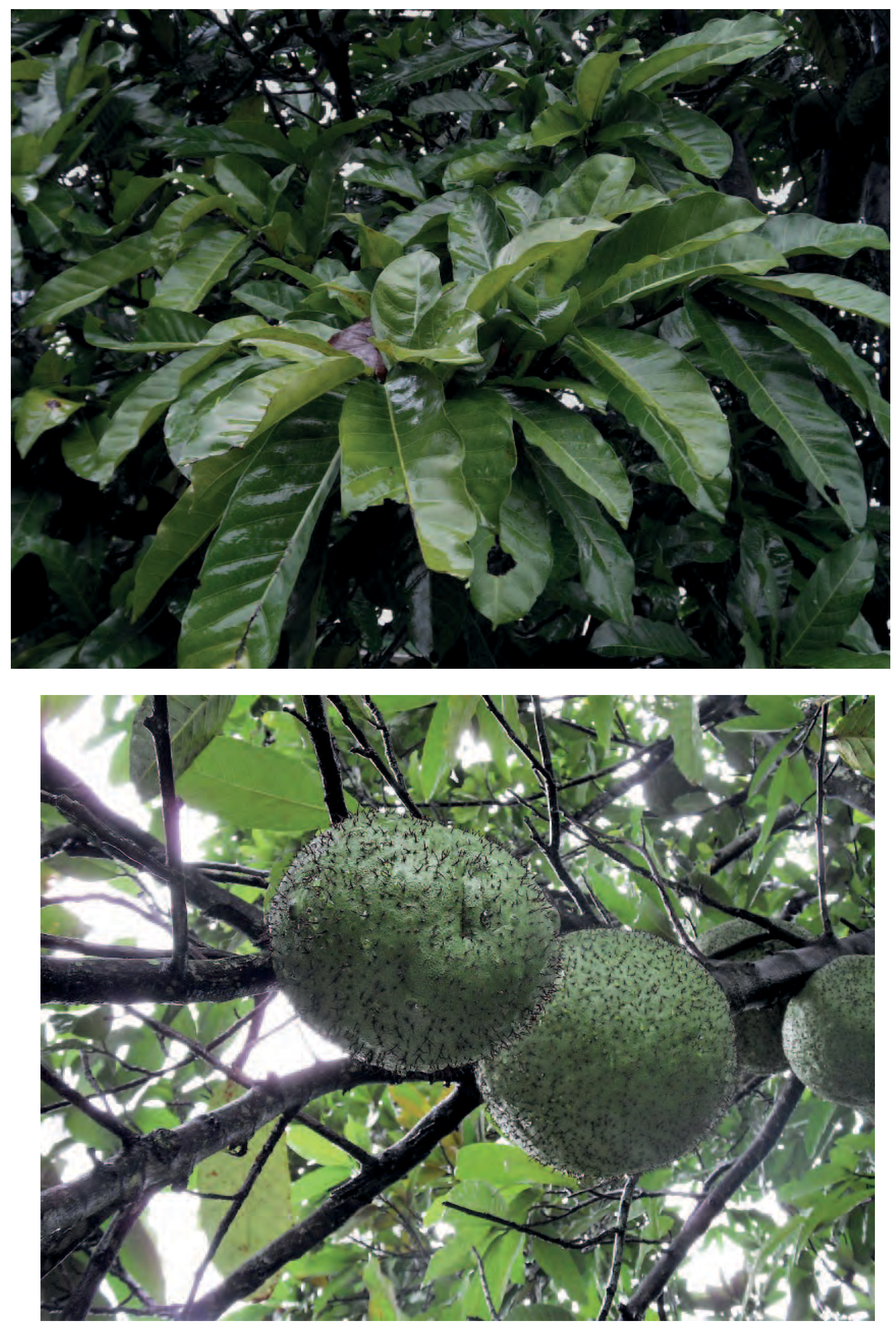

Jeunes fruits de Treculia africana 


\section{Trema orientalis}

Noms courants: Mudia nuni, kidia nuni (= ce que mangent les oiseaux), kiwandu ki mfinda (Kikongo), esesu, pesu, wendende (Lingala), charcoal tree (Angl.)

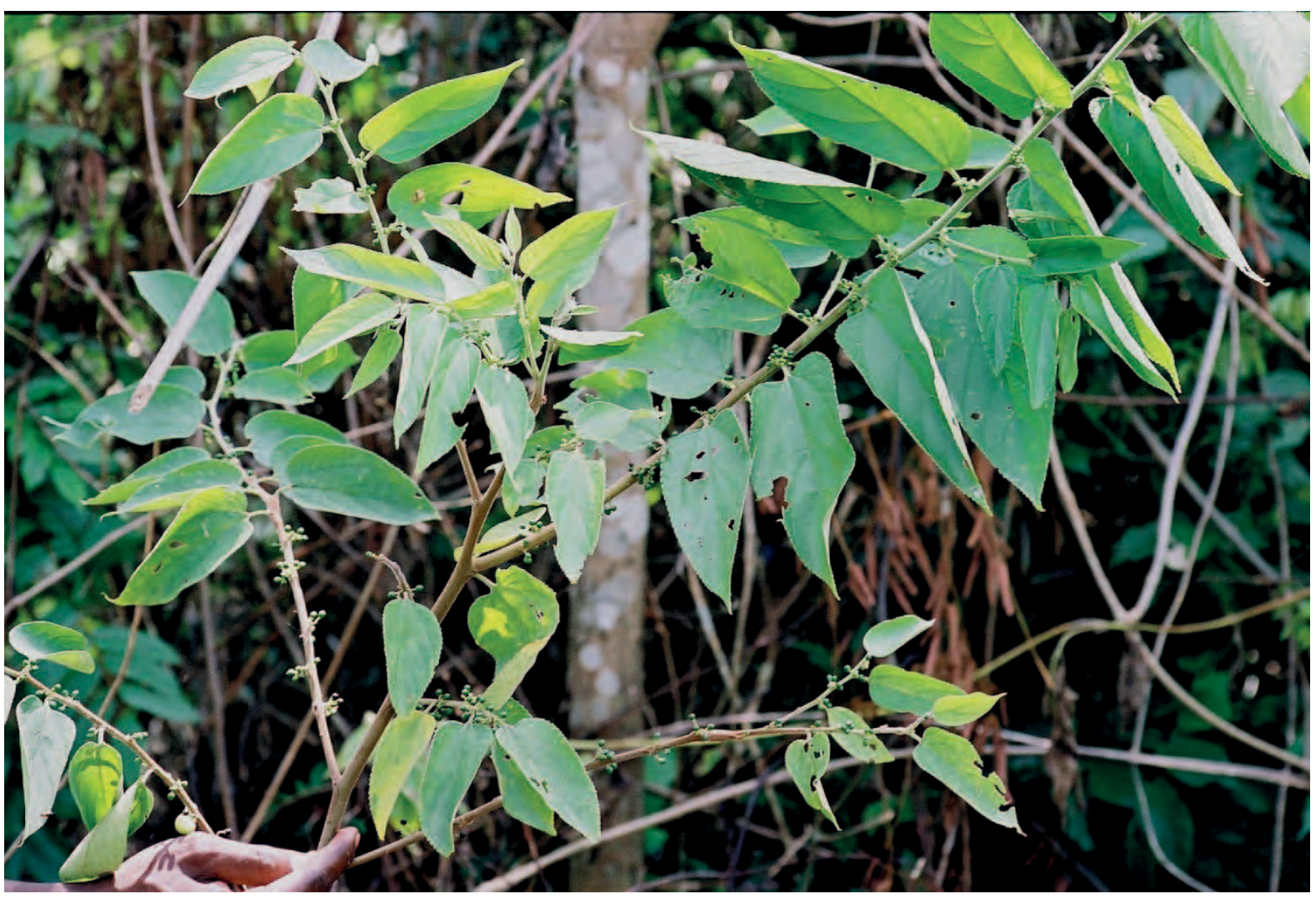

Description : Arbustes de 4 à $5 \mathrm{~m}$ de haut, à branches souples. Les feuilles asymétriques, alternes, pouvant avoir $16 \mathrm{~cm}$ de long, à bords finement dentés sur tout le tour, sont disposées régulièrement le long des branches. A chaque aisselle on trouve toute l'année de petits bouquets de fleurs blanches. Le petit fruit, charnu et noir à maturité, contient une seule graine noire.

Ecologie : Plante des forêts secondaires, préférant les zones à fortes pluies, commune dans les lisières, d'où elle envahit rapidement les clairières et sols perturbés, donnant souvent des peuplements purs, ou associée avec Harungana madagascariensis. Présente dans toute l'Asie et l'Afrique tropicale et à Madagascar.

Reproduction : Il faut semer rapidement les graines fraichement récoltées, pour obtenir un taux de germination d'environ $30 \%$. On peut aussi employer les semis spontanés ou les boutures.

Gestion : La plante pousse rapidement, et concurrence efficacement les herbes. Elle se taille facilement.

Usages : Au Kongo Central, on emploie une infusion des feuilles pour traiter les maux de dents. Les feuilles, l'écorce et la tige servent à traiter les dermatites, les désordres mentaux, la déshydratation, l'asthme, et l'épilepsie. On rapporte que l'on mange les fruits et les feuilles en R.D. Congo. Les chenilles comestibles Minsongo (Nudaurelia alopia), Bisu (Nudaurelia petiveri) et Mvinsu (Imbrasia epimethea) se nourrissent avec les feuilles. On emploie les troncs en construction, mais, bien que le bois résiste aux termites, il est peu durable. Le bois sert de bois de feu et pour le charbon de bois. Les feuilles, les fruits et les graines conviennent comme fourrage pour le bétail. Les abeilles visitent les fleurs. La plante fixe l'azote, et convient pour la fertilisation des sols. On l'emploie comme plante d'ombrage pour les jeunes plantations de Milicia excelsa, de café et de cacao ; sa présence signalerait les bons sols pour les cacaoyers. L'écorce donne une teinture noire, et les feuilles une teinture brune. L'écorce donne aussi des fibres robustes. L'écorce et la tige contiennent des saponines, on les a employées pour lutter contre les vers et comme remède contre la toux.

Références: Hauman 1948, Renier 1948, Nsimundele 1966 - 68, Williamson 1975, NAS 1980, Daeleman et Pauwels 1983, Pauwels 1993, Katende et al. 1995, Burkill 2000, Neuwinger 2000, Kibungu Kembelo 2003, Meunier et al. 2010, Lautenschläger et al. 2017 
Noms courants : Kituti, kisuku (Kikongo)

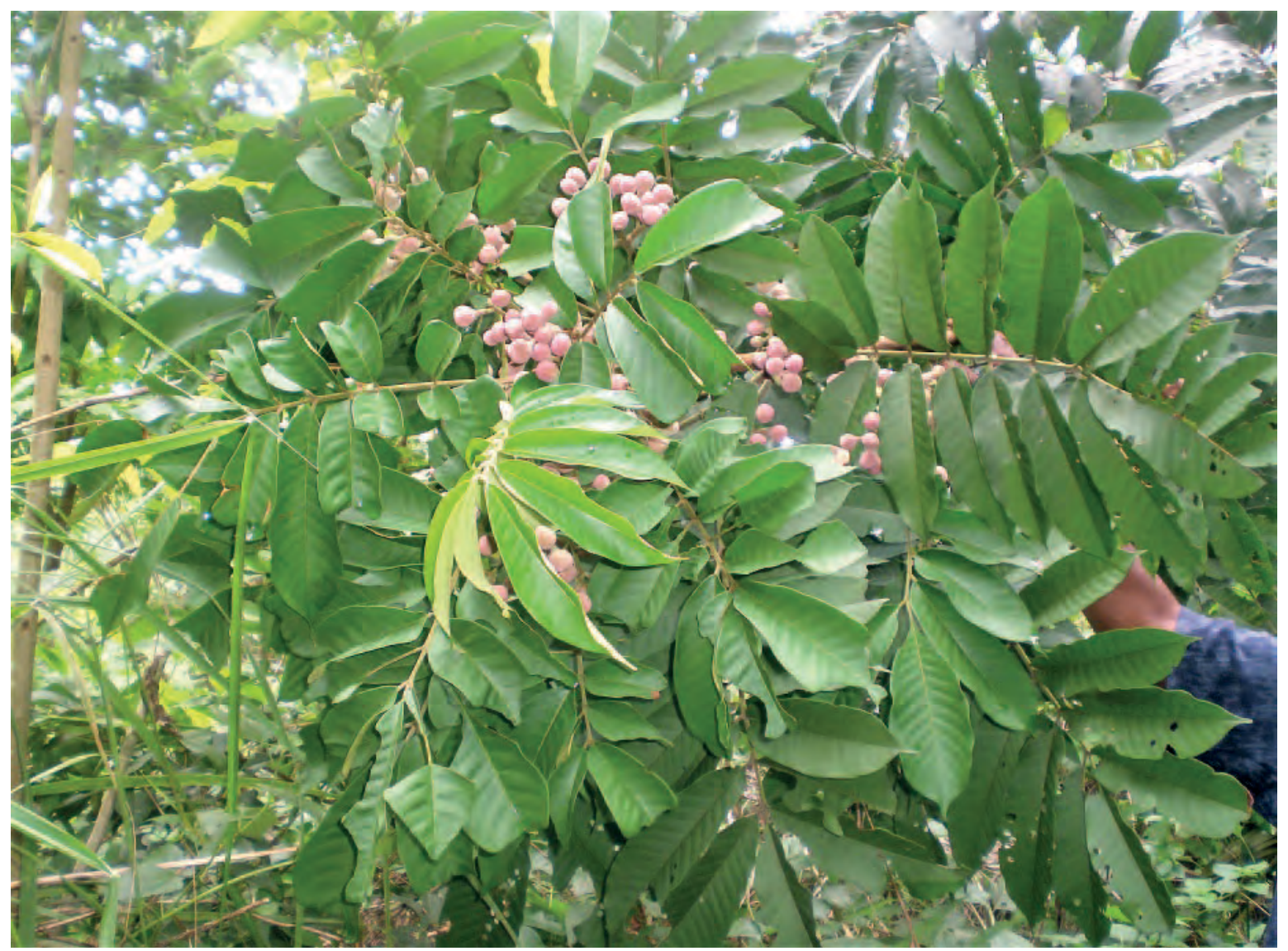

Photo prise à Kimuenza, Kinshasa en décembre

Description : Arbre atteignant $25 \mathrm{~m}$ de haut. La coupure dégage un latex crémeux à l'odeur de cèdre. Les feuilles composées ont 7 folioles sur un pétiole de 5 à $20 \mathrm{~cm}$. Les folioles ont 5 à 22 sur 2,5 à $9 \mathrm{~cm}$. L'inflorescence est une panicule épineuse de 2 à $15 \mathrm{~cm}$ de long. Les fleurs sont blanc verdâtre. Les fruits, d'environ $2,5 \mathrm{~cm}$ de long, sont couverts d'un feutre léger, rose à mauve. Les graines noires sont presqu'entièrement entourées d'un arille rouge.

Ecologie : Arbre présent en R.D. Congo dans les forêts de sol ferme au Kongo Central, au Kasal̈ et dans la forêt centrale.

Reproduction : D'autres espèces (par exemple $T$. prieureana) se reproduisent par graines.

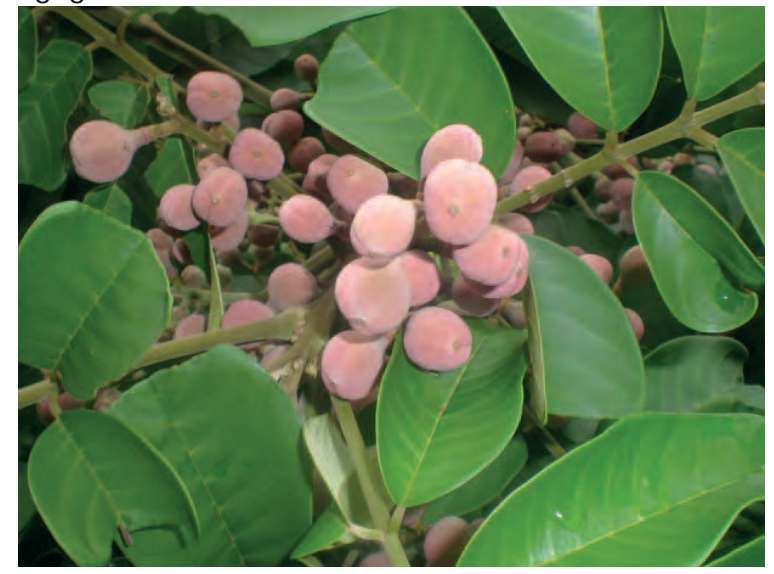

Usages: Les abeilles visitent les fleurs. On signale aussi qu'au Gabon Trichilia prieureana est visité par les abeilles. Les espèces deTrichilia spp. seraient l'une des principales sources de nourriture pour les abeilles en Afrique tropicale. Différentes parties de l'arbre ont des usages médicinaux.

Remarque : On trouve au Kongo Central deux autres espèces de Trichilia (Pauwels - Sermatophyta).

Références : Staner et Gilbert 1958, Raponda-Walker et Sillans 1961, Bouquet 1969, Ambougou 1991, Pauwels 1993, Hepburn et Radloff 1998, Neuwinger 2000 


\section{Trichocentrum splendidum}

Nom courant : Splendid Oncidium (Angl.)

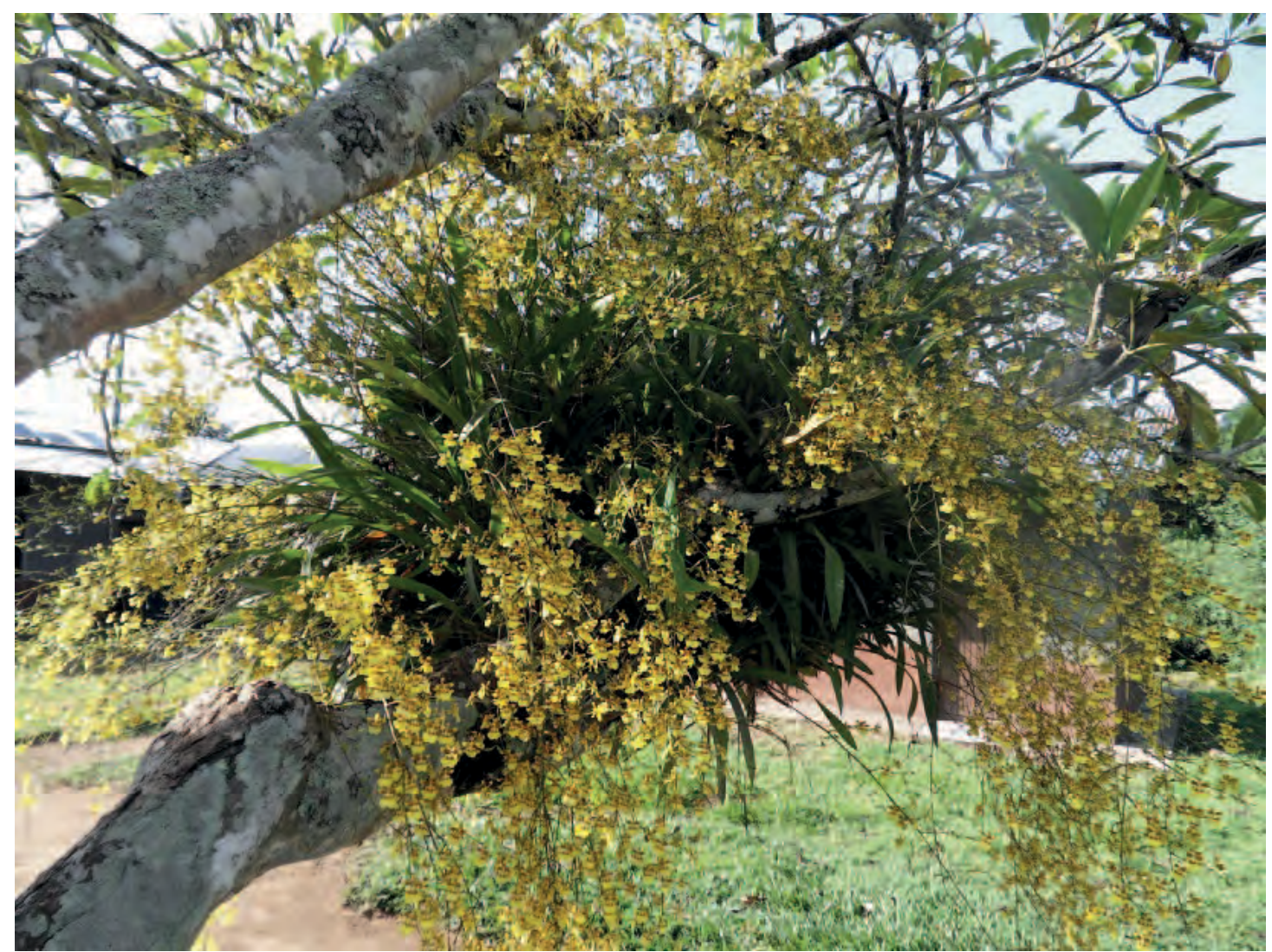

Trichocentrum splendidum poussant sur un safoutier

Description : Une espèce d'orchidée. Les pseudobulbes sont petits; les feuilles charnues ont jusqu'à $9 \mathrm{~cm}$ de long. Les grandes et belles fleurs, jaunes à blanches ponctuées de points marron, sont isolées, ou disposées en grappes de quelques fleurs.

Ecologie : Plante originaire du Guatemala, du Honduras et du Nicaragua où elle pousse sur des pentes rocheuses.

Gestion : La plante doit être maintenue dans des conditions semblables à celles de son milieu d'origine, sinon elle risque de pourrir. Beaucoup d'espèces apparentées d'Amérique centrale supportent une sécheresse prolongée au moins une partie de l'année, et ont donc développé des feuilles succulentes. Cette plante peut flétrir très sévèrement.

Usages : Plante ornementale. On considère que les espèces de Trichocentrum sont parmi les orchidées les plus séduisantes.

Références : www.orchidspecies.com (consulté le 12.12.18) 


\section{Trichoscypha oddonii}

\section{(Anacardiaceae)}

Noms courants : Biyoyo, panga ya singama (Kikongo)

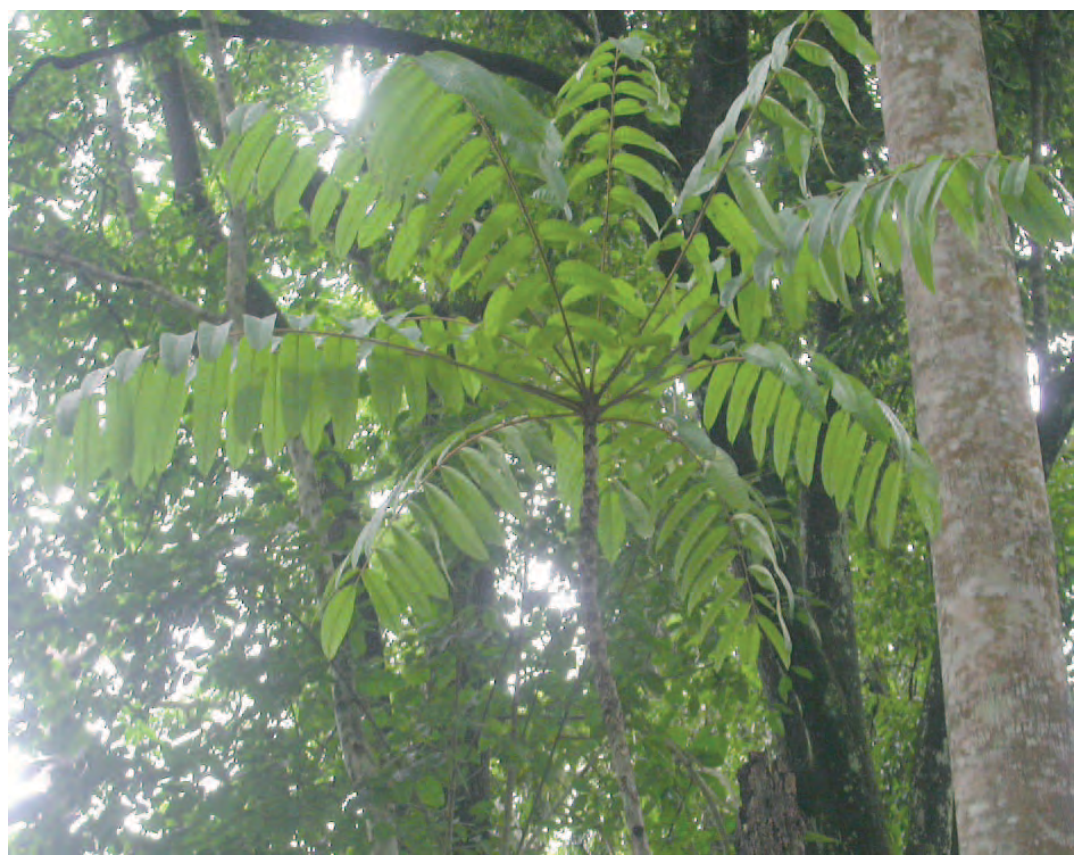

Description : Petit arbre non ramifié (ou avec de rares branches) de 5 à $15 \mathrm{~m}$ de haut. II porte une couronne de feuilles composées, pouvant avoir chacune $2 \mathrm{~m}$ de long, en haut de la tige principale. Les fleurs sont disposées en panicules de 15 à 25 $\mathrm{cm}$ sur le tronc. Les fruits, rouges à maturité, ont 4 à $5 \mathrm{~cm}$ de long.

Ecologie : Arbre des forêts denses humides, présent au Cameroun, au Gabon et en R.D. Congo (Kongo Central).

Usages : Les fruits, qui mûrissent en février et mars, sont comestibles mais plutôt aigres. Le bois, de couleur rose, a un grain très fin et se travaille bien.

Der Veken 1960, Daeleman et Pauwels 1983

Références : Renier 1948, Van

A droite : Arbre portant des fruits verts au jardin botanique de Kisantu.

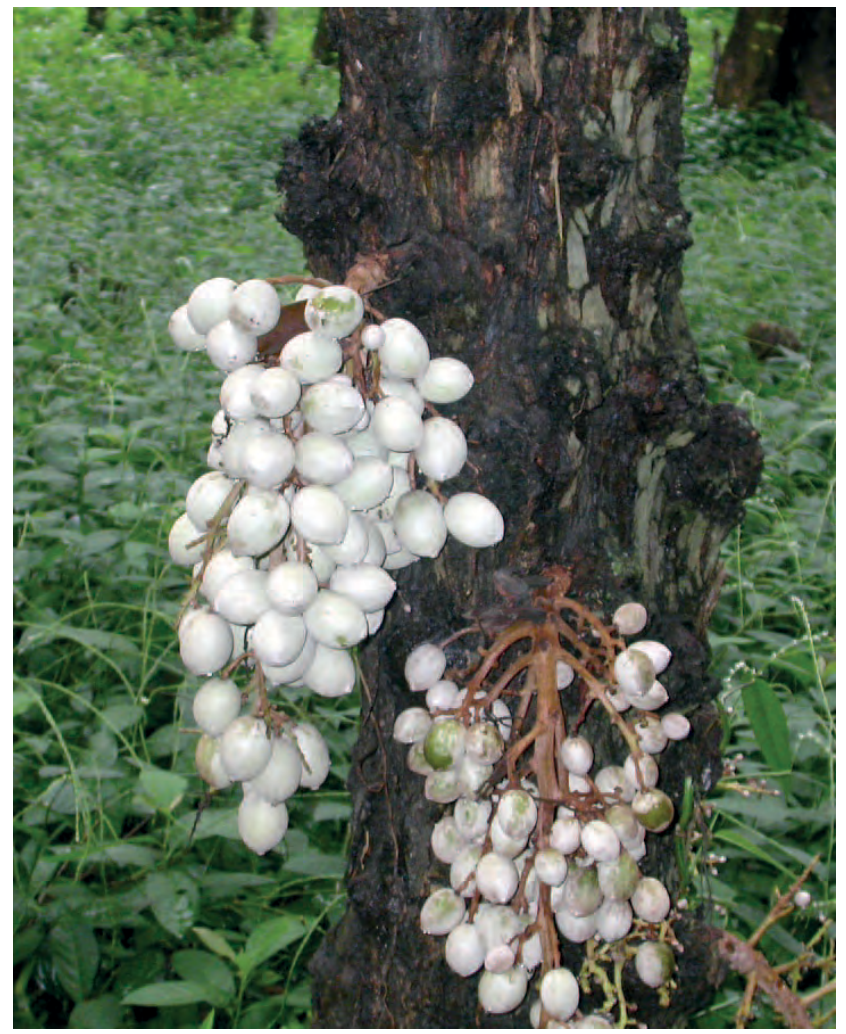




\section{Triclisia dictyophylla}

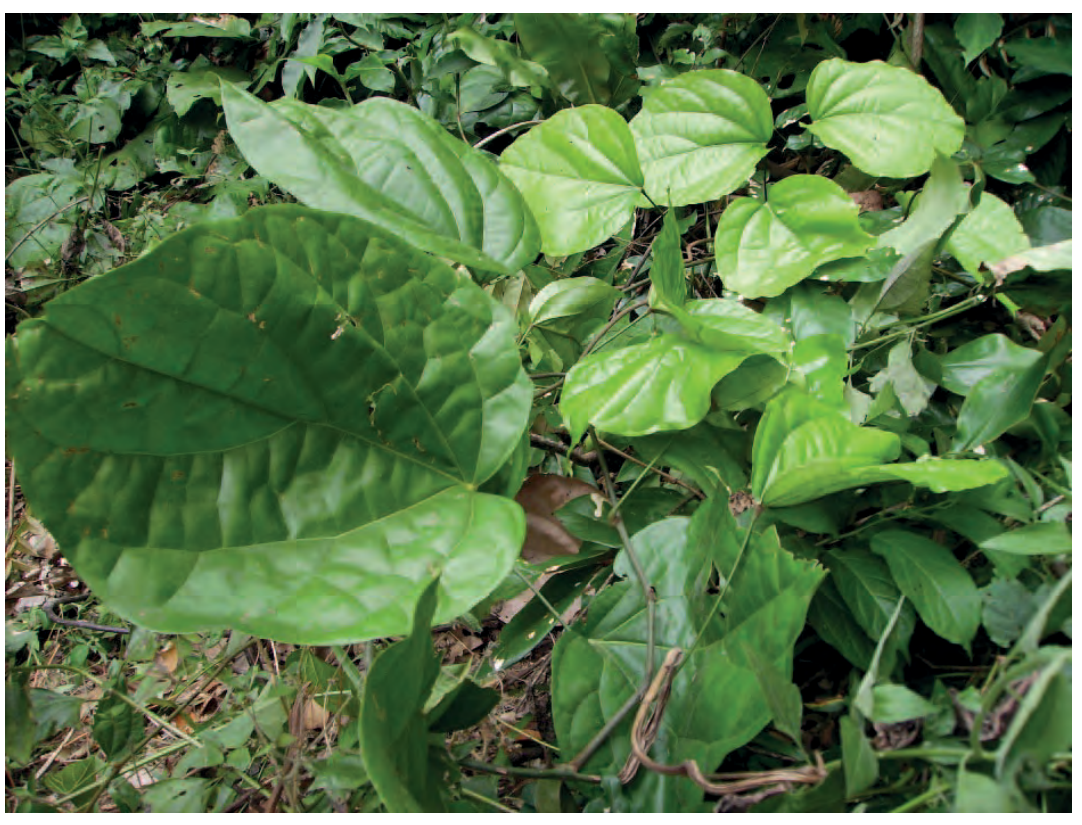

(Menispermaceae)

Synonyme $T$. gilletii

Noms courant Kinwani (Kikongo).

Description : Plante grimpante ou arbuste grimpant dont les tiges peuvent mesurer jusqu'à $30 \mathrm{~m}$ de long et $10 \mathrm{~cm}$ de diamètre. Feuilles jusqu'à $32 \mathrm{~cm}$ de long et $27 \mathrm{~cm}$ de large. Fruits c. 2,5 cm de long.

Ecologie: Présent dans les vieilles forêts du Libéria à la République centrafricaine et au sud de l'Éthiopie et au sud de l'Angola et de la R.D. Congo.

Propagation: Une espèce dioïque, des plantes mâles et femelles doivent être cultivées si des fruits et des graines sont

nécessaires.

Usages: La plante est généralement récoltée dans la nature à des fins médicinales. Dans la province de l'Équateur, les feuilles, les tiges, les racines et l'écorce de tige sont tous utilisés en médecine et sont parfois vendus sur les marchés locaux. Un extrait au méthanol de l'écorce de tige a montré une forte activité contre Plasmodium falciparum, l'une des causes du paludisme, et un effet significatif contre Trypanosoma brucei, qui cause la maladie du sommeil.

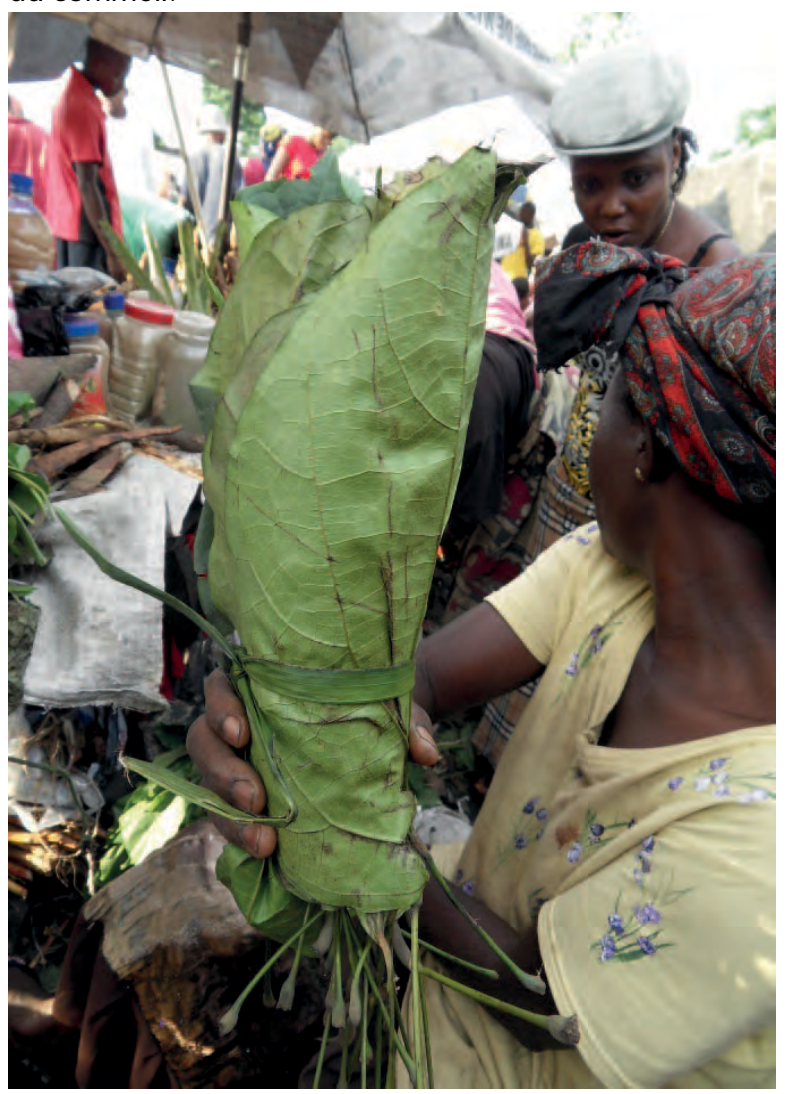

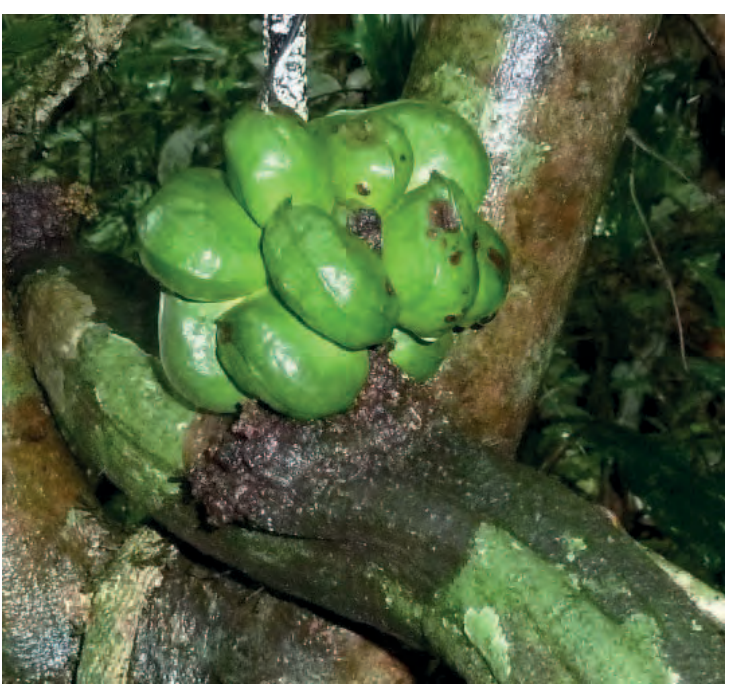

Fruits non mûrs : Carel J ongkind

Références : Renier 1948, Troupin 1951, Daeleman et Pauwels 1983, Pollard 2008, Konda Ku Mbuta et al. $2015 a$

Botte de feuilles en vente au marché de Selembao. 
Noms courants : Tridax couché, herbe caille (Fr.)

Description : Plante herbacée annuelle poilue et rampante, avec des tiges trainantes pouvant avoir $40 \mathrm{~cm}$ de haut. La tige est légèrement lignifiée, semi prostrée avec des ramifications basses sur une racine pivotante ligneuse fragile. Les feuilles sont simples, opposées, ovales ou lancéolées, de 5 à 7 sur 2 à $3 \mathrm{~cm}$, grossièrement dentées, pointues à l'apex, en coin à la base, sub-sessiles et assez rudes au toucher. L'inflorescence est terminale ou axillaire, sur un pédoncule souple pouvant avoir $20 \mathrm{~cm}$. Les fleurs périphériques sont trilobées, blanc crème, les fleurs du disque sont jaunes.

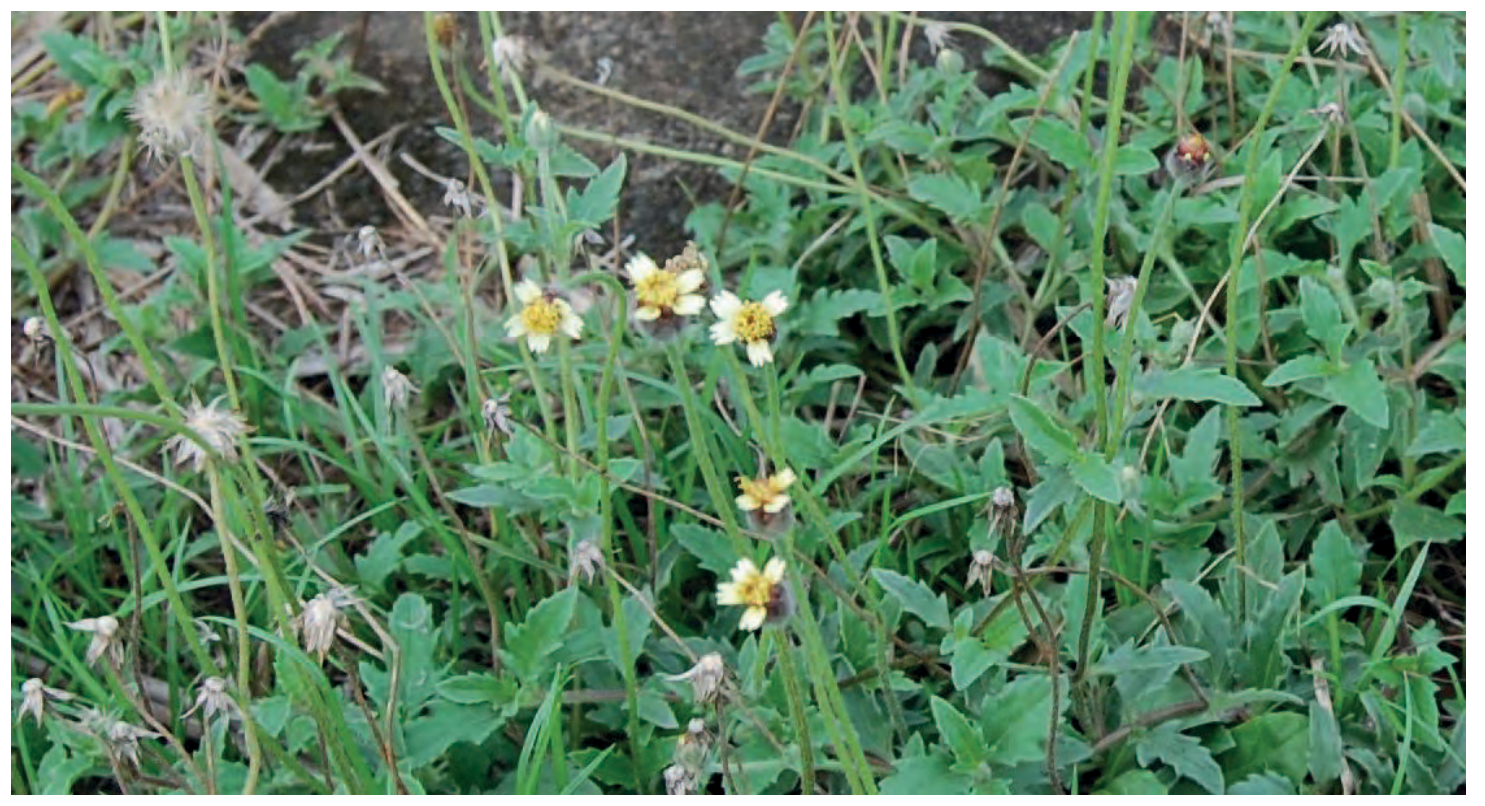

Photo: BetT Seeds

Ecologie : Plante originaire d'Amérique centrale, commune en Afrique occidentale et centrale, dans les espaces ouverts, les pelouses, les bords de route et les champs cultivés, sauf dans les zones les plus sèches. Supporte les sécheresses sévères.

Reproduction : Par graines, ou parfois à partir des racines avec les nœuds les plus bas.

Gestion : Très difficile à éradiquer.

Usages: Plante signalée comme source de nectar au Kongo Central. Les espèces de Tridax sont d'importantes sources de fourrage pour les abeilles dans les savanes africaines. La plante sert de nourriture pour les poules au Nigéria. En R.D. Congo, on emploie une décoction des feuilles contre la coqueluche.

Références: Burkill 1985, Akobundu et Agyakwa 1987, Hepburn et Radloff 1998, Konda Ku Mbuta et al. 2015a

Photo: Arjo Vanderjagt, Groningen, The Netherlands

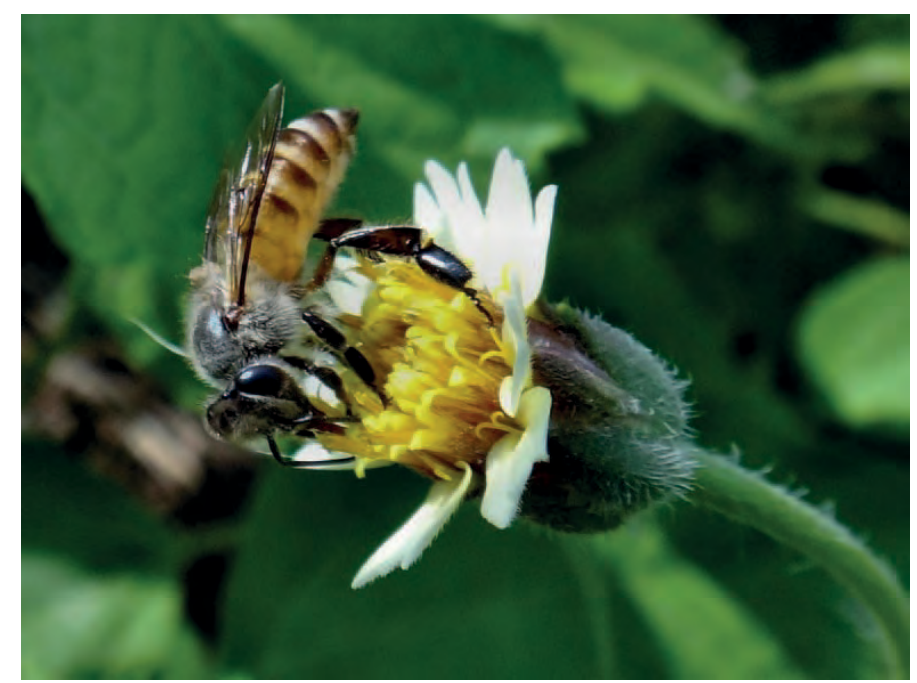




\section{Trilepisium madagascariense}

(Moraceae)

Synonyme : Bosqueia angolensis

Nom courant : Nsekeni (Kikongo)

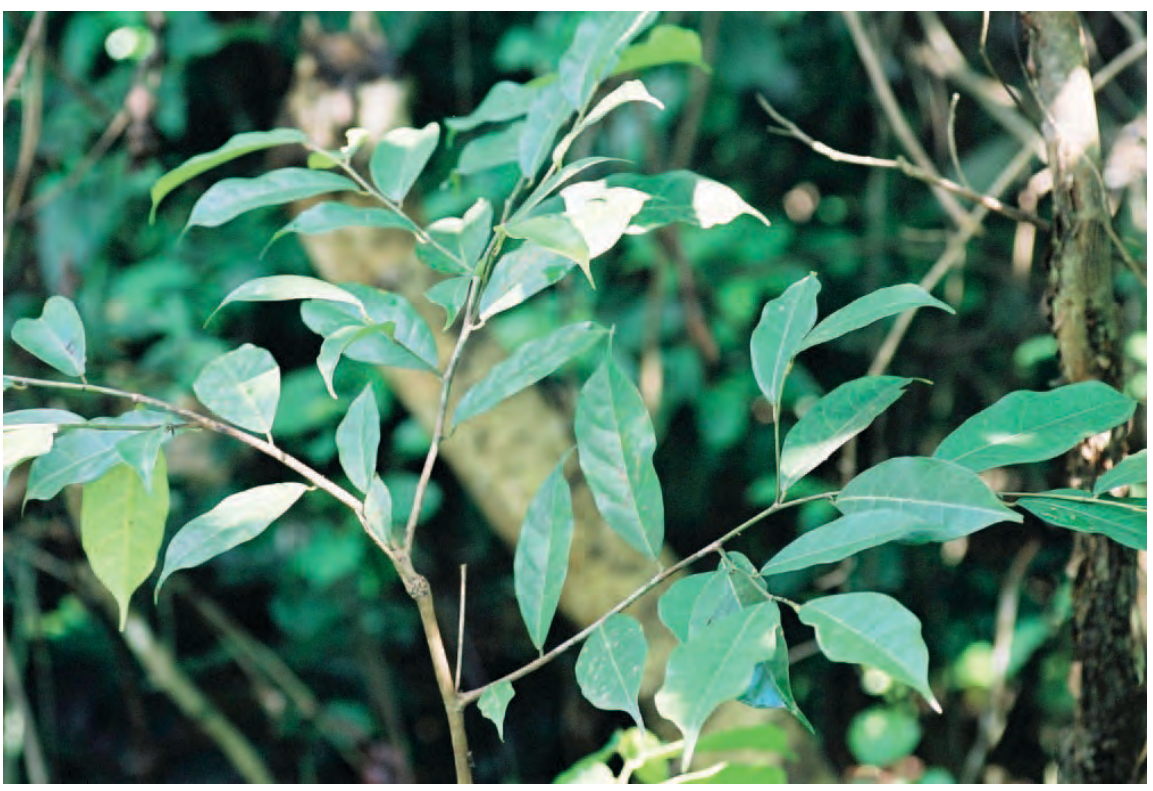

Description : Arbre pouvant avoir $35 \mathrm{~m}$ de haut, à tronc court et noueux et écorce grise lisse. Les entailles dans le tronc libèrent un latex blanc abondant, qui devient rouge à violet exposé à l'air. Les feuilles ont un pédoncule court; elles sont simples, alternes, coriaces, de couleur vert foncé brillant en dessus ; elles ont 6 à 14 sur 3 à $6 \mathrm{~cm}$, avec un bout étroit de 1 à 1,5 cm de long. Les fleurs mâles et femelles se développent dans un réceptacle en forme de cloche long d'environ $1.5 \mathrm{~cm}$, d'où pendent les étamines. long ; il devient noir pourpré à maturité. Le fruit a environ $2 \mathrm{~cm}$ de

Ecologie : Arbre des forêts primaires et secondaire, souvent près de l'eau, de la Guinée à l'Ethiopie, à l'Angola et à l'Afrique du Sud. Présent aussi à Madagascar et aux Seychelles.

Reproduction : Par graines, boutures, ou transplantation des semis spontanés.

Photo: J. Quicho Tanzania Plant Collaboration

Gestion : L'arbre supporte la taille et recèpe bien.

Usages : Les feuilles, découpées et cuites dans l'eau ou dans I'huile, se mangent comme légumes. Les fruits aussi sont comestibles; en période de famine, on mange les graines rôties (kimpundi). Le bois est blanchâtre avec des taches roses ; bien qu'il soit périssable dans le sol, on l'emploie pour la construction, la menuiserie et les manches de couteau ; on en fait des torches pour l'éclairage. Le latex brun clair est utilisé pour teindre les tissus, les paniers, et d'autres articles, et pour faire une encre indélébile. L'arbre a de nombreux usages médicinaux ; en particulier, on mâche les feuilles pour soulager les gastrites. On rapporte que les abeilles visitent les fleurs.

Références : De Wildeman 1903, Gillet et Pâque 1910, De Wildeman 1934, Hauman 1948, Renier 1948, Keay 1989, Konda Ku Mbuta et al. 1992, Peters et al. 1992, Bekele-Tesemma 1993, Pauwels 1993,

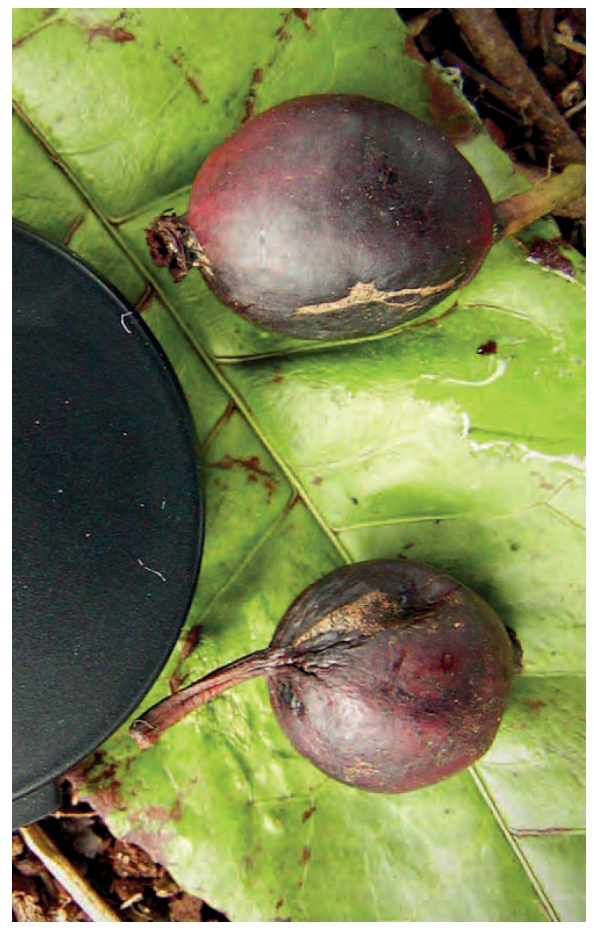
Beentje 1994, Burkill 1997, Neuwinger 2000, Nsimundele 2004 


\section{Tripsacum andersonii}

(Poaceae)

Nom courant : Guatemala grass (Angl.)

Description : Herbe pérenne en touffes à feuilles de $120 \mathrm{~cm}$, donnant rarement des fleurs.

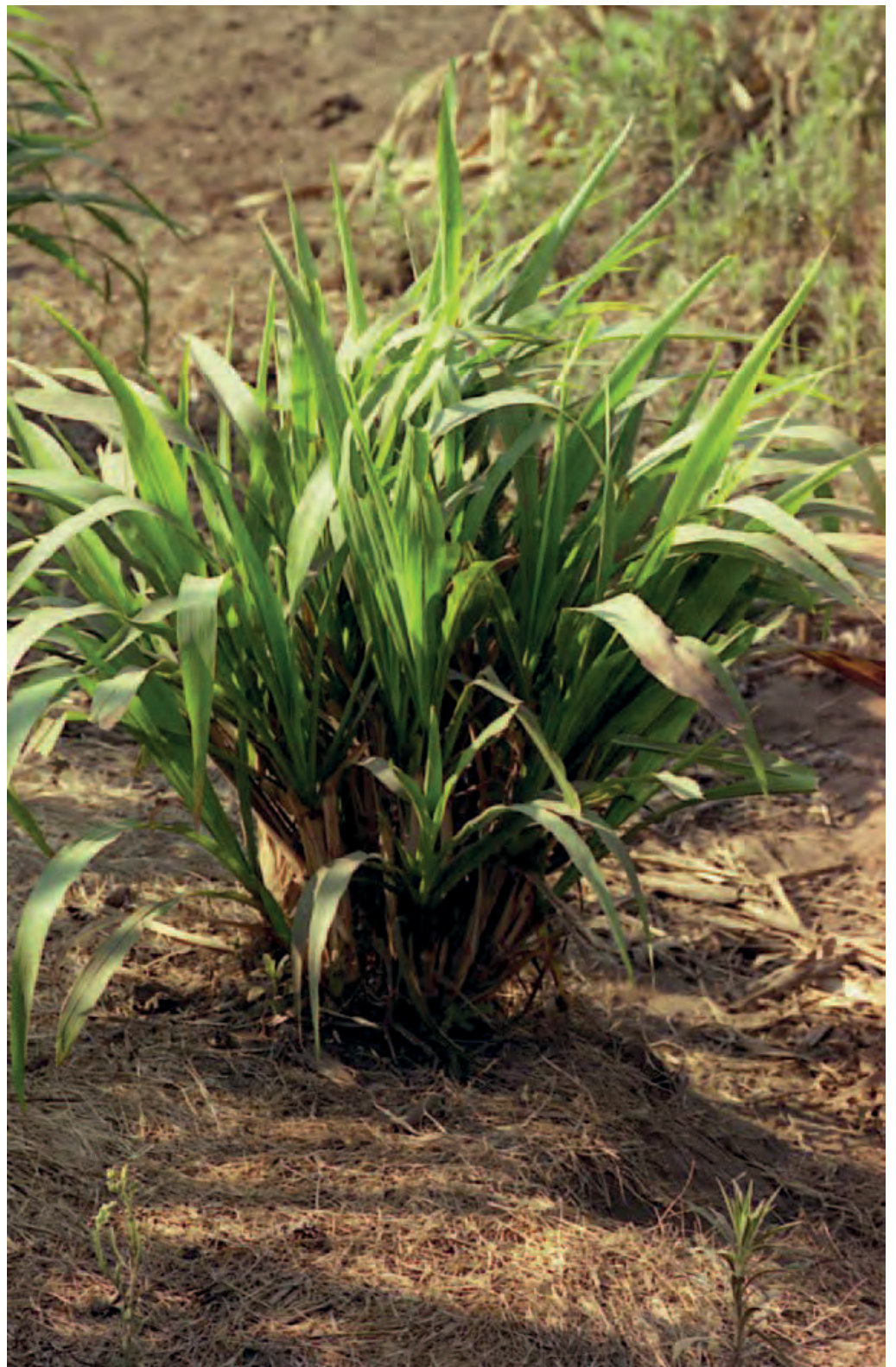

Ecologie : Probablement originaire d'Amérique Centrale, maintenant cultivée en R.D. Congo, au Ghana, en Côte d'Ivoire, au Kenya, au Rwanda et à Madagascar. Pousse vigoureusement même en altitude ou à l'ombre partielle, et sur une grande variété de sols, pourvu qu'elle ait suffisamment d'humidité.

Reproduction : Par division des touffes ou à partir du rhizome. La plante est assez lente à s'établir. La planter le long des lignes de niveau pour la conservation des sols et la production de fourrage.

Gestion : Pour le fourrage, couper à 10 à $15 \mathrm{~cm}$ quand les feuilles atteignent $100 \mathrm{~cm}$, ou toutes les six semaines.

Usages : Plante cultivée pour contrôler l'érosion et comme fourrage. On peut récolter jusqu'à 195 tonnes de fourrage frais (poids sec $40 \mathrm{t}$ ) par hectare en 13 mois. Si l'on récolte la repousse à $4,6,10$ et 12 semaines après la récolte précédente, on obtient des taux de protéines digestibles de $9.8,9.1,5.0$, et $2.2 \%$ pour nourrir le bétail.

Remarque : Cette plante est peu cultivée pour le moment, mais elle a un bon potentiel pour l'alimentation du bétail, et pour le contrôle des érosions si elle est plantée serrée le long des lignes de niveau.

Références : Bogdan 1977, Chen 1992 
Nom courant : Nsa masa (Kikongo)

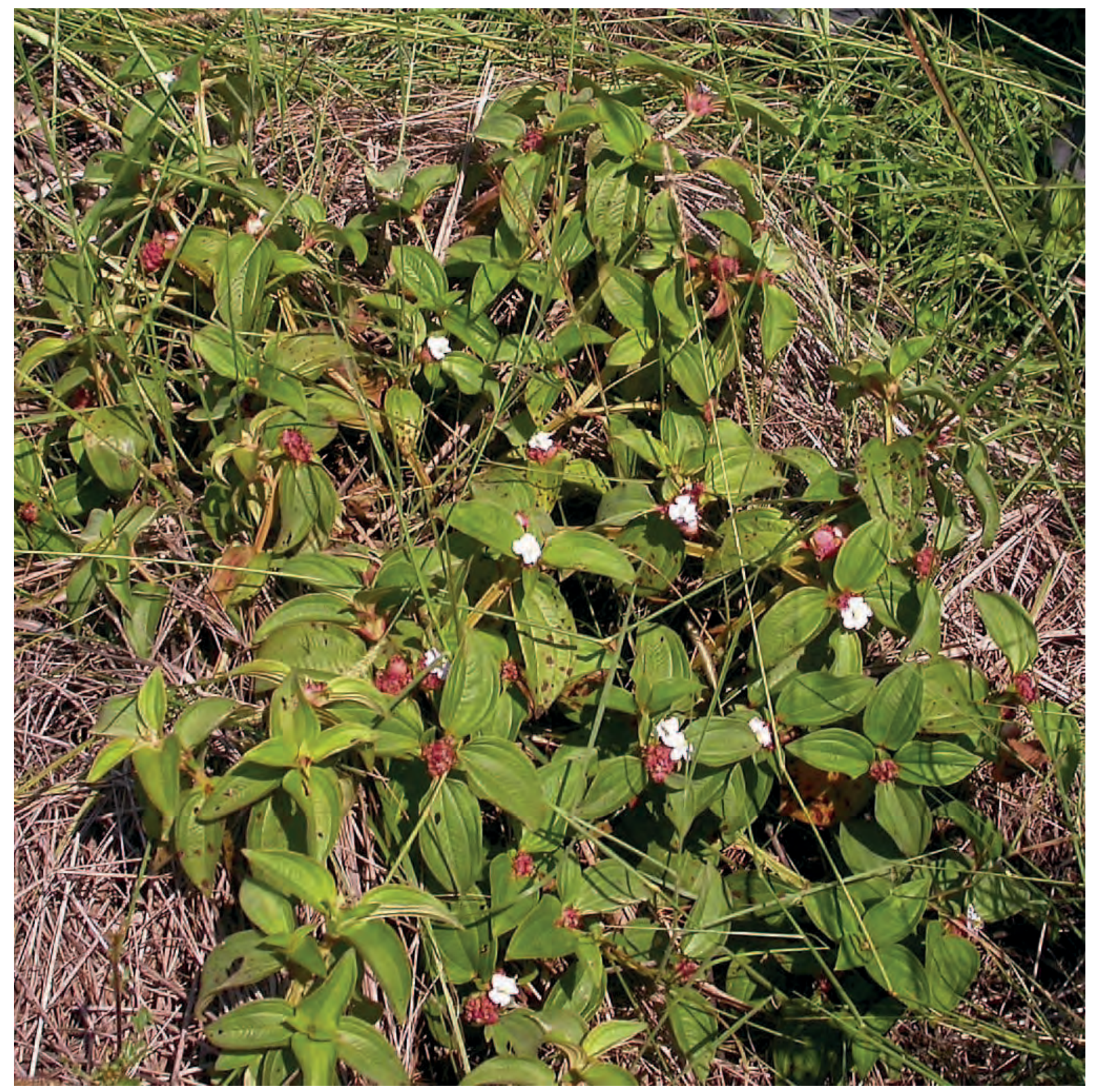

Description : Petite plante partiellement lignifiée, formant sur le sol une masse dense de tiges prostrées prenant racine aux nœuds. Tiges plus ou moins rondes. Feuilles jusqu'à 8 x $5 \mathrm{~cm}$. Fleurs habituellement blanches.

Ecologie : Cette plante se rencontre dans les clairières humides de la forêt pluviale de plaine, et le long des cours d'eau, en Ouganda, au Cameroun, en R.D. Congo et au Soudan.

Usages : Les fruits sont comestibles. Au Manianga, on mange les feuilles pour calmer les palpitations cardiaques.

Références : Renier 1948, Wickens 1975, Stevens 2011 


\section{Triumfetta cordifolia}

Noms courants : Mpunga, mpungala (Kikongo)

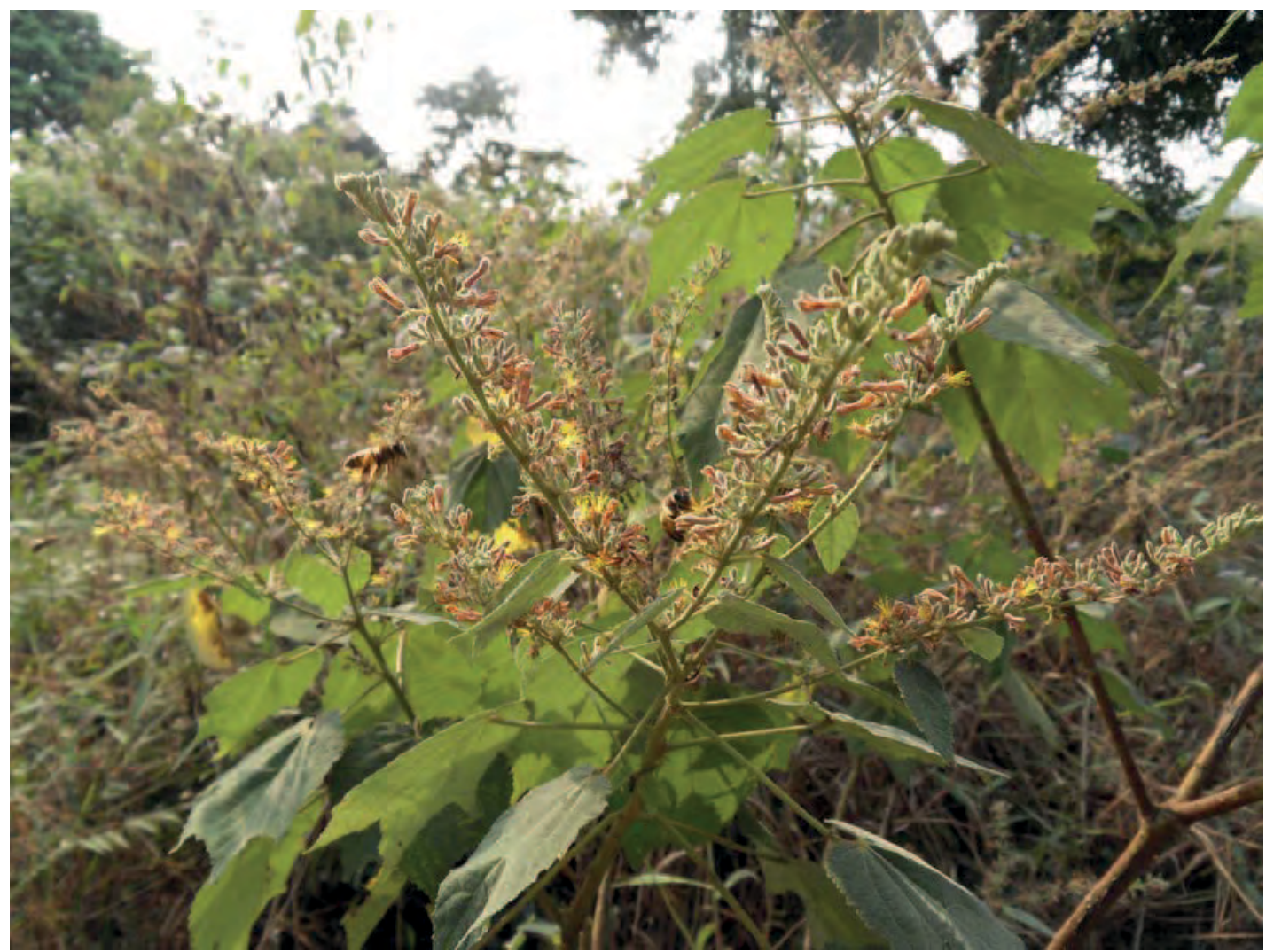

Description : Buisson semi ligneux dressé ou liane pouvant avoir $5 \mathrm{~m}$ de haut, avec des tiges poilues ou parfois lisses. Feuilles de tailles variables, jusqu'à 20 x $18 \mathrm{~cm}$. Petites fleurs, blanches à jaune orangé.

Ecologie : Adventice commune des champs cultivés et des recrus forestiers dans les zones humides, du Sénégal à l'Angola.

Reproduction : Par boutures de tiges portant des feuilles, à planter sur sol humide.

Gestion : La plante bénéficie de la culture en buttes, du paillage, et de l'ombrage. En coupant les tiges pour la récolte, on laisse un ou deux bourgeons à la base. On peut les récolter de nombreuses années de suite. On peut stocker l'écorce après l'avoir pelée sur les tiges.

\section{Triumfetta cordifolia fleurie en août}

Usages: Les fibres de la tige (lupungala, lupunga) ont donné lieu à une époque à un commerce important, en raison de leurs usages pour faire des cordes, des sacs et des emballages. Les feuilles sont comestibles. L'écorce des tiges feuillues contient des substances typiquement gluantes, que l'on extrait en ramollissant l'écorce dans l'eau chaude, puis en la pétrissant dans un peu d'eau propre. Au cours du pétrissage, les substances gluantes se dissolvent dans l'eau, et on les ajoute alors au ragoût. On rapporte que les fleurs sont un bon fourrage pour les abeilles, fournissant du nectar et du pollen de juin à août. Au Gabon, les abeilles butinent en décembre, juillet, août et

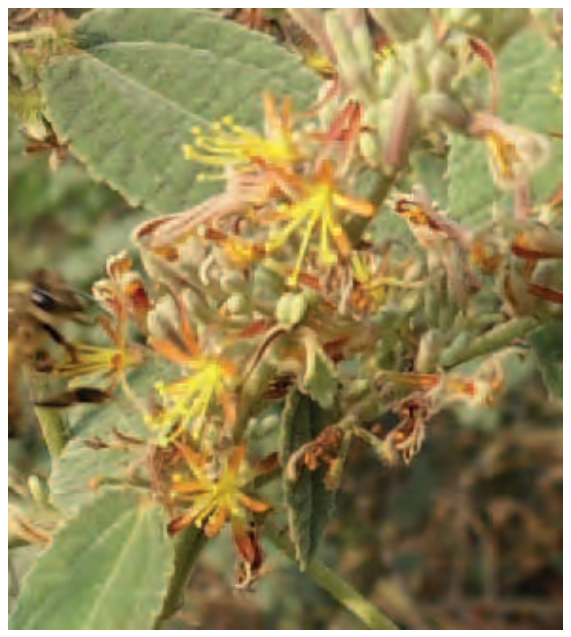
octobre.

Références : Renier 1948, Wilczek 1963, Daeleman et Pauwels 1983, Akobundu et Agyakwa 1987, Dupriez et De Leener 1989, Ambougou 1991, Peters et al. 1992, Raemaekers 2001, Grosser et al. 2018 


\section{Triumfetta rhomboidea}

Noms courants: Makambala, kukula, mpunga mpunga, kinseke, mvongala, nsolokoto (Kikongo), burweed (Angl.).

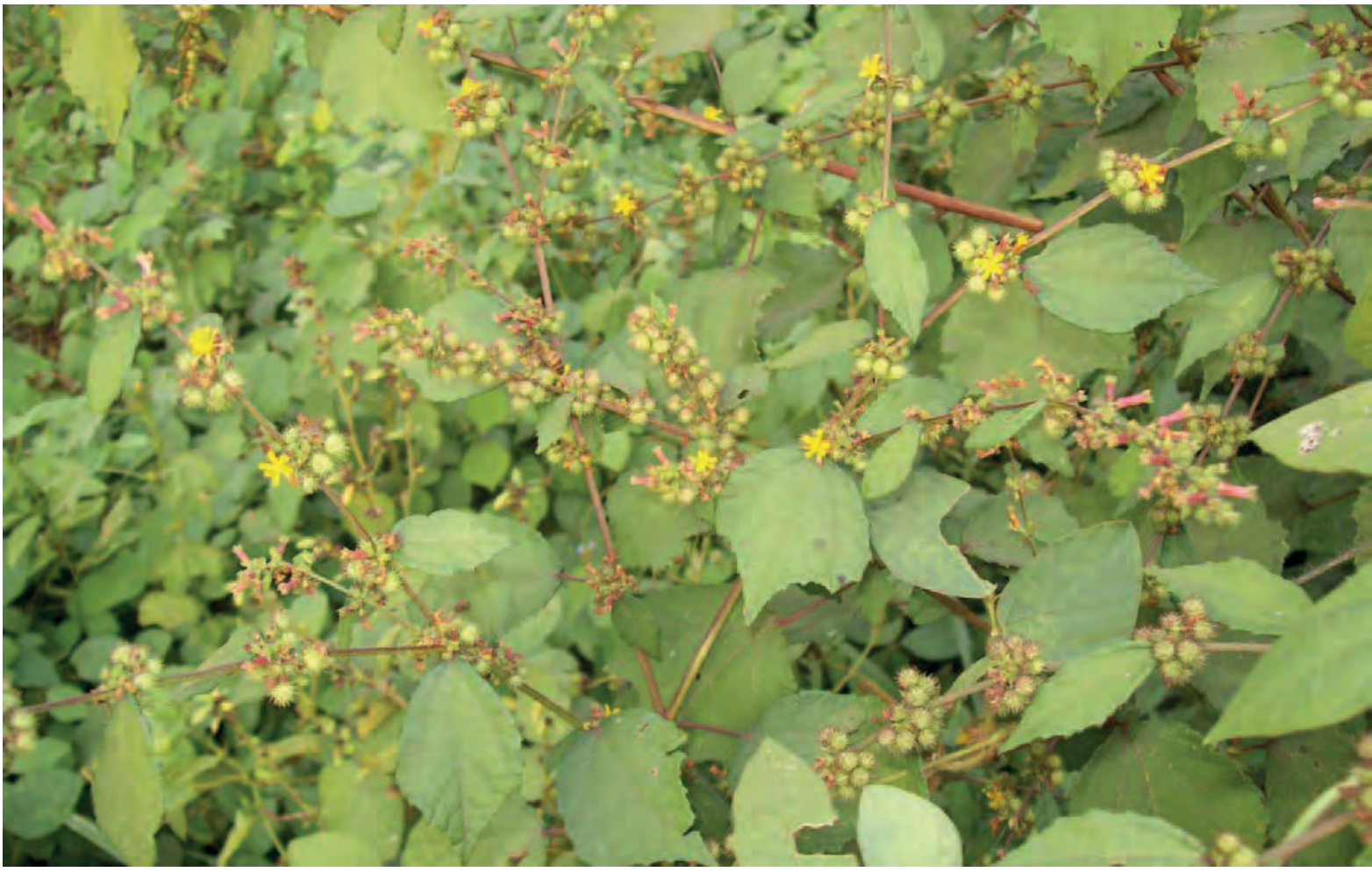

Triumfetta rhombifolia fleurie en mai

Description : Petit buisson poilu avec des tiges légères pouvant avoir 2,5 $\mathrm{m}$ de haut. Les feuilles basses ont deux lobes, et sont plus grandes que celles qui sont plus hautes sur la tige. Celles-ci sont simples et alternes. Les fleurs jaunes, de $8 \mathrm{~mm}$ de diamètre, se disposent en petits bouquets serrés. Les fruits portent des épines crochues de 1 $\mathrm{mm}$ de long.

Ecologie : Adventice commune des friches, des prairies et des champs cultivés, de 500 à $2.280 \mathrm{~m}$ d'altitude, signalée partout sous les tropiques et en Afrique du Sud.

Usages : On a observé en mai des abeilles très actives pour butiner le nectar et le pollen; mais cette plante n'est peut-être pas une source importante de miel. L'écorce de la tige est fibreuse; au Kongo Central, on l'emploie pour faire des cordes, des ficelles et des attaches; elle est potentiellement un substitut du jute. Les feuilles sont comestibles; en Afrique de I'Ouest on en met dans les soupes et dans les sauces. Au Kongo Central, on les pile dans l'eau et on obtient un lavement pour traiter la colique. Au Zimbabwe, on mange aussi les racines, pilées et cuites. En Afrique orientale, on emploie les racines pour traiter les maux de dents et la blessure de la circoncision.

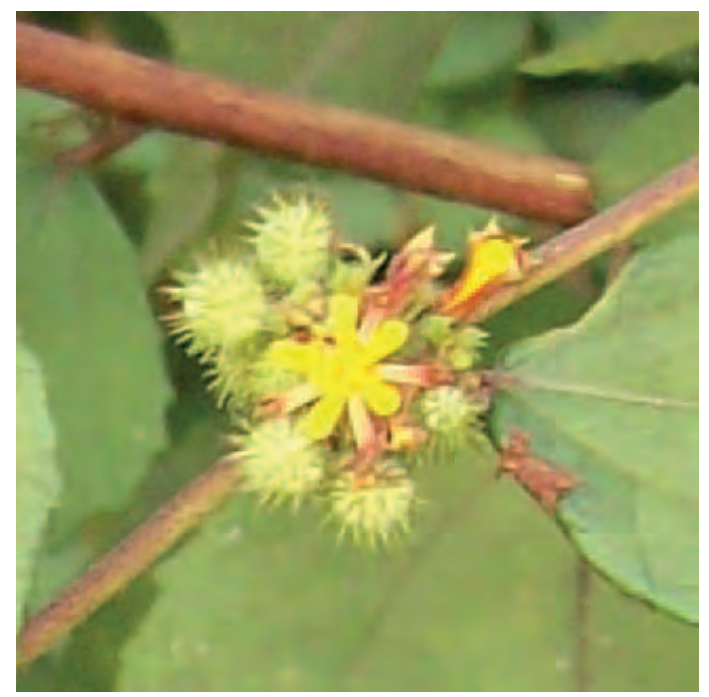

Remarque : On trouve aussi au Kongo Central une troisième espèce, T. setulosa.

Références : Gillet et Pâque 1910, Williamson 1975, Akobundu et Agyakwa 1987, Peters et al. 1992, Fichtl et Adi 1994, Burkill 2000, Nsimundele 2004, Kokwaro 2008, Communication personnelle - T. Rabenold 7.5.2020 


\section{Turraeanthus africanus}

Noms courants : Mfube (Kikongo), avodiré (Fr.), avodire (Angl.)(nom commercial)

Description : Arbre pouvant atteindre $35 \mathrm{~m}$ de haut, cannelé ou portant de courts contreforts à la base. Les feuilles ont des pétioles longs de 5 à $10 \mathrm{~cm}$, fortement épaissis à la base. Le rachis quadrangulaire, de 4 à $60 \mathrm{~cm}$ de long, porte 12 à 13 folioles alternes. Inflorescence en panicules pouvant avoir $30 \mathrm{~cm}$ de long. Fleurs de couleur blanche ou crème, avec des pétales soudés en tubes de 1,5 à $2 \mathrm{~cm}$ de long. Le fruit est une capsule en forme de poire, de $3 \mathrm{~cm}$ de diamètre, s'ouvrant en 4 valves.

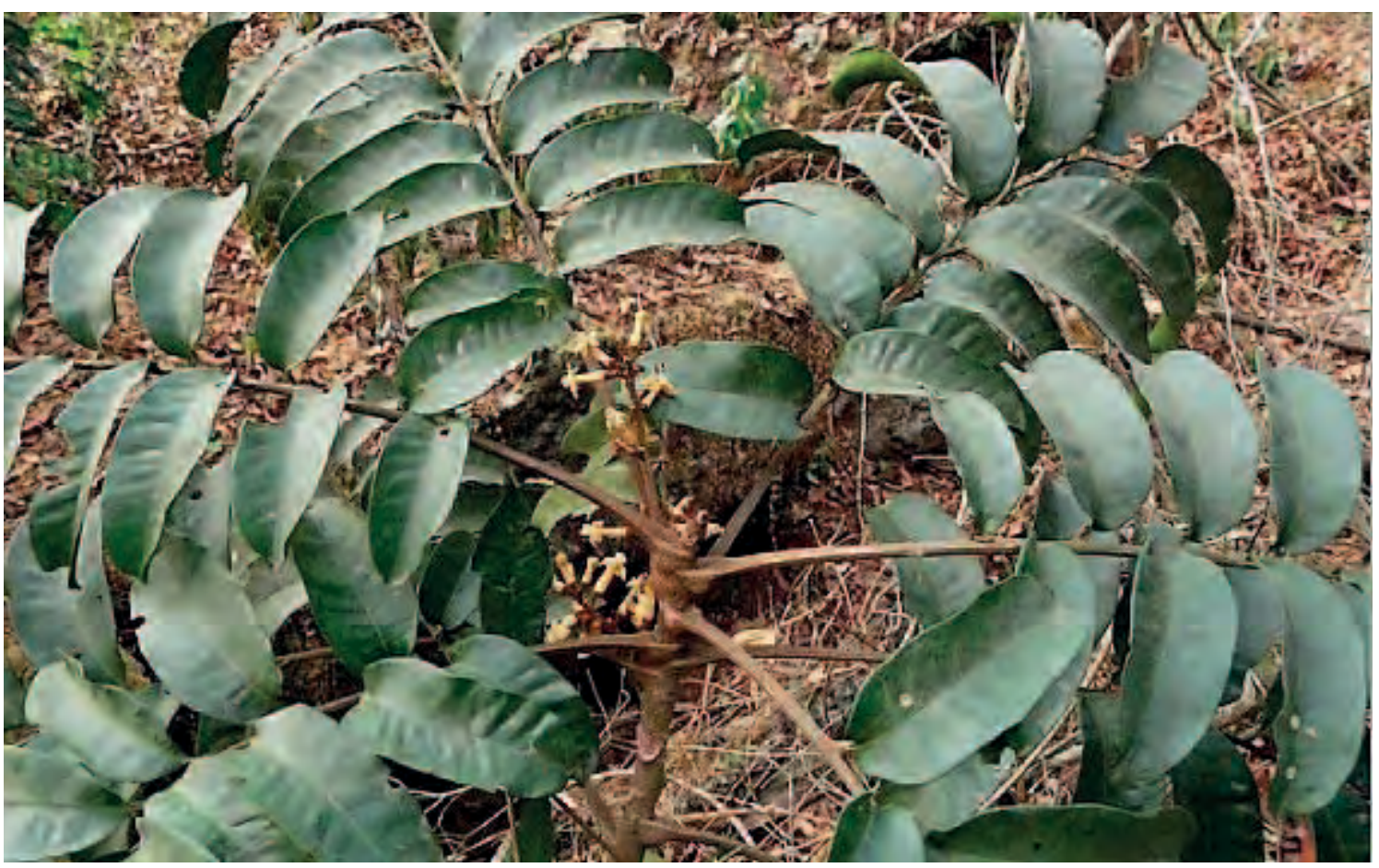

Les deux photos: Xander van der Burgt

Ecologie: Arbre des forêts de plaine, souvent près de l'eau, de la Côte d'Ivoire à l'Angola et à l'Ouganda.

Reproduction : On sème les graines immédiatement après les avoir récoltées : le taux de germination peut alors atteindre $80 \%$ en 5 à 7 semaines. Les semis requièrent un sol humide et une ombre profonde. On collecte occasionnellement au pied des arbres mères des semis spontanés pour les planter, mais il faut les conserver à l'humidité.

Usages : Le bois convient pour le mobilier, les instruments de musique et les placages, pour la construction légère, les planchers, la construction navale, les carrosseries, les jouets, les caisses, la tonnellerie, le tournage. On l'emploie comme bois de feu et pour le

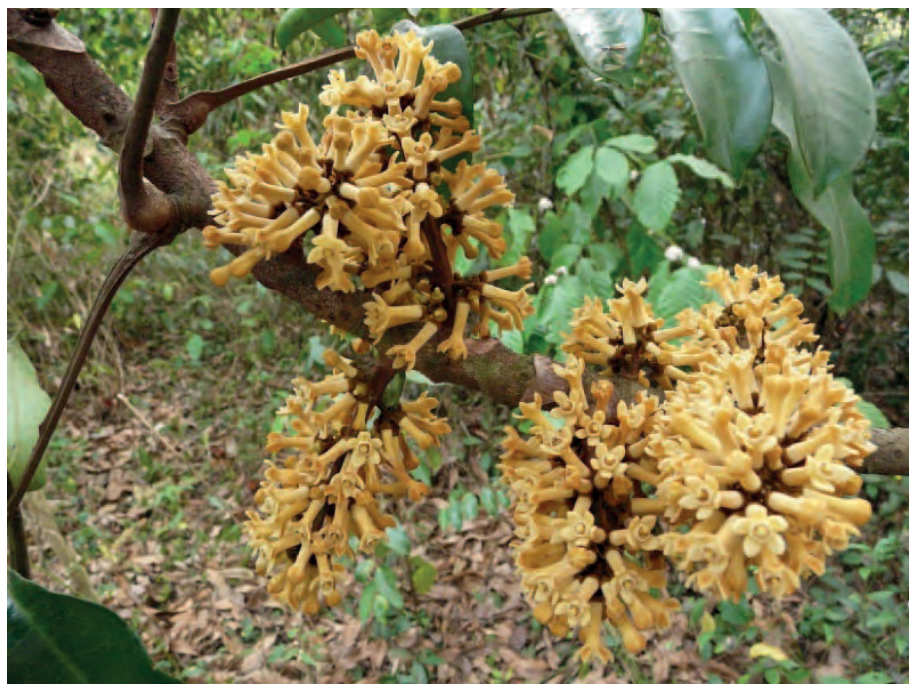
charbon de bois. L'écorce a des usages médicinaux occasionnels.

Références : Pauwels 1993, Katende et al. 1995, Burkill 1997, Neuwinger 2000, Nsimundele 2004, Hawthorne et J onkind 2006, Owusu 2008 
Noms courants : Munkomo (Kipindi), mutsiobokoko (Kimbala)

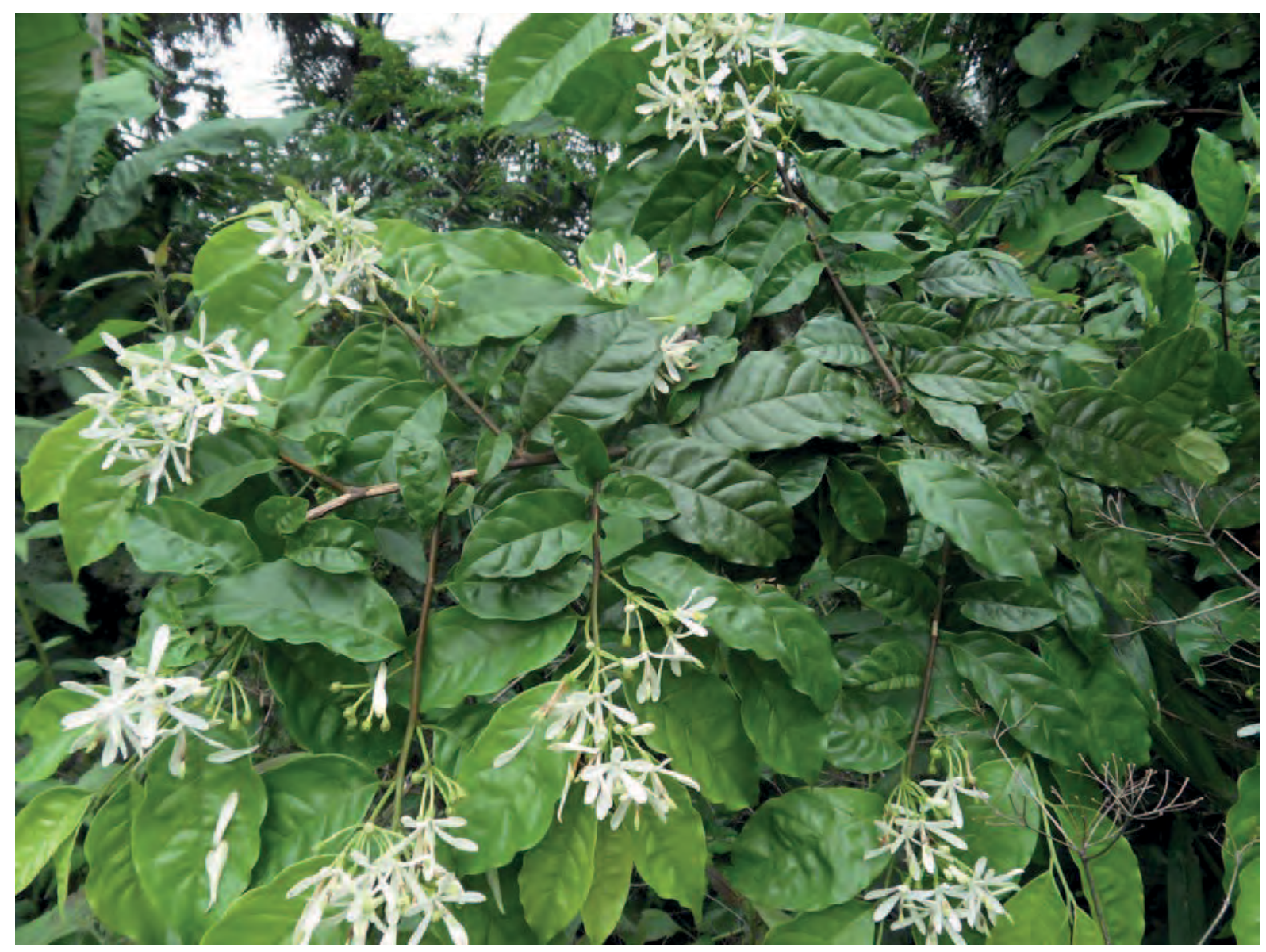

Turraea vogelii fleuri en décembre

Description : Plante grimpante, portant d'abord des poils fins, qui disparaissent ensuite. Les feuilles mesurent 7 à 16 sur 3 à $9 \mathrm{~cm}$. Le fruit est une capsule aplatie de 20 à $35 \mathrm{~mm}$ de diamètre, finement plissée, jaune vert, se divisant en 10 valves recourbées. Les graines sont noires et entourées d'un arille orange.

Ecologie : Cette plante se rencontre dans les forêts galeries, les lisières de forêts, les jachères, et les rives de cours d'eau, de la Côte d'I voire à l'Angola et à l'Ouganda.

Photo: David Harris / www.africanplants. senckenberg. de

Usages: Le fruit semblable à une vessie contient un liquide amer employé pour traiter

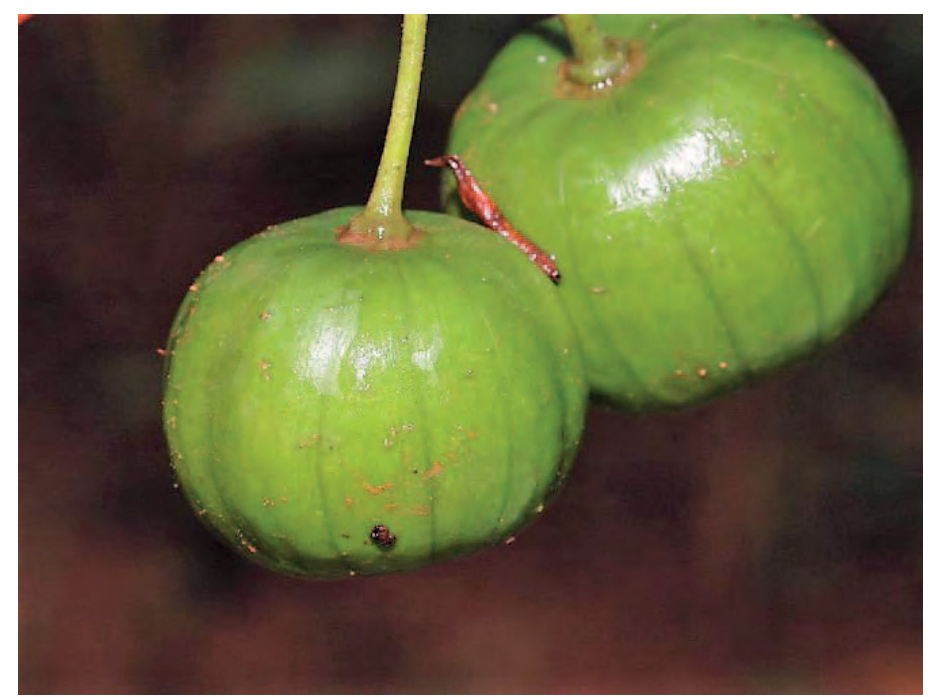
la filariose et les maux de tête. La pollinisation est peut-être assurée par les abeilles.

Références : Gillet 1927, Renier 1948, Eggeling et Dale 1951, Staner et Gilbert 1958, African Plant Database (Consulté le 6.11.2015) 


\section{Uapaca guineensis}

(Phyllanthaceae)

Noms courants : Kidianga, samfi (Kikongo), sugar plum (Angl.), rikio (commercial)

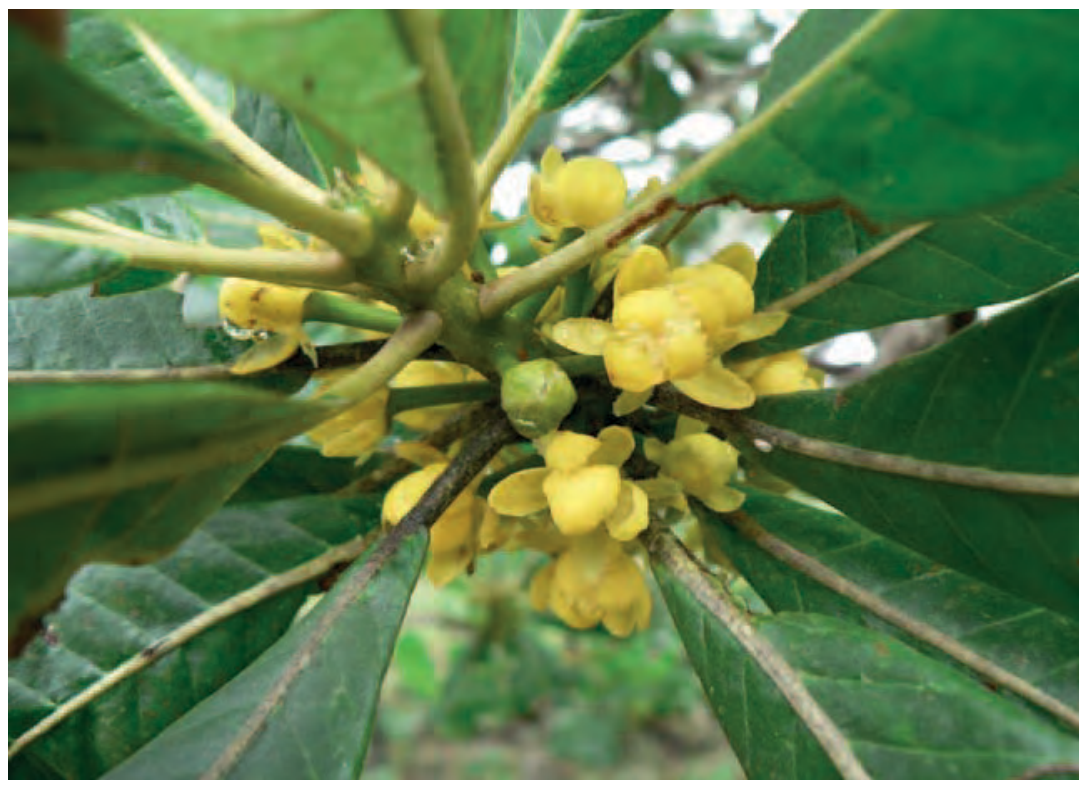

Description : Arbre sempervirent très ramifié atteignant $30 \mathrm{~m}$ de haut, s'appuyant sur des racines échasses proéminentes. II porte une couronne arrondie épaisse de feuilles de 10 à 25 sur 5 à $17 \mathrm{~cm}$, groupées au bout des branches. Les nombreuses fleurs mâles, vert jaune (voir à gauche) sont entourées de bractées jaune d'or. Les fleurs femelles sont comparables, mais disposées sur d'autres arbres et solitaires. Les fruits d'environ $2 \mathrm{~cm}$ de diamètre contiennent 2 à 4 graines.

Ecologie : Arbre présent dans les forêts, marécageuses ou de terre ferme, de la Sierra Leone à la Centrafrique et au Zimbabwe.

\section{Reproduction : Semer} seulement des graines nouvellement récoltées en pots, mais le taux de germination est souvent faible. On peut aussi faire des boutures ou transplanter les semis spontanés. II faut probablement de l'ombre aux jeunes plants.

Gestion: L'arbre peut se tailler et recèpe bien. La croissance est rapide si la plante est en terrain ouvert et sec, atteignant 5 mètres en 6 ans.

Les deux photos: G. Baumann West African Plant Database

Usages : Les fruits se mangent crus, leur goût est comparable à celui de l'avocat; au Nigéria on en fait une boisson rafraichissante. Le bois est rose, durable, facile à travailler; il convient pour la menuiserie et surtout le mobilier. On l'emploie aussi comme bois de feu et pour le charbon de bois. L'arbre est planté comme arbre d'ombrage, et pour la conservation des sols et des eaux. On le plante parfois dans les plantations de

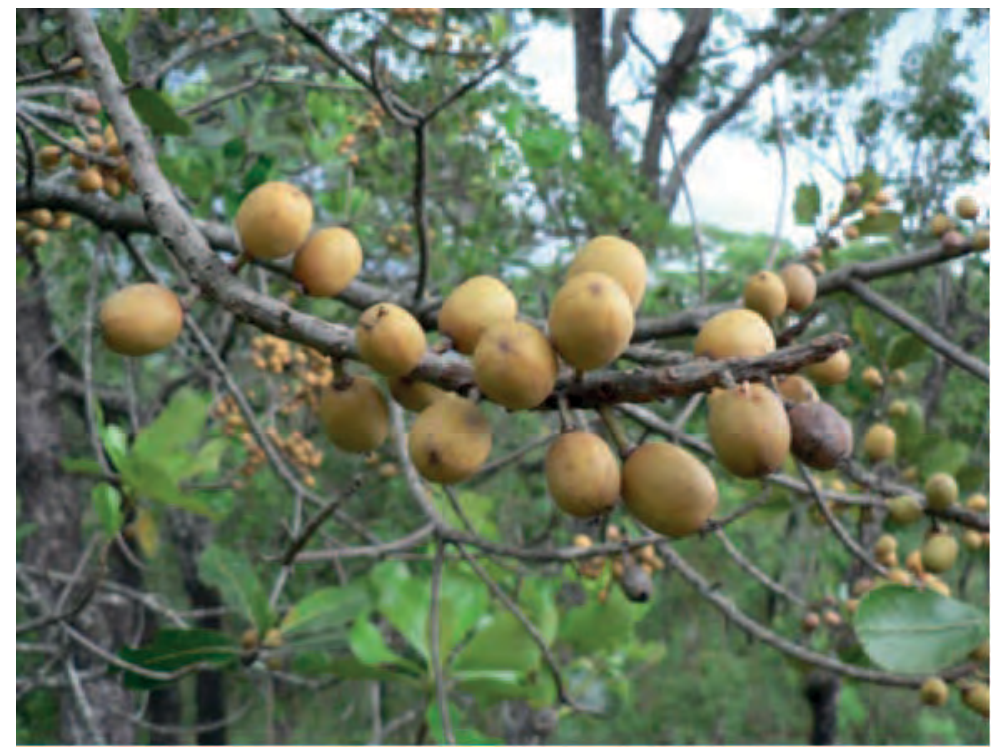
café et de cacao. Les racines s'emploient largement comme aphrodisiaque, et pour traiter l'impuissance masculine et la stérilité féminine. Les espèces d'Uapaca sont des plantes importantes pour les abeilles dans les savanes et dans les zones équatoriales d'Afrique.

Références : Renier 1948, Busson 1965, Nsimundele 1966 - 68, Pauwels 1993, Katende et al. 1995, Vivien et Faure 1996, Hepburn et Radloff 1998, Ruffo et al. 2002, Nsimundele 2004, Kitambala 2008, Harris et al. 2011 Breteler 2013, Ilunga wa Ilunga et Meerts 2020 


\section{Uncaria africana}

Noms courants : Kikoke ki masa (Kikongo), liane à hameçons (Fr.)

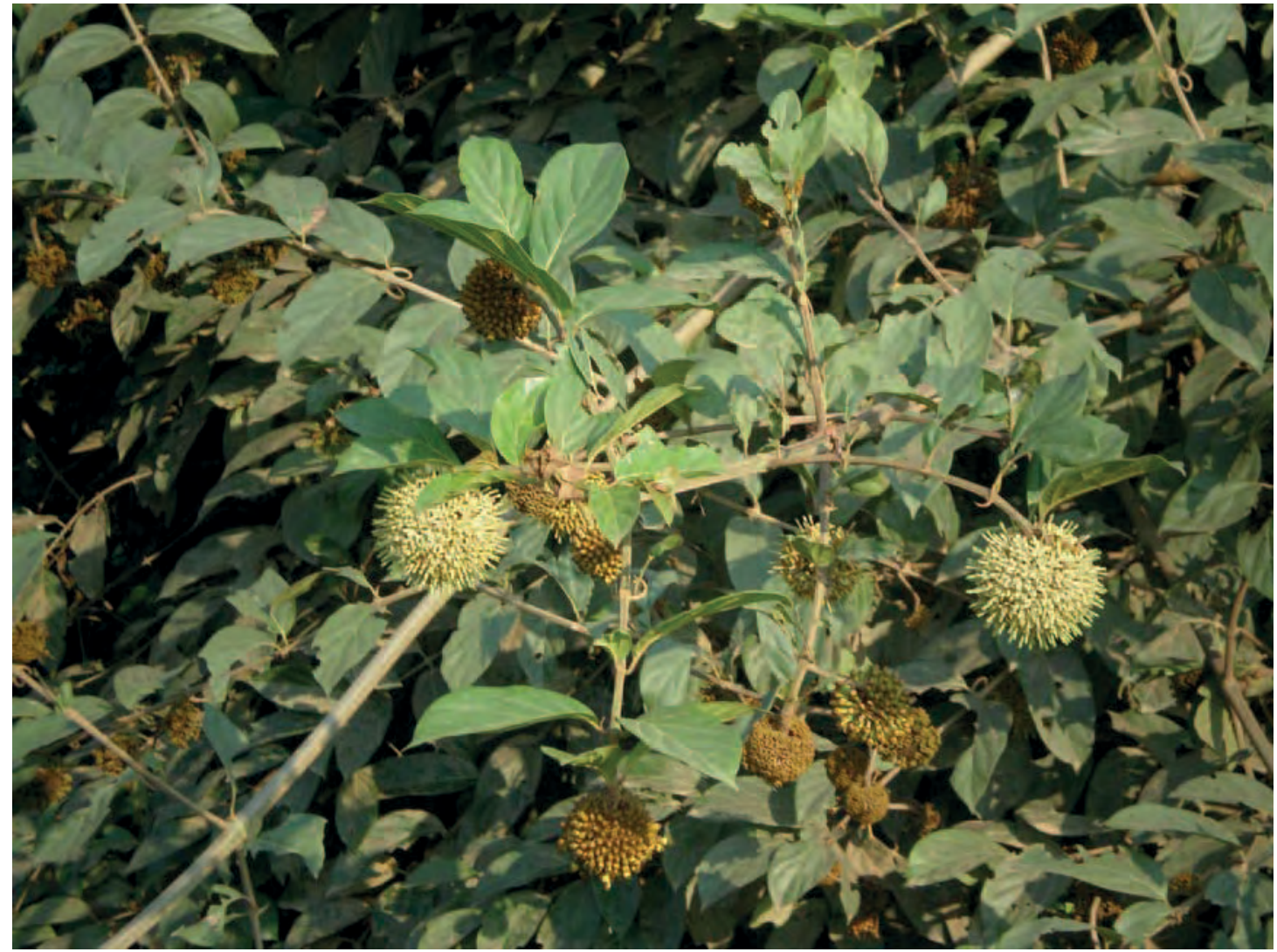

Uncaria africana en fleurs à Kilueka en octobre

Description : Liane grimpante jusqu'à $6 \mathrm{~m}$ de haut, avec de grandes épines crochues sur les tiges. Les feuilles mesurent 6 à 12 sur 2,5 à $6 \mathrm{~cm}$. Les fleurs, disposées en inflorescences terminales, sont jaune pâle et très parfumées. Elles ont $5 \mathrm{~cm}$ de diamètre, et leur taille augmente jusqu'à la maturité. Les fruits contiennent de toutes petites graines noires, dispersées par le vent.

Ecologie: Pousse près de l'eau dans les forêts secondaires, de la Guinée Bissau au Soudan, à la Tanzanie et à l'Angola.

Reproduction: $U$. gambir peut se cultiver par graines, ou mieux par boutures.

Usages: Cette plante a une variété d'usages médicinaux. Au Gabon, on boit un extrait de l'écorce contre les refroidissements. En Sierra Leone, on donne en bain de bouche contre les maux de dents une décoction concentrée des feuilles; et les feuilles contre les inflammations pulmonaires.

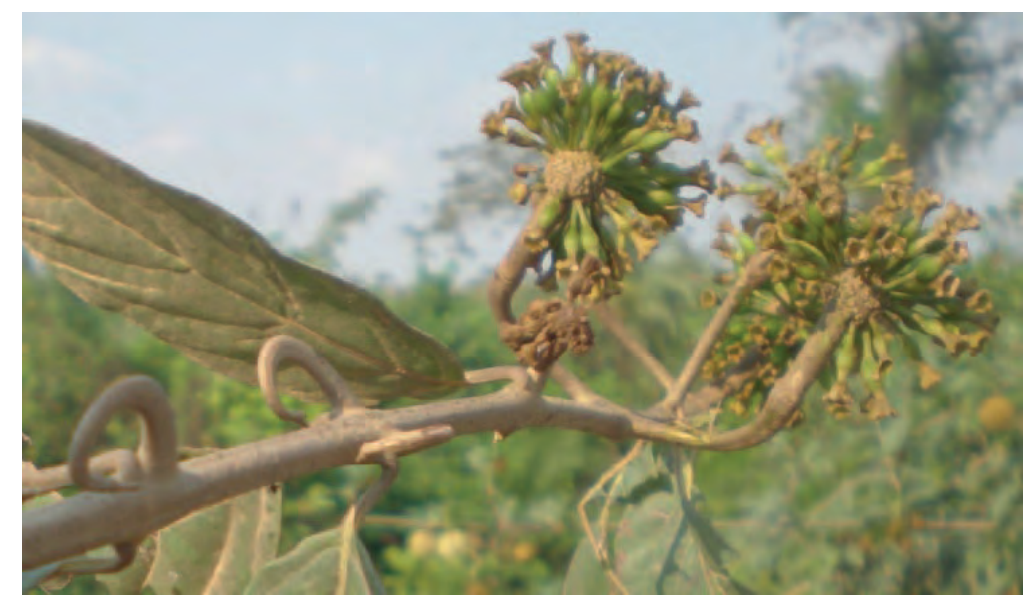

Chez les Dorobo (Kenya et Tanzanie), on donne à boire contre les désordres de l'estomac l'eau dans laquelle ont trempé les racines et l'écorce ; on boit une décoction de la racine et de l'écorce avec des os comme stimulant.

Références : Gillet et Pâque 1910, Holland 1922, Renier 1948, Irvine 1961, Hallé 1966, Daeleman et Pauwels 1983, Beentje 1994, Burkill 1997, White et Abernethy 1997, Neuwinger 2000, Kokwaro 2009 


\section{Uraria picta}

Noms courants : Nkongolo (Kikongo) (= arc en ciel), ifembe, indela (Lingala)

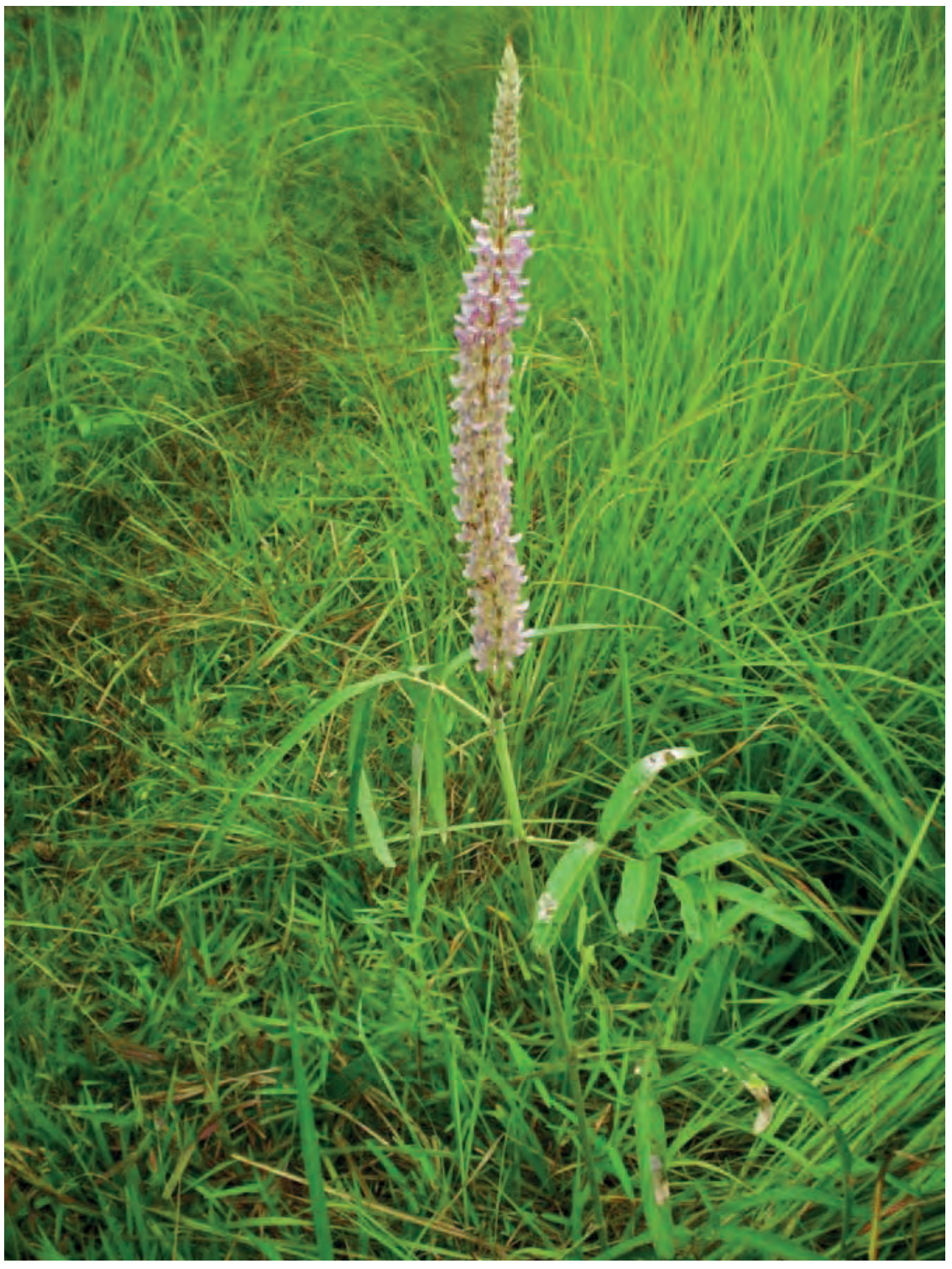

(Fabaceae)

Description: Plante herbacée non ramifiée semi ligneuse pouvant atteindre 1,5 $\mathrm{m}$ de haut. Les tiges sont couvertes de poils courts. Feuilles composées imparipennées. Les feuilles inférieures ont 2 à $8 \mathrm{~cm}$ de long et sont composées de 1 à 3 folioles ovées. Les feuilles supérieures ont 7 à $25 \mathrm{~cm}$ de long et sont composées de 5 à 9 folioles ovées-lancéolées. Inflorescence terminale en forme d'épi portant des fleurs serrées, longue de 20 à $35 \mathrm{~cm}$ et large de 2 à $3 \mathrm{~cm}$. La corolle est longue de $8-10 \mathrm{~mm}$ et de couleur rose, bleuâtre ou rougeâtre. Les fruits sont des gousses courtes composées de 4-5 articles tordus en accordéon. Les graines, brun clair, sont comprimées, oblongues ellipsoïdes.

Ecologie : Plante des savanes herbeuses, des bords de route et des lieux ouverts. Largement répandue de l'Afrique de l'Ouest au Soudan, à l'Angola, au Malawi et au Mozambique. Présente aussi en Asie et au Nord de l'Australie.

Usages : Le bétail brouterait cette plante. Les feuilles sont considérées

comme antiseptique. On emploie une préparation des feuilles pour traiter les crampes d'estomac. On cultive parfois cette plante comme plante de couverture, engrais vert ou plante d'ornement. Au Congo Brazzaville, les Bateke emploient la sève pour traiter les hémorroïdes.

Références: Gillet et Paque 1910, Renier 1948, Hauman et al. 1954, Bouquet 1969, Burkill 1995 et 2000 , Neuwinger 2000 


\section{Urena lobata}

(Malvaceae)

Noms courants: Dinkambwala, dinkambwadi, nkolokoso, mpungala fioti, (Kikongo), lotiti moindu (Lingala), Congo jute (Angl.)

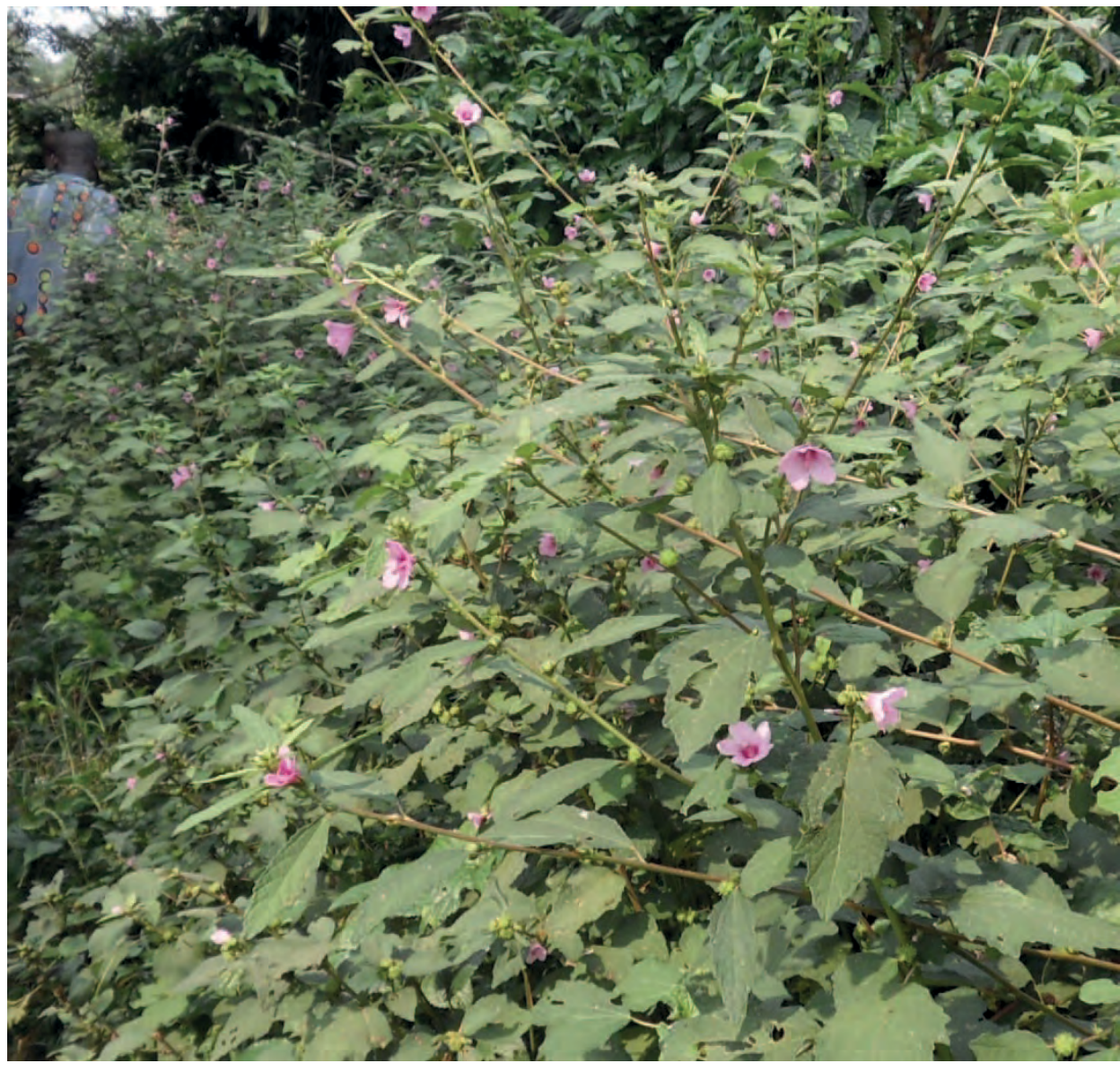

\section{Description :} Arbuste ligneux et fibreux pouvant atteindre $3 \mathrm{~m}$ de haut. Les feuilles sont très variables, même sur une même plante, et peuvent atteindre 7 $\mathrm{cm}$ de long. Fleurs axillaires situées à la partie supérieure de la tige, à 5 pétales obovales, de 1 à 2,5 $\mathrm{cm}$, roses avec un cœur violet ; étamines disposées en une colonne de 10 à $14 \mathrm{~mm}$ de long. Fruit composé de 5 parties à section triangulaire de 4 à 7 sur 3 à $4 \mathrm{~mm}$ contenant chacun une seule graine.

Ecologie : Adventice commune des champs cultivés, d'ordinaire près des villages. Pousse en plein soleil, généralement sur sol fertile et bien drainé ; présent partout en zones tropicales et subtropicales. Requiert un sol fertile.

Reproduction : A partir des graines.

Gestion : On peut couper la plante deux fois par an pour la production de fibres. ; dans ce cas, on la cultive comme plante annuelle. Elle risque d'épuiser le sol, et doit se cultiver en rotation avec d'autres cultures.

Usages : Cette plante a été largement cultivée pour la production de fibres en RD Congo dans les années 1950 à 1970, et l'est encore occasionnellement. La fibre est forte, fine, satinée. Elle a de bonnes propriétés pour la filature, et peut s'employer pour les cordages, les textiles, les tapis, les emballages, les tissus d'ameublement; mélangée avec d'autres fibres, elle convient pour les sacs d'emballage. La plante résiste aux termites et à l'eau. Différentes parties ont des usages médicinaux. Au Gabon, on

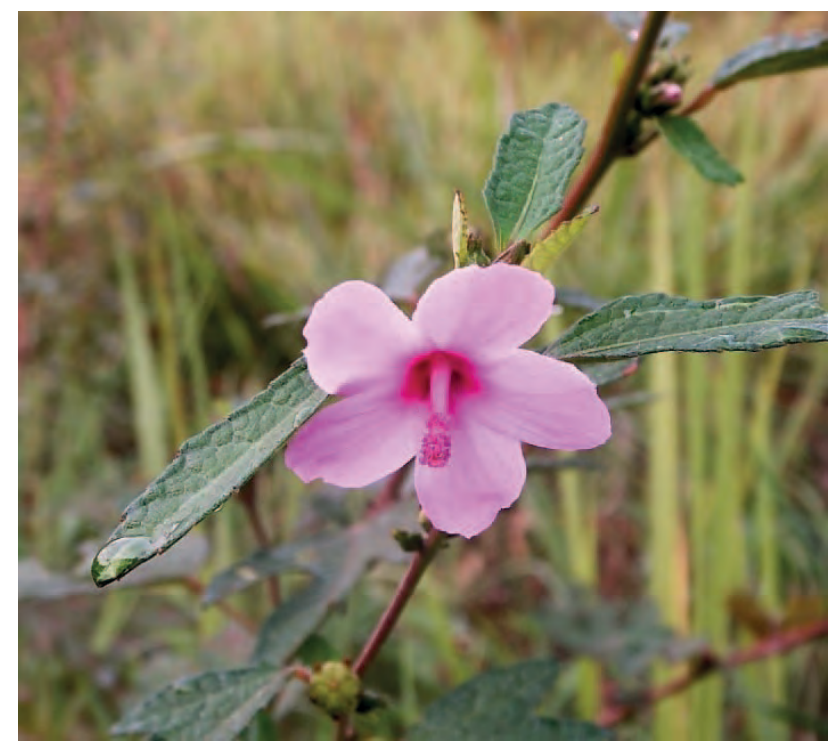
mange les jeunes feuilles. La plante peut constituer un aliment du bétail. Les fleurs sont un fourrage important pour les abeilles pendant la longue période de floraison.

Références : Gillet 1927, Renier 1948, Hauman 1963, Morton 1964, Busson 1965, Daeleman et Pauwels 1983, Akobundu et Agyakwa 1987, Ambougou 1991, Burkill 1997 


\section{Urera trinervis}

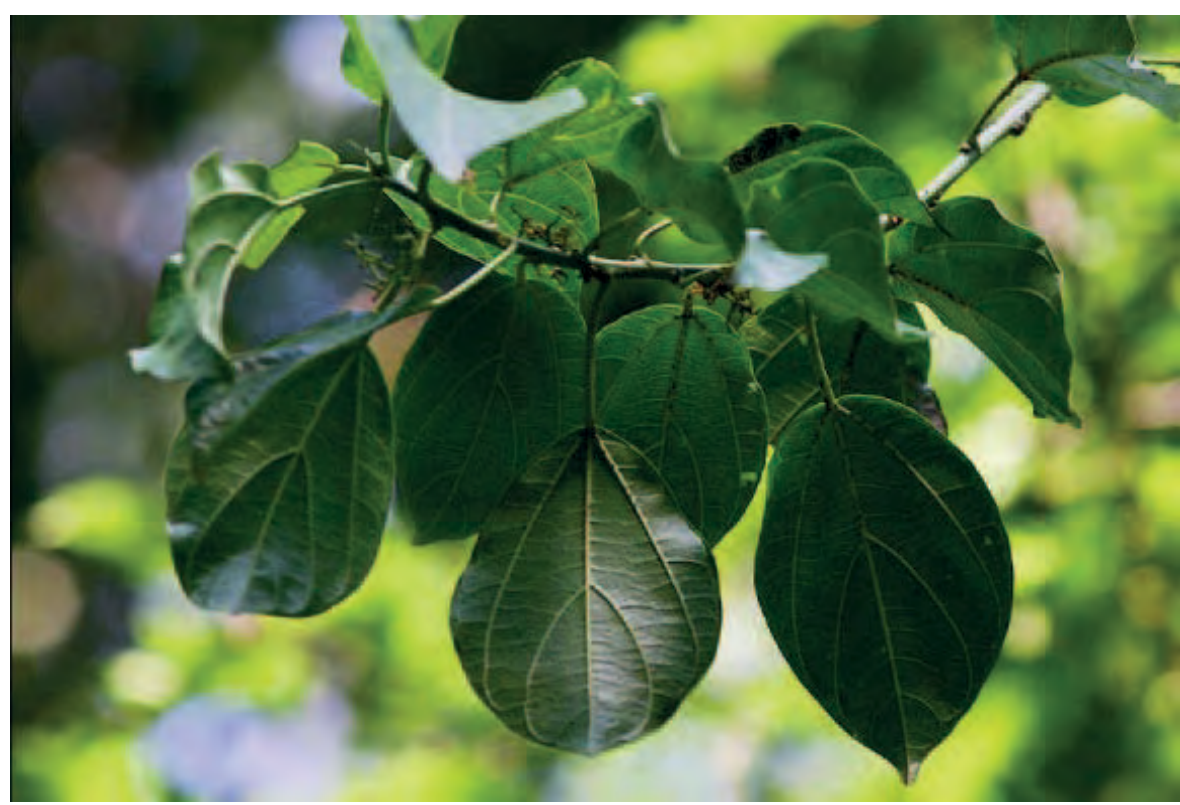

(Urticaceae)

Description : Liane semisucculente atteignant 60 $\mathrm{m}$ de long. tige atteignant $7 \mathrm{~cm}$ de diamètre, cylindrique, s'attachant grâce à ses racines adventives ; poils urticants habituellement seulement sur les inflorescences. Feuilles alternes, simples ; pétiole jusqu'à $6 \mathrm{~cm}$ de long; limbe elliptique, ovale ou obovale, atteignant $12 \mathrm{~cm}$ de long, Inflorescence: panicule axillaire lâche ; inflorescence mâle d'environ $6,5 \mathrm{~cm}$ de long, la femelle d'environ $2 \mathrm{~cm}$.

Photo: Bart Wursten

Ecologie : Lisières de forêts et clairières, parfois épiphyte. Urera trinervis est largement réparti dans les régions de forêts de basses terres d'Afrique tropicale, depuis le Ghana jusqu'au sud-ouest de l'Ethiopie et à l'Afrique du Sud (Natal).

Usages: $\quad$ Feuilles occasionnellement consommées cuites comme légume en RD Congo. La fibre de l'écorce est très recherchée pour faire des lignes de pêche et des cordages. Au Cameroun, les feuilles servent à traiter la gale. En Tanzanie, on mâche les feuilles et on avale leur jus pour traiter les problèmes biliaires. La tige coupée fournit un liquide potable, que l'on boit au Congo Brazzaville pour traiter les palpitations cardiaques. On ajoute la poudre des feuilles séchées à l'argile destinée à la fabrication des pots.

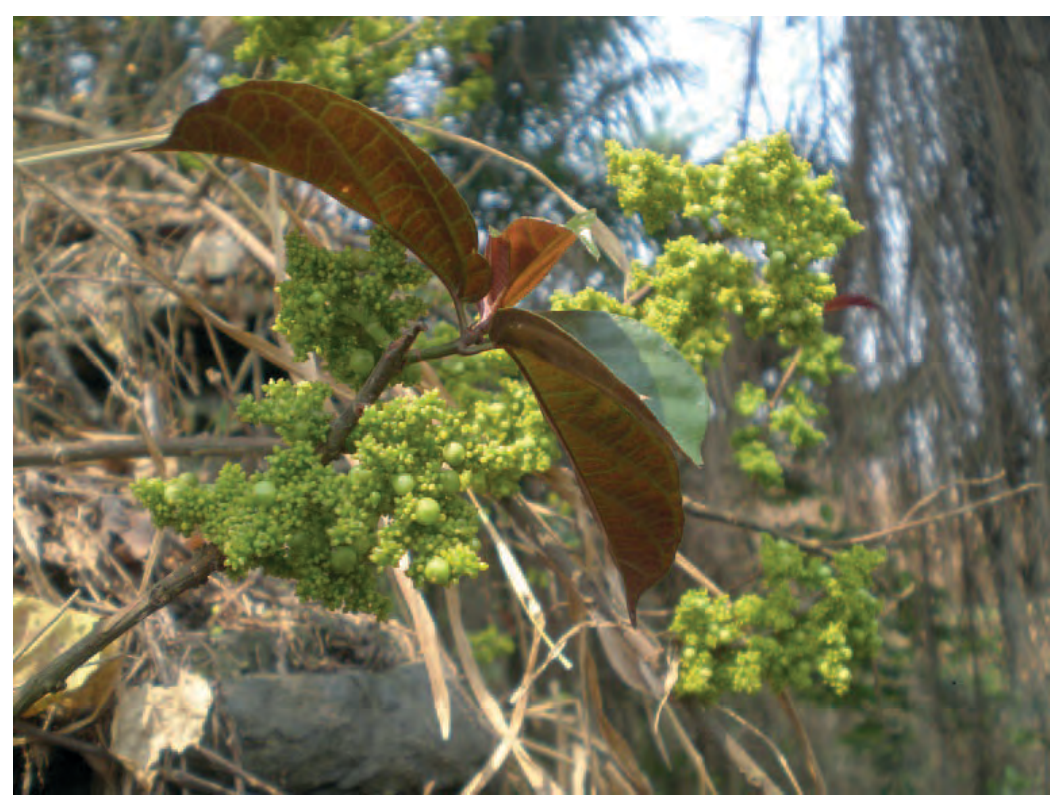

Urera flamigiana près de Kilueka

Remarque : Les feuilles d'U. flamigniana sont aussi comestibles, et la fibre des tiges de cette plante peut aussi s'employer pour les lignes et filets de pêche.

Références : Busson 1966, Burkill 2000, Bosch 2004 


\section{Usteria guineensis}

Noms courants : Impete, isake (Lingala)

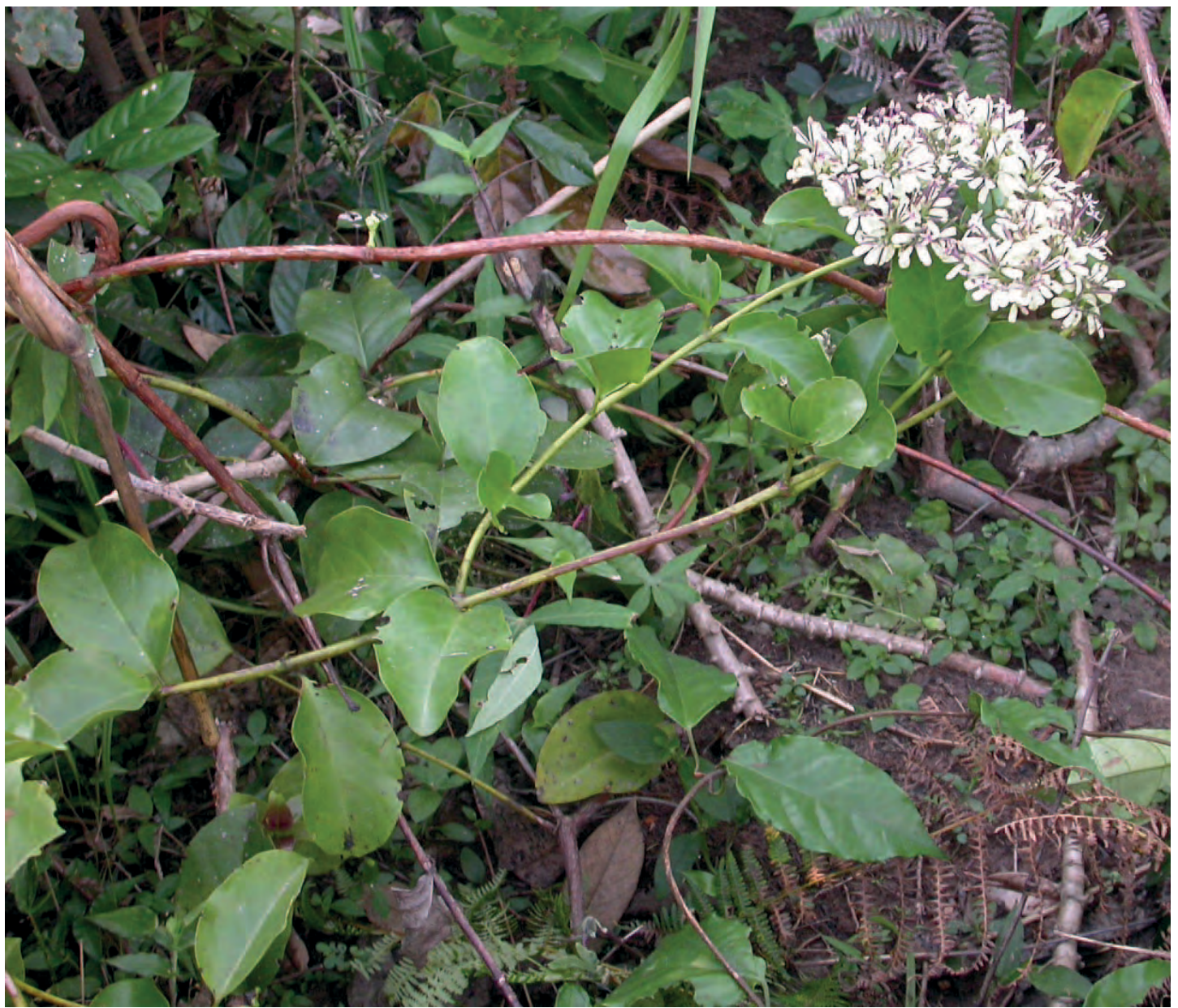

Usteria guineensis en fleurs au village de Kinsinga en janvier

Description : Liane grimpante à tiges légères pouvant atteindre $12 \mathrm{~m}$ de haut. Feuilles opposées, variables, de 2 à 14,5 sur 1,8 à $9,5 \mathrm{~cm}$, sur de courts pétioles qui sont parfois de couleur pourpre. Fleurs très parfumées, vert pâle, jaune pâle ou crème, avec parfois des taches pourpres. Les fruits sont des capsules pouvant avoir $5,8 \mathrm{~cm}$ de long.

Ecologie: Plante commune des forêts secondaires et des fourrés, dans toute l'Afrique de l'ouest et jusqu'en Angola.

Usages: Parfois cultivée comme plante ornementale. En Afrique de l'Ouest, on prend une décoction des racines ou des fruits contre la toux et les refroidissements.

Références: Renier 1948, Irvine 1961, Leeuwenberg et Bamps 1979, Pauwels 1993, Burkill 1995, Neuwinger 2000, de Ruijter 2007

Photo à droite : Adjima Thiombiano www. africanplants. senckenberg. de

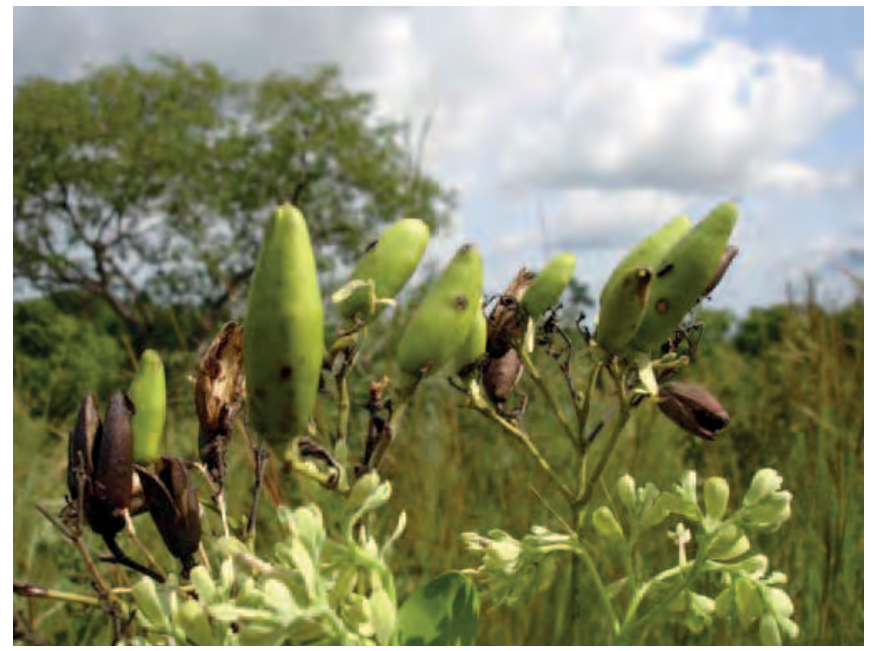




\section{Uvaria brevistipitata}

(Annonaceae)

Noms courants : Mankondo ma nsemfu (Kikongo)

Description : Arbuste. Feuilles de 5 à 17 sur 3 à $7 \mathrm{~cm}$ sur un pétiole de 5 à $7 \mathrm{~mm}$. Fleurs solitaires longues de

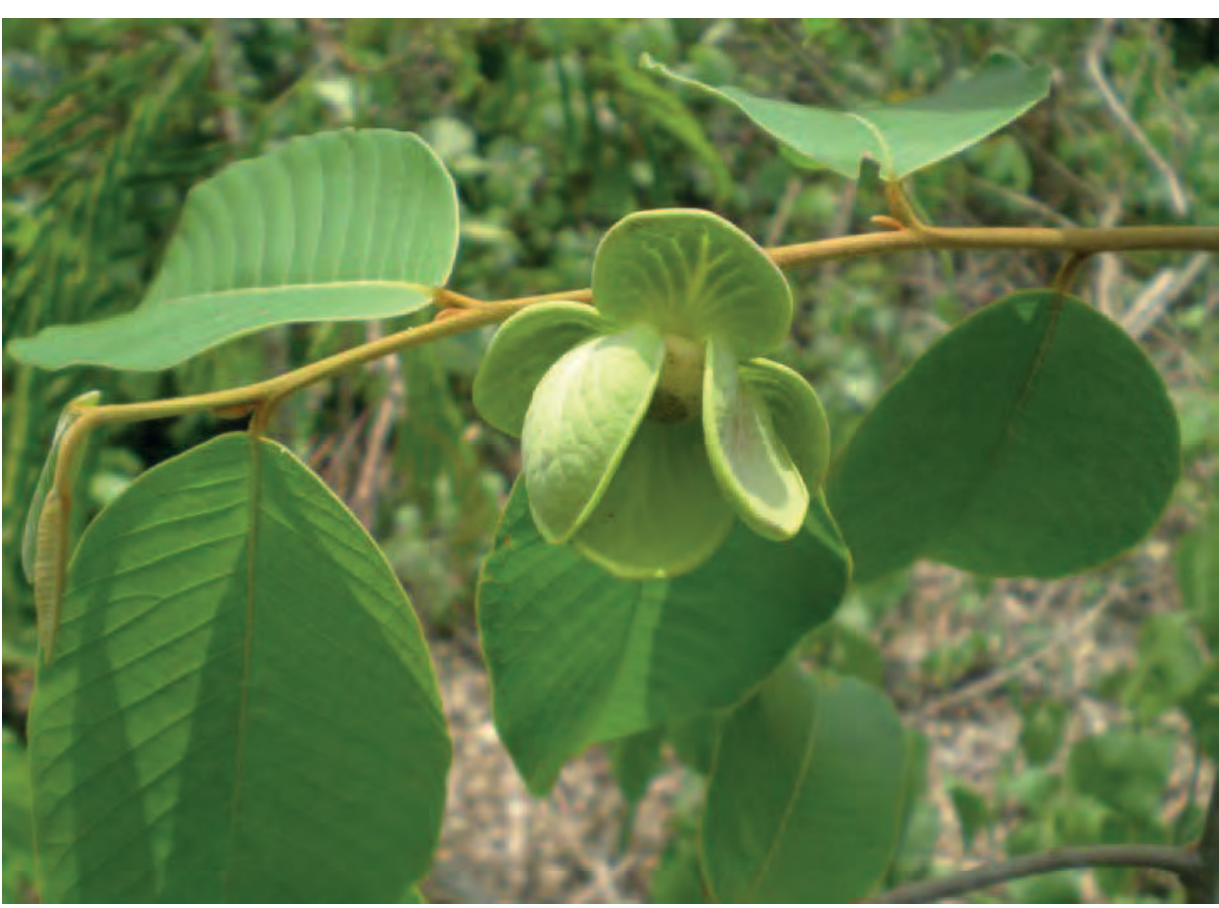

$1,5 \mathrm{~cm}$. Fruits longs de 2 à $2,2 \mathrm{~cm}$ contenant 8 à 12 graines.

Photo prise au village de Kinanga

Ecologie: Plante présente dans les clairières de la forêt associée avec des espèces de

Marantacées. On connait cette plante seulement au Kongo Central.

Usages : L'écorce permet de faire des cordes solides. On boit une décoction de l'écorce de la racine pour stimuler l'appétit. La même décoction sert à teindre les tissus. Le fruit serait

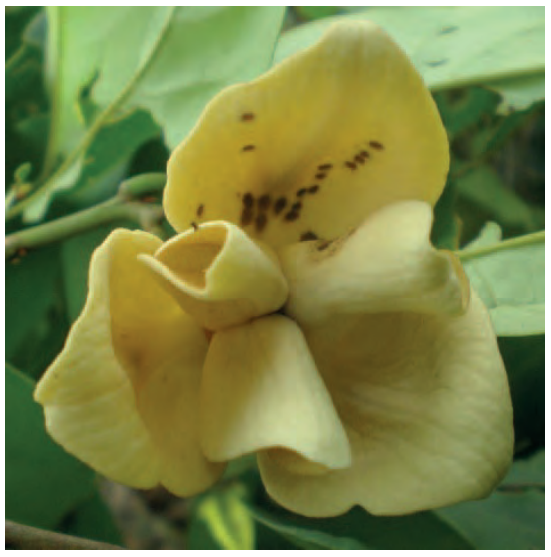
comestible. Un extrait des racines, associé à un extrait des feuilles d'Harungana madagascariensis serait efficace pour le traitement du VIH SIDA.

Références: De Wildeman 1934, Boutique 1951, Compère 1970, Lebrun et Stork 1991, Bashengezi 1997

A droite : Fruit photographié à la

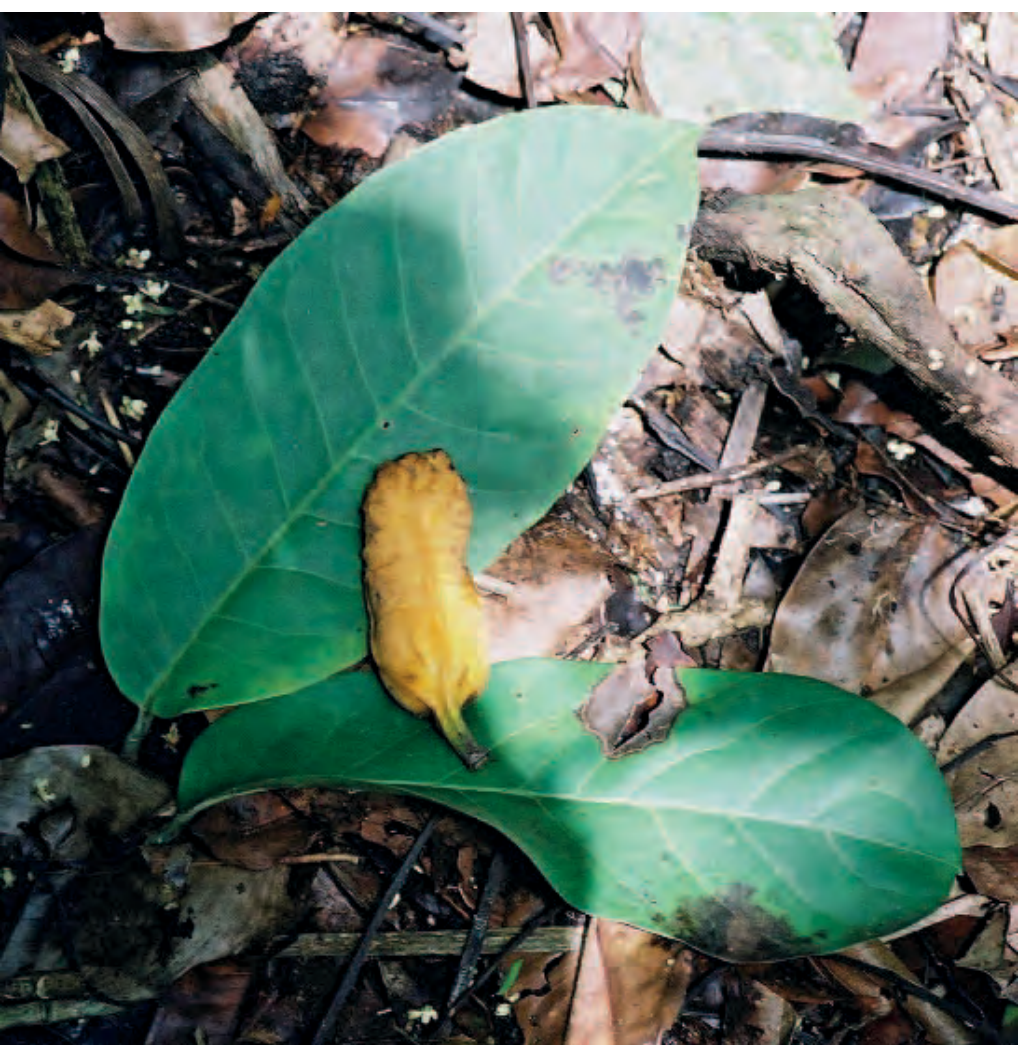




\section{Uvaria poggei}

Noms courants : Nginko-e-likebe (Turumbu)

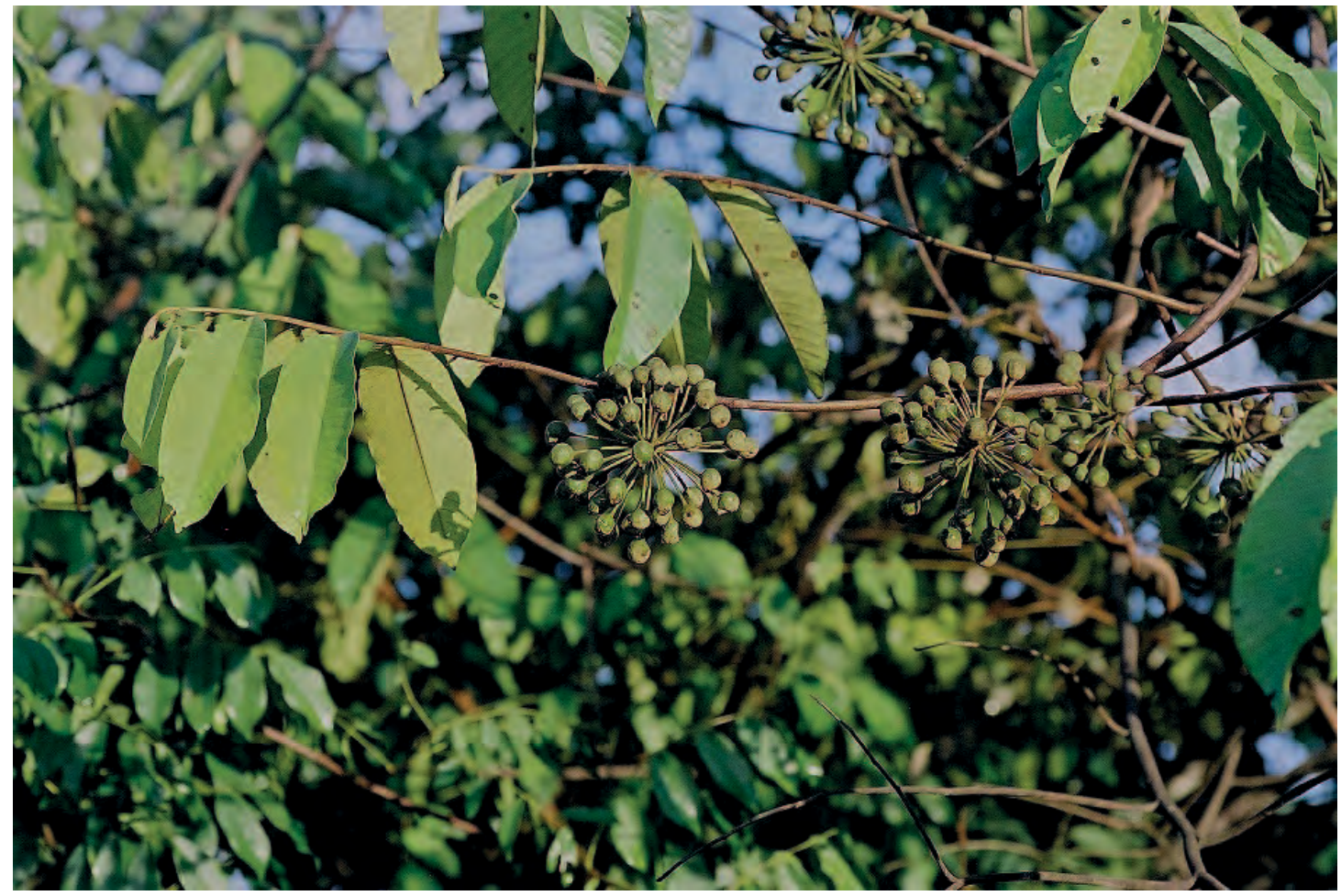

Uvaria poggei avec fruits à la lisière de la forêt, village de Kintudi.

Description : Liane très ramifiée pouvant atteindre 15 à $18 \mathrm{~m}$ de long et $10 \mathrm{~cm}$ de diamètre. Feuilles mesurant 8 à 19 sur 5 à $9 \mathrm{~cm}$. Fleurs solitaires.

Ecologie : Plante présente en RD Congo, au Congo Brazzaville et en Angola, dans les forêts pluviales, les lisières de forêts, et les anciennes terres cultivées.

Usages: Les fruits des espèces d'Uvaria contiennent une proportion de lipides excédant 20\%. Au Congo Brazzaville, on prescrit une décoction des feuilles fraiches contre la stérilité.

Références : Boutique 1951, Neuwinger 2000, African Plant Database (3.4.0) (Consulté le 4.1.2019) 
Uvaria scabrida

Nom courant : Mantusa (Kikongo)

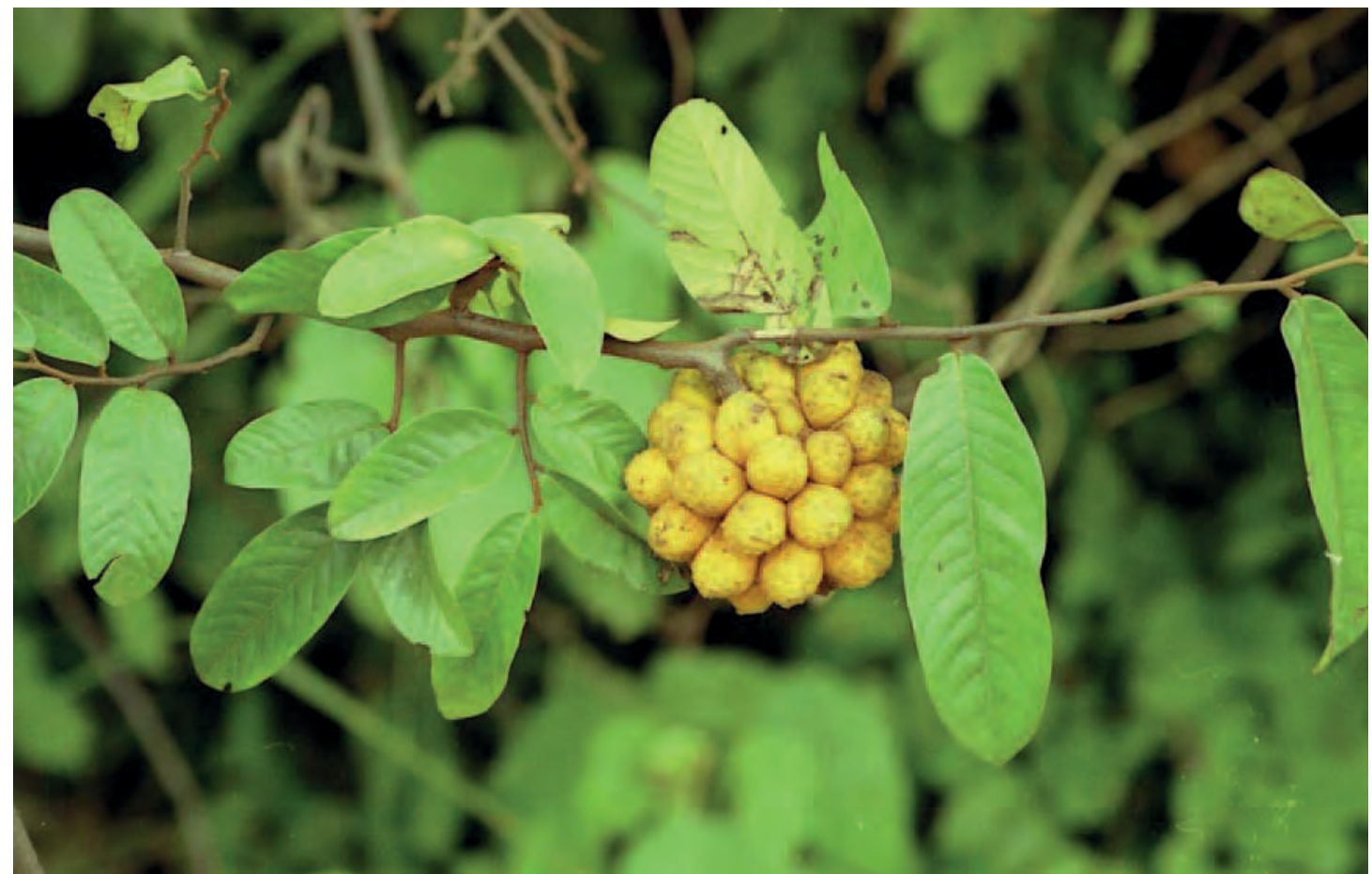

Description : Liane volubile très ramifiée pouvant atteindre $20 \mathrm{~m}$ de long et $20 \mathrm{~cm}$ de diamètre. Les feuilles mesurent 4 à 27 sur 2,2 à $9 \mathrm{~cm}$, sur des pétioles de 3 à $5 \mathrm{~mm}$. Les fleurs ont une odeur d'ananas, avec des pétales ovales vert jaunâtre de 18 à $30 \mathrm{~mm}$. Les fruits de 4 à $6 \mathrm{~cm}$ de diamètre sont composés de multiples petits fruits sphériques jaunes de 10 à $13 \mathrm{~mm}$ de diamètre.

Ecologie: Plante présente du Libéria à l'Angola, dans les forêts pluviales, les lisières de forêts, les forêts aux bords de cours d'eau, et les clairières.

Usages: La fibre de l'écorce s'emploie pour faire des filets de pêche. On prend une décoction de l'écorce des racines pour stimuler l'appétit. Le fruit serait comestible. En Côte d'Ivoire, on emploie cette plante pour le traitement de la folie.

Références : Renier 1948, Boutique 1951, Hutchinson et Dalziel 1972, Burkill 1985, Martin et al. 1987, Lebrun et Stork 2003 


\section{Vernonia amygdalina}

Noms courants : Mundudindudi, munkadinkadi, nlulu, malulu (Kikongo), nlulunlulu (Lingala), bitterleaf (Angl.).

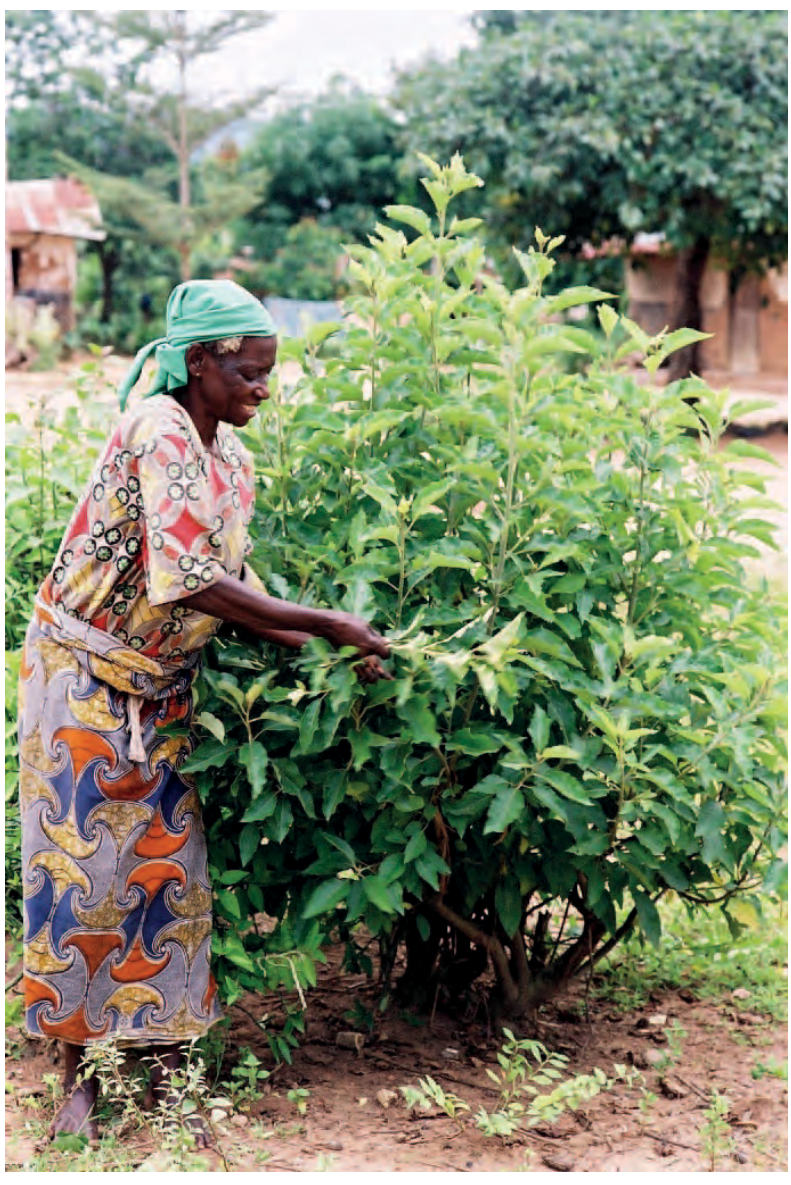

Description : Arbuste de 3 à $5 \mathrm{~m}$ de haut. Feuilles alternes, simples, pétiole de 0,2 à $4 \mathrm{~cm}$ de long, limbe ovale-elliptique à lancéolé de 4 à 15 sur 1 à $4 \mathrm{~cm}$, bords dentés. Certaines variétés cultivées ont des feuilles pubescentes qui paraissent grisâtres. L'inflorescence est composée de cymes terminales ombelliformes.

Ecologie : Plante largement distribuée et souvent cultivée en Afrique tropicale. Présente en savane et dans les marges forestières, formant souvent des fourrés. Peut pousser sur des sols pauvres.

Reproduction : Habituellement par boutures. On peut aussi utiliser les graines : récolter les inflorescences, les enfermer dans un sac en plastique et agiter pour faire sortir les graines. Semer en germoir et transplanter après quelques mois.

Gestion : La plante prend une allure qui dépend de son usage. Elle développe une allure arborescente si on coupe d'abord les branches latérales pour donner des perches, et que par la suite on taille le haut de la tige principale pour former la cime. Elle prend l'allure d'un buisson épais si l'on coupe régulièrement les tiges pour stimuler la production de feuilles.

Usages : Les feuilles se mangent comme légumes dans plusieurs pays (mais pas au Kongo Central). L'amertume des feuilles, souvent très prononcée, s'atténue en faisant bouillir les feuilles pilées, ou, avec de jeunes feuilles, en les trempant avec plusieurs changements d'eau. On peut les manger comme des épinards ou les ajouter aux soupes. Au Cameroun, la

culture de cette plante, que l'on appelle «ndole » est fréquente dans les jardins familiaux, et les feuilles constituent la base d'une préparation culinaire très appréciée, qui porte aussi le nom de ndole, avec de la pâte d'arachide, des épices et du poisson, de la viande ou des crevettes, qui conserve en partie l'amertume des feuilles. Au Kongo Central, les feuilles pilées et trempées dans l'eau s'emploient pour traiter les maladies du foie et à chasser les vers intestinaux. On applique aussi les feuilles pilées sur les infections cutanées et sur la gale. La moelle des tiges est connue comme médicament efficace contre les vers. Les pousses peuvent s'employer pour nettoyer les dents. On a observé les abeilles butinant le nectar en août. En Ethiopie, cette plante est une importante source de miel, donnant un miel brun parfumé. Le bois peut servir pour le

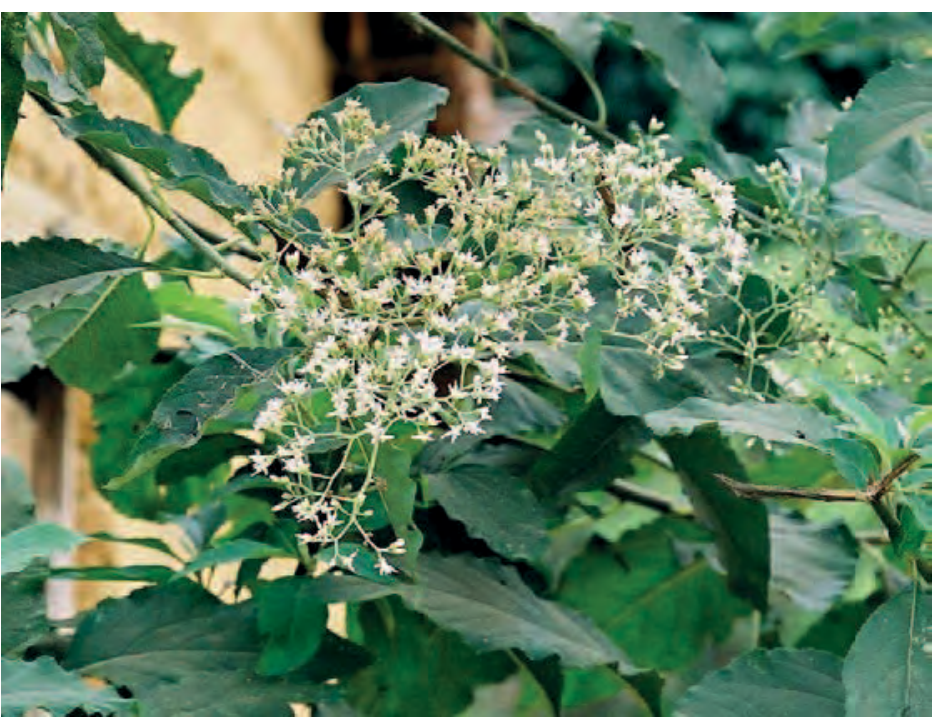
feu, il résiste aux termites.

Références : Renier 1948, Nsimundele 1966 - 68, Daeleman et Pauwels 1983, Burkill 1985, Dupriez et De Leener 1989, Mukoko Matondo 1991, Pauwels 1993, Fichtl et Adi 1994, Kalanda et Lisowski 1995, Martin et al. 1998, Maundu et al. 1999, Neuwinger 2000, Schippers 2002, Kibungu Kembelo 2003, Pousset 2004, Meunier et al. 2010, SEPASAL (Consulté le 7.12.2013), Latham et Konda Ku Mbuta 2017 


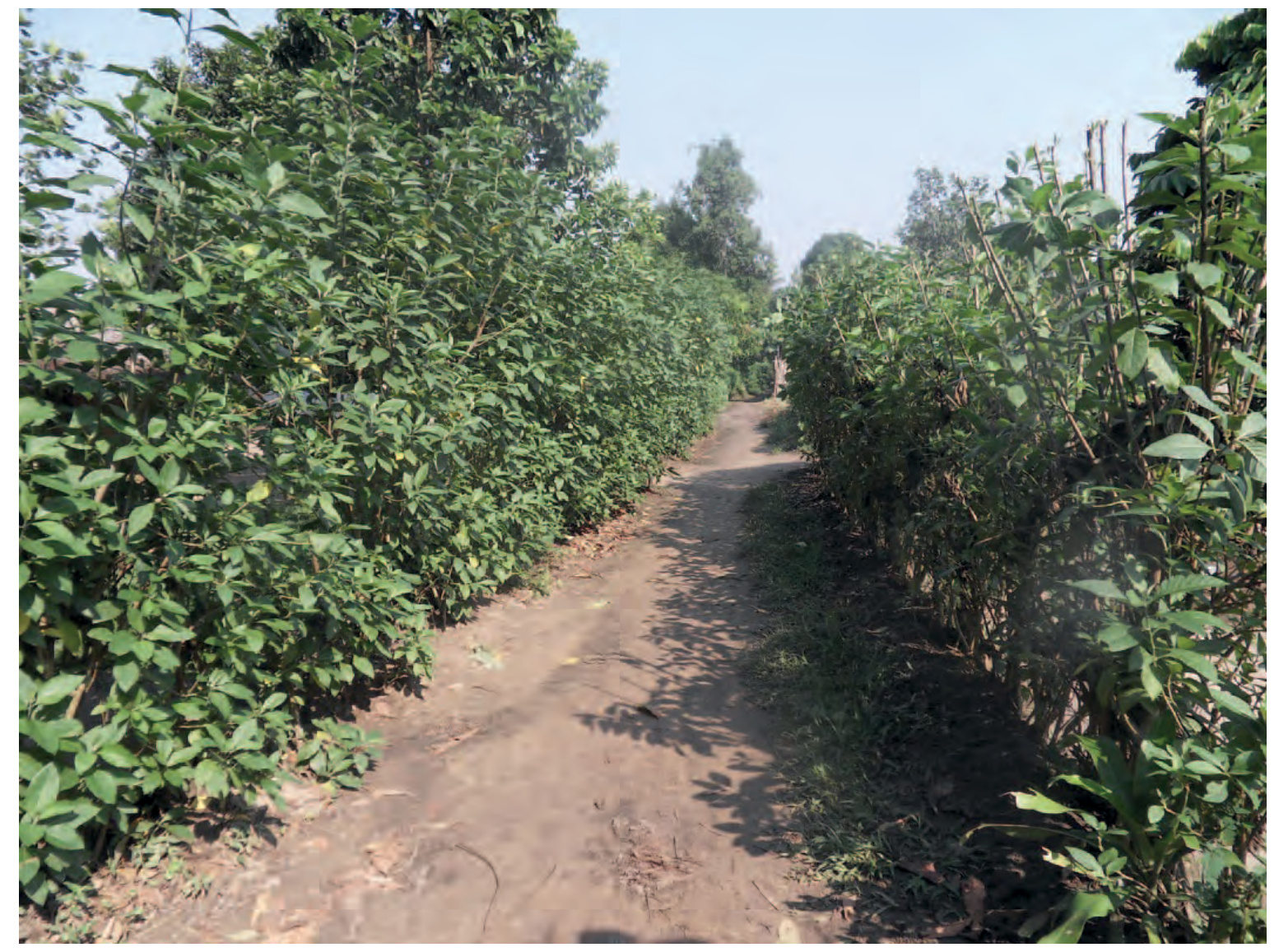

Vernonia amygdalina employée comme haie autour d'habitations.

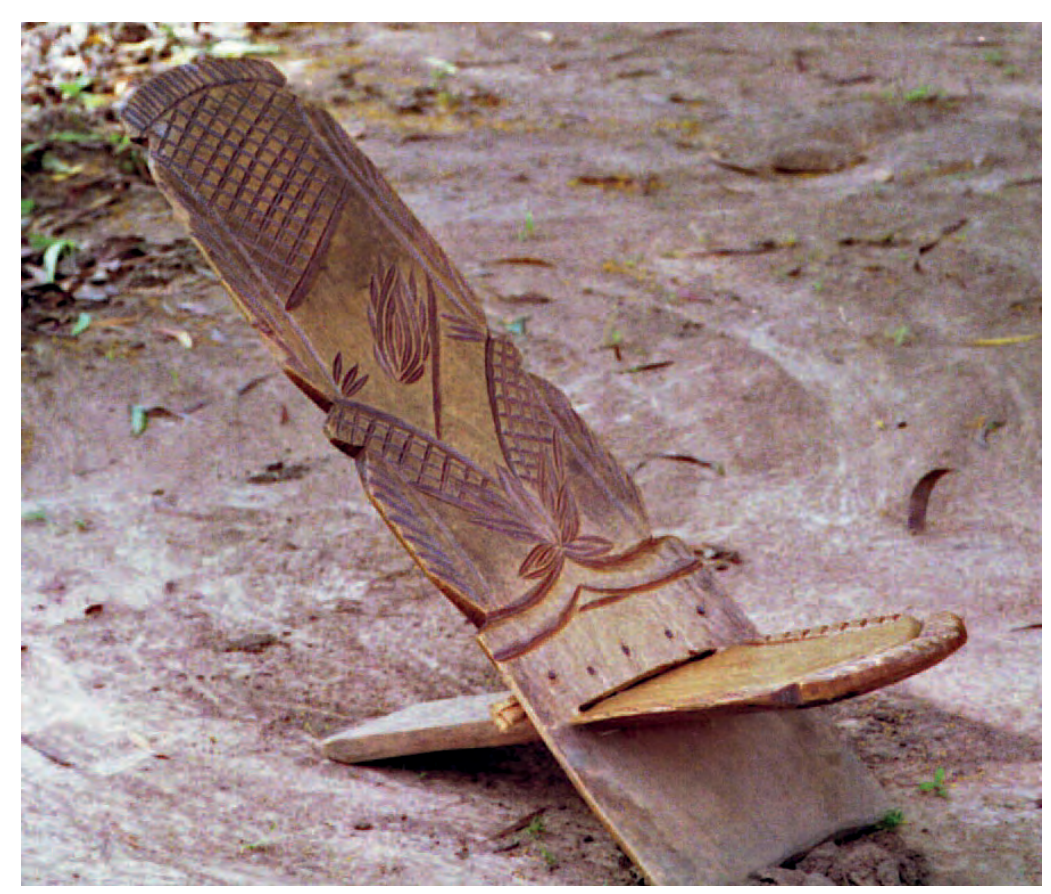

Chaise traditionnelle 


\section{Vernonia brazzavillensis}

(Asteraceae)

Noms courants : Mpuku mpuku, mangoma ngoma, mvuku, mvuku pembe (Kikongo)

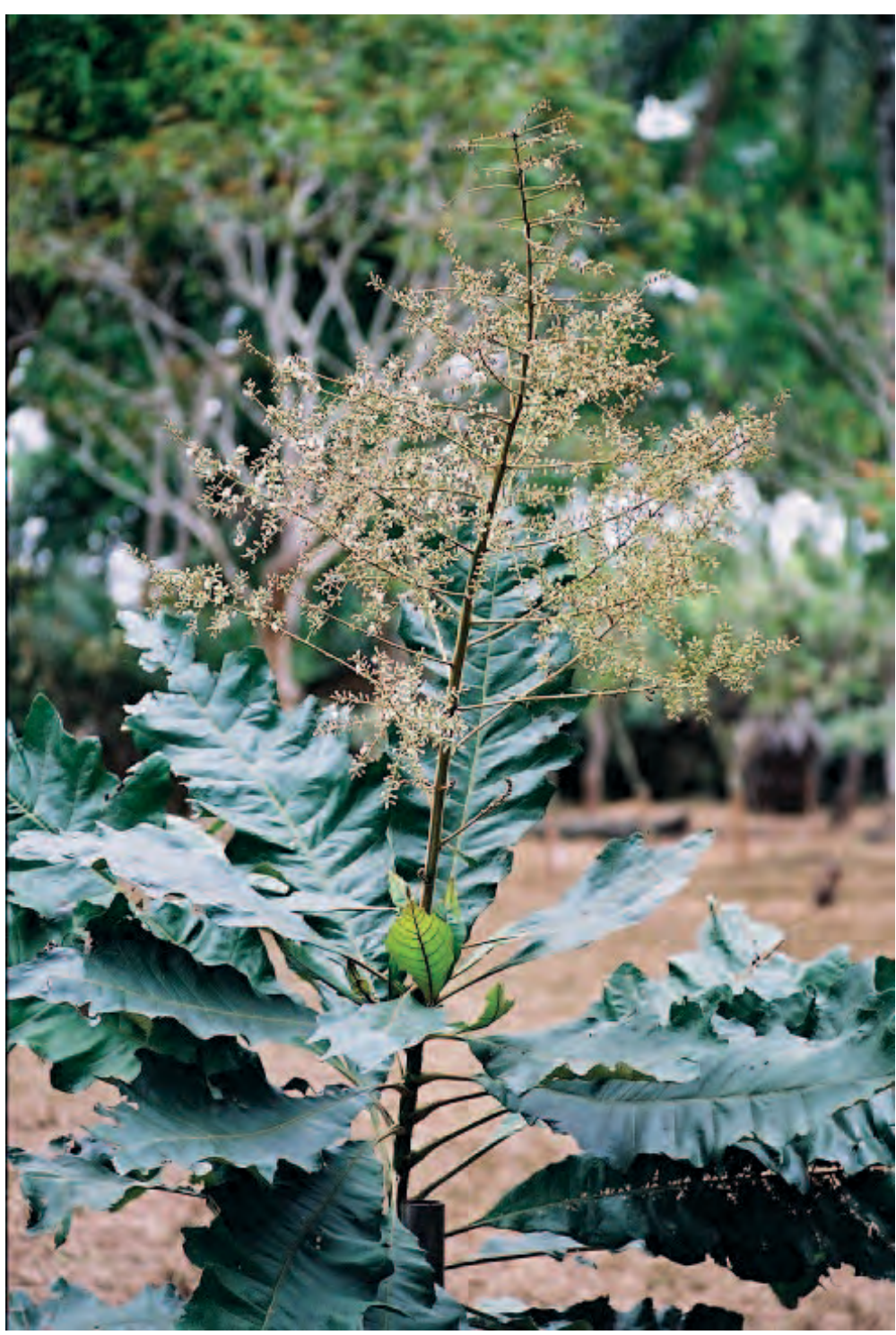

Description : Arbuste pouvant avoir 10 $\mathrm{m}$ de haut. Très grandes feuilles alternes, de 15 à 32 sur 6 à $12 \mathrm{~cm}$, groupées au bout des branches, avec pétioles élargis à la base, tomenteuses et blanchâtres en dessous. Fleurs disposées en grandes panicules longues de $60 \mathrm{~cm}$

Ecologie: Plante des forêts secondaires sur sols sableux, au Gabon, au Congo Brazzaville et en RD Congo (Kongo Central et Provinces du Kasaï).

Usages: Fourrage pour les abeilles, comme toutes les espèces de Vernonia, importantes à ce titre dans les savanes et les zones équatoriales d'Afrique, et qui donnent un miel au goût très fin.

Références : Crane 1975, Daeleman et Pauwels 1983, Pauwels 1993, Kalanda et Lisowski 1995, Hepburn et Radloff 1998

A gauche: Vernonia Brazzavillensis en fleurs en septembre à Mbanza Nzundu

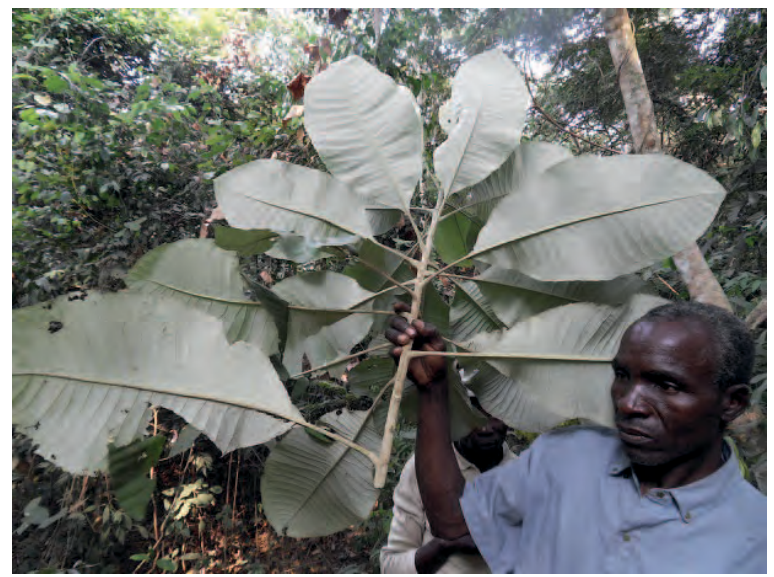




\section{Vernonia colorata}

(Asteraceae)

Noms courants: Nlulu, mundudi-ndudi ya ntela, ndudi-ndudi (Kikongo), bitter leaf (Angl.). Les noms sont souvent les mêmes que pour $V$. amygdalina.

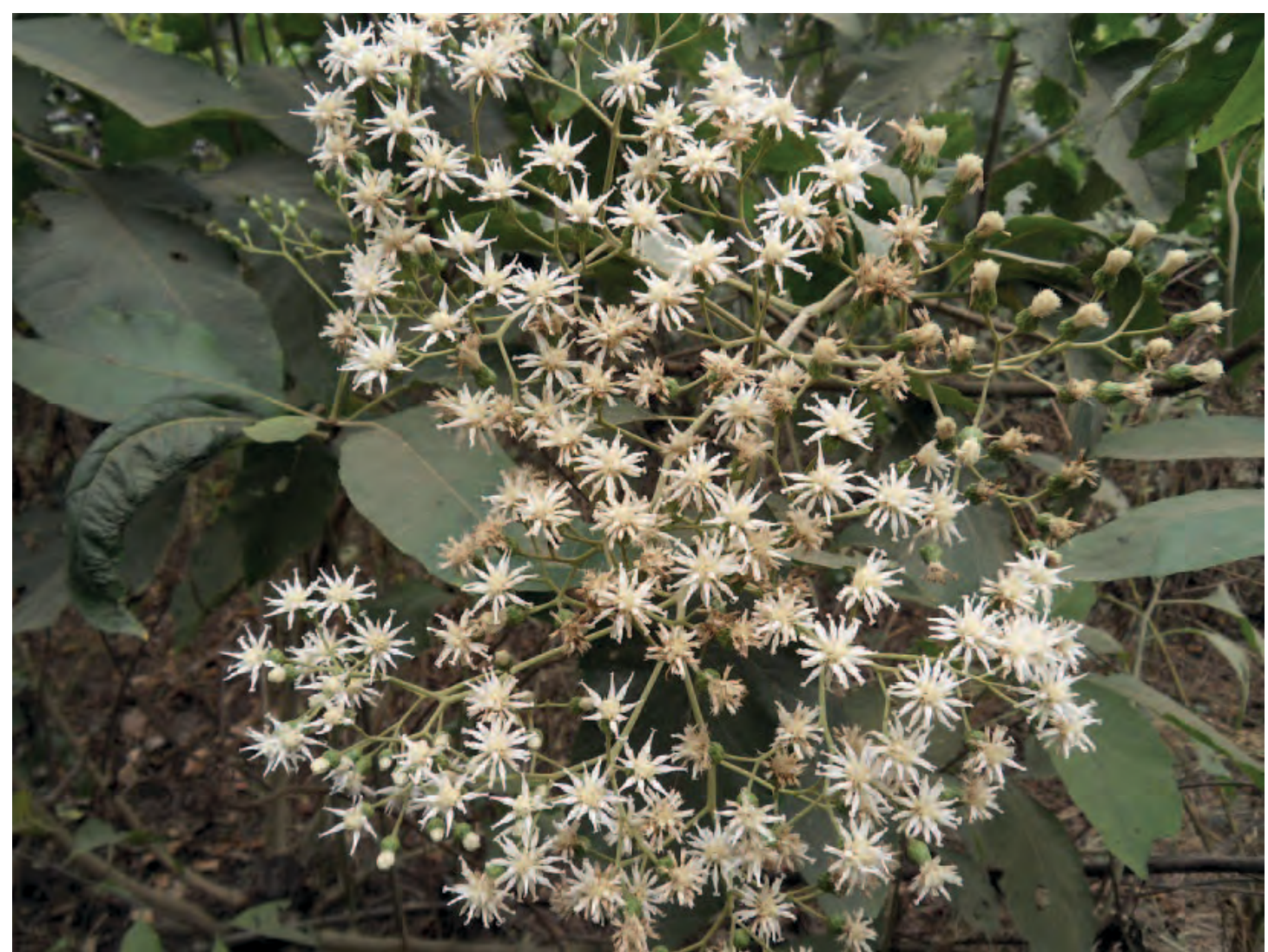

Vernonia colorata en fleurs en août

Description : Espèce très proche de $V$. amygdalina. Arbuste de 3 à $8 \mathrm{~m}$ de haut. Feuilles alternes, ovées à plus ou moins elliptiques, de 10 à 12 sur 5 à $9 \mathrm{~cm}$, rugueuses en dessus, finement poilues dessous. Nombreuses inflorescences jusqu'à $28 \mathrm{~cm}$ de diamètre, portées par des queues d'environ 1,8 cm. 10 à 26 fleurettes par inflorescence, à corolle blanche parfumée à 5 lobes, blanches ou mauve très pâle. Le fruit est un akène glabre à 10 côtes, avec une aigrette brun clair.

Ecologie : Plante des savanes et forêts, dans toute l'Afrique tropicale.

Reproduction : Par graines.

Usages : Les abeilles sont très actives sur les fleurs. La plante est connue comme médicament contre la gonorrhée dans les Provinces de l'Uélé, du Kongo Central et du Kivu. Au Maniema, on l'emploie contre la gale. Au Ghana, on cultive parfois cette plante pour ses feuilles très amères qui servent à traiter la fièvre. En RD Congo, la cendre sert à la préparation de sel végétal. Les tiges servent de bâtons à mâcher.

Références : J ex-Blake 1956, Dale et Greenway 1961, Irvine 1961, Crane 1975, Beentje 1994, Kalanda et Lisowski 1995, Hepburn et Radloff 1998, Burrows et Willis 2005 


\section{Vernonia doniana}

Synonyme : $V$. conferta

Noms courants : Mpuku mpuku, mangoma ngoma, tompa (Kikongo), soap tree (Angl.).

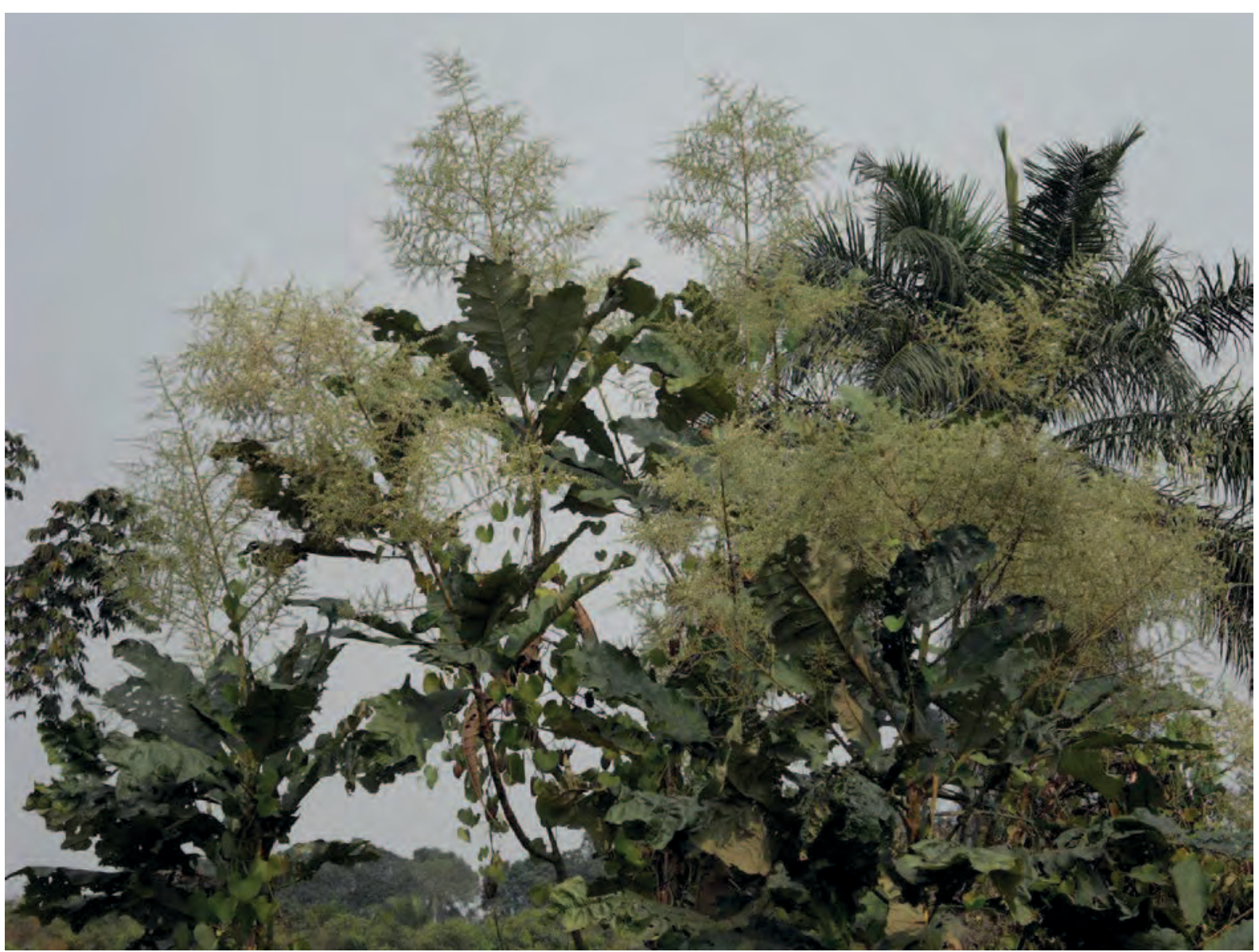

Vernonia doniana en fleurs en juin

Description : Arbuste de 6 à $8 \mathrm{~m}$ de haut, ayant une ressemblance avec Anthocleista et portant le même nom en kikongo. Feuilles de 50 à 62 sur $20 \mathrm{~cm}$, se rétrécissant progressivement vers la base, avec des bords ondulés. Petites inflorescences avec des fleurettes pourpres.

Ecologie : Plante des forêts secondaires et des jachères sur sols lourds, de la Guinée à l'Angola, et en Ouganda.

Usages: Quand cette plante est en fleurs, il parait que l'air a une odeur de miel ; les abeilles récoltent le nectar tôt le matin ; au Gabon, un peu plus tard pendant la saison des pluies. Les feuilles s'emploient comme purgatif. De la cendre des branches on extrait du sel végétal en R.D. Congo, et sert de base pour la fabrication de savon en Sierra Leone. On peut faire bouillir les jeunes pousses feuillues pour faire une soupe que l'on donne aux mères allaitantes pour stimuler la lactation.

Références : Burkill 1985, Keay 1989, Ambougou 1991, Pauwels 1993, Nsimundele 2004 


\section{Vernonia potamophila}

Noms courants : Kisunsa, nlulanlula, ntita (Kikongo)

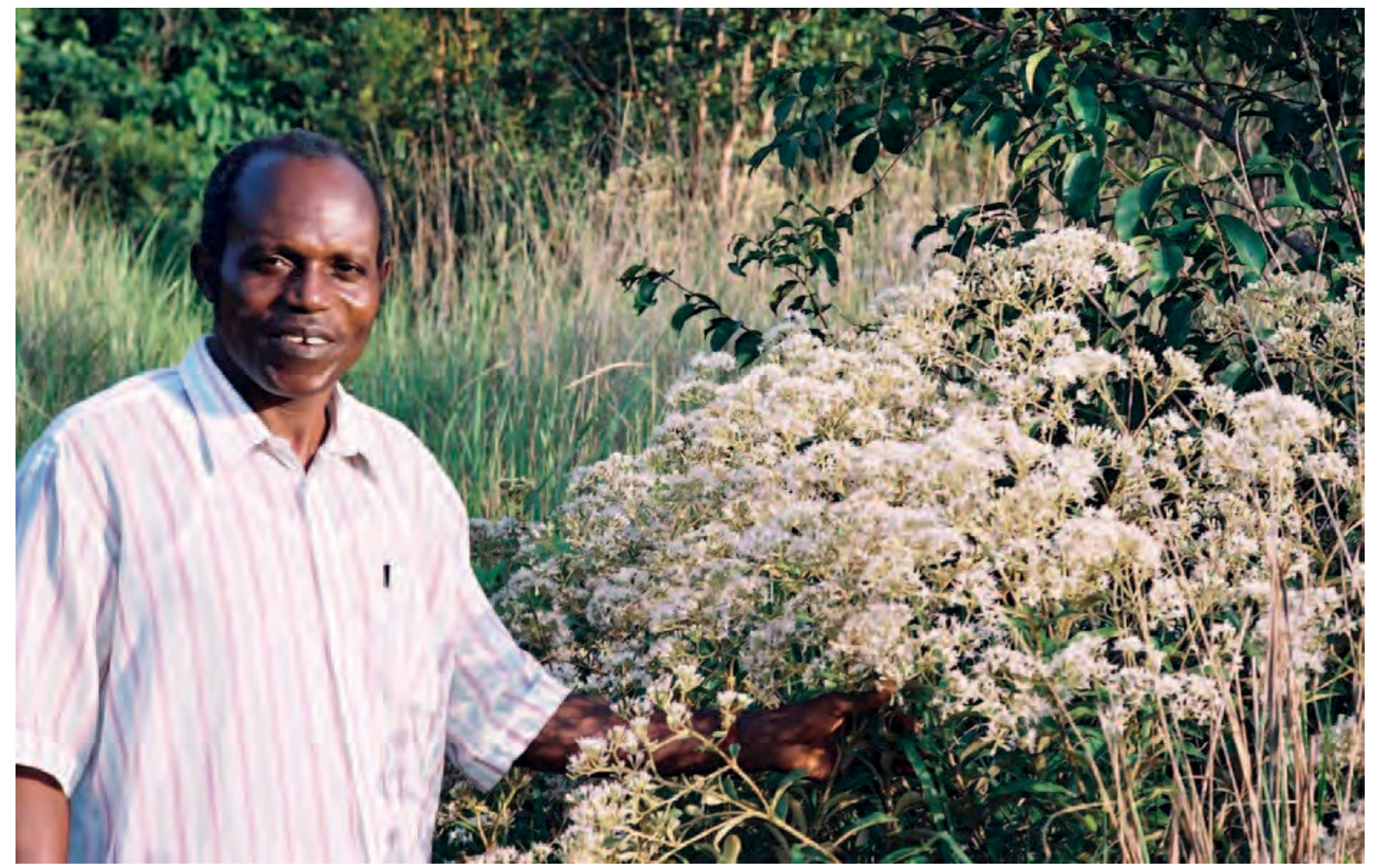

Vernonia potamophila en fleurs à Mingadi en janvier

Description : Buisson bas de 1 à 1,5m de haut. Les feuilles mesurent jusqu'à 10 sur $3 \mathrm{~cm}$. Les fleurs ont souvent une teinte pourpre.

Ecologie: La plante est commune dans quelques zones des savanes herbeuses et buissonnantes du Kongo Central. On la trouve aussi en Angola et en Afrique Centrale dans des forêts sèches sempervirentes.

Usages: On a observé la récolte de nectar par les abeilles le matin en janvier et février. Au Kongo Central, on applique les feuilles pilées sur les blessures comme analgésique et pour arrêter l'hémorragie. Pour soigner l'asthme des enfants, on leur fait mâcher les feuilles, ou on leur donne une macération des feuilles.

Références: Gillet et Pâque 1910, Daeleman et Pauwels 1983, Pope 1992, Neuwinger 2000, Latham et Konda Ku Mbuta 2017

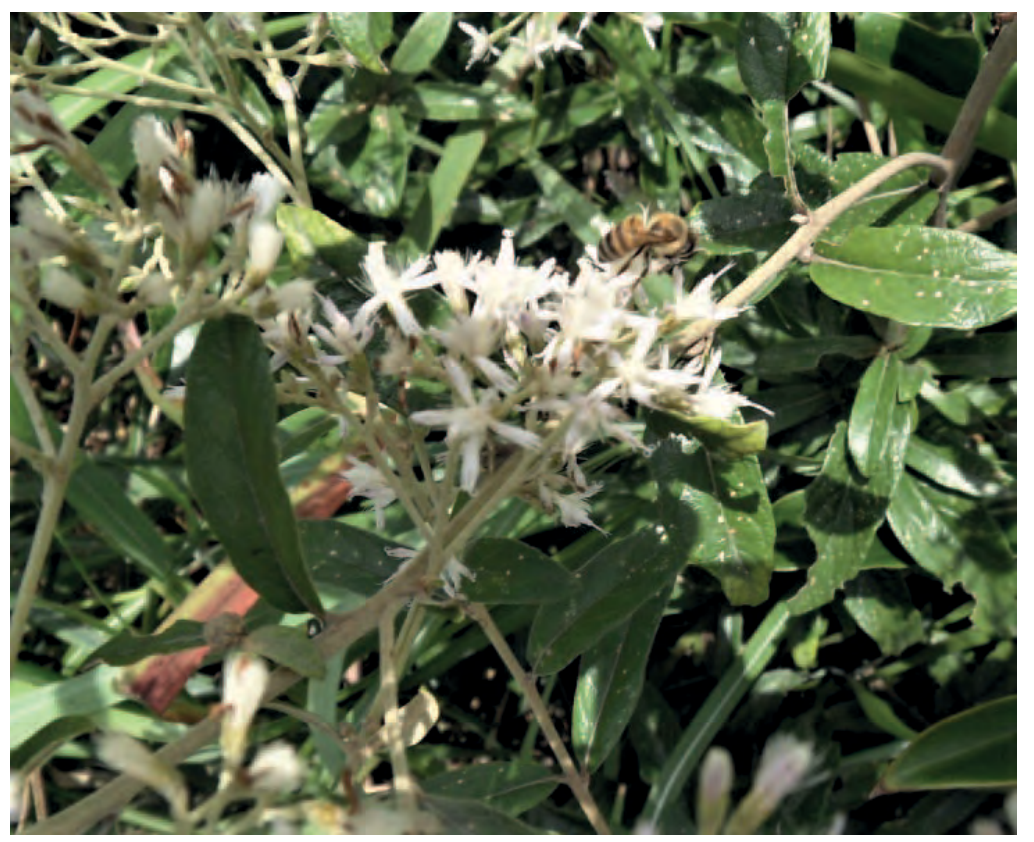


Synonyme : Voandzeia subterranea

Noms courants: Nguba nsamba, bimongi (Kikongo), voandzou, pois de terre (Fr.), Bambara groundnut (Angl.)

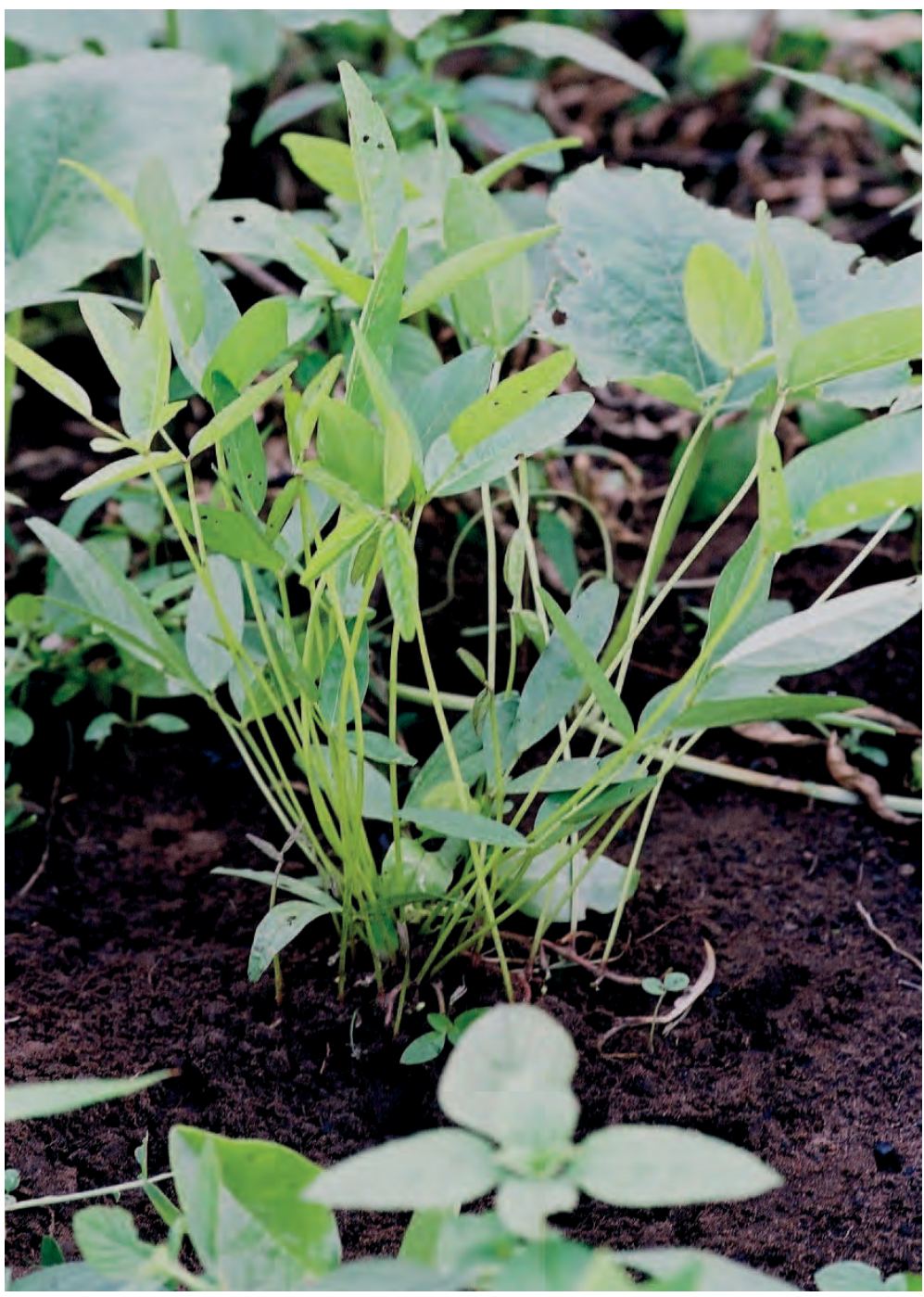

Description : Herbe touffue atteignant $40 \mathrm{~cm}$ de haut. Feuilles trifoliées, chaque foliole ayant 3 à 8 sur 2 à $4 \mathrm{~cm}$. Fleurs jaunes papilionacées. Après la pollinisation, le pédoncule s'étend et les gousses s'enfouissent dans le sol. Elles sont rondes, de $2,5 \mathrm{~cm}$ de diamètre, contenant d'ordinaire une seule graine.

Ecologie: On trouve le voandzou à l'état sauvage depuis le centre du Nigeria jusqu'au sud du Soudan, et il est désormais cultivé dans toute l'Afrique tropicale. La plante donne des récoltes sur les sols sableux relativement pauvres. II lui faut le soleil brillant, des pluies fréquentes et de hautes températures, mais il est tolérant à la sécheresse. Les pluies excessives pendant la formation des fruits limitent les récoltes.

Reproduction: Semer les graines décortiquées à l'espacement de $32 \times 20$ $\mathrm{cm}$.

Gestion: La plante demande un désherbage soigné, surtout quand elle est jeune. II faut biner le sol pour favoriser la production de graines. A la récolte, les fruits peuvent se perdre en s'arrachent de leur queue. Du semis à la récolte il faut normalement 4 mois. La production peut atteindre 500 à 1000 $\mathrm{kg}$ par hectare.

Usages: Les graines peuvent se manger cuites seules ou avec du maïs (parfois après trempage une nuit), frites, en purée, ou comme base d'un ragoût. On peut griller les graines séchées pour en faire une farine. On peut manger les graines avant maturité, fraiches, frites ou grillées. Elles ont une haute valeur nutritive et pas de toxicité. Les graines mûres peuvent contenir 16 à $21 \%$ de protéines, 4,5 à $6,5 \%$ de graisses, et 50 à $60 \%$ d'hydrates de carbone, constituant un régime équilibré. Cependant, leur consommation en grandes quantités peut donner des malaises à l'estomac ; il faut les préparer avec soin car elles peuvent être amères. La plante nodule bien et fixe l'azote.

Références : Renier 1948, Hauman et al. 1954, Van Den Abeele et Vandenput 1956, Busson 1965, Daeleman et Pauwels 1983, Maundu et al. 1999, Nsimundele 2004, Brink et al 2006, SEPASAL (Consulté le 22.7.2017)

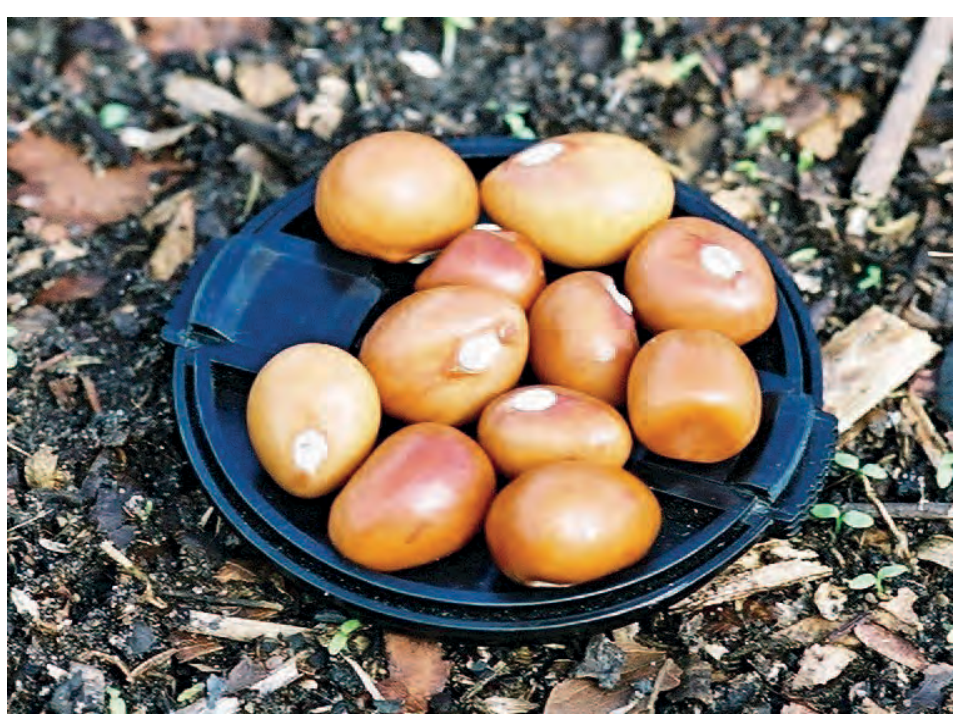




\section{Vigna unguiculata}

Noms courants : Nkasa, nkasa zikongo, nkasa zimbwenge, mbwenge (Kikongo), niébé, haricot kunde, dolique mongette (Fr.), cowpea (Angl.)

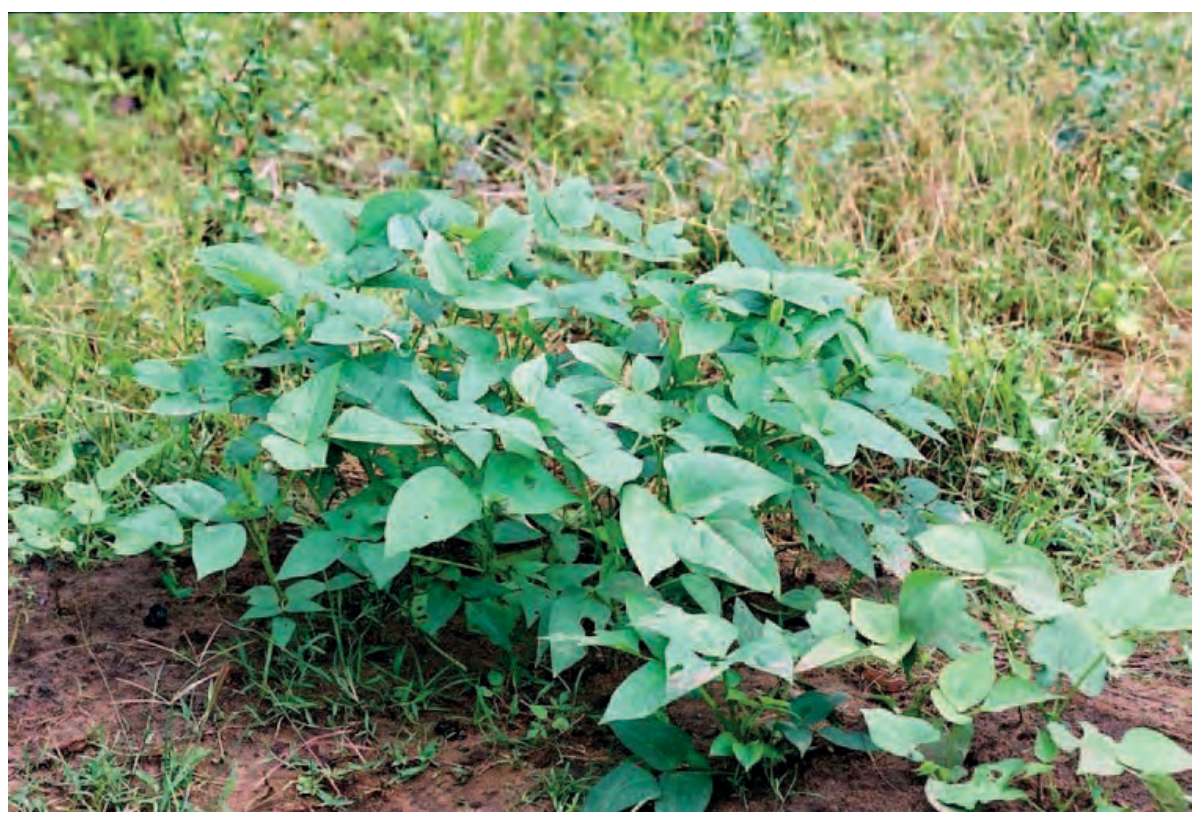

Description : Plante annuelle ou vivace, érigée ou grimpante. Les tiges, peu ramifiées, ont de 1 à $3 \mathrm{~m}$. Les feuilles portent des stipules de 6 à $20 \mathrm{~mm}$ munies d'un éperon à la base. Elles sont composées de trois folioles ovalesrhomboïdales, de 5 à 15 sur 4 à $6 \mathrm{~cm}$, les 2 folioles latéraux sont dissymétriques, à pétiolule plus court, à bord entier. Les fleurs papilionacées ont des pétales blanc jaunâtre ou roses, mauves, rouges, les ailes bleues à violettes, la carène généralement blanche et non spiralée.

Le fruit est une gousse cylindrique, un peu comprimée entre les graines, de 7,5 à 30 sur 0,6 à $1 \mathrm{~cm}$, enfermant plusieurs graines rouge foncé à noir, marbrées de noir ou de brun, oblongues-réniformes, de 6 à $12 \mathrm{~mm}$; avec un hile oblong, couvert d'un tissu blanc, à arille noirâtre en bourrelet.

Ecologie : Originaire d'Afrique, le niébé y aurait été domestique il y a plus de 3000 ans. La plante se cultive couramment en association avec des céréales. II lui faut des sols bien drainés. Dans les sols sableux, elle est souvent attaquée sévèrement par les nématodes.

Reproduction : Les graines conservent leur viabilité longtemps, pourvu qu'elles soient protégées des insectes. Si I'on n'a pas cultivé précédemment de niébé ou une plante apparentée, l'injection de rhizobium donne de meilleurs résultats.

Gestion : II y a souvent des problèmes avec les ravageurs. Il faut récolter les gousses avant maturité pour éviter leur destruction. On peut employer de l'huile de Jatropha Curcas concentrée à $10 \%$ comme insecticide pour contrôler les pucerons et les termites.

Usages : Les graines séchées jouent un rôle important dans I'alimentation en Afrique. Normalement, on les prépare avec des légumes, des épices et de l'huile de palme pour faire une soupe et accompagner les féculents. Leur contenu en protéines est de 22 à $25 \%$. On peut les employer aussi comme substitut du café. Les feuilles et les gousses vertes se mangent comme légumes; on peut les sécher pour les utiliser plus tard. On peut couper la plante au pied pour donner une succession de nouvelles pousses. Les feuilles peuvent servir

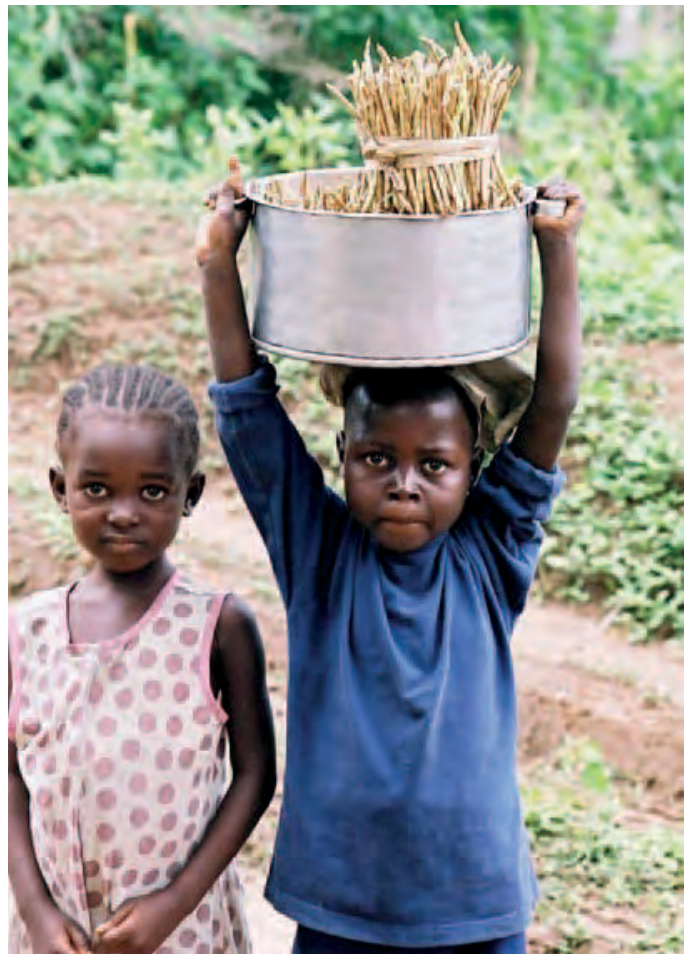
d'aliment du bétail. Les fibres de la tige servent de liens, pour les lignes et filets de pêche, la filature et le tissage. Au Kongo Central, les racines seraient comestibles et consommées comme légumes.

Références : Gillet et Pâque 1910, Hauman et al. 1954, Van Den Abeele et Vandenput 1956, Kay 1979, Daeleman et Pauwels 1983, Burkill 1995, Nsimundele 2004, Habou et al 2012 et 2014, SEPASAL (Consulté le 11.7.2017) 
Nom courant : Nkasa zimadeso (Kikongo)

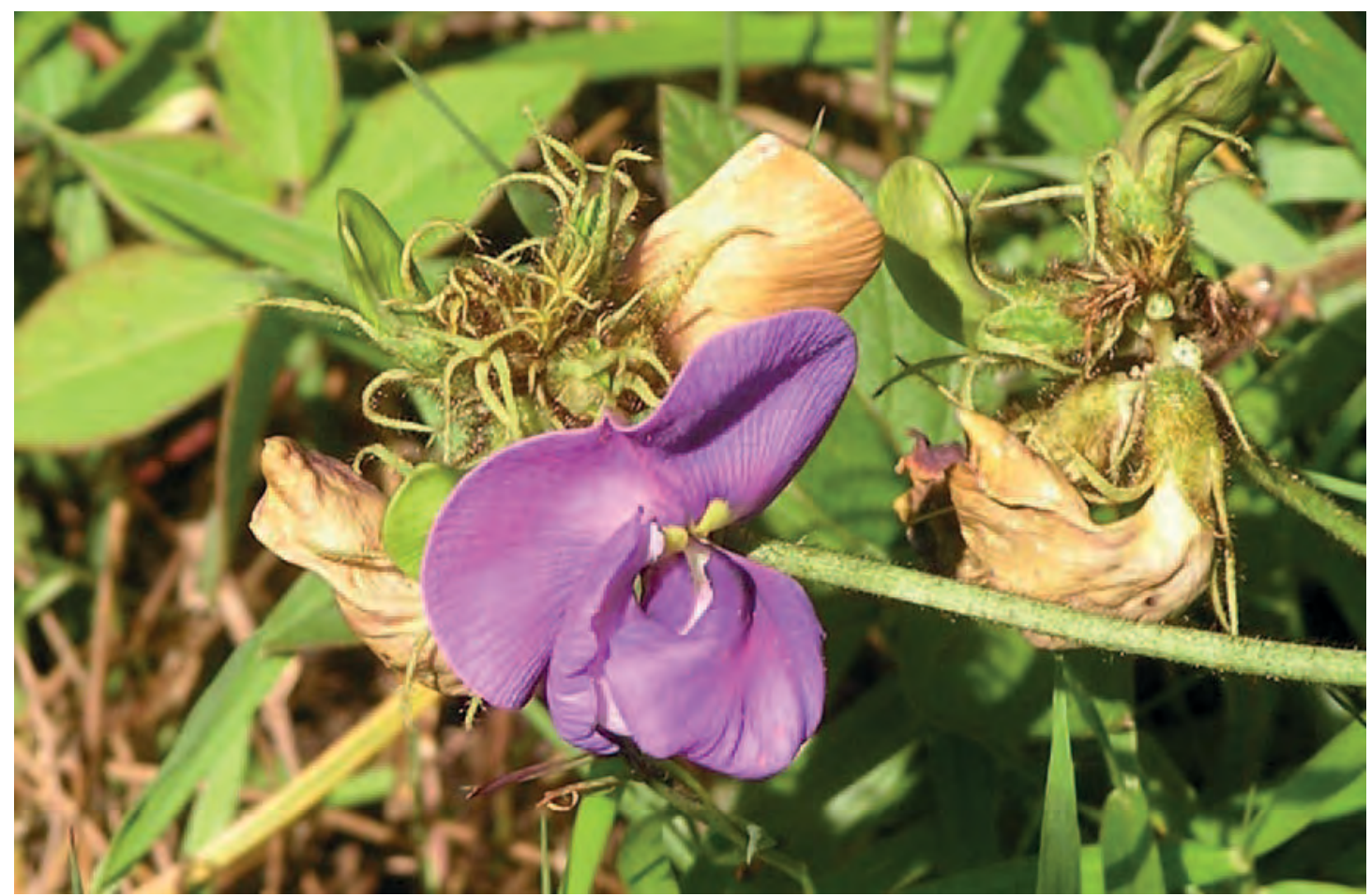

Les deux photos : David Watson

Description : Herbe volubile annuelle ou pérenne poussant sur un tubercule ligneux et grimpant sur d'autres plantes. Les tiges, d'ordinaire poilues, ont jusqu'à $3 \mathrm{~m}$ de long. Feuilles trifoliées lancéolées, pointues au bout et poilues sur les deux faces. La foliole terminale, de 6 sur $12 \mathrm{~cm}$, est plus grande que les deux autres. Les fleurs, de 2 à $3 \mathrm{~cm}$ de long, ont une quille lilas - mauve, torsadée d'un côté. Les gousses étroites ont $14 \mathrm{~cm}$ de long, et sont couvertes de poils bruns.

Ecologie: Plante commune du Nigéria à l'Afrique Orientale, au Malawi et à la Zambie. Présente aussi en Afrique du Sud et en Amérique du Sud. En Afrique orientale, elle est commune dans les savanes herbeuses et arbustives, et aux lisières de forêts, de 0 à 2200 $\mathrm{m}$, spécialement dans les parties centrale et occidentale de l'Afrique Orientale.

Reproduction : La plante donne des graines environ 90 jours après sa plantation.

Gestion : Cette plante pousse et se multiplie bien pendant les pluies. Elle est efficace pour supprimer les mauvaises herbes, mais ne résiste pas au feu. Elle reprend lentement après la taille.

Usages : Au Kongo Central, on mange les graines. En R.D. Congo, on donne une décoction des feuilles pour traiter les démangeaisons. Au Kenya, on mange les feuilles comme légumes. La plante fournit un fourrage apprécié par les animaux, malgré ses poils, mais des tests

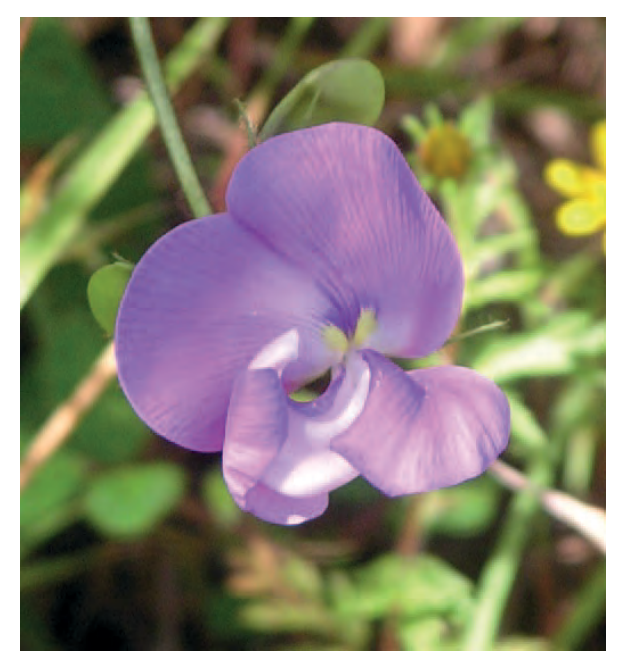
sur des parcelles non fertilisées n'ont donné des rendements que de $309 \mathrm{~kg} / \mathrm{ha}$ de matière sèche. La plante supporte mal la saison sèche. En Tanzanie, R.D. Congo et Zimbabwe, on mange le tubercule gonflé.

Références : Renier 1948, Hauman et al. 1954, Skerman 1977, Blundell 1987, Burkill 1995, Nsimundele 2004, Baumann 2005 


\section{Vitex bojeri}

Synonyme : Vitex ferruginea

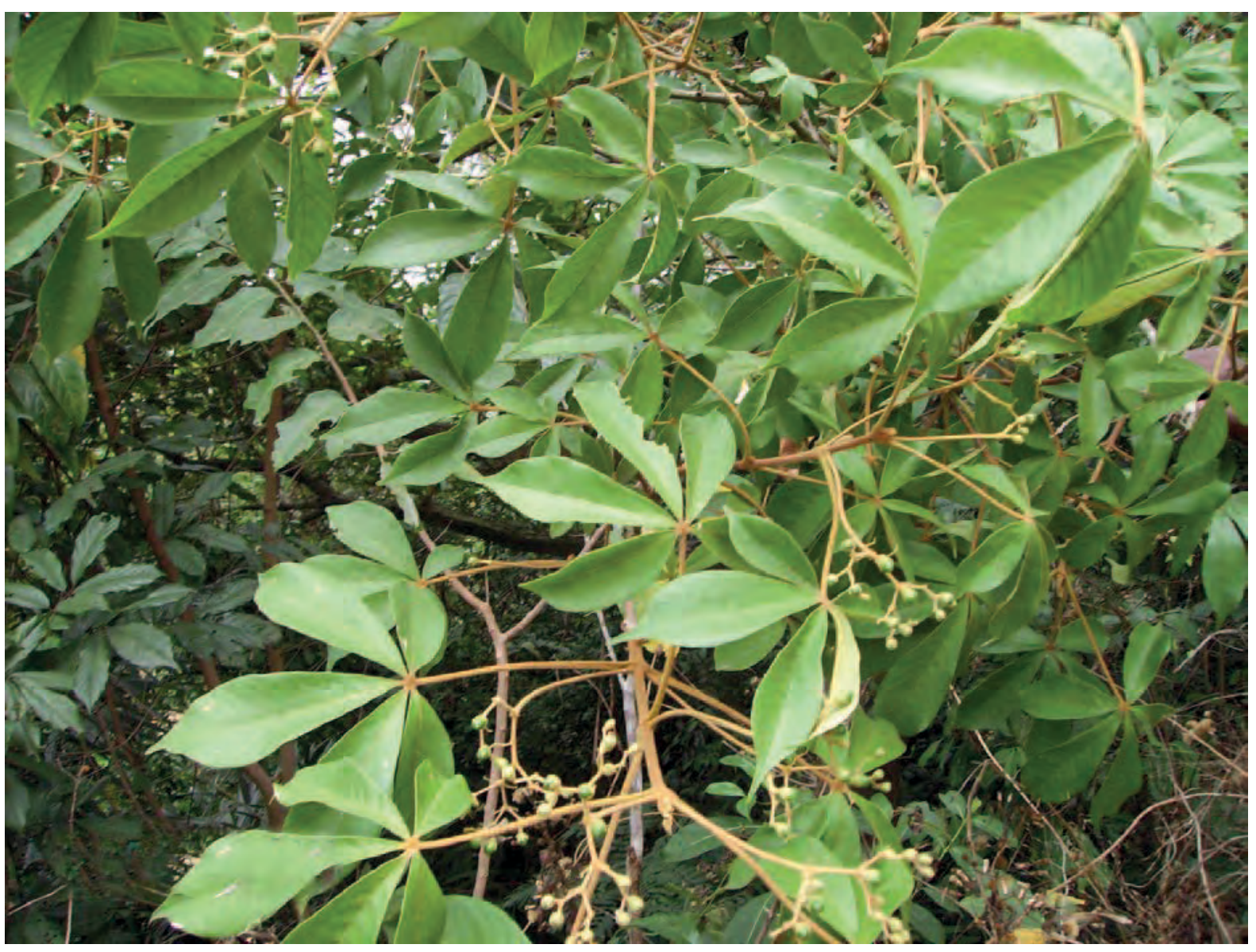

Description : Arbre aux feuilles composées palmées à 5 lobes. L'écorce du tronc et des vieilles branches est fissurée. Le rachis et le dessous des feuilles sont feutrés de poils ferrugineux. Inflorescence en racème poilu long de $20 \mathrm{~cm}$, très ramifié avec de petites fleurs. Fruits de $6 \mathrm{~mm}$ avec calice poilu.

Ecologie : Arbre présent en RD Congo dans les Provinces du Kongo Central, du Kwango et du Kwilu.

Usage : On rapporte qu'à Madimba le fruit se mange.

Références : Renier 1948, Communication personnelle - Kibungu Kembelo 


\section{Vitex congolensis var. congolensis}

Synonyme : V. gilletii

Noms courants: Finlungu ("petit bateau »), fiolongo, filu, kifilu, (Kikongo)

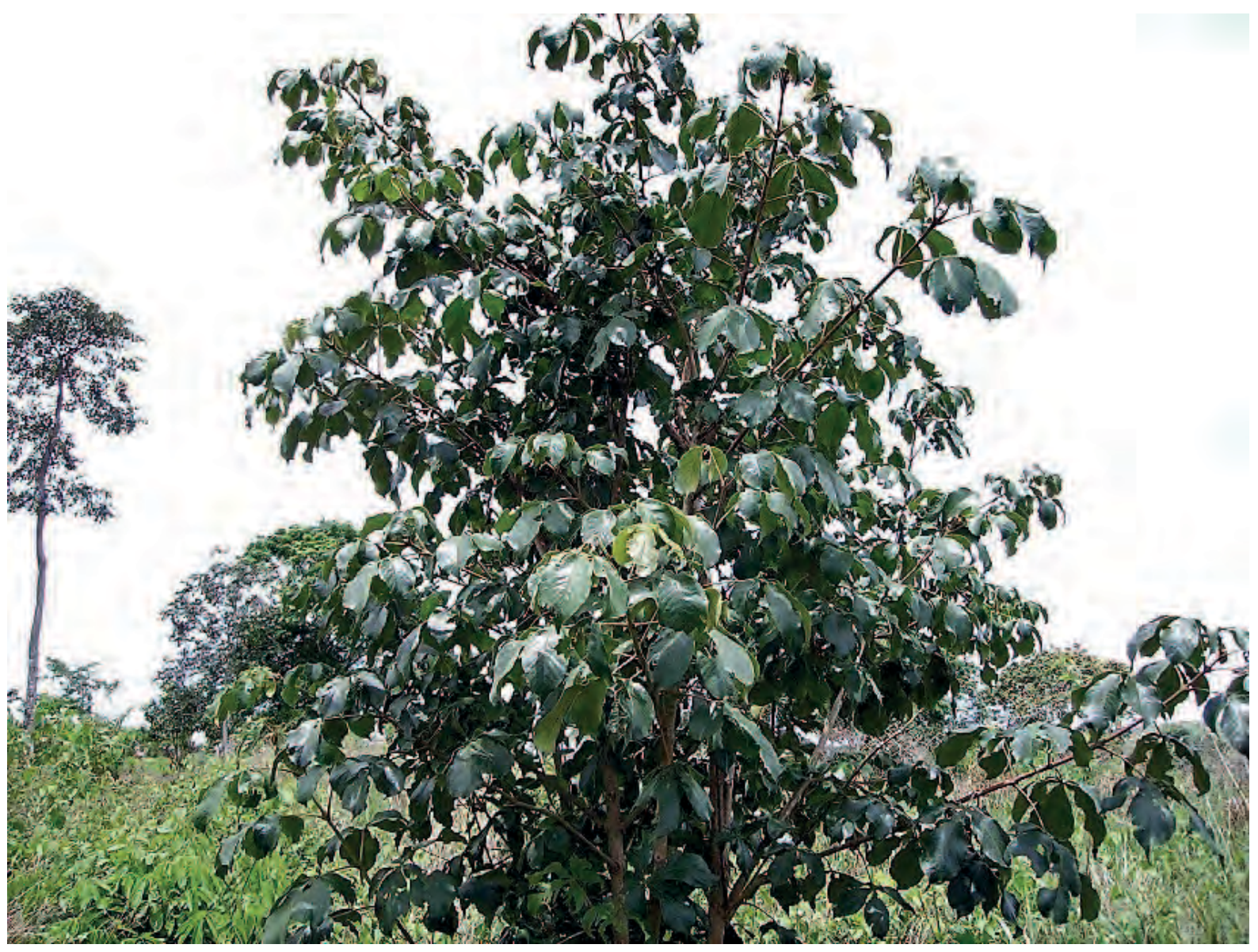

Description : Arbre de 4 à $20 \mathrm{~m}$ de haut aux tiges couvertes d'un velours de fins poils bruns. Feuilles opposées, composées à 5 folioles sessiles, obovales, en coin à la base, pointues au sommet, de 9 à 20 sur 3 à $5 \mathrm{~cm}$ pour la foliole centrale, avec des marges entières et légèrement ondulées. La face inférieure des feuilles est couverte d'un velours de poils fins. Inflorescence en cymes axillaires jusqu'à $25 \mathrm{~cm}$ de long. Fleurs au calice en cloche, à 5 lobes, long de $2,5 \mathrm{~mm}$; corolle violette de 5 à $7 \mathrm{~mm}$. Le fruit est une drupe ellipsoïde noirâtre de 7 à $15 \times 6$ à $10 \mathrm{~mm}$, munie à la base du calice persistant.

Ecologie: Plante des savanes et forêts dans l'ensemble de la R.D. Congo, à l'exception des Provinces montagneuses de l'Est. Également trouvé de la Côte d'I voire à l'Angola et à travers le Soudan.

Reproduction : Par boutures et par graines.

Usages : On utilise le bois, dur et résistant, pour fabriquer des mortiers pour piler le pondu ; mais ses usages sont limités car il est sujet aux déformations. Dans la Province de la Tshopo, on fait un thé avec les feuilles.

Références : Gillet et Paque 1910, Gillet 1927, Renier 1948, Pauwels 1993, Termote 2012, Meerts et Hasson 2016, Ilunga wa Ilunga et Meerts 2020. 
Noms courants : Fiolongo, mfiolongo (Kikongo), koro, prune noire (Fr.), West African plum (Angl.)

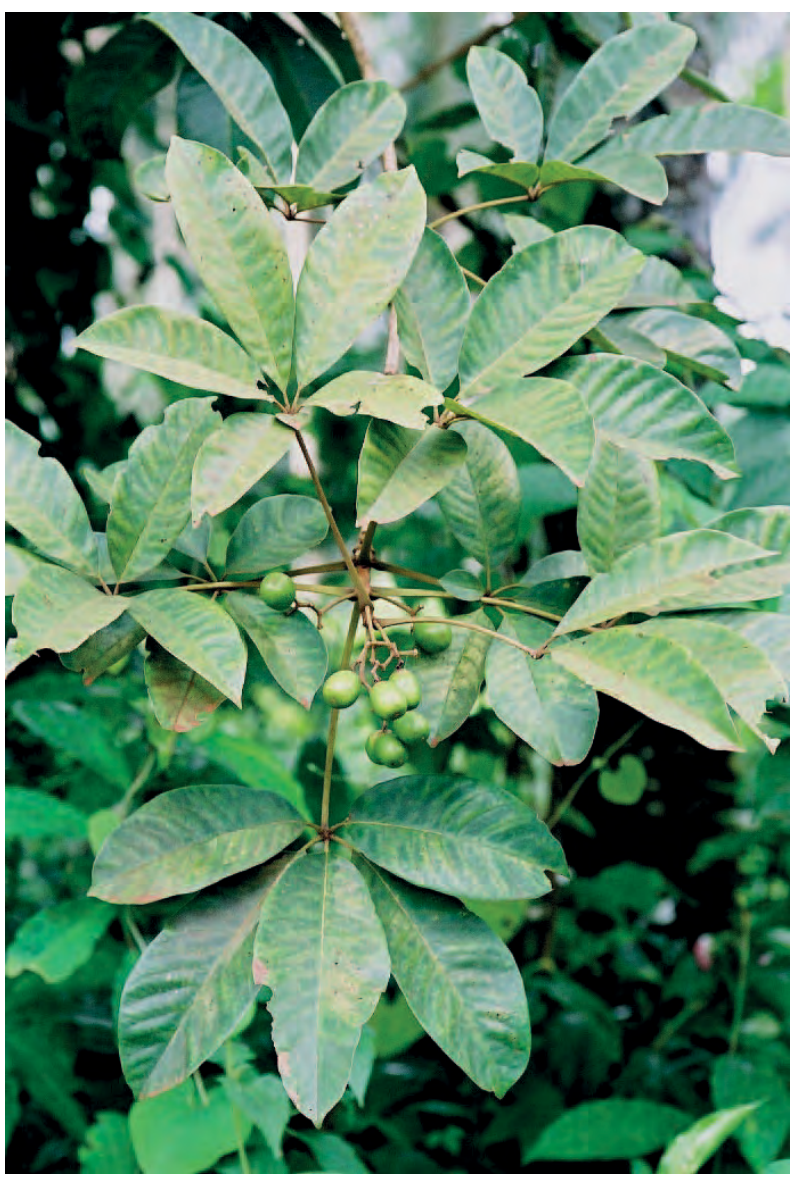

Description : Arbre pouvant atteindre $30 \mathrm{~m}$ de haut, avec une épaisse couronne arrondie. Feuilles composées de 5 - 7 folioles, de 5 à $18 \mathrm{~cm}$ de long, avec des pétioles de 5 à $15 \mathrm{~cm}$. Petites fleurs bleues ou violettes, quelques fleurs seulement s'ouvrant à la fois. Fruits oblongs de 15 à $30 \mathrm{~mm}$, d'abord verts, puis noir pourpré à maturité, munis du calice persistant de la fleur ; le fruit contient une pulpe farineuse noire ; les graines sont contenues dans un noyau très dur.

Ecologie: L'arbre demande un sol humide en profondeur. II pousse sur des sols divers, souvent alluviaux, et résiste au feu. On le trouve au bord de l'eau et dans les forêts secondaires, dans toute l'Afrique tropicale et aux îles Comores.

Reproduction : Le moyen le plus facile de reproduire cet arbre est de faire des boutures, spécialement des boutures de racines. L'arbre se reproduit naturellement par graines ; on pense que les feux de forêt induisent la germination en brisant la coque dure qui entoure la graine. Quand le fruit est mûr, nettoyer avec un couteau la peau et la pulpe autour de la coque ; laver et sécher ; tremper la coque dans l'eau 24 heures, en changeant l'eau après 12 heures; la germination est sporadique.

Gestion : La vitesse de croissance est moyenne. On peut cultiver l'arbre en plein champ ou en bordure de champ ; il peut se recéper.

Usages : Le fruit a un goût délicat et se mange cru ; on le vend parfois sur les marchés; il est une bonne source de vitamines $A$ et $B$. On peut manger les jeunes feuilles, ou les cuire comme légumes. Le bois est blanc à brun clair, léger, dur, résistant aux termites. On l'emploie pour le mobilier, les embarcations, les charpentes, les caisses. II peut servir aussi de bois de feu et pour le charbon de bois. Les feuilles peuvent servir de fourrage. L'écorce, les feuilles et les racines ont des usages médicinaux. L'écorce donne une teinture. Les feuilles servent à traiter la diarrhée et la dysenterie. Le fruit sert à améliorer la fécondité, et à traiter l'anémie, la jaunisse, la lèpre et la dysenterie. Pour traiter les infections des yeux, on injecte dans les yeux le jus de jeunes feuilles tendres pilées. Les chenilles comestibles Bisu (Nudaurelia dione) et Kelekele broutent les feuilles. Les abeilles butinent les fleurs et les fruits mûrs ; en Ethiopie, on aime suspendre les ruches aux branches de cet arbre. Cet arbre est utile pour la reforestation.

Références: Gillet 1927, Renier 1948, Daeleman et Pauwels 1983, FAO 1983,

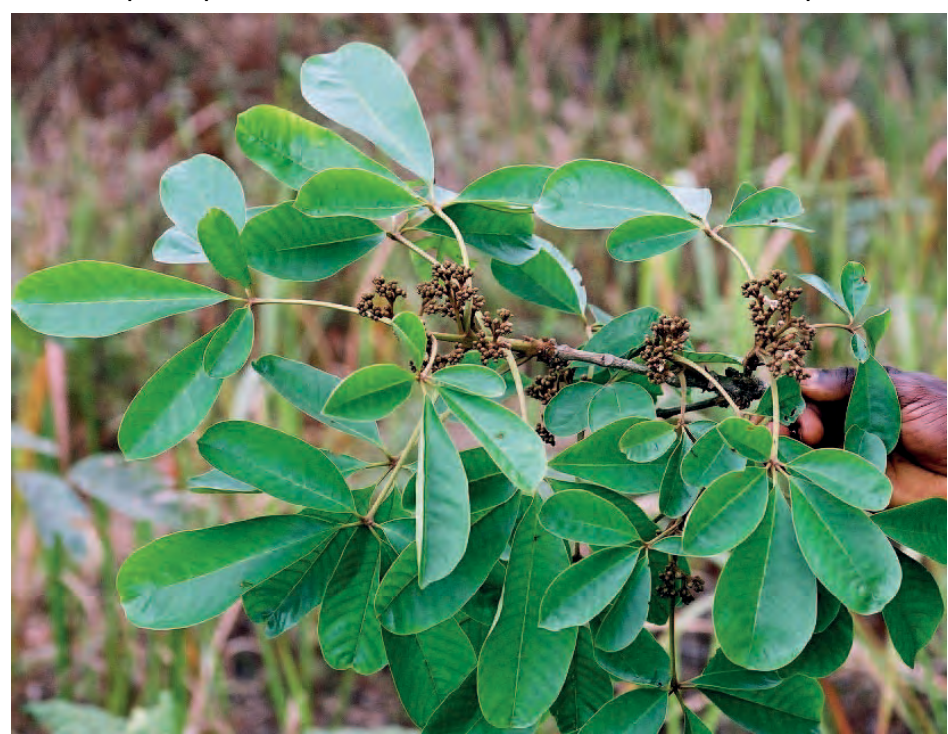
Bekele-Tesemma et al. 1993, Pauwels 1993, Msanga 1998, Orwa et al. 2009, Meunier et al. 2010, Sanoussi et al. 2012, SEPASAL (Consulté le 25.10.2018), Meerts 2020 


\section{Vitex madiensis}

Noms courants : Kifilu, kifilungu, bilikita, bilikwita, viluseke ya kaka (Kikongo)

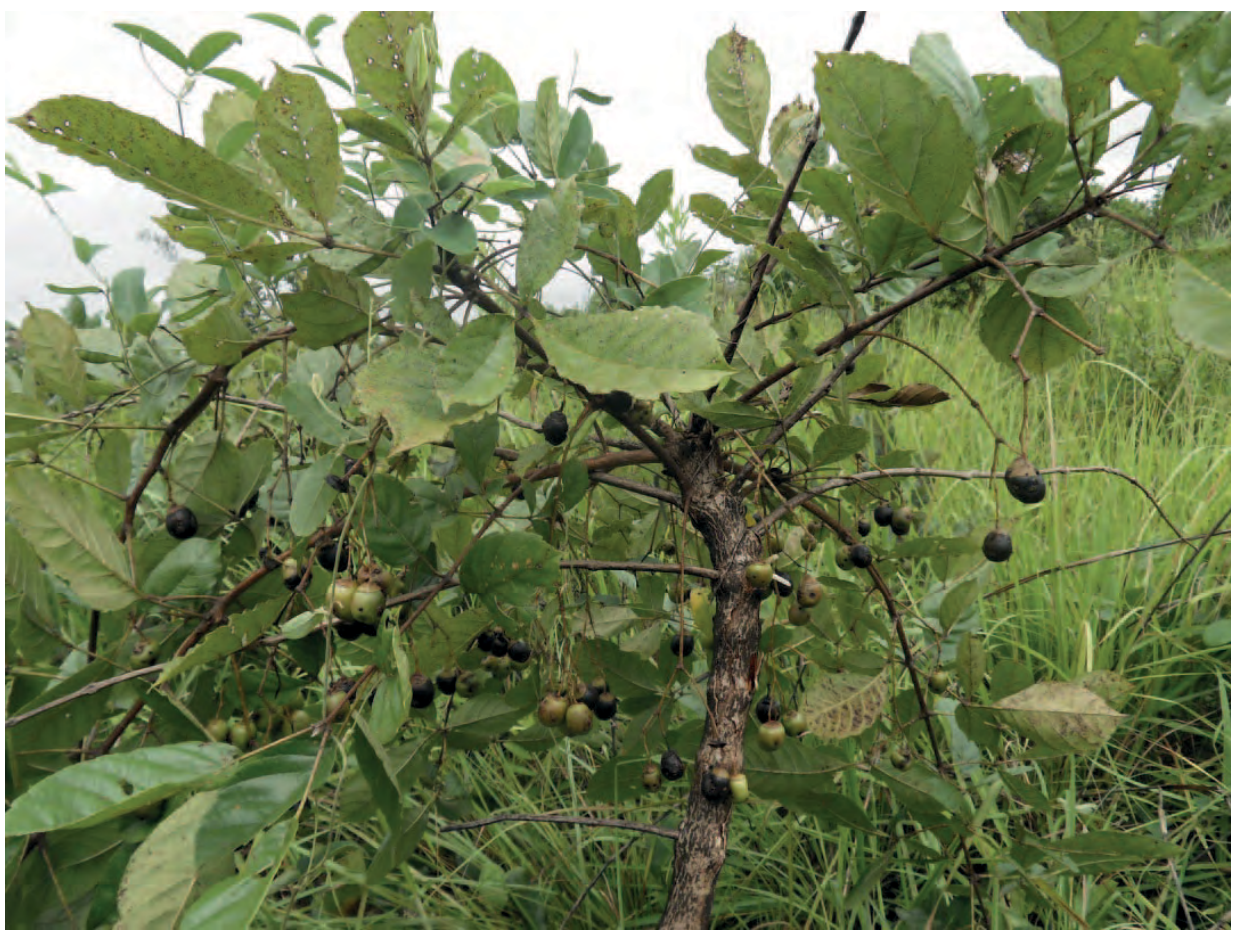

Description : Arbuste de 0,5 à $8 \mathrm{~m}$ de haut. Les feuilles sont composées de 3 folioles raides atteignant $12 \mathrm{~cm}$ de long, odorantes quand on les froisse. Fleurs blanc rosé avec des lobes bleu violet. Le fruit a $25-30 \mathrm{~mm}$ de long, il est d'abord vert brillant puis devient noir ; il est muni du calice persistant de la fleur.

Ecologie: Arbuste commun de la savane, de la Guinée à l'Ouganda et au Mozambique.

Reproduction : Récolter le fruit mûr, le

sécher au soleil et ôter la pulpe séchée. Semer directement en plein champ; on peut aussi transplanter les semis spontanés.

Gestion : Les souches reprennent facilement quand on a coupé l'arbre.

A droite : rameau fleuri

Usages: Les fruits ressemblent beaucoup à ceux de Vitex doniana. Ils sont délicieux, et très populaires partout où on les trouve. Ils contiennent

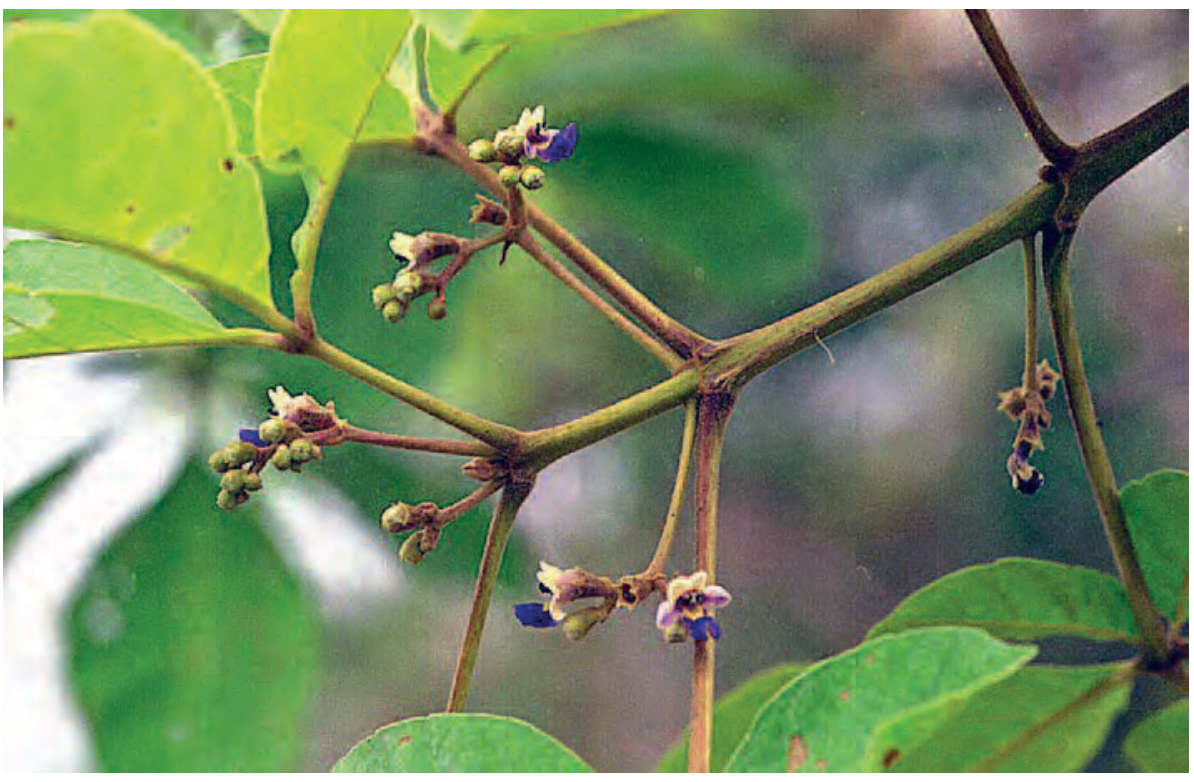
plus de fer que les oranges et sont riches en sucres mais pauvres en vitamine $C$. On donne une décoction des jeunes feuilles pour soigner la toux, les refroidissements, la diarrhée, la dysenterie et les hémorroïdes. Au Kongo Central, on emploie les racines bouillies pour traiter le diabète et les anémies. Les chenilles comestibles Bisu ( Nudaurelia petiveri) et Kaba (Lobobunaea phaedusa) se nourrissent des feuilles. Les abeilles butineraient le nectar en novembre. Le bétail mange les feuilles.

Références : Gillet 1927, De Wildeman 1934, Renier 1948, Delaude et Breyne 1971, Arkinstall 1979, Daeleman et Pauwels 1983, Mukoko Matondo 1991, Pauwels 1993, Katende et al. 1995, Burkill 2000, Neuwinger 2000, Nsimundele 2004, Latham 2008, Göhre et al. 2016, Ilunga wa Ilunga et Meerts 2020 
Noms courants : Munkodinkodi (Kikongo), Voacanga d'Afrique (Fr).

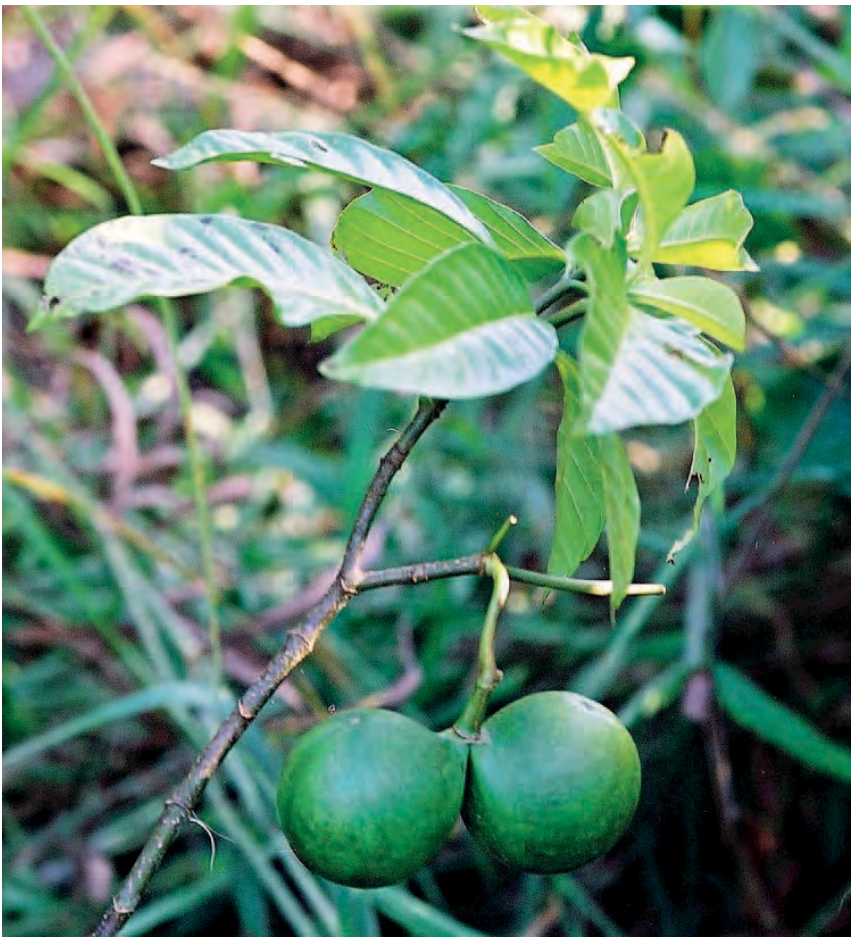

semaines et $90 \%$ après 7 semaines.

Description: Arbuste de 2 à $10 \mathrm{~m}$ de haut, se ramifiant près de la base, et formant une couronne basse étendue. L'écorce contient un peu de latex blanc. Feuilles opposées, de 7 à 40 sur 3 à $20 \mathrm{~cm}$, acuminées, vert foncé brillant en dessus. Fleurs crème, jaune ou brun, Le fruit est une paire de boules aplaties, de 3 à $8 \mathrm{~cm}$ de diamètre et de 2,5 à $7 \mathrm{~cm}$ d'épaisseur, vert foncé à taches vert clair. Chaque boule s'ouvre à maturité, laissant apparaitre une pulpe consistante jaune ou orange, contenant de nombreuses graines ellipsoïdes de 7 à $10 \mathrm{~mm}$ de long, brun foncé.

Ecologie: Plante de sous-bois des forêts secondaires, des forêts marécageuses, et des forêts galeries, dans toute l'Afrique tropicale.

Reproduction : Cueillir les fruits sur l'arbre avant qu'ils s'ouvrent ; les ouvrir à la main pour sortir la pulpe et les graines. Presser doucement la pulpe dans l'eau pour libérer les graines ; puis les sécher au soleil. On peut les conserver au frais jusqu'à 12 mois. On peut les tremper 12 heures dans l'eau pour hâter la germination, qui est en général bonne mais lente, atteignant $50 \%$ après 4

Gestion: L'espèce apparentée Voacanga thouarsii se taille et se recèpe facilement.

Usages : Cette plante a d'importants usages médicinaux ; on exporte les graines, principalement en Allemagne, où elles servent à produire des médicaments pour traiter les maladies cardiaques, I'hypertension artérielle et le cancer. Le latex peut servir de colle, soit seul, soit mélangé avec celui de divers Ficus. Les champignons comestibles Bunsambi poussent sur le tronc mort. L'écorce contient des fibres, employées au Nigéria pour faire des fils. Au Congo Brazzaville, on donne une décoction de la racine pour les problèmes cardiaques et la gonorrhée ; la plante sert aussi à traiter les plaies, furoncles, abcès, infections fongiques, onchocercose, et eczéma. Les écorces de $V$.

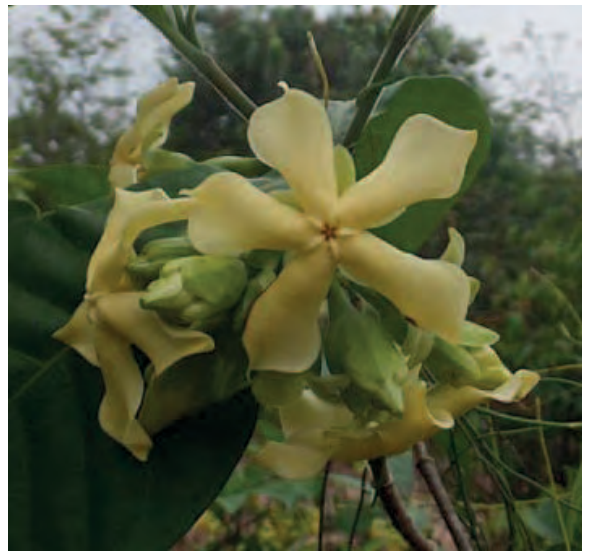
africana and $V$. thouarsii servent à traiter les ulcères d'estomac.

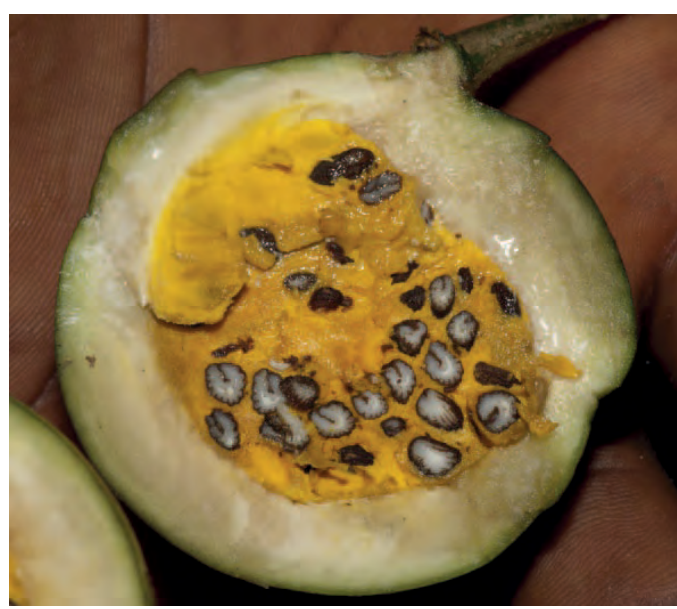

Remarque: L'exportation d'Afrique vers l'Europe de graines, écorces et racines atteint plusieurs centaines de tonnes par an, à des prix élevés, et les méthodes destructives de récolte pour le marché pharmaceutique international suscitent l'inquiétude du fait que l'espèce est en danger.

Références : Gillet et Pâque 1910, Gillet 1927, Renier 1948, Watt et Breyer-Brandwijk 1962, Nsimundele 1966 - 68, Bouquet 1969, Burkill 1985, I wu 1993, Pauwels 1993, Katende et al. 1995, Msanga 1998, Pousset 2004

Photo: David Harris/Royal Botanic Garden Edinburgh 


\section{Voacanga thouarsii}

Noms courants : Munkinya (Kikongo), voacanga de Thouars (Fr.), wild frangipani (Angl.)

Description : Arbre de 4 à $15 \mathrm{~m}$ de haut, se ramifiant dès la base, avec parfois des racines échasses en terrain marécageux. Ecorce contenant un peu de latex blanc. Feuilles de 6 à 25 sur 2 à $9 \mathrm{~cm}$, arrondies à l'apex, avec de petits trous épars sur les deux faces. Pétiole de 8 à $25 \mathrm{~mm}$ de long. Inflorescences en cymes longs de 9 à $21 \mathrm{~cm}$. Fleurs jaune pâle très odorantes de $15 \mathrm{~mm}$ de long. Fruit constitué de 2 boules séparées de 4 à $10 \mathrm{~cm}$ de diamètre, tachetées de vert pâle et foncé, à 2 valves, contenant de nombreuses graines. Graines obliquement ovoïdes ou ellipsoïdes, de 8 à $10 \mathrm{~mm}$ de long, finement verruqueuses, avec des sillons superficiels, brun foncé, arille orangé, pulpeux.

Ecologie : Arbre des forêts humides et des marécages, en Afrique tropicale, au Natal et à Madagascar.

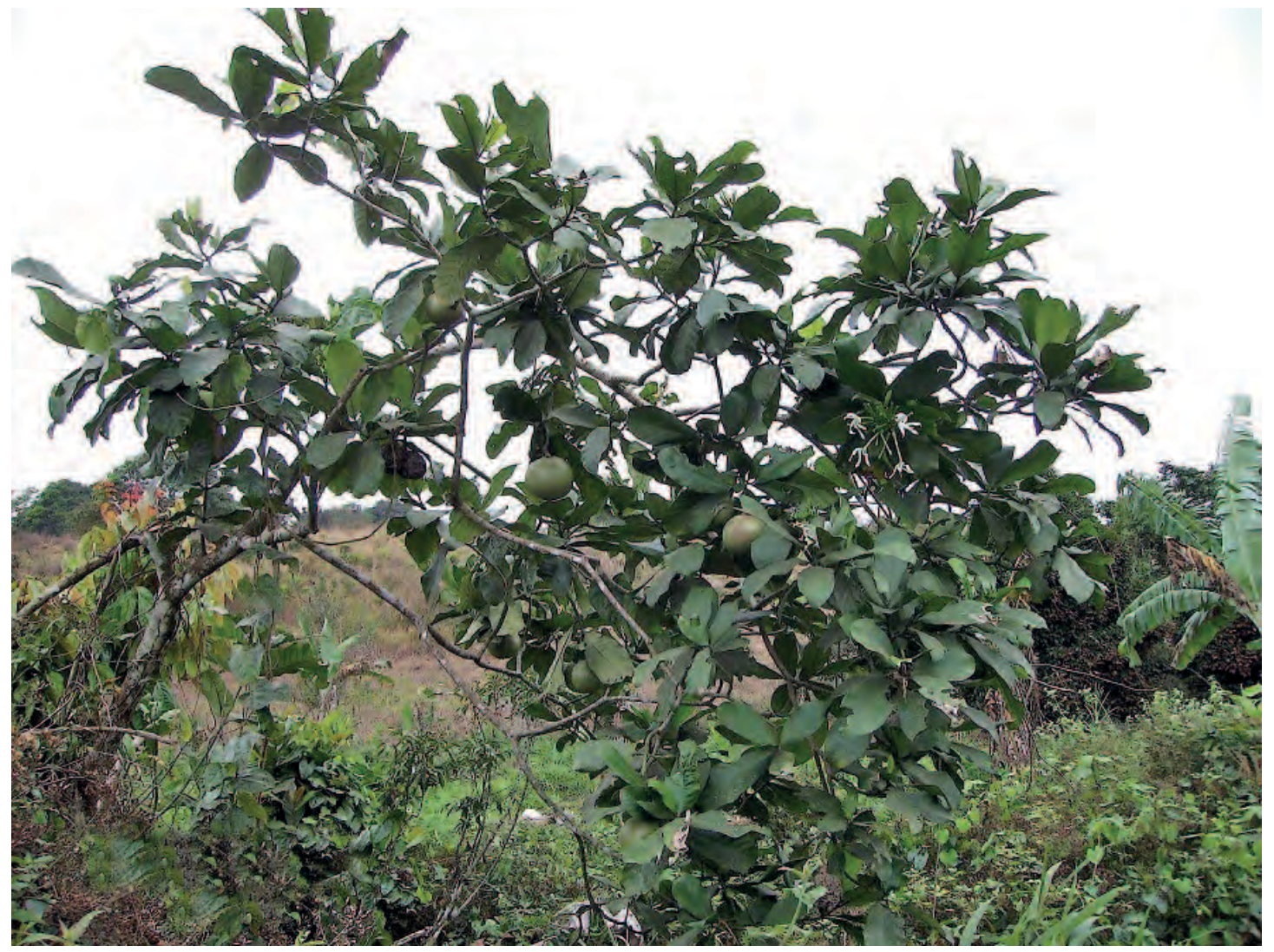

Reproduction: Prendre des semis spontanés, ou semer les graines dans des pots. Récolter les graines quand les fruits s'ouvrent, tremper une nuit. Les graines, gluantes, doivent se conserver dans le sable

Gestion : Cet arbre peut se conduire en taillis, et se recèpe bien.

A droite: Munkinya en fleurs en mars à Mato sur le Plateau Bateke

Usages: Le latex, les décoctions et infusions de l'écorce des tiges, des feuilles et des racines, s'appliquent sur les blessures, les brûlures et les douleurs; on les emploie pour traiter la gonorrhée, l'eczéma, les infections

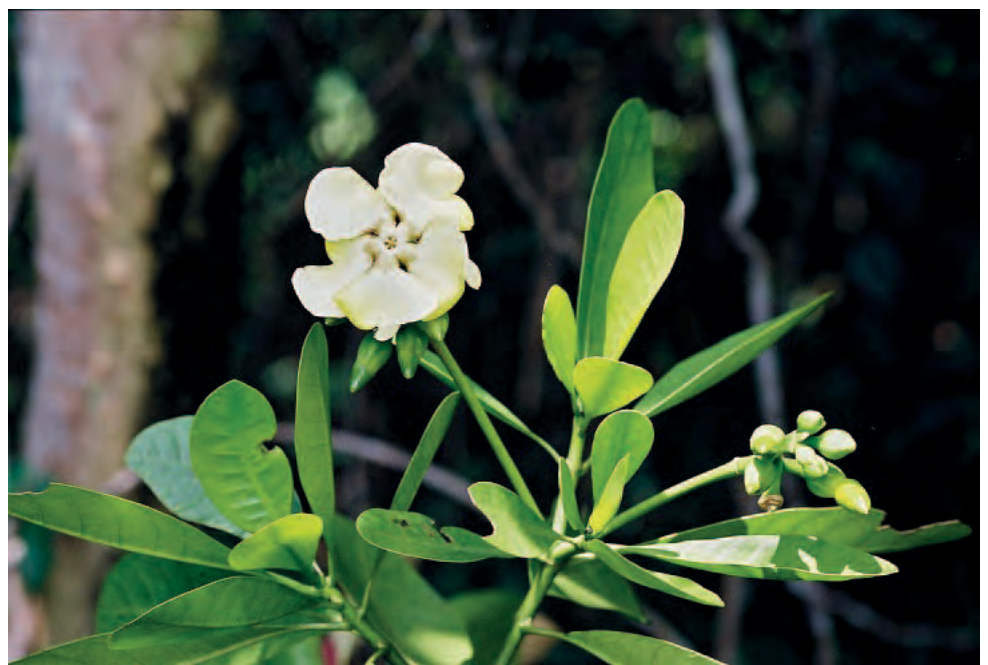
fongiques et la gale. En France et en Allemagne, on extrait des graines la tabersonine, qui est convertie en vincamine, composé largement employée en Europe comme sédatif du système nerveux central et pour le traitement des troubles vasculaires cérébraux chez les patients gériatriques. Les graines sont également exportées pour être employées dans des médicaments destinés à traiter les maladies de cœur, abaisser la pression sanguine 
et traiter les cancers. Le latex s'emploie aussi comme colle, par exemple pour fixer les couteaux dans leurs manches. Le tronc peut servir en construction. Au Soudan, on brûle le bois pour obtenir un sel végétal. Les espèces de Voacanga sont des plantes importantes pour le fourrage des abeilles dans les savanes humides d'Afrique.

Remarque: Plusieurs centaines de tonnes de graines de Voacanga sont exportées en particulier d'Afrique de l'Ouest, du Cameroun et de Madagascar à destination de firmes pharmaceutiques de France et d'Allemagne. Dans certaines régions, la récolte intensive de fruits et la coupe d'arbres pour recueillir leurs fruits afin de satisfaire la demande de graines de grandes firmes pharmaceutiques provoquent une disparition rapide de Voacanga thouarsii à l'état sauvage.

Références : Gillet 1927, Burkill 1985, Pauwels 1993, Katende 1995, Hepburn et Radloff 1998, Schmelzer 2006

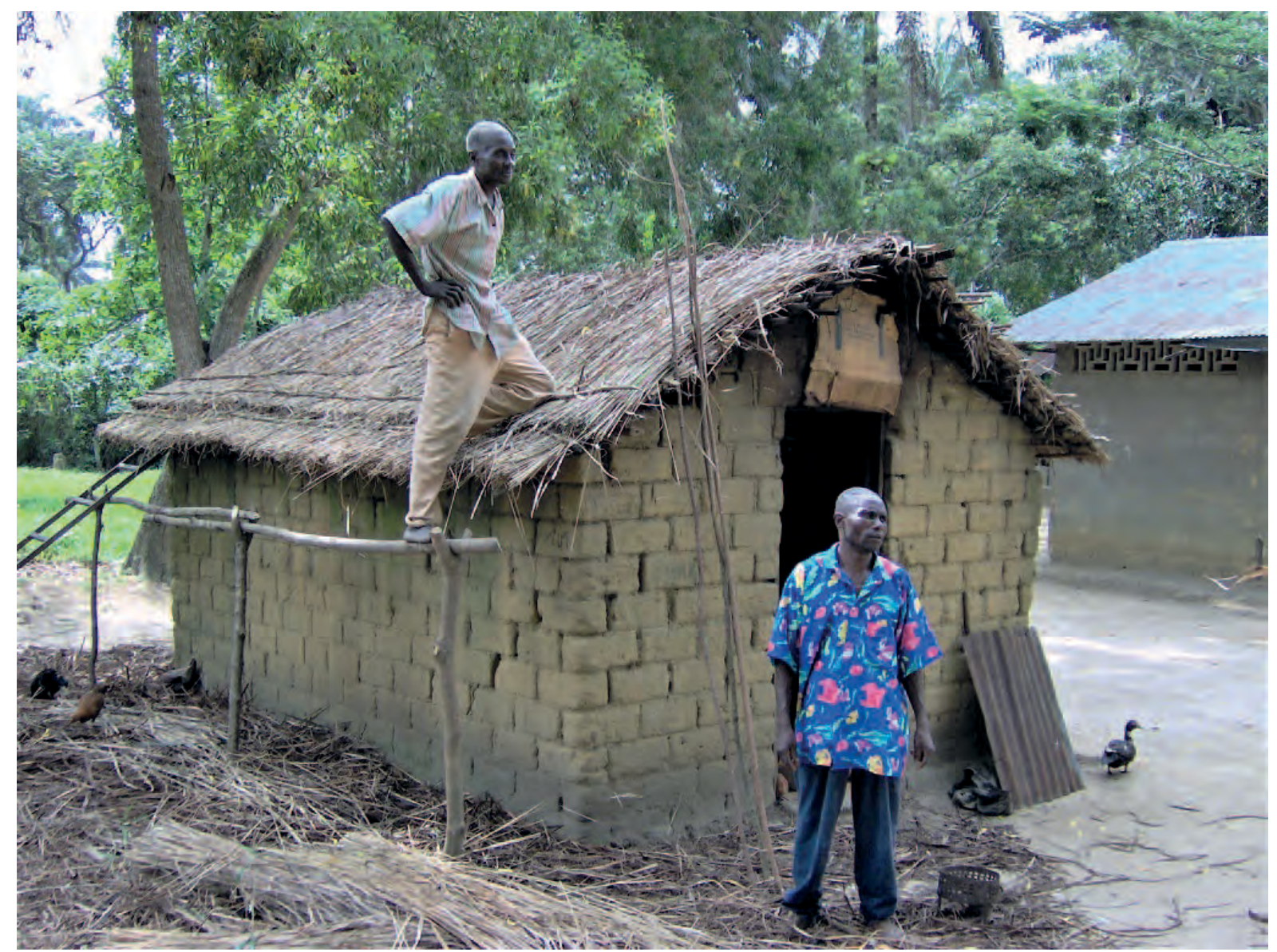

Toiture d'une cuisine à Mbanza Zundu 


\section{Waltheria indica}

Noms courants : Saku saku (Kikongo), mauve-gris (Fr.)

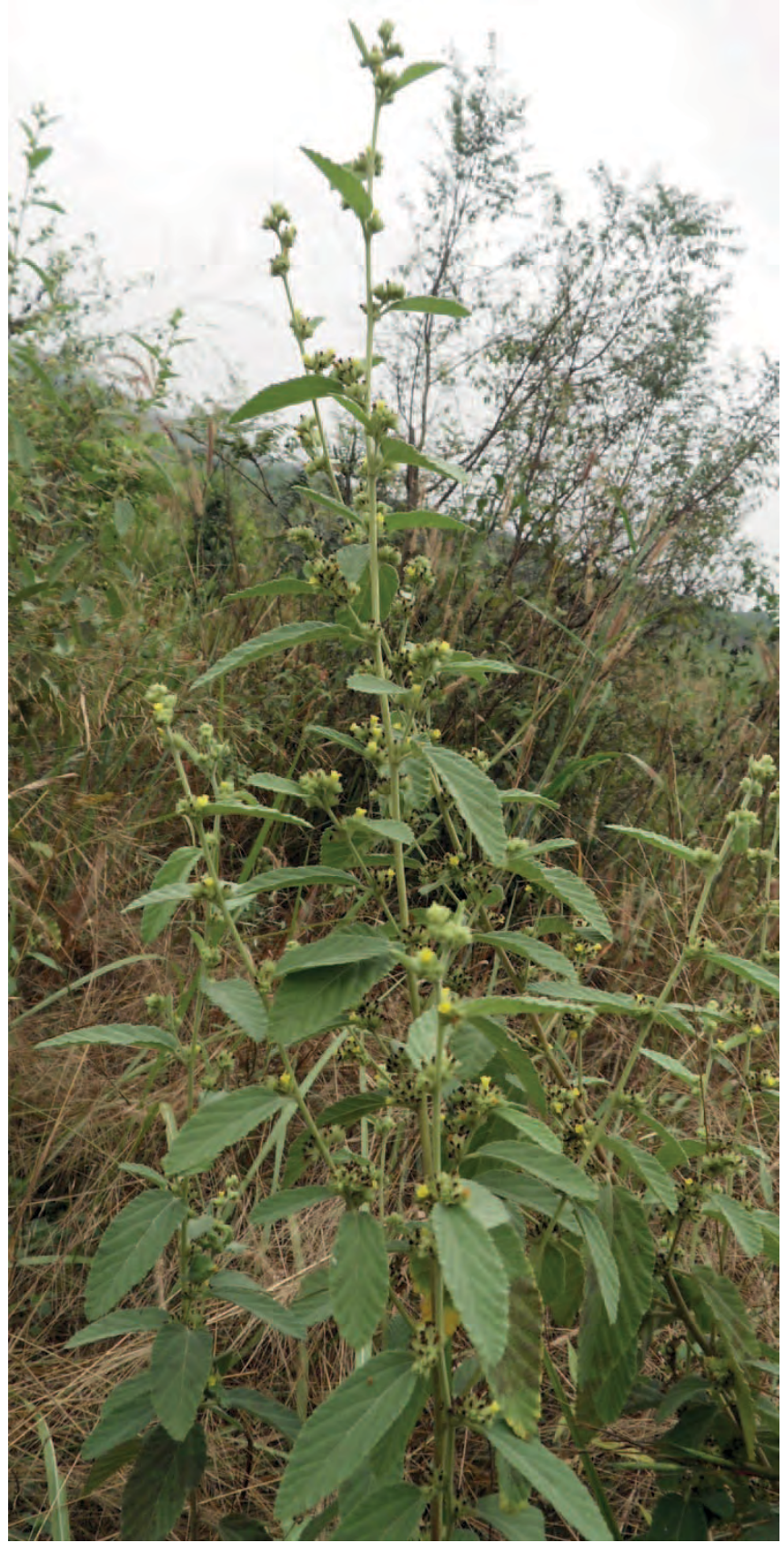

(Malvaceae)

Description : Plante herbacée dressée ou buisson atteignant $1,5 \mathrm{~m}$ de haut, à tige ligneuse souple, ramifiée et couverte de poils fins. Feuilles alternes atteignant $14 \times 6 \mathrm{~cm}$, dentées, de couleur vert-gris pâle, couvertes en dessous d'un tissu dense de poils fins. L'inflorescence est composée de fleurs serrées à l'aisselle des feuilles et à l'extrémité des tiges. Les fleurs sont petites, jaunes, virant à l'orange ou au brun en séchant. Leurs calices de 6 $\mathrm{mm}$ de long sont poilus. Le fruit est une capsule à deux valves contenant une seule graine ridée

Ecologie: Adventice commune des champs cultivés et des jachères, largement répandue en Afrique de l'Ouest. Pousse dans des habitats perturbés, secs, ou bien drainés s'ils sont humides. Ne tolère pas l'ombre, dépérit sous une canopée arborée fermée, et ne résiste pas à la compétition avec l'herbe dans les prairies épaisses. Résiste à la sécheresse.

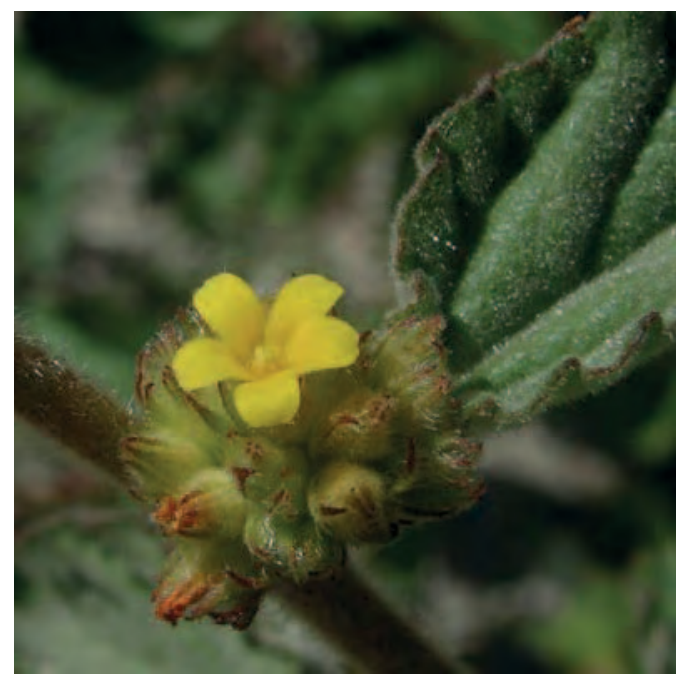

Photo : Burnt Umber

Reproduction : Par graines.

Usages: On a observé la visite des fleurs par les abeilles en juin au Kongo Central. Cette plante a de nombreux usages médicinaux en Afrique. On mange comme légume les feuilles, mucilagineuses. En Ouganda, on mélange les feuilles avec celles de dolique pour les cuire comme légumes. Le bétail broute la plante quand elle n'a pas de fruit. On se sert des tiges comme bâtons à mâcher.

Références : Renier 1948, Goode 1974, Akobundu et Agyakwa 1987, Burkill 2000, Neuwinger 2000, Nsimundele 2004, Kokwaro 2009 


\section{Whitfieldia elongata}

Nom courant : White candle (Angl.)

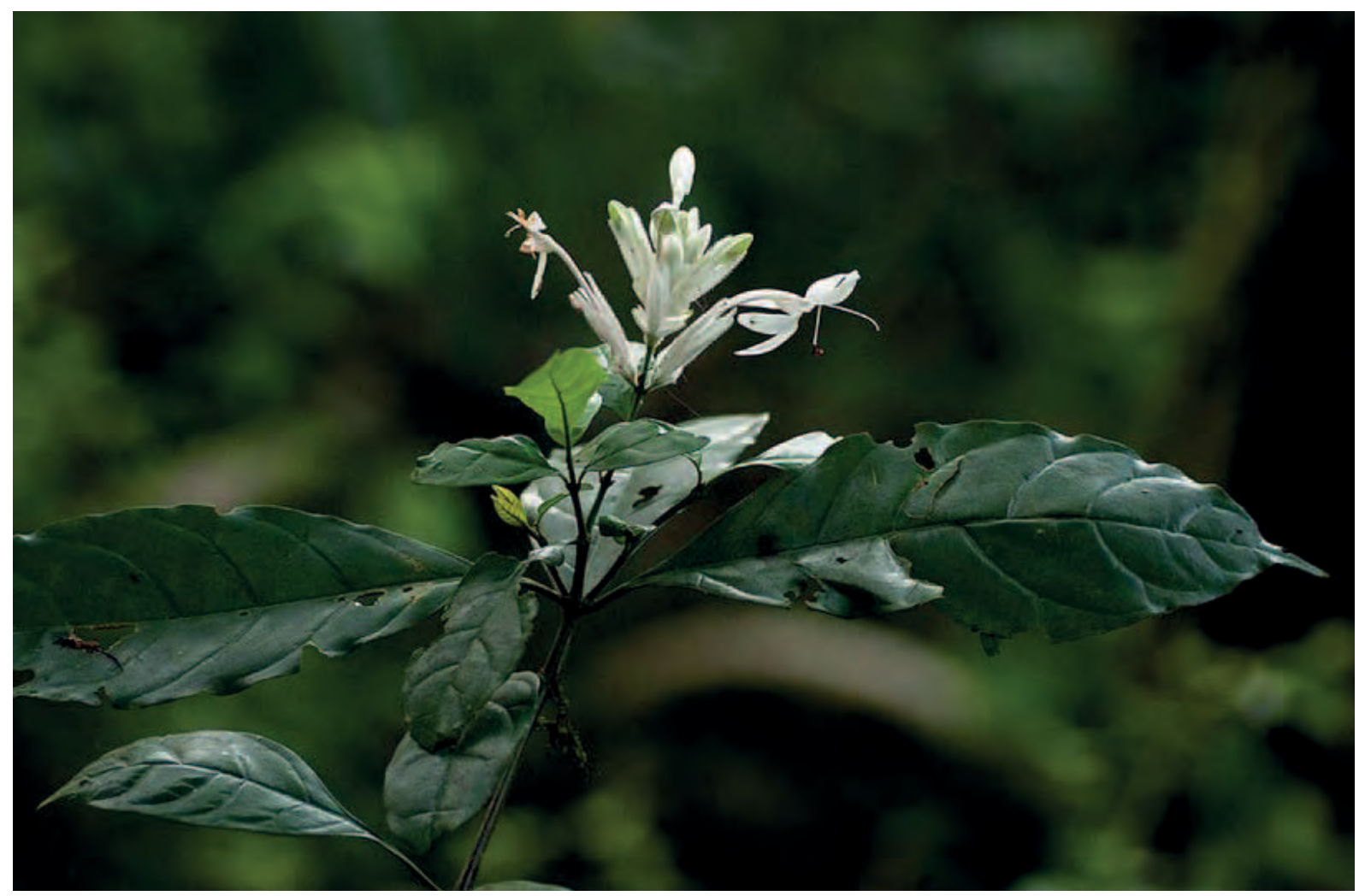

Photo : Bart Wursten

Description : Buisson irrégulier de 1,5 à $3 \mathrm{~m}$ de haut, ou, rarement liane. Les tiges sont légèrement anguleuses et rétrécies en-dessous des nœuds. La tige contient de la moelle. Les feuilles ont de 13 à 22 sur 4,5 à $9 \mathrm{~cm}$. La plante donne de belles fleurs blanches de 6 à $8 \mathrm{~cm}$ de long, avec un calice semblant porter des pétales, en panicules terminaux.

Ecologie : Plante présente dans les forêts ombreuses et humides et les forêts galeries, du sud du Nigéria à I'Angola, ainsi qu'au Soudan et en Tanzanie.

Usages: Au sud du Nigéria, on fabrique avec les tiges des broches de filature. Au Congo Brazzaville, on fait un cataplasme avec les feuilles pilées et chauffées pour traiter les bronchites; on mange les mêmes feuilles pour favoriser la conception. On boit une décoction des feuilles dans le vin de palme pour les maux d'estomac et contre les empoisonnements. En Tanzanie, on emploie les feuilles pour soulager les maux de tête. En R.D. Congo, on emploie les feuilles pour avoir une teinture noire. On mâche les racines contre les morsures de serpent.

Remarque : On trouve aussi au Kongo Central $W$. brazzae et $W$. thollonii.

Références : Renier 1948, Burkill 1985, Pauwels 1993, Neuwinger 2000, Kokwaro 2009 


\section{Xanthosoma sagittifolium}

Noms courants : Langa (Kikongo), macabo, chou caraïbe (Fr.), tannia, new cocoyam (Ang.)

Description : Plante herbacée pérenne de 1,3 à 2,5 m de haut sur un gros bulbe, ressemblant au taro (Colocasia), mais plus grande. La tige est courte, et les feuilles se situent au bout de grosses côtes. Feuilles en forme de flèches, de 45 à $90 \mathrm{~cm}$ de long, à pointes aigües et nervure centrale proéminente. Certaines plantes peuvent connaitre ou non la floraison. Le bulbe à la base de la plante produit 10 bulbilles latéraux (bourgeons végétatifs latéraux) de 10 à $25 \mathrm{~cm}$ de long.

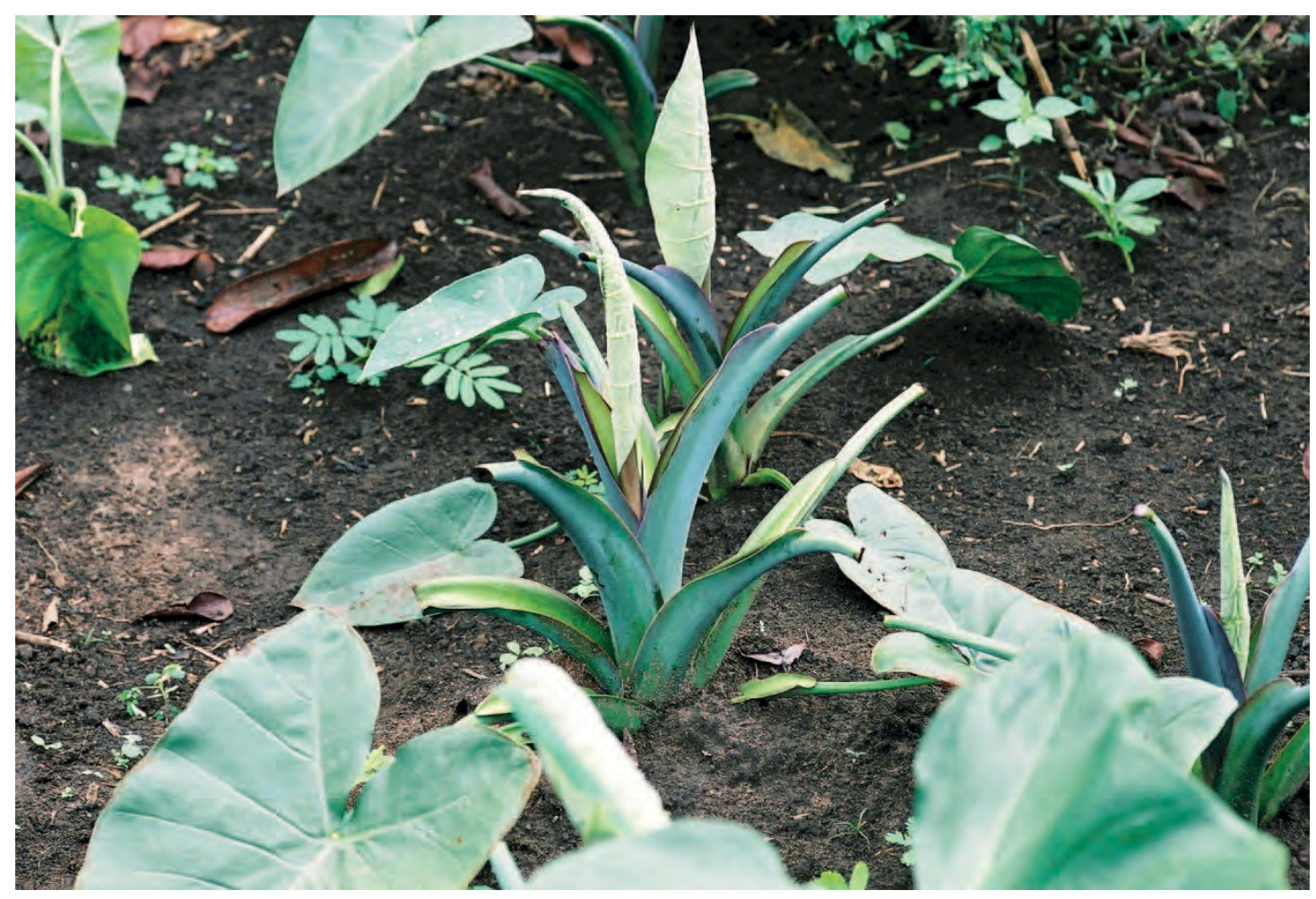

Macabo cultivé pour ses feuilles

Ecologie : Plante originaire d'Amérique tropicale, maintenant cultivée en Afrique, Asie et Polynésie. Prospère en conditions tropicales avec beaucoup de pluies et sols profonds bien drainés à l'abri des inondations. On peut la cultiver jusqu'à 2.000 d'altitude, et elle tolère mieux l'ombre et les sols pauvres que le taro.

Reproduction : On emploie les bulbilles au sommet du bulbe principal, avec un ou plusieurs bourgeons, et pesant environ $150 \mathrm{~g}$. Planter au début des pluies, de préférence sur des talus, avec la pointe du bourgeon vers le bas, à 7,5 à $10 \mathrm{~cm}$ de profondeur. On peut aussi planter des morceaux du bulbe, en laissant la pointe au-dessus du sol. Planter à l'espacement de 1 × $1 \mathrm{~m}$.

Gestion : On récolte les feuilles dès qu'elles commencent à jaunir, 9 à 12 mois après la plantation. On peut laisser les bulbes dans le sol ; après la première récolte, la plante peut continuer à produire des feuilles 6 années de suite. Les rendements peuvent être de 20 à 25 t/ha.

Usages : Au Kongo Central, le principal usage concerne les feuilles, surtout les jeunes feuilles, que l'on cuit et mange comme légumes après en avoir ôté la nervure centrale. Elles contiennent $2,5 \%$ de protéines en pourcentage du poids frais. Les bulbilles se mangent bouillis ou cuits au four.

Références : Gillet et Pâque 1910, Gillet 1927, Renier 1948, Kay 1973, Daeleman et Pauwels 1983, Tindall 1983, Burkill 1985, Raemaekers 2001 


\section{Xylopia aethiopica}

Noms courants : Nsombo, mukala, mukwa (Kikongo), poivrier de Guinée (Fr.), kimba or West African pepper (Angl.)

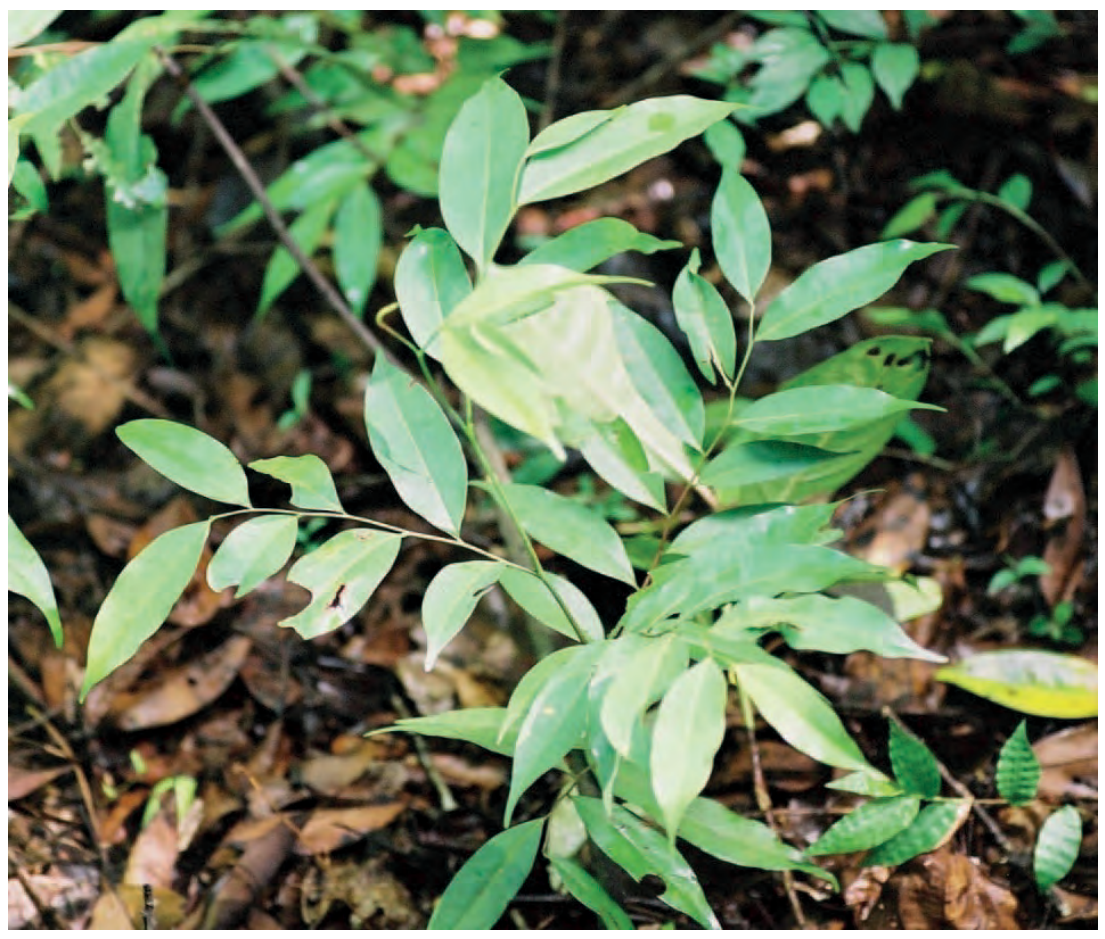

Description : Arbre jusqu'à 40 $m$ de haut, à fût droit, cime conique et feuillage vert sombre, Feuilles alternes, simples, à limbes elliptiques atteignant $20 \mathrm{x}$ $9 \mathrm{~cm}$, coriaces, à sommet aigu Fleurs trimères d'environ $5 \mathrm{~cm}$ de longueur, de couleur blanchâtre, très odorantes. Fruits : grappes de 20 à 30 follicules cylindriques, atteignant $6 \times 1 \mathrm{~cm}$, légèrement étranglés entre les graines, rouge-brun à l'extérieur, se retournant complètement après déhiscence, rouge vif à l'intérieur. Graines au nombre de 4 à 9 , mesurant 5 à 7 sur 2 à 4 $\mathrm{mm}$, brun luisant avec un arille orangé, à odeur poivrée.

Ecologie: Pousse dans les savanes et en lisière de forêts du Sénégal au Congo, à l'Angola, à la Tanzanie et à la Zambie. Cette espèce aime l'ombre.

Reproduction : Récolter les fruits mûrs, les mettre à sécher et séparer les graines. Les tremper 24 heures, et les semer en pots on en pleine terre.

Gestion : Cet arbre se taille et se recèpe bien.
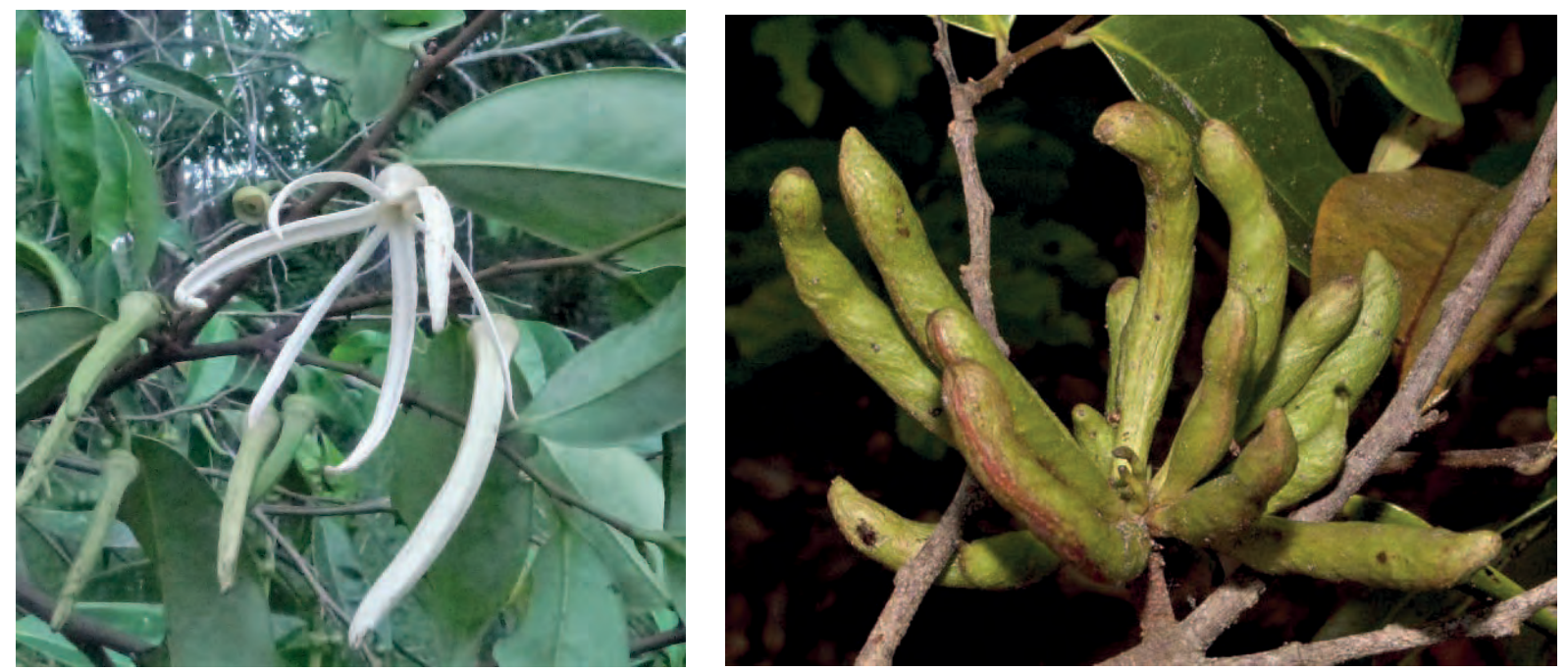

En haut : fleurs en décembre

A droite : fruits. David Harris/Royal Botanic Garden, Edinburgh

Usages : Le bois est jaune clair, moyennement lourd et résistant aux termites. Les troncs s'emploient spécialement en construction. Le bois sert en menuiserie générale. II peut aussi donner du charbon de bois. Les fruits séchés au goût de poivre servent d'épice dans les ragouts, et pour faire une bière épicée. Ils ont des usages médicinaux comme analgésiques, pour traiter les rhumatismes, les maux d'estomac, et la malaria. Ailleurs en Afrique, on emploie une décoction des graines ou de l'écorce pour soulager la toux et traiter les bronchites. Par endroits on en trouve sur les marchés. Un temps ils ont été exportés en Europe. Pour chasser les charançons, on fait un mélange des fruits pilés (appelé nkuba nkuba ou nkuva nkuva) avec du poivre de cayenne et des noix de kola. On 
met parfois le fruit dans l'eau pour la purifier. Les fleurs, qui apparaissent en saison sèche, sont attrayantes pour les abeilles. Les chenilles comestibles nsyangi broutent les feuilles.

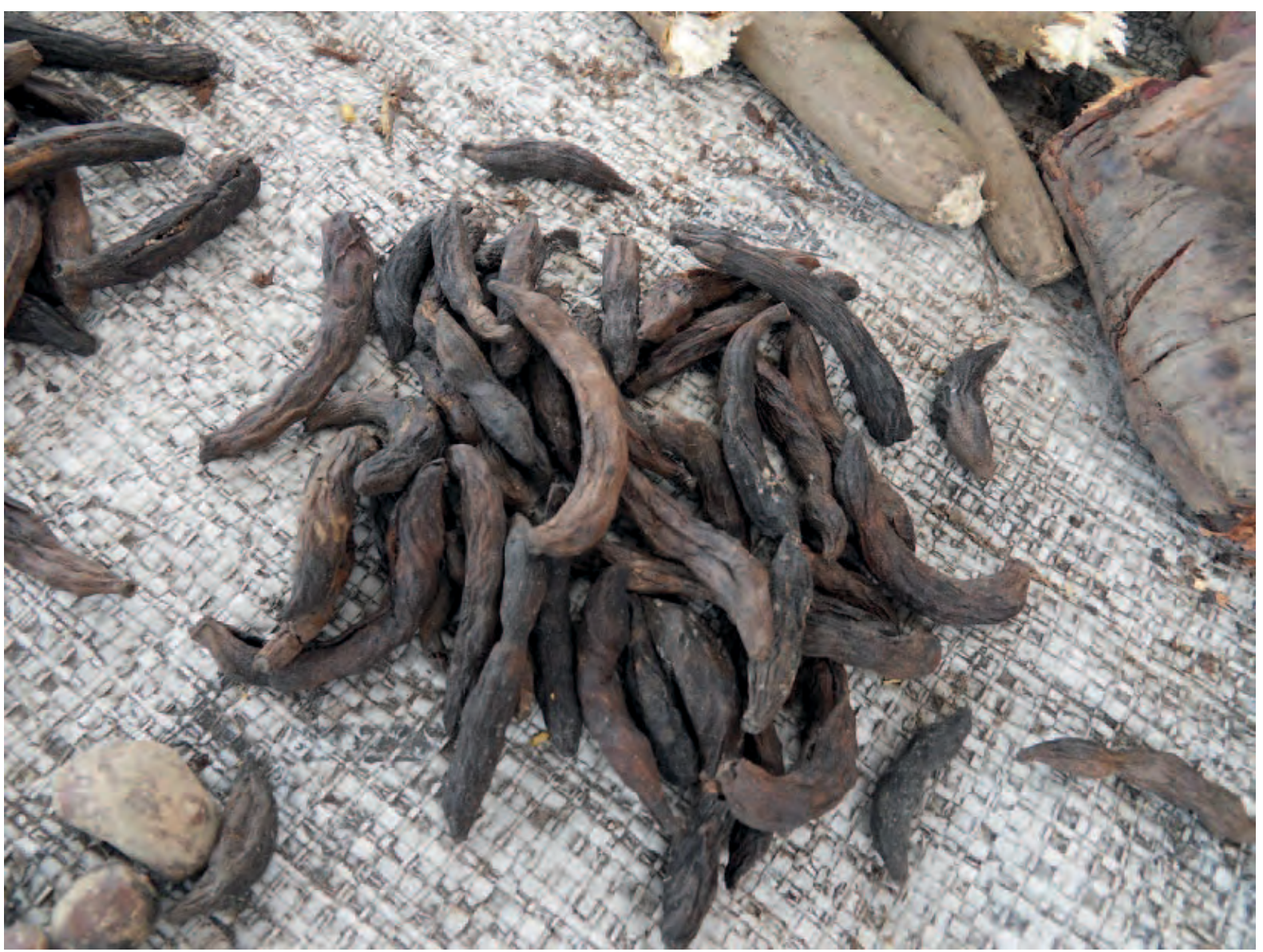

Fruits séchés en vente sur un marché

Références : Gillet et Pâque 1910, Renier 1948, Boutique 1951, Busson 1965, Nsimundele 1966 - 68, Burkill 1985, Pauwels 1993, Katende et al. 1995, Vivien et Faure 1996, Nsimundele 2004, Pousset 2004, Harris et al. 2011 


\section{Zanthoxylum gilletii}

Noms courants : Nkonko nkumanga, nsende nsende, nungu tsende (Kikongo), ekondo (Lingala), olon dur, citronnier d'Afrique (Fr.), African satinwood (Angl.)

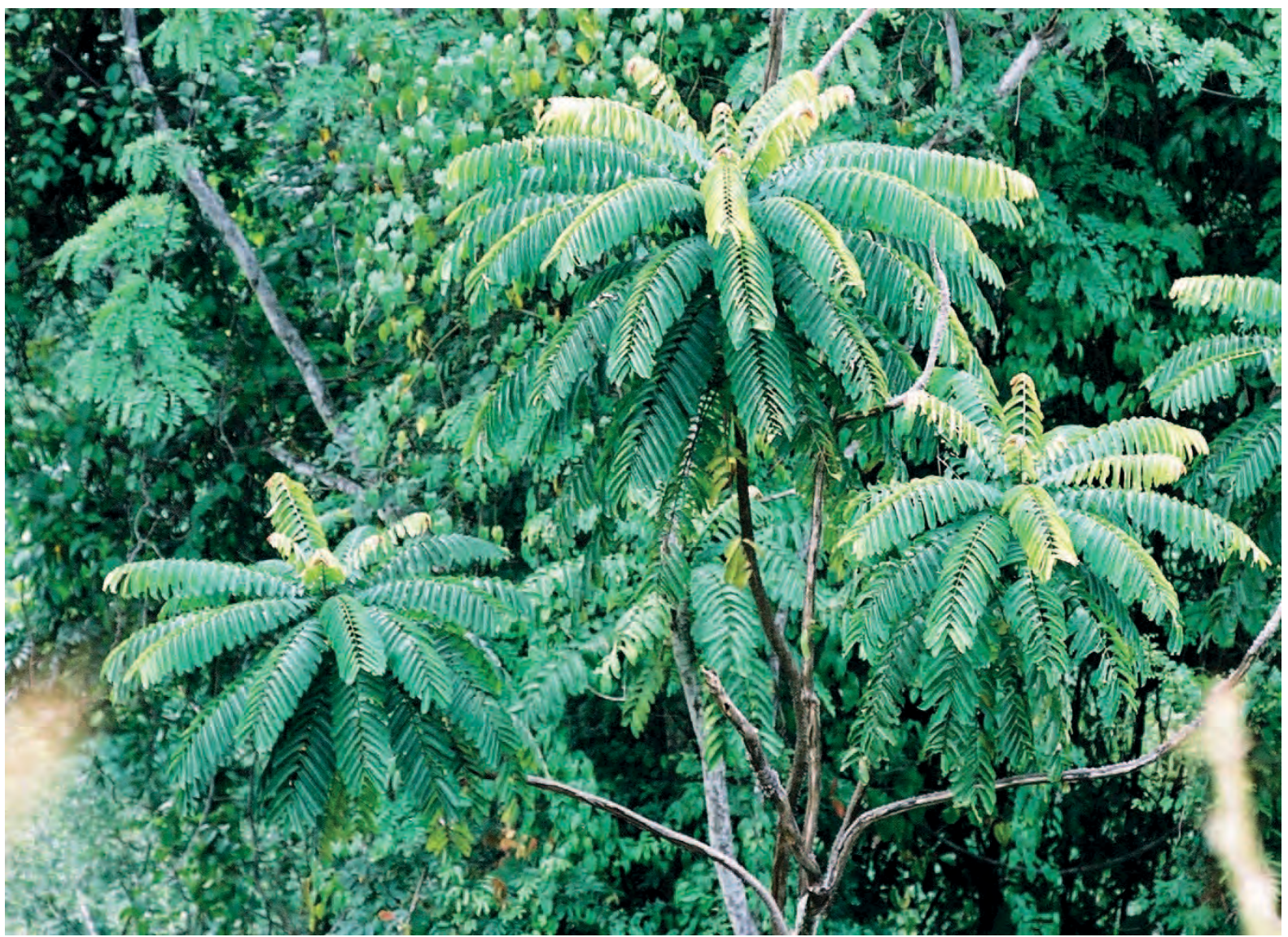

Description : Arbre à feuilles caduques jusqu'à $35 \mathrm{~m}$ de haut, à tronc droit, avec de nombreuses protubérances liégeuses atteignant $3 \mathrm{~cm}$ de long et pourvues d'aiguillons. Feuilles disposées en bouquets terminaux comprenant 20 paires de folioles, et une foliole terminale de 20 à $30 \mathrm{~cm}$ de long. Fleurs blanc crème, en inflorescences terminales de 20 à $30 \mathrm{~cm}$ de long. Fruits ronds et rouges, de 4 à $6 \mathrm{~mm}$ de diamètre, chacun contenant une graine noir brillant. Les fleurs mâles et femelles sont disposées sur des arbres différents.
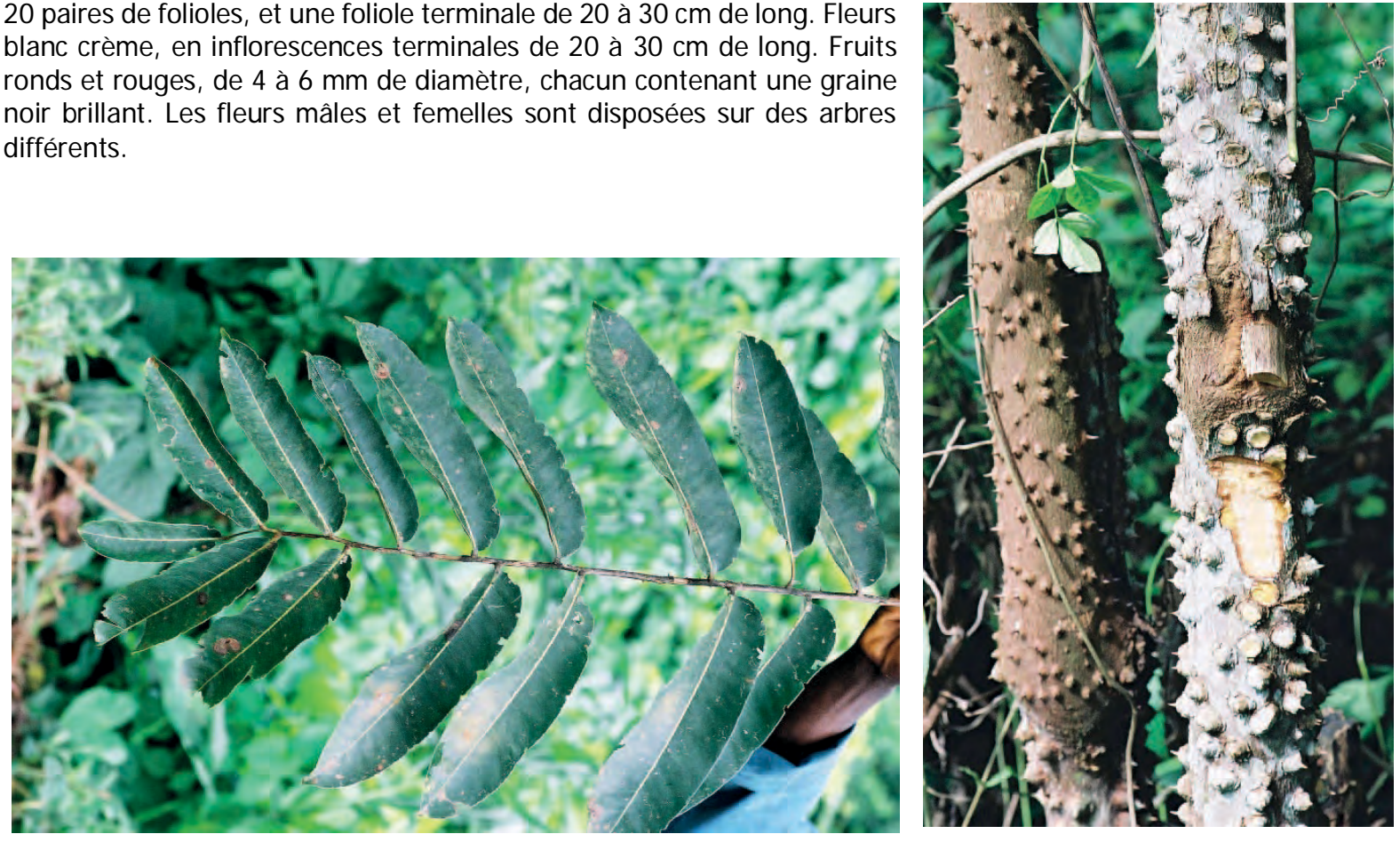
Ecologie : Arbre des forêts sempervirentes en Afrique occidentale et orientale, dans le bassin du Congo, au Soudan et en Angola. On le cultive en peuplements purs ou comme haie.

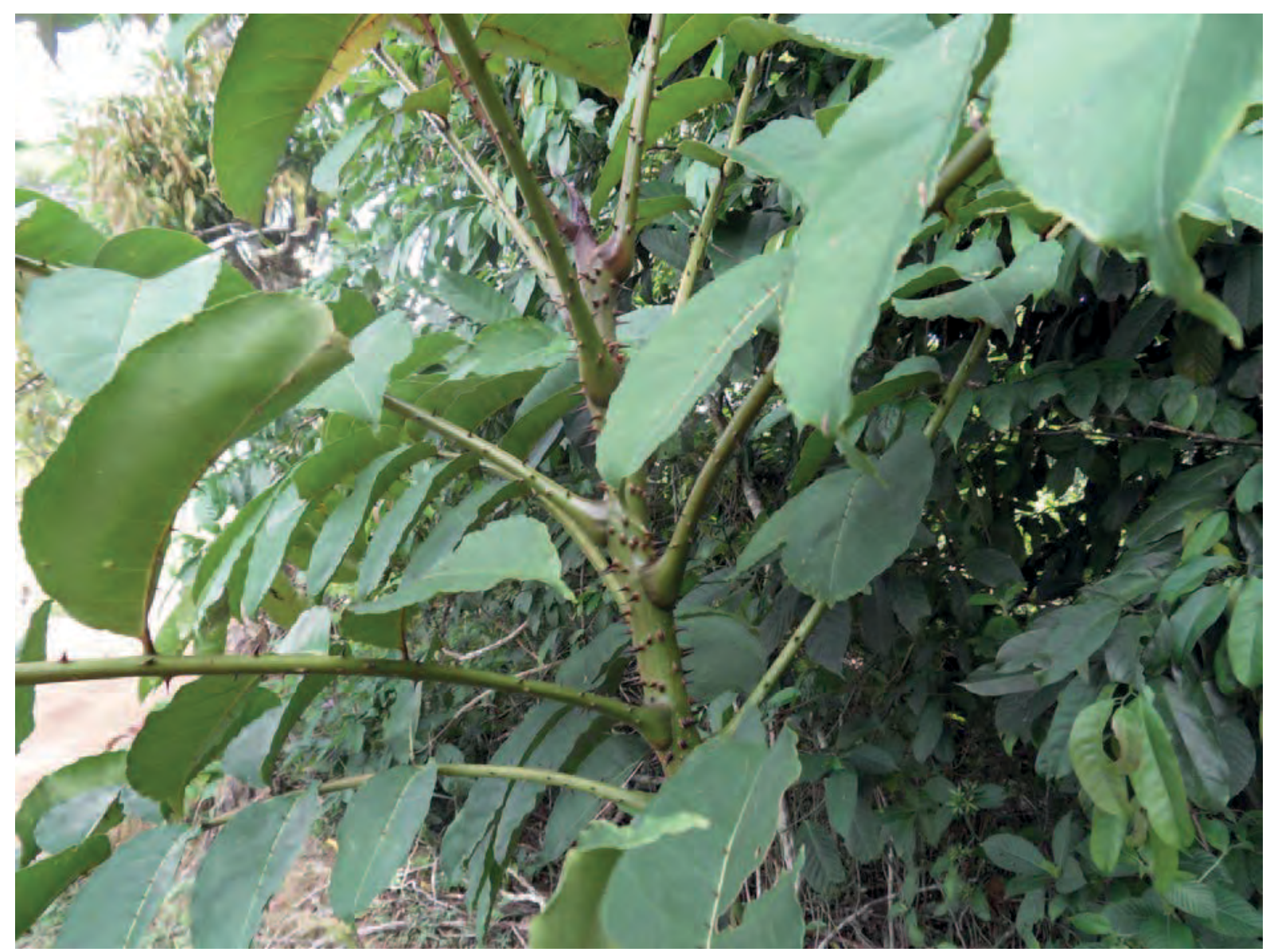

Reproduction : Peut se cultiver par graines, bien que la germination soit souvent médiocre. Cueillir le fruit avant qu'il s'ouvre, l'ouvrir et le sécher 1 ou 2 jours au soleil. Extraire les graines mais ne pas les laisser au soleil. On peut les conserver jusqu'à deux mois en ajoutant de la cendre pour les protéger des attaques d'insectes. Les semis ont besoin du plein soleil, et poussent bien sur les anciens champs cultivés. On a pratiqué le bouturage et le marcottage, qui ont donné de bons résultats.

Gestion : Cet arbre se recèpe bien.

Usage : Cet arbre est intéressant pour son bois, de couleur jaune et odorant, même s'il est parfois difficile à travailler. II prend un beau poli et se finit bien. II est durable, sauf au contact prolongé avec le sol. On l'emploie en construction, pour les pilons et mortiers, les menuiseries et huisseries intérieures, etc. II se cintre facilement à la vapeur. L'huile des graines serait comestible. L'écorce contient une résine toxique ; trempée dans l'eau, on l'emploie pour tuer les poux. Ce liquide sert aussi à traiter la fatigue, l'anxiété, et les maux de tête. On mâche l'écorce comme analgésique et pour soulager les maux de dents. Selon une croyance, les feuilles finement hachées avec du jus de citron soigneraient les morsures de serpents. Les jeunes bourgeons terminaux, sans les feuilles, ont une odeur douce, et servent à parfumer les sauces. Les abeilles butineraient le nectar et le pollen des fleurs en janvier.

Références : Butaye 1909, Gillet et Pâque 1910, Renier 1948, Gilbert 1958, Nsimundele 1966 - 68, Dupriez et De Leener 1989, Pauwels 1993, Katende et al. 1995, Burkill 1997, Kokwaro 2009, Meunier et al. 2010 
Noms courants : Sangu, sasi (Kikongo), masango (lingala) maïs (Fr.), maize (Angl.)

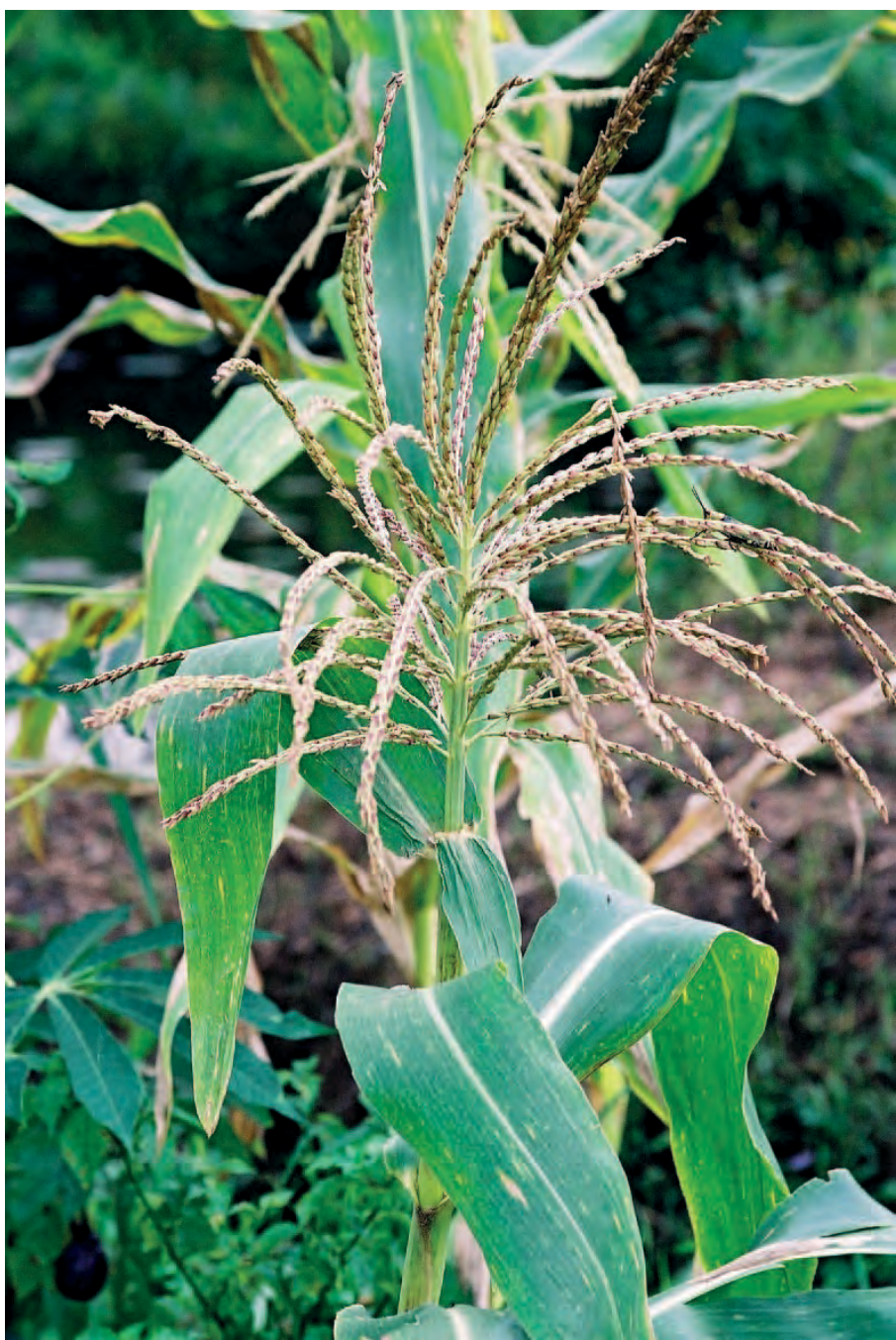

Description : Plante annuelle robuste de $3 \mathrm{~m}$ de haut. La tige unique, de diamètre variant de 5 à $6 \mathrm{~cm}$ est lignifiée et formée d'entrenœuds d'une vingtaine de centimètres séparés par autant de nœuds. Au niveau de chaque nœud est insérée une feuille alternativement d'un côté et de l'autre de la tige. Les feuilles ont jusqu'à $10 \mathrm{~cm}$ de large et un mètre de long, avec une gaine enserrant la tige et un limbe allongé en forme de ruban à nervures parallèles. Le système racinaire comprend un très grand nombre de racines adventives qui naissent sur les nœuds situés à la base de la tige. Ces racines forment un système qui peut atteindre une profondeur supérieure à un mètre. Les fleurs mâles sont groupées dans une panicule terminale. Les fleurs femelles se disposent en épi, entouré de feuilles modifiées, les spathes, qui enveloppent complètement l'épi, et se dessèchent à maturité des grains. Les fleurs sont cachées à l'intérieur des spathes ; seuls sont visibles les longs stigmates filiformes, appelées soies, qui forment un bouquet en haut des spathes, et sont disposées à accueillir les grains de pollen. Après fécondation, les grains grossissent à l'intérieur des spathes. A maturité, l'épi contient le plus souvent 400 à 500 grains de couleur en général jaune ou blanche. L'épi est de dimensions très variables (longueur de 5 à $45 \mathrm{~cm}$, diamètre de 3 à $8 \mathrm{~cm}$ ).

A gauche : Les inflorescences mâles sont une bonne source de pollen pour les abeilles

Ecologie: La domestication du maïs au Mexique aurait commencé il y a plus de 9000 ans. A l'arrivée des européens, le maïs était cultivé dans toutes les Amériques, de l'Argentine jusqu'au Canada. Depuis, le maïs s'est largement diffusé dans le monde entier. Aujourd'hui, la culture du maïs concerne près de 150 pays dans les cinq continents. Cette culture revêt des aspects très contrastés: depuis l'agriculture familiale manuelle jusqu'à la culture intensive. La sélection des variétés adaptées aux différents sols et climats, et aux différents modes de culture est très active. En RD Congo, I'INERA Yangambi a développé la variété ZE-169 qui peut produire $3 \mathrm{t} / \mathrm{ha}$ de grains ; I'INERA diffuse également des variétés adaptées aux différentes conditions écologiques du pays, originaires de divers pays africains (Zambie, Tanzanie, Nigéria, etc.). Le maïs est une culture de climats chauds ; il préfère les limons fertiles profonds, bien aérés et bien drainés, avec une humidité suffisante.

\section{A droite : Décorticage du maïs}

En Afrique, on le cultive en saison sèche sous irrigation le long des cours d'eau, et en saison des pluies, souvent associé au manioc. Le maïs

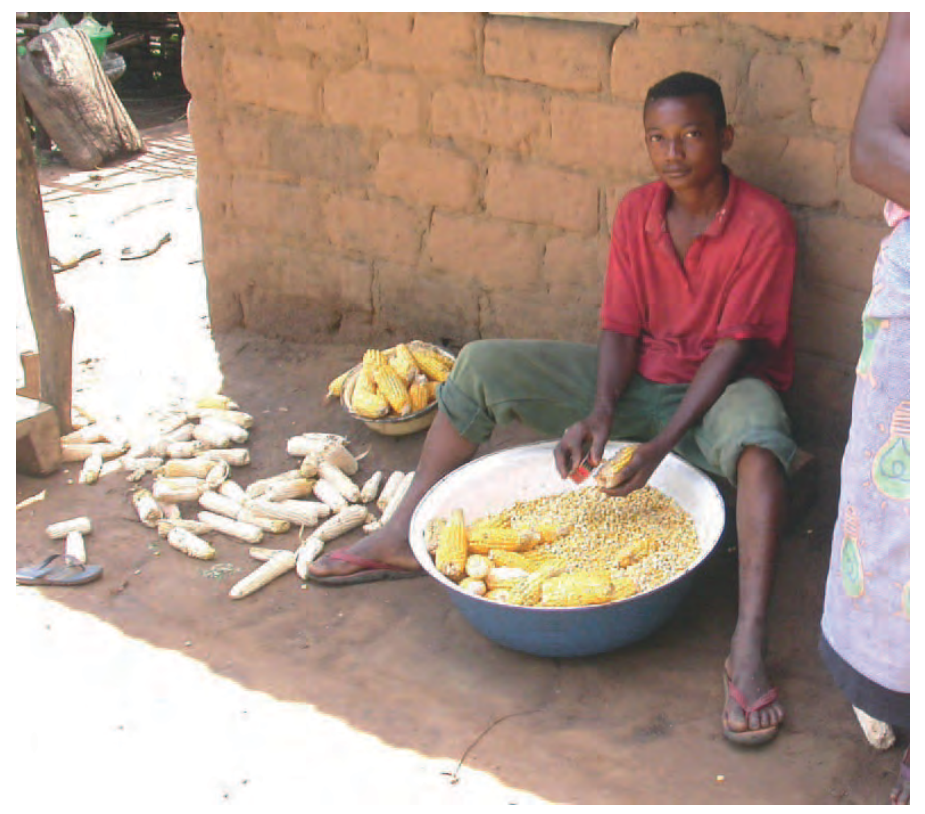


est souvent la première culture mise en place après la jachère forestière. On le cultive largement là où le système de jachères est bien maintenu.

Reproduction : par graines.

Gestion : Les insectes perforateurs des tiges sont un ennemi majeur. On peut les contrôler par le tabac ou par une solution de feuilles de Tephrosia vogelii que l'on verse l'intérieur de l'orifice central de la plante.

Usages : Le maïs est la céréale la plus produite au monde, la production de grains devançant légèrement celles du riz et du blé. Les deux premiers producteurs, États-Unis et Chine, représentent près de $60 \%$ du total mondial, Au niveau mondial, $67 \%$ du maïs produit sont utilisés pour l'alimentation animale, $27 \%$ pour l'alimentation humaine, $6 \%$ pour l'industrie alimentaire et applications diverses. En RD Congo, le maïs constitue l'alimentation de base des Provinces du Kasaï et du Katanga, et joue un rôle croissant dans l'alimentation des autres Provinces, notamment à Kinshasa et dans les Provinces du Kivu. Au Kongo Central, la récolte de maïs a lieu en janvier et février, fournissant de la nourriture à une époque où il y a peu d'autres récoltes disponibles. Les grains peuvent se manger avant maturité. Les grains secs moulus en farine sont souvent mélangés avec la farine de manioc pour préparer le foufou. Ils servent à l'alimentation des volailles et s'emploient pour préparer les aliments pour les volailles et les porcs. La farine sert à préparer diverses boissons alcoolisées. Elle sert aussi à préparer une sorte de pain. Les soies des épis non mûrs servent à traiter les problèmes urinaires ; le pollen est employé pour stimuler l'appétit. Les spathes autour des épis servent parfois à bourrer les matelas. Les abeilles butinent souvent le pollen des fleurs mâles pendant les pluies, et parfois aussi la sécrétion sucrée qui forme une rosée sur les feuilles ; ceci parfois en quantités suffisantes pour donner une production de miel.

Références : Gillet et Pâque 1910, Gillet 1927, Van Den Abeele et Vandenput 1956, Howes 1979, Daeleman et Pauwels 1983, Crane et al. 1984, Drachoussoff 1993, Stoll 2000, van Wyk et Wink 2004, Badu-Apraku et Fakorede 2006

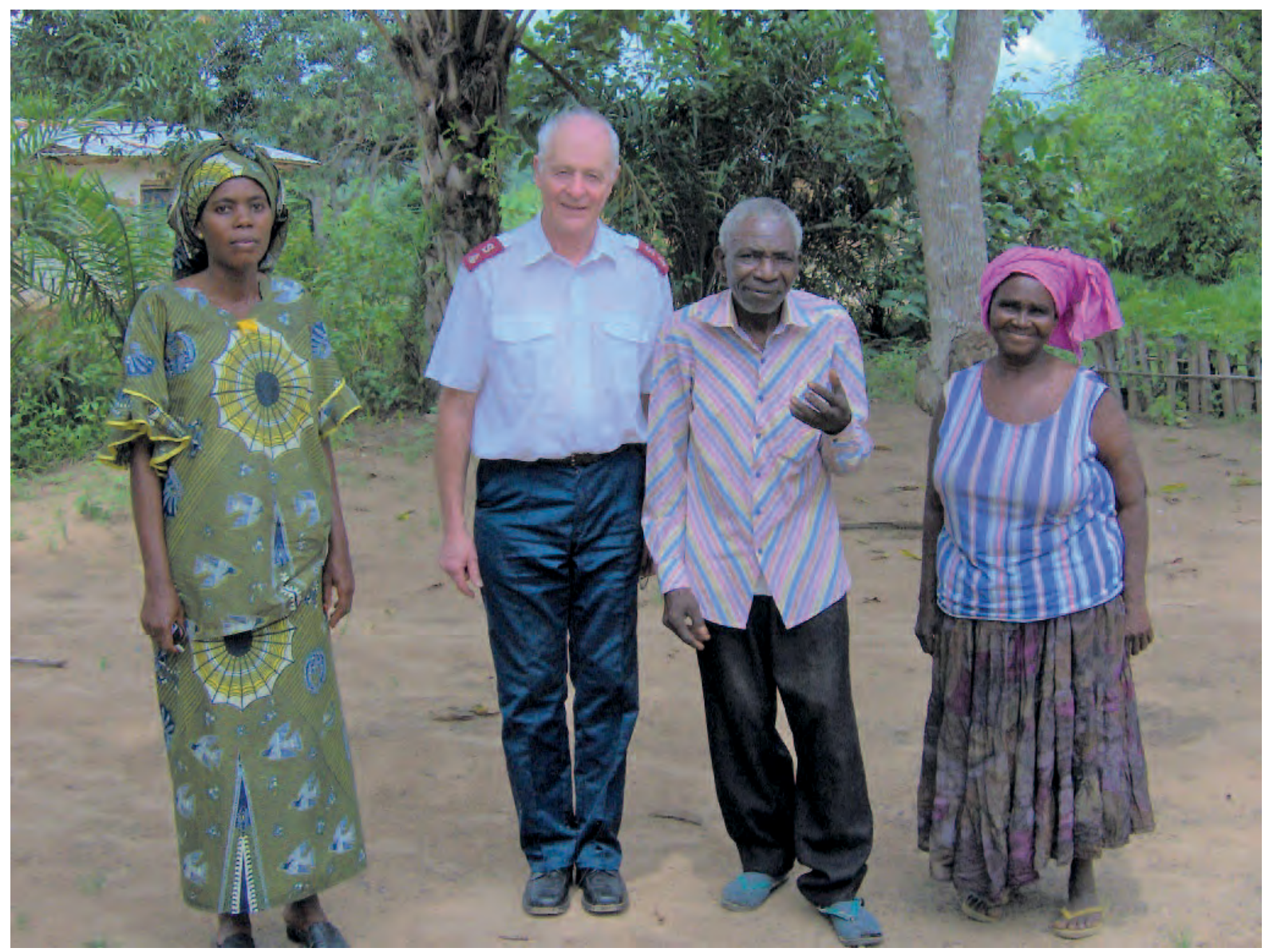

Thérèse Luvuma, Paul Latham et M. et Mme Nganga à Kasangulu. M. Nganga était un spécialiste des chenilles comestibles et a élevé pendant de nombreuses années des chenilles Cirina forda (Ngala) sur Crossopteryx febrifuga dans sa ferme. 
Noms courants : Tangawusa, tangawisi, tangawisa (Kikongo), gingembre (Fr.), ginger (Angl.)

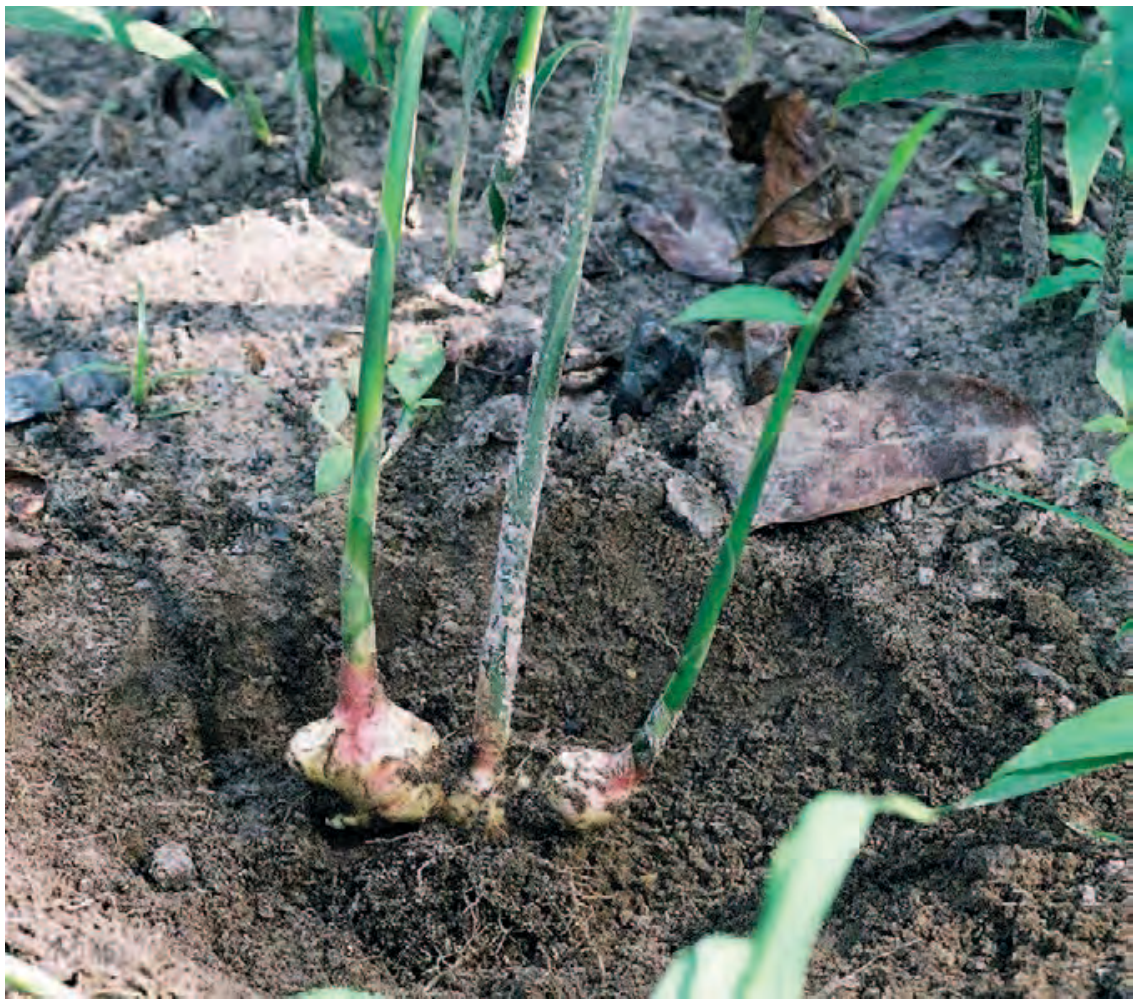

Description: Plante herbacée pérenne de $30 \mathrm{~cm}$ à $1 \mathrm{~m}$ de haut. Chaque tige porte des feuilles sessiles, lancéolées, de 15 à $30 \mathrm{~cm}$ de long. Les fleurs sont blanches et jaunes, ponctuées de rouge sur les lèvres, avec des bractées vertes et jaunes. La partie aérienne se développe sur un rhizome aromatique ramifié et irrégulier, qui pousse horizontalement juste en dessous de la surface du sol. Le gingembre se cultive en général en plante annuelle, pour son rhizome, que l'on récolte 9 à 10 mois après l'avoir planté.

Ecologie: Originaire d'Asie du Sud-Est, le gingembre est cultivé en Afrique depuis plus de 2000 ans ; il était connu et utilisé dans I'Empire romain. On le cultive sous les Tropiques du niveau de la mer à 1500 m d'altitude, avec une précipitation annuelle de 1500 à 2500 mm par an. Une courte saison sèche et chaude est bénéfique pour la plante. II peut se cultiver en plein soleil, mais tolère une ombre partielle. On peut le cultiver avec des pois cajan, ou l'intercaler dans des plantations d'arbres. Le sol doit être profond, bien drainé, facile à travailler et riche en humus. II ne supporte pas l'inondation.

Reproduction: Le gingembre se plante à partir de morceaux de rhizomes récemment récoltés, de 2,5 à $5 \mathrm{~cm}$ de long, portant au moins un bourgeon vigoureux. II vaut mieux stocker les rhizomes jusqu'à ce que des bourgeons commencent à germer. Le gingembre se cultive normalement sur des buttes ou des talus. Espacer les plantes de 20 à 30 $\mathrm{cm}$ et les planter à $7 \mathrm{~cm}$ de profondeur. Fournir un paillage, même de la sciure, après la plantation. Le sol doit être humide à la plantation. Pour éviter les ravageurs et les maladies transmises par le sol, éviter de planter le gingembre au même endroit à des intervalles plus courts que 3 à 4 ans.

Gestion : Les nouvelles pousses apparaissent 10 à 20 jours après la plantation ; on doit désherber et biner 2 ou 3 fois. La récolte est prête quand les feuilles jaunissent. Le contenu en huile essentielle et le piquant, ainsi que la proportion de fibres, augmentent avec l'âge du rhizome. Récolter avec soin pour éviter d'endommager le rhizome. Pour conserver le gingembre, récolter avant que le piquant et les fibres se développent trop. Après récolte, on nettoie les tubercules, on les trempe dans l'eau et on les gratte pour enlever la peau externe ; puis on les sèche 4 à 5 jours au soleil.

Usages: Le gingembre constitue une épice importante pour la cuisine, notamment au Japon, en Chine et en Inde. II sert à fabriquer des boissons rafraichissantes, alcoolisées ou non, et entre dans la composition du pain d'épices. En RD Congo, on mâche et suce les racines fraiches pour étancher la soif, et on en fait une boisson très populaire. Le gingembre s'emploie pour calmer les nausées, notamment nausées des transports (voiture, avion, bateau), et 
nausées de la grossesse ; et pour soulager les inflammations articulaires. Le gingembre en compresses chaudes sert de calmant pour toute douleur musculaire. On le donne pour faire transpirer, et pour aider à disperser la chaleur pendant une forte fièvre. Au Kongo Central, on emploie le gingembre pour traiter le rhume, les hémorroïdes, les angines et les vers intestinaux. Le gingembre africain est plus fort et plus piquant que celui de la J amaïque ou de Chine.

Références : Renier 1948, Purseglove 1972, Nair 1980, de Guzman et Siemonsma 1999, Burkill 2000, Kibungu Kembelo 2003, van Wyk et Wink 2004, Nzuki Bakwaye et al. 2013

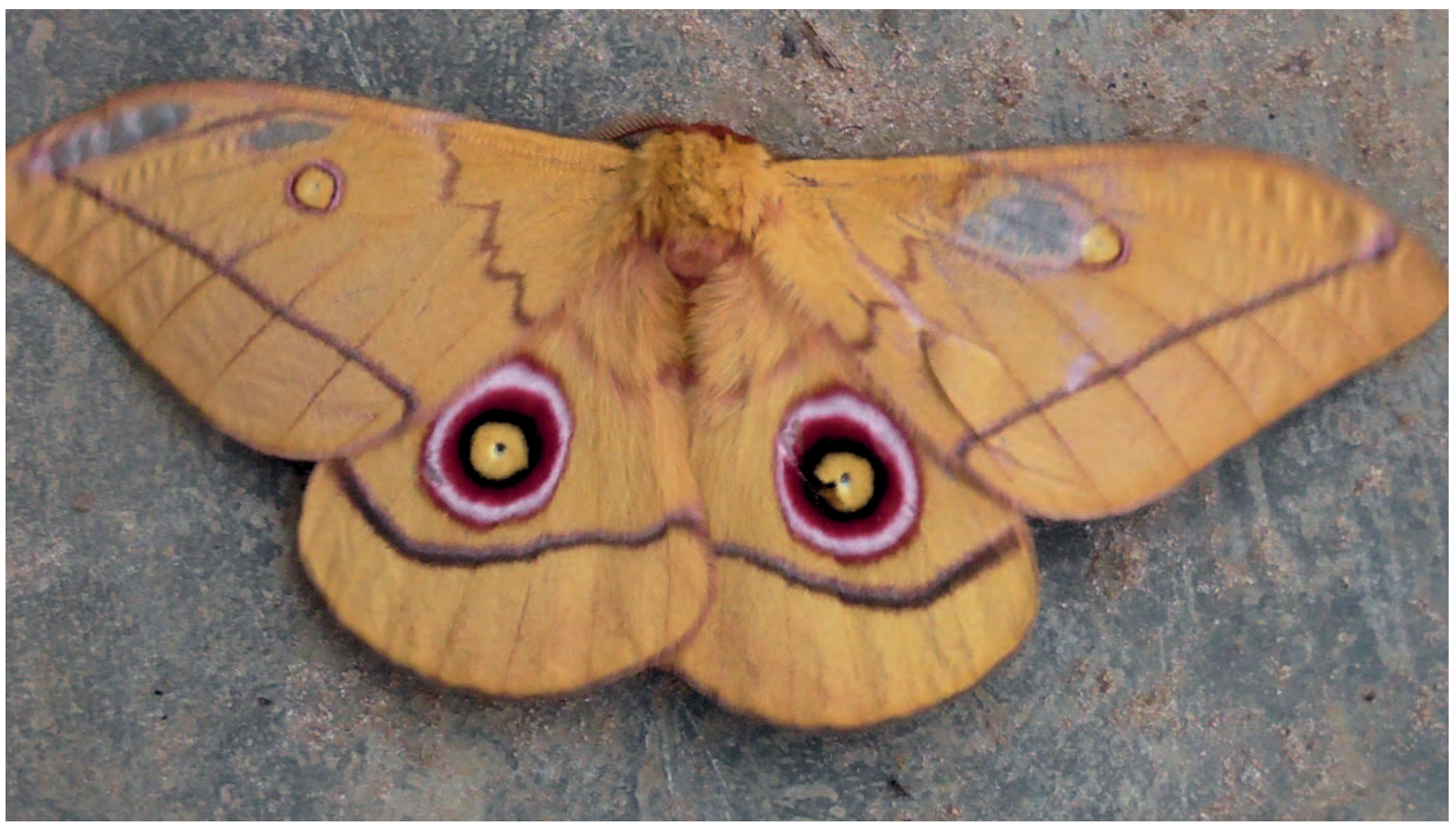

Kaba (Lobobunaea phaedusa) adult 


\section{Zinnia angustifolia}

Noms courants : Zinnia

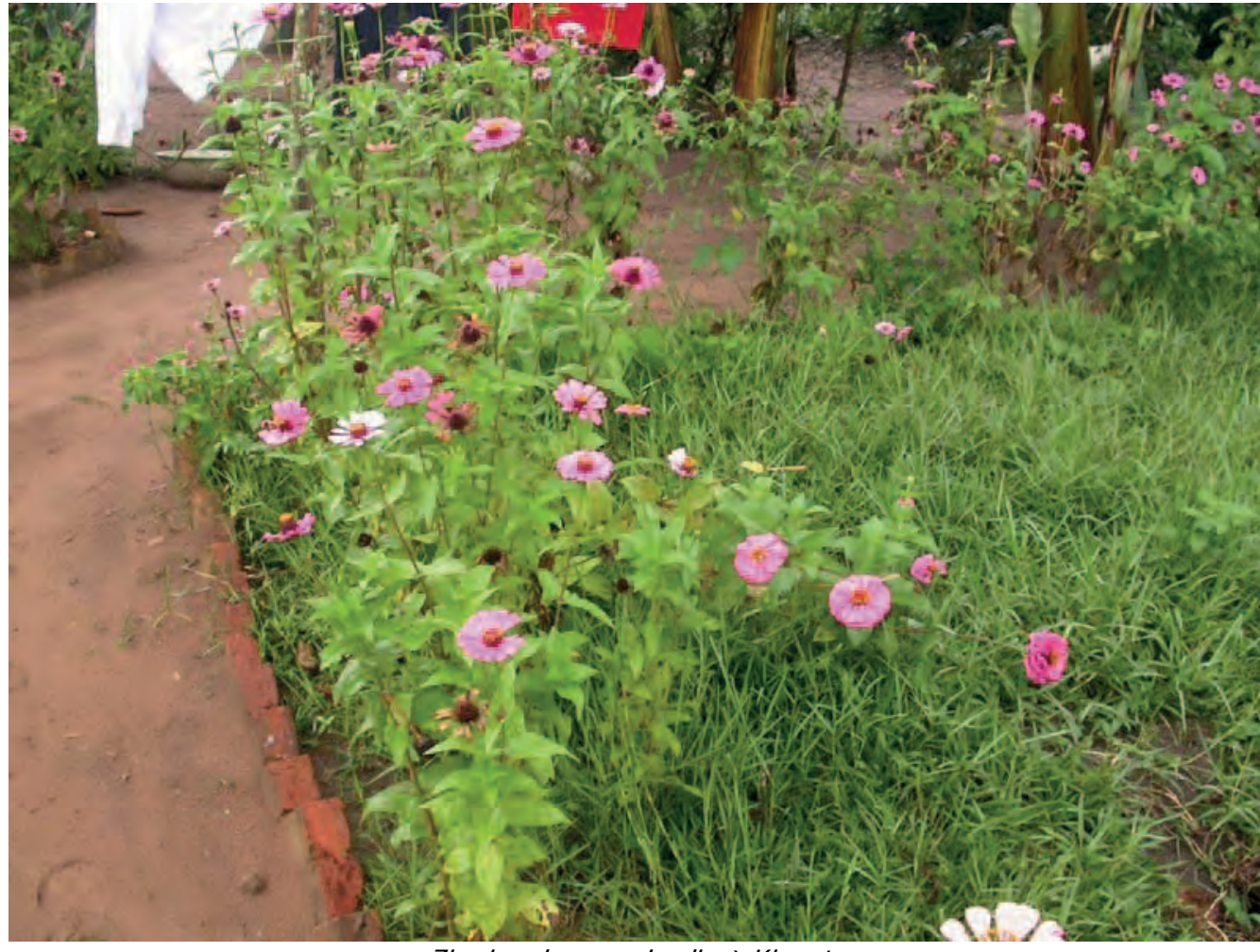

Zinnias dans un jardin à Kisantu

Description : Plante herbacée pérenne de 60 à $75 \mathrm{~cm}$ de haut. Feuilles vert clair, ovales ou lancéolées. II y a de nombreux hybrides, différents par la forme et la taille des inflorescences. Celles-ci, de $5 \mathrm{~cm}$ de diamètre en moyenne, sont abondantes, et peuvent être de couleur jaune, orange, rouge, rose ou pourpre, parfois bicolore.

Ecologie: Plante originaire du Mexique, répandue partout dans le monde. Préfère les sols légers, riches et bien drainés, et l'exposition en plein soleil.

Reproduction: Semer les graines directement là où les plantes fleuriront. On peut aussi les semer en pépinières, mais les semis transplantés sont assez lents à reprendre. Le mieux est de semer à plusieurs reprises, pour étendre la période de floraison.

Gestion : Pincer le haut des jeunes plantes pour favoriser la ramification.

Usages: Plante ornementale largement répandue dans les jardins. Au Kongo Central, les abeilles récoltent le pollen en janvier et février. En Angola, on sait que les

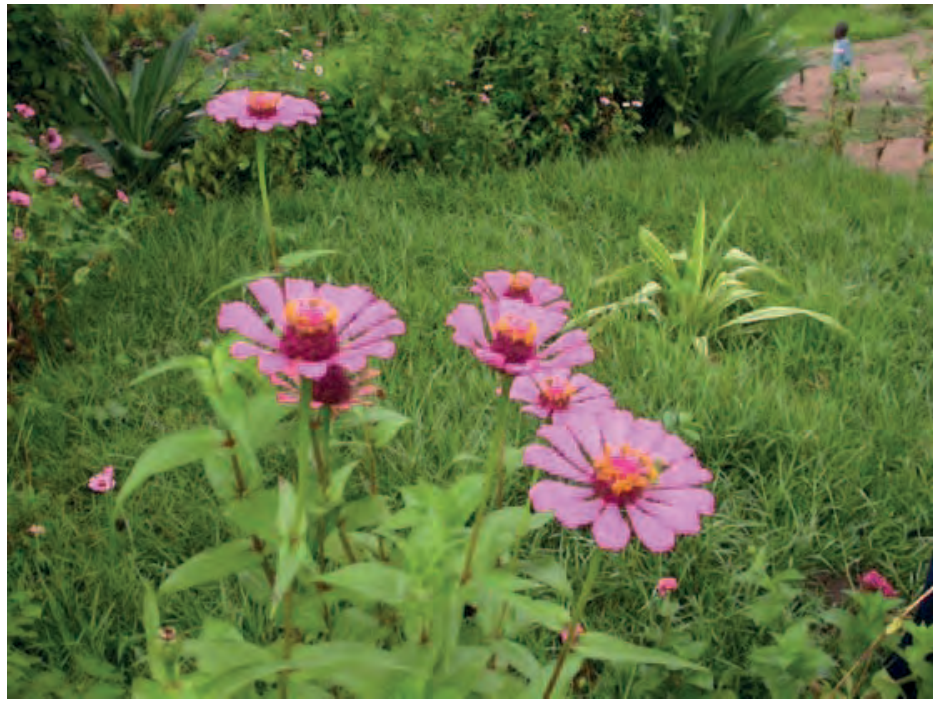
fleurs sont très appréciées par les abeilles.

Références : Dubois et Collart 1950, Portugal-Araújo 1974, Howes 1979, Macmillan 1991, Brickell 1998 


\section{Quelques champignons sauvages comestibles}

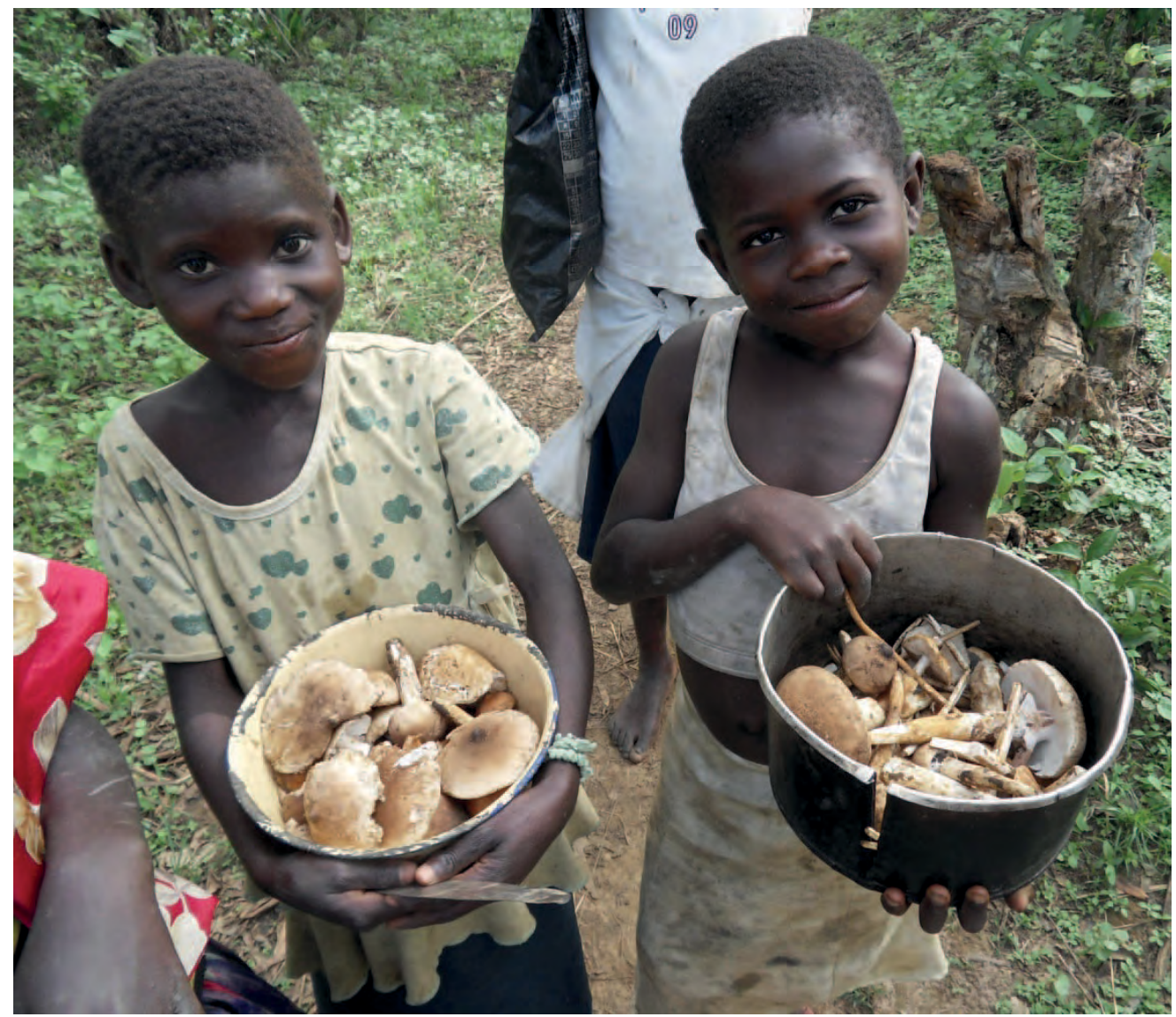

Les champignons Termitomyces letestui

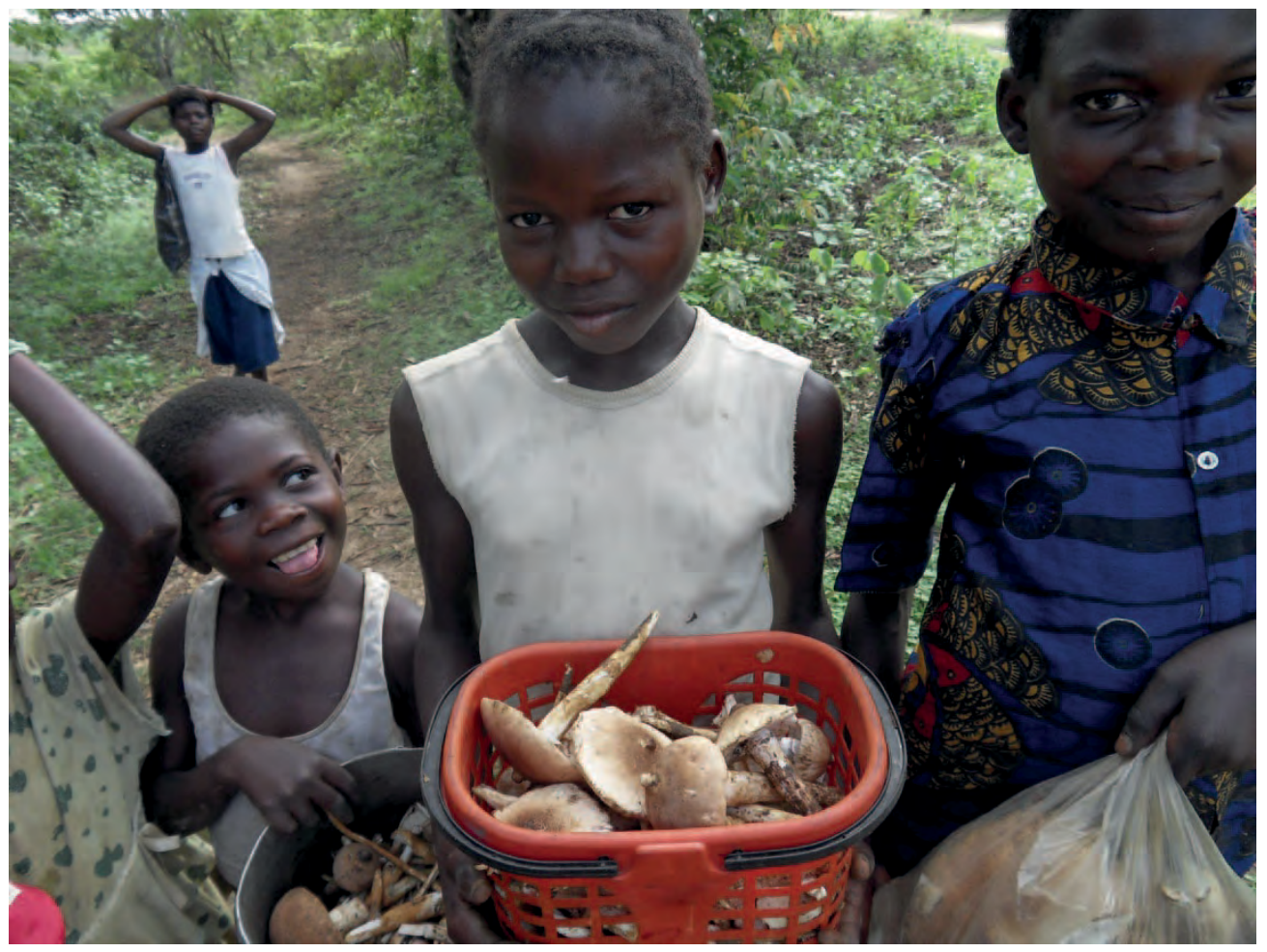




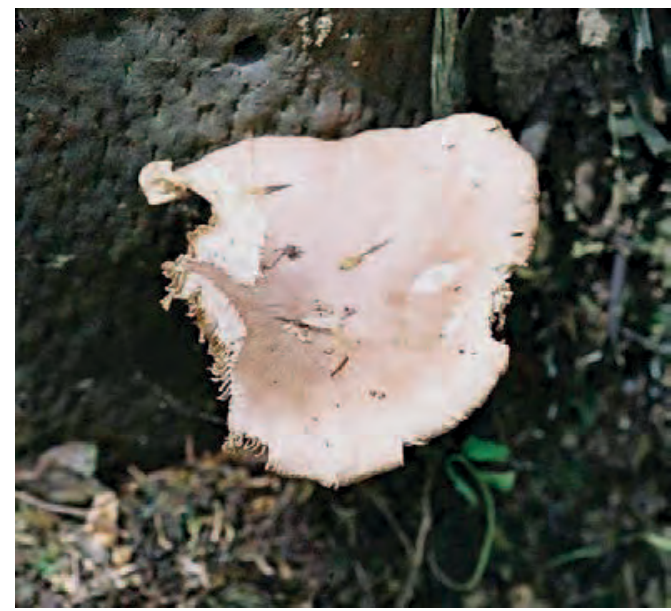

* Bubwaka bwaka pousse sur le tronc de palmier à huile et $d$ 'autres arbres bien ombragés. Ces champignons peuvent être de couleur rose ou blanche.

Bufwa ngudi pousse à l'ombre, à l'extrémité du tronc mort d'un palmier à huile.
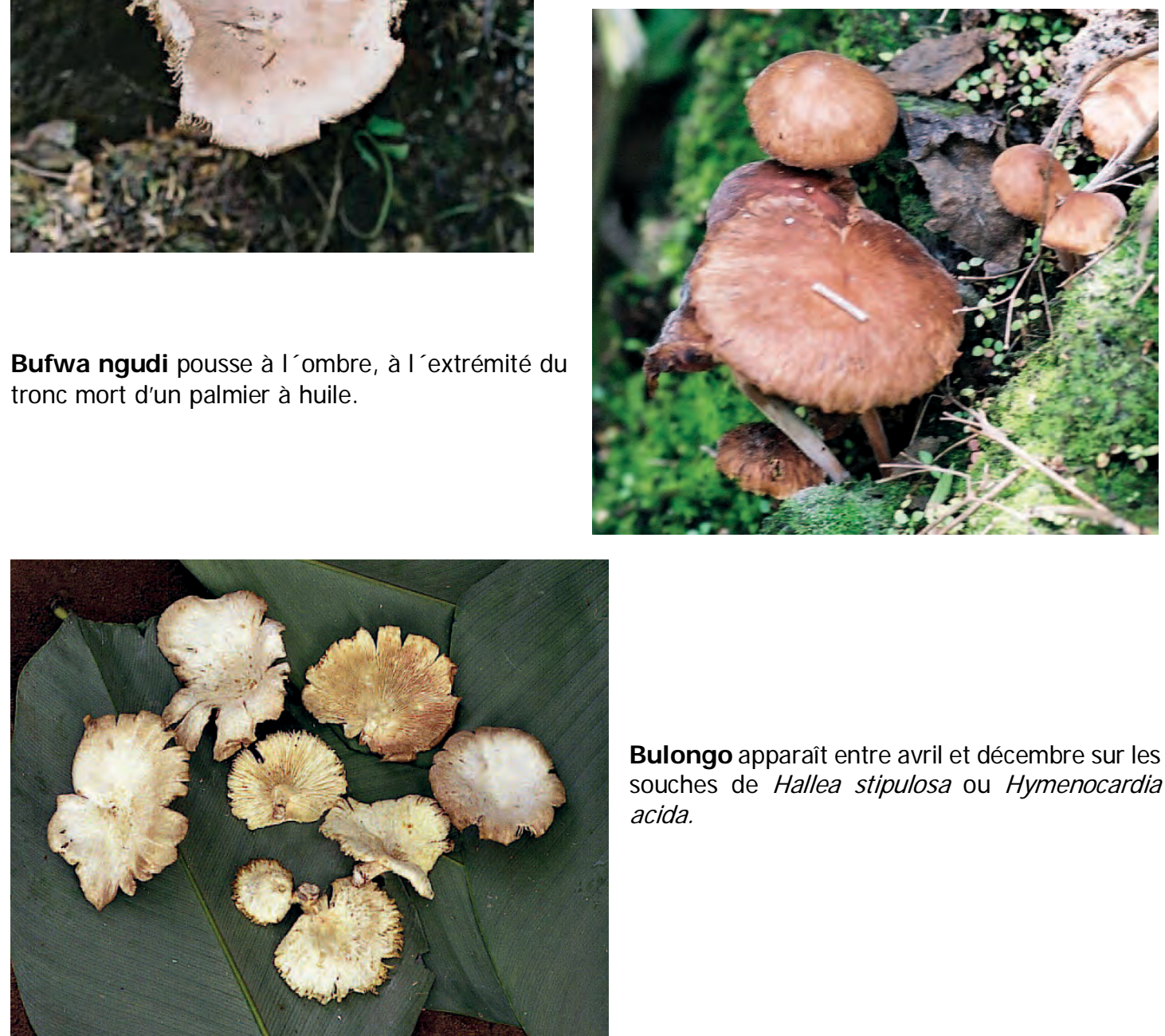

Bulongo apparaît entre avril et décembre sur les souches de Hallea stipulosa ou Hymenocardia acida.

Bunsambi nsambi (Polyporus arcularius) pousse sur les troncs des arbres morts (particulièrement Voacanga africana) et peut apparaître pendant toute l'année. On le cuit avec du sésame ou avec des graines de citrouille ou de courge.

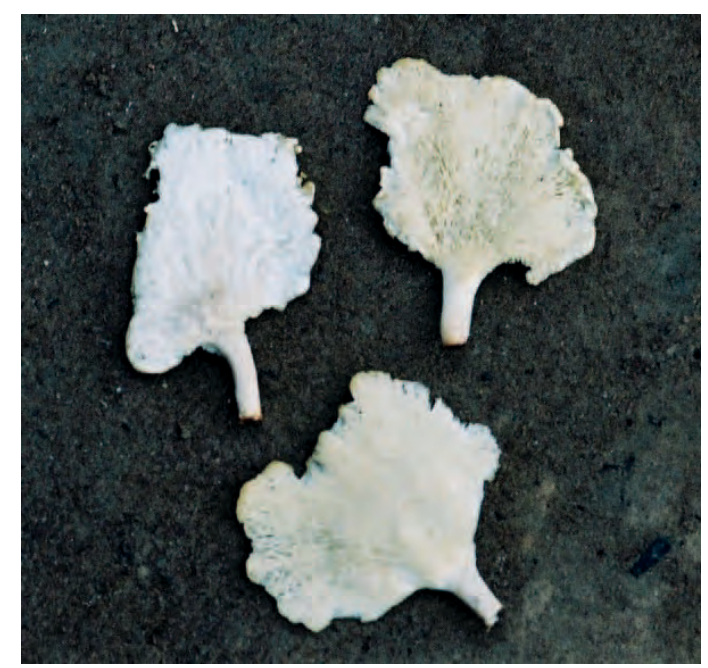




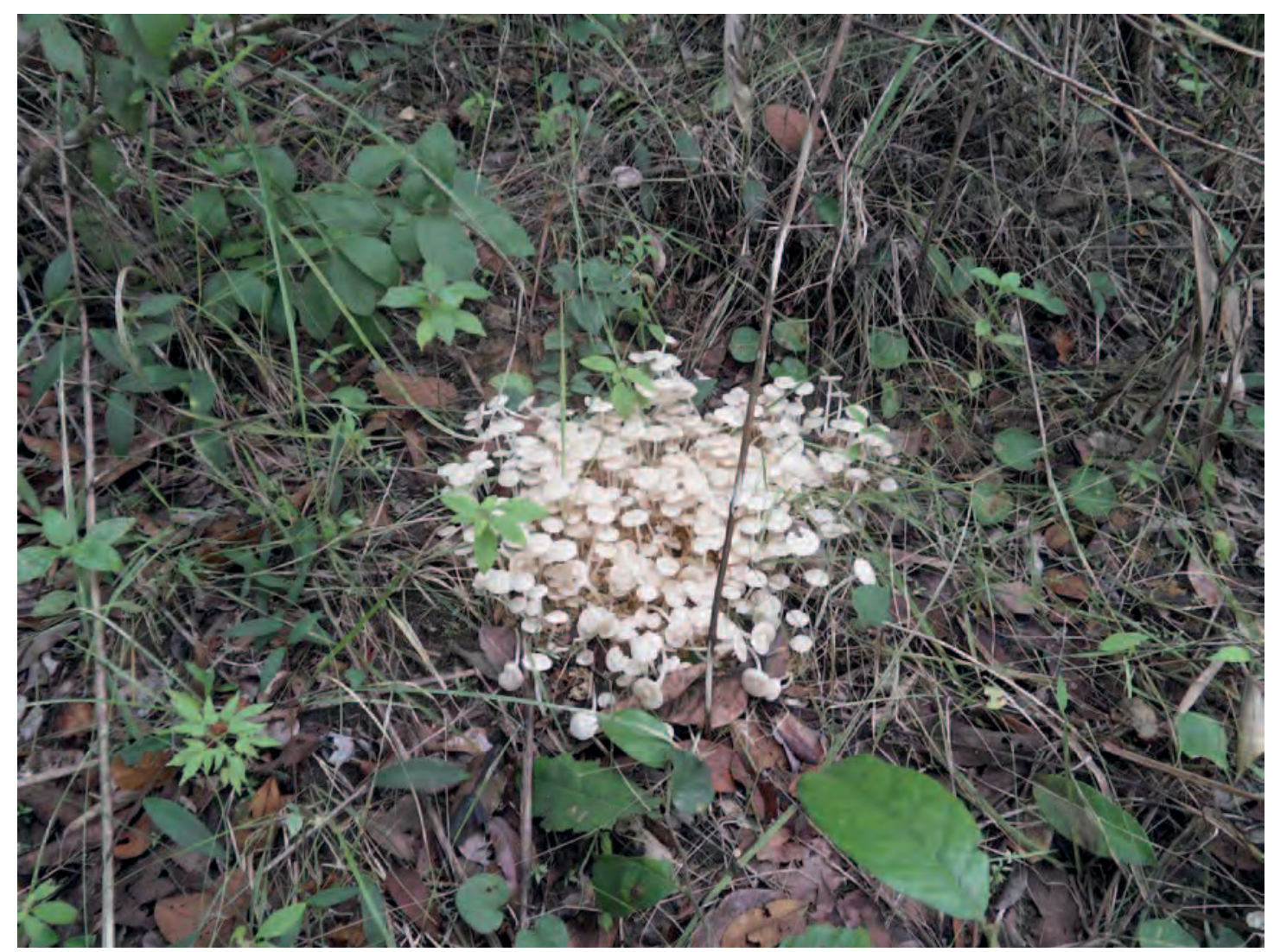

Termitomyces microcarpus

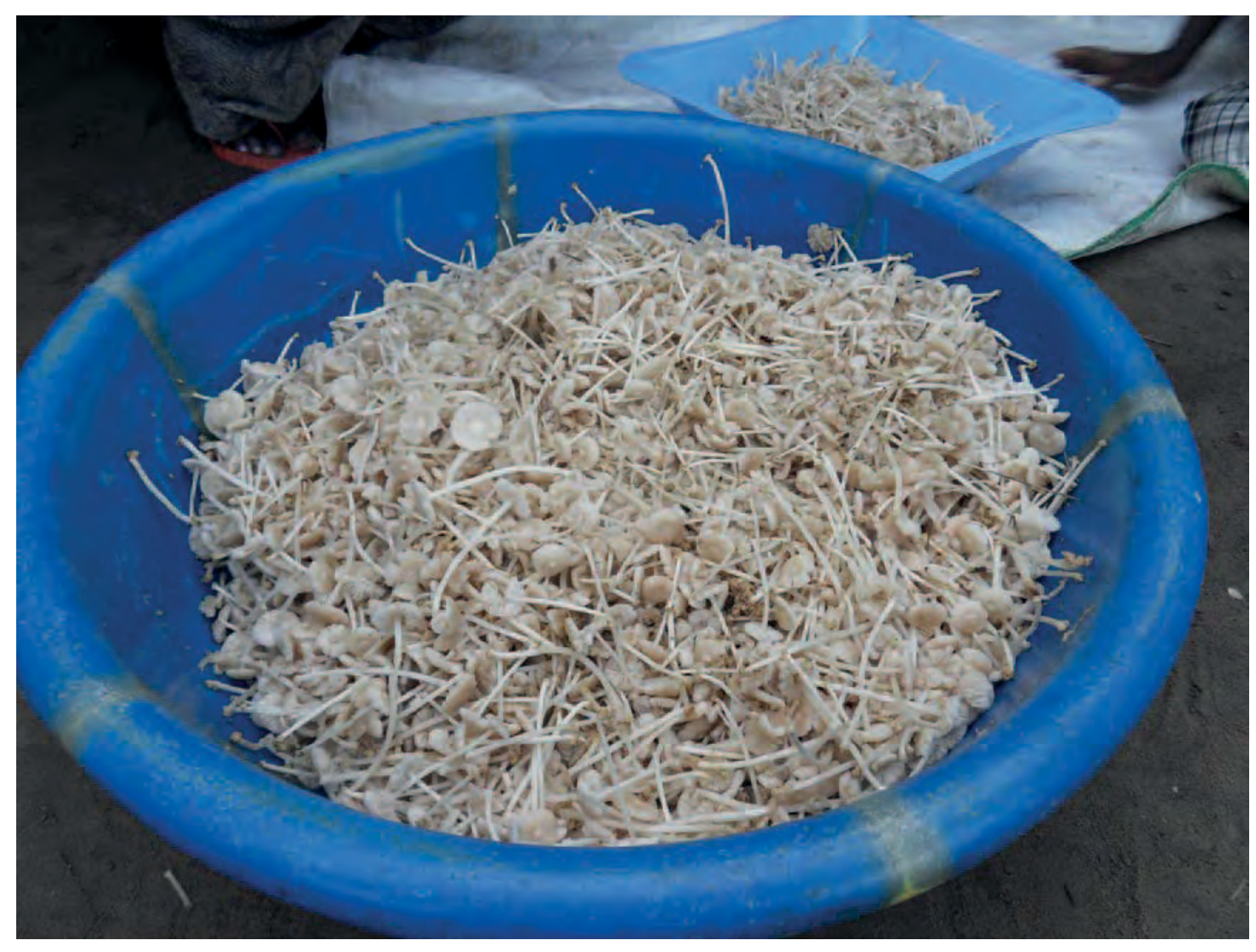




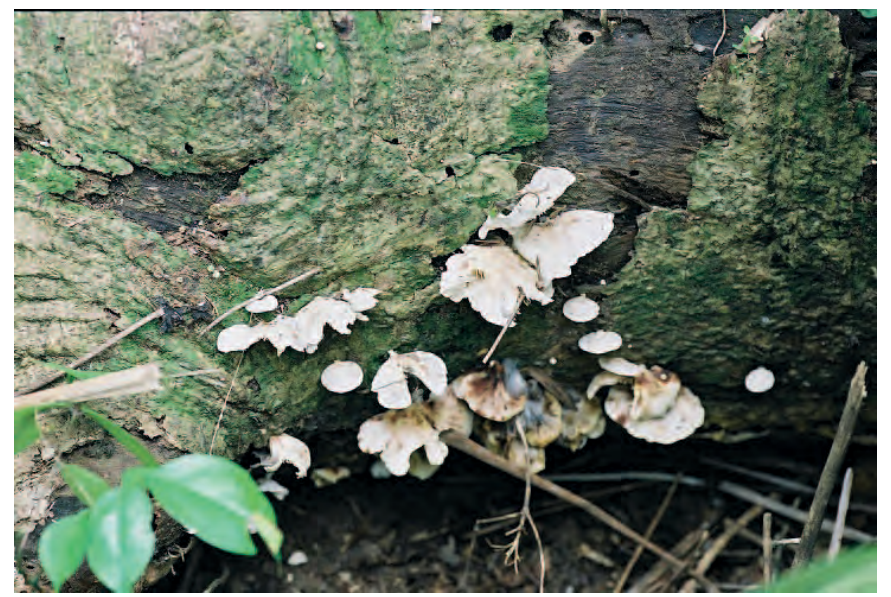

Nkaka bu bwaka bwaka Le « grandpère » de Bwaka bwaka. Sur un bois mort de Dacroydes edulis.

Lumvumvu (Lentinus cf. squarrosulus Mont.) pousse sur le bois mort dans les forêts.

\section{Image : Jacques Miaglia}
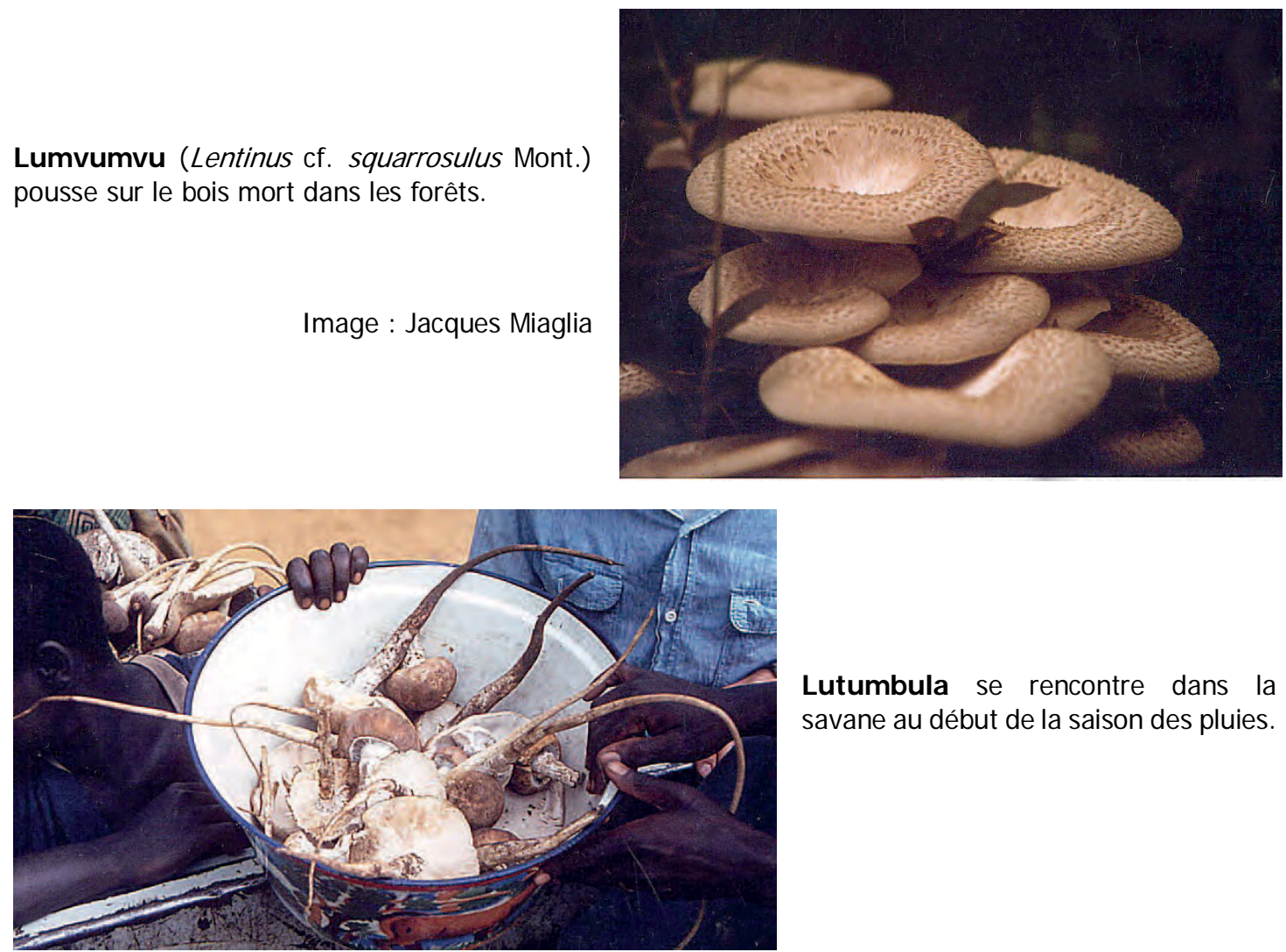

Lutumbula se rencontre dans la savane au début de la saison des pluies.

Bundolo Pousse à l'ombre, sur le sol entre les feuilles mortes.

* Les préfixes Bu et Lu sont interchangeables.

Vois aussi Dracaena mannii pour Bukutu kutu (Auricularia polytricha ou $A$. auricula-judae) et Elaeis guineensis pour Lumiengi (Psathyrella cf. tuberculata)

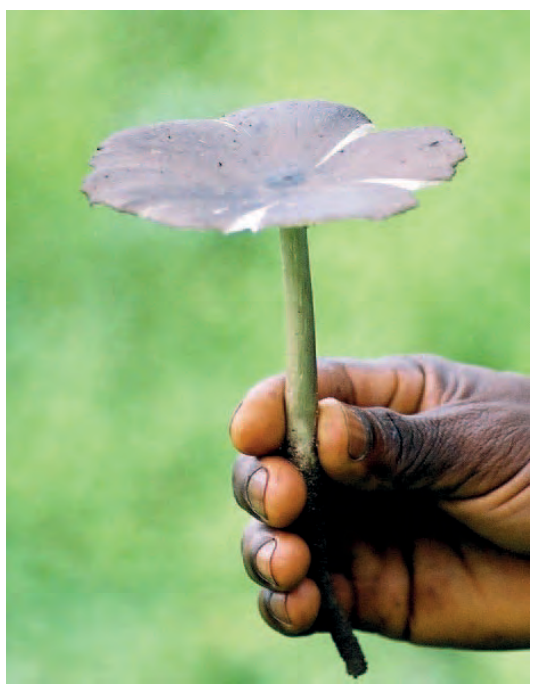




\section{Un gros champignon Termitomyces de Kimbao}
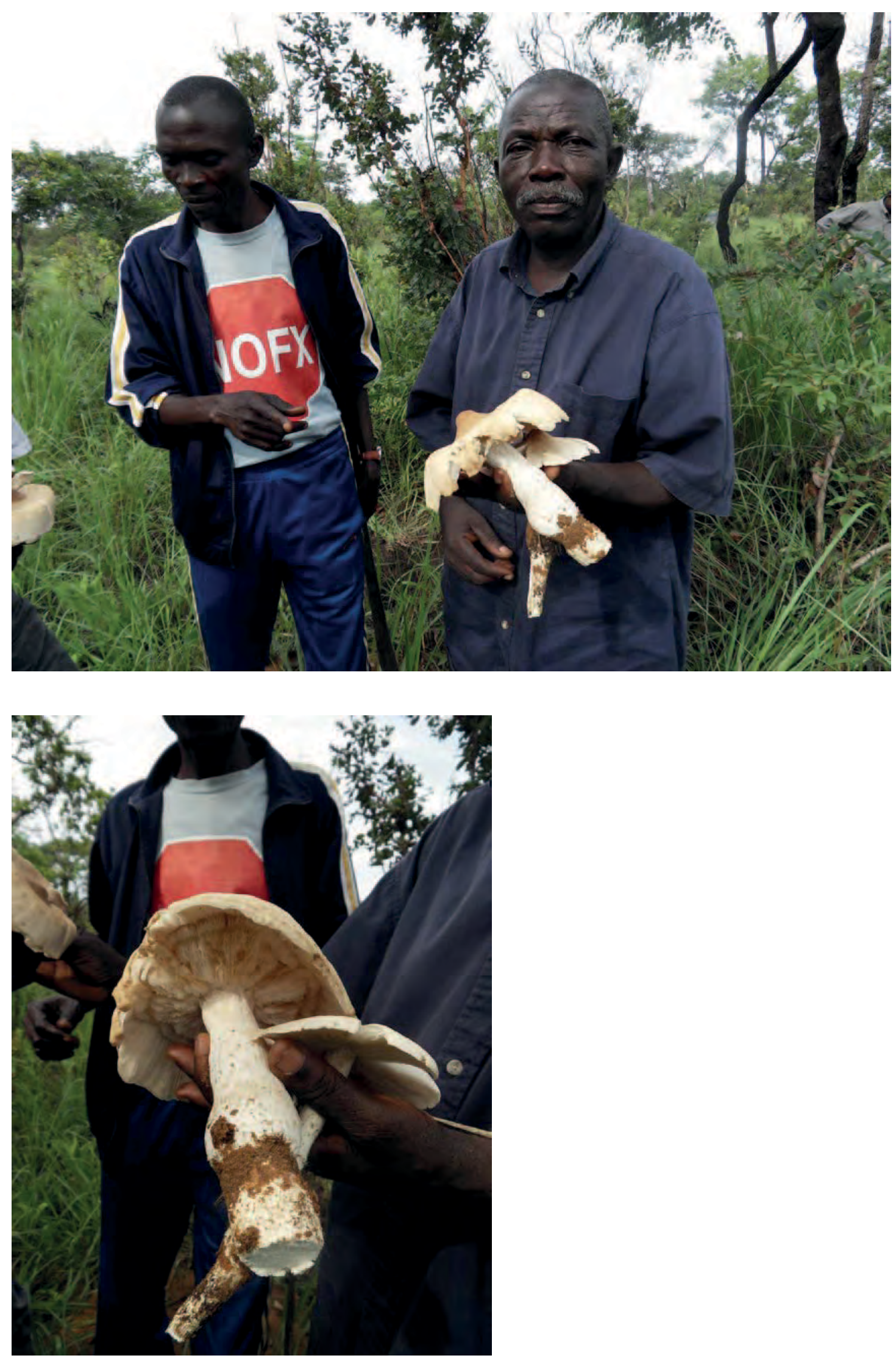

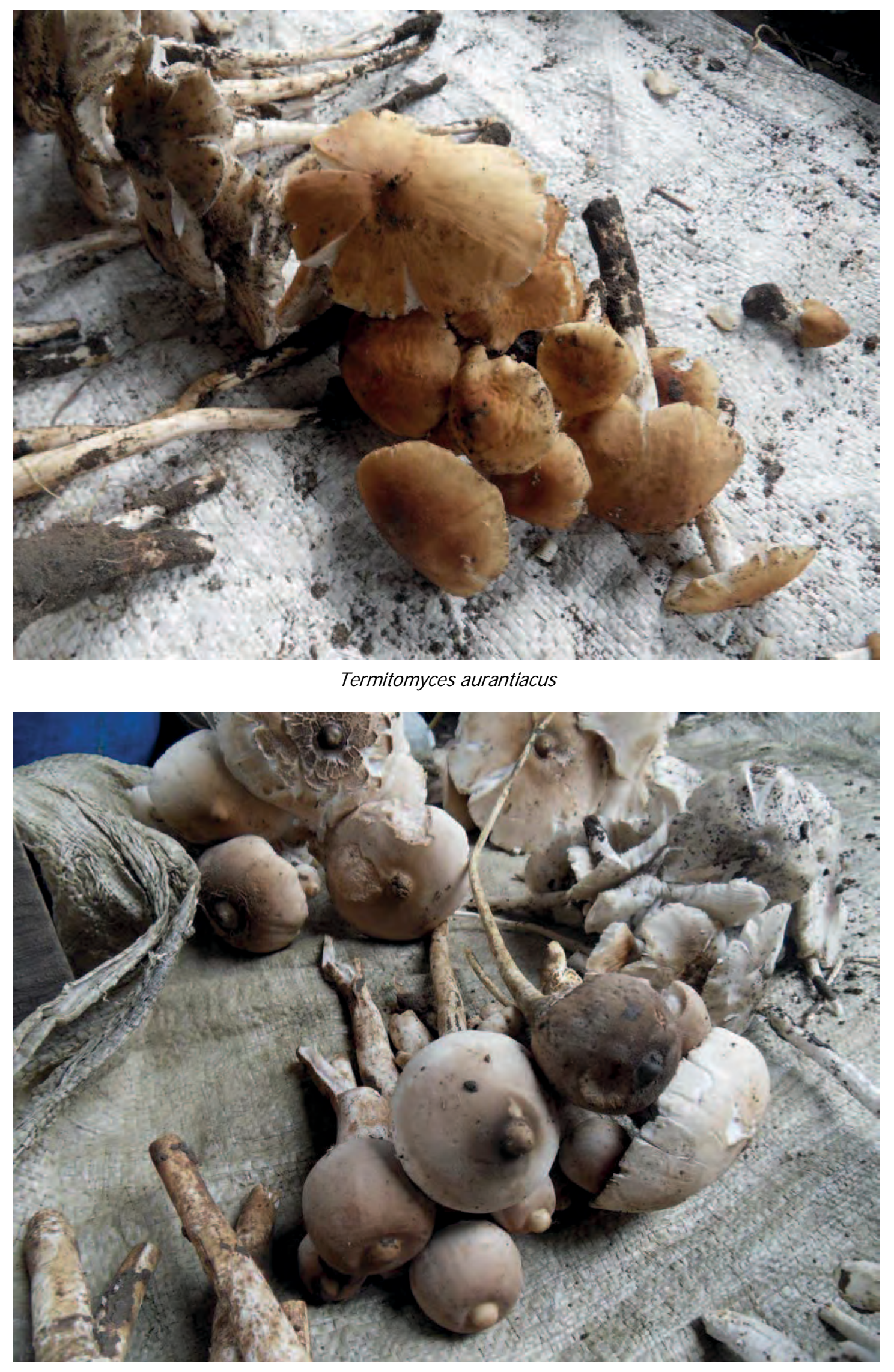

Termitomyces letestui 


\section{Certains vendeurs aux champignons}

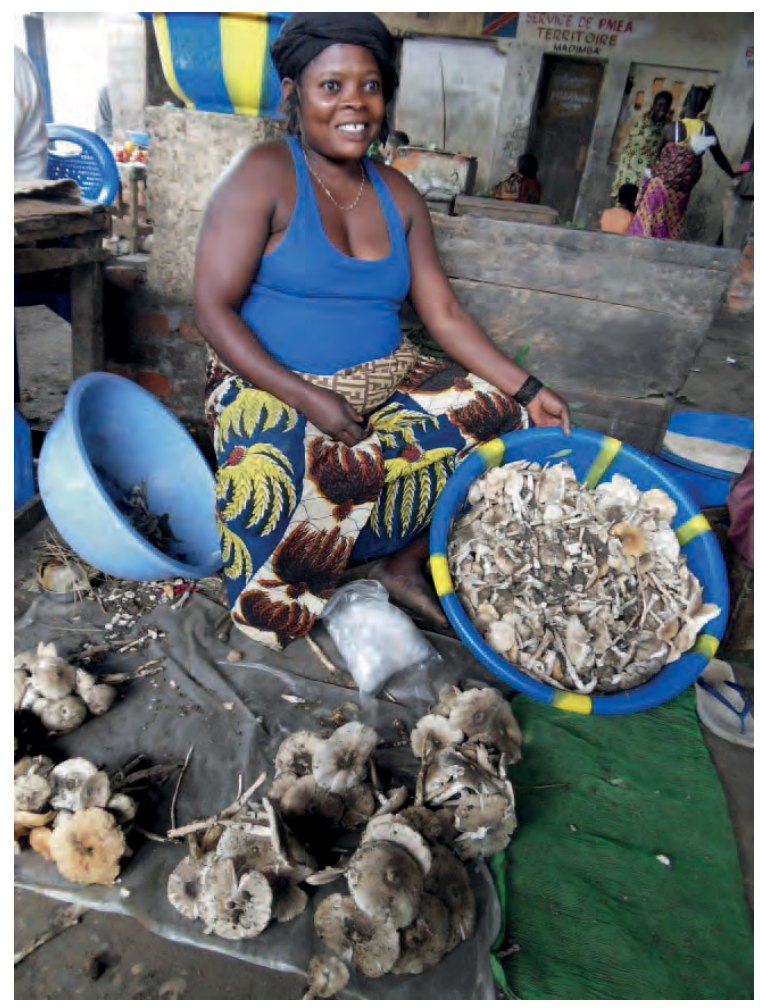

Termitomyces mammiformis

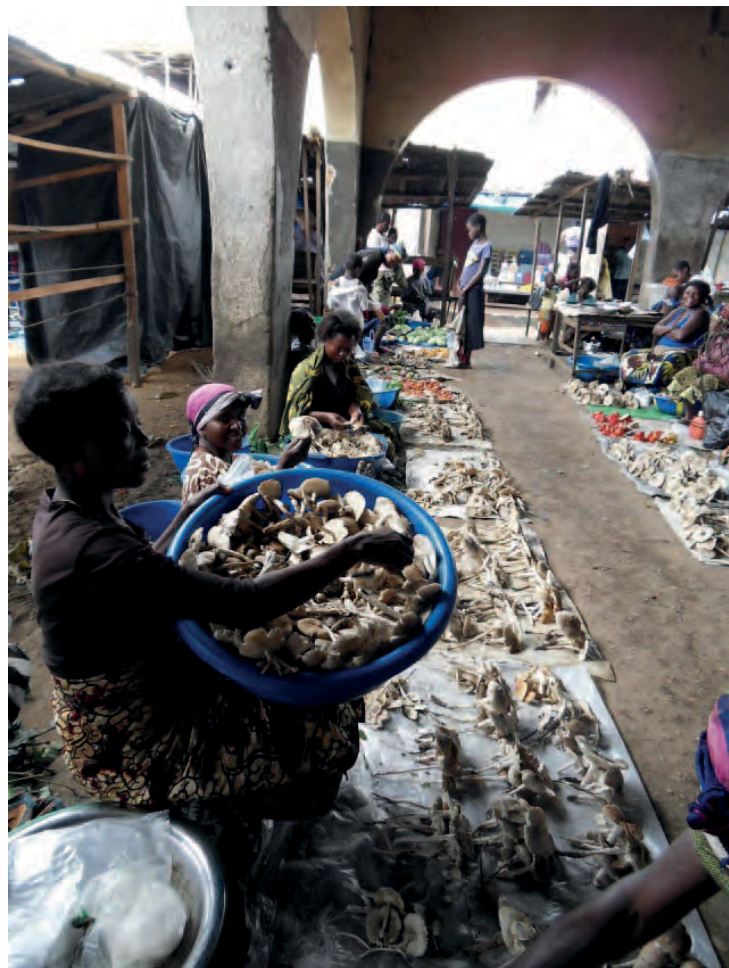

Termitomyces aurantiacus (avec capuchon orange) sur la gauche et au centre inférieur de la T. mammiformis (bouchon gris).

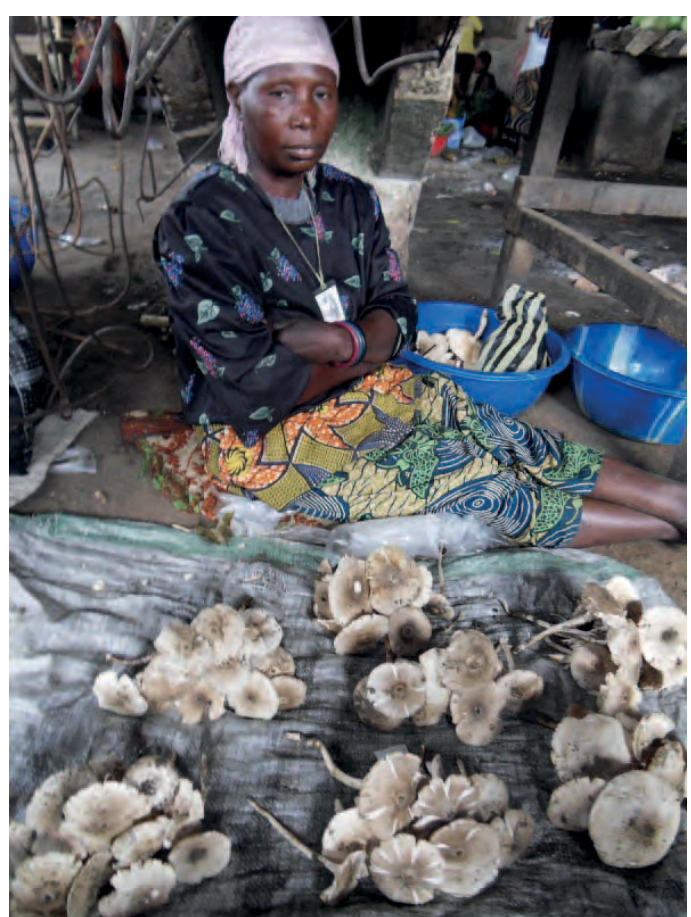

Marché du champignon à Kinshasa

Références Struyf in Gillet et Pâque 1910 p 9, Daeleman et Pauwels 1983, Eyi Ndong et al. 2011 


\section{Transformation traditionnelle du manioc au Kongo-Central}

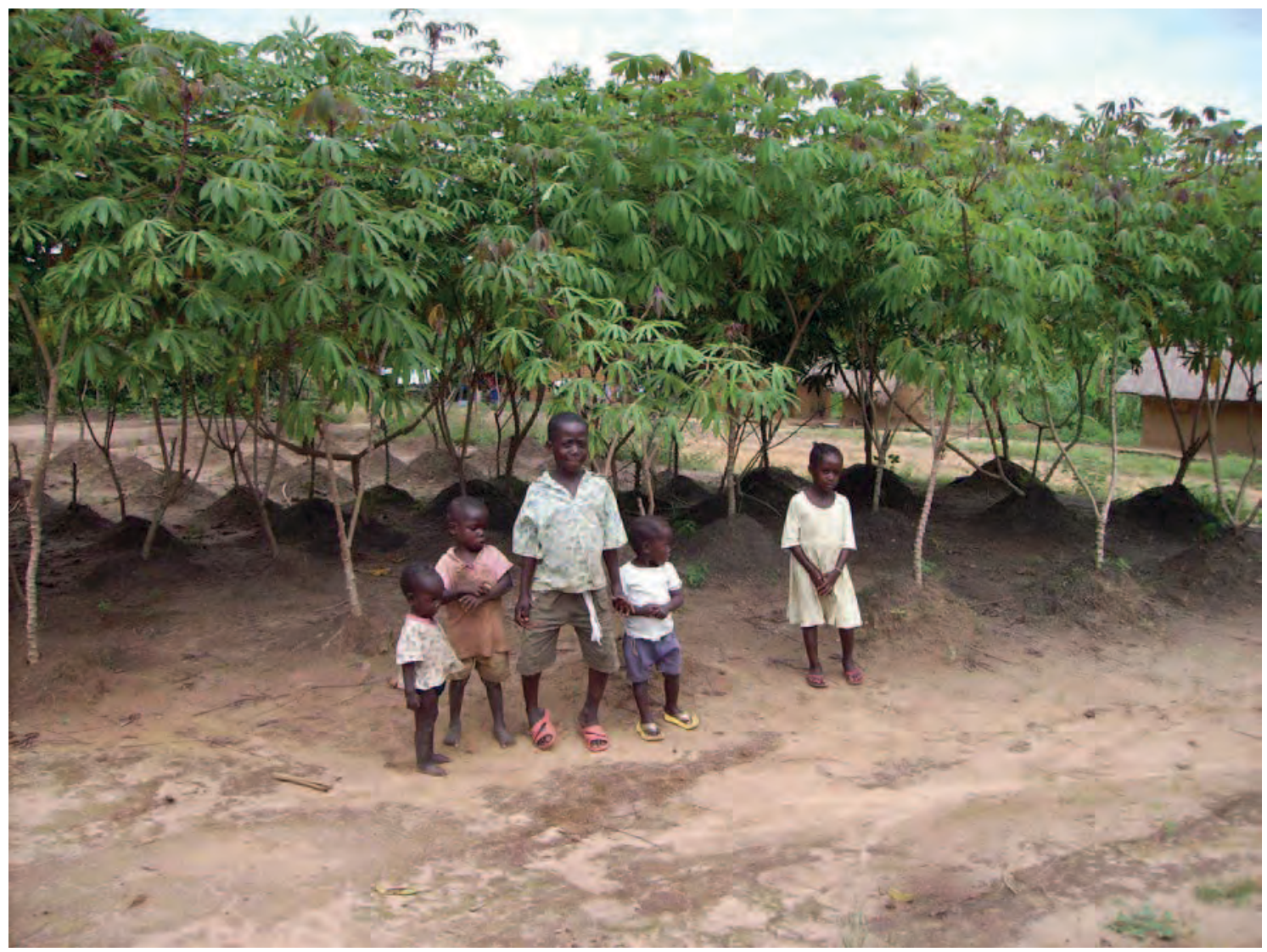

Culture du manioc en plein village de Kilueka

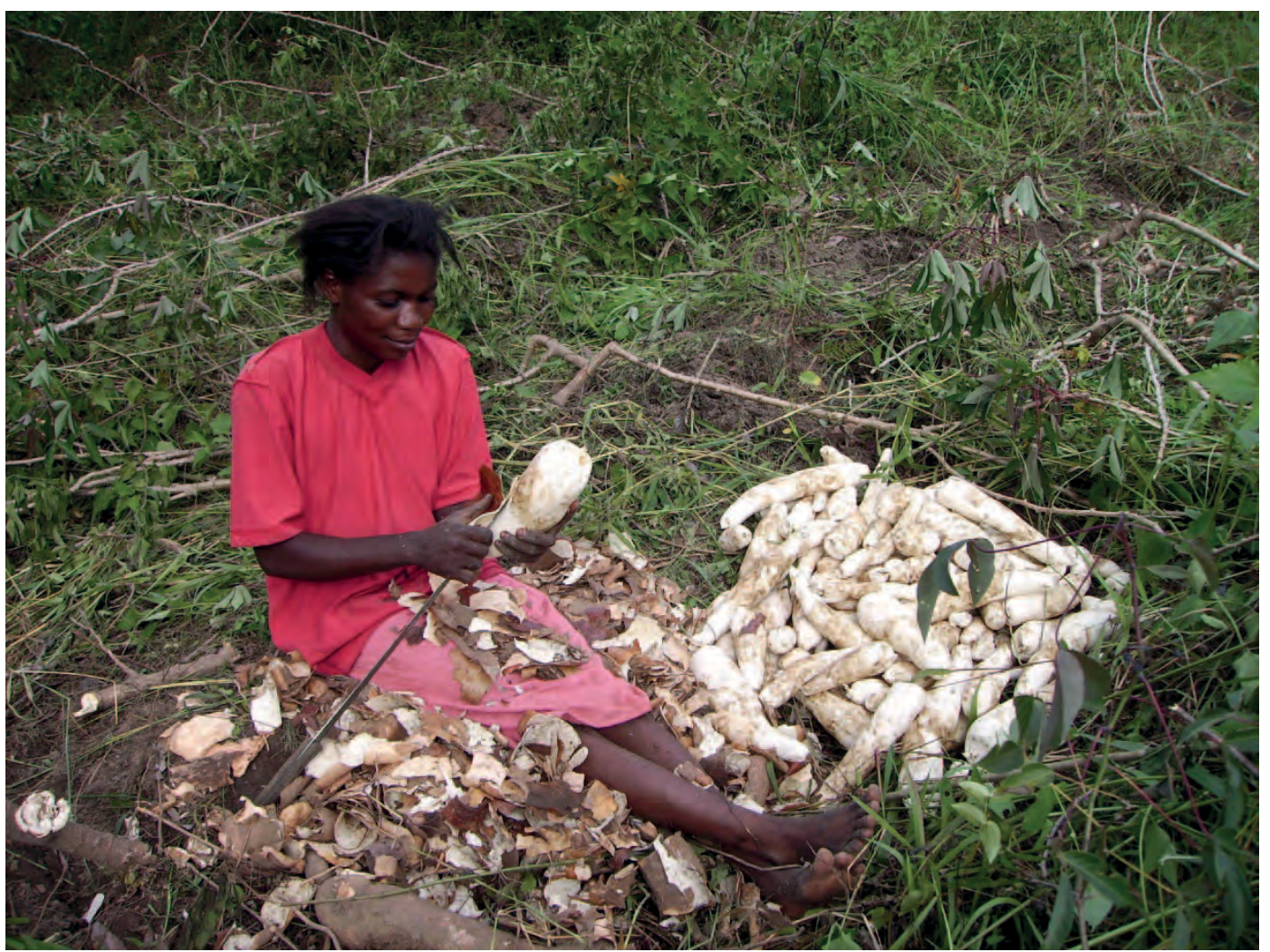

Récolte des tubercules et épluchage 


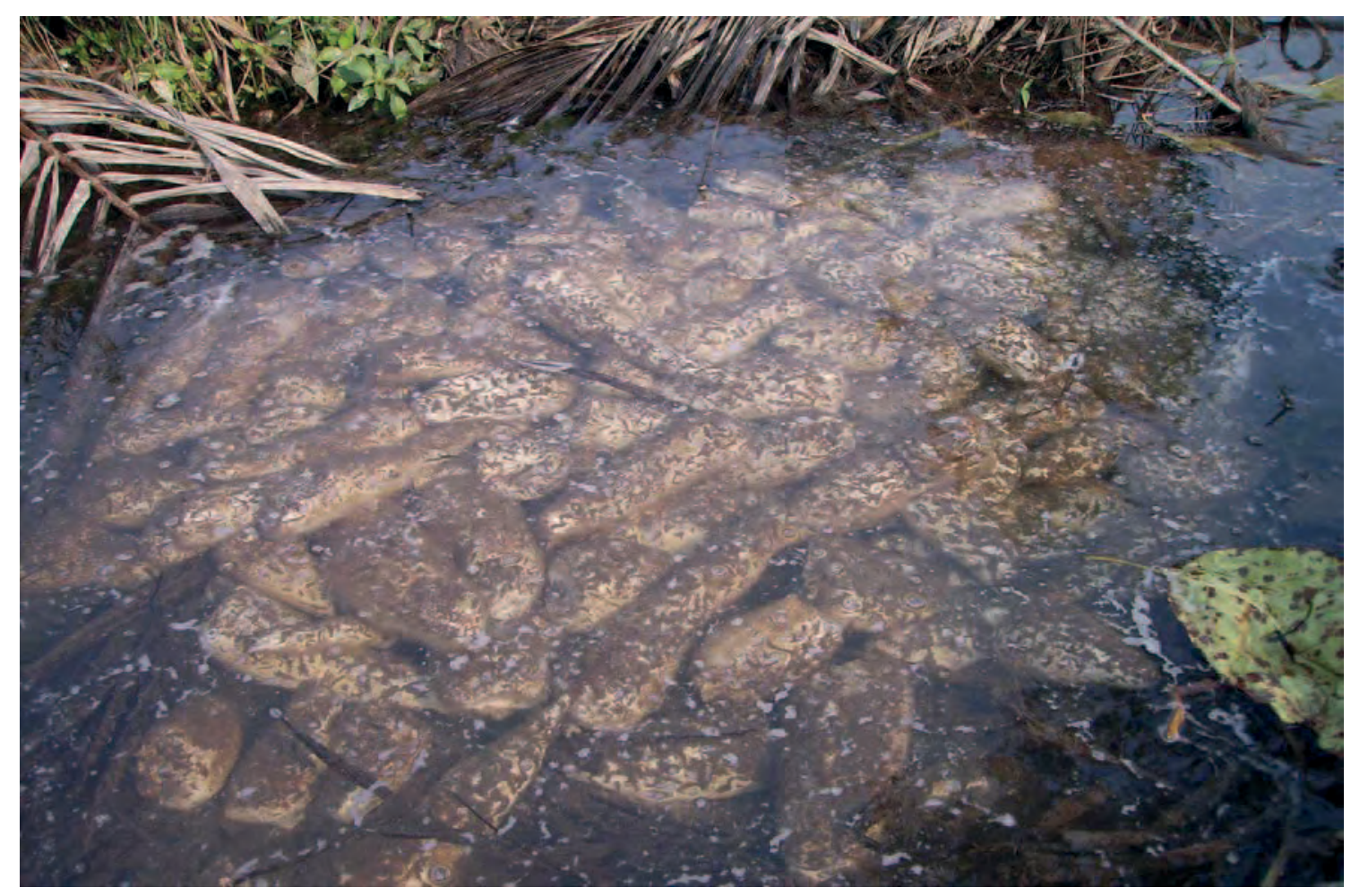

Rouissage du manioc

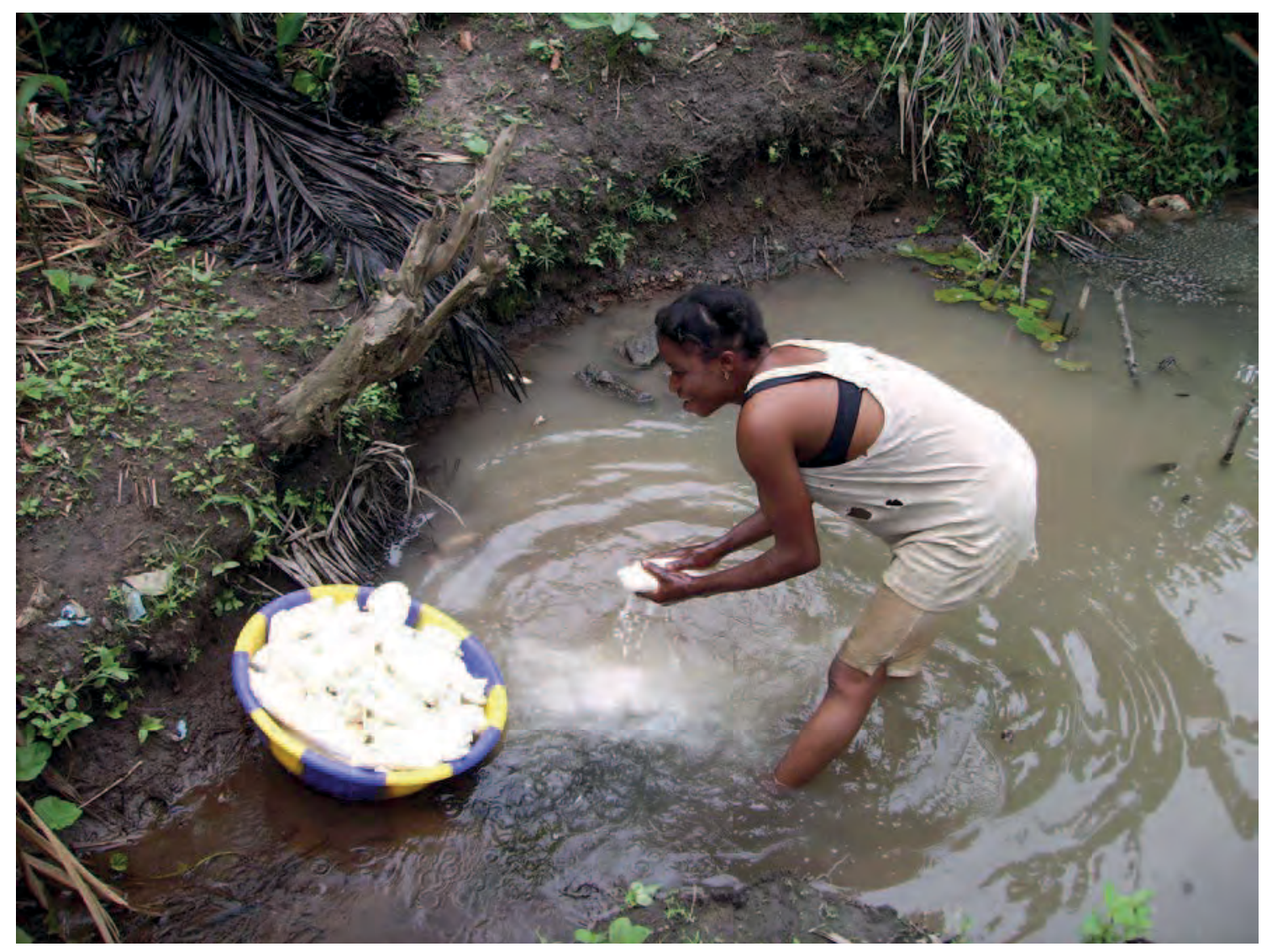

Nettoyage des tubercules au terme du rouissage 


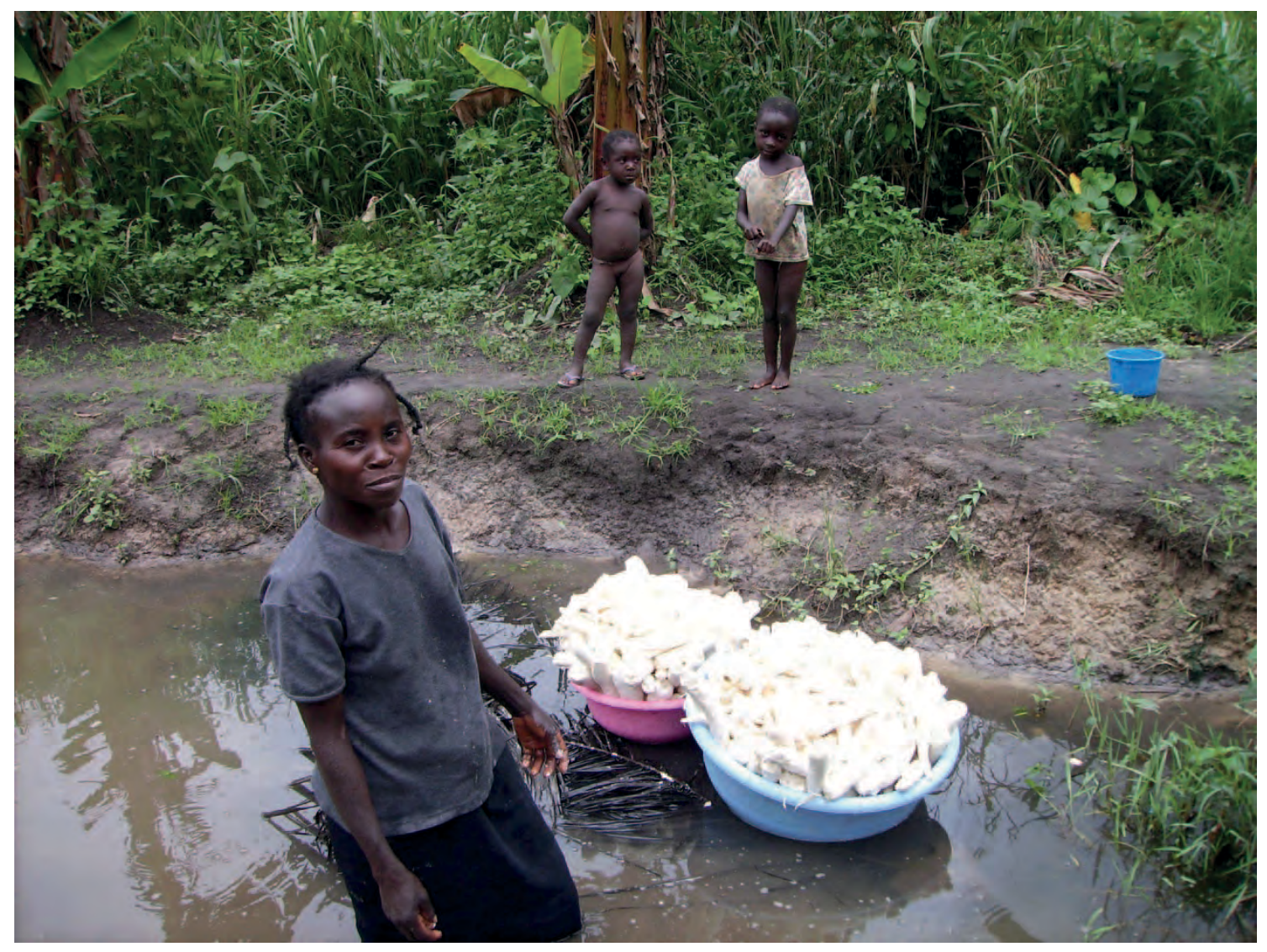

Tubercules nettoyés pour être séchés au soleil afin d'obtenir des cossettes (fufu)

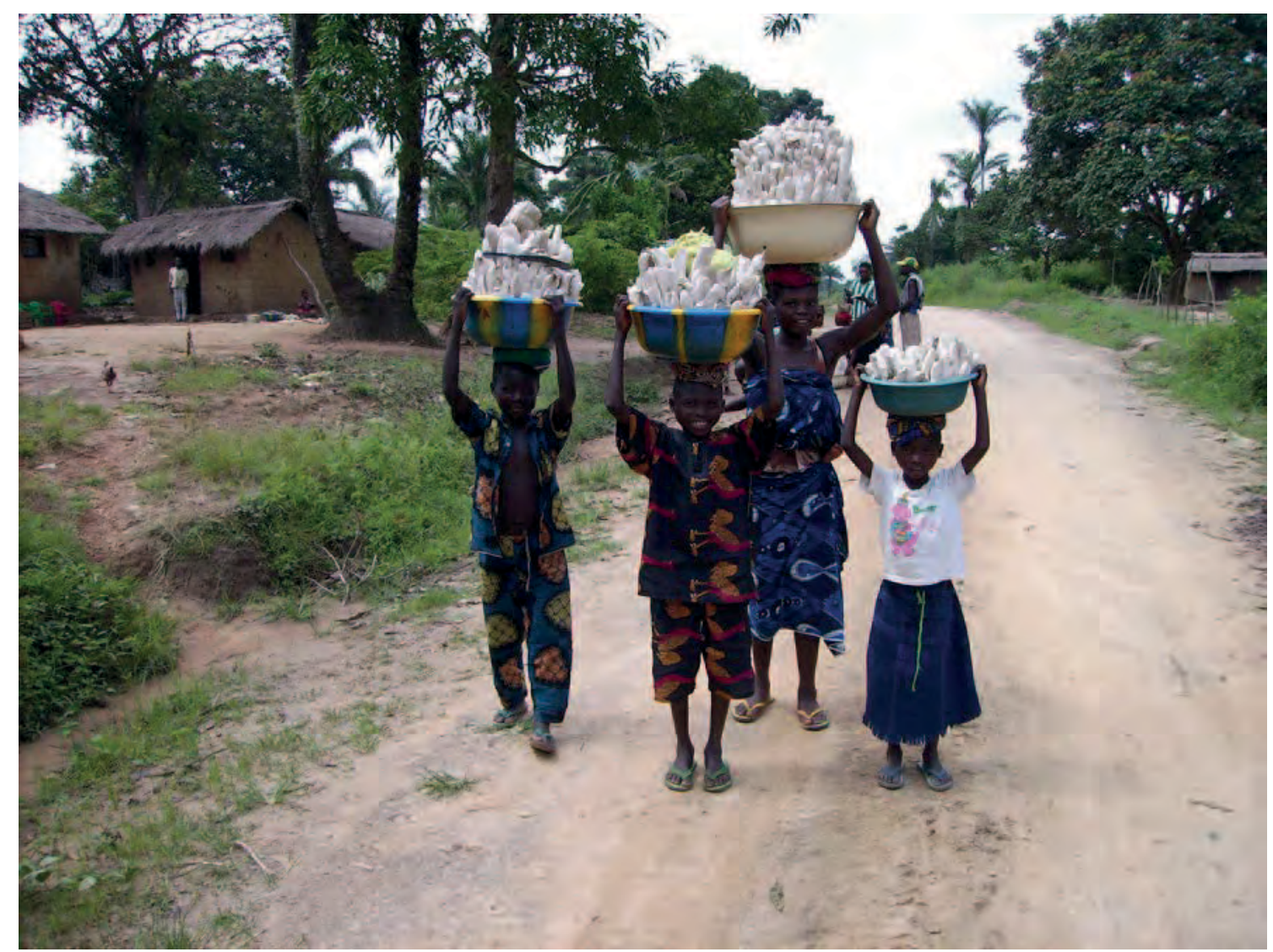

Cossettes de manioc en route pour être vendues au marché de Lemfu 


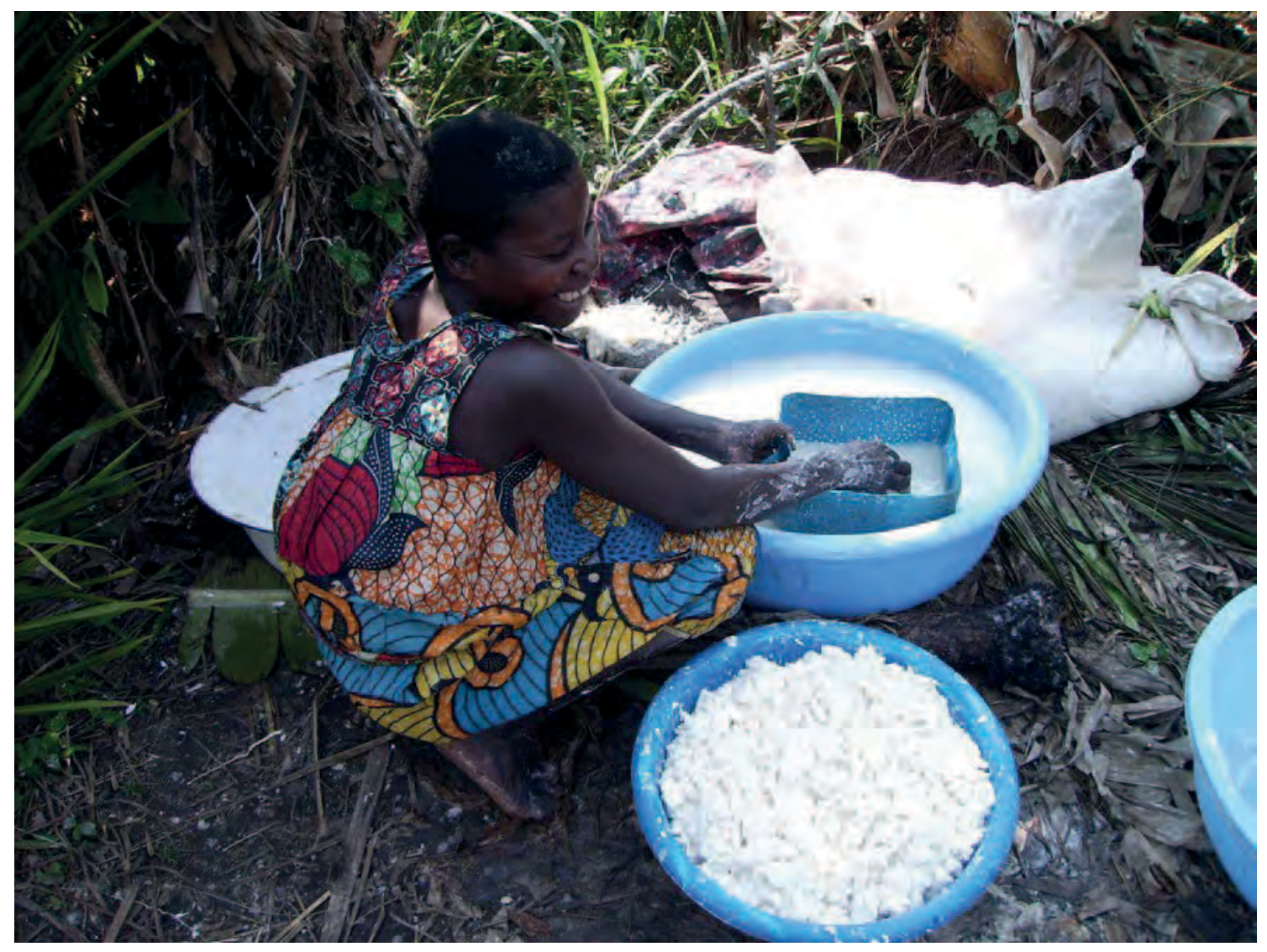

Tamisage de la pâte du manioc ramolli par le rouissage et égouttage dans un sac.

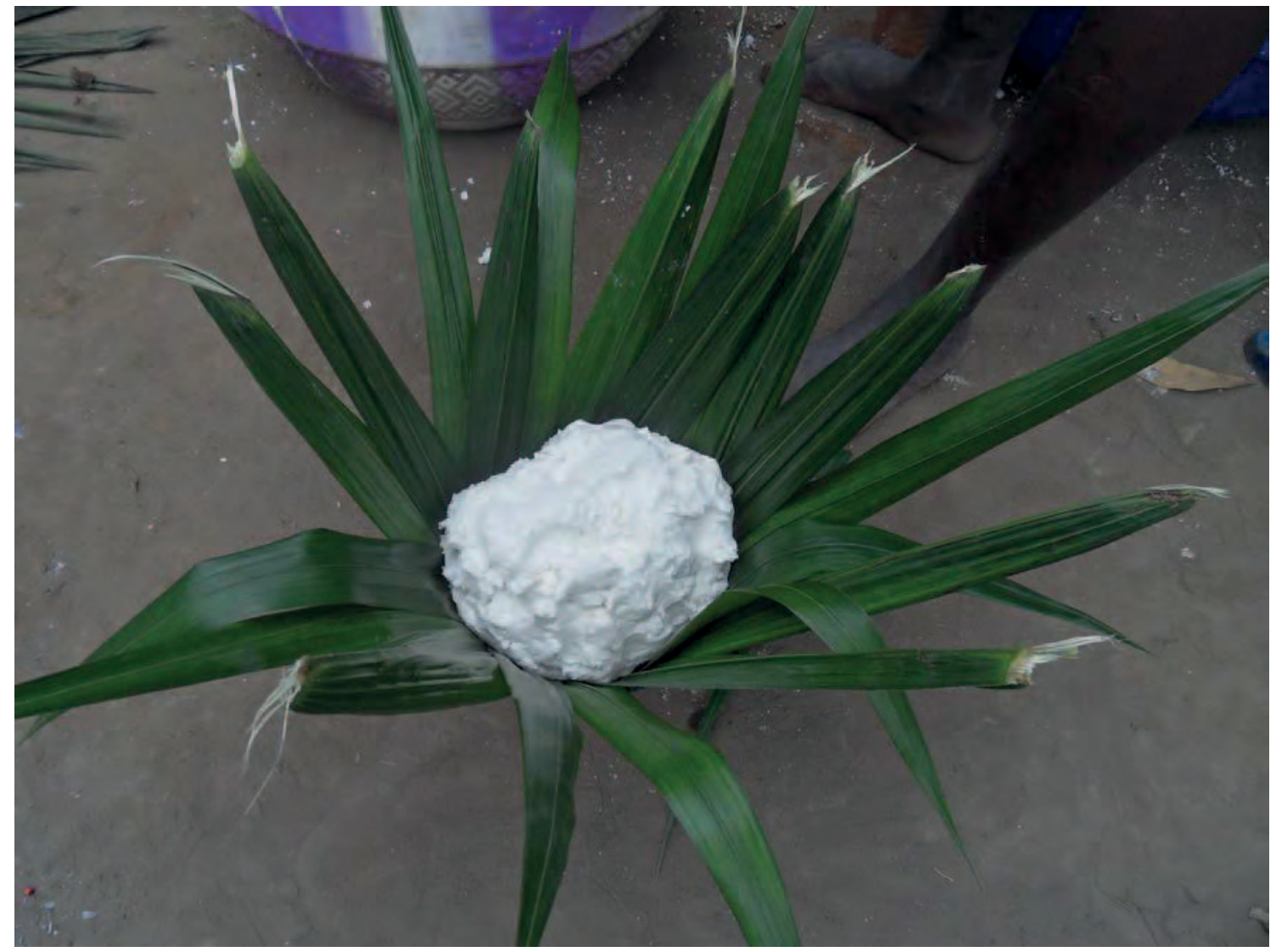

Après pilage, emballage pour une première cuisson (partielle) 


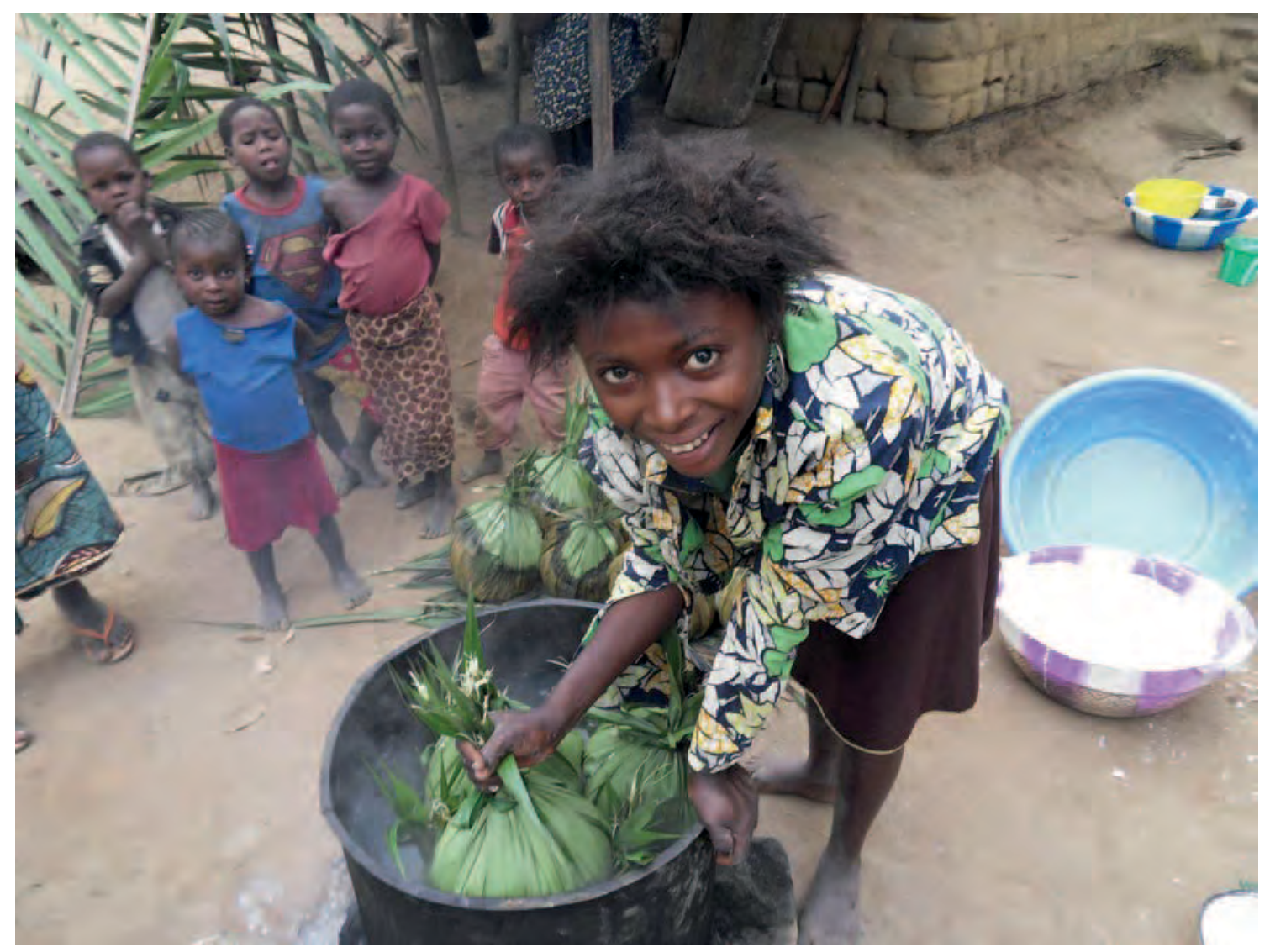

Première cuisson partielle

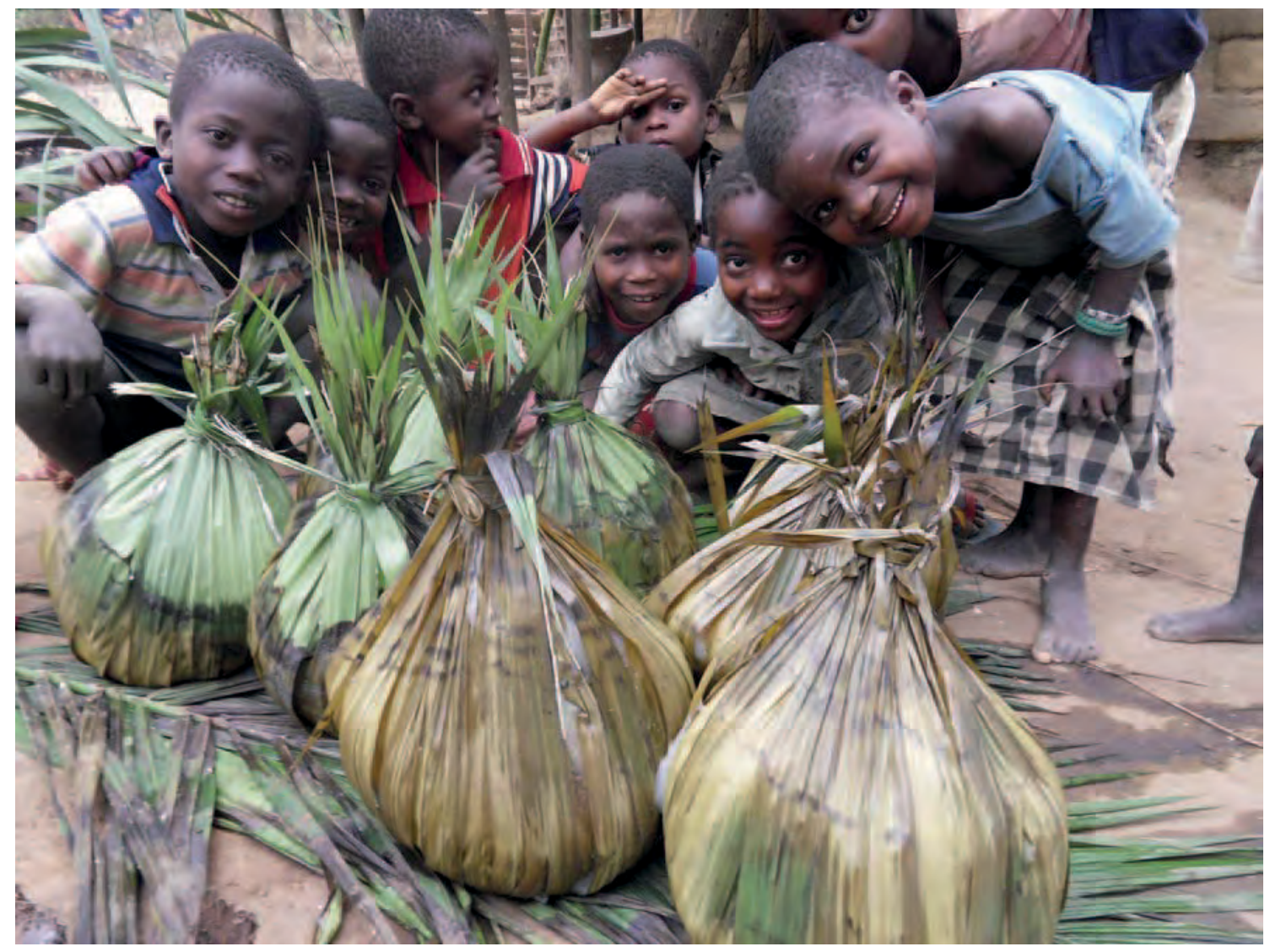

Résultat de la première cuisson de la chikwangue 


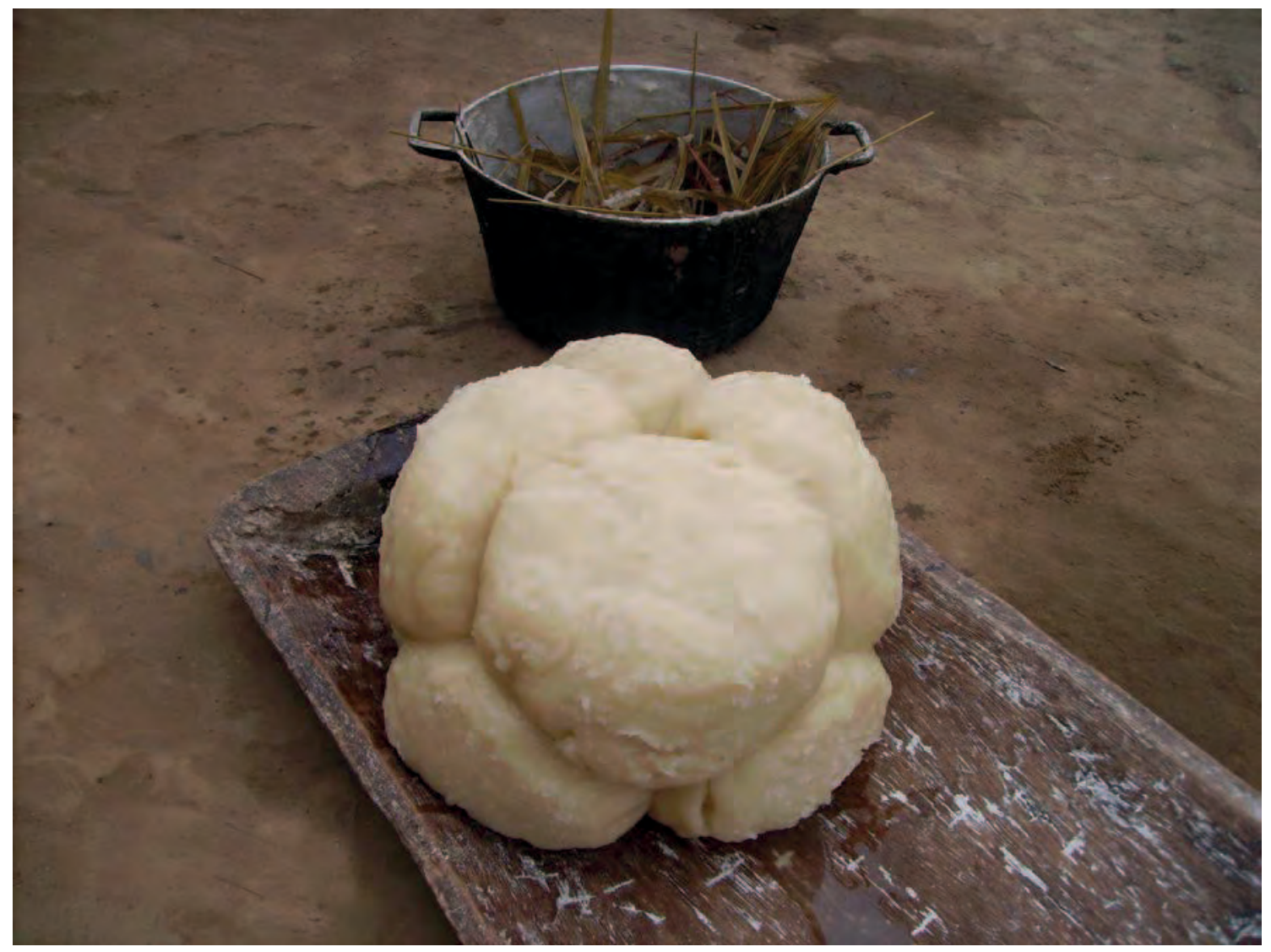

Chikwangue après la première cuisson

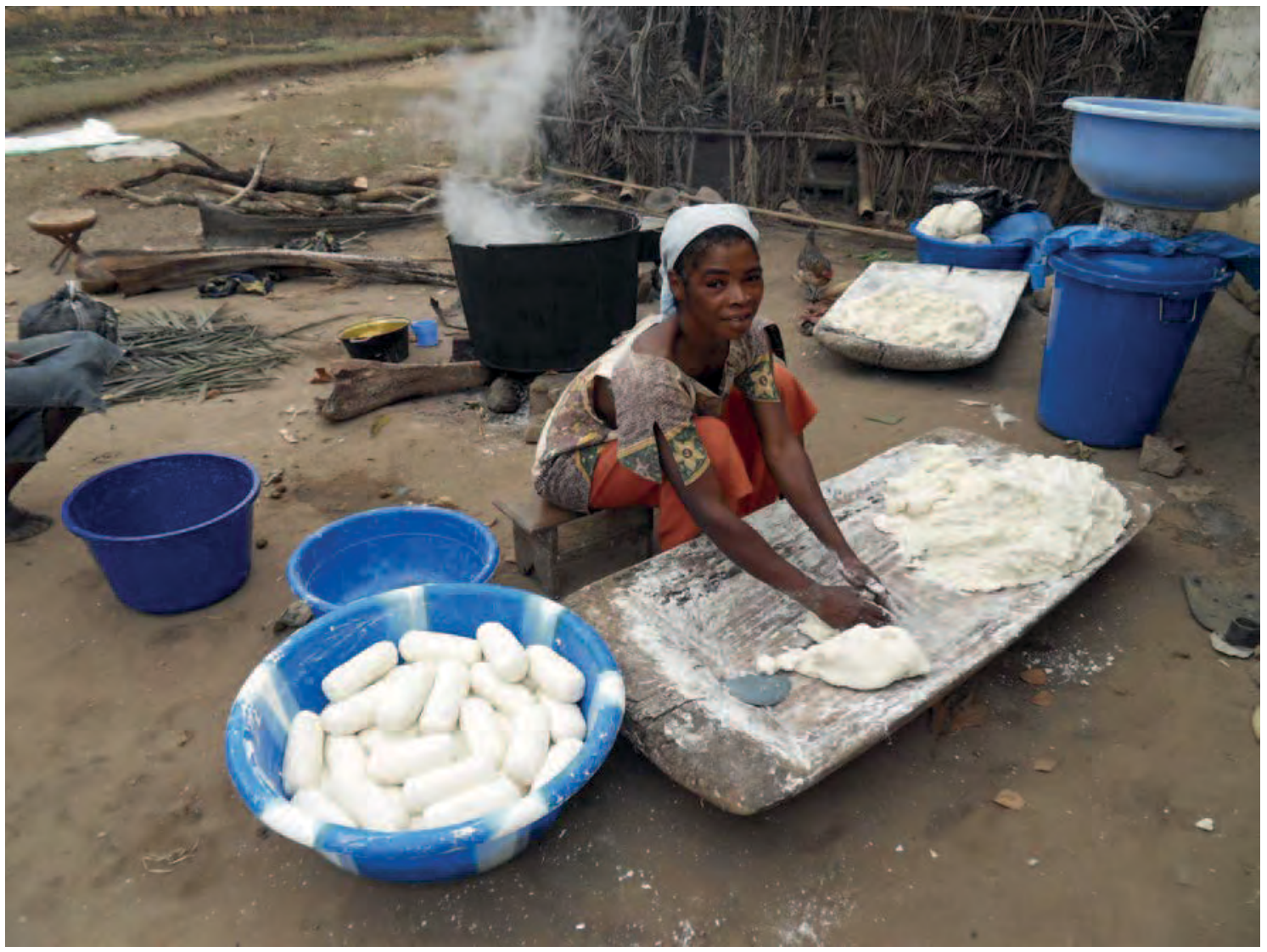

Façonnage proprement dit des chikwangues après la cuisson préliminaire. 


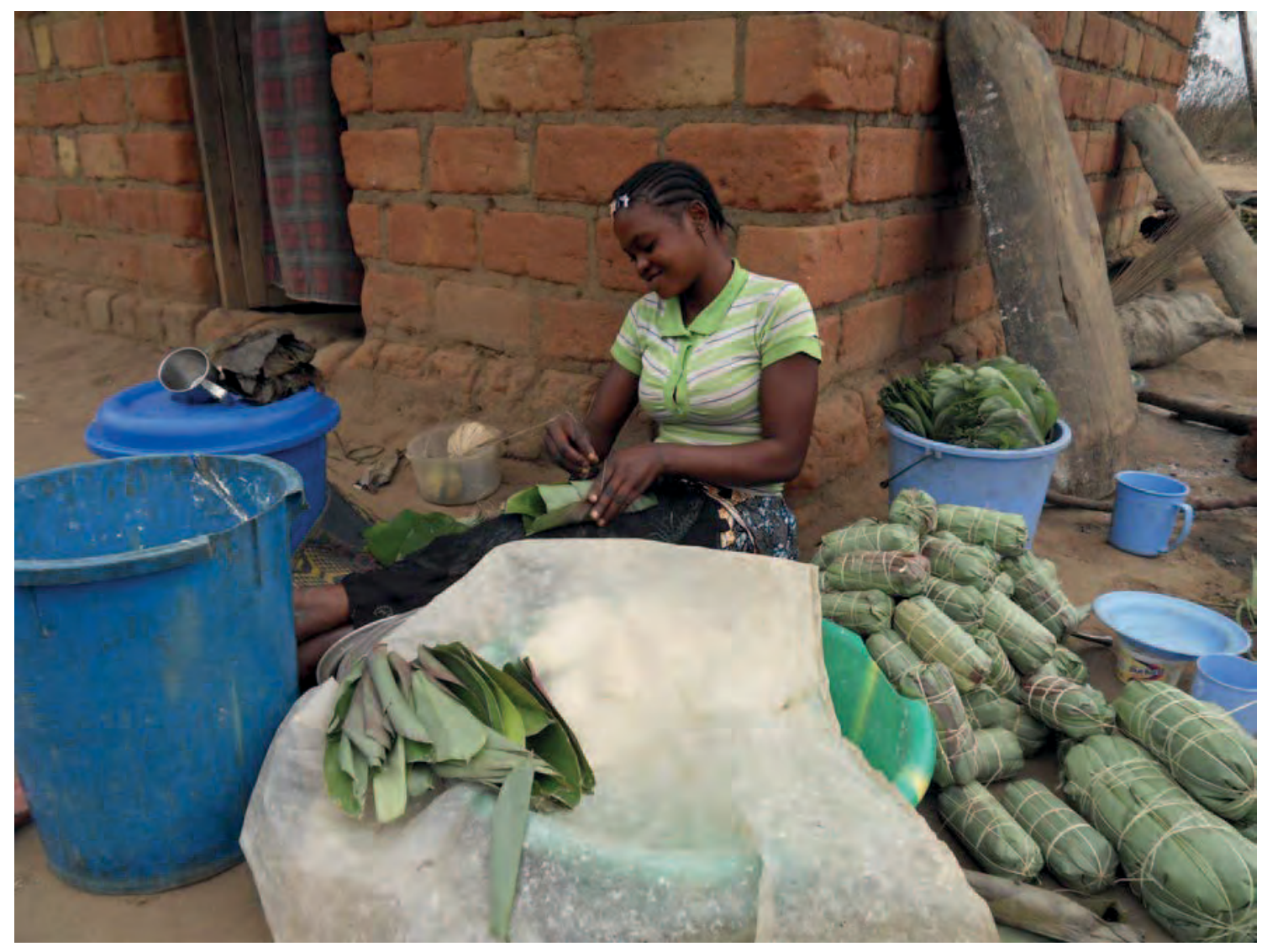

Emballage des chikwangues dans les feuilles de Haumania liebrechtsiana avec les fibres de pétiole de palmier.

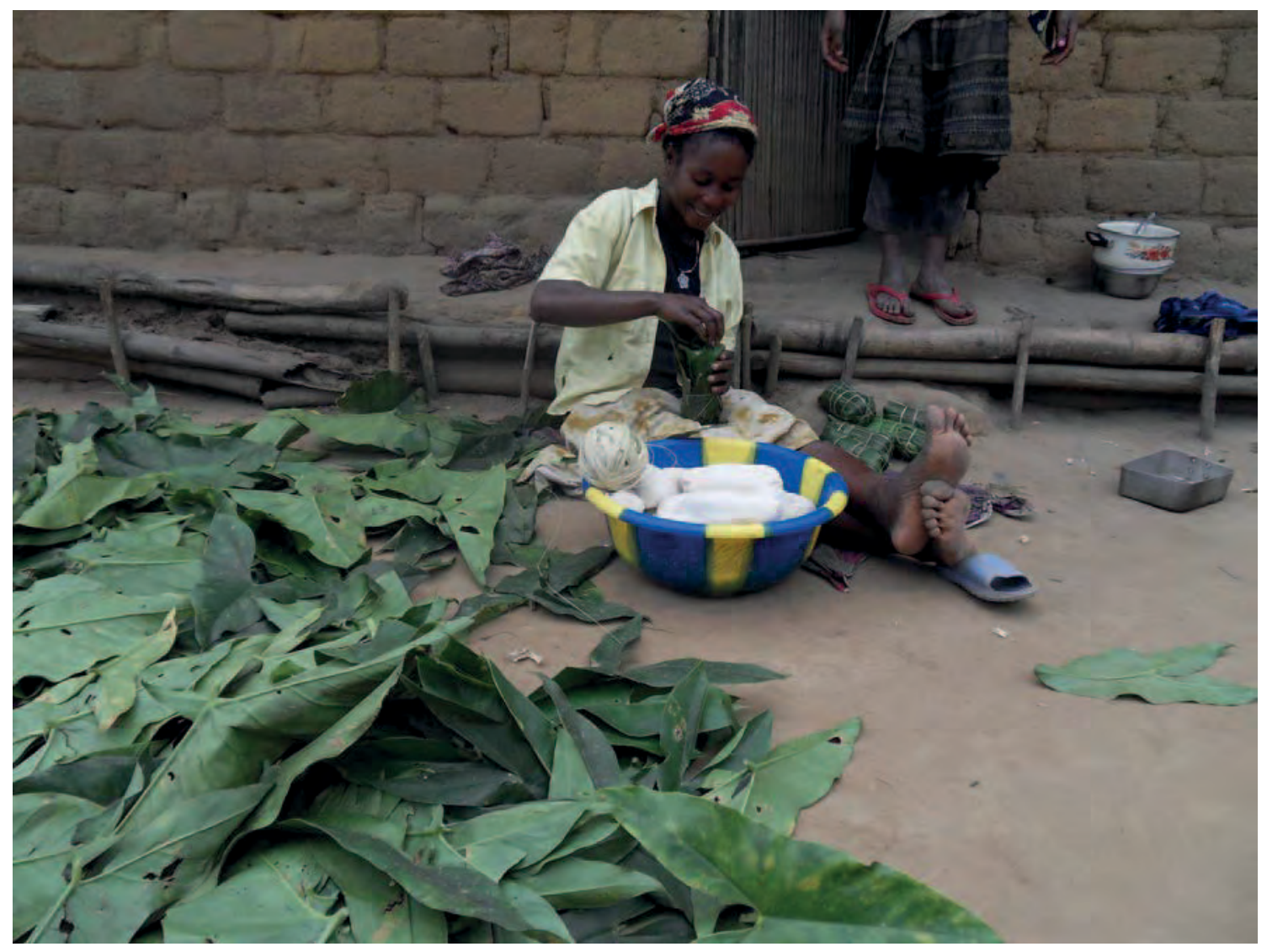

Emballage avec les feuilles de Lasimorpha senegalensis 


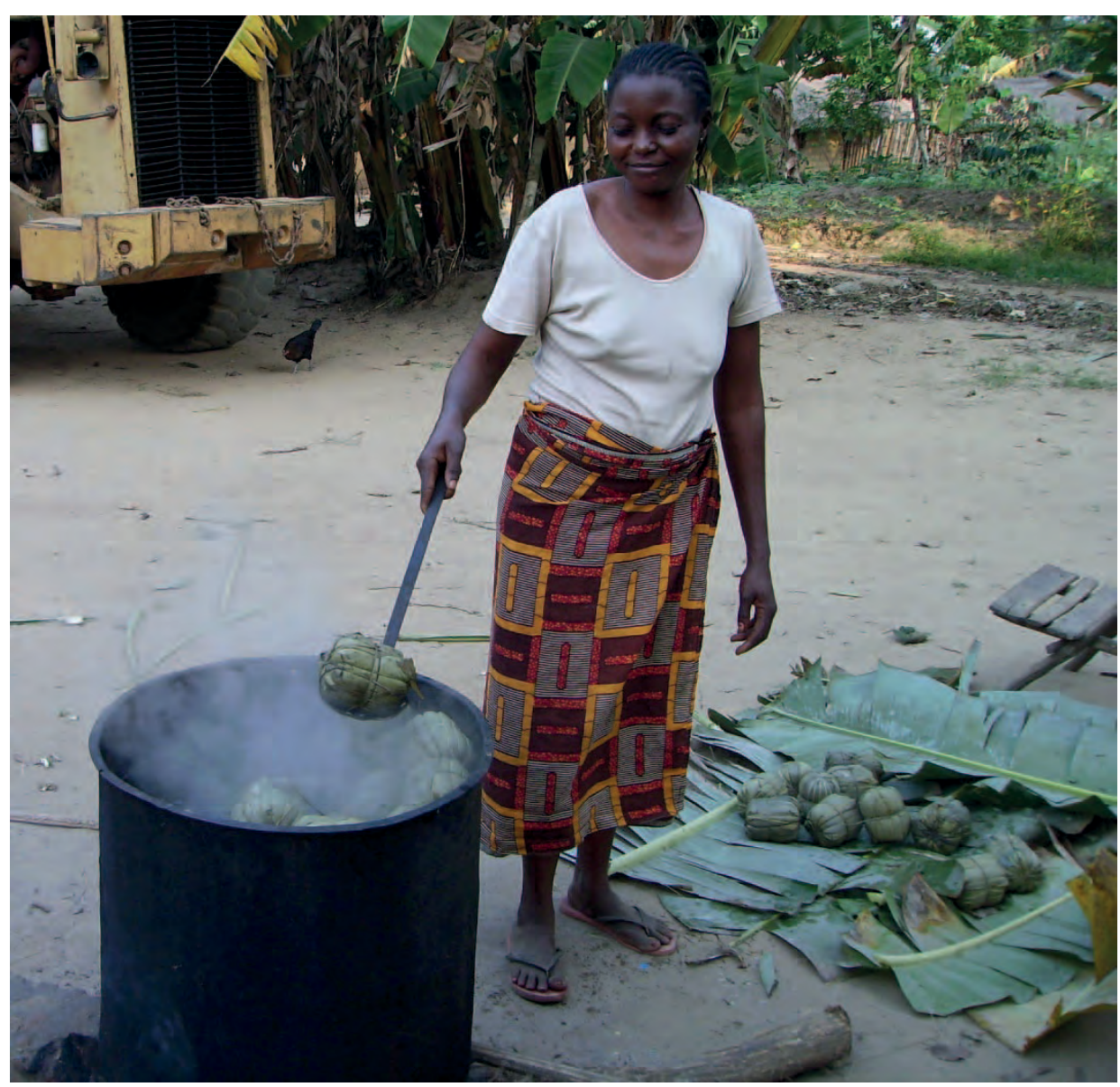

Chikwangues cuites, prêtes à la consommation

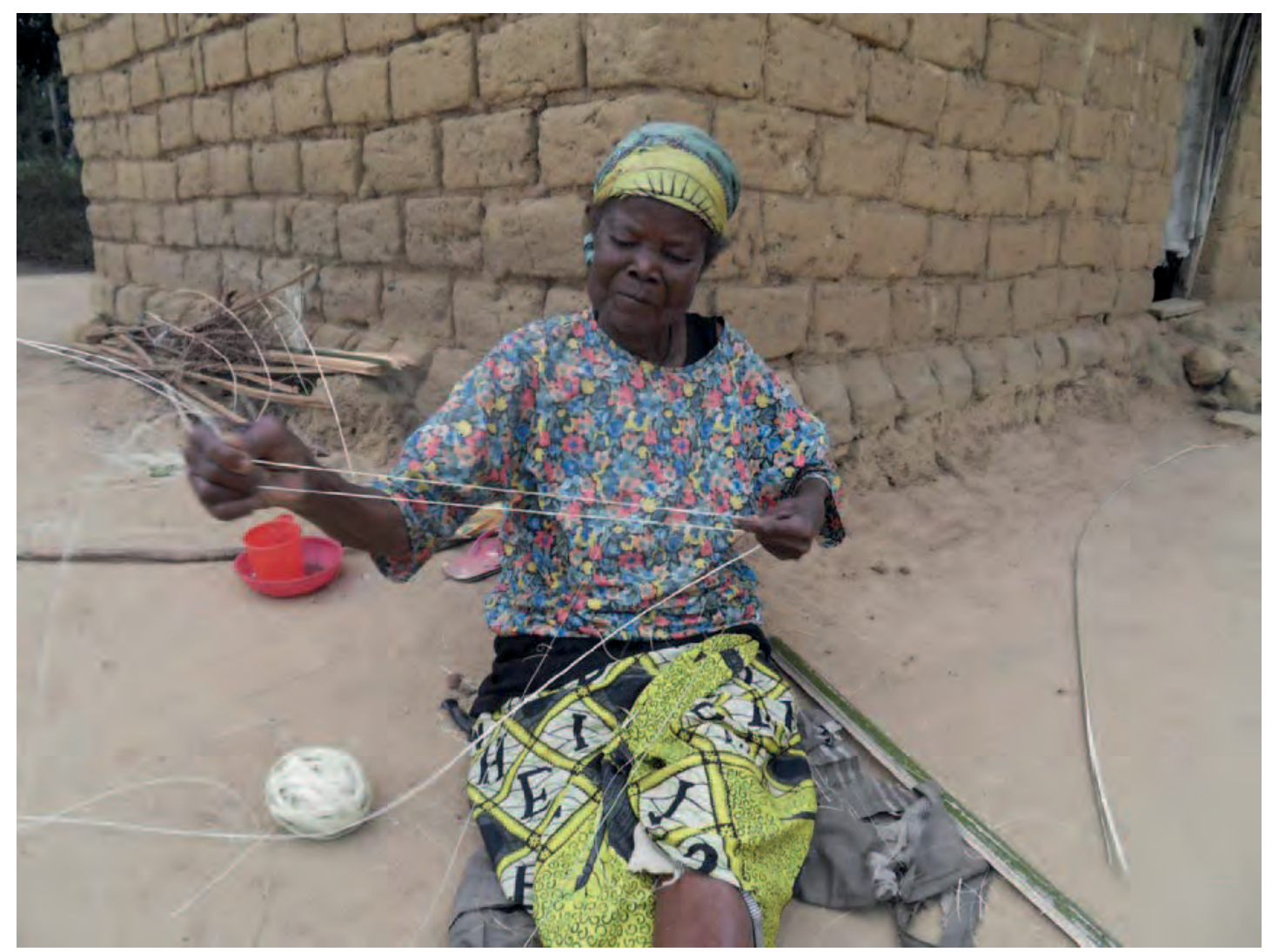

Extraction des fibres du pétiole de palmier à huile pour le ficelage de la chikwangue 


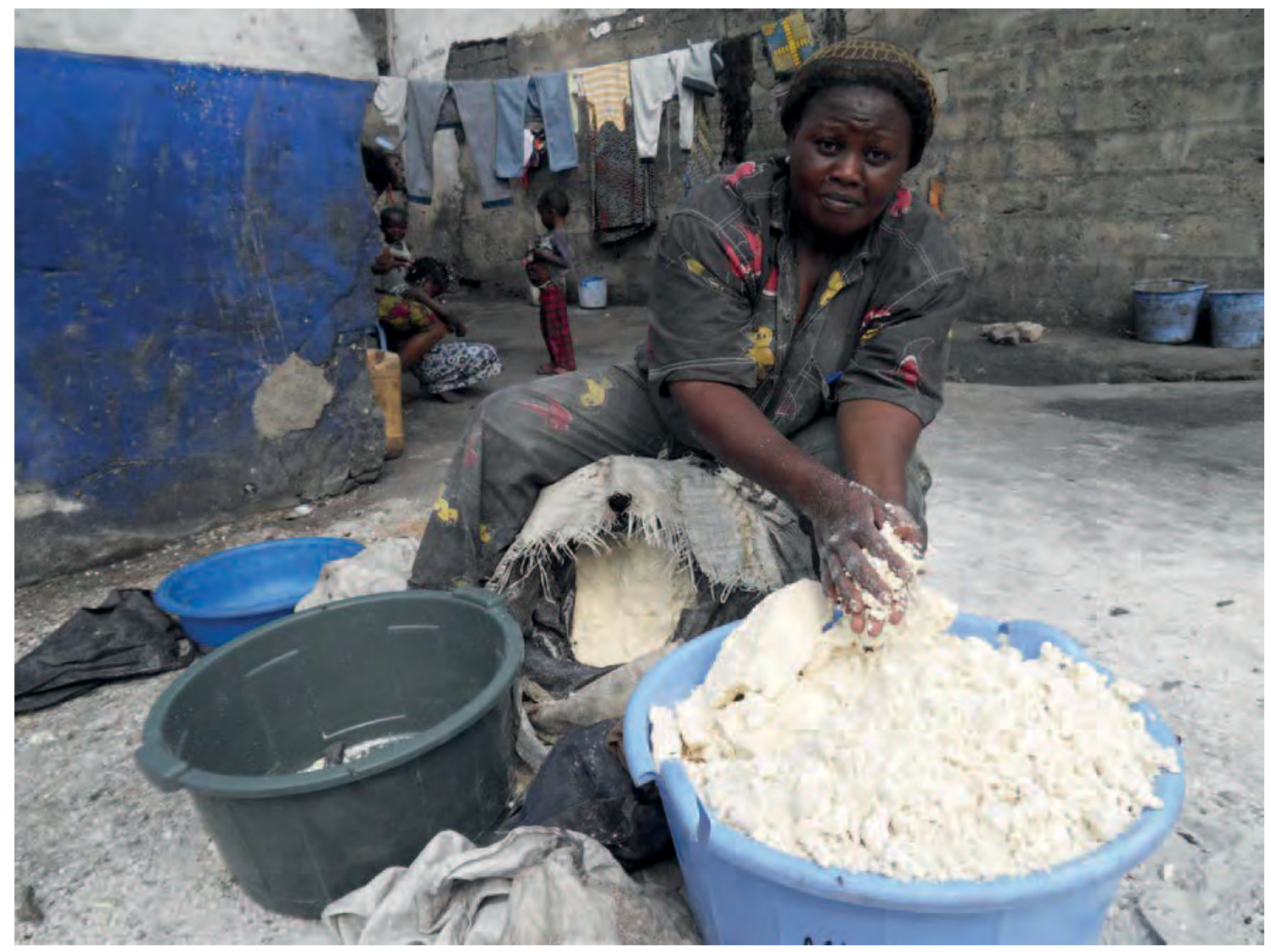

Manioc roui, nettoyé, écrasé, pressé et égoutté comme vendu sur le marché à Kinshasa

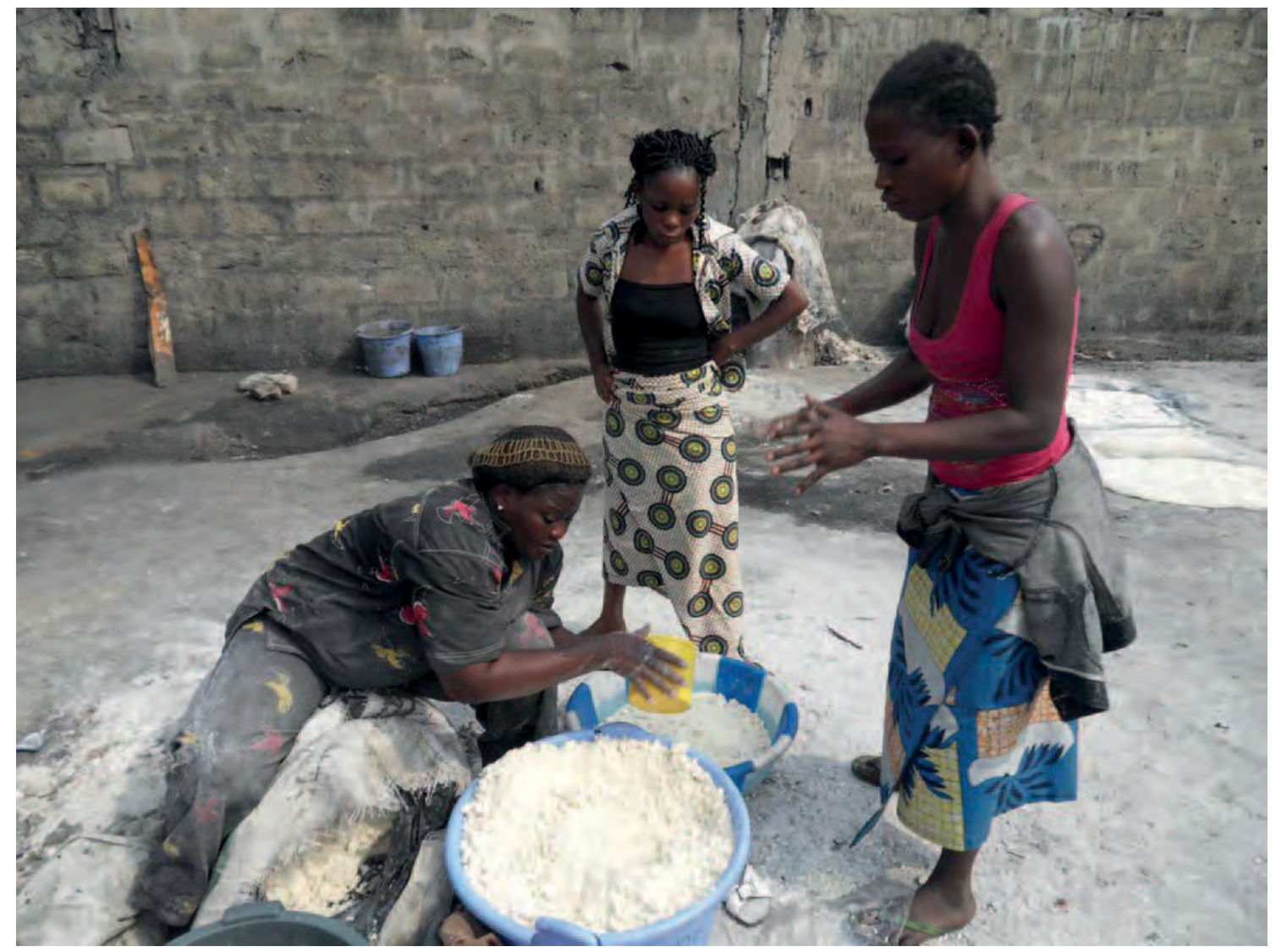

Vente du manioc roui, pressé et égoutté pour la préparation de la chikwangue en ville 


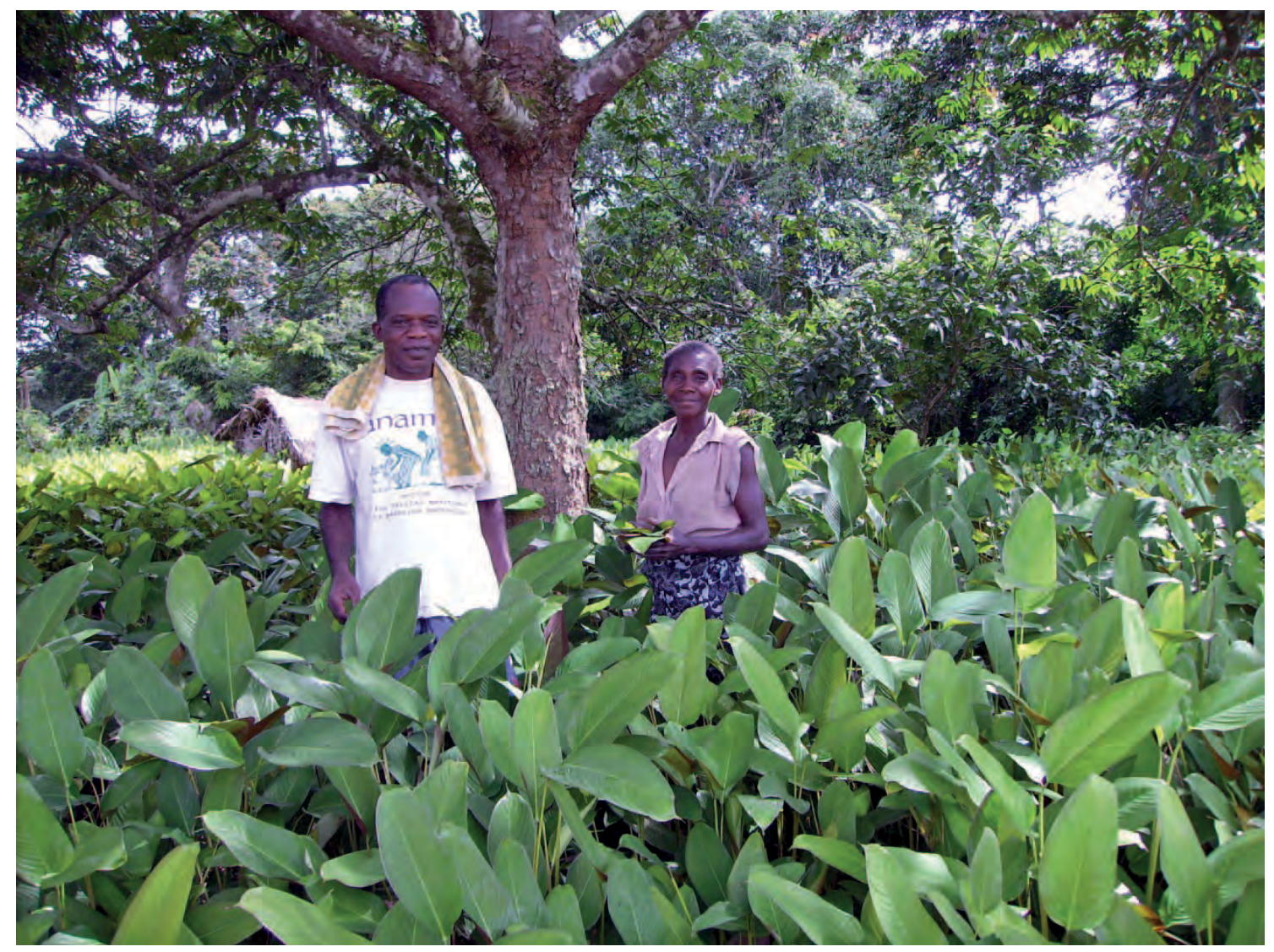

Haumania liebrechtsiana, feuilles pour emballer la chikwangue, actuellement de plus en plus cultivée autour des habitations

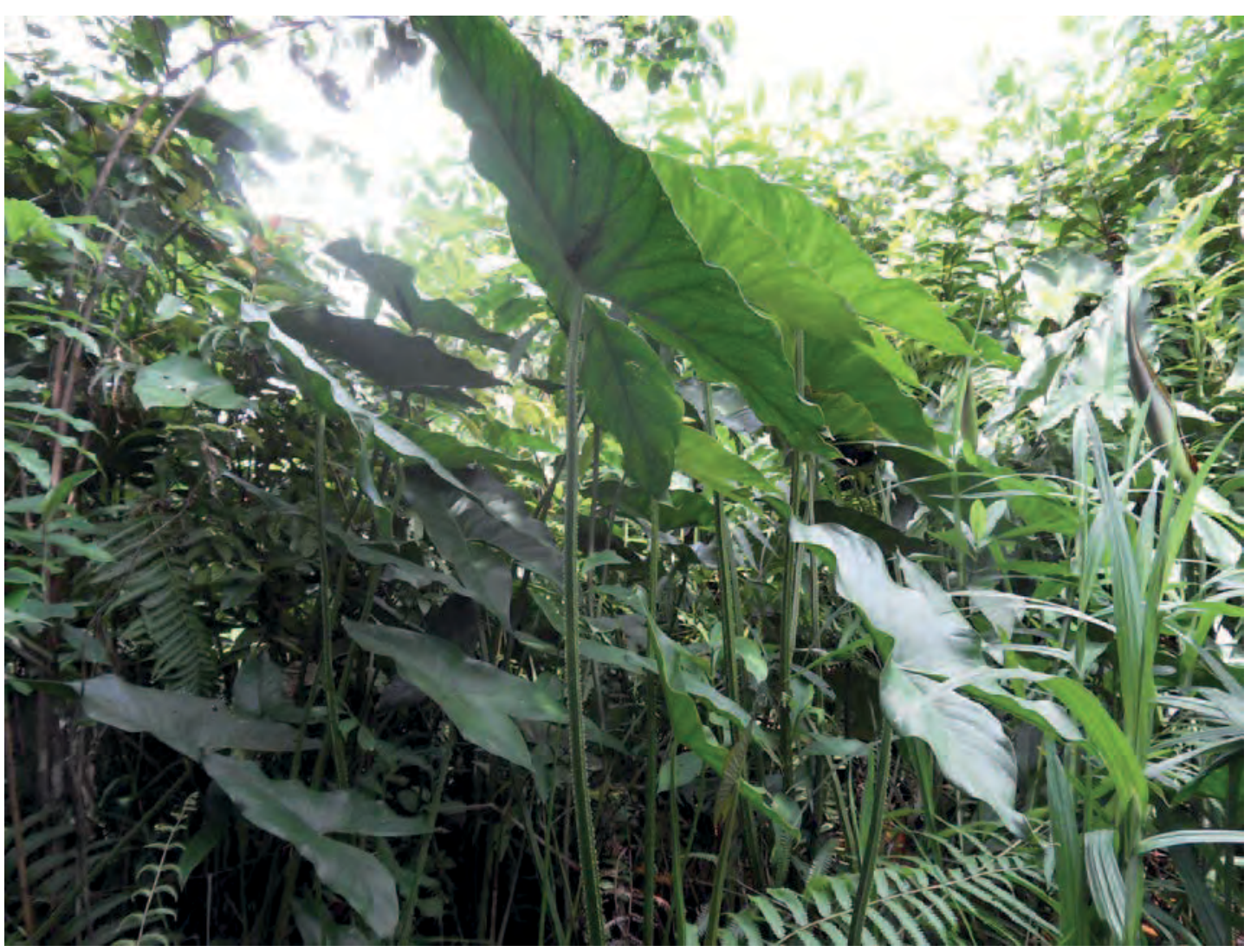

Lasimorpha senegalensis, feuilles aussi utilisées, la plante pousse dans les endroits humides 


\section{Références}

ABBIW, D. (1990) Useful Plants of Ghana. Royal Botanic Gardens, Kew. 337 pp.

ABDULLAHI, G, SULE, H., CHIMOYA I. \& ISAH, M. (2011) Diversity and relative Distribution of Honeybees Foraging Plants in some selected Reserves in Mubi Region, Sudan Savannah Ecological zone of Nigeria. www. pelagiaresearchlibrary.com

ABROL, D.P. (2015) Antigonon leptopus. Bee World 84 (3) 130-131

ABUKUTSA-ONYANGO, M.O. (2004) Basella alba L. In Grubben, G.J.H. \& Denton, O.A. (Eds.). Plant Resources of Tropical Africa 2. Vegetables. PROTA Foundation, Wageningen, Netherlands/ Backhuys Publishers, Leiden, Netherlands / CTA. p. 103 - 106.

ACHIGAN-DAKO, E., PASQUINI, M., ASSOGBA-KOMLAN, F., SOGNIGBÉ, N., DANSI, A., AMBROSEOJ I, B. (2009) Traditional Vegetables in Benin. Diversity, Distribution, Ecology, Agronomy, and Utility. Darwin I nitiative $252 \mathrm{pp}$.

ACLAND, J.D. (1971) East African Crops. FAO/Longman. 252 pp.

ADAM, K.A. \& KRAMPAH, E. (2005). Gmelina arborea Roxb. ex Sm. [I nternet] Record from PROTA4U. Louppe, D., Oteng-Amoako, A.A. \& Brink, M. (Editors). PROTA (Plant Resources of Tropical Africa / Ressources végétales de l'Afrique tropicale), Wageningen, Netherlands.

ADEBISI, A.A. \& LAIPO, D.O., (2007) Bridelia atroviridis Müll.Arg. [Internet] Record from PROTA4U. Schmelzer, G.H. \& Gurib-Fakim, A. (Editors). PROTA (Plant Resources of Tropical Africa / Ressources végétales de l'Afrique tropicale), Wageningen, Netherlands.

ADETULA, O.A. (2004) Asystasia gangetica(L.) T.Anderson. In Grubben, G.J.H. \& Denton, O.A. (Editors). Plant Resources of Tropical Africa 2. Vegetables PROTA Foundation, Wageningen, Netherlands/Backhuys Publishers, Leiden, Netherlands/CTA, Wageningen, Netherlands. pp. 100 102

ADRIAENS, E.-L. (1951) Recherches sur l'alimentation des populations au Kwango. Bull. Agric. du Congo belge 42: 227 - 552.

AFRI CAN PLANT DATABASE (APD) https://www.ville-ge.ch/musinfo/bd/cjb/africa/recherche. php

AGROFORESTREE Database http:// www. worldagroforestry.org/output/agroforestree-database

AKÉ ASSI, L., ABEYE, J., GUINKO, S., RIGUET, R. \& BANGAVOU, R. (1980) Médicine traditionnelle et pharmacopée - Contribution aux études ethnobotaniques et floristiques en République Centrafricaine. Agence de Coopération Culturelle et Technique, Paris, France. 140 pp.

AKOBUNDU, I.O. \& AGYAKWA, C.W. (1987) A Handbook of West African Weeds. I nternational Institute for Tropical Agriculture, Ibadan. 521 pp.

ALLEN, O.N. \& ALLEN, E.K. (1981) Leguminosae: A Source Book of Characteristics, Uses and Nodulation. University of Wisconsin. $812 \mathrm{pp}$.

ALVAREZ CRUZ, N.S. (2008) Phyllanthus niruroides Müll.Arg. [I nternet] Record from PROTA4U. Schmelzer, G.H. \& Gurib-Fakim, A. (Editors). PROTA (Plant Resources of Tropical Africa / Ressources végétales de l'Afrique tropicale), Wageningen, Netherlands.

AMBANG, Z, AMOUGOU, A., NDONGO, B., NANTIA, J. \& CHEWACHONG, G.M. (2009) Résistance à la mosaïque virale de Manihot glaziovii par greffage sur M. esculenta. Tropicultura 27, 1, 8 - 14

AMBOUGOU, A.V. (1991) Apis mellifera et les plantes mellifères Gabonais. Thèse Doctorat, Université de Paris 6. 14 pp.

AMOATEY, H.M., KLU, G.Y.P., BANSA, D., KUMAGA, F.K., ABOAGYE, L.M., BENNET-LARTEY, S.O. \& GAMEDOAGBAO, D.K. (2000) The African Yam Bean (Sphenostylis stenocarpa): A Neglected Crop in Ghana. West African Journal of Applied Ecology Vol. 1 pp. 53 - 60

AMPONSAH, K., CRENTSIL, O'R., ODAMTTEN, G.T., OFOSUHENE-DJ AN, W. (2002) Manual for the propagation and cultivation of medicinal plants of Ghana. Ed: F. Denis. Aburi Botanic Garden $32 \mathrm{pp}$.

ANI GBOGU, N.M. (1996) Ricinodendron heudelotti in Nigeria. International Centre for Research in Agroforestry (ICRAF) Agroforestry Today 8: 2.

ANTON-SMITH, J. (1964) The seed of Bombacopsis glabra as a possible economic crop. Rhod. J. Agric. Res. 2 (2): pp. $106-8$.

ARBONNI ER, M. (2004) Trees, shrubs and lianas of West African dry zones. CIRAD MAGRAF Publishers 3GMBH, MNHN 579 pp.

ARKINSTALL, W.W. (1979) Medicinal and useful plants collected in the Manianga district of the Republic of Zaïre. Revue de Recherche Scientifique, Zaïre. pp. 135 - 158.

AUBREVILLE, A., (1970) Légumineuses - Césalpinioidées (Leguminosae - Caesalpinioideae). Flore du Cameroun. Volume 9. Muséum National d'Histoire Naturelle, Paris, France. 339 pp.

AUBREY, A. (2001) Plumbago auriculata Lam. "http://www.plantzafrica.com"

AUBREY, A. (2003) Pterocarpus angolensisDC. "http:// www.plantzafrica.com" 
AUMEERUDDY, Y. \& PINGLO, F. (1988) Phytopractices in Tropical Regions. UNESCO. $71 \mathrm{pp}$.

AWEKE, G. (2007) Costus afer Ker Gawl. In Schmelzer, G.H. \& Gurib-Fakim, A. (Editors). Plant Resources of Tropical Africa 11(1). Medicinal plants 1. PROTA Foundation, Wageningen, Netherlands/Backhuys Publishers, Leiden, Netherlands/CTA, Wageningen, Netherlands. pp. 191 - 194

AYENI, E.A. \& ALIYU, N. (2018) Tetracarpidium conophorum (African walnut) Hutch. \& Dalziel: Ethnomedicinal uses and its therapeutic activities. Journal of Medicinal Plants for Economic Development. $10 \mathrm{pp}$.

BADU-APRAKU, B. \& FAKOREDE, M.A.B. (2006) Zea mays L. [Internet] Record from PROTA4U. Brink, M. \& Belay, G. (Eds.). PROTA (Plant Resources of Tropical Africa / Ressources végétales de l'Afrique tropicale), Wageningen, Netherlands.

BAKENGA, M., BAHATI, M. \& BALAGIZI, K. (2000) Inventaire des plantes mellifères de Bukavu et ses environs. Tropicultura 182 pp. $89-93$

BALE, S. (1948) Flore du Congo Belge et du Ruanda - Urundi : Piperaceae

BALLE, S. (1951) Flore du Congo Belge et du Ruanda - Urundi : Nyctaginaceae

BAMPS, P. (1970) Flore du Congo du Rwanda et du Burundi : Guttiferae

BAMPS, P. (1974) Flore d'Afrique Centrale (Zaïre - Rwanda - Burundi) : Araliaceae.

BAMPS, P. (1976) Flore d'Afrique Centrale (Zaïre - Rwanda - Burundi) : Flacourtiaceae I

BAMPS, P. (1976) Flore d'Afrique Centrale (Zaïre - Rwanda - Burundi) : Flacourtiaceae II

BAMPS, P. (1976) Flore d'Afrique Centrale (Zaïre - Rwanda - Burundi) : Passifloraceae

BAMPS, P. \& FARRON, C. (1967) Flore du Congo du Rwanda et du Burundi : Ochnaceae

BASHENGEZ, C.M. (1997) Purified extract of Uvaria brevistipitata and a process for obtaining the purified extract thereof. United States Patent 5607673.

BAUMANN, G. (2005) Photographic Guide to Wildflowers of Malawi. Wildlife and Environmental Society of Malawi, Limbe $259 \mathrm{pp}$.

BAXTER, J. (1995) Chromolaena odorata - weed for the killing or shrub for the tilling? Agroforestry Today (April-J une).

BEDI GI AN, D., (2004). Sesamum radiatum Thonn. ex Hornem. [Internet] Record from PROTA4U. Grubben, G.J.H. \& Denton, O.A. (Editors). PROTA (Plant Resources of Tropical Africa / Ressources végétales de l'Afrique tropicale), Wageningen, Netherlands.

BEENTJ E, H.J. (1982) A Monograph on Strophanthus (DC.) Apocynaceae. Meded. Landbouwhogeschool Wageningen. $191 \mathrm{pp}$.

BEENTJ E, H.J. (1994) Kenya Trees, Shrubs and Lianas. National Museums of Kenya. 722 pp.

BEENTJ E, H.J. . (2006) Strophanthus samentosusDC. [Internet] Record from PROTA4U. Schmelzer, G.H. \& Gurib-Fakim, A. (Eds.). PROTA (Plant Resources of Tropical Africa / Ressources végétales de I'Afrique tropicale), Wageningen, Netherlands.

BEENTJ E, H.J. (2021) Apocynaceae. Flore d'Afrique Centrale. Jardin Botanique de Meise. 321 pp.

BEHR, K. (2005) Ochna pulchra Hook.f. "http://www. plantzafrica.com"

BEI N, E., HABTE, B., J ABER, A., BIRNIE, A. \& TENGNÄS, B. (1996) Useful Trees and Shrubs in Eritrea. Regional Soil Conservation Unit, Nairobi. 422 pp.

BEKELE-TESEMMA, A., BI RNIE, A. \& TENGNÄS, B. (1993) Useful Trees and Shrubs for Ethiopia. Regional Soil Conservation Unit/SIDA. $474 \mathrm{pp}$.

BEN-BALA, K.D., 2008. Phyllanthus muellerianus (Kuntze) Exell. [Internet] Record from PROTA4U. Schmelzer, G.H. \& Gurib-Fakim, A. (Editors). PROTA (Plant Resources of Tropical Africa / Ressources végétales de l'Afrique tropicale), Wageningen, Netherlands.

BERG, C.C. \& WI EBES, J.T. (1992) African Fig Trees and Fig Wasps. North-Holland. 298 pp.

BIJTTEBI ER, J. (1981) Treculia africana. In Agroforestry and Fight against the Penury of Food in the Third World. XVII IUFRO World Congress, Kyoto, J apan. pp. 31 - 55.

BI KANDU, B., LUKOKI, F., HABARI, J.P., NTORE, S. \& SOSEF, M.S.M. (2020) Solanaceae. Flore d'Afrique Centrale

BI LOSO, A. \& LEJOLY. J. (2006) Etude de l'exploitation et du marché des produits forestiers non ligneux à Kinshasa. Tropicultura 24 (3) 183 - 188.

BI LOSO, M. A. (2010) Valorisation des Produits Forestiers Non Ligneux des Plateaux de Batéké en Périphérie de Kinshasa (R.D. Congo). Université de Kinshasa 235 pp.

BISHOP, H.G. (1992) Aeschynomene americana L. In: PROSEA (Plant Resources South-East Asia) Foundation, (ed. by Mannetje L., Jones R.M.). Bogor, Indonesia: http://www.proseanet.org

BLUNDELL, M. (1987) Wild Flowers of East Africa. Collins Photo Guide 464 pp.

BOGDAN, A.V. (1962) Grass pollination by bees in Kenya. Proceedings of the Linnean Society of London 173: $57-60$

BOGDAN, A. V. (1977) Tropical Pasture and Fodder Plants. Longman. 475 pp.

BONGERS, F., PARREN, M.P.E. \& TRAORE, D. (2005) Forest Climbing Plants of West Africa. CABI Publishing. 
$273 \mathrm{pp}$.

BONNEHIN, L. (2000) Domestication Paysanne des Arbres Fruitières Forestières. Cas de Coula edulis Baill. Coulacaceae et de Tieghemella heckelii Piere ex A. Chev. Sapotaceae autour de Parc National de Taï, Côté d'l voire. Thèse Université Wageningen. 149 pp.

BORGET, M. (1993) Spice Plants. The Tropical Agriculturalist Series 1993. CTAMMacmillan. 114 pp.

BOSCH, C.H. (2002) Spathodea campanulataP.Beauv. [Internet] Record from PROTA4U. Oyen, L.P.A. \& Lemmens, R.H.M.J. (Eds.). PROTA (Plant Resources of Tropical Africa / Ressources végétales de l'Afrique tropicale), Wageningen, Netherlands.

BOSCH, C.H. (2004) Acmella oleracea(L.) R.K.J ansen [Internet] Record from PROTA4U. Grubben, G.J .H. \& Denton, O.A. (Eds.). PROTA (Plant Resources of Tropical Africa / Ressources végétales de l'Afrique tropicale), Wageningen, Netherlands.

BOSCH, C.H. (2004) Canavalia gladiata (J acq.) DC. [Internet] Record from PROTA4U. Grubben, G.J.H. \& Denton, O.A. (Eds.). PROTA (Plant Resources of Tropical Africa / Ressources végétales de l'Afrique tropicale), Wageningen, Netherlands.

BOSCH, C.H. (2004) Emilia coccinea (Sims) G.Don. [I nternet] Record from PROTA4U. Grubben, G.J .H. \& Denton, O.A. (Eds.). PROTA (Plant Resources of Tropical Africa / Ressources végétales de l'Afrique tropicale), Wageningen, Netherlands.

BOSCH, C.H. (2004) Impatiens invingiï Hook.f. ex Oliv. [Internet] Record from PROTA4U. Grubben, G.J.H. \& Denton, O.A. (Eds.). PROTA (Plant Resources of Tropical Africa / Ressources végétales de l'Afrique tropicale), Wageningen, Netherlands.

BOSCH, C.H., (2004) Laportea ovalifolia (Schumach.) Chew. [Internet] Record from PROTA4U. Grubben, G.J.H. \& Denton, O.A. (Editors). PROTA (Plant Resources of Tropical Africa / Ressources végétales de l'Afrique tropicale), Wageningen, Netherlands.

BOSCH, C.H. (2004) Melochia corchorifolia L. [I nternet] Record from PROTA4U. Grubben, G.J.H. \& Denton, O.A. (Eds.). PROTA (Plant Resources of Tropical Africa / Ressources végétales de l'Afrique tropicale), Wageningen, Netherlands.

BOSCH, C.H., (2004). Moringa oleifera Lam. [Internet] Record from PROTA4U. Grubben, G.J.H. \& Denton, O.A. (Editors). PROTA (Plant Resources of Tropical Africa / Ressources végétales de l'Afrique tropicale), Wageningen, Netherlands.

BOSCH, C.H., (2004). Moringa stenopetala (Baker f.) Cufod. [Internet] Record from PROTA4U. Grubben, G.J.H. \& Denton, O.A. (Editors). PROTA (Plant Resources of Tropical Africa / Ressources végétales de l'Afrique tropicale), Wageningen, Netherlands.

BOSCH, C.H., (2004). Urera trinervis (Hochst.) Friis \& Immelman. [Internet] Record from PROTA4U. Grubben, G.J.H. \& Denton, O.A. (Editors). PROTA (Plant Resources of Tropical Africa / Ressources végétales de l'Afrique tropicale), Wageningen, Netherlands.

BOSCH, C.H. (2011) Anthonotha macrophylla P. Beauv. [I nternet] Record from PROTA4U. Grubben, G.J .H. \& Denton, O.A. (Eds.). PROTA (Plant Resources of Tropical Africa / Ressources végétales de I'Afrique tropicale), Wageningen, Netherlands.

BOSCH, C.H., (2011). Cryptolepis oblongifolia (Meisn.) Schltr. [Internet] Record from PROTA4U. Brink, M. \& Achigan-Dako, E.G. (Editors). PROTA (Plant Resources of Tropical Africa / Ressources végétales de l'Afrique tropicale), Wageningen, Netherlands.

BOSCH, C.H., (2011). Calycobolus heudelotii (Baker ex Oliv.) Heine. [I nternet] Record from PROTA4U. Schmelzer, G.H. \& Gurib-Fakim, A. (Editors). PROTA (Plant Resources of Tropical Africa / Ressources végétales de l'Afrique tropicale), Wageningen, Netherlands.

BOUMENDJ EL, A. et al. (2013) Occurrence of the synthetic analgesic Tramadol in an African medicinal plant. Angewandte Chemie. DOI : 10.1002/ange. 201305697.

BOUQUET, A. (1969) Féticheurs et Médecines Traditionnelles du Congo. Mém. ORSTOM, Paris. 282 pp.

BOUROBOU BOUROBOU, H.P. (2006) Tabernanthe ibogaBaill. [Internet] Record from PROTA4U. Schmelzer, G.H. \& Gurib-Fakim, A. (Eds.). PROTA (Plant Resources of Tropical Africa / Ressources végétales de l'Afrique tropicale), Wageningen, Netherlands.

BOUTIQUE, R. (1951) Flore du Congo Belge et du Ruanda-Urundi : Annonaceae

BOUTIQUE, R. (1960) Flore du Congo Belge et du Ruanda-Urundi : I cacinaceae

BOUTIQUE, R. (1967) Flore du Congo, du Rwanda et Burundi : Dilleniaceae

BOUTIQUE, R. (1968) Flore du Congo, du Rwanda et Burundi : Myrtaceae

BOWN, D. (1995) The Royal Horticultural Society Encyclopaedia of Herbs and Their Uses. Dorling Kindersley, London. $424 \mathrm{pp}$.

BOWN, D. (2000) Aroids. Plants of the Arum family. Timber Press. 468 pp.

BRETELER, F.J . (2013) Revision of Calycobolus (Convolvulaceae) in continental Africa. Plant Ecology and Evolution, Volume 146, Number 3, pp. 328-359

BRETELER, F.J. (2013) Uapaca (Phyllanthaceae) in the Guineo-Congolian forest region: a synoptic revision. Plant Ecology and Evolution 146 (1): 75-9 
BREWSTER, J.L. (1994) Onions and other Vegetable Alliums. CAB. 236 pp.

BRIDSON, D.M. \& VERDCOURT, B. (2003) Flora Zambesiaca 5:3 Rubiaceae

BRI NK, G., RAMOLEMANA, G.M. \& SIBUGA, K. P. (2006) Vigna subterranea (L.) Verdc. [Internet] Record from PROTA4U. Brink, M. \& Belay, G. (Editors). PROTA (Plant Resources of Tropical Africa / Ressources végétales de l'Afrique tropicale), Wageningen, Netherlands.

BRI NK, M. (2007) Chlamydocola chlamydantha (K.Schum.) M.Bodard. [Internet] Record from PROTA4U. Louppe, D., Oteng-Amoako, A.A. \& Brink, M. (Editors). PROTA (Plant Resources of Tropical Africa / Ressources végétales de l'Afrique tropicale), Wageningen, Netherlands.

BRI NK, M. (2010) Haumania liebrechtsiana (De Wild. \& T.Durand) J .Léonard. [I nternet] Record from PROTA4U. Brink, M. \& Achigan-Dako, E.G. (Editors). PROTA (Plant Resources of Tropical Africa / Ressources végétales de l'Afrique tropicale), Wageningen, Netherlands.

BRI NK, M. (2011). Marantochloa congensis (K.Schum.) J .Léonard \& Mullend. [Internet] Record from PROTA4U. Brink, M. \& Achigan-Dako, E.G. (Editors). PROTA (Plant Resources of Tropical Africa / Ressources végétales de l'Afrique tropicale), Wageningen, Netherlands.

BRI NK, M., (2011). Pandanus utilis Bory. [I nternet] Record from PROTA4U. Brink, M. \& Achigan-Dako, E.G. (Editors). PROTA (Plant Resources of Tropical Africa / Ressources végétales de l'Afrique tropicale), Wageningen, Netherlands.

BRI NK, M. (2011) Sclerosperma mannii H. Wendl. [Internet] Record from PROTA4U. Brink, M. \& AchiganDako, E.G. (Editors). PROTA (Plant Resources of Tropical Africa / Ressources végétales de l'Afrique tropicale), Wageningen, Netherlands.

BRYAN, J. \& GRIFFITHS, M. (1995) Manual of Bulbs. Timber Press. 383 pp.

BUKENYA-ZRABA, R. (2011) Hibiscus cannabinus L. [I nternet] Record from PROTA4U. Brink, M. \& AchiganDako, E.G. (Eds.). PROTA (Plant Resources of Tropical Africa / Ressources végétales de l'Afrique tropicale), Wageningen, Netherlands.

BULAKAL, B.P., ALONI, J. PALATA, J.C., MERGEAI, G. (2014) Performances de trois variétés de manioc (Manihot esculenta Crantz.) cultivées en association avec Stylosanthes guianensis(Aublet) Swartz dans les conditions du plateau des Batéké (ville-province de Kinshasa, RDC).

BUNYAPRAPHATSARA, N. \& LEMMENS, R.H.M.J. (1999) Aerva lanata (L.) A.L. J uss. Ex Schultes. In de Padua, L.S., Bunyapraphatsara, N. \& Lemmens, R.H.M.J. (Eds.) Plant Resources of South- East Asia No 12 (1) Medicinal and poisonous plants 1. Backhuys Publishers, Leiden, Netherlands. pp. $87 \& 88$.

BURKILL, H.M. (1985-2000) The Useful Plants of West Tropical Africa. Royal Botanic Gardens, Kew, United Kingdom. 2nd Edition. Vol. 1(1985), Families A-D, 960 pp.; Vol. 2 (1994), Families E-I, 636 pp., Vol. 3 (1995), Families J-L, 857 pp.; Vol. 4 (1997), Families M-R, 969 pp.; Vol. 5 (2000), Families S-Z, 686 pp., Vol. 6 (2004) General Index, 1263 pp.

BURRING, J.-H. (2004) Ficus /uteaVahl. "http://www.plantzafrica.com"

BURROWS, J. \& BURROWS, S. (2003) Figs of Southern \& South-Central Africa. Umdaus Press. 379 pp.

BURROWS, J. \& WILUS, C. (2005) Plants of the Nyika plateau. Southern African Botanical Diversity Network Report No. 31. South African National Biodiversity Institute. 405 pp.

BUSSON, F. (1965) Plantes alimentaires de l'Ouest Africain. Etude botanique, biologique et chemique. Marseille : Leconte. 568 pp.

BUTAYE, R. (1909) Dictionnaire Kikongo - Français, Français - Kikongo.

CAMERON, B. \& LOWE, L. (2017) Gardening in Eastern Africa. Kenya Horticultural Society. 678 pp.

CASTAGNÉ, J.B. (1983) L'apiculture au Congo Brazzaville. Bull. Tech. Apicole 10 (4), 197 - 208.

CHEN, C.P. (1992) Tripsacum andersoniij J.R. Gray. In 't Mannetje, L. \& Jones, R.M. (Eds.) 1992. Plant Resources of South-East Asia No 4. Forages. Pudoc Scientific Publishers, Wageningen, Netherlands. p 228 - 230.

CHEN, C.P. \& HUTTON, E.M. (1992) Panicum maximum Jacq. In 't Mannetje, L. \& J ones, R.M. (Eds.), 1992. Plant Resources of South-East Asia No 4. Forages. Pudoc Scientific Publishers, Wageningen, Netherlands. p 172 - 174.

CHUNG, K.-F., KONO, Y., WANG, C.-M. \& PENG, C.-I. (2008) Notes on Acmella (Asteraceae: Helianthaceae) in Taiwan. Botanical Studies 49: $73-82$.

CHWEYA, J.A. \& MNZAVA, N.A. (1997) Cat's whiskers. Cleome gynandra L. IPGRI, Rome. 54 pp. CJ B African Plant Database "http://www. ville-ge.ch/musinfo/bd/cjb/africa/index.php".

CJ B (See African Plant Database).

CLAUSS, B. (1992) Bees and Beekeeping in the North-Western Province of Zambia. Forest Dept./IRDP. Kadompo, Zambia. $168 \mathrm{pp}$.

COATES PALGRAVE, K.C. (1996) Trees of Southem Africa. Struik Publishers, Capetown. 959 pp.

COBBINA, J. \& REYNOLDS, L. (1988) The Potential for Indigenous Browse Species for Cultivation in 
Southeast Nigeria. International Livestock Centre for Africa (ILCA), I badan, Nigeria. 55 pp.

COMPÈRE, P. (1970) Carte des Sols et de la Végétation du Congo, du Rwanda et du Burundi - Ch. 25 BasCongo. Publications de l'I nstitut National pour l'étude agronomique du Congo (INEAC) Bruxelles

COURSEY, D.G. (1967) Yams. $230 \mathrm{pp}$.

CRANE, E. (1975) Honey : A comprehensive survey. Heineman, London 608 pp.

CRANE, E. \& WALKER, P. (1984) Pollination Directory for World Crops. International Bee Research Association (IBRA). 183 pp.

CRANE, E., WALKER, P. \& DAY, R. (1984) Directory of Important World Honey Sources. International Bee Research Association (IBRA). $384 \mathrm{pp}$.

CRI BB, P.J . \& LEEDAL, G.P. (1982) The Mountain Flowers of Southern Tanzania. Balkema, Rotterdam. 244 $\mathrm{pp}$.

DAELEMAN, J. \& PAUWELS, L. (1983) Notes d'ethnobotanique Ntandu (Kongo). Musée Royal de l'Afrique Centrale - Tervuren, Belgique. p. 151 - 255.

DALZEL, J.M. (1937) The Useful Plants of West Tropical Africa. Crown Agents, London. 612 pp.

DANFORTH, R.M. \& NOREN, P.D. (1994) Congo Native Fruits: twenty-five of the best fruits and nuts found in the rainforest and savanna areas of northwest Congo, Africa. Loko AF Program, Bangui, Central African Republic. 72 pp.

DARTEVELLE, E. (1951) Sur un Hespéride des environs de Léopoldville et remarques sur la valeur alimentaire des chenilles de Lépidoptères. Lambillionea LI (1-2): 12-16 et Lambillionea LI (3-4), 18-22.

DAVIES, F.S. \& ALBRIGO, L.G. (1994) Citrus. CAB I nternational. 254 pp.

DE GUZMAN, C.C. \& SIEMONSMA, J.S. (Eds.) (1999) Plant Resources of South-East Asia No 13. Spices. Backhuys Publishers, Leiden, Netherlands. 400 pp.

DELAUDE, C., DELAUDE, J. \& BREYNE, H. (1971) Plantes médicinales et ingrédients magique de grande marché de Kinshasa. Africa - Tervuren, 17, pp. 93 - 103

DENIS, P. (1932) L'huile du Pentadethra eetveldeana De Wildeman et Dur. Bull. Cercle bot. Congolais. 1 : 55.

DENTON, L. (1997) A Review of Corchorus olitorius L. in Nigeria. In African I ndigenous Vegetables Workshop Proceedings J an 13 - 18. Limbe, Cameroon. pp. 25 - 30

DENTON, O.A. (2004) Celosia argentea L. In Grubben, G.J.H. \& Denton, O.A. (Eds.). Plant Resources of Tropical Africa 2. Vegetables. PROTA Foundation, Wageningen, Netherlands/ Backhuys Publishers, Leiden, Netherlands / CTA. pp. $167-171$

DENTON, O.A. (2004) Crassocephalum crepidioides (Benth.) S. Moore. [Internet] Record from PROTA4U. Grubben, G.J.H. \& Denton, O.A. (Eds.). PROTA (Plant Resources of Tropical Africa / Ressources végétales de l'Afrique tropicale), Wageningen, Netherlands.

DE RUIJTER, A., (2006) Strophanthus we/witschii (Baill.) K. Schum. [Internet] Record from PROTA4U. Schmelzer, G.H. \& Gurib-Fakim, A. (Editors). PROTA (Plant Resources of Tropical Africa / Ressources végétales de l'Afrique tropicale), Wageningen, Netherlands.

DE RUIJ TER, A. (2006) Diplorhynchus condylocarpon (Müll.Arg.) Pichon. [I nternet] Record from PROTA4U. Schmelzer, G.H. \& Gurib-Fakim, A. (Editors) PROTA (Plant Resources of Tropical Africa / Ressources végétales de l'Afrique tropicale), Wageningen, Netherlands.

DE RUIJTER, A. (2007) Anthocleista liebrechtsiana De Wild. \& T. Durand. [Internet] Record from PROTA4U. Schmelzer, G.H. \& Gurib-Fakim, A. (Editors). PROTA (Plant Resources of Tropical Africa / Ressources végétales de l'Afrique tropicale), Wageningen, Netherlands.

DE RUIJTER, A. (2007) Paropsia brazzeana Baill. [Internet] Record from PROTA4U. Schmelzer, G.H. \& GuribFakim, A. (Editors). PROTA (Plant Resources of Tropical Africa / Ressources végétales de l'Afrique tropicale), Wageningen, Netherlands.

DE RUIJTER, A. (2007) Usteria guineensis Willd. [Internet] Record from PROTA4U. Schmelzer, G.H. \& GuribFakim, A. (Editors). PROTA (Plant Resources of Tropical Africa / Ressources végétales de l'Afrique tropicale), Wageningen, Netherlands.

DE RUIJTER, A. (2008) Albertisia villosa (Exell) Forman [Internet] Record from PROTA4U. Schmelzer, G.H. $\&$ Gurib-Fakim, A. (Editors). PROTA (Plant Resources of Tropical Africa / Ressources végétales de l'Afrique tropicale), Wageningen, Netherlands.

DERY, B.B. \& OTSYINA, R. (2001) The 10 priority medicinal trees of Shinyanga, Tanzania. Agroforestry Today 12: 5 - 8.

DE WIDEMAN, E. (1903) Notices sur des Plantes utiles ou intéressantes de la flore du Congo, Volume I Publication de l'État Indépendant du Congo p. 156 - 163.

DE WI LDEMAN, E. (1934) Documents pour l'Etude de l'Alimentation Vegetale de l'Indigène du Congo Belge. L'Acadamie Royale de Belgique. 263 pp.

DE WILDEMAN, E. (1938) Sur des plantes médicinales ou utiles du Mayumbe (Congo Belge). 97 pp.

DEWIT, J. \& WI LEMS, L. (1960) Flore du Congo Belge et du Ruanda - Urundi : Vitaceae 
DHETCHUVI, J.B.M.M. \& LEY, A.C. (2017) Flore d'Afrique Centrale : Marantaceae

DHLIWAYO, P. D. (2002) Underexploited tuber crops in Zmbabwe: a study on the production of Livingstone Potato ( Plectranthus esculentus ). Plant Genetic Resources Newsletter, No.130, pp.77-80.

DODGE, C. R. (1897) A descriptive catalogue of useful fiber plants of the world. USDA report no. 9. https://www. biodiversitylibrary.org

DOMIS, M. \& OYEN, L.P.A. (2008) Piper umbellatumL. [Internet] Record from PROTA4U. Schmelzer, G.H. \& Gurib-Fakim, A. (Eds.). PROTA (Plant Resources of Tropical Africa / Ressources végétales de l'Afrique tropicale), Wageningen, Netherlands.

DRACHOUSSOFF, V. (1947) Essai sur l'agriculture indigène au Bas-Congo. Bull. Agricole du Congo belge 38 (3\&4): p. $474-582,787-880$.

DRACHOUSSOFF, V. (Ed.)(1993) Rural Development in Central Africa 1908 - 1960/62. King Baudouin Foundation, Bruxelles. Volumes $1 \& 2.1164$ pp.

DRANSFIELD, J. (1986) Flora of Tropical East Africa : Palmae

DUBOIS, L. \& COLLART, E. (1950) L'apiculture au Congo-Belge et au Rwanda-Urundi. Direction Générale de l'Agriculture à Léopoldville. Direction de l'agriculture, de l'elevage et de la colonization, Bruxelles

DUKE, J.A. (1981) Handbook of Legumes of World Economic Importance. Plenum Press, New York. 345 pp.

DUKE, J .A. (1983) Duke, J., (1983) Eichhomia crassipes, in Handbook of Energy Crops. Available online: http://www. hort. purdue. edu/newcrop/duke energy/Eichorniacrassipes. html

DUKE, J .A. \& DUCELUER, J.L. (1993) Handbook of Alternative Cash Crops. CRC Press, Boca Raton, Florida. $544 \mathrm{pp}$.

DUPRIEZ, H. \& DE LEENER P. (1989) African Gardens and Orchards. CTA/Macmillan. 333 pp.

EBANYENLE, E., (2009) Lannea we/witschii (Hiern) Engl. [Internet] Record from PROTA4U. Lemmens, R.H.M.J ., Louppe, D. \& Oteng-Amoako, A.A. (Editors). PROTA (Plant Resources of Tropical Africa / Ressources végétales de l'Afrique tropicale), Wageningen, Netherlands.

EGGELING, W.J . \& DALE, I.R. (1951) The indigenous trees of the Uganda Protectorate. Entebbe 491 pp.

EGLI, A. \& KALI NGANIRE, A. (1988) Les Arbres et Arbustes Agroforestiers au Rwanda. Institut des Sciences Agronomique du Rwanda. $184 \mathrm{pp}$.

EGUNJ OBI, J.K. \& ADEBI SI, A.A. (2004) Cucumeropsis mannii Naudin. [I nternet] Record from PROTA4U. Grubben, G.J.H. \& Denton, O.A. (Eds.). PROTA (Plant Resources of Tropical Africa / Ressources végétales de l'Afrique tropicale), Wageningen, Netherlands.

EL JACK, A.E. (2004) Portulaca oleracea L. [I nternet] Record from PROTA4U. Grubben, G.J.H. \& Denton, O.A. (Eds.). PROTA (Plant Resources of Tropical Africa / Ressources végétales de l'Afrique tropicale), Wageningen, Netherlands.

ESPINA, P. \& ORDETX, R. (1983) Flora Apicola Tropical. Cartago, Costa Rica. 406 pp.

EVRARD, C. (1960) Flore du Congo Belge et du Ruanda-Urundi : Rhamnaceae

EYI NDONG, H., DEGREEF, J. \& DE KESEL, A. (2011) Champignons comestibles des forêts denses d'Afrique centrale. Vol 10 Abc Taxa. 254 pp.

FANSHAWE, D.B. (1972) Useful trees of Zambia for the agriculturalist. Lusaka. 127 pp.

FAYAZ, A. (2011) Encyclopedia of Tropical Plants. Bateman 720 pp.

FELIX- SI LVA, J., GI ORDANI, R.B., DA SILVA-JR., A.A., ZUCOLOTTO, S.M. and FERNANDES-PEDROSA M. D-F. (2014) Jatropha gossypiffolia L. (Euphorbiaceae): A Review of Traditional Uses, Phytochemistry, Pharmacology, and Toxicology of This Medicinal Plant. Hindawi Publishing Corporation. 32 pp.

FERNANDES, R. (2005) Flora Zambesiaca volume: 8 part 7 : Verbenaceae

FERNANDES, R. \& FERNANDES, A. (1978) Flora Zambesiaca volume 4 part 0 p. 220

FICHTL, R. \& ADI, A. (1994) Honeybee Flora of Ethiopia. Deutscher Entwicklungsdienst. German Development Service. 510 pp.

FICHTL, A. (2013) Trees bees use - Securidaca longepedunculata. Bees for Development Journa/ 109. p 12

FICHTL, A. (2014) Trees bees use - Parinari excelsa. Bees for Development Journa/113. p 7.

FISCHER, E.B. (1999) Flore d'Afrique Centrale (Congo-Kinshasa - Rwanda - Burundi) : Scrophulariaceae

FLORIDATA https://floridata.com/home

FOLKARD, G. \& SUTHERLAND, J. (1994) Moringa oleifera - a multipurpose tree. Footsteps (TEAR Fund) 20: Sept 1994.

FOOD \& AGRICULTURE ORGANIZATION (FAO) (1982) Fruit-bearing Forest Trees. 177 pp.

FOOD \& AGRICULTURE ORGANI ZATION (FAO) (1983) Food and Fruit-bearing Forest Species. 1: Examples from Eastern Africa. $172 \mathrm{pp}$.

FOOD \& AGRI CULTURE ORGANI ZATION (FAO) (1988) Traditional Food Plants. Rome. 593 pp.

FONTEM, D.A. \& SCHI PPERS, R.R. (2004) Solanum scabrum Mill. [I nternet] Record from PROTA4U. Grubben, G.J.H. \& Denton, O.A. (Eds.). PROTA (Plant Resources of Tropical Africa / Ressources végétales de l'Afrique tropicale), Wageningen, Netherlands.

FREE, J.B. (1993) Insect Pollination of Crops. (pdf) 684 pp. 
FREMOND, Y., ZILLER, R. \& DE NUCE DE LAMOTHE, M. (1966) The Coconut Palm. International Potash Institute, Berne. $227 \mathrm{pp}$.

FROST, L. \& GRIFITHS, A. (2001) Plants of Eden. The Eden Project

FUNDI KO, M. -C., VAN ANDEL, T., SOSEF, S.M. (2015) Vernacular plant names from the Democratic Republic of the Congo: Trends in folk taxonomy of the Kikongo, Kintandu, Kiswahili, Lingala and Mashi languages. https://www. researchgate. net/publication/321425962

GARNER, R.J . \& CHAUDHRI, S.A. (1988) The Propagation of Tropical Fruit Trees. Commonwealth Agric. Bureaux. $566 \mathrm{pp}$.

GEERINCK, D. (1971) Flore d'Afrique Centrale (Zaïre - Rwanda - Burundi) : Hypoxidaceae

GEERINCK, D. (1973) Flore d'Afrique Centrale (Zaïre - Rwanda - Burundi) : Amaryllidaceae

GEERINCK, D. (1984) Flore d'Afrique Centrale (Zaire - Rwanda - Burundi : Orchidaceae

GEERINCK, D. (2005) Flore du Congo Belge et du Ruanda-Urundi : I ridaceae

GEERINCK, D. (2015) Flore d'Afrique centrale, nouvelle série : Asphodelaceae

GERARD, J., LOUPPE, D. \& Oteng-Amoako, A.A. (Eds.) (2011) Afzelia bipindensis Harms. In: Lemmens, R.H.M.J. Prota 7 (2) : Timbers/Bois d'œuvre 2. [CD-Rom]. PROTA, Wageningen, Netherlands

GERMAIN, R. (1963) Flore du Congo du Rwanda et du Burundi : Huaceae

GERMAI N, R. (1963) Flore du Congo du Rwanda et du Burundi : Sterculiaceae

GILBERT, G. (1958) Flore du Congo Belge et du Ruanda - Urundi : Simaroubaceae

GILBERT, G. (1958) Flore du Congo Belge et du Ruanda - Urundi : I vingiaceae

GI LBERT, G. (1958) Flore du Congo Belge et du Ruanda - Urundi : Rutaceae

GI LBERT, G. \& BOUTI QUE, R. (1952) Flore du Congo Belge et du Ruanda - Urundi : Mimosaceae

GI LBERT, G. \& TROUPIN, G. (1951) Flore du Congo Belge et du Ruanda - Urundi : Myristicaceae

GILLET, J. \& PAQUE, E. (1910) Plantes Principales de la Region de Kisantu. Leur nom indigène, leur nom scientifique, leurs usages. Annales du Musée du Congo Belge, Botanique, Série v. 120 pp.

GILLET, J. (1927) Catalogue des Plantes du Jardin d'Essais de la Mission de Kisantu. Bruxelles 166 pp.

GLEN, H. \& MKHIPHENI NGWENYA (2005) Maesa lanceolata Forssk. http://pza.sanbi.org/maesa-lanceolata

GLOBAL I NVASIVE SPECI ES DATABASE http://www.iucngisd. org/gisd/

GODI N, V.J . \& SPENSLEY, P.C. (1971) Oils and Oil Seeds. No.1 in Crop and Product Digests. Tropical Products Institute. $170 \mathrm{pp}$.

GÖHRE, A., TOTO-NI ENGESSE, A. B., FUTURO, M., NEI NHUIS, C., LAUTENSCHLÄGER, T. (2016) Plants from disturbed savannah vegetation and their usage by Bakongo tribes in Uíge, Northern Angola. Joumal of Ethnobiology and Ethnomedicine 12: 42.

GOODE, P.M. (1974) Some Local Vegetables and Fruits of Uganda. Information and Visual Aids Centre, Dept. of Agriculture, Box 2, Entebbe, Uganda. 94 pp.

GOODE, P.M. (1989) Edible Plants of Uganda: the value of wild and cultivated plants as food. FAO, Rome. $146 \mathrm{pp}$.

GOPAL, B. (1987). Water Hyacinth, Aquatic plant studies 1. Elsevier Science publishing company inc, New York.

GRACE, O.M. (2008) Euphorbia tirucalli L. [Internet] Record from PROTA4U. Schmelzer, G.H. \& GuribFakim, A. (Eds.). PROTA (Plant Resources of Tropical Africa / Ressources végétales de l'Afrique tropicale), Wageningen, Netherlands.

GREENWAY, P.J. (1944 - 1945) Origins of some East African food plants. Part V. E. Afr. Agric. J.

GROSSER, P., SI EGEL, C., NEI NHUIS, C., LAUTENSCHLÄGER, T. (2018) Triumfetta cordifolia: A Valuable (African) Source for Biocomposites. BioResources 13 (4) 7671 - 7682

GRUBBEN, G.J.H. (1977) Tropical Vegetables and their Genetic Resources. International Board for Plant Genetic Resources, FAO, Rome. $197 \mathrm{pp}$.

GRUBBEN, G.J .H. (2004) Amaranthus cruentusL. In Grubben, G.J. .H. \& Denton, O.A. (Eds.). Plant Resources of Tropical Africa 2. Vegetables. PROTA Foundation, Wageningen, Netherlands/ Backhuys Publishers, Leiden, Netherlands / CTA.

GRUBBEN, G.J .H. \& EL TAHIR I BRAHAM MOHAMED (2004) Capsicum annuum L. In Grubben, G.J.H. \& Denton, O.A. (Eds.). Plant Resources of Tropical Africa 2. Vegetables. PROTA Foundation, Wageningen, Netherlands/ Backhuys Publishers, Leiden, Netherlands / CTA.

GRUBBEN, G.J.H. (2004) Ipomoea aquatica Forssk. [Internet] Record from PROTA4U. Grubben, G.J.H. \& Denton, O.A. (Eds.). PROTA (Plant Resources of Tropical Africa / Ressources végétales de l'Afrique tropicale), Wageningen, Netherlands.

GURIB-FAKIM, A. (2006) Heliotropium indicumL. [Internet] Record from PROTA4U. Schmelzer, G.H. \& Gurib-Fakim, A. (Editors). PROTA (Plant Resources of Tropical Africa / Ressources végétales de I'Afrique tropicale), Wageningen, Netherlands.

GURNAH, A.M. (1993) Abelmoschus manihot in SIEMONSMA, J.S. \& KASEM PILUEK (Eds.)(1993) Plant Resources of South East Asia (PROSEA). No. 8 Vegetables. Backhuys Publishers, Leiden. P. 60 - 62. 
HABOU, ZA., HAOUGUI, A., MERGEAI, G., HAUBRUGE, E., TOUDOU, A., VERHEGGEN, F.J. (2012) Insecticidal Effect of Jatropha curcas Oil on the Aphid Aphis fabae(Hemiptera: Aphididae) and on the main insect pests Associated with Cowpeas ( Vigna unguiculata) in Niger. Tropicultura 29, 4, $225-229$

HABOU, ZA., ADAM, T., MERGEAI, G., HAUBRUGE, E. \& VERHEGGEN, F.J. (2014) Effet du mode de conservation de l'huile de Jatropha curcas $L$. sur son efficacité lutte contre les principaux insectes ravageurs de niébé Vigna unguiculata(L.) Walp. au Niger. Tropicultura 32,4, 191 - 196

HALIM, R.A. (1992) Pueraria phaseoloides (Roxb.) Benth. Plant resources of South-East Asia. - Wageningen : Pudoc No. 4 Forges / 't Mannetje and R.M. Jones (eds.) pp. 192 - 195

HALLÉ, N. (1966) Flore du Gabon : Rubiaceae

HANKEY, A. (2003) Ficus sur Forssk. "http://www.plantzafrica.com"

HANKEY, A. \& MASHI NI NI, L. (2002) Setaria megaphylla (Steud) Dur. \& Schinz."http://www.plantzafrica.com"

HARLAN, J.R., DE WET, J.M.J., STEMLER, A.B.L. (1976) Origins of African Plant Domestication. Mouton: The Hague. pp. 465-478

HARRIS, D.J. \& WORTLEY, A.H. (2008) Sangha trees - An I/lustrated Identification Manual. Royal Botanic Garden, Edinburgh. 300 pp.

HARRIS, D.J . \& WORTLEY, A.H. (2018) Monograph of Aframomum (Zngiberaceae). Systematic Botany Monographs Volume 104. American Society of Plant Taxonomists. 204 pp.

HARRIS, D.J., MOUTSAMBOTE, J.-M., KAMI, E., FLORENCE, J., BRIDGEWATER, S.G.M. \& WORTLEY, A.H. (2011) An Introduction to the Trees from the North of the Republic of Congo. Royal Botanic Garden, Edinburgh. 208 pp.

HAUMAN, L. (1948) Flore du Congo Belge et du Ruanda-Urundi : Moraceae

HAUMAN, L. (1948) Flore du Congo Belge et du Ruanda-Urundi : Urticaceae

HAUMAN, L. (1951) Flore du Congo Belge et du Ruanda-Urundi : Aizoaceae

HAUMAN, L. (1951) Flore du Congo Belge et du Ruanda-Urundi : Amaranthaceae.

HAUMAN, L. (1951) Flore du Congo Belge et du Ruanda-Urundi : Basellaceae

HAUMAN, L. (1951) Flore du Congo Belge et du Ruanda-Urundi : Nymphaceae

HAUMAN, L. (1951) Flore du Congo Belge et du Ruanda-Urundi : Portulacaceae

HAUMAN, L. (1952) Flore du Congo Belge et du Ruanda-Urundi : Rosaceae

HAUMAN, L. (1958) Flore du Congo Belge et du Ruanda-Urundi : Dichapetalaceae

HAUMAN, L. (1960) Flore du Congo Belge et du Ruanda-Urundi : Sapindaceae

HAUMAN, L. (1963) Flore du Congo Belge et du Ruanda-Urundi : Malvaceae

HAUMAN, L., CRONQUIST, A., BOUTI QUE, R., MAJ OT-ROCHEZ, P., DUVIGNEAUD, P., ROBYNS, W. et WI LCZEK, R. (1954) Flore du Congo Belge et du Ruanda-Urundi : Papilionaceae

HAUMAN, L. \& WILCZEK, R. (1951) Flore du Congo Belge et du Ruanda-Urundi : Capparidaceae

HAWTHORNE, W. \& GYAKARI, N. (2006) Photoguide for the Forest Trees of Ghana. Oxford Forestry Institute. $432 \mathrm{pp}$.

HAWTHORNE, W. \& JONGKIND, W. (2006) Woody Plants of Western African Forests. Kew. 1023 pp. HDRA (2000) See HENRY DOUBLEDAY RESEARCH ASSOCIATION

HDRA (2000) Natural Pesticides No. TNP1. Chillipepper, Capsicum frutescens Tropical Advisory Service

HEINE, H. (1966) Flore du Gabon : Acanthaceae

HEI NZE, C., DITSCH, B., CONGO, M.F., MUSSANDI, I.J., NEINHUIS, C., LAUTENSCHLÄGE, T. (2017) First assessment of medicinal plants of Cuanza Norte, North Angola. Research \& Reviews 6:2 pp. $44-53$

HEINZE, C., DUNDÃO, M.D.F., NEINHUIS, C., LAUTENSCHLÄGER, T. (2019) Economic Potential of Selected Native Plants from Cuanza Norte, Northern Angola. Economic Botany 73, 96-111

HELLER, J. (1996) Physic nut: Jatropha curcasL. Rome, I taly: International Plant Genetic Resources Institute $66 \mathrm{pp}$.

HENDRO SUNARJ ONO, H. \& CORONEL, R.E. (1991) Plant Resources of South-East Asia. Wageningen: Pudoc No. 2 : Edible fruits and nuts / E.W.M. Verheij and R.E. Coronel (eds.) pp. 256 - 257

HENNING, R.K., (2007) Jatropha curcas L. [I nternet] Record from PROTA4U. van der Vossen, H.A.M. \& Mkamilo, G.S. (Editors). PROTA (Plant Resources of Tropical Africa / Ressources végétales de l'Afrique tropicale), Wageningen, Netherlands.

HENRY DOUBLEDAY RESEARCH ASSOCIATI ON (HDRA) (2000) Baobab, Adansonia digitata.

HEPBURN, H.E. \& RADLOFF, S.E. (1998) Honeybees of Africa. Springer 370 pp.

HERKLOTS, G.A.C. (1972) Vegetables in South-east Asia. Allen \& Unwin. 520 pp.

HILLS, R. \& WILKIN, P. (2021) Dioscoreaceae. Flore d'Afrique Centrale. Jardin Botanique de Meise. 59 pp.

HIND, N. \& BIGGS, N. (2003) Acmella oleracea. Compositae. Curtis Botanical Magazine 20 (1), 31 - 39

HIRT, H.M. \& M'PIA, B. (2001) Natural Medicine in the Tropics. Action for Natural Medicine (ANAMED). 160 
pp.

HOLLAND, J.H. (1922) The useful plants of Nigeria. Kew Bulletin Additional series IX. HMSO 963 pp.

HOLM, L.G., PLUCKNETT, D.L., PANCHO, J.V. \& HERBERGER, J.P. (1977) The Worlds Worst Weeds. Univ. Press of Hawaii, Honolulu. 610 pp.

HOLSTEI N, N. (2015) Monograph of Coccinia (Cucurbitaceae). PhytoKeys 54, 1-166

HOWES, F.N. (1979) Plants and Beekeeping. Faber \& Faber. 236 pp.

HULSTAERT, G. (1966) Notes de botanique Mongo. Acad. Roy. Des Sc. D’Outre-Mer, Classe des Sc. Nat. \& le Med., N.S. XV-3 212p.

HUMBERT, H. (1937) Flore de Madagascar : Cypéracées

HUTCHINSON, J. \& DALZIEL, J .M. (1972) Flora of West Tropical Africa. Retrieved December 2013 from http://www. ville-ge.ch/musinfo/bd/cjb/africa/

ICRAF = International Centre for Research in Agrofestry.

IITA = International Institute of Tropical Agriculture (various dates) Annual reports.

ILUNGA WA ILUNGA, E. \& MEERTS, P. (2020) Phyllanthaceae. Flore d'Afrique Centrale

INGRAM, V. (2011) Melliferous plants for Cameroon Highlands and Adamaoua Plateau honey. fao.org/forestry 24 pp.

IRVINE, F.R. (1930) Plants of the Gold Coast. Oxford. 521 pp.

IRVINE, F.R. (1952) Supplementary and Emergency Foods of West Africa. Econ. Botany 6:1

IRVINE, F.R. (1961) Woody Plants of Ghana. Oxford. 868 pp.

ISA IPOR (2001) Commelina diffusa Burm. F. In van Valkenburh, J.L.C.H. and Bunyapraphatsara, N. (Eds.): Plant Resources of South-East Asia No. 12(1). Medicinal and poisonous plants 1. Backhuys Publishers, Leiden, Netherlands. pp. 176 - 178.

IWU, M.M. (1993) Handbook of African Medicinal Plants. 435 pp.

JANSEN, P.C.M. (2004) Alternanthera sessilis (L.) DC. [I nternet] Record from PROTA4U. Grubben, G.J .H. \& Denton, O.A. (Editors). PROTA (Plant Resources of Tropical Africa / Ressources végétales de l'Afrique tropicale), Wageningen, Netherlands.

JANSEN, P.C.M. (2004) Cleome rutidosperma DC. [Internet] Record from PROTA4U. Grubben, G.J .H. \& Denton, O.A. (Eds.). PROTA (Plant Resources of Tropical Africa / Ressources végétales de l'Afrique tropicale), Wageningen, Netherlands.

JANSEN, P.C.M. (2005) Cosmos sulphureus Cav. [Internet] Record from PROTA4U. J ansen, P.C.M. \& Cardon, D. (Editors). PROTA (Plant Resources of Tropical Africa / Ressources végétales de l'Afrique tropicale), Wageningen, Netherlands.

JANSEN, P.C.M. (2005) CraterispermumschweinfurthiiHiem. [Internet] Record from PROTA4U. Jansen, P.C.M. \& Cardon, D. (Eds.). PROTA (Plant Resources of Tropical Africa / Ressources végétales de l'Afrique tropicale), Wageningen, Netherlands.

JANSEN, P.C.M. (2005) Curcuma longaL. [Internet] Record from PROTA4U. Jansen, P.C.M. \& Cardon, D. (Eds.). PROTA (Plant Resources of Tropical Africa / Ressources végétales de l'Afrique tropicale), Wageningen, Netherlands.

JANSEN, P.C.M., 2005. Ludwigia leptocarpa (Nutt.) H.Hara. [I nternet] Record from PROTA4U. J ansen, P.C.M. \& Cardon, D. (Editors). PROTA (Plant Resources of Tropical Africa / Ressources végétales de l'Afrique tropicale), Wageningen, Netherlands.

J ANSEN, P.C.M., (2006) Cannabis sativa L. [I nternet] Record from PROTA4U. Schmelzer, G.H. \& Gurib-Fakim, A. (Editors). PROTA (Plant Resources of Tropical Africa / Ressources végétales de l'Afrique tropicale), Wageningen, Netherlands.

JANSEN, P.C.M., (2006) Coix lacryma-jobi L. [I nternet] Record from PROTA4U. Brink, M. \& Belay, G. (Editors). PROTA (Plant Resources of Tropical Africa / Ressources végétales de l'Afrique tropicale), Wageningen, Netherlands.

J ANSEN, P.C.M. (2004) Gisekia pharnaceoides L. [Internet] Record from PROTA4U. Grubben, G.J.H. \& Denton, O.A. (Editors). PROTA (Plant Resources of Tropical Africa / Ressources végétales de I'Afrique tropicale), Wageningen, Netherlands.

JANSEN, P.C.M., 2004. Persicaria decipiens (R.Br.) K. L. Wilson. [Internet] Record from PROTA4U. Grubben, G.J .H. \& Denton, O.A. (Editors). PROTA (Plant Resources of Tropical Africa / Ressources végétales de l'Afrique tropicale), Wageningen, Netherlands.

JANZEN, J.M. (1978) The Quest for Therapy. Medical Pluralism in Lower Zaire. University of California Press. $266 \mathrm{pp}$.

JEX-BLAKE, A.J . (1957) Gardening in East Africa. Longmans 414 pp.

JIOFACK TAFOKOU, R.B., 2011. Greenwayodendron suaveolens (Engl. \& Diels) Verdc. [Internet] Record from PROTA4U. Lemmens, R.H.M.J ., Louppe, D. \& Oteng-Amoako, A.A. (Editors). PROTA (Plant Resources of Tropical Africa / Ressources végétales de l'Afrique tropicale), Wageningen, Netherlands.

J OFFE, P. (2003) Kigelia africana Lam. Benth. "http://www.plantzafrica.com"

J OHANNSMEI ER, M. (1975) Commercial beekeeping in the Transvaal in relation to honey plants. In 
Proceedings, International Congress of the Entomological Society of South Africa. pp. 181 - 184

J OHANNSMEIER, M. \& ALLSOPP, M. (1995) Bee plants of South African suburban gardens. South African Bee Journal67: 70 - 75.

J OHNSON, I. (2005) Oplismenus hirtellus (L.) P. Beauv. "http://www. plantzafrica.com"

J ONATHAN, J., (2003) Drymaria cordata (L.) Willd. ex Schultes. In: Lemmens, R.H.M.J. and Bunyapraphatsara, N. (Editors): Plant Resources of South-East Asia No 12(3): Medicinal and poisonous plants 3. PROSEA Foundation, Bogor, Indonesia. Database record: prota4u.org/prosea

J ONES, R. (1999) Beekeeping as a Business. IBRA/Commonwealth Secretariat. 70 pp.

KALANDA, K. \& LISOWSKI, S. (1995) Le Genre Vernonia (Asteraceae) dans la Flore d'Afrique Centrale (Zaïre, Rwanda, Burundi) : Fragmenta Floristica et Geobotanica 40 (2) : 547 - 717. Kraków, Poland ISSN 0015-931x

KANG, B.T. \& REYNOLDS, L. (Eds.)(1989) Alley Faming in the Humid and Subhumid Tropics. Int. Dev. Res. Centre, Canada. $249 \mathrm{pp}$.

KANI KA, B., AHUKA, M., OKITOKOKO, M., MULEBA, N., KITENGE, BOKMBE, M. (2004) L'huile de Raffia sese De Wild. Origine Congolais (R.D.C.) et quelques utilizations. Centre de recherché géologiques et miniers.

KASONGO, R.K., VAN RANST, E., VERDOOT, A., KANYANKAGOTE, P. \& BAERT, G. (2009) Impact of Acacia auriculiformis on the chemical fertility of sandy soils on the Batéké plateau, D.R. Congo. Soil Use and Management, March 2009, 25, 21-27

KASSI M, A.S.M., ARI PIN, A.M., ISHAK, N., HAIROM, N.H.H., FAUZ, N.A., RAZALI, N.F. \& ZAI NULABIDIN, M.H. (2016) Potential of Cogon grass (/mperata cylindrica) as an alternative fibre in paper-based industry. ARPN Journal of Engineering and Applied Sciences. Vol. 11, no. 4, 2681 - 2686

KATENDE, A.B., BIRNI E, A. \& TENGNÄS, B. (1995) Useful Trees and Shrubs for Uganda. RELMAVIIDA, Embassy of Sweden. $710 \mathrm{pp}$.

KATENDE, A.B., SSEGAWA, P. \& BIRNI E A. (1999) Wild Food Plants and Mushrooms of Uganda. RELMAJSIDA, Embassy of Sweden. $490 \mathrm{pp}$.

KAWANGA, V. (2006) Enythrophleum africanum(Welw. ex Benth.) Harms. [Internet] Record from PROTA4U. Schmelzer, G.H. \& Gurib-Fakim, A. (Editors). PROTA (Plant Resources of Tropical Africa / Ressources végétales de l'Afrique tropicale), Wageningen, Netherlands.

KAWANGA, V., (2007) Jatropha gossypiifolia L. [Internet] Record from PROTA4U. Schmelzer, G.H. \& GuribFakim, A. (Editors). PROTA (Plant Resources of Tropical Africa / Ressources végétales de l'Afrique tropicale), Wageningen, Netherlands.

KAY, D.E. (1973) Root Crops. Tropical Products Institute (TPI). 245 pp.

KAY, D.E. (1979) Food Legumes. Tropical Products I nstitute (TPI) 435 pp.

KEAY, R.W.J . (1989) Trees of Nigeria. Clarendon Press, Oxford. 476 pp.

KÉMEUZE, V.A. (2010) Trachyphrynium braunianum(K.Schum.) Baker. [I nternet] Record from PROTA4U. Brink, M. \& Achigan-Dako, E.G. (Eds.). PROTA (Plant Resources of Tropical Africa / Ressources végétales de l'Afrique tropicale), Wageningen, Netherlands.

KENGUE, J. (2002) Safou Dacryodes edulis G.Don (H.J.Lam.) International Centre for Under-utilized Crops, University of Southampton, U.K. 145 pp.

KERAUDREN-AYMONIN, M. (1975) Flore d'Afrique Centrale (Zaïre - Rwanda - Burundi) : Cucurbitaceae

KI BUNGU, KEMBELO, A.O. (1995) Plantes hôtes des chenilles comestibles. J ardin Botanique de Kisantu. (Personal communication 21.3.95)

KIBUNGU, KEMBELO, A.O. (2003) Quelques Plantes Médicinales du Bas-Congo et Leurs Usages. 197 pp.

KIBUNGU KEMBELO, P., NZUKI BAKWAYE, F., BELESI KATULA, H., WOUTER, V., VAN DAMME, P. (2021) Ethnobotanical characterization of medicinal plants used in Kisantu and Mbanza-Ngungu territories, Kongo Central Province in DR Congo. Jour. Ethnobiology \& Ethnomedicine 17:5 15 pp.

KI HWELE, D.V.N., MASSAWE, A.J., LWOGA, P.D., BURTON, S. (2001) Beekeeping in Tanzania. Ministry of Natural Resources \& Tourism. 169 pp.

KITAMBALA, M.M. (2008) Uapaca guineensis Müll.Arg. [I nternet] Record from PROTA4U. Schmelzer, G.H. \& Gurib-Fakim, A. (Eds.). PROTA (Plant Resources of Tropical Africa / Ressources végétales de l'Afrique tropicale), Wageningen, Netherlands.

KLACKENBERG, J. (2001) Notes on Secamonoideae (Apocynaceae) in Africa. ADANSONIA, sér. 323 (2) : 317-335

KOECHLIN, J . (1962) Flore du Gabon : Graminées

KOKWARO, J.O. (2009) Medicinal Plants of East Africa. University of Nairobi Press. 478 pp. 
KONDA KU MBUTA, A., MBEMBE BITENGEL, BAVUKI NI NA NGOMA \& ITUFA Y'OKOLO (1992) Contribution à l'inventaire des plantes alimentaires spontanées au Zaïre. Al Biruniya, Rev. Mar. Pharm., 8 (2), 97 - 109.

KONDA KU MBUTA, KABAKURA MWI MA, MBEMBE BITENGEL, ITUFA Y'OKOLO, MAHUKU KAVUNA, MAFUTA MANDANGA, MPOYI KALAMBAYI, NDEMANKENI IZAMAJ OLE, KADIMA KAZEMBE, KELELA BOOTO, NGIUVU VASAKI, BONGOMBOLA MWABONSI KA \& DUMU LODY (2015a) Plantes médicinales de traditions; Province de l'Equateur, RD Congo. $419 \mathrm{pp}$.

KONDA, K. M., BAVUKININA, N., LATHAM, P., MBEMBE, B., KONDA, K.R., DUMU, L., MAFUTA, M., KELELA, B., ITUFA, Y. \& KODONDI, K.K. (2015b) Plantes medicinales de la R.D. Congo - Données Préliminaires. $436 \mathrm{pp}$.

KONDA KU MBUTA, A. \& AMBUHL, D. (2019) Mbinzo. Vers l'élevage des chenilles comestibles Africaines. Edition Skyfood. $164 \mathrm{pp}$.

KOUAKOU, N'G. D.V., THYS, E., YAPI, Y.M., ASSIDJ O, E.N., MARNET, P.-J \& \& GRONGNET, J.-F. (2015) Effet de Panicum maximum J acq. associé à Euphorbia heterophylla L. Klotz. \& Garckesur la productivité de femelles durant le cycle de reproduction chez le cobaye (Cavia porcellus L.) Tropicultura 33, 4, $277-287$

KOUOKAM, J.C., JAHNS, Th. \& BECKER, H. (2002) Antimicrobial activity of the essential oil and some isolated sulphur-rich compounds from Scorodophloeus zenkeriHarms. Planta Medica 68 (12): $1082-1087$.

KUNLE, O., OKOGUN, J., EGAMANA, E., EMOJ EWWE, E. \& SHOK, M. (2003) Antimicrobial activity of various extracts and carvacrol from Lippia multiflora leaf extract. Phytomedicine $10: 59$ - 61.

LADIPO, D.O. \& BOLAND, D.J. (1995) Pentaclethra macrophylla: a multipurpose tree from Africa with potential for agroforestry in the tropics. Nitrogen Fixing Tree Association (NFTA). No. 95 - 05. 2 pp.

LAKSHMI, K. \& MOHANA RAO, G. (1998) Plants for bees: Guava. Bee World79(3): 135 - 137.

LAKSHMI, K, MOHANA RAO, G. \& SURYANARAYANA, M.C. (2000) Plants for bees: Cashew. Bee World 81(1) : $30-33$.

LALIKA, M.C.S. \& MACHANGU, J.S. (2008) Beekeeping for income generation and coastal forest conservation in Tanzania. Bees for Development Journal 884 - 6.

LAMAN, K.E. (1936) Dictionnaire Kikongo - Français. Mem. Inst. Royal Colonial belge. 1183 pp.

LATHAM, P. (2008) Chenilles comestibles et leur plantes nourricières dans la province du Bas-Congo. uww. researchgate net publication $44 \mathrm{pp}$.

LATHAM, P. \& KONDA KU MBUTA, A. (2017) Quelques plantes mellifères du Kongo Central, République Démocratique du Congo. uww.researchgate. net publication 312385021. 263 pp.

LAUNERT, E. (1971) Flora Zambesiaca volume:10 part:1 : Gramineae

LAUTENSCHLÄGER, T., NEINHUIS, C., MONIZI, M., MANDOMBE, J.L., FORSTER, A., HENLE, T., NUSS, M. (2017) Edible Insects of Northern Angola. African Invertebrates 58(2): 55-82 http://africaninvertebrates. pensoft.net/

LAUTENSCHLÄGER, T., MAWUNU, M., MACUNTIMA, P., MANDOMBE, J.L., BRANQUIMA, M.F., HEINZE, C., \& NEINHUIS, C. (2018) First large-scale ethnobotanical survey in the province of Uíge, northern Angola. Journal of Ethnobiology and Ethnomedicine 14: 5173 pp.

LAUTENSCHLÄGER, T, KEMPE, A., BUNK, K, MAWUNU, M, NEIHUIS, C. (2019) Biomechanics and Traditional Use of Raphia matombe Rachis in Northern Angola. Bioresources.com March

LAWALRÉE, A. (1970) Flore du Congo du Rwanda et du Burundi : Schzaeaceae

LAWALRÉE, A. (2000) Flore d'Afrique Centrale (Congo-Kinshasa - Rwanda - Burundi) : Nephrolepidaceae

LAWRENCE, A. (1993) Inga edulis : a tree for acid soils in the humid tropics. In Nitrogen Fixing Trees for Acid Soils. Nitrogen Fixing Tree Association (NFTA). 2 pp.

LEAKEY, C.L.A. \& WILLS, J.B. (Eds.) (1977) Food Crops of the Lowland Tropics. OUP. 345 pp.

LEBRUN, J. P. \& STORK, A.L. (1991). Enumération des plantes à fleurs d'Afrique tropicale. Généralités et Annonaceae à Pandanaceae. Énum. Pl. Fleurs Afr. Trop. 1:38

LEEUWENBERG, A.J .M. \& BAMPS, P. (1979) Flore d'Afrique Centrale (Zaïre - Rwanda - Burundi) : Loganiaceae

LEEUWENBERG, A.J.M. \& KUPICHA, F.K. (1985) Flora Zambesiaca : Apocynaceae

LEGER, S., (1997). The hidden gifts of nature: A description of today's use of plants in West Bushmanland (Namibia). [Internet] DED, German Development Service, Windhoek, Namibia \& Berlin, Germany. http://www. sigridleger.de/book/.

LEJ OLY, J. \& LISOWSKI, S. (1985) Le genre Calycobolus Willd. (Convolvulaceae). Bulletin duJ ardin botanique National de Belgique. 55, 27-60

LELOUP, M. (1956) Tree Planting Practices in Tropical Africa. F.A.O. 302 pp.

LEMMENS, R.H.M.J. (2008) Mammea africana Sabine. [Internet] Record from PROTA4U. Louppe, D., Oteng-Amoako, A.A. \& Brink, M. (Eds.). PROTA (Plant Resources of Tropical Africa / 
Ressources végétales de l'Afrique tropicale), Wageningen, Netherlands.

LEMMENS, R.H.M.J. (2007) Panda oleosa Pierre. [I nternet] Record from PROTA4U. van der Vossen, H.A.M. \& Mkamilo, G.S. (Eds.). PROTA (Plant Resources of Tropical Africa / Ressources végétales de l'Afrique tropicale), Wageningen, Netherlands.

LEMMENS, R.H.M.J. (2010) Paramacrolobium coeruleum (Taub.) J .Léonard. [Internet] Record from PROTA4U. Lemmens, R.H.M.J., Louppe, D. \& Oteng-Amoako, A.A. (Eds.). PROTA (Plant Resources of Tropical Africa / Ressources végétales de l'Afrique tropicale), Wageningen, Netherlands.

LEMMENS, R.H.M.]., 2012. Phyllocosmus africanus (Hook.f.) Klotzsch. [Internet] Record from PROTA4U. Lemmens, R.H.M.J., Louppe, D. \& Oteng-Amoako, A.A. (Editors). PROTA (Plant Resources of Tropical Africa / Ressources végétales de l'Afrique tropicale), Wageningen, Netherlands.

LEO, R. (2007) Sweet Tamarind - Pithecelobium dulce- Trees bees use. Bees for Development Journa/87 004 p. 9

LÉONARD, J . (1962 \& 1995) Flore d'Afrique Centrale (Zaire - Rwanda - Burundi) : Euphorbiaceae

LÉONARD, J. \& MOSANGO, M. (1985) Flore d'Afrique Centrale (Zaire - Rwanda - Burundi) : Hymenocardiaceae

LE ROUX, L-N. (2005) Bauhinia tomentosaL. "http://www.plantzafrica.com"

LETOUZEY, R. \& WHITE, F. (1978) Flore du Gabon : Chrysobalanaceae

LEYENS, T. \& LOBI N, W. (2009) Manual de Plantas Uteis de Angola. Bischöfliches Hilfswerk Misereor, Aachen, Germany. $181 \mathrm{pp}$.

LIBEN, L. (1968) Flore du Congo du Rwanda et du Burundi : Combretaceae

LIBEN, L. (1971) Flore du Congo du Rwanda et du Burundi : Lecythidaceae

LIBEN, L. (1977) Flore d'Afrique Centrale (Zaïre - Rwanda - Burundi) : Bignoniaceae

LIBEN, L. (1987) Flore d'Afrique Centrale (Zaïre - Rwanda - Burundi) : Rhizophoraceae

LIBERIAN FAUNA \& FLORA https://www. fauna-flora.org/countries/liberia

LINDSEY, K \& HIRT, H-M (1999) Use water hyacinth. ANAMED 114 pp.

LISOWSKI, S., MALAISSE, F., \& SYMOENS, J.J . (1970) Flore du Congo du Rwanda et du Burundi : Bixaceae

LISOWSKI, S., MALAISSE, F. \& SYMOENS, J.J. (1976) Flore d'Afrique Centrale (Zaïre - Rwanda - Burundi) : Taccaceae

LISOWSKI, S. (1989) Flore d'Afrique Centrale : Compositae (Deuxieme partie : tribu

Inuleae) LISOWSKI, S. (1991) Les Asteraceae dans la Flore d'Afrique Centrale (excl. Cichorieae,

Inuleae,

Vernonieae) : Fragmenta Floristica et Geobotanica 36 (1). Kraków. Poland ISSN 0015-931x.

LITHUDZHA, E. (2005) Boophone disticha (L.f.) herb. "http://www.plantzafrica.com"

LITHUDZHA, E. \& REYNOLDS, Y. (2004) Asystasia gangetica(L.) T. Anderson subsp. micrantha(Nees) Ensermu. "http://www.plantzafrica.com"

LITTLE, E.L. (1983) Common Fuelwood Crops, A handbook for their identification. Communi-Tech Associates, Morgantown, West Virginia. $354 \mathrm{pp}$.

LLAMAS, K. (2003) Tropical Flowering Plants. Timber Press. 423 pp.

LOBREAU-CALEN, D., DARCHEN, R., DARCHEN, B. \& LE THOMAS, A. (1989) The plants visited by Apis mellifera adansonii in Gabon and the Ivory Coast. Proc. 4 Int. Conf. Apic. trop. Climates, Cairo 1988 pp. $410-421$.

LOCK, J.M., HALL, J.B. \& ABBIW, D.K. (1977) The cultivation of melegueta pepper (Aframomum melegueta) in Ghana. Economic Botany 31, 321 - 330.

LOUIS, J., \& LÉONARD, J. (1948) Flore du Congo Belge et du Ruanda - Urundi : Olacaceae

LORENZ, H. (1992) Brazilian Trees: A Guide to the Cultivation and Identification of Brazilian Trees.

LOUPPE, D. (2007) Ongokea gore (Hua) Pierre. [Internet] Record from PROTA4U. van der Vossen, H.A.M. \& Mkamilo, G.S. (Eds.). PROTA (Plant Resources of Tropical Africa / Ressources végétales de l'Afrique tropicale), Wageningen, Netherlands.

MAAS \& MAAS-VAN DE KAMER (2016) The Cannaceae of the World. BLUMEA 53, 247-318

MAAS \& MAAS-VAN DE KAMER (2017) Costaceae. Flore d'Afrique Centrale, nouvelle série. M.S.M. Sosef, rédaction - J ardin botanique Meise $28 \mathrm{pp}$.

MABBERLEY, D.J. (2002) The Plant-book. Cambridge 858 pp.

MACDONALD, L. H. (Ed.) (1982) Agro-forestry in the African Humid Tropics. Proceedings of a Workshop held in Ibadan, Nigeria, 27 April - 1 May 1981. The United Nations University. 171 pp.

MACKI NDER, B.A. \& HARRIS, D.J. (2006) A Synopsis of the Genus Berlinia. Edinburgh Journal of Botany 63 $(2 \& 3), 161-182$

MACMILAN, H.F. (1991) Tropical Planting and Gardening. Macmillan. Revised by Barlow, H.S., Enoch, I., 
Russell, R.A. Published by the Malayan Nature Society, Kuala Lumpur. 767 pp.

MAI RURA, F.S. (2008) Physalis angulata L. [Internet] Record from PROTA4U. Schmelzer, G.H. \& GuribFakim, A. (Eds.). PROTA (Plant Resources of Tropical Africa / Ressources végétales de l'Afrique tropicale), Wageningen, Netherlands.

MAIRURA, F.S. \& SCHMELZTR, G.H. (2006) Tabemaemontana crassa Benth. [Internet] Record from PROTA4U. Schmelzer, G.H. \& Gurib-Fakim, A. (Editors). PROTA (Plant Resources of Tropical Africa / Ressources végétales de l'Afrique tropicale), Wageningen, Netherlands.

MAIRURA, F.S. \& SETSHOGO, M.P., (2008) Datura stramoniumL. [Intemet] Record from PROTA4U. Schmelzer, G.H. \& Gurib-Fakim, A. (Editors). PROTA (Plant Resources of Tropical Africa / Ressources végétales de l'Afrique tropicale), Wageningen, Netherlands.

MAKGAKGA, C. (2004) Cannabis sativa L. "http://www.plantzafrica.com"

MAKUMBELO, E., LUKOKI, L., SJ. PAULOS, J.J., LUVI NDULA, N. (2008) Stratégie de valorisation des espèces ressources des produits non ligneux de la savane des environs de Kinshasa: II. Enquête ethnobotanique (aspects médicinaux). Tropicultura 26, 3, 129-134.

MALAISSE, F. \& PARENT, G. (1980) Les Chenilles comestibles du Katanga meridional (Zaïre) Les Naturalistes Belges $61: 2$ - 24.

MALAISSE, F. (1997) Se Nourir en Forêt Claire Africaine. Gembloux. 384 pp.

MANDANGO, M. A, BOEMU, L. \& BONGOMBOLA, M. (1990) Plantes antidiabétiques de Kinshasa (Zaïre). Mitt. Inst. Al/g. Bot. Hamburg, 23b, 1021 - 1031

MAPONGMETSEM, P.M. \& TCHIEGANG, C. (1996) Ricinodendron heudelotiiin Cameroon. International Centre for Agroforestry (ICRAF) Agroforestry Today. 8:2.

MARTIN, F.W. CAMPBELL, C.W., RUBERTÉ, R.M. (1987) Perennial Fruits of the Tropics: An inventory. U.S. Department of Agriculture, Agriculture Handbook No. 642, 252 pp.

MARTIN, F.W., RUBERTÉ, R.M. \& MEITZNER, L.S. (1998) Edible Leaves of the Tropics. Echo. 194 pp.

MATU, E.N., 2011. Combretum platypterum (Welw.) Hutch. \& Dalziel. [Internet] Record from PROTA4U. Schmelzer, G.H. \& Gurib-Fakim, A. (Editors). PROTA (Plant Resources of Tropical Africa / Ressources végétales de l'Afrique tropicale), Wageningen, Netherlands.

MAUNDU, P.M., NGUGI, G.W. \& KABUYE, C.H.S. (1999) Traditional Food Crops of Kenya. National Museums of Kenya. 270 pp.

MAUNDU, P. \& TENGNAS, B. (2005) Useful Trees and Shrubs for Kenya. World Agroforestry Centre. 484 pp. MAYO, S.J . (1985) Flora of Tropical East Africa : Araceae.

MBANDU LUZOLAWU, P., LUBINI AYINGWEU, C., MOGUE KAMGA, S., STAUFFER, F.W. (2020) Palmae : Flora d'Afrique Centrale. Jardin Botanique, Meise.

MBEMBA, F. \& REMACLE, J. (1992) Inventaire et composition chimique des aliments et denrées alimentaires traditionnels du Kwango-Kwilu au Zaïre. Biochimie Alimentaire, University de Kinshasa (UNI KIN) et Biochimie Cellulaire, FUNDP, Belgique. $80 \mathrm{pp}$.

MBUYA, L.P., MSANGA, H.P., RUFFO, C.K., BIRNI E, A. \& TENGNÄS, B. (1994) Useful Trees and Shrubs for Tanzania. Swedish International Development Authority (SIDA). 542 pp.

MCDONNELL, M.B. (2001) Medicinal plants of El Salvador: The effectiveness of traditional healing. (Webpage).

MEERTS, P. \& HASSON, M. (2016) Arbres et arbustes du Haut-Katanga. Jardin botanique, Meise. 386 pp.

MEUNI ER, Q., LEMMENS, R., MORI N, A. (2010) Alternatives to Exotic Species in Uganda. Growth and Cultivation of 85 Indigenous Trees. Ed. French Embassy in Uganda, Belgian Technical Cooperation in Uganda, $210 \mathrm{pp}$.

MEUNI ER, Q., MOUMBOGOU, C. \& DOUCET, J.-L. (2015) Les Arbres Utiles du Gabon. Les Presse Agronomiqes de Gembloux. 340 pp.

MINENGU, J.D., MOBAMBO, P. \& MERGEAl, G. (2015) Analyses of the Technical/Economic of four Cropping Systems Involving Jatropha curcas L. in the Kinshasa Region (Democratic Republic of the Congo). Tropicultura2015, 33, 2, $67-76$

MI NENGU, J.D., MOBAMBO, P. \& MERGEAI, G. (2015) Dynamic and I mpact of Major I nsect Pests on Jatropha curcas L. in two Cropping systems with Contrasting Characteristics in Kinshasa Region (DRC). Tropicultura 2015, 33, 3, $163-175$

MI NENGU, J.D., MOBAMBO, P. \& MERGEAI, G. (2015) Etude des possibilités de production de Jatropha curcas $\mathrm{L}$. dans un couvert permanent de Stylosanthes guianensis (Aublet) Swartz en association avec le maïs (Zea mays L.) et le soja (Glycine max (L.) Merr.) dans les conditions de Plateau Bateke à Kinshasa. Tropicultura 2015, 33, 4, 309 - 321

MOORE, J. (1994) Plants of the Tongwe East Forest Reserve (Ugalla), Tanzania. TROPICS3(3/4) : 333 340.

MORENO, S.C., CARVALHO, G.A., PICANÇO, M.C., MARAIS, E.GF. \& PEREIRA, R.M. (2011) Bioactivity of compounds of Acmella oleraceaagainst Tuta absoluta (Meyrick) (Lepidoptera: Gelechiidae) and selectivity to two non-target species. Wileyonlinelibrary.com DOI 10.1002/ps.2274 
MORTON, J.F. (1961) West African Lilies and Orchids. Longmans 76 pp.

MORTON, J.F. (1962) Spanish needles. (Bidens pilosa L.) as a wild food resource. Econ. Bot. 16, 173 - 179.

MORTON, J.F. (1964) Honeybee plants of south Florida. Proc. of the Florida State Hort. Soc. 77, 415 - 436.

MORTON, J.F. (1967) The balsam pear - An edible, medicinal and toxic plant. Econ. Bot. 21, 57 - 68.

MORTON, J.F. (1987) Fruits of Warm Climates. Miami, FL. 506 pp.

MOSANGO, D.M., (2007) Alchornea floribunda Müll.Arg. [I nternet] Record from PROTA4U. Schmelzer, G.H. \& Gurib-Fakim, A. (Editors). PROTA (Plant Resources of Tropical Africa / Ressources végétales de l'Afrique tropicale), Wageningen, Netherlands.

MOSANGO, D.M., (2008) Peperomia pellucida (L.) Kunth. [I nternet] Record from PROTA4U. Schmelzer, G.H. \& Gurib-Fakim, A. (Editors). PROTA (Plant Resources of Tropical Africa / Ressources végétales de l'Afrique tropicale), Wageningen, Netherlands.

MSANGA, H.P. (1998) Seed Germination of Indigenous Trees in Tanzania. Natural Resources, Canadian Forest Senvice. $292 \mathrm{pp}$.

MUKOKO MATONDO (1991) Plantes médicinales et leurs usages. Centre de Vulgarisation Agricole, Kinshasa 2.

MUKOMA, T. (2005) Hos/undia opposita Vahl. "http://www.plantzafrica.com"

MUNGWI NI, Y., (2006) Plumbago zeylanica L. [Internet] Record from PROTA4U. Schmelzer, G.H. \& Gurib-Fakim, A. (Editors). PROTA (Plant Resources of Tropical Africa / Ressources végétales de I'Afrique tropicale), Wageningen, Netherlands.

MUNTHALI, S.M. \& MUGHOGHO, D.E.C. (1992) Economic incentives for conservation: bee-keeping and Saturniidae caterpillar utilization by rural communities. Biodiversity and Conservation 1, 143-154.

MVERE, B. (2004) Bidens pilosa L. In Grubben, G.J.H. \& Denton, O.A. (Eds.). Plant Resources of Tropical Africa 2. Vegetables. PROTA Foundation, Wageningen, Netherlands/ Backhuys Publishers, Leiden, Netherlands / CTA.

NAIR, P.K.R. (1980) Agroforestry Species. ICRAF. 336 pp.

NAKASONE, H.Y. \& PAULL, R.E. (1998) Tropical Fruits. CAB International. 445 pp.

NATIONAL ACADEMY OF SCI ENCES (1975) Underexploited Tropical Plants with Promising Economic value. $189 \mathrm{pp}$.

NATIONAL ACADEMY OF SCI ENCES (1979) Tropical Legumes. 332 pp.

NATIONAL ACADEMY OF SCI ENCES (1980, 1983) Firewood Crops 1237 p. \& 292 p.

NATIONAL ACADEMY OF SCI ENCES (1983) Mangium and Other Fast Growing Acacias for the Humid Tropics. $62 \mathrm{pp}$.

NDIA N'SOKI, M. K. (1994) Sagesse Kongo. 275 pp.

NEUWI NGER, H.D. (2000) African Traditional Medicine. Medpharm. 589 pp.

NFTA = Nitrogen Fixing Tree Association

NGANGA-Z (2000) Culture des chenilles pouvant vivre à Kasangulu. (unpublished)

NGEBULE, E. \& MBAKWE, R. (2001) Effect of pre-sowing and incubation treatment on germination of Garcinia kola (Heckel) seeds. Fruits, 566 pp. 437 - 442

NGUYEN NGHIA THIN \& NGUYEN TRNG THANH (2001) Dianella ensifolia (L.) DC. I. (Editors) n: van Valkenburg, J.L.C.H. and Bunyapraphatsara, N. (Editors): Plant Resources of South-East Asia No. 12(2). Medicinal and poisonous plants 2 Backhuys Publishers, Leiden, the Netherlands pp. 223-224.

NIANGADOUMA, R. (2010) Ficus exasperata Vahl. [Internet] Record from PROTA4U. Brink, M. \& Achigan-Dako, E.G. (Eds.). PROTA (Plant Resources of Tropical Africa / Ressources végétales de l'Afrique tropicale), Wageningen, Netherlands.

NIE, Y., DONG, X., HE, Y., YUAN, T., HAN, T., RAHMAN, K, QIN, L. \& ZHANG, Q. (2013) Medicinal plants of genus Curculigo: traditional uses and a phytochemical and ethnophamacological review. J. Ethnopharmcol. 2013 J une 3147 (3), 547-63

NONYANE, F. \& MASUPA, T. (2010) Burkea africana Hook. "http://www. plantzafrica.com"

NORDAL, K, ATIVU, S. \& POULSEN, A.D. (1997) Flora of Tropical East Africa : Anthericaceae

NOUMBISSI, M.N.B., TENDONKENG, F., ZOUGOU, T.G. \& TENDONKENG, E.P. (2014) Effect of Different Levels of Supplementation with Tithonia diversifolia (Hemsl.) A.Gray on Feed Intake and in vivo Digestibility of Pennisetum purpureumK. Schum. in Guinea Pigs (Cavia porcellus L). Tropicultura. 32, (3), 138-146

NSI MUNDELE NKONDO, L. (1966 -1968) Repertoire des plantes médicinales des régions Côtier (1), Mayumbe (2), Bas-Congo (3). (unpublished)

NSI MUNDELE NKONDO, L. (2004) Plantes Alimentaires du Bas-Congo. See http://users.telenet. be/cr28796/

NSI MUNDELE NKONDO, L., DIANSAMBU MAKANUA, I., DUBIEZ, E., PROCES, P., MARIEN, J.-N., PELTIER, R. \& VERMEULEN, C. (2010) Conserver ou manger la forêt ? Le paradoxe des paysans en périphérie de Kinshasa, RDC. Le Flamboyant J ulliet 66/67.

NTORE, S. \& LACHENAUD, O. (2020) Rubiaceae Tribu XVI. Colletoecemateae à XVIII. Lasiantheae 
NUGA, O.O., \& SETSHOGO, M.P. (2008) Datura mete/L. [Internet] Record from Protabase. Schmelzer, G.H. \& Gurib-Fakim, A. (Editors). PROTA (Plant Resources of Tropical Africa / Ressources végétales de l'Afrique tropicale), Wageningen, Netherlands.

NYE, P.H. \& GREENLAND D.J. (1960) The Soil under Shifting Cultivation. Commonwealth Agricultural Bureau (CAB). $156 \mathrm{pp}$.

NYUNAI, N. \& N IFUTIE, N. (2006) Picralima nitida(Stapf) T. Durand \& H. Durand. [I nternet] Record from PROTA4U. Schmelzer, G.H. \& Gurib-Fakim, A. (Eds.). PROTA (Plant Resources of Tropical Africa / Ressources végétales de l'Afrique tropicale), Wageningen, Netherlands.

NZZGBULE, E \& MBAKWE, R. (2001) Effect of pre-sowing and incubation treatment on germination of Garcinia kola (Heckel) seeds. Fruits 56 p. 437 - 442.

NZUKI BAKWAYE, F., KI NKWONO, E.K., SEKLE, B.J . (2011) Utilization du guano comme du Di-Ammonium Phosphate (DAP) dans la fertilisation du soja et de la tomate en République Démocratique du Congo. Tropicultura 29, 2, 114 - 120

NZUKI BAKWAYE, F., TERMOTE, C., KIBUNGU, K. \& VAN DAMME, P. (2013) Identification et importance locale des plantes médicinales utilisées dans la région de Mbanza-Ngungu, République démocratique du Congo. BOIS ET FORETS DES TROPIQUES Ghent University No. 316 (2) 64 78

OBENG, E.A., (2010). Blighia welwitschii(Hiern) Radlk. [Internet] Record from PROTA4U. Lemmens, R.H.M.J ., Louppe, D. \& Oteng-Amoako, A.A. (Editors). PROTA (Plant Resources of Tropical Africa / Ressources végétales de l'Afrique tropicale), Wageningen, Netherlands.

OBERPRI ELER, R. (1995) The Emperor Moths of Namibia. Ekoguild 91 pp.

OFORI, D.A. (2007) Milicia excelsa (Welw.) C.C. Berg. [I nternet] Record from PROTA4U. Louppe, D., OtengAmoako, A.A. \& Brink, M. (Eds.). PROTA (Plant Resources of Tropical Africa / Ressources végétales de l'Afrique tropicale), Wageningen, Netherlands.

OGENDO, J.O., BELMAIN, S.R., DENG, A.L. \& WALKER, D.J. (2003) Comparison of Toxic and Repellent Effects of Lantana camara L. with Tephrosia vogelii Hook. and a Synthetic Pesticide against Sitophilus zeamais Motschulsky (Coleoptera: Curculionidae) in Stored Maiz Grain. International Joumal of Tropical Insect Science 23 (2): 127 - 135

OHLER, J.G. (1988) Cashew. Koninklijk Instituut vor de Tropen. Communication 71.260 pp.

OKAFOR, J.C. (2004) Myrianthus arboreus P.Beauv. [I Internet] Record from PROTA4U. Grubben, G.J .H. \& Denton, O.A. (Eds.). PROTA (Plant Resources of Tropical Africa / Ressources végétales de l'Afrique

OKEKE, A.O. (2003) Three minute herbal treatment to reduce dental caries with a Newbouldia laevis based extract. American Journal of Undergraduate Research 2 (2): 1 - 4.

OKEYO, J.M. (2006) Erythrophleum suaveolens (Guill. \& Perr.) Brenan. [I nternet] Record from PROTA4U. Schmelzer, G.H. \& Gurib-Fakim, A. (Eds.). PROTA (Plant Resources of Tropical Africa /Ressources végétales de l'Afrique tropicale), Wageningen, Netherlands.

OKI GBO, B.N. (1978) Vegetables in Tropical Africa. In: Crop Genetic Resources in Africa. Proceedings of a workshop jointly organized by the Assoc. for the Advancement of Agric. Sciences in Africa and the IITA, Ibadan. p.128 - 147.

OKIY, G.E.O. (1960) Indigenous Nigerian food plants. J.W.Afr.Sci. Ass., 6(2) 117 - 21

OMINO, E.A. (2002) Flora of Tropical East Africa : Apocynaceae

ONOJA, S.O., EZEJ A, M.I., OMEH, Y.N., ONWUKWE, B.C. (2016) Antioxidant, anti-inflammatory and antinociceptive activities of methanolic extract of Justicia secundaVahl leaf. Alex J Med(2016), http://dx. doi.org/10.1016/j.ajme.2016.06.001

OOMEN, H.A.P.C. \& GRUBBEN, G.J.H. (1978) Tropical Leaf Vegetables in Human Nutrition. Royal Trop. Institute, Amsterdam. 140 pp.

OPUNI-FRI MPONG, N.Y. \& OPUNI-FRIMPONG, E. (2012) Naudea didemichii(De Wild. \&T.Durand) Merr. [Intemet] Record from PROTA4U. Lemmens, R.H.M.J., Louppe, D. \& Oteng-Amoako, A.A. (Eds.). PROTA (Plant Resources of Tropical Africa / Ressources végétales de l'Afrique tropicale), Wageningen, Netherlands.

ORWA, C., MUTUA, A., KINDT, R., J AMNADASS, R., SI MONS, A. (2009) Agroforestree Database: a tree reference and selection guide version 4.0. World Agroforestry Centre, Kenya.

ORWA, C. \& MUNJUGA, M., (2007) Allanblackia floribunda Oliv. [Internet] Record from PROTA4U. van der Vossen, H.A.M. \& Mkamilo, G.S. (Editors). PROTA (Plant Resources of Tropical Africa / Ressources végétales de l'Afrique tropicale), Wageningen, Netherlands.

OUDHIA, P. (2008) Phyllanthus amarus Schumach. \& Thonn. [Internet] Record from PROTA4U. Schmelzer, G.H. \& Gurib-Fakim, A. (Eds.). PROTA (Plant Resources of Tropical Africa / Ressources végétales de l'Afrique tropicale), Wageningen, Netherlands.

OWUSU, F.W., (2008) Turraeanthus africanus (Welw. ex C.DC.) Pellegr. [Internet] Record from PROTA4U. Louppe, D., Oteng-Amoako, A.A. \& Brink, M. (Editors). PROTA (Plant Resources of Tropical Africa I Ressources végétales de l'Afrique tropicale), Wageningen, Netherlands. 
OYEN, L.P.A., (2008) Jateorhiza macrantha (Hook.f.) Exell \& Mendonça. [I nternet] Record from PROTA4U. Schmelzer, G.H. \& Gurib-Fakim, A. (Editors). PROTA (Plant Resources of Tropical Africa / Ressources végétales de l'Afrique tropicale), Wageningen, Netherlands

OYEN, L.P.A., (2012) Maranthes glabra (Oliv.) Prance. [Internet] Record from PROTA4U. Lemmens, R.H.M.J., Louppe, D. \& Oteng-Amoako, A.A. (Editors). PROTA (Plant Resources of Tropical Africa / Ressources végétales de l'Afrique tropicale), Wageningen, Netherlands.

OYEN, L.P.A. \& LOUPPE, D. (2012) Staudtia kamerunensis Warb. [I nternet] Record from PROTA4U. Lemmens, R.H.M.J., Louppe, D. \& Oteng-Amoako, A.A. (Eds.). PROTA (Plant Resources of Tropical Africa / Ressources végétales de l'Afrique tropicale), Wageningen, Netherlands.

OYEN, L.P.A. \& LOUPPE, D. (2012). Staudtia kamerunensisWarb. [Internet] Record from PROTA4U. Lemmens, R.H.M.J ., Louppe, D. \& Oteng-Amoako, A.A. (Editors). PROTA (Plant Resources of Tropical Africa / Ressources végétales de l'Afrique tropicale), Wageningen, Netherlands.

PADMANABHAN, P. (1997) Rubber tree Hevea brasiliensis Bees for Development 4510

PATON, A. \& MEERTS, P. (2020) Flore d'Afrique centrale : Labiateae. Introduction. Sous-familles I Viticoideae et II Premnoideae

PAULUS, J. (1997) Extension of African Winged Bean in Zaire. In African Indigenous Vegetables - Workshop Proceedings J an 13 - 18. Limbe, Cameroon. 42 - 43.

PAUWELS, L. (1982) Plantes Vasculaires des environs de Kinshasa. 118 pp.

PAUWELS, L. (1993) Nzayilu N'ti - Guide des Arbres et Arbustes de la Region de Kinshasa - Brazzaville. J ardin Botanique national de Belgique. 495 pp.

PAUWELS, L. \& Breyne, H. (1978) Deux espèces rudérales nouvelles pour la Flore du Zaïre: Croton hirtus L'Hérit. (Euphorbiaceae) et Eupatorium odoratumL. (Compositae) Bull. Jard. Bot. Nat. Belg. Bull. Nat. Plantentuin Belg. 48: 433-435

PAUWELS, L., BREYNE, H. \&DELAUDE, C. (1999) Acosmium panamense(Fabaceae) arbre intéressant introduit en Afrique tropicale. Syst. Geogr. PI. 69, 3 - 7.

PELLETT, F.C. (1976) American Honey Plants. Dadant \& Sons 467 pp.

PENGE, O., BASHENGEZI, M., LONGANGA, O. \& FOEMI , K. (1988) Évaluation des activités antimicrobiennes de Syzygium guineense De Wild. (Myrtaceae), Revue Zairois des Sciences Nucléares, 3 (1 - 2) pp. $211-222$.

PENGE, 0. (2004) Treatment of diarrhoeal diseases with medical plants in the DRC. In Nature and Culture in the Democratic Republic of Congo. Tervuren pp. 137 - 144

PERSOON, J.G. M., VAN DILST, F.J.H., KUIJ PERS, R.P., LEEUWENBERG, AJ.M., VONK, G.J.A. (Ed.) (1992) The African Species of LandolphiaP Beauv. Series of Revisions of Apocynaceae XXXIV 232 pp.

PETERS, C.R., O'BRI EN, E.M. \& DRUMMOND, R. B. (1992) Edible Wild Plants of Sub Saharan Africa. Royal Botanic Gardens, Kew. 239 pp.

PETIT, E. (1958) Flore du Congo Belge et du Ruanda-Urundi : Polygalaceae

PHI LIPS, R. \& RIX, M. (1997) Conservatory and Indoor Plants Vol 1 \& 2. Macmillan. 286 \& 319 pp.

PHILIPSON, P.B. \& STEYN, C.F. (2008) Tetradenia (Lamiaceae) in Africa: new species and new combinations. Adansonia, sér. 3, 30 (1) : 177-196.

POLLARD B.] ., (2008) Triclisia dictyophylla Diels. [I nternet] Record from PROTA4U. Schmelzer, G.H. \& Gurib-Fakim, A. (Editors). PROTA (Plant Resources of Tropical Africa / Ressources végétales de I'Afrique tropicale), Wageningen, Netherlands.

POPE, G.V. (1992) Flora Zambesiaca : Asteraceae

POPE, G.V. (1996) Flora Zambesiaca : Euphorbiaceae

PORTUGAL-ARAÚJ O, V. DE (1974) Apiáros e instalações apícolas na extensão rural (tecnologia apícola) (planalto central de Angola). Nova Lisboa, Angola; Estado de Angola. 110 pp.

POUSSET, J.L. (2004) Plantes Médicinales d'Afrique. Secum/Édisud. 287 pp.

PRESBER, W., HEGENSCHEID, B., HERNANDEZ-ALVAREZ, H., HERRMANN, D. \& BRENDEL, C. (1992) Inhibition of the growth of Plasmodium falciparumand Plasmodium berghei in vitro by an extract of Cochlospermum angolense (Welw.) Acta tropica 50. 4 : pp. 331 - 338.

PURSEGLOVE, J.W. (1968) Tropical Crops: Dicotyledons. Vols. 1 \& 2 Longmans. 719 pp.

PURSEGLOVE, J.W. (1972) Tropical Crops: Monocotyledons. Vols. 1 \& 2 Longmans. 607 pp.

RAEMAEKERS, R.H. (2001) Crop Production in Tropical Africa. Directorate Generale for International Cooperation, DGI C, Brussels. 1540 pp.

RAGONE, D. (1997) Breadfruit. Artocarpus altilis (Parkinson) Fosberg. IPGRI. 77 pp.

RAPONDA-WALKER, A. \& SILLANS, R. (1961) Les Plantes Utiles du Gabon. Paul Lechevalier, Paris, France. $614 \mathrm{pp}$.

RENI ER, M. (1947) Notes sur des essais d'apiculture au Congo belge. Bull. Agricole du Congo Belge pp. 121 $-126$. 
RENIER, M. (1948) Flore du Kwango. 3 vols.

RENNER, S.S. (1989) Bellucia pentamera Naudin in Systematic Studies in the Melastomataceae. Memoirs of the New York Botanic Garden 50 pp. 18 - 21

ROBI NSON, R.W. et DECKER-WALTERS, D.S. (1997) Cucurbits. CAB International. 226 pp.

ROBYNS, W. (1948) Flore du Congo Belge et du Ruanda-Urundi : Cycadaceae

ROBYNS, W. (1948) Flore du Congo Belge et du Ruanda-Urundi : Gnetaceae

ROBYNS, W. (1951) Flore du Congo Belge et du Ruanda-Urundi : Moringaceae

ROBYNS, W. (1958) Flore du Congo Belge et du Ruanda-Urundi : Pandaceae

ROBYNS, W. (1963) Flore du Congo Belge et du Rwanda et du Burundi : Bombacaceae

ROBYNS, W. (1967) Flore du Congo Belge et du Rwanda et du Burundi : Cochlospermaceae

ROBYNS, A. (1995) Flore d'Afrique Centrale (Zaïre - Rwanda - Burundi) : Passifloraceae

ROBYNS. W. \& W LCZEK, R. (1951) Flore du Congo Belge et du Ruanda-Urundi : Lauraceae

ROCAS, A.N. Acosmium panamense(Benth.) Yakovlev pdf in Species Description vol. 2 p. 264, 265

ROCHELEAU, D., WEBER, F. \& FIELD-J UMA, A. (1988) Agroforestry in Dryland Africa. ICRAF. 311 pp.

ROODT, V. (1998) Common Wild Flowers of the Okavango Delta. Gaborone: Shell Oil Botswana. 174 pp.

ROOTHAERT, R., ARIMI, H.K. \& KAMAU, E. (1997) Indigenous fodder species in Kenya. International Centre for Research in Agroforestry (ICRAF). Agroforestry Today 9:3.

ROUBIK, D.W. (1995) Pollination of Cultivated Plants in the Tropics. FAO Agricultural Services Bulletin No.118. 196 pp.

ROYAL HORTICULTURAL SOCIETY (RHS) https://www. ms.org.uk/

RUFFO, C.K., BIRNIE, A. \& TENGNÄS, B. (2002) Edible Wild Plants of Tanzania. RELMASIDA, Embassy of Sweden. $764 \mathrm{pp}$.

SANGAT-ROEMANTYO, H., (1999) J usticia gendarussa Burm.f.[I nternet] Record from Proseabase. de Padua, L.S., Bunyapraphatsara, N. and Lemmens, R.H.M.J . (Editors). PROSEA (Plant Resources of South-East Asia) Foundation, Bogor, Indonesia. http://www. proseanet.org.

SANOUSSI, A., AHOTON, L.E., ODJ O, Th. (2012) Propagation of Black Plum ( Vitex doniana Sweet) using Stem and Root Cuttings in the Ecological Conditions of South Benin. Tropicultura 30, 2, 107 - 112

SCHI PPERS, R.R. (2002) African Indigenous Vegetables an Overview of the Cultivated Species. Chatham, UK (CD-ROM). $244 \mathrm{pp}$.

SCHIPPERS, R. R. \& BESONG, M.T. (2002) Gnetum africanumI n: Oyen, L.P.A. and Lemmens, R.H.M.J . (Eds.). Plant Resources of Tropical Africa. Precursor. PROTA Programme, Wageningen, Netherlands. p. 88 - 91.

SCHIPPERS, R. R. (2004) Légumes Africains Indigènes. Présentation des espèces cultivées. Margraf Publishers $482 \mathrm{pp}$.

SCHI PPERS, R.R. \& MNZAVA, N.A. (2007) Brassica juncea (L.) Czern. [Internet] Record from PROTA4U. van der Vossen, H.A.M. \& Mkamilo, G.S. (Eds.). PROTA (Plant Resources of Tropical Africa / Ressources végétales de l'Afrique tropicale), Wageningen, Netherlands.

SCHMELZFR, G.H., (2006) Baissea axillaris (Benth.) Hua. [Internet] Record from PROTA4U. Schmelzer, G.H. \& Gurib-Fakim, A. (Editors). PROTA (Plant Resources of Tropical Africa / Ressources végétales de l'Afrique tropicale), Wageningen, Netherlands.

SCHMELZER, G.H., (2006). Voacanga thouarsii Roem. \& Schult. [Internet] Record from PROTA4U. Schmelzer, G.H. \& Gurib-Fakim, A. (Editors). PROTA (Plant Resources of Tropical Africa / Ressources végétales de l'Afrique tropicale), Wageningen, Netherlands.

SCHMELZER, G.H. (2007) Catharanthus roseus (L.) G. Don. [Internet] Record from PROTA4U. Schmelzer, G.H. \& Gurib-Fakim, A. (Eds.). PROTA (Plant Resources of Tropical Africa / Ressources végétales de l'Afrique tropicale), Wageningen, Netherlands.

SCHMELZER, G.H., (2007) Macaranga spinosa Müll.Arg. [I nternet] Record from PROTA4U. Schmelzer, G.H. \& Gurib-Fakim, A. (Editors). PROTA (Plant Resources of Tropical Africa / Ressources végétales de l'Afrique tropicale), Wageningen, Netherlands.

SCHMELZER, G.H. (2007) Rauvolfia mannii Stapf. [Internet] Record from PROTA4U. Schmelzer, G.H. \& Gurib-Fakim, A. (Eds.). PROTA (Plant Resources of Tropical Africa / Ressources végétales de l'Afrique tropicale), Wageningen, Netherlands.

SCHMEL ZER, G.H. (2007) Rauvolfia vomitoria Afzel. [I nternet] Record from PROTA4U. Schmelzer, G.H. \& Gurib-Fakim, A. (Eds.). PROTA (Plant Resources of Tropical Africa / Ressources végétales de l'Afrique tropicale), Wageningen, Netherlands.

SCHMELZRR, G.H. (2007) Shirakiopsis elliptica (Hochst.) Esser. [I nternet] Record from PROTA4U. Schmelzer, G.H. \& Gurib-Fakim, A. (Eds.). PROTA (Plant Resources of Tropical Africa / Ressources végétales de l'Afrique tropicale), Wageningen, Netherlands.

SCHMELZER, G.H. (2008). Dichostemma glaucescens Pierre. [I nternet] Record from PROTA4U. Schmelzer, G.H. \& Gurib-Fakim, A. (Editors). PROTA (Plant Resources of Tropical Africa / Ressources végétales de l'Afrique tropicale), Wageningen, Netherlands 
SCHMELZER, G.H. (2008) Euphorbia candelabrum Trémaux ex Kotschy. [Internet] Record from PROTA4U. Schmelzer, G.H. \& Gurib-Fakim, A. (Editors). PROTA (Plant Resources of Tropical Africa / Ressources végétales de l'Afrique tropicale), Wageningen, Netherlands.

SCHMELZER, G.H. \& LEMMENS, R.H.M.J., (2008) Plagiostyles africana (Müll.Arg.) Prain. [Internet] Record from PROTA4U. Schmelzer, G.H. \& Gurib-Fakim, A. (Editors). PROTA (Plant Resources of Tropical Africa / Ressources végétales de l'Afrique tropicale), Wageningen, Netherlands.

SECOY, D.M. \& SMITH, A.E. (1983) Use of Plants in Control of Agricultural and Domsestic Pests. Economic Botany 3728 - 57

SEPASAL = Royal Botanic Gardens, Kew (1999) Survey of Economic Plants for Arid and Semi-Arid Lands (SEPASAL) database. Published on the Internet; "http://www.kew.org/ceb/sepasal".

SHIEMBO, P.N., NEWTON, A.C. \& LEAKEY, R.R.B. (1997) Vegetative propagation of Ricinodendron heudelotii, a West African fruit tree. J. Trop. For. Sci9 (4): 514 - 525.

SIDIBE, M. and WI LLIAM L.S, J.T. (2002) Baobab Adansonia digitata L. International Centre for Underutilized Crops, Southampton, U.K. 99 pp.

SIEMONSMA, J.S. et KASEM PILUEK (Eds.)(1993) Plant Resources of South-East Asia No 8. Vegetables. Pudoc Scientific Publishers, Wageningen, Netherlands. $412 \mathrm{pp}$.

SI EMONSMA, J.S. (1999) Aleurites moluccana (L.) Willd. in De Guzman, C.C. \& Siemonsma, J.S. (Eds.) Plant Resources of South-East Asia No. 13 Spices. Backhuys Publishers, Leiden, Netherlands.

SI EMONSMA, J.S. \& KOUAMÉ, C. (2004) Abelmoschus esculentus(L.) Moench. [I nternet] Record from PROTA4U. Grubben, G.J.H. \& Denton, O.A. (Eds.). PROTA (Plant Resources of Tropical Africa / Ressources végétales de l'Afrique tropicale), Wageningen, Netherlands.

SI LLANS, R. (1953) Sur quelques plantes médicinales de l'Afrique centrale. In: Revue internationale de botanique appliquée et d'agriculture tropicale, 31e année, bulletin n³45-346. pp. 407-427.

SIMON, J.E., CHARLES, D., CEBERT, E., GRANT, L., JANICK, J. \& WHIPKEY, A. (1990) Artemisia annua L. : $A$ promising aromatic and medicinal. p. 522-526. In: J. J anick and J.E. Simon (Eds.), Advance in new crops. Timber Press, Portland, OR.

SINGH, Y. (2004) Hypoxis angustifolia Lam. "http://www. plantzafrica.com"

SIREGAR, A. H. (1999) Brucea javanica (L.) Merr. In : De Padua, L.S., Bunyapraphatsara, N. and Lemmens, R.H.M.J . (Eds.): Plant Resources of South-East Asia No. 12(1). Medicinal and poisonous plants 1. Backhuys Publishers, Leiden, Netherlands. pp. 160 - 163.

SKERMAN, P.J. (1977) Tropical Forage Legumes. FAO Plant Production and Protection Series. No. 2. 609 pp.

SLAATS, J. (1995) Chromolaena odorata fallow in food cropping systems. An agronomic assessment in South West Ivory Coast. CIP - DATA Koninklijke Bibliotheek, Den Haag.

SMARTT, J. (1976) Tropical Pulses. Longman. 348 pp.

SMITH, F.G. (1957) Bee botany in East Africa. E. Afr. Agric. J. 23: 119 - 126.

SMITH, A.R. (1987) Flora of Tropical East Africa : Euphorbiaceae Part 1278 - 279

SOFIDIYA, M.O., ODUWOLE, B., BAMGBADE, E., ODUKOYA, O. \& ADENEKAN, S. (2011) Nutritional composition and antioxidant activities of Curculigo pilosa (Hypoxidaceae) rhizome. African J oumal of Biotechnology Vol. 10(75), pp. 17275-17281

SOLADOYE, M.O. (1985) A revision of Baphia (Leguminosae-Papilionoideae). Kew Bulletin. 40 (2), 291-386.

SRI HAJATI WIDODO (1999) Abelmoschus moschatus Medik. In Oyen, L.P.A. \& Nguyen Xuan Dung (Eds.), 1999. Plant Resources of South-East Asia No 19. Essential-oil plants. Backhuys Publishers, Leiden, Netherlands. pp. 53 - 57

SRI SETYATI HARI ADI (1991) Malpighia glabra L. In Verheij, E.W.M. and Coronel, R.E. (Eds.) Plant Resources of South-East Asia No 2. Edible fruits and nuts. Backhuys Publishers, Leiden, Netherlands. $198-200$

STANER, P. (1948) Flore du Congo Belge et du Ruanda-Urundi : Balanophoraceae

STANER, P. \& BOUTI QUE, R. (1937) Matériaux pour l'étude des plantes médicinales indigènes du Congo Belge. Académie Royale de Belgique, Bruxelles 228 pp. http://www. hear.org/pier/references/ pierref000444.htm"

STANER, P. \& GILBERT, G. (1958) Flore du Congo Belge et du Ruanda-Urundi : Meliaceae

STAPLES, G.W., HERBST, D.R. (2005) A Tropical Garden Flora: plants cultivated in the Hawailan Islands and other tropical places. Bishop Museum Press, Honolulu. 908 pp.

STEVELS, J.M.C. (1990) Légumes Traditionnels du Cameroun, une étude agro-botaniqe. Wageningen. 281 pp.

STEVENS, J. (2011) Flore a la Ferme Randu. Une collection dímages du sud-ouest Katanga R.D.C. Mission Press, Ndola, Zambia. $358 \mathrm{pp}$.

STOLL, G. (2000) Natural Crop Protection in the Tropics. Margraf Verlag. 376 pp. 
SUDIARTO \& RIFAI, M.A. (1991) Punica granatumL. Plant Resources of South-East Asia. - Wageningen : Pudoc No. 2 : Edible fruits and nuts/E.w.N. Verheij and R.E, Coronel (eds.)

SUNDERLAND, T.C.H., CLARK, L.E., \& VANTOME, P. (1999) Current research issues and prospects for conservation and development. FAO Non-Wood Forest Products of Central Africa.

SUNDERLAND, T.C.H. (2007) Field guide to the rattans of Africa. Kew Publishing. 66 pp.

SUNDERLAND, T.C.H. (2011) Calamus deërratus G.Mann \& H.Wendl. [Internet] Record from PROTA4U. Brink, M. \& Achigan-Dako, E.G. (Editors). PROTA (Plant Resources of Tropical Africa / Ressources végétales de l'Afrique tropicale), Wageningen, Netherlands.

SWABY, E.M. (1979) Breadfruit for economy. Scientific Research Council, Kingston, Jamaica 32 pp.

TABULA, T.K, MADOUNGOU, P., BAYONNE, L. (2005) Effets de l'iboga ( Tabernanthe iboga Baillon) sur les nématodes à galles (Meloidogynesp.) parasites de tomate. Tropicultura 23, 1, 6 - 10.

TAKAWI RA-NYENYA, R. (2005) Pterocarpus angolensisDC. [Internet] Record from PROTA4U. Louppe, D. Oteng-Amoako, A.A. \& Brink, M. (Eds.). PROTA (Plant Resources of Tropical Africa / Ressources végétales de l'Afrique tropicale), Wageningen, Netherlands.

TANAKA J . (1980) The San hunter-gatherers of the Kalahari: A study in Ecological Anthropology. University of Tokyo Press, Tokyo

TATON, A. (1967) Flore du Congo du Rwanda et du Burundi : Onagraceae

TATON, A. (1969) Flore du Congo du Rwanda et du Burundi : Violaceae

TATON, A. (1971) Flore du Congo du Rwanda et du Burundi : Boraginaceae

TATON, A. (1980) Flore d'Afrique Centrale (Zaire - Rwanda - Burundi) : Myrsinaceae

TAYLOR, G. (1927) The origin of adventitious growth in Acanthus montanus. Trans. Bot. Soc. Edinburgh 29, issue 1- 4.

TCHINDA, A.T. (2008) Entandrophragma angolense (Welw.) C.DC. [Internet] Record from PROTA4U. Louppe, D., Oteng-Amoako, A.A. \& Brink, M. (Eds.). PROTA (Plant Resources of Tropical Africa / Ressources végétales de l'Afrique tropicale), Wageningen, Netherlands.

TERESHIMA, H., KALALA, S. \& MALASI, N. (1991) Ethnobotany of the Lega people in the tropical rain forest of Eastern Zaïre: part 2, zone de Walikale. African study monographs, Suppl., 19: 1 - 60

TERMOTE, C. (2012) Wild edible plant use in Tshopo District, Democratic Republic of Congo. Faculteit Bio-ingenieurswetenschappen, Gent Universiteit. 294 pp.

TERRA, G.J.A. (1966) Tropical Vegetables. NOVIB/Koninlijk Instituut. 107 pp.

THAPA, R. \& WONGSIRI, S. (1997) Eupatorium odoratum: a honey plant for beekeepers in Thailand. Bee World 78 (4): 175 - 178

TINDALL, H.D. (1983) Vegetables in the Tropics. Macmillan. 533 pp.

T MANNETJ E, L. \& J ONES, R.M. (Eds.), 1992. Plant Resources of South-East Asia No 4. Forages. Pudoc Scientific Publishers, Wageningen, Netherlands. $300 \mathrm{pp}$.

TOLU ODUGBEMI (2006) Outlines and Pictures of Medicinal Plants from Nigeria. University of Lagos Press. $283 \mathrm{pp}$.

TOUSSAINT, L. (1951) Flore du Congo Belge et du Ruanda-Urundi : Crassulaceae

TOUSSAI NT, L. (1953) Flore du Congo Belge et du Ruanda-Urundi : Papilionaceae

TOUSSAINT, L., WILCZEK, R., GILLET, J.B. \& BOUTIQUE, R. (1951) Flore du Congo Belge et du RuandaUrundi : Papilionaceae (Sophoreae, Genisteae, Trifolieae et Loteae).

TOXOPEUS, H. \& BAAS, J. (2004) Brassica rapa L. [Intemet] Record from PROTA4U. Grubben, G.J.H. \& Denton, O.A. (Eds.). PROTA (Plant Resources of Tropical Africa / Ressources végétales de l'Afrique tropicale), Wageningen, Netherlands.

TREDGOLD, M.H. (1986) Food Plants of Zimbabwe. Mambo Press. 153 pp.

TROUPIN, G. (1951) Flore du Congo Belge et du Ruanda - Urundi : Menispermaceae

TROUPI N, G. (1952) Flore du Congo Belge et du Ruanda - Urundi : Connaraceae.

TROUPIN, G. (1958) Flore du Congo Belge et du Ruanda - Urundi : Burseraceae.

TURNBULL, J.W. (1987) Acacia auriculiformis- The adaptable tropical wattle. Nitrogen Fixing Tree Association (NFTA) Highlights. No. 87 - 03. 2 pp.

TURNBULL, J.W. \& KAMAS AWANG (1997) Acacia auriculiformis A. Cunn. ex Benth. In : Faridah Hanum, I \& van der Maesen, L.J.G. (Eds.): Plant Resources of South-East Asia No 11. Auxillary plants. Backhuys Publishers, Leiden, Netherlands. pp. 52 - 56.

UPHOF, J.C.Th. (1968) Dictionary of Economic Plants. Verlag von J. Cramer. 591 pp.

VANDE WEGHE, J.P. (2004) Fôrets d'Afrique Centrale, la nature et les hommes. Lannoo 367 pp.

VAN DEN ABEELE, M, \& VANDENPUT, R. (1956) Les Principales Cultures du Congo Belge. La direction de l'Agriculture, des Forêts et de l'Elevage, Ministère des Colonies, Bruxelles. 932 pp.

VAN DEN BELT, R.J. (1988) Cajanus cajan: It's more than just a pulse crop. Nitrogen Fixing Tree Association (NFTA) Highlights. No. 88 - 06. 2 pp.

VAN DER BURG, W.J. (2004) Asparagus flagellaris (Kunth) Baker. [Intemet] Record from PROTA4U. Grubben, G.J.H. \& Denton, O.A. (Eds.). PROTA (Plant Resources of Tropical Africa / Ressources 
végétales de l'Afrique tropicale), Wageningen, Netherlands.

VAN DER BURG, W.J. (2004) Commelina africanaL. [Internet] Record from PROTA4U. Grubben, G.J.H. \& Denton, O.A. (Eds.). PROTA (Plant Resources of Tropical Africa / Ressources végétales de l'Afrique tropicale), Wageningen, Netherlands.

VAN DER BURG, W.J. (2004) Costus phyllocephalus K.Schum. [I nternet] Record from PROTA4U. Grubben, G.J.H. \& Denton, O.A. (Eds.). PROTA (Plant Resources of Tropical Africa / Ressources végétales de l'Afrique tropicale), Wageningen, Netherlands.

VAN DER BURG, W.J. (2004) Dioscorea praehensilis Benth. [Internet] Record from PROTA4U. Grubben, G.J .H. \& Denton, O.A. (Eds.). PROTA (Plant Resources of Tropical Africa / Ressources végétales de l'Afrique tropicale), Wageningen, Netherlands.

VAN DER BURG, W.J. (2004) Ludwigia abyssinicaA.Rich. [I nternet] Record from PROTA4U. Grubben, G.J.H. \& Denton, O.A. (Editors). PROTA (Plant Resources of Tropical Africa / Ressources végétales de l'Afrique tropicale), Wageningen, Netherlands.

VAN DER VEKEN, P. (1960) Flore du Congo Belge et du Ruanda - Urundi : Anacardiaceae.

VAN EPENHUIJ SEN, C.W. (1974) La Culture des Légumes Indigènes au Nigéria. FAO. 113 pp.

VAN HARTEN, A.M. (1970) Melegueta pepper. Economic Botany24, 208 - 216.

VAN HOLTHOON, F.L. (1999) Phyllanthus amarusSchum. In de Padua, L.S., Bunyapraphatsara, N. \& Lemmens, R.H.M.J. (Eds.) Plant Resources of South-East Asia No 12 (1) Medicinal and poisonous plants 1. Backhuys Publishers, Leiden, Netherlands. pp. 387 - 388.

VAN VALKENBURG, J.L.C.H. \& BUNYAPRAPHATSARA, N. (Eds.)(2001) Plant Resources of South-East Asia No 12(2). Medicinal and poisonous plants 2. Backhuys Publishers, Leiden, Netherlands. $782 \mathrm{pp}$.

VAN VALKENBURG, J. \& DRANSFIELD, J. (2004) Hyphaene guineensis. Palms 48 (1) 10 - 16.

VAN WYK, B-E. (2005) Food Plants of the World. Briza publications. 480 pp.

VAN WYK, B-E., VAN OUTSHORN, B. \& GERICKE, N. (1997) Medicinal Plants of South Africa. Briza Publications, Pretoria. $304 \mathrm{pp}$.

VAN WYK, B-E. \& GERICKE, N. (2000) Peoples' Plants : A Guide to Useful Plants of Southern Africa. Briza Publications, Pretoria. $351 \mathrm{pp}$.

VAN WYK, B-E. \& VAN WYK, P. (1997) Field Guide to Trees of Southern Africa. Struik. 536 pp.

VAN WYK, B., VAN WYK, P. \& VAN WYK, B-E. (2000) Photographic Guide to Trees of South Africa. Briza Publications, Pretoria. $356 \mathrm{pp}$.

VAN WYK, B-E. \& WI NK, M. (2004) Medicinal Plants of the World. Briza Publications. 480 pp.

VAUGHAN, G. (2011) Cyperus papyrusL. [Internet] Record from PROTA4U. Brink, M. \& Achigan-Dako, E.G. (Eds.). PROTA (Plant Resources of Tropical Africa / Ressources végétales de l'Afrique tropicale), Wageningen, Netherlands.

VENTER, F. \& VENTER, J-A. (1996) Making the Most of Indigenous Trees. Briza Publications 305 pp.

VERDCOURT, B. (1963) Ipomoea involucrata. (Convolvulaceae) Flora of Tropical East Africa.

VERDCOURT, B. \& TRUMP, E.C. (1969) Common Poisonous Plants of East Africa. Collins. 254 pp.

VERHEIJ, E.W.M. \& CORONEL, R.E. (Eds.) (1991) Plant Resources of South East Asia (PROSEA). No. 2 Edible fruits and nuts. Backhuys Publishers, Leiden. $447 \mathrm{pp}$.

VERHEIJ, E.W.M. (2002) Dacryodes edulis (G.Don) H.J.Lam. [Internet] Record from PROTA4U. Oyen, L.P.A. \& Lemmens, R.H.M.J. (Eds.). PROTA (Plant Resources of Tropical Africa / Ressources végétales de l'Afrique tropicale), Wageningen, Netherlands.

VILLIERES, B. (1987) Le point sur l'apiculture; en Afrique tropicale. Groupe de Recherche et d'Exchanges Technologique. pp. 196 - 197.

VIVIEN, J. \& FAURE, J.J. (1988) Wild Fruit Trees of Cameroon. Original Title: Fruitiers sauvages du Cameroun. Fruits Paris. $416 \mathrm{pp}$.

VIVIEN, J. \& FAURE, J.J. (1996) Fruitiers Sauvage d'Afrique (espèces du Cameroun). Ministère français de la Coopération \& Centre Technique de Coopération Agricole et Rurale (CTA) 416 pp.

VON CARLOWITZ, P. G. \& WOLF, G.V. (1991) International Centre for Research in Agroforestry, Nairobi (Kenya) Potential and limitations of natural repellents against early destructive browsing by livestock and game 1991. (J) Agroforestry Systems Vol. 16 No. 1, pp. 33-40.

WAGNER, W.L., HERBST, D.R. and SOHMER, S.H. (1999) Manual of the Flowering Plants of Hawai't. Revised edition. University of Hawai'i Press, Honolulu. $644 \mathrm{pp}$.

WATT, J.M. \& BREYER- BRANDWIJ K, M.G. (1962) The Medicinal and Poisonous Plants of Southern and Eastern Africa. Livingstone. $1457 \mathrm{pp}$.

WHITE, F. (1978) Flora Zambesiaca Volume 4 Part: 0 Chrysobalanaceae

WHITE, F. (1987) Flore d'Afrique Centrale (Zaïre - Rwanda - Burundi): Ebenaceae

WHITE, L. \& ABERNETHY, K. (1997) A Guide to the Vegetation of the Lope Reserve, Gabon. Wildlife Conservation Society, New York 224 pp. 
WHITNEY, C.M. (1955) The Bermuda Garden. Garden Club of Bermuda.

WICKENS, G.E. (1975) Flora of Tropical East Africa : Melastomataceae

WI CKENS, G.E. (1982) The Baobab - Africa's upside-down tree. Kew bulletin 37 (2).

WI KI PEDI A website

WI LCZEK, R. (1958) Flore du Congo Belge et du Ruanda - Urundi : Linaceae

WI LCZEK, R. (1958) Flore du Congo Belge et du Ruanda - Urundi : Malphigiaceae

WI LCZEK, R. (1958) Flore du Congo Belge et du Ruanda - Urundi : Oxalidaceae

WI LCZEK, R. (1960) Flore du Congo Belge et du Ruanda - Urundi : Celastraceae

WI LCZEK, R. (1960) Flore du Congo Belge et du Ruanda - Urundi : Hippocrateaceae

WI LCZEK, R. (1963) Flore du Congo Belge et du Ruanda - Urundi : Tiliaceae

WILCZEK, R., LÉONARD, J., HAUMAN, L., HOYLE, A.C., STEYAERT, R., GI LBERT, G. \& BOUTIQUE, R. (1952) Flore du Congo Belge et du Ruanda - Urundi : Caesalpiniaceae.

WI LCZEK, R. \& SCHULZ正, G.M. (1960) Flore du Congo Belge et du Ruanda - Urundi : Balsaminaceae.

WI LD, H. (1965) The African species of the genus Melanthera Rohr. Kirkia 5 (J ournal of the Government Herbarium, Salisbury, Rhodesia)

WILKIN, P. (2001) Dioscoreaceae of South Central Africa. Kew Bulletin56:341 - 404 http://www.jstor.org/pss/4110963

WI LIAMS, R. O. (1949) The Useful and Ornamental Plants of Zanzibar and Pemba. Zanzibar Protectorate. $497 \mathrm{pp}$.

WILLIAMSON, J. (1975) Useful Plants of Malawi. University of Malawi, Zomba. 336 pp.

WI LSON, J.R.U., AJUONU, O., CENTER, T.D., HILL, M.P., JUUEN, M.H., KATAGIRA, F., NEUENSCHWANDER, P., NJOKA, S.W., OGWANG, J., REEDER, R.H. \& VAN, T. (2007) The decline of water hyacinth on Lake Victoria was due to biological control by Neochetina spp. Aquatic Botany, 87(1) 90 - 93.

WITT, A. \& LUKE, Q. (2019) Guide to the Naturalized and Invasive Plants of East Africa. CABI. 601 pp.

WORLD HEALTH ORGANIZATION (2012) Effectiveness of Non-Pharmaceutical Forms of Artemisia annua $L$. against Malaria. WHO Position Statement 4 pp.

WUSSOW J.R., URBATSCH, L.E., SULIIVAN G.A. (1985) Calea (Asteraceae) in Mexico and Jamaica. Systematic botany 10 (3) pp 241 - 267

ZIMUDZ, C. (2008) Adenia lobata (J acq.) Engl. In : Schmelzer, G.H. \& Gurib-Fakim, A. (Editors). Plant Resources of Tropical Africa 11(1). Medicinal plants 1. PROTA Foundation, Wageningen, Netherlands / Backhuys Publishers, Leiden, Netherlands / CTA, Wageningen, Netherlands. pp. 38 - 40

Z MUDZ, C. \& CARDON, D. (2005) Morinda lucida Benth. [I nternet] Record from PROTA4U. J ansen, P.C.M. \& Cardon, D. (Eds.). PROTA (Plant Resources of Tropical Africa / Ressources végétales de l'Afrique tropicale), Wageningen, Netherlands. 


\section{Glossaire}

\begin{tabular}{|c|c|}
\hline Adventice & Synonyme de "mauvaise herbe" \\
\hline Aisselle & $\begin{array}{l}\text { Emplacement au dessus de la base du pétiole d'une feuille, désigné par } \\
\text { l'angle que forme la tige et l'axe du pétiole. C'est dans cet emplacement que } \\
\text { naît un bourgeon. }\end{array}$ \\
\hline Axillaire & Naissant à la base d'une feuille. Organe axillaire. \\
\hline Bractée & $\begin{array}{l}\text { Feuille atrophiée sur les hampes florales ou feuille modifiée entre fleur et } \\
\text { feuille. }\end{array}$ \\
\hline Capsule & Fruit sec contenant plusieurs graines. \\
\hline Emétique & Qui fait vomir \\
\hline Etamine & Organe contenant ou portant le pollen. \\
\hline Glabre & Dépourvu de poils. \\
\hline Inflorescence & Partie florale de la plante. \\
\hline Lancéolé & En forme de fer de lance étroit et rétréci en pointe. \\
\hline Nodulation & Nœud - au niveau de l'insertion d'une feuille sur une tige. \\
\hline Ombelle & Inflorescence dont les pédoncules floraux sont tous issus d'un même point. \\
\hline Panicule & $\begin{array}{l}\text { Inflorescence dans laquelle les axes secondaires vont en décroissant de la } \\
\text { base au sommet. }\end{array}$ \\
\hline Pétiole & Partie inférieure de la feuille qui relie le limbe à la tige. \\
\hline Pédicelle & Petite tige portant une fleur ou plus généralement un organe. \\
\hline Pédoncule & Tige primaire ou axe de la hampe florale. \\
\hline Penné & Disposé de chaque côté d'un axe comme les barbes d'une plume. \\
\hline Phyllode & $\begin{array}{l}\text { Appareil foliacé constitué par le pétiole qui a été aplati et augmenté. Ex } \\
\text { plusieurs espèces d'Acacia }\end{array}$ \\
\hline Prostré & Couché sur le sol. \\
\hline Pubescent & Couvert de poils fins et courts. \\
\hline Racème & Inflorescence en forme de grappe. \\
\hline Racines adventives & Racines qui se développent sur la tige. \\
\hline Rhizome & $\begin{array}{l}\text { Tige souterraine ou affleurant généralement horizontale émettant des racines } \\
\text { et des tiges. }\end{array}$ \\
\hline Rhomboidal & En forme de losange. \\
\hline Scarification & $\begin{array}{l}\text { Se dit de l'action d'entailler l'épiderme d'une graine pour en activer la } \\
\text { germination une fois semée. }\end{array}$ \\
\hline Sessile & $\begin{array}{l}\text { Caractère d'une feuille, d'une fleur ou d'un organe dépourvu de tige et fixé } \\
\text { directement. }\end{array}$ \\
\hline Succulent & Se dit d'un organe charnu riche en eau. \\
\hline Tubercule & $\begin{array}{l}\text { Renflement souterrain de tige contenant des substances de réserve muni d'un } \\
\text { œil ou de plusieurs bourgeons. }\end{array}$ \\
\hline Verticille & Ensemble de pièces disposées en cercle autour d'un axe. \\
\hline Vivace & Plante qui vit plusieurs années. \\
\hline
\end{tabular}




\section{Index des photos générales}

Kalumba, Alphonse fabriquant un panier avec les tiges d'Eremospatha haullevilleana Couverture Village près de Mbanza Nzundu

Carte des districts de Cataractes \& Lukaya, Province du Kongo Central 7

Préparation de la terre pour la culture dans le district de Manianga 24

$\begin{array}{ll}\text { Erosion du sol } & 31\end{array}$

Quelques insectes comestibles $\quad 82$

Une pépinière à Kinsumbu village $\quad 83$

Un jeune charbonnier apprend le métier de son père 86

Un artisan avec un piège à rat sur la route du marché de Mbuba pour la vente 92

Culture de manioc après abattage de la forêt $\quad 95$

$\begin{array}{lr}\text { Un village du Kongo Central } & 105\end{array}$

$\begin{array}{lr}\text { Un potager en saison sèche } & 109\end{array}$

Enfants recueillant l'eau d'une source protégée $\quad 126$

Les jeunes arbres abattus pour le bois de chauffage empêchent le reboisement 144

Le bonheur dans les choses simples 183

Frère J ustin Gillet - une pancarte à l'entrée du jardin botanique de Kisantu 188

Avec les Nkunku qui commencent à revenir, le Nsimbiliki sont capturés avec un filet 203

Jachère forestière traditionnelle (nkunku) près du village de Mayenga 214

Le personnel du jardin botanique de Kisantu $\quad 258$

$\begin{array}{ll}\text { En route vers Kinshasa } & 277\end{array}$

$\begin{array}{ll}\text { Le vieux ferry à Luozi } & 277\end{array}$

$\begin{array}{ll}\text { Une forte colonie d'abeilles } & 297\end{array}$

Une ruche à barre supérieure à l'ombre d'un manguier 306

Un village dans le Manianga $\quad 330$

Un jeune producteur de charbon apprend le métier de son père $\quad 335$

Tata Nganga, instituteur et éleveur expert de chenilles, transférant des chenilles 337

Des gibiers de chauves-souris sont capturés et vendus comme nourriture 351

Des grillons (Nzenze) Brachytrupes membranaceus en vente 351

Peinture murale sur le mur de l'hôpital de Maluku $\quad 398$

Les enfants sont les principaux collectionneurs de chenilles $\quad 424$

Tartines d'igname vendus chauds au marché de Selembao 433

Les gens parcourront 20 à 30 km pour vendre des produits sur les marchés locaux 474

Papa Nsimba construit une maison à Kongo Central 495

Une maison construite à partir de la vente de miel $\quad 515$

L'insecte Nsingi nsingi, un ravageur majeur de Burkea africana $\quad 528$

Camions jouet fabriques par les enfants $\quad 535$

Viande de serpent $\quad 539$

Enfants préparant du manioc pour le repas du jour $\quad 544$

Des paquets d'Eremospatha haullevilleana en route vers le marché 600

Un groupe d'agriculteurs à Kinseki avec un lit de boutures ombragé $\quad 604$

Une charrue de bœuf labourant au Manianga $\quad 622$

Préparation de la « chikwangue » $\quad 629$

Les sachets qui servent à la plantation des arbres $\quad 631$

Boîte de capture avec un nouvel colonie d'abeilles 706 
Un commerçant transportant des tapis de couchage fabriqués à partir de Pandanus

candelabrum

Feux non contrôlés constituent un sérieux problème pour la régénération la jachère (Nkunku)

Chaise traditionnelle

815

Toiture d'une cuisine à Mbanza Zundu

829

Thérèse Luvuma, Paul Latham et $M$ et Mme Nganga à Kasangulu

838

Kaba ( Lobobunaea phaedusa) adult

840 


\section{Nom scientifique}

Achaea catocaloides

Acherontia atropus

Anaphe infracta

Anaphe panda

Anaphe reticulata

Anaphe sp.

Antheua sp.

Bunaea alcinoe

Cirina forda

Coeliades libeon

Cymothoe caenis

Daphnis nerii

Epidonta brunneomixta

Epidonta sp.

Gonimbrasia eblis

Gonimbrasia jamesoni

Haplozana nigrolineata

I mbrasia epimethea

Imbrasia obscura

Imbrasia truncata

Lobobunaea phaedusa

Micragone cana

Nudaurelia alopia

Nudaurelia anthina

Nudaurelia petiveri

Nudaurelia rectilineata

Nyodes pasinoides

Phalera sp.

Platysphinx stigmatica

Pseudobunaea sp.

Rhypopteryx poecilanthes

Samia ricini

\section{Nom en Kikongo}

Page

Minsangula

Munsona sona

N'kankiti

N'kankiti

Malombaloka

Makedi kedi

Ngala, n'kwati

N'boto

Nsani

Kindengula

Nsanga, mimbota bota,

mfundi

Kwesu

Minsendi

Nsindi, minsinda

Mvinsu, nvinsu

Minsendi

Mbambi

Kaba

Makuakua

Minsuka

Bisu

Minsendi

Miengeti

Munsona

Kaba

Nsongi

N'sani gata

Bata bata

Bidiaka

Biswangi, kiswangi

Bubu

Bubuta

Kelekele

Kiswangi

Masela

Matambungu

Mbwenge

Mbidi

Mbulunkutu

Mimpemba

Minkelele

Minsamba

Minsendi

Minsundi

Mukenga

Mumpemba

Mundele

Ndienga

Nkombo nseke

Nkulu (mfinda \& nseke)

N'kumbi

N'lombela

Nluti
$43,237,318,599,602$

237,513

126,127

$43,107,127,443,468$

127

$40,43,124-127$

510

$15,68,82,144,257,296,699,764$

$133,237,331,838$

513

568

669

$400,454,509$

$261,454,510,515$

$40,166,199,484,553$

14

$325,326,401$

$14,331,353,392,610,675,792$

$15,465,473,602$

$353,392,505,610,675$

$14,68,144,240,257,353,397,465,474,675,704$

722,826

760

$30,78,228,257,479,610,792$

$30,75,652$

$74,87,221,240,257,261,507,508,675,676,776$,

$792,825,826$

397

652

$465,509,517680$

$73,513,699$

722

756

677

115

377

377

760,762

221,825

568

509,510

145

487

$43,71,72,472,568,675$

$41,43,107,474,629,675,776$

$377,443,465,468,760,762$

126,128

656 
Nom en Kikongo

Nsanda

349

Nsanzungu

Nsatiti

704

Nsila

610,704

Nsinga

538,629

Nsungu ou Nsuangu

318

Nsyangi

574

Ntedi

834

Ntesi

346

Ntiti

513

Nziemo

704

Nziemode

465

Nziozu

465 
Biteko 652

Akeke (Lingala)

Alanganya (Lingala)

Alankagna (Lingala)

Ba di mabondo

Ba di madibu

Ba di magangu

Ba di magusu

Ba di masa

Ba di matombe

Ba di ndingi

Ba di ngasi

Ba di nkandi

Ba di nsamba

Ba di nseke

Ba kaziete

Badiandingi (Lingala)

Baimi (Lingala)

Baka nlele

Bampulukaka (Lingala)

Bana ba nzazi

Banga

Bangassu (Lingala)

Bangi (Lingala)

Bawu bawu

Bayombolo (Ngwaka)

Bekaie (Lingala)

Belezi

Bendo bendo

Biangala (Lingala)

Bigondie

Bikoke

Bikuku bi kiula

Bilembe (Tshiluba)

Bilikita

Bilikwita

Biloka loka (Lingala)

Bilolo (Lingala)

Bimongi

Bindiondi

Binsukula

Bionuda (Lingala)

Bisadi

Bisimba

Bitabe (Lingala)

Biteke
518

518

705

117

666, 705

661

248

664

117

311

202

311

Biteku teku (Lingala)

Biyoyo

243,619

Bobo

511

506

256

240

387

151

541

641

129

52,245

303

305

790

429, 726

161

520

589

647

148

713

575

386

324

525

548

633

519

751

752

826

826

619

728

820

491

728

58

289

Bofwole (Lingala)

Bognianga (Lingala)

Bokalaka (Lingala)

Bokamu (Lingala)

Bokana

Bokátola (Lingala)

477

514

26

36

50

390

390

315

246

50

596

790

625

78

625

161

554

36

161

270

596

269

26

154

68

391

103

548

377

647

207

201 
Index des noms communs

\section{Abalé} 610

Abricotier d'Afrique

477

Acacia

Acacia du Congo

601

Acalypha

Acerola

476

Adultery tree

100

Aerial yam

African arrowroot lily

African bitter yam

African black wood

African breadfruit

African crocus

African elemi

African false currant

African fan palm

African gladiolus

African greenheart

African jolanettle

African linden

African mammee apple

African milk bush

African milk tree

African moringa tree

African nightshade

African nutmeg

African pear

African potato

African rose wood

African satinwood

African teak

African tragacanth

African walnut

African winged bean

African yam bean

Aidan tree

Alamo vine

Alchornée fleurie

Allanblackia fat

Alui

Amarante

Amaranth

Ambay pumpwood

Ambravade
Ambrette

American joint vetch

Anacardier

Ananas

Anatto tree

Angel's trumpet

131

Angel's wings

135

Anglestem primrose willow

462

Ant tree

100

Apple mint

499

Arachide

79

Arachide de brousse $\quad 238$

Arbre à ail $\quad 708$

Arbre à calebasses $\quad 234$

Arbre à fourmis $\quad 100$

Arbre à pagaies $\quad 746$

Arbre à pain 85

Arbre à pain d'Afrique $\quad 790$

Arbre à pain indigène $\quad 541$

Arbre à pluie $\quad 45$

Arbre à semelles $\quad 601$

Arbre à soie 42

Arbre à tabatières $\quad 566$

Arbre candélabre $\quad 714$

Arbre corail $\quad 328$

Arbre de bonheur $\quad 178$

Arbre de feu $\quad 598$

Arbre du Cambodge $\quad 360$

Aristoloche 81

Armoise anuelle $\quad 83$

Arrow grass $\quad 789$

Arrowroot $\quad 486$

Asperge sauvage $\quad 88$

Asthma weed $\quad 342$

Attier $\quad 69$

Aubergine 733

Aubergine du diable $\quad 735$

Aubergine pois $\quad 735$

Avocado pear $\quad 608$

Avocatier 556,608

Avodiré 803

Badamier 775

Bahia grass $\quad 591$

Balai doux $\quad 707$

Balai poilu $\quad 724$

Balisier rouge $\quad 147$ 


\begin{tabular}{|c|c|}
\hline Balloon vine & 152 \\
\hline Balsamine & 409,410 \\
\hline Bambara groundnut & 820 \\
\hline Bamboo & 96 \\
\hline Bambou & 96 \\
\hline Banana, dessert & 536 \\
\hline Banane fruit & 536 \\
\hline Banane plantain & 536 \\
\hline $\begin{array}{l}\text { Bananier à fleurs } \\
\text { roses }\end{array}$ & 534 \\
\hline Bananier d'ornement & 534 \\
\hline Bancoulier & 48 \\
\hline Baobab & 23 \\
\hline Baquois & 584 \\
\hline Barbadine & 593 \\
\hline Barbados cherry & 476,606 \\
\hline Barbados lily & 390 \\
\hline Baselle & 102 \\
\hline Basilic & 556 \\
\hline Basilic africain & 557 \\
\hline Basket grass & 570 \\
\hline Baumier & 557 \\
\hline Bear's breeches & 19 \\
\hline Beef steak plant & 16 \\
\hline Bel de Calao & 81 \\
\hline Bell pepper & 149 \\
\hline Bellangère bâtarde & 735 \\
\hline Bellyache bush & 425 \\
\hline Ben ailé & 529 \\
\hline Beurre de bouandjo & 49 \\
\hline Bigaradier & 185 \\
\hline Bilihuete & 21 \\
\hline Bilinga & 543 \\
\hline Billy goat weed & 37 \\
\hline Billyweb sweetia & 21 \\
\hline Bird gooseberry & 393 \\
\hline Bissap & 389 \\
\hline Bitter gourd & 522 \\
\hline Bitter kola & 358 \\
\hline Bitter orange & 185 \\
\hline Bitterleaf & 814,817 \\
\hline Bixa & 112 \\
\hline Black benniseed & 719 \\
\hline Black catnip & 615 \\
\hline Blood root & 428 \\
\hline Bloodwood & 653 \\
\hline Blue trumpet vine & 787 \\
\hline
\end{tabular}

\begin{tabular}{|c|c|}
\hline $\begin{array}{l}\text { Blunt spurred ground } \\
\text { orchid }\end{array}$ & 337 \\
\hline Bois amer & 660,767 \\
\hline Bois d'or & 517,543 \\
\hline Bois de lait & 597 \\
\hline Bois de Quassia & 660 \\
\hline Bois de Suriname & 660 \\
\hline Bois horongue & 377 \\
\hline Bois noir & 512 \\
\hline Bois rouge & 332 \\
\hline Bois sacré & 767 \\
\hline Boleko oil & 569 \\
\hline Bombardier & 396 \\
\hline Boston fern & 548 \\
\hline Bottle gourd & 436 \\
\hline Bouandjo & 49 \\
\hline Boule de feu & 701 \\
\hline Boundary tree & 549 \\
\hline Bouton blanc & 55 \\
\hline Bowstring hemp & 696 \\
\hline Bracken & 652 \\
\hline Breadfruit & 85 \\
\hline Brède chevrette & 56 \\
\hline Brède mafane & 20 \\
\hline Brimstone tree & 526 \\
\hline Bristly starbur & 18 \\
\hline Broom cluster fig & 348 \\
\hline Broomweed & 723 \\
\hline Brown mustard & 120 \\
\hline Bubinga & 375 \\
\hline Budongo mahogany & 321 \\
\hline Buffalo grass & 585 \\
\hline Buffel grass & 721 \\
\hline Burrweed & 802 \\
\hline Bush mallow & 12 \\
\hline Bush morning glory & 417 \\
\hline Bush tea & 457 \\
\hline Bush tea bush & 407 \\
\hline Bush yam & 289 \\
\hline Butterfly pea & 164 \\
\hline Button grass & 520 \\
\hline Cacaoyer & 785 \\
\hline Café de la brousse & 574 \\
\hline Café puant & 715 \\
\hline Caféier robusta & 204 \\
\hline Caimite & 175 \\
\hline Caimito & 175 \\
\hline
\end{tabular}




\begin{tabular}{|c|c|c|c|}
\hline Cainitier & 175 & Chénopode vermifuge & 169 \\
\hline Cajou & 62 & Chien-dent & 411 \\
\hline Calabash & 436 & Chinese albizia & 42 \\
\hline Calabash tree & 234 & Chinese cabbage & 123 \\
\hline Calebasse & 436 & Chinese white & 122 \\
\hline Calico flower & 81 & cabbage & 198 \\
\hline Calliandra & 138 & Choculate veed & $\begin{array}{l}490 \\
832\end{array}$ \\
\hline Calopo & 140 & Chou caralbe & 832 \\
\hline \multirow{3}{*}{$\begin{array}{l}\text { Camel's foot tree } \\
\text { Cameroons gum } \\
\text { copal }\end{array}$} & 624 & Chou de Chine & 123 \\
\hline & \multirow{2}{*}{375} & Chou vert & 121 \\
\hline & & Chouchoute & 710 \\
\hline Camphor basil & 555 & Christmas bush & 46 \\
\hline Cananga oil & 143 & Christmas rose & 221,343 \\
\hline Candlenut tree & 48 & Christophine & 710 \\
\hline Cannabis & 148 & Chufa & 253 \\
\hline Canne à sucre & 691 & Ciboulette & 50 \\
\hline Cannelier de Ceylan & 178 & Cierge du Pérou & 165 \\
\hline Caoutchouc de Céara & 482 & Cinnamon & 178 \\
\hline Cape fig & 348 & Citronelle & 250 \\
\hline Cape gooseberry & 620 & Citronnier & 186 \\
\hline Caracasana & 340 & Citronnier d'Afrique & 835 \\
\hline Carambola & 91 & Clématite hirsute & 191 \\
\hline Carambolier & 91 & Clérodendron & 196 \\
\hline Cardamome sauvage & 32 & Climbing hemp weed & 506 \\
\hline $\begin{array}{l}\text { Caribbean copper } \\
\text { plant }\end{array}$ & 340 & $\begin{array}{l}\text { Climbing maidenhair } \\
\text { fern }\end{array}$ & 464 \\
\hline Cashew nut & 62 & Cluster yam & 288 \\
\hline Cassava & 480 & Coco plum & 174 \\
\hline Casse de Siam & 716 & Cocoa & 785 \\
\hline Castor oil & 677 & Coconut & 202 \\
\hline Cat's claw & 518 & Cocotier & 202 \\
\hline Cat's whiskers & 192 & Cocoyam, new & 832 \\
\hline Ceara rubber & 482 & Cour de boeuf & 67 \\
\hline Célosie argentée & 160 & Coffee senna & 715 \\
\hline Centro & 164 & Coffee, robusta & 204 \\
\hline $\begin{array}{l}\text { Chanvre de } \\
\text { Queensland }\end{array}$ & 725 & $\begin{array}{l}\text { Cogon grass } \\
\text { Common pheasant }\end{array}$ & 411 \\
\hline Chanvre de Guinée & 387 & $\begin{array}{l}\text { Common pheasant } \\
\text { berry }\end{array}$ & 489 \\
\hline $\begin{array}{l}\text { Chanvre, chanvre } \\
\text { indien }\end{array}$ & 148 & Concombre amer & 243 \\
\hline Chapeau de & & Confiture & 352 \\
\hline Monseigneur & 104 & Congo jute & 808 \\
\hline Chapeau de Napoléon & 155 & Conophor nut & 777 \\
\hline Charcoal tree & 792 & Copalier & 375 \\
\hline $\begin{array}{l}\text { Chardon de } \\
\text { montagne }\end{array}$ & 19 & Copper leaf & 16 \\
\hline Chayote & 710 & Coral creeper & 76 \\
\hline Chêne argenté & 374 & Cork wood tree & 675 \\
\hline Chêne d'Afrique & 507 & Corossol & 67 \\
\hline & & Corossol épineux & 67 \\
\hline
\end{tabular}




\begin{tabular}{|c|c|}
\hline Cosmos & 225 \\
\hline Cotonnier & 372 \\
\hline Country mallow & 12 \\
\hline Courge & 244 \\
\hline Courge éponge & 463 \\
\hline Cow foot leaf & 627 \\
\hline Cowpea & 821 \\
\hline Crab nut & 151 \\
\hline Creeping ox-eye & 740 \\
\hline Crenate orchid cactus & 322 \\
\hline Cresson de Para & 20 \\
\hline Croc de chien & 726 \\
\hline Cucolie écarlate & 316 \\
\hline Curare & 754 \\
\hline Dabema & 628 \\
\hline Dartrier & 713 \\
\hline Dattier sauvage & 614 \\
\hline Démoulai à gros fruits & 623 \\
\hline Dentelaire de Ceylan & 637 \\
\hline Devil bean & 238 \\
\hline Devil's trumpet & 264 \\
\hline Djimbo & 477 \\
\hline Dolique mongette & 821 \\
\hline Dragon tree & 302 \\
\hline Dragonnier & 302,305 \\
\hline Dutchman's pipe & 81 \\
\hline Dwarf copperleaf & 56 \\
\hline Dwarf Dracaena & 303 \\
\hline Dwarf mobola plum & 588 \\
\hline $\begin{array}{l}\text { Dwarf savanna ginger } \\
\text { lily }\end{array}$ & 229 \\
\hline Ebam & 623 \\
\hline Egg plant & 733 \\
\hline Egyptian cotton & 372 \\
\hline Elderberry & 694 \\
\hline Elemier d'Afrique & 145 \\
\hline Elengieye & 172 \\
\hline Elephant apple & 284 \\
\hline Elephant grass & 162 \\
\hline Elephant's ear & 135 \\
\hline Emilie & 316 \\
\hline Engrais vert & 788 \\
\hline Épinard Indien & 102 \\
\hline Épinard sauvage & 621 \\
\hline Éponge végétale & 463 \\
\hline Eru & 37 \\
\hline Erun & 33 \\
\hline
\end{tabular}

\begin{tabular}{|c|c|}
\hline Ethiopian mustard & 119 \\
\hline Eucayptus & 334 \\
\hline Euphorbe bicolore & 341 \\
\hline Euphorbe candélabre & 339 \\
\hline Euphorbe effilée & 344 \\
\hline False assegai & 469 \\
\hline False bougainvillea & 221 \\
\hline False mangosteen & 360 \\
\hline False nutmeg & 656 \\
\hline False roselle & 386 \\
\hline False rubber tree & 353,392 \\
\hline Fausse oseille & 389 \\
\hline $\begin{array}{l}\text { Fausse oseille de } \\
\text { Guinée }\end{array}$ & 38 \\
\hline Fausse tomate & 731 \\
\hline Faux baobab & 432 \\
\hline Faux goyavier & 646 \\
\hline Faux I péca & 649 \\
\hline Faux muscadier & 524,656 \\
\hline Faux noix muscade & 525 \\
\hline Feu de Dieu & 635 \\
\hline Figuier de Barbarie & 571 \\
\hline Finger Euphorbia & 344 \\
\hline Finger tree & 344 \\
\hline Fire bush & 376 \\
\hline Fire-ball lily & 116,701 \\
\hline Fish poison bean & 773 \\
\hline Flamboyant & 266 \\
\hline Flamboyant de l'Inde & 597 \\
\hline Flamboyant jaune & 597 \\
\hline Flax lily & 274 \\
\hline Fleabane & 324 \\
\hline Flowering banana & 534 \\
\hline Forest anchomanes & 64 \\
\hline Forest crinum & 235 \\
\hline Forest fever berny & 241 \\
\hline Forest mobola plum & 589 \\
\hline Forest sandpaper fig & 345 \\
\hline Forest yam & 289 \\
\hline Fougère & 652 \\
\hline Foxglove orchid & 337 \\
\hline Fragrant Dracaena & 304 \\
\hline Fraké & 776 \\
\hline Frangipani & 638 \\
\hline Frangipanier & 638 \\
\hline French bean & 612 \\
\hline Fromager & 158 \\
\hline
\end{tabular}


Fruit miracle

Galinsoga à petites fleurs

Gallant soldier

Ganges primrose

Garden balsam

Gardenia mâle

Garlic plant

Gboma egg plant

Giant leaved fig

Giant yellow mulberry

Gingembre

Ginger

Ginger bush

Ginger lily

Glaïeul africain

Glorieuse

Gloriosa lily

Glory bower vine

Gmelina

Golden dewdrop

Golden shower

Gombo

Gombo musqué

Goose grass

Goyavier

Goyavier acide

Grand sureau

Grande igname

Grassé

Grattelier

Greater yam

Grenadier

Grenadille

Gros baume

Groseille africane

Groseiller des

Barbades

Groseiller du Cap

Ground pineapple

Groundnut

Guatemala grass

Guava

Guinea grass

Guinea guava

Guinea hemp

Gynandro
Haricot de Lima

Haricot igname Africain

Haricot kunde

Haricot vert

Heart-leaf Sida

Hedge cactus

Hemp

Herb dure

Herbe à balai

Herbe à chapelets

Herbe à couleuvre

Herbe à couteau

Herbe à elephant

Herbe à marconnet

Herbe à Nicot

Herbe à paniers

Herbe au chagrin

Herbe au sorciers

Herbe caille

Herbe de Guinée

Herbe du diable

Herbe palissade

Herbe papillon

Herbe roulante

Herbe savane

Herbe sensbile

Hévéa

Hispid starbur

Hoffe

Hog plum

Hogweed

Holarrhene

Hophead

Hornbills calabash

Horn-pod tree

Horse scarer

Horseradish tree

Hot pepper

Hydrocotyle

I boga

Icaquier

Ice-cream bean tree

Igname amère

Igname de brousse

Impatient

Indian almond
611

741

821

612

724

165

148

725

498

208

605

674

162

739

550

570,724

615

37

797

585

265

118

384

116

18

519

385

18

287

743

115

392

99

473

296

116

529

150

163

767

174

414

288

289

409

775 


\begin{tabular}{|c|c|}
\hline Indian heliotrope & 384 \\
\hline Indian mustard & 120 \\
\hline Indian pennywort & 163 \\
\hline Indian plum & 352 \\
\hline Indian shot & 147 \\
\hline Indian walnut & 48 \\
\hline Indian wormseed & 169 \\
\hline Inga & 414 \\
\hline Iroko & 507 \\
\hline Isano oil & 569 \\
\hline I voire végétal & 705 \\
\hline J acinthe d'eau & 310 \\
\hline Jackfruit & 87 \\
\hline J acquier & 87 \\
\hline Jambolan & 759 \\
\hline Jambosier & 763 \\
\hline Jambosier rouge & 764 \\
\hline Jamelonier & 759 \\
\hline $\begin{array}{l}\text { Japanese bunching } \\
\text { onion }\end{array}$ & 50 \\
\hline Japanese poinsettia & 597 \\
\hline Java brucea & 130 \\
\hline Jew's mallow & 224 \\
\hline J imson weed & 265 \\
\hline Job's tears & 208 \\
\hline Joint vetch & 95 \\
\hline J onc vulgaire & 252 \\
\hline Jussie & 465 \\
\hline Kalahari pod berry & 272 \\
\hline Kale & 121 \\
\hline Kambala & 507 \\
\hline Kangkong & 415 \\
\hline Kapok & 158 \\
\hline Kapokier & 158 \\
\hline Karamanni wax & 756 \\
\hline Kénaf & 387 \\
\hline Kew weed & 356 \\
\hline Kimba pepper & 833 \\
\hline Knife grass & 674 \\
\hline Koko & 371 \\
\hline Kola & 209 \\
\hline Kolatier & 209 \\
\hline Koro & 825 \\
\hline Kudzu tropicale & 654 \\
\hline Kwango giant cycad & 317 \\
\hline Lagos spinach & 160 \\
\hline Langue de femme & 44 \\
\hline
\end{tabular}

Lantana $\quad 445$

Larmes de J ob 208

Larmilles 208

Laurier d'Afrique $\quad 361$

Lemon $\quad 186$

Lemon grass 250

$\begin{array}{ll}\text { Lesser forest fever } & 71\end{array}$

Liane à eau $\quad 778$

Liane à hameçons $\quad 806$

Liane aurore $\quad 658$

Liane corail 76

Liane de Kisanji $\quad 540$

Lilas de Perse 494

Lilas des Indes $\quad 437$

Lima bean $\quad 611$

Limba $\quad 776$

Limbali $\quad 363$

Lime $\quad 184$

Limettier $\quad 184$

Lion's tail $\quad 450$

Lis grimpant $\quad 366$

Lis rouge $\quad 390$

Litchi chevelu $\quad 546$

Livingstone potato 633

Logwood $\quad 426$

Loofah 463

Lucky bean 11

Macabo 832

Mackay bean $\quad 319$

Madagascar $\quad 156$

periwinkle

Madamé 775

Madras thorn $\quad 630$

Magic rope 563

Magloire 56

Mais 837

Maize 837

Malabar spinach $\quad 102$

Malay apple $\quad 764$

Malnommée 342

Mangium

Mango $\quad 478$

Mangosteen $\quad 359$

Mangoustanier $\quad 359$

Manguier $\quad 478$

Manguier sauvage $\quad 589$ 
Muscadier de 525

Manioc

480,849

Manioc

Manioc caoutchouc

Manioc de lièvre

Mauve des champs

Mexican shrubby

Mother-in-law's tongue

$$
\text { calabash }
$$

Muscadier du Gabon

Musk mallow

Napier grass 162

Neem 93

Neflier de Costa Rica $\quad 104$

Nénuphar $\quad 552$

Never-die 430

Néverdié 529

New cocoyam 832

Niando 47

Niébe 821

Nipple fruit $\quad 728$

Node weed 757

Noisette 230

Noix des Indes $\quad 48$

Northern black wattle 13

Noyer d'Afrique 460

Noyer d'Amerique $\quad 576$

Obéro 623

Oboto 477

Oil bean tree $\quad 601$

Oil palm 311

Okra 8

Old maid 364

Old woman's tears 393

Olon dur 835

Oplismène à poils 570

$$
\text { courts }
$$

$\begin{array}{ll}\text { Orange, sweet } & 187 \\ \text { Oranger amer } & 185\end{array}$

Oranger doux $\quad 187$

Ordeal tree 237,332

Oseille 9

Oseille chinoise 684

Oseille de Guinée $\quad 389$

Oseille indigene $\quad 387$

Ostrich plume 53

Otaheiti apple 742

Owala 601

Pain de singe 23

Pakchoi 122

Palette de peintre $\quad 135$

Palissandre d'Afrique 73

Palmier à huile $\quad 311$ 


\begin{tabular}{|c|c|c|c|}
\hline Palmier raphia & 661,664 & Pois cajan & 134 \\
\hline Palmier-rotin & 434 & Pois d'Angole & 134 \\
\hline Pap leaf & 613 & Pois de Coeur & 152 \\
\hline Papayer & 153 & Pois de terre & 820 \\
\hline Paprika pepper & 149 & Pois mascate & 531 \\
\hline Papyrus & 254 & Pois pouilleux & 531 \\
\hline Pâquerette chocolat & 89 & Pois quénique & 529 \\
\hline Para rubber & 385 & Pois sabre & 146 \\
\hline Paraguay burr & 17 & Pois sucré & 414 \\
\hline Parasolier & 538 & Poison d'épreuve & 332 \\
\hline Paspalum & 591 & Poivre & 625,626 \\
\hline Pastèque & 182 & Poivre de Cayenne & 150 \\
\hline Patate douce & 416 & Poivre de Guinée & 33 \\
\hline Pawpaw & 153 & Poivrier & 626 \\
\hline Pea eggplant & 735 & Poivrier de Guinée & 833 \\
\hline Pepermint & 500 & Poivron & 149 \\
\hline Pépéromie & 605 & Pole bean & 612 \\
\hline Pepper & 626 & Pomegranate & 655 \\
\hline Pepper elder & 605 & Pomme cajou & 62 \\
\hline Persian lilac & 494 & Pomme cannelle & 69 \\
\hline Pervenche de & 156 & Pomme de Cythère & 742 \\
\hline $\begin{array}{l}\text { Madagascar } \\
\text { Petit kola }\end{array}$ & 358 & Pomme en l'air & 287 \\
\hline Physic nut & 4230 & Pomme épineuse & 265 \\
\hline Pied de boeuf & 624 & Pomme surette & 175 \\
\hline Pied de poule & 374 & Pommier de Malaisie & 764 \\
\hline Pigeon bemy & $\begin{array}{r}314 \\
308679\end{array}$ & Pommier rose & 763 \\
\hline Pigeon nea & $\begin{array}{r}300,0 / 9 \\
134\end{array}$ & Pommier-rose & 763 \\
\hline Pigeon pea & 134 & Pompon de Marin & 139 \\
\hline Pilipili (Lingala) & 150 & Poor man's candle & 154 \\
\hline Piment & 149 & Pop-corn senna & 714 \\
\hline Piment capsique & 150 & Pop-gun tree & 747 \\
\hline Pineapple & 63 & Potato yam & 287 \\
\hline Pink cone ginger & 53 & Pourghère & 423 \\
\hline Pink tassel berry & 74 & Pourghère rouge & 425 \\
\hline Pink tassel flower & 139 & Pourpier & 640 \\
\hline Piquant blanc & 356 & Pourpier indigène & 364 \\
\hline Pissenlit & 231 & Prickly pear & 571 \\
\hline Plantain bananas & 536 & Pride of India & 437 \\
\hline Plante crayon & 344 & Prune noire & 825 \\
\hline Plante zigzag & 597 & Prunier d'Inde & 352 \\
\hline Pluie d'or & 658 & Prunier des Andes & 174 \\
\hline Plumbago & 636 & Prunier Mombin & 743 \\
\hline Poil à gratter & 198,531 & Pumpkin & 244 \\
\hline Poilu & 546 & Purple lantana & 446 \\
\hline Poinsettia & 343 & Purslane & 640 \\
\hline Pointe noire & 122 & Quassia wood & 660 \\
\hline Pois bâtard & 164 & & \\
\hline
\end{tabular}




\begin{tabular}{|c|c|}
\hline Queen of the night & 165 \\
\hline Queensland hemp & 725 \\
\hline Queue de lion & 450 \\
\hline Quinine de Cayenne & 660 \\
\hline Raffia palm & 661,664 \\
\hline Rain tree & 45 \\
\hline Raisinier des bois & 471 \\
\hline Ramboutan & 546 \\
\hline Rambutan & 546 \\
\hline Rat's tail & 745 \\
\hline Rattan & 136,323 \\
\hline Rattan, Large & 434 \\
\hline Rattle box & 238 \\
\hline Red flowered ragleaf & 231 \\
\hline Red ginger & 53 \\
\hline Red water tree & 332 \\
\hline Red-hot poker tree & 328 \\
\hline $\begin{array}{l}\text { Renouée à feuilles de } \\
\text { saule }\end{array}$ & 609 \\
\hline Resurrection plant & 431 \\
\hline Rice & 572 \\
\hline Ricin & 677 \\
\hline Rikio & 805 \\
\hline Ring-worm bush & 713 \\
\hline River bean & 720 \\
\hline Riz & 572 \\
\hline Robusta coffee & 204 \\
\hline Rocouyer & 112 \\
\hline Rônier & 117 \\
\hline Rose balsam & 409 \\
\hline Rose cactus & 607 \\
\hline Rose de Jéricho & 503 \\
\hline Rose de Noel & 343 \\
\hline Roselle & 389 \\
\hline Rotin & 136,323 \\
\hline Sablier & 396 \\
\hline Sacred wood & 767 \\
\hline Safoutier & 256 \\
\hline Safran des Indes & 246 \\
\hline Saman & 45 \\
\hline Sand box tree & 396 \\
\hline Sanguinaria & 428 \\
\hline Sansévière & 695,696 \\
\hline Sassy bark & 332 \\
\hline Saucissonnier & 432 \\
\hline Sausage tree & 432 \\
\hline Savanna gooseberny & 540 \\
\hline
\end{tabular}

Scarlet bush 375

Scarlet eggplant $\quad 728$

Scarlet fire spike $\quad 558$

Screw pine, common $\quad 584$

Sea island cotton $\quad 372$

Séné africain 714

Sésame 718

Sessile joy weed 56

Seville orange $\quad 185$

Siam weed $\quad 172$

Siamese cassia $\quad 716$

Sickle bush 280

Sida à feuilles en $\quad 724$

Signal grass $\quad 118$

Silk cotton tree $\quad 158$

Silk rubber 353

Simsim 718

Slender star lily 405

Snake bush 99

Snuff-box tree 566

Soap tree 818

Soja 368

Sonnettes 238

Sorgho 737

Sorghum 737

Souchet à papier 254

Souchet comestible 253

Soursop 67

South African tree 248

fern 368

Spanish needles $\quad 111$

Spider plant 192

Spider tresses $\quad 751$

Spiral ginger 226

Splendid Oncidium 794

Spreading dayflower 223

Squash 244

Star apple $\quad 175$

Star fruit $\quad 91$

Starbur 17

Stinkwood tree 610

Striga 715

Stylo 755

Sugar apple 69

Sugar cane $\quad 691$ 


\begin{tabular}{|c|c|}
\hline Sugar plum & 805 \\
\hline Sukuma wiki & 121 \\
\hline Sunflower & 382 \\
\hline Sunset hibiscus & 9 \\
\hline Sureau & 694 \\
\hline Sureau noir & 694 \\
\hline Swamp arum & 448 \\
\hline Swamp lily & 235 \\
\hline Swamp morning glory & 415 \\
\hline Sweet Annie & 83 \\
\hline Sweet basil & 556 \\
\hline Sweet broom weed & 707 \\
\hline Sweet pepper & 149 \\
\hline Sweet potato & 416 \\
\hline Sweet wormwood & 83 \\
\hline $\begin{array}{l}\text { Sweet-scented } \\
\text { Dracaena }\end{array}$ & 304 \\
\hline Sweetsop & 69 \\
\hline Sword bean & 146 \\
\hline Sword fern & 548 \\
\hline Tabac & 550 \\
\hline Tabasco pepper & 150 \\
\hline Tamarind & 770 \\
\hline Tamarinier & 770 \\
\hline Tannia & 832 \\
\hline Taro & 213 \\
\hline Tête de cochon & 732 \\
\hline Thick head & 231 \\
\hline Thorn apple & 265 \\
\hline Tiama blanc & 321 \\
\hline Tiger nut & 253 \\
\hline Tilleul d'Afrique & 521 \\
\hline Tobacco & 550 \\
\hline Tobasco pepper & 150 \\
\hline Tomate & 729 \\
\hline Tomate amère & 728 \\
\hline Tomate en arbre & 255 \\
\hline Tomatillo & 255 \\
\hline Tomato & 729 \\
\hline Toothache plant & 20 \\
\hline Tournesol & 382 \\
\hline Tournesol mexicain & 788 \\
\hline Tree basil & 557 \\
\hline Tree cassava & 482 \\
\hline Tree tomato & 255 \\
\hline Trente six oiseaux & 264 \\
\hline Tridax couché & 797 \\
\hline
\end{tabular}

$\begin{array}{ll}\text { Trompette de la mort } & 264 \\ \text { Trompette des anges } & 131 \\ \text { Trompette du diable } & 264 \\ \text { Tropical button weed } & 285 \\ \text { Tropical chickweed } & 307 \\ \text { Tropical kudzu } & 654\end{array}$

Tsana 113

Tulip tree 738

Tulipier du Gabon $\quad 738$

Tumbleweed $\quad 116$

Turmeric 246

Uenge (Lingala) $\quad 784$

Umbrella dracaena $\quad 274$

Umbrella tree $\quad 538$

Vacoa 584

Vaquois $\quad 584$

Vegetable pear $\quad 710$

Vegetable sponge $\quad 463$

Vegetable tallow tree $\quad 49$

Velvet bean 531

Velvet tree $\quad 504$

Verveine du Congo $\quad 457$

Vigne en caoutchouc $\quad 687$

Vine spinach $\quad 102$

Violet tree $\quad 711$

Voacanga d'Afrique $\quad 827$

Voacanga de Thouars $\quad 828$

Voandzou $\quad 820$

Wandering J ew 222,223

Water hyacinth $\quad 310$

Water lily $\quad 552$

Water primrose $\quad 461$

Water spinach $\quad 415$

Water tree $\quad 778$

Water yam 286

Water-berry 760

Waterleaf 769

Watermelon $\quad 182$

Welsh onion 50

Wenge 512

West African
boxwood

West African 124

West African
sarsaparilla

West African aloe $\quad 52$ 


\begin{tabular}{|c|c|}
\hline $\begin{array}{l}\text { West African black } \\
\text { pepper }\end{array}$ & 625 \\
\hline West African pepper & 833 \\
\hline West African plum & 825 \\
\hline West Indian holly & 449 \\
\hline White ball rubber & 440 \\
\hline White bottlebrush & 492 \\
\hline White buttons & 55 \\
\hline White candles & 831 \\
\hline White ginger & 37 \\
\hline White plumbago & 637 \\
\hline White rubber vine & 44 \\
\hline Wild asparagus & 58 \\
\hline Wild canna lily & 147 \\
\hline Wild cardamom & \\
\hline Wild custard apple & 68 \\
\hline Wild date palm & 614 \\
\hline Wild frangipani & 828 \\
\hline Wild poinsettia & 216,341 \\
\hline Wild rubber & 296 \\
\hline Wild Seringa & 133 \\
\hline Wild yam & 290 \\
\hline Willow weed & 609 \\
\hline Winged yam & 286 \\
\hline Wire grass & 314 \\
\hline Witches bean cake & 198 \\
\hline Woman's tongue tree & \\
\hline Wood rose & 503 \\
\hline Woodland croton & 241 \\
\hline Wulo & 7 \\
\hline Yellow bauhinia & 10 \\
\hline Yellow cassia & 71 \\
\hline Yellow commelina & 22 \\
\hline Yellow flame tree & 597 \\
\hline Yellow nut grass & 25 \\
\hline Yellow oleander & 15 \\
\hline Yellow passion fruit & 59 \\
\hline Yellow sorrel & 57 \\
\hline Yellow swamp orchid & 3. \\
\hline Yellow tassel flower & 3 \\
\hline Yellow trumpet tree & \\
\hline Ylang-ylang & \\
\hline Yoruba soft cane & 488 \\
\hline
\end{tabular}


Bosake

Bosanza (Lingala)

Bosasobe (Lingala)

Boso boso

Bossu (Lingala)

Bota masa

Botsimansombo (Lingala)

Botuko (Lingala)

Boussaka (Lingala)

Bovemba zombo (Lingala)

Bowa di nsende

Bu

Bubu

Bubwaka

Bubwaka bwaka

Buditu

Bufwa ngudi

Bukutukutu

Bula nima

Bulongo

Bulukutu

Bulukutu chinois

Bumuengi

Bunda bunda

Bundi nguma (Kiyaka)

Bundolo

Bungo (Swahili)

Bunguni

Bunkanga

Bunsambi

Bunzi

Bwalu

Bwalu ma nkusu

Bwalu ma nsende

Bwalu mabundu

Bwati

Bwati mfinda

Bwenzonda (Lingala)

Deso

Deso mangongo

Diamba

Diamba di nseke

Dibata bata

Dibimbi di muaka nungu

Didiya

Difuelenta
Dikedi (Lingala)

$$
\text { Dikuku }
$$

Diladila

484

Dilendila

Dimbu dingi

477

Dimbulu

441

Dimpemba mpemba

634

Dimputu

687

184

491

555

197

808

808

499,557

Dinkondi

Dinkondo di ngala

536

531

438

438,440

614

614

557

557

267,269

64

$245,301,405$$$
\text { Dioko dingumbi }
$$

645

442

608

185

185

556

Dizulu 


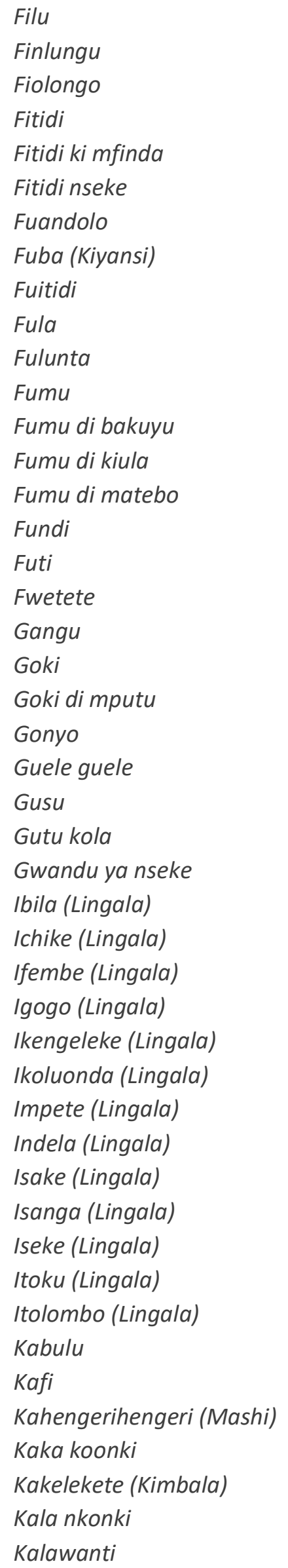

\begin{tabular}{|c|c|}
\hline 824 & Kalunga (Lingala) \\
\hline 824 & Kanga miese \\
\hline 824,825 & Kanga nzo \\
\hline $74,75,472$ & Kangeni \\
\hline 74 & Kangiya \\
\hline 75 & Kansingo \\
\hline 429 & Kapidi \\
\hline 650 & Kapunga punga (Tshiluba) \\
\hline 75 & Kasal-kangai (Kiluba) \\
\hline 265,715 & Kassa kassa \\
\hline 645 & Kasu \\
\hline 550 & Kasuwa \\
\hline 324 & Katalanga \\
\hline 324 & Kaya \\
\hline 324 & Kekansu \\
\hline 514 & Kekele (Lingala) \\
\hline 319,454 & Kembela \\
\hline 82,497 & Kenge \\
\hline 705 & Kiaka \\
\hline 442 & Kialakoko \\
\hline 592 & Kiangu \\
\hline 77 & Kibanda banda \\
\hline 769 & Kibofula \\
\hline 372 & Kiboto \\
\hline 163 & Kibulu \\
\hline 326 & Kibunsi \\
\hline 410 & Kibunsila \\
\hline 505 & Kibwa \\
\hline 807 & Kibwa mpimbidi \\
\hline 511 & Kidia nuni \\
\hline 399 & Kidiadi \\
\hline 725 & Kidianga \\
\hline 28,810 & Kidimbi \\
\hline 807 & Kidimbi ki nseke \\
\hline 810 & Kidimbu \\
\hline 413 & Kidiokodioko \\
\hline 505 & Kidisa \\
\hline 290 & Kidoka doka \\
\hline 627 & Kienga \\
\hline 174 & Kienga ki masa \\
\hline 204 & Kiese kiese \\
\hline 393 & Kifilu \\
\hline 429 & Kifilungu \\
\hline 294 & Kifitidi \\
\hline 753 & Kifitidi di nseke \\
\hline 25 & Kifubu \\
\hline
\end{tabular}




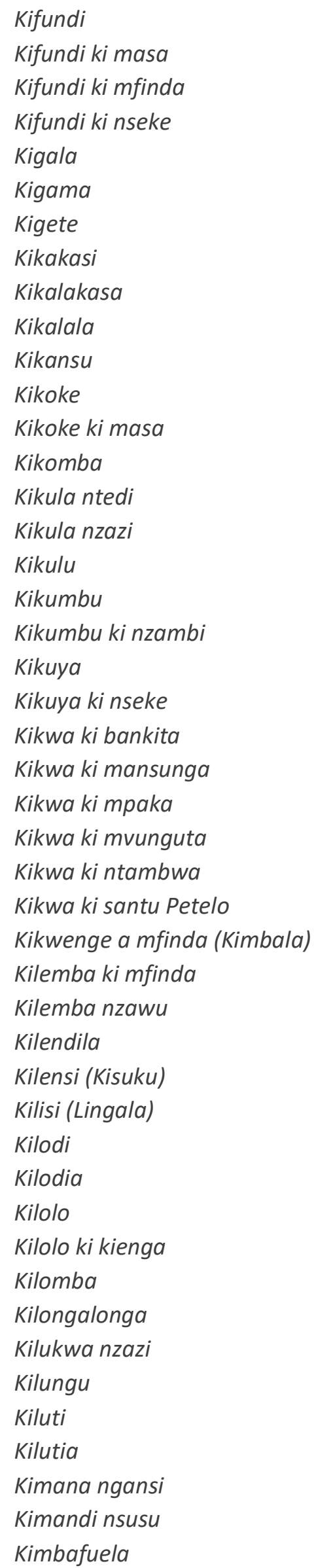

$260,454,514$

515

263

$259,261,262$

237

279

397

63

647

726

364

518

806

671,672

342

339

760

328

328

345

779

64

286

290

416

245

85

754

627

361

483

170

269

448

448

68,698

698

656

552

220

668, 669

363

73

111

727

649
Kimbaki

353

314

561

523

354

168,354

739

739

527

337

519

239

307

798

12

124,127

124

127

125

127

179

196

366

619

249,348

56

675

721

473

473

9, 10

246

301

198,199

451

380

324

51

32

802

489

$447,728,734$

447

458 
Kinsungu

Kinsungwa

Kintamba

Kintudi nimi

Kinuani (Kimbala)

Kinwani

Kinzala

Kinzenze

Kinzonzi

Kipapa (Tshiluba)

Kisadi

Kisadila

Kisakamba

Kisamfi

Kisani

Kisania

Kiseka

Kisele sele

Kisesa

Kisiamuna

Kisiele siele

Kisielele

Kisilu

Kisima

Kisokosoko

Kisola nkata

Kisongi

Kisu

Kisudi ki nkandi

Kisuku

Kisunsa

Kisyamuna

Kisyamuta

Kitete mbika

Kititi

Kitoko

Kitundibila

Kituntu

Kituntu ki nkadi

Kituti

Kityokolo

Kivinsu

Kiwandu ki mfinda

Kiwandu ki nseke

Kiwaya

Kiwenga ndumbu
574

574

301

107

408

795

388

392

545,685

35

289, 291

739

206

78

567

567

599

485

166

452

485

652

395

357

648

464

756

686

590

793

819

451

451

199

704

515

30

156

788

793

448

610

792

326

394, 559, 708

674
Kiziazi

778

780

739

95

519

661

172

109

378

Kolo di munsala

Kombi (Lingala)

Kombi kombi

Kombu kombu

369, 389

147

260

338

337

527

449

113

552

419

559

270

751

802

747

747

342

342

169, 696

77

789

404

656

82

626

422

506

130

443

222

187

186

186

187

187

445

213,832 


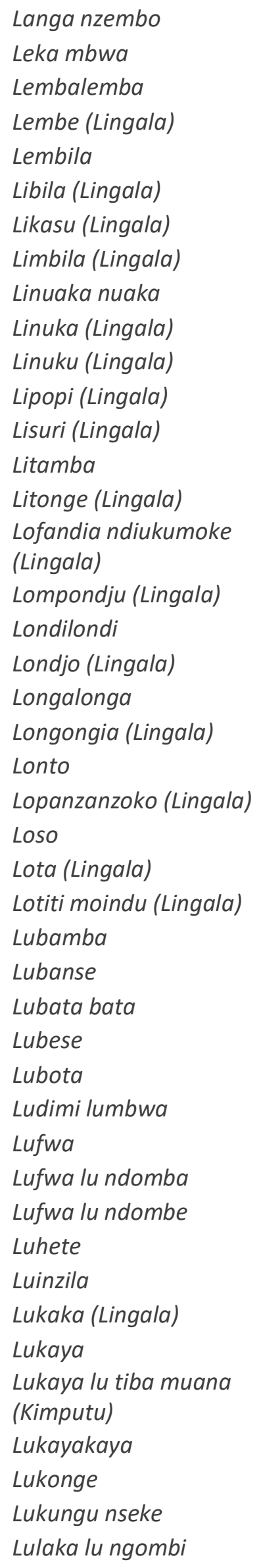

$\begin{array}{lll}390 & \text { Lulongu } & 521 \\ 497 & \text { Lumantu } & 729 \\ 129 & \text { Lumbabikwa (Kimbala) } & 422 \\ 715 & \text { Lumbalumba (Lingala) } & 557 \\ 247 & \text { Lumbusu } & 522 \\ 311 & \text { Lumiengi } & 312 \\ 209 & \text { Lumpokopoko } & 634\end{array}$

311 Lumvumvu 723, 725, 845

$715 \quad$ Lunama 269

$463 \quad$ Lundala ndala 160

$671 \quad$ Lungwila 691

769 Lunioka nioka 696

$270 \quad$ Lunsambisambi 639

369 Lunsu 586

438, 439, $442 \quad$ Lunwumu lu nseke 634

$672 \quad$ Lunzila nzila 268, 702

Lupunga 801

$564 \quad$ Lupungala 801

440 Lusaku saku 252

241 Lusangu sangu 251

$552 \quad$ Lutete 406

371 Lutumbula 845

$8 \quad$ Luyuki 431

671 Luyukiyuki 431

572 Luziezie 325,326

338 M'baka (Lingala) 113, 375

$808 \quad$ M'bila-na-mabele (Lingala) 786

$323 \quad$ M'vanzifioti 599

$381 \quad$ M'vula 430

229 Maba ma masa 248

587 Mabama yange (Teke) 459

517 Mabondo 705

383, $594 \quad$ Mabusu 260

293 Mabwati 106

293 Madamé (Lingala) 775

57 Madeso manene 612

397 Madia ma nlumba 223, 757

167 Madia ngulu (Mayumbe) 422

594 Madiadia 162

$196 \quad$ Madiata ngombe 17

$690 \quad$ Madiata nzau 17,18

363 Madimanga 186

63 Mafambu 477

653 Mafuku 24

$727 \quad$ Mafulu 174

Magangilu $\quad 378$ 


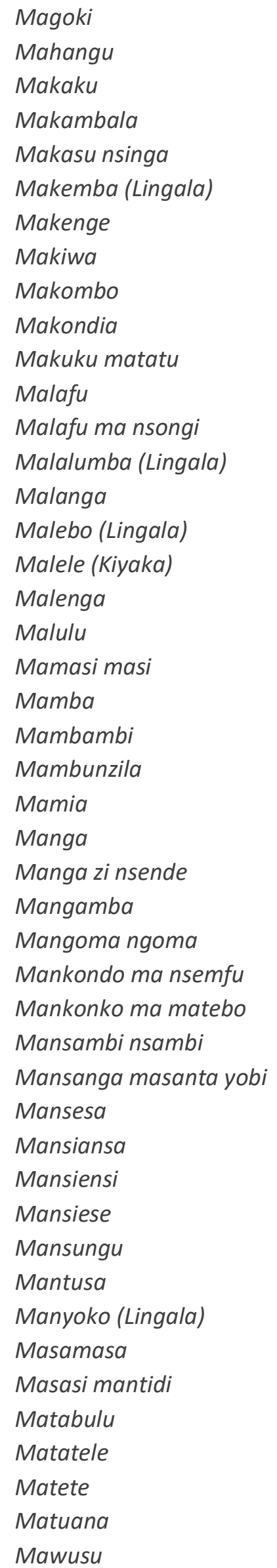

$\begin{array}{lll}438 & \text { Mayoko } & 621 \\ 705 & \text { Mazeha } & 369 \\ 595 & \text { Mazenya } & 764\end{array}$

802 Mbaka 773, 782

777 Mbala 416

536 Mbala (Lingala) 480

582 Mbalambala (Lingala) 415

451 Mbama 565

389 Mbamba 1, 323, 564

531 Mbandanzazi 520

194 Mbari 661

691 Mbendimbendi 212

450 Mbese 587

27 Mbidi 145

135 Mbika (Lingala) 182

117 Mbika malenge 244

317 Mbikankalu 436

244 Mbikansudi 243

814 Mbikantetu 182

283 Mbila esobe (Lingala) 66

176 Mboba 364

611 Mbolongu 733

46 Mbondi 693

705 Mbondo (Lingala) 754

478, $705 \quad$ Mbondo bololo (Lingala) 754

77,742 Mbongo mbongo 410

720 Mbonzi mbonzi (Lingala) 46

816,818 Mbota 517

811 Mbota masa 511

82 Mboti 272

715 Mboti mfinda 273

208 Mbotimfinda 273

239 Mbotinseke 272

239 Mbulu mbakala 162

471 Mbulunkutu 457, 487

471 Mbuma liboto (Lingala) 212

286 Mbuma makaku (Lingala) 212

813 Mbundu 314

$480 \quad$ Mbundu byala 314

$738 \quad$ Mbundungombe 67

737 Mbungu 66

150 Mbungumbungu 438

488 Mbwankanka 198, 199

$406 \quad$ Mbwembo 58

82 Mbwenge 509, 821

661 Mbwenge mputu 717 


Mdahamwitu (Swahili)
Mfiolongo
Mfube
Mfubu
Mfuki
Mfuma
Mfumbu
Mfumbwa
Mfungu
Mfungwa
Midon
Mika mi mbua
Mikaki
Mindindi (Kihungana)
Minkadi kadi
Minkeni
Minsanga
Minsengo
Minsumisumi
Misili (Kwango)
Mkadi (Swahili)
Mkwaju wa kihindi (Swahili)
Mlanyuni
Moa mba (Kiyombe)
Moambe
Moanga lombo
Moba
Mobambo (Lingala)
Mobe
Moete moa malala (Lingala)
Mokako (Lingala)
Mokenamischi (Tshiluba)
Mokende
Mokengereke (Lingala)
Mokoka (Lingala)
Mokonge (Lingala)
Molenda (Lingala)
Momo (Lingala)
Monbombo (Lingala)
Mondo
Montende-minu (Lingala)
Monanda (Lingala)
Mongangala)
Moingala)
Molangala)

$\begin{array}{rlr}393 & \text { Mosaka } & 311 \\ 825 & \text { Mosangavulu } & 227 \\ 803 & \text { Mosasolo (Lingala) } & 394 \\ 582 & \text { Motisosito } & 281 \\ 709 & \text { Mpakasa } & 671 \\ 158 & \text { Mpampanga (Lingala) } & 325 \\ 371 & \text { Mpanga (Lingala) } & 773 \\ 371 & \text { Mpangi nsafu } & 697 \\ 66 & \text { Mpansa makunsi } & 64 \\ 66 & \text { Mpapanya (Lingala) } & 595 \\ 486 & \text { Mpata kasakula } & 37 \\ 89 & \text { Mpempo } & 741 \\ 226 & \text { Mpempu } & 741 \\ 292 & \text { Mpenga } & 287 \\ 659 & \text { Mpete } & 397 \\ 226 & \text { Mpeya } & 525 \\ 692 & \text { Mpoki } & 765 \\ 692 & \text { Mpompa } & 328 \\ 100 & \text { Mpongo mpongo } & 181 \\ 652 & \text { Mpose (Lingala) } & 312 \\ 584 & \text { Mpoto zi mbwo } & 90 \\ 630 & \text { M. } & 816\end{array}$

$630 \quad$ 71,72, 816,

$393 \quad 818$

$373 \quad$ Mpuluka 423,677

312 Mpundi 286

245 Mpunga 801

419 Mpunga (Lingala) 189

538 Mpunga mpunga 802

$70 \quad$ Mpunga zi zanza 189

187 Mpungala 801

226 Mpungala fioti 808

$560 \quad$ Mpungala ki masa 189

531 Mpuvu 614

399 Mteremtere (Swahili) 393

161 Muanankasi 28

512 Muaza 722

8 Mubamfu 176

$288 \quad$ Mubango mbango 240

288 Mubula kondo (Kipindi). 751

443, $508 \quad$ Mubwongo 71

$193 \quad$ Mudia nuni 792

377 Mugete 397

58 Muindu 127

595 Muka 323

$595 \quad$ Mukala 833

594 Mukasa 525 
Mukayi (Kihungana)

Mukezo a temo (Kipende)

Mukolo wa nkwadi (Tshiluba)

Mukomamanga (Swahili)

Mukubi

Mukuku

Mukulumu

Mukwa

Mukwaya (Swahili)

Mulembelembe (Tshiluba)

Mulembo

Mulembwa

Mulu

Mulu nzazi

Mulumbwa (Tshiluba)

Mumbombo

Mumfiti (Kipindi)

Mumpala

Mumpemba

Mumpesempese

Mundenge

Mundi

Mundongo (Lingala)

Mundudidudi

Mundudi-ndudi ya ntela

Mundumbu (Manianga)

Munengena

Mungienge

Mungulungulu

Munkadi kadi

Munkeni

Munkenia

Munkinya

Munkodinkodi

Munkombo

Munkomo (Kipindi)

Munkuiza

Munsakala

Munsambi nsambi

Munsanga

Munsasa

Munsele bende

Munsele bende

Munsemfi

Munsense

Munsie
Muntomantoma

$$
\text { Muntomina }
$$

Muntusu 
N'teva

N'zanga (Lingala)

N'zungu n'tu

Nadeda

Namba azire (Lingala)

Nambandoli (Lingala)

Nanasi

Nbumi

Ndamba

Ndamimina

Ndekila

Ndemba

Ndemba ndemba

$\mathrm{Ndembi}$

Ndia ngulu

Ndiadi

Ndiadi mbulu

Ndimba

Ndimbu ndimbu

Ndimo ngai

Ndomba ndomba fioti

Ndosho ndosho

Ndudi ndudi

Ndulunsi

Ndulunsi i nseke

Ndumbu

Ndumbwa

Ndunga

Ndungu zi fioti

Ndungu zi kombo

Ndungu zi mafofolo

Ndungu zi matebo

Ndungu zi misitu

Ndungu zi ntendi

Ndungu zi nzo

Nfumba

Nfumfu

Ngadiadi

Ngadiadia

Ngadidi

Ngai ngai (Lingala)

Ngai ngai ya zamba

Ngaingai ya mfinda

Ngakala

Ngamba

Ngandu ngandu
402

106

715

239

386

386

63

753

499, 500

90

447

388

103

50

640

162

302, 305

776

309

186

505

449

817

242

242

734

56

473

150

149

149

668

668

150

33

198, 199

466, 467

358

358

358

9, 386, 389

211

470

708

288

325
Ngego

344

287

11

397

344

789

735

38

812

227

553

61,768

287

27,727

77

25

576

820

285

576

594

389

388

543

58

536

47

411

246

50

315

563

49

142, 788

496

285

161

845

348

564

700

697

429

51

436

711 
Nkamba

Nkamu

Nkanda diadi

Nkansu ngo

Nkari nkari

Nkasa

Nkasa kindongo

Nkasa nkumbi

Nkasa zikongo

Nkasa zimadeso

Nkasa zimbwenge

Nkasakasa

Nkasu

Nkau

Nkawu

Nke kiasa

Nkefu

Nkeka

Nkeka ngo

Nkeka za ngo

Nkekete

Nkela nkusu

Nkelekete

Nkenge kiasa

Nkengi

Nkenkele

Nkenkete

Nkenkina

Nkila mfwenge

Nkila ngombe

Nkila nkumbi

Nkingidi

Nkisu

Nkofi

Nkofi masa

Nkofi nkolula

Nkolokoso

Nkondo

Nkondo mfinda

Nkongolo

Nkonka ntu

Nkonki

Nkonko nkumanga

Nkoso

Nkuba nkuba

Nkubudi
646, 762

119, 120
Nkuka bangulu

Nkukuvungu

Nkula

Nkula diari

27, 232, 233

305

449

760

443

230

734

652

166

166 


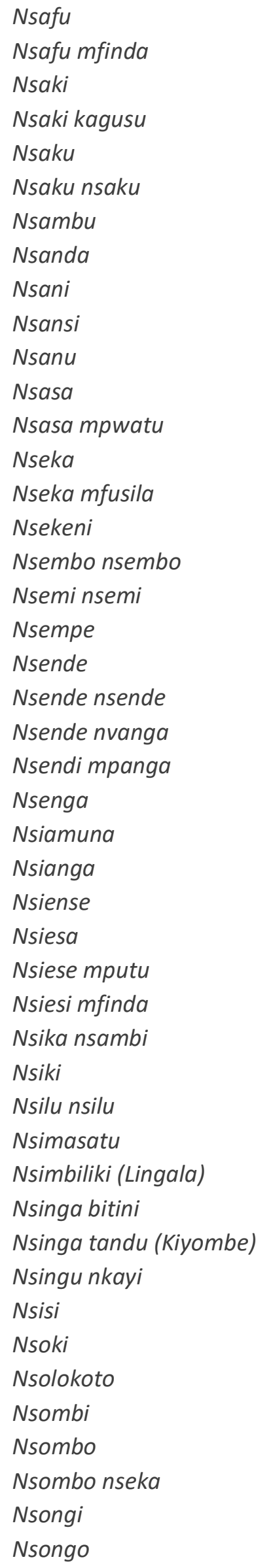

$\begin{array}{lll}256 & \text { Nsoni } & 411 \\ 145 & \text { Nsonia } & 411 \\ 481 & \text { Nsonia mputu } & 337 \\ 482 & \text { Nsoso } & 199 \\ 666 & \text { Nsudi bandumba (Kiyombe) } & 651 \\ 252 & \text { Nsudi nfuni } & 588 \\ 599 & \text { Nsudi nsudi } & 588\end{array}$

349 Nsumbala 216, 221

$567 \quad$ N'sumbé (Lingala) 90

$566 \quad$ Nsumbela 216, 221

$463 \quad$ Nsumbinsumbi 221

$490 \quad$ Nsumbila 216, 221

432, $738 \quad N s u n d a \quad 711$

$599 \quad$ Nsungi 790

599 Nsusa 330, 784

$798 \quad$ Nsusu menga 746

451, $452 \quad N s w a s u \quad 212$

288 Ntadianti 273

$756 \quad$ Ntata nkedinga 233

$616 \quad$ Nteke 112

$835 \quad$ Ntekwatekwa 652

$280 \quad$ Ntela 567

$280 \quad$ Ntetanteta 615

$538 \quad$ Ntete 789

$452 \quad$ Ntetu 182

54 Nti kafi 204

133, $318 \quad N$ ti nsansi 566

$318 \quad$ Ntidi 469, 737

266 Ntieti 569

$318 \quad$ Ntita 819

238 Ntiti 704

526 Ntiti mbwela 704

$540 \quad$ Ntoka 512

$500 \quad$ Ntongo ntongo 275

$203 \quad$ Ntu mbizi 189

179 Ntubungu 523

$285 \quad$ Ntumbensi 189

$779 \quad$ Ntundibila 30

155 Ntundulu 30, 34

$401 \quad N$ Nunu 377

111, $802 \quad$ Ntunzu (Lingala) 273

$312 \quad$ Ntuti 569

$833 \quad$ Nungu tsende 835

599 Nuwanda 270

$756 \quad$ Nvondongolo 296

$480 \quad$ Nwa nsongi 450 
Nwandu nwandu

Nyanga nzamba

Nyibu

Nzadi nzadi

Nzala kwenda

Nzamba

Nzanga

Nzanzeka

Nzau nti

Nzaza

Nzefo za ngo

Nzekenzeke

Nzenze

Nzete ya mbila

Nziazi

Nziazia

Nzibo

Nzila nzila

Nzoeto

Nzomfi

Nzumbu ziba

Nzundu

Nzundu nzundu

Okasa (Lingala)

Okekele (Turumbu)

Pakapaka

Panga ya singama

Pangi ya kuinini

Pangia ya nsania

Panza

Papaya mfinda

Pasipolomo

Payipayi

Penza

Pesu (Lingala)

Pete pete

Pilipili (Lingala)

Pokolunze (Kiyumbe)

Pondu

Punga

Racaba (Lingala)

Safi di nkanka

Saka saka

Saku

Saku saku

Samfi
325

586

644

369

11

586

54

389

321

790

749

330

82,351

311

778

778,780

49

268

80

378

118

453

19

715

562

91

795

90

564

601

595

591

153

273

792

397

149, 150

384

226, 824

758

56

595

480

240

830

805
Samu

569

837

769

566

468

786

837

608

43

238

250

250

140

22

628

287

733

463

121

281

418

670

56

427

387

839

839

839

232

739

161

56

56

715

39

621

621

415

664

818

298, 300 


\begin{tabular}{|c|c|}
\hline Tundu ngoma & 147 \\
\hline Tungwa & 689 \\
\hline Tusevo & 161 \\
\hline Tutu & 9 \\
\hline Uenge (Lingala) & 7 \\
\hline Uima (Lingala) & 129 \\
\hline Vamu & 6 \\
\hline Viazi maji (Swahili) & 633 \\
\hline Viluseke ya kaka & 8 \\
\hline Vinsu vinsu & 365 \\
\hline Vinzu vibsu & 369 \\
\hline Vunga vunga & 189 \\
\hline Waka (Lingala) & 3 \\
\hline Walu & 171,773 \\
\hline Wandu & 134 \\
\hline Wangila & 718 \\
\hline Wangila matebo & 719 \\
\hline Wanguila & 7 \\
\hline Wendende (Lingala) & 79 \\
\hline Wusu & 3 \\
\hline Wute (Lingala) & 3 \\
\hline Ya di ngazi & 31 \\
\hline Ya dia nseke & \\
\hline Yamuntu & 6 \\
\hline Yense & 4 \\
\hline Yesesa (Lingala) & 2 \\
\hline Yobi & 2 \\
\hline Yombo & 6 \\
\hline Yonsiyonsi & 5 \\
\hline Yumombulu (Kikusu) & 4 \\
\hline Zala di nkanka & \\
\hline Zamba & \\
\hline Zamba di nkanka & 5 \\
\hline Zekeke & \\
\hline Zenga bitini & 1 \\
\hline Zima tiya & \\
\hline Zowa zowa & 7 \\
\hline Zumbu (Yaka) & 668 \\
\hline
\end{tabular}


Index des noms communs

\section{Abalé} 610

Abricotier d'Afrique

477

Acacia

Acacia du Congo

601

Acalypha

Acerola

476

Adultery tree

100

Aerial yam

African arrowroot lily

African bitter yam

African black wood

African breadfruit

African crocus

African elemi

African false currant

African fan palm

African gladiolus

African greenheart

African jolanettle

African linden

African mammee apple

African milk bush

African milk tree

African moringa tree

African nightshade

African nutmeg

African pear

African potato

African rose wood

African satinwood

African teak

African tragacanth

African walnut

African winged bean

African yam bean

Aidan tree

Alamo vine

Alchornée fleurie

Allanblackia fat

Alui

Amarante

Amaranth

Ambay pumpwood

Ambravade
Ambrette

American joint vetch

Anacardier

Ananas

Anatto tree

Angel's trumpet

131

Angel's wings

135

Anglestem primrose willow

462

Ant tree

100

Apple mint

499

Arachide

79

Arachide de brousse $\quad 238$

Arbre à ail $\quad 708$

Arbre à calebasses $\quad 234$

Arbre à fourmis $\quad 100$

Arbre à pagaies $\quad 746$

Arbre à pain 85

Arbre à pain d'Afrique $\quad 790$

Arbre à pain indigène $\quad 541$

Arbre à pluie $\quad 45$

Arbre à semelles $\quad 601$

Arbre à soie 42

Arbre à tabatières $\quad 566$

Arbre candélabre $\quad 714$

Arbre corail $\quad 328$

Arbre de bonheur $\quad 178$

Arbre de feu $\quad 598$

Arbre du Cambodge $\quad 360$

Aristoloche 81

Armoise anuelle $\quad 83$

Arrow grass $\quad 789$

Arrowroot $\quad 486$

Asperge sauvage $\quad 88$

Asthma weed $\quad 342$

Attier $\quad 69$

Aubergine 733

Aubergine du diable $\quad 735$

Aubergine pois $\quad 735$

Avocado pear $\quad 608$

Avocatier 556,608

Avodiré 803

Badamier 775

Bahia grass $\quad 591$

Balai doux $\quad 707$

Balai poilu $\quad 724$

Balisier rouge $\quad 147$ 


\begin{tabular}{|c|c|}
\hline Balloon vine & 152 \\
\hline Balsamine & 409,410 \\
\hline Bambara groundnut & 820 \\
\hline Bamboo & 96 \\
\hline Bambou & 96 \\
\hline Banana, dessert & 536 \\
\hline Banane fruit & 536 \\
\hline Banane plantain & 536 \\
\hline $\begin{array}{l}\text { Bananier à fleurs } \\
\text { roses }\end{array}$ & 534 \\
\hline Bananier d'ornement & 534 \\
\hline Bancoulier & 48 \\
\hline Baobab & 23 \\
\hline Baquois & 584 \\
\hline Barbadine & 593 \\
\hline Barbados cherry & 476,606 \\
\hline Barbados lily & 390 \\
\hline Baselle & 102 \\
\hline Basilic & 556 \\
\hline Basilic africain & 557 \\
\hline Basket grass & 570 \\
\hline Baumier & 557 \\
\hline Bear's breeches & 19 \\
\hline Beef steak plant & 16 \\
\hline Bel de Calao & 81 \\
\hline Bell pepper & 149 \\
\hline Bellangère bâtarde & 735 \\
\hline Bellyache bush & 425 \\
\hline Ben ailé & 529 \\
\hline Beurre de bouandjo & 49 \\
\hline Bigaradier & 185 \\
\hline Bilihuete & 21 \\
\hline Bilinga & 543 \\
\hline Billy goat weed & 37 \\
\hline Billyweb sweetia & 21 \\
\hline Bird gooseberry & 393 \\
\hline Bissap & 389 \\
\hline Bitter gourd & 522 \\
\hline Bitter kola & 358 \\
\hline Bitter orange & 185 \\
\hline Bitterleaf & 814,817 \\
\hline Bixa & 112 \\
\hline Black benniseed & 719 \\
\hline Black catnip & 615 \\
\hline Blood root & 428 \\
\hline Bloodwood & 653 \\
\hline Blue trumpet vine & 787 \\
\hline
\end{tabular}

\begin{tabular}{|c|c|}
\hline $\begin{array}{l}\text { Blunt spurred ground } \\
\text { orchid }\end{array}$ & 337 \\
\hline Bois amer & 660,767 \\
\hline Bois d'or & 517,543 \\
\hline Bois de lait & 597 \\
\hline Bois de Quassia & 660 \\
\hline Bois de Suriname & 660 \\
\hline Bois horongue & 377 \\
\hline Bois noir & 512 \\
\hline Bois rouge & 332 \\
\hline Bois sacré & 767 \\
\hline Boleko oil & 569 \\
\hline Bombardier & 396 \\
\hline Boston fern & 548 \\
\hline Bottle gourd & 436 \\
\hline Bouandjo & 49 \\
\hline Boule de feu & 701 \\
\hline Boundary tree & 549 \\
\hline Bouton blanc & 55 \\
\hline Bowstring hemp & 696 \\
\hline Bracken & 652 \\
\hline Breadfruit & 85 \\
\hline Brède chevrette & 56 \\
\hline Brède mafane & 20 \\
\hline Brimstone tree & 526 \\
\hline Bristly starbur & 18 \\
\hline Broom cluster fig & 348 \\
\hline Broomweed & 723 \\
\hline Brown mustard & 120 \\
\hline Bubinga & 375 \\
\hline Budongo mahogany & 321 \\
\hline Buffalo grass & 585 \\
\hline Buffel grass & 721 \\
\hline Burrweed & 802 \\
\hline Bush mallow & 12 \\
\hline Bush morning glory & 417 \\
\hline Bush tea & 457 \\
\hline Bush tea bush & 407 \\
\hline Bush yam & 289 \\
\hline Butterfly pea & 164 \\
\hline Button grass & 520 \\
\hline Cacaoyer & 785 \\
\hline Café de la brousse & 574 \\
\hline Café puant & 715 \\
\hline Caféier robusta & 204 \\
\hline Caimite & 175 \\
\hline Caimito & 175 \\
\hline
\end{tabular}




\begin{tabular}{|c|c|c|c|}
\hline Cainitier & 175 & Chénopode vermifuge & 169 \\
\hline Cajou & 62 & Chien-dent & 411 \\
\hline Calabash & 436 & Chinese albizia & 42 \\
\hline Calabash tree & 234 & Chinese cabbage & 123 \\
\hline Calebasse & 436 & Chinese white & 122 \\
\hline Calico flower & 81 & cabbage & 198 \\
\hline Calliandra & 138 & Choculate veed & $\begin{array}{l}490 \\
832\end{array}$ \\
\hline Calopo & 140 & Chou caralbe & 832 \\
\hline \multirow{3}{*}{$\begin{array}{l}\text { Camel's foot tree } \\
\text { Cameroons gum } \\
\text { copal }\end{array}$} & 624 & Chou de Chine & 123 \\
\hline & \multirow{2}{*}{375} & Chou vert & 121 \\
\hline & & Chouchoute & 710 \\
\hline Camphor basil & 555 & Christmas bush & 46 \\
\hline Cananga oil & 143 & Christmas rose & 221,343 \\
\hline Candlenut tree & 48 & Christophine & 710 \\
\hline Cannabis & 148 & Chufa & 253 \\
\hline Canne à sucre & 691 & Ciboulette & 50 \\
\hline Cannellier de Ceylon & 178 & Cierge du Pérou & 165 \\
\hline Caoutchouc de Céara & 482 & Cinnamon & 178 \\
\hline Cape fig & 348 & Citronelle & 250 \\
\hline Cape gooseberry & 620 & Citronnier & 186 \\
\hline Caracasana & 340 & Citronnier d'Afrique & 835 \\
\hline Carambola & 91 & Clématite hirsute & 191 \\
\hline Carambolier & 91 & Clérodendron & 196 \\
\hline Cardamome sauvage & 32 & Climbing hemp weed & 506 \\
\hline $\begin{array}{l}\text { Caribbean copper } \\
\text { plant }\end{array}$ & 340 & $\begin{array}{l}\text { Climbing maidenhair } \\
\text { fern }\end{array}$ & 464 \\
\hline Cashew nut & 62 & Cluster yam & 288 \\
\hline Cassava & 480 & Coco plum & 174 \\
\hline Casse de Siam & 716 & Cocoa & 785 \\
\hline Castor oil & 677 & Coconut & 202 \\
\hline Cat's claw & 518 & Cocotier & 202 \\
\hline Cat's whiskers & 192 & Cocoyam, new & 832 \\
\hline Ceara rubber & 482 & Cour de boeuf & 67 \\
\hline Célosie argentée & 160 & Coffee senna & 715 \\
\hline Centro & 164 & Coffee, robusta & 204 \\
\hline $\begin{array}{l}\text { Chanvre de } \\
\text { Queensland }\end{array}$ & 725 & $\begin{array}{l}\text { Cogon grass } \\
\text { Common pheasant }\end{array}$ & 411 \\
\hline Chanvre de Guinée & 387 & berry & 489 \\
\hline $\begin{array}{l}\text { Chanvre, chanvre } \\
\text { indien }\end{array}$ & 148 & Concombre amer & 243 \\
\hline Chapeau de & & Confiture & 352 \\
\hline Monseigneur & 104 & Congo jute & 808 \\
\hline Chapeau de Napoléon & 155 & Conophor nut & 777 \\
\hline Charcoal tree & 792 & Copalier & 375 \\
\hline $\begin{array}{c}\text { Chardon de } \\
\text { montagne }\end{array}$ & 19 & Copper leaf & 16 \\
\hline Chayote & 710 & Coral creeper & 76 \\
\hline Chêne argenté & 374 & Cork wood tree & 675 \\
\hline Chêne d'Afrique & 507 & Corossol & 67 \\
\hline & & Corossol épineux & 67 \\
\hline
\end{tabular}




\begin{tabular}{|c|c|}
\hline Cosmos & 225 \\
\hline Cotonnier & 372 \\
\hline Country mallow & 12 \\
\hline Courge & 244 \\
\hline Courge éponge & 463 \\
\hline Cow foot leaf & 627 \\
\hline Cowpea & 821 \\
\hline Crab nut & 151 \\
\hline Creeping ox-eye & 740 \\
\hline Crenate orchid cactus & 322 \\
\hline Cresson de Para & 20 \\
\hline Croc de chien & 726 \\
\hline Cucolie écarlate & 316 \\
\hline Curare & 754 \\
\hline Dabema & 628 \\
\hline Dartrier & 713 \\
\hline Dattier sauvage & 614 \\
\hline Démoulai à gros fruits & 623 \\
\hline Dentelaire de Ceylan & 637 \\
\hline Devil bean & 238 \\
\hline Devil's trumpet & 264 \\
\hline Djimbo & 477 \\
\hline Dolique mongette & 821 \\
\hline Dragon tree & 302 \\
\hline Dragonnier & 302,305 \\
\hline Dutchman's pipe & 81 \\
\hline Dwarf copperleaf & 56 \\
\hline Dwarf Dracaena & 303 \\
\hline Dwarf mobola plum & 588 \\
\hline $\begin{array}{l}\text { Dwarf savanna ginger } \\
\text { lily }\end{array}$ & 229 \\
\hline Ebam & 623 \\
\hline Egg plant & 733 \\
\hline Egyptian cotton & 372 \\
\hline Elderberry & 694 \\
\hline Elemier d'Afrique & 145 \\
\hline Elengieye & 172 \\
\hline Elephant apple & 284 \\
\hline Elephant grass & 162 \\
\hline Elephant's ear & 135 \\
\hline Emilie & 316 \\
\hline Engrais vert & 788 \\
\hline Épinard Indien & 102 \\
\hline Épinard sauvage & 621 \\
\hline Éponge végétale & 463 \\
\hline Eru & 37 \\
\hline Erun & 33 \\
\hline
\end{tabular}

\begin{tabular}{|c|c|}
\hline Ethiopian mustard & 119 \\
\hline Eucayptus & 334 \\
\hline Euphorbe bicolore & 341 \\
\hline Euphorbe candélabre & 339 \\
\hline Euphorbe effilée & 344 \\
\hline False assegai & 469 \\
\hline False bougainvillea & 221 \\
\hline False mangosteen & 360 \\
\hline False nutmeg & 656 \\
\hline False roselle & 386 \\
\hline False rubber tree & 353,392 \\
\hline Fausse oseille & 389 \\
\hline $\begin{array}{l}\text { Fausse oseille de } \\
\text { Guinée }\end{array}$ & 38 \\
\hline Fausse tomate & 731 \\
\hline Faux baobab & 432 \\
\hline Faux goyavier & 646 \\
\hline Faux I péca & 649 \\
\hline Faux muscadier & 524,656 \\
\hline Faux noix muscade & 525 \\
\hline Feu de Dieu & 635 \\
\hline Figuier de Barbarie & 571 \\
\hline Finger Euphorbia & 344 \\
\hline Finger tree & 344 \\
\hline Fire bush & 376 \\
\hline Fire-ball lily & 116,701 \\
\hline Fish poison bean & 773 \\
\hline Flamboyant & 266 \\
\hline Flamboyant de l'Inde & 597 \\
\hline Flamboyant jaune & 597 \\
\hline Flax lily & 274 \\
\hline Fleabane & 324 \\
\hline Flowering banana & 534 \\
\hline Forest anchomanes & 64 \\
\hline Forest crinum & 235 \\
\hline Forest fever berny & 241 \\
\hline Forest mobola plum & 589 \\
\hline Forest sandpaper fig & 345 \\
\hline Forest yam & 289 \\
\hline Fougère & 652 \\
\hline Foxglove orchid & 337 \\
\hline Fragrant Dracaena & 304 \\
\hline Fraké & 776 \\
\hline Frangipani & 638 \\
\hline Frangipanier & 638 \\
\hline French bean & 612 \\
\hline Fromager & 158 \\
\hline
\end{tabular}


Fruit miracle

Galinsoga à petites fleurs

Gallant soldier

Ganges primrose

Garden balsam

Gardenia mâle

Garlic plant

Gboma egg plant

Giant leaved fig

Giant yellow mulberry

Gingembre

Ginger

Ginger bush

Ginger lily

Glaïeul africain

Glorieuse

Gloriosa lily

Glory bower vine

Gmelina

Golden dewdrop

Golden shower

Gombo

Gombo musqué

Goose grass

Goyavier

Goyavier acide

Grand sureau

Grande igname

Grassé

Grattelier

Greater yam

Grenadier

Grenadille

Gros baume

Groseille africane

Groseiller des

Barbades

Groseiller du Cap

Ground pineapple

Groundnut

Guatemala grass

Guava

Guinea grass

Guinea guava

Guinea hemp

Gynandro
Haricot de Lima

Haricot igname Africain

Haricot kunde

Haricot vert

Heart-leaf Sida

Hedge cactus

Hemp

Herb dure

Herbe à balai

Herbe à chapelets

Herbe à couleuvre

Herbe à couteau

Herbe à elephant

Herbe à marconnet

Herbe à Nicot

Herbe à paniers

Herbe au chagrin

Herbe au sorciers

Herbe caille

Herbe de Guinée

Herbe du diable

Herbe palissade

Herbe papillon

Herbe roulante

Herbe savane

Herbe sensbile

Hévéa

Hispid starbur

Hoffe

Hog plum

Hogweed

Holarrhene

Hophead

Hornbills calabash

Horn-pod tree

Horse scarer

Horseradish tree

Hot pepper

Hydrocotyle

I boga

Icaquier

Ice-cream bean tree

Igname amère

Igname de brousse

Impatient

Indian almond
611

741

821

612

724

165

148

725

498

208

605

674

162

739

550

570,724

615

37

797

585

265

118

384

116

18

519

385

18

287

743

115

392

99

473

296

116

529

150

163

767

174

414

288

289

409

775 


\begin{tabular}{|c|c|}
\hline Indian heliotrope & 384 \\
\hline Indian mustard & 120 \\
\hline Indian pennywort & 163 \\
\hline Indian plum & 352 \\
\hline Indian shot & 147 \\
\hline Indian walnut & 48 \\
\hline Indian wormseed & 169 \\
\hline Inga & 414 \\
\hline Iroko & 507 \\
\hline Isano oil & 569 \\
\hline I voire végétal & 705 \\
\hline J acinthe d'eau & 310 \\
\hline Jackfruit & 87 \\
\hline J acquier & 87 \\
\hline Jambolan & 759 \\
\hline Jambosier & 763 \\
\hline Jambosier rouge & 764 \\
\hline Jamelonier & 759 \\
\hline $\begin{array}{l}\text { Japanese bunching } \\
\text { onion }\end{array}$ & 50 \\
\hline Japanese poinsettia & 597 \\
\hline Java brucea & 130 \\
\hline Jew's mallow & 224 \\
\hline J imson weed & 265 \\
\hline Job's tears & 208 \\
\hline Joint vetch & 95 \\
\hline J onc vulgaire & 252 \\
\hline Jussie & 465 \\
\hline Kalahari pod berry & 272 \\
\hline Kale & 121 \\
\hline Kambala & 507 \\
\hline Kangkong & 415 \\
\hline Kapok & 158 \\
\hline Kapokier & 158 \\
\hline Karamanni wax & 756 \\
\hline Kénaf & 387 \\
\hline Kew weed & 356 \\
\hline Kimba pepper & 833 \\
\hline Knife grass & 674 \\
\hline Koko & 371 \\
\hline Kola & 209 \\
\hline Kolatier & 209 \\
\hline Koro & 825 \\
\hline Kudzu tropicale & 654 \\
\hline Kwango giant cycad & 317 \\
\hline Lagos spinach & 160 \\
\hline Langue de femme & 44 \\
\hline
\end{tabular}

Lantana $\quad 445$

Larmes de J ob 208

Larmilles 208

Laurier d'Afrique $\quad 361$

Lemon $\quad 186$

Lemon grass 250

$\begin{array}{ll}\text { Lesser forest fever } & 71\end{array}$

Liane à eau $\quad 778$

Liane à hameçons $\quad 806$

Liane aurore $\quad 658$

Liane corail 76

Liane de Kisanji $\quad 540$

Lilas de Perse 494

Lilas des Indes $\quad 437$

Lima bean $\quad 611$

Limba $\quad 776$

Limbali $\quad 363$

Lime $\quad 184$

Limettier $\quad 184$

Lion's tail $\quad 450$

Lis grimpant $\quad 366$

Lis rouge $\quad 390$

Litchi chevelu $\quad 546$

Livingstone potato 633

Logwood $\quad 426$

Loofah 463

Lucky bean 11

Macabo 832

Mackay bean $\quad 319$

Madagascar $\quad 156$

periwinkle

Madamé 775

Madras thorn $\quad 630$

Magic rope 563

Magloire 56

Mais 837

Maize 837

Malabar spinach $\quad 102$

Malay apple $\quad 764$

Malnommée 342

Mangium

Mango $\quad 478$

Mangosteen $\quad 359$

Mangoustanier $\quad 359$

Manguier $\quad 478$

Manguier sauvage $\quad 589$ 
Muscadier de 525

Manioc

480,849

Manioc

Manioc caoutchouc

Manioc de lièvre

Mauve des champs

Mexican shrubby

Mother-in-law's tongue

$$
\text { calabash }
$$

Muscadier du Gabon

Musk mallow

Napier grass 162

Neem 93

Neflier de Costa Rica $\quad 104$

Nénuphar $\quad 552$

Never-die 430

Néverdié 529

New cocoyam 832

Niando 47

Niébe 821

Nipple fruit $\quad 728$

Node weed 757

Noisette 230

Noix des Indes $\quad 48$

Northern black wattle 13

Noyer d'Afrique 460

Noyer d'Amerique $\quad 576$

Obéro 623

Oboto 477

Oil bean tree $\quad 601$

Oil palm 311

Okra 8

Old maid 364

Old woman's tears 393

Olon dur 835

Oplismène à poils 570

$$
\text { courts }
$$

$\begin{array}{ll}\text { Orange, sweet } & 187 \\ \text { Oranger amer } & 185\end{array}$

Oranger doux $\quad 187$

Ordeal tree 237,332

Oseille 9

Oseille chinoise 684

Oseille de Guinée $\quad 389$

Oseille indigene $\quad 387$

Ostrich plume 53

Otaheiti apple 742

Owala 601

Pain de singe 23

Pakchoi 122

Palette de peintre $\quad 135$

Palissandre d'Afrique 73

Palmier à huile $\quad 311$ 


\begin{tabular}{|c|c|c|c|}
\hline Palmier raphia & 661,664 & Pois cajan & 134 \\
\hline Palmier-rotin & 434 & Pois d'Angole & 134 \\
\hline Pap leaf & 613 & Pois de Coeur & 152 \\
\hline Papayer & 153 & Pois de terre & 820 \\
\hline Paprika pepper & 149 & Pois mascate & 531 \\
\hline Papyrus & 254 & Pois pouilleux & 531 \\
\hline Pâquerette chocolat & 89 & Pois quénique & 529 \\
\hline Para rubber & 385 & Pois sabre & 146 \\
\hline Paraguay burr & 17 & Pois sucré & 414 \\
\hline Parasolier & 538 & Poison d'épreuve & 332 \\
\hline Paspalum & 591 & Poivre & 625,626 \\
\hline Pastèque & 182 & Poivre de Cayenne & 150 \\
\hline Patate douce & 416 & Poivre de Guinée & 33 \\
\hline Pawpaw & 153 & Poivrier & 626 \\
\hline Pea eggplant & 735 & Poivrier de Guinée & 833 \\
\hline Pepermint & 500 & Poivron & 149 \\
\hline Pépéromie & 605 & Pole bean & 612 \\
\hline Pepper & 626 & Pomegranate & 655 \\
\hline Pepper elder & 605 & Pomme cajou & 62 \\
\hline Persian lilac & 494 & Pomme cannelle & 69 \\
\hline Pervenche de & 156 & Pomme de Cythère & 742 \\
\hline $\begin{array}{l}\text { Madagascar } \\
\text { Petit kola }\end{array}$ & 358 & Pomme en l'air & 287 \\
\hline Physic nut & 4230 & Pomme épineuse & 265 \\
\hline Pied de boeuf & 624 & Pomme surette & 175 \\
\hline Pied de poule & 374 & Pommier de Malaisie & 764 \\
\hline Pigeon bemy & $\begin{array}{r}314 \\
308679\end{array}$ & Pommier rose & 763 \\
\hline Pigeon nea & $\begin{array}{r}300,0 / 9 \\
134\end{array}$ & Pommier-rose & 763 \\
\hline Pigeon pea & 134 & Pompon de Marin & 139 \\
\hline Pilipili (Lingala) & 150 & Poor man's candle & 154 \\
\hline Piment & 149 & Pop-corn senna & 714 \\
\hline Piment capsique & 150 & Pop-gun tree & 747 \\
\hline Pineapple & 63 & Potato yam & 287 \\
\hline Pink cone ginger & 53 & Pourghère & 423 \\
\hline Pink tassel berry & 74 & Pourghère rouge & 425 \\
\hline Pink tassel flower & 139 & Pourpier & 640 \\
\hline Piquant blanc & 356 & Pourpier indigène & 364 \\
\hline Pissenlit & 231 & Prickly pear & 571 \\
\hline Plantain bananas & 536 & Pride of India & 437 \\
\hline Plante crayon & 344 & Prune noire & 825 \\
\hline Plante zigzag & 597 & Prunier d'Inde & 352 \\
\hline Pluie d'or & 658 & Prunier des Andes & 174 \\
\hline Plumbago & 636 & Prunier Mombin & 743 \\
\hline Poil à gratter & 198,531 & Pumpkin & 244 \\
\hline Poilu & 546 & Purple lantana & 446 \\
\hline Poinsettia & 343 & Purslane & 640 \\
\hline Pointe noire & 122 & Quassia wood & 660 \\
\hline Pois bâtard & 164 & & \\
\hline
\end{tabular}




\begin{tabular}{|c|c|}
\hline Queen of the night & 165 \\
\hline Queensland hemp & 725 \\
\hline Queue de lion & 450 \\
\hline Quinine de Cayenne & 660 \\
\hline Raffia palm & 661,664 \\
\hline Rain tree & 45 \\
\hline Raisinier des bois & 471 \\
\hline Ramboutan & 546 \\
\hline Rambutan & 546 \\
\hline Rat's tail & 745 \\
\hline Rattan & 136,323 \\
\hline Rattan, Large & 434 \\
\hline Rattle box & 238 \\
\hline Red flowered ragleaf & 231 \\
\hline Red ginger & 53 \\
\hline Red water tree & 332 \\
\hline Red-hot poker tree & 328 \\
\hline $\begin{array}{l}\text { Renouée à feuilles de } \\
\text { saule }\end{array}$ & 609 \\
\hline Resurrection plant & 431 \\
\hline Rice & 572 \\
\hline Ricin & 677 \\
\hline Rikio & 805 \\
\hline Ring-worm bush & 713 \\
\hline River bean & 720 \\
\hline Riz & 572 \\
\hline Robusta coffee & 204 \\
\hline Rocouyer & 112 \\
\hline Rônier & 117 \\
\hline Rose balsam & 409 \\
\hline Rose cactus & 607 \\
\hline Rose de Jéricho & 503 \\
\hline Rose de Noel & 343 \\
\hline Roselle & 389 \\
\hline Rotin & 136,323 \\
\hline Sablier & 396 \\
\hline Sacred wood & 767 \\
\hline Safoutier & 256 \\
\hline Safran des Indes & 246 \\
\hline Saman & 45 \\
\hline Sand box tree & 396 \\
\hline Sanguinaria & 428 \\
\hline Sansévière & 695,696 \\
\hline Sassy bark & 332 \\
\hline Saucissonnier & 432 \\
\hline Sausage tree & 432 \\
\hline Savanna gooseberny & 540 \\
\hline
\end{tabular}

Scarlet bush 375

Scarlet eggplant $\quad 728$

Scarlet fire spike $\quad 558$

Screw pine, common $\quad 584$

Sea island cotton $\quad 372$

Séné africain 714

Sésame 718

Sessile joy weed 56

Seville orange $\quad 185$

Siam weed $\quad 172$

Siamese cassia $\quad 716$

Sickle bush 280

Sida à feuilles en $\quad 724$

Signal grass $\quad 118$

Silk cotton tree $\quad 158$

Silk rubber 353

Simsim 718

Slender star lily 405

Snake bush 99

Snuff-box tree 566

Soap tree 818

Soja 368

Sonnettes 238

Sorgho 737

Sorghum 737

Souchet à papier 254

Souchet comestible 253

Soursop 67

South African tree 248

fern 368

Spanish needles $\quad 111$

Spider plant 192

Spider tresses $\quad 751$

Spiral ginger 226

Splendid Oncidium 794

Spreading dayflower 223

Squash 244

Star apple $\quad 175$

Star fruit $\quad 91$

Starbur 17

Stinkwood tree 610

Striga 715

Stylo 755

Sugar apple 69

Sugar cane $\quad 691$ 


\begin{tabular}{|c|c|}
\hline Sugar plum & 805 \\
\hline Sukuma wiki & 121 \\
\hline Sunflower & 382 \\
\hline Sunset hibiscus & 9 \\
\hline Sureau & 694 \\
\hline Sureau noir & 694 \\
\hline Swamp arum & 448 \\
\hline Swamp lily & 235 \\
\hline Swamp morning glory & 415 \\
\hline Sweet Annie & 83 \\
\hline Sweet basil & 556 \\
\hline Sweet broom weed & 707 \\
\hline Sweet pepper & 149 \\
\hline Sweet potato & 416 \\
\hline Sweet wormwood & 83 \\
\hline $\begin{array}{l}\text { Sweet-scented } \\
\text { Dracaena }\end{array}$ & 304 \\
\hline Sweetsop & 69 \\
\hline Sword bean & 146 \\
\hline Sword fern & 548 \\
\hline Tabac & 550 \\
\hline Tabasco pepper & 150 \\
\hline Tamarind & 770 \\
\hline Tamarinier & 770 \\
\hline Tannia & 832 \\
\hline Taro & 213 \\
\hline Tête de cochon & 732 \\
\hline Thick head & 231 \\
\hline Thorn apple & 265 \\
\hline Tiama blanc & 321 \\
\hline Tiger nut & 253 \\
\hline Tilleul d'Afrique & 521 \\
\hline Tobacco & 550 \\
\hline Tobasco pepper & 150 \\
\hline Tomate & 729 \\
\hline Tomate amère & 728 \\
\hline Tomate en arbre & 255 \\
\hline Tomatillo & 255 \\
\hline Tomato & 729 \\
\hline Toothache plant & 20 \\
\hline Tournesol & 382 \\
\hline Tournesol mexicain & 788 \\
\hline Tree basil & 557 \\
\hline Tree cassava & 482 \\
\hline Tree tomato & 255 \\
\hline Trente six oiseaux & 264 \\
\hline Tridax couché & 797 \\
\hline
\end{tabular}

$\begin{array}{ll}\text { Trompette de la mort } & 264 \\ \text { Trompette des anges } & 131 \\ \text { Trompette du diable } & 264 \\ \text { Tropical button weed } & 285 \\ \text { Tropical chickweed } & 307 \\ \text { Tropical kudzu } & 654\end{array}$

Tsana 113

Tulip tree 738

Tulipier du Gabon $\quad 738$

Tumbleweed $\quad 116$

Turmeric 246

Uenge (Lingala) $\quad 784$

Umbrella dracaena $\quad 274$

Umbrella tree $\quad 538$

Vacoa 584

Vaquois $\quad 584$

Vegetable pear $\quad 710$

Vegetable sponge $\quad 463$

Vegetable tallow tree $\quad 49$

Velvet bean 531

Velvet tree $\quad 504$

Verveine du Congo $\quad 457$

Vigne en caoutchouc $\quad 687$

Vine spinach $\quad 102$

Violet tree $\quad 711$

Voacanga d'Afrique $\quad 827$

Voacanga de Thouars $\quad 828$

Voandzou $\quad 820$

Wandering J ew 222,223

Water hyacinth $\quad 310$

Water lily $\quad 552$

Water primrose $\quad 461$

Water spinach $\quad 415$

Water tree $\quad 778$

Water yam 286

Water-berry 760

Waterleaf 769

Watermelon $\quad 182$

Welsh onion 50

Wenge 512

West African
boxwood

West African 124

West African
sarsaparilla

West African aloe $\quad 52$ 


\begin{tabular}{|c|c|}
\hline $\begin{array}{l}\text { West African black } \\
\text { pepper }\end{array}$ & 625 \\
\hline West African pepper & 833 \\
\hline West African plum & 825 \\
\hline West Indian holly & 449 \\
\hline White ball rubber & 440 \\
\hline White bottlebrush & 492 \\
\hline White buttons & 55 \\
\hline White candles & 831 \\
\hline White ginger & 37 \\
\hline White plumbago & 637 \\
\hline White rubber vine & 44 \\
\hline Wild asparagus & 58 \\
\hline Wild canna lily & 147 \\
\hline Wild cardamom & \\
\hline Wild custard apple & 68 \\
\hline Wild date palm & 614 \\
\hline Wild frangipani & 828 \\
\hline Wild poinsettia & 216,341 \\
\hline Wild rubber & 296 \\
\hline Wild Seringa & 133 \\
\hline Wild yam & 290 \\
\hline Willow weed & 609 \\
\hline Winged yam & 286 \\
\hline Wire grass & 314 \\
\hline Witches bean cake & 198 \\
\hline Woman's tongue tree & \\
\hline Wood rose & 503 \\
\hline Woodland croton & 241 \\
\hline Wulo & 7 \\
\hline Yellow bauhinia & 10 \\
\hline Yellow cassia & 71 \\
\hline Yellow commelina & 22 \\
\hline Yellow flame tree & 597 \\
\hline Yellow nut grass & 25 \\
\hline Yellow oleander & 15 \\
\hline Yellow passion fruit & 59 \\
\hline Yellow sorrel & 57 \\
\hline Yellow swamp orchid & 3. \\
\hline Yellow tassel flower & 3 \\
\hline Yellow trumpet tree & \\
\hline Ylang-ylang & \\
\hline Yoruba soft cane & 488 \\
\hline
\end{tabular}


Index des noms scientifiques

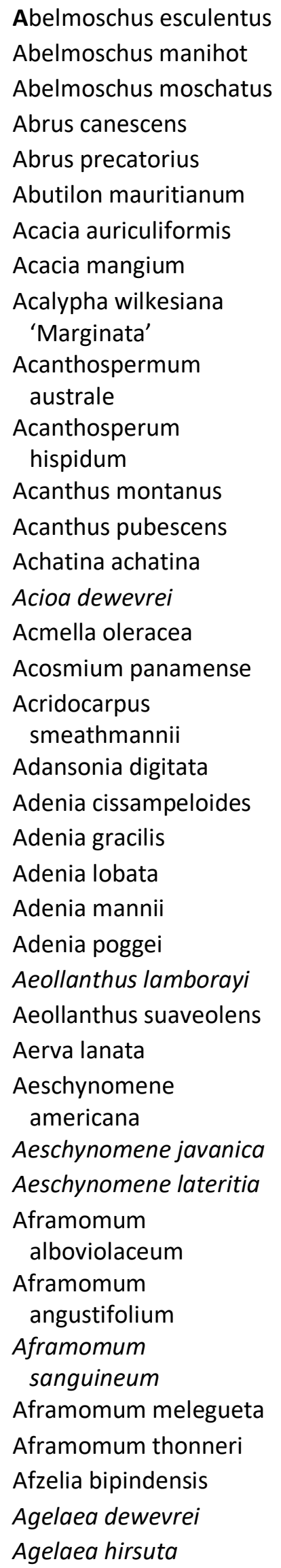

Agelaea paradoxa

Agelaea pentagyna

33, 524, 708, 789

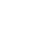

Agelaea poggeana

Albertisia villosa

Albizia adianthifolia var. adianthifolia

Albizia adianthifolia var. intermedia

41, 204

Albizia angolensis

Albizia chinensis

Albizia ferruginea

Albizia gummifera var.

$$
\text { ealensis }
$$

Albizia lebbeck

Albizia saman

Albizia stipulata

Alchornea cordifolia

Alchornea floribunda

30,46, 209

Aleurites moluccana

47

48

Allanblackia floribunda $\quad 49$

Allium fistulosum $\quad \mathbf{5 0}$

Allophylus africanus $\quad 51$

Aloe buettneri $\mathbf{5 2}$

Aloe congolensis 52

Alpinia grandis 53

Alpinia purpurata $\quad \mathbf{5 3}$

Alstonia boonei 54

Alstonia congensis $\quad 54$

Alternanthera brasiliana $\quad \mathbf{5 5}$

Alternanthera sessilis $\quad \mathbf{5 6}$

Alvesia rosmarinifolia $\quad \mathbf{5 7}$

Amaranthus blitum $\quad 59$

subsp. emarginatus

Amaranthus cruentus $\quad \mathbf{5 8}, 129,160$

Amaranthus dubius $\quad 60$

Amaranthus hybridus $\quad 58$

subsp. cruentus

Amaranthus spinosus $\quad 59$

Amorphophallus $\quad 61$

angolensis subsp.

angolensis

Amorphophallus

61

leopoldianus

Anacardium occidentale $\quad 62$

Ananas comosus $\quad 63$ 
Anchomanes difformis

Ancistrophyllum

secundiflorum

Aneilema aequinoctiale

Anisophyllea quangensis

Annona muricata

Annona senegalensis

var. oulotricha

Annona squamosa

Anonidium mannii

Anthocleista

liebrechtsiana

Anthocleista

schweinfurthii

Anthonotha macrophylla

Antidesma

membranaceum

Antidesma meiocarpum

Antidesma venosum

Antigonon leptopus

Antrocaryon klaineanum

Antrocaryon nannanii

Aoranthe cladantha

Arachis hypogaea

Argocoffeopsis eketensis

Aristolochia ringens

Artemisia annua

Artocarpus

heterophyllus

Artocarpus altilis

Artocarpus incisus

Artocarpus integrifolia

Asparagus flagellaris

Aspilia kotschyi

Asystasia gangetica var. micrantha

Auricularia cornea

Auricularia polytricha

Averrhoa carambola

Azadirachta indica

Baissea axillaris

Bakerophyton lateritium

Bambusa vulgaris

Baphia dewevrei

Baphia pilosa

Barleria lupulina

Barteria fistulosa
Barteria nigritiana

Basella alba

102

103

104

104

106

106

Berlinia gandiflora var.

bruneelii

Berlinia giorgii var.

107

Bertiera orthopetala

108

109

109

Bertiera racemosa var. racemosa

Bidens oligoflora

110

Bidens pilosa

111

112

113

114

114

115

576

116

117

798

118

82, 351, 539

Brachytrupes

membranaceus

119

119

119, 120

121

122

123

124

125

127

129

129

130

130

131

431

132 
Burkea africana

Byrsocarpus coccineus

Byrsocarpus viridis

Cajanus cajan

Caladium bicolor

Calamus deerratus

Calea urticifolia

Calliandra calothyrsis

Calliandra surinamis

Caloncoba welwitschii

Calopogonium

mucunoides

Calycobolus heudelotii

subsp. heudelotii

Camoensia scandens

Cananga odorata

Canarium schweinfurthii

Canavalia ensiformis

Canavalia gladiata

Canna indica

Cannabis sativa

Capsicum annuum

Capsicum chinense

Capsicum frutescens

Carapa procera

Cardiospermum

grandiflorum

Cardiospermum

halicacabum

Carica papaya

Carpolobia alba

Carpolobia glabrescens

Casacabela thevetia

Cassia alata

Cassia didymobotrya

Cassia occidentalis

Cassia siamea

Cassia spectabilis

Catharanthus roseus

Cecropia pachystachya

Ceiba pentandra

Celosia argentea

Celosia trigyna

Cenchrus purpureus

Centella asiatica

Centrosema pubescens

Cereus peruvianus
Chaetocarpus africanus

Chamaecrista kirkii var.

$$
\text { guineensis }
$$

$$
\text { Chamaesyce hirta }
$$

Chassalia pauwelsii

Chenopodium

ambrosioides

Chlamydocola chlamydantha

Chlorocodon whitei

Chlorophora excelsa

Chromolaena odorata

Chrysobalanus

atacorensis

Chrysobalanus icaco

subsp. atacorensis

Chrysophyllum

lacourtianum

Chrysophyllum cainito

$6,14,46,172$

174

174

176

175

Chytranthus

stenophyllus

Cinnamomum verum

178

Cissus aralioides

179

Cissus rubiginosa

181

Citrullus lanatus

182

Citrus aurantiifolia

184

Citrus aurantium

185

186

186

187

189

190

191

Clematis hirsuta var.

glabrescens

Cleome gynandra

192

Cleome rutidosperma

193

Clerodendrum

formicarum

Clerodendrum

schweinfurthii

Clerodendrum

splendens

Clerodendrum

uncinatum

Clitandra arnoldiana

Clitandra cymulosa

197, 227

Cnestis corniculata

198

Cnestis ferruginea 
Cnestis iomalla

Coccinea barteri

Cochlospermum

angolense

Cocos nucifera

Coffea canephora

Coffea eketensis

Coffea liberica

Cogniauxia podolaena

Cogniauxia trilobata

Coix lacryma-jobi

Cola acuminata

Cola marsupium

Coleus esculentus

Colletoecema dewevrei

Colletoecema tortistilum

Colocasia esculenta

Combretum

platypterum

Combretum celastoides

subsp. laxiflorum

Combretum confertum

Combretum falcatum

Combretum hensii

Combretum laxiflorum

Combretum psidioides

Combretum racemosum

Commelina africana

Commelina diffusa

Conyza aegyptiaca

Conyza sumatrensis

Corchorus olitorius

Cosmoa sulphureus

Costus afer

Costus Iucanusianus

Costus phyllocephalus

Costus spectabilis

Coula edulis

Crassocephalum crepidioides

Crassocephalum bojeri

Crassocephalum rubens

Craterispermum

cerinanthemum

Craterispermum

schweinfurthii

Crescentia cujete
209, 358

211

633

212

212

213

219

215

216

217

218

215

220

221

222

65,223

324

324

224

225

226

197, 227, 397

228

229

230

231

727

727

232

233

234
Crinum jagus

235

Crinum ornatum

236

Crossopteryx febrifuga

237

Crotalaria retusa

238

239

Croton mubango

Croton sylvaticus

204, 240, 524

Cryptolepis oblongifolia

241

242

Cucumeropsis edulis

273

243

244

245

246

247

248

249

250

251

471

252

253

254

255

448

256, 845

Dacryodes edulis

Dactyladenia buchneri

457

258

259

261

260

261

262

263

264

265

266

268

268

267, 572

268

162

269

270

271 
Dialium englerianum

Dialium pachyphyllum

Dianella ensifolia

Dichaetanthera africana

Dichaetanthera strigosa

Dichapetalum lujae

Dichostemma

glaucescens

Dichrostachys cinerea

subsp. platycarpa

Dicliptera verticillata

Dictyandra arborescens

Dictyophleba lucida

Dillenia indica

Diodella sarmentosa

Dioscorea alata

Dioscorea bulbifera

Dioscorea cayenensis

var. praehensilis

Dioscorea dumetorum

Dioscorea praehensilis

Dioscorea preussi subsp.

preussi

Dioscorea quartiniana

Dioscorea smilacifolia

Diospyros heterotricha

Diospyros iturensis

Diospyros mannii

Diplorhynchus

condylocarpon

Dissotis brazzae

Dissotis hensii

Dissotis senegambiensus

Dorstenia psilurus

Dracaena arborea

Dracaena aubryana

Dracaena fragrans

Dracaena mannii

Drymaria cordata

Duranta erecta

Duranta repens

Duvigneaudia inopinata

Ectadiopsis oblongifolia

Eichhornia crassipes

Elaeis guineensis

Eleusine indica

Eleutherine bulbosa
Eleutherine plicata

Entandrophragma

39

Epinetrum villosum

322

Epiphyllum crenatum

$1,323,600$

$$
\text { haullevilleana }
$$

Erigeron sumatrensis

324

Eriosema glomeratum

325

326

327

328

328

330

331

332

334

334

334

334

334

336

Eulophia angolensis var. angolensis

Eulophia cucullata

337

338

172

339

340

341

342

343

344

597

42

345

348

345

347 
Ficus lutea

Ficus ottoniifolia subsp. lucanda

Ficus sur

Ficus thonningii

Ficus umbellata

Flacourtia jangomas

Funtumia africana

Gaertnera paniculate

Galinsoga parviflora

Gambeya lacourtiana

Garcinia huillensis

Garcinia kola

Garcinia mangostana

Garcinia xanthochymus

Gardenia ternifolia subsp. jovis-tonantis

Geophila renaris

Gilbertiodendron

dewevrei

Gisekia pharnaceoides

Gladiolus dalenii

Globimetula braunii

Gloriosa superba

Glycine max

Glyphaea brevis

Gmelina arborea

Gnetum africanum

Gossypium barbadense

Greenwayodendron

suaveolens

Grevillea robusta

Guibourtia demeusei

Gynandropsis gynandra

Gynura crepidioides

Hallea stipulosa

Hamelia patens

Harrisonia abyssinica

Harungana

madagascariensis

Haumania liebrechtsiana

Hedychium coronarium

Heinsia crinita

Heisteria parvifolia

Helianthus annuus

Helichrysum

mechowianum
363,373

364

365

366

367

368

369

370

79, 371

372

373

374

375

192

231

521,843

137, 376

649

377, 792

$378,855,858$

379

380

381

382

383
Heliotropium indicum

384

$$
\text { Hevea brasiliensis }
$$

Hibiscus acetosella

Hibiscus cannabinus

Hibiscus esculentus

Hibiscus manihot

Hibiscus rostellatus

Hibiscus sabdariffa

Hippeastrum puniceum

Hippocratea myriantha

Holarrhena floribunda

Hoslundia opposita

Hua gabonii

Hugonia platysepala

Hura crepitans

Hymenocardia acida

Hymenocardia ulmoides

Hyparrhenia diplandra

Hyphaene guineensis

Hypoestes cancellata

Hypoestes forskaolii

Hypoxis angustifolia

Hypselodelphys

$$
\text { scandens }
$$

Hyptis suaveolens

Icacina manni

Impatiens balsamina

Impatiens irvingii

Imperata cylindrica

Indigofera indica

Indigofera paracapitata

Inga edulis

Ipomoea aquatica

Ipomoea batatas

Ipomoea fistulosa

Ipomoea involucrate

Ipomoea mauritiana

Irvingia smithii

Ixora brachypoda

Jateorhiza macrantha

Jatropha curcas

Jatropha gossypiifolia

Justicia gendarussa

Justicia insularis

Justicia secunda
385

386

387

8

9

388

386, 389

390

391

392

393

394, 434

395

396

397,843

397, 399

401

402

403

404

405

406

407

408

409

410

$14,15,112,172,370$, 411,598,755

412

413

414

415

416

417

418

419

420

421

422

423, 821

425

426

427

428 
Kalaharia schaijesii

Kalaharia uncinata

Kalanchoe crenata

Kalanchoe pinnata

Kigelia africana

Kotschya ochreata

Laccosperma

secundiflorum

Lagenaria siceraria

Lagerstroemia speciosa

Landolphia camptoloba

Landolphia congolensis

Landolphia dewevrei

Landolphia heudelotii

Landolphia lanceolata

Landolphia owariensis

Landolphia sp.

Lannea antiscorbutica

Lannea welwitschii

Lantana camara

Lantana montevidensis

Laportea ovalifolia

Lasimorpha senegalensis

Leea guineensis

Lentinus squarrosulus

Leonotis nepetifolia

Leptactina

liebrechtsiana

Leptactina leopoldi

secundi

Leptactina pynaertii

Leptaspis zeylanica

Leptoderris congolensis

Leptoderris ferruginea

Leucaena leucocephala

Lindackeria dentata

Lippia multiflora

Loeseneriella

clematoides

Lonchocarpus

griffonianus

Loranthus braunii

Loudetia demeusei

Lovoa trichilioides

Ludwigia abyssinca

Ludwigia leptocarps

Luffa cylindrica
441

442, 687

23, 227

443

444

445

446

447

448, 855,858

449

845

450

452

451

451

453

337,454

455

456

564

457

458

511

366

459

460

461

462

463
Lycopersicon esculentum

728

Lygodium microphyllum

464

Macaranga

schweinfurthii

Macaranga monandra

465

Macaranga saccifera

466

468

Macrolobium

macrophyllum

Macrolobium coeruleum

587

Maesa lanceolata var. lanceolata

Maesobotrya

vermeulenii

Maesobotrya bertriama

472

Maesobotrya staudtii

470

471

473

475

475

476

477

478

480

482

480

483

484

485

Maprounea africana

486

Maranthes glabra

487

Marantochloa congensis

488

Margaritaria discoidea

204, 489

Markhamia lutea

490

Markhamia tomentosa

490

Megaphrynium

macrostachyum

Melaleuca leucadendra

182,491

Melanthera scandens

492

Melia azedarach

493

Melinis amethystia

494

496

Melinis minutiflora

497

498

499

499

500

501 
Merremia tridentate

subsp. angustifolia

Merremia tuberosa

Miconia calvescens

Microdesmis puberula

Mikania chenopdiifolia

Milicia excelsa

Millettia drastica

Millettia eetveldeana

Millettia griffoniana

Millettia laurentii

Millettia macroura

Millettia theuszii

Millettia versicolor

Mimoca diplotricha

Mimosa pigra

Mimosa pudica

Mitracarpus hirtus

Mitracarpus villosus

Mitragyna stipulosa

Momordica charantia

Momordica foetida

Mondia whitei

Monodora angolensis

Monodora myristica

Morinda lucida

Morinda morindoides

Moringa oleifera

Moringa stenopetala

Mucuna pruriens

Murdannia simplex

Musa ornata

Musa spp.

Musanga cecropioides

Mussaenda arcuata

Mussaenda stenocarpa

Myrianthus arboreus

Napoleonaea imperialis

Napoleonaea vogelii

Nauclea diderrichii

Nelsonia canescens

Nephelium lappaceum

Nephrolepis biserrata

Newbouldia laevis

Nicotiana tabacum

Nymphaea lotus
Nymphaea maculata

552

Nymphaea nouchali

552

503

504

505

506

6, 507, 792

509

510

511

512

514

515

6, 517

519

518

519

520

520

521

522

522

523

524

525

526

527

529

530

531

533

534

536

538

540

643

541

542

542

543

545

546

548

549

550

129, 552

Ochna afzelii

Ochthococosmus

africanus var puberula

Ocimum americanum

555

Ocimum basilicum

Ocimum canum

251, 556

555

557, 685

557

558

558

559

560

561

562

563

563

563

564

565

566

64, 567

569

570

571

312

572

573

574

575

576

577

578

579

580

581

582, 730

584

Pandanus candelabrum

Pandanus utilis

164, 585, 654

Panicum maximum

586

587

Paramacrolobium

coeruleum

Parinari capensis 
Parinari excelsa

Paropsia brazzaeana

Paspalum notatum

Passiflora

quadrangularis

Passiflora edulis $\mathrm{f}$.

flavicarpa

Paullinia pinnata

Pauridiantha multiflora

subsp. Dewevrei

Pauridiantha viridiflora

Pedilanthus

tithymaloides

Peltophorum pterocarpum

Pennisetum purpureum

Pentaclethra

eetveldeana

Pentaclethra

macrophylla

Pentadiplandra

brazzeana

Peperomia pellucida

Pereskia aculeata

Pereskia grandifolia

Persea americana

Persicaria decipiens

Petersianthus

macrocarpus

Phaseolus lunatus

Phaseolus vulgaris

Phaulopsis imbricata

subsp. poggei

Phaulopsis poggei

Phoenix reclinata

Phyllanthus

muellerianus

Phyllanthus amarus

Phyllanthus discoideus

Phyllanthus niruroides

Phyllocosmus africanus

Physalis angulata

Physalis peruviana

Phytolacca dodecandra

Picralima nitida

Piliostigma thonningii

Piper guineense

Piper nigrum
$6,319,465,515$,

599

$6,600,601$

524,603

605

606

607

608

609

610

611

612

613

613

614

616

615

489

617

618

619

620

621

623

624

279,625

626
Piper pellucidum

africanum

630

Pithecellobium dulce

632

rosmarinifolium

Plectranthus esculentus $\quad \mathbf{6 3 3}$

Pleiotaxis eximia $\quad 634$

Pleiotaxis pulcherrima $\quad \mathbf{6 3 5}$

Plumbago auriculata $\quad \mathbf{6 3 6}$

Plumbago zeylanica $\quad 637$

Plumeria rubra $\quad \mathbf{6 3 8}$

Polyalthia suaveolens $\quad 373$

Polygala acicularis $\quad 639$

Polyporus tenuiculus $\quad 843$

Portulaca oleracea $\quad 640$

Pouchetia boumanniana $\quad 641$

Premna congolensis $\quad 642$

642

$\begin{array}{lr}\text { Psathyrella tuberculata } & 312,845 \\ \text { Pseudomussaenda } & \mathbf{6 4 3}\end{array}$

stenocarpa

Pseudospondias

microcarpa

Psidium guajava

644

645

646

647

648

febrifugum

649

650

651

652

652

Pteridium aquilinum

subsp. centrali

africanum

Pterocarpus angolensis $\quad 653$

Pueraria phaseoloides $\quad 654$

var. javanica

Punica granatum

655

Pycnanthus angolensis $\quad 656$

Pyrostegia venusta $\quad \mathbf{6 5 8}$

Quassia africana $\quad 659$

Quassia amara $\quad \mathbf{6 6 0}$ 
Quisqualis falcata

Quisqualis hensii

Raphia gentiliana

Raphia gilletii

Raphia laurentii

Raphia matombe

Raphia sese

Rauvolfia mannii

Rauvolfia vomitoria

Renealmia africana

Rhabdophyllum

arnoldianum

Rhabdophyllum

welwitschii

Rhipsalis baccifera

Rhynchosia mannii

Rhynchospora

corymbosa

Ricinodendron

heudelotii

Ricinus communis

Rinorea oblongifolia

Rivina humilis

Rothmannia octomera

Rourea coccinea subsp.

coccinea

Rourea coccinea subsp.

viridis

Rourea obliquifoliolata

Rumex usambarensis

Rungia congoensis

Rutdea olenotricha

Rutidea smithii

Saba comorensis

Saba florida

Sabicea africana

Sabicea mildbraedii

Saccharum officinarum

Salacia pynaertii

Samanea saman

Sambucus canadensis

Sansevieria longiflora

Sansevieria trifasciata

Santiria trimera

Sapium cornutum

Sapium ellipticum

Sarcocephalus latifolius
Sarcophrynium

arnoldianum

Sauvagesia erecta

Scadoxus multiflorus

700

701

Schwenckia americana

229, 702

Scleria secans

703

704

705

707

471, 708

709

710

524, 711

Securidaca

longipedunculata

713

714

715

716

717

718

718

718

719

720

721

721

722

723

724

725

726

726

727

728

729

731

732

733

734

27

735

736

737

738

739

740 
Sphenostylis stenocarpa

Spilanthes acmella

Spilanthes oleracea

Spondias cytherea

Spondias dulcis

Spondias mombin

Stachytarpheta

angustifolia

Stachytarpheta indica

Staudtia gabonensis

Staudtia kamerunensis

var. gabonensis

Steganotaenia araliacea

Sterculia tragacantha

Stipularia africana

Streptogyna crinita

Striga sp.

Strombosia grandifolia

Strophanthus

sarmentosus

Strophanthus

welwitschii

Strychnos cocculoides

Strychnos icaja

Strychnos pungens

Strychnos spinosa

Strychnos variabilis

Stylosanthes guianensis

Symphonia globulifera

Synedrella nodiflora

Synsepalum dulcificum

Syzygium cumini

Syzygium guineense

subsp. guineense

Syzygium guineense

subsp. macrocarpum

Syzygium jambos

Syzygium malaccense

Tabernaemontana

crassa

Tabernanthe elliptica

Tabernanthe iboga

Tacca leontopetaloides

Talinum triangulare

Tamarindus indica

Tapinanthus poggei

Tecoma stans
741

20

20

742

742

743

745

745

746

746

747

748

689

749

715

750

751

752

753

754

753

753

753

205, 481, 755

756

223, 757

758

759

760

762

763

764

765

766

730,767

768

769

770

129

772
Tephrosia vogelii

773

Terminalia catappa

775

Terminalia superba

776

847,848

aurantiacus

Termitomyces

848

mammiformis

Termitomyces

microcarpus

Termitomyces letestui

842,847

Termitomyces sp.

Tetracarpidium

conophorum

Tetracera alnifolia

Tetracera alnifolia

subsp. alnifolia

Tetracera poggei

Tetracera rosiflora

Tetradenia urticifolia

Tetrapleura tetraptera

843

Tetrorchidium

didymostemon

Theobroma cacao

Thevetia neriifolia

Thevetia peruviana

Thomandersia laurentii

Thonningia sanguinea

Thunbergia grandiflora

Tithonia diversifolia

Trachyphrynium

braunianum

Trachyphrynium

liebrechtsiana

Trachyphrynium

scandens

Treculia africana subsp.

africana

Trema orientalis

Trichilia gilletii

Trichocentrum

splendidum

Trichoscypha oddonii

Triclisia dictyophylla

Triclisia gilletii

Tridax procumbens

Trilepisium

madagascariense

Tripsacum andersonii

Tristemma leiocalyx
567,568

777

778

527

779

780

781

782

279, 784

785

155

155

196

786

787

788

789

378

406

790

792

793

794

795

796

796

797

798

799

800 


\begin{tabular}{|c|c|}
\hline Triumfetta cordifolia & 801 \\
\hline Triumfetta rhomboidei & 802 \\
\hline Turraea vogelii & 804 \\
\hline Turraea zenkeri & 544 \\
\hline Turraeanthus africanus & 803 \\
\hline Uapaca guineensis & 805 \\
\hline Uncaria africana & 806 \\
\hline Uraria picta & 807 \\
\hline Urena lobata & 189,808 \\
\hline Urera cameroonensis & 549 \\
\hline Urera flamignea & 809 \\
\hline Urera trinervis & 809 \\
\hline Usteria guineensis & 810 \\
\hline Uvaria brevistipitata & 811 \\
\hline Uvaria poggei & 812 \\
\hline Uvaria scabrida & 813 \\
\hline Vernonia amygdalina & 814 \\
\hline Vernonia brazzavillensis & 816 \\
\hline Vernonia colorata & 817 \\
\hline Vernonia conferta & 818 \\
\hline Vernonia doniana & 818 \\
\hline Vernonia potamophila & 819 \\
\hline Vigna subterranea & 820 \\
\hline Vigna unguiculata & 821 \\
\hline Vigna vexillate & 822 \\
\hline Vitex bojeri & 823 \\
\hline $\begin{array}{l}\text { Vitex congolensis var } \\
\text { congolensis }\end{array}$ & 824 \\
\hline Vitex doniana & 825 \\
\hline Vitex ferruginea & 823 \\
\hline Vitex gilletii & 824 \\
\hline Vitex madiensis & 826 \\
\hline Voacanga africana & 827,843 \\
\hline Voacanga thouarsii & 828 \\
\hline Voandzeia subterranea & 820 \\
\hline Waltheria indica & 830 \\
\hline Wedelia trilobata & 740 \\
\hline Whitfieldia elongata & 831 \\
\hline $\begin{array}{l}\text { Xanthosoma } \\
\text { sagittifolium }\end{array}$ & 213,832 \\
\hline Xylopia aethiopica & 524,833 \\
\hline Zanthoxylum gilletii & 835 \\
\hline Zea mays & 837 \\
\hline Zingiber officinale & 839 \\
\hline Zinnia angustifolia & \\
\hline
\end{tabular}


- Les végétaux et leurs produits sont de la première importance pour la vie de la population rurale de l'Afrique. Localement, ils sont couramment utilisés pour la construction, la fabrication des outils, l'emballage, comme aliments et médicaments, pour nourrir le bétail et pour la protection des cultures et des terres. Aussi, les insectes comestibles constituant une part importante de l'alimentation dans une grande partie de l'Afrique, se nourrissent de certaines plantes.

- Les abeilles récoltent le nectar et le pollen pour produire le miel qui est très apprécié par la population et s'avère être une précieuse source de revenus dans la province.

- La connaissance des utilisations et même des noms locaux de nombreuses de ces plantes est entrain de se perdre.

- Cette publication fournit des informations recueillies localement, ainsi que de la littérature disponible, pour plus de 800 plantes poussant dans la province du Kongo central en République Démocratique du Congo.

II s'agit d'une version corrigée qui omet quelques erreurs de formatage mineures de la version originale.

\section{ISBN 9780992898687}

